\title{
The Gatlin Site (41KR621): Investigating Archaic Lifeways on the Southern Edwards Plateau of Central Texas
}

Brett A. Houk

Department of Anthropology, Texas Tech University

Kevin A. Miller

SWCA

Eric R. Oksanen

Follow this and additional works at: https://scholarworks.sfasu.edu/ita

Part of the American Material Culture Commons, Archaeological Anthropology Commons, Environmental Studies Commons, Other American Studies Commons, Other Arts and Humanities Commons, Other History of Art, Architecture, and Archaeology Commons, and the United States History Commons

Tell us how this article helped you.

This Article is brought to you for free and open access by the Center for Regional Heritage Research at SFA ScholarWorks. It has been accepted for inclusion in Index of Texas Archaeology: Open Access Gray Literature from the Lone Star State by an authorized editor of SFA ScholarWorks. For more information, please contact cdsscholarworks@sfasu.edu. 


\section{The Gatlin Site (41KR621): Investigating Archaic Lifeways on the Southern Edwards Plateau of Central Texas}

\section{Licensing Statement}

This is a work for hire produced for the Texas Department of Transportation (TxDOT), which owns all rights, title, and interest in and to all data and other information developed for this project under its contract with the report producer. The report may be cited and brief passages from this publication may be reproduced without permission provided that credit is given to TxDOT and the firm that produced it. Permission to reprint an entire chapter, section, figures or tables must be obtained in advance from the Supervisor of the Archeological Studies Branch, Environmental Affairs Division, Texas Department of Transportation, 125 East 11th Street, Austin, Texas, 78701 
THE GATLIN SITE (41KR621):

INVESTIGATING ARCHAIC LIFEWAYS ON THE SOUTHERN EDWARDS PLATEAU

OF CENTRAL TEXAS

\author{
Prepared for \\ TEXAS DEPARTMENT OF TRANSPORTATION \\ 125 East 11th Street \\ Austin, Texas 78701 \\ Prepared by \\ Brett A. Houk, Kevin A. Miller, and Eric R. Oksanen \\ with contributions by \\ Charles D. Frederick, Michael E. Smith, W. Boone Law, Thomas R. Hester, Harry J. Shafer, \\ Mercedes C. Cody, Michael R. Chavez, and James T. Abbott
}

\author{
SWCA ENVIRONMENTAL CONSULTANTS \\ 4407 Monterey Oaks Boulevard \\ Building 1, Suite 110 \\ Austin, Texas 78749 \\ www.swca.com
}

Principal Investigator

Kevin A. Miller

Texas Antiquities Permit 3429 and 3532

SWCA Project Number 9862-053-AUS

SWCA Cultural Resources Report No. 2008-149

June 30, 2008 


\title{
THE GATLIN SITE (41KR621): \\ INVESTIGATING ARCHAIC LIFEWAYS ON THE SOUTHERN EDWARDS PLATEAU OF CENTRAL TEXAS
}

\author{
Copyright (C) 2008 \\ Texas Department of Transportation (TxDOT) and SWCA, Inc.
}

TxDOT and SWCA, Inc., jointly own all rights, title, and interest in and to all data and other information developed for this project under Contract 577XXSA002. Brief passages from this publication may be reproduced without permission provided that credit is given to TxDOT and SWCA, Inc. Permission to reprint an entire chapter, section, figures, or tables must be obtained in advance from the Supervisor of the Archeological Studies Program, Environmental Affairs Division, Texas Department of Transportation, 125 East $11^{\text {th }}$ Street, Austin, Texas 78701. Copies of this publication have been deposited with the Texas State Library in compliance with the State Depository requirements.

Printed by Ginny’s Printing, Austin, Texas.

jointly published by the

Texas Department of Transportation

Environmental Affairs Division

Archaeological Studies Program

Scott Pletka, Ph.D., Supervisor

Archeological Studies Program, Report No. 108

A. McGraw, Series Editor

and

SWCA, Inc.

Austin, Texas

SWCA Cultural Resources Report No. 2008-149

Texas Antiquities Permit 3429 and 3532

ISBN: 1-930788-78-9 


\section{EXECUTIVE SUMMARY}

From May 2004 through the summer of 2008 and on behalf of the Environmental Affairs Division (ENV) of the Texas Department of Transportation (TxDOT), SWCA Environmental Consultants (SWCA) undertook extensive archaeological investigations and analyses on the Gatlin site, 41KR621, located on the Guadalupe River, Kerr County, Texas. Work at the site was necessitated by the planned 1.15-mile extension of Spur 98 from its current limits to cross the Guadalupe River and terminate at FM 1338. As the project included both state and federal funding, TxDOT was required to comply with Section 106 of the National Historic Preservation Act, the implementing regulations of 36CFR Part 800, and the Texas Antiquities Code. In the case of 41KR621, since the archaeological site was determined eligible for listing under Criterion D and since impacts could not be avoided, a plan to mitigate the project effects was developed. The subsequent work in the form of data recovery is the primary basis of this report.

SWCA initially conducted the survey and site testing investigations along the Spur 98 corridor in May 2004. TxDOT then contracted SWCA to conduct the data recovery excavations under THC Antiquities Permit 3532. Data recovery excavations at 41KR621 spanned September through November 2004 and included the re-excavation of several backhoe trenches from the testing phase, excavation of new control trenches, removal of overburden in two areas of the site, and hand excavating roughly $145 \mathrm{~m}^{3}$ of the site in broad horizontal exposures. Combined, the testing and data recovery work resulting in the recovery of 37 burned rock features (including a buried burned rock midden), close to 50,000 pieces of debitage, 409 projectile points, 1,085 bifaces, 343 cores, over 400 flaked and non-chipped tools, and a modest amount of ecofacts.

The investigations documented four cultural occupations. The earliest of the Gatlin site's components, Occupation Zone (OZ) 1, contained Gower points and dates from approximately 6,800 B.P. to possibly as late as 6,000 B.P., falling within the Early Archaic. OZ2, a younger and more extensive Early Archaic occupation with mainly Gower and Martindale points, covers the period of ca. 6,100-4,500 B.P. The third zone, OZ3, a more compressed transitional phase between the Early to Middle Archaic dominated by Early Triangular diagnostic artifacts, is a component that produced dates of ca. 4,500-3,850 B.P. The youngest occupation, OZ4, which contained a burned rock midden but proved to be an admixture of broad temporal and cultural components, spans the Middle through Late Archaic periods, as evidenced by numerous diagnostic point types.

Utilizing one of the largest excavated samples of Early and Middle Archaic cultural deposits in the southern Edwards Plateau, the results of the study provide a unique look at human adaptation and basic lifeways at the site and surrounding region. Evidence indicates the Gatlin site was primarily utilized by small groups of foraging hunter-gatherers for short periods of time to acquire and process game, replenish their stocks of raw materials, and gear-up for future forays. The abundant game, plant foods, fuel, chert resources, and overall comfort of the riparian setting likely served as major draws for continuous occupation over thousands of years. Utilizing the projectile point sequence and suite of radiocarbon dates from 41KR621, the Early-Middle Archaic chronology of south Central Texas is revised and refined. Comparisons to other excavated sites in the region reveal new and important patterns regarding human adaptation during the Early and Middle Archaic on the southern Edwards Plateau.

All artifacts and project related materials will be curated at the Texas Archeological Research Laboratory. 


\section{ACKNOWLEDGEMENTS}

The successful completion of an archaeological study as complex as the multi-level investigations at 41KR621 requires the input, insight, labor, patience, sweat, and dedication of a great many people. First and foremost, we would like to thank the staff, past and present, of TxDOT ENV who made this project possible. These individuals, including Al McGraw, Dr. Owen Lindauer, Dr. Scott Pletka, Dr. Nancy Kenmotsu, and Dr. Jim Abbott, facilitated the field investigations, provided abundant support and direction for the study, and contributed crucial information throughout all phases of the project. Special thanks are given to Al McGraw, who was the primary catalyst in the development, execution, and success of the project. Mike Coward of the TxDOT area office in Kerrville was also particularly helpful in facilitating our work. Mary Kelly at TCB in San Antonio was very supportive during the survey and testing phases of investigations.

SWCA relied on the assistance of many experts and consultants throughout the various phases of the multi-disciplinary project. Chief among those deserving our thanks are Dr. Charles Frederick, Dr. Thomas Hester, and Dr. Harry Shafer, who contributed significant sections of this final report. The field investigations also benefited greatly from Dr. Frederick's initial geomorphological interpretations and ideas on site formation and integrity. Dr. Hester and Dr. Shafer provided an insightful analysis of the large projectile point assemblage. Other analysts who assisted in the process include Matthew Root (stone tool use wear studies), Dr. Leslie Bush (macrobtoanical study), Dr. Linda Scott Cummings (pollen/phytolith), Dr. M. E. Malainey (lipid residue/fatty acids), Robert Howells (freshwater mussel shells), and finally Dr. Lauri Thompson and Dr. Claude Bramblett who confirmed the identification of the human skeletal material. Karl Kibler and Dr. Steve Tomka peer reviewed a draft of this report and both provided invaluable comments.

Finally, we would like to thank all the employees at SWCA who contributed to the fieldwork, lab work, analysis, or writing. There are too many to name them all, but several deserve particular mention. Mr. Kevin Miller served as Principal Investigator throughout all phases of the project, calmly guiding project design, methodology and overall execution of the various phases of work. Dr. Brett Houk served as Project Archaeologist and successfully provided the hands on management of most phases of the project, a complex task spanning many years. Dr. Houk also was instrumental in the development of the research design and much of this report. W. Boone Law and Dr. Michael Smith, both former employees of SWCA, spearheaded the daily work on the analysis at one point or another and made this a better report than it would have been without their involvement. Eric Oksanen took over the report development and contributed insightful analyses and interpretations to the document. Carole Carpenter drafted our figures, and Lindsey Doubleday did an admirable job formatting the draft and final reports. Laura Acuña, the SWCA lab director, oversaw the processing and curation of the large collection of artifacts from 41KR621. Numerous individuals also contributed to the successful field and lab investigations of this project from start to finish, including, Mercedes C. Cody, Tina Neilsen, Jon Lowe, Ken Lawrence, Ernest Wingate, Kim Kersey, and Josh Gibbs. While a great many people contributed to this report, all errors or omissions are ultimately ours alone. 


\section{TABLE OF CONTENTS}

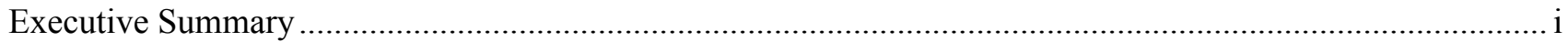

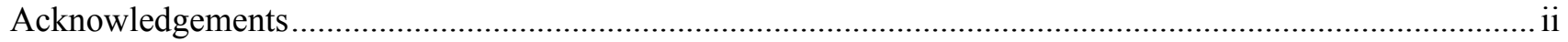

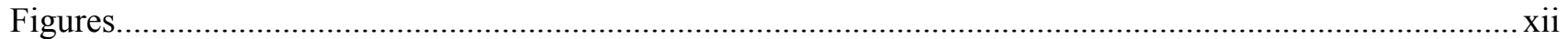

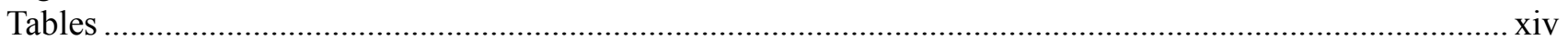

Chapter 1: Introduction to the Gatlin Site

By: Brett A. Houk

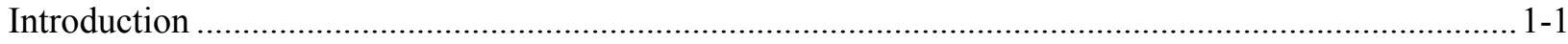

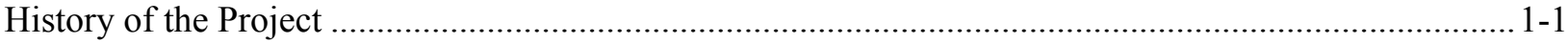

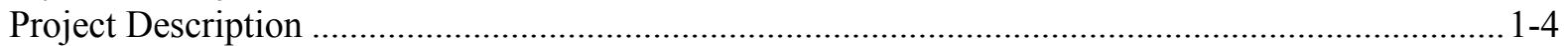

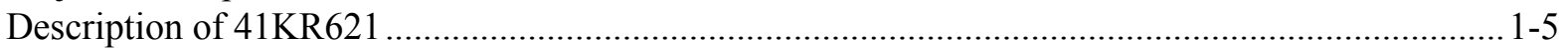

Data Recovery Investigations............................................................................................ 1-5

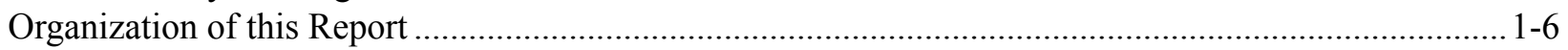

Chapter 2: Environmental Setting

By: Brett A. Houk

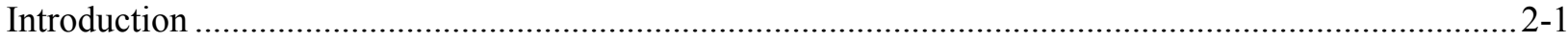

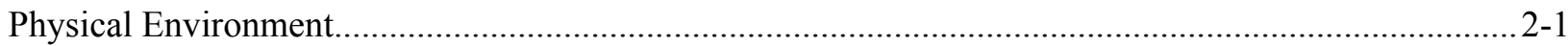

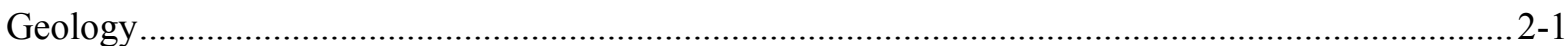

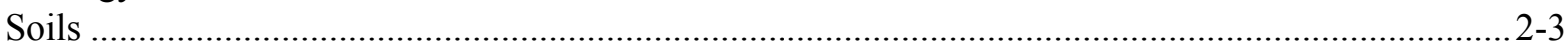

Climate

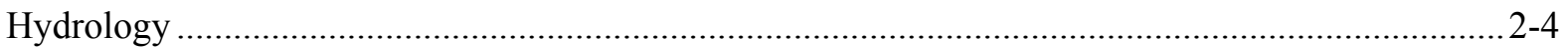

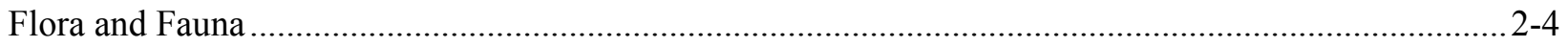

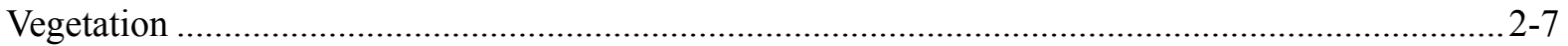

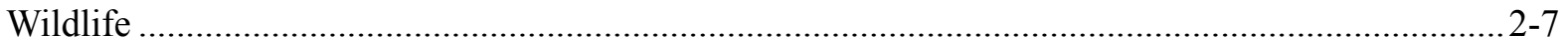

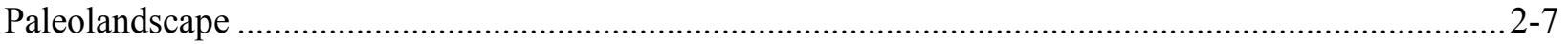

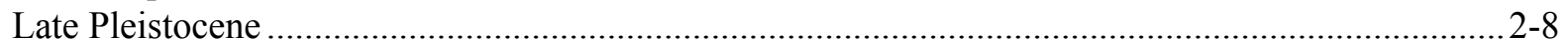

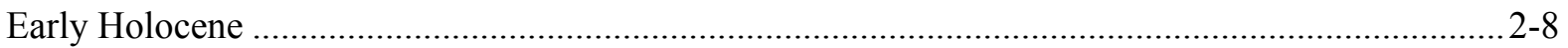

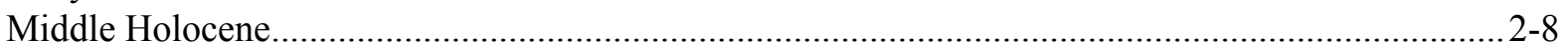

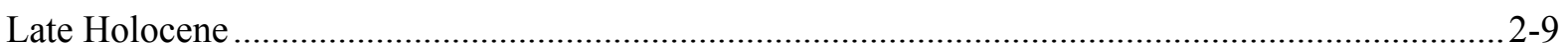

Chapter 3: Archaeological Setting

By: W. Boone Law

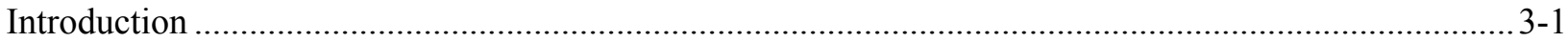

The Edwards Plateau as an Archaeological Region ......................................................................... $3-1$

Natural Resources of the Edwards Plateau................................................................................

An Archaeological Review of the Edwards Plateau .......................................................................... 3-3

The Archaic Period (8,800-1,300 в.р.) ……………………………………………………...... $3-4$

The Early Archaic Subperiod...................................................................................................

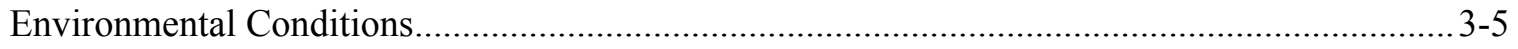

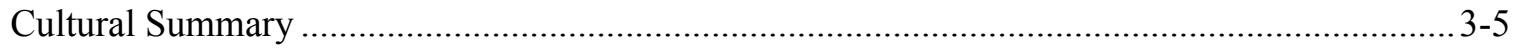

The Middle Archaic Subperiod........................................................................................... 3-14

Environmental Conditions............................................................................................ $3-14$

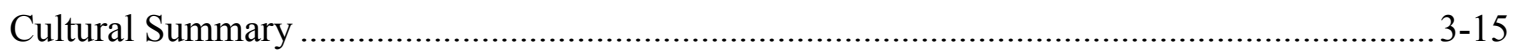


The Late Archaic Period

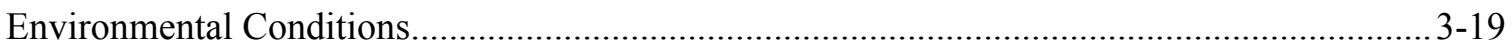

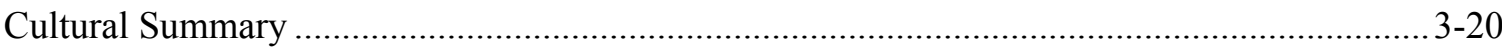

\section{Chapter 4: Survey and Testing Results (41KR621 and 41KR622)}

By: Michael E. Smith and Brett A. Houk

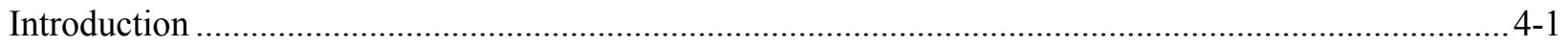

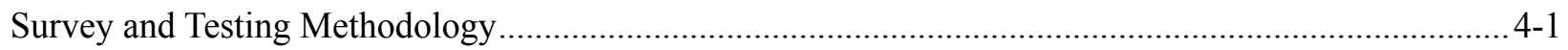

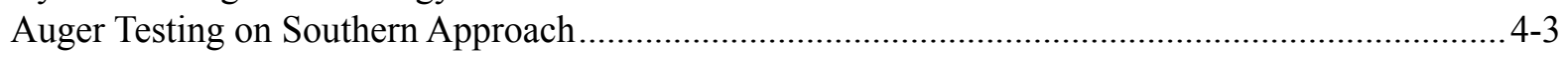

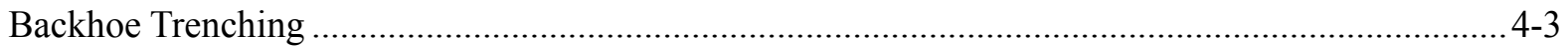

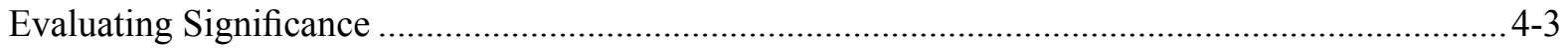

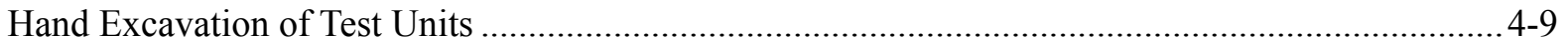

Survey and Testing Investigations of the Northern Approach (41KR622) ........................................... 4-9

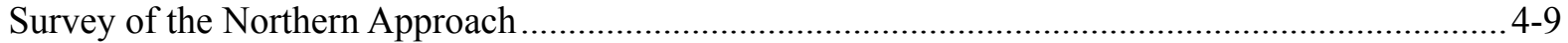

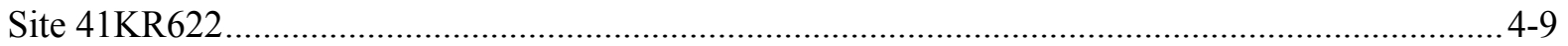

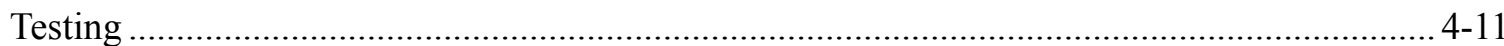

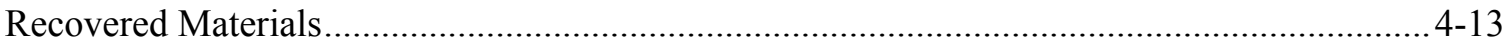

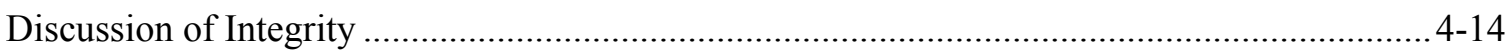

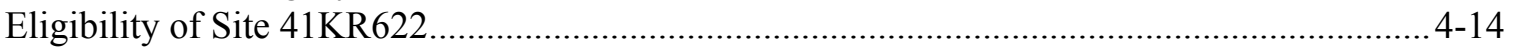

Survey and Testing Investigations of the Southern Approach (41KR621) .........................................4-14

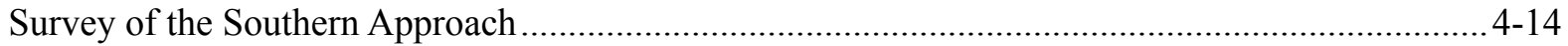

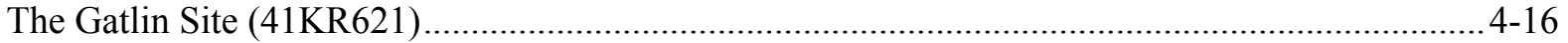

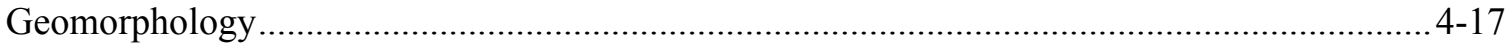

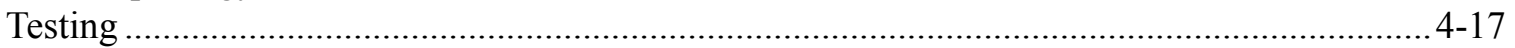

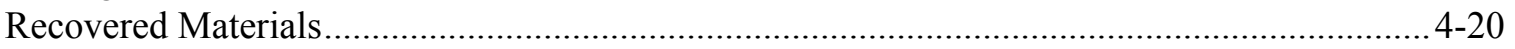

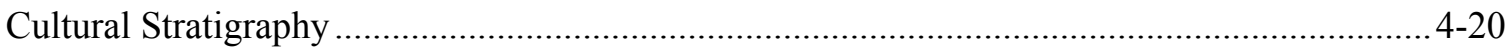

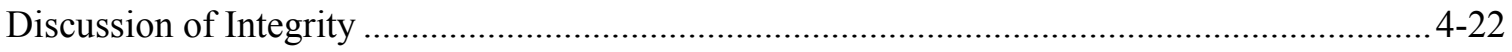

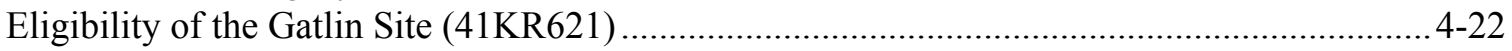

\section{Chapter 5: Data Recovery Research Design and Methodology}

By: W. Boone Law, Brett A. Houk, Kevin A. Miller, Charles D. Frederick, and Michael E. Smith

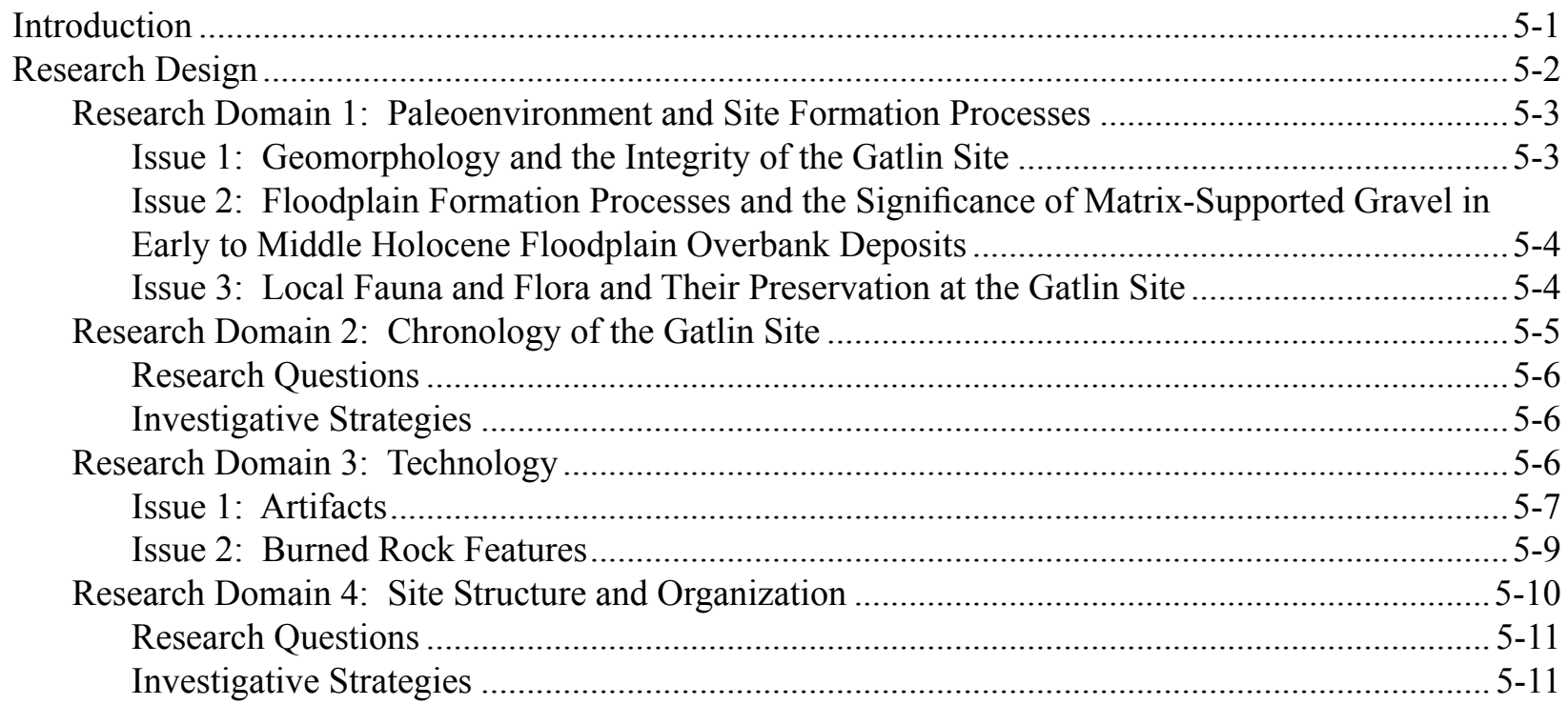




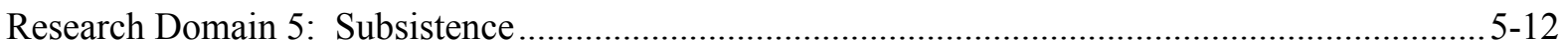

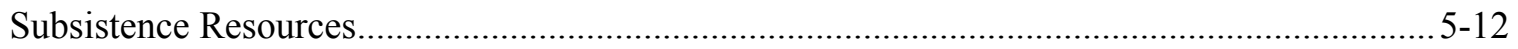

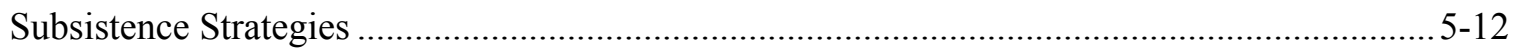

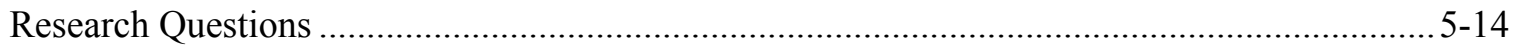

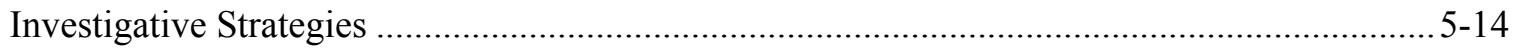

Research Domain 6: Evaluating the Project's Methodology ..................................................... 5-15

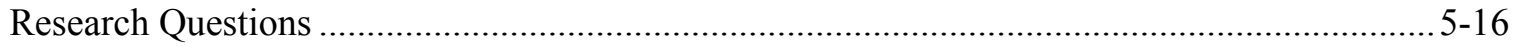

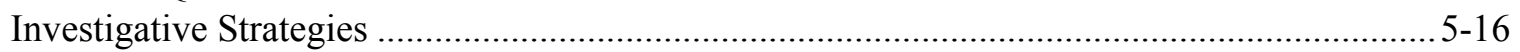

\section{Chapter 6: Paleoenvironment and Site Formation Processes}

By: Charles D. Frederick

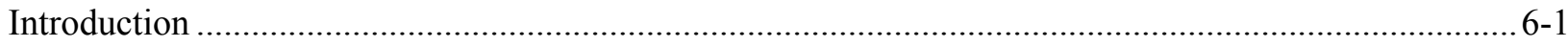

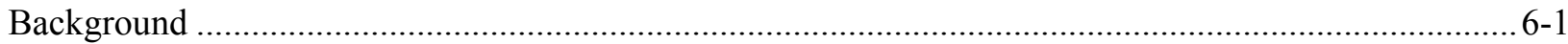

Historical Context of Early Holocene Alluviation: Late Pleistocene-Early Holocene Soil Erosion

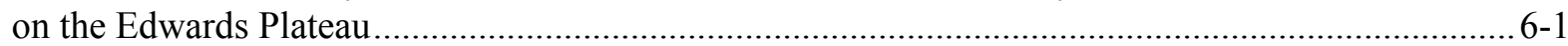

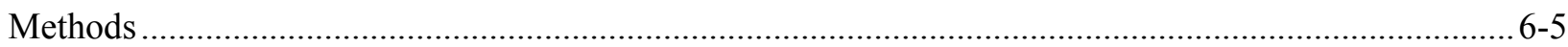

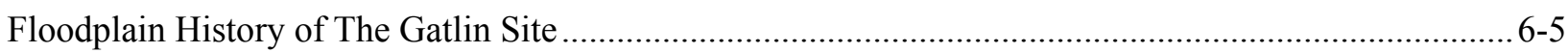

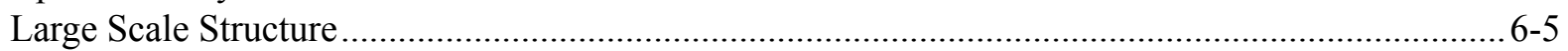

Changes in Floodplain Sedimentation Throughout the Period of Site Occupation .......................... 6-13

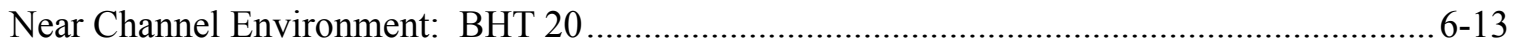

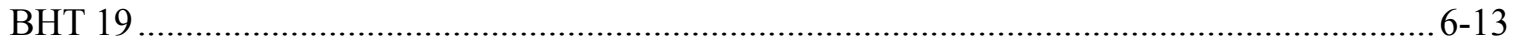

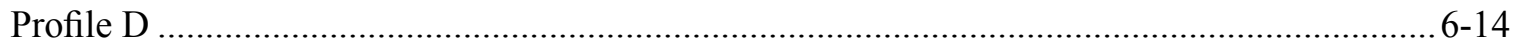

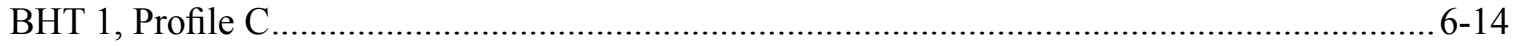

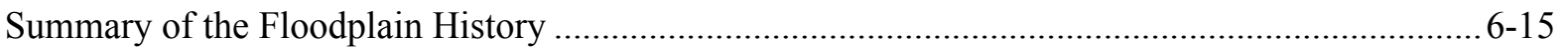

Floodplain Sedimentation Rates and Processes ....................................................................... 6-15

Background: Formation of Vertically Accreted Floodplains ....................................................... 6-15

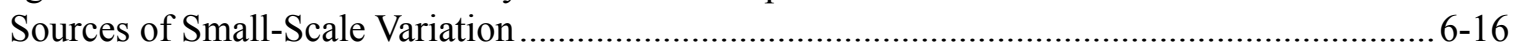

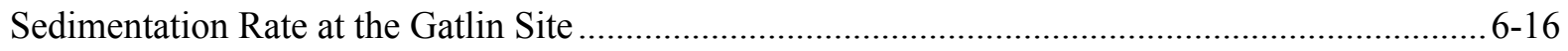

The Gatlin Site Compared with Other Central Texas Alluvial Sites ................................................. 6-17

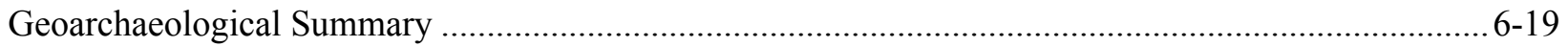

\section{Chapter 7: Data Recovery Methods and Summary of Results}

By: Michael E. Smith and Eric R. Oksanen

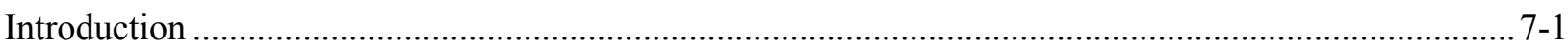

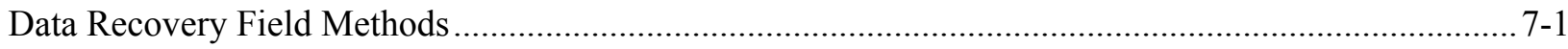

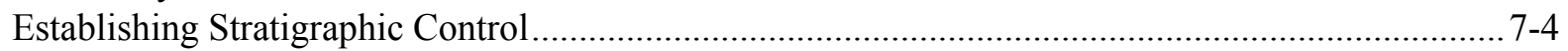

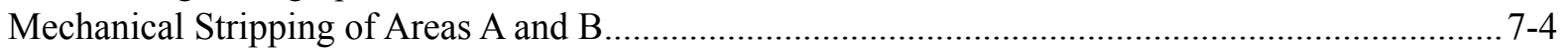

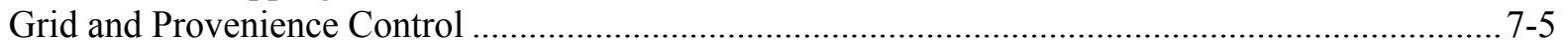

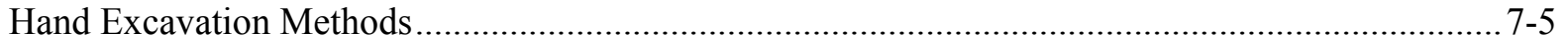

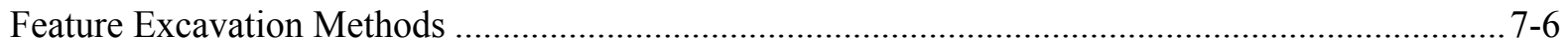

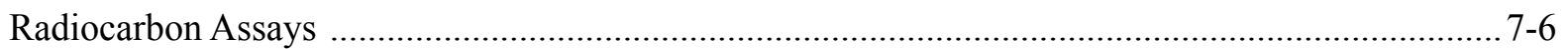

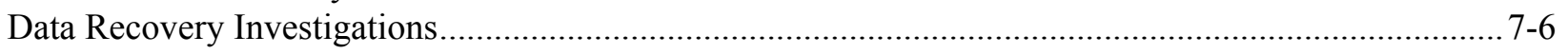

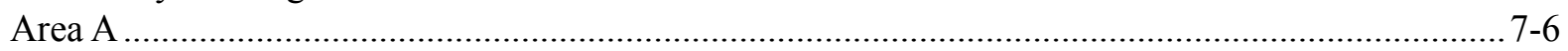

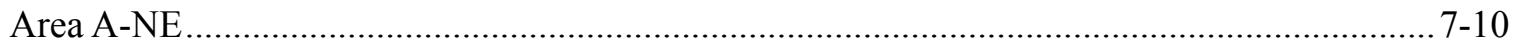

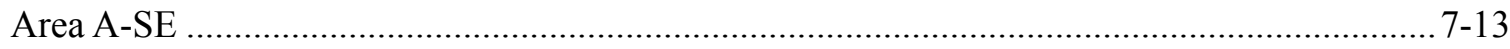

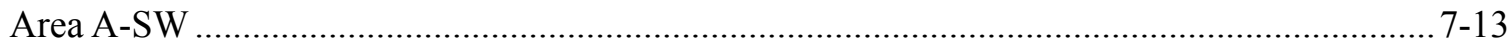

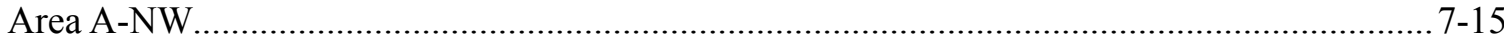


Area B

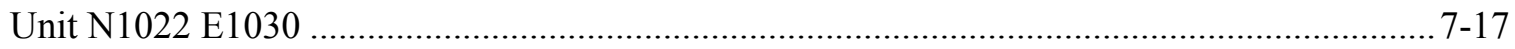

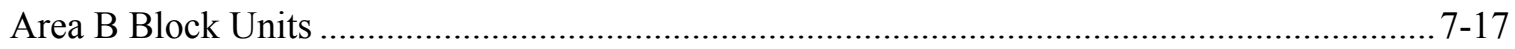

Burned Rock Midden .................................................................................................. $7-21$

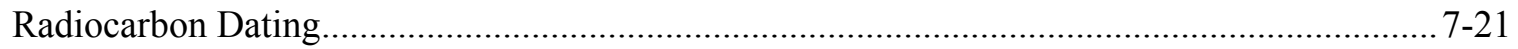

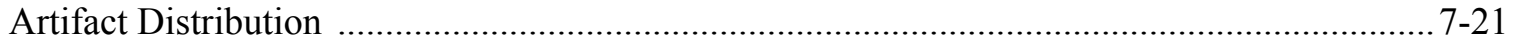

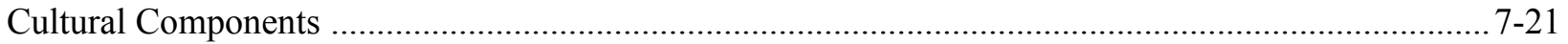

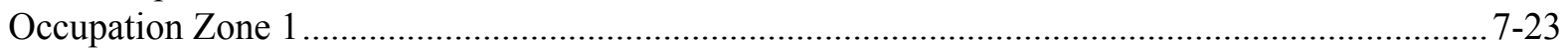

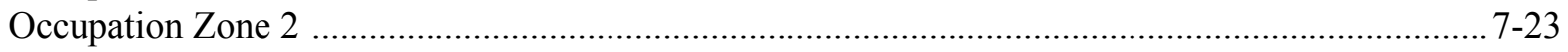

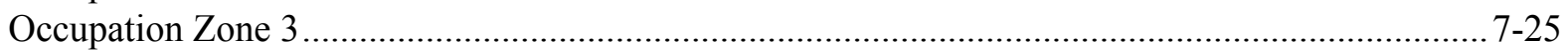

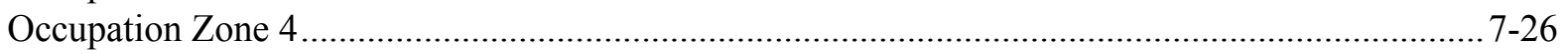

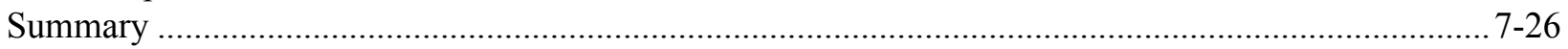

\section{Chapter 8: Occupation Zone 1}

By: Eric R. Oksanen, Mercedes C. Cody, and Kevin A. Miller

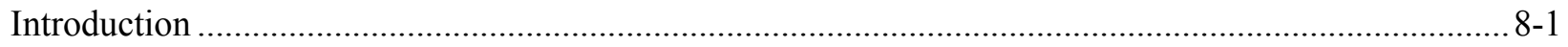

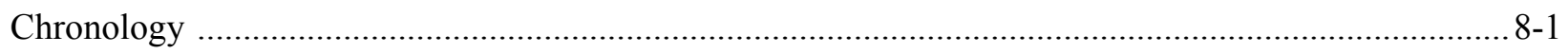

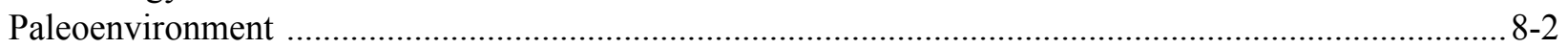

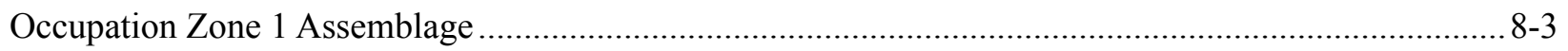

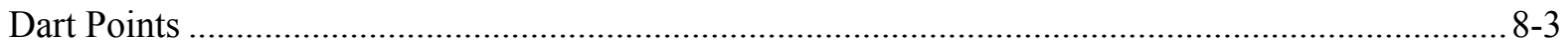

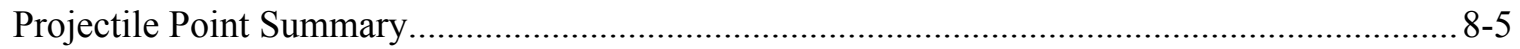

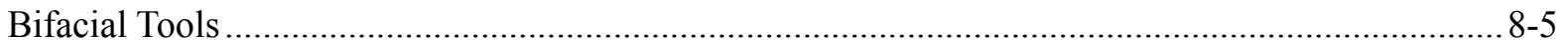

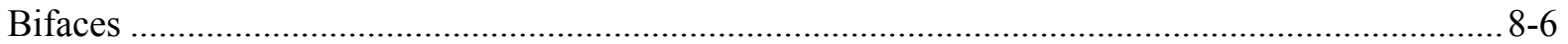

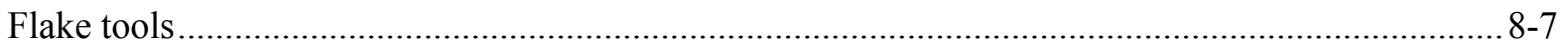

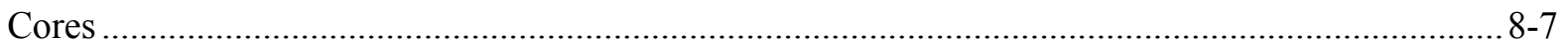

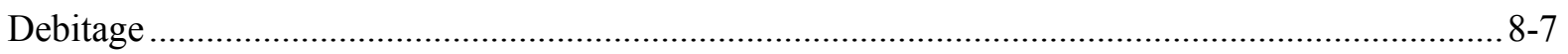

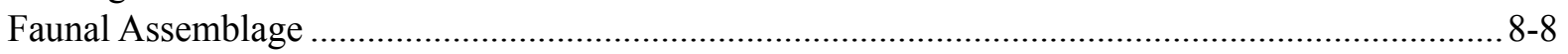

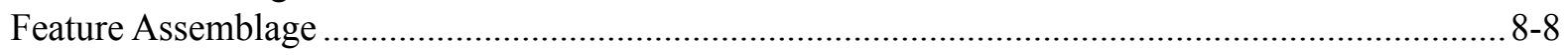

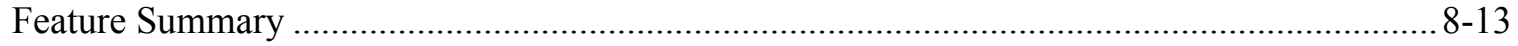

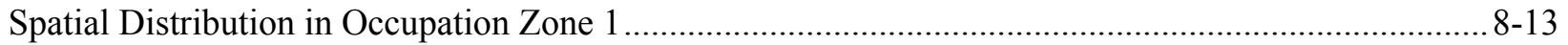

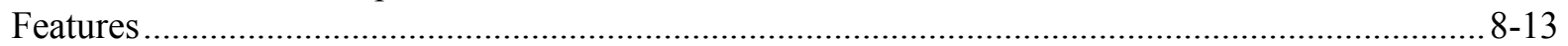

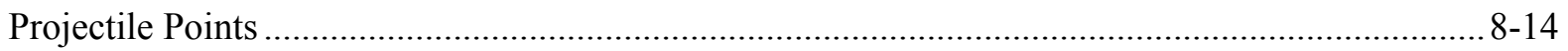

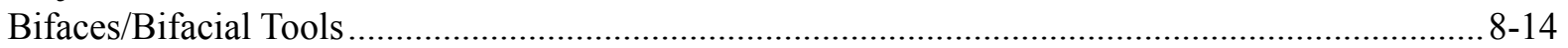

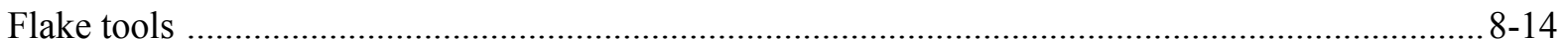

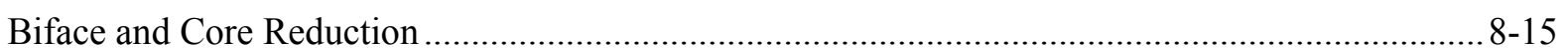

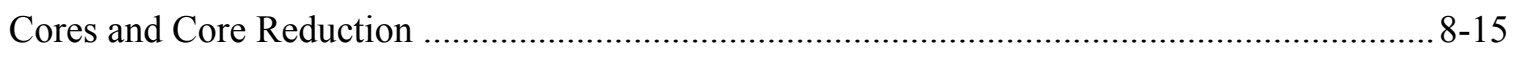

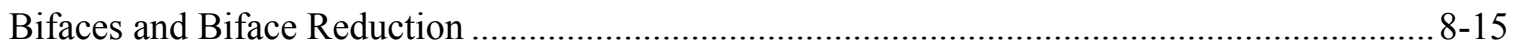

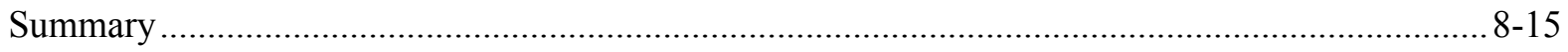

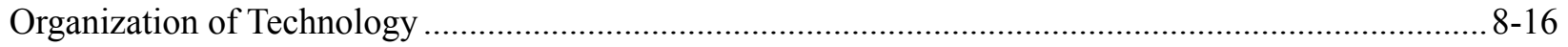

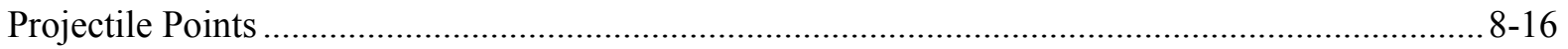

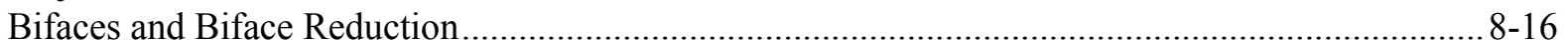

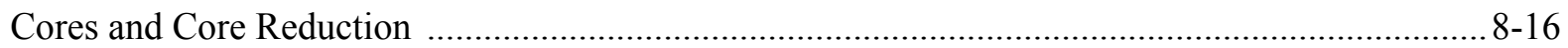

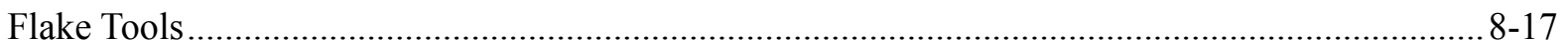

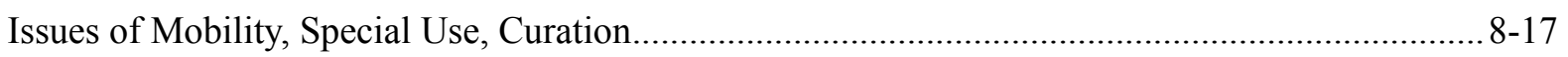

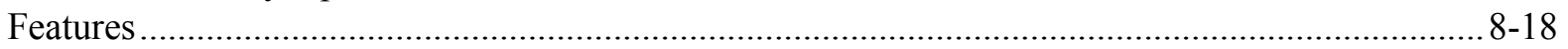

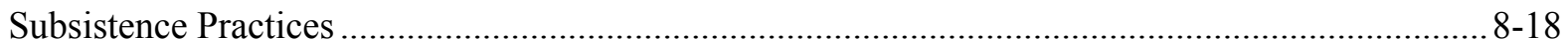

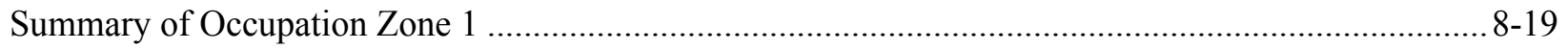




\section{Chapter 9: Occupation Zone 2}

By: Eric R. Oksanen, Mercedes C. Cody, and Kevin A. Miller

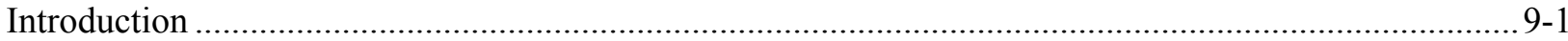

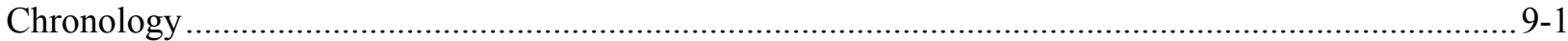

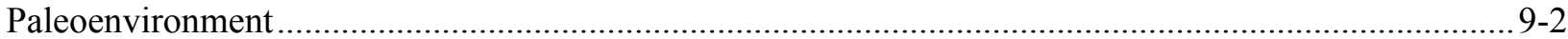

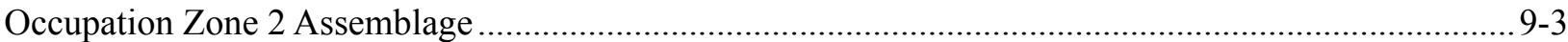

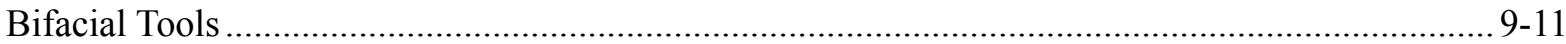

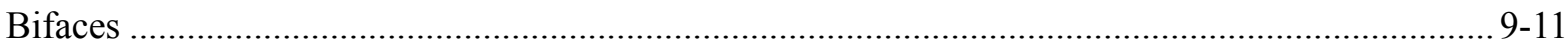

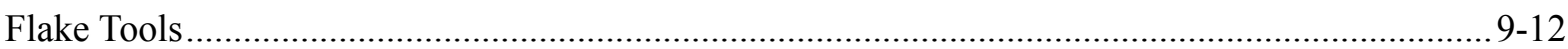

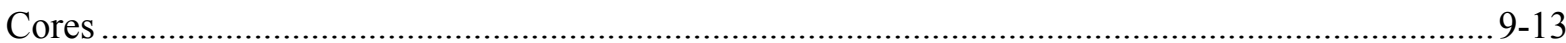

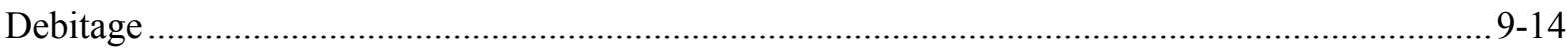

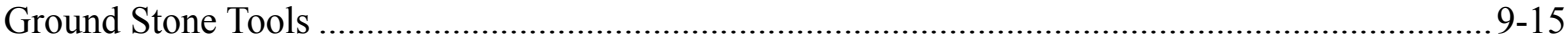

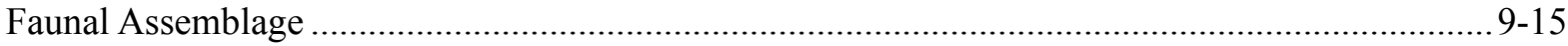

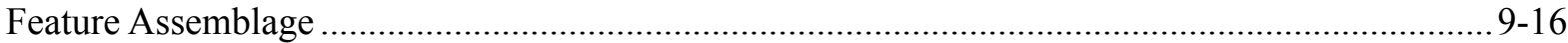

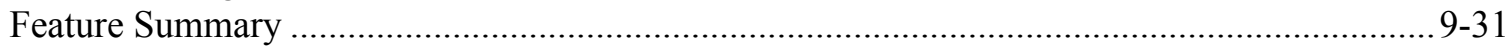

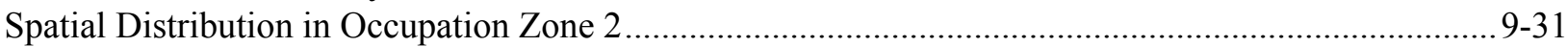

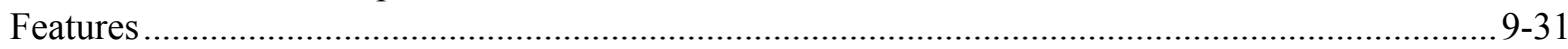

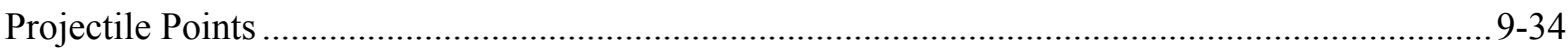

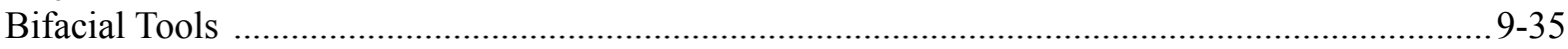

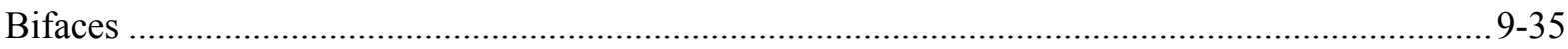

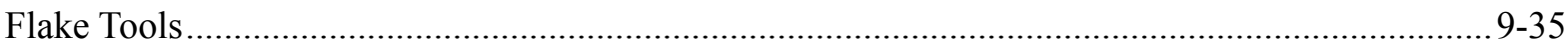

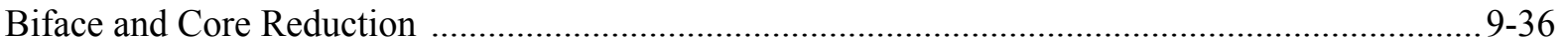

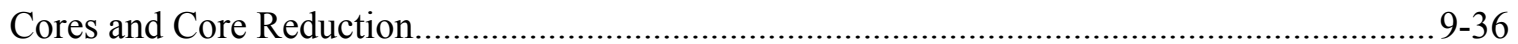

Bifaces and Biface Reduction ..................................................................................... 9-37

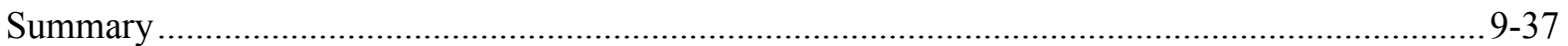

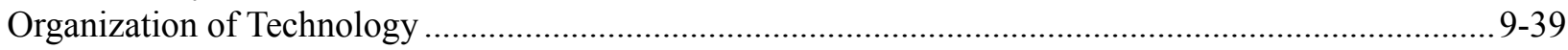

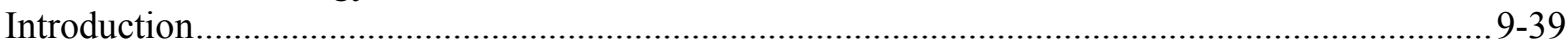

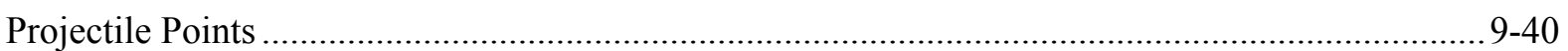

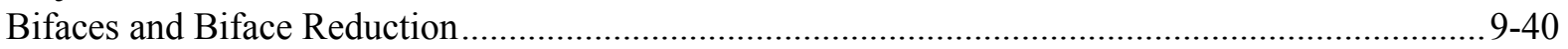

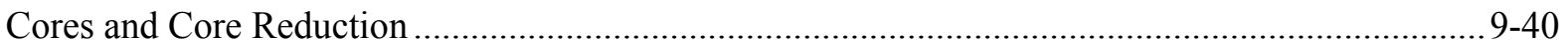

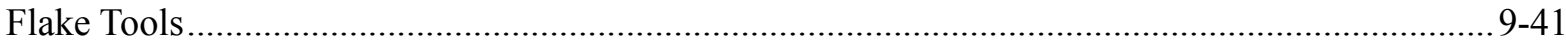

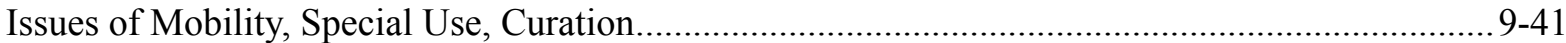

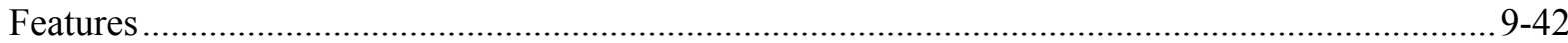

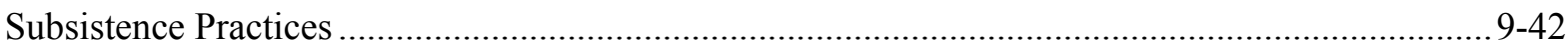

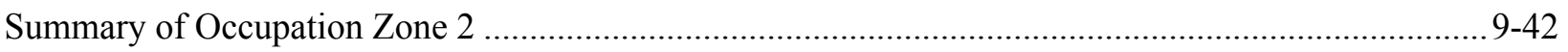

\section{Chapter 10: Occupation Zone 3}

By: Eric R. Oksanen, Mercedes C. Cody, and Kevin A. Miller

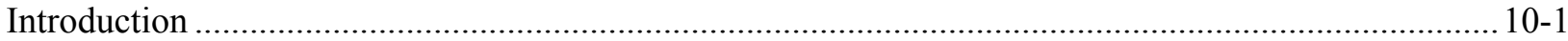

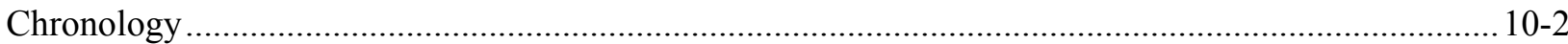

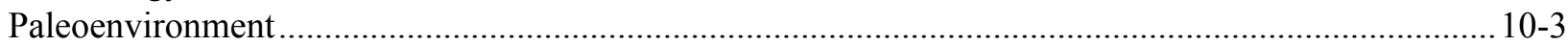

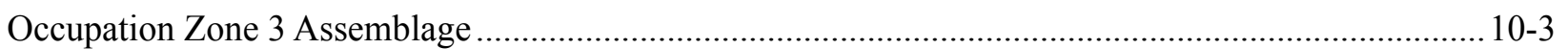

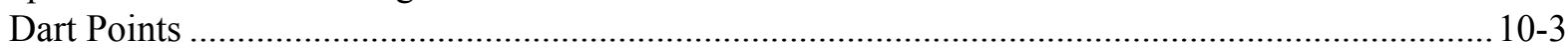

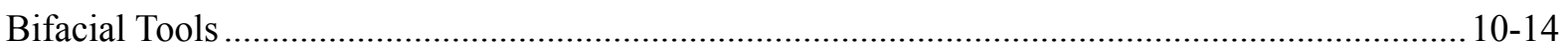

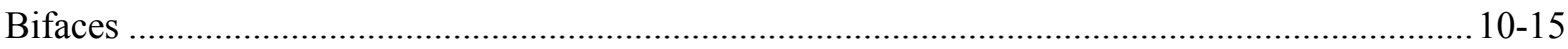

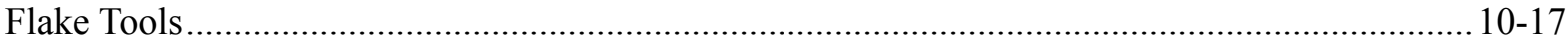

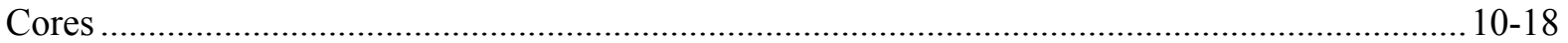


Debitage $10-18$

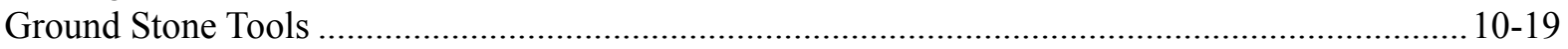

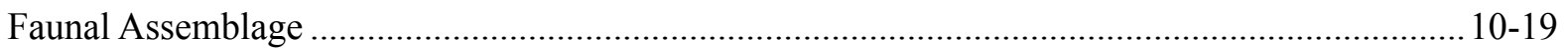

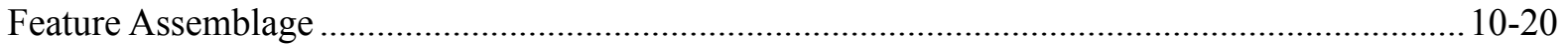

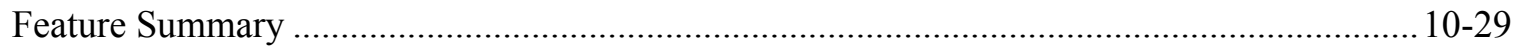

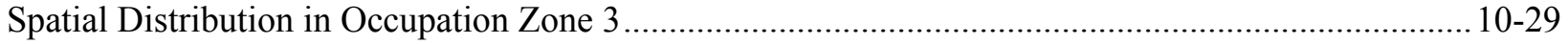

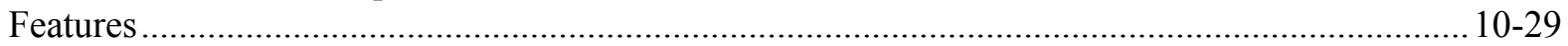

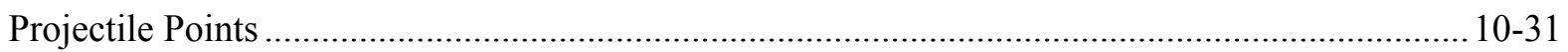

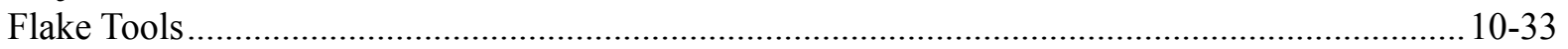

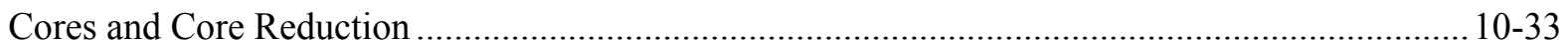

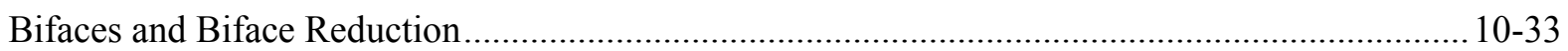

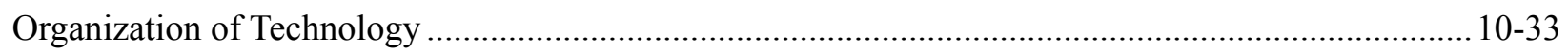

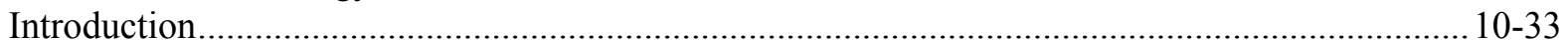

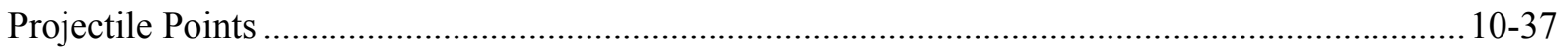

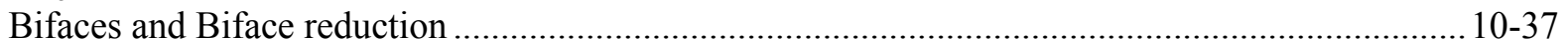

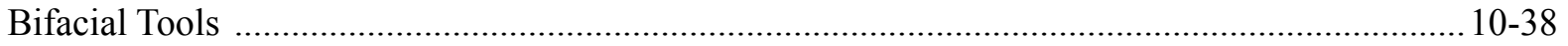

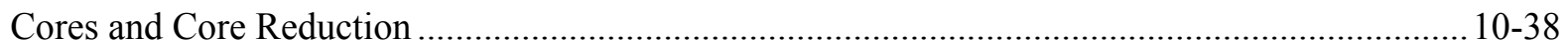

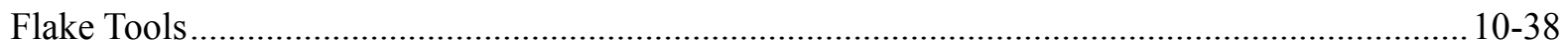

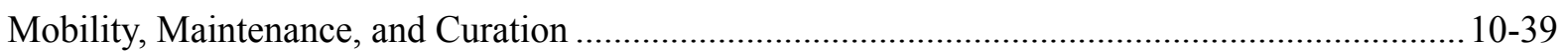

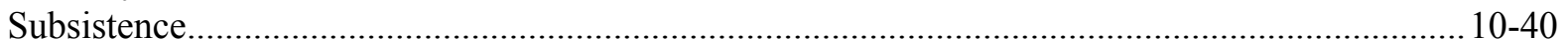

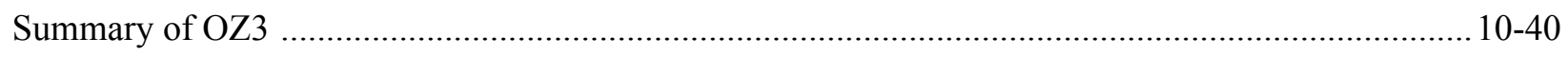

\section{Chapter 11: Occupation Zone 4}

By: Eric R. Oksanen, Mercedes C. Cody, and Kevin A. Miller

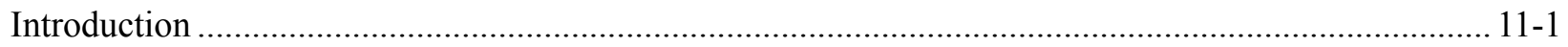

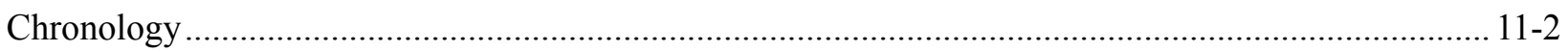

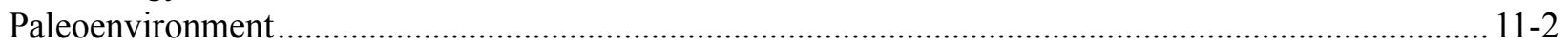

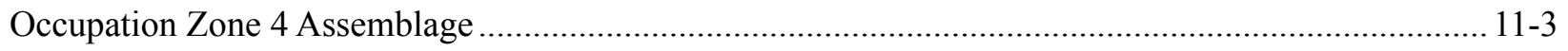

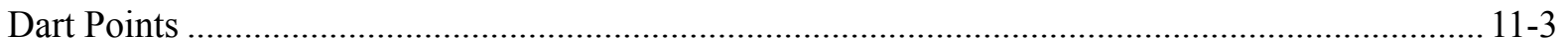

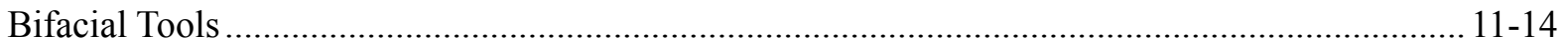

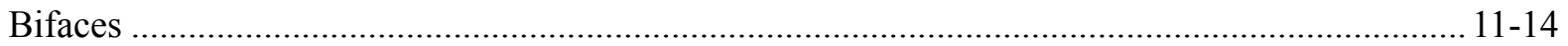

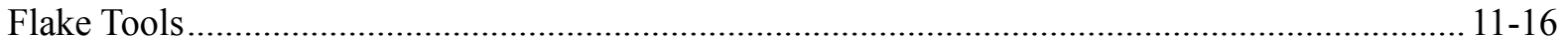

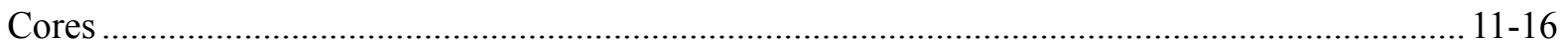

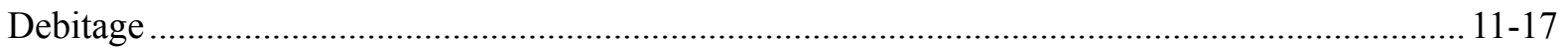

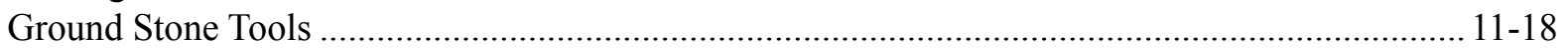

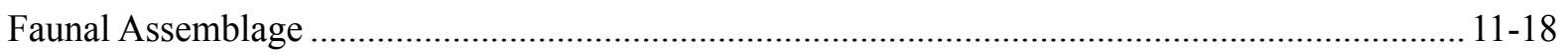

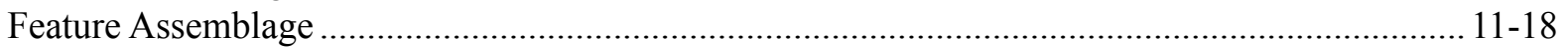

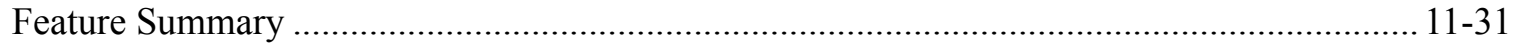

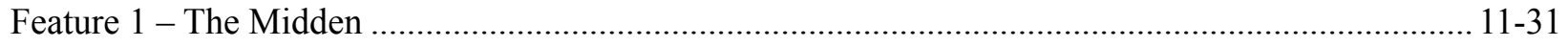

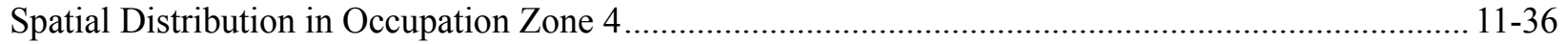

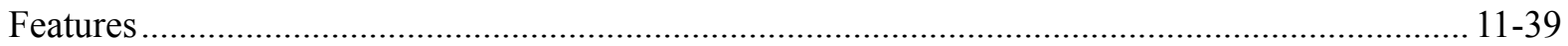

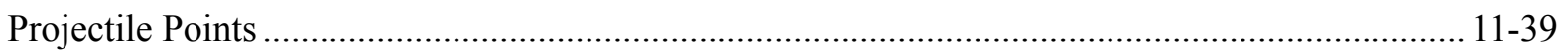

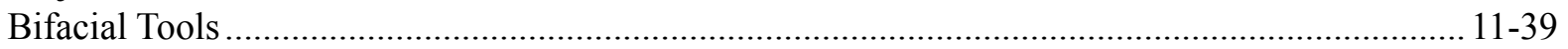

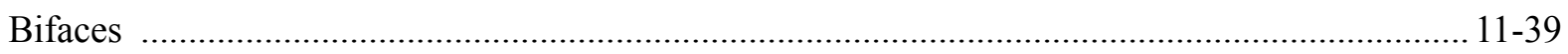

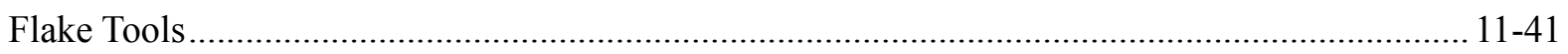

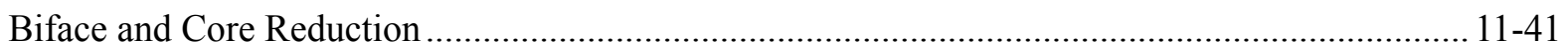

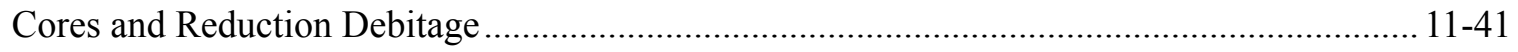

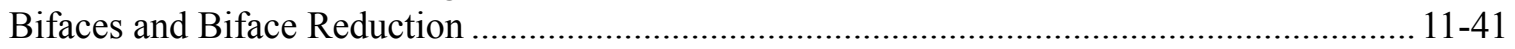




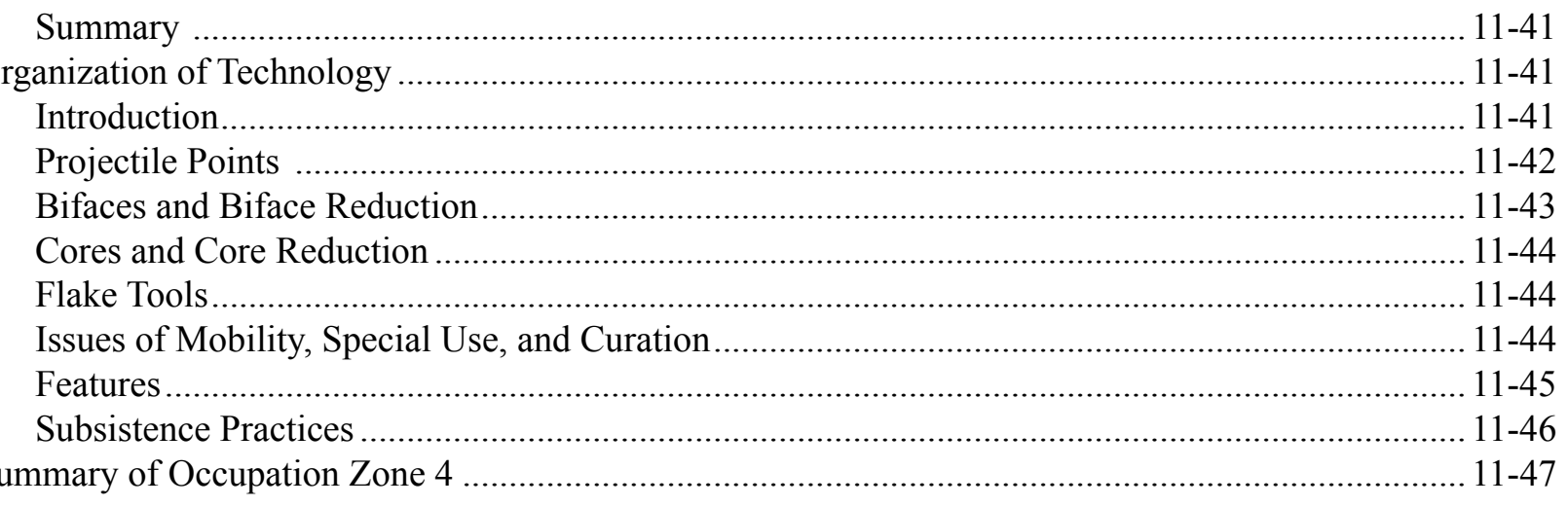

\section{Chapter 12: Continuity and Change at the Gatlin Site}

By: Eric R. Oksanen, Brett A. Houk, and Kevin A. Miller

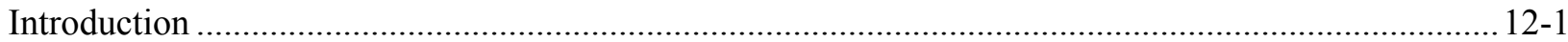

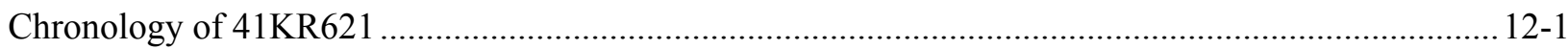

Temporal Structure of the Gatlin Site ............................................................................................... 12-1

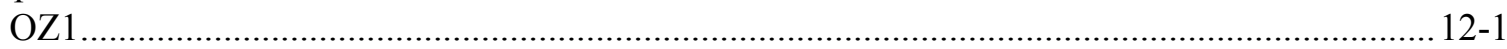

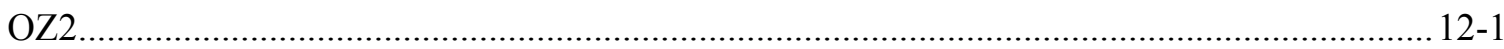

OZ3

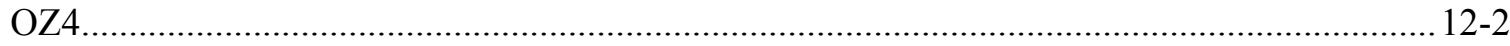

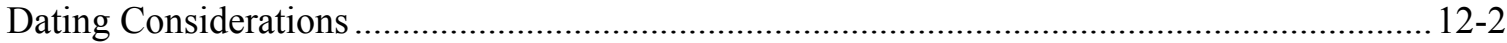

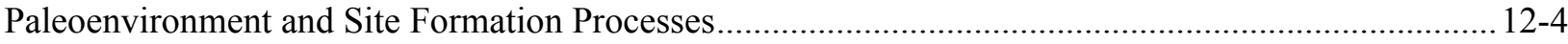

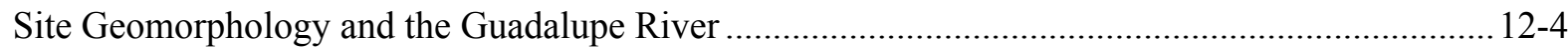

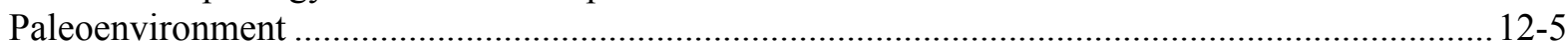

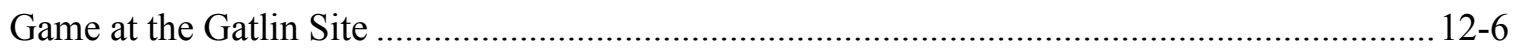

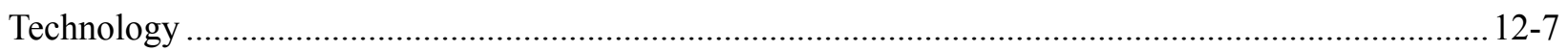

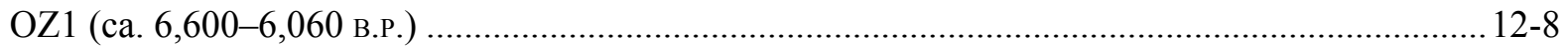

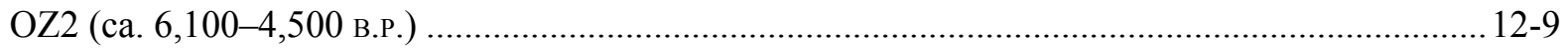

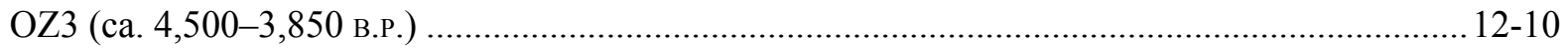

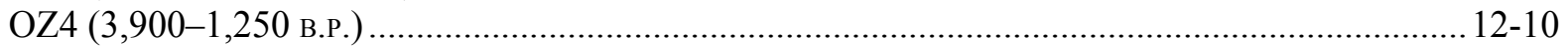

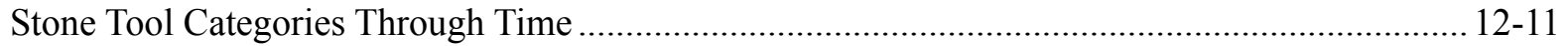

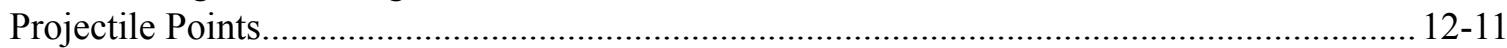

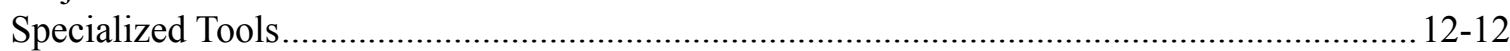

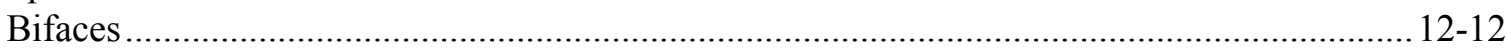

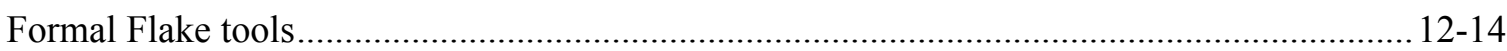

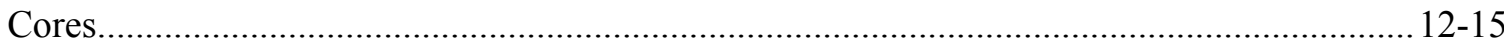

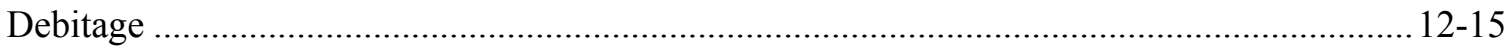

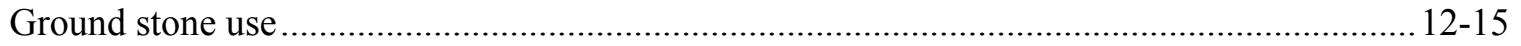

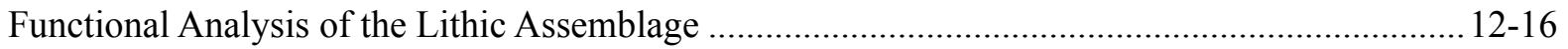

Lithic Assemblages Through Time- Implications for Technological Organization........................12-17

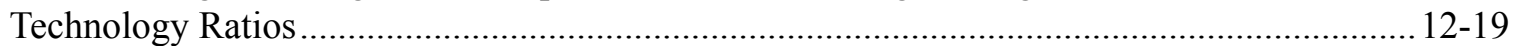

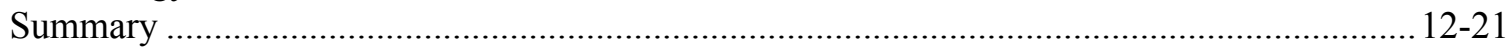

Burned Rock Technology at Gatlin...................................................................................... 12-21

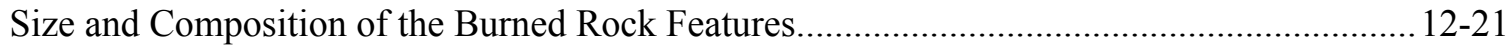

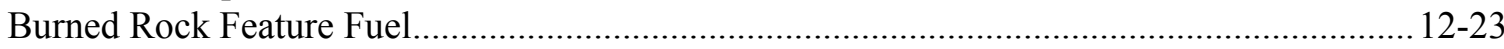

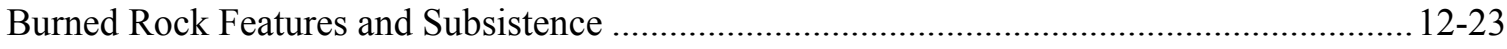

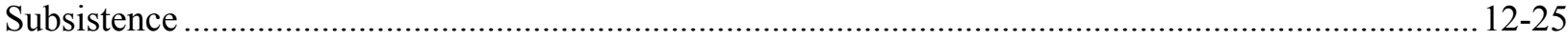


Site Structure and Organization

Hunter Gather Organization at the Gatlin Site ........................................................................ 12-27

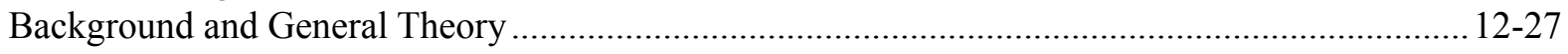

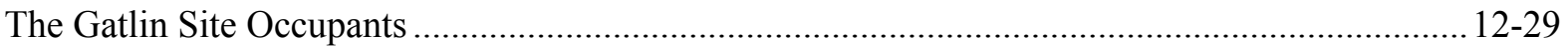

\section{Chapter 13: The Gatlin Site in a Regional Context}

By: Brett A. Houk, Eric R. Oksanen, and Kevin A. Miller

Introduction

The Gatlin Site and the Early-Middle Archaic Chronology of the Southern Edwards Plateau.............. 13-1

Assessing the Integrity of the Deposits and the Gatlin Early-Middle Archaic Sequence.................13-2

A Partial Chronology for the Southern Edwards Plateau ............................................................ 13-3

Contributions to the Regional Chronological Database ............................................................... 13-6

Paleolandscapes and Climate of Central Texas During the Middle Holocene........................................ 13-7

Regional Geomorphic Analyses of River and Stream Systems ...............................................................13-7

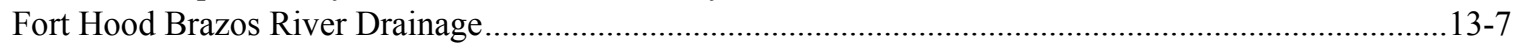

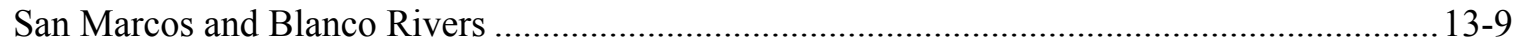

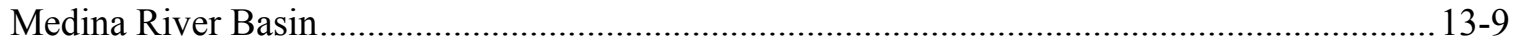

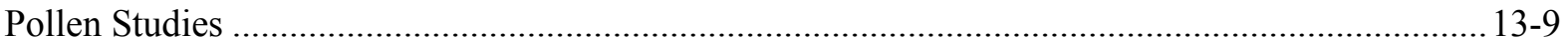

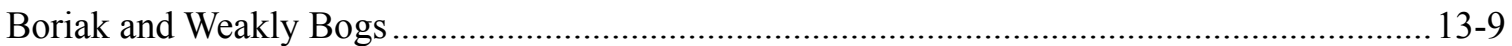

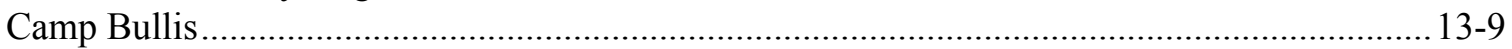

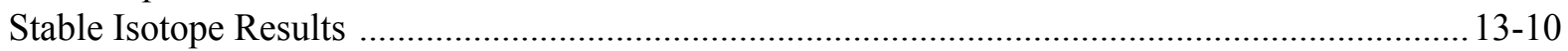

Archaeological Site Summaries of the Middle Holocene Paleoenviroment................................... 13-10

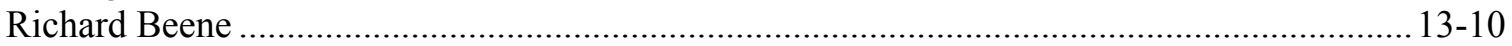

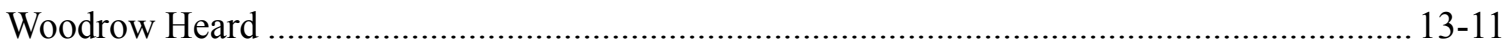

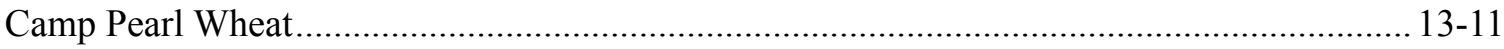

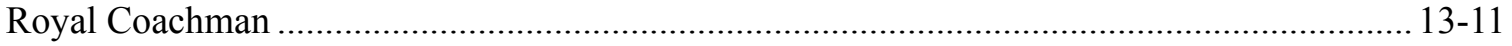

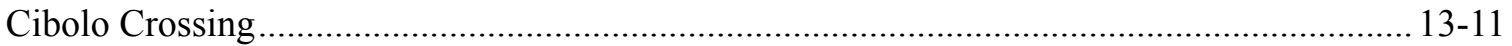

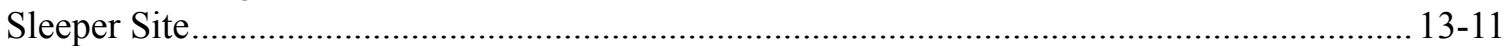

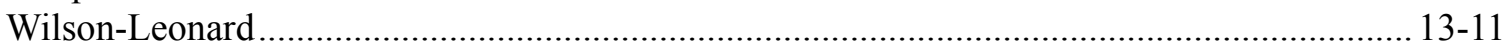

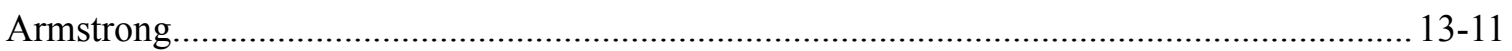

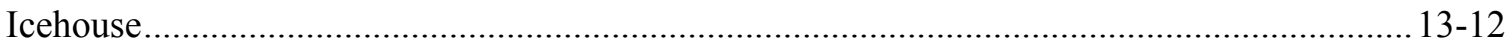

The Gatlin Site in Regional Paleocontext.............................................................................. 13-12

Early and Middle Archaic Adaptation on the Southern Edwards Plateau ..........................................13-13

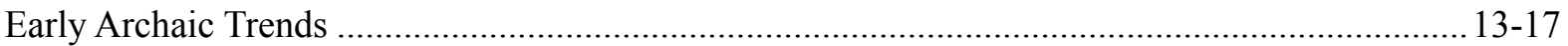

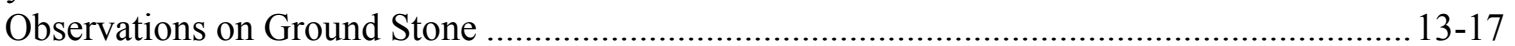

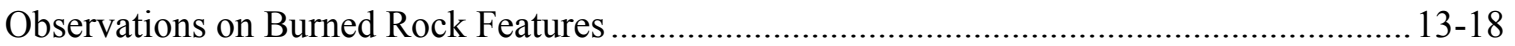

Observations on Gouges, Guadalupe Tools, Clear Fork Tools, and Scrapers ..........................13-18

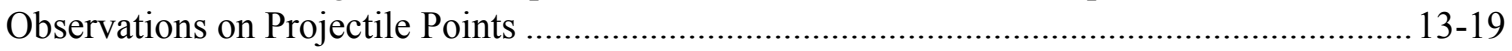

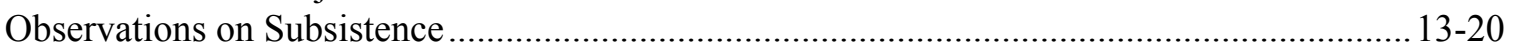

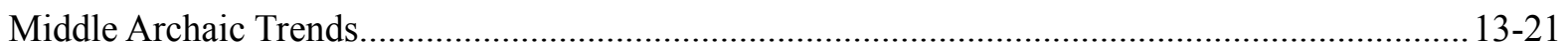

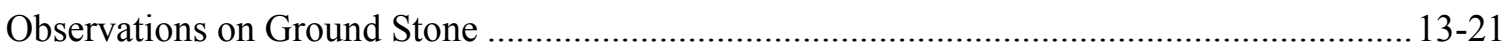

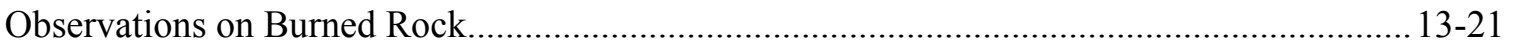

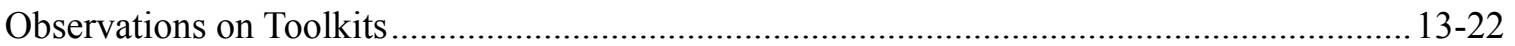

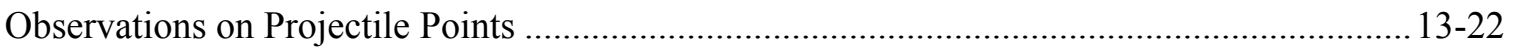

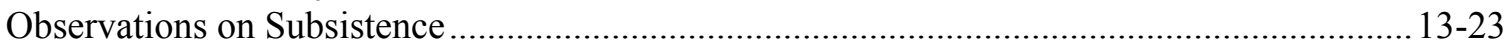

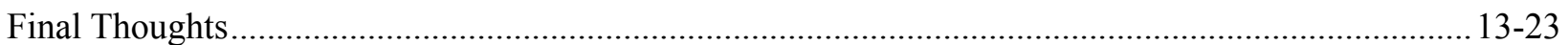

\section{References}


Appendix A: Geomorphology - Geoarchaeology

Appendix B: Radiocarbon Assays (Refer to CD-ROM)

Appendix C: Technology

Appendix D: Use Wear Analysis (Refer to CD-ROM)

Appendix E: Lithic Artifacts (Refer to CD-ROM)

Appendix F: Macrobotanical Studies (Refer to CD-ROM)

Appendix G: Pollen \& Phytolith Analysis (Refer to CD-ROM)

Appendix H: Lipid Residue Studies (Refer to CD-ROM)

Appendix I: Faunal Analysis (Refer to CD-ROM)

Appendix J: Mussel Shell Studies (Refer to CD-ROM)

Appendix K: Evaluation of Project Methodology 


\section{Figures}

1.1. Photograph of the Guadalupe River crossing in Spur 98 project area ......................................... 1-1

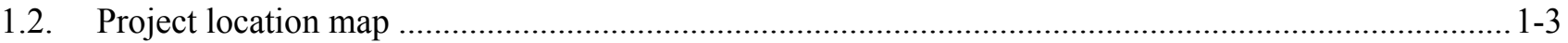

1.3. Photograph of grassy field and terrace at the Gatlin site during the survey of the Spur 98

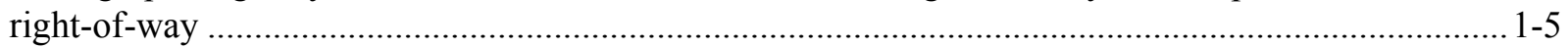

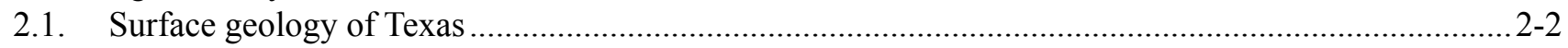

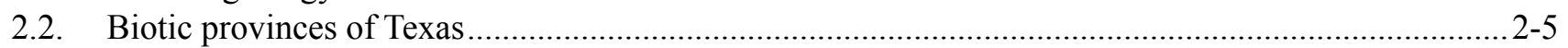

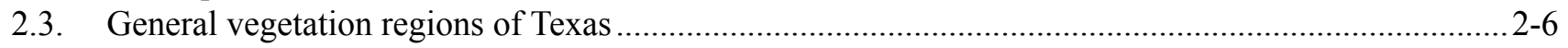

3.1. Representative Archaic archaeological sites of the Edwards Plateau Region ...................................3-9

4.1. Project location map, detail of the northern and southern approaches to the Guadalupe River ............ 4-2

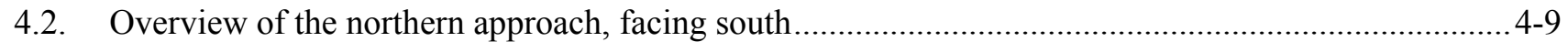

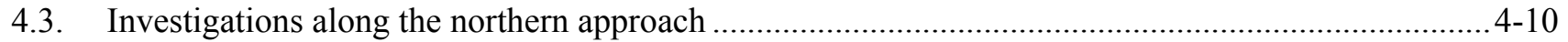

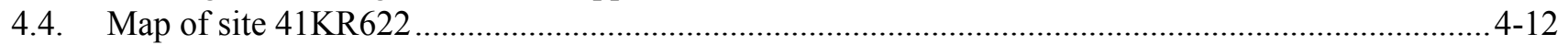

4.5. Site 41KR622 from southeast of Arcadia Loop Road ................................................................. 4-13

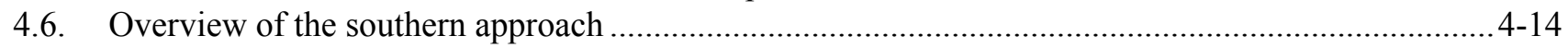

4.7. Survey and testing investigations along the southern approach ................................................. 4-15

4.8. Distribution of burned rock by auger test at the Gatlin site ...................................................... 4-16

4.9. Distribution of debitage by auger test at the Gatlin site............................................................... $4-17$

4.10. Profile of BHT 1 at the Gatlin site, showing the burned rock midden and B horizon below ............. 4-17

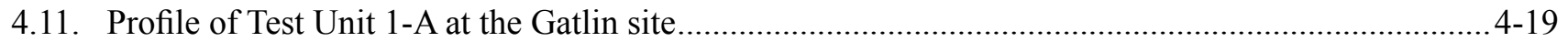

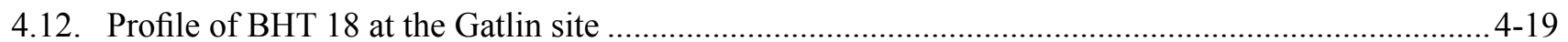

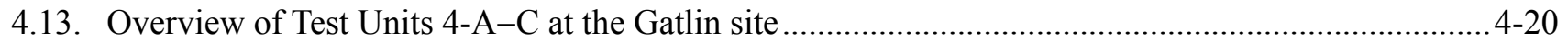

6.1. Data recovery excavations with select testing trenches and profiles ............................................. 6-2

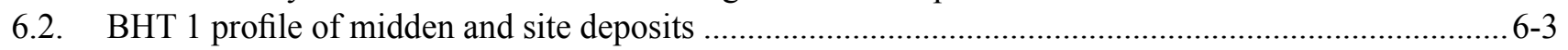

6.3. Data from four profiles within the Gatlin site. ...................................................................... 6-6

6.4. Geomorphic cross-section of the Guadalupe River floodplain at the Gatlin site............................. 6-12

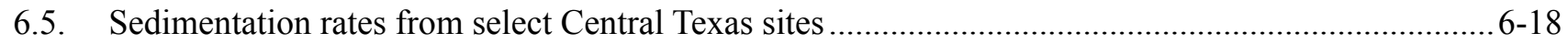

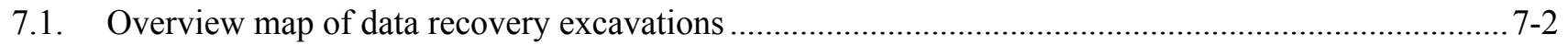

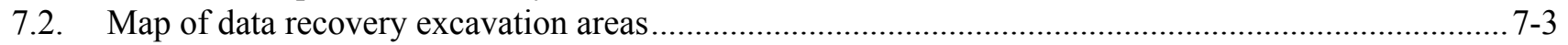

7.3. Mechanical stripping of Area A-NE, facing northeast............................................................... 7-4

7.4. Checkerboard excavations of alternating Feature Focused and Traditional units underway in

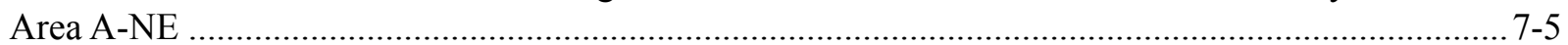

7.5. Overview of Area A, facing northeast; at center left is Area A-SW ............................................... 7-10

7.6. Area A-NE and Area A-SE excavation blocks and unit numbers ................................................ 7-11

7.7. Feature 12, small burned rock cluster, facing north............................................................... 7-12

7.8. Feature 25, a large burned rock cluster ................................................................................. $7-13$

7.9. Area A-NW and Area A-SW excavation blocks and unit numbers ............................................... 7-18

7.10. Typical density of non-feature burned rock within Area A-NW ................................................ 7-20

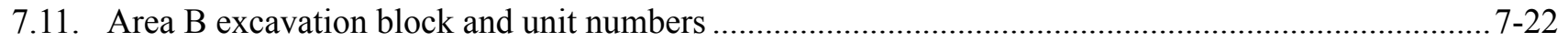

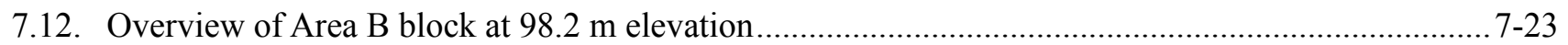

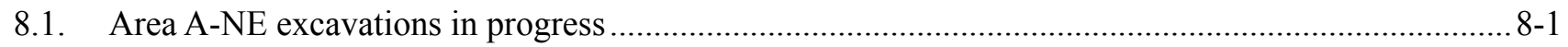

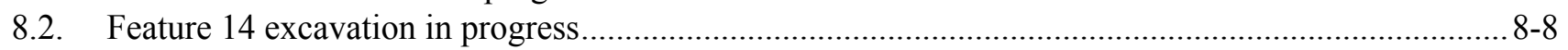

8.3. Occupation Zone 1 Area A-NE feature locations with projectile points and biface tools .................. 8-14

8.4. Occupation Zone 1 Area A-NE biface reduction flakes and biface distribution................................ 8-15

8.5. Occupation Zone 1 Area A-NE informal and formal flake tools distribution................................... 8-16

8.6. Occupation Zone 1 Area A-NE core reduction flakes and core distribution...................................... 8-17

9.1. Area A-SW excavations in progress facing Southwest................................................................ 9-1 
9.2. Feature 13 excavation in progress facing West....................................................................... 9-16

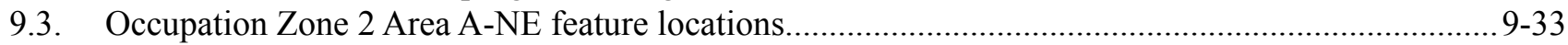

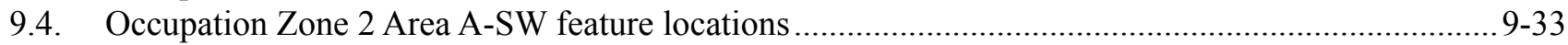

9.5. Occupation Zone 2 Area A-NW feature locations .....................................................................9-34

9.6. Occupation Zone 2 Area A-NE projectile point distribution ........................................................35

9.7. Occupation Zone 2 Area A-SW projectile point distribution....................................................... 9-36

9.8. Occupation Zone 2 Area A-NE biface reduction flakes and biface distribution ...............................9-37

9.9. Occupation Zone 2 Area A-SW biface reduction flakes and biface distribution .............................. 9-37

9.10. Occupation Zone 2 Area A-NE informal and formal flake tool distribution .................................. 9-38

9.11. Occupation Zone 2 Area A-SW informal and formal flake tool distribution.....................................9-38

9.12. Occupation Zone 2 Area A-NE core reduction flakes and core distribution....................................9-39

9.13. Occupation Zone 2 Area A-SW core reduction flakes and core distribution .................................. 9-39

10.1. Area A-SW excavations in progress facing southeast .......................................................... 10-1

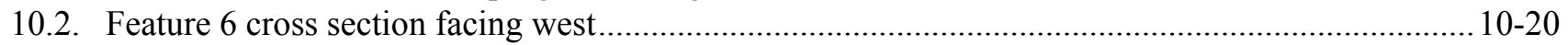

10.3 Occupation Zone 3 Area A-SW and Area A-NE feature locations ............................................ 10-31

10.4. Occupation Zone 3 Area A-NE projectile point distribution .................................................... 10-31

10.5. Occupation Zone 3 Area A-SW and Area A-NW projectile point distribution................................ 10-32

10.6. Occupation Zone 3 Area A-NE, Area A-NW, Area B, and Area B-SW informal and formal

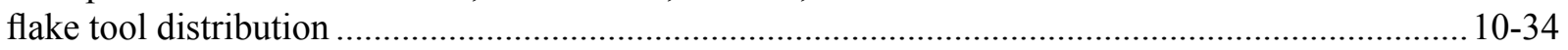

10.7. Occupation Zone 3 Area A-NE, Area A-NW, Area B, and Area A-SW core reduction flakes

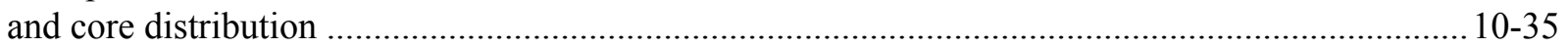

10.8. Occupation Zone 3 Area A-NE, Area A-NW, Area B, and Area A-SW biface reduction flakes

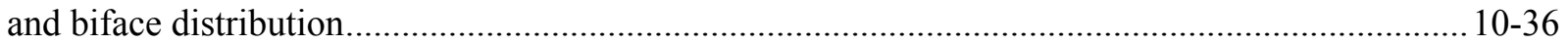

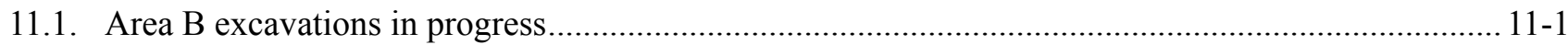

11.3. Occupation Zone 4 Area B feature locations are depicted to the left while Occupation Zone 4

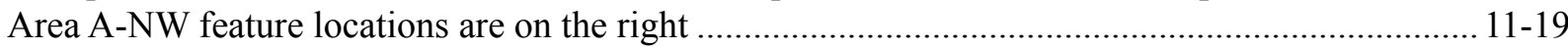

11.2. Midden profile backhoe trench 18 South wall ........................................................................... 11-19

11.4. Trenche, testing unit, and column sample locations across Feature 1 (Midden) ............................ 11-33

11.5. Feature 1 (Midden) spatial burned rock distribution .............................................................. 11-35

11.6. Feature 1 (Midden) spatial burned rock weights distribution ...................................................... 11-35

11.7. Feature 1 (Midden) spatial debitage distribution ................................................................. 11-36

11.8. Feature 1 (Midden) burned rock weights and counts, and debitage counts .................................... 11-37

11.9. Feature 1 (Midden) backhoe trench 18 and control trench 3 profile............................................. 11-38

11.10. Occupation Zone 4 Area B projectile point distribution ............................................................. 11-39

11.11. Occupation Zone 4 Area B biface reduction flakes and biface distribution; core reduction flake and core distribution; and informal and formal flake tools distribution ..................................... 11-40

12.1. Projectile point types by occupation zone .......................................................................... 12-2

12.2. Percentage of cumulative frequency of biface stages by occupation zone ................................... 12-13

12.3. Mean length of biface stages by occupation zone................................................................... 12-14

12.4. Cumulative frequency of tool categories within occupation zone .............................................. 12-19

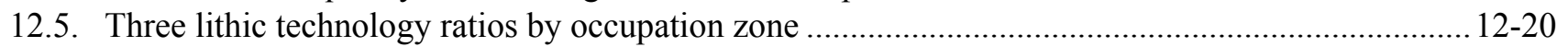

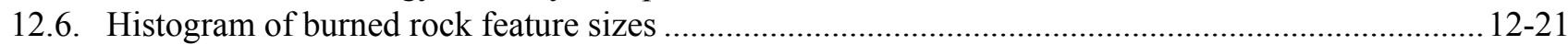

12.7. Distribution of burned rock feature sizes by occupation zone..................................................... 12-22

12.8. Burned rock size categories percentage quantities by occupation zone ........................................ 12-23

12.9. Percentage weight of burned rock size categories by occupation zone ......................................... 12-24

13.1. Seriation of major projectile point types by occupation zone at the Gatlin site ..............................13-3

13.2. Proposed regional chronology based on Gatlin site radiocarbon dates and projectile point seriation

13.3. Composite paleoenvironmental data from select sites in Central Texas correlated to the Gatlin site. 13-8 


\section{Tables}

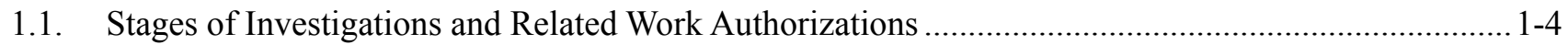

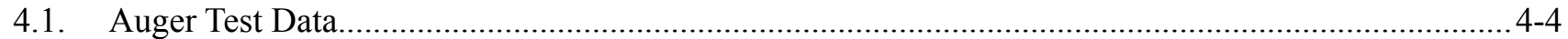

4.2. Column Sample Data from Backhoe Trenches in the Northern Approach ..................................... 4-11

4.3. Vertical Distribution of Cultural Materials from Test Unit 1 at Site 41KR622 ................................4-13

4.4. Summary of Radiocarbon Dates from Testing Excavations and their Proveniences......................... 4-18

4.5. Column Sample Data from Backhoe Trenches in the Southern Approach ....................................... 4-21

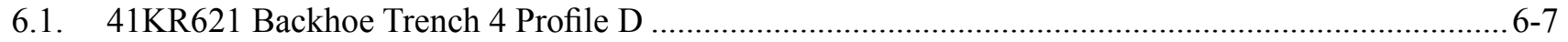

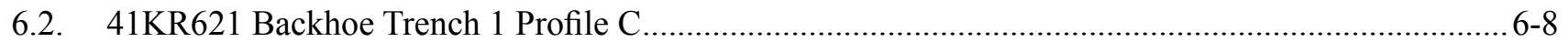

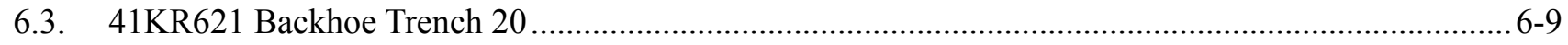

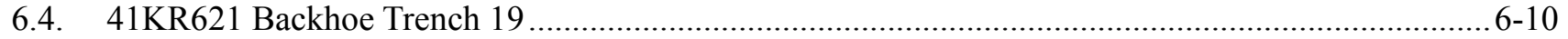

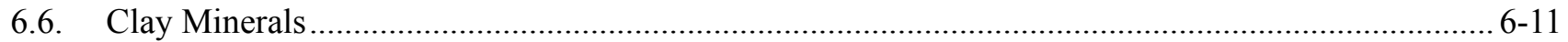

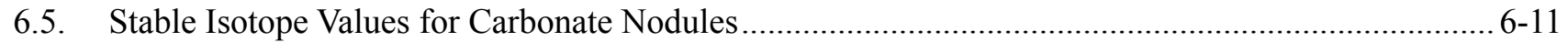

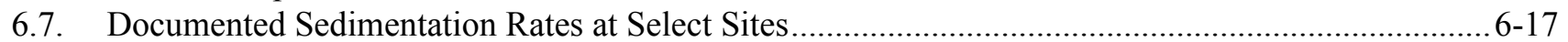

7.1. Summary of All Radiocarbon Dates and Their Proveniences........................................................ 7-7

7.2. Area A-NE Feature Distribution and Associations .................................................................. 7-14

7.3. Area A-NE Artifact Count and Density per Cubic Meter from Data Recovery Block Units ..............7-15

7.4. Vertical Distribution of Projectile Point Types within Data Recovery Units.................................... 7-16

7.5. Area A-SE Artifact Count and Density per Cubic Meter from Data Recovery Block Units...............7-17

7.6. Area A-SW Feature Distribution and Associations...................................................................... 7-19

7.7. Area A-SW Artifact Count and Density per Cubic Meter from Data Recovery Block Units.............. 7-20

7.8. Area A-NW Artifact Count and Density per Cubic Meter from Data Recovery Block Units ............. 7-21

7.9. Area B Feature Distribution and Associations ...................................................................... 7-24

7.10. Area B Artifact Count and Density per Cubic Meter from Data Recovery Block Units .................... 7-24

7.11. Debitage Densities within the Burned Rock Midden Column Samples ........................................... 7-25

8.1. Summary of Lithic Technology for Occupation Zone 1 ............................................................. 8-3

8.2. Occupation Zone 1 Attribute Measurements for General Bifaces by Stage ...................................... 8-6

8.3. Occupation Zone 1 Attribute Measurements for Complete Modified Flake Subcategories .................. 8-7

8.4. Biface, Core, and Indeterminate Reduction Flake Measurements from Occupation Zone 1 ............... 8-7

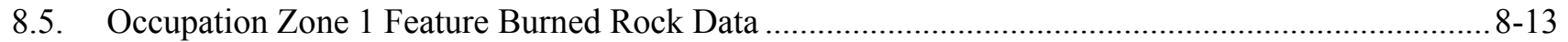

8.6. Occupation Zone 1 Formal and Informal Stone Tools..................................................................... 8-18

9.1. Paleoenvironmental Results from Pollen and Phytolith Samples from Occupation Zone 2 Features... 9-3

9.2. Summary of Lithic Technology for Occupation Zone 2 ................................................................ 9-4

9.3. Occupation Zone 2 Attribute Measurements for General Bifaces by Stage ..................................... 9-11

9.4. Occupation Zone 2 Attribute Measurements for Complete Modified Flake Subcategories ................9-13

9.5. Occupation Zone 2 Attribute Measurements for Complete Exhausted and Unexhausted Cores......... 9-14

9.6. Biface, Core, and Indeterminate Reduction Flake Measurements from Occupation Zone 2 .............. 9-15

9.7. Occupation Zone 2 Feature Burned Rock Data ..................................................................... 9-32

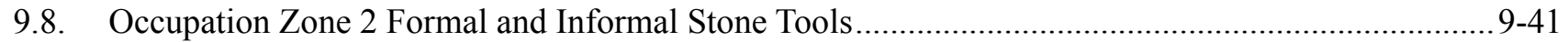

10.1. Summary of Lithic Technology for Occupation Zone 3 ................................................................. 10-4

10.2. Occupation Zone 3 Attribute Measurements for General Bifaces by Stage ..................................10-16

10.3. Occupation Zone 3 Attribute Measurements for Complete Modified Flake Subcategories .............. 10-17

10.4. Occupation Zone 3 Attribute Measurements for Complete Exhausted and Unexhausted Cores.......10-18

10.5. Biface, Core, Resharpening, and Indeterminate Flake Measurements from Occupation Zone 3....... 10-19

10.6. Occupation Zone 3 Feature Burned Rock Data ........................................................................ 10-30

10.7. Biface Stage Distribution for Occupation Zones 2 and 3 ....................................................10-38

10.8. Occupation Zone 3 Formal and Informal Stone Tools............................................................... 10-39 
11.1. Summary of Lithic Technology for Occupation Zone 4

11.2. Occupation Zone 4 Attribute Measurements for General Bifaces by Stage ................................... 11-15

11.3. Occupation Zone 4 Attribute Measurements for Complete Modified Flake Subcategories .............. 11-16

11.4. Occupation Zone 4 Attribute Measurements for Complete Exhausted and Unexhausted Cores...... 11-17

11.5. Biface, Core, Resharpening, and Indeterminate Reduction Flake Measurements from Occupation Zone 4

11.6. Occupation Zone 4 Feature Burned Rock Data ......................................................................... 11-32

11.7. Standardized Burned Rock and Debitage Data from Feature 1 (Midden) ....................................... 11-34

11.8. Occupation Zone 4 Formal and Informal Stone Tools.............................................................. 11-44

12.1. Lithic Assemblages from Occupation Zones ............................................................................... 12-8

12.2. Biface Reduction Stage Counts by Occupation Zone ................................................................ 12-12

12.3. Summary Table of Boone's Measure of Assemblage Heterogeneity for Bifaces by Occupation Zone.....

12.4. Formal Flake Tool Counts and Percentages by Occupation Zone .............................................12-14

12.5. Ratio of Unexhausted and Exhausted Cores .......................................................................... 12-15

12.6. Summary of Boone's Measure of Assemblage Heterogeneity for Cores by Occupation Zone......... 12-16

12.7. Counts and Percentage of Debitage by Flake Type ................................................................ 12-16

12.8. Summary of Bifacial Tool Functional Analysis ....................................................................... 12-17

12.9. Summary of Functional Analysis of Thin Bifaces ..................................................................... 12-18

12.10. Cumulative Frequency of Tool Categories within Occupation Zones .......................................... 12-19

12.11. Summary of Boone's Measure for Heterogeneity for Lithic Assemblage Summaries from Occupation Zones

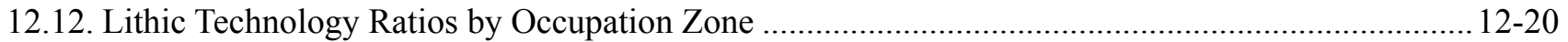

13.1. Data from Select Early Archaic Sites/Components Including the Gatlin Site............................... 13-14

13.2. Data from Select Middle Archaic Sites/Components Including the Gatlin Site ............................. 13-15 


\title{
Chapter 1
}

\section{Introduction to the Gatlin Site}

\author{
Brett A. Houk
}

\section{INTRODUCTION}

Over many millennia, before Europeans arrived in Texas, Native Americans repeatedly visited and occupied the banks of the Guadalupe River in what is today Kerr County (Figure 1.1). Through the intersection of human history, modern transportation planning, and preservation law, one of the areas where they lived, hunted, and generally carried on the business of being human came to be discovered, named, excavated, analyzed, and described. This report documents SWCA Environmental Consultants' (SWCA) investigations and subsequent interpretations of the cultural remains at the Gatlin site, 41 KR621-a remarkable prehistoric campsite in the Upper Guadalupe River Basin that was occupied between approximately 7,600 and 1,100 years ago.

The Gatlin site represents one of the largest Early-toMiddle Archaic artifact assemblages associated with radiocarbon dates from an excavated site in Central Texas and, therefore, contributes greatly to the regional archaeological data base and our understanding of human lifeways during the Archaic. In general, the Gatlin site chronology supports the relative sequence of point styles presented in both Collins (2004: Fig. 3.9a) and Johnson and Goode (1994:Figure 2), but provides chronometric ages for Gower, Martindale, Bell, Andice, Early Triangular, Nolan, and La Jita projectile point styles.

\section{History of the Project}

Since the proposed construction included both state and federal funding, the Texas Department of Transportation (TxDOT) was required to comply with Section 106 of the National Historic
Preservation Act, the implementing regulations of 36CFR Part 800, and the Texas Antiquities Code. TxDOT was required to identify all archeological sites within the area of potential effects, evaluate their eligibility for listing on the National Register of Historic Places and for designation as a State Archeological Landmark. The area of potential effects included all existing and new rights-of-way and other areas affected by the proposed project. In the case of 41 KR621, since the archeological site was determined eligible for listing under Criterion D in consultation with the SHPO and since impacts could not be avoided, a plan to mitigate the effects was developed. The subsequent scope of work in the form of data recovery is the basis of this report. All work was conducted under the terms and conditions of the First Amended Programmatic Agreement Among TxDOT, FHWA, SHPO, and the Advisory Council on Historic Preservation (2005).

The impetus for the investigations was the proposed, and now extant, extension of Spur 98 from its terminus on the southern bank of the Guadalupe River to Farm-

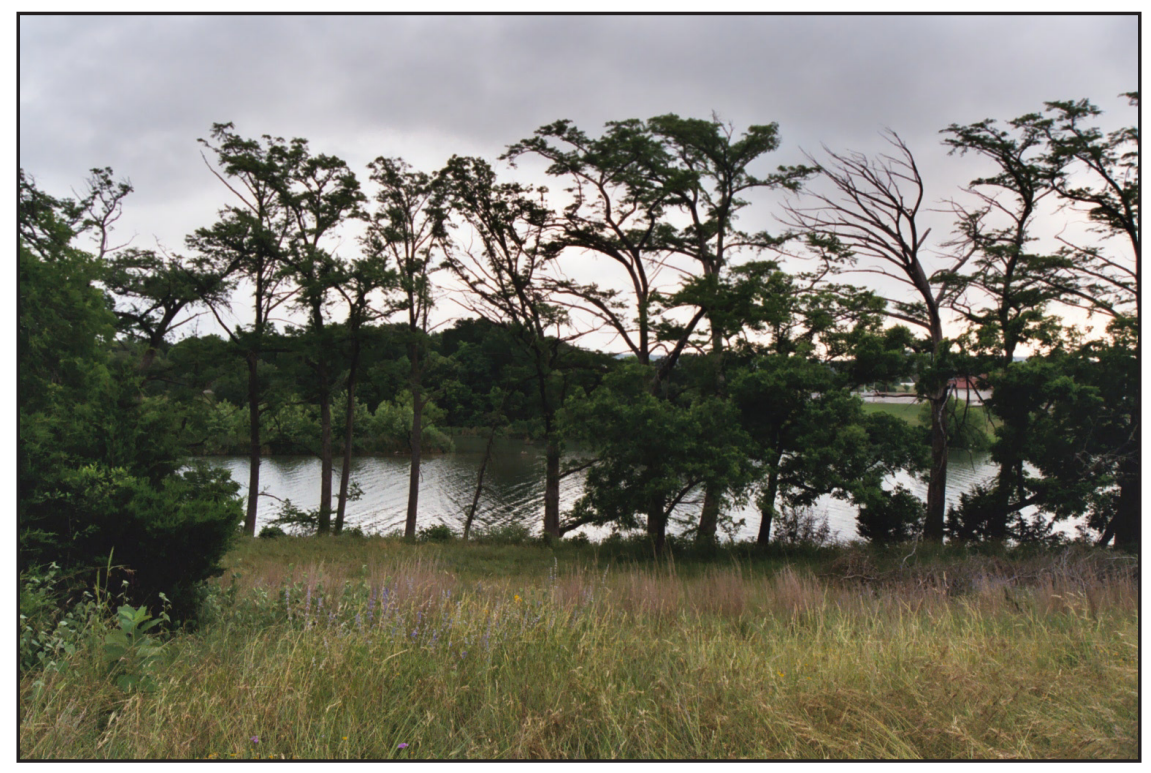

Figure 1.1. Photograph of the Guadalupe River crossing in Spur 98 project area. 
to-Market (FM) 1338, on the northern bank of the river (Figure 1.2). The construction project, one that had been long contemplated by the San Antonio District of TxDOT, involved new right-of-way that crossed a largely undisturbed terrace on the right bank of the Guadalupe River and included plans for a new bridge to span the river. Given the potential for cultural materials to be present in such a setting, archaeologists at TxDOT's Environmental Affairs Division (ENV) took an early interest in the project and conducted a preliminary study of the corridor as early as January 2000 (Abbott 2004). Those initial investigations involved geoarchaeological investigations consisting of 15 hollow auger cores, which were extracted from various locales along the proposed Spur 98 alignment (Abbott 2004:1). TxDOT archaeologists, during the coring, observed burned rock and other artifacts in a utility trench on the southern bank of the river within the limits of the proposed right-of-way, and two of the cores encountered buried cultural material "at several levels...suggesting that multiple components may be represented in the archaeological strata" (Abbot 2004:17).

Although a site was not designated at that time, TxDOT archaeologists were acutely aware of the high probability that stratified prehistoric materials would be encountered within the proposed right-ofway of Spur 98. This knowledge shaped subsequent planning with respect to future environmental compliance. However, a thorough study of the Spur 98 impact area would have to wait while TxDOT negotiated the purchase of new right-of-way on the southern approach to the river, and it was not until 2004 that it became possible to survey the alignment for cultural resources. Meanwhile, TxDOT's proposed construction schedule was working its way through the system, culminating with a letting date in late 2004. This put a certain amount of pressurethat would be felt throughout the various stages of investigation - on the environmental compliance process, requiring any and all archaeological investigations to be completed prior to the letting date.

It was during the initial stages of the cultural resources compliance process that SWCA became involved. SWCA was originally contracted by Turner Collie \& Braden, Inc. (TCB) to conduct the survey investigations along the Spur 98 corridor (Table 1.1). TCB, an engineering firm in San Antonio, was involved with some of the early engineering work on the project and had an on-call contract with the San Antonio District, through which the archaeological survey was subcontracted to SWCA. Given the anticipated discovery of a site and the looming letting date, SWCA, with input from TxDOT, developed an intensive survey program that included geoarchaeology and a contingency to conduct limited test excavations, if warranted. This work was performed May 17-June 26, 2004. Kevin A. Miller served as Principal Investigator for the project, which was conducted under Texas Historical Commission (THC) Antiquities Permit 3429.

The intensive survey resulted in the recording of sites 41KR621 and 41KR622, located within the proposed Spur 98 right-of-way on the southern and northern banks of the Guadalupe River, respectively. SWCA conducted limited archaeological testing at the two sites immediately after the survey and under the same Antiquities Permit. Based on the results of the survey and testing, SWCA recommended that 41KR622 is not eligible for National Register of Historic Places (NRHP) listing under criteria in 36 CFR 60.4 and does not warrant State Archeological Landmark (SAL) designation under criteria in 13 TAC 26.8 due to poor integrity and low potential data yield. However, the testing investigations at 41KR621, the Gatlin site, revealed that the site's cultural components were diverse and relatively intact, with stratified materials dating from the Early Archaic through the Late Archaic. As such, the site was found to be eligible for NRHP listing under Criterion D of 36 CFR 60.4 and warranted SAL designation under criteria in 13 TAC 26.8 .

Following the testing project, SWCA prepared an interim report on the results under the original TCB contract (Houk and Miller 2004a). Subsequently, TxDOT contracted SWCA to prepare a research design for data recovery excavations (Houk and Miller 2004b). This was accomplished in an extremely compressed time frame (see Table 1.1) because it was necessary to mobilize the field project as quickly as possible to meet the construction deadlines. 


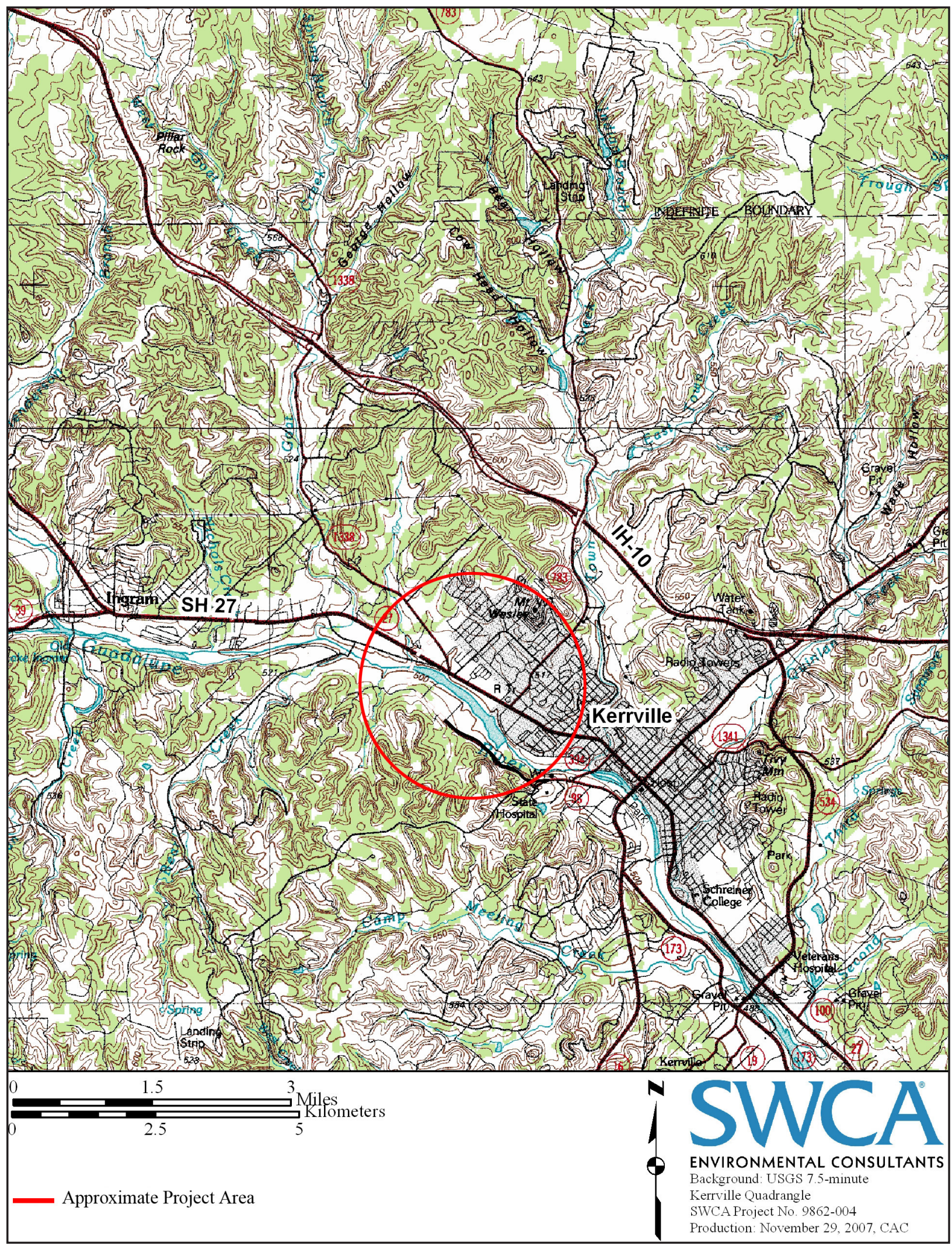

Figure 1.2. Project location map. 
Table 1.1. Stages of Investigations and Related Work Authorizations

\begin{tabular}{|c|c|c|c|c|}
\hline Phase of Investigation & Contract & $\begin{array}{c}\text { Work } \\
\text { Authorization(s) }\end{array}$ & Dates & $\begin{array}{c}\text { Texas } \\
\text { Antiquities Permit }\end{array}$ \\
\hline Survey and limited testing & $\begin{array}{c}\text { TCB/TxDOT Contract No. } \\
\text { 15-448P500 }\end{array}$ & $1,2,3$, and 4 & $\begin{array}{l}\text { May } 17,2004 \text { to } \\
\text { June } 26,2004\end{array}$ & 3429 \\
\hline $\begin{array}{c}\text { Data recovery research } \\
\text { design }\end{array}$ & $573 X X S A 007$ & 20 & $\begin{array}{l}\text { August 16, } 2004 \text { to } \\
\text { September } 2004\end{array}$ & \\
\hline Data recovery fieldwork & 573XXSA007 & 21 & $\begin{array}{l}\text { September 9, } 2004 \text { to } \\
\text { November 24, } 2004\end{array}$ & 3532 \\
\hline Analysis and reporting & 575XXSA005 & 1,6 , and 16 & $\begin{array}{l}\text { June } 7,2005 \text { to } \\
\text { August } 2008\end{array}$ & \\
\hline
\end{tabular}

Based on the proposed work plan and investigative strategies in the research design, ENV then contracted SWCA to conduct the data recovery excavations at the Gatlin site. Those investigations took place under THC Antiquities Permit 3532, and Kevin A. Miller again served as the Principal Investigator. Dr. Brett A. Houk was the Project Archaeologist and supervised the daily field operations. W. Boone Law assisted Dr. Houk as a Prehistoric Archaeologist and co-directed the data recovery excavations. The fieldwork took place from September 9 to November 24, 2004.

The analysis and reporting of the artifacts, samples, and field data collected during all phases of investigation began on June 7, 2005, and were completed with the production of this final report. Much of the analysis was overseen by Dr. Brett Houk and Boone Law, but Dr. Michael Smith, Eric Oksanen, and Kevin Miller were responsible for much of the actual reporting.

\section{Project Description}

The construction project that triggered the excavations at the Gatlin site was the extension of Spur 98 from its pre-2005 terminus on the southern bank of the Guadalupe River to FM 1338 on the northern bank of the river. The project area was 1.15 miles long and consisted of new right-of-way from the original terminus of Spur 98 to its new terminus at FM 1338 on the opposite bank of the Guadalupe River. The right-of-way width varies from 120 to about 220 feet. Spur 98's original alignment ended in an upland setting, west of State Highway (SH) 16. The extension encompassed an existing county road in the uplands, before dropping off the upland slopes on its approach to a new bridge spanning the Guadalupe River. From the base of the uplands, the right-of-way transects an asymmetric terrace complex on both sides of the river.

The undertaking was funded by state and federal monies. Initial archaeological investigations were implemented as required by Section 106 of the National Historic Preservation Act of 1966 as amended and under the terms and conditions of the Programmatic Agreement between TxDOT, THC, the Federal Highway Administration, and the Advisory Council on Historic Preservation.

The Spur 98 project area occupies a cut limestone valley in the Texas Hill Country, crossing the Guadalupe River west of downtown Kerrville, 2.5 miles west of the SH 16 Guadalupe River crossing. The southern portion of the project area-from the end of the original Spur 98 alignment-skirts the colluvial toeslope along the footprint of the county road on the southern side of the river valley for approximately $1 \mathrm{~km}$ before turning north and crossing the river. The southern approach crosses at least two terraces of the river and a narrow floodplain. Prior to the construction of the new road, this terrace complex contained grassy fields with scattered cedar elm and juniper trees growing along old fence lines. Large cypress trees lined the riverbank on the southern approach.

The northern approach, which occupies a broad terrace of the river, is more developed. Arcadia Loop (a two-lane asphalt road) and an abandoned commercial building were situated immediately north of the river, south of SH 27, within the right-of-way. After crossing SH 27, a four-lane road with a center turn lane, the right-of-way passed through a plowed field before intersecting FM 1338, its northern terminus. The vast majority of the northern approach was disturbed by the roadways, modifications for 
commercial development, and agricultural impacts prior to SWCA's initial investigations of the project area.

\section{DESCRIPTION OF 41 KR621}

Site 41KR621 is located on the southern approach of Spur 98 to the Guadalupe River, on the river's right bank. Prior to the construction of the road, this was a grassy field with no surface indication that a site was present; the cultural materials were completely buried (Figure 1.3). The site, as delineated by the survey, essentially covered the entire right-ofway - which varies from 100-220 feet wide on the approach - from the base of an upland toeslope at the southern end of the site to the scarp of the terrace above the river, a distance of approximately $200 \mathrm{~m}$. There were areas, however, within these boundaries with few or no artifacts. The site undoubtedly extends to the east and west beyond the limits of the rightof-way.

Survey and testing determined that the area with the densest cultural materials was at the southern end of the site, near the base of the toeslope of the valley margins. This area contained a burned rock midden that was completely buried by an admixture of colluvium and alluvium. The midden was encountered at the western edge of the right-of-way, but cultural materials and features associated with the midden extended across the width of the corridor. Beneath the midden component was a well-preserved and extensive Early Archaic component that covered over 1,650 $\mathrm{m}^{2}$. Because of its stratified occupations, extensive Early Archaic component, level of preservation, and diverse artifact assemblage, the site was determined to be eligible for NRHP and SAL status. Because avoidance was not feasible, SWCA recommended that data recovery be conducted at the site to mitigate the impacts from the proposed extension of Spur 98.

\section{Data Recovery Investigations}

The data recovery excavations targeted both the midden-related occupation at the site and the older Early Archaic component, with approximately twothirds of the field effort devoted to the latter. The initial research design proposed by SWCA revolved around two broad themes: (1) prehistoric culture change and continuity in the Upper Guadalupe River valley and geomorphology at 41KR621 and (2) implications for site preservation in southern Central Texas. In the final research design, which was prepared after the data recovery excavations had been completed, these themes were re-examined and modified with subdivisions into research domains that include paleoenvironment and site formation processes, chronology, technology, site structure and organization, and subsistence.

Many of the issues within the original research design were focused, in large part, on examining the spatial organization of the site (which unfortunately proved less than fruitful). Therefore, SWCA developed a methodology designed to maximize horizontal exposure while still recovering an adequate sample of artifacts from screened matrix. Because the approach SWCA employed was untested in Central Texas, a sixth research domain was added to the final research design: a critical evaluation of the methodology.

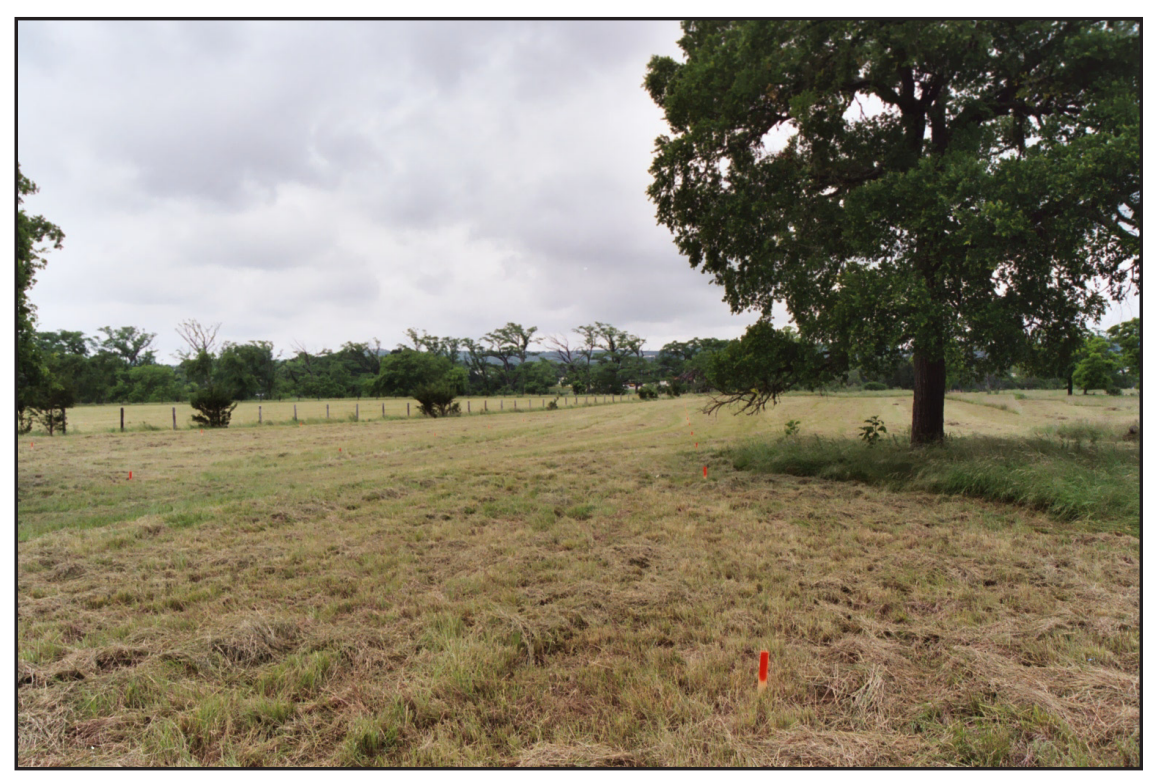

Figure 1.3. Photograph of grassy field and terrace at the Gatlin site during the survey of the Spur 98 right-of-way. 
The testing and data recovery investigations at the Gatlin site documented four cultural occupations, which are referred to in this report as Occupation Zones (OZ) 1-4. The earliest of the Gatlin site's components, OZ1, dates from approximately 6,800 B.P. to possibly as late as 6,000 B.P., falling within the Early Archaic. OZ2, which was a younger and more extensive Early Archaic occupation, yielded several burned rock features and appears to have covered the period of ca. 6,100-4,500 B.P. The third occupation zone, OZ3, is a Late Early to Early Middle Archaic component that produced dates of ca. 4,500-3,850 B.P. and diagnostic artifacts commonly associated with the end of the Early Archaic and the beginning of the Middle Archaic. OZ3 represents a more compressed deposit or a transitional phase between the two periods. The youngest occupation, OZ4, which proved to be an admixture of broad temporal and cultural components that were not the main focus of the excavations, spans the Middle through Late Archaic periods, as evidenced by radiocarbon dates and numerous diagnostic point types. This component includes the burned rock midden at the site.

\section{Organization of this Report}

This report is structured to present the necessary background information, data from the investigations, and application of the research design in as comprehensible a manner as possible, which was no easy feat given the scope and complexity of the investigations, the intricacy of the research issues, and the sheer volume of artifactual data collected. Chapters 2 and 3 provide background environmental and cultural setting discussions, which serve to frame 41KR621 contextually within the Central Texas archaeological region, generally, and the Upper Guadalupe River Basin, specifically. The results of the survey of the Spur 98 right-of-way and limited testing of the Gatlin site and 41KR622 are presented in Chapter 4; the survey and testing results have not been previously published except in interim report form.

Chapter 5 presents a streamlined version of the final data recovery research design and methodology. The full plan, which was based on the original research design, was prepared soon after testing and was subsequently revised after the excavations had been completed and the artifacts tabulated.

Chapter 6 is the first chapter in the report that directly addresses one of the six research domains presented in the research design. This chapter focuses on paleoenvironment and site formation processes as understood from the geomorphological investigation of the site and the results of special sample analyses. While Chapter 6 directly addresses one of the key research domains in this study, it also provides contextual information that anchors subsequent discussions of site formation and paleoenvironmental conditions. It is therefore presented before Chapter 7, which is a summary of the data recovery fieldwork and results.

Chapter 8 begins a series of four chapters devoted to the identified occupation zones at the site. Within each chapter, the research domains related to chronology, subsistence, and site structure and organization are discussed as they pertain to each occupation. This approach provides for essentially stand-alone discussions of each major cultural interval at the site and provides a basis for subsequent comparisons between components. In order, the component chapters address OZ1, the lower Early Archaic occupation (Chapter 8); OZ2, the upper Early Archaic occupation (Chapter 9); OZ3, the Early to Middle Archaic occupation (Chapter 10); and OZ4, the burned rock midden occupation (Chapter 11).

Chapter 12 discusses continuity and change at the Gatlin site. This is an in-depth comparison of the data from the four occupations and a comprehensive summary of the salient points of the study.

Chapter 13, the concluding chapter, takes the data from the Gatlin site and places it within the context of the cultural history of the southern Edwards Plateau. This chapter begins with a presentation of the chronology of the site, which was one of the six research domains, and then compares the site's sequence with the previously accepted regional sequence and other prominent sites to identify similarities and differences.

Supporting data are presented in eleven appendices to this report. The majority of the appendices are special study results and the analyses data and are included 
on the accompanying CD. Of note, three appendices are included in the printed document as they provide particularly important information to understanding the site and our conclusions. Appendix A provides critical supporting studies to the geomorphological investigations while Appendix $\mathrm{C}$ addresses the prehistoric technology research domain and includes discussions of artifacts and features at the site. Although this is a rather large and involved appendix, it presents necessary data for evaluating many component-specific research issues and questions, while at the same time providing important avenues for comparisons between components. Included as Appendix $\mathrm{K}$ is a discussion of the sixth research domain, which was a critical evaluation of the project's methodology. This discussion should prove useful to future researchers in Central Texas. 
1-8 Chapter 1 


\title{
Chapter 2
}

\section{Environmental Setting}

\author{
Brett A. Houk
}

\section{INTRODUCTION}

The Gatlin site is in the southern margins of the Edwards Plateau along the Guadalupe River. The plateau's southern and eastern margins are well defined by the Balcones Escarpment, a steep scarp formed by the Balcones fault zone. The fault zone passes near Waco, Austin, and San Antonio, making a bend to the west in Bexar County. It passes south of Kerrville through Medina and Uvalde Counties. The Edwards Plateau extends as far west as Brewster and Pecos Counties. Kerr County is in the portion of the plateau known as the Balcones Canyonlands or the Texas Hill Country, the rugged margin of the plateau that is dissected by numerous spring-fed rivers and streams.

This chapter describes the modern environment of the southern Edwards Plateau, including the geology, soils, hydrology, climate, flora, and fauna. The chapter concludes with a summary of the paleoenvironment of the Central Texas archaeological region as it is currently understood.

\section{Physical Environment}

The plateau is distinguishable from surrounding physiographic regions by its prominent Cretaceous-age limestone, dolomite, sandstone, and shale deposits. The eastern and southern extent of the Edwards Plateau is clearly demarcated by the uplifted and elevated Balcones Escarpment, which divides the plateau from the Blackland Prairie and South Texas Plain physiographic regions. The northern and western extent of the Edwards Plateau is relatively flat in comparison to the eastern and southern plateau margin, with the plateau slowly grading into mountain and basin physiographic regions in the west and plains regions in the north.

\section{GEOLOGY}

The Edwards Plateau (Figure 2.1) is near the center of Texas, with elevations ranging from approximately 600 feet above mean sea level (amsl) in its eastern portion to approximately 2,000 feet amsl in its western portion. This area attained its unique characteristics during the Cretaceous Period (144-66 million years ago), when shallow seas covered the area. Thick layers of limestone formed as calcareous animals died and settled to the bottom of the sea floor, gradually building massive sedimentary rock formations (Spearing 1991:9-10, 17).

The Cretaceous Period is subdivided into the Lower and Upper Cretaceous periods - the older lower groups are typically found in the eastern portion of the plateau and the younger upper groups are found across more than half the state. The Cretaceous rocks comprise nearly level layers of sandstone, marl, and limestone, from the bottom upward. In the lower layers, the limestone is soft, but as it grades upward it becomes hard and fractured.

In the vicinity of Kerrville, the tops of hills comprise Edwards limestone, which rests on top of Glen Rose limestone. The light-gray and thick-bedded Edwards formation, while present here, has been nearly completely eroded away farther west on top of the Edwards Plateau (Spearing 1991:127). Edwards limestone is well known for its chert-bearing capacity (Banks 1990). Glen Rose limestone is exposed in the Guadalupe River Valley and in the lower portions of hills in the Kerrville area (Spearing 1991:127).

As is common with many streams and rivers in the Balcones Canyonlands, large numbers of chert cobbles are present in the bedload of the Guadalupe River. In the case of the Guadalupe River, which begins in Kerr County, the chert cobbles near the Gatlin site are presumably derived from eroded Edwards limestone less than $60 \mathrm{~km}$ upstream of the site. A brief reconnaissance performed by SWCA of a roughly 2-5-mile radius around the site revealed numerous examples of in-situ bedrock cherts eroding from roadcuts and natural exposures. As cherts with similar colors and inclusions were seen in the river cobbles, these local 


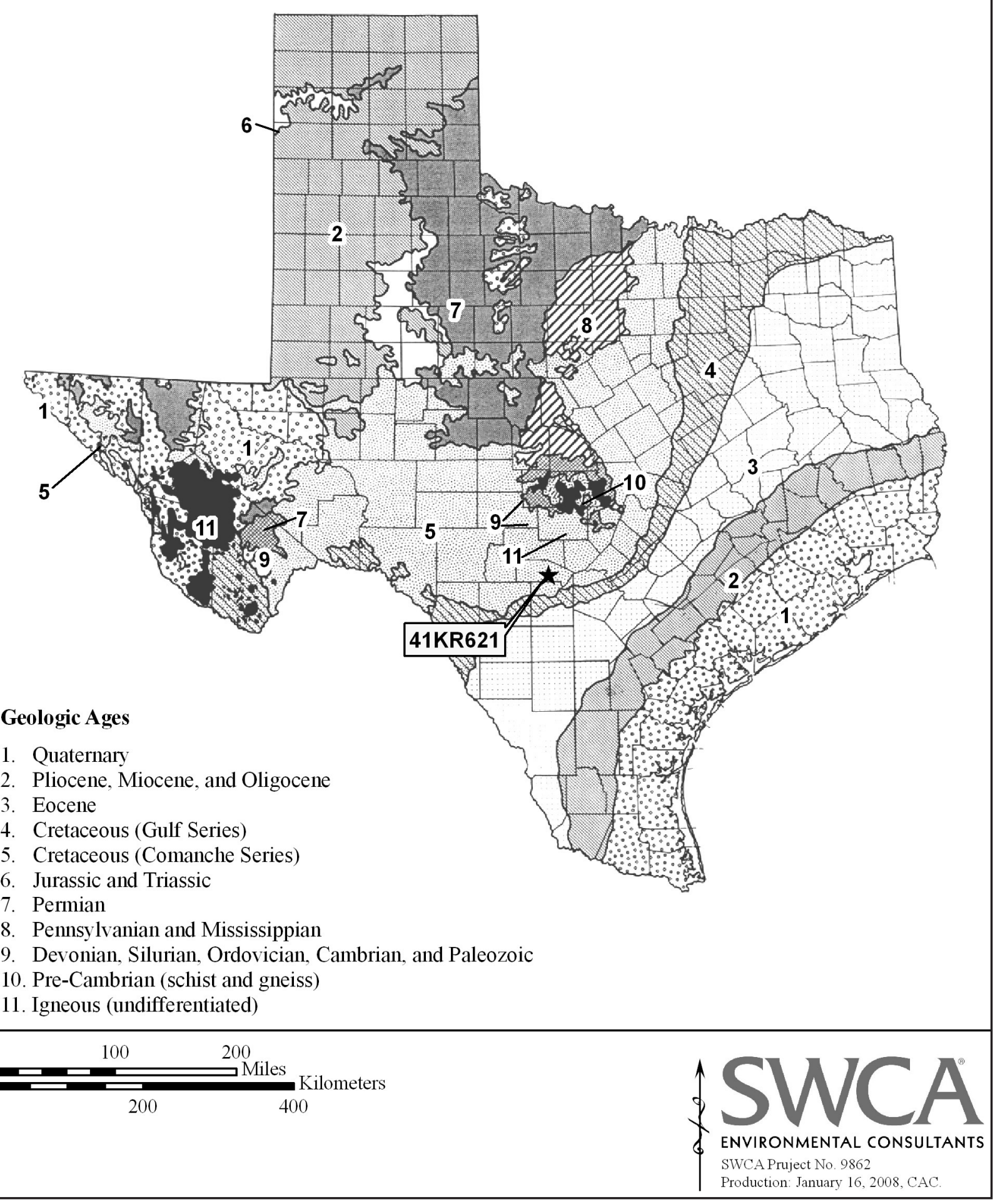

Figure 2.1. Surface geology of Texas. After Arbingast et al. (1976). 
bedrock resources undoubtedly contribute to the cherts and gravels that constitute the river bedload.

In the immediate project area, the surface geology comprises Pleistocene low terrace deposits and Holocene alluvium (Barnes 1981). These alluvial deposits are flanked by Glen Rose limestone, which is capped by Edwards limestone (Barnes 1981).

Approximately $55 \mathrm{~km}$ north of the Kerrville area is a broad structural dome known as the Llano Uplift. Rocks of the Precambrian, Cambrian, Ordovician, Devonian, Mississippian, Pennsylvanian, Permian, and Cretaceous periods are present within the Llano Uplift (Barnes 1981). The uplift is actually a physiographic basin (Sellards et al. 1981:30). Younger Cretaceous limestone that once covered the older rocks was eroded away, leaving a ring of limestone with higher elevations around the basin (Spearing 1991:123-124).

Most of the Precambrian igneous and metamorphic rocks in the uplift were first thrust above ground 1.35 billion years ago in a mountain-forming episode (Spearing 1991). Tectonic activity approximately 1 billion years ago metamorphosed and raised two earlier sedimentary units into two major metamorphic units-Valley Spring gneiss and Packsaddle schist, both of which contain large amounts of mica, hornblende, amphibole, and graphite (Sellards et al. 1981:32-33). Major granite constituents can include "quartz, microcline, and oligoclase with minor albite, biotite, muscovite, magnetite, apatite, zircon, tourmaline, and sericite" (Lidiak et al. 1961:268).

Four hundred million years of erosion nearly leveled the uplifted metamorphic rocks, after which advancing seas began to deposit Paleozoic sediments atop the Precambrian metamorphic rock. Further tectonic activity 300 million years ago tilted and faulted the metamorphic rocks, once again exposing them to erosion (Spearing 1991).

Cretaceous seas deposited sediments over the exposed Precambrian and Paleozoic rocks for roughly 140 million years. These sediments and the underlying rocks were then thrust upward approximately 2,000 feet in the Tertiary Period, forming the Edwards Plateau (Spearing 1991:124). Subsequent erosion of the Cretaceous Edwards limestone has once again exposed the Precambrian igneous and metamorphic rock, producing batholiths such as Enchanted Rock and Lone Grove in nearby Llano County.

Approximately $70 \mathrm{~km}$ south of Kerrville, the Edwards Plateau gives way to the South Texas Plain, where the surface geology becomes progressively younger closer to the Gulf coast. At the base of the Balcones Escarpment, the rocks are from the lower Tertiary Period (66-24 million years ago) and comprise primarily Wilcox Group mudstone and Midway Group clay and sand (Barnes 1983). Blanketing these groups in places are even younger Quaternary deposits including Leona Formation silts and gravels, which occur on wide terraces of the streams and rivers draining the Hill Country, and Uvalde Gravel, found on topographically high areas between the rivers (Barnes 1983).

\section{SoILS}

Within the Guadalupe River Valley, the terraces and floodplains comprise Nuvalde-Oakalla-Boerne unit soils. These are flanked by Eckrant-Kerrville-Rock Outcrop unit soils near Kerrville, and Doss-Kerrville unit soils farther downstream near Center Point (Dittemore and Coburn 1986).

The Nuvalde soils are found on terraces and foot slopes along floodplains of streams, while the Oakalla soils occur on floodplains of larger streams. Boerne soils, the third soil series in the first unit, are gently sloping soils on floodplains and alluvial fans (Dittemore and Coburn 1986:10).

On the hills flanking the river valley near Kerrville, the soils include gently undulating to steep Eckrant soils, with gently sloping to hilly Kerrville soils on ridges, side slopes, and foot slopes. Rock outcrops are interspersed in this unit (Dittemore and Coburn 1986:10).

At the Gatlin site, the mapped soils are predominately Nuvalde silty clay, 1-3 percent slopes, although Krum silty clay, 1-3 percent slopes, occurs in the northeastern corner of the right-of-way on the terrace above the Guadalupe River. Nuvalde silty clay occurs on terraces and foot slopes near the floodplain of the river and typically has slightly concave slopes (Dittemore and Coburn 1986:25). The surface layer comprises 12 inches of dark grayish-brown silty clay with progressively lighter subsoil below it (Dit- 
temore and Coburn 1986:25). The subsoil contains threads of calcium carbonate to 40 inches deep and threads, films, and soft nodules of calcium carbonate below that depth (Dittemore and Coburn 1986:25).

Krum silty clay, which occurs in valleys below limestone hills and along intermittent drainage channels, has a dark gray silty clay surface layer about 15 inches thick (Dittemore and Coburn 1986:22). The subsoil, to about 47 inches deep, is lighter in color, but contains vertical streaks of darker soil in closed cracks. Below this is a pale brown silty clay with numerous concretions and soft nodules of calcium carbonate (Dittemore and Coburn 1986:23).

\section{Climate}

In general, weather moves across Texas from west to east, although hurricanes and northers are the obvious exceptions to this rule. Rainfall generally decreases from east to west across the state, and this pattern holds true for the Edwards Plateau, as well. At the western edge of the plateau, the average rainfall is about 14 inches a year, and at the eastern edge, near Austin, it is closer to 32 inches per year (Spearing 1991).

Kerrville falls within a subtropical humid climatic zone, which is reflected in the average rainfall and temperature data (Larkin and Bomar 1983). In Kerr County, the annual average rainfall, calculated between 1951 and 1978, was 29.57 inches (Dittemore and Coburn 1986:Table 1). Within the same period, the average daily maximum temperature was 77.7 degrees and the average daily minimum temperature was 50.3 degrees (Dittemore and Coburn 1986: Table 1).

\section{HYDROLOGY}

The Edwards Plateau provides the backdrop for a complex system of aquifers, springs, and rivers. The Balcones Escarpment faulted along a hinge line (the Paleozoic Ouchita structural belt) which, based on sedimentation, tectonics, and hydrology, distinguishes the Edwards Plateau from the Rolling Plains and the Gulf Coastal Basin (Foley and Woodruff 1986). This faulting is responsible for much of the region's hydrology.

The Edwards Aquifer is a large $\left(67,200 \mathrm{~km}^{2}\right)$ underwater reservoir in west-central Texas in which water percolates through Lower Cretaceous limestone directly overlying relatively impermeable pre-Cretaceous formations (Barker et al. 1994). This percolation results in excellent water sources, including springs, creeks, and rivers.

The Gatlin site is located on the right bank of the Guadalupe River, which has its headwaters in Kerr County. The North Fork Guadalupe River and South Fork Guadalupe River begin in southwestern Kerr County and meet at Hunt, approximately $14.5 \mathrm{~km}$ west of the Gatlin site. Between the site and the confluence, several other streams, including Johnson Creek, Indian Creek, Bear Creek, and Goat Creek, feed the Guadalupe River. The Guadalupe River drains parts of 14 counties over its 250-mile course to the Gulf of Mexico.

\section{Flora ANd Fauna}

The Edwards Plateau, besides being distinctive in terms of its geology and hydrology, comprises its own natural region (Gould 1962) and its own biotic province, the Balconian (Blair 1950). The Balconian province occurs in central Texas only and extends from Upton County in west-central Texas south to Val Verde County, east to Bexar County, and north to Comanche County. Following earlier attempts at classifying the Texas environment (Bailey 1905; Dice 1943), Blair (1950) produced the classic reference on the Texas environment when he divided the state into seven distinct biotic provinces based mainly on flora and fauna (Figure 2.2). The Edwards Plateau comprises the Balconian province, a "hodgepodge" of faunal resources from four neighboring provinces (Blair 1950:112). While most of the fauna of the province are common in other parts of Texas, there are many unique troglodytic or cave faunas in the Balconian province. In contrast, the "vegetational aspect is quite unlike that of any other" biotic province in the state (Blair 1950:112). Arbingast et al. (1976:13) refer to the general vegetation region as Juniper-Oak-Mesquite Savanna (Figure 2.3).

Further work on the Balconian Province followed Blair's broader framework, focusing on mammalian studies (Davis 1974; Neck 1986), avifauna (Kutac and Caran 1994), herpetofauna (Dixon 1987; Vermersch 1992), and vegetation (Diamond et al. 1987; Enquist 1987; Gould 1962). Similar studies are available for the neighboring Tamaulipan province. 


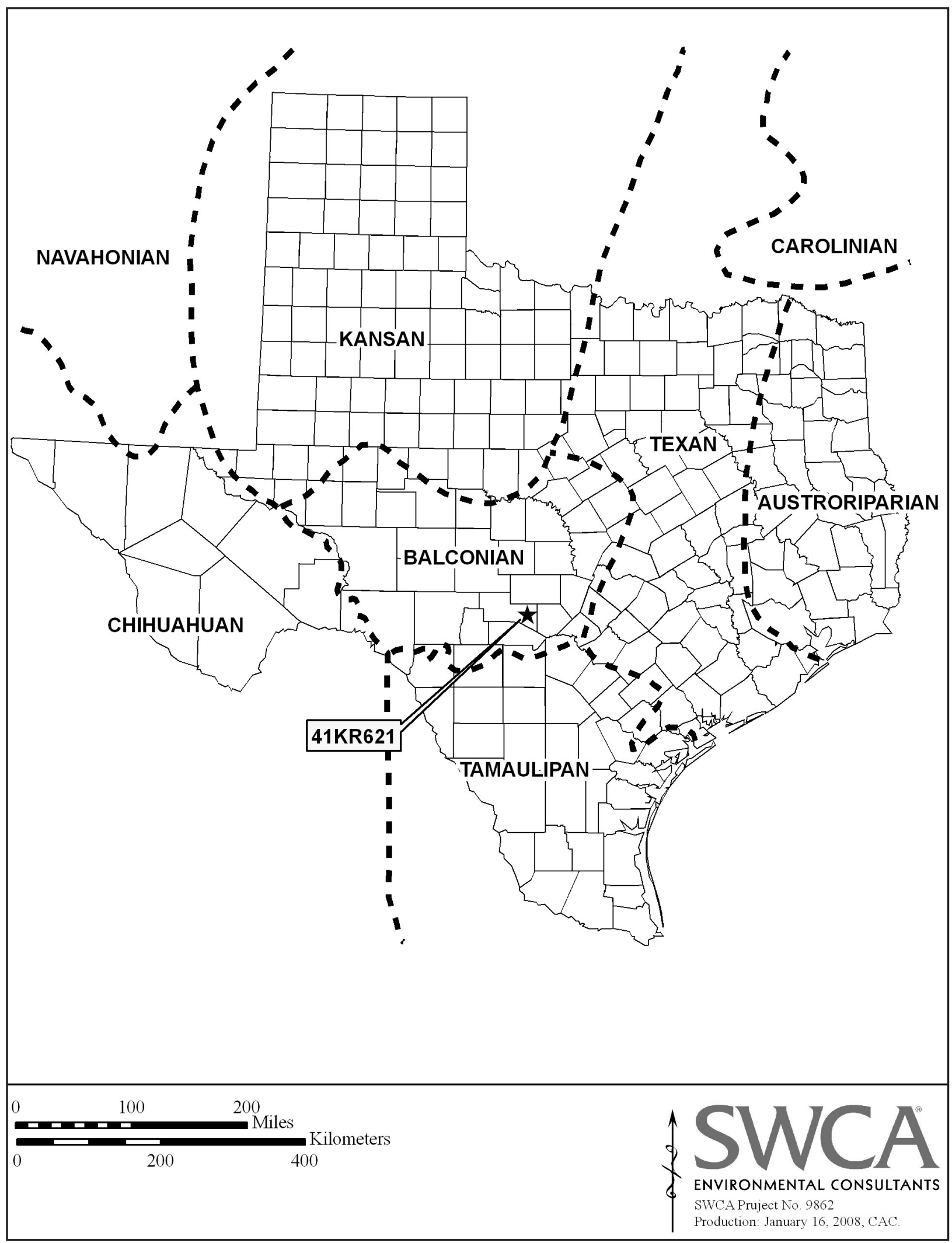

Figure 2.2. Biotic provinces of Texas. After Blair (1950:fig. 1). 


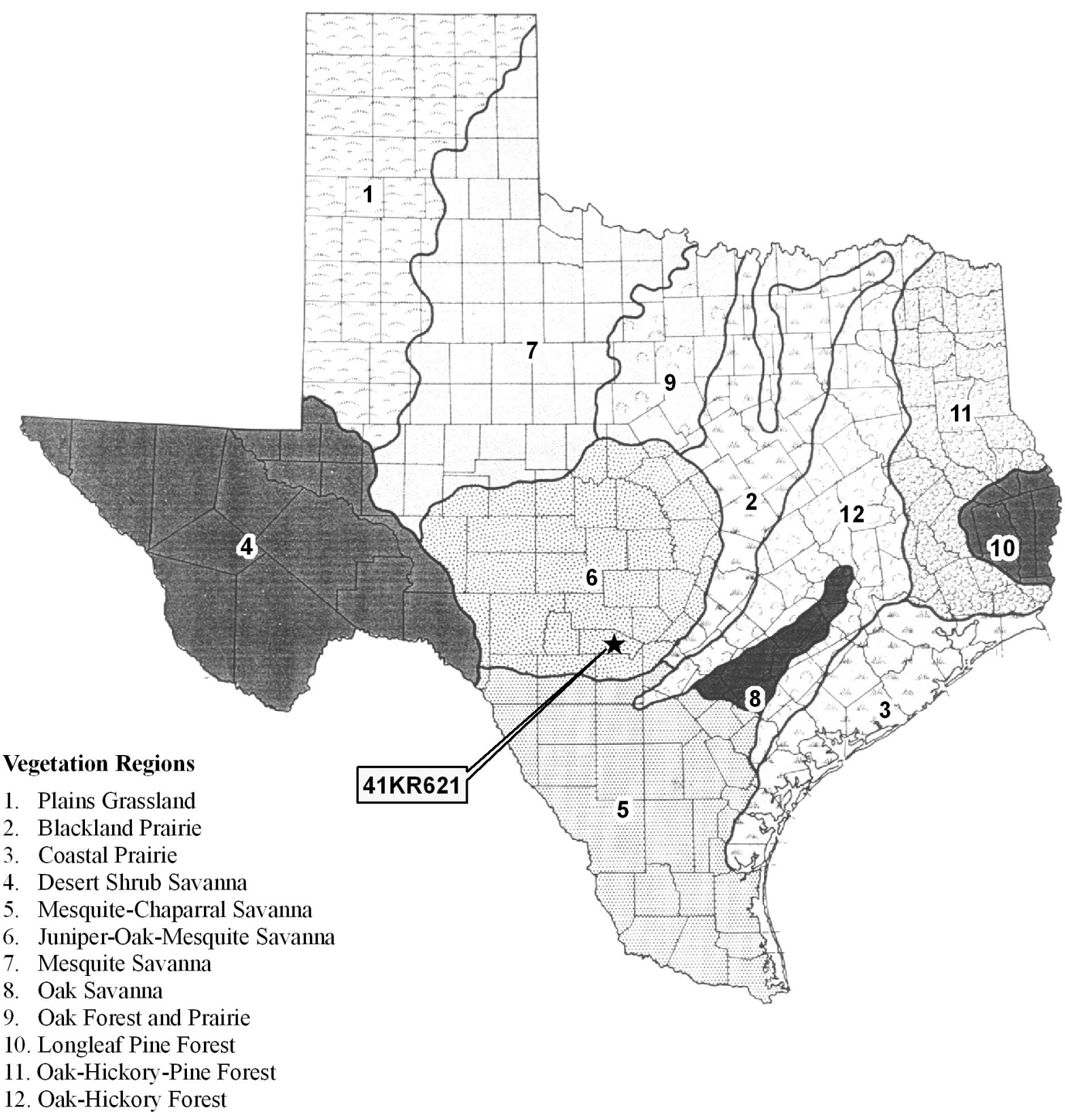

\begin{tabular}{|c|c|c|}
\hline 0 & 100 & $\begin{array}{l}200 \\
\text { Miles }\end{array}$ \\
\hline 0 & 200 & 400 \\
\hline
\end{tabular}

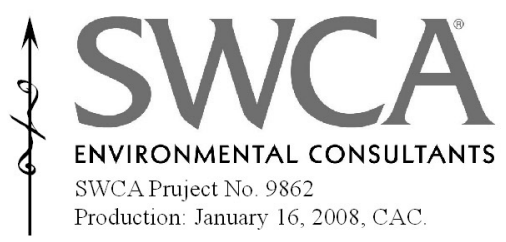

Figure 2.3. General vegetation regions of Texas. After Arbingast et al. (1976). 


\section{VEGETATION}

The Gatlin site is near the southern extreme of the Balconian province, which has a characteristic plant association of scrub forest with Mexican cedar (Juniperus mexicana), stunted live oak (Quercus virginiana), and various other less numerous species (Blair 1950:113). Among these are Texas oak (Quercus texana), Texas persimmon (Diospyros texana), and cedar elm (Ulmus crassifolia) according to Van Auken (1988). Mesquite (Prosopis glandulosa) also occurs throughout the province, and the floodplains of rivers and streams are occupied by a mesic forest of large live oak, elm, hackberry (Celtis laevigata), and pecan (Carya illinoinensis) trees (Blair 1950).

In the Balcones Canyonlands, diversity is greater than in other portions of the province. Bigtooth maple (Acer grandidentatum), American smoke tree (Cotinus obovatus), escarpment live oak (Quercus fusiformis), Texas madrone (Arbutus texana), lacey oak (Quercus glaucoides), bigelow oak (Quercus sinuate var. breviloba), escarpment black cherry (Prunus serotina var. esimia), and Mexican pinyon (Pinus cembroides) all occur (Simpson 1988).

The site area itself, prior to road construction, was a grassy pasture with primarily cedar elm, mesquite, and Mexican cedar trees growing along old and extant fence lines. At the northern limits of the site, impressive bald cypress (Taxodium distichum) trees grow along the banks of the Guadalupe River.

\section{WILDLIFE}

Blair (1950) states that 57 species of mammals are known from the Balconian province, though none of these are restricted to it. One land turtle, 16 species of lizard, 36 species of snakes, and 15 anuran species are found in the Balconian province (Blair 1950:113-115).

Approximately 50 percent of all nonmarine mammal species in Texas (as identified by Davis 1974) exist along the Balcones Escarpment on the southwestern edge of the plateau (Neck 1986). Common mammals of the area include white-tailed deer (Odocoileus virginianus), opossum (Didelphis virginiana), raccoon (Procyon lotor), nine-banded armadillo (Dasypus novemcinctus), black-tailed jackrabbit (Lepus californicus), and deer mouse (Peromyscus maniculatis).
Less common are the predatory mammals including the bobcat (Lynx rufus), coyote (Canis latrans), and gray fox (Urocyon cinereoargenteous). In addition to these common mammals, bison (Bison bison), mountain lion (Felis concolor), and black bear (Ursus americanus) would have been in the area prehistorically (Davis and Schmidly 1994).

Kutac (1994:47) notes that 349 species of bird are found regularly in south central Texas. The Balcones Canyonlands, in fact, is the main breeding area for the golden-cheeked warbler (Dendroica chrysoparia) and black-capped vireo (Vireo atricapillus), the former nesting only in 31 counties in Texas (Kutac 1994:47-48). Hampton (1994:113) reports 41 amphibians and 94 reptiles from the region, and Caran and Hubbs (1994:131) report 130 fish species in the area, using extant and historical data.

\section{Paleolandscape}

A theoretical shift in archaeology occurred in the 1960s (i.e., Binford 1962) and was soon being applied in Texas. The New Archeology, as this paradigm became known, had as one of its core issues the relationship between humans and their environment. The earliest efforts at New Archeology in Texas were in the Lower Pecos region of southwest Texas, where excellent preservation offered a variety of types of cultural and environmental information not present elsewhere in the state (Bryant 1966, 1967, 1969).

A host of researchers accomplished more work over the next 20 years in Texas, utilizing pollen analysis, faunal analysis, and climatic data (Bryant 1977; Bryant and Shafer 1977; Dillehay 1974; Gunn 1984; Gunn and Mahula 1977). Since then, the data set has been augmented by projects using geomorphology and geoarchaeology to examine landscape formation and evolution (Abbott 1993; Blum and Valastro 1992; Lintz et al. 1993; Nordt 1992, 1993). It is now common practice with both large archaeological projects and extended academic studies to interpret paleoenvironments on either site-specific or regional scales (Bousman 1998; Collins 2004; Johnson and Goode 1994; Potter and Black 1995; Potter et al. 1995; Ricklis and Collins 1994).

These studies are important for numerous reasons. As archaeology expanded from a cultural material perspective to a broader, systemic approach, it became 
useful to examine archaeological sites within an environmental setting. Utilizing data from other disciplines, it was soon apparent that the paleolandscape was a dynamic setting. Therefore, thorough investigations were necessary to interpret and reconstruct these past dynamic environments and their effects on relationships with human behavior.

Humans have occupied central Texas for approximately the last 11,500 years (Collins 2004). The earliest inhabitants lived during the close of the Pleistocene epoch, which ended ca. 10,000 в.P. The vast majority of prehistory has occurred in the Holocene epoch, which typically is divided into early, middle, and late periods. During this time span the environment has fluctuated dramatically. Research still has not produced a consensus on a general framework, and variation across the landscape on the micro- and mesoscale is always possible due to niches and biotic "islands" (Ellis et al. 1995). Most data come from pollen analysis and the study of mammalian remains.

\section{Late Pleistocene}

The Pleistocene was on the wane when humans first entered central Texas (11,500-10,500 B.P.). Unfortunately, conflicting data prevent researchers from devising a clear picture of the climate, and the situation is exacerbated by gaps in the environmental record (Stahle and Cleaveland 1995:51). Pollen and isotope evidence suggests a cool, dry period (Bousman 1992, 1994), while faunal evidence generally points to wetter conditions (Toomey et al. 1993). The late Pleistocene saw the end of the "Ice Age" megafauna. These animals included mammoth, mastodon, camel, horse, bison, saber-toothed cat, dire wolf, glyptodonts, and giant beaver. Vegetation, as recovered from pollen and/or macrobotanical samples, included pine, oak, hazelnut, maple, willow, ash, and birch trees (Bryant and Holloway 1985). Bousman's (1998) reinterpretation of pollen evidence in central Texas involved assessments of variations in arboreal pollen percentages and modern definitions of canopy cover. Based on this, it is postulated that "most of the Late Pleistocene plant communities were woodlands, and these samples certainly represent a mosaic of open to closed plant communities" (Bousman 1998:211).

\section{EARLy HoLOCENE}

The Early Holocene (10,500-7,500 в.P.) is in part a transitional period, as niches opened by the megafauna die-off were filled by both endemic and colonizing species. Data from Hall's Cave in Kerr County indicate small mammals more tolerant of drier conditions become more prevalent (Toomey et al. 1993). Pollen data (Bryant and Holloway 1985) generally reinforce this view; grasses became more dominant and tree cover fluctuated throughout this period. Bousman (1994:80) states that "woodland plant communities are reestablished by 8,700 B.P., but by 7,500 B.P. grass pollen again dominates." Mammalian communities become relatively modern during this time. Of note, the remains of smaller, modern bison, are scant in archaeological and paleontological sites during this period (Dillehay 1974). Representative vegetation included oaks, pines, pecans, and mixed grasses (Bryant and Holloway 1985).

\section{Midde Holocene}

Data for the Middle Holocene (7,500-5,000 в.P.) exhibit slight inconsistencies that may reflect fluctuations in the environment, but the general trend is towards increased aridity. This period is of particular significance for the Gatlin site because the earliest occupation there took place ca. 6,600-6,100 B.P. Soil evidence from Hall's Cave suggests severe desiccation on the Edwards Plateau (Toomey et al. 1993). Pollen records - according to Bryant and Holloway (1985) - indicate dry conditions, although Bousman's (1994:80) interpretation of the pollen record is that "arboreal pollen continues to drop until $6,800 \mathrm{yr}$ B.P. After a slight rise in arboreal pollen around 6,000 yr B.P., arboreal pollen declines until 5,000 yr B.P." Prairie dogs are absent from the Hall's Cave deposits during this time, suggesting a loss of preferred soil habitats due to erosion (Toomey et al. 1993). Bison returned to the southern plains around 6,000-5,200 B.P. (Dillehay 1974), indicating extensive grasslands were present by then. Tree species that prefer humid environments, such as hazelnut, basswood, and birch disappeared by the end of the Middle Holocene from Boriack Bog in Lee County (Bryant and Holloway 1985). Bousman's (1998:211) reinterpretation of central Texas pollen evidence concluded that "by 7,000 B.P. little arboreal cover remained on the eastern edge of central Texas and it 
is likely that open plant communities covered much of central Texas in the Middle Holocene."

\section{Late Holocene}

Environmental reconstruction efforts suggest the environment of the Late Holocene (5,000-1,000 B.P.) fluctuated greatly. Toomey et al. (1993:309) consider the period of 5,000-2,500 B.P. "drier than at any time during the last 20,000 years," a conclusion that is supported by a complete absence of mammals requiring mesic conditions in Late Holocene deposits from Hall's Cave, Schulze Cave in Edwards County (Dalquest et al. 1969), and Bering Sinkhole in Kerr County (Bement 1991). Pollen evidence generally supports this claim (Bousman 1994). However, other contradictory geomorphic evidence suggests the Pedernales River was continually aggrading due to mesic conditions (Blum and Valastro 1989).

The second half of the Late Holocene $(2,500-1,000$ B.P.) may have witnessed the return of more mesic conditions, but that is open to interpretation because some of the more prominent sites have yielded fairly minimal information for the last 2,000-3,000 years. For example, Boriack Bog in Lee County roughly 40 miles east of the Balcones Escarpment and Gause Bog in Milam County, have yielded detailed Holocene pollen records, but the Late Holocene is not represented in these records (Bryant 1977). Likewise, farther to the south, Hershop Bog is lacking the final 2,000 years of the pollen record (Larson et al. 1972). Hall's Cave deposits in Kerr County are fairly vague for the Late Archaic period (Johnson and Goode 1994; Toomey 1993; Toomey et al. 1993).

The best data on the latter half of the Late Holocene derive from Weakly Bog in Leon County, which provides a pollen record spanning the last 2,400 years (Holloway et al. 1987). According to the data, from 2,400-1,500 years ago, Quercus pollen counts were relatively high, suggesting the presence of oak woodlands and relatively mesic conditions. At 1,500 years ago, a sudden rapid decrease in Quercus pollen, coinciding with a rise in grass pollen is interpreted as indicative of the advent of the modern oak-savanna assemblage and comparatively drier conditions (Holloway et al. 1987). According to Bryant and Holloway (1985:63), other data from the region indicate the trends identified in Weakly Bog are regional in scope rather than local.
Bousman (1998:206), however, suggests otherwise in regards to the interpretation of the Weakly Bog data. Holloway et al. (1987) interpret the data as revealing a shift from forest to woodland (i.e., trending toward savanna conditions with increased grasses) coinciding with gradual warming and drying of the climate over the last 3000 years. Bousman (1998), in part based on the lack of a measurable increase in grass and composite pollen that should mark the proposed vegetation shift, indicates the perceived rate of pollen influx is a factor of a "very local change in the depositional environment." According to Bousman's (1998:207) interpretation, the sequence at Weakly Bog indicates a sequence of oak woodland changing to oak-hickory woodland and the climate becoming "progressively moist through the Late Holocene, and this is exactly the reverse of the interpretation offered by Holloway et al. (1987)." 
2-10 Chapter 2 


\title{
Chapter 3
}

\section{Archaeological Setting}

\author{
W. Boone Law
}

\section{INTRODUCTION}

The Gatlin site is in the upper Guadalupe River basin of the south-central Edwards Plateau within a research zone traditionally described as the Central Texas archaeological area (Black 1989; Collins 2004; Prewitt 1981, 1983). This archaeological area is environmentally and topographically diverse, and much of this diversity is expressed in the archaeological record. It is important to recognize that the Central Texas archaeological area does not represent a definitive cultural boundary nor does it embody a precise geographical area (see Ellis and Black 1997; Ellis et al. 1995). This research reality is very apparent at the Gatlin site, as many of the stone tools, site features, and the site structure itself exhibit obvious archaeological (and presumed cultural) affinities with materials in other archaeological areas as well as other Central Texas sites.

One of the primary aims of SWCA's investigations at the Gatlin site was to develop a local archaeological model for Archaic subsistence and settlement in the south-central Edwards Plateau. However, to accomplish this task, it is necessary to study the site within its broader regional context. A small amount of professional archaeological research has been performed in the vicinity of the Gatlin site; however, this information is somewhat outdated and limited in comparison to the dataset available from other areas of the plateau. It is important for these local studies to be considered in the Gatlin site analysis, but the investigations cannot rely on this information alone. Archaeological patterns documented at other regional sites are equally important in the study of the Gatlin site archaeological record.

Excavations at the Gatlin site yielded temporally diagnostic stone tools and features that indicate the site was intermittently occupied throughout most of the Archaic period. Radiocarbon dates from various features at the Gatlin site also attest to an exclusively Archaic occupation; thus, it appears that the Gatlin site offers a unique opportunity to examine Archaic lifeways in the south-central Edwards Plateau.

Considering these factors, this chapter offers a synthesis of the Edwards Plateau archaeological record for the Archaic period with summaries of relevant sites. This includes a brief discussion of archaeological areas of the Edwards Plateau, the natural resources of the region, and an archaeological review of the Archaic period. Particular emphasis is placed on archaeological sites and models that offer information pertinent to the research domains posited for the Gatlin site (see Chapter 5). Whenever possible, locally relevant archaeological patterns are presented and discussed within the broader regional context. These area sites and archaeological patterns are considered further in Chapter 13, which specifically addresses the contributions of the Gatlin site to the overall understanding of the Archaic in the Edwards Plateau region.

\section{The Edwards Plateau as an Archaeological Region}

Over the past 50 years, many researchers have discussed the difficulties of defining archaeological areas of the Edwards Plateau (Collins 2004; Ellis and Black 1997; Ellis et al. 1995; Prewitt 1981, 1983; Suhm 1960; Suhm et al. 1954). Presently there are two wellaccepted archaeological regions on the plateau. The western semi-arid and desertic area of the plateau is commonly referred to as the Lower Pecos archaeological area or region (e.g., Bement 1989; Shafer 1986; Turpin 1991, 2004). The eastern woodland and hill country area is conventionally described as the Central Texas archaeological area or region (Black 1989; Collins 2004; Prewitt 1981, 1983). These two archaeological areas are defined through a combination of physiographic, climatic, and biogeographic characteristics that are thought to have partially influenced prehistoric subsistence and settlement systems. They are also defined by a perceived cultural consistency within the archaeological record, namely, similarities 


\section{3-2 Chapter 3}

among particular projectile point styles, site types, and site features.

As mentioned, it is important to point out that an archaeological area is not an official delineation of a prehistoric cultural boundary or tribal area (Ellis and Black 1997; Ellis et al. 1995). Rather, it is an arbitrary study area that is uniquely defined by each researcher. Ellis and Black (1997:23) address this issue best when they state that an archaeological area is "a convenient label for study areas that vary greatly in size and extent according to the nature of the particular problem at hand and the state of knowledge at the time." Thus, an archaeological area provides a framework for modeling the prehistory of a specific geographic area but does not always define the prehistoric cultural boundaries for a region.

Most researchers understand that the archaeological record is variable, and evidence for cultural continuity within the record is erratic, particularly when viewed across a large region like the Edwards Plateau. Despite this, many within the cultural resources management community continue to relate to the archaeological record as if it were uniform cultural strata, where collective cultural histories are shared across large areas. Most often, culture histories are applied to sites using a fossil-type approach, where supposed temporally diagnostic projectile points and stone tools are used to discern the cultural record. Some argue that cultural continuity and cultural identity are observable through stone tool technologies; however, this proposition is somewhat difficult to verify considering that prehistoric populations were residentially mobile, foraged over large areas, and interacted with other nomadic groups. Group interaction resulted in the dissemination of trade items and community knowledge, especially on subjects regarding day-to-day subsistence and technologies. It is likely that many interacting groups were culturally distinct, yet shared similar stone tool technologies, land-use systems, and foraging methods across the plateau (see Johnson 1994). Moreover, it is also likely that many stone tool technologies developed gradually over time, and may appear earlier or later in different areas of the plateau or may be completely absent from the archaeological record in other areas. Due to the complex nature of hunter-gatherer technological organization and subsistence-settlement systems, it is impractical to propose continuity of cultural practices or lifeways based on projectile point technologies alone.

Black (1989:35) points out that regional chronologies can only be constructed after variation within much of the regional record is explained. Therefore, researchers should work towards developing chronological sequences locally, within smaller areas of the larger region. For instance, Black (1989) cites a model put forth of the cultural phases of Stillhouse Hollow reservoir as an example of a good locally developed cultural history (see Sorrow et al. 1967). The research of Johnson (1991), Black and McGraw (1985), Goode (2002), and Decker et al. (2000) offer similar examples of locally developed cultural histories.

\section{Natural Resources of the Edwards Plateau}

As a biogeographical region, the Edwards Plateau is rich in natural resources. Geological faulting across the plateau forms the Edwards and the Balcones aquifer systems, which discharge at over 1,000 springs (Rose 2004). Conventional wisdom and field observation indicate that most, if not all, of these springs were utilized during the long record of human prehistory in Texas. Most natural spring locations in Texas have documented archaeological sites (Brune 1981).

The Edwards Plateau is also rich in raw materials such as chert, a cryptocrystalline siliceous rock that is excellent for stone tool manufacture. Chert concretions formed within several members of the Edwards Limestone, making this raw material widely available across the plateau. As the soft carbonaterich limestone dissolved or eroded away, the harder chert concretions were exposed and freed from the formation. Eventually, gravity and erosion washed the chert into local rivers or streams, and waterrounded chert cobbles became widely distributed throughout the watercourses of the plateau. This observation is particularly relevant for the Gatlin site where chert cobbles are readily available from the Guadalupe River's bed. In fact, approximately 10 miles upstream from the Gatlin site, an in situ source of these materials can be observed eroding into the Guadalupe River drainage. These chert materials derive from the Fort Terrett and Segovia 
members of the Edwards Limestone group and occur as amorphous nodules or flat, tabular strata.

In some areas, water-rounded chert gravels may be found naturally occurring atop upland ground surfaces. These lag gravel deposits occur primarily along the eastern and southern margins of the plateau and are the result of late Tertiary or early Quaternary river channel outflows (Byrd 1971). Interestingly, these lag gravel deposits represent areas that were once the lowest elevations in the landscape (Aber 1997).

Prehistorically, the biota of the Edwards Plateau included a diverse array of plant and animal wildlife. Like all biological organisms, the frequency and distribution of the native biota fluctuated throughout time. Paleoenvironmental and paleoclimatic evidence suggests that over the past 11,500 years, prehistoric hunting and gathering populations have modified their subsistence and settlement strategies in order to adjust to changes in regional biota (Bement 1994; Bousman 1998a; Toomey et al. 1993). Despite these changes, which in some cases resulted in extinctions, the Edwards Plateau was and continues to be an archaeological region rich in diverse plant and animal resources.

\section{An Archaeological Review of the Edwards Plateau}

To consider the archaeology of the Gatlin site in its regional and local context, a temporal scale must be established for reference and comparison. The Edwards Plateau has been continuously occupied for at least 11,500 years, and for the purpose of research, archaeologists generally divide the prehistoric record of this region into three broad archaeological periods - the Paleoindian, the Archaic, and the Late Prehistoric. The earliest distinctive archaeological period was the Paleoindian period, which covers a time frame from ca. $11,500-8,800$ B.P. This was followed by the long Archaic period, which lasted from approximately 8,800-1,300 B.P. Following the Archaic was the Late Prehistoric period, which began around 1,300 years ago and ended with the beginning of the Historic period ca. 400 B.P.

The early part of the Paleoindian period has been characterized as a time when small bands of highly mobile hunters and gatherers used long, unstemmed lanceolate-shaped projectile points (e.g., Clovis, Folsom, and Plainview types) as spear or lance tips to hunt megafauna species such as mammoth, mastodon, camel, and Bison antiquus. These early groups foraged across large geographical areas and supplemented their hunting diet with a diverse assemblage of plants and smaller animals (Bousman et al. 2004; Collins 2004:117). In the middle of the Paleoindian period, around 10,500 B.P., a massive extinction occurred across North America, which resulted in the loss of 35 genera of large Pleistocene megafauna, including Bison antiquus (Grayson 2001). From this time onward, the general character of the Paleoindian period became somewhat transitional. These later Paleoindian populations continued to lead a highly nomadic lifestyle, which included hunting and foraging over wide areas; however, much of the archaeological evidence suggests that the Paleoindian subsistence and settlement was gradually acquiring a more Archaic-like adaptation (Bousman et al. 2004:96).

The archaeological record and subsistence-settlement pattern of Archaic peoples is distinctively different from the preceding Paleoindian period. Generally speaking, Archaic life on the Edwards Plateau reflects a more localized adaptation to the region. The most commonly recovered materials from the Archaic period are burned rock features and stemmed dart points. The prevalence of burned rock features in the Archaic suggests that there was an increased investment in the cooking of local foods (plants in particular) and infers that residential mobility decreased (Prewitt 1981:73; Suhm et al. 1954:18). Unlike the previous Paleoindian period, nearly all Archaic projectile point technologies are represented by stemmed dart points. The point types of the Archaic period vary greatly in size and morphology, yet they seem to share the same underlying function. Dart points were presumably hafted onto a spear or spear foreshaft and hurled at wild game using a spear thrower (atlatl).

Around 1,300 years ago, Archaic spear-thrower technologies were replaced by the bow and arrow. The shift between these two distinctive hunting technologies marks the beginning of the Late Prehistoric period (Collins 2004:122). The transition from the spear-thrower to the bow and arrow is inferred through the appearance of arrow points, which are 
much smaller and more lightweight than previous dart point forms. Burned rock midden use reaches its peak during the early part of the Late Prehistoric, thereby suggesting a continuation of the basic subsistence pattern established in the Archaic. In the latter half of Late Prehistoric, pottery appears alongside a suite of specialized bison hunting technologies such as beveled bifaces, large thin bifaces, hide scrapers, and prismatic blades (Collins 2004:123). The appearance of these technologies implies that an increased dependence on bison in the subsistence base had developed by the end of the Late Prehistoric (Johnson 1994).

Excavations at the Gatlin site yielded temporally diagnostic stone tools and features that indicate the site was intermittently occupied throughout most of the Archaic period. No evidence was recovered to suggest that Paleoindian or Late Prehistoric populations utilized the site. Radiocarbon dates from various features at the Gatlin site also attest to an exclusively Archaic occupation; thus, it appears that the Gatlin site offers a unique opportunity to examine Archaic lifeways in the south-central Edwards Plateau. Since only Archaic-age components were recovered from the Gatlin site, the following regional archaeological review will focus on synthesizing the Archaic period archaeological record for the Edwards Plateau. Thus, the Paleoindian and Late Prehistoric periods are not considered in the context of this review.

The archaeological review offered below is somewhat unconventional in comparison to previously published syntheses (Bement 1989; Black 1989; Collins 2004; Johnson and Goode 1994, 1995; Prewitt 1981, 1983; Turpin 1991, 2004). Instead of offering a long narrative of the regional prehistory, this review is presented through a series of topical subheadings (e.g., environmental conditions, cultural summary, and representative sites). This presentation style is intended to direct the reader to the subject of interest and to effectively summarize complex issues in the regional archaeological record.

\section{The Archaic Period $(8,800-1,300$ B.P. $)$}

Most of the human record on the Edwards Plateau may be attributed to the long Archaic period, which represents a time frame of roughly 7,500 years $(8,800-1,300$ B.P.). Due to its extensive temporal length, the Archaic, as described herein, is divided into three broad subperiods - the Early Archaic, the Middle Archaic, and the Late Archaic (Black 1989; Collins 2004; Johnson and Goode 1995).

In general, the Archaic archaeological record depicts a well-adapted, technologically conservative hunter-gatherer society that intensively exploited local plant and animal resources. Significant technological changes (and implied cultural changes) are documented throughout the Archaic, most notably, in stone tool technologies and hot rock cooking technologies. Site structure and site formation processes also changed throughout the Archaic and appear to be intrinsically linked to cultural and natural processes. Similarly, extreme paleoclimatic fluctuations occurred throughout the Archaic, which are presumed to have spurred changes in local environmental conditions, subsistence, and the overall pattern of prehistoric land use.

The following sections aim to present what has been learned about Archaic life on the plateau, and to determine where gaps exist in our current understanding of the period. These discussions are presented by each Archaic subperiod in order to diachronically describe the environmental and cultural record of the Archaic. Particular emphasis is placed on the Early Archaic subperiod because it is the most well-preserved archaeological dataset recovered from the Gatlin site. The Middle and Late Archaic components from the Gatlin site are more mixed and compressed in comparison to the Early Archaic site component.

\section{The EARLy ARCHAIC SUbPERIod}

Absolute Time Period: ca. 8,800-6,000 B.P.

Relative Archaeological Period: Follows the Paleoindian period, precedes the Middle Archaic subperiod.

Geological Time Period: Early Middle Holocene.

Diagnostic Projectile Point Types: Lanceolate (Unfluted) Forms: Angostura and Thrall; Stemmed (Dart Point) Forms: Early split-stem, Early barbed, Early corner-notched, Gower, Uvalde, Baker, Merrell, Bandy, and Martindale. 


\section{Environmental Conditions}

\section{PALEOCLIMATE}

There is considerable debate about the climatic conditions experienced on the Edwards Plateau during the early Middle Holocene. The general impression portrayed by most paleoclimatic research suggests that a warming and drying trend began during the early Middle Holocene and persisted, to varying degrees, into the Late Holocene. For example, Collins (2004) and Nordt et al. (1994, 2002) contend that the general climate experienced by Early Archaic populations was warmer and drier than present-day climatic conditions. Collins (2004) argues that the pollen and fluvial geologic data indicate that there was an oscillation effect during the early Middle Holocene as the climate transitioned from moderately wet conditions to extremely dry conditions and then returned to moderately dry conditions. Based on carbon isotopes collected from alluvial deposits, Nordt et al. (1994, 2002) argue that the Middle Holocene became increasingly warmer and drier, culminating in a peak warm period ca. 5,000 B.P. during the Middle Archaic. This pattern is loosely substantiated by Bousman's (1998) pollen research, which documents two extreme dry intervals at 6,500 and 5,000 B.P. Alternatively, Johnson and Goode (1995) cite evidence that the beginning of the Early Archaic subperiod is marked by a brief warm and dry interval ca. $8,500-8,000$ B.P. This interval was followed by a long, cool and wet period that lasted from approximately $8,000-5,750$ B.P. Although conditions warmer and drier than present were experienced across the entire plateau during the Early Archaic (and the entire Archaic period for that matter), the western plateau was probably drier in comparison to the east due to the moister air currents from the Gulf of Mexico (Johnson and Goode 1995).

\section{FLORA}

As climatic conditions became progressively warmer and drier, plant species adapted to cooler and moister conditions by migrating into the wetter valleys and canyons of the plateau. Erosional areas along hillslopes and valleys were populated with communities of cacti and other succulent plants such as yucca, sotol, lechugilla, and prickly pear (Shafer 1986:43). Intermingled among these succulent species were shrubby stands of mesquite, mountain laurel, juniper, and a wide variety of acacias. Scattered stands of oak and grasslands thrived along the upland prairies and drainages of the plateau. River terraces were occupied by a variety of large trees including oak, pecan, walnut, cottonwood, cypress, and some conifers (Shafer 1986:43). These general plant communities existed throughout the entire Archaic period, but fluctuations in their abundance and distribution occurred over time. Bousman's (1998:212) pollen research suggests that open grasslands were the preeminent plant community on the eastern plateau from 8,000-2,000 B.P. Similarly, Bryant and Larson's (1968:64) research at the Devil's Mouth site, in the western plateau, shows a sharp reduction in pinyon pine pollen 8,000-7,000 years ago and an increase in xeric-adapted plant species throughout the remainder of the Archaic period.

\section{FAUNA}

Most of the mammal and reptile species from the Late Paleoindian subperiod continued to occupy the various ecotones of the plateau throughout the Archaic period. Upland prairies and woodlands were occupied by deer, pronghorn antelope, bears, coyotes, wolves, mountain lions, bobcats, gray fox, gophers, prairie dogs, rabbits, and an array of other small rodents (Blair 1950; Shafer 1986). Rabbits, squirrels, rodents, lizards, snakes, and other reptiles subsisted along major drainage and canyon areas, while beavers, turtles, amphibians, fish, and freshwater mussels inhabited all major rivers and streams.

The most archaeologically significant change to the Early Archaic faunal community was a decreased bison (Bison bison) population in the region. Increased aridity may have caused bison populations to migrate north for most of the Early Archaic, as bison remains are apparently scarce or absent from the regional archaeological record (Collins 2004; Dillehay 1974). At the end of the subperiod, around 6,000 B.P., bison reappeared on the plateau during a climatically cooler and wetter period (Johnson and Goode 1995).

\section{Cultural Summary}

\section{SETtLEMENT AND SubSistenCE}

Prehistoric settlement and subsistence during the Early Archaic was dramatically different from the preceding Paleoindian period. Research suggests 
that Early Archaic people became increasingly reliant on local resources and residential mobility decreased (Prewitt 1981:73; Suhm et al. 1954:18). Early Archaic populations utilized base camps for longer periods, perhaps seasonally, and hunted a diverse array of small (e.g., snakes, turtles, rodents, rabbits), medium (e.g., opossums and raccoons), and large (e.g., deer and antelope) game, fished local rivers, and cooked wild plant bulbs in earth ovens. It is possible that the reduction in residential mobility and the increased reliance on local resources were related to a diminished bison population, especially since bison hunting was previously a key component of Paleoindian life. However, there are other less visible variables that may also be responsible for triggering these changes in the subsistence-settlement system, including population increase, tribal territoriality issues, and/or climatic change.

During the Early Archaic, hunting technologies gradually shift from lanceolate-shaped projectile points to stemmed point forms. The reason for this change is still poorly understood, but it is almost certainly related to the development of a more localized, broad-based hunting and gathering economy that necessitated differing point types for different game (Johnson and Goode 1994; Story 1985). By the start of the Early Archaic, well-established resident populations lived in every biogeographical region of Texas. Resources were better understood, and populations supplemented their hunting diet with a diverse assemblage of processed plant foods. This is most evident through the use of hot rock cooking technologies, which become commonplace at Early Archaic sites. Early Archaic burned rock features are most often small- to medium-sized hearths or earth ovens, with minimal evidence of reuse. However, at a few Early Archaic sites (e.g., Wilson-Leonard, Number-6, and Loeve), the archaeological evidence suggests that these small- to medium-sized hearths and earth ovens evolved into a much bigger cooking feature - the burned rock midden.

A burned rock midden is a large, dense feature of burned rocks and ash-stained soil that has regularly or intermittently accumulated from use and reuse as a thermal cooking feature (Black and Ellis 1997; Mahoney et al. 2003a; Suhm 1960). Burned rock middens increase in number and use throughout the Archaic period, however it seems that their techno- logical roots stem from the Early Archaic subperiod (Black and Creel 1997; Collins et al. 1998; Decker et al. 2000). Burned rock midden technology appears to have first developed in the eastern plateau around $8,500-8,000$ years ago and gradually migrated into the western plateau areas ca. 6,500-5,000 years ago (Decker et al. 2000:301). These large features vary greatly in size and form, but share the common functional purpose of serving as an earth oven or similar cooking device (Black and Creel 1997; Prewitt 1994; Weir 1976).

Collins (2004:120) and McKinney (1981) point out that a large number of Early Archaic sites are documented along the eastern and southern margins of the Edwards Plateau. They argue that if our current understanding of Early Archaic site distribution reflects prehistoric land use, then the Early Archaic was a time period when people were living in the better-watered parts of the Edwards Plateau. Their arguments may be correct, especially since paleoclimate data suggests that water availability was an issue during much of the Archaic period. However, it is argued here that the Early Archaic site distribution pattern is more likely the result of sampling error. It is true that the eastern and southern margins of the plateau are the better watered of the region. This is due to the fact that the Edwards Aquifer discharge zone coincides with the major fault zones along the eastern and southern plateau (Rose 2004). This critical water resource is important to major population centers today, and significant development along the discharge zone is ongoing. Incidentally, a large amount of contract archaeology work is conducted in this area. In comparison to the rest of the plateau region, more archaeological surveys and excavations have been conducted along its eastern and southern margins than in the central and western area of the plateau. Consequently, Collins' (2004) and McKinney's (1981) proposed distribution of Early Archaic sites may be a skewed representation of Early Archaic settlement. Collins' (2004) assessment that water availability was important during the Early Archaic is more reasonable, however. If this is the case, then Early Archaic sites are likely to occur near most major spring localities and along the major river basins of the Edwards Plateau. 


\section{SOCIAL ORGANIZATION}

The social organization of Early Archaic groups is difficult to demonstrate due to the static nature of the archaeological record. Gender and kinship relations, political structure, oral traditions, mythology, religious beliefs, and similar cognitive insights are not well-preserved archaeologically; however, despite these limitations, a few educated inferences may be made about social structure and lifestyle of Early Archaic peoples.

Based on ethnographic accounts of contemporary and historic hunter-gatherer societies, it may be deduced that Archaic groups, like hunter-gatherer groups worldwide, foraged in small family bands and periodically joined up with other bands to form larger groups (see Steward 1955). Anthropological research has shown that hunter-gatherer societies are largely egalitarian (Lee 1979; Steward 1955), and this egalitarian model most likely applies to the Archaic social structure of the Edwards Plateau. Leadership is informal in an egalitarian society and labor tasks are usually divided by sex and age. Studies have also shown that hunter-gatherer groups feel a deep spiritual connection to their native territories and often schedule ceremonial activities into their foraging system (Gould 1969, 1980; Lee 1979). It is likely that the Archaic hunter-gatherers of the plateau felt a similar connection to the prehistoric landscape and participated in ceremonial or spiritual activities.

Compared to the previous Paleoindian period, Early Archaic peoples were less residentially mobile, that is, they occupied sites for longer periods (perhaps even seasonally) and often revisited these locations for generations. There is little evidence for residential structures in the Early Archaic, but this may be due to poor preservation. There is at least one instance of a small, hut-like structure documented on the Edwards Plateau, ca. 8,400 B.P., at the Turkey Bend Ranch Site (Lintz et al. 1995). This structure would have been large enough to accommodate a small family band of hunter-gatherers for a short period. Similar structures were presumably constructed elsewhere on the plateau during the Early Archaic; however, no others have been documented for this period.

It is unknown what religious or cosmological beliefs Early Archaic peoples shared. Evidence for
Early Archaic expressive culture such as pictographs, petroglyphs, or engraved stones is not evident for this period.

\section{TECHNOLOGY}

\section{Cooking Technology}

Archaic peoples utilized hot rock cooking technology, in various forms, for the processing and cooking of plant and animal foods. Consequently, burned rock (usually burned limestone or sandstone) is commonly found at Archaic-period sites. Burned rock features from the Archaic period are typically described as (1) hearths, (2) clusters, (3) scatters, (4) pavements, or (5) middens (Mahoney et al. 2003a:71-72). The discussion of burned features by Mahoney et al. (2003a) provides good definitions and descriptions of these hot rock cooking features. Additionally, extensive research into the function and distribution of hot rock cooking technologies on the Edwards Plateau has been documented by Black et al. (1997). These thorough studies offer considerable insight into the cooking methods employed by Archaic peoples.

Hot rock cooking features are documented at most Early Archaic-period sites. Throughout the Archaic, the basic function of these features changed very little. In fact, the only significant changes in burned rock cooking technology appear to be in the feature form, frequency, and distribution. The usage of hot rock cooking technology appears to be widespread on the Edwards Plateau during the Early Archaic, although the number and frequency of burned rock features is considerably less than in later Archaic subperiods. Early Archaic burned rock features occur in various forms (see Black et al. 1997; Collins et al. 1998; Mahoney et al. 2003a); however, in general, most Early Archaic burned rock features may be described as small- to medium-sized burned rock clusters, hearths, or scatters. Eventually, the more massive-sized burned rock midden feature appears at a few sites along the eastern plateau ca. $8,500-8,000$ years ago. Gradually, burned rock midden use migrates into the western area of the plateau ca. 6,500-5,000 B.P. (Decker et al. 2000:301).

\section{Stone Tool Technology}

Most of the projectile point technologies of the Early Archaic are stemmed dart points, but several varieties of unstemmed lanceolate-shaped point forms, such 
as Angostura and Thrall, that were used during the beginning of the subperiod. Angostura and Thrall points were once thought to be Late Paleoindian in age, yet recent research indicates that the lanceolate point forms were in use between 8,800 and 8,000 B.P. (Bousman et al. 2004). Around 8,000 B.P., stemmed point varieties such as Early Split Stem, Gower, Uvalde, Baker, Merrell, and Martindale became widespread across the central and eastern Edwards Plateau. These stemmed varieties have bifurcate (i.e., forked or split) stems and are corner-notched. Although they do share technological similarities, Early Split Stem, Gower, Uvalde, Baker, Merrell, and Martindale are morphologically and temporally distinct (Hester and Shafer, this volume). Bandy points are similar to these early bifurcate point forms, except that they are basally notched (as opposed to corner-notched). Despite this difference, Bandy points share close temporal and technological affinities with the Martindale point form (Hester and Shafer, this volume).

A number of other stone tool technologies appear during the Early Archaic, reflecting an increased diversity of activities from the preceding Paleoindian period. Grinding stones (e.g., manos and metates) are documented in Early Archaic contexts at the Sleeper site (Johnson 1991). Clear Fork tools (bifacial and unifacial) and Guadalupe bifaces, which were apparently for woodworking, are widely reported at several Early Archaic sites (Black and McGraw 1985; Collins et al. 1998; Hudler 1997).

\section{Representative Early Archaic Sites}

The site summaries offered below discuss the Early Archaic components from some of the better-represented sites on the Edwards Plateau. The purpose of these summaries is to highlight regional variations in the archaeological record and discuss the moresignificant contributions that these sites have made to our understanding of the regional prehistory. The following site summaries are presented in geographical order, beginning in the west and moving eastward across the Edwards Plateau (Figure 3.1).

Baker Cave (41VV213) - More than 9,000 years of human prehistory are documented at Baker Cave. The cave itself is actually a very large rockshelter high up on a canyon wall in Val Verde County. The Early Archaic record of Baker Cave is suggestive of more-arid adaptations in the western plateau. Evidence of the use of desertic plants such as sotol and lechugilla first appear in the Early Archaic record. Vegetal matter recovered from the Early Archaic zone of Baker Cave includes mescal beans, pecans, walnuts, and acorns (Word and Douglas 1970). A few badly decomposed sandals, whittled sticks, woven mat fragments, and netting were present in the Early Archaic component, however, the preservation of perishable materials is not as good as that of the Middle Archaic and Late Archaic components at the site (Chadderdon 1983). There is a marked increase in the number of fire-cracked limestone features during the Early Archaic, suggesting greater reliance on hot rock cooking technology. A number of Early Archaic projectile point styles were recovered from Baker Cave, including Early Barbed, Bandy, and Baker points, all of which are early corner-notched point technologies. As indicated by its name, Baker Cave is the classic site type for the Baker point.

Eagle Cave (41VV167) - Located near the town of Langtry in western Val Verde County, this very large rockshelter contains a deep, multicomponent midden deposit. The earliest stratum, Stratum V, yielded an approximate date range of $8,750-8,550$ B.P. (Ross 1965). Early Barbed and Angostura projectile points were recovered from this Early Archaic stratum. Also recovered were three slab-lined pit features, a woven mat fragment, bone awls, and a painted pebble (Decker et al. 2000:71).

Devil's Mouth (41VV188) - Located at the confluence of the Devil's River and the Rio Grande, this well-stratified terrace site contains deposits spanning the past 9,000 years (Johnson 1964; Sorrow 1968). Like most open occupation sites, investigations at the Devil's Mouth site recovered very little perishable material. The most significant contributions that this site makes to our understanding of the Early Archaic are from its pollen record and stone tool assemblage. Bryant and Larson's (1968:64) pollen study indicates that the region was densely covered with pinyon pine trees 7,000-8,000 years ago. Following this period, the pollen record suggests that the region was consumed by hyper-arid conditions and the surrounding pinyon parklands were replaced by grassland savanna. Stone tools recovered from Early Archaic levels of the site include Angostura, Lerma, and Early Barbed points. Unfortunately, no 


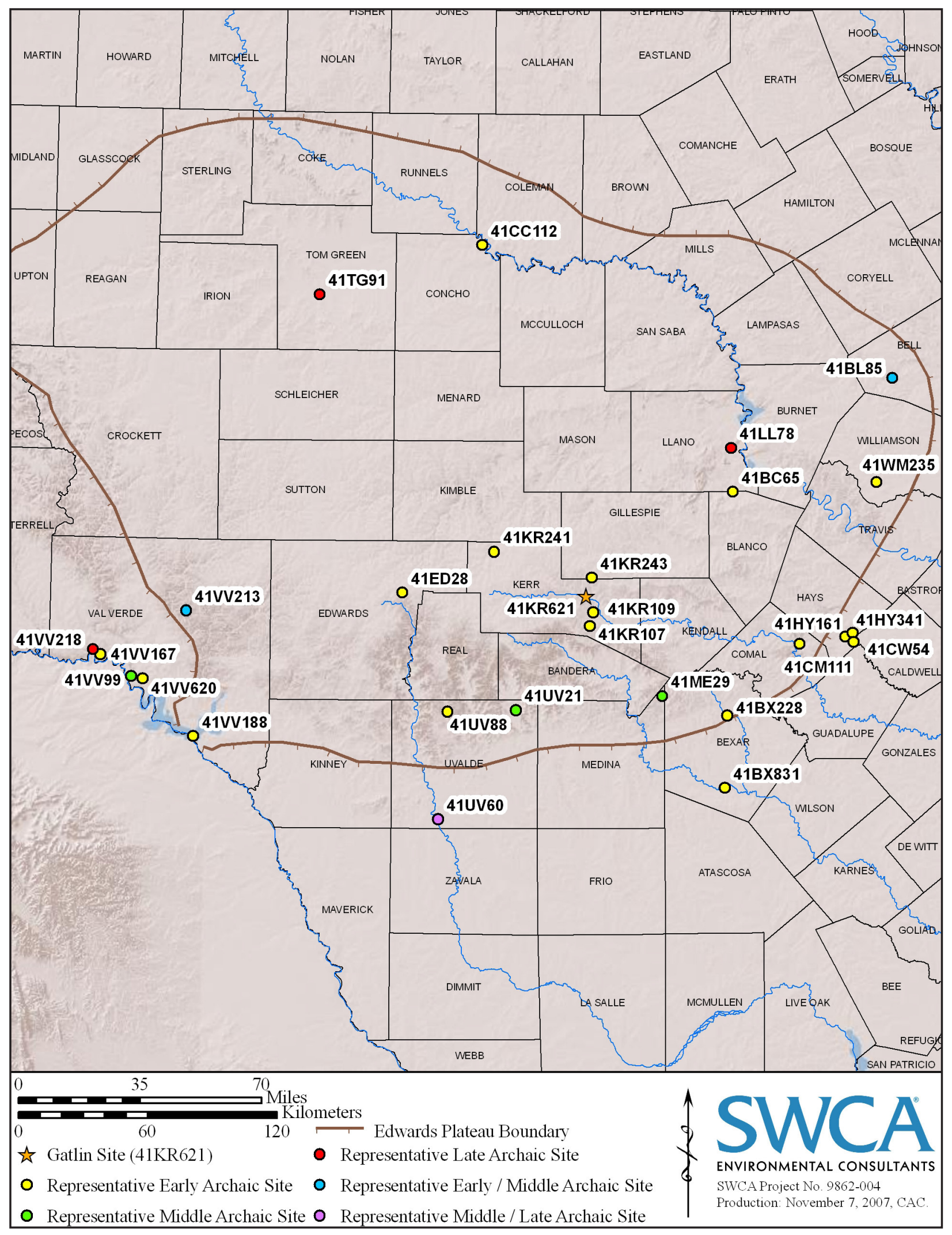

Figure 3.1. Representative Archaic archaeological sites of the Edwards Plateau Region. 
radiocarbon dates are available for the Early Archaic components of the Devil's Mouth site.

Varga (41ED28) - The Varga site is in central Edwards County and is one of the most thoroughly investigated Early Archaic sites studied thus far. A full report on the Varga excavations is currently in preparation; information here is based on an interim report (Quigg 2005). Varga is a stratified open terrace site with Early Archaic through Late Prehistoric cultural deposits. The Early Archaic component contained nine burned rock features, two hearths, and seven burned rock discard areas. Bulk food processing was not evident in any of these features. Overall preservation of faunal materials was poor, with only a small sample of deer and bison fragments identified. Botanical preservation was fair and included several woody species (e.g., pine, oak, pecan, juniper, and mesquite), presumably used for fuel, and a number of potentially consumed plants such as wild carrot, walnut, and prickly pear seeds. An extremely large Early Archaic projectile point assemblage was recovered from the site $(n=170)$. The projectile points include Early Corner-Notched, Gower, Uvalde, Baker, Merrell, Bandy, and Martindale points. No non-local cherts are represented in the assemblage; thus it appears that locally procured Edwards chert varieties were used for stone tool manufacture (Quigg 2005).

Woodrow Heard (41 UV88) - The Woodrow Heard site is an extensive open occupation site on a large terrace of the Dry Frio River in northern Uvalde County. The site was utilized intermittently by Archaic hunter-gatherer groups between 8,300 and 3,500 years ago (Decker et al. 2000). Excavations at Woodrow Heard targeted the Early Archaic deposits, which underlay a large Middle Archaic-aged burned rock midden. The Early Archaic deposits included 26 small burned rock hearth features, which were associated with Angostura, Baker, Bell, Martindale, and Uvalde points. Based on site stratigraphy, features, projectile point types, and radiocarbon dates, two generalized occupational components were proposed for the Early Archaic subperiod at Woodrow Heard - the Angostura component (ca. 8,400-8,000 B.P.) and a later Early Archaic component (ca. 8,000-6,500 в.P.). Decker et al. (2000:296) discuss the Angostura component as a time when the climate was cooler and moister than today. Live oak trees growing on the terrace were utilized for firewood. Sotol and/or yucca were cooked in the burned rock features. A diverse range of small, medium, and large mammals was hunted, and freshwater mussels were occasionally cooked and eaten at the site.

The next Early Archaic component at Woodrow Heard documents a similar pattern of land use, subsistence, and general lifestyle. The primary differences between these components are in the prevailing climate regime and stone tool technologies. Decker et al. (2000:298) believe that near the end of the Early Archaic, climatic conditions shifted towards slightly warmer and drier conditions, perhaps around 6,400 B.P. The projectile point types associated with the later Early Archaic component are Uvalde, Baker, and Martindale. There is no noticeable difference between the burned rock cooking technologies utilized during the Angostura occupation interval and the later Early Archaic occupation. Also, land-use patterns of the later Early Archaic were relatively the same as in the Angostura interval. The most striking difference between the Angostura and late Early Archaic was the alteration of the vegetation in response to the changing climatic conditions. In addition to live oaks, juniper and pinyon pine trees were burned for fuel. Sotol and/or yucca may also have been more abundant due to the warmer and drier climate. A diverse array of mammals was hunted, and fish and mussels occasionally supplemented the diet. Decker et al. (2000) believe that these Early Archaic adaptations established the general land-use and subsistence patterns that persisted through the remainder of the Archaic period.

Bering Sinkhole (41KR241) - The Bering Sinkhole formed in the Cretaceous-age bedrock of the southcentral Edwards Plateau in Kerr County. It was used for over 5,500 years as a repository for the dead. At least 23 individuals were dropped or lowered into the Bering Sinkhole for interment during the Early Archaic (Bement 1994). Martindale and Uvalde projectile points were recovered from levels corresponding with these Early Archaic burials. Bement's (1994) analysis of the sinkhole's faunal assemblage suggested that a progressive paleoclimatic drying trend began ca. 7,000 years ago, during the Early Archaic. 
Turkey Bend Ranch (41CC112) - The Turkey Bend Ranch site is an open terrace site near the confluence of the Concho and Colorado Rivers in northern Concho County. The most significant discovery at this site is the remains of an approximately 8,400year-old Early Archaic structure (Lintz et al. 1995). The remains of the structure consisted of 16 small rock clusters believed to be post-supporting stones, a large central hearth, and portions of one exterior rock hearth. No direct evidence was obtained about the shape of the shelter's superstructure; however, the material remains suggest that the structure had a roughly circular plan view and a floor area of 24.6 $\mathrm{m}^{2}$. No diagnostic projectile points were identified in association with the structure, although a small artifact assemblage of cores, bifaces, unifaces, a ground stone fragment, and small debitage assemblage were recovered. Based on this assemblage, Lintz et al. (1995:180) concluded that activities in or near the structure were primarily hide processing, woodworking, butchering, and clam cooking.

The remains of the Turkey Bend Ranch habitation feature are important because they demonstrate an early example of shelter construction in the Archaic period. Many ethnographic accounts of hunter-gatherers have documented the construction of similar hut like structures by nomadic peoples (Lee 1979, 1984). It is not unreasonable to consider that similar perishable structures were utilized on the Edwards Plateau throughout the Archaic.

Camp Pearl Wheat (41KR243) - Located along Town Creek near Kerrville and not far from the Gatlin site, excavations at Camp Pearl Wheat recovered an isolated Early Archaic terrace site estimated to be 5,100-6,100 years old (Collins et al. 1990). A very small artifact assemblage and six burned rock hearth features were documented. The "meagerness" of the assemblage suggests that occupation at the site was short term. Two Early Archaic projectile point types-Martindale and Uvalde-were recovered from the excavations at Camp Pearl Wheat (Collins et al. 1990). Patination is reported to be present on many of the stone tools from the Early Archaic, which suggests that these tools rested on a stable ground surface for an extensive period of time before being buried by fluvial events. Archeomagnetic and lipid residue studies revealed the burned rock features cooked both plants and animals, and they were oftentimes reused. Overall, Camp Pearl Wheat appears to have been occupied on one or more occasions by small groups exploiting the local plant and animal resources (Collins et al. 1990).

Shep (41KR109) and Wounded Eye (41KR107) - These two sites are shallow upland sites in southern Kerr County. Both of these sites have small burned rock middens and a mixed assemblage of Middle and Early Archaic projectile points (Luke 1980). Projectile points recovered from these sites include Angostura, Nolan-like, Travis-like, Early Triangular, and Bell points. The significance of these sites is that they suggest that burned rock midden development on the south-central Edwards Plateau began sometime during the late Early Archaic.

Sleeper (41BC65) - The Sleeper site is an open occupation terrace site along West Walnut Creek in northern Blanco County. A wide range of Early Archaic projectile point types was recovered from the Sleeper site, which suggests that the deposit formed over a long period of time, similar to the Gatlin site. The projectile point assemblage includes Gower, Uvalde, Martindale, and a number of untyped early split stem varieties. The Early Archaic component was rich with burned rock features and included a "rock stratum" of scattered burned sandstone and burned rock piles believed to have been used as "baking heaps" (Johnson 1991). Plant and mollusk remains were documented at the Sleeper site, but their numbers are comparatively small. Perhaps the most notable component of the Early Archaic assemblage was the large number of ground stone implements recovered from the site. The presence of these implements demonstrates that the milling of nuts or seeds occurred during the Early Archaic.

Panther Springs Creek (41BX228) - The Panther Springs Creek site is an open occupation terrace site along the Salado Creek watershed in northern San Antonio. The site was intermittently occupied by hunter-gatherer groups from the Early Archaic through Late Prehistoric periods. Black and McGraw (1985) attribute the Early Archaic deposits to what they describe as the Local Period 5 site component. Diagnostic projectile points and tools preserved within this component include Martindale points as well as Guadalupe bifaces and Clear Fork tools. An uncorrected radiocarbon date from the Local Period 5 site component gave an age estimate of $4720 \pm 170$ 
B.P. (Black and McGraw 1985:238). In calibrated years, the age of this component is approximately 5,900-4,900 B.P., which places the sample within the latter half of the Early Archaic archaeological period. No formal features were recorded from the Local Period 5 site component, although several burned rock clusters were noted. Black and McGraw (1985:274) suggest that these rock clusters represent scattered hearths, cleaned-out rock ovens, or stone boiling dumps.

The overall preservation of botanical and faunal materials was poor within the Early Archaic component. Faunal species identified included white-tailed deer, rabbit, badger, gopher, turtle, and possibly raccoon, red fox, and dog (Black and McGraw 1985:274). Recognized wood species included walnut, ash, and acacia. Mussel shell was rarely observed in the Local Period 5 assemblage. The most significant aspect of the Early Archaic component was the diverse stone artifact assemblage. Black and McGraw (1985:274-275) believe that this diversity infers that a wide variety of activities were taking place at the site. The Local Period 5 component may have been a multi-functional base camp occupation. Although the Early Archaic assemblage is distinctive and different from later cultural components, Black and McGraw (1985:275) agree that the general pattern of settlement and subsistence varies little throughout later Archaic site deposits.

Richard Beene (41BX831) - This site is a multicomponent open occupation terrace site in southern Bexar County, discovered during the construction of the spillway for the now defunct Applewhite Reservoir project. The terrace at the Richard Beene site is $14 \mathrm{~m}$ deep and contains at least 20 stratigraphically distinct archaeological deposits. The Early Archaic surfaces date to ca. 8,700, 8,000, 7,800, 7,600, 6,900, and 6,500 B.P. (Thoms 2005). The Early Archaic site components contain the most diverse array of tool types recovered from the sites. The diverse nature of these materials seems to be indicative of a wide-range of residential activities including woodworking. The Early Archaic projectile point assemblage is represented by Angostura, Uvalde, Baker, and Martindale points. The Early Archaic assemblage also includes Dalton adzes and Clear Fork bifaces, which are believed to have functioned as woodworking adzes. Other than mussel shell, fau- nal remains are generally scant throughout the Early Archaic assemblage. Early Archaic features with and without fire-cracked rock are represented at Richard Beene. In cases where fire-cracked rocks are present, the rock material is of locally procured sandstone. Similarly, chert is locally procured as cobbles from the Medina River. In Thoms' (2005) opinion, only very subtle changes occurred in the general settlement-subsistence pattern over the past 9,000 years. He believes these minor changes are most easily attributed to the number of families encamped at any given time and the degree to which game animal or root food procurement dominated their subsistence pursuits (Thoms 2005).

Ice House (41HY161) - The site is on the grounds of Texas State University, near the confluence of the San Marcos River and an intermittent tributary, Sessom Creek. The location is at the edge of the Blackland Prairies and the Edwards Plateau, with abundant natural resources-including high quality chert-and permanent water. Artifacts from Paleoindian through the Archaic period have been recovered from the Ice House site. The first investigations were conducted underwater in the San Marcos River channel by Joel Shiner (1983) in 1981. The discovery of human remains during construction activity resulted in additional investigations in 1982 that recorded the remains of at least two individuals (Garber and Glassman 1992). Additional investigations by Ford and Lyle (1998) and by Lyle et Al. (2000) recovered Late Paleoindian, Early Archaic, and Late Archaic projectile points.

In 2004, data recovery excavations in a 3 x 4-m block recorded a series of Early Archaic occupations associated with Gower points. Radiocarbon dates from bone fragments define a range of ca. 7,700-6,650 B.P. through approximately $80 \mathrm{~cm}$ of deposits. The assemblage suggests that during this period, the site functioned as a hunting camp and retooling station, as exhausted tools were discarded and replaced. There were two small burned rock features, less than 60 $\mathrm{cm}$ diameter. Recovered faunal remains include deer, very large mammals (i.e., bison), small and medium mammals, birds, turtles, fish and the mandible of a canid that may be a domesticated dog (Oksanen 2005). The site is significant in that it contains an isolatable Early Archaic component that contains at least four separate occupations. 
Holt (41HY341) - Located on a terrace above the Blanco River in San Marcos, the Holt site contained an Early Archaic component, a Middle Archaic component, and a possibly Late Paleoindian occupation. The Early Archaic was represented by a Gower component, estimated at 7,000-6,000 B.P. (although there were no radiocarbon assays from the zone). This was overlay by a Middle Archaic component that was radiocarbon dated to ca. 4,740 B.P. (Brownlow 2004). The charcoal was from an earth oven, Feature 4, in Zone III. The only diagnostic lithic material from Zone III was three Early Triangular points.

Armstrong (41CW54) - The Armstrong site is along a dry paleochannel of the Blanco River northeast of the present day confluence of the San Marcos and Blanco Rivers. The site contained deeply buried, stratified deposits from Paleoindian through Early Archaic periods. Projectile point styles noted included St. Mary's Hall, Golondrina-Barber, Angostura, Hoxie, and Gower. Investigations conducted in 1999 (Oksanen et al. 2002) and 2000 (Oksanen and Schroeder 2002; Schroeder 2002) documented four occupation zones. Analyses included functional use-wear on lithic tools, diatom, phytolith and macrobotanical samples, fauna, textural analyses, magnetic susceptibility, lipid residue, and DNA.

In Occupation Zone 3 at the site, a species of Camessia bulb was recovered from Feature 2. It is probable that the camas bulb was roasted in an earth oven to make it edible. The bulbs of geophytes were widely consumed by Archaic peoples of the Edwards Plateau, and it appears that the Early Archaic inhabitants were processing these geophytes in earth ovens to increase their digestibility (Acuña 2006; Derring 1997). A radiocarbon date from charcoal within the feature was ca. 6,780 B.P. The charcoal is thought to be intrusive, although it is within the range of dates from OZ1 at the Gatlin site. The Armstrong sites's Occupation Zone 4 is the most relative component for comparisons with the Gatlin site investigations. Radiocarbon dates from Occupation Zone 4 were from ca. 8,080-7,960 B.P. Burned rock was found scattered throughout the zone, however, the only recorded features were related to lithic reduction. A Hoxie point was recovered from Occupation Zone 4. Hoxie points have been viewed as the predecessor to Gower points (Collins 2004), while others (Dockall and Pevny 2005) view them as part of a split stemmed point continuum that includes Gower-like points. At Wilson-Leonard, Hoxie and Gower appear to grade into each other, in that there are examples with characteristic traits of each (Dial et al. 1998:352). In Occupation Zone 4 of the Armstrong site, subsistence data included the remains of pronghorn antelope, deer, and small mammal. Stone tool forms were drills and bifacial gouges, and flake tools used as scrapers on plant and animal remains. Lipid analysis from burned rock collected throughout the zone suggests that both plant and animal foods were processed in fires. The lithic assemblage suggests that the site was used as a hunting camp and for tool refitting and maintenance (Schroeder 2002).

Paleoenvironmental data indicates there was a gradual summer warming between ca. 8,500-8,000 B.P. (Cummings 2002:154). Between ca. 7,500 B.P. conditions alternate between a slight warming and cooling as the composition of $\mathrm{C} 3$ and $\mathrm{C} 4$ grasses oscillates. After ca. 6,600 B.P., C4 grass begins to dominate, suggesting gradually warmer and drier climatic conditions (Schroeder 2002:49).

Wilson-Leonard (41WM235) - Located in Austin, Travis County, the Early Archaic deposits of Wilson-Leonard are more stratigraphically isolated and better represented by features and cultural materials than later Archaic subperiods at the site. The Early Archaic materials of Wilson-Leonard have contributed to our understanding of: (1) the relative antiquity of the subperiod, (2) prominent diagnostic projectile point types and technology, (3) subsistence commodities and technologies, and (4) site organization and features. Radiocarbon dates securely place the beginning of the Wilson-Leonard Early Archaic between 8,800-8,700 B.P. (Collins et al. 1998:239). The Early Archaic occupation yielded more features than any other archaeological period or subperiod represented at the site. Over 100 burned rock features were recorded in the Early Archaic deposits of Wilson-Leonard. These features consisted primarily of burned rock clusters; however, burned rock scatters, burned rock accumulations, burned rock basins, and a burned rock midden were also represented. The burned rock midden is of particular archaeological significance because it marks the emergence of these large cooking features during the latter half of the Early Archaic (Collins et al. 1998:236). 
Projectile point technologies represented during the earlier part of the Wilson-Leonard Early Archaic included lanceolate forms (e.g., Angostura and Thrall) and stemmed point forms (e.g., Hoxie and Gower). A small number of Late Paleoindian points (e.g., Golondrina, Barber, and St. Mary's Hall) were also recovered from these earlier Early Archaic levels. These specimens have been interpreted by Collins et al. (1998:220) as intrusive specimens from earlier origins or as point forms that began in the Late Paleoindian subperiod and continued to be in vogue into the early part of the Early Archaic. In the latter half of the Early Archaic, Uvalde, Baker, Bandy, and Martindale points became the principle projectile points represented in the assemblage. Another technological change recognized in the later Early Archaic is the appearance of unifacial Clear Fork tools. Bifacial Clear Fork tools were present throughout the Late Paleoindian and most of the Archaic period, but the unifacial Clear Fork tool form did not appear until the later Early Archaic (Collins et al. 1998:223-224).

Subsistence during the Early Archaic at WilsonLeonard appears to have focused on a diverse assemblage of floral and faunal resources. Fish, freshwater mussels, turtles, snakes, rabbits, whitetail deer, and antelope are among the faunal materials recovered from some of the burned rock features. The most significant find from the burned rock features at Wilson-Leonard was the presence of wild hyacinth or camas, a starchy geophyte that is rarely preserved in the archaeological record. The geophytes recovered from Wilson-Leonard were dated to ca. 8,000 B.P. Collins et al. (1998:239) believe that the cooking of geophytes in the burned rocks features at WilsonLeonard represents an important addition to the subsistence base as well as technology.

Landslide (41BL85) - This stratified terrace site is along the Lampasas River in southwestern Bell County. The Landslide excavation report is often cited by researchers for its seemingly diachronic projectile point sequence (Sorrow et al. 1967). The Early Archaic projectile point sequence begins with Angostura, followed conformably by Gower, Martindale, and Bell. This was one of the first sites excavated in Central Texas that was able to demonstrate an Early Archaic projectile point sequence. Like most open sites, organic preservation was generally poor, with fragmented bone and mussel shell composing most of the meager faunal assemblage. Early Archaic burned rock features were documented at the site, demonstrating the widespread use of hot rock cooking features.

\section{The Middle Archaic Subperiod}

Absolute Time Period: ca. 6,000-4,000 B.P.

Relative Time Period: Follows the Early Archaic subperiod, precedes the Late Archaic subperiod.

Geological Time Period: Late Middle Holocene.

Diagnostic Projectile Point Types: Stemmed (Dart Point) Forms: Andice/Bell Calf Creek), Nolan, La Jita, Travis, Pandale, Taylor, Langtry, and Val Verde; Unstemmed (Dart Point) Forms: Early Triangular (Turner and Hester 1999).

\section{Environmental Conditions}

\section{Paleoclimate}

During the beginning of the Middle Archaic, from approximately 5,750-5,250 B.P., Johnson and Goode (1995:73) contend that a brief warm and dry period arose. Hudler (2000) also documents a major climatic shift towards warmer and drier conditions ca. 5,300 B.P., followed by a very brief wet interval. Johnson and Goode (1995:73) also believe this dry period was followed by a short period of climatic amelioration between 5,250-4,600 B.P. with moderately wet and cool conditions.

The palaeoclimate of the late Middle Holocene and the end of the Middle Archaic is characterized as a comparatively long, dry climatic interval called the Hypsithermal. Across the Edwards Plateau researchers have documented a decrease in precipitation rates and an increase in temperature during this time period (Bousman 1998a; Collins 2004; Johnson and Goode 1995; Mear 1995; Nordt et al. 1994, 2002; Russ et al. 2000; Toomey et al. 1993). Although the palaeoclimatic conditions experienced during the Middle Archaic were the driest experienced on the Edwards Plateau in the last 10,000 years, the precise timing and extent of the Hypsithermal interval is debatable. In the eastern plateau, Johnson and Goode (1995:74) contend that the "Dry Edwards Interval" was most pronounced from 4,400-2,600 B.P. In the western plateau, a major erosional event 
documented within a Pecos River terrace suggests that an extensive dry spell occurred ca. 5,000 в.P. (Dibble 1967).

\section{FLORA}

For the most part, the plant communities that were established in the Early Archaic were still present in the Middle Archaic subperiod. The most significant change to these plant communities appears to be their distribution. Current research suggests that the hyper-arid conditions experienced during the Middle Archaic may have allowed for more desert-adapted plant species (e.g., sotol, yucca, and lechugilla) expanding their communities into the central and eastern regions of the Edwards Plateau (Collins 2004; Dering 1999). Although more desert-adapted species may have expanded their range eastward, Bousman's (1998a:212) research suggests that open grasslands continued to be the principal plant community on the eastern plateau.

\section{FAUNA}

At the beginning of the subperiod around 6,000 B.P., bison reappeared on the plateau during a climatically cooler and wetter period (Johnson and Goode 1995). This climatic interval was apparently short-lived as bison abundance diminished again around 5,000 B.P. (Collins 2004). All of the other major animals species documented in the Early Archaic subperiod continued to occupy various ecotones of the Edwards Plateau during the Middle Archaic. Toomey et al. (1993) document a significant increase in frequency of desert shrew remains at Halls Cave in Kerr County, suggesting that desert-adapted mammals were thriving in the central plateau region. Despite this increased aridity, deer, antelope, rabbits, fish, mussels, and other animals continued be readily available across the region and provided a satisfactory subsistence base.

\section{Cultural Summary}

\section{SETtLement and SubSistence}

The Middle Archaic is marked by a significant increase in archaeological sites on the Edwards Plateau. It is difficult to determine if this increase is due to a larger, denser population or an increase in residential mobility (Turpin 2004). In either case, there is abundant evidence that settlement and subsistence became more regionally specialized during this time. For example, burned rock midden use proliferated during the Middle Archaic (Black and Creel 1997; Prewitt 1981, 1983, 1994; Shafer 1986). There is widespread evidence supporting an increased reliance on the processing of geophytes and succulent plant bulbs such as sotol, yucca, and lechugilla in burned rock middens (Dering 1999).

Hunting during the Middle Archaic was very similar to the Early Archaic. Although obvious changes in projectile point morphology are evident, the underlying hunting technology continued to focus on the taking of deer, antelope, rabbits, and other small- and medium-sized animals. Middle Archaic peoples continued to procure fish and mussels from local rivers, and to gather nuts, acorns, grass seeds, berries, and other wild fruits. These resources provided seasonal staples to the subsistence base.

\section{Soctal Organization}

The social organization of the Middle Archaic population was probably very similar to organization during the Early Archaic. Like contemporary hunter-gatherer societies worldwide, Middle Archaic hunter-gatherer society was generally egalitarian and organized into small family bands (see Steward 1955). However, though cultural continuity is evident through the periods, the Middle Archaic likely coincided with the emergence of more distinctive territoriality and social identification (Story 1985:44). Some researchers cite the proliferation of projectile point styles, cemeteries, and burned rock middens as evidence of such trends (Story 1985).

There is limited evidence for house structures in the Middle Archaic, however post-molds for a hut like structure at the Lions Creek site in Burnet County have been documented (Johnson 1997). Small, perishable structures like these support the notion that mobile family groups subsisted on the central plateau throughout the Middle Archaic.

Increased aridity during the Middle Archaic may have led to increased territoriality in some areas of the plateau, especially in arid regions where food resources were presumably scarcer. Increased territoriality may be reflected in changes in mortuary practices. There are several locations on the Edwards Plateau where Middle Archaic interments have been 
found in sinkholes such as the Seminole Sink or the Bering Sinkhole in Kerr County. The use of these sinkholes as natural graves began first at Bering Sinkhole during the Early Archaic and then during the early Middle Archaic, ca. 6,000-5,000 years ago, at Seminole Sink, and continued into the Late Prehistoric period. In both instances, no distinctions could be made between the age, sex, or social status of the interred burials, thus reaffirming the egalitarian nature of Middle Archaic hunter-gatherer society (Bement 1994; Turpin 1986). Inter-group violence is often associated with territoriality; however, analysis of Middle Archaic burials recovered from the Seminole Sink and Bering Sinkhole did not recover any direct evidence for violent death (Bement 1994; Turpin 1986).

The most direct evidence for Middle Archaic territoriality is implied through rock art, which is concentrated in the arid Lower Pecos archaeological area of the western Edwards Plateau. Unlike other areas, the Lower Pecos exhibits a stylistically consistent polychromatic pictograph form that is believed to have originated in the Middle Archaic ca. 4,0003,000 years ago (Shafer 1986; Turpin 2004). This pictograph style, described conventionally as the Pecos River style, is geographically confined to the Rio Grande and the Devil's and Pecos Rivers of the western plateau and northern Mexico. It is possible that this form of expressive culture may reflect territoriality or at the least, a shared cosmology. It may also indicate a leadership division in Middle Archaic society, as the artists, presumably religious leaders, evidently had specialized insights into the spiritual world. Many archaeological researchers believe that the Lower Pecos style represents one of the earliest and most elaborate, religious art forms in North America (Boyd 2003; Shafer 1986; Turpin 2004).

\section{TECHNOLOGY}

\section{Cooking Technology}

Hot rock cooking technologies continue to be employed during the Middle Archaic. Burned rock hearths, scatters, and concentrations are common at Middle Archaic sites; however, none of these features is more pronounced than the burned rock midden. Burned rock middens are widely documented at Middle Archaic sites on the Edwards Plateau. Johnson and Goode (1994) suggest that the primary function of Middle Archaic burned rock middens was to cook xerophytic plants such as sotol, lechugilla, and yucca, which apparently thrived on the plateau during the Middle Archaic.

Three distinct types of burned rock middens documented during the Middle Archaic are (1) sheet middens, (2) dome middens, and (3) annular middens (Mahoney et al. 2003a; Prewitt 1994). Sheet middens are loose accumulations of displaced and mixed burned rocks, usually derived from several burned rock features. The rock displacement may be caused by natural or cultural processes, including erosion, flooding, feature maintenance, and/or reuse. Dome middens are round, dome-shaped accumulations of burned rock that can be several feet thick. Dome middens form through repeated feature use and maintenance, thus resulting in a massive, dense accumulation of burned rock. Annular middens (also called crescent, ring, or donut middens) are circular or semicircular-shaped accumulations of burned rock with a centralized depression. Like dome middens, they may be several feet thick. The centralized depression is believed to have once been the central cooking feature of an earth oven.

\section{Stone Tool Technology}

Characteristic Middle Archaic projectile points from the Edwards Plateau include Early Triangular, Andice/Bell (Calf Creek), Nolan, La Jita, Travis, Pandale, Taylor, Langtry, and Val Verde. Early Triangular dart points appear in the beginning of the Middle Archaic subperiod, around 5,000 B.P. (Hester and Shafer, Appendix C). As suggested by the name, these dart points are unstemmed and triangular in shape. They are known to occur in association with Bell and Andice points, which are basally notched, stemmed point forms (Mahoney et al. 2003a; Sorrow et al. 1967). Wyckoff's (1995) research suggests that Bell and Andice points (jointly described as Calf Creek points) are intrinsically linked to bison hunting. Their appearance at the beginning of the Middle Archaic is presumably related to the return of bison to the area ca. 5,000 B.P.

The other projectile point types appear slightly later in the Middle Archaic record and persist, to varying degrees, to the end of the subperiod. Although there are clear morphological differences between these points, they all have squarish to rectangular stems 
with weak, rounded, or abrupt shoulders. Pandale points are typically found in the southwestern plateau, although they have also been recovered from eastern plateau sites such as the Royal Coachman site (Mahoney et al. 2003a) and the Panther Springs Creek site (Black and McGraw 1985). Pandale points have alternately beveled stems, which is a technological attribute they share with many La Jita and Nolan points (Turner and Hester 1999). Turner and Hester (1999:140) suggest the La Jita points may represent an earlier, unfinished reduction stage of the Nolan point though the Gatlin assemblage seems to contradict this. In outline, Travis points are morphologically similar to Nolan points, except they are not beveled.

As was the case for the Early Archaic, ground stone technologies are evident at many Middle Archaic sites. In fact, Johnson and Goode (1995:92) assert that most of the manos and metates found on the Edwards Plateau are attributable to Middle Archaic sites. If Johnson and Goode (1995) are correct, then milling technologies must have proliferated in the Middle Archaic. As in the Early Archaic, bifaces, scrapers, and modified flakes also composed a significant portion of the Middle Archaic toolkit. In some instances biface caches have been recovered, marking the beginning of biface caching behavior in Texas (Miller 1993). Guadalupe bifaces and Clear Fork tools have been recovered from some Middle Archaic assemblages, but less frequently than in Early Archaic contexts.

\section{Representative Middle ArChaIC Sites}

Compared to other archaeological periods and subperiods, there are relatively few well-preserved Middle Archaic sites. This is largely due to the dry climatic conditions in place during the Middle Holocene. In some parts of the plateau, the rate of soil deposition slowed or stopped during this time, so that many Middle Archaic site surfaces became mixed or compressed with later occupations or deflated from soil erosion. Also, since burned rock midden use became widespread during the Middle Archaic, maintenance activities (e.g., the unearthing and reburial of rock and soil) related to burned rock midden use may have contributed to the mixture observed at many Middle Archaic sites.
The following site summaries discuss some of the better-represented Middle Archaic components from the Edwards Plateau. These summaries underscore variation in the archaeological record and highlight significant contributions that these sites have made to our understanding of the regional prehistory. Like the previous section, sites are discussed in geographical order, from west to east across the Edwards Plateau (Figure 3.1).

Arenosa Shelter (41VV99) - Arenosa Shelter is a limestone overhang near the confluence of the Pecos River and the Rio Grande. The shelter itself and the terraced area immediately outside the shelter have been progressively infilled by deep, fine-grained alluvial sediments of the Pecos River. Cultural deposits dating from the Early Archaic through the Late Prehistoric are preserved within various alluvial strata of the shelter and terrace deposit. Dibble's (1967) reporting of the Arenosa excavations makes two contributions to our understanding of the regional archaeological record. First, it offers a relative point chronology for the Archaic period of the Lower Pecos region. Secondly, it documents a major erosional event during the Middle Archaic, ca. 5,000 B.P., when much of the terrace degraded. It is likely that this erosional event marks the peak of the mid-Holocene Hypsithermal that was experienced across much of the Edwards Plateau.

Baker Cave (41VV213) - The Middle Archaic deposits from Baker Cave are rich in fire-cracked rock and ash. They also contained an abundant amount of plant remains and perishable artifacts. The variety of plant remains recovered from the Middle Archaic levels are more or less the same as those represented in the Early Archaic, with one exception-sotol. Sotol leaves first appear in the Middle Archaic context of Baker Cave (Chadderdon 1983:92). Shafer (1986:77) has recognized that the occurrence of lechugilla within Lower Pecos sites drops significantly in the Middle Archaic, and it is somewhat replaced by sotol. He adds, however, that this shift in plant use was not particularly significant to the local economy since both plants are processed and cooked in the same manner.

Several perishable cultural items were recovered from the excavations including sandals, knotted fiber, netting, matting, and cordage produced from local fibrous plants such as lechugilla (Chadderdon 1983; 
Word and Douglas 1970). Dart points represented in the Middle Archaic deposit include Pandale, Langtry, and Val Verde points. The distribution of these point types is widespread across the western Edwards Plateau, and they occur at most Middle Archaic sites in the Lower Pecos.

Jonas Terrace (41ME29) - The Jonas Terrace site is an open occupation terrace site located along San Geronimo Creek, a tributary of the Medina River. The earliest occupation of the terrace was during the early Middle Archaic, around 5,500 B.P., when small groups of peoples camped on the terrace for a short period of time (Johnson 1995). An increase in site use and occupation became more pronounced during the Middle Archaic. The density of the debitage and stone tools discarded at the terrace indicate that the Middle Archaic occupation was much longer than an overnight stay. La Jita points are the preeminent Middle Archaic point type represented at the site. A few small hot rock cooking features are also present in these Middle Archaic contexts; however, Dering's (1995) analysis of these features, did not recover any charred plant remains.

The most significant prehistoric event evidenced in the Jonas Terrace record is the peak of the mid-Holocene Hypsithermal ca. 4,600 B.P. Geomorphic evidence suggests that the floodplain of San Geronimo Creek stopped aggrading at this time and site erosion occurred. After this event, the Jonas Terrace site was utilized more often and appears to have been an important seasonal camp for groups utilizing Pedernales and Montell points (see also Late Archaic subperiod). The development of a large burned rock midden is also noted at this time. Dering's (1995:303) study of the burned rock midden matrix documented the presence of charred sotol/yucca, Liliaceae bulb fragments, and prickly pear seeds during the late Middle Archaic. Bone preservation at the site was poor, although Shaffer (1995:308) was able to identify the charred remains of deer, pronghorn, and Bison bison. With exceptions to changes in climate and stone tool technologies, the general patterns of site use and subsistence activities documented at Jonas Terrace continue throughout the Late Archaic subperiod.

La Jita Site (41UV21) - The La Jita site is an open terrace occupation site along the Sabinal River in northeastern Uvalde County. The cultural materials recovered from the site include Early Archaic through Late Prehistoric components. The Middle Archaic occupation of the La Jita site was intermittent, and the deposits formed through numerous brief periods of site use by generations of resident population. There are three burned-rock middens present that Hester (1971) attributes to Middle Archaic peoples. Pandale, Langtry, Nolan, Travis, and La Jita (named after the site) points are attributable to the Middle Archaic compoent. Hester (1971:118) notes that it is impossible to distinguish any clear vertical separation between these Middle Archaic projectile point types. This problem may be related to slowed soil development due to the mid-Holocene Hypsithermal or disturbances caused from intermittent burned rock midden use. Hester (1971:119) argues that Middle Archaic activities at the La Jita site were focused around the burned rock middens; however, it should be noted that there are also a few Middle Archaic burned rock hearth features in the terrace area adjacent to the midden. Stone artifacts recovered from within the midden matrix were rare, as was bone. More thermally altered stone artifacts were present in the terrace deposits adjacent to the burned to rock midden than within the midden matrix itself.

Landslide (41BL85) - The Middle Archaic deposits recovered from the Landslide site are described by Sorrow et al. (1967) as Occupational Phase 4. Archaeological materials recovered from Occupational Phase 4 rest conformably beneath a burned rock midden in Stratum IIIa. The Middle Archaic cultural deposit consists of Nolan and Travis, points - with some later Bulverde and Pedernales points intermixed - as well as an array of scrapers, burins, bifaces, and other knapping debris. Organic preservation is poor throughout this Middle Archaic deposit, and although burned rock features are present throughout the Archaic sequence of the Landslide site, no associated features were recovered for Occupational Phase 4 . The significance of the Landslide site stems from its uniform stratigraphic record. Since Middle Archaic deposits are often eroded due to the mid-Holocene Hypsithermal, archaeological deposits from this subperiod are often compressed or mixed. The Landslide site offers a somewhat rare example of Middle Archaic archaeological materials resting conformably between Early and Late Archaic deposits. 
Royal Coachman (41CM111) - The Royal Coachman site is a multicomponent open occupation terrace site along Cordova Creek in Comal County. The best-preserved cultural deposit derives from the lower depositional zone of the site, which dates to ca. 5,000-4,700 B.P. (Tomka et al. 2003). Seven burned rock features were identified from this lower zone, including a large, deflated burned rock sheet midden that extended across most of the site. A fairly abundant sample of mussel shell was collected among these features, indicating that mollusks were consumed. Vertebrate preservation was poor and consisted of only a small assemblage of fragmented remains. Two archaeological components were identified for this period, and together, these components appear to represent a technological transition from the early Middle Archaic to the late Middle Archaic. The first and older component was defined by materials such as Andice, Bell, and Early Triangular points. The second component was identified by Nolan and Pandale points, both of which are later Middle Archaic point forms. Although some separation existed between these components, undulations across the prehistoric occupation surface prevented these components from being definitively separated.

Early Triangular points are the best temporally defined artifacts from the Royal Coachman site. Radiocarbon assays from the site suggest that the Early Triangular points were deposited at the site between ca. 5,000-4,700 B.P., which is in agreement with the previously reported age range for this point type (Turner and Hester 1999). The problem, however, is not the age estimate but the context of the materials. An admixture of Andice, Bell, Nolan, and Pandale points was also recovered from proveniences that contained the Early Triangular points. Tomka et al. (2003:89) suggest that this admixture may have broad implications for early Middle Archaic site preservation on the southern and eastern margins of the Edwards Plateau. They argue that the dry mid-Holocene climate altered stream flow regimes, which resulted in a slow rate of soil deposition and a relatively stable terrace surface. They point out that the evidence for a stable, non-aggrading surface is widely documented across the Edwards Plateau ca. 5,000 years ago (see Collins 2004; Cooke et al. 2003; Dibble 1967; Nordt 1992). This time period correlates roughly with the early Middle Archaic, which may explain why many of the associated archaeo- logical components are mixed from this time period. This problem may have wide-ranging implications for many sites in the Edwards Plateau.

Seminole Sink (41VV620) - This large, vertical sinkhole is in Seminole Canyon State Park near Comstock, Texas. This sinkhole functioned as a prehistoric cemetery for at least 22 individuals (Turpin 1988). The corpses were dropped through the vertical shaft of the sinkhole and compacted into one stratum. Radiometric dates taken from three separate bones yielded uncorrected results ranging between 5,750-4,700 в.P. (Decker et al. 2000). This is significant because it establishes the occurrence of formal mortuary practices and the use of sinkholes as funerary features in the Middle Archaic.

\section{The Late Archaic Period}

Absolute Time Period: ca. 4,000-1,300 B.P.

Relative Archaeological Time Period: Follows the Middle Archaic subperiod, precedes the Late Prehistoric Period. The following includes the transitional period between the Late Archaic and Late Prehistoric, often referred to as the Transitional Archaic period or as the Late Archaic II (Johnson and Goode 1994, 1995).

Geological Time Period: Late Holocene.

Diagnostic Projectile Point Types: Stemmed (Dart Point) Forms: Bulverde, Pedernales, Montell, Lange, Marshall, Williams, Marcos, Castroville, Shumla, Ensor, Frio, Fairland, and Darl (Prewitt 1981, 1983; Turner and Hester 1999); Unstemmed (Dart Point) Forms: Kinney, and Tortugas (Turner and Hester 1999).

\section{Environmental Conditions}

\section{PALEOCLIMATE}

Shortly after 3,000 B.P., a brief cool and wet period was experienced on the Edwards Plateau. This climatic trend is believed to have lasted around 1,500 years; however, this estimate is based on a limited paleoclimatic dataset from the past 2,000-3,000 years. The best data available on the Late Archaic paleoclimate comes from the macrofauna assemblages recovered from Hall's Cave and the Bering Sinkhole, both in Kerr County. An analysis of the Hall's Cave faunal assemblage led Toomey et al. (1993:310) to 
conclude that more mesic-adapted animal species inhabited the Edwards Plateau between 2,500-1,000 B.P. Similarly, Bement's (1994:50) analysis of the Bering Sinkhole macrofauna assemblage indicates that desert-adapted animal species, such as the desert cottontail (Sylvilagus audubonii), disappear from the record ca. 2,700-1,000 B.P., thus implying a return to wetter (and presumably cooler) climatic conditions.

There are very little data available on the Late Holocene pollen record of the Edwards Plateau, forcing researchers to rely on pollen data gathered from adjacent biogeographical regions. An important pollen record often cited as analogous with the Edwards Plateau region comes from Weakly Bog in Leon County (Bryant and Holloway 1985:63). Located east of the plateau, the Weakly Bog dataset details the pollen record of the last 2,400 years (Holloway et al. 1987). According to the data, from 2,400-1,500 years ago, oak pollen counts were relatively high, suggesting oak woodlands were abundant and relatively mesic conditions persisted in the region. Around 1,500 years ago, oak pollen rapidly decreased and grass pollen increased. This change has been interpreted as the advent of the modern oak-savanna community and the beginning of comparatively drier climate (Holloway et al. 1987).

Bousman (1998:206) offers a different interpretation of the Weakly Bog data. He argues that there is no measurable increase in grass pollen, as suggested by Holloway et al. (1987). Bousman (1998:207) believes that the Weakly Bog data actually document a shift from oak woodlands to oak-hickory woodlands. In this scenario Bousman (1998:207) suggests that the Late Holocene climate was becoming "progressively moist," which is exactly opposite the interpretation offered by Holloway et al. (1987). Bousman's (1998) alternative interpretation highlights the problem of applying the pollen record from other biogeographical regions to the Edwards Plateau and demonstrates the need for more pollen research in the plateau region.

\section{FLORA}

Although changes in plant distribution occurred, the general plant communities that were established in the Early Archaic continued to persist into the Late Archaic subperiod. The cooler and wetter climate of the Late Archaic probably encouraged the spread of grasses. Evidence of broad grassland areas is indirectly supported by the return of bison to the region (Collins 1995; Dillehay 1974).

\section{FAUNA}

Near the end of the Late Archaic, ca. 1,500 B.P., bison reappear in the archaeological record (Collins 2004; Dillehay 1974). All of the important game species (e.g., deer, pronghorn antelope, rabbit, squirrel, and turtles) that were hunted in the previous subperiods continued to occupy their ecological niches in the Late Archaic. The general health and abundance of wildlife was probably very good during this time. At Hall's Cave, Toomey et al. (1993:310) documented the return of several mesic-adapted species in the faunal assemblage, including the woodland vole, the eastern pipestrile bat, and the least shrew. The return of these species suggests that water availability was more widespread, a situation that was undoubtedly beneficial to overall health and population of local wildlife.

\section{Cultural Summary}

\section{SETtLEMENT AND SubSISTENCE}

The Late Archaic subperiod saw a continuation of the general subsistence pattern utilized for most of the Archaic period; however, a few differences are apparent. Late Archaic people subsisted in a wetter and cooler climate than previously endured during the Middle Archaic. Perhaps this is a reason why Late Archaic sites are more common or at least more numerous than earlier Archaic period sites (Black 1989; Collins 2004). Some researchers argue that population increased during the Late Archaic, thereby accounting for the abundance of Late Archaic sites (Prewitt 1981; Weir 1976).

Increasingly complex cultural manifestations are characterized in the Late Archaic archaeological record, and increased population size may have contributed to this complexity. Territoriality issues may have also been more commonplace in the Late Archaic. This argument is somewhat supported by the development of more formal cemeteries in many areas of Texas (Hall 1981; Lukowski 1987; Taylor 1995). 
Compared to previous subperiods, an extremely diverse assemblage of projectile point forms was utilized during the Late Archaic. Some of these points, such as Lange, Castroville, and Montell were apparently used for bison hunting (Dibble and Lorrain 1968); however, all of the points would have functioned adequately in the hunting of small to large game. As mentioned, bison appear to be an important game resource during the Late Archaic. Evidence for this is best attested in the Late Archaic deposits of Bonfire Shelter, where the remains of over 800 bison were recovered (Dibble and Lorrain 1968).

\section{SOCIAL OrGANIZATION}

Late Archaic social organization continues in the long, conservative hunter-gatherer social tradition established during the previous Archaic subperiods. Like during the Early Archaic and Middle Archaic subperiods, Late Archaic people subsisted as residentially mobile family bands in a largely egalitarian society but with evidence of increasing populations and complexity. Despite these subtle changes, Late Archaic peoples hunted game and cooked plant foods in nearly the same manner as earlier Archaic peoples.

The dense nature of many site deposits documented and the high concentration of Late Archaic sites on the Edwards Plateau implies that population size significantly increased. Population increase may have led to the development of specialized trade networks and territories across the plateau and other areas of Texas. Increased territoriality is implied by the widespread development of Late Archaic cemeteries in prairie areas south and southeast of the Edwards Plateau (Hall 1981; Lukowski 1987; Taylor 1995). Burials from these cemeteries often contain grave goods such as marine shell ornaments (from the Texas coast), boatstones (from Arkansas), and corner tang knives (from the Edwards Plateau). The presence of these items ultimately suggests that plateau populations participated in some form of a trade system during the Late Archaic (Hall 1981). A rise in the occurrence of caches of bifaces also reflects these increasing interactions and trading networks, as high quality chert raw materials were traded into resource poor areas to meet increasing demands from groups on the plains or the Caddo in northeast Texas (Miller 1993).
Stylistically consistent rock art forms continue to be largely restricted to the arid Lower Pecos area of the plateau. The preeminent rock art style of the Late Archaic is the monochromatic Red Linear style, which is stylistically different from the previous Pecos River form. Turpin (2004:272) believes that the appearance of the Red Linear style is correlated with a Late Archaic intrusion of bison hunters. Red Linear style often depicts males in conflict, deer hunting scenes, sexual intercourse, pregnancy, and childbirth (Turpin 2004). These rock art themes give insight into the events and social values that were important to the lifestyle of Late Archaic people.

\section{TECHNOLOGY}

\section{Cooking Technology}

Hot rock cooking technologies developed in previous periods continued to be employed during the Late Archaic. All of the various burned rock features observed earlier in the Archaic period are observed in Late Archaic contexts. Burned rock middens are a very common Late Archaic site feature, suggesting that burned rock midden use was more prevalent than during the Middle Archaic. Many of the burned rock middens that formed during the Middle Archaic continued to be used by Late Archaic peoples (Black and Creel 1997). Due to the continued reuse and maintenance of middens by later peoples, many temporally distinct archaeological components were often mixed by the prehistoric peoples themselves. This phenomenon occurs frequently at Late Archaic sites.

\section{Stone Tool Technology}

Various projectile point forms were utilized during the Late Archaic. Point forms that appear at the beginning of the Late Archaic include Pedernales, Kinney, and Tortugas points. Kinney is an unstemmed, triangular to elongate-triangular shaped dart point or knife with a concave basal margin. Pedernales points have bifurcated stems and a narrow to broad, often leaf-shaped blade (Turner and Hester 1999). Despite the morphological differences, Goode (2002) argues that Kinney and Pedernales points are culturally and technologically linked, and their distribution may be indicative of a cultural area. Tortugas points are similar to Kinney in that they are triangular to elongate-triangular shaped, unstemmed points. Turner and Hester's (1999) research shows 
that the distribution of Tortugas and Kinney points are similar across Texas; however, Tortugas points are generally considered a classic South Texas Plain point form.

Montell, Lange, Marshall, Williams, Marcos, Castroville, and Shumla points appear slightly later in the subperiod. Except for Montell, which bears some technological similarities to Pedernales (Johnson 1995), the aforementioned point forms are technologically similar. Lange, Marshall, Williams, Marcos, Castroville, and Shumla are all broad-bladed points that generally have expanding stems and prominent, barbed shoulders. There are subtle, morphological differences between these points, which are best illustrated in Turner and Hester (1999). Although these points occur widely across the Edwards Plateau, some generalities of their distribution may be offered. Lange, Marshall, and Williams points are generally found at sites on the central and eastern plateau, and Castroville and Shumla points are common to the central and western plateau (Prewitt 1995; Turner and Hester 1999). Marcos points occur widely across the plateau region. Many of these early Late Archaic points were apparently used for bison hunting (Dibble and Lorrain 1968).

In the latter half of the Late Archaic subperiod, another group of technologically similar points emerged. Ensor, Fairland, and Frio points appeared on the plateau ca. 2,200 B.P. and were utilized throughout the remainder of the Late Archaic, which is sometimes referred to as the Transitional Archaic. These points are generally small and crude in comparison to earlier Late Archaic point forms. Ensor, Fairland, and Frio points have shallow basal side-notches, which form weak to abrupt shoulders. Frio points have a V-shaped basal notch on their stem, giving the point a "fish-tail" appearance. Ensor and Fairland stem bases are generally straight to slightly concave. The distribution of Ensor, Fairland, and Frio points is widespread; they are recovered from sites all across the Edwards Plateau.

Approximately 1,800 years ago, a distinctive point form called Darl appeared in the Late Archaic (Turner and Hester 1999). Darl points are also found at sites all across the plateau. They are small and have straight, rectangular stems that are occasionally beveled. The morphology of Darl points is distinctively different from the Ensor, Frio, and Fairland group and may represent the precursor of arrow points in the Late Prehistoric (Carpenter et al. 2006).

Ground stone technologies continued to be utilized in the Late Archaic. As in earlier Archaic subperiods, bifaces, scrapers, and modified flakes comprised a significant portion of the Late Archaic tool assemblage. Biface caches are also recovered from Late Archaic contexts on the Edwards Plateau (Miller 1993).

\section{Representative Late Archaic Sites}

The following section discusses a small selection of Late Archaic sites from the Edwards Plateau. Like many Middle Archaic sites, some Late Archaic site deposits are often mixed because of maintenance activities of burned rock middens. The sites discussed below were selected based on the integrity (i.e., unmixed or undisturbed) of their Late Archaic component. These site summaries are intended to accentuate regional variation in the Late Archaic archaeological record and draw attention to the contributions these sites have made to our understanding of the regional prehistoric record. This is not intended to be a laundry list of excavated Late Archaic sites. As in the previous sections, sites are discussed in geographical order, from west to east across the Edwards Plateau (Figure 3.1).

Bonfire Shelter (41VV218) - Approximately 2,600-3,000 years ago, a bison jump event occurred at Bonfire Shelter (Dibble and Lorrain 1968; Turpin 1991). An estimated 800 individual bison (Bison bison) were stampeded over the bluff immediately overlying the shelter. The bison were butchered and their remains were left to decompose inside the rockshelter. The rotting carcasses are believed to have ignited spontaneously, resulting in an entire burned horizon of bone and ash across the rockshelter deposit. Small hearths were used during the butchering process, and numerous stone tools were recovered among these skeletons, including Marshall, Montell, and Castroville points. Researchers suggest that a brief mesic interval in the early Late Archaic fostered the spread of grasslands in the Lower Pecos and attracted bison back into the region (Shafer 1986; Turpin 1986).

41TG91 - Site 41TG91 is an open occupation terrace site along the South Concho River in central Tom Green County. The age of the site deposits range 
from Late Archaic through the Late Prehistoric. The earliest Late Archaic deposits from the site date to approximately 2,600 B.P. and are associated with Marcos dart points (Creel 1990). A slab-lined basin and other burned rock hearth features were recovered in the upper Late Archaic horizon. A dense concentration of mussel shell was associated with these features. The only projectile point recovered from the upper Late Archaic deposit resembles the Ensor type. The overall impression of subsistence at the site suggests that the occupants were consuming deer, prairie dogs, cottontails, jackrabbits, turtles, fish, river mussels, and various other animals (Creel 1990:221). Bison, although present, does not appear to have been an important food for most of the Late Archaic; however, its absence could be due to seasonality (Creel 1990:221).

Anthon (41UV60) - The Anthon site is an open site in southern Uvalde County on a terrace of the Nueces River. Numerous occupations are reported for the Late Archaic subperiod at the Anthon site (Goode 2002). Despite this, very little is understood about the social structure and subsistence practices of the Late Archaic peoples who inhabited the site. The earliest materials recovered from the Anthon site are approximately 4,000-3,000 years old and are affiliated with Pedernales and Kinney points (Goode 2002). Goode (2002:241) believes that evidence of population growth or cultural expansion was widespread at sites across the south-central Edwards Plateau at this time, and the proliferation of Pedernales and Kinney points deposited at Late Archaic sites is connected to this population or cultural growth.

Goode (2002) also believes that the occupation of the Anthon site primarily occurred during the fall, the optimum season for hunting ruminants (hoofed mammals) and collecting acorns and nuts. A number of small hearth features from the Pedernales/Kinney component are noted in the Anthon report, but these features are spatially widespread and have poor organic preservation. Possibly the most significant contribution of the Anthon site study was the demonstration that Pedernales and Kinney points share a close temporal and technological relationship, hence implying a strong cultural link between the two projectile point forms.
The most significant changes documented in the Late Archaic record of the Anthon site are in projectile point technologies. Around 3,000 B.P., Pedernales and Kinney points were replaced by Marshall, Montell, Castroville, and Marcos forms. Goode (2002:242) argues that Marshall points are technologically similar to Pedernales points and implies that they may represent a continuation of the tradition. Castroville and Marcos points are technologically different than Pedernales and Marshall points, most noticeably in their expanding stems. Goode (2002:243) believes that these point types may represent the product of a separate culture or, at the least, suggest a certain degree of interaction between cultural groups. $\mathrm{He}$ also connects the expanding stem point technologies to a shift toward a cooler and wetter climate (Goode 2002:243). Mounting evidence suggests that a brief mesic interval was experienced during the Late Archaic (Bryant and Shafer 1977; Johnson and Goode 1994). Wetter conditions likely attracted bison to migrate south of their normal range and into areas of the Edwards Plateau and South Texas. The aforementioned changes in projectile point technologies may therefore represent an increased emphasis on bison hunting.

Around 2,200 years ago, Ensor, Fairland, and Frio dart point types appeared at the Anthon site and replaced the previous projectile point forms. These diagnostic artifacts are widespread across most the Edwards Plateau and persist as major projectile point styles until the arrow point technologies appeared in the Late Prehistoric period.

Slab (41LL78) - The Slab site is an open occupation site on the left terrace of the Llano River in east-central Llano County. Though, Early Archaic through Late Prehistoric cultural deposits are present at the site, the Late Archaic component is the most abundant and well-represented archaeological deposit. Numerous circular Late Archaic burned rock features were documented at the Slab site. Patterson (1987) interpreted these circular features as structural remains with central hearths. These structures are believed to have functioned as temporary dwellings. No organic materials were recovered from the excavations of the Slab site, thus the age of the features are based on temporally diagnostic stone tools. Projectile points recovered from the Late Archaic subperiod include Marcos and Castro- 


\section{3-24 Chapter 3}

ville point types followed by Darl, Ensor, Frio, and Fairland points. Patterson (1987) concludes that the Slab site was seasonally utilized as a base camp, and the reuse of this site through time indicates that the site met the subsistence needs for generations of hunter-gatherers. 


\title{
Chapter 4
}

\section{Survey And Testing Results (41KR621 And 41KR622)}

\author{
Michael E. Smith and Brett A. Houk
}

\section{INTRODUCTION}

The following chapter describes the survey and testing investigations that were conducted on the Spur 98 project prior to any data recovery work on 41KR621. In May and June 2004, SWCA conducted an intensive archaeological survey along the proposed extension of Spur 98 in Kerr County for TCB on behalf of the San Antonio District of TxDOT (Houk and Miller 2004a). TxDOT archeological staff originally identified the archeological potential of the locale through background research, by an initial field inspection, and the presence of cultural materials exposed in recent open utility trenches that bisected the site area. The potential depth of deposits was subsequently confirmed by initial geoarcheological testing of the area (Abbott 2004).

Prior to the extension of the roadway, Spur 98 ended approximately 2.2 miles west of the Spur 98/SH 16 intersection. The extension began at the old road terminus, traveled northwest about 3,000 feet, and then headed northeast, crossing both the Guadalupe River and SH 27 before ending at FM 1338. The total length of the project was 1.15 miles, including approximately 0.6 mile of uplands at the eastern end of the project area. The remainder of the extension crossed terraces on the southern and northern sides of the Guadalupe River.

Given the extensive natural erosion, shallow soils, and broad exposures of cretaceous bedrock deposits in the rural upland southern portion of the project area, TxDOT determined that the upland 0.6-mile portion had little or no potential to contain intact or significant archaeological deposits and no survey was warranted. In contrast, the terrace deposits along the Guadalupe River were determined to have a moderate to high potential for intact significant buried archaeological deposits and thus warranted intensive hand and mechanical investigations (Figure 4.1).

During the course of the survey, two prehistoric archaeological sites, the Gatlin site (41KR621) and
Site 41KR622, were documented within the right-ofway's southern and northern approaches to the river, respectively. Because the project was operating under a compressed timeframe, the original proposed scope of work and Texas Antiquities Permit application provided for limited testing, which was conducted concurrently with the survey efforts in order to assess the research potential of each site and its eligibility for listing in the NRHP or for designation as an SAL. TxDOT required no formal research designs for either site for this stage of the project.

Because the Gatlin site was soon recommended for data recovery, the detailed analysis of the cultural and organic materials recovered during the survey and testing efforts was saved for after the data recovery excavations, in order that all site materials could be analyzed and presented as a comprehensive assemblage. Likewise, the full presentation of features, artifacts, and chronological indicators will be reserved for later chapters in order to integrate them with the results of the data recovery program. What follows is a brief summation of the methodology and results of the survey of the project's northern and southern approaches to the Guadalupe River and the testing programs of Site 41KR622 and the Gatlin site.

\section{Survey and Testing Methodology}

TxDOT personnel originally observed cultural materials within the southern project approach while conducting fieldwork for an alluvial stratigraphic study of the Guadalupe system (Abbott 2004), and recognized the high potential for encountering a significant site. At that time, right-of-entry was not available and site investigation was delayed until TxDOT obtained the property (Al McGraw, personal communication). Once subsurface explorations were initiated, SWCA employed a more intensive survey regime than typically required. This included systematic auger testing and backhoe trenching to investigate the broad alluvial terraces along the southern approach to the Guadal- 


\section{Restricted}

\section{Contains Site Information}

Figure 4.1. Project location map, detail of the northern and southern approaches to the Guadalupe River. 
upe River. With the discovery of cultural materials, hand excavation soon followed to determine site eligibility.

At the time of the survey, most of the northern approach had been impacted by modern development. For this reason, investigations north of the river consisted of a pedestrian survey supplemented by systematic backhoe trenching and minimal hand excavations at $41 \mathrm{KR} 622$.

\section{Auger Testing on Southern Approach}

Investigations began with an initial mapping of the southern approach that included establishing a grid across the right-of-way using a digital theodolite. Once the grid was established, SWCA systematically excavated auger tests at $10-\mathrm{m}$ intervals across the right-of-way. Each test was approximately $30 \mathrm{~cm}$ in diameter and excavated in rough natural levels (Table 4.1). The resulting fill was screened through $1 / 4$-inch wire mesh. When excavations were complete, each hole was backfilled and the area returned to its pre-excavation state.

The matrix and cultural materials encountered by each auger test were counted, described, and documented, with collection limited only to stone tools. The resulting artifact count was used to generate a density map of cultural materials across the right-ofway on the southern approach. This map guided the subsequent placement of backhoe trenches.

\section{BACKHOE TRENCHING}

Along the northern approach, SWCA excavated backhoe trenches within the proposed right-of-way at regular intervals. A geoarchaeologist also guided trench placement in some cases to examine specific settings for geomorphological data. Eight trenches (BHTs 10-17) were placed along this approach.

On the southern approach, SWCA proposed an intensive and systematic backhoe-trenching program to define site boundaries and test site significance. The number and placement of trenches were dependent upon the results of the auger testing and the recommendations of the geoarchaeologist. Trenches were excavated along the established grid to maintain horizontal control. Although the length of the trenches varied, most measured approximately $10 \mathrm{~m}$ long, $0.75 \mathrm{~m}$ wide, and $1.5 \mathrm{~m}$ deep. Deeper trenches were excavated in certain areas to explore for more deeply buried deposits. These trenches were stepped back to comply with all applicable safety regulations. Ten trenches (BHTs 1-9 and 18) were excavated along the southern approach.

All trenching was monitored throughout the course of excavation by an experienced archaeologist. Once each trench was excavated, it was examined by an archaeologist and the geoarchaeologist, who recorded detailed soil descriptions. All features encountered during trenching were documented.

A column of soil was excavated and screened down one side of each trench on the southern approach and selected trenches on the northern approach. The columns were roughly $30 \times 30 \mathrm{~cm}$ in size, extending from the ground surface to the base of the trench. Soil from each column was removed in $20-\mathrm{cm}$ levels and screened through $1 / 4$-inch screen mesh. The artifacts from each column sample were quantified and recorded in the field, but only tools and diagnostic artifacts were collected. The entire process was thoroughly photo-documented.

\section{EVALUATING Significance}

Once the two archaeological sites were recognized, SWCA recommended that their eligibility for NRHP and SAL nomination be dependent upon levels of contextual integrity, chronology, potential data yield, and preservation potential. The testing investigations focused on two main issues: integrity and potential data yield. SWCA proposed that, for either site to be found significant under Criterion D, the site's deposits had to demonstrate good integrity and adequate data yield potential to address research questions that would contribute to the understanding of the regional prehistory. Using this approach, a site with good integrity but few artifacts or low artifact diversity, no dateable materials, no features, and poor preservation of organics would not be able to contribute new or important information. Similarly, if a site were found to have abundant artifacts and materials but poor archaeological integrity, it would also not be considered significant. Both backhoe trenching and hand excavations were utilized to address these issues. 


\section{4-4 Chapter 4}

Table 4.1. Auger Test Data

\begin{tabular}{|c|c|c|c|c|c|c|c|}
\hline Northing & Easting & Level & Depth (cmbs) & Soil Color & Soil Texture & Artifacts & Comments \\
\hline \multirow{2}{*}{1100} & \multirow{2}{*}{1010} & 1 & $0-29$ & 10YR3/2 & Silty loam & tertiary flake & snail shell present \\
\hline & & 2 & $29-80$ & 10YR6/4 & Silty loam & & gravel at $80 \mathrm{cmbs}$ \\
\hline \multirow{2}{*}{1100} & \multirow{2}{*}{1020} & 1 & $0-60$ & 10YR3/2 & Clay loam & fire cracked chert & \\
\hline & & 2 & $60-90$ & 10YR4/4 & Clay loam & & \\
\hline \multirow{2}{*}{1100} & \multirow{2}{*}{1030} & 1 & $0-30$ & 10YR3/2 & Silty loam & & \\
\hline & & 2 & $30-82$ & 10YR6/4 & Silty loam & & gravel at $80 \mathrm{cmbs}$ \\
\hline \multirow{2}{*}{1100} & \multirow{2}{*}{1040} & 1 & $0-60$ & 10YR3/2 & Clay loam & tertiary flake & \\
\hline & & 2 & $60-85$ & 10YR4/4 & Clay loam & & \\
\hline \multirow{2}{*}{1100} & \multirow{2}{*}{1050} & 1 & $0-50$ & 10YR3/1 & Clay loam & & \\
\hline & & 2 & $50-100$ & 10YR4/4 & Gravely clay loam & & \\
\hline \multirow{2}{*}{1100} & \multirow{2}{*}{1060} & 1 & $0-50$ & 10YR3/1 & Clay loam & & \\
\hline & & 2 & $50-90$ & 10YR4/4 & Clay loam & & \\
\hline \multirow{2}{*}{1100} & \multirow{2}{*}{1070} & 1 & $0-69$ & 10YR3/2 & Silty loam & burned rock & \\
\hline & & 2 & $69-90$ & 10YR6/4 & Silty loam & burned rock & \\
\hline \multirow{2}{*}{1110} & \multirow{2}{*}{1010} & 1 & $0-55$ & 10YR3/1 & Clay loam & & \\
\hline & & 2 & $55-110$ & 10YR4/4 & Gravely clay loam & & \\
\hline \multirow{2}{*}{1110} & \multirow{2}{*}{1020} & 1 & $0-70$ & 10YR3/2 & Clay loam & tertiary flake & \\
\hline & & 2 & $70-90$ & 10YR4/4 & Clay loam & & \\
\hline \multirow{2}{*}{1110} & \multirow{2}{*}{1030} & 1 & $0-55$ & 10YR3/1 & Clay loam & & \\
\hline & & 2 & $55-110$ & 10YR4/4 & Gravely clay loam & fire cracked chert & \\
\hline \multirow{2}{*}{1110} & \multirow{2}{*}{1040} & 1 & $0-70$ & 10YR3/2 & Clay loam & & \\
\hline & & 2 & $70-86$ & 10YR4/4 & Clay loam & & \\
\hline \multirow{2}{*}{1110} & 1050 & 1 & $0-55$ & 10YR3/1 & Clay loam & & \\
\hline & 1050 & 2 & $55-110$ & 10YR4/4 & Gravely clay loam & & \\
\hline 1110 & 1060 & 1 & $0-53$ & 10YR3/2 & Clay loam & & snail shell present \\
\hline 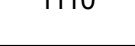 & 1000 & 2 & $53-94$ & 10YR6/4 & Clay loam & burned rock; flake & \\
\hline 1110 & 1070 & 1 & $0-90$ & 10YR3/2 & Silty clay loam & & \\
\hline 11110 & 1070 & 2 & $90-100$ & 10YR3/3 & Silty clay loam & burned rock & \\
\hline 1120 & 1010 & 1 & $0-60$ & 10YR3/2 & Clay loam & & \\
\hline $11<0$ & TUto & 2 & $60-75$ & 10YR4/4 & Clay loam & & \\
\hline 1120 & 1020 & 1 & $0-55$ & 10YR3/1 & Clay loam & & \\
\hline 1120 & $10<0$ & 2 & $55-110$ & 10YR4/4 & Gravely clay loam & fire cracked chert & \\
\hline 1120 & 1030 & 1 & $0-60$ & 10YR3/2 & Clay loam & & \\
\hline 1120 & 1000 & 2 & $60-75$ & 10YR4/4 & Clay loam & & \\
\hline 1120 & 1040 & 1 & $0-70$ & 10YR3/2 & Clay loam & & \\
\hline $11<0$ & $10+0$ & 2 & $70-90$ & 10YR4/4 & Clay loam & & \\
\hline 1120 & 1050 & 1 & $0-40$ & 10YR3/2 & Clay loam & & \\
\hline $11<0$ & 1000 & 2 & $40-100$ & 10YR4/4 & Clay loam & & \\
\hline 1120 & 1070 & 1 & $0-60$ & 10YR3/2 & Clay loam & & \\
\hline 1180 & TU10 & 2 & $60-90$ & 10YR6/4 & Clay loam & & \\
\hline 1120 & 1060 & 1 & $0-44$ & 10YR3/2 & Clay loam & & \\
\hline 1120 & 1000 & 2 & $44-93$ & 10YR6/4 & Clay loam & flake & \\
\hline 1130 & 1070 & 1 & $0-60$ & 10YR3/1 & Clay loam & & \\
\hline 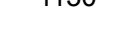 & TOTO & 2 & $60-100$ & 10YR3/6 & Clay loam & burned rock & \\
\hline
\end{tabular}


Table 4.1. Auger Test Data, continued

\begin{tabular}{|c|c|c|c|c|c|c|c|}
\hline Northing & Easting & Level & Depth (cmbs) & Soil Color & Soil Texture & Artifacts & Comments \\
\hline \multirow{2}{*}{1130} & \multirow{2}{*}{1050} & 1 & $0-80$ & 10YR3/2 & Clay loam & & \\
\hline & & 2 & $80-120$ & 10YR4/4 & Clay loam & & \\
\hline \multirow{2}{*}{1130} & \multirow{2}{*}{1010} & 1 & $0-34$ & 10YR3/2 & Clay loam & & \\
\hline & & 2 & $34-100$ & 10YR4/4 & Clay loam & & \\
\hline \multirow{2}{*}{1130} & \multirow{2}{*}{1030} & 1 & $0-38$ & 10YR3/2 & Clay loam & & \\
\hline & & 2 & $38-95$ & 10YR4/4 & Clay loam & & \\
\hline \multirow{2}{*}{1130} & \multirow{2}{*}{1040} & 1 & $0-70$ & 10YR3/1 & Clay loam & & \\
\hline & & 2 & $70-110$ & 10YR4/2 & Clay loam & & \\
\hline \multirow{2}{*}{1130} & \multirow{2}{*}{1020} & 1 & $0-50$ & 10YR3/1 & Clay loam & & \\
\hline & & 2 & $50-100$ & 10YR4/2 & Clay loam & & \\
\hline \multirow{2}{*}{1140} & \multirow{2}{*}{1010} & 1 & $0-60$ & 10YR3/2 & Clay loam & flake & \\
\hline & & 2 & $60-110$ & 10YR4/4 & Clay loam & & \\
\hline \multirow{2}{*}{1140} & \multirow{2}{*}{1020} & 1 & $0-38$ & 10YR3/2 & Silty loam & & \\
\hline & & 2 & $38-100$ & 10YR4/4 & Silty loam & & \\
\hline \multirow{2}{*}{1140} & \multirow{2}{*}{1030} & 1 & $0-40$ & 10YR3/2 & Clay loam & & \\
\hline & & 2 & $40-100$ & 10YR3/4 & Clay loam & & \\
\hline \multirow{2}{*}{1140} & \multirow{2}{*}{1040} & 1 & $0-40$ & 10YR3/2 & Clay loam & & \\
\hline & & 2 & $40-100$ & 10YR3/4 & Clay loam & & \\
\hline \multirow{2}{*}{1140} & \multirow{2}{*}{1050} & 1 & $0-80$ & 10YR3/2 & Clay loam & & \\
\hline & & 2 & 80-104 & 10YR4/4 & Clay loam & & Rabdotus shell \\
\hline \multirow{2}{*}{1140} & \multirow{2}{*}{1060} & 1 & $0-70$ & 10YR3/2 & Clay loam & & \\
\hline & & 2 & $70-100$ & 10YR4/4 & Clay loam & & \\
\hline 1140 & 107 & 1 & $0-64$ & 10YR3/2 & Clay loam & & \\
\hline טרות & 1010 & 2 & $64-86$ & 10YR4/4 & Clay loam & & \\
\hline 1150 & 105 & 1 & $0-62$ & 10YR3/2 & Clay loam & flake & snail shell present \\
\hline 1100 & 1000 & 2 & $62-100$ & 10YR4/4 & Clay loam & & \\
\hline 1150 & 1040 & 1 & $0-40$ & 10YR3/2 & Silty loam & & \\
\hline 1100 & $10+0$ & 2 & $40-97$ & 10YR4/3 & Silty loam & & \\
\hline 1170 & 1060 & 1 & $0-2$ & 10YR3/2 & Silty loam & & \\
\hline 110 & 1000 & 2 & $2-54$ & 10YR3/2 & Sandy loam & flake & gravel at $55 \mathrm{cmbs}$ \\
\hline 1150 & 1060 & 1 & $0-38$ & 10YR3/2 & Clay loam & & snail shell present \\
\hline 1100 & 1000 & 2 & $38-90$ & 10YR6/4 & Silty loam & & snail shell present \\
\hline 1170 & 1050 & 1 & $0-40$ & 10YR6/4 & Sandy loam & flake & gravel at $41 \mathrm{cmbs}$ \\
\hline 1150 & 1070 & 1 & $0-60$ & 10YR3/2 & Clay loam & & \\
\hline 1100 & 1010 & 2 & $60-100$ & 10YR3/3 & Clay loam & & \\
\hline 1160 & 1070 & 1 & $0-50$ & 10YR3/2 & Clay loam & & \\
\hline 1100 & 1070 & 2 & $50-100$ & 10YR4/4 & Clay loam & burned rock & \\
\hline 1160 & 1060 & 1 & $0-35$ & 10YR3/2 & Sandy loam & & \\
\hline 1100 & 1000 & 2 & $35-90$ & 10YR4/4 & Silty loam & & snail shell present \\
\hline 1160 & 105 & 1 & $0-30$ & 10YR3/2 & Clay loam & flake & \\
\hline 1100 & 1050 & 2 & $30-105$ & 10YR4/4 & Sandy loam & & \\
\hline 1180 & 1070 & 1 & $0-10$ & 10YR3/2 & Sandy loam & & \\
\hline 1100 & 1010 & 2 & $10-40$ & 10YR4/4 & Sandy loam & & gravel at $15 \mathrm{cmbs}$ \\
\hline 1150 & 1030 & 1 & $0-50$ & 10YR3/2 & Clay loam & & \\
\hline 1100 & 1000 & 2 & 50-110 & 10YR4/4 & Clay loam & & \\
\hline
\end{tabular}


Table 4.1. Auger Test Data, continued

\begin{tabular}{|c|c|c|c|c|c|c|c|}
\hline Northing & Easting & Level & Depth (cmbs) & Soil Color & Soil Texture & Artifacts & Comments \\
\hline \multirow{3}{*}{1160} & \multirow{3}{*}{1030} & 1 & $0-30$ & 10YR3/2 & Clay loam & & \\
\hline & & 2 & $30-90$ & 10YR4/4 & Silty loam & & \\
\hline & & 3 & $90-110$ & 10YR4/4 & Silty loam & & \\
\hline \multirow{2}{*}{1160} & \multirow{2}{*}{1040} & 1 & $0-38$ & 10YR3/2 & Silty loam & burned rock; flake & \\
\hline & & 2 & $38-87$ & 10YR4/4 & Silty loam & & gravel at $87 \mathrm{cmbs}$ \\
\hline \multirow{3}{*}{1080} & \multirow{3}{*}{1070} & 1 & $0-10$ & 10YR3/2 & Clay loam & flake & \\
\hline & & 2 & $10-76$ & 10YR6/4 & Clay loam & burned rocks; flakes & \\
\hline & & 3 & $76-88$ & 10YR6/3 & Silty clay loam & burned rocks; flakes & \\
\hline \multirow{2}{*}{1060} & \multirow{2}{*}{1070} & 1 & $0-45$ & 10YR3/3 & Clay loam & burned rocks & \\
\hline & & 2 & $45-85$ & 10YR4/6 & Silty loam & burned rocks; flakes & \\
\hline \multirow{2}{*}{1040} & \multirow{2}{*}{1070} & 1 & $0-90$ & 10YR3/2 & Silty clay loam & & \\
\hline & & 2 & $90-100$ & 10YR3/3 & Silty clay loam & burned rocks; flakes & \\
\hline \multirow{2}{*}{1090} & \multirow{2}{*}{1070} & 1 & $0-90$ & 10YR3/2 & Silty clay loam & & \\
\hline & & 2 & $90-100$ & 10YR3/3 & Silty clay loam & burned rock & \\
\hline \multirow[b]{2}{*}{1070} & \multirow[b]{2}{*}{1070} & 1 & $0-60$ & 10YR3/1 & Clay loam & & \\
\hline & & 2 & $60-100$ & 10YR3/6 & Clay loam & $\begin{array}{c}\text { fire cracked chert; } \\
\text { burned rock; debitage }\end{array}$ & \\
\hline \multirow[b]{2}{*}{1050} & \multirow[b]{2}{*}{1070} & 1 & $0-60$ & 10YR3/1 & Clay loam & & \\
\hline & & 2 & $60-95$ & 10YR4/3 & Clay loam & $\begin{array}{l}\text { fire cracked chert; } \\
\text { burned rock }\end{array}$ & \\
\hline \multirow{2}{*}{1020} & \multirow{2}{*}{1070} & 1 & $0-70$ & 10YR3/2 & Clay loam & burned rocks & \\
\hline & & 2 & $70-100$ & 10YR3/3 & Clay loam & flakes & \\
\hline \multirow{2}{*}{1000} & \multirow{2}{*}{1070} & 1 & $0-5$ & 10YR6/6 & Sandy loam & & \\
\hline & & 2 & $5-60$ & 10YR3/3 & Silty loam & & \\
\hline \multirow{2}{*}{1000} & \multirow{2}{*}{1040} & 1 & $0-80$ & 10YR3/3 & Clay loam & burned rocks; flakes & \\
\hline & & 2 & $80-100$ & 10YR4/4 & Clay loam & & \\
\hline \multirow{2}{*}{1050} & 1050 & 1 & $0-40$ & 10YR3/2 & Silty loam & burned rocks; flake; core & \\
\hline & 1000 & 2 & $40-93$ & 10YR4/4 & Clay loam & burned rocks; flakes & \\
\hline & & 1 & $0-10$ & 10YR5/6 & Silty loam & burned rocks; flake; core & \\
\hline 1020 & 1050 & 2 & $10-44$ & 10YR3/2 & Silty loam & & charcoal present \\
\hline & & 3 & $44-90$ & 10YR4/4 & Clay loam & & \\
\hline & & 1 & $0-5$ & 10YR5/6 & Silty loam & burned rock & \\
\hline 1010 & 1040 & 2 & $5-39$ & 10YR3/2 & Clay loam & burned rocks; flakes & charcoal present \\
\hline & & 3 & $39-100$ & 10YR4/4 & Clay loam & burned rock; flake & charcoal present \\
\hline & & 1 & $0-15$ & 10YR5/6 & Silty loam & flakes & \\
\hline 1030 & 1060 & 2 & $15-52$ & 10YR2/2 & Silty loam & burned rocks; flakes & \\
\hline & & 3 & $52-102$ & 10YR4/1 & Clay loam & burned rock; flakes & \\
\hline & & 1 & $0-18$ & 10YR5/6 & Silty loam & & \\
\hline 1010 & 1050 & 2 & $18-40$ & 10YR3/2 & Clay loam & burned rock; flake & \\
\hline & & 3 & $40-112$ & 10YR4/4 & Clay loam & burned rocks; flakes & \\
\hline & & 1 & $0-10$ & 10YR5/6 & Silty loam & & \\
\hline 1010 & 1060 & 2 & $10-52$ & 10YR3/2 & Clay loam & burned rocks; flake; core & \\
\hline & & 3 & $52-90$ & 10YR6/4 & Clay loam & burned rock & snail shell present \\
\hline 1050 & 1060 & 1 & $0-45$ & 10YR3/2 & Clay loam & $\begin{array}{l}\text { burned rocks; flakes; } \\
\text { core } \\
\end{array}$ & \\
\hline & & 2 & $45-100$ & 10YR6/4 & Silty loam & burned rocks & \\
\hline
\end{tabular}


Table 4.1. Auger Test Data, continued

\begin{tabular}{|c|c|c|c|c|c|c|c|}
\hline Northing & Easting & Level & Depth (cmbs) & Soil Color & Soil Texture & Artifacts & Comments \\
\hline \multirow{2}{*}{1070} & \multirow{2}{*}{1060} & 1 & $0-40$ & 10YR3/2 & Clay loam & burned rock; flake & \\
\hline & & 2 & $40-90$ & 10YR6/4 & Clay loam & burned rocks; flakes & \\
\hline \multirow{2}{*}{1040} & \multirow{2}{*}{1020} & 1 & $0-85$ & 10YR3/2 & Clay loam & burned rocks; flakes & \\
\hline & & 2 & $85-95$ & 10YR4/4 & Clay loam & & \\
\hline \multirow{2}{*}{1050} & \multirow{2}{*}{1030} & 1 & $0-85$ & 10YR3/2 & Clay loam & burned rocks; flakes & \\
\hline & & 2 & $85-105$ & 10YR4/4 & Clay loam & & \\
\hline \multirow{2}{*}{1030} & \multirow{2}{*}{1030} & 1 & $0-20$ & 10YR3/2 & Loam & & \\
\hline & & 2 & $20-115$ & 10YR3/2 & Clay loam & burned rocks; flakes & \\
\hline 1040 & 1050 & 1 & $0-94$ & 10YR3/2 & Clay loam & burned rocks; flakes & \\
\hline \multirow{2}{*}{1070} & \multirow{2}{*}{1050} & 1 & $0-38$ & 10YR3/2 & Clay loam & & \\
\hline & & 2 & $38-110$ & 10YR4/4 & Clay loam & & \\
\hline \multirow{2}{*}{1030} & \multirow{2}{*}{1040} & 1 & $0-10$ & 10YR3/2 & Loam & & \\
\hline & & 2 & $10-120$ & 10YR3/2 & Clay loam & burned rocks; flakes & charcoal present \\
\hline \multirow{2}{*}{1020} & \multirow{2}{*}{1040} & 1 & $0-38$ & 10YR3/1 & Clay loam & & \\
\hline & & 2 & $38-112$ & 10YR4/4 & Clay loam & burned rocks; flakes & \\
\hline \multirow{3}{*}{1000} & \multirow{3}{*}{1050} & 1 & $0-12$ & 10YR6/4 & Silty loam & & \\
\hline & & 2 & $12-60$ & 10YR3/2 & Clay loam & & charcoal present \\
\hline & & 3 & $60-110$ & 10YR4/3 & Clay loam & & \\
\hline \multirow{2}{*}{1050} & \multirow{2}{*}{1040} & 1 & $0-90$ & 10YR3/2 & Clay loam & burned rocks; flakes & \\
\hline & & 2 & $90-110$ & 10YR5/4 & Clay loam & & \\
\hline \multirow{2}{*}{1050} & \multirow{2}{*}{1020} & 1 & $0-60$ & 10YR3/2 & Clay loam & burned rocks; flakes & \\
\hline & & 2 & $60-105$ & 10YR4/4 & Clay loam & & \\
\hline \multirow{2}{*}{1030} & \multirow{2}{*}{1020} & 1 & $0-60$ & 10YR3/2 & Clay loam & burned rocks; flakes & \\
\hline & & 2 & $60-120$ & 10YR4/4 & Clay loam & & \\
\hline \multirow{2}{*}{1040} & 1030 & 1 & $0-80$ & 10YR3/2 & Clay loam & burned rocks; flakes & \\
\hline & 1000 & 2 & $80-120$ & 10YR4/4 & Gravely clay loam & & \\
\hline 1010 & 1010 & 1 & $0-60$ & 10YR3/2 & Clay loam & burned rocks; flakes & \\
\hline 1040 & 1040 & 2 & $60-120$ & 10YR4/4 & Clay loam & & \\
\hline 1000 & 1020 & 1 & $0-60$ & 10YR3/2 & Clay loam & burned rocks; flakes & \\
\hline $10 \angle 0$ & 1030 & 2 & $60-70$ & 10YR3/4 & Clay loam & burned rocks; flakes & \\
\hline 1060 & 1050 & 1 & $0-60$ & 10YR3/2 & Clay loam & & \\
\hline 1000 & & 2 & $60-100$ & 10YR4/4 & Clay loam & burned rock & \\
\hline & & 1 & $0-15$ & 10YR6/4 & Silty loam & & \\
\hline 1000 & 1060 & 2 & $15-50$ & 10YR3/2 & Clay loam & burned rocks; flakes & \\
\hline & & 3 & $50-105$ & 10YR4/3 & Clay loam & & \\
\hline & & 1 & $0-10$ & 10YR6/4 & Silty loam & & \\
\hline 1020 & 1060 & 2 & $10-70$ & 10YR3/2 & Clay loam & $\begin{array}{c}\text { burned rocks; flake; } \\
\text { scraper }\end{array}$ & \\
\hline & & 3 & $70-110$ & 10YR4/3 & Clay loam & & \\
\hline $10 \mathrm{c}$ & $10 \mathrm{co}$ & 1 & $0-50$ & 10YR3/2 & Clay loam & & \\
\hline 1000 & 1000 & 2 & $50-100$ & 10YR6/4 & Clay loam & burned rocks; flake & \\
\hline 1080 & 1060 & 1 & $0-50$ & 10YR3/2 & Clay loam & burned rock; flakes & \\
\hline 1000 & 1000 & 2 & $50-100$ & 10YR6/4 & Clay loam & burned rocks & \\
\hline 1000 & 1060 & 1 & $0-38$ & 10YR3/2 & Clay loam & flake & \\
\hline 1090 & 1000 & 2 & $38-84$ & 10YR6/4 & Clay loam & burned rock; flakes & \\
\hline
\end{tabular}


Table 4.1. Auger Test Data, continued

\begin{tabular}{|c|c|c|c|c|c|c|c|}
\hline Northing & Easting & Level & Depth (cmbs) & Soil Color & Soil Texture & Artifacts & Comments \\
\hline \multirow[t]{2}{*}{1040} & \multirow[t]{2}{*}{1060} & 1 & $0-60$ & 10YR2/2 & Clay loam & $\begin{array}{l}\text { burned rocks; flakes; } \\
\text { core }\end{array}$ & \\
\hline & & 2 & $60-100$ & 10YR3/6 & Clay loam & burned rocks & \\
\hline 1010 & 1070 & 1 & $0-70$ & 10YR3/2 & Clay & & snail shell present \\
\hline \multirow{2}{*}{1030} & \multirow{2}{*}{1070} & 1 & $0-8$ & 10YR6/4 & Clay loam & burned rock; flakes & \\
\hline & & 2 & $8-20$ & 10YR3/2 & Clay & & \\
\hline \multirow{2}{*}{1070} & \multirow{2}{*}{1010} & 1 & $0-30$ & 10YR3/2 & Clay loam & burned rock; flake & \\
\hline & & 2 & $30-69$ & 10YR6/4 & Silty loam & burned rocks & \\
\hline \multirow{2}{*}{1090} & \multirow{2}{*}{1010} & 1 & $0-30$ & 10YR3/3 & Silty loam & & \\
\hline & & 2 & $30-80$ & 10YR6/4 & Silty loam & & gravel at $80 \mathrm{cmbs}$ \\
\hline \multirow{2}{*}{1080} & \multirow{2}{*}{1010} & 1 & $0-48$ & 10YR3/2 & Clay loam & burned rocks; flakes & \\
\hline & & 2 & $48-100$ & 10YR4/4 & Silty loam & burned rock & \\
\hline \multirow{2}{*}{1090} & \multirow{2}{*}{1030} & 1 & $0-43$ & 10YR3/2 & Silty loam & & \\
\hline & & 2 & $43-100$ & 10YR6/4 & Silty loam & & \\
\hline \multirow[t]{2}{*}{1070} & \multirow[t]{2}{*}{1040} & 1 & $0-48$ & 10YR3/2 & Clay loam & $\begin{array}{l}\text { burned rocks; flakes; } \\
\text { core }\end{array}$ & \\
\hline & & 2 & $48-92$ & 10YR6/4 & Silty loam & burned rocks; flakes & \\
\hline \multirow{2}{*}{1080} & \multirow{2}{*}{1030} & 1 & $0-37$ & 10YR3/2 & Clay loam & burned rocks & snail shell present \\
\hline & & 2 & $37-100$ & 10YR4/4 & Silty loam & & \\
\hline \multirow{2}{*}{1090} & \multirow{2}{*}{1050} & 1 & $1-32$ & 10YR3/2 & Silty loam & burned rocks & \\
\hline & & 2 & $32-100$ & 10YR4/4 & Silty loam & biface fragment & \\
\hline \multirow{2}{*}{1060} & \multirow{2}{*}{1040} & 1 & $0-66$ & 10YR3/2 & Clay loam & burned rocks; flakes & \\
\hline & & 2 & $66-99$ & 10YR4/4 & Silty loam & burned rocks; flakes & \\
\hline \multirow{2}{*}{1060} & \multirow{2}{*}{1010} & 1 & $0-63$ & 10YR3/2 & Silty loam & burned rocks; flakes & \\
\hline & & 2 & $63-100$ & 10YR4/4 & Silty loam & burned rocks; flakes & \\
\hline \multirow{2}{*}{1090} & 1000 & 1 & $0-50$ & 10YR3/2 & Clay loam & flake & \\
\hline & 1000 & 2 & $50-90$ & 10YR4/4 & Clay loam & & gravel at $80 \mathrm{cmbs}$ \\
\hline 1090 & 1020 & 1 & $0-80$ & 10YR3/3 & Clay loam & burned rocks; flake & \\
\hline 1050 & $10<0$ & 2 & $80-115$ & 10YR4/4 & Clay loam & & \\
\hline 1090 & 1040 & 1 & $0-55$ & 10YR3/2 & Clay loam & burned rock & \\
\hline 1000 & ש & 2 & $55-110$ & 10YR4/4 & Clay loam & & \\
\hline 1060 & 1020 & 1 & $0-70$ & 10YR3/2 & Clay loam & burned rocks; flakes & \\
\hline 1000 & $10<0$ & 2 & $70-90$ & 10YR4/4 & Clay loam & & \\
\hline 1060 & 1030 & 1 & $0-70$ & 10YR3/2 & Clay loam & $\begin{array}{l}\text { burned rocks; flakes; } \\
\text { biface }\end{array}$ & \\
\hline & & 2 & $70-100$ & 10YR4/4 & Clay loam & & \\
\hline 1070 & 1030 & 1 & $0-70$ & 10YR3/2 & Clay loam & burned rocks; flakes & \\
\hline Toro & 1000 & 2 & $70-110$ & 10YR4/4 & Clay loam & & \\
\hline 1070 & 1020 & 1 & $0-65$ & 10YR3/2 & Clay loam & burned rocks; flakes & \\
\hline Tor & $10<0$ & 2 & $65-120$ & 10YR4/4 & Clay loam & & \\
\hline 1080 & 1020 & 1 & $0-65$ & 10YR3/2 & Clay loam & burned rocks; flakes & \\
\hline 1000 & $10<0$ & 2 & $65-120$ & 10YR4/4 & Clay loam & & \\
\hline 1080 & 1040 & 1 & $0-40$ & 10YR3/2 & Clay loam & burned rock & \\
\hline 1000 & 1040 & 2 & $40-95$ & 10YR4/4 & Clay loam & flake & \\
\hline 1080 & 1050 & 1 & $0-60$ & 10YR3/2 & Clay loam & burned rock & \\
\hline 1000 & 1000 & 2 & $60-110$ & 10YR4/4 & Clay loam & flakes & \\
\hline
\end{tabular}




\section{HAND EXCAVATION OF TEST UNITS}

Hand excavations of units focused primarily on features or important cultural deposits discovered during backhoe trenching. Test units (TUs) were, with two exceptions, 1 x 1-m in size and excavated in arbitrary $10-\mathrm{cm}$ levels. These exceptions were the $1.5 \times 1.0-\mathrm{m}$ Unit 3-A and the $2 \times 1-\mathrm{m}$ Unit 5-A, both on the southern project approach. All were documented using standardized field forms and with photographs. All soils were screened through $1 / 4$-inch hardware mesh, and all artifacts and pertinent faunal or floral remains were collected for analysis. Features encountered during the investigations were carefully exposed, documented, and excavated.

\section{Survey ANd Testing InVestigations of the Northern ApProach (41KR622)}

\section{SURVEY OF THE NORTHERN APPROACH}

The northern approach to the Guadalupe River is divided in two parts by SH 27. North of the highway, the right-of-way crosses a plowed field before terminating at FM 1338 (Figure 4.2). A light scatter of cultural materials was observed within this field. The scatter was confined to the western edge of the right-of-way and comprised several small burned limestone fragments and less than a dozen pieces of lithic debitage spread over $100 \mathrm{~m}$ of new rightof-way.

Five backhoe trenches (BHTs $12,13,14,16$, and 17) were excavated within the plowed field north of SH 27 (Figure 4.3). Column samples were excavated on all trenches except BHTs 13 and 17, where dense clay precluded hand excavations (Table 4.2). The column sample excavations yielded a combined total of only three pieces of debitage. Because the materials were confined to the disturbed plow zone, the context of these materials was considered questionable, and the integrity very poor. This area was not designated an archaeological site because density of artifacts was very low and none of the materials appeared to be in primary context.

South of SH 27, the proposed right-of-way is occupied by a two-lane asphalt road and a partially developed commercial lot with an abandoned structure. During an initial inspection of the project area, the crew noted a light scatter of debitage and burned rock in a disturbed portion of the commercial lot near the river. This material was observed to extend to the west, beyond the limits of the right-of-way, in an area with apparent ground disturbances.

Three trenches (BHTs 10,11, and 15) were excavated across this area to explore for subsurface cultural materials. Cultural materials were found in moderate quantities in the column samples at BHTs 10 and 15. Based on the results of the surface inspection and trenching, the field crew designated this concentration Site 41KR622.

\section{SITE 41KR622}

Site 41KR622 is a prehistoric site in the southern portion of a commercial lot between SH 27 and Arcadia Loop Road (Figures 4.4 and 4.5). The site occupies an approximately $20 \times 20-\mathrm{m}$ area within the right-of-way, but has been truncated on its eastern and southern margins by the construction of a modern road. The construction of parking lots and buildings has also impacted the site to the north

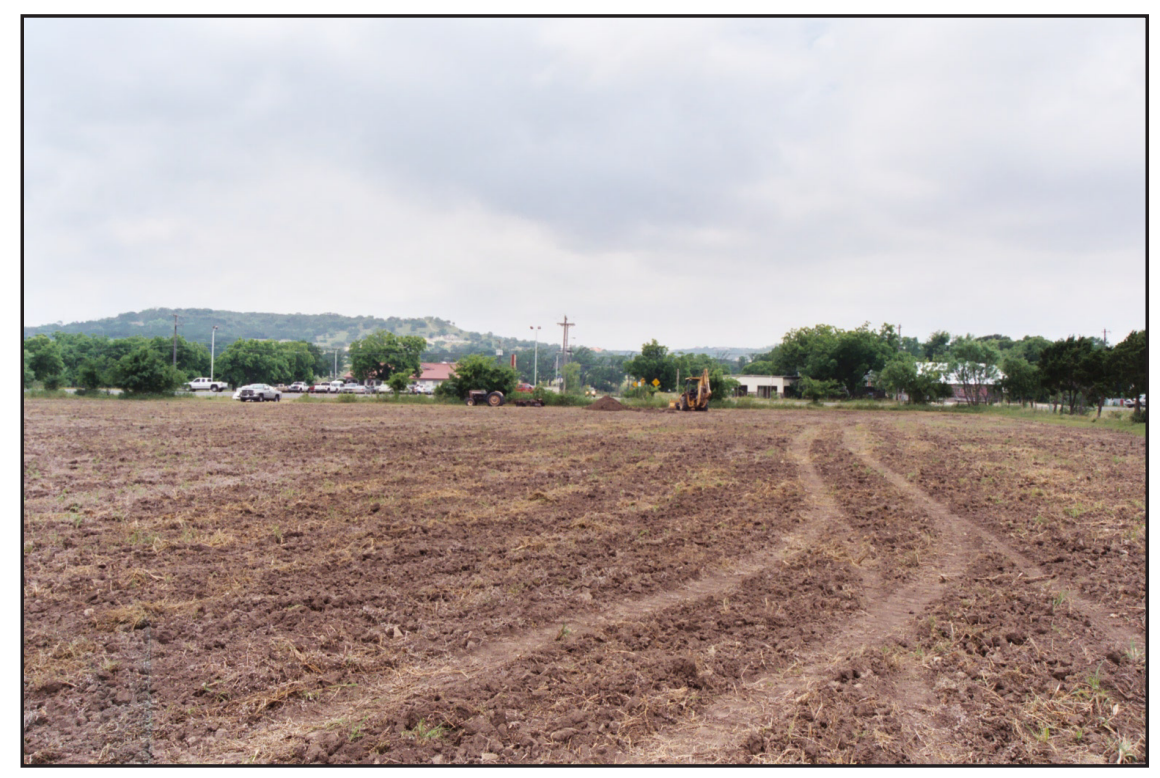

Figure 4.2. Overview of the northern approach, facing south. 


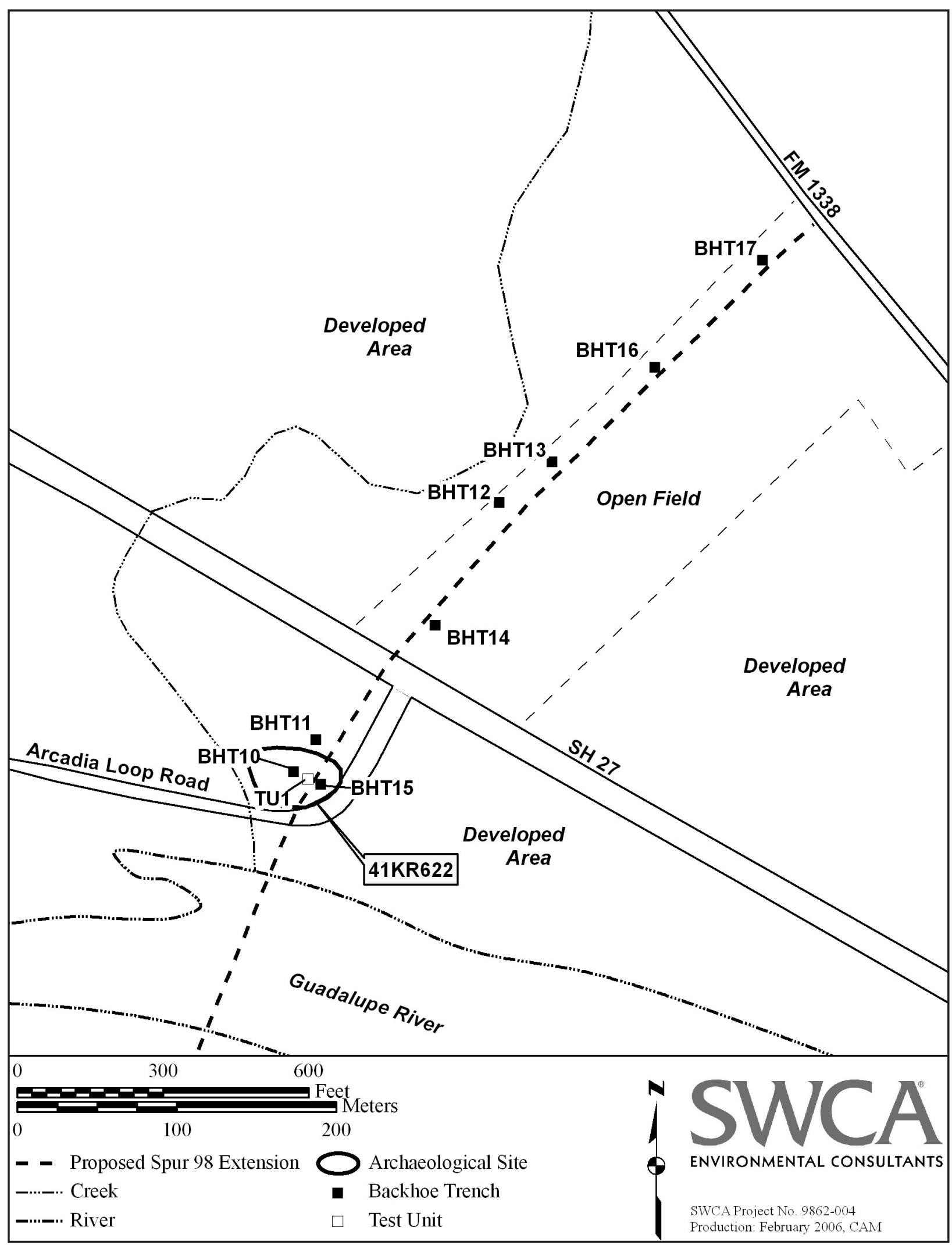

Figure 4.3. Investigations along the northern approach. 
Table 4.2. Column Sample Data from Backhoe Trenches in the Northern Approach

\begin{tabular}{|c|c|c|c|c|c|c|c|c|}
\hline & Site & & Depth $(\mathrm{cm})$ & & & & & \\
\hline BHT & Site & Level & Top & Bottom & Debitage & FCR & Bone/Shell & Tools \\
\hline \multirow{4}{*}{10} & \multirow{4}{*}{ 41KR622 } & 1 & 0 & 20 & 8 & & & \\
\hline & & 2 & 20 & 40 & 50 & 1 & & \\
\hline & & 3 & 40 & 60 & 15 & 3 & & \\
\hline & & 4 & 60 & 80 & 1 & & & \\
\hline \multirow{5}{*}{11} & \multirow{5}{*}{ None } & 1 & 0 & 30 & & & & \\
\hline & & 2 & 30 & 50 & & & & \\
\hline & & 3 & 50 & 70 & & & & \\
\hline & & 4 & 70 & 90 & & & & \\
\hline & & 5 & 90 & 110 & & 1 & & \\
\hline \multirow{4}{*}{12} & \multirow{4}{*}{ None } & 1 & 0 & 20 & & & & \\
\hline & & 2 & 20 & 40 & 1 & & & \\
\hline & & 3 & 40 & 60 & & & & \\
\hline & & 4 & 60 & 80 & & & & \\
\hline \multirow{4}{*}{14} & \multirow{4}{*}{ None } & 1 & 0 & 20 & & & & \\
\hline & & 2 & 20 & 40 & & & & \\
\hline & & 3 & 40 & 60 & & & & \\
\hline & & 4 & 60 & 80 & & & & \\
\hline \multirow{5}{*}{15} & \multirow{5}{*}{ 41KR622 } & 1 & 0 & 20 & 1 & & & \\
\hline & & 2 & 20 & 40 & 13 & 3 & & \\
\hline & & 3 & 40 & 60 & 14 & 3 & & \\
\hline & & 4 & 60 & 80 & & & & \\
\hline & & 5 & 80 & 100 & & & & \\
\hline \multirow{3}{*}{16} & \multirow{3}{*}{ None } & 1 & 0 & 20 & & & & \\
\hline & & 2 & 20 & 40 & 1 & & & \\
\hline & & 3 & 40 & 60 & 1 & & & \\
\hline
\end{tabular}

and northwest. Observed materials suggest that the site extends westward outside the Spur 98 corridor towards the confluence of a small, unnamed creek and the Guadalupe River.

Located adjacent to the T1 scarp, which overlooks the river's modern channel, Site 41KR622 is in the Late Pleistocene/Holocene fill of Unit 3, as defined by Abbott (2004). The left cutbank of the small, unnamed creek, lying outside the right-of-way, revealed a shallowly buried burned rock midden, most of which has been destroyed by prior mechanical excavation. This site would have been situated immediately adjacent to the channel of the Guadalupe River at one time, but that channel is likely to have been much less deeply incised than today.

\section{Testing}

Although the backhoe trench excavations in the vicinity of Site 41KR622 (BHTs 10, 11, and 15) encountered only moderate amounts of cultural material in an overall heavily disturbed setting, the geoarchaeologist believed the setting to be conducive to preservation of buried cultural materials with good integrity. For this reason, he recommended excavating a single $1-\mathrm{x} 1-\mathrm{m}$ test unit at the site to assess the deposits. TU 1 was located roughly between BHTs 10 and 15 . It was excavated by hand to a depth of $1 \mathrm{~m}$ below surface; the uppermost $10-\mathrm{cm}$ level was not screened due to clear disturbance from modern road-fill. 


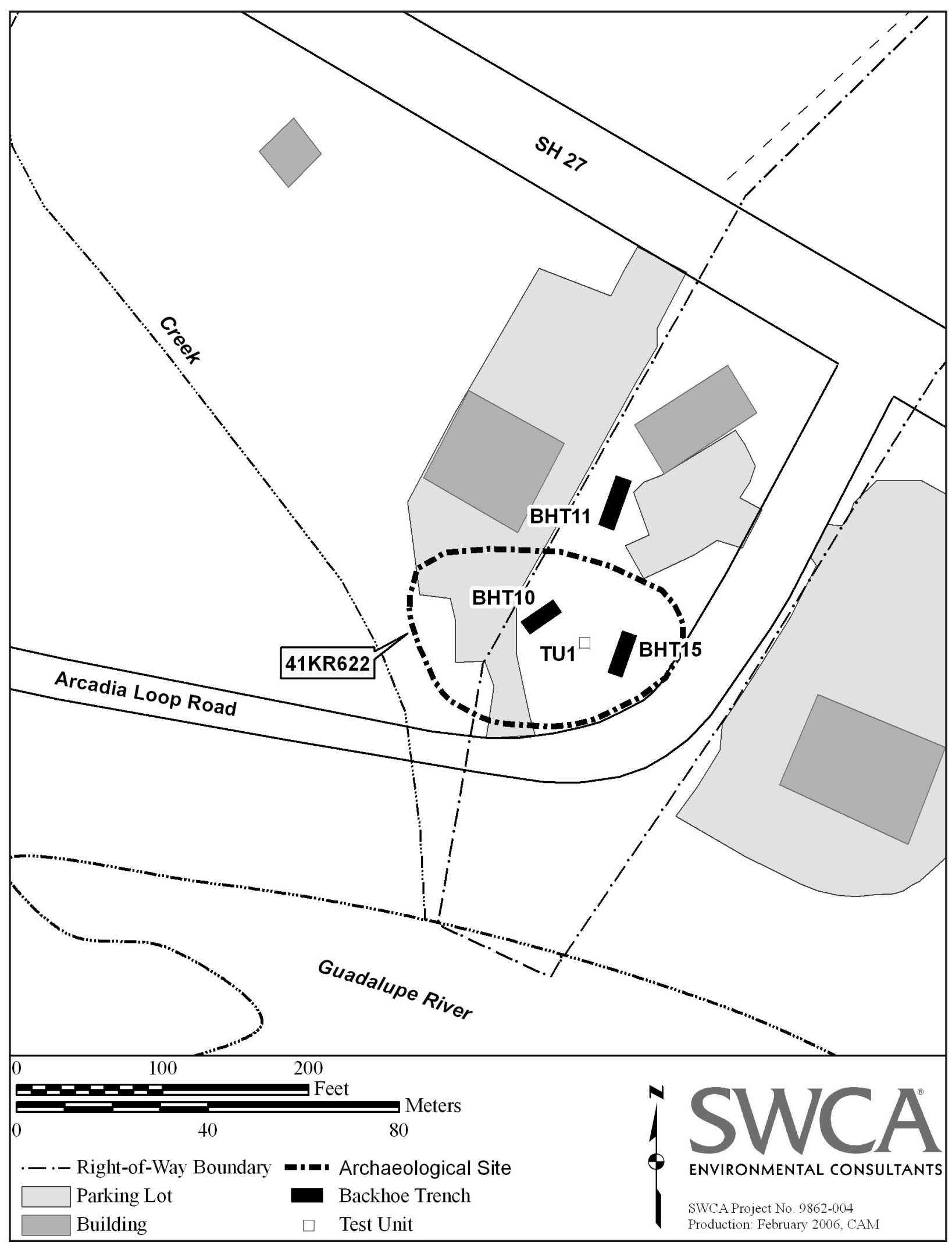

Figure 4.4. Map of site 41KR622. 


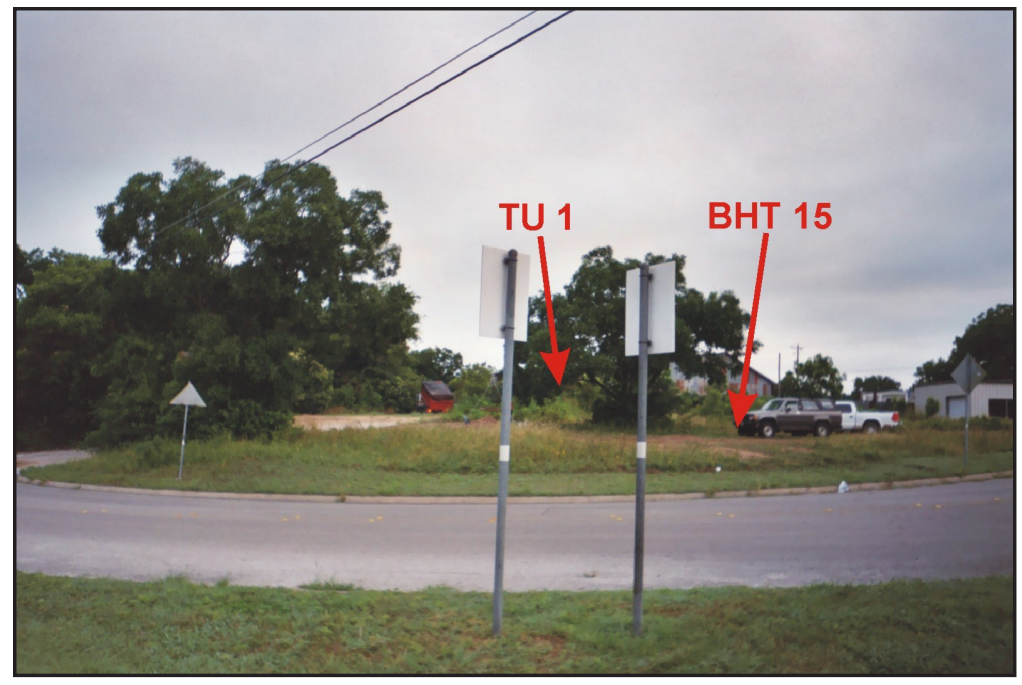

Figure 4.5. Site 41KR622 from southeast of Arcadia Loop Road.

\section{Recovered Materials}

During the backhoe trench excavations, three middle- to late-stage biface fragments were collected from the backdirt of the trenches within the site limits. All three exhibit light to moderate patination on both faces, suggesting some exposure to the elements before burial.

The excavation of TU 1 yielded moderate amounts of cultural material (Table 4.3), including $5.87 \mathrm{~kg}$ of burned rock, 1,074 pieces of debitage, three biface fragments, one Montell point base, and two pieces of modern glass. The debitage is primarily late-stage reduction debris, and most displays light to moderate patination. One of the bifaces is an early-stage production failure, one is a late-stage proximal fragment, and the third is the tip or barb of a projectile point. All three are lightly patinated on both faces. Most of artifacts were found within the upper $60 \mathrm{~cm}$ of soils, with only debitage occurring in the remaining four levels, in numbers decreasing significantly with depth, with a low peak in Level 8.

The only diagnostic artifact from Site 41 KR622 is a heavily patinated Montell stem, which was found between 50 and $60 \mathrm{~cm}$ below ground surface (cmbs). A barb was broken during excavation, revealing the $1-\mathrm{mm}$ thick patina, which completely obscures the dark brown, fine-grained chert raw material. This single diagnostic suggests at least a limited occupation within the Late Archaic period (e.g., Turner and Hester 1999:157). All materials collected from the site are curated at the Texas Archeological Research Laboratory (TARL).

\section{Horizontal Distribution of MATERIAL}

Because only limited excavations were conducted at Site 41KR622 and the investigation was restricted to the proposed new right-of-way, relatively little is known about the horizontal distribution of material. Artifacts were visible on the surface within the stated limits of the site, and subsurface cultural materials were found in both backhoe trenches and the hand-excavated test unit. Cultural materials were also observed extending to the west, beyond the limits of the right-of-way.

\section{Vertical Distribution of Material}

As Tables 4.2 and 4.3 indicate, most of the cultural materials at the site are confined to the upper $50 \mathrm{~cm}$ of deposits. Below that depth, artifacts are still present, but with decreasing frequency in all levels but Level 8 , which had a low peak in debitage. Two pieces of modern glass were found during the excavations, with one as deep as 30-40 cmbs. No artifacts were

Table 4.3. Vertical Distribution of Cultural Materials from Test Unit 1 at Site 41KR622

\begin{tabular}{|c|c|c|c|c|c|c|c|}
\hline \multirow[b]{2}{*}{ Level } & \multicolumn{2}{|c|}{ Depth (cmbs) } & \multirow[b]{2}{*}{ Debitage } & \multirow[b]{2}{*}{ Bifaces } & \multirow{2}{*}{$\begin{array}{c}\text { Projectile } \\
\text { Points }\end{array}$} & \multirow{2}{*}{\begin{tabular}{|} 
Burned Rock \\
$(\mathrm{kg})$
\end{tabular}} & \multirow[b]{2}{*}{ Glass } \\
\hline & Top & Bottom & & & & & \\
\hline 1 & 0 & 10 & & & & & \\
\hline 2 & 10 & 20 & 89 & & & 1.3 & 1 \\
\hline 3 & 20 & 30 & 287 & 2 & & 3.2 & \\
\hline 4 & 30 & 40 & 387 & 1 & & 1.1 & 1 \\
\hline 5 & 40 & 50 & 115 & & & 0.2 & \\
\hline 6 & 50 & 60 & 91 & & 1 (Montell) & 0.05 & \\
\hline 7 & 60 & 70 & 29 & & & & \\
\hline 8 & 70 & 80 & 50 & & & & \\
\hline 9 & 80 & 90 & 20 & & & & \\
\hline 10 & 90 & 100 & 6 & & & 0.02 & \\
\hline
\end{tabular}


recovered from deeper than $60 \mathrm{cmbs}$ in either of the two backhoe trench (BHTs 10 and 15) column samples from the site.

\section{Discussion of INTEgRITY}

Site 41KR622 has been severely impacted by the construction of Arcadia Loop Road, which presumably destroyed the eastern and southern margins of the site, and through the use of the area as a commercial property. The surface of the site is clearly disturbed, as a two-track road passes from an abandoned commercial building north of the site to an adjacent lot on the west. The upper deposits of the site have evidence of some mixing of materials, as indicated by the fragments of glass in the second and fourth excavation levels of TU 1.

\section{Eligibility of Site 41KR622}

Site 41KR622 has been severely impacted both within the right-of-way and on its western limits. Unfortunately, most of the cultural materials are confined to the upper $60 \mathrm{~cm}$ of deposits at the site, which is the portion of the profile exhibiting the most severely degraded integrity. Low densities of cultural material were encountered in TU 1 between 60 and $100 \mathrm{cmbs}$, but no cultural materials were recovered in either backhoe trench column sample from that depth range. The site has limited data yield potential due to the lack of integrity, features, and artifact assemblage diversity. For these reasons, SWCA recommended, and the THC concurred, that Site 41KR622 is not eligible for NRHP listing and does not warrant SAL designation. No additional investigations are necessary. Subsequent to the SWCA testing program and finding of no significance, the portions of the site in the Spur 98 project area were destroyed.

\section{SuRVey AND Testing InVestigations of THE SOUTHERn APPROACH (41KR621)}

\section{SURVEY OF THE SOUTHERN APPROACH}

Unlike the area north of the Guadalupe River, the southern approach was relatively undisturbed, consisting of grassy pasture with scattered cedar elms and juniper (Figure 4.6). Prior to subsurface investigations, SWCA established a vertical datum and horizontal grid across this portion of the right-of-way, with the southeastern stake occupying the N1000, E1070 coordinate (Figure 4.7). This grid extended $180 \mathrm{~m}$ to the north, widening from approximately 40 $\mathrm{m}$ at the southern end to over $70 \mathrm{~m}$ at N1090. It was oriented approximately 24 degrees east of magnetic north in order for grid north to parallel the eastern edge of the right-of-way.

In all, 106 auger tests (ATs) were excavated across the southern approach along the established metric grid. No excavations were conducted south of the N1000 line for two reasons: the terrain began to rise onto the colluvial toeslope of the uplands and the exact location of a buried phone line near the base of the slope was unknown at the time of auger testing.

Sixty-nine (65 percent) of the auger tests encountered cultural materials, which generally occurred in two clusters: a large cluster south of the N1110 line and

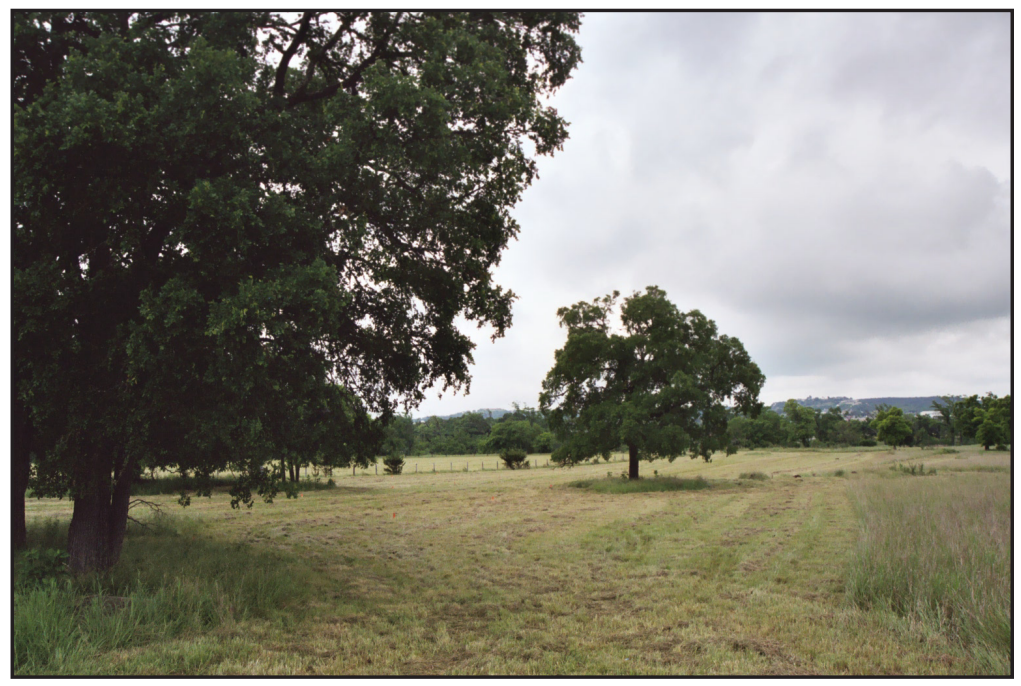

Figure 4.6. Overview of the southern approach, facing north towards the Guadalupe River and overlooking the Gatlin site. 


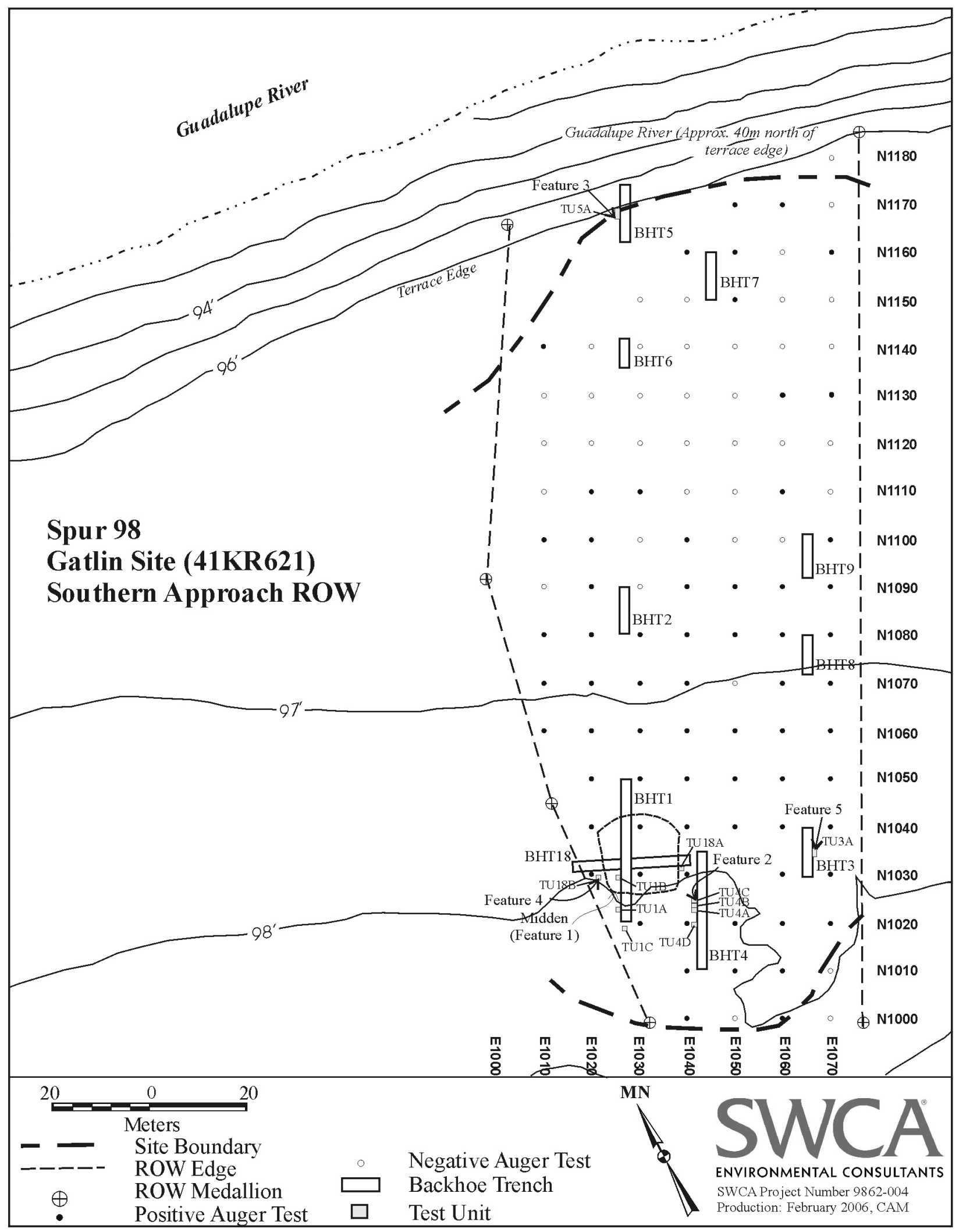

Figure 4.7. Survey and testing investigations along the southern approach. 
a small concentration near the terrace scarp, around N1150 to N1170 (Figures 4.7-4.9). Most of the positive auger tests, however, contained very little cultural materials. The greatest density was found between N1020 to N1050, highlighted by AT N1030 E1030, which contained over 200 pieces of burned rock (see Figure 4.8).

Based on the results of the auger testing, nine backhoe trenches (BHTs 1-9) were excavated across the extent of the approach (see Figure 4.7). BHT 1 was placed in the southwestern corner of the grid to examine the higher density cultural deposits discovered by AT N1030 E1030. Extending approximately 30 $\mathrm{m}$, BHT 1 encountered a buried burned rock midden, which was subsequently designated Feature 1 (Figure 4.10). The geoarchaeological examination of this trench suggested that colluvial deposits extended from the toeslope to the midden, preserving the deposits below (Frederick 2004:23).

Additional smaller burned rock features were noted to the east in the profiles of BHTs 3 and 4; during the testing phase, these were designated Features 5 and 2 , respectively. On the terrace scarp at the northern extent of the grid, BHT 5 exposed Feature 3, a small concentration of burned rock.

Data from the column samples excavated along each trench generally conformed to the results of the auger testing, with most of the cultural material appearing within the southern portion of the surveyed area (Table 4.4). Lesser amounts were found across the right-of-way in the other column samples. Based on the auger tests, backhoe trenches, and column samples findings, SWCA recorded this area as Site 41KR621 and named it the Gatlin site.

Auger testing proved extremely effective in locating the buried deposits of 41KR621, including the burned rock midden at the site, which was not visible on the surface. As such, it is an extremely efficient site discovery tool. It fails, however, as a method of evaluating site structure or integrity. Therefore, auger testing at this level of investigation was supplemented with controlled vertical excavations, such as column samples, shovel tests, or test units, to assess more fully the nature of the discovered cultural deposits.

\section{THE GATLIN SITE (41KR621)}

As defined by the survey efforts, the Gatlin site extends from the scarp above the Guadalupe River channel to the base of the upland toeslope, approximately $200 \mathrm{~m}$ to the south. Presently, its width is dictated by the confines of the right-of-way, although the site undoubtedly extends to the east and west beyond these limits.

Presented below is a brief description of the geomorphology and testing activities at the Gatlin site and their results. Full discussions of the features, artifacts, and chronological indicators recovered from the survey and testing phases will be presented within the following chapters alongside the results of the data recovery operations. This organizational arrangement will provide an integrated view of the site as a whole.

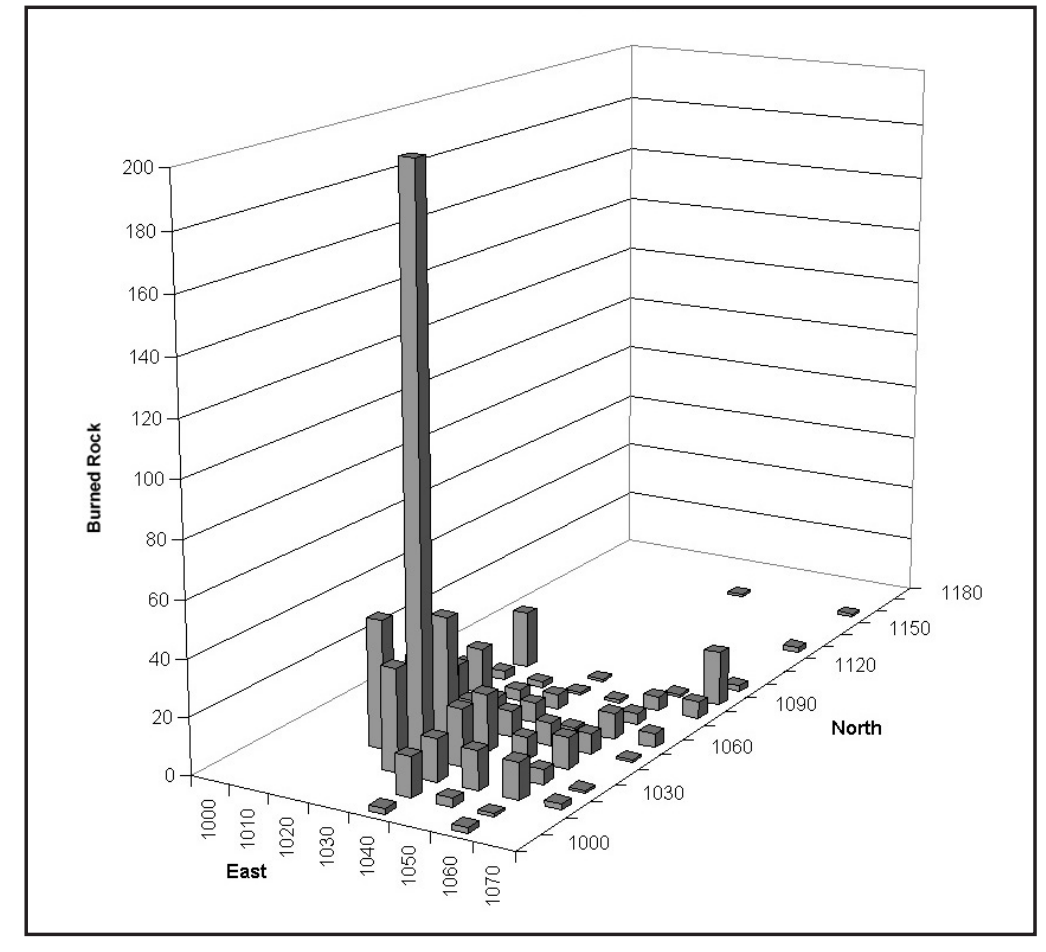

Figure 4.8. Distribution of burned rock by auger test at the Gatlin site. 


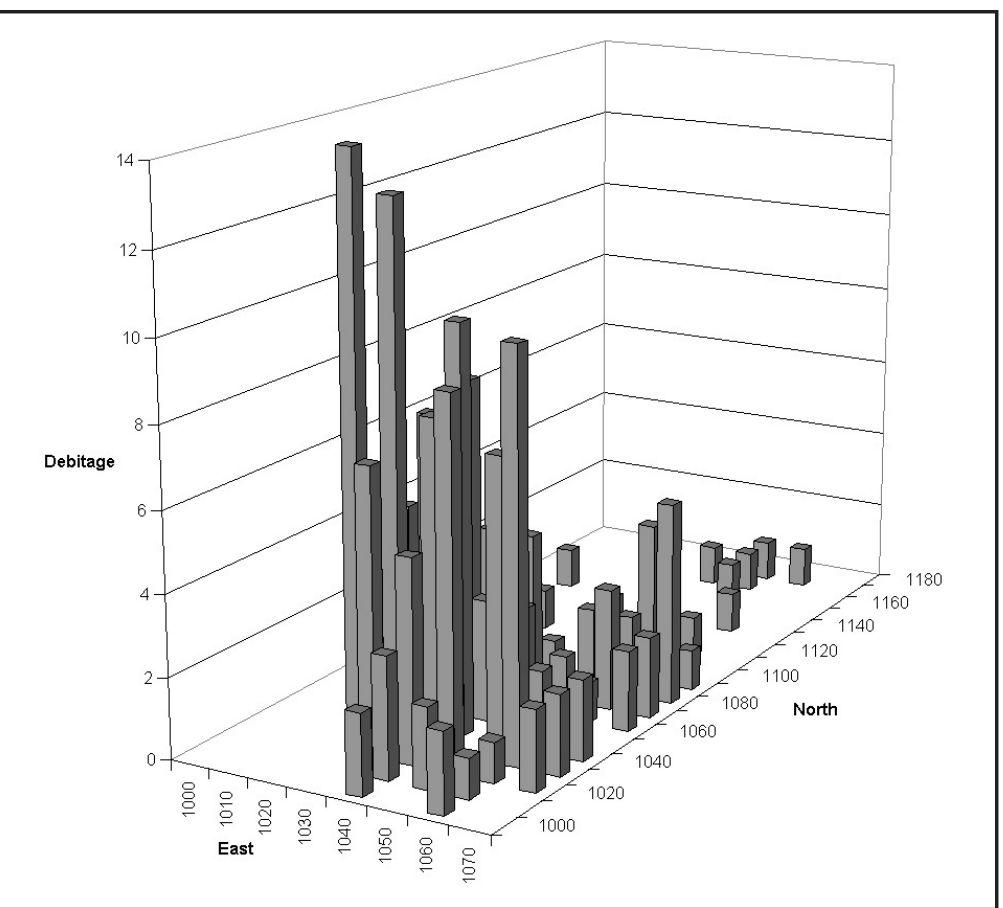

Figure 4.9. Distribution of debitage by auger test at the Gatlin site.

\section{GEOMORPHOLOGY}

The natural stratigraphy of the Gatlin site is discussed in detail within Chapter 6, but a brief summary is provided below in order to facilitate the presentation of the testing results. The geomorphological investigations revealed that the archaeological remains of the Gatlin site were situated within a single Late Pleistocene to Middle Holocene alluvial fill (Abbott's [2004:15] Unit 3; Appendix II). Although minor variances were observed in the soils across the site, in general, a very dark grayish silty clay loam A horizon was seen to overlay a B horizon of brown to yellowish brown clay loam (see Figure 4.10). It was within the upper levels of this B horizon that the site's Early Archaic occupation was situated. The A horizon harbored the Middle to Transitional Archaic materials, including the burned rock midden, which occurred just above the top of the B horizon. At the site's southern end, trenches revealed colluvial deposits extending north from the toeslope to the burned rock midden. This redeposited
C horizon resulted in the burial of the burned rock midden and its related components.

\section{Testing}

Because of TxDOT's compressed time frame, testing of the Gatlin site occurred immediately following its discovery. Testing consisted of 11 hand excavation units, totaling approximately $12 \mathrm{~m}^{3}$ of deposits, and an additional backhoe trench (see Figure 4.7).

Initial hand excavations targeted the burned rock midden at the southwestern end of the site, which had been revealed by BHT 1 and lies within the A horizon. Three test units were placed within this area: TU 1-A (Figure 4.11) and TU 1$\mathrm{C}$ in the deposits buried by colluvium south of the midden, and TU 1-B within the midden itself. These produced cultural materials suggesting that (1) the midden was formed progressively within the Middle to Transitional Archaic periods, and (2) apparently intact Early Archaic deposits lay beneath it in the top of the B horizon.

An additional backhoe trench, BHT 18, was excavated to define the midden's east-west extent (see Figure 4.7). Perpendicular to BHT 1, BHT 18 extended from the western edge of the right-of-way,

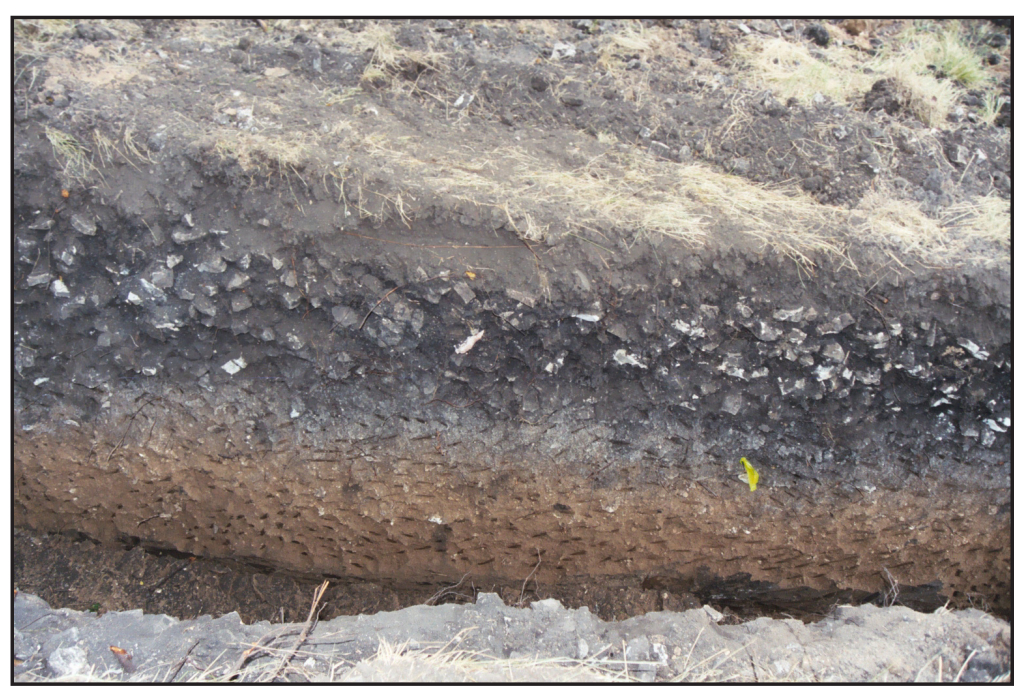

Figure 4.10. Profile of BHT 1 at the Gatlin site, showing the burned rock midden and $\mathrm{B}$ horizon below. 


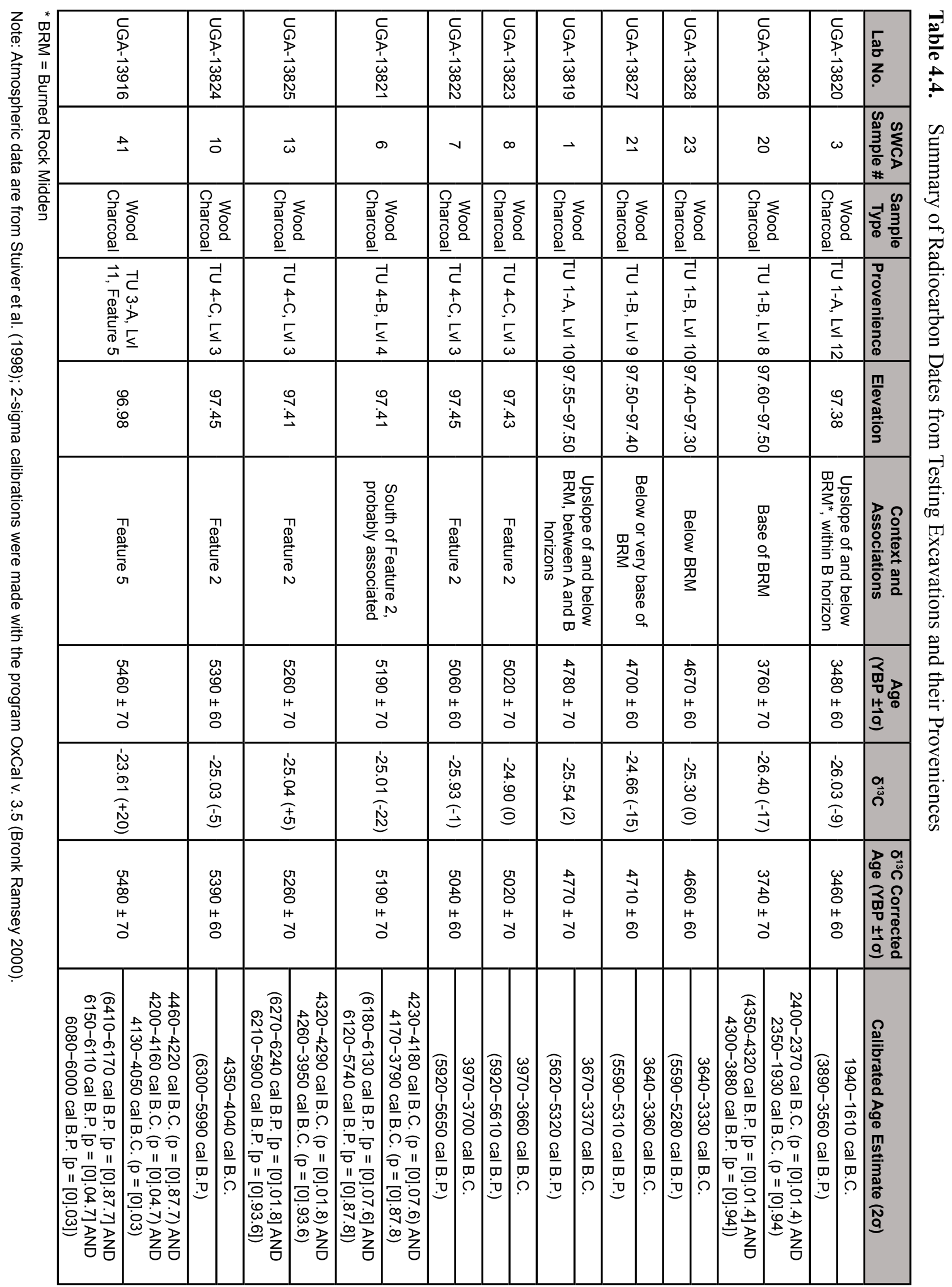




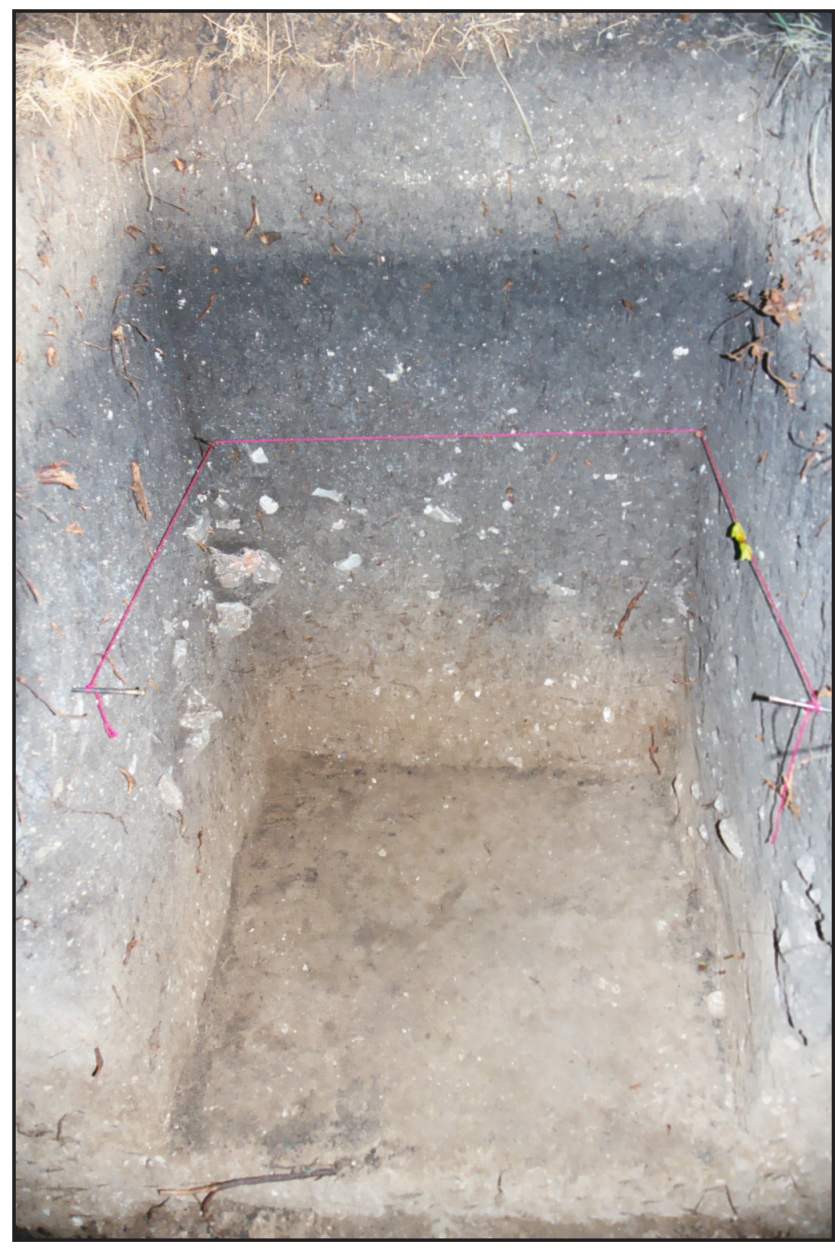

Figure 4.11. Profile of Test Unit 1-A at the Gatlin site.

cutting through the midden to the east and revealing the presence of two distinct pits visible in the base of the midden (Figure 4.12). Two units were excavated at either end of this trench, outside the midden limits. TU 18-A, east of the midden, was designed to explore a potential burned rock feature observed in the trench floor, but was curtailed due to flooding. TU 18-B, west of the burned rock midden, was placed to further test the Middle-Transitional Archaic deposits, and resulted in the discovery of Feature 4, a small cluster of burned limestone possibly associated with the midden.

Southeast of the midden, the second area targeted by hand excavations was near of BHT 4 (see Figure 4.7). Here, Early Archaic projectile points and several pieces of animal bone had been recovered from the trench's western profile in association with a zone containing burned rock. Three contiguous units (TUs 4-A-C) specifically targeted the top of the B horizon, which harbored the site's Early Archaic deposits and the burned rock concentration, designated Feature 2 (Figure 4.13). A fourth unit, TU 4-D, acted as a control for the trench's entire cultural sequence. In this area, the natural stratigraphy slopes slightly downward to the north, and artifacts appeared concentrated in two layers. The first, approximately $10 \mathrm{~cm}$ thick, was associated with an Andice base and a probable Bulverde point. The second, $10 \mathrm{~cm}$ below and about $20 \mathrm{~cm}$ in thickness, corresponded with Feature 2 and produced several Early Archaic points.

The site's Early Archaic component was further explored by TU 3-A, a 2 x 1-m unit adjacent to BHT 3, east of the midden at the eastern edge of the site. The focus of this unit was Feature 5, a burned rock scatter consisting of a large tabular limestone block situated within a semi-circle of burned rock cobbles. Debitage counts, which were consistently low above, increased significantly within the level of the feature.

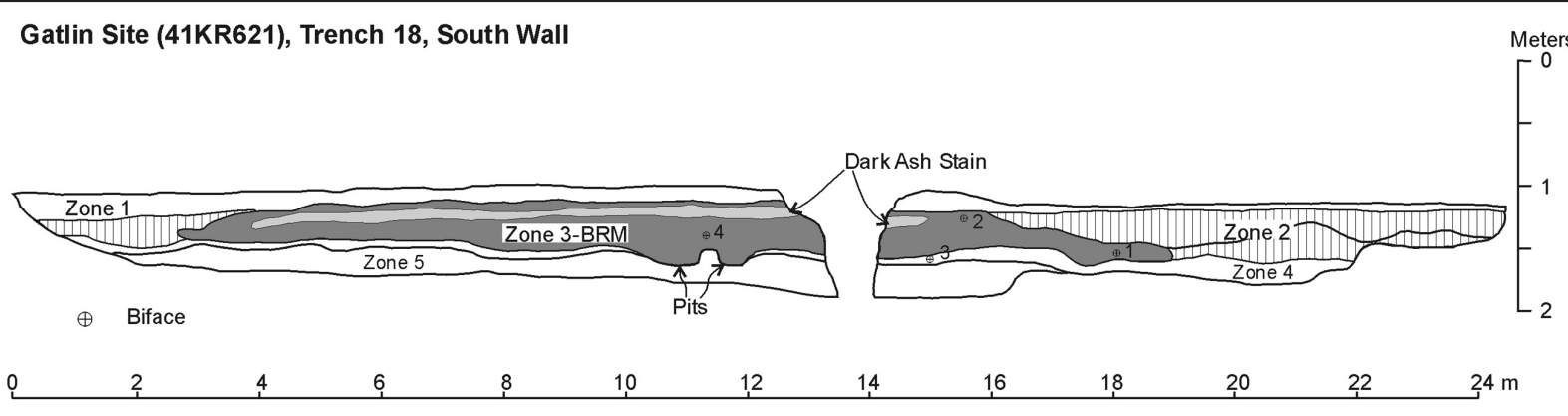

Figure 4.12. Profile of BHT 18 at the Gatlin site. 


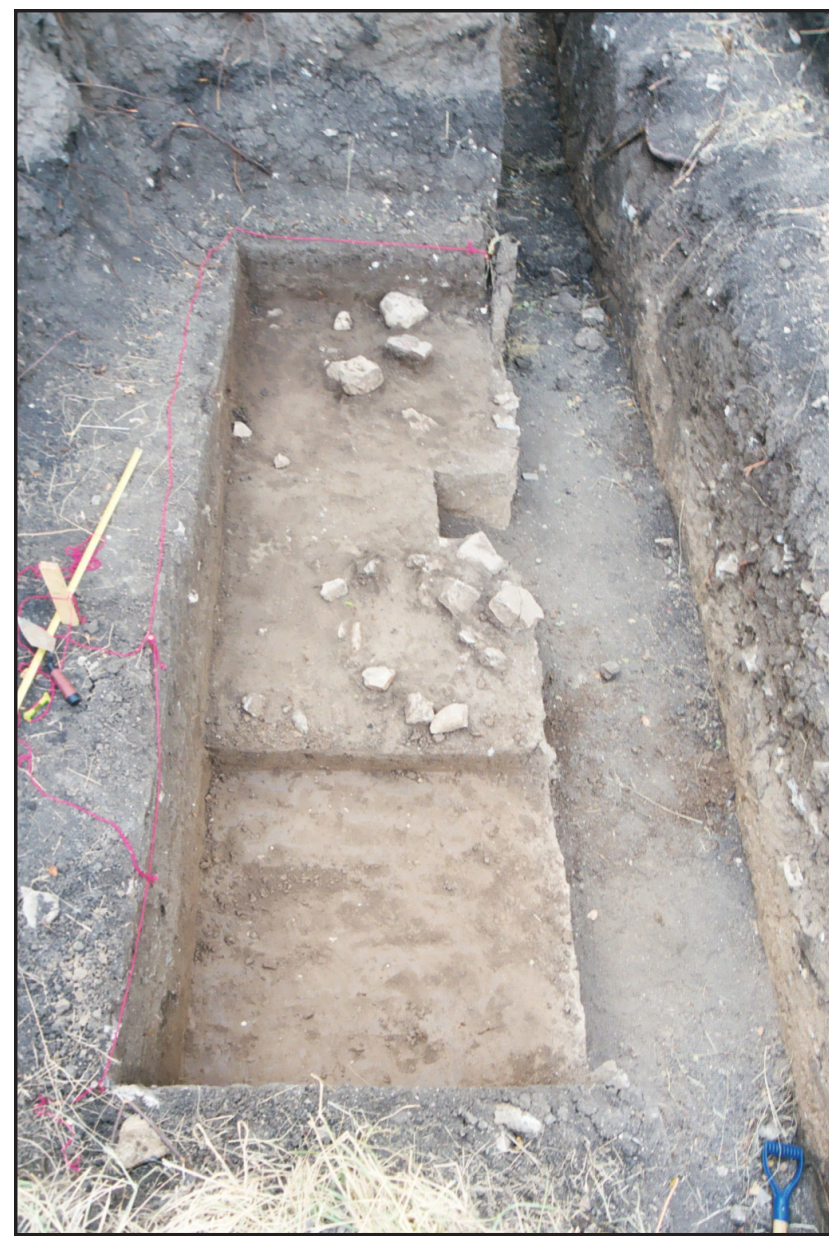

Figure 4.13. Overview of Test Units $4-\mathrm{A}-\mathrm{C}$ at the Gatlin site. Unit 4-A, in the foreground, is at an elevation of 97.2 $\mathrm{m}$; Units 4-B and 4-C are at $97.3 \mathrm{~m}$ and show the last vestiges of Feature 2.

On the terrace scarp far to the north, TU 5-A was placed to investigate the site's northernmost extent (see Figure 4.7). This $2 \times 1-\mathrm{m}$ unit focused on Feature 3 , a burned rock concentration overlying a gravel deposit within which a prominent Bk horizon had formed. Associated cultural materials were sparse and lacked temporally diagnostic artifacts.

\section{ReCOVERed Materials}

The artifact assemblage from the testing phase of investigations at the Gatlin site proved to be diverse and associated with multiple cultural components. Over 15,000 pieces of debitage were collected from the test unit excavations, along with 170 bifaces, 60 projectile points, 30 cores, 15 unifaces, and seven ground stone or battered stone artifacts. Among the projectile points, 63 percent represent types commonly associated with the Early Archaic period (such as Martindale, Baker, and Gower), although Middle, Late, and Transitional Archaic types are represented as well. Five features were identified, including a substantial burned rock midden and four smaller concentrations of burned rock. Also recovered were faunal remains, charcoal, and possibly macrobotanical remains, suggesting organic preservation at the site was reasonably good.

Of the many radiocarbon samples collected, 11 were submitted for analysis from a variety of contexts (Table 4.5). Radiocarbon dates for the Early Archaic materials ranged between ca. 5500 and $4460(6410$ and 5280 cal B.P. at 2-sigma). A radiocarbon sample from the base of the burned rock midden was dated at 3740 \pm 70 (calibrated at 2-sigma as $4350-4320$ cal в.P. $(\mathrm{p}=[0] .01 .4)$ and $4300-3880$ cal B.P. $(\mathrm{p}=$ [0].94)).

\section{Cultural Stratigraphy}

Site stratigraphy and the preliminary examinations of the vertical and horizontal distributions of cultural materials clearly indicated a significant amount of cultural material related to a pre-midden, Early Archaic component. This component appeared to be situated at the top of the B horizon, and was observed to extend across the width of the right-of-way, below the midden, below middenrelated components near BHT 4, and in the area of BHT 3, where younger cultural materials did not appear prevalent. This Early Archaic component produced Features 2 and 5, as well as numerous diagnostic points, including several examples of the Martindale and Gower types. This component also appeared to have some finer stratigraphic separation, hinting at the presence of several Early Archaic occupations.

Above the B horizon, a series of cultural components were observed to occupy the A Horizon. Most of the material associated with these periods of occupation occurred near of the burned rock midden and extend temporally from the Middle through Transitional Archaic sub-periods. Included within this zone are the midden (Feature 1), Feature 4, and a variety of diagnostic point types, including La Jita, Nolan, Langtry, Bulverde, and Pedernales, among others. 
Table 4.5. Column Sample Data from Backhoe Trenches in the Southern Approach

\begin{tabular}{|c|c|c|c|c|c|c|c|c|}
\hline \multirow[b]{2}{*}{ ВHT } & \multirow[b]{2}{*}{ Site } & \multirow[b]{2}{*}{ Level } & \multicolumn{2}{|c|}{ Elevation (m) } & \multirow[b]{2}{*}{ Debitage } & \multirow{2}{*}{$\begin{array}{l}\text { Burned } \\
\text { Rock }\end{array}$} & \multirow{2}{*}{$\begin{array}{l}\text { Bonel } \\
\text { Shell }\end{array}$} & \multirow[b]{2}{*}{ Tools } \\
\hline & & & Top & Bottom & & & & \\
\hline \multirow{10}{*}{$\begin{array}{c}1, \\
\text { CS } 1\end{array}$} & \multirow{10}{*}{ 41KR621 } & 1 & 98.64 & 98.60 & & & & \\
\hline & & 2 & 98.60 & 98.40 & 4 & & & \\
\hline & & 3 & 98.40 & 98.20 & 31 & & & \\
\hline & & 4 & 98.20 & 98.00 & 92 & 9 & & 1 \\
\hline & & 5 & 98.00 & 97.80 & 137 & 34 & & 1 \\
\hline & & 6 & 97.80 & 97.60 & 89 & 39 & & \\
\hline & & 7 & 97.60 & 97.40 & 42 & 5 & 7 & \\
\hline & & 8 & 97.40 & 97.20 & 11 & 5 & & \\
\hline & & 9 & 97.20 & 97.00 & & & & \\
\hline & & 10 & 97.00 & 96.80 & & & & \\
\hline \multirow{9}{*}{$\begin{array}{c}1, \\
\text { cs } 2\end{array}$} & \multirow{9}{*}{ 41KR621 } & 1 & 98.51 & 98.40 & 8 & & & \\
\hline & & 2 & 98.40 & 98.20 & 9 & & & \\
\hline & & 3 & 98.20 & 98.00 & 18 & 56 & & \\
\hline & & 4 & 98.00 & 97.80 & 18 & 102 & & \\
\hline & & 5 & 97.80 & 97.60 & 16 & 71 & 2 & \\
\hline & & 6 & 97.60 & 97.40 & 71 & 14 & 1 & \\
\hline & & 7 & 97.40 & 97.20 & 30 & 1 & 1 & \\
\hline & & 8 & 97.20 & 97.00 & 8 & & & \\
\hline & & 9 & 97.00 & 96.80 & & & & \\
\hline \multirow{5}{*}{2} & \multirow{5}{*}{ 41KR621 } & 1 & 97.00 & 96.80 & 4 & & & \\
\hline & & 2 & 96.80 & 96.60 & 5 & 1 & & \\
\hline & & 3 & 96.60 & 96.40 & 4 & 2 & & \\
\hline & & 4 & 96.40 & 96.20 & 6 & 2 & & \\
\hline & & 5 & 96.20 & 96.00 & & & & \\
\hline \multirow{7}{*}{3} & \multirow{7}{*}{$41 \mathrm{KR} 621$} & 1 & 98.20 & 98.00 & & & & \\
\hline & & 2 & 98.00 & 97.80 & 7 & 2 & & \\
\hline & & 3 & 97.80 & 97.60 & 6 & & & \\
\hline & & 4 & 97.60 & 97.40 & 12 & & & \\
\hline & & 5 & 97.40 & 97.20 & 3 & 2 & & \\
\hline & & 6 & 97.20 & 97.00 & 7 & 6 & & \\
\hline & & 7 & 97.00 & 96.80 & & & & \\
\hline \multirow{8}{*}{4} & \multirow{8}{*}{ 41KR621 } & 1 & 98.48 & 98.40 & & & & \\
\hline & & 2 & 98.40 & 98.20 & 4 & 2 & & \\
\hline & & 3 & 98.20 & 98.00 & 14 & 3 & & \\
\hline & & 4 & 98.00 & 97.80 & 64 & 5 & & \\
\hline & & 5 & 97.80 & 97.60 & 49 & 10 & 1 & \\
\hline & & 6 & 97.60 & 97.40 & 50 & 6 & & 1 \\
\hline & & 7 & 97.40 & 97.20 & 39 & & 1 & \\
\hline & & 8 & 97.20 & 97.00 & 4 & & & \\
\hline
\end{tabular}

\begin{tabular}{|c|c|c|c|c|c|c|c|c|}
\hline \multirow[b]{2}{*}{ BHT } & \multirow[b]{2}{*}{ Site } & \multirow[b]{2}{*}{ Level } & \multicolumn{2}{|c|}{ Elevation $(\mathrm{m})$} & \multirow[b]{2}{*}{ Debitage } & \multirow{2}{*}{$\begin{array}{l}\text { Burned } \\
\text { Rock }\end{array}$} & \multirow{2}{*}{$\begin{array}{l}\text { Bonel } \\
\text { Shell }\end{array}$} & \multirow[b]{2}{*}{ Tools } \\
\hline & & & Top & Bottom & & & & \\
\hline \multirow{6}{*}{5} & \multirow{6}{*}{$41 \mathrm{KR} 621$} & 1 & 96.70 & 96.60 & 2 & & & \\
\hline & & 2 & 96.60 & 96.40 & 6 & & & \\
\hline & & 3 & 96.40 & 96.20 & 6 & 2 & & \\
\hline & & 4 & 96.20 & 96.00 & 4 & 2 & & \\
\hline & & 5 & 96.00 & 95.80 & 2 & 1 & & \\
\hline & & 6 & 95.80 & 95.60 & 2 & & & \\
\hline \multirow{6}{*}{6} & \multirow{6}{*}{ 41KR621 } & 1 & 96.58 & 96.50 & & & & \\
\hline & & 2 & 96.50 & 96.30 & 2 & & & \\
\hline & & 3 & 96.30 & 96.10 & 2 & & & \\
\hline & & 4 & 96.10 & 95.90 & & & & \\
\hline & & 5 & 95.90 & 95.70 & & & & \\
\hline & & 6 & 95.70 & 95.50 & & & & \\
\hline \multirow{4}{*}{7} & \multirow{4}{*}{$41 \mathrm{KR} 621$} & 1 & 96.43 & 96.23 & 1 & & & \\
\hline & & 2 & 96.23 & 96.03 & 1 & & & \\
\hline & & 3 & 96.03 & 95.83 & 1 & & & \\
\hline & & 4 & 95.83 & 95.63 & 2 & & & \\
\hline \multirow{7}{*}{8} & \multirow{7}{*}{ 41KR621 } & 1 & 97.20 & 97.00 & 4 & 1 & & \\
\hline & & 2 & 97.00 & 96.80 & 4 & & & \\
\hline & & 3 & 96.80 & 96.60 & & 1 & & \\
\hline & & 4 & 96.60 & 96.40 & & 1 & 2 & 1 \\
\hline & & 5 & 96.40 & 96.20 & & & & \\
\hline & & 6 & 96.20 & 96.00 & & & & \\
\hline & & 7 & 96.00 & 95.80 & & & & \\
\hline \multirow{5}{*}{9} & \multirow{5}{*}{$41 \mathrm{KR} 621$} & 1 & 96.60 & 96.40 & & & & \\
\hline & & 2 & 96.40 & 96.20 & 1 & & & \\
\hline & & 3 & 96.20 & 96.00 & 2 & & & \\
\hline & & 4 & 96.00 & 95.80 & 2 & 1 & & \\
\hline & & 5 & 95.80 & 95.60 & & & & \\
\hline
\end{tabular}




\section{Discussion OF INTEGRITY}

The testing results indicated that the cultural components at the Gatlin site had good integrity with stratified cultural components. Initial radiocarbon results supported the field interpretation that multiple, stratigraphically discrete occupations were present at the site. Most of the cultural material was in the southern portion of the site, which occupied a transitional zone between colluvial and alluvial depositional contexts. The burned rock midden straddles a low-relief scarp, which seems to have separated colluvial deposition on the southern side from primarily alluvial deposition on the northern side (Frederick 2004:23). Throughout its prolonged use period, the midden appears to have been progressively buried, especially on the upslope or southern side, where several distinct occupation surfaces appeared to articulate with the midden crest. Even more significantly, the presence of the Early Archaic deposits below the midden and the presence of intact features argued for good site preservation.

\section{Eligibility of the Gatlin Site (41KR621)}

Based on the high degree of integrity of the cultural components and the potentially high data yield of the site, SWCA recommended, and TxDOT and the THC concurred, that the Gatlin site was eligible for NRHP nomination and warranted designation as a SAL. In particular, the site was considered to have the potential to address specific research questions related to the sequence of cultural development along the southern Edwards Plateau, landscape and geomorphological conditions affecting preservation potential, technological organization, and patterns of prehistoric use of cultural space (Houk and Miller 2004b), all of which will be more fully detailed in the following chapter.

For these reasons, data recovery investigations were recommended to mitigate the adverse effects to the site that would result from the construction of Spur 98. These were suggested to take the form of large block excavations specifically targeting the southern portion of the site. Given time constraints and the site's recommendation for data recovery, the detailed analysis of the cultural and organic materials yielded by the survey and testing efforts was reserved for after the data recovery excavations, allowing all site materials to be considered together. 


\title{
Chapter 5
}

\section{Data Recovery Research Design and Methodology}

\author{
W. Boone Law, Brett A. Houk, Kevin A. Miuer, Charies D. Frederick, and Michaele. Sm ith
}

\section{INTRODUCTION}

Due to the compressed time frame for the Spur 98 project, no formal research design was provided for the testing phase of the Gatlin site. Prior to conducting the data recovery excavations, however, SWCA prepared a preliminary research design oriented around two broad research themes (Houk and Miller 2004b). These were derived from the data collected while testing the site and were understood to be provisional avenues of research that could be retained, modified, or discarded as seemed appropriate based on the data recovery results. These original research themes were (1) Prehistoric Culture Change and Continuity in the Upper Guadalupe River Valley, Central Texas, 4000 B.C.-A.D. 500 and (2) Geomorphology at 41KR621 and Implications for Site Preservation in the Upper Guadalupe River Valley and Southern Central Texas.

To best address these topics, specific methods were adopted for the data recovery field efforts (see Chapter 7 for full descriptions of the data recovery field methodology). Block excavations comprising multiple 2 x $2-\mathrm{m}$ units were employed in order to provide areas of wide horizontal exposure for the identification of features and the living spaces in between. The block of Area A, excavated to the east of the burned rock midden, focused primarily on the site's Early Archaic component. Area B was placed south of the midden, where the separation of Middle and Late Archaic midden-related components was thought to be greatest due to colluvial deposition. Additionally, two types of hand-excavated units - dubbed Traditional and Feature Focused—were used to uncover as large an area as possible for the detection of features and patterns of features, while still recovering an adequate sample of artifacts to address the technological research questions. The excavated matrix of traditional units was screened, while that of feature-focused units was not, thereby sacrificing one form of data (namely quantifiable artifact data) for the sake of exposing more of the site.
Once the excavations were completed and the recovered materials quantified, the original research themes were revisited and the specific research issues and questions posed for each were reevaluated. Based on the results of the data recovery excavations, several of the research questions were discarded and new ones proposed (Houk et al. 2005). Various observations made during the analysis of the artifacts and special samples further refined the research issues and methodology. One such observation was the probable mixing or compression of the Middle-Transitional Archaic levels at the site, which suggested that detailed analysis of these levels would not produce significant results; sampling methods were therefore modified accordingly. The final research design reflects both this evolution and various refinements resulting from TxDOT review comments.

The final six research domains that form the framework for guiding the analysis and interpretation of the archaeological investigations of the Gatlin site are:

1. Paleoenvironment and Site Formation Processes.

2. Chronology of the Gatlin site.

3. Technological Organization.

4. Site Structure and Activities.

5. Subsistence Strategies.

6. Evaluation of the Project Methodology.

These domains are the building blocks for interpreting the form and function of the Gatlin site and how the site changed through time. They also form a foundation for investigating the behavior of the human occupants who utilized the site at specific periods. Many of these research themes and the approaches taken to address them are interlinked and build upon one another. While some of these domains are addressed in similarly named chapters, elements of these and the remaining domains are interwoven throughout the course of this 


\section{5-2 Chapter 5}

report in order to better present comprehensive discussions of each site component.

Within each domain below, a discussion of the research background for each topic and its relevance to the Gatlin site is followed by the specific questions asked of the data and a summary of the methods used to address them. The research design presented here has been pared significantly from the original in order to present the themes and basic methods used most clearly. Full descriptions of the methods have been integrated within the pertinent chapters. Detailed discussion and interpretation of the research domains are presented in Chapters 12 and 13.

\section{Research Design}

Whereas there was often heated debate among archaeologists in the 1960s-1980s about theoretical orientation and theory in general, "North American archaeology today involves relatively little discussion of general theory and relatively few attempts to build or contribute to such theory" (Hegmon 2003:233). Most North American archaeologists fall into the category that Hegmon (2003:217) calls processual-plus, practicing a broad array of approaches incorporating many elements of postprocessual archaeology into the processualism of previous decades. There is an interest in specific cases as they relate to larger contexts, and less of a concern with explicitly addressing general laws of cultural processes (Hegmon 2003:217, 233).

The research design for the Gatlin site could be characterized as proceeding generally from a processualplus orientation. In this approach, rather than viewing adaptation as "somehow something that happened to cultures," it is thought of as how humans lived on the landscape, "conceptualized as a result of human problem solving, a land use or subsistence strategy" (Hegmon 2003:228). This is a melding of the postprocessual concern with agency and the processual concern with adaptation. This is essentially what Whitley (1998:11) called a moderate post-processual approach. In such an approach, "there is a true and objective past, although we may not be able to recognize it," and the purpose of archaeology is "not necessarily to discover truth (an objective past), but to attempt to move increasingly closer to it" (Whitely 1998:11). This is done not through the critical tests of processual archaeology (i.e., emphasizing falsi- fication as the preferred means of testing theories), but - as this research design prefers - through a procedure of "inference to the best hypothesis," using empirical evidence to select the best hypothesis from a group of competing hypotheses (e.g., Kelley and Hanen 1988). Rather than testing rigid theories against various sets of data, the data are explored for patterns, and those patterns are interpreted through different hypotheses.

This approach is strongly reflected in the examination of technology (i.e., material culture) at the site. Technology in the processual-plus approach has social significance, "both in the sense that some technologies are symbolically charged... and regarding the linkage of technological styles with social identity" (Hegmon 2003:224). This is not to say that technology cannot or should not be viewed systemically, but rather, that it should also be viewed in other ways. This is reflected in the two approaches to investigating technology at the site outlined in this research design - one organizational and one stylistic.

However, to say that the research proceeded along purely processual-plus or moderate post-processual means would be inaccurate. The deliberate descriptive reporting of the 1960 s with the intent and necessity of building geographically regionalized databases also resulted in incomplete and fragmentary regional chronologies. Although updated in the intervening decades some postulated cultural intervals are still characterized by little more than a handful of horizon markers. The acceleration of CRM studies has sometimes shifted from first gear to fourth by attempting to apply middle range theory in a partial vacuum of substantive or refined descriptive data. The nature of not only the archaeological record in Texas, but the way in which that record has been studied in the past, necessitates that research begin with more traditional approaches, such as the culture historical approach. In fact, several characteristics of 41KR621 make the study of chronology (culture history) at the site applicable to the region and not just the site.

The realities of Cultural Resources Management (CRM) archaeology offer additional challenges to theory and interpretation. In the case of the Gatlin site, interpretations were somewhat hindered by the fact that the site almost certainly extends outside of the right-of-way to the east and west. Therefore, 
the excavated percentage of the actual site remains unknown, and this fact must be recognized prior to making any conclusions about the cultural activities that took place there. For this reason, the excavation methodology at the Gatlin site was designed to collect a valid sample of the portion of the site that was within the right-of-way (Houk and Miller 2004b), which is assumed to be representative of the types of materials and activities that took place at the entire site. The analyses of the results of these investigations, as embodied within the research domains described below, therefore reflect the effort to interpret the Gatlin site as a whole, considering not only the inhabitants' activities and their relationships to their environment, but also how those relate to the larger regional context through time.

\section{RESEARCH DomaIN 1: PaleoENVIRonment AND Site Formation Processes}

The paleoenvironment was an important factor in the prehistoric landscape, not only influencing the way people lived in the region, but also affecting the way the landscape evolved and the site formed. An examination of the geomorphology and site formation processes at the Gatlin site was, therefore, a critical first step in evaluating the nature of the archaeological record. This was initiated with Abbott's (2004) study of the Guadalupe River drainage basin and continued with Frederick's (2004) work during the survey and testing program, which built upon Abbott's findings and focused on the stratigraphic arrangement of the Gatlin site. The data recovery fieldwork expanded upon these with additional geomorphological investigations, largely aimed at investigating the site stratigraphy, the paleoenvironmental implication of matrix-supported gravels in the floodplain deposits, and factors influencing organic preservation at the site. Each of these three topics is integral to reconstructing the local paleoenvironment and the processes that resulted in the formation of the archaeological record at the Gatlin site.

\section{ISSUE 1: GeOMORPHOLOGY AND THE INTEGRITY OF THE Gatlin Site}

The geomorphological investigations of the site's natural stratigraphy were essential in evaluating the site's cultural sequence and its integrity. These observations determined that deposits of a primarily colluvial nature had accumulated south of the midden, possibly harboring stratified deposits associated with the midden's development within the buried A horizon. Early Archaic components were observed within the B horizon, stratigraphically separated from the site's later occupations. By identifying these occupation periods and evaluating the processes and rates by which they were buried, the geomorphological investigations greatly aid in elucidating the history of the site and the region as a whole.

\section{RESEARCH QUESTIONS}

Issues regarding the Gatlin site's paleoenvironment and stratigraphic integrity include:

- Where was the Guadalupe River located in relation to the site during the various periods of occupation?

- How does the stratigraphic sequence identified at the Gatlin site compare with other alluvial sequences in central Texas, in general, and with streams on the southern rim of the Edwards Plateau in particular?

- How does the sedimentation rate here compare to other central Texas streams?

- Was the rate of colluvial deposition near the midden constant or did it fluctuate through time?

- Are there spatial variations in the local sedimentation rate within the block excavations that facilitated or complicated stratigraphic resolution of different age occupations?

\section{INVESTIGATIVE STRATEGIES}

The following methods were employed in order to evaluate the paleoenvironment of the Gatlin site and to determine the degree of integrity of the archaeological deposits.

A. Stratigraphic profiles from mechanical trenching were used to reconstruct the stratigraphic and temporal structure of the deposits at the Gatlin site.

B. Core data compiled by Abbott (2004) was integrated with Frederick's (2004) stratigraphic data and the radiocarbon dates in 
order to present a more comprehensive picture of the Gatlin site as it relates to the Guadalupe River valley as a whole.

C. Information on stream deposits at the Gatlin site was correlated with that from other sites on the southern rim of the Edwards Plateau, such as the Footbridge site (41CM2), the Woodrow Heard site (41UV88), the Royal Coachman site (41CM111), the Varga site (41ED28), and the Richard Beene site (41BX831).

\section{Issue 2: Floodplain Formation Processes and the Significance of Matrix-Supported Gravel in Early to Middle Holocene Floodplain Overbank Deposits}

The geomorphological investigations at the Gatlin site revealed the presence of matrix-supported gravel deposits within various contexts across the terrace. Geologically uncommon, these can result from a variety of depositional or post-depositional processes. The determination of which processes created the matrix-supported gravels in the early Holocene Guadalupe River alluvial deposits has prominent implications for interpreting the contextual integrity of the cultural remains at the Gatlin site, as well as long-term changes in the soil erosion and alluvial sedimentation. This issue also incorporates a wider regional scale, as possibly catastrophic depositional processes would have implications for sites throughout the Upper Guadalupe River valley.

\section{RESEARCH QUESTIONS}

Questions raised by the phenomenon of matrix-supported gravels are:

- What process or combination of processes account for the matrix-supported gravels observed at the Gatlin site?

- Can the presence of these gravels be used as a measure of archaeological integrity at this and other alluvial sites?

\section{INVESTIGATIVE STRATEGIES}

In order to address these research questions, a number of site specific and wider regional approaches were used. These include:
A. Various analyses (e.g., petrographic, granulometric, $x$-ray diffraction, thin section and stable carbon isotope) were performed on soil samples to determine the deposition processes active at the site.

B. Recent gravel lag deposits on the Medina River were examined to provide comparable data for the deposition of matrix-supported gravels at the Gatlin site.

C. A literature review was conducted of comparative sites and studies in central Texas to provide information on early Holocene soil erosion in central Texas and the geomorphic effects of flooding on central Texas streams.

\section{Issue 3: Local Fauna and Flora and Their Preservation at the Gatlin Site}

The types of materials observed during the testing and data recovery excavations included burned and unburned animal bone, burned seeds and wood, and other charred materials. These materials are potentially valuable for the determination of the climatic conditions in place throughout time at the Gatlin site. Such information also has the potential to provide information about little known huntergatherer exploitation patterns of the river valley's former inhabitants.

The examination of the recovered organic materials, of which bone proved to be most abundant, also provided implications for the integrity of the Gatlin site. Observations during the testing and data recovery excavations noted that bone preservation appeared to be patterned stratigraphically, with better preservation at depth, and poor preservation high in the profile. Considerable spatial variation in bone preservation across the occupation surfaces was also observed. While it is possible that these patterns may indicate original discard behavior, it is equally likely that they are simply the result of selective bone preservation. A better understanding of the causes of these patterns is therefore important for assessing organic preservation and determining to what extent the recovered organic remains represent the original conditions at the site. 


\section{RESEARCH QUESTIONS}

Issues concerning the flora/fauna of the Gatlin site and their implications for preservation include the following questions.

- Do the macrobotanical remains permit any insight on the past vegetation at the Gatlin site, and what do they suggest about diachronically changing climatic conditions?

- What available faunal resources are indicated by the bone recovered at the site, and do these vary with time?

- Is the level of preservation consistent in all cultural components at the site?

- Do the faunal and macrobotanical remains show the same patterns in preservation?

\section{INVESTIGATIVE STRATEGIES}

The methodology used to address these questions included:

A. Information on available plant species was obtained from macrobotanical, pollen/phytolith, and lipid analyses.

B. Faunal remains were identified and categorized by taxon and element.

C. The faunal remains from the site were analyzed for spatial and stratigraphic patterns of bone preservation (see Appendix I).

\section{Research Domain 2: Chronology of THE GATLIN SITE}

As Thomas (1981:7) notes, there are three main objectives in archaeology: to develop cultural chronologies, to "reconstruct prehistoric lifeways; and the ultimate objective is to explain cultural processes." This research domain is concerned with the first objective, and draws upon the culture historical approach to achieve it. This approach was the dominant paradigm in American archaeology until the 1950s, and, although it has received its share of criticism, it is still an important school of thought, one that was largely subsumed by later theoretical approaches. Initially, culture historical studies were concerned with establishing chronologies of sites and cultures through the classification of artifacts and sites and placing them in temporal and spatial order (Shafer 1997:9-10). The basic premise behind this approach was that an appropriate goal of archaeology was the identification of cultural groups and their histories. The method for investigating these groups was the study of stylistic variation in material cultural (i.e., artifacts) because, the approach assumes, variation in styles among artifact types reflects different cultural groups.

In Texas, this approach arrived early and stayed late. What Collins (1995:362) referred to as a "preoccupation with chronology" has become almost an obsession with projectile points, the primary stylistic building blocks of culture histories in Texas. Often, culture history sections of CRM reports read more like a summary of projectile point types than a discussion of actual culture history. That archaeologists in Texas remain concerned with culture history should not be surprising because the information is a required component of CRM reports reviewed by the THC. Collins (1995:361-362), however, observed that over the "last 40 years, archeological efforts in Texas have excessively emphasized questions of chronology, have failed to identify and sustain a focus on but a few other issues of substance, and have not adequately understood the nature of the archeological record."

Chronology building, however, remains an essential task in Central Texas, in part because of previous researchers' failure to understand the nature of the archaeological record. In many cases, as Collins (1995:371) notes, chronologies have been based on materials from poor archaeological contexts (e.g., mixed components, poor stratification, and unclear associations between artifacts and radiocarbon samples). Data from sites that can contribute to refining local and regional chronologies remain important, even 10 years after Collins' (1995) critique.

Previous archaeological studies in the Guadalupe River valley have contributed to the understanding of the state's archaeological record and include the development of the region's first chronological sequence. This resulted from investigations in 1962 of three sites in the middle Guadalupe River valley at Canyon Reservoir, about 60 miles south of the Gatlin site (Johnson et al. 1962). A key element to this work was the viability and usefulness of evaluating several sites to identify the character 
of prehistoric exploitation and occupations in a local setting. Johnson's early work was subsequently addressed and expanded by others to form more recent and broader regional chronologies, such as that developed by Collins (1998).

The data from the Gatlin site can contribute to the refinement of these regional chronologies. The site produced significant areas of stratified deposits with good preservation of charcoal suitable for radiocarbon dating. Additionally, the site yielded numerous diagnostic tool forms within the stratified deposits, often more diverse and in quantities far larger than those observed at comparable sites in the vicinity (e.g., Camp Pearl Wheat [41KR243]). This combination of factors was crucial in the attempt to establish a local chronological sequence with absolute dates linked to relative-dating markers, such as projectile points and other specialized tool forms. For the Gatlin site, the development of a local chronological sequence was a necessary research tool for investigating similarities and differences with the culture history and cultural change of other sites in the region. Indeed, establishing the occupation history of the site and identifying the time periods with discrete living surfaces and stratigraphically isolable components was also a necessary precursor to investigating the other research domains.

\section{Research Questions}

The following research questions were posed of the data from the Gatlin site.

- What is the chronology of the various occupations at the Gatlin site?

- Which time periods or occupations have discrete living surfaces or can best be isolated stratigraphically?

- What is the intensity of occupation during each time period?

- How do the absolute dates associated with temporally diagnostic artifacts at the Gatlin site compare to other sites in the region (e.g., the Camp Pearl Wheat site [41KR243], the Royal Coachman site [41CM111], the Woodrow Heard site [41UV88], the Varga site [41ED28], the Richard Beene site [41BX831], and the Footbridge site
[41CM2])? If there is significant variation, how can it be explained?

- Are certain temporally diagnostic artifacts more sensitive chronological markers than others?

- How does the Gatlin site chronology compare to previously established chronologies for southern Central Texas?

\section{InVESTigative STRATegies}

The following approaches were taken to address these research questions.

A. A geomorphological identification and assessment of the site's natural stratigraphy was conducted in order to determine the integrity of site deposits (see Research Domain 1).

B. Projectile points and other temporally diagnostic tool forms were classified into established types for use as relative dating markers.

C. Absolute dates were obtained from radiocarbon and select bulk matrix samples recovered from natural stratigraphic contexts and features.

D. Absolute and relative dates were compared to the natural stratigraphy in order to identify mixed, compressed, or isolable cultural components.

E. A detailed review of, and comparison with, established site-specific and regional chronologies was undertaken to place the Gatlin site within a regional context and to identify areas where the site's data can fill existing gaps or clarify outstanding chronological issues.

\section{Research Domain 3：TeChNology}

The organization of prehistoric technology at the Gatlin site is a reflection of cultural adaptations to the environment, subsistence strategies, and an expression of, perhaps, group affinity. Technology pervades almost all aspects of prehistoric lifeways and provides data on group size, patterns of resource exploitation, subsistence, and social organization. 
Because of its stratified components, rich artifact assemblage, buried burned rock midden, numerous features, and apparently isolable living surfaces, the Gatlin site was deemed to be well suited to addressing many issues of technology.

If culture is viewed as "a system composed of technological, social, and ideological subsystems" (Kennett 1996:246), then technology is the most easily accessible component of prehistoric cultures. It is also frequently the only component of culture preserved at prehistoric sites. Technology is a fundamental aspect of cultural adaptation to the environment, and most of the archaeological evidence from the Gatlin site is directly related to this issue. Lithic tools, hearths, ovens, and ground stone tools relate to the extraction of resources. The interpretation of these data can yield evidence of technological organization, which includes mobility, raw material exploitation, reduction strategies, and diachronic change. These technological manifestations are divided below into two discussions, one addressing portable artifacts and the second focusing on burned rock features.

\section{Issue 1: Artifacts}

While technology can refer to almost any aspect of material culture-from toothpicks to trombones-in prehistoric hunter-gatherer archaeology, technology generally refers to items related to subsistence and production of material culture. Unfortunately, only a small fraction of the items that make up a prehistoric technological system are preserved in the archaeological record. Items made of stone, bone, and shell are typically preserved, while items made of wood, fiber, hide, and other perishable materials are not. We can sometimes infer their presence from the preserved technological components. For instance, by comparing Central Texas artifacts to collections from other parts of the country, we assume dart points were hafted on wooden foreshafts and attached to wooden spears. Additionally, by examining use-wear on tools it may be possible to infer what types of materials were being cut, scraped, or otherwise worked. This, however, is like inferring that a picture once hung on a wall because the nail is still in place-we know the picture was there, but we do not know what it looked like. "Archaeology is the search for fact. Not truth..." (Boam 1989) but the very nature of archaeological "facts" makes their study problematic — perhaps best exemplified by our study of technology. "The archaeological record is an indirect reflection of behavior, and cannot give us direct behavioral observations" (Whitley 1998:9). This is a prime reason for employing middle-range theories to bridge the gap between empirical fact and the conclusions to be derived from it.

CRM archaeology has long had a bias toward a culture history approach to the study and classification of various technological components. Typically, artifacts are sorted into broad classes (e.g., lithics) and then further subdivided into smaller categories (e.g., bifaces). These analytical categories often become the end product of the analyses, never attempting to move from fact to interpretation. These analytical categories, however, can be useful starting points for analysis as long as they are related to some subsystem of culture (such as stone tool production as it relates to the larger subsystem of technological organization).

The Gatlin site investigations employed organizational and stylistic approaches to the study of technology (e.g., Owens 2003). Treating technology as "an integrated system of knowledge and techniques through which humans solve problems and/or respond to change in their natural and social environments," the analysis is organized according to subsystems of technology (Owens 2003:45). This approach is an attempt to move from the physical components of technology (the archaeological facts that make up the artifact assemblage, for example) to the "operational knowledge" the prehistoric huntergatherers implemented in the pursuit of specific goals (Owens 2003:45).

Owens' (2003:45) justification for using an organizational approach to technology is that "technological systems are not organized ... according to artifact classes." This approach proposes that "raw material procurement, tool design and production, toolkit design and use, and tool maintenance occupy different sequential positions within a technological system, and each stage is differentially influenced by, constrained by, and responsive to external factors" (Owens 2003:45). At the outset, it is important to observe that this organizational approach is not without bias, as these "sequential positions" may not have emic counterparts, but are, rather, constructs propagated by the researcher. 
The primary components of technology (in descending order of sample size) represented at the Gatlin site are chipped stone, burned rock, ground stone, and bone (as possible tools). In fact, the combined Gatlin site assemblage includes over 145,000 pieces of debitage, 1,300 bifaces and biface fragments, 400 projectile points and point fragments, 300 cores, 100 modified flakes, and ground/battered stone tools. Thus, the discussion of technology focuses on those aspects of the data set, with the understanding that the sample is biased by two primary factors: that perishable items are not preserved and that the excavated volume represents an unknown percentage of total site deposits, and therefore may not be representative of the total range of technology at the site or in all cultural components.

\section{RESEARCH QUESTIONS}

The lithic artifact assemblage from the Gatlin site was judged to be of adequate size and richness and from suitable contexts to address the following questions.

- Were the occupants of the Gatlin site using raw materials from the river extensively, or even exclusively, to make their chipped stone tools, or were other sources exploited as well? Does this change over time?

- Were the occupants producing expedient tools, formal tools, or both, and how does this relate to the inhabitants' economic system?

- What are the ratios between expedient and formal tools in each temporal analytical unit?

- Is it possible to quantify the frequency of tool maintenance versus tool production at the site?

- What types of "retooling" took place at the site? What does this indicate for artifact use-life?

- Do the large, thin bifaces at the site represent some sort of specialized production by the occupants of the Gatlin site?

- If specialized production is taking place, why is it? What does it represent in terms of behavior and adaptation? What was the function of these bifaces?

- What types of ground stone artifacts are present at the site and with which time periods are they associated? Are these associated primarily with the Middle Archaic, as suggested by Johnson and Goode (1995:92)? What were the ground stone artifacts being used to process and what does this indicate about adaptation and resource exploitation?

- What tool types are prevalent at the Gatlin site? What does the infrequency or absence of certain tool types common in this region during the Archaic period (e.g., Clear Fork tools, Guadalupe tools) suggest for activities at the site?

- What does use-wear indicate about tool use at the site? What activities are suggested?

- What patterns of manufacture and use are evident on the Early Triangular points at the site?

\section{INVESTIGATIVE STRATEGIES}

The methods used to address the questions pertaining to the Gatlin site's lithic artifact assemblage are provided below.

A. Samples of local raw material specimens from various contexts were collected and compared with stone tools and debitage from the Gatlin site.

B. The artifact assemblage was sorted and classified into established type categories. Metric analyses were performed on select samples of each tool type.

C. Debitage was subjected to an initial sampling and sorting into categories. Complete flakes were sorted by size, and attribute-specific analysis was performed on a sample of platform-bearing flakes in order to provide data on reduction sequences, reduction strategies, and knapping activities.

D. Refit and conjoin analyses were performed on lithic debitage and cores to identify possible knapping floors. 
E. Projectile points and other temporally diagnostic tool forms were classified into established types (see Appendix E), and detailed metric analyses were performed on those judged to be from non-mixed contexts.

F. Macroscopic and microscopic use-wear analyses were performed on a select sample of tools to provide data on tool function, tool rejuvenation, and plant/animal exploitation.

\section{Issue 2: Burned Rock Features}

With the exception of lithic flaking debris, burned rock is the most frequently occurring artifact type recovered from archaeological contexts in Central Texas. In fact, at the Gatlin site itself, over 50,000 $(4,300 \mathrm{~kg})$ pieces of burned rock were quantified in the field from non-feature contexts, the excavated portion of the large midden, and 31 smaller features composed primarily of burned rock. Of the features, most appear to be associated with Early and Middle Archaic occupations at the site, while the midden itself began forming in the Middle Archaic and most likely saw accumulation through the Transitional Archaic.

Long recognized as indicators of prehistoric occupation, such concentrations of burned rock have been the focus of speculation and oftentimes looting. Concentrations of burned rock occur in a variety of forms including (1) very large, dense mounds known as middens; (2) smaller, discrete, structured groups of rocks associated with in situ oxidized soils, commonly referred to as hearths; (3) clusters similar to the previous form yet lacking in situ oxidized soils; (4) thin, irregularly patterned scatters of burned rock; and (5) burned rock pavements (Mahoney et al. 2003a:71-72). Systematic archaeological investigations have led to a more comprehensive view of these ubiquitous cultural features (Black et al. 1997; Collins and Ricklis 1994; Creel 1986; Hester 1991; Nickels et al. 1998; Weir 1976).

In terms of prehistoric construction and utilization of burned rock features, the most commonly attributed functions are as ovens or hearths (Black et al. 1997). The thermal properties of stone, specifically limestone and sandstone, were clearly recognized by the ancient indigenous groups of Central Texas.
However, the recognition in modern times that these were often ovens or kitchen middens has obscured the potential for examining the wide range of cultural activities that resulted in the accumulation of burned rock. Indeed, ethnographic/ethnohistoric examples abound for the use of such features within ritual, social, or medicinal contexts as well (Ellis 1997:48-50). Additionally, other technological processes may have taken place around such features, such as the heat treatment of lithic resources to facilitate controlled flaking.

What is clear is that burned rock features represent the implementation of fire-oriented technologies, in which heated rocks provided a simple yet effective means of controlling heat. In terms of cooking, heated rocks could be used to transfer heat through a number of methods, such as baking, boiling, steaming, frying, grilling, or smoking (Ellis 1997:52). The basic advantage of cooking food is that it allows the exploitation of a wider range of subsistence sources. Cooking (1) enables food to be stored for longer periods of time, (2) enhances certain foods' nutritive values, and (3) chemically alters the structure of some foods, thus making them more easily digestible or less toxic (Ellis 1997:50). Indeed, research on burned rock middens indicates that the features were instrumental in the processing of various geophytes-plants with underground bulbs or tubers (Dering1999; Thoms 1989; Wandsnider 1997).

The various cooking methods mentioned above, when used with a common technology such as heated limestone or sandstone rocks, exhibit archaeological signatures in the form of burned rock clusters (Ellis 1997:60). Clusters with in situ oxidized soils indicate direct heating, while those without may represent secondary deposition, possibly from hearth maintenance or the discard of expended boiling stones (Mahoney et al. 2003a). The repetition of group activities related to plant and animal processing, food preparation, and cooking can be directly related to the materials recovered from the matrix of burned rock features. Charred plant remains, charred and uncharred animal bones, burned and unburned mussel shell, as well as chipped and ground stone implements can be linked to the lifeways of ancient hunter-gatherers. Although preservation at the Gatlin site proved not to be as good as originally hoped, the site features yielded charcoal, faunal remains, 
and lipid residues, which were used to aid in the interpretation of feature function.

\section{RESEARCH QUESTIONS}

The analysis of the numerous features uncovered at the Gatlin site may provide answers to questions such as:

- What types of features and activity areas are present at the Gatlin site, and does the feature assemblage change through time?

- What types of food were the inhabitants processing in the burned rock features? Does feature form reflect differences in cooking processes in use at the Gatlin site?

- What types of fuel were used in the site's burned rock features? Does this change over time?

- Does the burned rock midden at the Gatlin site have a central feature or other recognizable features within its fabric?

- Why are so many artifacts included in the midden? Is this related to how the midden was used, how it was created, or some other factor(s)? How does the artifact assemblage from units within the midden compare to the assemblage from units outside the midden?

\section{INVESTIGATIVE STRATEGIES}

The interpretation of the burned rock features was addressed with the following methodology.

A. Features were analyzed for form through careful documentation during excavation.

B. Features were analyzed for function through the processing of special samples (flotation, pollen/phytolith, wood charcoal identification, and residue).

C. Technological data from the Gatlin site was compared to similar data sets from other sites to identify unique, unusual, and common traits for individual time periods.

\section{Research Domain 4: Site Structure AND ORGANIZATION}

Over the last 40 years, a basic principal of archaeological research has been the premise that material remains in the archaeological record are ordered in discernible patterns, and that these patterns can be interpreted to reveal behavioral or social processes. This principal is encapsulated in Binford's (1964:425) reference to the archaeological record as a "fossilized society." Binford (1977) is further attributed with significant advances along these lines by developing and advocating so-called middle-range theory (a term borrowed from sociology), which seeks to provide a means of interpreting archaeological patterns by applying well-established theory and observation such as those derived from ethnohistorical and experimental or replicative studies. Possibly Binford's most significant contribution, which later formed the basis of criticism of his own works, was the notion that patterns could not be effectively explained unless the range of causal processes was understood. Advancing this principle by attacking Binford on his own grounds, Schiffer (1972), who first coined the term "formation processes," recognized that patterns in archaeological records derived not only from cultural processes (which he called C-transforms), but also natural processes ( $\mathrm{N}$-transforms). Consequently, the archaeological record did not reflect "fossilized society", but a "systemic context" that derived from depositional and post-depositional processes, both natural and cultural, that affected the relationships among material remains (Schiffer 1972).

Schiffer's (1972) work, in addition to many other contributors', helped develop the view that patterns in the archaeological record developed from potentially numerous causes, and interpretation of spatial patterns must consider natural and cultural processes. Once cultural patterns can be distinguished, a well-established body of general principals based on behavioral archaeology, ethnoarchaeology, and experimental archaeology can be employed to reveal cultural and behavioral patterns (Schiffer 1995).

A number of other contributions to the study of archaeological structure, which Binford (1983) defines as the arrangement of features and artifacts, come from the so-called post-processualist school. From this approach, archaeology has developed a 
growing emphasis on the significance and function of empty space between features (from Derrida's [1978] notion of difference) and the archaeology of the individual (based in part on Bourdieu's [1977] notion of habitus).

During the testing at the Gatlin site, excavations revealed burned rock features, artifacts, charcoal, and faunal remains that represented sets of related activities in both the Early Archaic component and the midden-related Middle Archaic component. While isolated features could be discerned in the limited exposures afforded by the widely scattered test units and backhoe trenches, correlations among the features could not be positively defined. Therefore, one primary research question in the original data recovery plan was to determine if associations could be drawn between features by opening up broad exposures to get a wide view of the range of contemporary behaviors occurring on the site.

A substantial body of ethnohistorical data has established that there are regularities in the use of space in hunter-gatherer camps, and that these patterns reveal social and economic behaviors. For example, Lee (1979:30-31) notes an ethnographic example in which fireplaces, which were associated with huts, were located in the central part of the site and cooking pits were situated on the periphery of the occupational area. Accordingly, the spatial patterns of different technological features, designated "site furniture" (Binford 1983) or "structures apparantes" (Leroi-Gourhan 1984), reveal economic and social patterns. While the testing data from the Gatlin site were too limited to infer either "evident" (archaeological) or "latent" (behavioral) structures (Leroi-Gourhan 1972), data recovery excavations focused on addressing these issues by comparing the technological aspects, inferring functions, and defining spatial arrangement of the features and artifacts over a wider area. Among the latent structures that can be potentially addressed by intrasite patterning are group size, organization, and length of occupation.

The field investigations suggested that the Gatlin site was an excellent candidate for investigating such issues and how they may have changed through time, since the site appeared to possess some degree of separation between cultural components that could allow for the exploration of time-specific living surfaces and related hunter/gatherer lifeways. In contrast, many sites investigated from this time period (ca. 5,500 в.P.) reflect a depositional stability that resulted in artifactual mixing and the formation of palimpsest assemblages, thereby hindering the examination of spatial patterning and time-specific technology and change (Mahoney et al. 2003a:65-67). While data recovery excavations and analyses subsequent to the testing revealed the site to have more compression than initially believed, this research issue was still viable and pursued in the study.

\section{Research Questions}

In order to explore spatial patterning and its implications for interpreting hunter/gatherer behavior at the Gatlin site, the following questions were posed of the data.

- How are features and activity areas distributed across the site?

- How are the features related spatially and chronologically to one another?

- Are there hearths adjacent and related to the midden, as surmised by Black et al. (1997)?

- Are patterns in feature and activity area distribution evident?

- Do these patterns change through time at the site? Are there apparent differences in use intensity?

- What do these patterns indicate about social structure/organization, group size, and behavior at the site?

- Are traces of habitation structures evident at the site?

- Can the possible locations of habitation structures be inferred through the distribution of features, artifacts, and negative space?

\section{InVestigative STRategies}

The following approaches were proposed to address the research questions.

A. During the data recovery investigations, block excavations were employed to obtain 
large horizontal exposures for the identification of features, activity areas, and possibly structural remains.

B. Vertical provenience data were correlated with stratigraphic associations to relate contemporaneous sets of features.

C. Horizontal provenience information was employed to construct spatial distribution maps of features and point-plotted artifacts of the Early Archaic components.

D. Feature function was evaluated based on the results of special analyses, associated artifacts, and comparison with examples from other sites (see discussion in Research Domain 3).

E. Combined analyses were conducted to identify possible knapping floors or isolable living surfaces (see Research Domain 3).

F. Patterns of features and negative space were sought in order to make inferences on site organization and possible locations of structures.

G. Intersite comparisons of site organization and use of space were made with previously excavated regional sites.

\section{Research Domain 5: Subsistence}

The study of subsistence is an important aspect of reconstructing prehistoric lifeways, as much of huntergatherer technology was related to subsistence strategies. However, investigations of subsistence tend to collapse the identification of subsistence resources and subsistence strategies into one analysis (see Ellis et al. 1994:151-152). The two are obviously related, but the more appropriate means of investigating subsistence is to first address the issue of subsistence resources and then examine the strategies employed to exploit those resources.

\section{Subsistence Resources}

The subsistence resources, or subsistence base, available to the inhabitants of the Gatlin site presumably changed through time as the paleoenvironment changed. Therefore, the study of the resource base is closely tied to the paleoenvironmental investigations (see Research Domain 1). Many of the same sources of data can be used to address both topics, but the identification of economic plant and animal species at the site is necessary to investigate the resources that were actually exploited as part of the subsistence strategy.

The investigations at the Gatlin site produced a wide variety of evidence for subsistence resources. Mussel shell and various faunal remains point to the exploitation of the nearby river, while pollen/phytolith, macrobotanical evidence, and lipid analysis provided clues as to the array of vegetal resources available to the site's occupants. The evidence of certain flora and fauna was also used to examine issues of seasonality, and consequently hunter-gatherer mobility, while the presence of bison teeth within Early Archaic levels raised questions of both the climate in which they flourished and the technological adaptations used to exploit them.

\section{Subsistence Strategies}

The testing and data recovery excavations at the Gatlin site recovered a large and diverse archaeological assemblage that is in large part related to subsistence strategies. The Gatlin site's dataset can therefore aid in reconstructing past subsistence behaviors and broaden our knowledge of prehistoric lifeways in the Upper Guadalupe River valley. However, deciphering the Gatlin site's assemblage is a complicated process that requires an understanding of archaeological subsistence models and how subsistence relates to palaeoenvironment and technology.

One researcher who has greatly influenced the way in which archaeologists model subsistence is Binford $(1979,1980)$. Binford (1980) argues that there is a correlation between an archaeological assemblage and prehistoric subsistence behaviors. An archaeological assemblage, he contends, comprises an array of subsistence technologies that can be characterized as expedient or curated. Expedient technologies are manufactured on site from local raw materials, used, and discarded to meet the need of the moment. Curated technologies are specifically produced in anticipation of use and are characterized by their multifunctional properties and prolonged use-lives. Binford (1980) implies that expedient technologies are reflective of unplanned subsistence behaviors, which are ethnographically consistent with the behaviors observed of frequently mobile foraging 
groups. Curated technologies, on the other hand, are indicative of planned subsistence behaviors, and as Binford (1980) suggests, may be related to increased sedentism (even seasonal) or limited access to resources.

To illustrate the differences and the expected archaeological patterning from these subsistence strategies, Binford (1980) defined two main groups: Foragers and Collectors. In reality, they represent the extremes of subsistence strategy, and the scheme should be viewed as a continuum. Collectors are seasonally mobile, and send out task groups to acquire and return with resources. They are more likely to use curated tools designed for specific activities. Foragers make residential moves to resource-rich areas, which they exploit until the resource is depleted. They practice residential mobility, where the group moves frequently as a whole between areas. They practice encounter-based hunting and use a generalized tool kit that is readily adaptable. In their base camps they utilize materials at hand for expedient tools. Collectors are expected to favor more tool diversity and specialization because they frequently target individual resources for bulk processing.

Binford's $(1979,1980)$ subsistence-settlement model has been heavily scrutinized by archaeologists, and it is widely recognized that there are significant problems with his model (e.g., Bamforth 1986; Kelly 1992; Torrence 1983, 1989). The main criticism of his model is that the technology/subsistence strategy relationship is easily affected by multiple variables including environmental stress (Bamforth 1986), time-stress constraints (Torrence 1983, 1989), and resource availability (Bamforth 1986; Kelly 1992). In Binford's $(1979,1980)$ defense, however, it is important to point out that his characterization of expedient and curated technologies are intended to be used by archaeologists as a means of conceptualizing subsistence strategies. They are not categorical subsistence types, and variation within the model should be expected (as outlined by Bamforth 1986, 1991; Bleed 1986; Kelly 1992; Shott 1986; Torrence 1983, 1989).

Kuhn (1995), like others before him, recognized the problems of modeling subsistence behaviors based solely on the identification of curated and expedient technologies. To circumvent this problem, Kuhn (1995:22) developed his concept of provisioning, which refers to the "depth of planning in artifact production, transport, maintenance, and the strategies by which potential needs are met." Provisioning is a term intended to merge Binford's (1979, 1980) concepts of curated (planned) and expedient (unplanned) subsistence technologies. Kuhn argues that it not possible for any prehistoric group to rely solely upon expedient technologies since resources (natural and biotic) are rarely widespread across a landscape. Therefore, all human subsistence behaviors must incorporate a curated technological component to ensure that resources are available for future needs.

Furthermore, Kuhn (1995) contends that even on-thespot expedient stone tool use entails some level of future planning. For instance, the choice to conserve a limited, non-locally available curated technology for future activities or anticipated situations may result in the seemingly "expedient" use and discard of a locally abundant resource. Thus, in this case, expedient stone tool usage is part of a larger plan to preserve a curated technology for future needs.

Kuhn (1995) describes two subsistence strategies that are involved in the formation of an archaeological assemblage (1) the provisioning of individuals and (2) the provisioning of places. The provisioning of individuals refers to the strategy of carrying and transporting materials in anticipation of potential future need via a personal mobile toolkit (Kuhn 1995:22). The provisioning of places refers to a strategy that copes with anticipated resource requirements by stockpiling locations with resources that are likely to be needed.

The provisioning of individuals strategy assumes that there are limits on the number and size of provisions (e.g., stone tools, raw materials, consumables) that mobile hunter-gatherers can efficiently carry. As a result, individuals will carry a mobile toolkit of items that can be easily maintained and reworked to increase their use-lives and multifunctional qualities (Bleed 1986; Dibble 1995; Shott 1986). Greater mobility is also often correlated with greater uncertainty over reprovisioning opportunities, thus mobile individuals tend to make use of high quality raw materials and curated technologies that increase the performance and reliability of their mobile toolkits (Bleed 1986). Also, since mobility sets limits on what people can carry, individuals likely employed 


\section{5-14 Chapter 5}

strategies to conserve their mobile toolkit by utilizing the immediate resources encountered on their journeys (Kelley 1988; Kuhn 1989, 1994, 1995). Such resources may include locally available raw materials suitable for manufacture of expedient tools or the scavenging, rejuvenation, and reuse of previously discarded materials and features.

The provisioning of places subsistence strategy deals with the anticipated need of resources by provisioning locations where supplies are likely to be needed (e.g., raw materials, tools, and consumables). Kuhn (1995) suggests that stone artifact assemblages formed by this planning strategy are distinguished by their toolmaking potential (e.g., unmodified raw materials, large cores and flakes, unfinished tools, and non-utilized curated stone tools). Similarly, features formed at such localities are characterized by their multifunctional qualities and extensive usage/reusage (e.g., burned rock middens).

The Gatlin site's excavations revealed that prehistoric populations have revisited the site for millennia. Determining which provisioning strategies influenced the formation of the Gatlin site's archaeological assemblage will hopefully allow archaeologists to model patterns of prehistoric subsistence in the Upper Guadalupe River Basin.

The study of subsistence is intrinsically related to four of the other five archaeological research domains. Available animal and plant resources at the Gatlin site fluctuated through time, linking subsistence to paleoenvironment and chronology. Much of the preserved technology at the site is directly related to subsistence (procuring and processing plants and animals). The patterning of features and activity areas also relates to subsistence-related activities at the site. Therefore, the other four archaeological research domains provide data relevant to subsistence studies while at the same time being informed by subsistence-related data. Furthermore, subsistence data can be used to investigate various models of hunter-gatherer organization and mobility.

\section{Research Questions}

Questions pertinent to the exploration of this domain include:

- What subsistence-related plant and animal species are preserved in the archaeological record?
- Is seasonality of occupation indicated by either the faunal or floral remains?

- What kinds of subsistence-related technologies are represented at the Gatlin site? Conversely, what kinds of subsistence-related technologies are absent or infrequently represented at the site?

- What do the presence/absence of subsistence-related technologies imply about site function, seasonal site use, and environmental setting?

- Is there evidence of change in the faunal or floral resources being exploited through time at the site? Is there evidence of change in the subsistence technologies used to exploit them?

- What types of animal processing took place at the site?

- Can the subsistence data from the site be used to infer degree of group mobility?

- What types of wood were used for fuel? Do these vary with time or types of features?

- Is there a correlation between the appearance/disappearance of bison in the archaeological record and any changes in subsistence technology at the site (such as the introduction of new projectile point types or changes in burned rock feature/midden construction)?

\section{Investigative STRategies}

The investigative methods employed in addressing these research questions include:

A. The site's faunal assemblage was analyzed for species identification, number of individual specimens (NISP) and minimum number of individuals (MNI), and evidence of cultural modification (e.g., cut marks, impact fractures).

B. Freshwater mussel shell was quantified and identified by species.

C. Archaeobotanical analysis and identification of plant species was performed on feature flotation materials and charcoal samples. 
D. Pollen/phytolith samples from feature contexts were identified to provide information on available plant species.

E. Identification of subsistence resources was based upon palaeoclimatic, stone tool use-wear, and burned rock lipid data (see Research Domains 1 and 3).

F. Subsistence strategies employed at the Gatlin site were modeled using data collected from the stone artifact assemblage, stone tool use-wear, burned rock feature samples, archaeobotanical remains, faunal remains, radiocarbon samples, and geomorphic samples.

G. Patterns revealed through investigation of the previous domains were examined to determine which prehistoric provisioning strategies were employed at the Gatlin site.

\section{RESEARCH Domain 6: EVALUATING THE PRoJeCt's METHODOLOGY}

It is the responsibility of archaeologists as scientists to describe not only their data, but also how they collected that data so that others may evaluate the legitimacy of their conclusions. Beyond the resource being investigated - the nature of which is beyond the archaeologist's control - two factors primarily influence the quality of archaeological data: the prefield plan or scope-of-work and the way in which that plan is implemented. This research domain critically examines the methodology proposed for the Gatlin site and the manner in which it was executed in the field. The goal of this exercise was to highlight strengths and weaknesses in the approach to benefit future investigators.

The project proceeded from the beginning under somewhat unusual circumstances, which affected the methodology for survey, testing, and data recovery. Because TxDOT suspected a large archaeological site was located on the southern Spur 98 approach prior to any investigations, SWCA conducted a more intensive survey than would normally have been proposed. This survey utilized auger testing and backhoe trenching to prospect for buried cultural materials. Additionally, SWCA operated under a compressed time frame, necessitating the initiation of testing immediately following the survey. Once testing was completed, SWCA prepared an interim report summarizing the investigations, but did not complete any detailed artifact analyses or special sample processing other than limited radiocarbon analysis. The initial research design was prepared subsequently, based on the preliminary results of survey and testing.

Prior to the data recovery excavations, SWCA proposed a methodology for investigating the Gatlin site that was designed to maximize the collection of data relevant to the various research issues outlined in the initial research design (Houk and Miller 2004b). The field methods included backhoe trenching, mechanical stripping, and hand excavations. These methods were utilized in that order to identify the relevant cultural components, remove non-sensitive deposits, and to investigate the targeted materials. At the heart of the methodology was a series of compromises, three more significant than others. First, assumptions were made about the nature of the younger deposits away from the midden, and large portions of the post-Early Archaic materials were mechanically removed with only minimal documentation. Second, within Area A, (which targeted the Early Archaic component) artifact recovery was minimized in favor of maximizing the amount of horizontal exposure. Third, investigations of the burned rock midden were minimized, and greater attention was paid to the midden-related components in Area B.

The operationalizing of the proposed scope of work also influenced the nature of the collected information. This includes a variety of factors such as the design of the field forms, the excavation procedures developed by the supervisory staff, crew size, weather, equipment, and the decision-making processes used by all levels of the professional staff.

This critical and objective evaluation of the project's methodology was a valuable exercise that will hopefully benefit TxDOT, SWCA, and future archaeological projects. For the data recovery phase, the excavation methodology proposed for the Gatlin site was one that had not been previously used by SWCA. Specifically, the use of Feature Focused excavations was a departure from the company's standard excavation approach. Ultimately, the effectiveness and usefulness of the methodology will be tied to the ability of the collected data to answer the research 
questions posed in this research design. This critical evaluation is presented as Appendix $\mathrm{K}$ and includes recommendations to improve the methodology.

\section{Research Questions}

The questions addressed within this topic include:

- How effective was auger testing as a survey method? How do the auger test results compare to the backhoe trench data?

- Did the fact that survey and testing were planned together prior to any investigations adversely affect the testing phase?

- How and why did the proposed methodology change during implementation?

- Did the use of Feature Focused units create data gaps that adversely affected the understanding and interpretation of the Early Archaic component?

- Did the use of 2 x 2-m units excavated in quadrants offer any apparent benefits over 1 x 1-m units?

- What effect did the project schedule, from survey to data recovery, have on the methods and excavations?

- How much did weather affect the excavations, and how could that effect have been minimized?

- Were the field forms and recording procedures adequate and appropriate?

- What factors played a part in the decisionmaking process related to where excavation units were placed?

\section{InVESTIGATIVE STRATEgIES}

In order to answer the research questions, the following methods were employed.

A. A project narrative was written, which outlined when and why certain steps were taken in the field.

B. Elements of the original scope of work that either did not work or had to be modified were identified and assessed.
C. In general, this research domain was investigated through an objective review of the methods and data to identify how the methodology affected the quality of the data and the validity of the resulting interpretations, as related to the other five research domains. 


\title{
Chapter 6
}

\section{Paleoenvironment and Site Formation Processes}

\author{
Charles D. Frederick
}

\section{INTRODUCTION}

This chapter presents the results of site specific investigations at the Gatlin site (41KR621) performed by Charles D. Frederick in association with SWCA's testing and data recovery excavations at the site. This section of the report describes the internal structure of one of the four alluvial units identified by Abbott and the stratigraphic context of the prehistoric occupations at the Gatlin site. The following chapter relies heavily on a previously unpublished core study performed on the Guadalupe River at two locations by James $\mathrm{T}$. Abbott (TxDOT, ENV). Abbott's study is presented in Appendix A. To the best of our knowledge, this comprises the only stratigraphic work performed to date on the Guadalupe River and provides a basic radiocarbondated alluvial stratigraphic sequence where the Guadalupe River crosses Interstate 35 near New Braunfels, and at the proposed Spur 98 extension. The reader is encouraged to read this study prior to this chapter as Abbott's alluvial unit classifications and results form the broader backdrop for the detailed site study. Finally, Appendix A also includes the matrix-supported gravels study conducted at the site and the supporting backhoe trench descriptions for this chapter.

\section{BACKGROUND}

Geoarchaeological investigations at the Gatlin site occurred in two phases: (1) a testing phase and (2) a data recovery phase. The testing phase involved the excavation of trenches on the $T_{1}$ surface south of the river in direct proximity to the Gatlin site (Appendix A), as well as on the $T_{1}$ surface north of the river in the Spur 98 right of way (Figure 6.1). This work discovered one archaeological site on the north side of the river (41KR622) which had largely been destroyed by construction. It also provided more detail on the near-surface stratigraphic setting of the Gatlin site and revealed the buried burned rock midden (Figure 6.2). Geoarchaeological investigations performed during the data recovery phase were designed to elaborate on the site setting, geological processes that influenced its formation, and how alluviation at the Gatlin site may reflect soil erosion on the Edwards Plateau during the Late Pleistocene to Middle Holocene period. These investigations were designed to build on Abbott's coring of the Spur 98 alignment, which identified four alluvial stratigraphic units within the right-of-way. This chapter explores in detail the evolution of the Late Pleistocene to Middle Holocene alluvial deposit (Unit 3), within which the Gatlin site cultural deposits reside. Most attention is directed at the latter stages of Unit 3 deposition, which is concomitant with occupation of the site. Observations derived from the Abbott's work and testing phase trenching were the source of a directed study on the formation processes associated with matrix-supported gravels that were observed in several stratigraphic settings, and the results of this study are presented in Appendix A.

\section{Historical Context of Early Holocene Alluviation: Late Pleistocene-Early Holocene SoIl Erosion on the Edwards Plateau}

The close of the Pleistocene was a period of considerable environmental change in central Texas. Changes in global climate associated with the end of the last ice age had profound implications for most landscapes, and central Texas was no different. Unlike higher latitude landscapes where ponds and bogs offer settings conducive to preserving evidence of past environmental changes, arriving at a clear image of central Texas paleoenvironments is more challenging. Several studies have examined environmental change in this region through detailed reconstruction and analysis of fluvial deposits (e.g., Nordt 2004; Blum et al. 1994; Blum 1987), fossil vertebrate remains in cave deposits (Toomey 1993; Blum et al. 1994; Graham 1976; 1985), fossil pollen (Bryant and Holloway 1985), and carbon isotopes (Cooke 2005; Nordt et al. 2002; 1994), but clarity and detail of past landscapes are often elusive owing to variations in geochronology, organic matter 


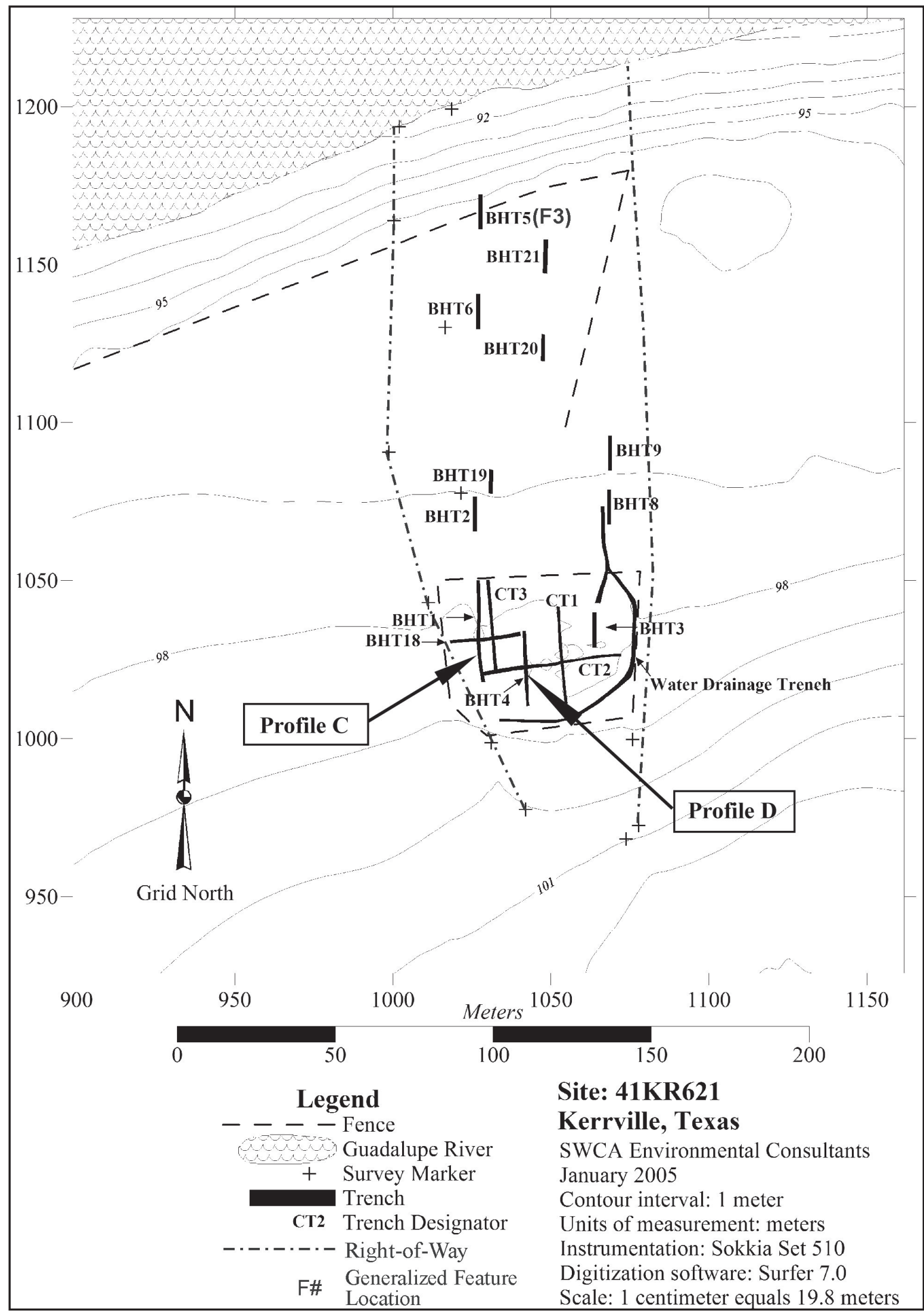

Figure 6.1. Data recovery excavations with select testing trenches and profiles. 
preservation, and ambiguous data sets (see Cooke 2005:141 for a recent comparison of Late Quaternary climate records that illustrate this point).

As discussed by Abbott (Appendix A), it was in this period that most streams abandoned their former floodplains, became deeply incised and formed new, lower floodplains. Details of the late Pleistocene climate in this region are widely debated, but there is a general consensus that full glacial conditions were generally cooler and moister than today, and then became warmer and drier at the start of the Holocene. There is some evidence that the Late Glacial Younger Dryas interval was one of briefly warmer and drier conditions in this region (e.g., Cooke 2005; Nordt et al. 2002; Toomey 1993), but few studies have sufficient detail to record it. The vegetation on the Edwards Plateau appears to have been grassland or very open savanna in the full glacial period, and carbon isotopic studies suggest that the composition of this grassland shifted between $\mathrm{C}_{3}$ and $\mathrm{C}_{4}$ taxa becoming more $\mathrm{C}_{4}$ dominated as the Holocene progressed. It was also in this period that the soils on the Edwards Plateau began to erode (discussed in more detail below). Although all of these changes affected the landscape in proximity to the Gatlin site, it was the recent observations on the timing and nature of soil erosion that were thought to have particular relevance, in part because of the ubiquity of deposits at this site that comprised fine-grained muds with gravels suspended within them (matrix supported gravels).

Various authors have speculated about soil erosion in central Texas during the late Pleistocene and Early to Middle Holocene, but the nature, timing and magnitude of erosion estimates differs considerably from one study to another. The most detailed and best dated studies, Nordt's (1992, 2004) work with alluvial stratigraphy at Fort Hood and multidisciplinary studies from Hall's Cave in Kerr County (Cooke 2005; Cooke et al. 2003; Toomey 1993), on the southern margin of the Edwards Plateau, derive from quite different settings and portray the edaphic changes in very different terms.

Nordt $(2004: 299 ; 2002)$ speculates that the change in alluvial deposit composition from yellow and gray detrital carbonate-rich sediment in the Early Holocene Georgetown alluvium to reddish and yellowish brown colors of the Fort Hood Alluvium starting

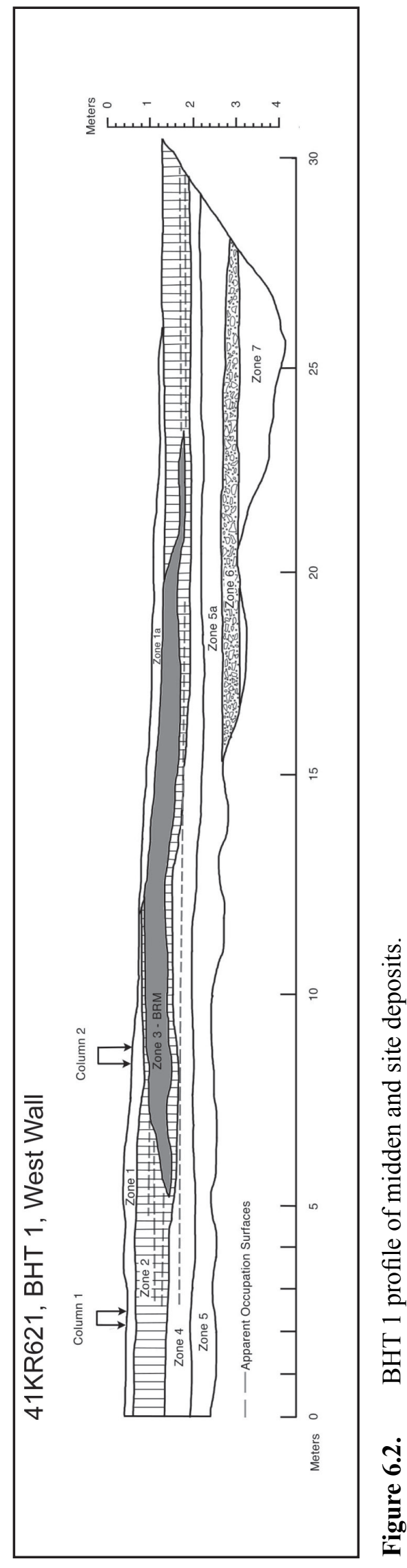


around 7,000 B.P. is attributable to the entrainment of upland soils in the Cowhouse Creek catchment when incising tributary channels penetrated into upland settings where thicker soils existed. Nordt in part attributes this to an abrupt shift to warmer temperatures and a shift to warm season $\mathrm{C}_{4}$ grasslands around 8,000 B.P. which may have promoted widespread erosion in the uplands.

This is later and more punctuated than the image Toomey (1993) derived from analysis of the fauna and sediments within Hall's Cave. Toomey (1993:455-460) identifies five periods of soil history on the Edwards Plateau, beginning with incremental erosion of deep red soils formed under a grassland or very open savanna environment starting around 20,000 B.P. and ending around 8,000 B.P. Around 8,000 B.P. red soils give way to red-brown ones in Hall's Cave and similar sites such as Bering Sinkhole, and this deposit persisted until about 5,000 B.P., after which Toomey infers the soil mantle to have been about $1 \mathrm{~m}$ thick based on the absence of the burrowing Prairie Dog (Cynomys sp.), the extirpation of moles (Scalopus aquaticus) and the presence of gophers (Geomys sp.) and the Texas Kangaroo rat (Dipodomys elator). Between 5,000 and 2,000 B.P. the deposits in Hall's Cave changed to a very dark brown color and the main fossorial mammal changes from eastern pocket gophers (Geomys sp.) to smooth toothed pocket gophers (Thomomys sp.) and the yellow faced pocket gopher (Cratogeomys castanops), which is consistent with an increasingly shallower and drier soil cover. The shift to black deposits around 2,000 B.P. and slightly earlier at Bering Sinkhole and the general absence of gophers marked the onset of the modern shallow, stony soils.

Recent strontium isotopic work on hackberry seeds (Celtis sp.) and tooth enamel of gophers (Geomys sp.) and voles (Microtus sp.) from Hall's Cave by Cooke (2005; Cooke et al. 2003) has provided an independent assessment of Late Pleistocene and Holocene soil erosion that largely supports Toomey's work. Cooke exploited the difference in the stable isotopic ratio of ${ }^{87} \mathrm{Sr} /{ }^{86} \mathrm{Sr}$ found in silicate soil materials (high values) and the Cretaceous bedrock (low values) to model the thickness of the soil through time. By examining this ratio in fossil remains of trees and burrowing mammals of different age, Cooke calculated that there has been a progressive denudation which began around 15,000 B.P. and ended around 5,000 B.P. that resulted in the loss of an estimated $1.8 \mathrm{~m}$ of soil from the Edwards Plateau surface around Hall's Cave. Almost half of that ( 80 $\mathrm{cm}$ ) is estimated to have been eroded in the period between 12,000 and 5,000 B.P. Although slightly different from Toomey's work, and lacking the multiple lines of complimentary evidence Toomey marshaled, Cooke's study provides a useful corroboration of Toomey's work on this issue.

Considered together, these studies present very different impressions of soil erosion in central Texas during the Late Pleistocene and Early Holocene. The differences may be largely due to setting, but it is also possible that there were regional variations in soil erosion in this period. Evidence supporting the latter position may be found in comparing the character of Late Pleistocene-Early Holocene alluvial deposits contemporary with the Georgetown Alluvium at Fort Hood, from the southern part of the Edwards Plateau. Perhaps the best example is from the Culebra Creek site on the west side of San Antonio, where two alluvial units formed in the Late Pleistocene and Early Holocene (Nordt 2001). Unit II was dated to the interval between 17,000 and 11,000 B.P., and Unit III began to form shortly after 11,000 B.P. and continued until around 4,000 B.P. Interestingly, Unit II is reddish yellow in color (7.5YR 5/6 to $6 / 6$ ) and Unit III is a strong brown (7.5YR 4/3). Alluvial Units I and II on the Upper Leon Creek in northern Bexar County (Nordt 1996) exhibit a similar color change, as do Units II and III identified by Abbott (Appendix A) for the Guadalupe River at the Gatlin site (although the age of Abbott's Unit II can only be speculated upon owing to a lack of radiocarbon dates from this deposit). The fact that the color of late Pleistocene and Early Holocene alluvium along the southern Edwards Plateau compares favorably with the eroded soils observed in Hall's Cave implies that the differences in Late Quaternary erosion histories described above are probably due to spatial variation in soil erosion. In specific, it appears that there was gradual erosion of deep red soils beginning in the Late Pleistocene and persisting into the Middle Holocene along the southern Edwards Plateau, whereas erosion of upland soils on the northern remnants of the Edwards Plateau on the Lampasas Cut Plain occurred later and lasted for a shorter period, perhaps 
in part owing to a less extensive upland soil mantle in that region.

\section{Methods}

The floodplain history and the formation processes active at the Gatlin site were evaluated through the characterization of four vertical profiles of the alluvial/colluvial deposits from the site (Figure 6.3). Profiles from BHT 20, BHT 19, and BHT 1 Profile C represent a north to south transect from the cutbank overlooking the modern channel, to the southern valley margin. BHT 1 Profile C and Profile D on Test Unit 4D both represent distal floodplain facies but they vary in the amount of recent colluvial cover present. Profile D was collected to the east of the burned rock midden, where colluvial sedimentation was not as pronounced as it was in BHT 1 Profile $\mathrm{C}$ immediately upslope of the midden.

For each profile the particle size distribution was determined using the sieve-hydrometer method (Day 1965; Gee and Bauder 1986), and the calcium carbonate equivalent was determined gasometrically by means of a chittick apparatus (Dreimanis 1962). For profiles from BHT 19, BHT 20, and BHT 1 Profile C, the mineralogy of the clay size fraction ( $<4$ micron) was determined by X-ray diffraction (Talbot 2006), and oriented clods were collected from various positions in the profile for micromorphology. The clods were air dried, subsequently vacuum impregnated, then submitted to National Petrographic Labs for thin section preparation. Thin sections were examined using plane and polarized light under a low-magnification binocular microscope and a petrographic microscope. Features described in thin section employ the nomenclature of Bullock et al. (1985). The stable isotopic composition of the calcium carbonate nodules present in two profiles (BHT 19 and BHT 1 Profile C) was determined by Dr. David Dettman at the University of Arizona Stable Isotopic Lab. The results of many of these analyses are presented on Figure 6.3 and the accompanying data are presented in Tables 6.1-6.6.

\section{Floodplain History of the Gatlin SITE}

\section{LARGE SCALE STRUCTURE}

Stratigraphic data gathered by coring during the survey phase by Abbott (Appendix A) together with trenches excavated during testing (Appendix A) provide a detailed cross-sectional image of the Guadalupe River deposits from the modern channel to the southern valley wall. These data have been integrated into a single figure (Figure 6.4), which depicts the major lithological variation within the Late Pleistocene to Middle Holocene alluvium (Unit 3), the stratigraphic unit identified by Abbott (Appendix A) which contains the Gatlin site deposits.

One of the most striking attributes of this figure is the dramatic shift in depositional facies which occurs throughout the period of Unit 3 aggradation. As Abbott (Appendix A) noted, deposition appears to have started in the Late Pleistocene with extensive lateral accretion deposits which most likely reflect a phase of widespread channel migration across the valley floor following channel entrenchment in the early phases of Unit 3 deposition, before 12,500 years ago. Through time, however, lateral mobility of the channel became increasingly restricted towards the center of the valley while at the same time the floodplain/floodbasin facies expanded. By 10,000 years ago a distinct fine-grained floodbasin facies had formed along the southern half of the $\mathrm{T}_{1}$ surface, and from this point on the channel was effectively in the same location as today. There also appears to be a prominent northward slope to the deposits within the overbank facies deposits. During the Early Archaic period occupation, the Guadalupe River channel appears to have been about where it is now, although perhaps not as deeply entrenched as it is today. Although no Middle to Late Holocene alluvial fill is present in the valley along the line of Spur 98, it is likely that channel entrenchment occurred sometime after around 5,000 years ago as Abbott (Appendix A) speculates, given the dramatic decline in sedimentation rate that is observed on this surface after that point in time (see discussion below). 


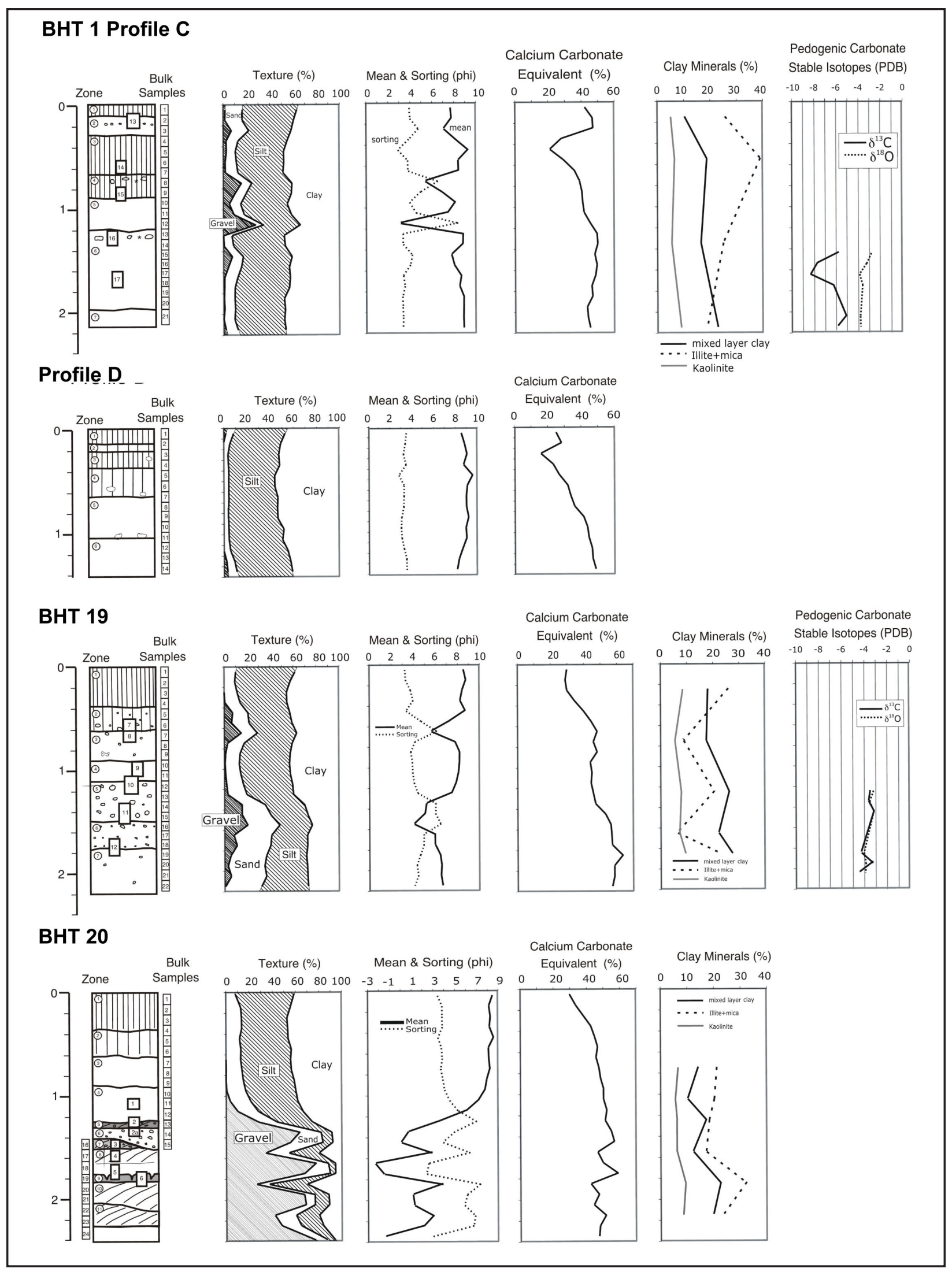

Figure 6.3. Data from four profiles within the Gatlin site. 
Table 6.1. $\quad 41 K R 621$ Backhoe Trench 4 Profile D

\begin{tabular}{|c|c|c|c|c|c|c|c|c|c|c|c|c|}
\hline \multicolumn{12}{|c|}{ With Gravel } & \multirow{2}{*}{$\begin{array}{l}\text { Calcium Carbonate } \\
\text { Equivalent }<2 \mathrm{~mm}(\%)\end{array}$} \\
\hline Number & Depth & $\% \geq 63 \mu$ & $\% \geq 2 \mu$ & $\%$ Gravel & $\%$ Sand & $\%$ Silt & $\%$ Clay & Mean & SD & Skew & Kurt & \\
\hline 1 & 0.050 & 9.0 & 53.5 & 2.3 & 6.7 & 44.5 & 46.5 & 8.65 & 3.60 & 0.01 & 0.60 & 25.0 \\
\hline 2 & 0.150 & 5.7 & 49.4 & 0.2 & 5.5 & 43.7 & 50.6 & 8.93 & 3.50 & -0.03 & 0.39 & 28.2 \\
\hline 3 & 0.250 & 4.1 & 48.0 & 0.2 & 3.9 & 43.9 & 52.0 & 9.16 & 3.33 & -0.02 & 0.40 & 15.9 \\
\hline 4 & 0.350 & 4.6 & 48.8 & 0.3 & 4.3 & 44.2 & 51.2 & 8.85 & 3.58 & -0.07 & 0.32 & 23.2 \\
\hline 5 & 0.450 & 5.0 & 44.3 & 0.3 & 4.7 & 39.3 & 55.7 & 9.67 & 2.93 & 0.02 & -1.53 & 26.8 \\
\hline 6 & 0.550 & 4.9 & 44.6 & 0.3 & 4.6 & 39.7 & 55.4 & 9.18 & 3.40 & -0.12 & 0.40 & 31.8 \\
\hline 7 & 0.650 & 5.0 & 47.2 & 0.4 & 4.6 & 42.2 & 52.8 & 9.09 & 3.39 & -0.05 & 0.41 & 33.6 \\
\hline 8 & 0.750 & 4.7 & 46.7 & 0.5 & 4.2 & 42.1 & 53.3 & 9.11 & 3.37 & -0.05 & 0.40 & 35.9 \\
\hline 9 & 0.850 & 4.5 & 47.2 & 0.1 & 4.4 & 42.7 & 52.8 & 9.29 & 3.18 & 0.02 & 0.47 & 41.4 \\
\hline 10 & 0.950 & 4.7 & 52.3 & 0.2 & 4.4 & 47.6 & 47.7 & 9.05 & 3.14 & 0.08 & 0.49 & 43.7 \\
\hline 11 & 1.050 & 5.0 & 51.1 & 0.2 & 4.7 & 46.2 & 48.9 & 9.12 & 3.19 & 0.08 & 0.48 & 44.6 \\
\hline 12 & 1.150 & 6.1 & 55.7 & 0.4 & 5.7 & 49.6 & 44.3 & 8.76 & 3.39 & 0.10 & 0.45 & 46.4 \\
\hline 13 & 1.250 & 9.8 & 58.0 & 2.7 & 7.1 & 48.2 & 42.0 & 8.43 & 3.62 & 0.06 & 0.56 & 46.9 \\
\hline 14 & 1.350 & 11.7 & 59.5 & 3.8 & 7.9 & 47.8 & 40.5 & 8.25 & 3.65 & 0.03 & 0.67 & 48.7 \\
\hline
\end{tabular}

\begin{tabular}{|c|c|c|c|c|c|c|c|c|c|c|c|c|}
\hline \multicolumn{1}{|c|}{ Without Gravel } \\
\hline Number & Depth & $\% \geq 6 \mathbf{\mu} \boldsymbol{\mu}$ & $\% \mathbf{2} \boldsymbol{\mu}$ & $\%$ Gravel & \% Sand & \% Silt & \% Clay & Mean & SD & Skew & Kurt & Textural Class \\
\hline 1 & 0.050 & 6.9 & 52.4 & 2.3 & 6.9 & 45.5 & 47.6 & 8.81 & 3.48 & 0.02 & 0.45 & silty clay \\
2 & 0.150 & 5.5 & 49.3 & 0.2 & 5.5 & 43.8 & 50.7 & 8.94 & 3.49 & -0.03 & 0.39 & silty clay \\
3 & 0.250 & 3.9 & 47.9 & 0.2 & 3.9 & 44.0 & 52.1 & 9.17 & 3.33 & -0.02 & 0.40 & silty clay \\
4 & 0.350 & 4.3 & 48.7 & 0.3 & 4.3 & 44.3 & 51.3 & 8.86 & 3.57 & -0.07 & 0.32 & silty clay \\
5 & 0.450 & 4.7 & 44.1 & 0.3 & 4.7 & 39.4 & 55.9 & 9.16 & 3.44 & -0.14 & 0.38 & clay \\
6 & 0.550 & 4.6 & 44.4 & 0.3 & 4.6 & 39.8 & 55.6 & 9.20 & 3.39 & -0.11 & 0.40 & clay \\
7 & 0.650 & 4.6 & 47.0 & 0.4 & 4.6 & 42.3 & 53.0 & 9.12 & 3.37 & -0.04 & 0.40 & silty clay \\
8 & 0.750 & 4.2 & 46.5 & 0.5 & 4.2 & 42.2 & 53.5 & 9.14 & 3.35 & -0.04 & 0.41 & silty clay \\
9 & 0.850 & 4.4 & 47.1 & 0.1 & 4.4 & 42.7 & 52.9 & 9.30 & 3.17 & 0.02 & 0.48 & silty clay \\
10 & 0.950 & 4.4 & 52.1 & 0.2 & 4.4 & 47.7 & 47.9 & 9.06 & 3.13 & 0.08 & 0.49 & silty clay \\
11 & 1.050 & 4.7 & 51.0 & 0.2 & 4.7 & 46.3 & 49.0 & 9.13 & 3.18 & 0.08 & 0.48 & silty clay \\
12 & 1.150 & 5.7 & 55.5 & 0.4 & 5.7 & 49.8 & 44.5 & 8.78 & 3.37 & 0.10 & 0.44 & silty clay \\
13 & 1.250 & 7.3 & 56.8 & 2.7 & 7.3 & 49.5 & 43.2 & 8.61 & 3.49 & 0.08 & 0.45 & silty clay \\
14 & 1.350 & 8.2 & 57.9 & 3.8 & 8.2 & 49.7 & 42.1 & 8.51 & 3.47 & 0.06 & 0.49 & silty clay \\
\hline
\end{tabular}


Table 6.2. $41 \mathrm{KR} 621$ Backhoe Trench 1 Profile C

\begin{tabular}{|c|c|c|c|c|c|c|c|c|c|c|c|c|}
\hline \multicolumn{12}{|c|}{ With Gravel } & \multirow{2}{*}{$\begin{array}{l}\text { Calcium Carbonate } \\
\text { Equivalent }<2 \mathrm{~mm}(\%)\end{array}$} \\
\hline Number & Depth & $\% \geq 63 \mu$ & $\% \geq 2 \mu$ & $\%$ Gravel & $\%$ Sand & $\%$ Silt & $\%$ Clay & Mean & SD & Skew & Kurt & \\
\hline 1 & 0.050 & 16.9 & 63.7 & 2.2 & 14.7 & 46.8 & 36.3 & 7.77 & 3.99 & 0.03 & 0.64 & 42.3 \\
\hline 2 & 0.150 & 16.8 & 60.8 & 2.0 & 14.8 & 44.0 & 39.2 & 7.85 & 4.02 & -0.03 & 0.63 & 46.9 \\
\hline 3 & 0.250 & 22.4 & 58.6 & 7.6 & 14.8 & 36.2 & 41.4 & 7.16 & 4.80 & -0.21 & 0.65 & 47.3 \\
\hline 4 & 0.350 & 13.0 & 55.1 & 2.8 & 10.3 & 42.1 & 44.9 & 8.24 & 3.92 & -0.06 & 0.59 & 28.2 \\
\hline 5 & 0.450 & 10.8 & 52.1 & 3.1 & 7.7 & 41.3 & 47.9 & 9.38 & 2.93 & 0.21 & -0.80 & 21.3 \\
\hline 6 & 0.550 & 11.7 & 52.4 & 2.0 & 9.7 & 40.7 & 47.6 & 8.47 & 3.84 & -0.06 & 0.67 & 29.5 \\
\hline 7 & 0.650 & 12.9 & 51.5 & 2.2 & 10.6 & 38.7 & 48.5 & 8.49 & 3.85 & -0.08 & 0.68 & 35.9 \\
\hline 8 & 0.750 & 24.9 & 59.4 & 16.1 & 8.8 & 34.5 & 40.6 & 5.47 & 6.55 & -0.36 & \#N/A! & 39.1 \\
\hline 9 & 0.850 & 20.0 & 58.8 & 10.5 & 9.5 & 38.8 & 41.2 & 7.00 & 5.00 & -0.21 & \#N/A! & 40.5 \\
\hline 10 & 0.950 & 15.3 & 55.2 & 5.6 & 9.7 & 39.9 & 44.8 & 8.22 & 4.00 & -0.04 & 0.87 & 40.9 \\
\hline 11 & 1.050 & 18.4 & 58.8 & 9.6 & 8.8 & 40.4 & 41.2 & 7.54 & 4.58 & -0.09 & 0.90 & 41.9 \\
\hline 12 & 1.150 & 35.0 & 66.6 & 28.2 & 6.8 & 31.6 & 33.4 & $\# \mathrm{~N} / \mathrm{A} !$ & \#N/A! & $\# \mathrm{~N} / \mathrm{A}$ ! & \#N/A! & 45.5 \\
\hline 13 & 1.250 & 7.6 & 52.5 & 0.6 & 7.0 & 45.0 & 47.5 & 8.92 & 3.41 & 0.07 & 0.54 & 49.6 \\
\hline 14 & 1.350 & 9.1 & 53.4 & 1.0 & 8.1 & 44.4 & 46.6 & 8.89 & 3.41 & 0.10 & 0.64 & 50.1 \\
\hline 15 & 1.450 & 17.4 & 59.3 & 8.0 & 9.4 & 41.9 & 40.7 & 7.86 & 4.23 & -0.02 & 0.23 & 48.2 \\
\hline 16 & 1.550 & 15.7 & 56.9 & 4.7 & 11.1 & 41.2 & 43.1 & 8.11 & 4.05 & -0.02 & 0.72 & 49.6 \\
\hline 17 & 1.650 & 12.5 & 57.6 & 1.3 & 11.2 & 45.1 & 42.4 & 8.74 & 3.42 & 0.22 & 0.74 & 48.7 \\
\hline 18 & 1.750 & 10.2 & 56.8 & 1.2 & 9.0 & 46.6 & 43.2 & 8.59 & 3.56 & 0.13 & 0.57 & 46.4 \\
\hline 19 & 1.850 & 9.1 & 51.5 & 1.0 & 9.1 & 42.4 & 48.5 & 8.97 & 3.35 & 0.05 & 0.59 & 46.9 \\
\hline 20 & 1.950 & 9.1 & 52.0 & 1.3 & 9.1 & 42.9 & 48.0 & 8.96 & 3.38 & 0.07 & 0.58 & 43.7 \\
\hline 21 & 2.050 & 9.4 & 52.2 & 0.5 & 9.4 & 42.7 & 47.8 & 8.94 & 3.40 & 0.07 & 0.58 & 44.1 \\
\hline 22 & 2.150 & 10.3 & 51.3 & 2.5 & 10.3 & 41.0 & 48.7 & 8.96 & 3.38 & 0.04 & 0.62 & 45.5 \\
\hline
\end{tabular}

\begin{tabular}{|c|c|c|c|c|c|c|c|c|c|c|c|c|}
\hline \multicolumn{13}{|c|}{ Without Gravel } \\
\hline Number & Depth & $\% \geq 63 \mu$ & $\% \geq 2 \mu$ & $\%$ Gravel & $\%$ Sand & $\%$ Silt & $\%$ Clay & Mean & SD & Skew & Kurt & Textural Class \\
\hline 1 & 0.050 & 15.0 & 62.9 & 2.2 & 15.0 & 47.9 & 37.1 & 8.05 & 3.76 & 0.08 & 0.65 & silty clay loam \\
\hline 2 & 0.150 & 15.1 & 60.1 & 2.0 & 15.1 & 44.9 & 40.0 & 8.02 & 3.89 & -0.01 & 0.62 & silty clay loam \\
\hline 3 & 0.250 & 16.0 & 55.2 & 7.6 & 16.0 & 39.2 & 44.8 & 8.06 & 4.06 & -0.12 & 0.50 & clay \\
\hline 4 & 0.350 & 10.5 & 53.8 & 2.8 & 10.5 & 43.3 & 46.2 & 8.48 & 3.73 & -0.03 & 0.53 & silty clay \\
\hline 5 & 0.450 & 8.0 & 50.6 & 3.1 & 8.0 & 42.6 & 49.4 & 8.85 & 3.51 & -0.02 & 0.57 & silty clay \\
\hline 6 & 0.550 & 9.9 & 51.4 & 2.0 & 9.9 & 41.5 & 48.6 & 8.61 & 3.73 & -0.05 & 0.62 & silty clay \\
\hline 7 & 0.650 & 10.9 & 50.4 & 2.2 & 10.9 & 39.6 & 49.6 & 8.70 & 3.67 & -0.06 & 0.65 & clay \\
\hline 8 & 0.750 & 10.5 & 51.6 & 16.1 & 10.5 & 41.1 & 48.4 & 8.64 & 3.69 & -0.04 & 0.63 & silty clay \\
\hline 9 & 0.850 & 10.7 & 54.0 & 10.5 & 10.7 & 43.3 & 46.0 & 8.59 & 3.62 & -0.00 & 0.66 & silty clay \\
\hline 10 & 0.950 & 10.3 & 52.6 & 5.6 & 10.3 & 42.3 & 47.4 & 8.67 & 3.65 & -0.00 & 0.63 & silty clay \\
\hline 11 & 1.050 & 9.7 & 54.4 & 9.6 & 9.7 & 44.7 & 45.6 & 8.61 & 3.69 & 0.06 & 0.58 & silty clay \\
\hline 12 & 1.150 & 9.4 & 53.4 & 28.2 & 9.4 & 44.0 & 46.6 & 8.82 & 3.46 & 0.07 & 0.65 & silty clay \\
\hline 13 & 1.250 & 7.0 & 52.2 & 0.6 & 7.0 & 45.2 & 47.8 & 8.96 & 3.38 & 0.07 & 0.51 & silty clay \\
\hline 14 & 1.350 & 8.2 & 53.0 & 1.0 & 8.2 & 44.8 & 47.0 & 8.96 & 3.35 & 0.11 & 0.59 & silty clay \\
\hline 15 & 1.450 & 10.2 & 55.7 & 8.0 & 10.2 & 45.5 & 44.3 & 8.64 & 3.60 & 0.10 & 0.56 & silty clay \\
\hline 16 & 1.550 & 11.6 & 54.8 & 4.7 & 11.6 & 43.2 & 45.2 & 8.49 & 3.76 & 0.03 & 0.56 & silty clay \\
\hline 17 & 1.650 & 11.4 & 57.1 & 1.3 & 11.4 & 45.7 & 42.9 & 8.80 & 3.38 & 0.23 & 0.69 & silty clay \\
\hline 18 & 1.750 & 9.1 & 56.3 & 1.2 & 9.1 & 47.2 & 43.7 & 8.70 & 3.47 & 0.14 & 0.54 & silty clay \\
\hline 19 & 1.850 & 10.0 & 52.0 & 1.0 & 9.0 & 42.0 & 48.0 & 8.92 & 3.39 & 0.04 & 0.63 & silty clay \\
\hline 20 & 1.950 & 10.3 & 52.6 & 1.3 & 9.0 & 42.3 & 47.4 & 8.87 & 3.45 & 0.06 & 0.62 & silty clay \\
\hline 21 & 2.050 & 9.9 & 52.4 & 0.5 & 9.4 & 42.5 & 47.6 & 8.92 & 3.42 & 0.07 & 0.60 & silty clay \\
\hline 22 & 2.150 & 12.5 & 52.5 & 2.5 & 10.0 & 39.9 & 47.5 & 8.78 & 3.52 & 0.02 & 0.70 & clay \\
\hline
\end{tabular}


Table 6.3. 41KR621 Backhoe Trench 20

\begin{tabular}{|c|c|c|c|c|c|c|c|c|c|c|c|c|}
\hline \multicolumn{12}{|c|}{ With Gravel } & \multirow{2}{*}{$\begin{array}{l}\text { Calcium Carbonate } \\
\text { Equivalent }<2 \mathrm{~mm}(\%)\end{array}$} \\
\hline Number & Depth & $\% \geq 63 \mu$ & $\% \geq 2 \mu$ & $\%$ Gravel & $\%$ Sand & $\%$ Silt & $\%$ Clay & Mean & SD & Skew & Kurt & \\
\hline 1 & 0.050 & 10.0 & 57.8 & 0.0 & 9.9 & 47.8 & 42.2 & 8.58 & 3.46 & 0.10 & 0.61 & 30.0 \\
\hline 2 & 0.150 & 13.2 & 55.8 & 0.3 & 13.0 & 42.6 & 44.2 & 8.24 & 3.88 & -0.05 & 0.54 & 33.6 \\
\hline 3 & 0.250 & 13.9 & 53.0 & 0.3 & 13.6 & 39.1 & 47.0 & 8.37 & 3.89 & -0.08 & 0.52 & 38.2 \\
\hline 4 & 0.350 & 14.0 & 53.6 & 0.2 & 13.8 & 39.6 & 46.4 & 8.29 & 3.91 & -0.09 & 0.50 & 42.8 \\
\hline 5 & 0.450 & 12.1 & 54.0 & 0.0 & 12.1 & 41.9 & 46.0 & 8.66 & 3.50 & 0.01 & -0.26 & 45.0 \\
\hline 6 & 0.550 & 13.2 & 56.7 & 0.1 & 13.1 & 43.5 & 43.3 & 8.20 & 3.82 & -0.06 & 0.49 & 46.9 \\
\hline 7 & 0.650 & 13.0 & 56.1 & 0.4 & 12.6 & 43.1 & 43.9 & 8.22 & 3.89 & -0.05 & 0.49 & 46.0 \\
\hline 8 & 0.750 & 14.2 & 56.7 & 0.5 & 13.7 & 42.6 & 43.3 & 8.32 & 3.76 & -0.01 & 0.61 & 47.8 \\
\hline 9 & 0.850 & 15.3 & 59.1 & 0.4 & 14.9 & 43.8 & 40.9 & 8.04 & 3.94 & -0.04 & 0.58 & 48.7 \\
\hline 10 & 0.950 & 17.2 & 60.5 & 0.9 & 16.4 & 43.3 & 39.5 & 7.86 & 4.09 & -0.01 & 0.54 & 50.5 \\
\hline 11 & 1.050 & 21.6 & 62.2 & 4.0 & 17.6 & 40.6 & 37.8 & 7.26 & 4.55 & -0.11 & 0.50 & 50.5 \\
\hline 12 & 1.150 & 28.4 & 66.7 & 10.7 & 17.6 & 38.3 & 33.3 & 6.16 & 5.35 & -0.20 & 0.59 & 52.3 \\
\hline 13 & 1.250 & 44.4 & 74.7 & 28.4 & 16.0 & 30.3 & 25.3 & 3.66 & 7.02 & -0.20 & 0.24 & 51.4 \\
\hline 14 & 1.350 & 82.1 & 91.4 & 64.0 & 18.2 & 9.2 & 8.6 & 0.82 & 5.03 & 0.63 & \#N/A! & 55.1 \\
\hline 15 & 1.450 & 83.7 & 92.2 & 55.8 & 27.9 & 8.5 & 7.8 & 0.17 & 3.93 & 0.43 & 0.78 & 56.9 \\
\hline 16 & 1.550 & 54.4 & 80.5 & 34.5 & 19.9 & 26.1 & 19.5 & 2.97 & 6.41 & 0.08 & 0.33 & 46.9 \\
\hline 17 & 1.650 & 88.3 & 94.4 & 77.9 & 10.4 & 6.1 & 5.6 & -2.20 & 2.64 & 0.39 & \#N/A! & 50.1 \\
\hline 18 & 1.750 & 90.0 & 94.6 & 67.9 & 22.0 & 4.6 & 5.4 & -1.41 & 2.43 & 0.36 & 1.93 & 59.2 \\
\hline 19 & 1.850 & 37.5 & 70.3 & 26.7 & 10.9 & 32.8 & 29.7 & 3.98 & 7.39 & -0.29 & 0.20 & 42.8 \\
\hline 20 & 1.950 & 76.8 & 88.7 & 67.7 & 9.1 & 11.9 & 11.3 & 1.24 & 6.18 & 0.72 & \#N/A! & 47.8 \\
\hline 21 & 2.050 & 76.9 & 89.3 & 69.1 & 7.8 & 12.4 & 10.7 & 1.38 & 5.92 & 0.76 & 0.41 & 44.6 \\
\hline 22 & 2.150 & 60.6 & 80.6 & 42.5 & 18.1 & 20.0 & 19.4 & 3.15 & 6.90 & 0.35 & 0.26 & 51.9 \\
\hline 23 & 2.250 & 65.0 & 83.9 & 48.3 & 16.7 & 19.0 & 16.1 & 2.24 & 6.75 & 0.40 & \#N/A! & 48.2 \\
\hline 24 & 2.350 & 86.5 & 92.8 & 73.3 & 13.2 & 6.3 & 7.2 & -1.32 & 2.99 & 0.50 & 1.54 & 47.8 \\
\hline
\end{tabular}

\begin{tabular}{|c|c|c|c|c|c|c|c|c|c|c|c|c|}
\hline \multicolumn{13}{|c|}{ Without Gravel } \\
\hline Number & Depth & $\% \geq 63 \mu$ & $\% \geq 2 \mu$ & $\%$ Gravel & $\%$ Sand & $\%$ Silt & $\%$ Clay & Mean & SD & Skew & Kurt & Textural Class \\
\hline 1 & 0.050 & 9.9 & 57.7 & 0.0 & 9.9 & 47.8 & 42.3 & 8.58 & 3.46 & 0.10 & 0.61 & silty clay \\
\hline 2 & 0.150 & 13.0 & 55.7 & 0.3 & 13.0 & 42.7 & 44.3 & 8.30 & 3.82 & -0.04 & 0.55 & silty clay \\
\hline 3 & 0.250 & 13.6 & 52.9 & 0.3 & 13.6 & 39.3 & 47.1 & 8.39 & 3.88 & -0.07 & 0.52 & clay \\
\hline 4 & 0.350 & 13.9 & 53.6 & 0.2 & 13.9 & 39.7 & 46.4 & 8.31 & 3.89 & -0.09 & 0.50 & clay \\
\hline 5 & 0.450 & 12.1 & 54.0 & 0.0 & 12.1 & 41.9 & 46.0 & 8.35 & 3.81 & -0.07 & 0.48 & silty clay \\
\hline 6 & 0.550 & 13.1 & 56.6 & 0.1 & 13.1 & 43.5 & 43.4 & 8.22 & 3.81 & -0.05 & 0.50 & silty clay \\
\hline 7 & 0.650 & 12.7 & 55.9 & 0.4 & 12.7 & 43.2 & 44.1 & 8.26 & 3.86 & -0.04 & 0.48 & silty clay \\
\hline 8 & 0.750 & 13.8 & 56.5 & 0.5 & 13.8 & 42.8 & 43.5 & 8.23 & 3.86 & -0.03 & 0.55 & silty clay \\
\hline 9 & 0.850 & 14.9 & 58.9 & 0.4 & 14.9 & 44.0 & 41.1 & 8.08 & 3.92 & -0.03 & 0.57 & silty clay \\
\hline 10 & 0.950 & 16.5 & 60.2 & 0.9 & 16.5 & 43.7 & 39.8 & 7.94 & 4.03 & -0.00 & 0.54 & silty clay \\
\hline 11 & 1.050 & 18.4 & 60.6 & 4.0 & 18.4 & 42.2 & 39.4 & 7.73 & 4.16 & -0.05 & 0.53 & silty clay \\
\hline 12 & 1.150 & 19.8 & 62.7 & 10.7 & 19.8 & 43.0 & 37.3 & 7.52 & 4.25 & -0.06 & 0.49 & silty clay \\
\hline 13 & 1.250 & 22.4 & 64.7 & 28.4 & 22.4 & 42.3 & 35.3 & 7.09 & 4.53 & -0.11 & 0.45 & silty clay \\
\hline 14 & 1.350 & 50.4 & 76.0 & 64.0 & 50.4 & 25.6 & 24.0 & 5.17 & 5.23 & 0.25 & 0.28 & sandy clay loam \\
\hline 15 & 1.450 & 63.1 & 82.4 & 55.8 & 63.1 & 19.3 & 17.6 & 4.53 & 4.69 & 0.76 & 0.39 & sandy loam \\
\hline 16 & 1.550 & 30.4 & 70.2 & 34.5 & 30.4 & 39.8 & 29.8 & 5.79 & 5.06 & -0.23 & 0.32 & clay loam \\
\hline 17 & 1.650 & 47.1 & 74.5 & 77.9 & 47.1 & 27.4 & 25.5 & 5.35 & 5.57 & 0.11 & 0.24 & sandy clay loam \\
\hline 18 & 1.750 & 68.7 & 83.1 & 67.9 & 68.7 & 14.3 & 16.9 & 4.64 & 4.91 & 0.74 & 0.36 & sandy loam \\
\hline 19 & 1.850 & 14.8 & 59.5 & 26.7 & 14.8 & 44.8 & 40.5 & 8.12 & 3.95 & 0.05 & 0.57 & silty clay \\
\hline 20 & 1.950 & 28.1 & 65.1 & 67.7 & 28.1 & 37.0 & 34.9 & 6.34 & 5.41 & -0.19 & 0.26 & clay loam \\
\hline 21 & 2.050 & 25.2 & 65.2 & 69.1 & 25.2 & 40.0 & 34.8 & 6.64 & 5.18 & -0.15 & 0.30 & clay loam \\
\hline 22 & 2.150 & 31.5 & 66.3 & 42.5 & 31.5 & 34.8 & 33.7 & 6.39 & 5.33 & -0.13 & 0.26 & clay loam \\
\hline 23 & 2.250 & 32.2 & 68.9 & 48.3 & 32.2 & 36.7 & 31.1 & 6.15 & 5.37 & -0.11 & 0.26 & clay loam \\
\hline 24 & 2.350 & 49.5 & 73.1 & 73.3 & 49.5 & 23.6 & 26.9 & 5.47 & 5.44 & 0.23 & 0.25 & sandy clay loam \\
\hline
\end{tabular}


Table 6.4. 41KR621 Backhoe Trench 19

\begin{tabular}{|c|c|c|c|c|c|c|c|c|c|c|c|c|}
\hline \multicolumn{13}{|c|}{ With Gravel } \\
\hline Number & Depth & $\% \geq 63 \mu$ & $\% \geq 2 \mu$ & $\%$ Gravel & $\%$ Sand & $\%$ Silt & $\%$ Clay & Mean & SD & Skew & Kurt & Equivalent $<2 \mathrm{~mm}(\%)$ \\
\hline 1 & 0.050 & 10.4 & 62.0 & 0.3 & 10.2 & 51.6 & 38.0 & 8.61 & 3.28 & 0.22 & 0.67 & 30.0 \\
\hline 2 & 0.150 & 9.6 & 57.5 & 0.2 & 9.4 & 47.9 & 42.5 & 8.83 & 3.32 & 0.20 & 0.63 & 29.1 \\
\hline 3 & 0.250 & 11.7 & 54.6 & 0.4 & 11.3 & 43.0 & 45.4 & 8.50 & 3.78 & 0.03 & 0.50 & 30.0 \\
\hline 4 & 0.350 & 14.2 & 54.9 & 1.0 & 13.2 & 40.7 & 45.2 & 8.31 & 4.00 & 0.01 & 0.49 & 34.6 \\
\hline 5 & 0.450 & 21.0 & 57.4 & 7.7 & 13.3 & 36.4 & 42.6 & 8.77 & 3.38 & 0.25 & 1.18 & 40.0 \\
\hline 6 & 0.550 & 21.9 & 59.3 & 6.9 & 15.1 & 37.4 & 40.7 & 7.36 & 4.72 & -0.12 & 0.77 & 44.6 \\
\hline 7 & 0.650 & 29.2 & 63.4 & 15.2 & 14.0 & 34.2 & 36.6 & 5.70 & 6.16 & -0.31 & 0.44 & 48.2 \\
\hline 8 & 0.750 & 17.6 & 59.4 & 3.3 & 14.3 & 41.8 & 40.6 & 7.85 & 4.17 & 0.13 & 0.60 & 46.0 \\
\hline 9 & 0.850 & 14.0 & 57.6 & 1.4 & 12.6 & 43.5 & 42.4 & 8.26 & 3.78 & -0.01 & 0.58 & 48.2 \\
\hline 10 & 0.950 & 13.3 & 57.1 & 1.0 & 12.3 & 43.7 & 43.0 & 8.24 & 3.94 & 0.00 & 0.47 & 44.1 \\
\hline 11 & 1.050 & 14.6 & 57.8 & 1.4 & 13.2 & 43.2 & 42.2 & 8.16 & 3.96 & -0.00 & 0.54 & 45.0 \\
\hline 12 & 1.150 & 16.9 & 59.6 & 2.3 & 14.6 & 42.8 & 40.4 & 7.94 & 4.09 & -0.02 & 0.56 & 44.6 \\
\hline 13 & 1.250 & 19.9 & 60.5 & 3.4 & 16.5 & 40.6 & 39.5 & 7.55 & 4.42 & -0.09 & 0.51 & 46.0 \\
\hline 14 & 1.350 & 35.8 & 70.0 & 15.8 & 20.0 & 34.2 & 30.0 & 5.26 & 6.06 & -0.23 & 0.43 & 47.3 \\
\hline 15 & 1.450 & 40.7 & 72.9 & 15.8 & 24.8 & 32.3 & 27.1 & 5.12 & 6.03 & -0.09 & 0.25 & 53.3 \\
\hline 16 & 1.550 & 48.5 & 76.8 & 20.5 & 28.0 & 28.3 & 23.2 & 4.14 & 6.49 & -0.03 & 0.37 & 56.4 \\
\hline 17 & 1.650 & 41.3 & 72.4 & 8.5 & 32.8 & 31.1 & 27.6 & 6.04 & 4.99 & 0.12 & 0.60 & 56.9 \\
\hline 18 & 1.750 & 40.5 & 72.6 & 11.2 & 29.2 & 32.1 & 27.4 & 6.04 & 4.97 & 0.05 & 0.65 & 57.4 \\
\hline 19 & 1.850 & 36.7 & 71.6 & 5.8 & 31.0 & 34.8 & 28.4 & 6.50 & 4.65 & 0.05 & 0.59 & 63.7 \\
\hline 20 & 1.950 & 35.2 & 72.3 & 3.4 & 31.8 & 37.2 & 27.7 & 6.62 & 4.33 & 0.09 & 0.42 & 58.7 \\
\hline 21 & 2.050 & 36.8 & 72.7 & 6.1 & 30.7 & 35.9 & 27.3 & 6.57 & 4.46 & 0.13 & 0.93 & 58.7 \\
\hline 22 & 2.150 & 32.4 & 73.2 & 1.1 & 31.3 & 40.8 & 26.8 & 6.72 & 4.13 & 0.09 & 0.40 & 57.4 \\
\hline
\end{tabular}

\begin{tabular}{|c|c|c|c|c|c|c|c|c|c|c|c|c|}
\hline \\
\hline \multicolumn{13}{|c|}{\begin{tabular}{|l|c|l|l|l|l|l|l|l|} 
Without Gravel \\
Number & Depth & $\% \geq 63 \mu$ & $\% \geq 2 \mu$ & $\%$ Gravel & $\%$ Sand & $\%$ Silt & $\%$ Clay & Mean \\
\end{tabular}} \\
\hline 1 & 0.050 & 10.2 & 61.9 & 0.3 & 10.2 & 51.7 & 38.1 & 8.64 & 3.25 & 0.23 & 0.67 & silty clay loam \\
\hline 2 & 0.150 & 9.4 & 57.5 & 0.2 & 9.4 & 48.1 & 42.5 & 8.84 & 3.32 & 0.20 & 0.62 & silty clay \\
\hline 3 & 0.250 & 11.3 & 54.4 & 0.4 & 11.3 & 43.1 & 45.6 & 8.54 & 3.75 & 0.04 & 0.49 & silty clay \\
\hline 4 & 0.350 & 13.3 & 54.4 & 1.0 & 13.3 & 41.1 & 45.6 & 8.37 & 3.96 & 0.02 & 0.47 & silty clay \\
\hline 5 & 0.450 & 14.4 & 53.9 & 7.7 & 14.4 & 39.5 & 46.1 & 8.28 & 4.02 & -0.05 & 0.47 & clay \\
\hline 6 & 0.550 & 16.2 & 56.3 & 6.9 & 16.2 & 40.2 & 43.7 & 8.09 & 4.12 & -0.03 & 0.48 & silty clay \\
\hline 7 & 0.650 & 16.5 & 56.8 & 15.2 & 16.5 & 40.3 & 43.2 & 8.04 & 4.14 & -0.05 & 0.50 & silty clay \\
\hline 8 & 0.750 & 14.8 & 58.0 & 3.3 & 14.8 & 43.2 & 42.0 & 8.14 & 3.95 & 0.12 & 0.52 & silty clay \\
\hline 9 & 0.850 & 12.8 & 56.9 & 1.4 & 12.8 & 44.2 & 43.1 & 8.42 & 3.65 & 0.02 & 0.56 & silty clay \\
\hline 10 & 0.950 & 12.4 & 56.6 & 1.0 & 12.4 & 44.2 & 43.4 & 8.36 & 3.84 & 0.02 & 0.46 & silty clay \\
\hline 11 & 1.050 & 13.4 & 57.2 & 1.4 & 13.4 & 43.8 & 42.8 & 8.24 & 3.91 & 0.00 & 0.49 & silty clay \\
\hline 12 & 1.150 & 14.9 & 58.7 & 2.3 & 14.9 & 43.8 & 41.3 & 8.12 & 3.96 & 0.01 & 0.51 & silty clay \\
\hline 13 & 1.250 & 17.1 & 59.1 & 3.4 & 17.1 & 42.1 & 40.9 & 7.92 & 4.12 & -0.04 & 0.50 & silty clay \\
\hline 14 & 1.350 & 23.8 & 64.4 & 15.8 & 23.8 & 40.7 & 35.6 & 7.19 & 4.56 & -0.07 & 0.38 & silty clay \\
\hline 15 & 1.450 & 29.5 & 67.8 & 15.8 & 29.5 & 38.3 & 32.2 & 6.78 & 4.83 & -0.06 & 0.35 & clay loam \\
\hline 16 & 1.550 & 35.2 & 70.8 & 20.5 & 35.2 & 35.6 & 29.2 & 6.46 & 4.86 & 0.03 & 0.33 & clay loam \\
\hline 17 & 1.650 & 35.8 & 69.8 & 8.5 & 35.8 & 34.0 & 30.2 & 6.55 & 4.73 & 0.07 & 0.33 & clay loam \\
\hline 18 & 1.750 & 32.9 & 69.1 & 11.2 & 32.9 & 36.2 & 30.9 & 6.76 & 4.58 & 0.02 & 0.33 & clay loam \\
\hline 19 & 1.850 & 32.9 & 69.9 & 5.8 & 32.9 & 37.0 & 30.1 & 6.83 & 4.48 & 0.05 & 0.34 & clay loam \\
\hline 20 & 1.950 & 32.9 & 71.4 & 3.4 & 32.9 & 38.5 & 28.7 & 6.80 & 4.26 & 0.09 & 0.37 & clay loam \\
\hline 21 & 2.050 & 32.7 & 70.9 & 6.1 & 32.7 & 38.2 & 29.1 & 6.89 & 4.32 & 0.12 & 0.34 & clay loam \\
\hline 22 & 2.150 & 31.7 & 72.9 & 1.1 & 31.7 & 41.2 & 27.1 & 6.78 & 4.11 & 0.09 & 0.39 & loam \\
\hline
\end{tabular}


Table 6.5. Stable Isotope Values for Carbonate Nodules

\begin{tabular}{|c|c|c|c|c|c|c|}
\hline Trench & Sample & Depth & d13C VPDB & d180 VPDB & C Std Dev & O Std Dev \\
\hline BHT-21 & & & & & & \\
& 15 & 1.45 & -5.66 & -2.78 & 0.031 & 0.089 \\
& 16 & 1.55 & -7.56 & -3.21 & 0.049 & 0.039 \\
& 17 & 1.65 & -8.09 & -3.84 & 0.028 & 0.027 \\
& 18 & 1.75 & -6.13 & -3.56 & 0.019 & 0.052 \\
& 21 & 2.05 & -4.94 & -3.77 & 0.027 & 0.054 \\
& 22 & 2.15 & -5.71 & -3.75 & 0.019 & 0.069 \\
\hline BHT-19 & 13 & 1.25 & -3.34 & -3.15 & 0.034 & 0.042 \\
& 14 & 1.35 & -3.48 & -3.47 & 0.017 & 0.090 \\
& 15 & 1.45 & -3.01 & -3.11 & 0.028 & 0.039 \\
& 19 & 1.85 & -4.12 & -3.97 & 0.034 & 0.060 \\
& 20 & 1.95 & -3.11 & -3.81 & 0.015 & 0.032 \\
& 21 & 2.05 & -4.31 & -3.87 & 0.030 & 0.054 \\
\hline
\end{tabular}

Table 6.6. Clay Minerals

\begin{tabular}{|c|c|c|c|c|c|c|c|c|c|}
\hline 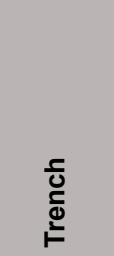 & $\frac{\frac{0}{0}}{\frac{\frac{0}{\sigma}}{\pi}}$ & 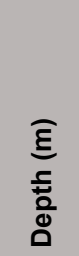 & 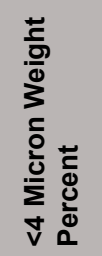 & 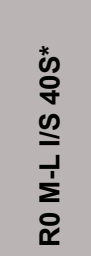 & 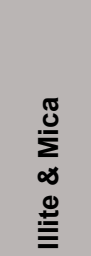 & 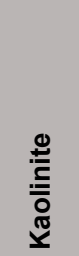 & $\begin{array}{l}\frac{N}{\mathbb{N}} \\
\frac{\mathfrak{J}}{0}\end{array}$ & $\frac{\stackrel{ \pm}{0}}{\frac{0}{\pi}}$ & 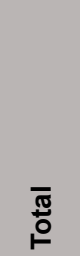 \\
\hline \multirow[t]{4}{*}{ BHT-1 } & 2 & 0.15 & $30.2 \%$ & $11 \%$ & $26 \%$ & $5.3 \%$ & $6.5 \%$ & $51 \%$ & $100 \%$ \\
\hline & 6 & 0.55 & $45.7 \%$ & $19 \%$ & $39 \%$ & $6.7 \%$ & $6.9 \%$ & $28 \%$ & $100 \%$ \\
\hline & 14 & 1.35 & $29.9 \%$ & $17 \%$ & $25 \%$ & $5.6 \%$ & $7.3 \%$ & $45 \%$ & $100 \%$ \\
\hline & 22 & 2.15 & $42.7 \%$ & $23 \%$ & $19 \%$ & $9.2 \%$ & $7.5 \%$ & $41 \%$ & $100 \%$ \\
\hline \multirow[t]{5}{*}{ BHT-19 } & 3 & 0.25 & $28.1 \%$ & $19 \%$ & $26 \%$ & $8.7 \%$ & $9.0 \%$ & $37 \%$ & $100 \%$ \\
\hline & 8 & 0.75 & $40.8 \%$ & $18 \%$ & $9.3 \%$ & $5.7 \%$ & $6.5 \%$ & $61 \%$ & $100 \%$ \\
\hline & 13 & 1.25 & $25.6 \%$ & $27 \%$ & $21 \%$ & $8.1 \%$ & $8.1 \%$ & $36 \%$ & $100 \%$ \\
\hline & 17 & 1.65 & $32.8 \%$ & $23 \%$ & $6.8 \%$ & $7.4 \%$ & $12 \%$ & $51 \%$ & $100 \%$ \\
\hline & 19 & 1.85 & $23.0 \%$ & $28 \%$ & $23 \%$ & $9.7 \%$ & $7.3 \%$ & $32 \%$ & $100 \%$ \\
\hline \multirow[t]{6}{*}{ BHT-20 } & 8 & 0.75 & $41.7 \%$ & $15 \%$ & $22 \%$ & $6.7 \%$ & $5.0 \%$ & $52 \%$ & $100 \%$ \\
\hline & 11 & 1.05 & $24.4 \%$ & $11 \%$ & $21 \%$ & $5.8 \%$ & $11 \%$ & $52 \%$ & $100 \%$ \\
\hline & 13 & 1.25 & $37.1 \%$ & $18 \%$ & $19 \%$ & $6.4 \%$ & $6.9 \%$ & $50 \%$ & $100 \%$ \\
\hline & 16 & 1.55 & $24.9 \%$ & $13 \%$ & $18 \%$ & $6.4 \%$ & $14 \%$ & $49 \%$ & $100 \%$ \\
\hline & 19 & 1.85 & $31.9 \%$ & $23 \%$ & $33 \%$ & $9.6 \%$ & $9.2 \%$ & $26 \%$ & $100 \%$ \\
\hline & 22 & 2.15 & $37.7 \%$ & $20 \%$ & $24 \%$ & $8.7 \%$ & $10 \%$ & $37 \%$ & $100 \%$ \\
\hline
\end{tabular}




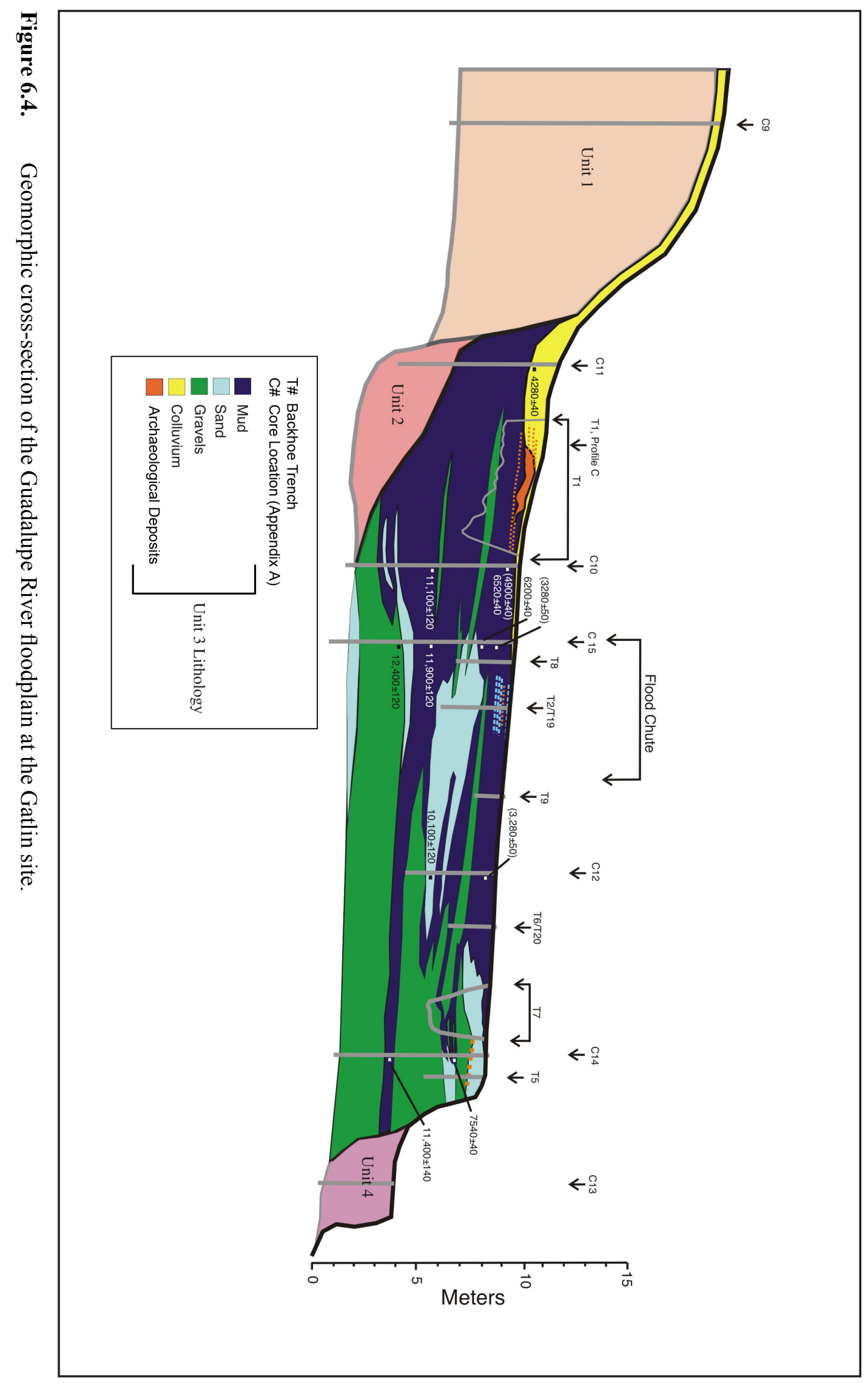


Changes in Floodplain SEDIMENTATION Throughout the Period of Site OCCUPATION

Examination of the properties of the alluvial sediments at the site provides information on the nature of alluvial conditions during the period of Unit 3 deposition, and occupation of the site. Figure 6.3 depicts the results of analysis of four vertical profiles that were selected for characterization and the following section describes the results for each section in detail.

\section{Near Channel Environment: BHT 20}

The deposits in this trench can be separated into two distinct facies: (1) channel/near channel overbank gravelly facies and (2) a floodplain facies. To the north of BHT 20, a very low-density prehistoric occupation surface was identified between the two facies in BHT 5 during testing. Below $1.2 \mathrm{~m}$, the deposits in BHT 20 consist of alternating beds of gravel and mud. The deposits appear to represent discrete overbank flood deposits from floods that were large enough to lift gravel from the channel onto the floodplain margin. At the time these sediments were deposited the Guadalupe channel was close to where it is now, slightly to the north of this exposure. It is difficult to determine what the difference in elevation between the channel and the floodplain might have been at the time these gravelly sediments were deposited, but it is unlikely to have been as deeply entrenched as today.

The upper $1.2 \mathrm{~m}$ of this profile represents a floodbasin facies, and it is interesting to note how little sand and gravel is present in these deposits, despite the apparent proximity of this location to the channel. The granulometric properties of the floodbasin facies in this profile are nearly identical to the distal floodplain facies (Profile D), and differ only in the fact that they continue to fine upward to the top of the profile whereas the distal floodplain profiles (Profile D and BHT 1 Profile C) were both affected by colluvial sedimentation after Unit 3 deposition slowed, and they therefore tend to coarsen near the top of the profile.

The soil formed in this exposure exhibited an A-AB$\mathrm{Bw}-\mathrm{Bk} 1-\mathrm{Bk} 2-\mathrm{Bk} 3-\mathrm{C}$ horizon sequence, and the $\mathrm{Bk}$ horizon was manifested as small septaric carbonate nodules and filaments in fine-grained sediments (Zones 4 and 5), and pendant cements on gravel clasts in the open framework gravelly deposits. Calcium carbonate content increased downwards, with the A horizon containing 20 percent less than the $\mathrm{C}$ horizons at depth, and there was no discernible increase in carbonate within the Bk horizons, but it was clearly apparent in the field and in thin section.

\section{BHT 19}

This profile is approximately half way between the modern cutbank and the southern valley wall, and represents a medial floodplain setting. This profile was selected for characterization because of the anomalous amount of matrix-supported gravel present. The field description and the granulometric results show two prominent coarse textured zones, one between 1.3 and $1.8 \mathrm{~m}$, and another between 0.7 and $0.4 \mathrm{~m}$. Few event-specific flood deposits were present in these zones in BHT 19, but BHT 2 (located very close to BHT 19) did exhibit three discontinuous gravel stringers in the upper of these two zones, as well as a $30-\mathrm{cm}$-diameter boulder. Between the gravel-rich zones, the mean particle size appears to show a gradual fining upward and the swelling (or mixed-layer) clays decrease in frequency from bottom to top.

The gravels in this trench are interpreted as alluvial in origin (see Appendix A for a more detailed discussion), and this portion of the floodplain appears to be a flood chute that was active only during exceptionally large-magnitude floods. The concentration of gravels in the medial floodplain setting is consistent with modern observations on the effects of large magnitude overbank floods on hill country streams (e.g., Baker 1977; Sullivan 1983). In such floods, the thread of maximum current velocity moves toward the inside of meanders, onto the middle floodplain environment, thereby straightening its course and avoiding the increased channel roughness (owing to the presence of a fringing Cypress woodland) and winding paths of the low water channels. These straighter flow paths are often associated with gravel deposition on the floodplain, and the mechanics of this are discussed in Appendix A. The deposits in BHT 19 appear to record at least two periods of large magnitude overbank flooding in a period that is estimated to be between roughly 6,000 and 4,000 в.P. 
(although the precise age of these deposits was not determined by radiocarbon dating).

The soil formed in this exposure exhibited an A-AB$\mathrm{Bw}-\mathrm{Bk} 1-\mathrm{Bk} 2-\mathrm{C}$ horizon sequence, and the stage II Bk horizon exhibited common calcium carbonate filaments and up to 3 percent septaric calcium carbonate nodules which were as large as $8 \mathrm{~mm}$ in diameter. Like BHT 20, the A horizon had been leached of calcium carbonate and contained about 20 percent less than the $\mathrm{C}$ horizon at depth. The stable carbon isotopic composition for carbonate nodules collected from six samples between $120 \mathrm{cmbs}$ and $210 \mathrm{cmbs}$ below yielded values between -3.01 and $-4.31 \%$ PDB which, in combination with the petrographic appearance of these nodules, supports a pedogenic origin for these features (e.g., West et al. 1988). No significant isotopic trend with depth below surface was observed.

\section{Profile D}

This profile was in a distal floodplain setting adjacent to Test Unit 4D (along the west wall of BHT 4, immediately west of excavation Area A NW) due east of BHT 1 Profile C. It appeared to have been less affected by recent colluvial sedmentation than BHT 1, Profile C (below). The granulometric results from this profile show a gradual fining upward trend, which reverses slightly just below the top of the profile where colluvial sediment with small gravel content is present. The fine-grained nature of these deposits is representative of the deposits throughout most of the block excavations, with the exception of Area B, which was more like the BHT 1 Profile $\mathrm{C}$ column. In general, though, examination of the profile and the laboratory results suggests that there was variation in the mode of deposition in this setting during the period the site was occupied.

The soil formed in this exposure exhibited an A$\mathrm{AC}-2 \mathrm{Ab}-2 \mathrm{AB}-2 \mathrm{Bw}-2 \mathrm{Bk}$ horizon sequence. The interface between the floodplain alluvium and the colluvium is subltly represented by the lithology, but easily observed on Figure 6.3 on the carbonate content curve, which shows a dramatic decrease at the interface of the two deposits, which is attributable in part to carbonate depletion within the A horizon formed in the alluvial muds.

\section{BHT 1, Profile C}

This profile was situated immediately upslope and south of the burned rock midden, and part of the burned rock midden debris is present within the column samples between 0.6 and $1.2 \mathrm{~m}$ deep. The top $30 \mathrm{~cm}$ of this profile is recent colluvium (also called the upper colluvium), the deposition of which fossilized the A-horizon that envelops and buries the burned rock midden. The gravel in the upper colluvium largely consists of reworked calcium carbonate nodules from Abbott's Unit 1, which is exposed upslope of the site. As with Profile D, the boundary between the upper colluvium and the buried A horizon is clearly depicted by the carbonate content.

The fine-grained matrix of the buried A horizon (Zones 3 and 4) is derived from a mixture of alluvial overbank and colluvial sediment, and the gravel content illustrated for Zones 3-5 is largely cultural material and Zone 4 is the tail end of the burned rock midden. A small amount of gravel is present throughout the deposits beneath the midden and this appears to be colluvial in origin (as was surmised by Abbott from his examination of Core 11; see Appendix A for more discussion of this issue).

The soil profile exposed in this part of BHT 1 exhibited an A-AC-2Ab1-2Ab2-2Bk1-2Bk2-2Bk3 horizon sequence. The Bk horizons exhibit filamentous as well as nodular forms, both of which appear to be pedogenic in origin. Six presumably pedogenic calcium carbonate nodules were collected in a vertical sequence from the lower half of this profile and their stable carbon isotopic composition assayed. The resulting values ranged from -8.09 to $-4.04 \%$ PDB which, considered in light of their petrographic appearance, supports the inference that these nodules are pedogenic. A slight increase in total carbonate is present near the top of Zone 6, in the vicinity of the Early Archaic occupation surface, and this may be attributable to the accumulation of pedogenic carbonate, but as Nordt et al. (1998) has demonstrated, assessment of pedogenic carbonate content on the basis of field inspection, carbonate assay, and thin section analysis all fail to detect the actual amount of pedogenic carbonate that may be present for soils developed in calcareous alluvium. 


\section{SUMmary of THE Floodplain HISTORY}

The deposits beneath the first terrace of the Guadalupe River at the Gatlin site-which are contemporary with prehistoric occupation of the site-record a history of river activity in the Late Pleistocene to Middle Holocene. This history is mostly one of overbank floods, which deposited massive muddy sediment in all settings except the middle of the floodplain, where a high-water channel or chute appears to have been located. Channel deposits that appear to precede the occupation of the Gatlin site are present immediately adjacent to the modern channel, and it is likely that the channel (when the site was occupied) was located somewhere in this vicinity. At the rear of the floodplain, where the most of the prehistoric occupations were centered, a small amount of slope derived sediment accumulated and was interbedded with floodplain muds during the period of occupation. A considerably greater amount of colluvial sediment was added recently, possibly in the Historic period. But in general terms, the low-energy depositional environment at the rear of the floodplain was conducive to the preservation of prehistoric archaeological sites, as Abbott (Appendix A) concluded. Large floods periodically occurred that led to high-energy flow conditions on the floodplain to the north of the burned rock midden and the core of the site. It is likely that prehistoric occupation surfaces in this area were adversely affected (or moved) by the floodwaters.

\section{Floodplain Sedimentation Rates and Processes}

Although it is clear that the Guadalupe River has experienced repeated large magnitude floods during the formation of the Late Pleistocene to Middle Holocene fill (Unit 3), these floods are not necessarily attributable to accelerated soil erosion. While it seems likely that the color of the Unit 3 deposits reflects source materials eroding in the uplands, a more specific linkage with upland erosion is not immediately apparent. Periods of exceptional soil erosion that may be preserved in alluvial archives are evidence of rapid alluvial sedimentation. For instance, Knox (2006) notes that the vertical accretion sedimentation rate may reflect periods of unusually rapid soil erosion. Although seemingly true, these data must be interpreted cautiously as sedimentation rates can be affected by processes other than simply the rate of soil erosion. The following section evaluates the sedimentation rates observed at the Gatlin site in the context of the processes associated with the creation of vertically accreted floodplains. In particular, a discussion of factors that influence sedimentation rates in these settings precedes an examination the apparent sedimentation rates at the Gatlin site, which is then compared to sedimentation rates from other alluvial archaeological sites in central Texas.

\section{BACKGROUND: FORMATION OF VERTICALLY ACCRETED FLOODPLAINS}

Early research into the formation of river floodplains, primarily based on observations of meandering streams, suggested that lateral movement by the channel was the primary process by which floodplains were created and that the deposition of sediment from suspension by overbank flooding was a minor process (e.g., Wolman and Leopold 1957). But short-term observations of historic floodplain formation (e.g., Schumm 1977; Schumm and Lichty 1963) as well as longer-term evidence derived from archaeological excavations (e.g., Ritter and Kinsey 1973) have shown that vertical accretion can be a major process of floodplain formation. In reality, floodplain sediment accumulation is a balance between vertical accretion of the floodplain by sedimentation and floodplain destruction by lateral migration by the channel (Pickup 1991:469). As Abbott (Appen$\operatorname{dix}$ A) noted, the Unit 3 Guadalupe floodplain has formed through both lateral and vertical accretion, with lateral accretion prevailing in the early phases of sedimentation during the Late Pleistocene, and vertical accretion being the dominant process from roughly 12,000 to 5,000 в.P.

The major process which controls the development of vertical accretion floodplains is the ability of the stream to flood the surface. This is primarily a function of the height of the floodplain surface above the channel and the flood frequency. Flood frequency and flood magnitude are inversely related, with small floods occurring frequently and large magnitude floods being less common as the magnitude increases. Hence, floodplains formed by vertical accretion grow rapidly in height at first, and then, once they reach the height of the most common floods, their vertical growth slows as the 
frequency of inundation declines (e.g., Ritter 1975, 1986:265-267). This process is reflected in the sedimentation rates within an alluvial fill with rapid accretion in the early stages of floodplain formation, and a gradual decrease in sedimentation rate as the floodplain grows in height.

Although this general process is the main factor that controls floodplain sedimentation rates, variations in sedimentation rates within vertically accreted floodplains can also be caused by local topographic features, large-scale events such as channel migration, avulsion or incision, as well as the accuracy of dating methods employed. The method influences the calculation of sedimentation rates, but not the sedimentation rate, per se.

\section{Sources of Small-Scale V ARIation}

Two prominent influences of local sedimentation rate variation are the distance from the channel and topography. Both flood sediment grain size and accumulation rate are strongly dependant upon landscape position with near channel areas receiving more and coarse sediment (Asselman and Middelkoop 1993; Pizzuto 1987; Törnqvist and Bridge 2002). Sediment size and deposit thickness both decrease away from the channel, and this is true for event-specific deposits (e.g., Hudson 2005, 2006) as well as long term accumulations (e.g., Törnqvist and Bridge 2002). There is also evidence that areas immediately adjacent to the channel may experience net erosion during flooding (e.g. Gomez et al. 1997), especially in areas where flow onto the floodplain is concentrated as in areas where levees fail (either naturally as in crevasse splays or in the case of artificial levees).

In general terms, low lying areas, regardless of scale will receive accelerated sedimentation during any given flood owing to a greater water depth during the flood. Water depth is one of the principal controls on floodplain sedimentation as the amount of sediment deposited is proportional to the total mass of sediment in the overlying water column, which is directly related to the water depth (Walling and He 1997:218). In deep depressions individual flood deposits may be observed (typically fining upward flood couplets or slack water deposits) which are deposited from suspension by sediment laden water where flow velocities are slow during inundation (e.g., Jarrett and England 2002; Kochel and Baker 1982). Hence, microtopographic features such as depressions may exhibit accelerated sedimentation rates, whereas, topographically elevated (but still inundated) areas will experience less and slower sediment deposition. Larger scale depressions like abandoned channels (a common form of depression on alluvial floodplains) may also experience accelerated deposition (e.g., Ferring 1994; Fering and Yates 1997; Nordt 2003:84) or erosion owing to higher current velocities (Walling and He 1997:218).

Dramatic changes in the sedimentation rate can also be caused by factors other than flood frequency and topography, such as channel migration or channel entrenchment, both of which alter the probability of local flooding by changing the geometry of the floodplain itself. In the case of mixed bedrock-alluvial rivers like the Guadalupe at Kerrville (Keen-Zebert 2005; Keen-Zebert and Curran 2006) dramatic decreases in floodplain sedimentation are most likely to be caused by channel entrenchment, given that the extent of lateral migration of the channel is strongly limited by the finite dimensions of the bedrock valley. Another factor that can affect the sedimentation rate is the precision of the geochronological methods used to determine the age of the alluvial deposits. It is well known that bulk sediment dates are prone to age errors from as few as a hundred years to several thousand years (see discussion by Abbott in Appendix A) and for this reason, where possible, radiocarbon assays on charcoal from cultural features were used in the calculations (although this was not always possible).

\section{SEdimentation Rate at the Gatlin Site}

The sedimentation rate observed within Unit 3 at the Gatlin site is similar to other alluvial terrace deposits in central Texas being fairly rapid during the early phases and gradually becoming slower through time as the floodplain became progressively higher (Table 6.7 and Figure 6.5). During the Late Pleistocene the deposit was aggrading at a rate of approximately 0.95 $\mathrm{mm} /$ year (or 10.6 years $/ \mathrm{cm}$ ), and then slowed from about $0.61 \mathrm{~mm} /$ year $(16.3$ years $/ \mathrm{cm})$ around $2.8 \mathrm{~m}$, to $0.42 \mathrm{~mm} /$ year $(19.03$ years $/ \mathrm{cm})$ around $1.4 \mathrm{~m}$ deep. The apparent rate of sedimentation within the area of the block excavations was slow with values of 0.21 $\mathrm{mm} /$ year (46.91 years/cm) away from the burned 
Table 6.7. Documented Sedimentation Rates at Select Sites

\begin{tabular}{|l|l|c|c|c|}
\hline \multirow{2}{*}{ Archaeological Site } & \multicolumn{1}{|c|}{ Context } & \multicolumn{3}{|c|}{ Sedimentation Rate } \\
\cline { 3 - 5 } Culebra Creek Site & Unit Illa, & 0.28 & 36 & 230 \\
& B1BX126 & 0.25 & 39.43 & 145 \\
& Nolow Midden & 0.34 & 29.67 & 60 \\
& Midden & 0.11 & 93.5 & 35 \\
& Midden & 0.11 & 87.2 & 12.5 \\
\hline Richard Beene Site & Unit & & & \\
41BX831 & A4 & 3.61 & 2.77 & 986.5 \\
& A5 & 1.18 & 8.51 & 494 \\
& A6 & 1.04 & 9.58 & 197 \\
& A7 & 0.1 & 99.5 & 50 \\
\hline Woodrow Heard Site & Unit II & 0.3 & 32.9 & 50 \\
41UV88 & & 0.47 & 21.23 & 132.5 \\
& & 0.29 & 34 & 180 \\
& & 1.79 & 5.57 & 230 \\
& & 2 & 5 & 300 \\
\hline 41KR621 & Away from midden & 0.21 & 46.91 & 54 \\
& core of terrace & 0.52 & 19.03 & 138 \\
& core of terrace & 0.61 & 16.3 & 275 \\
& core of terrace & 0.95 & 10.57 & 465 \\
& behind midden & 0.19 & 42.97 & 55 \\
\hline
\end{tabular}

rock midden, and $0.19 \mathrm{~mm} /$ year (42.97 years $/ \mathrm{cm}$ ) behind the midden.

\section{The Gatlin Site Compared With Other Central TeXas AlluVial Sites}

As expected, the sedimentation rates calculated for central Texas streams from data generated by archaeological studies, demonstrate that all alluvial deposits show declining sedimentation rates with increasing elevation (see Table 6.7). Below depths of about $2.5 \mathrm{~m}$, sedimentation rates are generally high-between 0.6 and $4 \mathrm{~mm}$ per year. Within the top $50 \mathrm{~cm}$, very slow rates are observed, with many sites requiring more than 40 years to accumulate a single centimeter of sediment, and some as long as 130 years $(<0.3 \mathrm{~mm} /$ year $)$. These rates are directly comparable with vertical accretion sedimentation rates observed by Knox (2006) for the Upper Mississippi Valley prior to European settlement, where he documented floodplain sedimentation rates between 0.4 to $2 \mathrm{~mm} /$ year for the first 2,000 years of floodplain formation, and then a gradual decrease to $0.2 \mathrm{~mm} /$ year after that. Knox observed sedimentation rates between 2 and $20 \mathrm{~mm} /$ year for the period of Euro-American agriculture which he attributes to accelerated soil erosion.

Interestingly, the only Texas river deposits examined here that approach this sedimentation rate are the Early Holocene sediments at the Richard Beene site (41BX831, Unit A4; Mandel et al. [in press]) which were accumulating at a rate of about $3.6 \mathrm{~mm} /$ year in the period between 7,000 and 8,000 years ago. This deposit is deep within the core of the Applewhite Terrace, in a position where a rapid sedimentation rate is to be expected. The alluvial sedimentation rate at the Gatlin site was not rapid at this time, but was within a normal range.

Given that the sedimentation rate within any given alluvial fill appears to be strongly conditioned by floodplain mechanics, one wonders whether or not the floodplain vertical accretion sedimentation rate would necessarily reflect a dramatic change in sediment yield. Where such changes have been observed in the Historical period (e.g., Knox 2006; Lecce 1997), the increase in sediment yield associated with increased soil erosion was also accompanied by an increase in discharge which promoted the development of new meanderbelts that could accommodate the new flow regime. Hence, it would seem likely that a period of exceptionally high soil erosion would lead to a fairly obvious adjustment of the channel and floodplain which would be reflected in the alluvial stratigraphy. However, in this particular case, the channel of the Guadalupe River for the period in question was destroyed by subsequent channel incision during the development of the modern channel, so direct examination of the channel is not possible. 


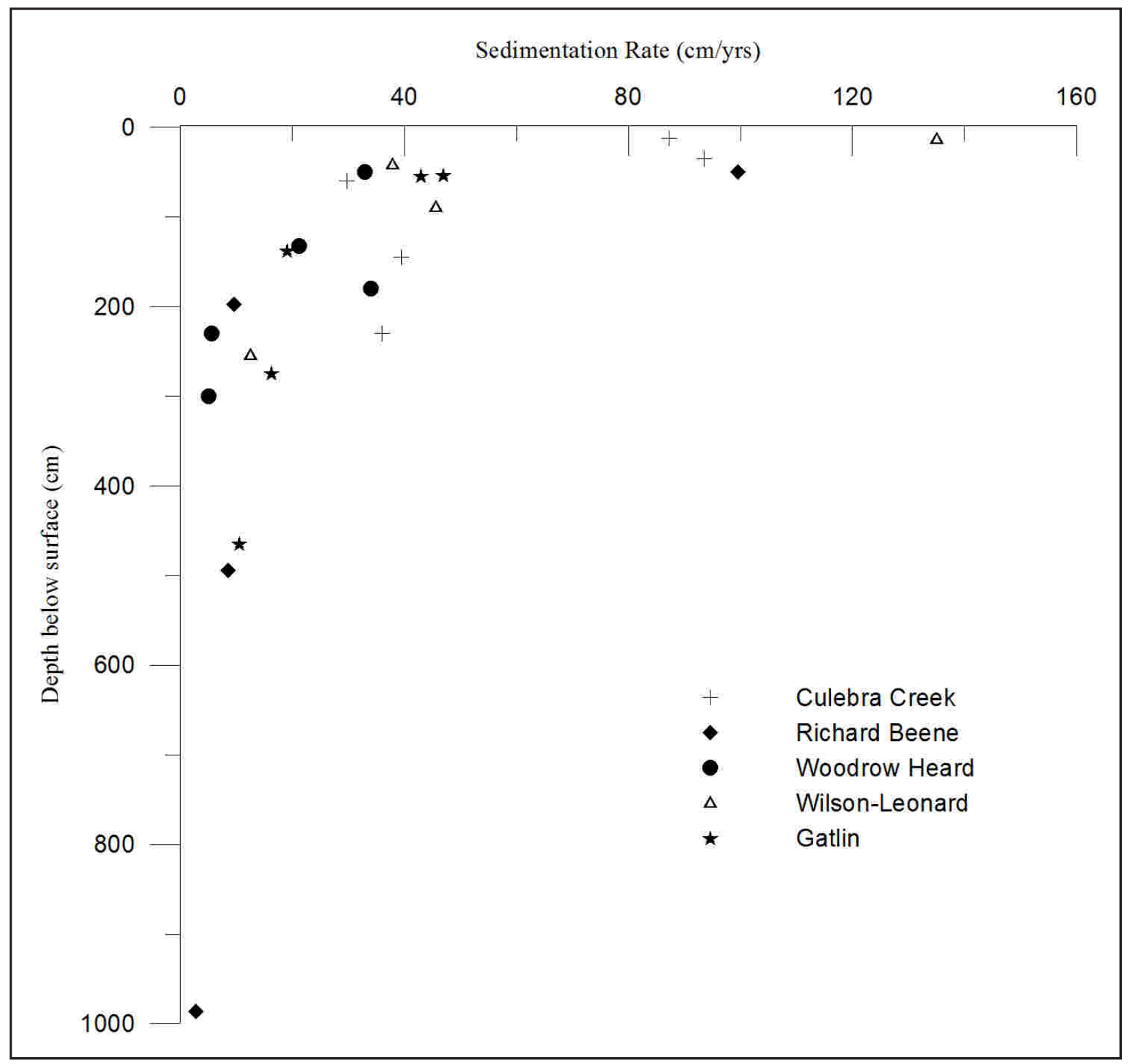

Figure 6.5. Sedimentation rates from select Central Texas sites.

In summary, one of the streams in central Texas for which sedimentation rates were examined exhibited rapid sediment accumulation in the latter part of the period, which Toomey (1993) and Cooke (2005) have identified as a period of soil erosion on the Edwards Plateau. However, most streams do not exhibit similar sedimentation rates. Indeed, a literature review on floodplain sedimentation and the processes which influence it, as well as an examination of floodplain sedimentation rates for several central Texas streams suggest that the floodplain sedimentation rate, although potentially offering a means of identifying periods of accelerated soil erosion, is more strongly influenced by the mechanics governing the formation of vertically accreted floodplains (specifically the floodplain height with respect to flood frequency), and that this process may obscure evidence of accelerated soil erosion. The sedimentation rates observed at the Gatlin site during the period it was occupied were slow, especially when compared to the apparent sedimentation rates during the early period of Unit 3 aggradation. Furthermore, sedimentation rates calculated from the testing phase suggest that, contrary to early impressions, there is only a small difference in sediment accumulation rate behind the burned rock midden where there appears to have been more colluvial influence, than away from it. 


\section{Geoarchaeological Summary}

Most of the Archaic occupations at the Gatlin site were situated towards the margin of the active Guadalupe River floodplain. Although a few shortterm occupation surfaces were observed across the floodplain during testing, repeated settlement of the valley margin appeared to be favored, before, and definitely after the construction of the burned rock midden. This settlement preference was not one that maximized proximity to water, but rather was close to the valley margin for some unknown reason. Proximity to other resources or flood avoidance are but two possible explanations.

The channel of the Guadalupe River was located about the same place it is today, or slightly to the north at this time, and it may have already incised by the time of the first Early Archaic occupation of the Gatlin site. Throughout the period of occupation, the floodplain was periodically inundated by floodwater, and a few of these floods were largemagnitude catastrophic floods. Floods of this scale were probably similar to historically observed floods in this part of central Texas that were attributable to extreme precipitation events and have recurrence intervals between 250 and 500 years (e.g., Curran et al. 2005; Sullivan 1983). The matrix-supported gravelly muds in the middle floodplain are interpreted to be the vestiges of a flood chute of the Guadalupe River that was active during such large magnitude overbank floods. This chute most likely originates several hundred meters upstream of the site where the river makes a gentle bend to the north. At least two phases of large magnitude flooding (each presumably comprised more than one event) separated and followed by a period of less dramatic flooding are indicated by the deposits in BHTs 2 and 19. Although no dates are available from the chute deposits, the presence of cultural materials in Zone 2 and correlation with BHT 1 suggests that this chute was active intermittently during occupation of the site and the gravelly deposits suggest that this feature may have served as an immediate source of alluvial gravel at times. The absence of alluvial gravel in the distal floodplain setting during the period of occupation suggests that the destructive influence of these floods did not extend to the valley margin.
Although there were recurrent large floods, the sedimentation rate at the site does not appear to have been very rapid during the period of occupation, and the deposition at this site does not appear to have been significantly different from other central Texas streams. The color of the Late Pleistocene-Early Holocene alluvial deposits here and at the southern Edwards Plateau support the description of soil erosion identified by Toomey (1993) and more recently quantified by Cooke (2005) and Cooke et al. (2002), who note the incremental denudation of deep red soils from the southern Edwards Plateau in this period. This is distinctly at odds with inferences about soil erosion on the Lampasas Cut Plain, where a dramatic change in the color of the alluvial sediments begins in the 8,000-7,000 B.P. year period. The differences between these records are probably attributable to spatial and temporal variations in soil erosion in the Late Pleistocene and Early Holocene.

The absence of discrete, identifiable flood deposits (event-specific slack water sediments; see discussion on floodplain sedimentation rates) within the area of block excavations is attributed to two processes: (1) the nature of the primary deposition, and (2) the influence of post-depositional pedoturbation. Evidence from modern studies of floodplain sedimentation demonstrates that event-specific floodplain deposits form in areas where floodwaters were deep. This promotes the deposition of variable-texture slackwater sediments that accumulate relatively rapidly (as in the case of near channel overbank environments [e.g., Frederick et al. 2006] tributary channel mouths [e.g., Baker and Kochel 1988; Kochel 1980] and floodplain depressions [e.g., Ferring 1994; Ferring and Yates 1997]). Floodbasin settings generally accumulate thick bodies of massive mud which are normally deposited in thin increments. The other process which mitigates against the preservation of event-specific flood deposits in this setting is the slow sedimentation rate which favors incorporation of each newly deposited mud drape into the soil by fauna and flora. Subtle variations in the stratigraphic separation of the occupation surfaces observed during excavation may be attributable to micro-relief on the floodplain surface that would have resulted in subtly different sedimentation rates during flooding. 
At the rear of the floodplain, two phases of colluvial accumulation are apparent: (1) an early, slow aggradation phase that was concomitant with alluvial floodplain sedimentation as well as prehistoric occupation of the site and is represented by a cumulic A horizon, especially to the south of the midden, and (2) a more-recent phase that buried the first one and introduced relatively carbonate-rich sediment, much of which was derived from Unit I, immediately upslope. The first phase is clearly of prehistoric age, but the second is much younger and may have formed in the Historic period. 


\title{
Chapter 7
}

\section{Data Recovery Methods and Summary of Results}

\author{
Michael E. Smith and Eric R. Oksanen
}

\section{INTRODUCTION}

Data recovery excavations and an additional geomorphological assessment were conducted at the Gatlin site from September to November 2004 (Law et al. 2005). Although the site extends to the scarp above the Guadalupe River, the data recovery program focused on the southern portion of the site, where the testing program indicated that artifact density and site integrity were highest (Figure 7.1). The excavations were also by necessity limited to within the boundaries of the right-of-way, outside of which the site almost certainly extends in both directions.

This chapter presents a summary of the results of the data recovery field investigations and the methodology used to achieve them. While this chapter touches upon the individual features and artifacts as they relate to the stratigraphic context, detailed descriptions and discussions of these are reserved for Appendix C, and interpretations of their significance are treated more fully in the subsequent chapters that deal specifically with the site's temporal components. These component chapters, each dealing with a broad cultural period of occupation at the Gatlin site, also include expanded discussions of the stratigraphy and the spatial relations of their relevant features.

The testing and data recovery investigations at the Gatlin site documented four cultural occupations. The latest, which proved to be an admixture of broad temporal and cultural components that were not the main focus of the excavations, spanned the Middle through Late Archaic periods, as evidenced by radiocarbon dates from ca. 3,900-1,250 B.P. and numerous diagnostic point types. This component was associated with the largest of the site's features (the burned rock midden) and is referred to as OZ4. The second component, dubbed OZ3, is a Late Early to Middle Archaic component that produced dates of ca. $4500-3850$ в.P. and diagnostic artifacts from both of the eponymous periods; this may represent either compression or a transitional phase between the two periods. Below this was an extensive component, referred to as OZ2, which was an Upper Early Archaic occupation that yielded several burned rock features and appears to have spanned the period of ca. 6,100-4,500 B.P. The earliest and most ephemeral of the Gatlin site's components dates from approximately 6,800-6,060 B.P. and falls within the Lower Early Archaic, and is termed OZ1.

\section{Data Recovery Field Methods}

The data recovery excavations at the Gatlin site initially targeted the two broad cultural components that were recognized during testing: the Middle-Late Archaic component, associated with the burned rock midden, and the pre-midden, Early Archaic components. At the time of the testing investigations, the Late Early to Middle Late Archaic OZ3 and the division between OZs 1 and 2 (the Upper and Lower Early Archaic) were not yet recognized. Incidental to this, the Gatlin site's geomorphological record was further investigated during data recovery operations, with the purpose of shedding greater light upon the site's formation processes; the results of this work are presented in Chapter 6. To collect data applicable to the research objectives (see Chapter 5; Houk and Miller 2004b), during the data recovery operations SWCA archaeologists opened large block excavations in an effort to create broad, horizontal exposures and implemented a robust sampling strategy to collect fine matrix from a variety of contexts.

Block excavations were conducted in two areas, Areas A and B (Figure 7.2). Area A, the largest was located east of the burned rock midden to investigate the site's Early Archaic components, which were reached by the mechanical removal of the overburden. Area B, the second block, was located south of the midden and west of Area A. It targeted the components related to the midden's use and formation. In addition to these excavation blocks, the data recovery program included additional backhoe trenching and sampling of various 


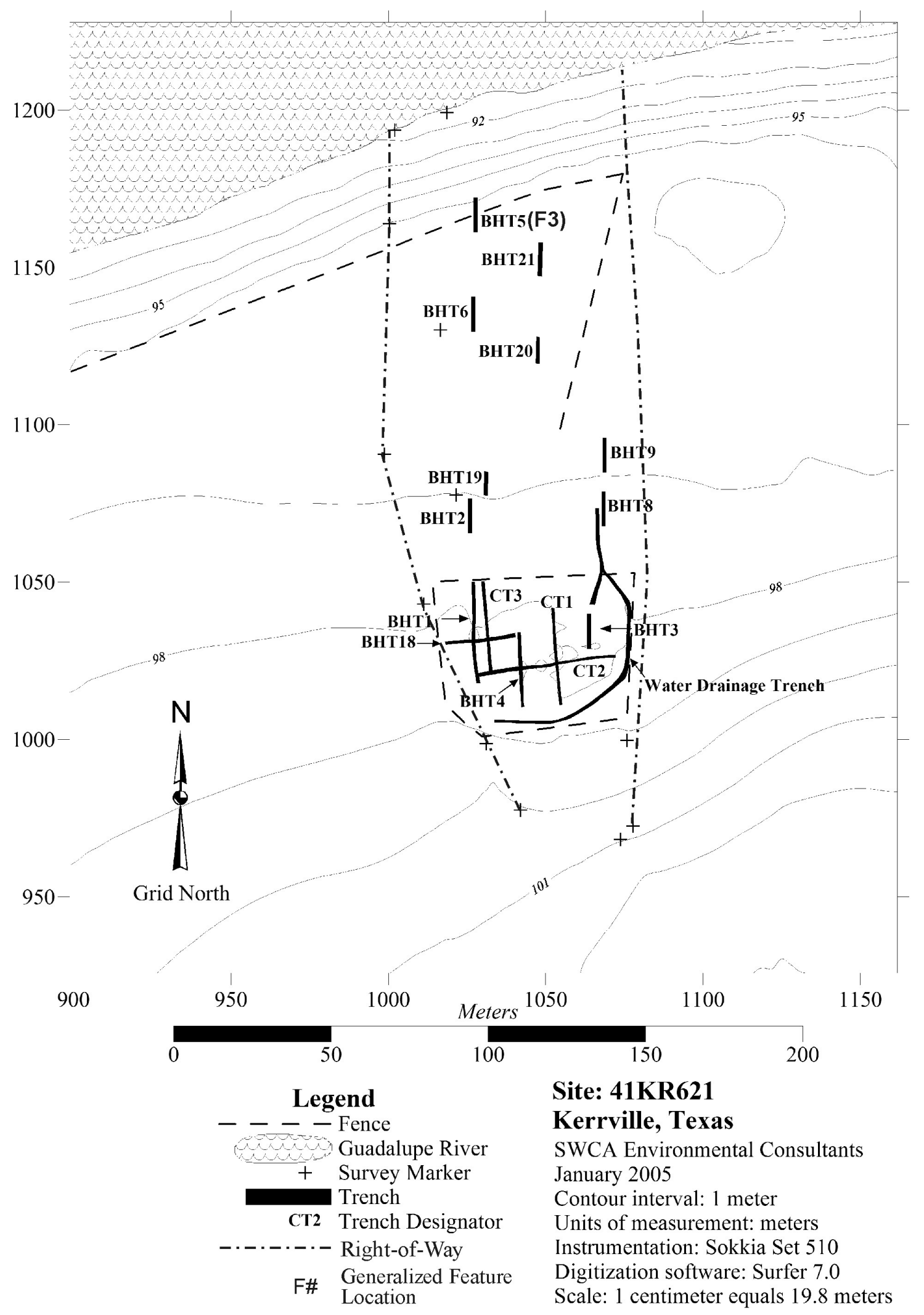

Figure 7.1. Overview map of data recovery excavations. 


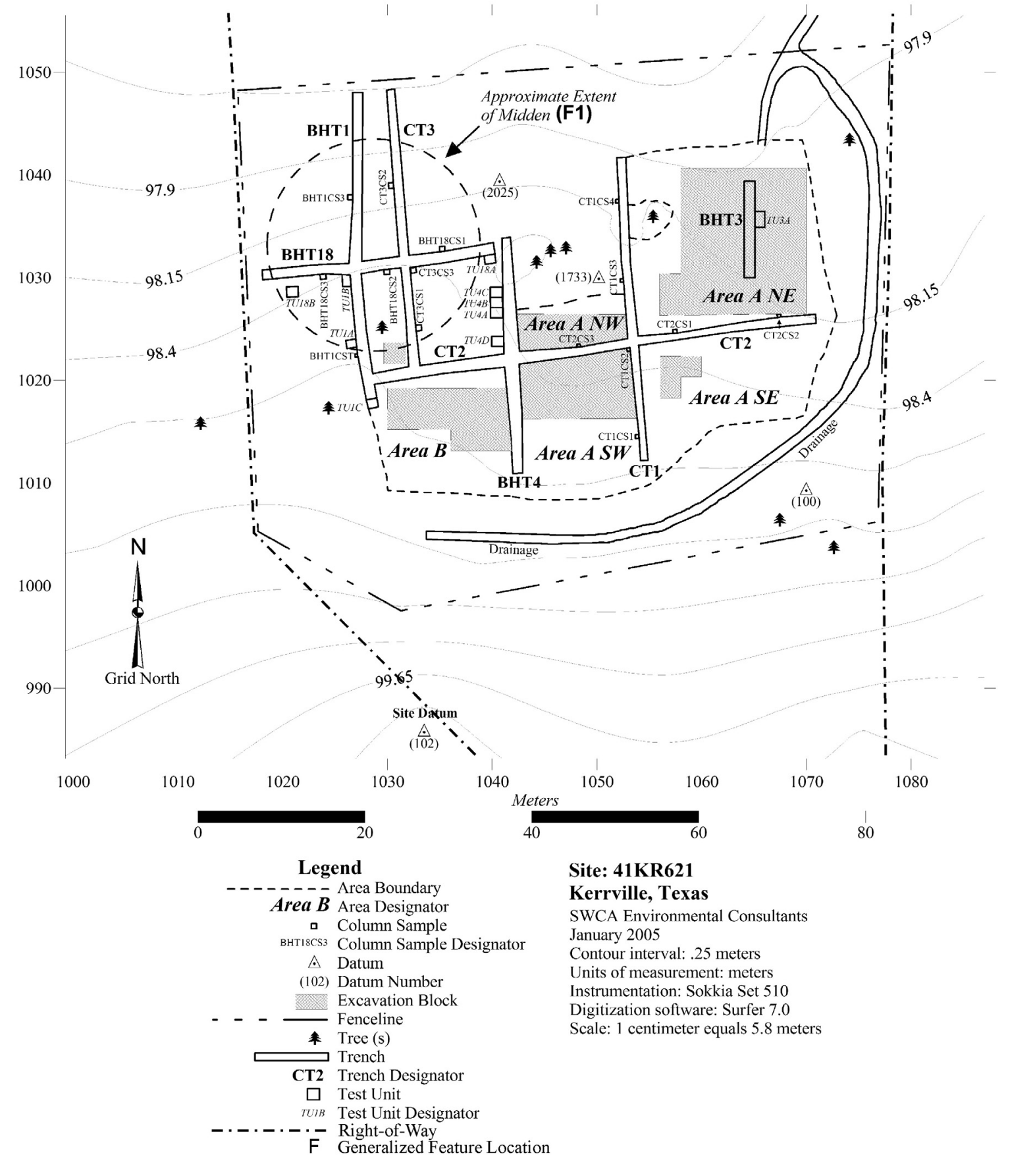

Figure 7.2. Map of data recovery excavation areas. 
parts of the site, which included the burned rock midden itself (Feature 1).

\section{ESTABLISHING Stratigraphic CONTROL}

To provide stratigraphic exposures for a geomorphological assessment, data recovery investigations reexcavated four of the trenches from the testing phase: BHTs 1, 3, 4, and 18 (see Figure 7.1). Additionally, three new backhoe trenches were excavated to provide geomorphic and archaeological control for the overburden removal in Areas A and B. These new trenches were referred to as Control Trenches (CTs) 1, 2, and 3 (see Figure 7.2). Two of these trenches, CTs 1 and 2, effectively divided Area A into rough quadrants, referred to hereafter as Areas A-NE, ASE, A-NW, and A-SW (see Figure 7.2).

The control trenches were examined and recorded by the project geoarchaeologist prior to the Area A overburden removal to identify the stratigraphic zone containing the Early Archaic component. Testing excavations indicated that the Early Archaic surface gradually declines (the approximate slope is up to 1.8 $\mathrm{cm}$ per meter) in elevation as one moves eastward and northward from BHT 4 to BHT 3. This slope is similar to that of the modern day ground surface at the Gatlin site.

Archaeologists examined the walls of the new control trenches and reopened backhoe trenches to identify any features or artifacts exposed in profile. Column samples $(30 \times 30 \mathrm{~cm})$ were extracted at 10-m intervals along one wall of each control trench to sample the cultural deposits exposed by the trenches; in all, 14 column samples (CS) were excavated. Detailed stratigraphic descriptions and drawings of each control trench were recorded, and the trenches were photographed.

In addition to the control trenches, a single long trench was excavated south and east of the excavation blocks to divert rainwater run-off from the hill slope south of the site around the excavations. It also aided in drainage, a significant issue in the later stages of the data recovery operations. No fea- tures and few artifacts were observed in this trench.

\section{MECHANICAL STRIPPING OF AREAS A AND B}

To facilitate the excavations of targeted components at the site, large amounts of overburden were mechanically stripped from Areas A (Figure 7.3) and B. This was accomplished by excavating roughly $10 \mathrm{~cm}$ of material (vertically) at a time in each area of the site. The intention was to use a Gradall to remove the overburden to approximately $5-10 \mathrm{~cm}$ above the top of the cultural components to be investigated. In practice, this proved more complicated than originally planned. The greatest difficulty arose in Area A, where the natural and cultural stratigraphy slopes downward from southwest to northeast. Identifying the top of the targeted Early Archaic component was problematic across the large horizontal area being stripped, and the project archaeologist generally erred on the side of caution, having the Gradall stop excavating too shallowly rather than too deeply.

Initial hand excavations, which began in Area A-NE, quickly determined that the Gradall had not reached the top of the Early Archaic component in Area A. To compensate for this, the project archaeologist employed a combination of hand excavations without screening and the use of a mini-backhoe to remove

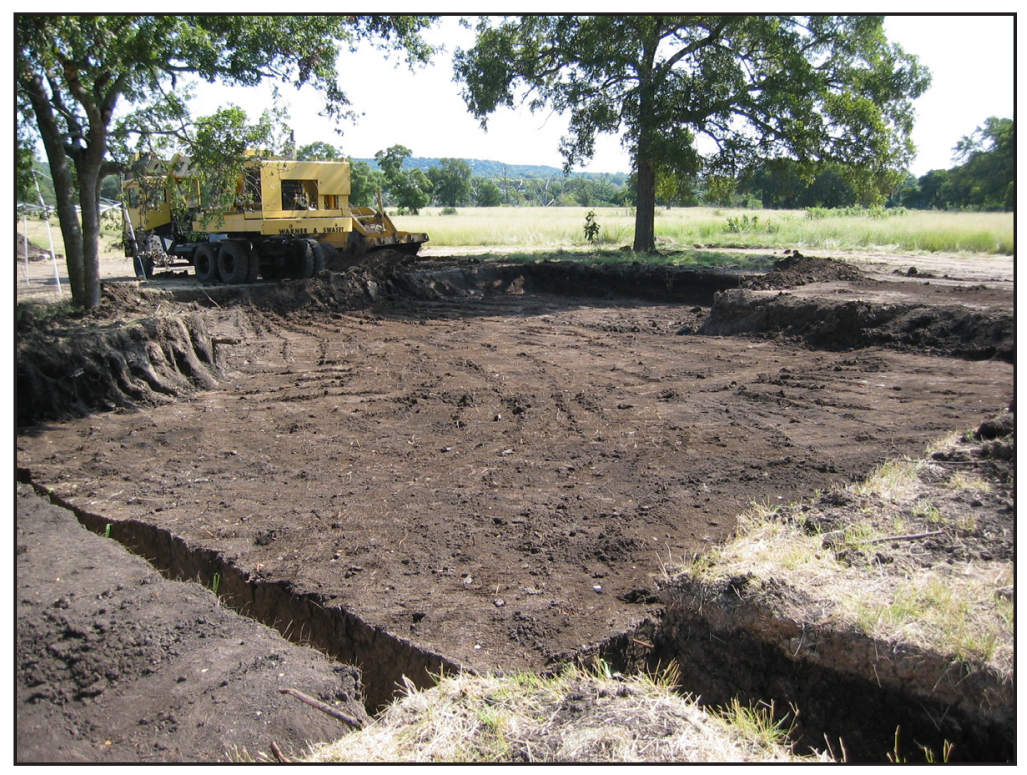

Figure 7.3. Mechanical stripping of Area A-NE, facing northeast. 
5-15 cm of material in Area A's northeast, southeast, and southwest quadrants.

In Area B, the targetzonewas an A horizon - containing the burned rock midden and midden-related components - which underlies a culturally sterile colluvial deposit. The transition zone between these deposits was sharp and easily distinguished, and the Gradall removed the colluvial deposits to approximately 5-10 $\mathrm{cm}$ above the A horizon.

Occasionally, features were observed during the mechanical and hand stripping. Such features were then defined by hand excavation, recorded, and removed before stripping in their area continued.

\section{Grid and Provenience Control}

Once the area was mechanically stripped, a total data station (TDS) was used to reestablish the grid used during the survey and testing phases and to establish vertical datum locations across Areas A and $\mathrm{B}$. Throughout the entire duration of the data recovery fieldwork, the TDS was used to maintain provenience control, plot artifacts, and map features and activity areas.

\section{HAND EXCAVATION METHODS}

In Area A, hand excavations focused on the exposure of a large area to identify features and feature patterning and in doing so, still recover an adequate sample of artifacts to investigate Early Archaic technological organization. To accomplish this, SWCA developed an excavation methodology that included two types of hand-excavation units. The first involved traditional excavation procedures, in which excavated soil matrix was screened to collect artifacts and associated cultural materials. The second excavation method focused on exposing a larger horizontal area at the expense of collecting most artifacts within each unit. The intent was to increase the excavated area to expeditiously locate and expose more features and activity areas; the excavated matrix within these units was not screened unless a feature was encountered. These two excavation approaches are hereafter referred to as traditional and feature-focused excavations, respectively. For the most part, these two excavation methods were evenly distributed across the Area A excavation units in a checkerboard-like pattern (Figure 7.4). In Area B, the excavations began exclusively with traditional units, in order to focus on discerning separate living surfaces associated with the burned rock midden, a possibility suggested by the testing investigations. Due to time constraints and the necessity of exposing an adequate surface area, some units were later designated as feature-focused units in their lowest levels.

In both methods, the units were $2 \times 2-m$ in size and excavated in 10-cm arbitrary levels. Each unit was aligned to the metric horizontal grid established during testing, and the southwestern corner of each $2 \times 2-m$ unit served as the unit's official designation (e.g., N1000 E1000). If a unit was excavated using traditional methods, then the $2 \times 2-m$ unit was further divided into four $1 \times 1-\mathrm{m}$ quadrants- $\mathrm{NW}, \mathrm{NE}, \mathrm{SW}$, and $\mathrm{SE}$ - for greater accuracy in recording artifact provenience. In this case, each 1 x 1-m quadrant was excavated individually, and the resulting matrix was screened through $1 / 4$-inch mesh. In a feature-focused excavation, the unit was not divided into quadrants, and the entire $10-\mathrm{cm}$ level was excavated without screening, unless a feature was encountered. Only

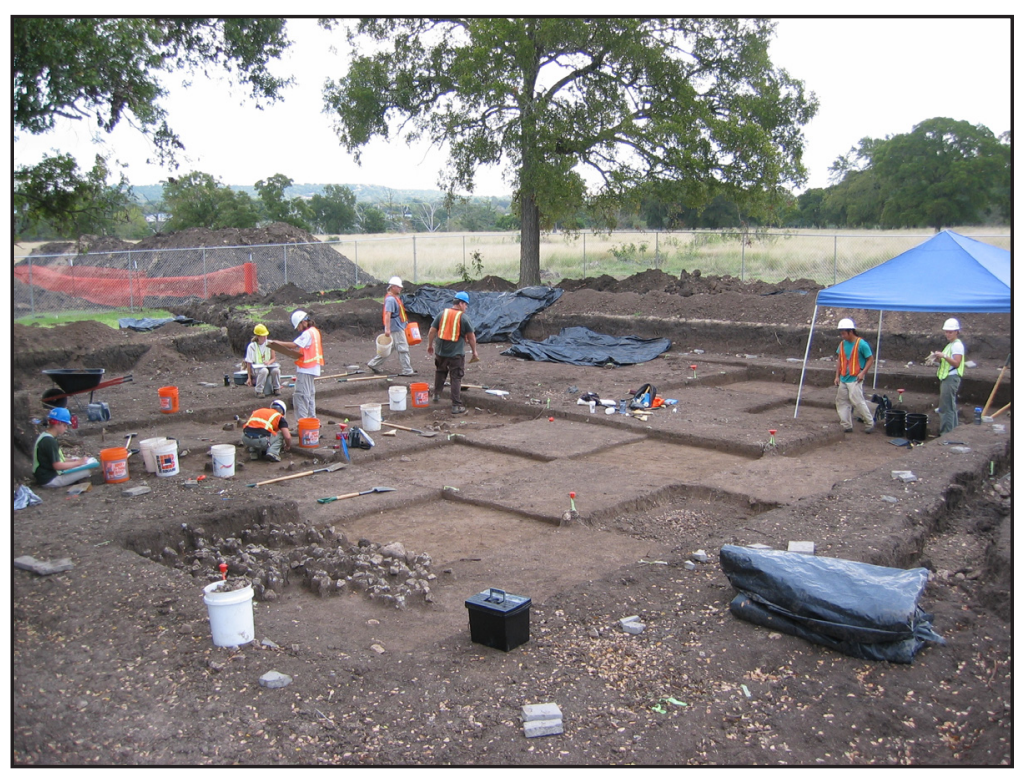

Figure 7.4. Checkerboard excavations of alternating Feature Focused and Traditional units underway in Area A-NE, facing northeast. 
stone tools, charcoal, and other unique samples were collected from feature-focused units. When possible, horizontal and vertical provenience was recorded for diagnostic stone tools. As mentioned above, a third type of hand excavation was developed in the field to compensate for the failure of the Gradall to remove enough overburden. Once the grid had been established over the stripped areas and several units had been excavated, the project archaeologist determined that the excavations were not yet in the target component. It was therefore decided to hand strip the area to the desired starting elevation(s). Hand-stripped units were excavated as 2 × 2-m units, but were not screened. When a feature was encountered, it was documented and sampled appropriately; artifact provenience and collection methodology for hand stripped units followed that of the feature-focused units. Across the site in all unit types, a TDS was utilized for precise provenience control on excavation units, elevation datums, feature dimensions, and most diagnostic artifacts.

\section{FEATURE EXCAVATION METHODS}

As an important data set, features received special treatment. Each recovered feature was numbered, exposed in plan view, drawn, and photographed. Additionally, each feature was described and documented, with the size, weights, and positions of clusters of burned rock carefully recorded. Most features were cross-sectioned and thoroughly sampled. Charcoal samples were collected when available, and bulk matrix samples were taken from various contexts. The coarse matrix (burned rock) was size-sorted, counted, and weighed, and rock samples were collected for possible organic residue analysis. The fine matrix was screened through $1 / 8$ inch mesh in the field.

\section{RADIOCARBON ASSAYS}

Absolute dating of the Gatlin site relied primarily on Accelerator Mass Spectrometry (AMS) radiocarbon dating of charcoal taken from feature contexts, although dates were obtained from non-feature contexts and limited radiometric analysis of bulk matrix samples as well. An intensive and integrated suite of radiometric dates was employed, beginning with 11 testing phase samples submitted to the University of Georgia's Center for Applied Isotope Studies (see Appendix B). Following the data recovery op- erations, the initial dates were supplemented by 36 carbon samples and two bulk matrix samples, which were chosen, in consultation with TxDOT, from an assemblage of $14{ }^{14} \mathrm{C}$ samples from the testing investigations and $101{ }^{14} \mathrm{C}$ samples and 40 bulk matrix samples from data recovery. These samples were submitted to Beta Analytic, Inc., of Miami, Florida, in a two-staged approach to better tighten the site's chronology; all but four produced viable dates.

Radiocarbon dates from the survey and testing phases and the data recovery program are provided in Table 7.1.

\section{Data Recovery Investigations}

The data recovery investigations concentrated on the southern portion of the Gatlin site, which the survey and testing efforts had indicated contained the densest accumulations of cultural material. More specifically, the work was focused on the lower Early Archaic and Early Archaic/Middle Archaic transition occupational deposits. Based on consultations with TxDOT archaeologists and factors such as lack of integrity and redundancy, the upper Middle to Late Archaic deposits and the associated midden were explored much less than the older occupations. In fact, portions of the upper Late Archaic cultural deposits were mechanically stripped to expedite excavations on the Early Archaic occupations. The boundaries of the southern portion of the site were estimated to cover an area of approximately $2,700 \mathrm{~m}^{2}$, of which the area south of the N1050 line, comprising 1,650 $\mathrm{m}^{2}$, was judged to have the best integrity. Excavations were focused in two primary blocks, the larger Area A with four sub-blocks east of the midden, and the smaller Area B south of the feature. Excavations proceeded in both blocks concurrently, resulting in a total of over $150 \mathrm{~m}^{3}$ of soil excavated by hand in both traditional and feature-focused units.

\section{AREA A}

Area A was intended to focus on the Gatlin site's Early Archaic component identified during the testing phase (Figure 7.5). Located to the east and southeast of the burned rock midden, this area was further divided by the intersection of CTs 1 and 2 into four unequal quadrants (see Figure 7.2), each referred to by its cardinal position within the area: NE, SE, NW, and SW. Prior to the beginning of 
Table 7.1. Summary of All Radiocarbon Dates and Their Proveniences

\begin{tabular}{|c|c|c|c|c|c|c|c|c|c|c|c|}
\hline Lab No. & Area & $\begin{array}{c}\text { SWCA } \\
\text { Sample \# }\end{array}$ & $\begin{array}{c}\text { Sample } \\
\text { Type }\end{array}$ & Unit & Provenience & Elevation & $\begin{array}{l}\text { Context and } \\
\text { Associations }\end{array}$ & $\begin{array}{c}\text { Measured Age } \\
(\mathrm{YBP} \pm 1 \sigma)\end{array}$ & $\delta^{13} \mathrm{C}$ & $\begin{array}{c}\text { Conventional } \\
\text { Date } \\
(\mathrm{YBP} \pm 1 \sigma)\end{array}$ & Calibrated Age Estimate $(2 \sigma)$ \\
\hline \multirow{2}{*}{$\begin{array}{c}\text { UGA- } \\
13916^{*}\end{array}$} & \multirow{2}{*}{ A-NE } & \multirow{2}{*}{41} & \multirow{2}{*}{$\begin{array}{c}\text { Wood } \\
\text { Charcoal }\end{array}$} & \multirow{2}{*}{ TU 3-A } & \multirow{2}{*}{ Lvl 11} & \multirow{2}{*}{96.98} & \multirow{2}{*}{ Feature 5} & \multirow{2}{*}{$5460 \pm 70$} & \multirow{2}{*}{$\begin{array}{l}-23.61 \\
(+20)\end{array}$} & \multirow{2}{*}{$5480 \pm 70$} & $\begin{array}{c}4460-4220 \mathrm{cal} \text { B.c. }(p= \\
[0] .87 .7) \text { and } 4200-4160 \\
\text { cal B.c. }(p=[0] .04 .7) \text { and } \\
4130-4050 \text { cal B.c. }(p=[0] .03)\end{array}$ \\
\hline & & & & & & & & & & & $\begin{array}{c}6410-6170 \mathrm{cal} \text { B.P. }(p= \\
[0] \cdot 87.7) \text { and } 6150-6110 \\
\text { cal B.P. }(p=[0] \cdot 04.7) \text { and } \\
6080-6000 \mathrm{cal} \text { B.P. }(p=[0] .03)\end{array}$ \\
\hline \multirow{2}{*}{$\begin{array}{c}\text { Beta- } \\
206114 \\
\end{array}$} & \multirow[b]{2}{*}{ A-NE } & \multirow{2}{*}{ C-5 } & \multirow{2}{*}{$\begin{array}{c}\text { Wood } \\
\text { Charcoal }\end{array}$} & \multirow{2}{*}{$\begin{array}{c}\text { Gradall } \\
\text { Stripping }\end{array}$} & \multirow{2}{*}{$\begin{array}{l}\text { Within } \\
\text { Feature } 7\end{array}$} & \multirow{2}{*}{97.19} & \multirow{2}{*}{ Feature 7} & \multirow{2}{*}{$3390 \pm 40$} & \multirow{2}{*}{$\begin{array}{l}24.5 \\
0 / 00\end{array}$} & \multirow{2}{*}{$3400 \pm 40$} & $1760-1610$ cal B.c. \\
\hline & & & & & & & & & & & $3720-3560$ cal B.P. \\
\hline \multirow{2}{*}{$\begin{array}{c}\text { Beta- } \\
206116\end{array}$} & \multirow{2}{*}{ A-NE } & \multirow{2}{*}{ C-12 } & \multirow{2}{*}{$\begin{array}{c}\text { Wood } \\
\text { Charcoal }\end{array}$} & \multirow{2}{*}{$\begin{array}{l}\text { N1027 } \\
\text { E1056 }\end{array}$} & \multirow{2}{*}{$\begin{array}{l}\text { N1028.12 } \\
\text { E1057.06 }\end{array}$} & 9740 & $\begin{array}{l}\text { Feature } 19 \\
\text { (Southern }\end{array}$ & $4120+40$ & $-25.7 \mid$ & $4110+40$ & $\begin{array}{l}2870-2570 \text { cal B.c. and } \\
2520-2500 \text { cal B.c. }\end{array}$ \\
\hline & & & & & & 91.40 & Portion) & $4120 \pm 40$ & o/oo & $4110 \pm 40$ & $\begin{array}{l}4820-4520 \text { cal B.P. and } \\
4470-4450 \text { cal B.P. }\end{array}$ \\
\hline $\begin{array}{c}\text { Beta- } \\
206118\end{array}$ & A-NE & C-17 & $\begin{array}{c}\text { Wood } \\
\text { Charcoal }\end{array}$ & $\begin{array}{l}\text { N1029 } \\
\text { E1056 }\end{array}$ & $\begin{array}{l}\text { N1029.90 } \\
\text { E1056.85 }\end{array}$ & 97.27 & $\begin{array}{l}\text { Feature } 19 \\
\text { (Northern } \\
\text { Portion) }\end{array}$ & $\begin{array}{l}113.5 \pm 0.6 \\
\mathrm{pMC}\end{array}$ & $\begin{array}{c}-25.3 \\
0 / 00\end{array}$ & $\begin{array}{l}113.6 \pm 0.6 \\
\mathrm{pMC}\end{array}$ & $\begin{array}{l}\text { The reported result indicates } \\
\text { an age of post } 0 \text { B.P. and has } \\
\text { been reported as a percent } \\
\text { of the modern reference } \\
\text { standard, indicating the } \\
\text { material was living within the } \\
\text { last } 50 \text { years. }\end{array}$ \\
\hline Beta- & A-NF & $C-16$ & Wood & N1031 & N1032.49 & 9720 & None & $3740+40$ & -19.4 & $3830+40$ & $2450-2140$ cal B.c. \\
\hline 207379 & ATIVE & $=-10$ & Charcoal & E1058 & E1059.69 & $91 . \angle 0$ & TVurle & $0140 \pm 40$ & o/oo & $5000 \pm 40$ & $4400-4100$ cal B.P. \\
\hline Beta- & A-NF & $C-14$ & Wood & N1029 & N1029.50 & 9720 & None & $5360+40$ & -25.3 & $5360+40$ & $4320-4050$ cal B.c. \\
\hline 207378 & D. & $0-14$ & Charcoal & E1068 & E1068.26 & $91 . \angle 0$ & TNute & 0000140 & o/oo & 0000140 & $6280-6000$ cal B.P. \\
\hline Beta- & & & Wood & N1027 & N1028.70 & & & & $\mid-26.2$ & & 4230-3970 cal B.c. \\
\hline 206119 & A-IVE & $C-\angle 0$ & |Charcoal & $\begin{array}{c}\text { Elubo- } \\
1068\end{array}$ & E1067.65 & $91.2-91.1$ & reature $\angle 2$ & $5 \angle 80 \pm 50$ & o/oo & $5200 \pm 50$ & $6180-5920$ cal в.P. \\
\hline & & & & & & & Feature 25 & & & & $3370-3100$ cal B.C. \\
\hline $\begin{array}{c}\text { Beta- } \\
207380\end{array}$ & A-NE & C-35 & $\begin{array}{c}\text { Wood } \\
\text { Charcoal }\end{array}$ & $\begin{array}{l}\text { N1033 } \\
\text { E1058 }\end{array}$ & $\begin{array}{l}\mathrm{N} 1034.53 \\
\mathrm{E} 1059.48\end{array}$ & 97.05 & \begin{tabular}{|c|} 
direct date. \\
May be \\
associated \\
with Feature \\
5 from Testing \\
Phase II \\
\end{tabular} & $4540 \pm 40$ & $\begin{array}{c}-24.4 \\
0 / 00\end{array}$ & $4550 \pm 40$ & 5320-5050 cal B.P. \\
\hline $\mathrm{n} / \mathrm{a}$ & A-NE & C-30 & $\begin{array}{c}\text { Wood } \\
\text { Charcoal }\end{array}$ & $\begin{array}{l}\text { N1033 } \\
\text { E1058 }\end{array}$ & $\begin{array}{l}\mathrm{N} 1034.2 \\
\mathrm{E} 1058.82\end{array}$ & 97.04 & Feature 25 & $\mathrm{n} / \mathrm{a}$ & $\mathrm{n} / \mathrm{a}$ & $\mathrm{n} / \mathrm{a}$ & $\begin{array}{c}\text { Insufficient charcoal to obtain } \\
\text { date }\end{array}$ \\
\hline Beta- & & Co 14 & Wood & N1035 & N1035.96 E & & 5ontum ? & & -25.2 & & $\begin{array}{l}5200-5180 \text { cal в.c. and } \\
5080-4910 \text { cal B.c. }\end{array}$ \\
\hline 206122 & A-NE & C-44 & Charcoal & E1058 & 1058.47 & 96.97 & Feature 26 & $6100 \pm 40$ & o/oo & $6100 \pm 40$ & $\begin{array}{l}7150-7130 \text { cal B.P. and } \\
7020-6860 \text { cal B.P. }\end{array}$ \\
\hline Beta- & A-NF & $C-11$ & Wood & N1027 & N1027.80 & 96.97 & Feature 14 & $6570+50$ & 25.1 & $6570+50$ & $5620-5470$ cal в.c. \\
\hline 206115 & A-IVE & $2-11$ & Charcoal & E1060 & E1060.43 & 90.91 & reature 14 & $0510 \pm 00$ & o/oo & $0510 \pm 00$ & $7570-7420$ cal B.P. \\
\hline Beta- & & & Wood & N1029 & N1029.20 & & Provides basal & & -26.6 & & $5480-5330$ cal B.c. \\
\hline 207382 & A-IVE & $c-40$ & |Charcoal & E1056 & E1056.15 & $9.94-96.89$ & $\begin{array}{c}\text { date ror Area } \\
\text { A-NE }\end{array}$ & $6480 \pm 40$ & o/oo & $6450 \pm 40$ & $7430-7280$ cal B.P. \\
\hline UGA- & 1 & 6 & Wood & T & 10 & 07.11 & $\begin{array}{l}\text { South of } \\
\text { Feature } 2\end{array}$ & & -25.01 & & $\begin{array}{c}4230-4180 \text { cal B.c. }(p= \\
[0] .07 .6) \text { and } 4170-3790 \mathrm{cal} \\
\text { B.c. }(p=[0] .87 .8)\end{array}$ \\
\hline $13821^{*}$ & A-INVV & 0 & |Charcoal| & $104-6$ & LVI 4 & 91.41 & $\begin{array}{l}\text { probably } \\
\text { associated }\end{array}$ & $5190 \pm 10$ & $(-22)$ & $5190 \pm 10$ & $\begin{array}{c}6180-6130 \mathrm{cal} \text { B.P. }(p= \\
[0] .07 .6) \text { and } 6120-5740 \mathrm{cal} \\
\text { B.P. }(p=[0] .87 .8)\end{array}$ \\
\hline UGA- & A_ANW & 7 & Wood & TTI & 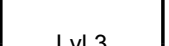 & 9745 & Fe? & 506 & -25.93 & 50 & $3970-3700$ cal в.с. \\
\hline $13822^{*}$ & 年 & 1 & Charcoal & (1) & Live & 51.70 & पcture & $0000-00$ & $(-1$ & ט & 5920-5650 cal в.P. \\
\hline UGA- & A-NW & 8 & od & TU 4-C & Jyl 3 & 9743 & Feature ? & $5020+70$ & -24.90 & $5020+70$ & 3970-3660 cal B.c. \\
\hline $13823^{*}$ & A-IVVV & 0 & Charcoal & (10 & Livo & 91.40 & reature 2 & $50<0 \pm 10$ & (0) & $50<0 \pm 10$ & 5920-5610 cal в.P. \\
\hline UGA- & A-NWW & 10 & & TH & 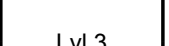 & 9745 & Feature? & $5390+60$ & -25.03 & $5390+60$ & $4350-4040$ cal B.c. \\
\hline $13824^{*}$ & metivav & 10 & Charcoal & (10 & Live & $51.4 \mathrm{~J}$ & Tature 2 & 0050100 & $(-5)$ & 3050 & 6300-5990 cal B.P. \\
\hline
\end{tabular}




\section{7-8 Chapter 7}

Table 7.1. Summary of All Radiocarbon Dates and Their Proveniences, continued

\begin{tabular}{|c|c|c|c|c|c|c|c|c|c|c|c|}
\hline Lab No. & Area & $\begin{array}{c}\text { SWCA } \\
\text { Sample \# }\end{array}$ & $\begin{array}{c}\text { Sample } \\
\text { Type }\end{array}$ & Unit & Provenience & Elevation & $\begin{array}{l}\text { Context and } \\
\text { Associations }\end{array}$ & $\begin{array}{c}\text { Measured Age } \\
(\mathrm{YBP} \pm 1 \sigma)\end{array}$ & $\delta^{13} \mathrm{C}$ & \begin{tabular}{|c|} 
Conventional \\
Date \\
$(\mathrm{YBP} \pm 1 \sigma)$
\end{tabular} & Calibrated Age Estimate $(2 \sigma)$ \\
\hline \multirow{2}{*}{$\begin{array}{l}\text { UGA- } \\
13825^{*}\end{array}$} & \multirow{2}{*}{ A-NW } & \multirow{2}{*}{13} & \multirow{2}{*}{$\begin{array}{c}\text { Wood } \\
\text { Charcoal }\end{array}$} & \multirow{2}{*}{ TU 4-C } & \multirow{2}{*}{ Lvl 3} & \multirow{2}{*}{97.41} & \multirow{2}{*}{ Feature 2} & \multirow{2}{*}{$5260 \pm 70$} & \multirow{2}{*}{$\begin{array}{c}-25.04 \\
(+5)\end{array}$} & \multirow{2}{*}{$5260 \pm 70$} & $\begin{array}{c}4320-4290 \text { cal B.c. }(p= \\
[0] .01 .8) \text { and } 4260-3950 \text { cal } \\
\text { B.c. }(p=[0] .93 .6)\end{array}$ \\
\hline & & & & & & & & & & & $\begin{array}{c}6270-6240 \mathrm{cal} \text { B.P. }(p= \\
[0] .01 .8) \text { and } 6210-5900 \mathrm{cal} \\
\text { B.P. }(p=[0] .93 .6)\end{array}$ \\
\hline \multirow{2}{*}{$\begin{array}{c}\text { Beta- } \\
207388\end{array}$} & \multirow{2}{*}{ A-NW } & \multirow{2}{*}{ C-85 } & \multirow{2}{*}{$\begin{array}{c}\text { Wood } \\
\text { Charcoal }\end{array}$} & \multirow{2}{*}{$\begin{array}{l}\text { N1025 } \\
\text { E1042 }\end{array}$} & \multirow{2}{*}{$\begin{array}{c}\mathrm{N} 1026.42 \\
\text { E1042.30- } \\
1042.80\end{array}$} & \multirow{2}{*}{97.72} & \multirow{2}{*}{$\begin{array}{l}\text { No Feature } \\
\text { Association }\end{array}$} & \multirow{2}{*}{$200 \pm 40$} & \multirow{2}{*}{$\begin{array}{c}-27.4 \\
\text { o/oo }\end{array}$} & \multirow{2}{*}{$160 \pm 40 \mathrm{BP}$} & cal A.D. $1660-1950$ \\
\hline & & & & & & & & & & & $290-0$ cal B.P. \\
\hline \multirow{2}{*}{$\begin{array}{l}\text { Beta- } \\
206133\end{array}$} & \multirow{2}{*}{ A-NW } & \multirow{2}{*}{ C-101 } & \multirow{2}{*}{$\begin{array}{c}\text { Wood } \\
\text { Charcoal }\end{array}$} & \multirow{2}{*}{$\begin{array}{l}\text { N1023 } \\
\text { E1042 }\end{array}$} & N1023.94 & & Excavation & & $\mid-25.2$ & & $\begin{array}{l}2550-2540 \text { cal B.c. and } \\
2490-2300 \text { cal B.c. }\end{array}$ \\
\hline & & & & & E1042.71 & 91.50 & $\begin{array}{l}\text { Base Area } \\
\text { A-NW }\end{array}$ & $3930 \pm 40$ & o/oo & $3930 \pm 40 \mathrm{Br}$ & $\begin{array}{l}4500-4480 \mathrm{cal} \text { B.P. and } \\
4440-4250 \text { cal B.P. }\end{array}$ \\
\hline & & & & & & & $\begin{array}{l}\text { No Feature } \\
\text { Association. }\end{array}$ & & & & $\begin{array}{l}3270-3240 \text { cal B.c. and } \\
3110-2910 \text { cal B.c. }\end{array}$ \\
\hline \begin{tabular}{|c|} 
Beta- \\
207390
\end{tabular} & A-NW & C-100 & $\left|\begin{array}{c}\text { Wood } \\
\text { Charcoal }\end{array}\right|$ & $\begin{array}{l}\mathrm{N} 1025 \\
\mathrm{E} 1048\end{array}$ & $\begin{array}{l}\text { N1025.90 } \\
\text { E1049.70 }\end{array}$ & 97.50 & $\begin{array}{c}\text { However may } \\
\text { provide Basal } \\
\text { date for Area } \\
\text { A-NW }\end{array}$ & $4400 \pm 40$ & \begin{tabular}{|c|}
-25.2 \\
$0 / 00$
\end{tabular} & $4400 \pm 40 \mathrm{BP}$ & $\begin{array}{l}5220-5190 \mathrm{cal} \mathrm{B.P.} \mathrm{and} \\
5060-4860 \mathrm{cal} \text { B.P. }\end{array}$ \\
\hline Beta- & $D_{0} \cos t$ & 010 & Wood & N1021 & N1021.94 & 0765 & Direct Date of & 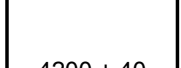 & -24.6 & $1210+10$ & $\begin{array}{l}2900-2850 \text { cal B.c. and } \\
2820-2670 \text { cal B.c. }\end{array}$ \\
\hline 207377 & A-svV & $2-13$ & |Charcoal| & E1044 & E1045.01 & 91.00 & Feature 16 & $4 \angle 00 \pm 40$ & o/oo & $4 \angle 10 \pm 40$ & $\begin{array}{l}4850-4800 \mathrm{cal} \text { B.P. and } \\
4770-4620 \text { cal B.P. }\end{array}$ \\
\hline Beta- & A_sw & $C-13$ & Wood & N1021 & Feature 16 & 9765 & Direct Date of & $4140+40$ & $\mid-25.2$ & $4140+40$ & $2880-2580$ cal B.c. \\
\hline 206117 & A & $2-10$ & Charcoal & E1044 & redure io & 91.05 & Feature 16 & $4140 \pm 40$ & o/oo & $4140 \pm 40$ & $4830-4530$ cal B.P. \\
\hline Beta- & $A_{-} s w$ & $C-55$ & Wood & N1019 & N1019.20 & 9761 & In same level & $190+40$ & $\mid-27.7$ & $150+40$ & cal A.D. $1660-1950$ \\
\hline 207383 & $A-s, V$ & $(-55$ & Charcoal & E1046 & E1047.8 & 97.61 & as Feature 16 & $190 \pm 40$ & o/oo & $150 \pm 40$ & $290-0$ cal B.P. \\
\hline Beta- & $A$ cins & & Wood & N1019 & N1020.85 & & Above Feature & & $|-25.1|$ & & $4470-4340$ cal B.c. \\
\hline 207384 & A-SWV & C-63 & Charcoal & E1044 & E1044.20 & 97.55 & $\begin{array}{l}33 \text { (may be } \\
\text { associated) }\end{array}$ & $55 / 0 \pm 40$ & o/oo & $55 / 0 \pm 40$ & $6420-6290$ cal B.P. \\
\hline Beta- & A-sW & C-58 & Wood & N1017 & N1018.4 & $9755-97.50$ & Feature 13 & $4950+40$ & $\mid-23.6$ & $4970+40$ & $\begin{array}{c}3910-3880 \text { cal B.c. and } \\
3800-3660 \text { cal B.c. }\end{array}$ \\
\hline 206124 & A-svV & & |Charcoal| & E1052 & E1052.00 & $91.00-91.50$ & reature is & $4900 \pm 40$ & o/oo & $4910 \pm 40$ & $\begin{array}{c}5860-5830 \mathrm{cal} \text { B.P. and } \\
5750-5610 \text { cal B.P. }\end{array}$ \\
\hline Beta- & A_sw & $C-67$ & Wood & N1019 & N1020.01 & 9752 & Direct Date & $4960+40$ & $\mid-24.5$ & $4970+40$ & $\begin{array}{c}3910-3880 \text { cal B.c. and } \\
3800-3660 \text { cal B.C. }\end{array}$ \\
\hline 207385 & A-colv & (U) & Charcoal| & E1048 & E1049.68 & 91.02 & Bison Teeth? & $4900 \pm 40$ & \begin{tabular}{|l|} 
\\
\end{tabular}$/ 00$ & $4510 \pm 40$ & $\begin{array}{l}5860-5830 \mathrm{cal} \text { B.P. and } \\
5750-5610 \mathrm{cal} \text { B.P. }\end{array}$ \\
\hline Beta- & A_sw & $C-73$ & Wood & Feature & N1020.20 & 9750 & Direct Date & $4080+40$ & $|-24.1|$ & $4090+40$ & $\begin{array}{l}2860-2800 \text { cal B.c. and } \\
2760-2550 \text { cal B.c. and } \\
2540-2490 \text { cal B.c. }\end{array}$ \\
\hline 207386 & A-sov & $0-10$ & Charcoal & $34-C$ & E1049.60 & 91.00 & Feature 34 & $4000 \pm 40$ & \begin{tabular}{|l|} 
\\
\end{tabular}$/ \% 0$ & $4090 \pm 40$ & $\begin{array}{l}4810-4750 \mathrm{cal} \text { B.P. and } \\
4710-4500 \mathrm{cal} \text { B.P. and } \\
4480-4440 \text { cal B.P. }\end{array}$ \\
\hline Beta- & A_sw & $C-74$ & Wood & N1019 & N1020.90 & 9750 & Feature 34 r & $4990+50$ & $\mid-25.2$ & $4990+50$ & $3940-3660$ cal B.c. \\
\hline 206128 & A-colv & $v^{-17}$ & Charcoal & E1048 & E1049.95 & 91.00 & redure $34-6$ & 4590150 & o/oo & $4950 \pm 00$ & 5890-5610 cal B.P. \\
\hline Beta- & A-SW & $C-64$ & Wood & N1019 & N1020.8 & 9749 & Bison Teeth & $5330+40$ & $|-25.4|$ & $5320+1$ & $4250-4040$ cal B.c. \\
\hline 206125 & $A-3 \mathrm{VV}$ & $2-04$ & Charcoal & E1048 & E1048.4 & 91.49 & Disoni leentin & $5030 \pm 40$ & o/oo & $50 \angle 0 \pm 40$ & $6200-5990$ cal B.P. \\
\hline Beta- & A_sw & C-77 77 & Wood & N1021 & N1022.38 & 97.47 & 10cm Below & $5110+10$ & -24.2 & $12+3$ & $4340-4220$ cal в.с. \\
\hline 207387 & $A-s, V$ & 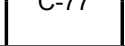 & Charcoal & E1046 & E1047.43 & $97.4 t$ & Feature 16 & $5410 \pm 40$ & o/oo & $54 \angle U \pm 40$ & $6290-6170$ cal B.P. \\
\hline Beta- & A-SW & C-68 & Wood & N1019 & N1020.90 & 9745 & Feature 33 & $5440+40$ & -25.2 & $5440+40$ & $4350-4230$ cal в.c. \\
\hline 206126 & $A-S W V$ & C-68 & Charcoal & E1044 & E1044.55 & 97.45 & Feature 33 & $5440 \pm 40$ & o/oo & $5440 \pm 40$ & $6300-6180$ cal B.P. \\
\hline & & & & & & & Associated & & & & cal A.D. $70-380$ \\
\hline $\begin{array}{c}\text { Beta- } \\
207391\end{array}$ & B & S-12 & $\begin{array}{c}\text { Bulk soil } \\
\text { matrix }\end{array}$ & $\begin{array}{l}\mathrm{N} 1016 \\
\mathrm{E} 1032\end{array}$ & Feature 9 & $98.3-98.2$ & $\begin{array}{c}\text { with Late } \\
\text { Archaic } \\
\text { Feature } 9 \text { and } \\
\text { Midden Use }\end{array}$ & $1690 \pm 60$ & \begin{tabular}{|c|}
-17.7 \\
$0 / 00$
\end{tabular} & $1810 \pm 60$ & $1880-1570$ cal в.P. \\
\hline
\end{tabular}


Table 7.1. Summary of All Radiocarbon Dates and Their Proveniences, continued

\begin{tabular}{|c|c|c|c|c|c|c|c|c|c|c|c|}
\hline Lab No. & Area & $\begin{array}{c}\text { SWCA } \\
\text { Sample \# }\end{array}$ & $\begin{array}{c}\text { Sample } \\
\text { Type }\end{array}$ & Unit & Provenience & Elevation & $\begin{array}{l}\text { Context and } \\
\text { Associations }\end{array}$ & $\begin{array}{c}\text { Measured Age } \\
(\mathrm{YBP} \pm 1 \sigma)\end{array}$ & $\delta^{13} \mathrm{C}$ & \begin{tabular}{|c|} 
Conventional \\
Date \\
(YBP $\pm 1 \sigma)$
\end{tabular} & Calibrated Age Estimate $(2 \sigma)$ \\
\hline \multirow[b]{2}{*}{\begin{tabular}{|c|} 
Beta- \\
207392
\end{tabular}} & \multirow[b]{2}{*}{ B } & \multirow[b]{2}{*}{ S-13 } & \multirow[b]{2}{*}{$\begin{array}{c}\text { Bulk soil } \\
\text { matrix }\end{array}$} & \multirow[b]{2}{*}{$\begin{array}{l}\text { N1018 } \\
\text { E1036 }\end{array}$} & \multirow[b]{2}{*}{ Feature 10} & \multirow[b]{2}{*}{$98.3-98.2$} & \multirow{2}{*}{$\begin{array}{c}\text { Associated } \\
\text { with Late } \\
\text { Archaic } \\
\text { Feature } 10 \text { and } \\
\text { Midden Use }\end{array}$} & \multirow[b]{2}{*}{$1170 \pm 60$} & \multirow[b]{2}{*}{$\begin{array}{c}-17.8 \\
0 / 00\end{array}$} & \multirow[b]{2}{*}{$1290 \pm 60$} & cal A.D. $650-880$ \\
\hline & & & & & & & & & & & 1300-1070 cal B.P. \\
\hline \multirow{2}{*}{$\begin{array}{c}\text { Beta- } \\
206132\end{array}$} & \multirow{2}{*}{ B } & \multirow{2}{*}{ C-94 } & \multirow{2}{*}{$\begin{array}{c}\text { Wood } \\
\text { Charcoal }\end{array}$} & \multirow{2}{*}{$\begin{array}{l}\text { N1014 } \\
\text { E1038 }\end{array}$} & \multirow{2}{*}{$\begin{array}{l}\text { N1015.58 } \\
\text { E1038.10 }\end{array}$} & \multirow{2}{*}{97.94} & \multirow{2}{*}{ Feature 37} & \multirow{2}{*}{$3830 \pm 40$} & \multirow{2}{*}{$\begin{array}{c}-24.0 \\
0 / 00\end{array}$} & \multirow{2}{*}{$3850 \pm 40$} & $2460-2200$ cal в.c. \\
\hline & & & & & & & & & & & $4410-4150 \mathrm{cal}$ B.P. \\
\hline \multirow{2}{*}{\begin{tabular}{|c|} 
Beta- \\
207389
\end{tabular}} & \multirow{2}{*}{ B } & \multirow{2}{*}{ C-91 } & \multirow{2}{*}{$\begin{array}{c}\text { Wood } \\
\text { Charcoal }\end{array}$} & N1014 & N1015.19 & 9791 & Above Feature & $4620+40$ & $\mid-25.9$ & $4610+40$ & $\begin{array}{l}3510-3430 \text { cal B.c. and } \\
3390-3340 \text { cal B.c. }\end{array}$ \\
\hline & & & & E1036 & E1036.51 & 91.91 & 38 & $4020 \pm 40$ & o/oo & $4010 \pm 40$ & $\begin{array}{l}5460-5380 \text { cal B.P. and } \\
5340-5290 \text { cal B.P. }\end{array}$ \\
\hline Beta- & $R_{1}$ & $C-93$ & Wood & N1014 & N1014.20 & 9788 & Fenture 38 & $4560+40$ & $|-27.0|$ & $4530+40$ & $3360-3090$ cal в.c. \\
\hline 206131 & B & $c-93$ & Charcoal & E1036 & E1036.50 & 97.88 & Feature 38 & $4560 \pm 40$ & o/oo & $4530 \pm 40$ & 5310-5040 cal B.P. \\
\hline Beta- & $B$ & $C-38$ & Wood & N1016 & N1016.20 & & Below Feature & & $\mid-24.9$ & $3750+40$ & $2290-2030$ cal B.c. \\
\hline 207381 & B & $C-38$ & Charcoal & E1030 & E1031.80 & 97.86 & 11 & $3 / 50 \pm 40$ & o/oo & $3 / 50 \pm 40$ & $4240-3980$ cal B.P. \\
\hline Beta- & $R$ & $C-50$ & Wood & N1018 & N1018.96 & 0776 & Enoturn 28 & $1980+10$ & $\mid-25.0$ & $1080+10$ & $\begin{array}{l}3920-3870 \text { cal B.c. and } \\
3810-3660 \text { cal B.c. }\end{array}$ \\
\hline 206123 & $\mathrm{~B}$ & $u-50$ & |Charcoal| & E1032 & E1032.60 & 91.10 & reature $\angle 0$ & $4900 \pm 40$ & o/oo & $4900 \pm 40$ & $\begin{array}{l}5870-5820 \text { cal B.P. and } \\
5760-5610 \text { cal B.P. }\end{array}$ \\
\hline Beta- & $R_{1}$ & $C-11$ & Wood & N1016 & N1017.03 & $9773-9770$ & Excavation & $4930+40$ & $\mid-24.8$ & $4930+40$ & $3780-3650$ cal в.с. \\
\hline 206121 & $B$ & $C-41$ & Charcoal & E1036 & E1037.6 & $91.13-97.10$ & Base Area B & $4930 \pm 40$ & o/oo & $4930 \pm 40$ & $5730-5600$ cal B.P. \\
\hline \begin{tabular}{|l|} 
UGA- \\
$13819^{*}$
\end{tabular} & Midden & 1 & Wood & TU 1-A & $\mid T U$ 1-A, LVI $10 \mid$ & $97.55-97.50$ & $\begin{array}{l}\text { Upslope of and } \\
\text { below Feature }\end{array}$ & $4780 \pm 70$ & -25.54 & $4770 \pm 70$ & $3670-3370$ cal в.c. \\
\hline & & & & & & & $\mid \begin{array}{c}\text { 1, between A } \\
\text { and B horizons }\end{array}$ & & & & $5620-5320$ cal B.P. \\
\hline & & & & & & & Upslope of and & & & & $1940-1610$ cal в.с. \\
\hline \begin{tabular}{|l|} 
UGA- \\
$13820^{*}$
\end{tabular} & Midden & 3 & $\mid \begin{array}{c}\text { Wood } \\
\text { Charcoal }\end{array}$ & TU 1-A & Lvl 12 & 97.38 & $\begin{array}{c}\text { below Feature } \\
\text { 1, within B } \\
\text { horizon }\end{array}$ & $3480 \pm 60$ & $\begin{array}{c}-26.03 \\
(-9)\end{array}$ & $3460 \pm 60$ & 3890-3560 cal B.P. \\
\hline UGA- & Middent & 20 & Wood & $T T 1-R$ & 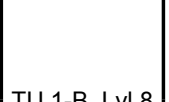 & $9760-9750$ & Base of & $3760+70$ & $\mid-26.40$ & $3740+70$ & $\begin{array}{c}2400-2370 \text { cal B.c. }(p= \\
[0] .01 .4) \text { and } 2350-1930 \mathrm{cal} \\
\text { B.c. }(p=[0] .94)\end{array}$ \\
\hline $13826^{*}$ & fivinarentin & 20 & |Charcoal| & 10 1-B & 10 T-B, LVI 8 & $97.60-97.50$ & Feature 1 & $3 / 60 \pm 10$ & $(-17)$ & $3740 \pm 70$ & $\begin{array}{c}4350-4320 \mathrm{cal} \mathrm{B.P.}[p= \\
[0] .01 .4] \text { and } 4300-3880 \mathrm{cal} \\
\text { B.P. }[p=[0] .94])\end{array}$ \\
\hline UGA- & Middont & 21 & Wood & TT 1 & T 1 & $0750-0740$ & Below or & $1700+60$ & $\mid-24.66$ & $1710+60$ & $3640-3360$ cal B.c. \\
\hline $13827^{*}$ & Jiviaden & 21 & |Charcoal| & | 10 - & 10 I-B, LVIY & $91.50-91.40$ & Feature 1 & $4 / 00 \pm 60$ & $(-15)$ & $4 \pi 10 \pm 60$ & $5590-5310$ cal B.P. \\
\hline UGA- & Middon & 23 & Wood & T & 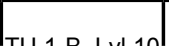 & $0740-0730$ & Below Feature & $1670+60$ & -25.30 & $1660+$ & $3640-3330$ cal в.c. \\
\hline $13828^{*}$ & fivianent & 20 & Charcoal & | & $101-\mathrm{B}, \mathrm{LV} 1 \mathrm{10}$ & $91.40-91.30$ & 1 & $46 / 0 \pm 60$ & $(0)$ & $4000 \pm 00$ & $5590-5280$ cal B.P. \\
\hline Beta- & Midden & C-71 & Wood & CT3, & In south wall & 9762 & Feature 1 & $2150+50$ & -26.6 & $2120+50$ & $\begin{array}{c}360-290 \text { cal B.C. and } 230-30 \\
\text { cal B.c. }\end{array}$ \\
\hline 206127 & & & |Charcoal| & $\operatorname{cs} 3$ & SE corner & & middle profile & & o/oo & & $\begin{array}{l}2310-2240 \text { cal B.P. and } \\
2180-1980 \text { cal B.P. }\end{array}$ \\
\hline Beta- & Mir & $c^{3}$ & Wood & BHT 18, & SE Sontinn & 751 & Middle Feature & $600+10$ & $|-25.9|$ & 69 & $\begin{array}{l}2190-2170 \text { cal в.c. and } \\
2150-1940 \text { cal B.C. }\end{array}$ \\
\hline 207376 & |Midden & $C-3$ & Charcoal & cs3 & SE Section & 97.54 & 1 date & $3690 \pm 40$ & o/oo & $3680 \pm 40$ & $\begin{array}{l}4140-4120 \text { cal B.P. and } \\
4100-3900 \text { cal B.P. }\end{array}$ \\
\hline Beta- & Middon & 2 & Wood & BHT 1, & $138=89$ & 0718 & Upslope of & 2 & $\mid-24.4$ & $5090+10$ & 4220-3980 cal в.c. \\
\hline $207374^{*}$ & givaden & 2 & |Charcoal| & TU 1-A & IN30 E08 & 91.48 & Feature 1 & $5 \angle 50 \pm 40$ & o/oo & $5 \angle 00 \pm 40$ & $6270-5920$ cal в.P. \\
\hline Beta- & Mi & C-75 & Wood & СТ3, & N1031.25 & 9745 & JFeature & $4 t^{\prime}$ & $\mid-25.7$ & $42+2$ & $\begin{array}{l}2900-2850 \text { cal B.c. and } \\
2820-2670 \text { cal B.c. }\end{array}$ \\
\hline 206129 & jivinuent & $2-12$ & Charcoal| & CS3 & E1032.32 & $91.4 \mathrm{~J}$ & frealuie i nase & $4 \angle \angle O I 40$ & o/oo & $4 \angle 10 \pm 40$ & $\begin{array}{l}4850-4800 \mathrm{cal} \text { B.P. and } \\
4770-4620 \text { cal B.P. }\end{array}$ \\
\hline $\mathrm{n} / \mathrm{a}$ & Midden & C-79 & $\begin{array}{c}\text { Wood } \\
\text { Charcoal }\end{array}$ & $\begin{array}{l}\text { CT3 } \\
\text { CS3 }\end{array}$ & $\begin{array}{l}\mathrm{N} 1031.10 \\
\mathrm{E} 1032.37\end{array}$ & 97.31 & $\begin{array}{c}\text { Below Feature } \\
1\end{array}$ & $\mathrm{n} / \mathrm{a}$ & $\mathrm{n} / \mathrm{a}$ & $\mathrm{n} / \mathrm{a}$ & $\begin{array}{c}\text { Insufficient charcoal to obtain } \\
\text { date }\end{array}$ \\
\hline
\end{tabular}


Table 7.1. Summary of All Radiocarbon Dates and Their Proveniences, continued

\begin{tabular}{|c|c|c|c|c|c|c|c|c|c|c|c|}
\hline Lab No. & Area & $\begin{array}{c}\text { SWCA } \\
\text { Sample \# }\end{array}$ & $\begin{array}{c}\text { Sample } \\
\text { Type }\end{array}$ & Unit & Provenience & Elevation & $\begin{array}{l}\text { Context and } \\
\text { Associations }\end{array}$ & $\begin{array}{c}\text { Measured Age } \\
(\mathrm{YBP} \pm 1 \sigma)\end{array}$ & $\delta^{13} \mathrm{C}$ & $\begin{array}{c}\text { Conventional } \\
\text { Date } \\
\text { (YBP } \pm 1 \sigma \text { ) }\end{array}$ & Calibrated Age Estimate $(2 \sigma)$ \\
\hline \multirow[b]{2}{*}{$\begin{array}{l}\text { Beta- } \\
207375\end{array}$} & \multirow[b]{2}{*}{ Midden } & \multirow[b]{2}{*}{ C-2 } & \multirow[b]{2}{*}{$\begin{array}{l}\text { Wood } \\
\text { Charcoal }\end{array}$} & \multirow[b]{2}{*}{$\begin{array}{c}\text { BHT 18, } \\
\text { CS1 }\end{array}$} & \multirow[b]{2}{*}{ NW Section } & \multirow[b]{2}{*}{97.23} & \multirow{2}{*}{$\begin{array}{c}\text { Below Feature } \\
1 \text { base and } \\
\text { within yellowish } \\
\text { brown soil } \\
\text { horizon }\end{array}$} & \multirow[b]{2}{*}{$5740+/-40 \mathrm{BP}$} & \multirow[b]{2}{*}{$\begin{array}{l}22.4 \\
\text { o/oo }\end{array}$} & \multirow[b]{2}{*}{$5780 \pm 40$} & $4720-4520$ cal в.c. \\
\hline & & & & & & & & & & & $6670-6470$ cal B.P. \\
\hline
\end{tabular}

* Sample from testing investigations.

Note: For the Beta samples, 2 sigma calibrations were made with the program INTCAL98 (Stuiver et al. 1998). For the UGA samples, atmospheric data are from Stuiver et al. (1998); 2 sigma calibrations were made with the program OxCal v. 3.5 (Bronk Ramsey 2000).

excavations, seven column samples were excavated within Area A from the two control trenches: CT1, CS1-4 and CT2, CS1-3. Excavated from the ground surface to approximately $1.2 \mathrm{~m}$ in depth, these aided in identifying the stratigraphic levels targeted during the mechanical stripping.

The mechanical stripping of Area A removed soils to approximately $30-50 \mathrm{~cm}$ below ground surface. Hand excavations were then conducted within the stripped area. Over the course of the fieldwork, $108.71 \mathrm{~m}^{3}$ of soil was excavated by hand from all of the Area A quadrants combined. Of these, 20.60 $\mathrm{m}^{3}$ (19 percent) were stripped by hand to reach the targeted Early Archaic components. In order to expose a large surface area for the identification of features and possible living floors, a combination of traditional and feature-focused units was employed within each quadrant of Area A. In all, traditional units accounted for $38.48 \mathrm{~m}^{3}$ (35 percent) of soil, while $49.63 \mathrm{~m}^{3}$ (46 percent) were excavated as feature-focused units.

\section{Area A-NE}

The block excavations of Area A-NE constituted the largest contiguous excavation area at the Gatlin site. These were oriented around BHT 3 and TU 3-A from the site's testing phase (Figure 7.6; see Figure 7.2), which had produced Feature 5 and associated Early Archaic materials. Thirty-one $2 \mathrm{x}$ 2-m units were excavated in a roughly L-shaped area, extending primarily west and south of BHT 3 . These covered a surface area of $124 \mathrm{~m}^{2}$ and typically began approximately $50 \mathrm{~cm}$ below the original ground surface. Fifteen of these excavation units were traditional units, and 16 were feature-focused.

Excavations were initiated within the southern portion of Area A-NE and expanded northwards over the course of the fieldwork. Unit N1033 E1062, one of the first units opened, was excavated as a featurefocused unit from an elevation of 97.5-96.7 $\mathrm{m}$. This unit functioned as a sondage to determine the depths of the targeted levels within the block. The results of the sondage precipitated the hand stripping of an additional $20 \mathrm{~cm}$ from the machine-scraped surface within Area A-NE to reach the Early Archaic materials beneath, as described in the methodology above. The remaining units were terminated at 96.9 $\mathrm{m}$, as artifact densities between 97.0 and $96.9 \mathrm{~m}$

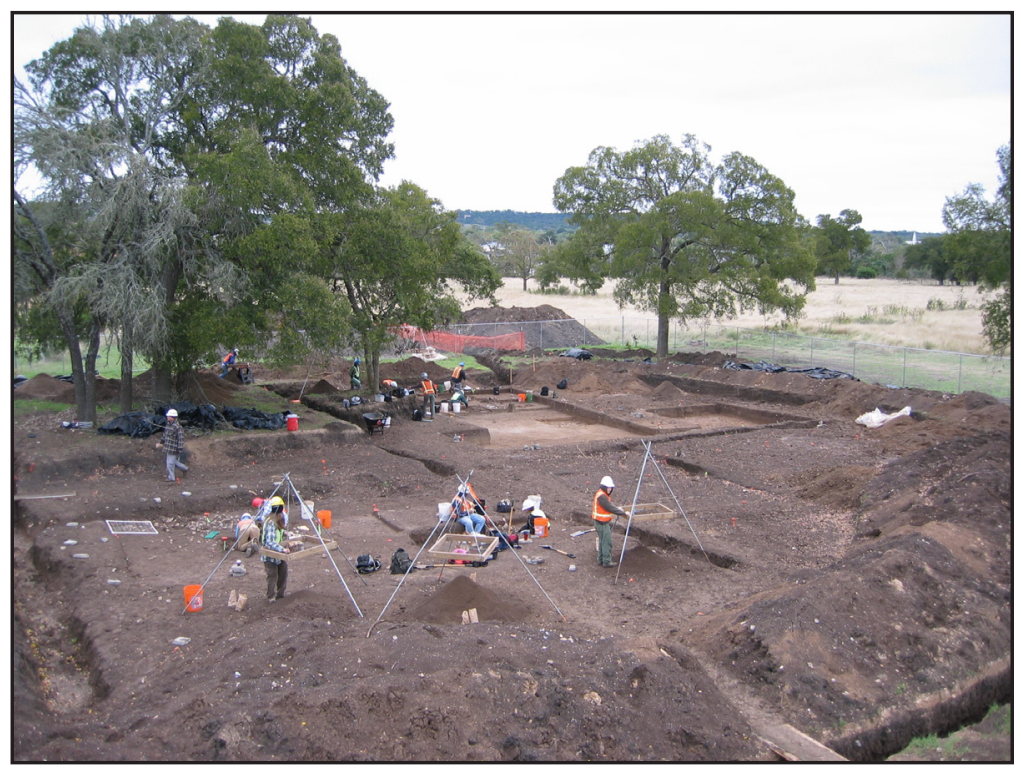

Figure 7.5. Overview of Area A, facing northeast; at center left is Area A-SW. Area A-NE occupies the background. 


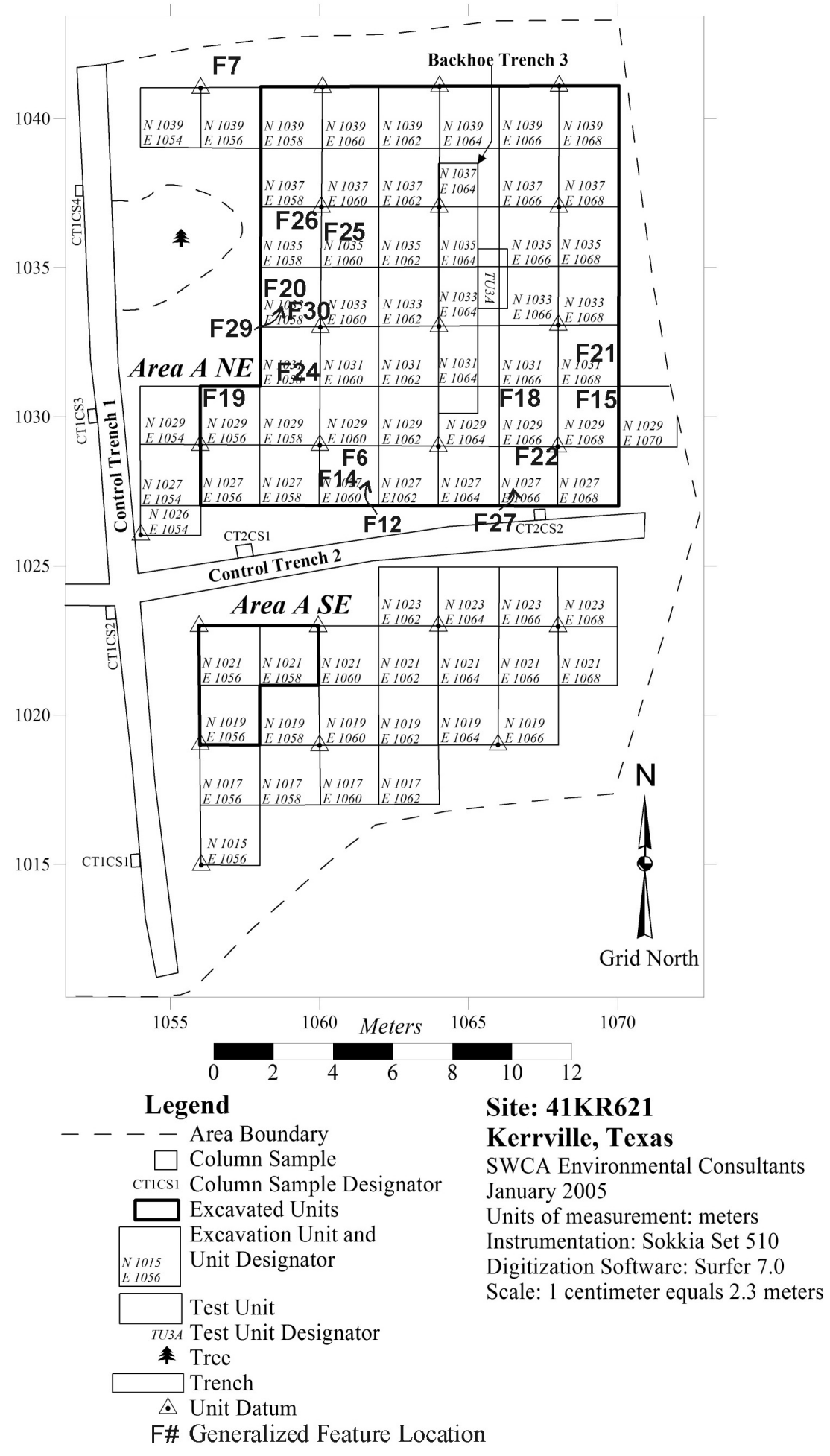

Figure 7.6. Area A-NE and Area A-SE excavation blocks and unit numbers. 


\section{7-12 Chapter 7}

were observed to drop significantly. This trend was especially visible within the southern portion of Area A-NE, where the natural ground surface was higher in elevation.

Machine stripping revealed two burned rock features (Features 6 and 7), both of which were defined by hand excavation methods. During hand excavations, another dense cluster of burned rock, Feature 19, was observed.

Due to the natural slope and the wide exposure of Area A-NE, the depth of the soil horizons varied. In the lower B horizon 13 features were documented: Features 12, 14, 15, 18, 20, 21, 22, 24, 25, 26, 27, 29, and 30. Most of these consisted of burned rock concentrations of various sizes and density (Figures 7.7 and 7.8), while two (Features 29 and 30), located at the lowest level of excavations, comprised small clusters of debitage, burned rock, and gravels. Within the B horizon, the features were in roughly three divisible occupation zones, as discerned by radiocarbon dates and relative positioning (Table 7.2; see Figure 7.8). These are introduced at the end of this chapter and will be more fully discussed within the individual cultural component chapters. In all, 16 features were documented within Area A-NE.

A slight change in soil color-from brown to dark yellowish brown-was observed in the final levels of Unit N1033 E1062 between 96.9 and $96.8 \mathrm{~m}$. This corresponded with an increase in gravels and a relative dearth of cultural materials; for this reason, excavations were terminated within this stratum.

\section{RADIOCARBON DATING - AREA A-NE}

Radiocarbon samples from upper soil horizon in Area A-NE provided a $1 \sigma$ conventional radiocarbon date of $3830 \pm 40$ B.P. and a second at $4110 \pm 40$ B.P. (see Table 7.1). Within the B horizon, two samples have $1 \sigma$ conventional radiocarbon dates of $5260 \pm 50$ B.P. and $5360 \pm 40$ B.P. These appear to correlate fairly well with the $1 \sigma$ conventional radiocarbon date obtained from Feature 5 during the testing phase, of $5480 \pm 70$ B.P. Near the base of the block excava- tions, two samples yielded $1 \sigma$ conventional radiocarbon dates of $6450 \pm 40$ B.P. and $6570 \pm 50$ B.P. While these dates fit the stratigraphy well, an anomalous $1 \sigma$ conventional radiocarbon date of $4550 \pm 40$ B.P. came from Feature 25. This feature is stratigraphically associated with Feature 26; however, Feature 26 has a $1 \sigma$ conventional radiocarbon date of $6100 \pm 40$ B.P.

\section{Artifact Distribution}

Artifact densities within Area A-NE were relatively low in comparison to those of the other excavation areas, although numerous diagnostic points were recovered (Tables 7.3 and 7.4). With few exceptions, the stratigraphic arrangement of these point types appears to adhere well with the established relative chronologies (see Appendix $\mathrm{C}$ for individual point chronologies). Within the lower margin of the excavated B horizon (97.0-96.9 m), a single specimen of the Early Barbed, Devil's Variant type and a single Gower point were recovered, both in relatively close proximity to Feature 27. An anomalous point, typed as Pandale, was found beneath Feature 25 at the same level.

Above, ranging from 97.2-97.0, Martindale points predominated with 20 specimens, two of which were of the Narrow Stem variety. Other Early Archaic types were also present within these two levels, including Gower ( $\mathrm{n}=11)$, Bandy $(\mathrm{n}=5)$, and Early Barbed, Devil's Variant ( $\mathrm{n}=1)$. No significant

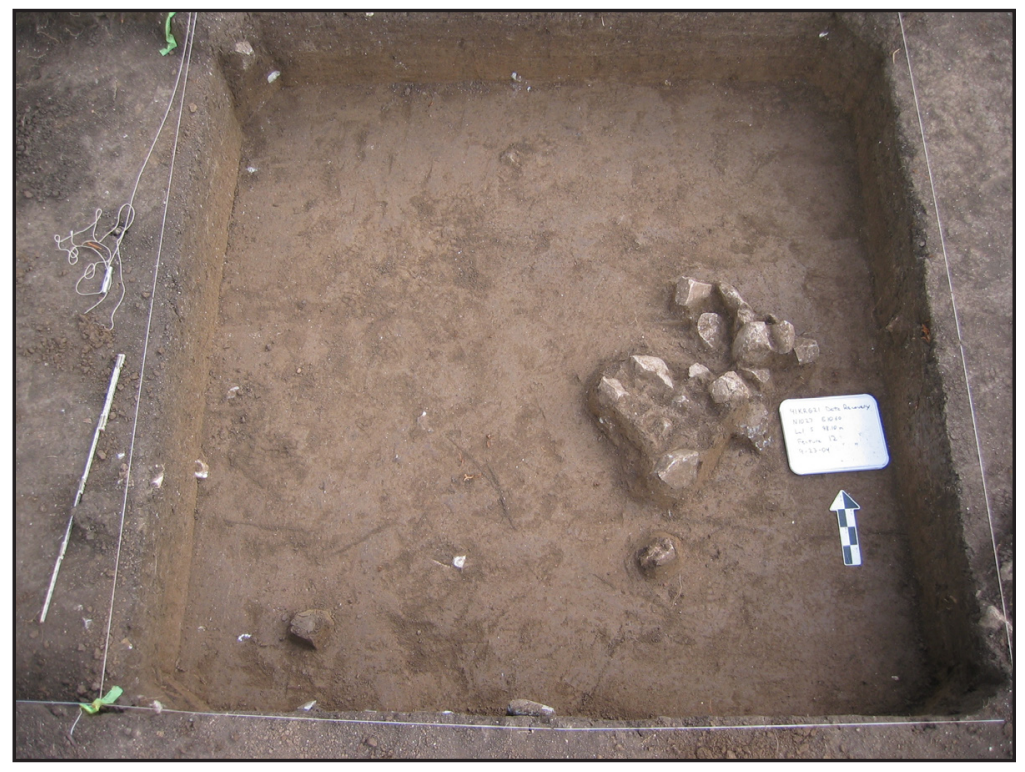

Figure 7.7. Feature 12, small burned rock cluster, facing north. 


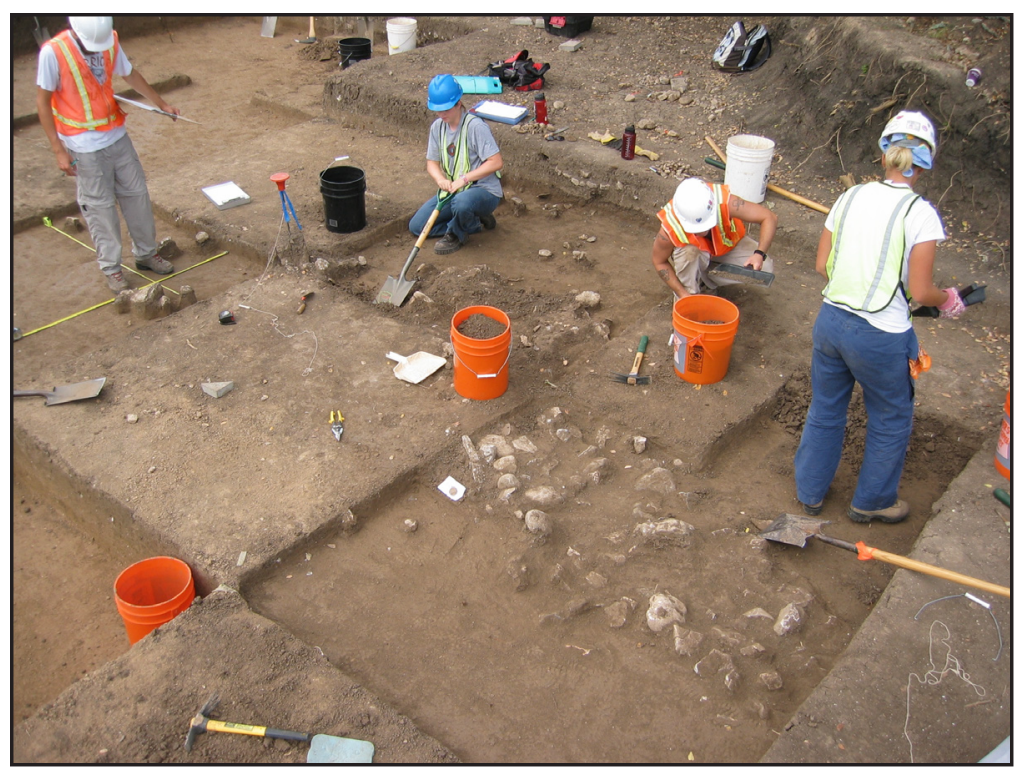

Figure 7.8. Feature 25, a large burned rock cluster, facing southwest. Note the basin-shaped Feature 20 in the unit wall, illustrating the relative positions of the features.

stratigraphic relationship was observed between the Martindale and Gower points, as specimens of both types appeared intermingled indiscriminately. Three Early Triangular points and a single Bell point were also encountered, primarily at the northern end of Area A-NE where the slope resulted in a lower natural ground surface and, presumably, soils were correspondingly younger. A single Marcos point from the southeastern corner of the excavation area appears anomalous.

At the margin of the soil horizons and higher (97.4-97.2 m), Early Archaic types such as Gower $(n=9)$, Martindale $(n=9)$, and Bandy $(n=3)$ were still prevalent, primarily within the southern portion of the block. However, levels also saw an increase in temporally later point types, including Early Triangular $(n=9)$ and Nolan $(n=3)$, and single examples of Andice, Lange, and Bulverde points. At even higher elevations, the stripping of Area A-NE produced small numbers of La Jita, Nolan, and Lange points.

\section{Area A-SE}

Area A-SE was east of CT 1 and south of CT 2 (see Figures 7.2 and 7.6). Although a much larger area was stripped for excavation, only five 2 x $2-\mathrm{m}$ units were opened. These were hand excavated as feature- focused units. Most were excavated to an elevation of $97.5 \mathrm{~m}$ to target the Early Archaic components, which, due to the natural slope, occupied a higher elevation in Area A-SE than in Area A-NE. Following the initial clearing, however, Area A-SE was abandoned in favor of pursuing excavations within Areas A-NE and A-SW.

In the limited excavations at Area A-SE, no features were recorded, although 17 bifaces and biface fragments and a concentration of burned rock were observed in Unit N1021 E1058. No carbon samples were obtained to date this block, and the only diagnostic artifact recovered was a fragmentary Andice point. Except for the rather high number of bifaces, artifact densities were low (Table 7.5). A single soil change within this area revealed a black silty clay loam yielding to dark brown silty clay beneath.

\section{Area A-SW}

Excavations in Area A-SW incorporated 15 units measuring $2 \times 2-\mathrm{m}$. Some were truncated by CT 1 or CT 2 (Figure 7.9; see Figure 7.2). The initial unit, N1017 E1050, was excavated to $97.2 \mathrm{~m}$ and functioned as a sondage to determine the extent of the targeted components. Following this, 11 units were hand stripped to roughly $97.7 \mathrm{~m}$ and then excavated normally — six as traditional units and five as feature-focused - to an elevation of $97.4 \mathrm{~m}$. The three remaining units (Units N1021 E1048-E1052) were hand stripped to an elevation of $97.6 \mathrm{~m}$, but not pursued further.

Within Area A-SW, the very dark grayish brown silty clay loam of the upper soil horizons continued to an elevation of approximately 97.6-97.5 m, overlying the brown to yellowish-brown clay loam of the lower $\mathrm{B}$ horizon. Excavations identified seven features in this block. Five features (Features 13, 16/17, 32, 34, 35 ) were found at varying depths within the upper horizon, all of which consisted primarily of burned rock clusters (see Figure 7.9; Table 7.6). Features 13, 34 , and 35 occurred near the lower elevation of this horizon, and may be more appropriately associated 
Table 7.2. Area A-NE Feature Distribution and Associations

\begin{tabular}{|c|c|c|c|c|c|c|c|c|}
\hline Area & Feat. & Component & Description & Elevation & \begin{tabular}{|c|} 
Direct Date \\
(2 sigma cal B.P.)
\end{tabular} & $\begin{array}{l}\text { Relative } \\
\text { Dating }\end{array}$ & $\begin{array}{c}\text { Soil } \\
\text { Horizon }\end{array}$ & Associated Points \\
\hline \multirow[t]{15}{*}{ A-NE } & $\mathrm{F} 7$ & \begin{tabular}{|c|} 
Occupation \\
Zone 4
\end{tabular} & $\begin{array}{l}\text { Burned rock cluster, } \\
\text { shallow basin }\end{array}$ & $97.46-97.21$ & $3720-3560$ & & $\begin{array}{l}\text { 2Ab2?/ } \\
2 \mathrm{Bw}\end{array}$ & Early Triangular \\
\hline & F6 & $\begin{array}{c}\text { Occupation } \\
\text { Zone } 3\end{array}$ & $\begin{array}{l}\text { Burned rock cluster, } \\
\text { basin-shaped }\end{array}$ & $97.85-97.4$ & None & & $\begin{array}{c}\text { 2Ab1/ } \\
2 \mathrm{Ab} 2 \\
\text { interface }\end{array}$ & $\begin{array}{l}\text { Lange, La Jita, } \\
\text { Narrow Stem } \\
\text { Martindale }\end{array}$ \\
\hline & $\mathrm{F} 20$ & $\begin{array}{c}\text { Occupation } \\
\text { Zone } 3\end{array}$ & \begin{tabular}{|c|}
$\begin{array}{c}\text { Small burned rock } \\
\text { cluster, rock-lined } \\
\text { hearth, basinlike shape } \\
\text { with some layering }\end{array}$ \\
\end{tabular} & $97.30-97.19$ & None & $\begin{array}{c}4400-4100 \\
\text { below, to } \\
\text { south }\end{array}$ & $2 \mathrm{Bw}$ & $\begin{array}{l}\text { Early Triangular, } \\
\text { Martindale, Nolan }\end{array}$ \\
\hline & F15 & \begin{tabular}{|c|} 
Occupation \\
Zone 3
\end{tabular} & $\begin{array}{l}\text { Burned rock scatter, } \\
\text { relatively flat }\end{array}$ & $97.48-97.22$ & None & $\begin{array}{c}\text { above } \\
6280-6000\end{array}$ & $2 \mathrm{Bw}$ & $\begin{array}{l}\text { None directly } \\
\text { associated }\end{array}$ \\
\hline & F18 & $\begin{array}{c}\text { Occupation } \\
\text { Zone } 3\end{array}$ & $\begin{array}{l}\text { Small burned rock } \\
\text { cluster, relatively flat }\end{array}$ & $97.3-97.15$ & None & & $2 \mathrm{Bw}$ & $\begin{array}{l}\text { None directly } \\
\text { associated }\end{array}$ \\
\hline & F19 & $\begin{array}{c}\text { Occupation } \\
\text { Zone } 3\end{array}$ & $\begin{array}{l}\text { Burned rock scatter/ } \\
\text { incipient midden }\end{array}$ & $97.46-97.22$ & $\begin{array}{c}4820-4520 \text { and } \\
4470-4450\end{array}$ & & $\begin{array}{l}2 \mathrm{Ab} 2 \mathrm{I} \\
2 \mathrm{Bw}\end{array}$ & $\begin{array}{l}\text { Early Triangular, } \\
\text { Gower, Martindale }\end{array}$ \\
\hline & $\mathrm{F} 24$ & \begin{tabular}{|c|} 
Occupation \\
Zone 2
\end{tabular} & $\begin{array}{l}\text { Small burned rock } \\
\text { cluster, flat }\end{array}$ & $97.2-97.1$ & None & $\begin{array}{c}4400-4100 \\
\text { above }\end{array}$ & 2Bw & $\begin{array}{l}\text { None directly } \\
\text { associated }\end{array}$ \\
\hline & F21 & \begin{tabular}{|c|} 
Occupation \\
Zone 2
\end{tabular} & $\begin{array}{c}\text { Small burned rock } \\
\text { cluster, some layering }\end{array}$ & 97.23-97.07 & None & $\begin{array}{c}6280-6000 \\
\text { above, to } \\
\text { south }\end{array}$ & $2 \mathrm{Bw}$ & Martindale \\
\hline & $\mathrm{F} 22$ & \begin{tabular}{|c|} 
Occupation \\
Zone 2
\end{tabular} & $\begin{array}{c}\text { Burned rock cluster with } \\
\text { associated scatter }\end{array}$ & $97.2-97.04$ & $6180-5920$ & & $2 \mathrm{Bw}$ & Martindale, Untyped \\
\hline & F12 & \begin{tabular}{|l|} 
Occupation \\
Zone 2
\end{tabular} & $\begin{array}{l}\text { Small burned rock } \\
\text { cluster, relatively flat }\end{array}$ & $97.26-97.12$ & None & above F14 & $2 B w$ & Untyped \\
\hline & $\mathrm{F}^{*}$ & \begin{tabular}{|c|} 
Occupation \\
Zone 2
\end{tabular} & $\begin{array}{c}\text { Burned rock scatter } \\
\text { with associated partially } \\
\text { excavated cluster, flat }\end{array}$ & $97.1-96.9$ & $\begin{array}{c}6410-6170 \text { and } \\
6150-6110 \text { and } \\
6080-6000\end{array}$ & & $\begin{array}{l}\text { Upper B } \\
\text { horizon }\end{array}$ & $\begin{array}{l}\text { None directly } \\
\text { associated }\end{array}$ \\
\hline & $\begin{array}{l}\text { F25/ } \\
\text { F26 }\end{array}$ & \begin{tabular}{|c|} 
Occupation \\
Zone 2
\end{tabular} & $\begin{array}{l}\text { Burned rock cluster, } \\
\text { relatively flat }\end{array}$ & \begin{tabular}{|c|}
$97.07-96.95 /$ \\
$97.13-96.96$
\end{tabular} & $\begin{array}{c}5320-5050 / \\
7150-7130 \text { and } \\
7020-6860\end{array}$ & & $2 \mathrm{Bw}$ & $\begin{array}{l}\text { Bandy, Gower, } \\
\text { Martindale }\end{array}$ \\
\hline & F14 & \begin{tabular}{|c|} 
Occupation \\
Zone 1
\end{tabular} & $\begin{array}{c}\text { Small burned rock } \\
\text { cluster, basinlike shape }\end{array}$ & $97.12-96.97$ & $7570-7420$ & below F12 & 2Bw & $\begin{array}{l}\text { None directly } \\
\text { associated }\end{array}$ \\
\hline & $\mathrm{F} 29 / 30$ & $\begin{array}{c}\text { Occupation } \\
\text { Zone } 1\end{array}$ & $\begin{array}{l}\text { Small clusters of burned } \\
\text { rock, debitage, pebbles, } \\
\text { relatively flat }\end{array}$ & \begin{tabular}{|l|}
$96.93-96.88 /$ \\
$96.96-96.92$
\end{tabular} & None & & $2 B w$ & $\begin{array}{l}\text { None directly } \\
\text { associated }\end{array}$ \\
\hline & F27 & $\begin{array}{l}\text { Occupation } \\
\text { Zone } 1\end{array}$ & $\begin{array}{l}\text { Small burned rock } \\
\text { cluster, relatively flat }\end{array}$ & 97.01-96.95 & None & & $2 B w$ & $\begin{array}{c}\text { Early Barbed, Devil's } \\
\text { Variant }\end{array}$ \\
\hline
\end{tabular}

${ }^{*}$ Feature from testing.

with the B horizon beneath. Of these, Feature 34 (actually three closely associated small burned rock clusters) had relatively good organic preservation and produced ample faunal evidence, including bison bone. The B horizon contained two features: Feature 31 (a small burned rock cluster) and Feature 33 (a dense cluster of lithic debitage in association with a large chert slab from which detached flakes were able to be conjoined) (see Appendix C).

\section{RADIOCARBON DATING - AREA A-SW}

Three $1 \sigma$ conventional radiocarbon dates from Area A-SW suggest a temporal range for the upper portion of the B horizon between ca. 5,570-5,420 B.P. (see Table 7.1). Near the boundary of the B and upper horizons, Feature 34 produced two $1 \sigma$ conventional radiocarbon dates with an average age of $4978 \pm 31$ B.P., one at $5320 \pm 40$ B.P., and a fourth assay with a date of $4090 \pm 40$ B.P. All were found within $3 \mathrm{~cm}$ of elevation and $1 \mathrm{~m}$ horizontally of each other. While the earlier dates may be associated with the B hori- 
Table 7.3. Area A-NE Artifact Count and Density per Cubic Meter from Data Recovery Block Units

\begin{tabular}{|c|c|c|c|c|c|c|c|c|c|}
\hline \multirow{2}{*}{\multicolumn{2}{|c|}{ Cultural Horizon }} & \multicolumn{8}{|c|}{ Artifact Type } \\
\hline & & Biface & Core & Debitage* $^{*}$ & Fauna* & Ground Stone & Manuport & Mod. Flake & Proj. Point \\
\hline Occupation Zone 3 & & 104 & 40 & 7660 & 106 & 4 & 0 & 60 & 40 \\
\hline artifacts per $\mathrm{m}^{3}$ & 34.40 & 3.0 & 1.2 & 111.3 & 1.5 & 0.1 & 0.0 & 1.7 & 1.2 \\
\hline Occupation Zone 2 & & 70 & 37 & 9371 & 230 & 1 & 1 & 67 & 57 \\
\hline artifacts per $\mathrm{m}^{3}$ & 22.80 & 3.1 & 1.6 & 205.5 & 5.0 & 0.0 & 0.0 & 2.9 & 2.5 \\
\hline Occupation Zone 1 & & 19 & 2 & 1336 & 28 & 1 & 0 & 9 & 6 \\
\hline artifacts per $\mathrm{m}^{3}$ & 14.50 & 1.3 & 0.1 & 46.1 & 1.0 & 0.1 & 0.0 & 0.6 & 0.4 \\
\hline
\end{tabular}

zon just below the feature, the latest may suggest a moderate degree of compression. A charcoal sample recovered from Feature 13, also at the soil boundary, returned a $1 \sigma$ conventional radiocarbon date of $4970 \pm 40$ B.P. consistent with the average of two dates from Feature 34. Above, an average of two assays from Feature $16 / 17$ was $4170 \pm 28$ B.P.

\section{Artifact Distribution}

Within the B horizon, Early Archaic point types predominate, including Gower, Martindale, Baker, and Early Triangular (see Table 7.4). At the boundary of the B and upper soil horizons and above, numerous Early Triangular points were recovered, with 10 occurring between 97.6 and $97.7 \mathrm{~m}$ in elevation. These levels also yielded small numbers of Martindale, Gower, Bell, Andice, and Lange points. Within the upper excavated levels (97.6-97.8 m), Middle Archaic Nolan points and a single La Jita occurred; additional La Jita examples were recovered from the backdirt generated during mechanical stripping, suggesting a later relative date for that type.

In contrast to Area A-NE, artifact totals were relatively high (Table 7.7), with nearly twice the number of bifaces occurring and most units producing multiple stone tools and moderate debitage counts, primarily within the higher soil horizons. Though relatively small in size and number, faunal materials were also relatively prevalent within these levels in comparison to the other areas of the site, suggesting an area of either more-intense food processing or better organic preservation. Below, within the B horizon, artifact density decreased significantly.

\section{Area A-NW}

As fieldwork progressed, it appeared that the Gatlin site might harbor an isolable component representing a possible transition from the late Early to early Middle Archaic periods, an occurrence rare within Central Texas archaeology (Mahoney et al. 2003a:91). Because this possible occupation layer appeared to have been mechanically removed as overburden within other areas of the site, such as Area A-NE, TxDOT permitted the excavation of supplemental units in Area A-NW to pursue this component.

Area A-NW lies immediately southeast of TUs 4A-C, which produced Feature 2, and comprised 10 excavation units $(2 \times 2-\mathrm{m})$; portions of two units were cut by BHT 4 to the west, and three units were truncated by CT 2 to the south (see Figures 7.2 and 7.9). These units were hand stripped from 97.8-97.7 $\mathrm{m}$ and then excavated by usual methods - six traditional and four feature-focused-to an elevation of $97.5 \mathrm{~m}$.

Only one feature was encountered within Area A-NW. This was Feature 8, a pair of burned rock clusters, which was discovered within the dark grayish brown upper soil horizon during the mechanical stripping of the area (see Figure 7.9). Relatively high amounts of burned rock were observed throughout this block, but these lacked any discernible patterning or definite feature association (Figure 7.10).

\section{RADIOCARBon Dating - AREA A-NW}

Radiocarbon assays obtained from Unit N1023 E1042 at $97.5 \mathrm{~m}$ provided a $1 \sigma$ conventional radiocarbon date of $3930 \pm 40$ B.P. (see Table 7.1). 
Table 7.4. Vertical Distribution of Projectile Point Types within Data Recovery Units

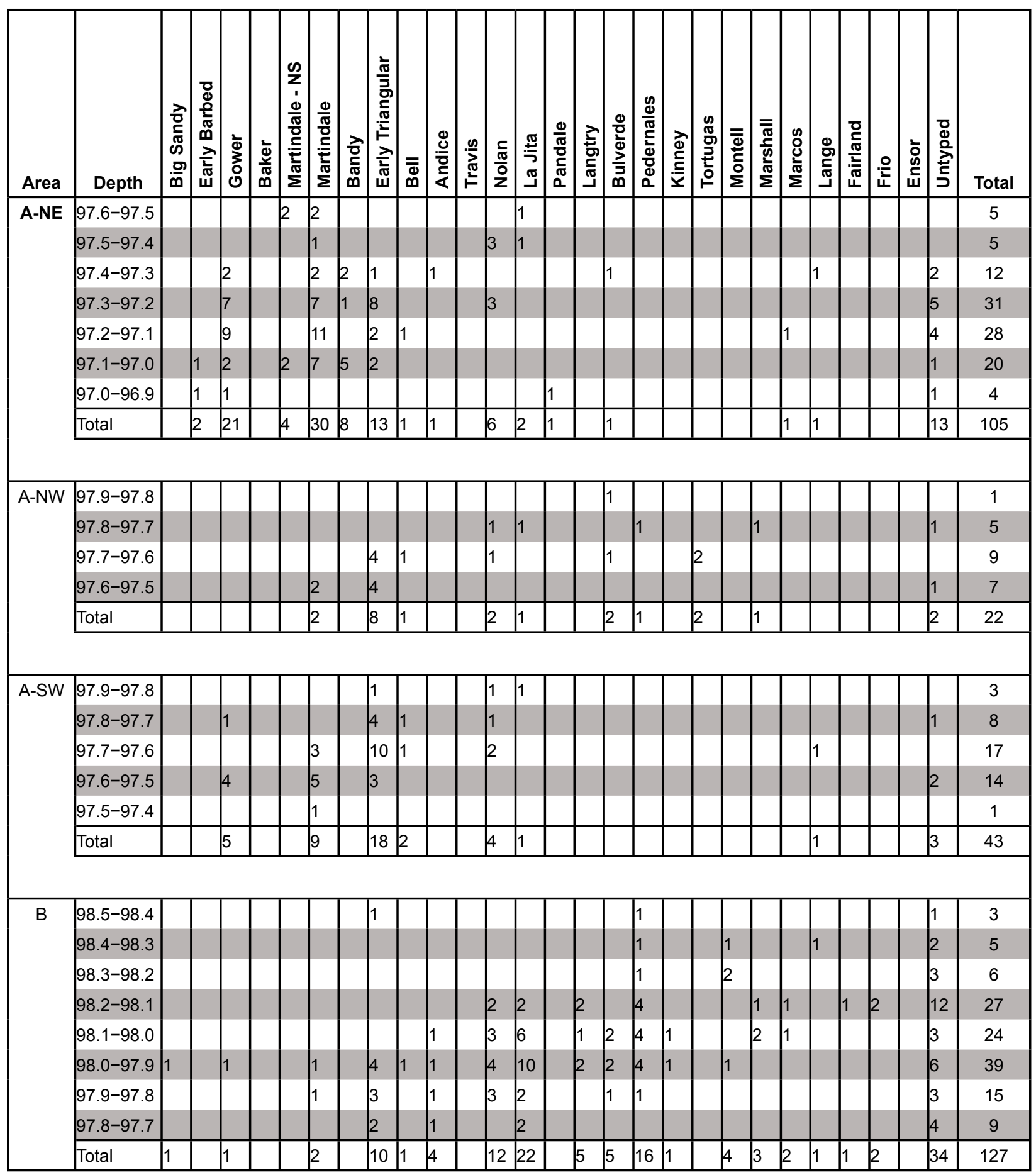

Note: totals do not include points from Column Samples or points from screening of multiple 10-cm levels. 
Table 7.5. Area A-SE Artifact Count and Density per Cubic Meter from Data Recovery Block Units

\begin{tabular}{|cc|c|c|c|c|c|c|c|c|}
\cline { 2 - 11 } \multicolumn{1}{c|}{} & \multicolumn{9}{c|}{ Artifact Type } \\
\hline Cultural Horizon & Biface & Core & Debitage & Fauna & Ground Stone & Manuport & Mod. Flake & Proj. Point \\
\hline Occupation Zone 3 & 22 & 2 & 0 & 0 & 0 & 0 & 6 & 1 \\
\hline artifacts per $\mathrm{m}^{3}$ & 3.16 & 7.0 & 0.6 & 0.0 & 0.0 & 0.0 & 0.0 & 1.9 & 0.3 \\
\hline
\end{tabular}

Another sample at the same elevation but farther to the northeast (within Unit N1025 E1048) had a $1 \sigma$ conventional radiocarbon date of $4400 \pm 40$ B.P. This second sample should have been younger or of the same age as the first sample, since the site slopes downwards to the north. This shows the complexity of making chronological associations between surfaces and artifacts separated over short distances.

\section{Artifact Distribution}

The densities of lithic tools were much higher-over twice the densities of bifaces, four times the cores, and three times the ground stones - than those within the corresponding components of Area ANE, while debitage counts remained similar (Table 7.8). Single examples of Pedernales, Nolan, La Jita, and Marshall points were found during hand stripping between 97.8 and $97.7 \mathrm{~m}$ (see Table 7.4). Nine points-Nolan, Bulverde, Bell, two Tortugas, and four Early Triangular - were recovered from between 97.7 and $97.6 \mathrm{~m}$. The final level, 97.6-97.5 $\mathrm{m}$, produced four points of the Early Triangular type and two Martindale points.

\section{AREA B}

Area B was just south of the burned rock midden and encompassed a block of contiguous units and a single 2 x 2-m unit (N1022 E1030) (Figures 7.11 and 7.12; see Figure 7.2). The latter was situated near the southern edge of the midden and was separated from the contiguous units by CT 2 . The exploration of Area B consisted primarily of traditional units, focusing on discerning possible stratified deposits associated with the use and formation of the burned rock midden.

The area of overburden mechanically stripped in Area B measured approximately $12.0 \times 10.0 \times 0.2$ $\mathrm{m}$, a volume of $24 \mathrm{~m}^{3}$. Of the total $43.04 \mathrm{~m}^{3}$ of soil dug by hand within Area B throughout the course of the excavations, $28.44 \mathrm{~m}^{3}$ were excavated as traditional units. Feature-focused excavations, which were introduced within Area B at the later stages of fieldwork, accounted for the remaining $14.60 \mathrm{~m}^{3}$.

\section{UNIT N1022 E1030}

Placed northwest of the juncture of CTs 2 and 3, this single $2 \times 2-m$ excavation unit was intended to address the midden's structure more directly than the block units of Area B. It was hoped that this unit would explore the edge or margin of the midden. Beneath an approximately $25-\mathrm{cm}$-thick colluvial layer, soils consisted of $30 \mathrm{~cm}$ of black silty clay loam; these appeared to continue beyond the unit's arbitrary termination at an elevation of $98.1 \mathrm{~m}$. Some burned rock was present, but not in large quantities, suggesting that the unit did intersect the southern margin of the midden, and that most of the unit was outside of the midden. Single examples of Early Triangular and Pedernales points overlay examples of the Late Archaic Lange and Montell types, indicating mixing. Unfortunately, due to a variety of factors such as tree roots, time, focus on the Early Archaic cultural remains, and inclement weather, this unit was abandoned prior to its full completion.

\section{Area B Block Units}

The block of contiguous units comprised 15 units ( $2 \times 2-m)$, of which the three easternmost units were slightly truncated by BHT 4 (see Figure 7.11). This area originally consisted of 10 units-Units N1016-1018 to E1030-E1038 - most of which were excavated to $97.7 \mathrm{~m}$. A single unit, Unit N1016 E1038, extended to $97.6 \mathrm{~m}$ and functioned as a sondage for determining the ending levels of subsequent units.

The discovery of a fragment of a human skull (Feature 23) within Unit N1016 E1038 prompted the placement of five supplemental $2 \times 2-m$ units to the south and east for the purpose of determining 


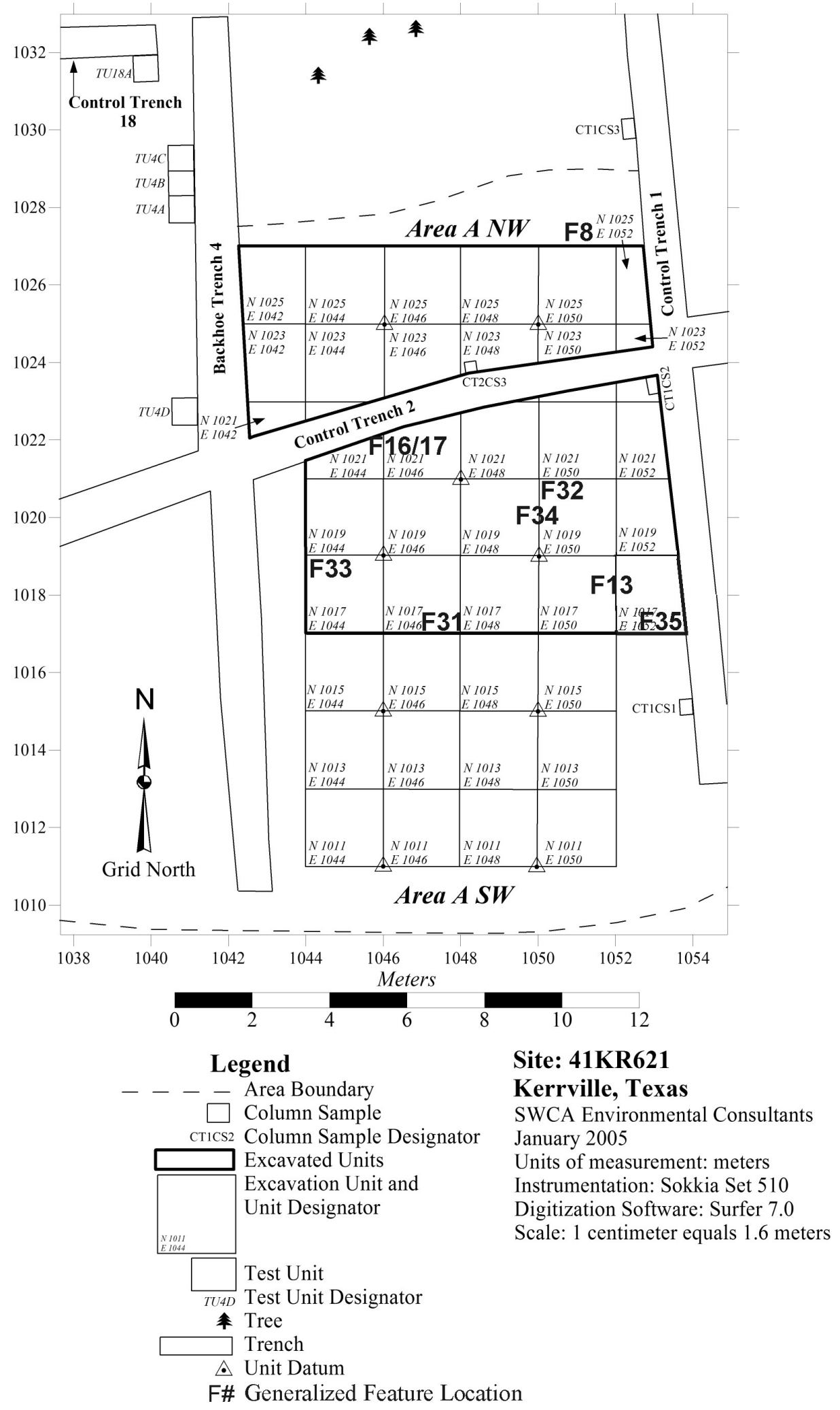

Figure 7.9. Area A-NW and Area A-SW excavation blocks and unit numbers. 
Table 7.6. Area A-SW Feature Distribution and Associations

\begin{tabular}{|c|c|c|c|c|c|c|c|c|}
\hline Area & Feat. & Component & Description & Elevation & $\begin{array}{c}\text { Direct Date } \\
\text { (2-sigma cal B.P.) }\end{array}$ & $\begin{array}{l}\text { Relative } \\
\text { Dating }\end{array}$ & $\begin{array}{c}\text { Soil } \\
\text { Horizon }\end{array}$ & Associated Points \\
\hline \multirow[t]{10}{*}{ A-SW } & F16/17 & $\begin{array}{c}\text { Occupation } \\
\text { Zone } 3\end{array}$ & $\begin{array}{c}\text { Burned rock cluster } \\
\text { (F16) and scatter } \\
\text { (F17) }\end{array}$ & 97.77-97.55 & $\begin{array}{c}4830-4530 / \\
4850-4800 \text { and } \\
4770-4620\end{array}$ & & $\begin{array}{c}\text { base of } \\
2 \mathrm{Ab} 2\end{array}$ & $\begin{array}{c}\text { Associated: Bell, Early } \\
\text { Triangular, } \\
\text { Martindale }\end{array}$ \\
\hline & F32 & $\begin{array}{l}\text { Occupation } \\
\text { Zone } 3\end{array}$ & $\begin{array}{c}\text { Cluster of debitage } \\
\text { cluster and some } \\
\text { burned rock }\end{array}$ & $97.71-97.62$ & None & above F34 & $2 \mathrm{Ab} 2$ & $\begin{array}{c}\text { Above-Adjacent: Early } \\
\text { Triangular, Nolan, } \\
\text { Untyped }\end{array}$ \\
\hline & F31 & $\begin{array}{l}\text { Occupation } \\
\text { Zone } 2\end{array}$ & $\begin{array}{c}\text { Small burned rock } \\
\text { cluster, relatively } \\
\text { flat }\end{array}$ & $97.7-97.58$ & None & $\begin{array}{l}\text { southwestern } \\
\text { corner }\end{array}$ & $\begin{array}{l}\text { Upper } \\
2 \mathrm{Bw}\end{array}$ & $\begin{array}{c}\text { Above-Adjacent: Early } \\
\text { Triangular, } \\
\text { Gower }\end{array}$ \\
\hline & \multirow{4}{*}{ F34 } & \multirow{4}{*}{$\begin{array}{l}\text { Occupation } \\
\text { Zone } 2\end{array}$} & \multirow{4}{*}{$\begin{array}{c}\text { Three small } \\
\text { burned rock } \\
\text { clusters (internal } \\
\text { concentrations A-C) } \\
\text { with associated } \\
\text { scatter }\end{array}$} & \multirow{4}{*}{$97.61-97.47$} & $5890-5610$ & \multirow{4}{*}{ below F32 } & \multirow{4}{*}{$\begin{array}{c}\text { base of } \\
2 A B k\end{array}$} & \multirow{4}{*}{$\begin{array}{l}\text { Associated: Gower, } \\
\text { Martindale }\end{array}$} \\
\hline & & & & & $\begin{array}{c}5860-5830 \text { and } \\
5750-5610\end{array}$ & & & \\
\hline & & & & & $\begin{array}{c}4810-4750 \text { and } \\
4710-4500 \text { and } \\
4480-4440\end{array}$ & & & \\
\hline & & & & & $6200-5990$ & & & \\
\hline & F13 & $\begin{array}{l}\text { Occupation } \\
\text { Zone } 2\end{array}$ & $\begin{array}{c}\text { Burned rock cluster, } \\
\text { flat }\end{array}$ & $97.75-97.49$ & $\begin{array}{c}5860-5830 \text { and } \\
5750-5610\end{array}$ & Above F35? & $\begin{array}{l}\text { Base of } \\
\text { 2Ab2/ } \\
\text { Upper B } \\
\text { horizon }\end{array}$ & Associated: Martindale \\
\hline & F35 & $\begin{array}{l}\text { Occupation } \\
\text { Zone } 2\end{array}$ & $\begin{array}{c}\text { Small burned rock } \\
\text { cluster, basin- } \\
\text { shaped }\end{array}$ & $97.55-97.43$ & None & $\begin{array}{c}5860-5610 \\
\text { above?, } \\
\text { below F13? }\end{array}$ & $2 \mathrm{ABk}$ & $\begin{array}{c}\text { Above-Adjacent: } \\
\text { Baker, Early Triangular, } \\
\text { La Jita, Martindale, } \\
\text { Nolan }\end{array}$ \\
\hline & F33 & $\begin{array}{l}\text { Occupation } \\
\text { Zone } 2\end{array}$ & $\begin{array}{l}\text { Debitage cluster, } \\
\text { flat }\end{array}$ & $97.61-97.51$ & $6300-6180$ & $\begin{array}{l}6420-6290 \\
\text { above }\end{array}$ & $\begin{array}{l}\text { Upper } \\
2 \mathrm{Bk}\end{array}$ & $\begin{array}{l}\text { Associated: Andice, } \\
\text { Early Triangular, } \\
\text { Gower, Martindale }\end{array}$ \\
\hline
\end{tabular}

whether this was an isolated occurrence or part of a burial. These units were excavated as feature-focused units to just above the level of the feature and subsequently as traditional units, terminating below the feature at $97.8 \mathrm{~m}$. These revealed no further evidence of human remains.

Excavations within Area B were conducted primarily within the $2 \mathrm{Ab}$ horizons. The black silty clay upper horizon extended to around $98.1 \mathrm{~m}$ in elevation, and the lower, very dark grayish brown stratum was roughly $30 \mathrm{~cm}$ thick, yielding to the brown/dark yellowish brown $\mathrm{B}$ horizon in most of the units. Features 9,10 , and 11 , two burned rock clusters and a concentration of burned caliche-like material, were found at roughly similar elevations (Table 7.9; see Figure 7.12). Below these, the lower soil horizon contained additional burned rock concentrations, Features 36 and 37, and Feature 23, the human skull fragment mentioned above. Feature 28, an amorphous cluster of burned rock, appeared to occur at the boundary of the $2 \mathrm{Ab}$ and lower $\mathrm{B}$ horizon, but may be better associated with the latter. Only Feature 38, a small, discrete cluster of burned rock, was resting clearly within the soils of the $B$ horizon. In all, eight features were exposed and explored in Area B.

\section{Radiocarbon Dating - AREA B}

Assays from Features 9 and 10 provided respective $1 \sigma$ conventional radiocarbon dates of $1810 \pm 60$ B.P. and $1290 \pm 60$ B.P. indicating a fairly late association (see Table 7.1). Charcoal from Feature 37, from an elevation of $97.94 \mathrm{~m}$, yielded a $1 \sigma$ conventional radiocarbon date of $3850 \pm 40$ B.P. A second sample from a non-feature context to the northwest produced a similar $1 \sigma$ conventional radiocarbon date of $3750 \pm 40$ B.P. at $97.86 \mathrm{~m}$, near the base of the stratum. At the contact with the lower B horizons, two charcoal samples taken near the top of Feature 38 provided an average $1 \sigma$ conventional radiocarbon date of $4570 \pm 28$ B.P. A single charcoal sample assay from Feature 28, at a slightly lower elevation of $97.76 \mathrm{~m}$, has a $1 \sigma$ conventional radiocarbon date of $4980 \pm 40$ B.P. This correlates well with a non-feature 
Table 7.7. Area A-SW Artifact Count and Density per Cubic Meter from Data Recovery Block Units

\begin{tabular}{|c|c|c|c|c|c|c|c|c|}
\hline \multirow[b]{2}{*}{ Cultural Horizon } & \multicolumn{8}{|c|}{ Artifact Type } \\
\hline & Biface & Core & Debitage* $^{*}$ & Fauna* & Ground Stone & Manuport & Mod. Flake & Proj. Point \\
\hline Occupation Zone 3 & 71 & 21 & 4334 & 250 & 0 & 0 & 29 & 28 \\
\hline artifacts per $\mathrm{m}^{3} \quad 12.12$ & 5.9 & 1.7 & 178.8 & 10.3 & 0.0 & 0.0 & 2.4 & 2.3 \\
\hline Occupation Zone 2 & 62 & 14 & 5605 & 949 & 0 & 0 & 29 & 18 \\
\hline artifacts per $\mathrm{m}^{3} \quad 10.40$ & 6.0 & 1.3 & 269.5 & 45.6 & 0.0 & 0.0 & 2.8 & 1.7 \\
\hline
\end{tabular}

* Denotes that the count is representative of a $50 \%$ sample due to excavation strategy; the volume has therefore been divided by half to reflect this. Numbers may be slightly inflated due to collection within features.

sample from the southeast at $97.73-97.00 \mathrm{~m}$, which has a $1 \sigma$ conventional radiocarbon date of $4930 \pm 40$ B.P. Like those of Areas A-NE and SW, the radiocarbon results from Area $\mathrm{B}$ also suggest a rather slow accumulation of sediment at the site.

\section{Artifact Distribution}

Artifact densities within Area B were observed, in general, to be much higher than those within Area A (Table 7.10). This appears to roughly correspond with the difference in soil stratigraphy, with Area B occupying primarily the upper $2 \mathrm{Ab}$ strata, and Area A the lower boundary of these and the subsequent B horizon. Debitage totals were consistently higher within the upper strata of Area B (typically exceeding 1,000 pieces per $10-\mathrm{cm}$ level of a 2 × 2 -m unit) and with certain levels totaling between 3,000 and 4,000 pieces. Bifaces and other lithic tools were equally abundant, with a significant peak occurring between 98.1 and $97.9 \mathrm{~m}$ in elevation. Both debitage and tool counts dropped sharply within the upper B horizon. In contrast, organic preservation within the upper soils was better than in the lower levels.

Points recovered from the uppermost 2Ab horizon comprised small numbers (three or less) of a variety of Middle and Late Archaic types, including Langtry, Nolan, La Jita, Fairland, Montell, Marcos, Marshall, and Frio, and a high number $(\mathrm{n}=8)$ of Pedernales points (see Table 7.4). Most of these Pedernales and Middle Archaic types (Nolan, La Jita, and Langtry) were found at the lower margin of the horizon, although some mixing was evident.
These types were recovered in far larger numbers within the lower zone of the 2AB horizon: 11 Pedernales, 10 Nolan, and 17 La Jita. This horizon also contained a mixture of Early Triangular points $(n=7)$, Bulverde points $(\mathrm{n}=5)$, and small numbers (three or less) of Kinney, Marcos, Marshall, Montell, Langtry, Bell, Andice, Martindale, and Big Sandy points. Although these imply a fair degree of mixing within the upper levels, in the overall stratigraphic picture most of Early and Middle Archaic points underlie those of the Late Archaic.

Only two examples of Early Triangular and La Jita points and a single specimen of the Andice type were recovered from within the B horizon. Although radiocarbon dates from within the $\mathrm{B}$ horizon suggest the presence of the Upper Early Archaic component, none of the associated point types-Martindale,

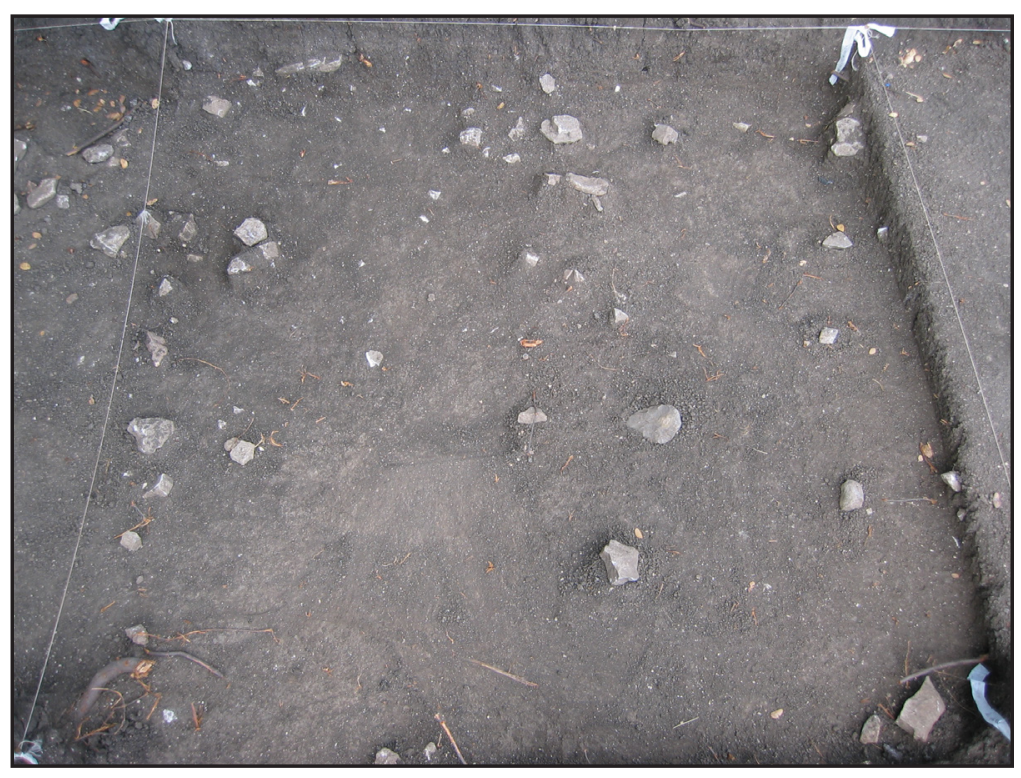

Figure 7.10. Typical density of non-feature burned rock within Area A-NW, facing north. 
Table 7.8. Area A-NW Artifact Count and Density per Cubic Meter from Data Recovery Block Units

\begin{tabular}{|c|c|c|c|c|c|c|c|c|}
\cline { 2 - 10 } \multicolumn{1}{c|}{} & \multicolumn{9}{c|}{ Artifact Type } \\
\hline Cultural Horizon & Biface & Core & Debitage* $^{*}$ & Fauna* $^{*}$ & Ground Stone & Manuport & Mod. Flake & Proj. Point \\
\hline Occupation Zone 3 & 91 & 61 & 4444 & 169 & 4 & 1 & 36 & 21 \\
\hline artifacts per $\mathrm{m}^{3}$ 12.92 & 7.0 & 4.7 & 172.0 & 6.5 & 0.3 & 0.1 & 2.8 & 1.6 \\
\hline
\end{tabular}

* Denotes that the count is representative of a $50 \%$ sample due to excavation strategy; the volume has therefore been divided by half to reflect this. Numbers may be slightly inflated due to collection within features.

Bandy, and Gower-appear within this stratum in Area B. This may be due to various factors such as the higher elevation of Area B, the heightened activity associated with the nearby midden, or the relatively shallow termination of excavations within this stratum.

\section{BURNED ROCK MIDDEN}

As mentioned, hand excavations were focused on the horizontal exposures of the Early Archaic occupations in Area A. Work in the midden was scaled back and oriented towards gathering basic structural and compositional data on the feature. In order to more fully explore the extent of the burned rock midden (Feature 1), two testing trenches were reopened (BHTs 1 and 18), an additional trench (CT 3) was excavated, and seven $30 \times 30-\mathrm{cm}$ column samples were placed along the backhoe trenches within the midden's boundaries: BHT 18, CS 1-3; CT 3, CS 1-3; BHT 1, CS 1 and CS 3 (see Figure 7.2). These efforts revealed the burned rock midden to be approximately $80 \mathrm{~cm}$ thick at its center. Occupying the upper $2 \mathrm{Ab}$ soil horizons, the midden rests above the brown to yellowish brown B horizon.

Additionally, the reopening and reexamination of BHT 18 revealed the presence of several possible pits within the trench's northern and southern walls. These were coeval with the midden, extending from the midden's base into the B horizon below. These pits were most likely related to the early use of the midden, as they underlie most of the burned rock and clearly cut into the underlying cultural component.

\section{Radiocarbon Dating}

Two radiocarbon assays were obtained from CT 3 and CS 3 near the center of the midden. The first was recovered from the middle of the midden at an elevation of $97.62 \mathrm{~m}$; this yielded a $1 \sigma$ conventional radiocarbon date of $2120 \pm 50$. The second, from the base of midden at $97.45 \mathrm{~m}$, produced a $1 \sigma$ conventional radiocarbon date of $4210 \pm 40$ B.P. Beneath the midden within the B horizon, BHT 18, CS 1 had a $1 \sigma$ conventional radiocarbon date of $5780 \pm 40$ B.P.

\section{Artifact Distribution}

Lithic debitage densities proved to be much higher within the column samples located away from the center of the midden (Table 7.11). These dropped significantly when excavations reached the B horizon below the midden. Within the midden's center, debitage counts were far lower, although still average to high in comparison with the other components of the site. The column samples produced a range of projectile points, including single examples of the following types: Marshall, Pedernales, Early Triangular, Narrow Stem Martindale, and Gower. A single Narrow Stem Martindale was encountered within the $\mathrm{B}$ horizon beneath the midden.

\section{Cultural Components}

In order to address the issues of synchronic and diachronic patterning of artifacts, activity areas, and features at the Gatlin site, steps were taken to identify and isolate cultural components (here defined as broad cultural/temporal zones that correlate to the established prehistoric record) from the excavation data. These were not always immediately distinguishable, as the various occupations were not separated vertically by clear divisions of sterile levels. Rather, the presence of cultural materials was generally consistent throughout, with only features, radiocarbon samples, temporally diagnostic artifacts, and subtle variations in artifact density providing hints as to the isolation of components or occupation zones. Within certain of the site's components an admixture of temporal indicators was observed, and the apparent compression of components was evidenced in others; the site's lower levels, how- 


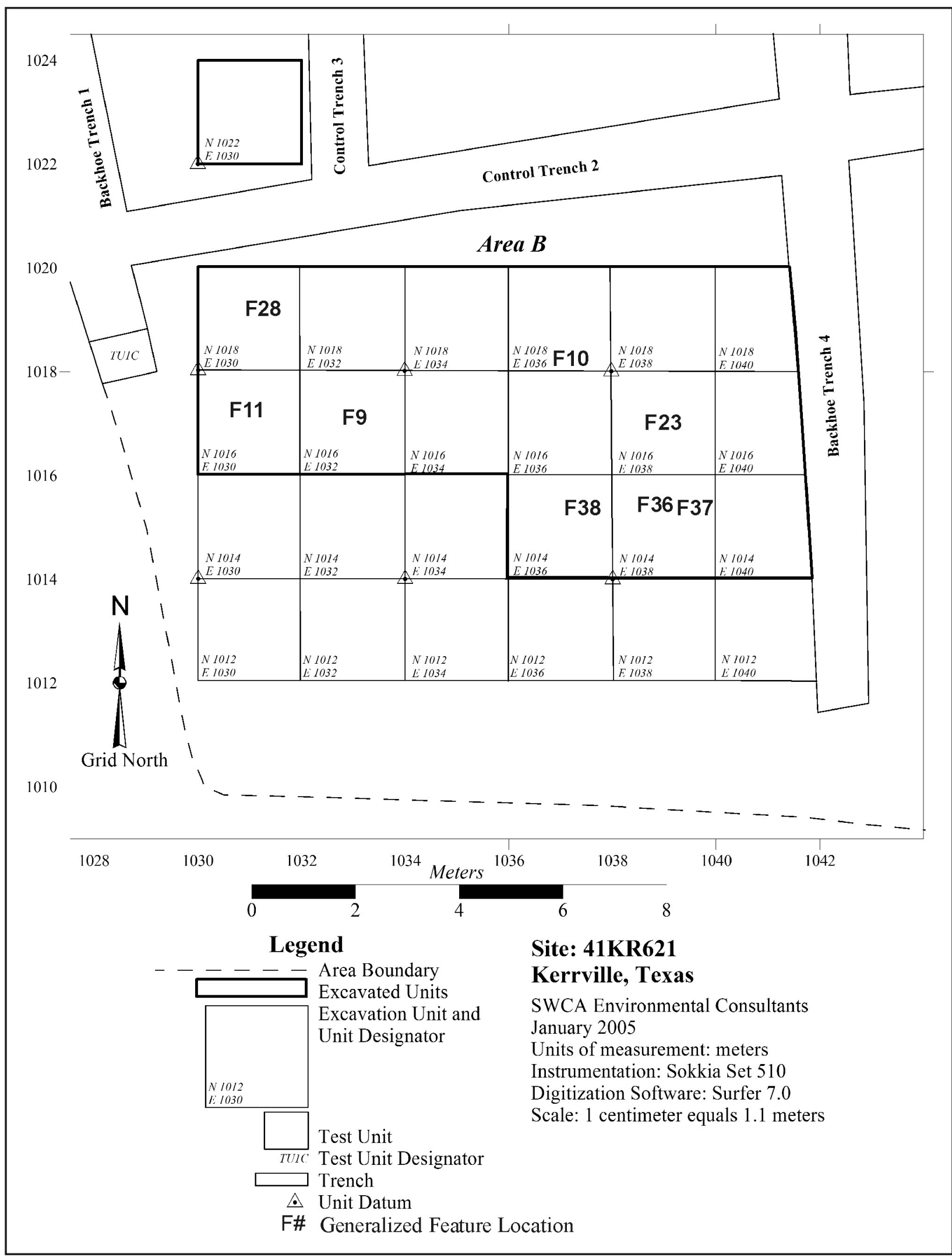

Figure 7.11. Area B excavation block and unit numbers. 


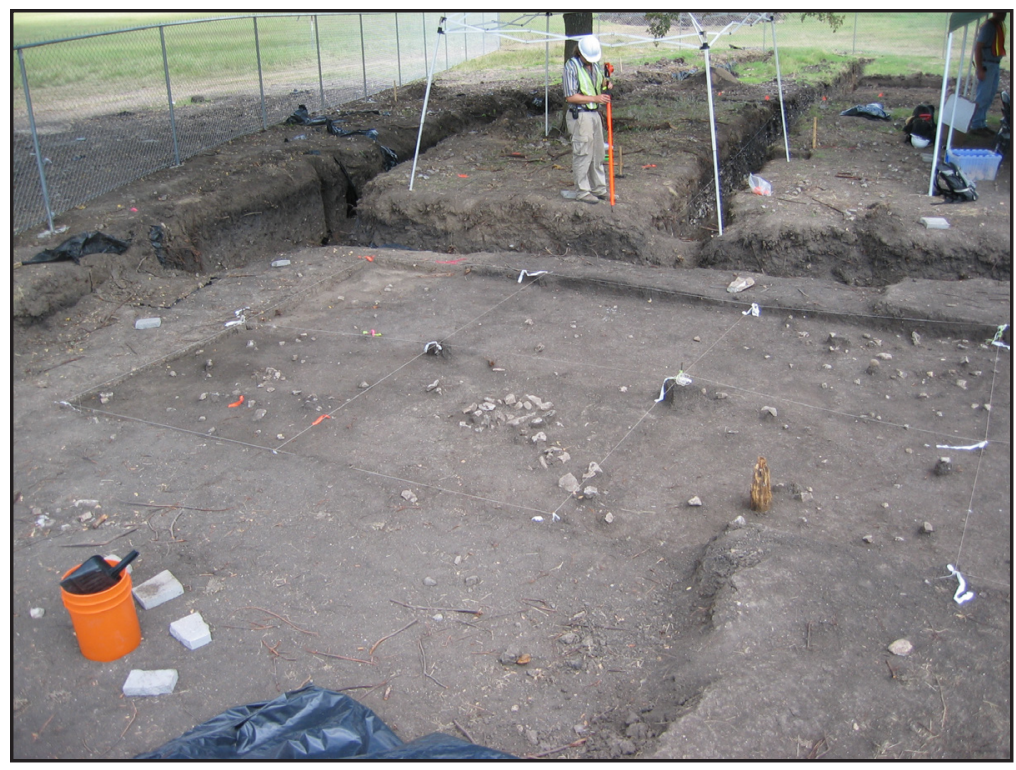

Figure 7.12. Overview of Area B block at $98.2 \mathrm{~m}$ elevation, facing north/northwest toward the midden.

temporal components and also between the individual feature analytical units within each component.

This comprehensive examination of the data suggests that four stratified cultural components can be defined with relative clarity at the Gatlin site: two isolable Early Archaic components, one overlying the other, referred to as OZs 2 and 1; a possible Late Early to Early Middle Archaic component (OZ3); and a Middle to Late Archaic component, with which the burned rock midden is associated (OZ4). These occupations, briefly outlined below, are discussed fully within Chapters 8-11, and subjected to a diachronic comparison in Chapter 12.

\section{OCCUPATION ZONE 1}

ever, appeared to exhibit a somewhat higher degree of separation. Additionally, the natural stratigraphy of the site, with its downhill slope from southwest to northeast, prevented strict vertical comparisons across the wide areas both within and between the individual excavation blocks.

For these reasons, it was necessary to first identify the components vertically and then to define them horizontally through the data set. Radiocarbon assays and temporally diagnostic artifacts were examined to discern the absolute and relative dates of features and to assess the site's stratigraphic integrity. These were then correlated across the site with elevations and the natural strata identified within the control trenches and the geomorphological analysis. The point plotting of artifacts within the field and conjoin analyses of debitage were also employed, when possible, to identify possible knapping floors and living surfaces. Feature form (e.g., basin-shaped, flat, piled) was also used to detect living surfaces; when the approximate corresponding level was determined, artifacts from the same $10-\mathrm{cm}$ level within an approximately $1-\mathrm{m}$ radius of the feature were grouped together to form a possible feature analytical unit. When the data permitted, connections were then drawn between analogously dated features and their related floors to reconstruct the living spaces in between. Such an approach allows comparisons both between the larger
The lower Early Archaic occupation is the earliest of the Gatlin site components, appearing within the lowest levels of the excavated B horizon. While OZ1 most likely extended farther horizontally, it was observed exclusively within Area A-NE due to the limitations of the data recovery program. Assays suggest that the occupation spanned from approximately $6,600-6,060$ B.P., based on $1 \sigma$ conventional radiocarbon dates.

OZ1 is represented materially by four discrete features, two associated points of the Early Barbed, Devil's Variant type, Gower and Martindale points, and small numbers of debitage and other chipped stone tools. This component represents a relatively discrete and distinguishable occupation, which can shed light on the earliest prehistoric lifeways at the Gatlin site and provide a valuable comparison and contrast for the site's later occupations.

\section{OCCUPATION ZONE 2}

Occupying the upper margins of the B horizon, OZ2 was identified (through diagnostic point types and absolute dates) primarily within Areas A-NE and A-SW. Compared to the younger components, this component appears to be relatively intact and of good integrity. 
Table 7.9. Area B Feature Distribution and Associations

\begin{tabular}{|c|c|c|c|c|c|c|c|c|}
\hline Area & Feat. & Component & Description & Elevation & $\begin{array}{c}\text { Direct Date } \\
\text { (2-sigma cal B.P.) }\end{array}$ & $\begin{array}{l}\text { Relative } \\
\text { Dating }\end{array}$ & $\begin{array}{c}\text { Soil } \\
\text { Horizon }\end{array}$ & Associated Points \\
\hline \multirow[t]{8}{*}{ B } & F9 & $\begin{array}{c}\text { Occupation } \\
\text { Zone } 4\end{array}$ & $\begin{array}{c}\text { Small burned rock } \\
\text { cluster, relatively } \\
\text { flat }\end{array}$ & $98.3-98.2$ & $1880-1570$ & & $2 A b 1$ & $\begin{array}{l}\text { Above-Adjacent: Montell, } \\
\text { Untyped / Below-Adjacent: } \\
\text { La Jita, Marshall, Nolan, } \\
\text { Pedernales, Untyped }\end{array}$ \\
\hline & F10 & $\begin{array}{c}\text { Occupation } \\
\text { Zone } 4\end{array}$ & $\begin{array}{c}\text { Small burned } \\
\text { rock cluster, slight } \\
\text { basin-shape with } \\
\text { some layering }\end{array}$ & 98.3-98.14 & $1300-1070$ & & $2 A b 1$ & $\begin{array}{c}\text { Above-Adjacent: } \\
\text { Pedernales, Untyped / } \\
\text { Below-Adjacent: Frio, La } \\
\text { Jita, Pedernales, Untyped }\end{array}$ \\
\hline & F11 & $\begin{array}{c}\text { Occupation } \\
\text { Zone } 4\end{array}$ & $\begin{array}{c}\text { Small cluster of } \\
\text { burned material, } \\
\text { shallow basin-like }\end{array}$ & $98.25-98.12$ & None & $\begin{array}{c}4240-3980 \text { far } \\
\text { below }\end{array}$ & $2 A b 1$ & $\begin{array}{c}\text { Above-Adjacent: Untyped } \\
\text { / Below-Adjacent: Langtry, } \\
\text { Marshall, Pedernales, } \\
\text { Untyped }\end{array}$ \\
\hline & F23 & \begin{tabular}{|c|}
$\begin{array}{c}\text { Occupation } \\
\text { Zone } 4\end{array}$ \\
\end{tabular} & $\begin{array}{c}\text { Human skull } \\
\text { fragments }\end{array}$ & $98.02-97.95$ & None & & $2 \mathrm{ABk}$ & \\
\hline & F36 & \begin{tabular}{|c|} 
Occupation \\
Zone 4
\end{tabular} & $\begin{array}{c}\text { Small burned rock } \\
\text { cluster, stacked, } \\
\text { relatively flat base }\end{array}$ & $98.12-97.97$ & None & $\begin{array}{c}4410-4150 \\
\text { below; above } \\
\text { F37? }\end{array}$ & $2 \mathrm{ABk}$ & $\begin{array}{l}\text { Associated: La Jita, Untyped } \\
\text { / Above-Adjacent: Andice, } \\
\text { Bulverde, Kinney, La Jita, } \\
\text { Nolan / Below-Adjacent: } \\
\text { Big Sandy, Bulverde, Early } \\
\text { Triangular, Kinney, La Jita }\end{array}$ \\
\hline & F37 & $\begin{array}{c}\text { Occupation } \\
\text { Zone } 4\end{array}$ & $\begin{array}{c}\text { Small burned rock } \\
\text { cluster, relatively } \\
\text { flat }\end{array}$ & 98.03-97.93 & $\begin{array}{c}4410-4150 ; \\
\text { Charcoal near but } \\
\text { not from feature }\end{array}$ & below F36? & $2 A B k$ & $\begin{array}{c}\text { Associated: Bulverde, La } \\
\text { Jita / Above-Adjacent: } \\
\text { Bulverde, Kinney, La Jita, } \\
\text { Untyped / Below-Adjacent: } \\
\text { Early Triangular, La Jita, } \\
\text { Martindale }\end{array}$ \\
\hline & F38 & $\begin{array}{c}\text { Occupation } \\
\text { Zone } 3\end{array}$ & $\begin{array}{c}\text { Small burned rock } \\
\text { cluster, relatively } \\
\text { flat }\end{array}$ & 97.9-97.76 & $\begin{array}{c}5460-5380 \text { and } \\
5340-5290 \\
\text { just above } \\
5310-5040 \\
\end{array}$ & $\mid \begin{array}{c}5730-5600 \\
\text { below, to north }\end{array}$ & $2 \mathrm{Bk}$ & $\begin{array}{c}\text { Associated: Early Triangular, } \\
\text { La Jita / Above-Adjacent: } \\
\text { Bulverde, Kinney, La Jita, } \\
\text { Untyped }\end{array}$ \\
\hline & F28 & \begin{tabular}{|c|} 
Occupation \\
Zone 2
\end{tabular} & $\begin{array}{c}\text { Small burned rock } \\
\text { cluster, relatively } \\
\text { flat }\end{array}$ & 97.82-97.72 & $\begin{array}{c}5870-5820 \text { and } \\
5760-5610\end{array}$ & & $2 A b$ & $\begin{array}{c}\text { Associated: Untyped / } \\
\text { Above-Adjacent: Andice, } \\
\text { La Jita, Nolan, Pedernales, } \\
\text { Untyped }\end{array}$ \\
\hline
\end{tabular}

Table 7.10. Area B Artifact Count and Density per Cubic Meter from Data Recovery Block Units

\begin{tabular}{|c|c|c|c|c|c|c|c|c|}
\hline \multirow[b]{2}{*}{ Cultural Horizon } & \multicolumn{8}{|c|}{ Artifact Type } \\
\hline & Biface & Core & Debitage & Fauna & Ground Stone & Manuport & Mod. Flake & Proj. Point \\
\hline Occupation Zone 4 & 470 & 97 & 91688 & 648 & 2 & 2 & 94 & 121 \\
\hline Volume $\left(\mathrm{m}^{3}\right) \quad 36.04$ & 13.0 & 2.7 & 2544.1 & 18.0 & 0.1 & 0.1 & 2.6 & 3.4 \\
\hline Occupation Zone 3 & 49 & 21 & 3984 & 172 & 0 & 1 & 20 & 9 \\
\hline Volume $\left(\mathrm{m}^{3}\right)$ & 2.3 & 0.5 & 454.3 & 3.2 & 0.0 & 0.0 & 0.5 & 0.6 \\
\hline
\end{tabular}


Table 7.11. Debitage Densities within the Burned Rock Midden Column Samples

\begin{tabular}{|c|c|c|c|c|c|c|c|}
\hline $\begin{array}{l}\text { Relative } \\
\text { Position }\end{array}$ & North & North & West & Central & East-Central & East & South \\
\hline Level & BHT 1/ CS 3 & CT $3 /$ CS 2 & BHT 18/ CS 3 & BHT 18/ CS 2 & CT $3 /$ CS 3 & BHT 18/ CS 1 & CT $3 /$ CS 1 \\
\hline 1 & -- & -- & 25 & -- & -- & 11 & -- \\
\hline 2 & 23 & 47 & 20 & 27 & 54 & 21 & -- \\
\hline 3 & 124 & 264 & 137 & 51 & 19 & 5 & 18 \\
\hline 4 & 98 & 130 & 157 & 35 & 50 & 10 & 113 \\
\hline 5 & 91 & 124 & 193 & 34 & 46 & 12 & 75 \\
\hline 6 & 64 & 123 & 176 & 24 & 50 & 20 & 82 \\
\hline 7 & 118 & 25 & 404 & 31 & 20 & 16 & 94 \\
\hline 8 & 50 & -- & 329 & 39 & 22 & 40 & 20 \\
\hline 9 & 102 & & 257 & 21 & 33 & 93 & 218 \\
\hline 10 & 15 & & 191 & 36 & 24 & 12 & 225 \\
\hline 11 & -- & & 94 & 33 & 14 & 47 & 145 \\
\hline 12 & & & 26 & 4 & -- & 34 & -- \\
\hline 13 & & & -- & 0 & & 0 & \\
\hline 14 & & & & -- & & -- & \\
\hline Totals & 685 & 713 & 2009 & 335 & 332 & 321 & 990 \\
\hline
\end{tabular}

-- Denotes not screened or not excavated.

All levels are in 10-cm increments except for Level 1, which was often up to $30 \mathrm{~cm}$ in thickness.

The associated point assemblage from OZ2 comprises a number of projectile point types typically identified with the Early Archaic: Gower, Martindale, Narrow Stem Martindale (see Appendix C), Bandy, and Baker. These appear to correlate relatively well with the temporal range provided by $1 \sigma$ conventional radiocarbon dates, which range between approximately 6,100-4,500 B.P. A similar date was obtained from a feature at the base of excavations within Area $\mathrm{B}$, with a mixture of Middle and Late Archaic point types immediately (within 10-20 cm) above.

Within Area A, however, the upper Early Archaic component is spatially extensive and exhibits little, if any, compression. Indeed, the excavators did not observe much patination on the lithics from this component, suggesting that the artifacts were not deposited on a stable surface, but were fairly rapidly buried. In all, seven features from Area A$\mathrm{NE}$, five from Area A-SW, one from a testing unit in the vicinity of Area A-NW, and one from Area B have been identified with this component, providing ample evidence with which to examine the use of space, subsistence strategies, and other avenues for interpretation of Early Archaic lifeways at the Gatlin site.

\section{OCCUPATION ZONE 3}

The data recovery excavations discerned what appeared to be an extensive component with discrete features, associated charcoal, and a proliferation of Early Triangular and Nolan points. These, along with examples of the Bell and Andice types, suggested a component reflecting the transition between the Early and Middle Archaic periods, a cultural interval that is relatively elusive in Central Texas archaeology (Mahoney et al. 2003a:91). Previously undistinguished during the testing phase, this component became the focus of supplemental excavations within Area A-NW, as discussed above.

Located primarily within the lower $2 \mathrm{Ab}$ horizon and the upper margin of the $\mathrm{B}$ horizon, this component was observed to varying extents in Areas A-NE, A-NW, and A-SW, and possibly Area B. Eight features are associated with OZ3, based on their stratigraphic relations and $1 \sigma$ conventional radiocarbon dates, which indicate an occupation spanning $4,500-3,850$ в.P. 
While the numerous Early Triangular points could indicate a possible discrete occupation, the radiocarbon assays and varied point assemblage (both earlier and later types occur) suggest a moderate degree of compression due to reduced sedimentation rates. Moreover, the features of this component are, in general, not as small or discrete as those observed in the underlying horizon, and the burned rock itself is comparatively smaller and more fragmented. Regardless, related studies have shown that even somewhat mixed sites on stable landforms can address important issues such as climatic changes, tool manufacture and use, and general prehistoric behavioral patterns (Mahoney et al. 2003a). Moreover, this component produced some of the better-preserved faunal remains at the site, which shed light on the nature of subsistence during this period.

\section{OCCUPATION ZONE 4}

The youngest component at the Gatlin site, extending from the Middle to the Late Archaic, was observed predominantly in Area B within the buried deposits south of and within the burned rock midden. While this component may once have extended more widely across the site, the machine stripping of the upper levels precluded any possible identification of Middle to Late Archaic occupation within Area A. While the testing operations suggested that colluvial deposition had steadily buried successive isolated living surfaces, the analysis of the projectile point typology, subsequent to the data recovery program, indicated that most of the deposits appeared temporally mixed. This was presumably due to cultural activities associated with the use and formation of the nearby midden. In addition, the subsequent geomorphic assessment found the colluvial deposition to be less intense than initially suspected (Chapter 6). Yet despite the apparent mixing, these periods still represent a major occupation of the site and therefore merit some consideration, albeit in a somewhat less detailed fashion than that warranted by the more intact portions of the site.

Within the deposits associated with OZ4, 10 features - including the burned rock midden-were found at varying elevations, and $1 \sigma$ conventional radiocarbon dates indicate a temporal range from approximately 3,900 B.P. to as late as 1,290 B.P. Numerous artifacts associated with these occupations were recovered, including many diagnostic point types covering all periods. Buried by the colluvial horizon, OZ4 occupied the upper 2Ab soil horizons on the site.

Although many of the specific issues raised within the research design cannot be answered for this component due to the compromised temporal integrity of these deposits, information concerning site organization and stone tool technology during this period can still be gleaned. As such, this component, which appears to represent multiple mixed and inseparable occupations, is treated in Chapter 11 as a broad temporal analytical unit related to the period of time when the midden was in use.

\section{Summary}

Data recovery excavations at the Gatlin site began with the re-excavation of selected testing trenches, the placement of additional backhoe trenches for both stratigraphic control and geomorphological studies, and the excavation of 14 column samples $(30 \times 30-\mathrm{cm})$. These were followed by extensive block excavations resulting in over $150 \mathrm{~m}^{3}$ of soil excavated by hand. Most was from Area A, of which a combined $20.60 \mathrm{~m}^{3}$ of soil were hand-stripped and $108.71 \mathrm{~m}^{3}$ were removed in controlled excavation units. These focused on the site's Early Archaic components as well as the more compressed late Early to early Middle Archaic occupation, which was identified during the course of excavations. Area B, located within deposits associated with the burned rock midden, accounted for $43.04 \mathrm{~m}^{3}$ of soil excavated in controlled units.

The data recovery investigations revealed that the Middle and Late Archaic levels south of the midden in Area B were mixed to a far greater degree than had been suggested previously by the site's testing phase. This appears due in part to the relatively slow rate of accumulation of sediment observed throughout the site, based on a comparison of radiocarbon assays and their elevations (also see Chapter 6 for a discussion of the geomorphic conditions). This was also observed to be a factor within Area A, where the Late Early to Early Middle Archaic deposits exhibited a moderate degree of compression, although a greater percentage of identifiable faunal remains. Though failing to deliver the high degree of organic preservation predicted during the testing phase, the lowest 
levels of Area A proved to have a higher degree of integrity and produced numerous features, radiocarbon dates, and diagnostic point types indicating two relatively distinct subcomponents dating to the Early Archaic. Together, these components provide a continuous view of life throughout the Archaic period in the Upper Guadalupe River Basin. 
7-28 Chapter 7 


\title{
Chapter 8
}

\section{OCCupation Zone 1}

\author{
Eric R. Oksanen, Mercedes C. Cody, and Kevin A. Miller
}

\section{INTRODUCTION}

OZ1 is the oldest excavated occupation zone at the Gatlin site. Contained in Area A-NE, approximately $124 \mathrm{~m}^{2}$ was exposed (Figure 8.1; see Figure 7.6). Thirty-one units $(2 \times 2-\mathrm{m})$ were divided into 15 traditional hand excavated units and 16 feature focused units. Approximately $14.50 \mathrm{~m}^{3}$ of deposits were excavated from OZ1. The cultural materials date to the Early Archaic period within Central Texas (Collins 1995; Johnson and Goode 1995) and South Texas archaeological chronologies (Hester 2004). OZ1 represents the smallest occupation zone defined and sampled, as it was mainly contained in one restricted portion of the site encountered late in the investigations. This hinders interpretations on overall site usage during this occupation as the full spatial extent of this zone is unknown. The cultural materials in OZ1 are the remnants of repeated short duration visitations to the site by small groups. In episodes occurring possibly hundreds of years apart, the occupants made bifaces from the abundant fine grain local chert, made flake tools from cores, and refurbished their projectiles. There is evidence that they hunted and used burned rock features for cooking. The relatively sparse density of artifacts and the few small features accumulated over a potential 600 -year period suggest the site was one of numerous similar regional sites that were briefly occupied repeatedly. Abundant high-quality lithic raw materials may have been one of many attractions of the site, but there is no evidence of extensive quarrying or reduction during OZ1, rather it appears that activities at the site were oriented around the immediate, general, subsistence activities of individuals or small groups.

\section{Chronology}

The oldest cultural radiocarbon date for $\mathrm{OZ} 1$ is a $1 \sigma$ conventional radiocarbon date of $6570 \pm 50$ B.P. from Feature 14 (Beta-206115). The terminal date of OZ1 is $6100 \pm 40$ B.P. (Beta-206122; $1 \sigma$ conventional radiocarbon date), defined by a charcoal sample analyzed from Feature 26 in OZ2. Although the elevations of the two samples are the same at 96.97 $\mathrm{m}$, Feature 26, a possible earth oven, may be intrusive from a higher elevation. Alternately, the charcoal in Feature 14 may represent residual wood. The more likely scenario is that Feature 26 represents a later occupation. A chi squared comparison of the two dates shows they are unlikely to be related $\left(X^{2}=43.8 ; \mathrm{dfl}\right.$; $\mathrm{p}>.05)$. Therefore an estimated range in radiocarbon years for OZ1 is ca. 6,600-6,060 B.P.

The temporally diagnostic lithic artifacts from OZ1 were a Gower point, two Early Barbed points, a Martindale point, and a Pandale point. Based on previous excavations, Gower points are the demonstrably oldest diagnostic, followed by Early Barbed, Martindale, and Pandale. Based on chronological data from other sites, the Gower, Early Barbed, and Martindale point types fall within the specified temporal range of OZ1. For

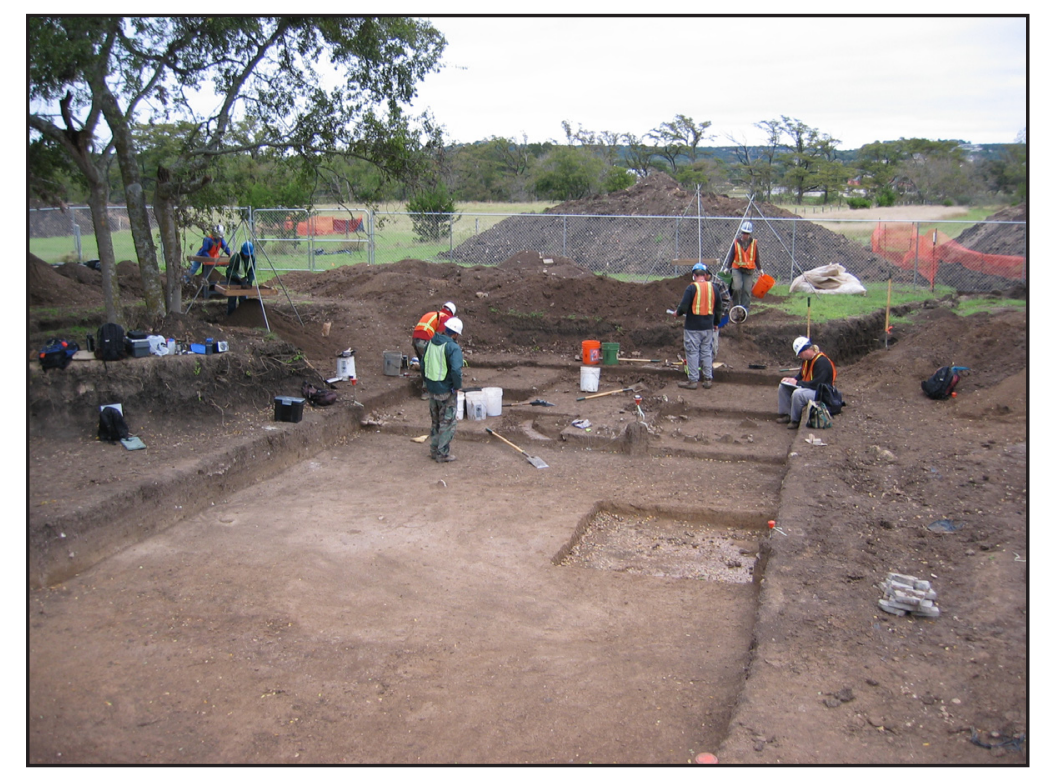

Figure 8.1. Area A-NE excavations in progress facing north. 


\section{8-2 Chapter 8}

example, at 41HY161 in San Marcos, only Gower points were recovered from deposits dated between ca. 7,700-6,650 B.P. (Oksanen 2005). Early Barbed points are problematic to date. At the Eckols site in Travis County, an AMS date from the base of the Early Split Stem zone was approximately 6,500 B.P. (Karbula 2000:58). Karbula (2000:75) compared the split stem points to the Lower Medina component at Richard Beene, dating to ca. 6,900 B.P. Dockall and Pevney (2007:203) classify the Early Barbedlike points as Baker. At the Wilson Leonard site, points classified as Expanding Stem, Concave Base $\mathrm{D}$, are similar to the Gatlin site specimens (Dial et al. 1998). Most of these points were from Unit IIIb, which is poorly dated between ca. 5,560-3,800 B.P. (Stafford 1998:1058). At the Woodrow Heard site, similar points are typed as Bell (Decker et al. 2000). Decker et al. (2000) view the points as part of the southern Early Barbed tradition that predates Calf Creek and Bell points from the Eastern Woodlands. The wide range of Early Barbed is attributed to the Early Archaic from ca. 8,900-5,500 B.P. (Decker et al. 2000:256). According to Collins (2004:Figure 3.9a), Martindale points also have a wide temporal range from ca. 7,000-6,000 B.P. as part of the Uvalde and Martindale point style continuum. The Pandale point is clearly intrusive since, according to Shafer and Hester (see Appendix C), the date range for Pandale points from Lower Pecos sites is ca. $4,700-4,100$ в.Р.

\section{Paleoenvironment}

All of the occupation zones investigated at the Gatlin site were contained in what Frederick (Chapter 6) described as depositional Unit 3. OZ1 is likely the living surface identified by Frederick in BHT 3 in Zone 4 (2Bw soil horizon) at approximately $120 \mathrm{~cm}$ below ground surface (see Chapter 6). During this time frame, the Guadalupe River was entrenched near to, or within, its present channel, which had the effect of gradually lessening alluvial deposition within the floodplain. The low deposition rates were punctuated by extreme floods, one or two of which could be expected to occur within the OZ1 date range. Low deposition was also due in part to the position of the site at the river valley margin.

The vegetation record was reconstructed using the results of the special studies samples collected from features. The pollen and phytoliths recovered from Features 14 and 27 differ slightly, which could be the result of differential preservation. Feature 14 pollen samples contained the highest levels of oak (Quercus sp.) detected at the Gatlin site and smaller quantities of mustard family and hackberry seed that may have been processed in the feature (Cummings et al. Appendix G). Charcoal fragments did not conclusively identify oak, and the possible fuel source of the feature was an indeterminate hardwood. However, given the high levels of oak pollen, it seems reasonable to assume that oak was locally available as a fuel source. Phytoliths, silica bodies that can form within grasses, can be diagnostic as to environmental conditions. The composition of the phytolith assemblage from Feature 14 indicates moderate moisture conditions. Feature 27 contains pollens from numerous weedy plants in the mustard and legume families, mallow and cheeseweed. These species prefer a disturbed soil environment and are species that can be utilized for a variety of purposes. Buliform phytoliths can be produced by grasses as a response to wet conditions. The presence of buliform phytoliths from Feature 27 suggest that local conditions were wet, perhaps as sediments accumulated in the feature and retained elevated levels of moisture. The elevated levels of festucoid phytoliths suggest a cool, moist, growth season in either the spring or fall.

A mussel shell pseudocardinal tooth was identified as Tampico pearlymussel (Cyrtonaias tampicoensis). Prehistorically, the species was common in major drainages although less so throughout the Guadalupe drainage system. Today, the species is absent from the Upper Guadalupe because of drought and artificial impacts from dewatering and scouring floods (Howells, Appendix J).

The sum of the paleoenvironmental data suggests both xeric and mesic conditions at the site. However, we believe the few moister/cooler climatic markers may be more indicative of seasonal variation along the riverine corridor. Overall, the climate conditions were likely slightly drier and warmer than a modern analogue. Bousman's vegetation model from Boriak and Weekly Bogs pollen data identified a period of abrupt grassland expansion from ca. 8,000-6,500 B.P. and a brief period of arboreal expansion around $6,500-6,000$ B.P. This brief period of arboreal 
expansion lasted perhaps a few hundred years before arboreal cover plunged to its lowest levels ca. 5,000 B.P. (Bousman 1998:211, Figure 7). Despite the brief expansion of arboreal cover, along the eastern edge of the Edwards Plateau, conditions were still drier than between $9,000-8,000$ B.P. A drier climatic model also agrees with the climatic sequence of Central Texas proposed by Collins (1995) that suggests this time period included a more xeric environment. The slight discrepancy between local conditions and regional patterning is likely the result of the immediate environs, where the riparian corridor has a moderating effect.

\section{Occupation Zone 1 Assemblage}

Both technological and subsistence information was recovered from OZ1. Subsistence evidence is scant and the only surviving evidence of the technology used during OZ1 was lithic artifacts in the form of tools, tool manufacturing debris, and features, (Table 8.1). There were four designated features from OZ1, all of which contained burned rock. Features 29 and 30 have an unknown function, while Features 14 and 27 are the remnants of small cooking or heating elements.

The tool assemblage of OZ1 is represented by six projectile points, 17 bifaces, two bifacial tools, nine modified flake tools, two cores, and one piece of possible ground stone. Diagnostic tools within the assemblage consist of five of the projectile points; the sixth projectile point is untyped. The diagnostic projectile points include one complete Pandale point, and fragments of a Martindale, Gower, and two Early Barbed Devil's variant points. These points are consistent with the Early Archaic dates attributed to OZ1 from the radiocarbon dates reported, aside from the Pandale point, which is typically consistent with Middle Archaic dates. Individual attribute data for lithic tools, lithic cores, and ground stone/ manuports are presented in Appendix E, consisting of D.1-D.7.

\section{Dart Points}

The six projectile points recovered within OZ1 represent the smallest quantity of points from any occupation zone at the site. Five of the projectile points are temporally diagnostic types. Four of these point styles are associated with the Early Archaic period, and include one Gower point, one Martindale point, and two Early Barbed Devil's Variant points. The one Pandale point is associated with the Middle Archaic period. There is only one untypable point within this occupation zone. The following counts and descriptions refer only to the specimens discovered within this zone. Projectile point type morphology and metric attributes information is located within Appendix C, with individual metric attribute information located within Appendix E.1.

Table 8.1. Summary of Lithic Technology for Occupation Zone 1

\begin{tabular}{|c|c|c|}
\hline Category & Count & Description \\
\hline Features & 4 & $14,27,29,30$ \\
\hline \multirow{5}{*}{ Projectile Points } & \multirow{5}{*}{6} & 1 Gower \\
\hline & & 2 Early Barbed \\
\hline & & 1 Martindale \\
\hline & & 1 Pandale \\
\hline & & 1 Untyped \\
\hline Bifacial Tools & 2 & Butted Bifaces \\
\hline \multirow{5}{*}{ Bifaces } & \multirow{5}{*}{17} & 1 Stage 1 \\
\hline & & 1 Stage 2 \\
\hline & & 3 Stage 3 \\
\hline & & 2 Stage 4 \\
\hline & & 8 Stage 5 \\
\hline Flake Tools-Formal & 1 & End Scraper \\
\hline \multirow{2}{*}{ Flake Tools-Expedient } & \multirow{2}{*}{8} & 3 Modified Flakes \\
\hline & & 5 Utilized Flakes \\
\hline Cores & 2 & Multidirectional \\
\hline Ground Stone tools & 1 & Indeterminate fragment \\
\hline Total Flakes and Fragments from Traditional Units & 692 & \\
\hline Core Reduction Flakes & 86 & \\
\hline Biface Reduction Flakes & 188 & 8 notching flakes \\
\hline Indeterminate Flakes & 45 & \\
\hline Total Proximal Fragments & 203 & \\
\hline Total of Complete Flakes & 116 & \\
\hline Complete Flakes Percentage of Total & $16.73 \%$ & \\
\hline Ratio of Bifaces to Cores & $9.5: 1$ & \\
\hline
\end{tabular}


Early Barbed DeviL's Variant

$(n=2)$ (Lots 571, 641.1) (see Appendix C, Figure 7 h, i)

Nominal Attributes: Flaking pattern is only apparent on one of these points as an oblique parallel pattern.

Condition and Breakage: One of these specimens is a shoulder fragment with an impact/snap fracture and thermal breakage. The other point is a basal fragment ending in a snap fracture, and has postdepositional excavation damage as well.

\section{Reworking and Beveling: N/A}

Use-wear: N/A

Raw Material Attributes: Raw material for these points consists of local Edwards fine-grained chert. Heat evidence is apparent with potlids on

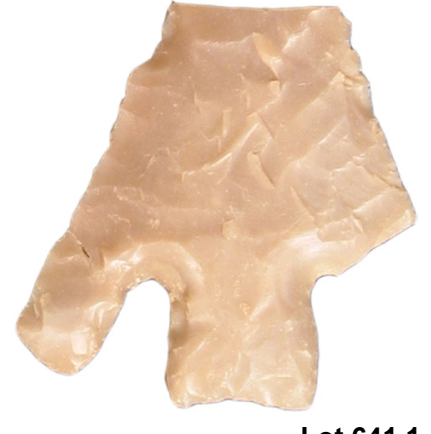

Lot 641.1 one of the specimens.

Comments: These are large barbed points similar to Bell, but have wider squared tip barbs that slightly flare and indented bases. It has been suggested by Decker et al. (2000:256) that Early Barbed predates Calf Creek and Bell, and may have a Pecos River valley origin.

\section{Gower}

$(\mathrm{n}=1)$

\section{Subtype:}

\section{Gower A}

$(\mathrm{n}=1)($ Lot 497.1$)$

Nominal Attributes: The flaking pattern is chevron.

Condition and Breakage: The specimen is a basal fragment with an impact fracture.

Reworking and Beveling: N/A

Use-wear: N/A

Raw Material Attributes: The point is made of local Edwards fine-grained chert.

\section{Martindale}

$(\mathrm{n}=1)$

\section{Subtype:}

\section{Martindale A} $(\mathrm{n}=1)($ Lot 590) (see Appendix C, Figure 3a)

Nominal Attributes: The flaking is an oblique parallel pattern.

Condition and Breakage: The specimen is a basal fragment with a distal impact fracture.

Reworking and Beveling: There is evidence of reworking along the blade of this point.

Use-wear: The specimen was utilized as a dart point and light-duty knife before an impact fracture and was recycled as a burin.

Raw Material Attributes: This point is made of local Edwards fine-grained chert.

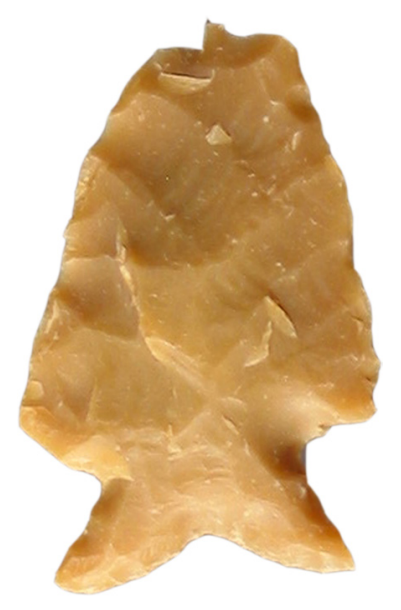

Comments: The blade is exceptionally well thinned. 
Pandale

$(\mathrm{n}=1)$ (Lot 314) (see Appendix C Figure 9 i)

Nominal Attributes: The point is a late stage preform, manufactured from a flake with a platform remnant still present. It has a crude, random, flaking pattern.

Condition and Breakage: The specimen is complete.

Reworking and Beveling: The stem is slightly twisted

Use-wear: N/A

Raw Material Attributes: The point is made of local Edwards fine-grained chert.

Comments: The Pandale type is associated with the Middle Archaic of South Texas, and the specimen is intrusive in OZ1. Though typical of the Lower Pecos area, Pandale points are occasionally found at sites in the southwestern Edwards Plateau (Decker et al. 2000; Hester 1971).

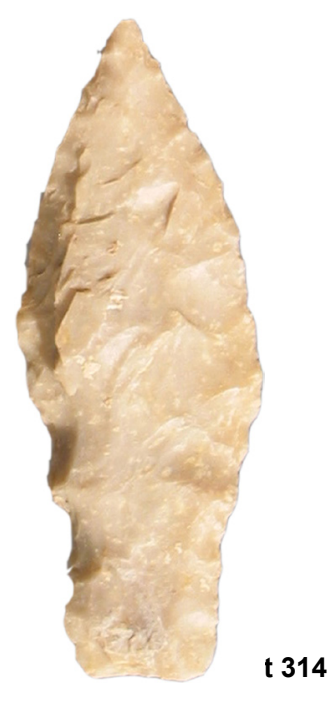

UNTYPABLE

$(\mathrm{n}=1)($ Lot 349)

Nominal Attributes: N/A

Condition and Breakage: This point is a basal fragment with a snapped tip.

Reworking and Beveling: The specimen is described as crudely reworked.

Use-wear: N/A

Raw Material Attributes: Raw material for this point is local Edwards fine-grained chert.

Comments: Limited attributes, including condition, breakage, heat evidence, and weight were recorded for untyped projectile points.

\section{Projectile Point Summary}

Five of the points have probable use damage from impact, while the Martindale point was recycled as an expedient burin after it was broken. The condition of the points suggests that they were discarded during episodes of retooling and refitting, when broken points were unhafted and replaced with new points. One of the Early Barbed Devil's Variant points was probably discarded into a fire of sufficient heat to cause fracturing. The necessary heat is usually the result of cultural fire, and the point was found within $1 \mathrm{~m}$ of Feature 14.

\section{BIFACIAL TOOLS}

Two butted bifaces were recovered in OZ1. One specimen (Lot 211.1) is made from a small chert cobble and all of its edges are trimmed. Cortex remains on the center of one face. The distal edge is battered, with a large $(23 \times 28-\mathrm{mm})$ flake having removed a segment of the bit. The distal edge damage is consistent with impact, suggesting that the tool was used against a hard material. The specimen has the appearance of being an intended biface, for which further reduction was stopped because of the flaws in the material. The other butted biface (Lot 640.1) is made from a small wedge-shaped chert cobble with cortex on the proximal end. Its trimmed edge incorporates over half of its circumference and the complete right lateral margin. The possible use-wear at the distal end has irregular patterned flake scarring which terminates in shallow hinge terminations that are consistent with impact. Flake scars at the proximal butted end suggest a possible use of the specimen as a wedge, with the poll end as the striking surface. The lateral platform preparation and thinning flattened the one surface and enhanced the wedge profile. In sum, these two tools were likely produced and used on site for various activities or processes. It is also possible that they represent a curated technology, and 
that they were left or cached at the site for future use. Dial and Collins (1998) classified similar tools from Wilson-Leonard as core tools, emphasizing their function. These were variously known as choppers and scrapers, having a bifacial distal end created by the removal of several large flakes and generally retaining 50 percent or more cortex.

\section{BIFACES}

Seventeen bifaces were recovered from OZ1 at the Gatlin site. All of the bifaces were made from finegrained chert that was available locally and was reflected in the debitage. The stage categorization of the bifaces was: Stage $1(n=1)$, Stage $2(n=1)$, Stage 3 $(n=3)$, Stage $4(n=2)$, and Stage $5(N=8)$ bifaces. Two of the bifaces did not contain enough attributes to be defined in the five category stages and were labeled as indeterminate specimens. Biface measurements for OZ1 specimens are in Table 8.2.

The Stage 1 biface is a thermally fractured basal fragment of fine-grained chert with less than 25 percent cortex. The overall shape of the biface is impossible to determine due to the size of the fragment. The Stage 2 biface is a complete specimen in an ovate shape. Less than 25 percent of cortex is still present on the lightly patinated fine-grained chert biface.

The Stage 3 bifaces are all fragments with two specimens broken during manufacture. All the bifaces are relatively small with an average maximum thickness of $10.6 \mathrm{~mm}$ and are made from fine-grained chert with no cortex present. One of the fragments has potlid scars showing evidence of burning. The two fine-grained chert Stage 4 bifaces were also broken during manufacture. The thickness of the fragments is less than the Stage 3 bifaces with an average of $9.4 \mathrm{~mm}$. One specimen has less than 25 percent of cortex still present while the other has none. Neither of the Stage 4 bifaces showed evidence of heat treatment.

The most numerous biface recovered from OZ1 were the Stage 5 bifaces including one complete biface, two distal fragments, four medial fragments, and one indeterminate fragment. The complete Stage 5 biface is made from an interior flake and has a pointed oval shape with rounded proximal corners (see Appendix $\mathrm{C}$, Figure 34, a). The biface is made of a fine-grained chert with no cortex present. Micro wear was initially attributed to portions of the lateral edges; however, the specimen was not submitted for use-wear analysis. The Stage 5 biface fragments are all made from a fine-grained chert with no cortex present. Three of the specimens have evidence of breakage due to manufacture and one through use. The rest have indeterminate breakages. Lastly, only one of the Stage 5 biface specimens displays evidence of heat treatment with the presence of pot lids.

The remaining two indeterminate biface fragments are relatively small fragments. Both bifaces are made from fine-grained chert, with one of the bifaces scarred with thermal potlids from being

Table 8.2. Occupation Zone 1 Attribute Measurements for General Bifaces by Stage

\begin{tabular}{|c|c|c|c|c|c|c|c|c|}
\hline & & \multicolumn{6}{|c|}{ Stage } & \multirow[b]{2}{*}{ Total } \\
\hline & & 1 & 2 & 3 & 4 & 5 & Indeter & \\
\hline \multirow{2}{*}{ Max L } & $\mathrm{N}$ & & 1 & & & 1 & & 2 \\
\hline & Mean & & 81.60 & & & 60.90 & & 71.25 \\
\hline \multirow{2}{*}{ Max W } & $\mathrm{N}$ & 1 & 1 & 2 & & 4 & & 8 \\
\hline & Mean & 65.20 & 68.30 & 31.10 & & 23.98 & & 36.45 \\
\hline \multirow{2}{*}{ Max Th } & $\mathrm{N}$ & 1 & 1 & 3 & 2 & 8 & 2 & 17 \\
\hline & Mean & 18.30 & 21.40 & 10.60 & 9.40 & 7.49 & 5.10 & 9.44 \\
\hline \multirow{2}{*}{ W/T Ratio } & $\mathrm{N}$ & 1 & 1 & 3 & 2 & 8 & 2 & 17 \\
\hline & Mean & 3.56 & 3.19 & 1.74 & 0.00 & 1.86 & 0.00 & 1.58 \\
\hline \multirow{2}{*}{ Weight } & $\mathrm{N}$ & 1 & 1 & 3 & 2 & 8 & 2 & 17 \\
\hline & Mean & 43.00 & 108.80 & 14.03 & 14.05 & 14.23 & 3.95 & 20.22 \\
\hline \multirow{2}{*}{ Edge Angle } & $\mathrm{N}$ & 1 & 1 & 3 & 1 & 8 & 2 & 16 \\
\hline & Mean & 37.00 & 42.00 & 30.67 & 30.00 & 27.13 & 22.50 & 28.94 \\
\hline
\end{tabular}


burned. The breakage on the other indeterminate fragment appears to be from manufacture.

\section{FLAKE TOOLS}

The modified flake tools recovered from OZ1 consist of one end scraper, five retouched flakes, and three utilized flakes (Table 8.3). The end scraper is a complete unifacial scraper with continuous flaking along the dorsal side. No dorsal cortex is present on the scraper. Approximately 48 percent of the circular scraper's overall perimeter length has been retouched. The five retouched flakes consist of one proximal fragment, one distal fragment, two longitudinal fragments, and one indeterminate fragment. The utilized flakes consist of one complete flake, one proximal fragment, and one indeterminate fragment. The complete utilized flake is an elongated flake with utilization along the distal and right lateral margin. The utilized portion of the flake accounts for approximately 58 percent of the total perimeter length.

\section{CORES}

Two cores were recovered in OZ1. Both cores are exhausted multidirectional core fragments from tabular chert parent material. Each fragment has minimal flake scars with maximum flake scars lengths of $47.4 \mathrm{~mm}$ and $49.1 \mathrm{~mm}$, respectively. Neither of the cores shows evidence of heat treatment.

\section{DEBITAGE}

Debitage recovered from the Traditional Excavation units is used in this section. The measurements for the debitage by flake reduction method are in Table 8.4. Cortex was notably rare on biface reduction flakes, with 89 percent of the flakes having no cortex and 9 percent having 1-25 percent cortex. This is a strong indicator that the initial reduction of the biface blanks was occurring either elsewhere on site or off-site. On the core reduction flakes, 35 percent of the flakes had no cortex, 22 percent had from 1-25 percent cortex, 12.8 percent had 26-50
Table 8.4. Biface, Core, and Indeterminate Reduction Flake Measurements from Occupation Zone 1

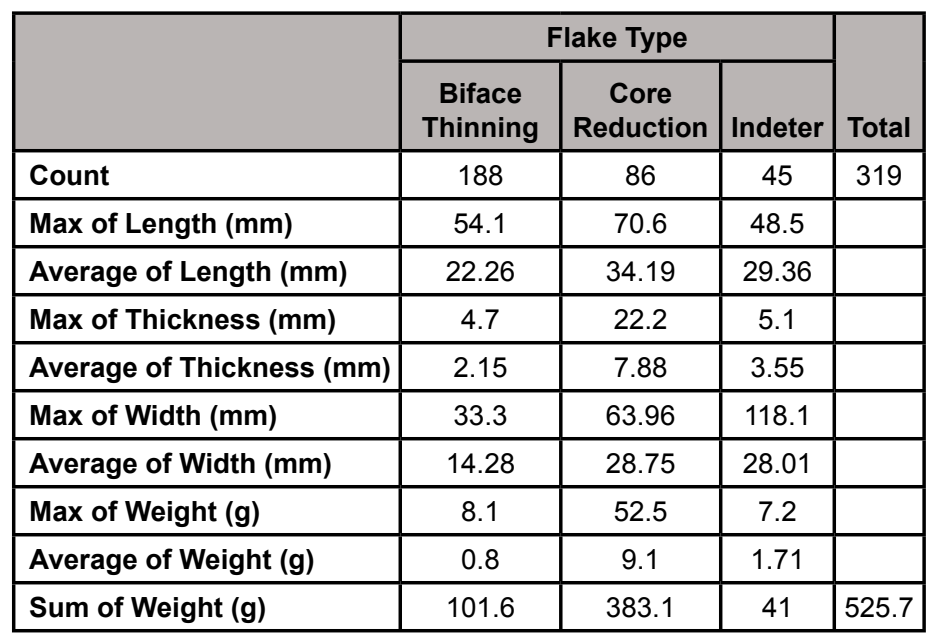

percent cortex, 11.6 percent had 51-75 percent, and 17.4 percent had $76-99$ percent. There was a single flake with 100 percent cortex. This distribution indicates that some raw cobbles were being reduced on site. Interestingly, there is no significant difference between the average length of a core reduction flake and the amount of remaining cortex. This suggests that there was uniformity in the size of the selected cores. The measurements from the indeterminate flakes are closer in thickness and weight to biface thinning flakes, while the width of the flakes is similar to core reduction flakes, and the average length being between biface and core reduction. This could be the result of a different type or hardness of percussor used to thin bifaces.

There were eight notching flakes in the biface thinning debitage. These are typically later stage
Table 8.3. Occupation Zone 1 Attribute Measurements for Complete Modified Flake Subcategories

\begin{tabular}{|l|l|c|c|c|}
\hline \multicolumn{2}{l|}{} & End Scraper & Utilized Flake & Total \\
\hline Count & N & 1 & 1 & 2 \\
\hline Length & Mean & 47.93 & 49.67 & 48.80 \\
\hline Width & Mean & 46.73 & 39.01 & 42.87 \\
\hline Thickness & Mean & 7.98 & 20.46 & 14.22 \\
\hline Weight & Mean & 25.30 & 46.60 & 35.95 \\
\hline Perimeter Length & Mean & 150.02 & 150.86 & 150.44 \\
\hline Perimeter Retouch Length & Mean & 71.58 & 87.00 & 79.29 \\
\hline Marginal Retouch \% & Mean & 0.48 & 0.58 & 0.53 \\
\hline Max Edge Angle & Mean & 75.00 & 80.00 & 77.50 \\
\hline
\end{tabular}




\section{8-8 Chapter 8}

or final stage flakes that can also be created during episodes of refurbishment or resharpening. The presence of these flakes implies that hafted tools such as projectile points were being finished at OZ1. These types of flakes would be created by the notching of Early Barbed and Martindale points.

\section{FAUNAL ASSEMBLAGE}

The faunal assemblage from OZ1 includes 50 specimens weighing a total of $29.5 \mathrm{~g}$. Seven fragments weighing $1.6 \mathrm{~g}$ are from white-tailed deer (Odocoileus virginianus). Overall, the faunal assemblage is highly fragmented and weathered and the damage appears to be post-depositional factors.

\section{FEATURE ASSEMbLAGE}

The four features within OZ1 were all within Area A-NE and include Features 14, 27, 29, and 30-the fewest features within any one occupation zone at the Gatlin site (Figure 8.2). Features 14 and 27 were small burned rock clusters; however, Features 29 and 30 are unusual, small mixed clusters of debris that were unlike any of the other features encountered at the site, and were believed to be related to each other. The full results of special studies from these features are in Appendices E through I.

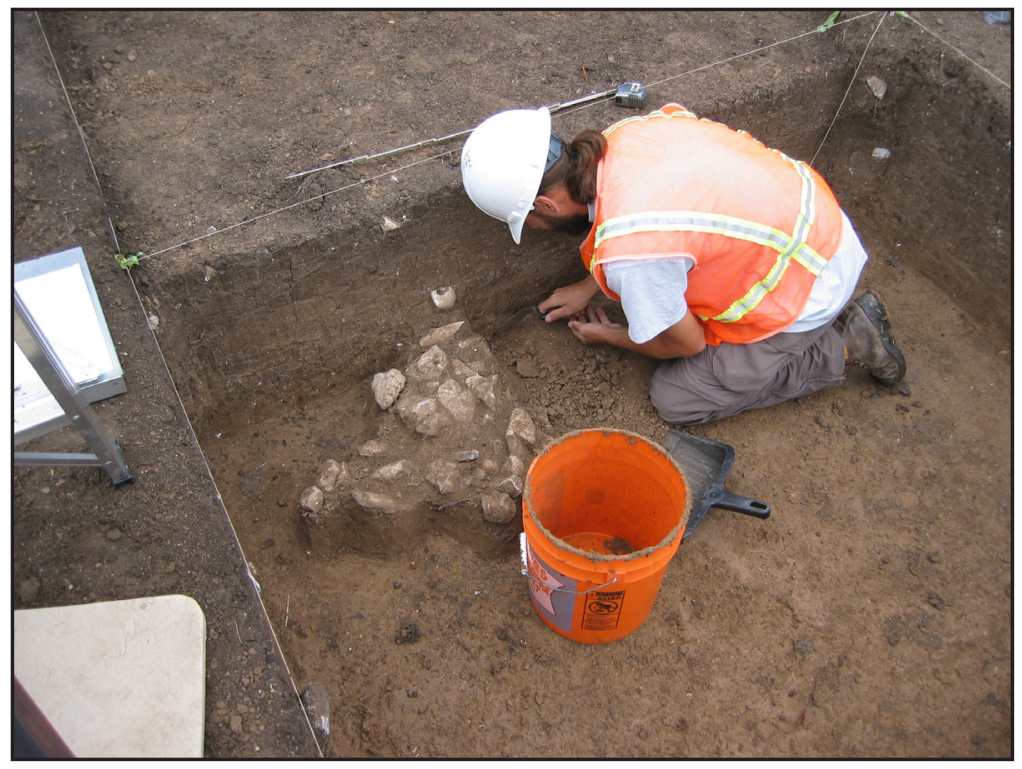

Figure 8.2. Feature 14 excavation in progress facing west. 


\begin{tabular}{|c|c|c|c|c|}
\hline 르 $\Delta$ & & Pollen & \multicolumn{2}{|c|}{$\begin{array}{l}\text { Quercus. Exploitable: mustard family and } \\
\text { hackberry }\end{array}$} \\
\hline & & Flotation Results & \multicolumn{2}{|l|}{ Hackberry } \\
\hline & & Radiocarbon Dates & \multicolumn{2}{|c|}{$\begin{array}{l}\text { Beta- } 206115: 6570 \pm 50 \text { B.P., } \\
7570-7420 \text { cal B.P., from base of feature } \\
\text { at } 96.97 \mathrm{~m}\end{array}$} \\
\hline Feature Type & Small burned rock cluster & $\begin{array}{l}\text { Associated floor } \\
\text { elevation range }(\mathrm{m})\end{array}$ & \multicolumn{2}{|l|}{$97.10-97.00 \mathrm{~m}$} \\
\hline Occupation Zone & 1 & \multirow{2}{*}{$\begin{array}{l}\text { Associated Diagnostics } \\
\text { (Lot No. and elevation) }\end{array}$} & \multirow{2}{*}{\multicolumn{2}{|c|}{ None }} \\
\hline Stratigraphic Context & Within 2Bw horizon & & & \\
\hline Area & A-NE & \multirow{8}{*}{$\begin{array}{l}\text { Diagnostics above and } \\
\text { adjacent to feature } \\
\text { (Lot No.) } \\
\text { proximity radius }=2.0 \mathrm{~m} \\
\text { proximity elevation }=0.2 \mathrm{~m}\end{array}$} & Gower (452) & $97.20-97.10 \mathrm{~m}$ \\
\hline Provenience & N1027 E1060 & & Martindale (465.2) & $97.30-97.20 \mathrm{~m}$ \\
\hline Center & N1027.70 E1060.34 & & $\begin{array}{l}\text { Early Barbed, } \\
\text { Devil's Variant (571) }\end{array}$ & $97.07 \mathrm{~m}$ \\
\hline Top Elevation & $97.12 \mathrm{~m}$ & & Gower (564) & $97.25 \mathrm{~m}$ \\
\hline Bottom Elevation & $96.97 \mathrm{~m}$ & & Gower (565) & $97.22 \mathrm{~m}$ \\
\hline Size & $80 \times 60 \mathrm{~cm}$ & & Untyped (566) & $97.25 \mathrm{~m}$ \\
\hline Shape & Roughly oval, basin like shape & & Untyped (568) & $97.12 \mathrm{~m}$ \\
\hline Fuel Type & Indeterminable hardwood & & Gower (554.1) & $97.30-97.20 \mathrm{~m}$ \\
\hline Lipids & $\begin{array}{l}\text { Borderline moderate-high and high fat } \\
\text { content food } \\
\text { (most likely of plant origin) }\end{array}$ & \multirow{2}{*}{$\begin{array}{l}\text { Diagnostics below and } \\
\text { adjacent to feature } \\
\text { (Lot No.) } \\
\text { proximity radius }=2.0 \mathrm{~m} \\
\text { proximity elevation }=0.1 \mathrm{~m}\end{array}$} & \multirow{2}{*}{\multicolumn{2}{|c|}{ None }} \\
\hline Faunal Evidence & $\begin{array}{l}\text { Unidentifiable bone fragments; mussel } \\
\text { shell in same level }\end{array}$ & & & \\
\hline \multicolumn{5}{|l|}{ Description } \\
\hline \multicolumn{2}{|c|}{$\begin{array}{l}\text { Feature } 14 \text { was a very dense cluster of burned rock } \\
\text { encountered within the } 2 \mathrm{Bw} \text { soil horizon, approximately } 1 \\
\mathrm{~m} \text { southwest of and slightly below Feature } 12 \text {. The feature } \\
\text { was roughly oval in outline and extended } 80 \times 60 \mathrm{~cm} \text {, } \\
\text { oriented north-south. In cross section, the feature had a } \\
\text { very shallow, basin like shape, and was approximately } 15 \\
\mathrm{~cm} \text { thick at its extreme points. There was no distinguishable } \\
\text { difference observed between the feature matrix and the } \\
\text { surrounding soil. }\end{array}$} & s & & \\
\hline \multicolumn{2}{|c|}{$\begin{array}{l}\text { All of the burned rock within Feature } 14 \text { was limestone. } \\
\text { A total of } 77 \text { burned rock specimens was recovered from } \\
\text { Feature } 14 \text {. These specimens ranged from approximately } \\
5-15 \mathrm{~cm} \text { in diameter and weighed a combined } 16.5 \mathrm{~kg} \text {. } \\
\text { The burned rocks observed within the feature were a mixture } \\
\text { of shapes: flat slabs, rounded, and angular. More than } \\
50 \text { percent of the burned rocks within the feature were } \\
\text { overlapping one another, and most ( }>67 \text { percent) of the } \\
\text { burned rocks were unfractured. }\end{array}$} & & & \\
\hline $\begin{array}{l}\text { Debitage, faun } \\
\text { observed throug } \\
\text { of the Early Barb } \\
\text { same unit as the }\end{array}$ & $\begin{array}{l}\text { ials, and some charcoal were } \\
\text { eature matrix. A single dart point } \\
\text { 's Variant type was located in the } \\
\text { within the same } 10-\mathrm{cm} \text { level. }\end{array}$ & \multicolumn{3}{|c|}{ Overview of Feature 14.} \\
\hline
\end{tabular}




\begin{tabular}{|c|c|c|c|c|}
\hline E & & Pollen & \multicolumn{2}{|c|}{$\begin{array}{l}\text { Quercus, High-spine Asteraceae. } \\
\text { Exploitable: mustard family, legume, } \\
\text { and mallow family }\end{array}$} \\
\hline & & Flotation Results & \multicolumn{2}{|l|}{ None } \\
\hline Feature Type & Small burned rock cluster & Radiocarbon Dates & \multicolumn{2}{|l|}{ None } \\
\hline Occupation Zone & 1 & \multirow{2}{*}{$\begin{array}{l}\text { Associated floor } \\
\text { elevation range }(\mathrm{m})\end{array}$} & \multirow{2}{*}{\multicolumn{2}{|c|}{$97.00-96.90 \mathrm{~m}$}} \\
\hline Stratigraphic Context & Within 2Bw horizon & & & \\
\hline Area & A-NE & \multirow{2}{*}{$\begin{array}{l}\text { Associated Diagnostics } \\
\text { (Lot No. and elevation) }\end{array}$} & \multirow{2}{*}{$\begin{array}{l}\text { Early Barbed, } \\
\text { Devil's Variant (641.1) }\end{array}$} & \multirow{2}{*}{$97.00 \mathrm{~m}$} \\
\hline Provenience & N1027 E1066 & & & \\
\hline Center & N1027.40 E1066.50 & \multirow{5}{*}{$\begin{array}{l}\text { Diagnostics above and adjacent to } \\
\text { feature (Lot No.) } \\
\text { proximity radius }=2.0 \mathrm{~m} \\
\text { proximity elevation }=0.30 \mathrm{~m}\end{array}$} & Untyped (609) & $97.24 \mathrm{~m}$ \\
\hline Top Elevation & $97.01 \mathrm{~m}$ & & Early Triangular (647) & $97.25 \mathrm{~m}$ \\
\hline Bottom Elevation & $96.95 \mathrm{~m}$ & & Martindale (652) & $97.20 \mathrm{~m}$ \\
\hline Size & $50 \times 40 \mathrm{~cm}$ & & Untyped (617) & $97.10 \mathrm{~m}$ \\
\hline Shape & Amorphous, relatively flat & & Martindale (638) & $97.28 \mathrm{~m}$ \\
\hline Fuel Type & Indeterminable & \multirow{3}{*}{$\begin{array}{l}\text { Diagnostics below and adjacent to } \\
\text { feature (Lot No.) } \\
\text { proximity radius }=2.0 \mathrm{~m} \\
\text { proximity elevation }=0.1 \mathrm{~m}\end{array}$} & \multirow{3}{*}{\multicolumn{2}{|c|}{ None }} \\
\hline Lipids & $\mathrm{N} / \mathrm{A}$ & & & \\
\hline Faunal Evidence & $\begin{array}{l}\text { White-tailed deer tooth fragments in } \\
\text { same level }\end{array}$ & & & \\
\hline
\end{tabular}

\section{Description}

Feature 27 was a very small, dense cluster of burned rock encountered within the $2 \mathrm{Bw}$ soil horizon. The feature was amorphous in shape, measuring approximately $50-x-40-\mathrm{cm}$ horizontally and only $6 \mathrm{~cm}$ thick. In cross section, the feature displayed no definitive shape or rock layering and no discernible difference between the feature matrix and the surrounding soil.

All of the burned rock within Feature 27 was limestone. The general size of the rocks was much smaller than what was typically observed in the Area A-NE features. A total of 53 burned rock specimens was recovered, weighing a total of $2.1 \mathrm{~kg}$. Most of the burned rocks were unfractured and consisted of a mixture of rounded and angular shapes; less than 50 percent of the rocks were articulated. Charcoal was not present within the feature, and no other evidence of in situ burning (e.g., staining or thermally altered sediment) was observed throughout the feature matrix.

Very little debitage and no bone or charcoal were observed within the feature matrix or throughout the level of the feature. A single Early Barbed, Devil's Variant dart point was recovered while screening soil from the quadrant and level of Feature 27.

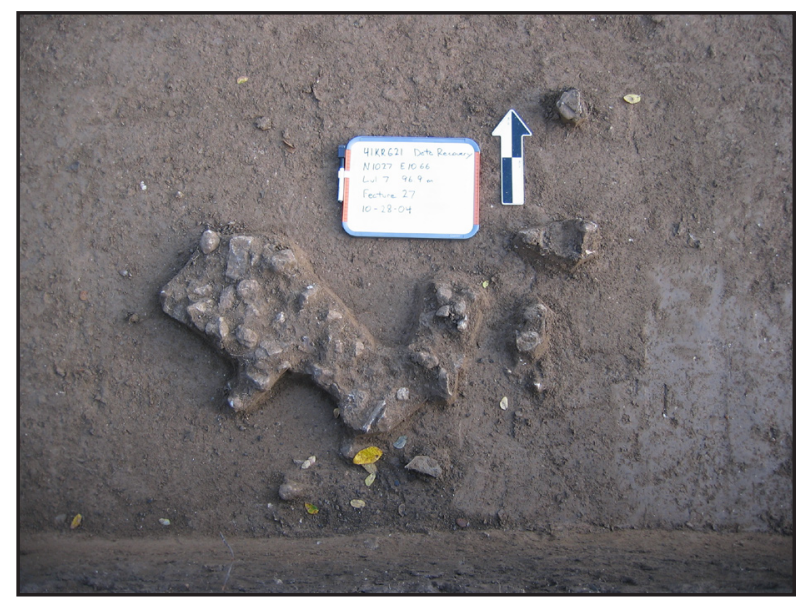

Overview of Feature 27. 


\begin{tabular}{|c|c|c|c|c|}
\hline 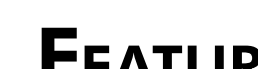 & & $\begin{array}{l}\text { Associated floor } \\
\text { elevation range }(\mathrm{m})\end{array}$ & \multicolumn{2}{|l|}{$97.00-96.90 \mathrm{~m}$} \\
\hline & & $\begin{array}{l}\text { Associated Diagnostics } \\
\text { (Lot No. and elevation) }\end{array}$ & \multicolumn{2}{|l|}{ None } \\
\hline Feature Type & $\begin{array}{l}\text { Small cluster of burned rock, debitage, } \\
\text { pebbles }\end{array}$ & \multirow{15}{*}{$\begin{array}{l}\text { Diagnostics above and adjacent } \\
\text { to feature } \\
\text { (Lot No.) } \\
\text { proximity radius }=2.0 \mathrm{~m} \\
\text { proximity elevation }=0.1 \mathrm{~m}\end{array}$} & Martindale (303) & $94.25 \mathrm{~m}$ \\
\hline Occunation 70 no & $e_{1}$ & & Early Triangular & $97.24 \mathrm{~m}$ \\
\hline Ctrotinnonis $\mathrm{Conto}$ & & & & \\
\hline Stratigraphic Context & Within 2Bw horizon & & Martindale (307) & $97.11 \mathrm{~m}$ \\
\hline Area & $\mathrm{A}-\mathrm{NE}$ & & Gower (310) & $97.01 \mathrm{~m}$ \\
\hline Provenience & N1033 E1058 & & Martindale (311) & $97.06 \mathrm{~m}$ \\
\hline Center & N1033.08 E1058.44 & & Pandale (314) & $96.92 \mathrm{~m}$ \\
\hline Top Elevation & $96.93 \mathrm{~m}$ & & Gower (320.2) & $97.20-97.10 \mathrm{~m}$ \\
\hline Bottom Elevation & $96.88 \mathrm{~m}$ & & Gower (320.3) & $97.20-97.10 \mathrm{~m}$ \\
\hline Size & $18 \times 12 \mathrm{~cm}$ & & Lange (327) & $97.30 \mathrm{~m}$ \\
\hline Shape & Roughly circular, relatively flat & & Martindale (329) & $97.15 \mathrm{~m}$ \\
\hline Fuel Type & N/A & & Martindale (330.2) & $97.10-97.00 \mathrm{~m}$ \\
\hline Lipids & N/A & & Nolan (339.1) & $97.30-97.20 \mathrm{~m}$ \\
\hline \multirow[t]{2}{*}{ Faunal Evidence } & \multirow{2}{*}{$\begin{array}{l}\text { None associated with feature; } \\
\text { unidentifiable bone fragments in same } \\
\text { level }\end{array}$} & & $\begin{array}{l}\text { Early Triangular } \\
\text { (345) }\end{array}$ & $97.25 \mathrm{~m}$ \\
\hline & & & Untyped (349) & $96.92 \mathrm{~m}$ \\
\hline Pollen & $\mathrm{N} / \mathrm{A}$ & \multirow{3}{*}{$\begin{array}{l}\text { Diagnostics below and adjacent } \\
\text { to feature (Lot No.) } \\
\text { proximity radius }=2.0 \mathrm{~m} \\
\text { proximity elevation }=0.1 \mathrm{~m}\end{array}$} & \multirow{3}{*}{\multicolumn{2}{|c|}{ None }} \\
\hline Flotation Results & N/A & & & \\
\hline Radiocarbon Dates & None & & & \\
\hline
\end{tabular}

\section{Description}

Feature 29 was approximately $1 \mathrm{~m}$ southwest of Feature 30 at roughly the same elevation in the western portion of Area A-NE. These features shared similar characteristics and were probably related. Both features were within the 2Bw stratigraphic profile, beneath Feature 25.

Feature 29 was a very small, roughly circular cluster of burned rock, debitage, and gravels all less than $5 \mathrm{~cm}$ in maximum dimension. The feature measured $18 \times 12 \mathrm{~cm}$ horizontally and $5 \mathrm{~cm}$ thick. In cross section, the feature had no clear basin and no significant layering of rock. There was no discernible difference between the feature matrix and the surrounding soil.

Features 29 and 30 are unlike other features encountered at the site. The tight concentrations of small gravels that composed these features are unique in comparison to other features at $41 \mathrm{KR} 621$. The function of these two features is unknown.

No bone or charcoal was found within the matrix of Feature 29. Although no diagnostic projectile points were found in direct association with the feature, an untyped dart point and an anomalous Pandale point were found within $1 \mathrm{~m}$ in the $10-\mathrm{cm}$ estimated floor level.

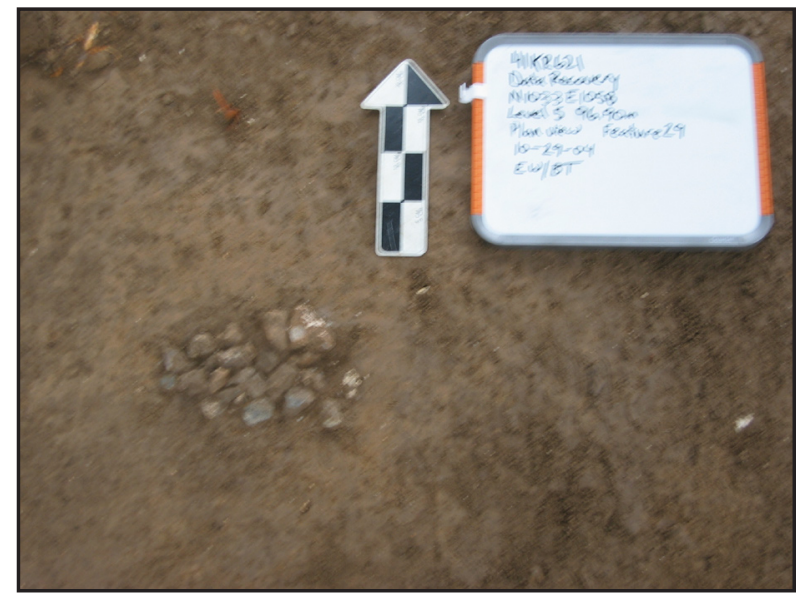

Overview of Feature 29. 


\section{8-12 Chapter 8}

\begin{tabular}{|c|c|c|c|c|}
\hline ? & & $\begin{array}{l}\text { Associated floor } \\
\text { elevation range }(\mathrm{m})\end{array}$ & \multicolumn{2}{|l|}{$97.00-96.90 \mathrm{~m}$} \\
\hline & & $\begin{array}{l}\text { Associated Diagnostics } \\
\text { (Lot No. and elevation) }\end{array}$ & \multicolumn{2}{|l|}{ None } \\
\hline & & \multirow{16}{*}{$\begin{array}{l}\text { Diagnostics above and } \\
\text { adjacent to feature } \\
\text { (Lot No.) } \\
\text { proximity radius }=2.0 \mathrm{~m} \\
\text { proximity elevation }=0.3 \mathrm{~m}\end{array}$} & Martindale (303) & $97.25 \mathrm{~m}$ \\
\hline & & & Early Triangular (304) & $97.24 \mathrm{~m}$ \\
\hline \multirow{2}{*}{ Feature Type } & \multirow{2}{*}{$\begin{array}{l}\text { Small cluster of burned rock, } \\
\text { debitage, pebbles }\end{array}$} & & Martindale (307) & $97.11 \mathrm{~m}$ \\
\hline & & & Gower (310) & $97.01 \mathrm{~m}$ \\
\hline Occupation Zone & 1 & & Martindale (311) & $97.06 \mathrm{~m}$ \\
\hline Stratigraphic Context & Within 2Bw horizon & & Pandale (314) & $96.92 \mathrm{~m}$ \\
\hline Area & A-NE & & Gower (320.2) & $97.20-97.10 \mathrm{~m}$ \\
\hline Provenience & N1033 E1058 & & Gower (320.3) & $97.20-97.10 \mathrm{~m}$ \\
\hline Center & N1033.64 E1059.60 & & & \\
\hline Top Elevation & $96.96 \mathrm{~m}$ & & Lange (327) & $97.30 \mathrm{~m}$ \\
\hline Bottom Elevation & $96.92 \mathrm{~m}$ & & Martindale (329) & $97.15 \mathrm{~m}$ \\
\hline Size & $25 \times 20 \mathrm{~cm}$ & & Martindale (330.2) & $97.10-97.00 \mathrm{~m}$ \\
\hline Shape & Kidney-shaped, relatively flat & & Nolan (339.1) & $97.30-97.20 \mathrm{~m}$ \\
\hline Fuel Type & N/A & & & \\
\hline Lipids & $\mathrm{N} / \mathrm{A}$ & & Early Triangular (345) & $97.25 \mathrm{~m}$ \\
\hline \multirow[t]{2}{*}{ Faunal Evidence } & \multirow{2}{*}{$\begin{array}{l}\text { None associated with feature; } \\
\text { unidentifiable bone fragments } \\
\text { in same level }\end{array}$} & & Untyped (349) & $96.29 \mathrm{~m}$ \\
\hline & & \multirow{4}{*}{$\begin{array}{l}\text { Diagnostics below and } \\
\text { adjacent to feature } \\
\text { (Lot No.) } \\
\text { proximity radius }=2.0 \mathrm{~m} \\
\text { proximity elevation }=0.1 \mathrm{~m}\end{array}$} & \multirow{4}{*}{\multicolumn{2}{|c|}{ None }} \\
\hline Pollen & N/A & & & \\
\hline Flotation Results & N/A & & & \\
\hline Radiocarbon Dates & None & & & \\
\hline
\end{tabular}

\section{Description}

Feature 30 was approximately $1 \mathrm{~m}$ northeast of Feature 29 at roughly the same elevation in the western portion of Area A-NE. These features shared similar characteristics and were probably related. Both features were within the 2Bw stratigraphic profile, beneath Feature 25.

Feature 30 was a small compact cluster of burned rock, debitage, and gravels less than $5 \mathrm{~cm}$ in maximum length. The feature was kidney-shaped and opened northward. It measured $25 \times 20 \mathrm{~cm}$ horizontally and $4 \mathrm{~cm}$ thick. There was no distinctive shape or significant layering of the feature matrix in cross section, and there was no observable difference between the feature matrix and the surrounding 2Bw soil horizon.

Features 29 and 30 are unlike other features at the site. The tight concentrations of small gravels that composed these features are unique in comparison to other features at 41 KR621. The function of these two features is unknown.
No bone or charcoal was found within the matrix of Feature 30. Although no diagnostic projectile points were found in direct association with the feature, an untyped dart point and anomalous Pandale point were found within $1 \mathrm{~m}$ in the $10-\mathrm{cm}$ estimated floor level.

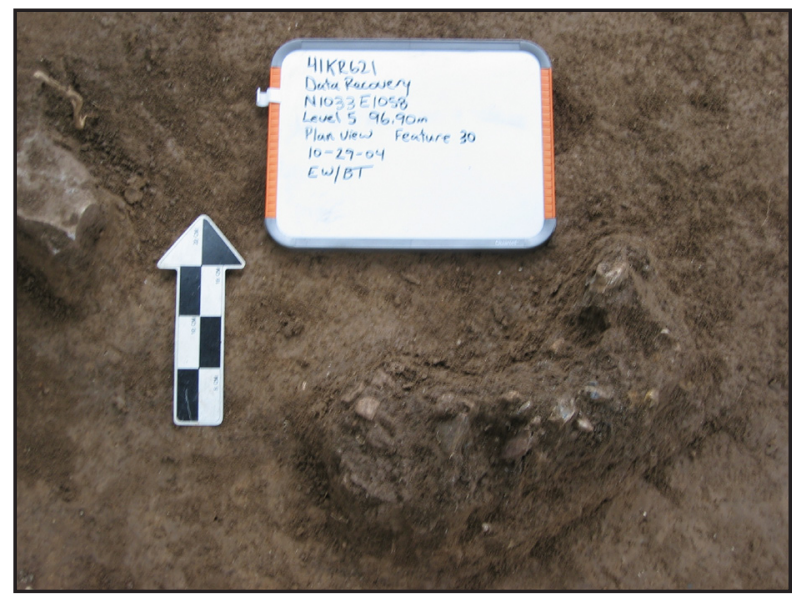

Overview of Feature 30. 


\section{Feature Summary}

OZ1 contained four features, all with of small clusters of burned rock. The limestone rock within these features was relatively intact (not highly fractured) and small and without evidence of in situ burning (e.g., staining or thermally altered sediment) among the features in this zone except for some slight charcoal within Feature 14 (Table 8.5).

Pollen studies revealed the presence of Quercus sp. within Features 14 and 27, and high-spine Asteraceae from Feature 27. Lipid residue and fatty acid composition analyses on rock from Feature 14 revealed lipid residues from a borderline moderatehigh and high fat content food, most likely of plant origin. Overall, the characteristics of Feature 27 suggest that it was a dump pile of debris, perhaps rocks pulled from a hearth. In contrast, Feature 14 fits the more classic Early Archaic small grilling feature utilized for various purposes.

Features 29 and 30 contained minor amounts of burned limestone rock, debitage, and small gravels. Features 29 and 30 varied in shape and were roughly circular and kidney-shaped respectively, and with almost flat cross sections. Features 29 and 30 had the smallest dimensions, $18 \times 12 \mathrm{~cm}$ and 25 x $20 \mathrm{~cm}$, respectively, with thicknesses ranging between $4-5 \mathrm{~cm}$. There was no pollen and phytolith data available for Features 29 and 30. Whether these are small culturally related discard piles or features of natural origin (artifacts clustered in old rodent burrows) is unknown.

\section{Spatial Distribution in OCCUPATION Zone 1}

The excavation area with significant OZ1 deposits was A-NE (see Figure 7.6). The sampling grid used at the Gatlin site varied from 2-m grid squares to $1 \mathrm{~m}$, though when possible, provenience data was correlated to the $1-\mathrm{m}$ grid. The data examined in the analysis were features, projectile points, bifaces, flake tools, cores, and debitage.

\section{FEATURES}

This section examines the vertical and horizontal arrangement of artifact classes and features within OZ1 (Figure 8.3). A nearest-neighbor spatial analysis was calculated for the four features. The observed average distance between feature centers was 3.61 $\mathrm{m}$, and the nearest-neighbor coefficient of 1.11 was closest to a random distribution value. Although the feature distribution does not appear to be spatially patterned throughout A-NE, Features 29 and 30 are approximately $1 \mathrm{~m}$ apart, had a similar composition, and had base elevations within $4 \mathrm{~cm}$ of each other. These two features are unlike the other two features from OZ1 or any of the features from the site, and their close proximity to each other suggests they are related. The remaining two burned rock features, 14 and 27, were along the southern boundary of the excavation area, which is where the majority of bifaces were recovered. The base elevation of these two features was within $2 \mathrm{~cm}$.

Table 8.5. Occupation Zone 1 Feature Burned Rock Data

\begin{tabular}{|c|c|c|c|}
\hline & Feature & 14 & 27 \\
\hline & Rock Type & Limestone & Limestone \\
\hline \multirow{4}{*}{$<5 \mathrm{~cm}$} & $\#$ & 20 & 38 \\
\hline & kg & 0.4 & 1 \\
\hline & $\%$ total rock size & 26.0 & 71.7 \\
\hline & $\%$ total weight & 2. & 47.6 \\
\hline \multirow{4}{*}{$5-10 \mathrm{~cm}$} & $\#$ & 42 & 15 \\
\hline & kg & 8.4 & 1.1 \\
\hline & $\%$ total rock size & 54.5 & 28.3 \\
\hline & $\%$ total weight & 50.9 & 52.4 \\
\hline \multirow{4}{*}{$10-15 \mathrm{~cm}$} & $\#$ & 15 & \\
\hline & kg & 7.7 & \\
\hline & $\%$ total rock size & $19.5 \%$ & \\
\hline & $\%$ total weight & $46.7 \%$ & \\
\hline \multicolumn{2}{|l|}{ Total \# } & 77 & 53 \\
\hline \multicolumn{2}{|l|}{ Total Weight } & 16.5 & 2.1 \\
\hline \multicolumn{2}{|l|}{ Shape ${ }^{1}$} & mixed & mixed \\
\hline \multicolumn{2}{|l|}{ Condition ${ }^{1}$} & unfractured & unfractured \\
\hline \multicolumn{2}{|l|}{ Density $^{2}$} & overlapping & adjoining \\
\hline \multicolumn{2}{|l|}{ Fine Matrix } & $\begin{array}{l}\text { Undifferentiated, } \\
\text { some charcoal }\end{array}$ & Undifferentiated \\
\hline
\end{tabular}

* No burned rock data from Features 29 and 30

${ }^{1}$ Implies that more than $67 \%$ of the rocks associated with this feature share this trait. Mixed represents a combination of two or more traits.

${ }^{2}$ Adjoining implies that $<50 \%$ of the rocks were touching. Adjacent means that $>50 \%$ of the rocks were touching. 


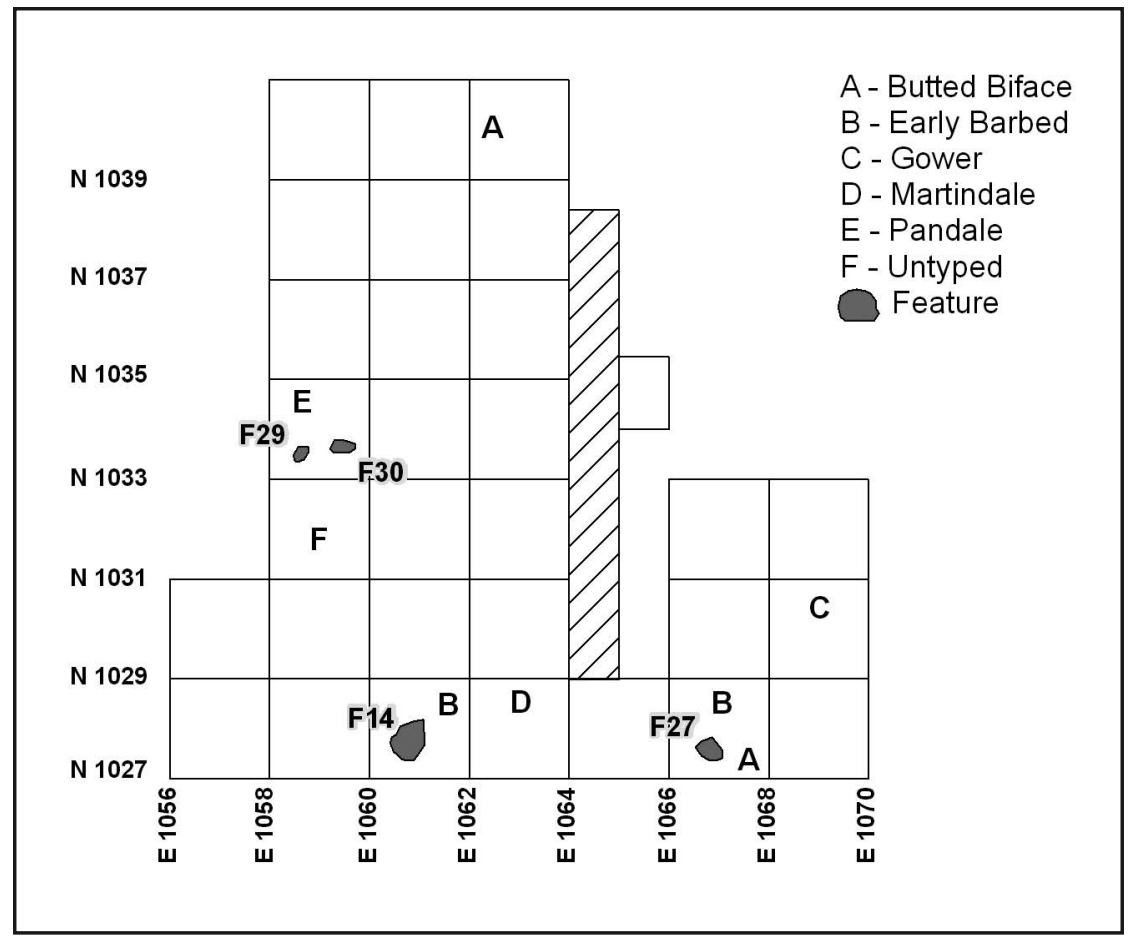

Figure 8.3. Occupation Zone 1 Area A-NE feature locations with projectile points and biface tools. postdate Gower, while the Pandale is the youngest and likely an intrusive artifact.

\section{BIFACES/BIFACIAL TOOLS}

There were 17 bifaces and two butted bifaces that could be assigned to a reduction state. As shown in Figure 8.4, biface density is higher at the southern end of the block where eight of the bifaces were recovered from the southernmost units, and three of these units had two bifaces. Late stage bifaces are the predominant type. The biface distribution is similar to the projectile point distribution. Although none of the tools were submitted for use-wear analysis, an examination of macro edge damage using criteria outlined by Keeley (1980) identified possible use-wear traces on
Both groups of features were located in areas of higher densities of burned rock. Of the $96.6 \mathrm{~kg}$ of burned rock reported from A-NE, approximately $28.6 \mathrm{~kg}$ (30 percent) was from the combined feature weight of Features 14 and 27. Along the southern 2-m boundary of the block, over $52 \mathrm{~kg}$ (or more than 50 percent) of the burned rock by weight was recovered. The other highest weights were in the units contiguous to Unit N1033 E 1058 and Features 29 and 30 where approximately $16 \mathrm{~kg}$ of burned rock were recovered. Though the statistics suggest their distribution is random, the features are concentrated along the southern edge of the block.

\section{Projectile Points}

The projectile points were in the southern half of the block, where the burned rock weight was greater (see Figure 8.3). Both of the Early Barbed points were found in proximity to Features 14 and 27, respectively. The radiocarbon date from Feature 14 was ca. 6,600 B.P., well within the proposed range for Early Barbed points (see Appendix C). The Early Barbed is thought to predate Martindale points and five of the bifaces: the two butted bifaces, two late stage bifaces (Lots 551.1 and 575), and Lot 535, a Stage 2 biface. Four of the five bifaces were along the southern edge of the block. Eight of the bifaces were broken during manufacture, and only one was broken from use.

\section{FLAKE TOOLS}

There were nine flake tools: one end scraper, five retouched flakes, and three utilized flakes (Figure 8.5). There is less association between features and flake tools and less of the spatial concentration in the south than was observed with the points and bifaces. The end scraper (Lot 497.2) was in Unit N1029 E1068, the same unit as the Gower point, and was made from a sequence flake. There was one sequence flake noted in the debitage from the unit to the south, N1027 E1068, although no Use-wear was present. Only two of the flake tool specimens were complete; the rest were fragments presumably broken during use and then discarded. 


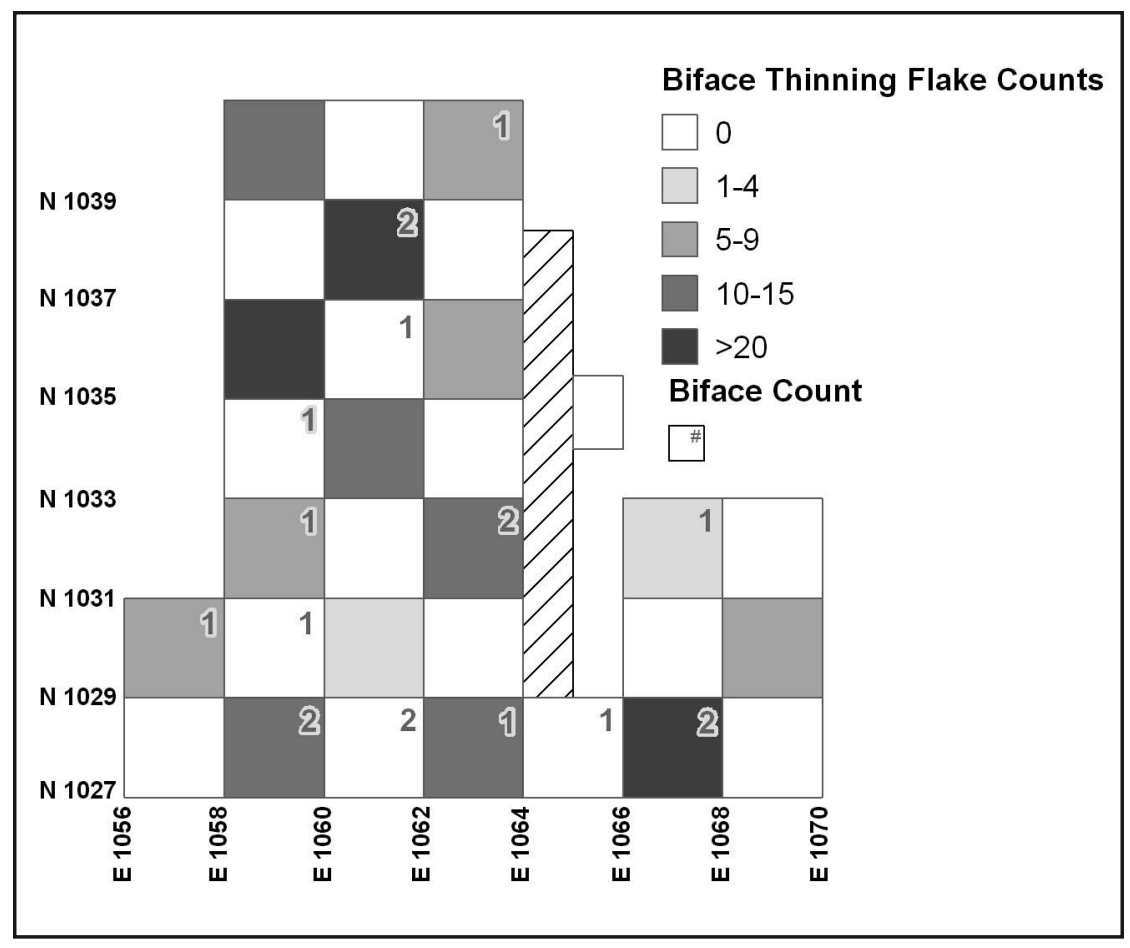

Figure 8.4. Occupation Zone 1 Area A-NE biface reduction flakes and biface distribution.

\section{BIFACE AND CORE REDUCTION}

Core and biface reduction flakes are distributed unevenly between the traditional excavation units. The counts from the two types of reduction for each unit were compared to an average random distribution of flakes across the units using a t-test analysis. The variation in flake counts from an average distribution shows the distribution differs from the expected norm at $\mathrm{t}=-2.66$; df $15 ; \mathrm{p}<.05$. The average number of biface thinning flakes per unit was $12.5 \pm 8.8$, and the average number of core flakes was $5.7 \pm 4.5$ per unit, suggesting more intensive biface production at the site.

\section{Cores and Core Reduction}

As shown in Figure 8.6, there is no significant association between cores and core reduction flakes. Most (61 of 86) flakes had less than 50 percent dorsal cortex remaining and initial cortex reduction was probably occurring off-site or in another area of the site. The distribution of the debitage indicates that it was not an intensive activity at this area of the site. The amount of debitage also suggests brief episodes of flint knapping by a small number of individuals.

\section{Bifaces ANd Biface REDUCTION}

The distribution of bifaces and biface reduction flakes is shown in Figure 8.4. Two of the three traditional units containing two bifaces each have higher than average biface reduction flake counts. Almost 90 percent of the debitage had no cortex, and with an average length of 22.5 $\mathrm{mm}$, initial reduction occurred off-site or elsewhere at the site. There are too few flakes to determine associations between higher flake counts and biface distribution.

\section{SUMMARY}

Most OZ1 artifacts are clustered at the southern half of Area A-NE, where activities appear to have been more intensively concentrated. The close proximity of Features 29 and 30, a unique feature type, is more than likely not a coincidence, though the function of the features is unknown. The other possible association is between the southern two features, 14 and 27, and the two Early Barbed Devil's Variant points. The Early Barbed Devil's Variant type predates Martindale and postdates or is coeval with Gower points. The radiocarbon date from Feature 14 is within the estimated date range for the point type. The sparse numbers of tools represent short term repeated visits to the site over at least several hundred years based upon the projectile points. Small groups or individuals used the site for brief intervals to refit, manufacture, and refurbish their lithic tools and supplies. The small size of Features 14 and 27 indicates they were used by one or a few individuals. Small bone fragments were identifiable to white tailed deer, and other fragments were from large-sized mammals. Hunting is inferred from the presence of the dart points and the exhausted end scraper. 


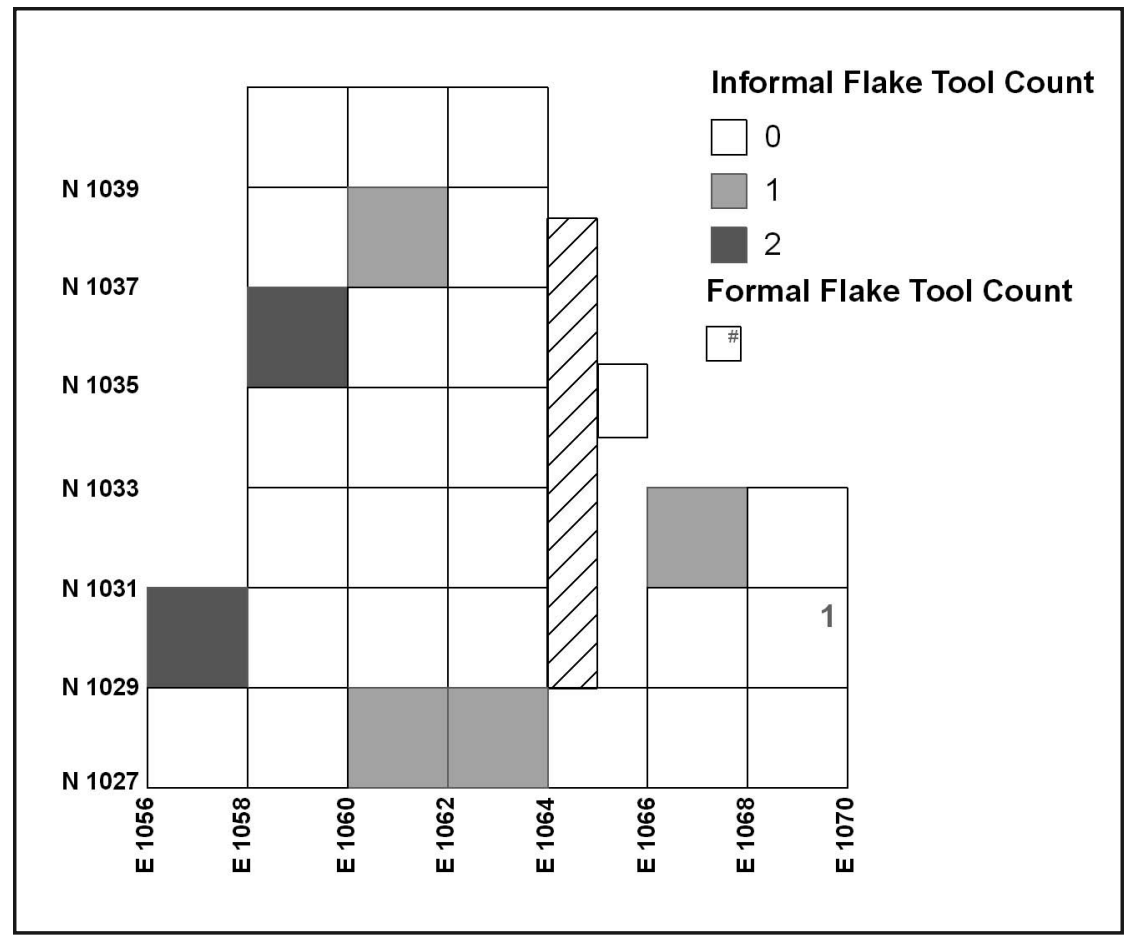

Figure 8.5. Occupation Zone 1 Area A-NE informal and formal flake tools distribution.

\section{Organization of Technology}

Materials from OZ1 suggest small groups of mobile hunter gatherers visited the Gatlin site to procure lithic material, manufacture bifaces and flake tools, and refit and repair their projectiles. The lack of lithic tool diversity and the small size of the burned rock features support the interpretation that the site was used for short duration visits by small groups of foragers. Bifaces, manufactured on site from locally available chert, were the dominant tool form. Late-stage manufacturing failures were the most common biface type, which suggests that the end result of biface production was finished tools such as projectile points, bifacial knives, or portable, biface blanks. An untyped manufacturing failure of a point, also suggests that projectile points were produced at the site, and cores and flake tools were relatively rare.

\section{Projectile Points}

The Gower, an Early Barbed Devil's Variant, and Martindale were broken by impact; the other Early Barbed Devil's Variant was snapped through use or resharpening, while the untyped fragment was broken during manufacture. Only the Martindale point was utilized after initial breakage, as the other specimens were too damaged for further use. The condition of the points and their methods of breakage suggest that they were discarded during the process of refitting.

\section{BIFACES AND BIFACE REDUCTION}

The 17 bifaces and two butted bifaces were made from locally available materials. Both early and late stages of manufacturing are represented, with Stage 5 $(n=8)$ being the most numerous. The two main parent sources for the biface blanks were from the reduction of cobbles and from large flakes. Cobble reduction was most evident in butted bifaces, and was the likely flake source for the large, thin, bifaces. As shown in Table 8.4 , based on the length and thickness of biface flakes, they are too small to serve as blanks for any but the smallest bifaces. Overall, the average size of the biface reduction flakes is overwhelmingly characteristic of both later stage and smaller biface reduction. Only 23 of the biface reduction flakes had any cortex remaining and 19 of those had less than 26 percent cortex, indicating that initial reduction was conducted in the unexcavated areas of the site or off-site. A complete Stage 5 biface was made on an interior flake, while the other Stage 5 specimens had indeterminate parent sources. It is probable that smaller bifaces were made from hard hammer flakes. Manufacturing failure was the most numerous breakage pattern $(n=8)$ with only one biface possibly broken during use.

\section{CORES AND CORE REDUCTION}

Although biface production appears to be the dominant lithic activity, core reduction was also occurring. The apparent primary goal of the core reduction was to produce flakes for expedient use and as blanks for formal tools such as scrapers and the smaller bifaces. The ratio of core reduction flakes 


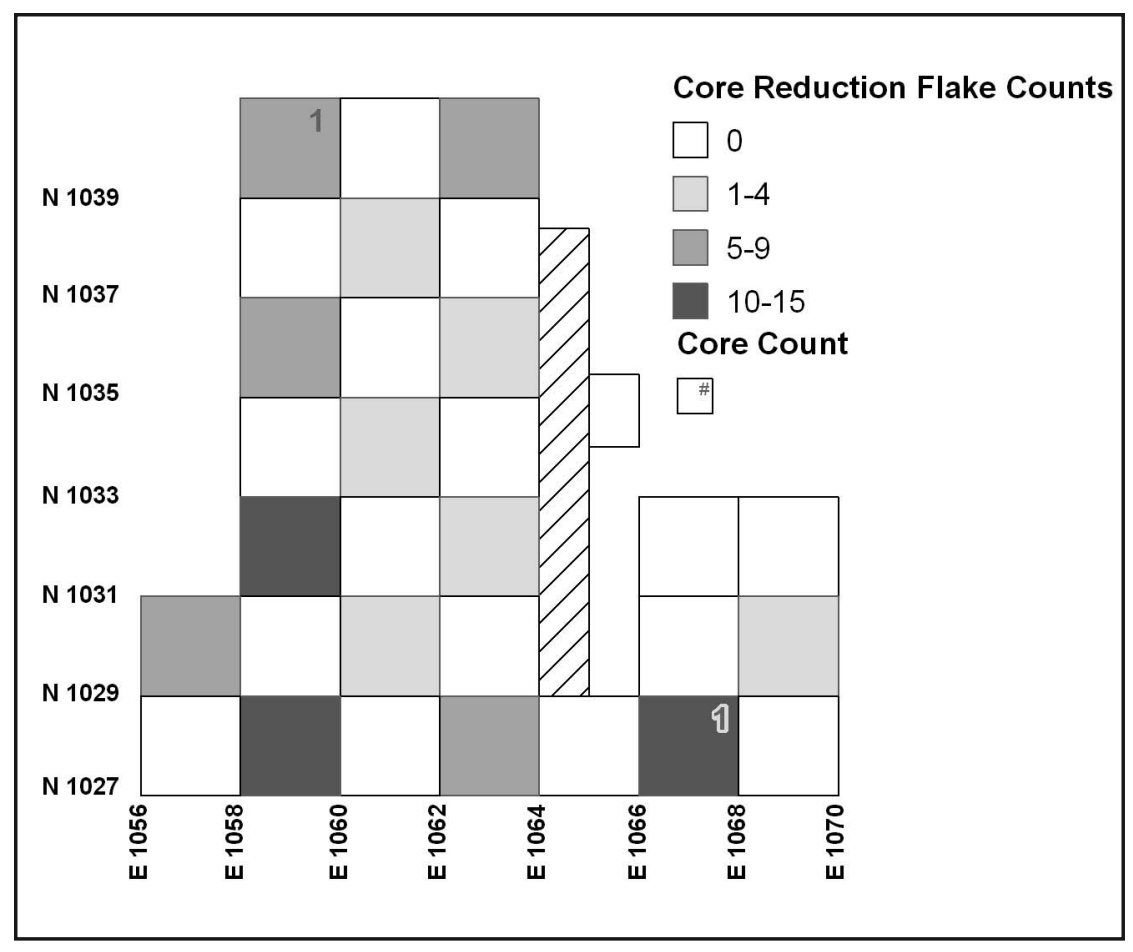

Figure 8.6. Occupation Zone 1 Area A-NE core reduction flakes and core distribution.

ISSUES OF MOBILITY, SPECIAL USE, CURATION

According to Parry and Kelly (1987), sedentism is accompanied by a rise in expedient tool usage, which they measured using the ratio of cores compared with bifaces through time, with higher numbers of cores indicating increasing sedentism. Bifaces were used as a measure of formalized tool usage and associated with greater mobility. The ratio of bifaces to cores in OZ1 is 9.5:1, which according to their data, indicates high mobility. This supports a model for the site as a destination for small, mobile, groups. The discarded dart points, exhausted cores, and bifaces were made from locally available material. One activity at the site was lithic refitting,

to biface reduction flakes was $0.455: 1$, the highest ratio of any of the occupation zones. The size and characteristics of the core reduction debitage indicate that more cores were reduced than the two that were recovered. These two cores were exhausted, multidirectional, and made from local upland tabular chert cobbles. Other cores (represented by the debitage) may have been totally exhausted or curated and removed from the site.

\section{FLAKE TOOLS}

The source of blanks for the two complete flake tools were hard hammer core reduction flakes. The broken specimens, given the minimal amount of modification, were more likely broken as the result of use or post-depositional effects, rather then during manufacture. Like the cores, all of the flake tools were made from local chert. The end scraper was made on a sequence flake, a deliberate method of producing a thick, uniform, flake, from a short core surface such as the edges of tabular cobbles. This suggests that the core was prepared and specifically maintained to produce sequence flake blanks. where gear was repaired, exhausted materials discarded, and new material obtained. The large butted bifaces and the ground stone fragment may represent site furniture, where these tools were either abandoned at the site, or were cached for future use. The minimum investment in time in the manufacture of butted bifaces made them a kind of expedient formal tool form.

The application of the concept of curated tools for interpreting hunter gatherer foraging strategies and technological organization has been a source of debate (Bamforth 1986; Binford 1980; Kelly 1992; Kuhn 1995; Torrence 1983, 1989). In general, higher amounts of curated tools are believed to be indicative of one of two scenarios: (1) mobile hunters or foragers who maintain a hunting-oriented tool kit; or (2) a task-oriented collector group using specific tools to perform a particular, planned task. For the Gatlin study, curated tools include projectile points, bifaces, formal flake tools, and shaped cores. Non-curated tools include utilized and minimally modified flakes and some multi-directional cores. Like most examples, the differences between curated and non-curated assemblages is a continuum and not 
dichotomous. Within the definition of curation are cached tools, made for anticipated future use. These can be biface blanks, or ground stone tools such as manos and metates that were left on site for future use. In OZ1 the curated tool ratio to non-curated is $26: 8$, or 3.25:1. Taking into account the high percentage of projectile points and bifaces, the overall lithic toolkit supports the notion that the OZ1 inhabitants were mobile hunters, who were familiar with the area, and used the site to replenish lithic supplies. The lack of diversity in the assemblage suggests that visits to the site were of short duration, and that most of the late stage biface blanks were intended for reduction to tools or transport. The high percentage of tertiary debitage suggests that some final tool manufacturing and refurbishing occurred on site. Tool maintenance is evident from the discard of exhausted projectile points and the broken untyped base fragment. Part of tool maintenance is the refurbishing of projectile systems, and the condition of the point specimens suggests that some were intentionally discarded rather than repaired (i.e. the Martindale).

Another measure of mobility and site usage is the comparison of formal to informal tools. Formal tools include all stages of bifaces, bifacial tools, projectile points, flake tools such as scrapers, and prepared cores. Informal tools, or expedient tools, include multidirectional cores, utilized and retouched flakes, and core tools. Essentially, tools that require advanced preparation, transportability, and anticipated use are formal tools (Andrefsky 1998:213). Informal tools are expedient or casual, made for single use or short duration, and are discarded rather than refurbished. They are usually made and used locally and not transported (Andrefsky 1998:213). The difference between formal and informal is a continuum rather than a dichotomy, and even within a class there are degrees of difference such as between butted bifaces and Stage 5 bifaces. The categories and counts for Formal and Informal are displayed in Table 8.6. The ratio of formal to informal tools is 2.6:1

\section{FEATURES}

The four burned rock features can be divided into two groups based upon composition and perceived function: Group 1, Features 29 and 30; and Group 2, Features 14 and 27. Group 1 features were small clusters of burned material and small gravels with an unknown function, although the tight clusters are similar to discard piles from stone boiling containers. These two features were approximately $1.2 \mathrm{~m}$ apart and, based upon their composition and size, they may be related. While the function of Features 29 and 30 is unknown, these compact clusters of material could be refuse or clean out from another type of feature.

Group 2 features are similar to small burned rock features from Early Archaic sites as outlined by Clabaugh and Thoms (2007) and Tennis (1996), where small clusters of hot rocks were used for cooking and heat. Cooking methods ranged from grilling on rocks, grilling over a fire, to indirect heating, while the small size of the features meant they had limited capacity and were not used for bulk processing. There were no definitive spatial associations between the artifacts and features such as burned bifaces and proximity to burned rock features. Features 14 and 27 were burned rock clusters of a type expected from small groups for their cooking and heating requirements. Lipid residue suggests both animals and plants were processed.

\section{Subsistence Practices}

Despite the presence of mussel shell, its inclusion in OZ1 is limited to several individual specimens and, therefore, is not hypothesized as a substantial source of subsistence. The faunal assemblage is practically non-existent from this occupation zone though it undoubtedly once held remains that have likely deteriorated over the course of thousands of years.

Hunting is inferred during OZ1 based on the presence of the deer bone fragments and discarded

Table 8.6. Occupation Zone 1 Formal and Informal Stone Tools

\begin{tabular}{|c|c|c|c|c|c|c|c|c|}
\hline & $\begin{array}{c}\text { Projectile } \\
\text { Points }\end{array}$ & Bifaces & $\begin{array}{c}\text { Bifacial } \\
\text { Tools }\end{array}$ & $\begin{array}{c}\text { Flake } \\
\text { Tools }\end{array}$ & $\begin{array}{c}\text { Prepared } \\
\text { Cores }\end{array}$ & $\begin{array}{c}\text { Retouched and } \\
\text { Utilized Flakes }\end{array}$ & $\begin{array}{c}\text { Multidirectional } \\
\text { Cores }\end{array}$ & Total \\
\hline Formal & 6 & 17 & 2 & 1 & 0 & & & 26 \\
\hline Informal & & & & & & 8 & 2 & 10 \\
\hline Ratio & & & & & & & & $2.6: 1$ \\
\hline
\end{tabular}


and impact damaged projectile points. The results of lipid analysis were inconclusive for animal remains; however, plants may have been processed. Open sites of this age in Central Texas generally lack substantive assemblages of preserved faunal remains. Differential preservation rates between taxa (larger animal bones are more likely to be preserved), and within taxa (more robust elements are likely to survive), means that the result may be a skewed representation of the faunal assemblage.

\section{Summary OF OCCupation Zone 1}

Between ca. 6,600-6,100 B.P., small groups of hunter gatherers repeatedly visited the Gatlin site. During the earliest visits, the climate was slightly drier at the beginning then today's climate. During the Early Archaic several authors (Johnson 1991; McKinney 1981; Story 1985) have noted the concentration of sites along the edges of the Edwards Plateau and along the larger stream systems. During periods of increasing aridity, the Guadalupe riparian corridor would have served as a refuge for wildlife and people.

During OZ1, landscape stability was punctuated by brief periods of alluvial deposition from the river. With the exception of the anomalous Pandale point, the rest of the diagnostic points occur at other sites within the chronological boundary of OZ1. If projectile points are used as cultural markers, at least three possibly separate (but likely overlapping or contemporaneous) occupations are implied, beginning with Gower, then Early Barbed, and then Martindale. And, if the site functioned as a retooling stop, the discarded points may have been from single episodes of visitation. Although artifacts were concentrated in the southern end of the excavation block as opposed to being equally distributed, the overall quantity of material was low, again suggesting small groups or individuals were using the site.

Potentially the most significant of these visits was from the makers of the Early Barbed points. Given the perceived association with Features 14 and 27, the Early Barbed points and features may be contemporaneous, and, based on pollen and phytolith data from Feature 27, the site may have been utilized during the spring or fall.
OZ1 data indicates that the Gatlin site was sporadically used and does not appear to be part of a Collector or Processor logistic site network. It would be more appropriately classified as a Forager or Traveler short-term camp. The inhabitants were reducing bifaces to late-stage blanks or finished bifaces, and finished bifaces left at the site were crude bifacial choppers. The one formal flake tool was an exhausted scraper. The reduction of cores suggests that flakes, including sequence flakes, were produced to make bifaces as well as possibly new scrapers, but this was not a dominant site activity.

Overall, the lithic assemblage, including the features, is characteristic of small, mobile, groups or individual hunters who stayed briefly at the site. The biface to core ratio of 9.5:1 suggests that the visitors to the Gatlin site represented in OZ1 were highly mobile. The lack of tool diversity and features suggests that other activities were conducted elsewhere, and that lithic material was procured locally and reduced during the course of hunting. 
8-20 Chapter 8 


\title{
Chapter 9
}

\section{OCCUPATION ZoNe 2}

\author{
Eric R. Oksanen, Mercedes C. Cody, and Kevin A. Miller
}

\section{INTRODUCTION}

OZ2 contains cultural materials associated with the latter part of the Early Archaic and two dominant projectile point styles, Gower and Martindale. Gower points predate and transition to Martindale points in major regional cultural chronologies (Collins 2004; Johnson and Goode 1994); and OZ2 reflects this trend. While this change in point styles occurs, the OZ2 assemblage reflects a remarkable level of technological continuity with the earlier occupations at the Gatlin site, suggesting various degrees of cultural continuity. Though there are some discrepancies between established dates for projectile point styles found in OZ2 and radiocarbon dates obtained from the feature assemblage, the radiometric date range for the occupation is ca. 6,100-4,600 B.P. with the greater number of dates falling between ca. 5,400-4,600 в.P.

Located primarily in Areas A-NE and A-SW, approximately $33.2 \mathrm{~m}^{3}$ of OZ2 was excavated during data recovery, and $170 \mathrm{~m}^{2}$ of overall surface was exposed (Figure 9.1; see Figure 7.6). In Area A-NE, 16 traditional and 15 feature-focused $2 \mathrm{x}$ 2-m units were excavated, and, in A-SW, six traditional units and five feature focused units were excavated. Site usage appears to increase in OZ2 compared to OZ1, possibly the result of more frequent visitations by larger groups with more intensive activities, as reflected in more numerous and larger features, a greater diversity in projectile point styles, and more lithic debris and tools. The presence of two drills and two gouges indicate a modest increase in the range of activities that were practiced.

A significant activity at the Gatlin site was biface reduction and, like OZ1, most of the initial biface reduction to blanks was occurring off-site. Core reduction activities also increased and so did the use of flake tools. Multiple specimens of the same style of projectile points indicate that larger groups may have used the site and/or that the site was repeatedly revisited. The use of earth oven technology indicates a change in both food resources and processing methods, and possibly larger group sizes. The scarcity of domestic artifacts supports a view that during OZ2, logistical foraging groups briefly occupied the Gatlin site. The repeated occupations by what were likely the same groups, based upon projectile point styles, also suggests that they were "mapped" onto the local resources.

\section{Chronology}

The dating of OZ2 was problematic because of several anomalous radiocarbon dates, even from within the same features. This also suggests a moderate level of compression and overprinting in the occupation zone. For example, Feature 34 was a composite feature that had an overall range from ca. 5,000-4,100 B.P. (see Table 7.1). It is possible that the constituent parts of Feature 34 represent separate uses and that they are

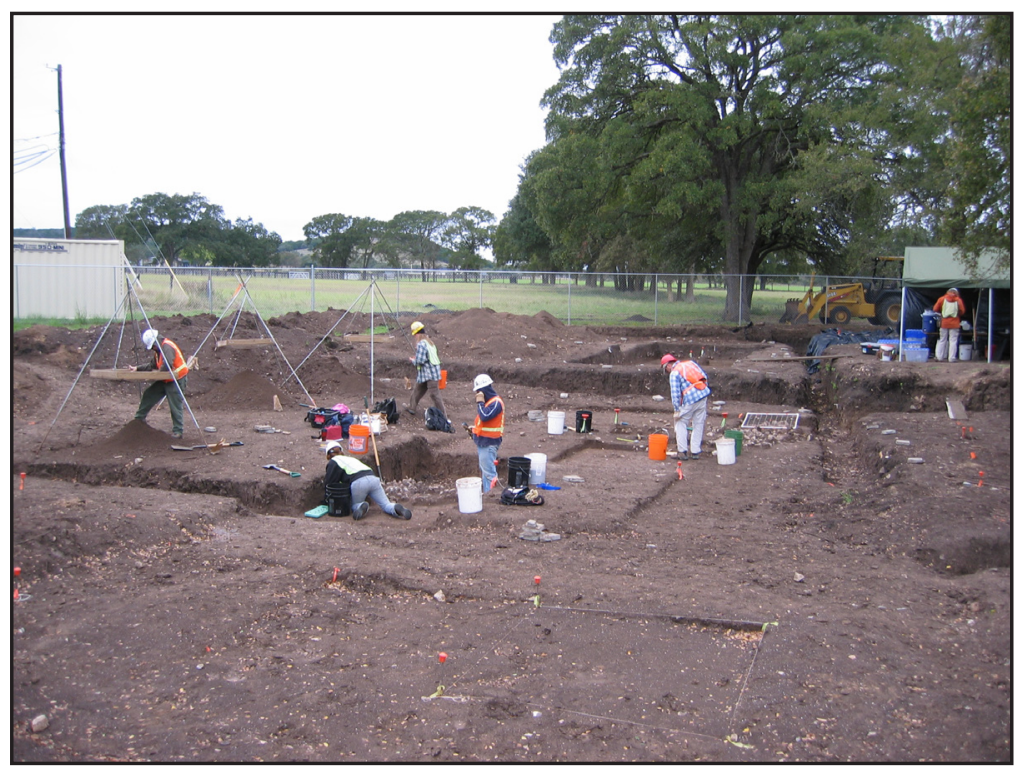

Figure 9.1. Area A-SW excavations in progress facing southwest. 
different features, or that a portion of Feature 34 was utilized or scavenged by later visitors. Features 33 at $5440 \pm 40$ в.P. (Beta 206126; $1 \sigma$ conventional radiocarbon date) is a secure early cultural date for OZ2 from the data recovery excavations. Other early $1 \sigma$ conventional radiocarbon dates are Feature 5 (testing), $5480 \pm 70$ в.P.; and Feature 22, $5260 \pm 50$ в.P.

The oldest $1 \sigma$ conventional radiocarbon date within OZ2 comes from Feature 26 (Beta-206122) at $6100 \pm 40$ B.P. Feature 26 is near Feature 25, which has a $1 \sigma$ conventional radiocarbon of $4540 \pm 40$ в.P. Both Features 25 and 26 are at the stratigraphic boundary between OZ1 and OZ2. The radiocarbon assay from Feature 26 may represent remnant carbon from OZ1. These two dates are clearly unrelated and suggest that there was localized mixing of sediments. The elevation of the stratigraphic boundary between $\mathrm{OZ1}$ and OZ2 varied across the site and followed the natural landform.

The temporally diagnostic projectile points are primarily from the Early Archaic. As listed by estimated chronological order from oldest to youngest they are Gower, Baker, Martindale and Bandy, Bell and Andice, and Early Triangular. The latter three types are considered to be late Early Archaic or early Middle Archaic types. A Late Archaic Marcos point was also recovered from OZ2, but it is clearly intrusive. The dating of Gower is problematic as many sites with the best isolated Gower components (Landslide and Sleeper, for instance) have not been dated chronometrically. Gower is generally believed to occur in a range from ca. 8,000-7,000 B.P. (Collins 2004:Figure 3.9a) Gower points have been dated in secure context from ca. 7,700-6,650 B.P. in San Marcos (Oksanen 2005). Baker, Martindale, and Bandy are thought to be contemporaneous with each other with a date range of ca. 7,000-6,000 B.P. (Appendix C). Bell, Andice, and Early Triangular are included in the Middle Archaic of other chronologies such as Collins (2004) and Johnson and Goode (1994), but are included with the Early Archaic following a south Texas chronology (Hester 2004:138). Collins estimates the range for Calf Creek, Bell, and Andice at ca. 6,000-5,000 B.P (2004:Figure 3a). As noted in Appendix C, Bell points were dated at Cibolo Crossing site at 5,300-4,800 B.P. based upon three radiocarbon dates from Feature 19 (Kibler and Scott 2000:74) The estimated date range for these points is ca. 5,000-4,100 B.P. in Central Texas. Along the Texas coast, an Andice point fragment was recovered from deposits aged from ca. 4,750-4,200 B.P. (Ricklis 2004:Figure 5.5 d,f).

When including the radiocarbon assay from Feature 26, the estimated range for OZ2 encompasses the later periods for Gower, Baker, Martindale, and Bandy and the beginning date for Bell, Andice, and Early Triangular (Collins 2004:Figure 3.9a). There is an overlap in the radiocarbon dates from features between OZ1 and OZ2, which suggests that the numerous Gower points $(n=21)$ continued in use for a longer period of time, and were contemporaneous with Martindale and Bandy points (and similarities with Baker suggest a stylistic connection), or are from an earlier occupation. The more likely scenario is that the Gower points represent remnant occupations from OZ1. This coincides with a period of slow deposition and landscape stability that is evident from Features 25 and 26.

\section{Paleoenvironment}

Using a start date of ca. 5,400 B.P. for examining sedimentation rates, there is no discernible difference in the geomorphology from OZ1, although sediment accumulation continued to slow from a rate of approximately $1 \mathrm{~cm}$ per 19 years to $1 \mathrm{~cm}$ per 44 years. The $1 \mathrm{~cm} / 44$ years estimate by Frederick (see Chapter 6) agrees with the projected deposition of 20 $\mathrm{cm}$ accumulating over 800 years, from 5,400-4,600 B.P. The slowing accumulation is due in part to the entrenchment of the river, which reduced the frequency of overbank flooding (see Chapter 6).

During the time represented by OZ2, the Guadalupe River contained more water than today and had a more stable flood regime, based on the presence of two mussel shell pseudocardinal teeth identified to the species Tampico pearlymussel (Cyrtonaias tampicoensis). Prehistorically the species was common in major drainages, although less so in the Guadalupe River drainage system. Today, the species is absent from the upper Guadalupe River because of drought and artificial impacts from dewatering and scouring floods (Howells, Appendix J). At the beginning of OZ2, the phytolith composition from Feature 26 suggests that this was a period of drier conditions, even drier than the Middle Archaic, based on samples from the burned rock midden (Table 9.1). 
Table 9.1. Paleoenvironmental Results from Pollen and Phytolith Samples from Occupation Zone 2 Features

\begin{tabular}{|l|c|c|c|c|c|c|c|c|c|c|c|c|}
\hline Feature & 5 & 12 & 13 & 21 & 22 & 24 & 25 & 26 & 31 & 33 & 34 & 35 \\
\hline Age (B.P.) & $5480 \pm 70$ & & & & $5260 \pm 50$ & & $4550 \pm 40$ & $6100 \pm 40$ & & $5440 \pm 40$ & $4990 \pm 50$ & \\
\hline Moisture & Moist & Dry & Dry & Dry & Dry & Dry & Wet & Dry & Wet & Wet & Moist & Dry \\
\hline Temperature & Cool & & & & & Cool & Cool & & & Cool & Cool & \\
\hline
\end{tabular}

Possible seasonality is noted in several of the feature pollen and phytolith records. The dissolution of phytoliths attributed to pooling of water suggests features were abandoned and retained water after use, during periods of cooler conditions. Other features contain grass phytoliths indicating drier conditions. Lipid signatures from the features were high fat animal (large herbivore) and plant, and suggested that sufficient habitat was available for bison. Faunal remains include deer and bison from near Feature 26.

In sum, infrequent but periodic flooding between ca. 6,100-4,600 B.P. buried cultural deposits in OZ2. Between these flooding events were long periods of surface stability. The phytolith and pollen signatures suggest some degree of seasonality at the site. The paleoenvironmental signature from OZ2 correlates with the proposed sequence from Collins (2004:Figure $3.9 \mathrm{~b}$ ) of considerably more-xeric conditions, with the exceptions due to seasonal variation. The date range of OZ2 is also within the maximum grasslands extent, calculated from using pollen from Boriak Bog, from 5,500-4,500 B.P. (Bousman 1998:209).

\section{Occupation Zone 2 Assemblage}

A variety of artifacts and ecofacts comprise the OZ2 assemblage. Artifacts are mainly the byproducts of lithic technology, represented by the assemblage of tools, debitage, and features. Ecofacts mainly include the faunal assemblage but also the results of special studies from features. Technologically, in OZ2, there are three main groups represented by projectile points, and each of the groups represents a different era of the Early Archaic. The three groups and the era they represent are: Gower, later part of the early Early Archaic; Martindale (late Early Archaic) and Early Triangular (terminal Early Archaic). As shown in Table 9.2, in addition to the large increase in the number of projectile points, there is a large increase in the quantity of other stone tools, especially in bifaces, formal flake tools, and cores. The change from a biface to core ratio of $9.5: 1$ in OZ1 to $2.1: 1$ in OZ2 is a dramatic change; however, there is still little overall diversity in tool types, as was observed in OZ1. Individual attribute data for lithic tools, lithic cores, and ground stone/manuports is presented in Appendix E, consisting of E.1 through E.7.

There were 14 features excavated from OZ2: 13 were burned rock thermal features for cooking and/or heating, and one was an activity area represented by a reduced, partially refitted, core. The burned rock features are almost evenly split between small clusters up to $1 \mathrm{~m}$ in diameter and larger clusters or scatters of several meters. The size division is likely functional, but is indirectly related to site population and subsistence practices. The smaller features were used for individuals or small groups, while larger features were used for processing of larger quantities of foodstuffs presumably for larger groups. Anomalous radiocarbon dates suggest portions of the larger features may have been reused or scavenged for rocks by later site occupants to construct other features. The increase in artifacts and features when compared to OZ1 suggests that the site was utilized more frequently by small groups or perhaps by several larger groups.

\section{Dart Points}

There were 88 projectile points attributed to OZ2 during testing and data recovery excavations at the Gatlin site. These points mainly include diagnostic types associated with the early and later portions of the Early Archaic period ( $\mathrm{n}=64)$, such as Gower, Baker, Bandy and Martindale, and Martindale Narrow Stem. These are followed by those associated with the late Early Archaic/early Middle Archaic period ( $n=13)$, including Andice, Bell, and Early Triangular. There was one projectile point, a Marcos, associated with the Late Archaic period within this zone. Additionally, 10 of the projectile points recovered from this zone are untypable dart points. 


\section{9-4 Chapter 9}

Of note, the majority of Martindale points were encountered within this zone. The following counts and descriptions only refer to the specimens within OZ2. Projectile point type morphology and metric attributes information is located within Appendix $\mathrm{C}$, with individual metric attributes information presented in Appendix E.1.

Table 9.2. Summary of Lithic Technology for Occupation Zone 2

\begin{tabular}{|c|c|c|}
\hline Category & Count & Description \\
\hline Features & 14 & $\begin{array}{l}2,5,12,13,21,22 \\
24,25,26,28,31 \\
33,34,35\end{array}$ \\
\hline \multirow{10}{*}{ Projectile Points } & \multirow{10}{*}{88} & 1 Andice \\
\hline & & 1 Baker \\
\hline & & 5 Bandy \\
\hline & & 2 Bell \\
\hline & & 10 Early Triangular \\
\hline & & 21 Gower \\
\hline & & 1 Marcos \\
\hline & & 34 Martindale \\
\hline & & $\begin{array}{l}3 \text { Martindale- Narrow } \\
\text { stem }\end{array}$ \\
\hline & & 10 Untypable \\
\hline \multirow{3}{*}{ Bifacial Tools } & \multirow{3}{*}{5} & 2 Drills \\
\hline & & 2 Clear Fork Tools \\
\hline & & 1 Butted Biface \\
\hline \multirow{6}{*}{ Bifaces } & \multirow{6}{*}{139} & 3 Stage 1 \\
\hline & & 11 Stage 2 \\
\hline & & 21 Stage 3 \\
\hline & & 28 Stage 4 \\
\hline & & 50 Stage 5 \\
\hline & & 26 Unknown \\
\hline
\end{tabular}

\begin{tabular}{|c|c|c|}
\hline Category & Count & Description \\
\hline \multirow{5}{*}{ Flake Tools-Formal } & \multirow{5}{*}{31} & $\begin{array}{l}9 \text { End and Side } \\
\text { Scraper }\end{array}$ \\
\hline & & 14 End Scraper \\
\hline & & 1 Full Side Scraper \\
\hline & & 5 Side Scraper \\
\hline & & 2 Graver \\
\hline \multirow{2}{*}{ Flake Tools-Expedient } & \multirow{2}{*}{85} & 18 Utilized \\
\hline & & 67 Retouched \\
\hline \multirow{6}{*}{ Cores } & \multirow{6}{*}{63} & 4 Bidirectional \\
\hline & & 12 Bifacial \\
\hline & & 1 Bipolar \\
\hline & & 5 Indeterminate \\
\hline & & 39 Multidirectional \\
\hline & & 2 Slab \\
\hline Ground Stone tools & 1 & Metate fragment \\
\hline $\begin{array}{l}\text { Total Flakes and Fragments } \\
\text { from Traditional Units }\end{array}$ & 3382 & \\
\hline Core Reduction Flakes & 619 & \\
\hline Biface Reduction Flakes & 2307 & \\
\hline Indeterminate Flakes & 454 & \\
\hline Total Proximal Fragments & 2182 & \\
\hline Total of Complete Flakes & 1200 & \\
\hline $\begin{array}{l}\text { Complete Flakes Percentage } \\
\text { of Total }\end{array}$ & $35.50 \%$ & \\
\hline Ratio of Bifaces to Cores & $2.21: 1$ & \\
\hline
\end{tabular}

\section{ANDiCe}

$(\mathrm{n}=1)($ Lot 841; Appendix C, Figure $7 \mathrm{c})$

Nominal Attributes: Flaking pattern is indeterminate for this specimen.

Condition and Breakage: The point is a shoulder/barb fragment with an impact breakage.

Reworking and Beveling: N/A

Use-wear: N/A

Raw Material Attributes: Raw material is local Edwards fine-grained chert.

Comments: Of the nine Andice points discovered throughout the entire Gatlin site only one was recovered from OZ2. 
BAKER

$(\mathrm{n}=1)($ Lot 909; Appendix C, Figure 5)

Nominal Attributes: This point has an asymmetrical blade. Flaking pattern is oblique parallel.

Condition and Breakage: This point is complete with no breakage.

Reworking and Beveling: The blade is heavily reworked, probably originally broad and long, and the specimen has a left bevel.

Use-wear: N/A

Raw Material Attributes: Raw material is local Edwards fine-grained chert.

Comments: This was the only Baker point discovered at the Gatlin site.

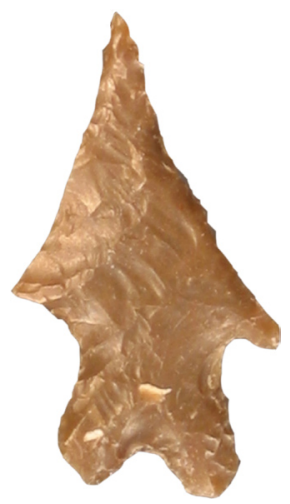

Lot 909

\section{BANDY}

$(\mathrm{n}=5)($ Lots 198, 228, 279.1, 505, 662; Appendix C, Figure 2 b, a, h, d, f)

Nominal Attributes: Flaking patterns for these points include two exhibiting a chevron pattern and one demonstrating a collateral pattern. One of the Bandy points exhibits a flake blank remnant surface and appears to be manufactured from a flake. Two of the Bandy points exhibit light serration and serrated blades.

Condition and Breakage: Four of these points are complete. Of these, one displays no breakage, while the remainder exhibit a snap fracture at the distal tip, some indeterminate breakage, and in one case an impact fracture. Only one of the Bandy points is incomplete, a basal fragment, with evidence of a snap fracture.

Reworking and Beveling: Evidence of reworking is present along the blade of two of the points.

Use-wear: Use-wear analysis was completed on all of these specimens except for one. Of those subjected to analysis, all were primarily utilized as dart projectile points, and of those three were multifunctional tools also used as light duty knives and butchering implements on soft animal mate-

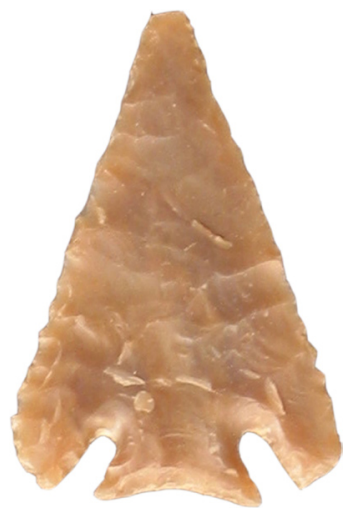

Lot 198 rial.

Raw Material Attributes: All of these points are composed of local Edwards fine-grained chert. Heat evidence is apparent on one specimen. Patination occurs on one specimen and is light $(<50$ percent).

Comments: Bandy points are consistently recovered from Early Archaic contexts.

BELL

$(\mathrm{n}=2)$ (Lots 82.1, 277.1; Appendix C, Figure 7 g, Lot 277.1)

Nominal Attributes: One of these points exhibits an oblique parallel flaking pattern.

Condition and Breakage: Both of these points are basal fragments with evidence of impact fractures.

Reworking and Beveling: Reworking is evident along the blade of one of these points, as well as a right bevel (twist to left).

Use-wear: N/A

Raw Material Attributes: The raw material for both of these specimens is local Edwards fine-grained chert. Only one shows evidence of light patination ( $<50$ percent). 


\section{Eariy Triangular \\ $(\mathrm{n}=10)$}

\section{Subtype Early Triangular A}

$(\mathrm{n}=5)($ Lots 82.2, 187, 271, 531, 955; Appendix C, Figure 8 a, Lot 82.2)

Nominal Attributes: Four of these points exhibit oblique parallel flaking patterns, while one exhibits an oblique subparallel flaking pattern.

Condition and Breakage: Three of the specimens are complete; two display no breakage, and one was broken during excavation but refit. The fourth specimen is a basal fragment with evidence of an impact fracture and some indeterminate breakage as well. The final specimen was broken during excavation but refit. It is a blade fragment, with evidence of an impact fracture along the remaining distal margin.

Reworking and Beveling: Reworking is apparent along the blades of four of these points, specifically along the tip of one and blades of three. Two blades demonstrate a left bevel. One of the specimens was not reworked, but was manufactured with a slight twist or bevel to the right.

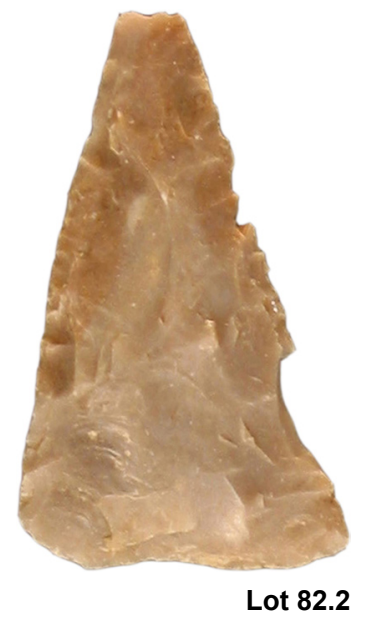

Use-wear: Two of these specimens were subjected to use-wear analysis, which classified one as a light duty knife or butchering implement, probably functioning as a projectile point as well. The other is a broad bladed tool utilized as a light duty knife or butchering implement, but not as a projectile point.

Raw Material Attributes: All of these specimens are made of local Edwards fine-grained chert.

Comments: Out of a total of 22 Early Triangular A projectile points recovered throughout the entire Gatlin site, five were encountered within OZ2.

\section{Subtype Early Triangular B}

$(\mathrm{n}=5)($ Lots 197, 304, 853, 868, 943)

Nominal Attributes: Two of the Early Triangular B points have oblique parallel flaking patterns, and one has an oblique subparallel pattern. The remaining two points exhibited indeterminate flaking patterns due to the condition of the specimens.

Condition and Breakage: Two of these points are complete, both missing tiny or small portions of the distal margin due to impact breakage. One of these complete specimens is also missing approximately 15 percent of its basal margin due to an indeterminate break. The remaining points are classified as basal fragments. Of these, two are missing the distal margin and a large portion of the blade due to an impact breakage in one case and an impact/snap breakage in the other.

Reworking and Beveling: Reworking is evident along the blades of three of these points.

Use-wear: N/A

Raw Material Attributes: Raw material for all of these points is local Edwards fine-grained chert.

Comments: The most frequent cause of breakage was due to direct impact resulting in a smashed tip or a bending break with its characteristic reverse fluting originating from the top or subsequent break at the tip. 


\section{Gower}

$(\mathrm{n}=21)$

\section{Subtype Gower A}

$(\mathrm{n}=8)($ Lots 223, 273, 310, 336, 483, 565, 594.1, 1550; Appendix C, Figure 6 a, Lot 483 ; b, Lot1550)

Nominal Attributes: Four of these points exhibit an oblique subparallel flaking pattern, while three demonstrate an oblique parallel flaking pattern.

Condition and Breakage: Two of these points are classified as complete, with no breakage observed for one and an impact fracture on the other. Five of the points are classified as basal fragments, all exhibiting snap fractures. The final point is a stem fragment with evidence of an impact fracture.

Reworking and Beveling: Reworking is evident along the blade of four of these points and along the blade and stem of one.

Use-wear: Use-wear analysis was performed on four of these points and determined that all four functioned as projectile points. Two of the four also had functioned as cutting tools; one as a knife or butchering implement and the other as a light duty cutting tool or butchering implement.

Raw Material Attributes: The raw material for all of these points is local Edwards

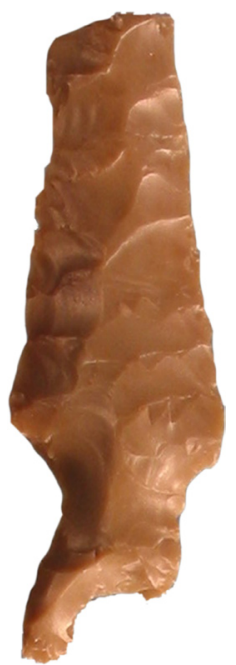
fine-grained chert. Heat evidence is present on two of these points, one demonstrating potlids and crazing, and the other showing signs of reddening.

\section{Subtype Gower B}

$(\mathrm{n}=10)($ Lots 272, 320.2, 320.3, 335, 532.2, 554.1, 564, 840.1, 889.1, 1557; Appendix C, Figure 6 d, Lot 335; e, Lot 554.1; f, Lot 564)

Nominal Attributes: Four of these points exhibit an oblique parallel flaking pattern, while another four demonstrate an oblique subparallel flaking pattern, and one point displays a random flaking pattern.

Condition and Breakage: Three of the Gower B points are complete with two exhibiting no breakage, and one demonstrating a snap fracture at the distal tip/margin. Six of the Gower B points are basal fragments. Of these, three exhibit snap fractures, and two demonstrate use-wear impact fractures. The last of these basal fragments shows signs of post depositional excavation damage. One of the Gower $\mathrm{B}$ points is a blade fragment with evidence of an impact fracture.

Reworking and Beveling: Most of these points are reworked. Six exhibit reworking along the blade, one demonstrates reworking along the blade and stem, and one is reworked at the stem.

Use-wear: Five of these points were subjected to use-wear analysis out of which four functioned as dart points, and one was utilized to cut relatively hard, moderately resistant materials such as soaked antler or hard wood.

Raw Material Attributes: All of these points are made of local Edwards fine-grained chert.

Comments: This Gower stem form is characterized by approximately straight stems and concave bases, with pointed or slightly blunted basal corners. 


\section{Subtype Gower C}

$(\mathrm{n}=3)$ (Lots 89.2, 244.2, 452; Appendix C, Figure 6 g, Lot 244.2)

Nominal Attributes: Two of these points display some flaking pattern including an oblique subparallel pattern and a parallel pattern.

Condition and Breakage: Only one of these points is a complete specimen exhibiting evidence of an impact/snap fracture, and some indeterminate breakage. Another of these points is categorized as a basal fragment exhibiting an impact/snap fracture and some indeterminate breakage. The final point is a stem fragment with evidence of multiple breaks.

Reworking and Beveling: Evidence of reworking along the blade is present on two of these specimens, with evidence of right beveling apparent on one of these two reworked points.

Use-wear: N/A

Raw Material Attributes: All of these points are composed of local Edwards fine-grained chert. Only one point exhibits light ( $<50$ percent) patination.

\section{Marcos}

$(\mathrm{n}=1)($ Lot 503.1; Appendix C, Figure $13 \mathrm{f})$

Nominal Attributes: Flaking pattern for this specimen is indeterminate.

Condition and Breakage: This point is a basal fragment resulting from what appears to be a snap fracture.

\section{Reworking and Beveling: N/A}

Use-wear: N/A

Raw Material Attributes: This point is made of local Edwards fine-grained chert.

Comments: There were only three Marcos points recovered from the Gatlin site, and this specimen is clearly intrusive into OZ2.

\section{Martindale}

$(\mathrm{n}=37)$

\section{Subtype Martindale A}

$(\mathrm{n}=13)$ (Lots 74.4, 89.1, 90.4, 99.4, 235.2, 240, 284, 482, 533, 867, 885, 936.1, 962; Appendix C, Figure 3 a, Lot 74.4; c, Lot 867)

Nominal Attributes: Most of the Martindale A points exhibit oblique subparallel, oblique parallel, and chevron flaking patterns, while only one displays a subparallel pattern. Of note, one specimen is lightly serrated along the blade edge.

Condition and Breakage: Four of these points are complete; three are unbroken, and one exhibits a use break. Eight of the specimens are basal fragments; six of which exhibit impact fractures, and two of which exhibit snap fractures. The last of these points is a stem fragment broken by an impact fracture.

Reworking and Beveling: Evidence of reworking is observed along the blade of seven of these points and along the blade and stem of one. A slight twist to the left is apparent among two of these points.

Use-wear: Use-wear analysis performed on four of the specimens revealed they all functioned as dart points. Further, one of the four was also a light duty cutting tool that was recycled as a burin after fracture. Another of the four was utilized as a burin as well.

Raw Material Attributes: The raw material for all of these points is local Edwards fine-grained chert. Heat evidence is apparent on two of the specimens with reddening on one and potlids and reddening on the other. Light ( $<50$ percent) patination is only evident on one point. 


\section{Subtype Martindale B}

$(\mathrm{n}=7)$ (Lots 196, 283, 292.3, 307, 329, 880, 927; Appendix C, Figure 3 f, Lot 292.3; d, Lot 307; e, Lot 927)

Nominal Attributes: There are a variety of flake patterns among these points including oblique parallel, oblique subparallel, subparallel, chevron, and random. One point displays a flake blank remnant surface.

Condition and Breakage: Three of these points are complete and do not demonstrate any breakage. The remaining specimens are basal fragments; two exhibit snap fractures, and two have impact fractures.

Reworking and Beveling: Most of these points show signs of reworking, particularly along their blades. Some have been reworked along the blade and stem. For one of the specimens, the retouching results in a slight twist to the left, and for another it results in a slight twisting or beveling of the edge to the right.

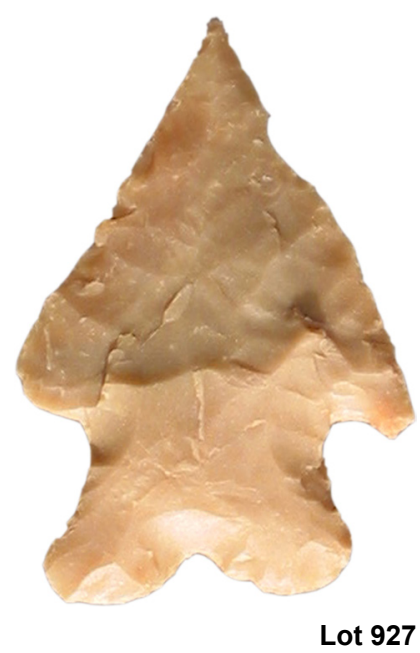

Use-wear: Two of these points were submitted for use-wear analysis, and both functioned as dart points. In addition, one was also used as a plane for woodworking and the other was also utilized as a light-duty knife or butchering implement.

Raw Material Attributes: All of these points are made of local Edwards fine-grained chert. Only one exhibits evidence of heating in the form of reddening.

Comments: This stem group is characterized by expanding stems with a U-shaped notch, and rounded basal edges.

\section{Subtype Martindale C}

$(\mathrm{n}=12)($ Lots 84.1, 84.2, 100.3, 113.1, 177, 195, 236, 278, 311, 330.2, 638, 661; Appendix C, Figure $3 \mathrm{~h}$, Lot 638; i, Lot 661)

Nominal Attributes: Most of these points, five, exhibit oblique subparallel flaking patterns. Other points exhibit random, oblique parallel, and chevron flaking patterns. Of note, one of these points appears to be a preform. Additionally, another appears to be manufactured from a flake.

Condition and Breakage: Four of these points are complete enough were all metrics could be measured, with three exhibiting no breakage, and one demonstrating an impact fracture, as well as some indeterminate breakage. The remaining specimens are all basal fragments. Four of the basal fragments exhibit impact fractures, and three exhibit snap fractures. One also exhibits a burin. The final basal fragment shows signs of a snap fracturing, which may be due to a manufacture failure.

Reworking and Beveling: Most of these points exhibit reworking along the blade. Only one of these demonstrates a twist to the left

Use-wear: Use-wear analysis was performed on five of these points revealing all were utilized as dart points. Additionally, one was used as a knife or butchering implement and another has unclear usewear that may be the result of utilization as a light duty knife or butchering implement.

Raw Material Attributes: All of the specimens are composed of local Edwards fine-grained chert. Heat evidence is apparent through reddening for only one of these specimens. Light ( $<50$ percent) patination is observed on only one of these points.

Comments: These points lack the typical Martindale fish-tail base and exhibit indented bases with usually sharp edges. 


\section{Martindale-like}

$(\mathrm{n}=2)$ (Lots 303, 488.1)

Nominal Attributes: One of these points exhibits a subparallel flaking pattern, and the other demonstrates an oblique subparallel pattern. Of note, one of these specimens may be a preform.

Condition and Breakage: One specimen is complete with no breakage, while the other is a basal fragment with a snap fracture.

Reworking and Beveling: Only one of these points exhibits reworking.

Use-wear: Only one of these points was submitted for use-wear, which revealed it functioned as a knife to cut moderately resistant materials. There was no indication that it functioned as a projectile point.

Raw Material Attributes: Both of these points are made from local Edwards fine-grained chert. Only one of the specimens exhibits light $(<50$ percent) patination.

Comments: These points closely resemble Martindale points, but were not classified as such due to missing or damaged base portions.

\section{Martindale-Narrow Stem}

$(\mathrm{n}=3)$ (Lots 408.2, 653, 1033.2; Appendix C, Figure 4 b, d, and e)

Nominal Attributes: Flaking patterns observed among these points were oblique parallel, oblique subparallel, and random.

Condition and Breakage: One of these points is complete with evidence of a snap fracture. The other two specimens are basal fragments demonstrating impact and snap fractures.

Reworking and Beveling: Reworking is evident along the blade of all three specimens. One of the three points exhibits a twist to the left.

Use-wear: Use-wear analysis was conducted on only one of these specimens, which was utilized exclusively as a dart point.

Raw Material Attributes: Raw material for all three specimens is local Edwards fine-grained chert. One of the specimens exhibits evidence of heating in the form of reddening, as well as light patination ( $<50$ percent).

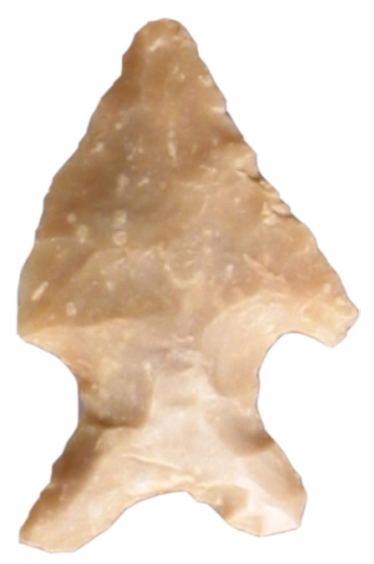

Lot 408.2

Comments: Discussion in Appendix C suggests this is a potentially important variant of Martindale consisting of points that have been reworked, which has reduced the size of the blades.

\section{UNTYPABLE}

$(\mathrm{n}=10)$ (Lots 90.3, 188, 513, 524, 566, 568, 609, 617, 926.1, 942; Appendix C, Figure 18 d, Lot 617; i, Lot 568)

Nominal Attributes: Flaking pattern was only recorded for one of these points, which had an oblique subparallel pattern.

Condition and Breakage: Condition and breakage of all of these points are highly varied. Only one of these points, a small corner-notched specimen, is complete and unbroken. Another of the specimens is a blade fragment missing the stem due to a snap fracture. Three of the points are identified from shoulder fragments, one of which exhibits thermal breakage, and two of which exhibit multiple breaks, such as use and

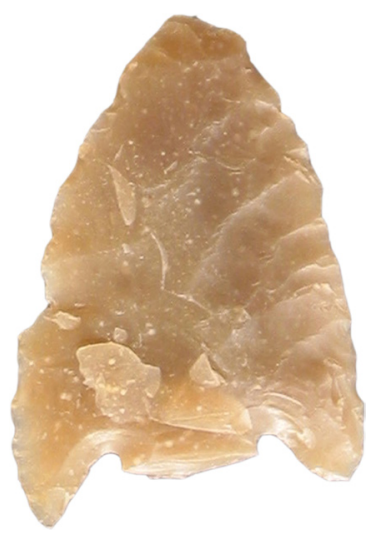


indeterminate fractures. Three of the specimens are basal fragments. One of these is in three pieces exhibiting thermal breakage, and another is in two pieces, demonstrating multiple breaks due to snap fractures and post depositional excavation damage. The third basal fragment was broken by an impact fracture. One of the specimens is a stem/ear fragment, broken by thermal damage. Specimen condition is indeterminate for one of the points, although it appears to be a stem/ear fragment, possibly from a Martindale point, with multiple indeterminate breakages.

Reworking and Beveling: Reworking is evident on three of these points.

Use-wear: N/A

Raw Material Attributes: All of these specimens are composed of local Edwards fine-grained chert. Heat evidence is observed on three of these through potlids, with one demonstrating crazing as well. Patination was only recorded on one of these points.

Comments: Limited attributes, including only condition, breakage, heat evidence, patination, and weight, were recorded for untypable projectile points, all of which are highly fragmented.

\section{BIFACIAL TOOLS}

Five bifacial tools were recovered from OZ2, including two drills, two Clear Fork tools, and a butted biface. Use-wear analysis of the drill Lot 199 (see Appendix C, Figure $42 \mathrm{c}$ ), identified two possible uses; as a cutting tool for hide and as an awl for piercing hide. The other drill specimen, Lot 462, is a distal tip that shows evidence of reworking and may have been recycled from another larger biface (see Appendix $\mathrm{C}$, Figure $42 \mathrm{f}$ ). Of note, the two Clear Fork tools recovered in OZ2 display the characteristics of Stage 3 bifaces. The two Clear Fork Tools are specimens Lot 925 and Lot 871 (see Appendix C, Figure 44 a and c). Both are complete specimens that have been resharpened and were probably hafted. Use-wear analysis of both specimens indicates use in a lowangle percussive fashion against a moderately hard surface. The butted biface, Lot 512.1, is trimmed along the long axis of a cobble and was probably used in both a cutting and chopping action.

\section{BIFACES}

A total of 139 general bifaces was recovered from OZ2 at the Gatlin site. The general bifaces were classified into the five stages of reduction as follows: Stage $1(n=3)$, Stage $2(n=11)$, Stage $3(n=21)$, Stage $4(n=28)$, and Stage $5(n=50)$ (Table 9.3). In addition, 26 bifaces were categorized as indeterminate stage due to a lack of significant attributes.

Table 9.3. Occupation Zone 2 Attribute Measurements for General Bifaces by Stage

\begin{tabular}{|c|c|c|c|c|c|c|c|c|}
\hline & \multicolumn{6}{|c|}{ Stage } & \multirow[b]{2}{*}{ Total } \\
\hline & & 1 & 2 & 3 & 4 & 5 & Indeter & \\
\hline \multirow{2}{*}{ Max L } & $\mathrm{N}$ & 1 & 7 & 3 & 5 & 7 & & 23 \\
\hline & Mean & 93.10 & 77.83 & 64.53 & 79.58 & 70.63 & & 74.95 \\
\hline \multirow{2}{*}{ Max W } & $\mathrm{N}$ & 2 & 8 & 16 & 19 & 27 & & 72 \\
\hline & Mean & 82.75 & 56.04 & 43.26 & 43.84 & 37.30 & & 43.70 \\
\hline \multirow{2}{*}{ Max Th } & $\mathrm{N}$ & 3 & 11 & 21 & 27 & 47 & 23 & 132 \\
\hline & Mean & 30.20 & 20.97 & 11.55 & 11.16 & 7.27 & 6.65 & 10.30 \\
\hline \multirow{2}{*}{ W/T Ratio } & $\mathrm{N}$ & 3 & 11 & 21 & 27 & 47 & 23 & 132 \\
\hline & Mean & 1.88 & 1.86 & 3.07 & 2.90 & 2.82 & 0.00 & 2.28 \\
\hline \multirow{2}{*}{ Weight } & $\mathrm{N}$ & 3 & 11 & 21 & 28 & 50 & 26 & 139 \\
\hline & Mean & 121.57 & 97.95 & 23.62 & 31.41 & 13.23 & 3.97 & 25.77 \\
\hline \multirow{2}{*}{ Edge Angle } & $\mathrm{N}$ & 3 & 11 & 21 & 25 & 50 & 23 & 133 \\
\hline & Mean & 45.67 & 41.64 & 31.57 & 30.60 & 26.22 & 25.13 & 29.41 \\
\hline
\end{tabular}




\section{9-12 Chapter 9}

Of the three Stage 1 bifaces, only one is completethe other two have manufacture breaks. All are made from a fine-grained chert with less than 25 percent cortex. The average edge angle of the Stage 1 bifaces is 45.7 degrees. None of the Stage 1 bifaces shows evidence of heat treatment.

The 11 Stage 2 bifaces consist of seven complete bifaces, one marginal fragment, and three indeterminate biface fragments. All the Stage 2 bifaces are made from a fine-grained chert, with most having less than 25 percent or no cortex present $(n=8)$, and the remaining having between 25 and 50 percent. Of the complete Stage 2 bifaces, five are ovate shaped, one is a teardrop, and one is round. The complete Stage 2 bifaces have an average edge angle of 42.3 degrees. The marginal fragment and two of the indeterminate fragments appear to have manufacturing breaks; the breakage of the last bifacial fragment is indeterminate. The average edge angle of the four bifacial fragments is 40.5 degrees. None of the Stage 2 bifaces shows evidence of heat treatment.

The 21 Stage 3 bifaces consist of three complete bifaces, one basal fragment, one distal fragment, one marginal fragment, one medial fragment, and 14 indeterminate fragments. Two of the complete bifaces are pointed oval shapes, and the third complete biface is ovate. One of the pointed oval shaped bifaces has no cortex, while the other two complete specimens have less than 25 percent cortex. The average edge angle for the three complete bifaces is 32.3 degrees. Of the 18 Stage 3 bifacial fragments, 14 show evidence of manufacturing breakage, and two have indeterminate breakage. The remaining two bifacial fragments show evidence of thermal breakage. In addition to the two bifaces with thermal breakage, three other biface fragments and one of the complete bifaces show evidence of heat treatment.

The 28 Stage 4 bifaces recovered from OZ2 consist of five complete bifaces, six basal fragments, six distal fragments, one medial fragment, three marginal fragments, and seven indeterminate fragments. Two of the complete bifaces are pointed oval shaped and made of a fine-grained chert with no cortex. The remaining complete bifaces consist of two ovate shaped bifaces and one subtriangular shaped biface. Both of the ovate bifaces are made of a fine-grained chert; one has no cortex, and the other has less than
25 percent cortex present. The subtriangular biface is made of fine-grained chert with less than 25 percent cortex and shows evidence of burning with the presence of potlids. All of the biface fragments display breakage from manufacture with the exception of one of the marginal fragments, which has indeterminate breakage. Overall, the average edge angle of the Stage 4 bifaces is 30.7 degrees.

Because Stage 5 is the final stage of biface reduction, determining the overall shape of some of the Stage 5 bifacial fragments was easier than it was for fragments from earlier reduction stages. Of the 50 complete and bifacial fragments recovered from OZ2, eight are pointed oval, three are subtriangular, two are ovate, one is lanceolate, and two are amorphous fragments. The rest are bifacial fragments of indeterminate biface shape. Five of the pointed, oval-shaped Stage 5 bifaces are complete, three more are basal fragments, and another is a distal fragment. The subtriangular bifaces consist of one complete specimen, one distal fragment, and one basal fragment. The complete biface (Lot 849) is a small bifacial tool with one pointed end and one rounded end (see Appendix C, Figure 40 c). Use-wear analysis determined that the rounded end was used to scrape fresh hides and was resharpened, while the pointed end was probably placed in a haft. Both of the ovate bifaces are complete and show evidence of use-wear. Analysis of one of the ovate bifaces (Lot 975, see Appendix $C$, Figure 40 a) determined that the specimen was used for cutting moderately resistant materials such as wood or soaked antler and was extensively resharpened. Of all the Stage 5 biface specimens, seven show evidence of burning including one of the pointed oval shaped bifaces.

\section{FLAKE TOOLS}

The modified flake tools recovered from OZ2 consist of 14 end scrapers, nine end and side scrapers, five side scrapers, one full sided scraper, two gravers, 18 utilized flakes, and 67 retouched flakes (Table 9.4). The end scrapers consist of 10 complete specimens, two distal fragments, one longitudinal fragment, and one indeterminate fragment. Most of the complete end scrapers $(\mathrm{n}=8)$ are unifacially modified along the distal margin, with the remaining complete scrapers consisting of a specimen bidirectionally modified along the distal and right lateral margins 
Table 9.4. Occupation Zone 2 Attribute Measurements for Complete Modified Flake Subcategories

\begin{tabular}{|l|l|c|c|c|c|c|c|c|c|}
\hline \multicolumn{2}{|l|}{} & $\begin{array}{c}\text { End } \\
\text { Scraper }\end{array}$ & $\begin{array}{c}\text { End \& Side } \\
\text { Scraper }\end{array}$ & $\begin{array}{c}\text { Side } \\
\text { Scraper }\end{array}$ & $\begin{array}{c}\text { Full Sided } \\
\text { Scraper }\end{array}$ & Graver & $\begin{array}{c}\text { Utilized } \\
\text { Flake }\end{array}$ & $\begin{array}{c}\text { Retouched } \\
\text { Flake }\end{array}$ & \begin{tabular}{c} 
Total \\
\hline Count
\end{tabular} \\
N & 10 & 8 & 3 & 1 & 2 & 12 & 23 & 59 \\
\hline Length & Mean & 60.50 & 65.00 & 70.96 & 48.12 & 43.94 & 66.63 & 59.89 & 61.80 \\
\hline Width & Mean & 60.46 & 51.56 & 53.16 & 47.73 & 73.04 & 63.35 & 54.71 & 57.34 \\
\hline Thickness & Mean & 14.66 & 13.88 & 12.11 & 9.14 & 9.32 & 14.26 & 15.35 & 14.34 \\
\hline Weight & Mean & 57.69 & 53.91 & 58.47 & 25.40 & 26.40 & 64.78 & 56.68 & 56.66 \\
\hline $\begin{array}{l}\text { Perimeter } \\
\text { Length }\end{array}$ & Mean & 196.83 & 194.74 & 206.01 & 152.33 & 190.49 & 205.53 & 195.24 & 197.19 \\
\hline $\begin{array}{l}\text { Perimeter } \\
\text { Retouch Length }\end{array}$ & Mean & 77.08 & 104.62 & 69.44 & 152.33 & 97.47 & 64.06 & 59.30 & 72.81 \\
\hline $\begin{array}{l}\text { Marginal } \\
\text { Retouch \% }\end{array}$ & Mean & 0.39 & 0.54 & 0.33 & 1.00 & 0.53 & 0.27 & 0.31 & 0.36 \\
\hline Max Edge Angle & Mean & 48.14 & 46.50 & 47.67 & 60.00 & 44.00 & 42.55 & 49.10 & 47.21 \\
\hline
\end{tabular}

and a unifacial specimen modified along the distal and left lateral margins. On average, 40 percent of the perimeter length is modified on the complete specimens. Only one of the 10 complete end scrapers exhibits heat damage which caused slight fracture and minimal breakage.

Eight of the nine end and side scrapers recovered from OZ2 are complete. The remaining scraper is a marginal fragment with unifacial modifications along the left lateral margin towards the dorsal side. Of the complete tools, modifications to the specimens are evenly distributed between right lateral and distal margin modifications $(n=4)$ and left lateral and distal margin modifications $(n=4)$, with one specimen containing left, right, and distal margin modifications. One of the left lateral and distal margin scrapers was analyzed for use-wear and was determined to be a resharpened scraper used on fresh hides. Overall, the modified portions of the complete end and side scrapers account for an average of 54 percent of the entire perimeter lengths of each specimen. None of the specimens exhibit evidence of heat treatment.

The five side scrapers recovered consist of three complete specimens, one medial fragment, and a longitudinal fragment. Of the three complete specimens, two are modified along the right lateral margin and the third is along the left lateral margin. The one scraper with modifications on all sides is predominantly circular in shape with continuous unifacial modification to the entire perimeter towards the dorsal surface. None of the side scrapers show evidence of heat treatment.
The two gravers are complete specimens with most of the modifications to their distal margins. One of the gravers has slight modifications to the left lateral margins, suggesting it was possibly utilized as a perforator.

The remaining modified tools consist of 67 retouched flakes and 18 utilized flakes. These tools are generally considered to be expedient tools, with the retouched flakes having minimal modification scars, and the utilized flakes showing evidence of modification from simple use. Use-wear analysis determined that one of the marginally retouched flakes was struck from an unprepared core and used to scrape fresh hides and cut soft substances such as meat or hide. None of the expediently modified tools displays evidence of heat modification.

\section{CORES}

There were 63 cores recovered from OZ2. The assemblage consisted of 12 bifacial, 39 multidirectional, four bidirectional, two slab, one bipolar, and five indeterminate specimens (Table 9.5). The 12 bifacial cores consist of seven complete tabular cores, three complete nodular cores, one tabular core fragment, and one indeterminate core fragment. Most of the bifacial cores are made from fine-grained chert $(\mathrm{n}=10)$ and are from a riverine procurement locale $(n=7)$. One is made from upland lag gravel, and the rest are from an indeterminate locale. Three of the bifacial cores display possible use-wear. Only one of the bifacial cores has evidence of burning with slight reddening. 
Table 9.5. Occupation Zone 2 Attribute Measurements for Complete Exhausted and Unexhausted Cores

\begin{tabular}{|l|l|c|c|c|c|c|c|}
\hline \multicolumn{2}{l|}{} & Bifacial & Multidirectional & Bidirectional & Slab & Bipolar & Total \\
\hline Count & $\mathrm{N}$ & 10 & 27 & 4 & 1 & 1 & 43 \\
\hline Max Length & Mean & 102.86 & 92.05 & 94.02 & 33.00 & 133.21 & 94.33 \\
\hline Max Width & Mean & 79.00 & 75.53 & 70.43 & 25.00 & 85.55 & 74.92 \\
\hline Max Thickness & Mean & 39.90 & 36.53 & 30.66 & 3.50 & 42.12 & 36.13 \\
\hline Weight & Mean & 284.65 & 255.83 & 221.88 & 4600.00 & 656.00 & 369.71 \\
\hline Max Flake Scar Length & Mean & 44.11 & 44.91 & 37.77 & 5.00 & 38.24 & 42.98 \\
\hline \# Flake Scars & Mean & 6.30 & 5.48 & 7.00 & 3.00 & 6.00 & 5.77 \\
\hline
\end{tabular}

The multidirectional cores consist of 27 complete specimens and 12 core fragments. Thirteen of the complete multidirectional cores are made from tabular parent materials from riverine environments. The remaining complete cores are equally divided between nodular and indeterminate specimens from either riverine or indeterminate procurement locales. Eleven of the complete specimens were exhausted. Use-wear was observed on four of the non-exhausted cores. Only two of the multidirectional cores have evidence of heat exposure sufficient to cause crazing.

The four bidirectional cores are all complete, and two are exhausted. All the bidirectional cores are made of fine-grained chert from varying procurement locations. Two are from a riverine environment, one is from upland lag gravel, and one is from an indeterminate procurement locale. None of the bidirectional cores show evidence of heat treatment.

The one bipolar core is made from a fine-grained tabular chert from a riverine environment. The complete specimen has a maximum of six flake scars with a maximum scar length of $38.2 \mathrm{~mm}$. Some of the flake scars are possibly unintentional byproducts of the bipolar core reduction.

Two slab cores were recovered from OZ2. The two specimens consist of one complete coarse-grained chert specimen and one coarse-grained chert core fragment. Neither is exhausted nor shows evidence of heat treatment. The five indeterminate cores are all fine-grained chert core fragments. They display minimal flake scars $(<2)$ with one of the fragments having five flake scars. All five are relatively small and are therefore considered exhausted. None of the indeterminate cores displays evidence of heat treatment.
Regarding cores, as discussed below, Feature 33 was a dense cluster of chert debitage, with associated bone fragments, charcoal flecks, and a few pieces of burned rock found beneath a large tabular block of chert. This feature represents an apparent knapping floor including numerous large flakes and fragments of chert debitage. A conjoin analysis of the recovered litihic materials revealed that many of flakes and fragments originated from the same cobble/core, although a complete reconstruction was not possible due to numerous missing pieces.

An alternative interpretation is that Feature 33 represents a secondary refuse pile, given the large flakes, bone, and burned rock that is evident, despite no in situ evidence of burned soil. The absence of smaller flakes in Feature 33 could be a consequence of smaller-sized items being less prone to be swept up and removed from maintained areas. A secondary refuse pile would suggest that areas of the site were maintained and cleaned. This type of behavior would further suggest that the occupation may have been relatively lengthy.

\section{DEBITAGE}

The debitage analysis used flakes recovered from Traditional Units and focused on the two major reduction techniques-biface thinning and core reduction. The metric data for debitage recovered in OZ2 are in Table 9.6.

As in OZ1, cortex was rare on biface thinning flakes from OZ2, with 88 percent having no cortex, and almost 98 percent having less than 50 percent cortex. Of the core reduction flakes, over 5 percent had 100percent dorsal cortex; however, the percentages of core reduction flakes with less than 50 percent cortex was very similar to OZ1. 
Table 9.6. Biface, Core, and Indeterminate Reduction Flake Measurements from Occupation Zone 2

\begin{tabular}{|l|c|c|c|c|}
\hline \multirow{2}{*}{} & \multicolumn{3}{|c|}{ Flake Type } & \multirow{2}{*}{} \\
\cline { 2 - 4 } & $\begin{array}{c}\text { Biface } \\
\text { Thinning }\end{array}$ & $\begin{array}{c}\text { Core } \\
\text { Reduction }\end{array}$ & Indeter & Total \\
\hline Count & 2305 & 625 & 454 & 3384 \\
\hline Max of Length $\mathbf{( m m )}$ & 71.3 & 127.4 & 49 & 127.4 \\
\hline Average of Length $\mathbf{( m m )}$ & 20.86 & 39.6 & 21.13 & 25.9 \\
\hline Max of Thickness $\mathbf{( m m )}$ & 24.7 & 44.2 & 11.2 & 44.2 \\
\hline Average of Thickness $\mathbf{( m m})$ & 2.36 & 8.29 & 3.44 & 4.09 \\
\hline Max of Width $\mathbf{( m m )}$ & 55.7 & 83.5 & 55.1 & 83.5 \\
\hline Average of Width $\mathbf{( m m )}$ & 14.8 & 30.1 & 17.68 & 19.27 \\
\hline Max of Wt $\mathbf{( g )}$ & 25.6 & 134.7 & 11.2 & 134.7 \\
\hline Average of Weight $\mathbf{( g )}$ & 0.77 & 8.88 & 1.25 & 1.96 \\
\hline Sum of Weight $\mathbf{( g )}$ & 1213.32 & 2707.3 & 368.7 & 4289.32 \\
\hline
\end{tabular}

ments suggests that it may have fractured in place from heating. The specimen was probably discarded intentionally within the feature.

Specimen Lot 300.5 (see Appendix C, Figure 70) is a roughly spherical hammerstone made from a tabular chert fragment, and weighs $715 \mathrm{~g}$.

\section{FAUNAL ASSEMBLAGE}

The faunal assemblage from OZ2 includes 2,053 specimens weighing a total of 1,230.6 grams. Three taxa are recognizable in the assemblage, bison (Bison bison), whitetailed deer (Odocoileus virginianus) and eastern cottontail (Sylvilagus floridanus). The bison is represented by one fairly well-

The measurements from biface thinning flakes are comparable to those from OZ1, demonstrating the similarities in raw material size and in biface reduction strategies between OZ1 and OZ2. The average length of core reduction flakes increases over OZ1, as do the number of flakes with 100 percent cortex, evidence that some initial core reduction occurred on site. The larger core reduction flakes coincide with the increase in flaked tool production. Overall, there are more similarities than differences between OZ2 and OZ1 debitage, such as the proportions of biface flakes to core flakes and the overall emphasis on biface production.

The partial refit of a core from Feature 33 shows the amount of blocky, non-flake material created during core reduction. This example demonstrates that the number of platform flakes per core is probably lower than generally thought. Over 95 percent of the debitage showed no evidence of heating or burning, suggesting there is a weak or non-existent association of hearths with flint knapping. This can also be an indicator of the intensity and duration of an occupation as longer and more-frequent occupations would have more chances for debitage to be exposed to, or disposed of, in fires.

\section{GRound Stone Tools}

Specimen Lot 75.2 is a fragmented metate weighing $2.2 \mathrm{~kg}$ from within Feature 5. Although the specimen did not appear to be burned, the refit of the frag- preserved $2^{\text {nd }}$ molar fragment weighing 53.4 grams. The white-tailed deer is represented by the fragmentary proximal end of antler, distal-medial portions of a first phalange, and a very heavily fragmented metacarpal. One lightly burned, large mammal fragment was also identified but the remaining specimens are very small, highly weathered fragments. In general, the unidentifiable fragments primarily appear to be highly weathered large- to medium-sized mammal bone, likely white-tailed deer or very fragmented bison elements. The eastern cottontail bone fragment is a radius. Burning was noted on 24 percent of the specimens, much of it very heavy, resulting in calcining of the bone. Almost all (99 percent) of the bone was classified as fragmented or extremely fragmented bone, reflecting the degraded nature of the assemblage. Slight to extreme weathering in the form of cracking and fragmentation was noted on most specimens. No cultural modifications in the forms of cutmarks or green-bone breaks were evident on any of the specimens. The fragmentary conditional of the faunal assemblage appears to be caused by post-depositional factors.

Overall, the poor state of preservation of the OZ2 faunal assemblage hinders interpretations on foraging and butchering systems as well as reconstructing the general subsistence base and environmental conditions. It is obvious that large game in the form of bison and white-tailed deer formed a primary component of their overall hunting strategy. The presence of the teeth from both species suggests whole animals 
or select cranial portions (mandibles) where brought back to the site as opposed to strictly front or hind portions. The overall absence of other species/taxa in the assemblage suggests a rather limited range of animal exploitation. However this interpretation must be weighed against the poor preservation of the bone and the likelihood that other species may have been present, but are no longer visible.

\section{FEATURE ASSEMbLaGE}

There were 14 designated features in OZ2. The features within OZ2 were within Areas A-NE and A-SW. These were Features 2, 5, 12, 13, 21, 22, 24, 25, 26, 28, 31, 33, 34, and 35 (Figure 9.2; see Figures 7.6 and 7.9). It is important to note that within OZ2, Features 2, 5, 21, 26, and 31 were not completely excavated due to their extensions beyond the excavation limits. Further subdivisions and associations were designated among some of these features, such as Feature $34 \mathrm{~A}-\mathrm{C}$, which includes small burned rock clusters/internal concentrations with an associated scatter; Feature 5, which was a scatter with an associated burned rock cluster; and Feature 22 that is composed of a burned rock cluster with an associated scatter. Notably, of the features within this zone, Feature 33 was a dense cluster of chert debitage, with associated bone fragments, charcoal flecks, and a few pieces of burned rock found beneath a large tabular block of chert. This feature represents an apparent knapping floor including numerous large flakes and fragments of chert debitage. A conjoin analysis of the recovered lithic materials revealed that many of the flakes and fragments originated from the same cobble/core, although a complete reconstruction was not possible due to many missing pieces. The full results of special studies from these features are presented in Appendices E through I.

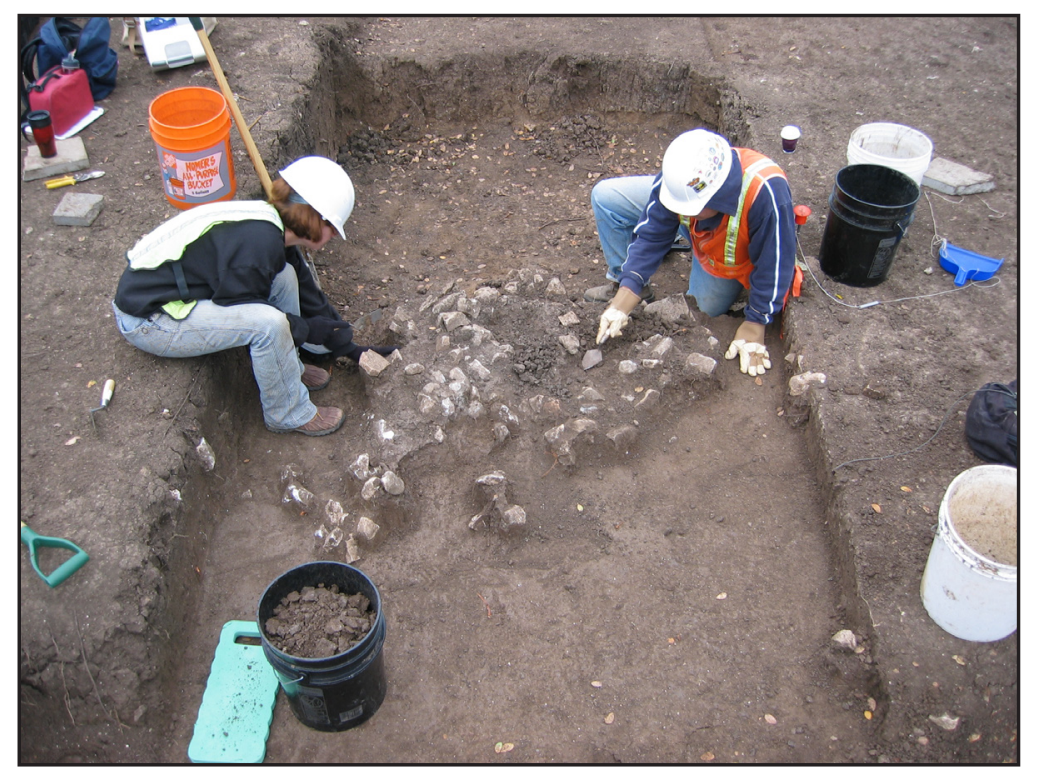

Figure 9.2. Feature 13 excavation in progress facing west. 


\begin{tabular}{|c|c|c|c|c|}
\hline & & Flotation Results & \multicolumn{2}{|l|}{ None } \\
\hline & & \multirow[b]{3}{*}{ Radiocarbon Dates } & \multirow{3}{*}{\multicolumn{2}{|c|}{$\begin{array}{l}\text { UGA-13823: } 5020 \pm 70 \text { B.P., } \\
5920-5610 \text { cal B.P. at } 97.43 \mathrm{~m} \text {; UGA- } \\
13822: 5040 \pm 60 \text { B.P., } 5920-5650 \\
\text { cal B.P. at } 97.45 \mathrm{~m} \text {; UGA- } 13825: 5260 \\
\pm 70 \text { B.P., } 6270-6240 \text { cal B.P. AND } \\
6210-5900 \text { cal B.P. at } 97.41 \mathrm{~m} \text {; UGA- } \\
13824: 5390 \pm 60 \text { B.P., } 6300-5990 \text { cal } \\
\text { B.P. at } 97.45 \mathrm{~m}\end{array}$}} \\
\hline Feature Type & Burned rock cluster & & & \\
\hline Occupation Zone & 2 & & & \\
\hline Stratigraphic Context & B horizon & \multirow{2}{*}{$\begin{array}{l}\text { Associated floor } \\
\text { elevation range }(\mathrm{m})\end{array}$} & \multirow{2}{*}{\multicolumn{2}{|c|}{$97.50-97.30 \mathrm{~m}$}} \\
\hline Area & BHT 4 & & & \\
\hline Provenience & TU 4-C & \multirow{4}{*}{$\begin{array}{l}\text { Associated Diagnostics } \\
\text { (Lot No. and elevation) }\end{array}$} & Martindale (89.1) & $97.50-97.40 \mathrm{~m}$ \\
\hline Center & N/A & & Gower (89.2) & $97.50-97.40 \mathrm{~m}$ \\
\hline Top Elevation & $97.50 \mathrm{~m}$ & & Martindale (90.4) & $97.40-97.30 \mathrm{~m}$ \\
\hline Bottom Elevation & $97.30 \mathrm{~m}$ & & Martindale (99.4) & $97.40-97.30 \mathrm{~m}$ \\
\hline Size & $150 \times 100 \mathrm{~cm}$ & \multirow{3}{*}{$\begin{array}{l}\text { Diagnostics above and adja- } \\
\text { cent to feature (Lot No.): } \\
\text { proximity radius }=2.0 \mathrm{~m}, \\
\text { proximity elevation }=0.2 \mathrm{~m}\end{array}$} & Early Triangular (82.2) & $97.39 \mathrm{~m}$ \\
\hline Shape & Amorphous; flat & & & \\
\hline Fuel Type & Plateau live oak & & Bell (96.4) & $97.54 \mathrm{~m}$ \\
\hline Lipids & N/A & \multirow{4}{*}{$\begin{array}{l}\text { Diagnostics below and } \\
\text { adjacent to feature (Lot } \mathrm{No} \text {.): } \\
\text { proximity radius }=2.0 \mathrm{~m}, \\
\text { proximity elevation }=0.2 \mathrm{~m}\end{array}$} & Bell (82.1) & $97.30 \mathrm{~m}$ \\
\hline & White-tailed deer and unidentifiable frag- & & Martindale (84.1) & $97.30-97.20 \mathrm{~m}$ \\
\hline Faunal Evidence & ments & & Martindale (84.2) & $97.30-97.20 \mathrm{~m}$ \\
\hline Pollen & N/A & & Martindale (100.3) & $97.30-97.20 \mathrm{~m}$ \\
\hline
\end{tabular}

\section{Description}

Feature 2 consisted of an irregular, loose cluster of burned rock and associated materials on top of the B soil horizon. The exact limits of the feature were not defined during excavations, although the field plan maps suggest the feature measured approximately $150 \times 100 \mathrm{~cm}$ horizontally. Most of the feature appeared to occupy TU 4-C and extended into the northern portion of TU 4-B. Vertically, the feature was approximately $20 \mathrm{~cm}$ thick, although the lower boundary was poorly defined. In cross section, no coherent layering of rocks was apparent; the lower boundary was distinguished by a relatively flat surface of burned earth. The boundaries of Feature 2 were further defined by significant amounts of charcoal, burned earth, and faunal materials among the loose cluster of burned rocks.

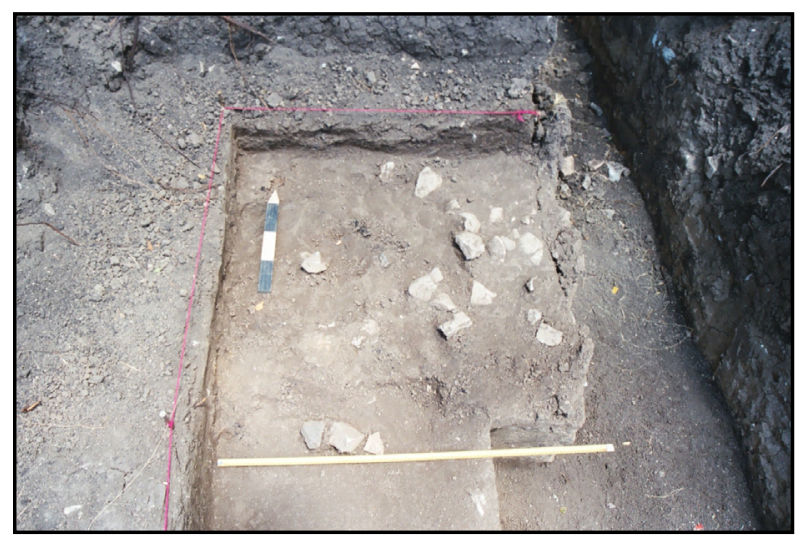

Overview of Feature 2 within Level 3 of TU 4-C.
All of the burned rocks within Feature 2 were limestone. A total of 68 burned limestone rocks was recovered from the feature, and their combined weight was $7.2 \mathrm{~kg}$. The exact morphology of the specimens was not noted.

The cultural materials in and around the feature included significant quantities of white-tailed deer bone fragments, unidentifiable bone fragments, and 473 pieces of debitage. Due to relatively good preservation, four carbon samples were submitted for dating (see Feature 2 table). Temporally diagnostic artifacts associated within a $1-\mathrm{m}$ radius of the feature's center and within the $20-\mathrm{cm}$ estimated floor elevation consisted of three Martindale dart points and one Gower dart point. Several temporally diagnostic projectile points were also recovered within a $2-\mathrm{m}$ radius and within $20 \mathrm{~cm}$ of the feature's associated floor elevation.

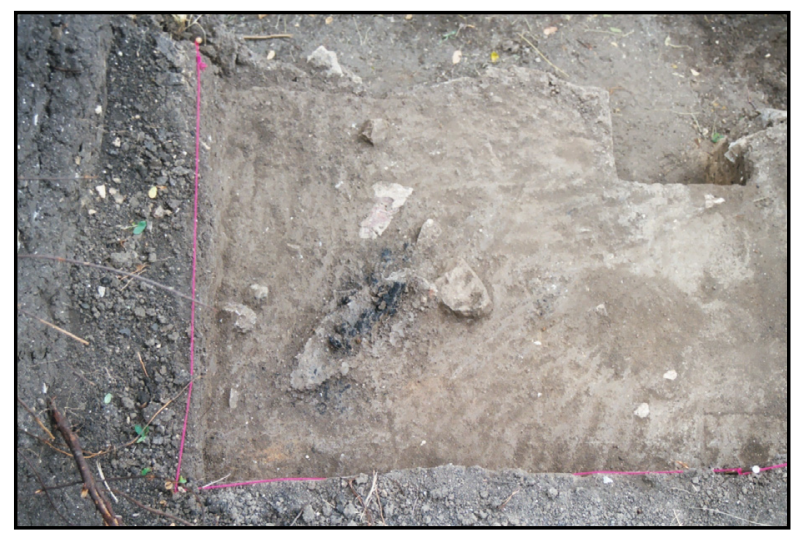

Overview of burned wood at bottom of Level 3 within TU 4-C. 


\begin{tabular}{|c|c|c|c|c|}
\hline & & Faunal Evidence & \multicolumn{2}{|l|}{ Unidentifiable } \\
\hline & & Pollen & \multicolumn{2}{|c|}{$\begin{array}{l}\text { Exploitable: hickory, umbel family, and } \\
\text { mustard family. Root starches: umbel } \\
\text { family, legumes, or grass seed. }\end{array}$} \\
\hline Feature Type & $\begin{array}{l}\text { Burned rock scatter with associated par- } \\
\text { tially excavated cluster }\end{array}$ & Flotation Results & \multicolumn{2}{|l|}{ Cedar elm leaves } \\
\hline Occupation Zone & 2 & \multirow{2}{*}{ Radiocarbon Dates } & \multirow{2}{*}{\multicolumn{2}{|c|}{$\begin{array}{l}\text { UGA-13916: } 5480 \pm 70 \text { B.P., } 6410- \\
6170 \text { AND 6150-6110 AND } 6080- \\
6000 \text { cal B.P. within feature at } 96.98 \mathrm{~m}\end{array}$}} \\
\hline Stratigraphic Context & Upper B horizon & & & \\
\hline Area & BHT 3 & \multirow{2}{*}{$\begin{array}{l}\text { Associated floor } \\
\text { elevation range }(\mathrm{m})\end{array}$} & \multirow{2}{*}{\multicolumn{2}{|c|}{$97.10-97.00 \mathrm{~m}$}} \\
\hline Provenience & TU 3-A & & & \\
\hline Center & ca. N1034.70 E1065.70 & $\begin{array}{l}\text { Associated Diagnostics } \\
\text { (Lot No. and elevation) }\end{array}$ & \multicolumn{2}{|l|}{ None } \\
\hline Top Elevation & $97.10 \mathrm{~m}$ & \multirow{3}{*}{$\begin{array}{l}\text { Diagnostics above and } \\
\text { adjacent to feature (Lot No.) } \\
\text { proximity radius }=2.0 \mathrm{~m} \\
\text { proximity elevation }=0.1 \mathrm{~m}\end{array}$} & \multirow{3}{*}{ Martindale (74.4) } & \multirow{3}{*}{$97.10-97.00 \mathrm{~m}$} \\
\hline Bottom Elevation & $96.90 \mathrm{~m}$ & & & \\
\hline Size & $110 \times 100 \mathrm{~cm}$ & & & \\
\hline Shape & Semi-circular; flat & \multirow{3}{*}{$\begin{array}{l}\text { Diagnostics below and } \\
\text { adjacent to feature (Lot No.) } \\
\text { proximity radius }=2.0 \mathrm{~m} \\
\text { proximity elevation }=0.1 \mathrm{~m}\end{array}$} & \multirow{3}{*}{\multicolumn{2}{|c|}{ None }} \\
\hline Fuel Type & Indeterminable wood & & & \\
\hline Lipids & N/A & & & \\
\hline
\end{tabular}

\section{Description}

Feature 5 was encountered in TU 3-A during the testing investigations at $41 \mathrm{KR} 621$. TU 3-A was a $1.5 \times 1.0-\mathrm{m}$ unit placed adjacent to $\mathrm{BHT} 3$. These rocks composing Feature 5 were found approximately $120 \mathrm{cmbs}$ in the top of the B horizon or the very base of the $A$ horizon, preserved within a bench in the trench. No cultural materials, charcoal, or staining were observed in association with the rocks.

At its top, the feature consisted of a scatter of burned limestone rock. At approximately $97.10 \mathrm{~m}$ some patterning became apparent. At this elevation, a large tabular limestone block was situated within a semicircle of burned rock cobbles. The burned rock along the periphery of the feature consisted of a mixture of angular and tabular limestone rocks. A few thermally altered chert cobbles were also present. The burned rocks had no evidence of patterning vertically (e.g., stacking). The fine matrix within the feature was indistinguishable from the surrounding soil. No indication of in situ burn activities was observed within the feature (e.g., stained or thermally altered sediment). However, some

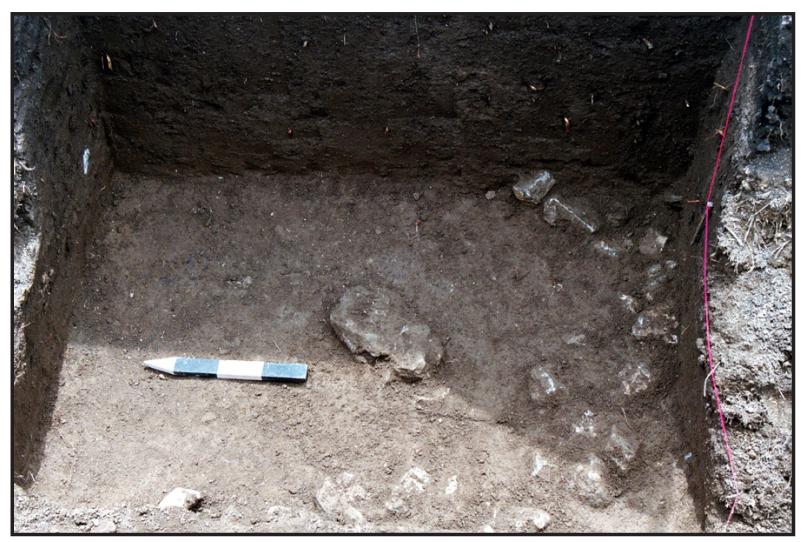

Overview of Feature 5 at $96.90 \mathrm{~m}$. charcoal and carbon flecking were observed and recovered beneath the large central limestone fragment and several burned rocks along the periphery.

The horizontal extent of Feature 5 was minimally $110 \mathrm{x}$ $100 \mathrm{~cm}$, and the feature was $20 \mathrm{~cm}$ thick. The feature continued into the eastern wall of TU 3-A and was not fully exposed.

The artifact assemblage associated with the estimated 10$\mathrm{cm}$ floor level of Feature 5 consisted of debitage, a single biface, a possible metate (Lot 75.2), and faunal remains. The quantities of faunal remains and chipped stone tools were generally low for each level. Pollen recovered from Feature 5 represents various starches, suggesting that foods such as roots and seeds may have been processed within the feature. 


\begin{tabular}{|c|c|c|c|c|}
\hline & & Flotation Results & \multicolumn{2}{|c|}{ Charred: Little walnut nutshell } \\
\hline & & Radiocarbon Dates & \multicolumn{2}{|l|}{ None } \\
\hline & & $\begin{array}{l}\text { Associated floor } \\
\text { elevation range }(\mathrm{m})\end{array}$ & \multicolumn{2}{|l|}{$97.20-97.10 \mathrm{~m}$} \\
\hline Feature Type & Small burned rock cluster & \multirow{2}{*}{$\begin{array}{l}\text { Associated Diagnostics } \\
\text { (Lot No. and elevation) }\end{array}$} & \multirow{2}{*}{ Untyped (568) } & \multirow{2}{*}{$91.12 \mathrm{~m}$} \\
\hline Occupation Zone & 2 & & & \\
\hline Stratigraphic Context & Within 2Bw horizon & \multirow{9}{*}{$\begin{array}{l}\text { Diagnostics above and } \\
\text { adjacent to feature (Lot No.) } \\
\text { proximity radius }=2.0 \mathrm{~m} \\
\text { proximity elevation }=0.1 \mathrm{~m}\end{array}$} & Bulverde (470) & $97.39 \mathrm{~m}$ \\
\hline Area & A-NE & & Martindale (471) & $97.24 \mathrm{~m}$ \\
\hline Provenience & N1027 E1060 & & Martindale (465.2) & $97.30-97.20 \mathrm{~m}$ \\
\hline Center & N1027.98 E1061.50 & & Gower (564) & $97.25 \mathrm{~m}$ \\
\hline Top Elevation & $97.26 \mathrm{~m}$ & & Gower (565) & $97.22 \mathrm{~m}$ \\
\hline Bottom Elevation & $97.12 \mathrm{~m}$ & & Nolan (586) & $97.40 \mathrm{~m}$ \\
\hline Size & $66 \times 46 \mathrm{~cm}$ & & Martindale (590) & $97.06 \mathrm{~m}$ \\
\hline Shape & Roughly oval; relatively flat & & Untyped (562.4) & $97.40-97.30 \mathrm{~m}$ \\
\hline Fuel Type & Indeterminable hardwood & & Untyped (566) & $97.25 \mathrm{~m}$ \\
\hline Lipids & $\begin{array}{l}\text { High fat content food } \\
\text { (seed/animal fat) }\end{array}$ & \multirow{3}{*}{$\begin{array}{l}\text { Diagnostics below and } \\
\text { adjacent to feature (Lot No.) } \\
\text { proximity radius }=2.0 \mathrm{~m} \\
\text { proximity elevation }=0.1 \mathrm{~m}\end{array}$} & \multirow{3}{*}{$\begin{array}{l}\text { Early Barbed, } \\
\text { Devil's Variant (571) }\end{array}$} & \multirow{3}{*}{$97.07 \mathrm{~m}$} \\
\hline Faunal Evidence & None & & & \\
\hline Pollen & No plants of economic value & & & \\
\hline
\end{tabular}

\section{Description}

Feature 12 consisted of a small discrete cluster of burned rock located within the $2 \mathrm{Bw}$ soil horizon. The feature was roughly oval in outline, measuring $66 \times 46 \mathrm{~cm}$ horizontally and $14 \mathrm{~cm}$ thick. In cross section, there was no apparent layering of the burned rock, although burned rocks in the northern portion of the feature were more tightly grouped. There was no distinguishable difference between the feature's fine matrix and the surrounding soil.

All of the burned rock within Feature 12 was limestone. A total of 77 burned rock specimens was recovered from the feature. Combined, these specimens weighed $11.7 \mathrm{~kg}$. Most (>67 percent) of the burned rocks were rounded in shape, yet their physical condition was a mixture of highly fragmented rocks and specimens fractured in situ. Despite the mixed physical condition of the burned rocks, more than 50 percent of the burned rocks within the feature overlapped one another.

No organics (bone, mussel shell, or charcoal) were found within the feature matrix, although a small sample of charred nutshell was collected from the matrix. This cluster represents evidence of in situ burning and suggests good preservation for the feature. No temporally diagnostic artifacts were present in the associated $10-\mathrm{cm}$ floor level within $1 \mathrm{~m}$ of the feature's edges.

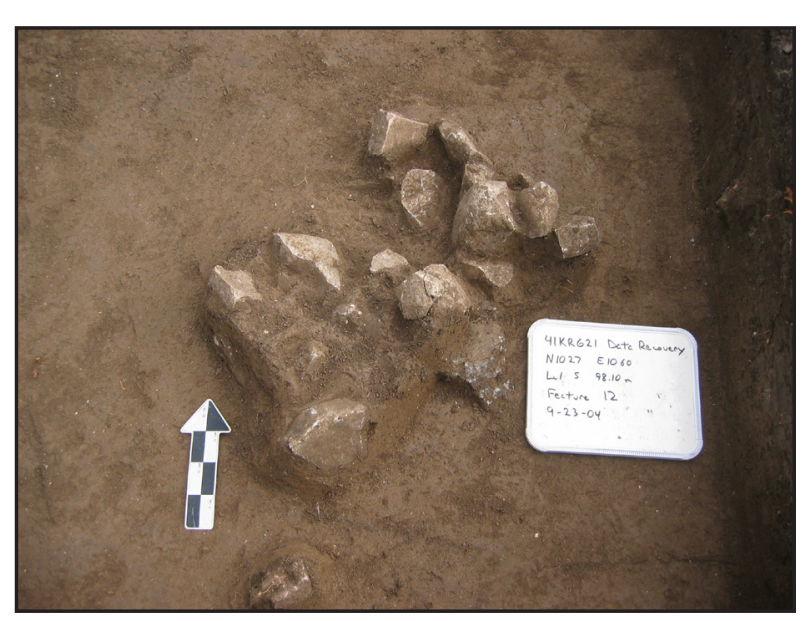

Overview of Feature 12. 


\begin{tabular}{|c|c|c|c|c|}
\hline & & Flotation Results & \multicolumn{2}{|l|}{ Chenopodium } \\
\hline & & Radiocarbon Dates & \multicolumn{2}{|c|}{$\begin{array}{l}\text { Beta- } 206124: 4970 \pm 40 \text { в.P., } 5860-5830 \\
\text { AND } 5750-5610 \text { cal B.P. within feature at } \\
97.55-97.50 \mathrm{~m}\end{array}$} \\
\hline & & $\begin{array}{l}\text { Associated floor } \\
\text { elevation range }(\mathrm{m})\end{array}$ & \multicolumn{2}{|l|}{$97.60-97.50 \mathrm{~m}$} \\
\hline Feature Type & Burned rock cluster & \multirow{2}{*}{$\begin{array}{l}\text { Associated Diagnostics } \\
\text { (Lot No. and elevation) }\end{array}$} & \multirow{2}{*}{ Martindale (962) } & \multirow{2}{*}{$97.53 \mathrm{~m}$} \\
\hline Occupation Zone & 2 & & & \\
\hline Stratigraphic Context & Base of $2 \mathrm{Ab} 2$ horizon, upper $B$ horizon & \multirow{9}{*}{$\begin{array}{l}\text { Diagnostics above and } \\
\text { adjacent to feature } \\
\text { (Lot No.) } \\
\text { proximity radius }=2.0 \mathrm{~m} \\
\text { proximity elevation }=0.2 \mathrm{~m}\end{array}$} & Early Triangular (892) & $97.65 \mathrm{~m}$ \\
\hline Area & A-SW & & Early Triangular (893) & $97.63 \mathrm{~m}$ \\
\hline Provenience & N1017 E1050-1052 & & Early Triangluar(897.1) & $97.70-97.60 \mathrm{~m}$ \\
\hline Center & N1017.83 E1052.15 & & Early Triangular (898) & $97.69 \mathrm{~m}$ \\
\hline Top Elevation & $97.75 \mathrm{~m}$ & & Untyped (904.7) & $97.75 \mathrm{~m}$ \\
\hline Bottom Elevation & $97.49 \mathrm{~m}$ & & Nolan (906) & $97.66 \mathrm{~m}$ \\
\hline Size & $165 \times 135 \mathrm{~cm}$ & & Early Triangular (967) & $97.78 \mathrm{~m}$ \\
\hline Shape & Roughly circular, ring like; flat & & Nolan (958) & $97.8 \mathrm{~m}$ \\
\hline Fuel Type & Juniper, indeterminable hardwood & & Nolan (1563) & $97.74 \mathrm{~m}$ \\
\hline Lipids & N/A & \multirow{3}{*}{\begin{tabular}{|l|} 
Diagnostics below and \\
adjacent to feature \\
(Lot No.) \\
proximity radius $=2.0 \mathrm{~m}$ \\
proximity elevation $=0.1 \mathrm{~m}$
\end{tabular}} & \multirow{3}{*}{ Baker (909) } & \multirow{3}{*}{$97.45 \mathrm{~m}$} \\
\hline Faunal Evidence & $\begin{array}{l}\text { White-tailed deer, unidentifiable bone frag- } \\
\text { ments in same level }\end{array}$ & & & \\
\hline Pollen & Exploitable: hackberry & & & \\
\hline
\end{tabular}

\section{Description}

Feature 13 was a roughly circular, ring-like cluster of burned limestone approximately $165 \times 135 \mathrm{~cm}$, oriented east-west. Located at the base of the 2Ab2 horizon and terminating on the $2 \mathrm{Bw}$ horizon, the feature had a maximum thickness of $26 \mathrm{~cm}$. The densest concentration of burned rock was within the center of the feature. When Feature 13 was bisected no distinguishable profile shape, or layering was observed. Some soil discoloration was observed near the center of the feature, and dense concentrations of black charcoal were observed above, within, and below the rocks; samples were collected near the feature base.

In total, 194 burned limestone rocks, weighing $55 \mathrm{~kg}$, were associated with Feature 13. The burned rocks within the feature were a mixture of rounded and angular specimens. Most (>67 percent) of the burned rock specimens were fractured in situ, and more than 50 percent of the burned rocks were touching and overlapping one another. Due to the well-preserved organic content of this feature, several soil samples were collected.

Seventy-three pieces of debitage, including one modified flake, were found within the feature matrix, along with charcoal and some bone. No diagnostic point types were recovered from within the feature matrix, although a single Martindale point was recorded from the estimated $10-\mathrm{cm}$ floor level within $1 \mathrm{~m}$ of the feature.
Feature 13 was immediately north of Feature 35, which was basin-shaped and, at a lower elevation than Feature 13. Because of some slight overlapping in the bottom elevations of Feature 13 and the top elevations of Feature 35 , it is likely that the two features were contemporaneous. It is also possible that the southernmost stones of Feature 13 may actually have been associated with the upper layer of Feature 35.

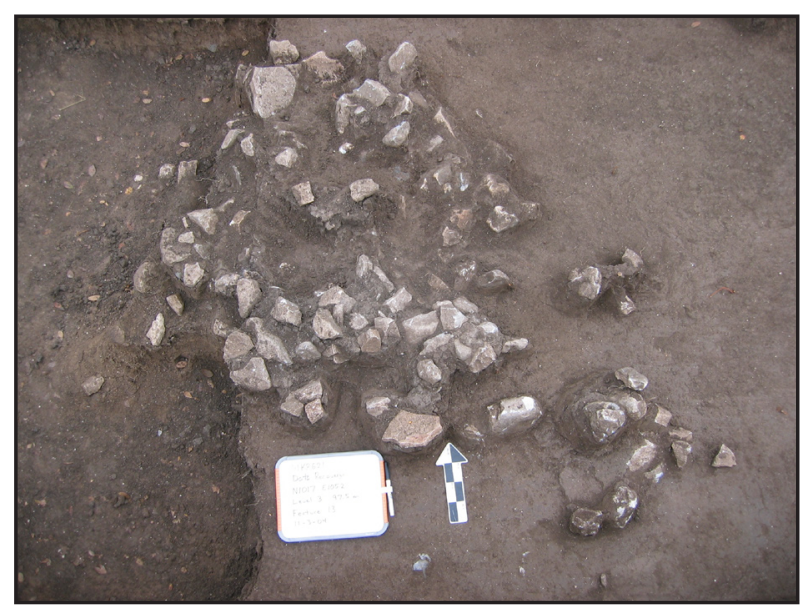

Overview of Feature 13. 


\begin{tabular}{|c|c|c|c|c|}
\hline & & Lipids & \multicolumn{2}{|l|}{ N/A } \\
\hline & & Faunal Evidence & \multicolumn{2}{|l|}{ None } \\
\hline & & Pollen & \multicolumn{2}{|c|}{$\begin{array}{l}\text { Quercus, thistle, Low-spine Asteraceae. } \\
\text { Post-occupation: mustard family }\end{array}$} \\
\hline Feature Type & Small burned rock cluster & & \multirow{2}{*}{\multicolumn{2}{|c|}{ Prostrate spurge }} \\
\hline Occupation Zone & 2 & Flotation Results & & \\
\hline Stratigraphic Context & Within 2Bw horizon & Radiocarbon Dates & \multicolumn{2}{|l|}{ None } \\
\hline Area & A-NE & $\begin{array}{l}\text { Associated floor } \\
\text { elevation range }(m)\end{array}$ & \multicolumn{2}{|l|}{$97.20-97.10 \mathrm{~m}$} \\
\hline Provenience & N1031 E1068 & \multirow{2}{*}{$\begin{array}{l}\text { Associated Diagnostics } \\
\text { (Lot No. and elevation) }\end{array}$} & \multirow[b]{2}{*}{ Martindale (488.1) } & \multirow[b]{2}{*}{$97.20-97.10 \mathrm{~m}$} \\
\hline Center & N1031.85E1070.00 & & & \\
\hline Top Elevation & $97.23 \mathrm{~m}$ & \multirow{3}{*}{$\begin{array}{l}\text { Diagnostics above and } \\
\text { adjacent to feature (Lot No.) } \\
\text { proximity radius }=2.0 \mathrm{~m} \\
\text { proximity elevation }=0.2 \mathrm{~m}\end{array}$} & \multirow{3}{*}{ Untyped (493.1) } & \multirow{3}{*}{$97.40-97.30 \mathrm{~m}$} \\
\hline Bottom Elevation & $97.07 \mathrm{~m}$ & & & \\
\hline Size & $80 \times 50 \mathrm{~cm}$ & & & \\
\hline Shape & Roughly circular; some layering & \multirow{2}{*}{$\begin{array}{l}\text { Diagnostics below and } \\
\text { adjacent to feature (Lot No.) } \\
\text { proximity radius }=2.0 \mathrm{~m} \\
\text { proximity elevation }=0.2 \mathrm{~m}\end{array}$} & \multirow[t]{2}{*}{ Gower (497.1) } & \multirow[t]{2}{*}{$97.00-96.90 \mathrm{~m}$} \\
\hline Fuel Type & Plateau live oak & & & \\
\hline
\end{tabular}

\section{Description}

Feature 21 was a small, discrete cluster of burned rock found within the $2 \mathrm{Bw}$ soil horizon. Approximately half of the feature extended beyond SWCA's excavations into the unit's eastern wall. Given the shape of the excavated portion, it appears that Feature 21 was roughly circular, with an estimated diameter of $80 \mathrm{~cm}$.

In cross section, no distinctive shape was observable; however, rock layering was present. The feature was $16 \mathrm{~cm}$ thick. Other than the burned rock, no evidence of burning was observed within, around, or below the feature matrix. Correspondingly, there was no noticeable difference between the internal feature matrix and the surrounding soil.

All of the burned rock within Feature 21 was limestone. A total of 31 burned rock specimens was recovered from the feature, weighing a total of $29.1 \mathrm{~kg}$. The physical shapes of the burned rocks were a mixture of flat limestone slabs and angular rocks. Although the rocks were clearly burned, most were unfractured. The burned rocks were densely packed with more than 50 percent of the burned rocks adjacent to and touching one another.

Only one dart point, a Martindale point, was recovered within $1 \mathrm{~m}$ of the feature's margins within the estimated $10-\mathrm{cm}$ floor level. No bone fragments or other organic materials were recovered.

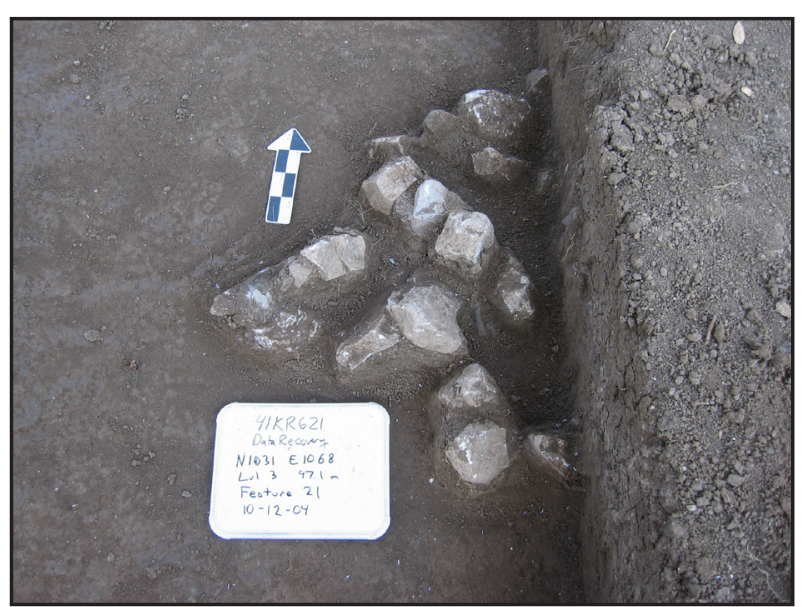

Overview of Feature 21. 


\begin{tabular}{|c|c|c|c|c|}
\hline & & Radiocarbon Dates & \multicolumn{2}{|c|}{$\begin{array}{l}\text { Beta } 206119: 5260 \pm 50 \text { в.P., } \\
6180-5920 \text { cal B.P. within feature at } \\
97.20-97.10 \mathrm{~m}\end{array}$} \\
\hline Feature Type & $\begin{array}{l}\text { Burned rock cluster with associated } \\
\text { scatter }\end{array}$ & $\begin{array}{l}\text { Associated floor } \\
\text { elevation range }(\mathrm{m})\end{array}$ & \multicolumn{2}{|l|}{$97.20-97.10 \mathrm{~m}$} \\
\hline Occupation Zone & 2 & \multirow{3}{*}{$\begin{array}{l}\text { Associated Diagnostics } \\
\text { (Lot No. and elevation) }\end{array}$} & Martindale (482) & $97.11 \mathrm{~m}$ \\
\hline Stratigraphic Context & Within 2Bw horizon & & Untyped (513) & $\begin{array}{l}97.20- \\
97.10 \mathrm{~m}\end{array}$ \\
\hline Area & A-NE & & Untyped (617) & $97.10 \mathrm{~m}$ \\
\hline Provenience & N1027 E1066-1068 & \multirow{9}{*}{$\begin{array}{l}\text { Diagnostics above and } \\
\text { adjacent to feature (Lot } \mathrm{No} \text {.) } \\
\text { proximity radius }=2.0 \mathrm{~m} \\
\text { proximity elevation }=0.1 \mathrm{~m}\end{array}$} & \multirow{2}{*}{ Untyped (513) } & \multirow{2}{*}{$\begin{array}{l}97.20- \\
97.10 \mathrm{~m}\end{array}$} \\
\hline Center & N1028.38 E1067.88 & & & \\
\hline Top Elevation & $97.20 \mathrm{~m}$ & & Untyped (609) & $97.24 \mathrm{~m}$ \\
\hline Bottom Elevation & $97.04 \mathrm{~m}$ & & Untyped (617) & $97.1 \mathrm{~m}$ \\
\hline Size & $200 \times 120 \mathrm{~cm}$ & & Matindale (638) & $97.28 \mathrm{~m}$ \\
\hline Shape & Roughly circular; slight layering & & Early Triangular (646) & $97.23 \mathrm{~m}$ \\
\hline Fuel Type & Indeterminable & & Early Triangular (647) & $97.25 \mathrm{~m}$ \\
\hline Lipids & Medium fat content food (mesquite/ & & Martindale (652) & $97.2 \mathrm{~m}$ \\
\hline & & & Martindale (653) & $97.01 \mathrm{~m}$ \\
\hline Faunal Evidence & Unidentifiable bone fragments & \multirow{3}{*}{$\begin{array}{l}\text { Diagnostics below and } \\
\text { adjacent to feature (Lot No.) } \\
\text { proximity radius }=2.0 \mathrm{~m} \\
\text { proximity elevation }=0.2 \mathrm{~m}\end{array}$} & \multirow{3}{*}{$\begin{array}{l}\text { Early Barbed, Devil's Vari- } \\
\text { ant }(641.1)\end{array}$} & \multirow{3}{*}{$\begin{array}{l}97.00- \\
96.90 \mathrm{~m}\end{array}$} \\
\hline Pollen & $\begin{array}{l}\text { Post-occupation: Thistle, mustard family, } \\
\text { and mallow family }\end{array}$ & & & \\
\hline Flotation Results & Grass family & & & \\
\hline
\end{tabular}

\section{Description}

Located within the $2 \mathrm{Bw}$ horizon, Feature 22 was a roughly circular cluster of burned rock with a line of loose burned rocks extending away to the southeast. The main circular cluster was approximately $120 \mathrm{~cm}$ in diameter; with the addition of the associated scatter, the maximum dimension increased to $200 \mathrm{~cm}$.

Approximately $16 \mathrm{~cm}$ thick, the feature displayed no formal layering of burned rock in cross section and no noticeable difference between the internal feature matrix and the surrounding soil. However, some slight stacking of burned rock was evident along the outer margins of the circular cluster, the center of which was relatively devoid of burned rock.

Many of the burned rocks within this feature were vertically slanting and facing east. In addition, the easternmost stones of the circular cluster and the component rocks of the associated scatter were generally found resting at slightly lower elevations than those to the west, most likely reflecting the natural slope at the site.

A total of 179 burned rock specimens was recovered from the feature and associated scatter. These burned rock specimens weighed a total of $54.1 \mathrm{~kg}$. The shape of the burned rocks was a mixture of angular rocks and flat slabs of limestone. Most (>67 percent) of the burned rocks were unfractured, and less than 50 percent of the burned rocks were touching one another. The rocks within the circular portion of the feature were observed to be more tightly clustered than those within the scatter, which were generally more fractured. These appear to suggest that the feature was dismantled, perhaps while hot, to remove foodstuffs cooked within, thereby resulting in the hollow center of the circular cluster and the associated tailing of rocks to the southeast.

Several bone fragments were retrieved from the feature as well as 20 unusual fragments of burned clay. A total of 261 fragments of debitage was collected from the feature matrix, the majority of which exhibited burning. Three dart points were recovered from the $10-\mathrm{cm}$ floor level within the 1 -m radius surrounding the feature's margins, including a single Martindale point and two untyped specimens.

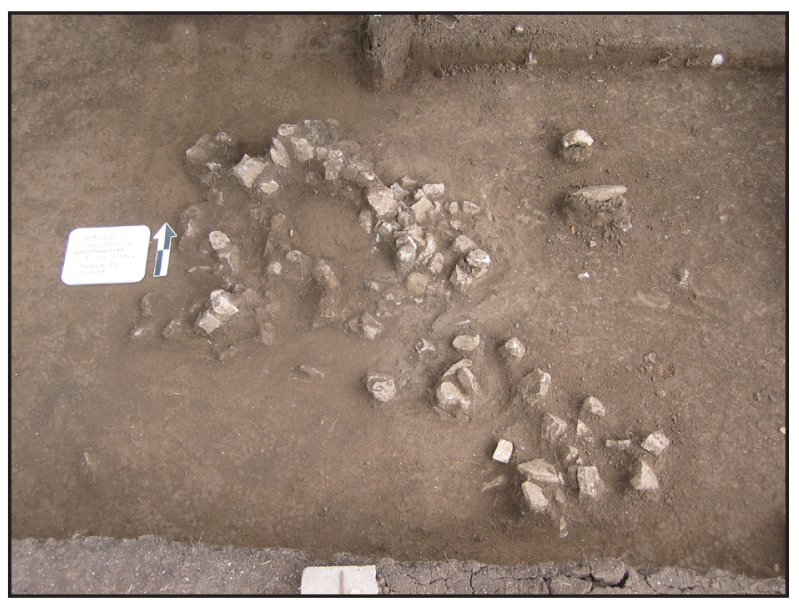

Overview of Feature 22. The main circular component of the feature is in the upper left, and the scatter is in the lower right corner. 


\begin{tabular}{|c|c|c|c|c|}
\hline & & Pollen & \multicolumn{2}{|c|}{$\begin{array}{l}\text { Post-occupation: mustard family, mallow } \\
\text { family, and elm (modern?) }\end{array}$} \\
\hline & & Flotation Results & \multicolumn{2}{|l|}{ Hackberry, bud } \\
\hline Feature Type & Small burned rock cluster & Radiocarbon Dates & \multicolumn{2}{|l|}{ None } \\
\hline Occupation Zone & 2 & Associated floor & \multirow{2}{*}{\multicolumn{2}{|c|}{$97.20-97.10 \mathrm{~m}$}} \\
\hline Stratigraphic Context & Within 2Bw horizon & & & \\
\hline Area & $\mathrm{A}-\mathrm{NE}$ & $\begin{array}{l}\text { Associated Diagnostics } \\
\text { (Lot No. and elevation) }\end{array}$ & \multicolumn{2}{|l|}{ None } \\
\hline Provenience & N1031 E1058 & \multirow{7}{*}{$\begin{array}{l}\text { Diagnostics above and } \\
\text { adjacent to feature (Lot No.) } \\
\text { proximity radius }=2.0 \mathrm{~m} \\
\text { proximity elevation }=0.20 \mathrm{~m}\end{array}$} & Martindale (303) & $97.25 \mathrm{~m}$ \\
\hline Center & N1031.34 E1058.24 & & Early Triangular (304) & $97.24 \mathrm{~m}$ \\
\hline Top Elevation & $97.20 \mathrm{~m}$ & & Martindale (307) & $97.11 \mathrm{~m}$ \\
\hline Bottom Elevation & $97.10 \mathrm{~m}$ & & Martindale (311) & $97.06 \mathrm{~m}$ \\
\hline Size & $46 \times 33 \mathrm{~cm}$ & & Andice (363) & $97.34 \mathrm{~m}$ \\
\hline Shape & Roughly circular, flat & & \multirow{2}{*}{ Martindale (465.2) } & $97.30-$ \\
\hline Fuel Type & Indeterminable & & & $97.20 \mathrm{~m}$ \\
\hline Lipids & $\mathrm{N} / \mathrm{A}$ & \multirow{2}{*}{$\begin{array}{l}\text { Diagnostics below and } \\
\text { adjacent to feature (Lot No.) } \\
\text { proximity radius }=2.0 \mathrm{~m} \\
\text { proximity elevation }=0.1 \mathrm{~m}\end{array}$} & \multirow{2}{*}{\multicolumn{2}{|c|}{ None }} \\
\hline Faunal Evidence & $\begin{array}{l}\text { Unidentifiable bone fragments in same } \\
\text { level }\end{array}$ & & & \\
\hline
\end{tabular}

\section{Description}

Feature 24 was a small, discrete cluster of burned rock found in the $2 \mathrm{Bw}$ horizon. It was roughly circular in outline, measuring $46 \times 33 \mathrm{~cm}$ and oriented roughly north-south. The feature lies adjacent to the western baulk of Area A$\mathrm{NE}$, and it is possible that it may have extended slightly farther in this direction. The feature was $10 \mathrm{~cm}$ thick with no apparent basin, pit, or rock layering observed in cross section. There was no distinction between the color of the internal feature matrix and the surrounding sediment, and no evidence of thermal alteration was observed below, within, or around the feature.

All of the burned rock within Feature 24 was limestone. The burned rock specimens $(n=14)$ that formed the feature had a combined weight of $3.1 \mathrm{~kg}$. The majority (>67 percent) of

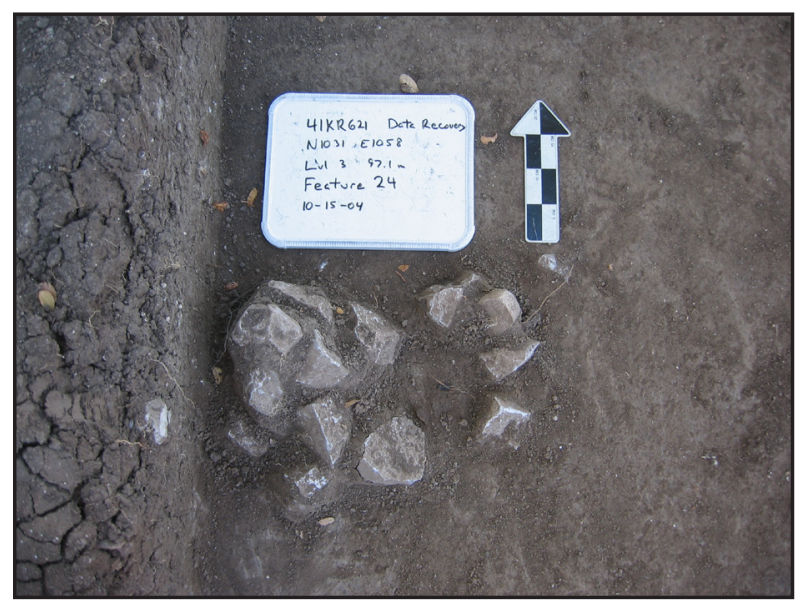

Overview of Feature 24. the burned rocks associated with Feature 24 were angular and unfractured, and most (>50 percent) of the burned rocks were touching and overlapping one another.

No diagnostic projectile point types were found within the $10-\mathrm{cm}$ floor level within $1 \mathrm{~m}$ of this feature's margins. Ninety-two pieces of debitage were recovered from throughout the feature matrix. Although no bone was found within the feature matrix, seven unidentifiable fragments were found in the same level within the unit. 


\begin{tabular}{|c|c|c|c|c|}
\hline 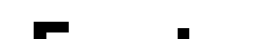 & & \multirow{4}{*}{$\begin{array}{l}\text { Associated Diagnostics } \\
\text { (Lot No. and elevation) }\end{array}$} & Gower (310) & $97.01 \mathrm{~m}$ \\
\hline & & & Martindale (311) & $97.06 \mathrm{~m}$ \\
\hline & & & Martindale (661) & $97.00 \mathrm{~m}$ \\
\hline & & & Bandy (662) & $97.10 \mathrm{~m}$ \\
\hline Feature Type & Burned rock cluster & \multirow{17}{*}{$\begin{array}{l}\text { Diagnostics above and } \\
\text { adjacent to feature (Lot No.) } \\
\text { proximity radius }=2.0 \mathrm{~m} \\
\text { proximity elevation }=0.1 \mathrm{~m}\end{array}$} & Gower (223) & $97.10 \mathrm{~m}$ \\
\hline Occupation Zone & 2 & & Bandy (228) & $97.02 \mathrm{~m}$ \\
\hline Stratigraphic Context & Within 2Bw horizon & & \multirow{2}{*}{ Martindale (235.2) } & \multirow{2}{*}{$\begin{array}{l}97.20- \\
97.10 \mathrm{~m}\end{array}$} \\
\hline Area & A-NE & & & \\
\hline \multirow{2}{*}{ Provenience } & \multirow{2}{*}{$\begin{array}{l}\text { N1033 E1058-1060; N1035 E1058- } \\
1060 ; \text { N1037 E1060-1062 }\end{array}$} & & Martindale (236) & $97.12 \mathrm{~m}$ \\
\hline & & & \multirow{2}{*}{ Gower (244.2) } & $97.20-$ \\
\hline Center & N1035.80 E1060.60 & & & $97.10 \mathrm{~m}$ \\
\hline Top Elevation & $97.07 \mathrm{~m}$ & & Early Triangular (271) & $97.14 \mathrm{~m}$ \\
\hline Bottom Elevation & $96.95 \mathrm{~m}$ & & Gower (272) & $97.10 \mathrm{~m}$ \\
\hline Size & $450 \times 80 \mathrm{~cm}$ & & Gower (273) & $97.10 \mathrm{~m}$ \\
\hline Shape & Elongated oval, relatively flat & & Martindale (283) & $97.20-$ \\
\hline Fuel Type & Indeterminable & & & \\
\hline & Very high fat content food & & Martindale (284) & $97.10 \mathrm{~m}$ \\
\hline Lipids & (seed/animal fat) & & Martindale (292.3) & $\begin{array}{l}97.20- \\
97.10 \mathrm{~m}\end{array}$ \\
\hline Faunal Evidence & $\begin{array}{l}\text { Unidentifiable bone fragments, some } \\
\text { burned; mussel shell in same level }\end{array}$ & & Gower (320.2) & $\begin{array}{l}97.20- \\
97.10 \mathrm{~m}\end{array}$ \\
\hline Pollen & $\begin{array}{l}\text { Exploitable: grass (possible seed process- } \\
\text { ing) }\end{array}$ & & Gower (320.3) & $\begin{array}{l}97.20- \\
97.10 \mathrm{~m}\end{array}$ \\
\hline Flotation Results & Chenopodium, prostrate spurge & & Martindale (330.2) & $97.10 \mathrm{~m}$ \\
\hline Radiocarbon Dates & $\begin{array}{l}\text { Beta } 207380: 4550 \pm 40 \text { B.P., } 5320- \\
5050 \text { cal B.P. within feature at } 97.05 \mathrm{~m}\end{array}$ & Diagnostics below and & & \\
\hline $\begin{array}{l}\text { Associated floor } \\
\text { elevation range }(\mathrm{m})\end{array}$ & $97.10-97.00 \mathrm{~m}$ & $\begin{array}{l}\text { proximity radius }=2.0 \mathrm{~m} \\
\text { proximity elevation }=0.1 \mathrm{~m}\end{array}$ & None & \\
\hline
\end{tabular}

\section{Description}

Feature 25 extended across six units in the northeastern portion of Area A-NE. Feature 25 was in close proximity to Feature 26, and the two features were most likely related. Both features were within the $2 \mathrm{Bw}$ soil horizon.

Feature 25 was a large, very dense cluster of burned rock. Long and roughly ovate in outline, the feature measured approximately $450 \times 80 \mathrm{~cm}$, oriented northeast-southwest. The feature was $12 \mathrm{~cm}$ thick with no apparent basin, pit, or significant rock layering observed in cross section. There was no distinguishable difference between the feature matrix and the surrounding soil.

Most of the burned rock within Feature 25 was limestone $(n=396)$, weighing $141.1 \mathrm{~kg}$. Only one burned rock was sandstone weighing $0.2 \mathrm{~kg}$. Most of the feature was composed of a mixture of large angular and rounded burned rocks. Most of the burned rocks appeared to be unfractured, and those that were, were fractured in situ.

Evidence of burning was apparent within a small patch of burned soil matrix. Some charcoal was observed within the feature matrix, but its occurrence was not widespread. No other distinction between the feature soil matrix and surrounding soil was observed. Bone found within the feature matrix proved unidentifiable.
A Martindale point (Lot 661) and a Bandy point (Lot 662) were recovered from within the feature matrix itself, and debitage was also observed and collected throughout the feature matrix. Additionally, several dart points were recovered from the estimated $10-\mathrm{cm}$ floor level surrounding Features 25 and 26. These included two Gower points, two Martindale points, and a Bandy point.

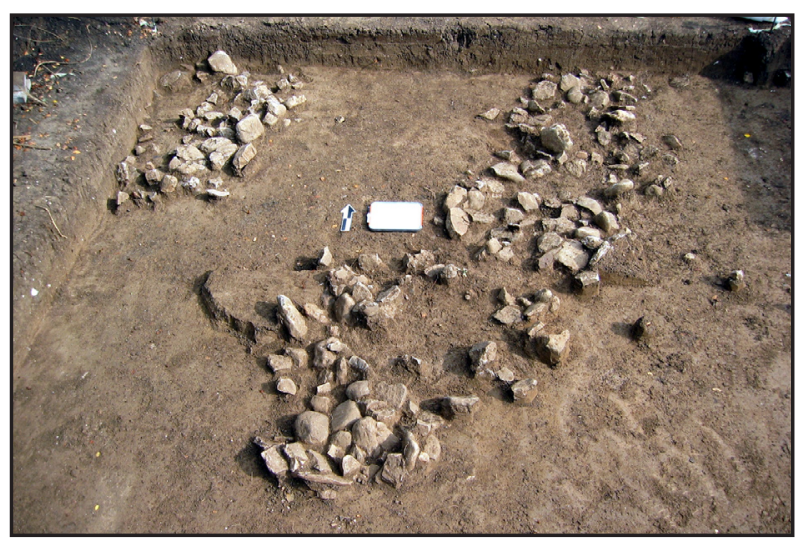

Overview of Feature 25 (right) and Feature 26 (in upper left corner). 


\begin{tabular}{|c|c|c|c|c|}
\hline r & & Pollen & \multicolumn{2}{|c|}{$\begin{array}{l}\text { Quercus. Exploitable: umbel family and } \\
\text { nightshade family; post-occupational: } \\
\text { legume and mallow family }\end{array}$} \\
\hline & & Flotation Results & \multicolumn{2}{|c|}{ Charred: hickory/walnut nutshell } \\
\hline & & Radiocarbon Dates & \multicolumn{2}{|c|}{$\begin{array}{l}\text { Beta: } 206122: 6100 \pm 40 \text { B.P., } \\
7150-7130 \text { AND } 7020-6860 \mathrm{cal} \text { B.P. at } \\
\text { base of feature at } 96.97 \mathrm{~m}\end{array}$} \\
\hline & & $\begin{array}{l}\text { Associated floor } \\
\text { elevation range }(\mathrm{m})\end{array}$ & \multicolumn{2}{|l|}{$97.10-97.00 \mathrm{~m}$} \\
\hline Feature Type & Burned rock cluster & \multirow{2}{*}{$\begin{array}{l}\text { Associated Diagnostics } \\
\text { (Lot No. and elevation) }\end{array}$} & \multicolumn{2}{|l|}{ None } \\
\hline Occupation Zone & 2 & & Gower (223) & $9710-9700 \mathrm{~m}$ \\
\hline Stratigraphic Context & Within 2Bw horizon & \multirow{10}{*}{$\begin{array}{l}\text { Diagnostics above and } \\
\text { adjacent to feature (Lot No.) } \\
\text { proximity radius }=2.0 \mathrm{~m} \text { prox- } \\
\text { imity elevation }=0.1 \mathrm{~m}\end{array}$} & Bandv (228) & \\
\hline Area & A-NE & & & \\
\hline Provenience & N1035-1037 E1058 & & 8. & 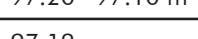 \\
\hline Center & N1036.60 E1058.40 & & Marminale (230) & $91.12 \mathrm{~m}$ \\
\hline Top Elevation & $9713 \mathrm{~m}$ & & Gower (244.2) & $97.20-97.10 \mathrm{~m}$ \\
\hline & & & Nolan (266) & $97.28 \mathrm{~m}$ \\
\hline Botrom Elevation & $96.96 \mathrm{~m}$ & & Martindale (267) & $97.30-97.20 \mathrm{~m}$ \\
\hline Size & $180 \times 100 \mathrm{~cm}$ & & Gower (310) & $97.01 \mathrm{~m}$ \\
\hline Shape & Oval, relatively flat & & Martindale (311) & $97.06 \mathrm{~m}$ \\
\hline Fuel Type & Indeterminable wood & & Martindale (330.2) & $97.10-97.00 \mathrm{~m}$ \\
\hline Lipids & $\begin{array}{l}\text { Borderline high and very high fat content } \\
\text { food }\end{array}$ & \multirow{2}{*}{$\begin{array}{l}\text { Diagnostics below and } \\
\text { adjacent to feature (Lot No.) } \\
\text { proximity radius }=2.0 \mathrm{~m} \text { prox- } \\
\text { imity elevation }=0.1 \mathrm{~m}\end{array}$} & \multirow{2}{*}{\multicolumn{2}{|c|}{ None }} \\
\hline Faunal Evidence & $\begin{array}{l}\text { Unidentifiable bone fragments associated } \\
\text { with feature and in same level }\end{array}$ & & & \\
\hline
\end{tabular}

\section{Description}

Feature 26 was a dense, oval cluster of burned rock occurring within the $2 \mathrm{Bw}$ horizon. Located $1.5 \mathrm{~m}$ northwest of Feature 25, the feature extended into the western baulk of Area A-NE, which was not excavated. As a result, the exposed portion of the feature measured $180 \times 100 \mathrm{~cm}$ north-south, with the east-west dimension somewhat truncated from its original extent. The feature was $17 \mathrm{~cm}$ thick with no discernible rock patterning or layering observed in cross section.

All of the burned rock within Feature 26 was limestone $(n=134)$ and weighed $63.4 \mathrm{~kg}$. Like Feature 25, most of the burned rocks were a mixture of large angular and rounded pieces of limestone. Most of the burned rocks appeared to be unfractured, and those that were, were fractured in situ.

Small flecks of charcoal, including two samples recovered from the feature's base, were noticed throughout the feature matrix and provided evidence of burning within the feature. Other than charcoal, no other evidence of burning was apparent, and no other distinction between the feature soil matrix and surrounding soil was observed.
Bone, charcoal, and debitage were observed throughout the feature matrix and collected. No temporally diagnostic projectile point types were recovered from the estimated $10-\mathrm{cm}$ floor level within $1 \mathrm{~m}$ of Feature 26's outer margins. Several diagnostic points were found within the vicinity of related Feature 25, however, including points of the types Martindale, Bandy, and Gower.

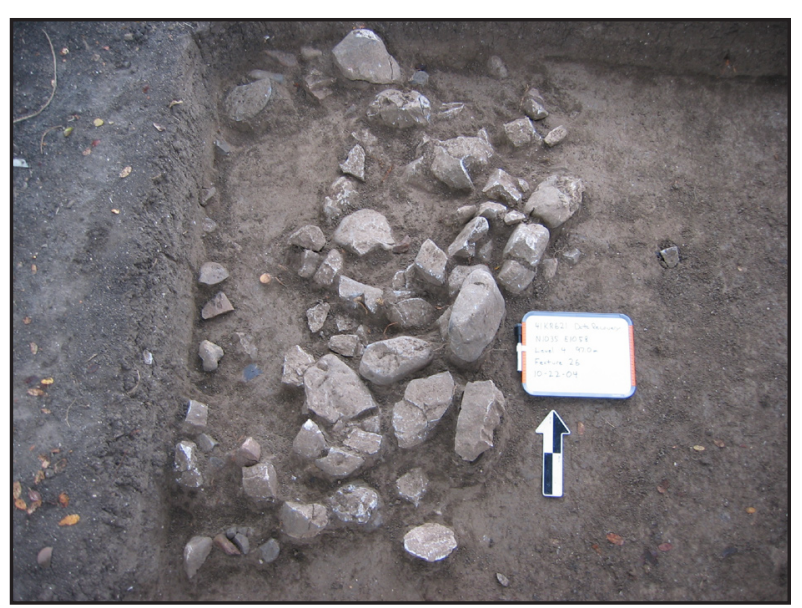

Close-up of Feature 26. 


\section{Feature 28}

\begin{tabular}{|l|l|}
\hline Feature Type & Small burned rock cluster \\
\hline Occupation Zone & 2 \\
\hline Stratigraphic Context & $2 \mathrm{Ab}$ \\
\hline Area & $\mathrm{B}$ \\
\hline Provenience & $\mathrm{N} 1018 \mathrm{E} 1030-1032$ \\
\hline Center & $\mathrm{N} 1019.20 \mathrm{E} 1031.60$ \\
\hline Top Elevation & $97.82 \mathrm{~m}$ \\
\hline Bottom Elevation & $97.72 \mathrm{~m}$ \\
\hline Size & $75 \times 60$ cm \\
\hline Shape & Relatively circular; relatively flat \\
\hline Fuel Type & Plateau live oak \\
\hline Lipids & N/A \\
\hline Faunal Evidence & Unidentifiable tooth enamel \\
\hline Pollen & $\begin{array}{l}\text { Quercus. Exploitable: cheno-ams, mustard } \\
\text { family, and hackberry }\end{array}$ \\
\hline
\end{tabular}

\begin{tabular}{|c|c|c|}
\hline Flotation Results & \multicolumn{2}{|c|}{$\begin{array}{l}\text { Hackberry, cedar elm leaves, bud, and } \\
\text { prostrate spurge. Charred remains: walnut } \\
\text { nutshell and one indeterminable seed }\end{array}$} \\
\hline Radiocarbon Dates & \multicolumn{2}{|c|}{$\begin{array}{l}\text { Beta-206123: } 4980 \pm 40 \text { B.P., } 5870- \\
5820 \text { AND } 5760-5610 \text { cal B.P. at } 97.76 \mathrm{~m}\end{array}$} \\
\hline $\begin{array}{l}\text { Associated floor } \\
\text { elevation range }(\mathrm{m})\end{array}$ & \multicolumn{2}{|l|}{$97.80-97.70 \mathrm{~m}$} \\
\hline $\begin{array}{l}\text { Associated Diagnostics (Lot } \\
\text { No. and elevation) }\end{array}$ & Untyped (1 145) & $97.72 \mathrm{~m}$ \\
\hline \multirow{11}{*}{$\begin{array}{l}\text { Diagnostics above and adja- } \\
\text { cent to feature (Lot No.) } \\
\text { proximity radius }=2.0 \mathrm{~m} \\
\text { proximity elevation }=0.20 \mathrm{~m}\end{array}$} & Andice (1315.2) & $97.80 \mathrm{~m}$ \\
\hline & Untyped (1121.1) & $98.00-97.90 \mathrm{~m}$ \\
\hline & Pedernales (1 128.1) & $98.00-97.90 \mathrm{~m}$ \\
\hline & Pedernales (1128.2) & $98.00-97.80 \mathrm{~m}$ \\
\hline & La Jita (1 138) & $97.82 \mathrm{~m}$ \\
\hline & Nolan (1139) & $97.82 \mathrm{~m}$ \\
\hline & Nolan (1141) & $97.82 \mathrm{~m}$ \\
\hline & Untyped (1142( & $98.82 \mathrm{~m}$ \\
\hline & Untyped (1 160.1) & $98.00-97.90 \mathrm{~m}$ \\
\hline & Untyped (1 183.4) & $97.90-97.80 \mathrm{~m}$ \\
\hline & Untyped (1184) & $97.83 \mathrm{~m}$ \\
\hline $\begin{array}{l}\text { Diagnostics below and adja- } \\
\text { cent to feature (Lot No.) } \\
\text { proximity radius }=2.0 \mathrm{~m} \\
\text { proximity elevation }=0.10 \mathrm{~m}\end{array}$ & \multicolumn{2}{|l|}{ None } \\
\hline
\end{tabular}

\section{Description}

Feature 28 was a dense, relatively circular cluster of burned rock, approximately $75 \times 60 \mathrm{~cm}$ in horizontal dimensions, oriented east-west. The feature was within the $2 \mathrm{Ab}$ and $B$ ? horizons and was $10 \mathrm{~cm}$ thick at its maximum dimensions.

The burned rocks of Feature 28 were tightly clumped together with no apparent layering. When the feature was bisected, no distinguishable basin or soil discoloration was apparent. A total of 124 burned rock specimens was recovered from Feature 28 and, weighed $24.0 \mathrm{~kg}$. The burned rocks were limestone and angular in shape. These were a mixture of rocks fractured in situ and were highly fragmented specimens-most of which were adjacent to one another.

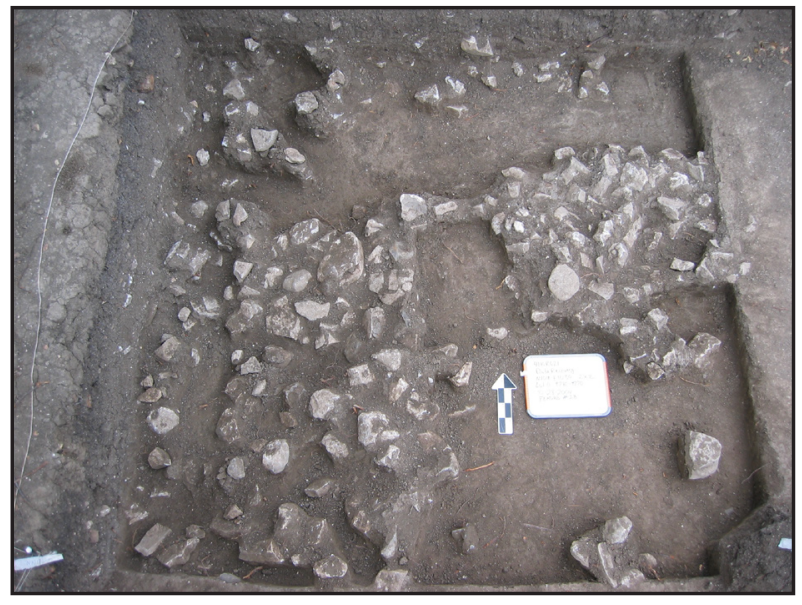

Overview of Feature 28.
Burned rocks were commonly found throughout the entire unit/level, and it is likely that some of the rocks on the western side of the unit/level were associated with Feature 28. These were not recorded as part of the feature, however, because they were widely dispersed and not tightly clustered.

A total of 132 pieces of debitage was collected from the feature matrix along with eight fragments of faunal bone. Only very fine fragments of charcoal were present intermittently beneath the burned rocks of the feature. An Andice point and an untyped dart point were found within the feature's estimated $10-\mathrm{cm}$ floor level and a $1-\mathrm{m}$ radius of its outer boundaries.

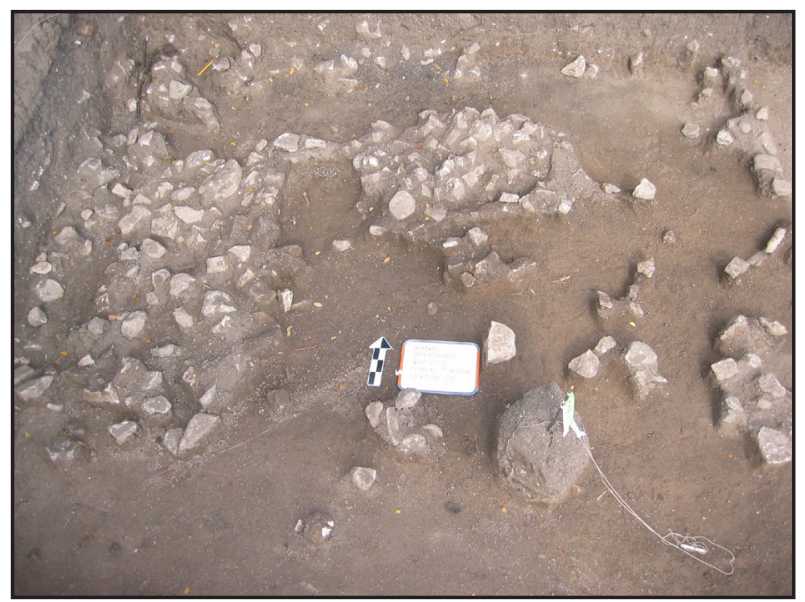

Overview of Feature 28 with surrounding unit expanded to east. 


\begin{tabular}{|c|c|c|c|c|}
\hline & & \multirow[t]{2}{*}{ Pollen } & \multirow{2}{*}{\multicolumn{2}{|c|}{$\begin{array}{l}\text { High-spine Asteraceae, Liguliflorae, } \\
\text { thistle, Low-spine Asteraceae. Exploit- } \\
\text { able (and possibly post-occupational) } \\
\text { mustard family, mint, and mallow } \\
\text { family }\end{array}$}} \\
\hline Feature Type & Small burned rock cluster & & & \\
\hline Occupation Zone & 2 & Flotation Results & \multicolumn{2}{|l|}{$\mathrm{N} / \mathrm{A}$} \\
\hline Stratigraphic Context & Upper 2Bw horizon & Radiocarbon Dates & \multicolumn{2}{|l|}{ None } \\
\hline Area & A-SW & \multirow{2}{*}{$\begin{array}{l}\text { Associated floor } \\
\text { elevation range }(\mathrm{m})\end{array}$} & \multirow{2}{*}{\multicolumn{2}{|c|}{$97.70-97.60 \mathrm{~m}$}} \\
\hline Provenience & N1017 E1046 & & & \\
\hline Center & N1017.18 E1047.06 & \multirow{2}{*}{$\begin{array}{l}\text { Associated Diagnostics } \\
\text { (Lot No. and elevation) }\end{array}$} & \multirow{2}{*}{\multicolumn{2}{|c|}{ None }} \\
\hline Top Elevation & $97.70 \mathrm{~m}$ & & & \\
\hline Bottom Elevation & $97.58 \mathrm{~m}$ & \multirow{3}{*}{$\begin{array}{l}\text { Diagnostics above and } \\
\text { adjacent to feature (Lot No.) } \\
\text { proximity radius }=2.0 \mathrm{~m} \\
\text { proximity elevation }=0.1 \mathrm{~m}\end{array}$} & \multirow[t]{2}{*}{ Gower (944) } & \multirow[t]{2}{*}{$97.70 \mathrm{~m}$} \\
\hline Size & $68 \times 42 \mathrm{~cm}$ & & & \\
\hline Shape & Roughly circular, relatively flat & & Early Triangular (955) & $97.68 \mathrm{~m}$ \\
\hline Fuel Type & Live oak charcoal nearby & \multirow{3}{*}{$\begin{array}{l}\text { Diagnostics below and } \\
\text { adjacent to feature (Lot No.) } \\
\text { proximity radius }=2.0 \mathrm{~m} \\
\text { proximity elevation }=0.1 \mathrm{~m}\end{array}$} & Untyped (942) & $97.52 \mathrm{~m}$ \\
\hline Lipids & N/A & & \multirow{2}{*}{ Early Triangular (943) } & \multirow{2}{*}{$97.50 \mathrm{~m}$} \\
\hline Faunal Evidence & None & & & \\
\hline
\end{tabular}

\section{Description}

Feature 31 was a small cluster of burned rock associated with the upper $2 \mathrm{Bw}$ stratigraphic profile. The feature measured $68 \times 42 \mathrm{~cm}$, oriented east-west, and was $12 \mathrm{~cm}$ thick. The feature was at the southern edge of Area A-SW and may have extended slightly into the unexcavated southern baulk. No significant layering of burned rock was observed in the feature cross section, and no difference was observed between the feature matrix and the surrounding soil.

The burned rock within Feature 31 was composed entirely of limestone. A total of 44 burned rock specimens was recovered from Feature 31. These burned rock specimens weighed $9.1 \mathrm{~kg}$. These consisted of a mixture of angular rocks, rounded specimens, and flat slabs of limestone. The rocks were a combination of those fractured in situ and intact specimens. Most of the burned rocks were overlapping and touching.

No diagnostic projectile points were found in association with Feature 31 or within the estimated $10-\mathrm{cm}$ floor level and $1-m$ horizontal radius. Only six fragments of debitage were collected from the feature matrix. No bone, mussel shell, or charcoal were found within the feature matrix.

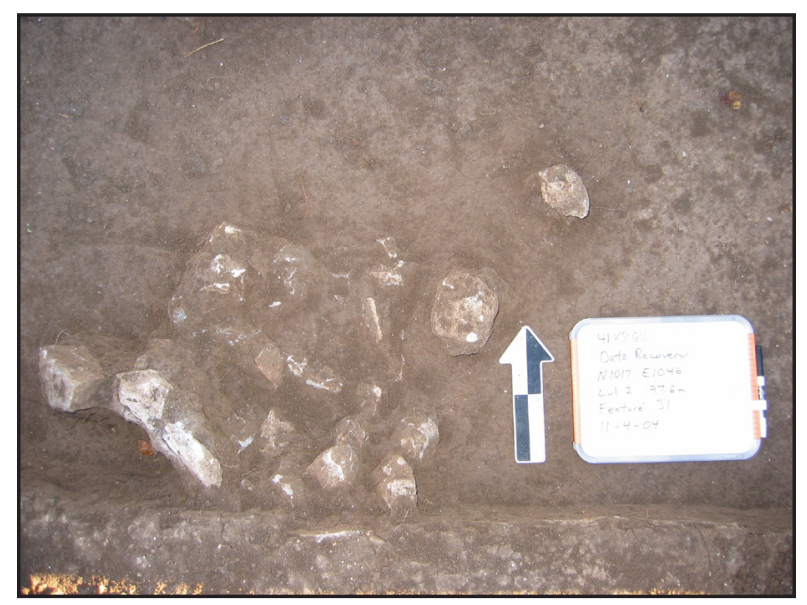

Overview of Feature 31. 


\begin{tabular}{|c|c|c|c|c|}
\hline 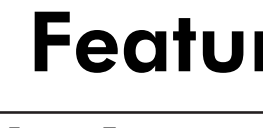 & & Radiocarbon Dates & \multicolumn{2}{|c|}{$\begin{array}{l}\text { Beta-206126: } 5440 \pm 40 \text { в.P., } 6300-6180 \\
\text { cal B.P. within feature at } 97.45 \mathrm{~m} \text {; Beta- } \\
207384: 5570 \pm 40 \text { в.P., } 6420-6290 \text { cal } \\
\text { B.P. at top at } 97.55 \mathrm{~m}\end{array}$} \\
\hline \multirow{2}{*}{$\begin{array}{l}\text { Feature Type } \\
\text { Occupation Zone }\end{array}$} & Debitage cluster & \multirow{2}{*}{$\begin{array}{l}\text { Associated floor } \\
\text { elevation range }(\mathrm{m})\end{array}$} & \multirow{2}{*}{\multicolumn{2}{|c|}{$97.60-97.50 \mathrm{~m}$}} \\
\hline & 2 & & & \\
\hline Stratigraphic Context & Upper 2Bk horizon & \multirow{4}{*}{$\begin{array}{l}\text { Associated Diagnostics } \\
\text { (Lot No. and elevation) }\end{array}$} & Gower (840.1) & $97.60-97.50 \mathrm{~m}$ \\
\hline Area & A-SW & & Andice (841) & $97.56 \mathrm{~m}$ \\
\hline \multirow{2}{*}{ Provenience } & \multirow{2}{*}{$\begin{array}{l}\text { N1019 E1044 (NW); } \\
\text { N1021 E1044 (SW) }\end{array}$} & & Martindale (867) & $97.58 \mathrm{~m}$ \\
\hline & & & Early Triangular (868) & $97.56 \mathrm{~m}$ \\
\hline Center & N1020.92 E1044.50 & \multirow{8}{*}{$\begin{array}{l}\text { Diagnostics above and } \\
\text { adjacent to feature (Lot No.) } \\
\text { proximity radius }=2.0 \mathrm{~m} \\
\text { proximity elevation }=0.1 \mathrm{~m}\end{array}$} & Early Triangular (860) & $97.75 \mathrm{~m}$ \\
\hline Top Elevation & $97.61 \mathrm{~m}$ & & Martindale (862) & $97.60 \mathrm{~m}$ \\
\hline Bottom Elevation & $97.51 \mathrm{~m}$ & & Lange (863) & $97.63 \mathrm{~m}$ \\
\hline Size & $65 \times 35 \mathrm{~cm}$ & & Martindale (864) & $97.60 \mathrm{~m}$ \\
\hline Shape & Roughly circular, flat & & Early Triangular (994) & $97.65 \mathrm{~m}$ \\
\hline Fuel Type & Live oak & & Early Triangular (996) & $97.72 \mathrm{~m}$ \\
\hline Lipids & Large herbivore (possibly with plant) & & Early Triangular (997) & $97.65 \mathrm{~m}$ \\
\hline \multirow[t]{2}{*}{ Faunal Evidence } & \multirow{2}{*}{$\begin{array}{l}\text { Bison/deer, white-tailed deer, small mammal, } \\
\text { unidentifiable bone fragments; mussel shell } \\
\text { in same level }\end{array}$} & & Martindale (998) & $97.67 \mathrm{~m}$ \\
\hline & & \multirow{3}{*}{$\begin{array}{l}\text { Diagnostics below and } \\
\text { adjacent to feature (Lot No.) } \\
\text { proximity radius }=2.0 \mathrm{~m} \\
\text { proximity elevation }=0.1 \mathrm{~m}\end{array}$} & \multirow{3}{*}{ Clear Fork Tool (871) } & \multirow{3}{*}{$94.40 \mathrm{~m}$} \\
\hline Pollen & Exploitable: umbel family and mallow family & & & \\
\hline Flotation Results & Hackberry, cedar elm, hickory/walnut family & & & \\
\hline
\end{tabular}

\section{Description}

Feature 33 was a dense cluster of chert debitage, bone fragments, charcoal flecks, and a few pieces of burned rock found beneath a large tabular block of chert. The feature was found within the $2 \mathrm{Bk}$ horizon and oriented in a northeast-southwest direction, measuring roughly $65 \mathrm{x}$ $35 \mathrm{~cm}$. The feature was approximately $10 \mathrm{~cm}$ thick and relatively flat, with no significant layering of burned rock observed in the feature's cross section.

No difference was observed between the internal feature matrix and the surrounding soil color. However, charcoal flecks and bone fragments were observed throughout the

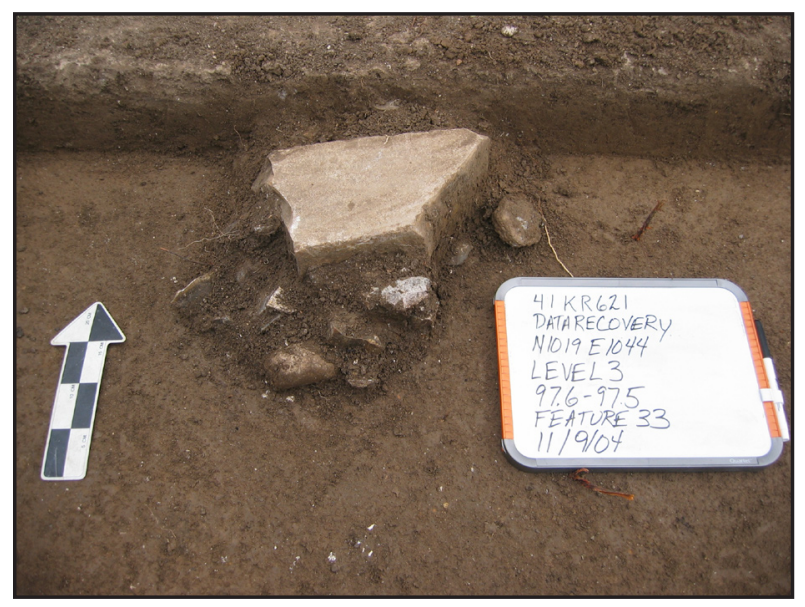

Overview of Feature 33. feature matrix. The 15 burned rocks found within Feature 33 were limestone, with a combined weight of $3.2 \mathrm{~kg}$. The rocks were mostly angular and a mixture of unfractured specimens, rocks fractured in situ, and intact specimens. Most of the rocks were adjoining one another.

A total 187 pieces of chert debitage and 180 bone fragments were collected from within the Feature 33 matrix. These included many large flakes and fragments of chert debitage. A conjoin analysis has revealed that many of these belonged to the same original cobble, although several missing pieces precluded a complete reconstruction. The diagnostic artifacts found within a rough 1 -m radius of the feature's edges and within the estimated $10-\mathrm{cm}$ floor level include an Early Triangular point, an Andice point, a Gower point, and a Martindale point. 


\begin{tabular}{|c|c|c|c|c|}
\hline & & Flotation Results & \multicolumn{2}{|l|}{ Cedar elm } \\
\hline & & \multirow{5}{*}{ Radiocarbon Dates } & \multirow{5}{*}{\multicolumn{2}{|c|}{$\begin{array}{l}\text { Beta- } 206128: 4990 \pm 50 \text { в.P., } 5890-5610 \text { cal } \\
\text { B.P. within concentration C at } 97.50 \mathrm{~m} \text {; Beta- } \\
207385: 4970 \pm 40 \text { B.P., } 5860-5830 \text { AND } \\
5750-5610 \text { cal B.P. within feature at } 97.52 \mathrm{~m} \text {; } \\
\text { Beta- } 207386: 4090 \pm 40 \text { B.P., } 4810-4750 \\
\text { AND } 4710-4500 \text { AND } 4480-4440 \text { cal в.P. } \\
\text { within feature at } 97.50 \text {; Beta- } 206125: 5320 \pm \\
40 \text { в.P., } 6200-5990 \text { cal B.P. within feature at } \\
97.49 \mathrm{~m}\end{array}$}} \\
\hline Feature Type & $\begin{array}{l}\text { Three small burned rock clusters (internal con- } \\
\text { centrations } A-C \text { ) with an associated scatter }\end{array}$ & & & \\
\hline Occupation Zone & 2 & & & \\
\hline Stratigraphic Context & Base of $2 A B k$ horizon & & & \\
\hline Area & A-SW & & & \\
\hline Provenience & N1019 E1046-1048 & $\begin{array}{l}\text { Associated floor } \\
\text { elevation range }(\mathrm{m})\end{array}$ & \multicolumn{2}{|l|}{$97.60-97.50 \mathrm{~m}$} \\
\hline \multirow{2}{*}{ Center } & \multirow{2}{*}{$\begin{array}{l}\text { A: N1019.98 E1048.96 } \\
\text { B: N1019.40 E1048.20 } \\
\text { C: N1020.20 E1049.45 }\end{array}$} & \multirow{2}{*}{$\begin{array}{l}\text { Associated Diagnostics } \\
\text { (Lot No. and elevation) }\end{array}$} & Martindale (885) & $97.57 \mathrm{~m}$ \\
\hline & & & Gower (1557) & $97.56 \mathrm{~m}$ \\
\hline Top Elevation & A: $97.55 \mathrm{~m} ; \mathrm{B}: 97.60 \mathrm{~m} ; \mathrm{C}: 97.61 \mathrm{~m}$ & \multirow{9}{*}{$\begin{array}{l}\text { Diagnostics above and } \\
\text { adjacent to feature } \\
\text { (Lot No.) } \\
\text { proximity radius }=2.0 \mathrm{~m} \\
\text { proximity elevation }= \\
0.1 \mathrm{~m}\end{array}$} & Gower (889.1) & $97.60-97.50 \mathrm{~m}$ \\
\hline Bottom Elevation & A: $97.47 \mathrm{~m} ; \mathrm{B}: 97.47 \mathrm{~m} ; \mathrm{C}: 97.48 \mathrm{~m}$ & & Untyped (942) & $97.52 \mathrm{~m}$ \\
\hline \multirow{2}{*}{ Size } & \multirow{2}{*}{$\begin{array}{l}\text { A: } 70 \times 50 \mathrm{~cm} ; \text { B: } 80 \times 50 \mathrm{~cm} ; C: 60 \times 30 \mathrm{~cm} ; \\
\text { Associated scatter: } 240 \times 180 \mathrm{~cm}\end{array}$} & & Early Triangular (943) & $97.5 \mathrm{~m}$ \\
\hline & & & Gower (944) & $97.7 \mathrm{~m}$ \\
\hline Shape & $\begin{array}{l}\text { Three oval concentrations }(A-C) \text { with an associ- } \\
\text { ated amorphous scatter; relatively flat }\end{array}$ & & Early Triangular (955) & $97.68 \mathrm{~m}$ \\
\hline Fuel Type & Live oak & & Bell $(1000$ & $97.63 \mathrm{~m}$ \\
\hline \multirow[b]{2}{*}{ Lipids } & \multirow{2}{*}{$\begin{array}{l}\text { Borderline medium and moderate-high fat } \\
\text { content food }\end{array}$} & & Gower (1550) & $97.57 \mathrm{~m}$ \\
\hline & & & Nolan (1553 & $97.63 \mathrm{~m}$ \\
\hline \multirow[b]{2}{*}{ Faunal Evidence } & \multirow{2}{*}{$\begin{array}{l}\text { Feature in general: bison, white-tailed deer, } \\
\text { small mammal, unidentifiable bone fragments; } \\
\text { B: white-tailed deer, large mammal, and un- } \\
\text { identifiable bone fragments; C: large mammal } \\
\text { bones }\end{array}$} & & Early Triangular (1554) & $97.68 \mathrm{~m}$ \\
\hline & & \multirow{2}{*}{$\begin{array}{l}\text { Diagnostics below and } \\
\text { adjacent to feature (Lot } \\
\text { No.) proximity radius = } \\
2.0 \mathrm{~m} \text { proximity elevation } \\
=0.1 \mathrm{~m}\end{array}$} & \multirow[t]{2}{*}{ Martindale (880) } & \multirow[t]{2}{*}{$97.45 \mathrm{~m}$} \\
\hline Pollen & Pinus & & & \\
\hline
\end{tabular}

\section{Description}

Feature 34 was a poorly defined amorphous cluster of burned rock with three internal concentrations (Concentrations $A, B$, and C). The feature designation was bestowed on this deposit because significant concentrations of burned rock, charcoal, and faunal material were found within the unit.

The feature was a widely dispersed collection of burned rock that extended across two units near the base of the 2ABk soil horizon. The maximum surface area covered by the feature was $180 \mathrm{~cm}$ (north-south) x $240 \mathrm{~cm}$ (east-west). The three areas of concentrated burned rock within this area were resting flatly at roughly the same surface elevation.

The dimensions of Concentration $A$ were approximately $70 \times 50 \mathrm{~cm}$, (east-west) and $8 \mathrm{~cm}$ thick. Concentration B measured approximately $80 \times 50 \mathrm{~cm}$, (east-west) and 13 $\mathrm{cm}$ thick. The final cluster, Concentration $\mathrm{C}$, had horizontal dimensions of approximately $60 \times 30 \mathrm{~cm}$, (east-west) and was $13 \mathrm{~cm}$ thick.

Except within the three defined concentrations, most of the Feature 34 burned rock was widely dispersed. In contrast, the concentrations were tightly clumped together and roughly oval in shape. All of the burned rock concentrations were relatively flat in profile and no soil discoloration was apparent between the internal feature matrix and surrounding soil strata.

A total of 238 burned rock specimens was recovered from the Feature 34 area, which weighed $40.7 \mathrm{~kg}$. All of the burned rocks were limestone and most were angular in shape.

Feature 34 had better organic preservation than was typically found elsewhere at the Gatlin site. Several large and burned faunal bone fragments were included among the 278 pieces of bone found within the feature. While most were unidentifiable, some fragments belonging to bison and white-tailed deer were noted. Charcoal fragments were abundant throughout the feature. Dart points found within $1 \mathrm{~m}$ of the feature's extent included one Martindale point and a Gower point.

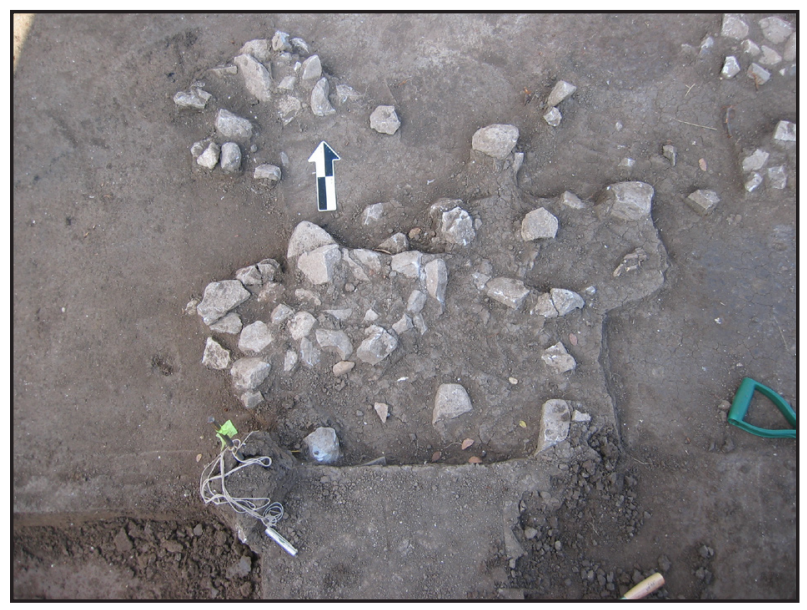

Overview of Feature 34. 


\begin{tabular}{|c|c|c|c|c|}
\hline & & Flotation Results & \multicolumn{2}{|l|}{ Grass family } \\
\hline & & Radiocarbon Dates & \multicolumn{2}{|l|}{ None } \\
\hline & & \multirow{2}{*}{$\begin{array}{l}\text { Associated floor } \\
\text { elevation range }(\mathrm{m})\end{array}$} & \multirow{2}{*}{\multicolumn{2}{|c|}{$97.60-97.50 \mathrm{~m}$}} \\
\hline Feature Type & Small burned rock cluster & & & \\
\hline Occupation Zone & 2 & \multirow{2}{*}{$\begin{array}{l}\text { Associated Diagnostics } \\
\text { (Lot No. and elevation) }\end{array}$} & \multicolumn{2}{|l|}{ None } \\
\hline Stratigraphic Context & Within 2ABk horizon & & \multirow[b]{2}{*}{ Early Triangular (897.1) } & \multirow{2}{*}{$\begin{array}{l}97.60- \\
97.50 \mathrm{~m}\end{array}$} \\
\hline Area & A-SW & \multirow{9}{*}{$\begin{array}{l}\text { Diagnostics above and } \\
\text { adjacent to feature (Lot No.) } \\
\text { proximity radius }=2.0 \mathrm{~m} \\
\text { proximity elevation }=0.4 \mathrm{~m}\end{array}$} & & \\
\hline Provenience & N1017 E1052 & & Early Triangular (898) & $97.69 \mathrm{~m}$ \\
\hline Center & N1017.18 E1052.46 & & Nolan (906) & $97.66 \mathrm{~m}$ \\
\hline Top Elevation & $97.55 \mathrm{~m}$ & & Baker (909) & $97.45 \mathrm{~m}$ \\
\hline Bottom Elevation & $97.43 \mathrm{~m}$ & & La Jita (959) & $97.83 \mathrm{~m}$ \\
\hline Size & $95 \times 63 \mathrm{~cm}$ & & Nolan (958) & $97.8 \mathrm{~m} ;$ \\
\hline Shape & Roughly circular, basin-shaped & & Martindale (962) & $97.53 \mathrm{~m}$ \\
\hline Fuel Type & Plateau live oak & & Early Triangular (966) & $97.89 \mathrm{~m}$ \\
\hline Lipids & N/A & & Early Triangular (967) & $98.78 \mathrm{~m}$ \\
\hline Faunal Evidence & $\begin{array}{l}\text { White-tailed deer, unidentifiable bone } \\
\text { fragments in same level }\end{array}$ & \multirow{2}{*}{$\begin{array}{l}\text { Diagnostics below and } \\
\text { adjacent to feature (Lot No.) } \\
\text { proximity radius }=2.0 \mathrm{~m} \\
\text { proximity elevation }=0.1 \mathrm{~m}\end{array}$} & \multirow{2}{*}{\multicolumn{2}{|c|}{ None }} \\
\hline Pollen & $\begin{array}{l}\text { Alnus. Exploitable: mustard family and } \\
\text { mallow family }\end{array}$ & & & \\
\hline
\end{tabular}

\section{Description}

Feature 35 was a compact cluster of mostly large pieces of burned rock found within the 2Abk horizon. The feature appeared roughly ovate in plan view and measured $95 \mathrm{x}$ $63 \mathrm{~cm}$, (east-west). In cross section, the feature was revealed to be $12 \mathrm{~cm}$ thick and basin-shaped. No noticeable difference was observed between internal feature matrix and surrounding soil.

All of the burned rock within Feature 35 was limestone. A total of 52 burned rocks, weighing $8.2 \mathrm{~kg}$, constituted the coarse matrix. The shape of the burned rocks was mostly representative of rounded specimens with angular fractures. Most of the burned rocks recovered within this feature touched and overlapped.

Feature 35 was immediately south of Feature 13, and its uppermost elevation was approximately $5 \mathrm{~cm}$ higher than the lowest point of Feature 13. While most of Feature 13 was observed at a higher elevation, it appears to have been relatively flat and resting directly on the ancient ground surface. Feature 35, in contrast, was basin-shaped and thus excavated into the surface below. A few of the burned rocks recorded as part of Feature 13 directly overlie Feature 35; however, these appear to be relative outliers in comparison to the main cluster of Feature 13 and may originally have been part of Feature 35. As such, it is possible that Features 13 and 35 were contemporary.
Only three pieces of debitage were recovered from within the feature matrix, and no charcoal or bone was observed or collected from the feature. No other evidence of in situ burning was present. No diagnostic projectile points were recovered within a $1-\mathrm{m}$ radius of the feature within the feature's $10-\mathrm{cm}$ level.

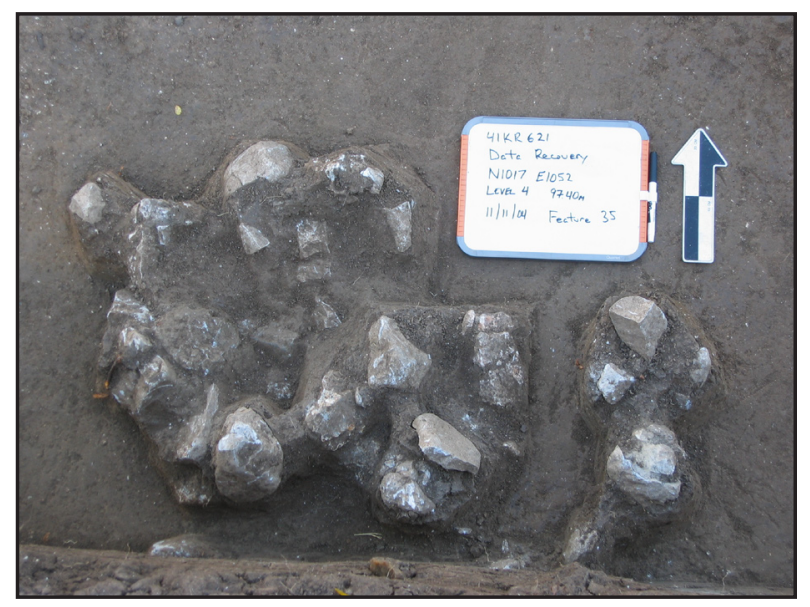

Overview of Feature 35. 


\section{Feature Summary}

Overall, the feature assemblage in OZ2 is dominated by small (1-m diameter or less) circular to oval clusters of burned limestone rock. However, there are several larger scatters/clusters in the zone (e.g., Features 5,13 and 26) that may be earth ovens, feature types not seen in OZ1. Feature 22 exhibited a rather distinct form involving a ring-like shape, devoid of burned rocks in the center, with a loose scatter or tail of burned rock extending out in a mostly straight line from the cluster, most likely the remains of an upper layer or lid. Most of the cross sections of the features within OZ2 were flat or relatively flat with thicknesses ranging from $10-25 \mathrm{~cm}$. The exception to this was Feature 25, a rather large elongated burned rock cluster, covering a 12 -cm-thick, $450 \mathrm{x}$ 80-cm area.

Burned rock counts ranged greatly, from 10-50 rocks in the smaller features to almost 400 rocks in the largest (Table 9.7). Burned rock sizes among OZ2 features ranged from 5 to $>15 \mathrm{~cm}$ with the highest percentage of rocks within the $5-10 \mathrm{~cm}$ range. Of note, Features 25 and 26 contained some of the largest burned rocks, many in the $>15 \mathrm{~cm}$ range. Most features exhibited a range of fractured, partially fractured, and unfractured rock. Most of the features within OZ2 exhibited some slight observed distinguishable differences between the feature matrix and surrounding soils. Evidence of such, including discolored soils, charcoal, and in situ burning, was encountered in several features.

Special samples were recovered from many features in OZ2, providing radiocarbon, fuel, macrobotanical, pollen/phytolith, faunal, and lipid residue data. Most of the features within OZ2 contained carbonized wood samples with most fuel types identified as plateau live oak or live oak $(n=7)$, followed by indeterminable wood or hardwood $(n=4)$, and indeterminable fuel type $(n=3)$. Root starches from umbel, legumes, or grass seed were recovered within Feature 5. Lipid residue studies were conducted on six of the features within OZ2 with the usual inconclusive results, including a variety of fatty acid compositions of animal and plant remains.

In conclusion, the feature assemblage from $\mathrm{OZ2}$ is a mix of both small-,and medium- to large-sized burned rock accumulations. Small circular hearths predominate, however, and may have been utilized for heating (hearths) or to prepare small quantities of food through grilling. The preparation of larger portions of food is reflected by several features that are likely earth ovens, feature types not seen in the previous OZ1. The unusual arrangement of Features 25 and 26 is also intriguing and may represent recycling of older features, scavenging, or other functional scenarios. Feature 33 indicates the nature of select core reduction being performed on the site and also suggests some level of spatial integrity in the occupation zone. As a whole, however, the burned rock features reflect the nature of the small groups who briefly occupied the Gatlin site.

\section{Spatial Distribution in OcCupation ZONE 2}

This section considers the vertical and horizontal arrangement of artifact classes and features in OZ2, spanning up to 800 years in the Early Archaic. The excavation areas with significant OZ2 deposits are ASW and A-NE. The sampling grid used at the Gatlin site varied from $2-\mathrm{m}$ grid squares to $1-\mathrm{m}$, though, when possible, provenience data was correlated to the 1-m grid. The data examined in the analysis were features, projectile points, bifaces, flake tools, cores, and debitage.

\section{FEATURES}

Within OZ2, 12 of the 14 features were in Areas A$\mathrm{NE}(\mathrm{n}=7)$ (Figure 9.3) and A-SW (n=5) (Figure 9.4). One feature was observed in Area B and another in Area A-NW BHT 4 (Figure 9.5). A nearest-neighbor analysis was performed for Areas A-NE and A-SW, measured from the centroid of each feature. Feature 5 was in BHT 3 and was not included in the nearest-neighbor analysis since it was an isolated unit. The use of feature-focused and traditional units does not affect the nearest-neighbor calculations as it would for other types of piece-plotted data. The nearest-neighbor analysis gives an average distance between adjacent features and can be used to assess the relative density of features within an occupation and estimate the number of features still unexposed. This analysis can also be used to estimate the number of sample units necessary to detect a representative number of features (Shennan 1997:388). 


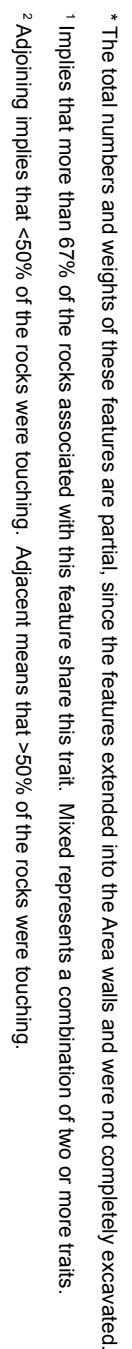

\begin{tabular}{|c|c|c|c|c|c|c|c|c|c|c|c|c|c|c|c|c|c|c|c|}
\hline$\underset{\omega}{\omega}$ & \multicolumn{4}{|c|}{$\Psi$} & $\omega_{\omega}^{\infty}$ & $\underset{*}{\stackrel{\omega}{*}}$ & $\approx$ & \multicolumn{2}{|c|}{$\widetilde{\Im}$} & $\tilde{N}$ & \multicolumn{2}{|r|}{ N } & $\stackrel{\sim}{*}$ & $\vec{\omega}$ & \multicolumn{2}{|c|}{$\vec{v} \mid$ or } & $\approx$ & \multicolumn{2}{|l|}{ 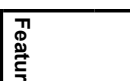 } \\
\hline 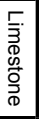 & 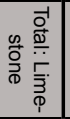 & 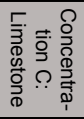 & 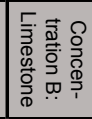 & 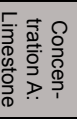 & 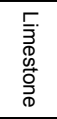 & 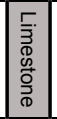 & 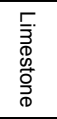 & 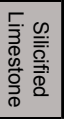 & 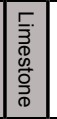 & 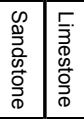 & \begin{tabular}{|l|} 
\\
$\overline{3}$ \\
0 \\
0 \\
0 \\
0 \\
0 \\
\end{tabular} & 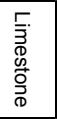 & 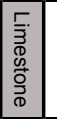 & 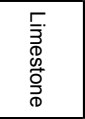 & 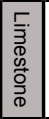 & 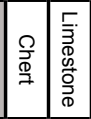 & 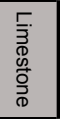 & 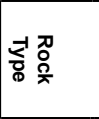 & \\
\hline$\tilde{\Xi}$ & & & $\infty$ & $\omega$ & $A$ & \begin{tabular}{|l|} 
\\
\end{tabular} & $\vec{\infty}$ & & जे & $\infty$ & ब & 电 & 0 & G & के & \begin{tabular}{|c|c|}
$\vec{A}$ \\
\end{tabular} & $\underline{\omega}$ & \# & \\
\hline$\stackrel{0}{\dot{\omega}}$ & & & i & $\stackrel{\circ}{-}$ & $\stackrel{\circ}{\dot{S}}$ & \begin{tabular}{|l|} 
\\
\end{tabular} & o & & $\stackrel{\rho}{i}$ & $\overrightarrow{\dot{\Delta}}$ & i & $\stackrel{N}{\omega}$ & \begin{tabular}{|l|l|} 
& \\
\end{tabular} & $\stackrel{\circ}{-}$ & \begin{tabular}{|l|} 
\\
\end{tabular} & \begin{tabular}{l|l}
$\dot{D}$ & + \\
\end{tabular} & $\begin{array}{l}0 \\
\infty \\
\infty\end{array}$ & $\bar{\Omega}$ & \\
\hline 思 & & & $\underset{\infty}{\vec{\perp}}$ & $\underset{\omega}{\tilde{\omega}}$ & $\stackrel{\widetilde{N}}{v}$ & $\left|\begin{array}{|c|}\vec{y} \\
0\end{array}\right|$ & $\underset{i}{\overrightarrow{0}}$ & & $|\overrightarrow{\vec{N}}|$ & $\stackrel{\vec{\sigma}}{v}$ & $\begin{array}{c}\vec{N} \\
0 \\
0\end{array}$ & 志 & $\mid \begin{array}{l}\tilde{O} \\
0 \\
0\end{array}$ & No & $\mid \begin{array}{l}0 \\
0 \\
\rightarrow\end{array}$ & 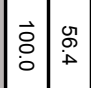 & $\begin{array}{l}\text { ST } \\
\stackrel{1}{+} \\
\end{array}$ & 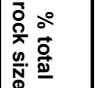 & \begin{tabular}{|l|}
$\hat{y}$ \\
$\hat{O}$ \\
$\underline{3}$
\end{tabular} \\
\hline $\begin{array}{l}\vec{\infty} \\
\infty\end{array}$ & & & $\vec{\sigma}$ & $\stackrel{\vec{\infty}}{+}$ & $\stackrel{\omega}{\rightarrow}$ & $\mid \overrightarrow{0}$ & ì & & ì & $\dot{i}$ & $\mid \begin{array}{l}\tilde{N} \\
\sigma \\
\sigma\end{array}$ & $\vec{\omega}$ & 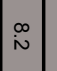 & $\stackrel{\dot{v}}{ }$ & $\stackrel{\sim}{\rightarrow}$ & \begin{tabular}{|l|l}
$\overrightarrow{0}$ & $\overrightarrow{\vec{\theta}}$ \\
0
\end{tabular} & $\overrightarrow{\vec{\Xi}}$ & 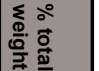 & \\
\hline$\vec{\omega}$ & & $\overrightarrow{\vec{\omega}}$ & $\underset{\sim}{\omega}$ & 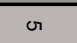 & $\overrightarrow{0}$ & $\approx$ & 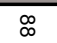 & $N$ & 8 & $\vec{\Phi}$ & $\infty$ & $\sigma$ & \begin{tabular}{|l|} 
के \\
\end{tabular} & $\vec{b}$ & $\tilde{G}$ & 2 & $\omega$ & $\#$ & \\
\hline $\overrightarrow{\dot{\infty}}$ & & $\begin{array}{l}N \\
\tilde{0}\end{array}$ & $\underline{\omega}$ & i & $\stackrel{N}{\omega}$ & \begin{tabular}{|l|}
\multicolumn{1}{|c|}{} \\
0
\end{tabular} & $\begin{array}{l}\overrightarrow{\vec{P}} \\
\stackrel{+}{A}\end{array}$ & $\vec{i}$ & \begin{tabular}{|l|} 
\\
$\infty$ \\
\end{tabular} & $\begin{array}{l}\omega \\
\stackrel{\omega}{\infty} \\
\end{array}$ & \begin{tabular}{|l|l|}
$N$ \\
\end{tabular} & $\stackrel{\vec{N}}{\vec{v}}$ & \begin{tabular}{|l|}
$\vec{N}$ \\
\\
\end{tabular} & $\begin{array}{l} \\
\omega \\
\infty \\
\infty\end{array}$ & \begin{tabular}{|l|}
$\circ$ \\
$\rightarrow$ \\
\end{tabular} & $\vec{\infty}$ & $\sigma$ & $\bar{\Omega}$ & \\
\hline $\begin{array}{c}\tilde{y} \\
0 \\
0\end{array}$ & & ने & $\begin{array}{l}0 \\
\text {. } \\
\omega\end{array}$ & $\begin{array}{l}\text { की } \\
\text { or }\end{array}$ & $\stackrel{g}{v}$ & $\left|\begin{array}{c}0 \\
0 \\
\hdashline\end{array}\right|$ & $\overrightarrow{\overrightarrow{0}}$ & $\overrightarrow{\dot{r}}$ & $\mid \begin{array}{l} \pm \\
\infty\end{array}$ & $\stackrel{\vec{g}}{v}$ & 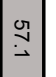 & $\underset{\substack{N \\
i}}{i}$ & $\mid \vec{\sigma}$ & $\stackrel{N}{N}$ & 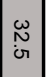 & $\left|\begin{array}{l}\omega \\
\omega \\
\sigma \\
\sigma\end{array}\right|$ & $\stackrel{ \pm}{ \pm}$ & 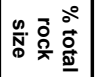 & $\begin{array}{l}1 \\
\overrightarrow{0} \\
0 \\
0\end{array}$ \\
\hline $\begin{array}{c}\tilde{0} \\
:\end{array}$ & & $\stackrel{P}{+}$ & $\stackrel{\vec{N}}{-}$ & 岕 & $\overrightarrow{\overrightarrow{0}}$ & \begin{tabular}{|c|} 
\\
0 \\
0 \\
0
\end{tabular} & : & $\vec{\circ}$ & $\vec{s}$ & $\begin{array}{l}N \\
N \\
\text { vin }\end{array}$ & $\begin{array}{l}7 \\
\therefore\end{array}$ & $\stackrel{0}{\circ}$ & $\overrightarrow{\vec{v}}$ & $\begin{array}{l}\text { ज. } \\
\text { D }\end{array}$ & $\begin{array}{l}0 \\
N \\
N\end{array}$ & \begin{tabular}{|l|}
$\vec{b}$ \\
\\
\end{tabular} & $\underset{\omega}{\infty}$ & 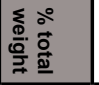 & \\
\hline 0 & & $A$ & $\vec{N}$ & $\omega$ & $\rightarrow$ & 0 & $\vec{f}$ & & 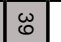 & 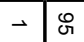 & & $N$ & o & की & $\checkmark$ & N & $\rightarrow$ & \# & \\
\hline $\begin{array}{c}\omega \\
0 \\
0\end{array}$ & & $\vec{\sigma}$ & $\stackrel{M}{N}$ & $\vec{\omega}$ & $\begin{array}{l}\circ \\
\infty\end{array}$ & $\overrightarrow{\mathrm{N}}$ & के & & \begin{tabular}{|l|}
\multirow{N}{*}{} \\
$\dot{v}$
\end{tabular} & \begin{tabular}{l|l} 
\\
\end{tabular} & & 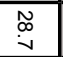 & \begin{tabular}{|c|}
$\overrightarrow{+}$ \\
$\infty$ \\
$\infty$
\end{tabular} & \begin{tabular}{l|}
$\vec{\infty}$ \\
$\infty$ \\
$\infty$
\end{tabular} & or & $\vec{\omega}$ & $\therefore$ & $\bar{\theta}$ & \\
\hline$\vec{\omega}$ & & $\begin{array}{c}\tilde{N} \\
\text { ir }\end{array}$ & $\underset{N}{N}$ & $\stackrel{N}{N}$ & $\dot{\infty}$ & $\mid \begin{array}{c}\tilde{N} \\
\dot{O} \\
\dot{\sigma}\end{array}$ & $\overrightarrow{\vec{\omega}}$ & & 苂 & \begin{tabular}{l|l}
$\stackrel{N}{\tilde{\omega}}$ & $\stackrel{\tilde{H}}{0}$
\end{tabular} & & $\overrightarrow{\stackrel{N}{\omega}}$ & $\mid \begin{array}{l}\vec{\circ} \\
\vec{\Phi}\end{array}$ & $\underset{\sim}{N}$ & $\stackrel{\circ}{-}$ & $\stackrel{0}{-}$ & $\overrightarrow{i r}$ & 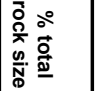 & $\mid \begin{array}{l}0 \\
i \\
\omega \\
a \\
a\end{array}$ \\
\hline 焉 & & $\begin{array}{l}\omega \\
\text { जu } \\
\sigma\end{array}$ & $\stackrel{\vec{\omega}}{\vec{\omega}}$ & $\stackrel{9}{\overrightarrow{0}}$ & $\begin{array}{l}\tilde{N} \\
\text { Ŏ }\end{array}$ & $\mid \begin{array}{c}\hat{N} \\
\dot{\oplus}\end{array}$ & 诵 & & \begin{tabular}{|l}
$\omega$ \\
+ \\
$\sigma$
\end{tabular} & $\underset{\omega}{\omega}$ & & $\begin{array}{c}\mathscr{\omega} \\
0\end{array}$ & $\mid \begin{array}{l}0 \\
0 \\
\omega\end{array}$ & $\stackrel{\substack{ \pm N}}{ }$ & $\underset{\sim}{\stackrel{N}{\sim}}$ & $\stackrel{\substack{\omega \\
\sim}}{\sim}$ & $\stackrel{\leftrightarrow}{\circ}$ & 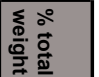 & \\
\hline$\rightarrow$ & & & N & & & & $A$ & & $\vec{A}$ & $\omega_{\infty}$ & & $\rightarrow$ & & $\rightarrow$ & & $N$ & & \# & \\
\hline $\begin{array}{c}\text { in } \\
\text { in }\end{array}$ & & & $\overrightarrow{0}$ & & & & $\stackrel{N}{\perp}$ & & \begin{tabular}{|l|} 
\\
0 \\
0
\end{tabular} & $\begin{array}{ll}J_{0} \\
\infty\end{array}$ & & $\overrightarrow{\vec{\perp}}$ & & 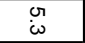 & & $\omega$ & & $\underline{a}$ & \\
\hline$\vec{\bullet}$ & & & $\stackrel{\omega}{v}$ & & & & $\underset{\sim}{N}$ & & $\overrightarrow{0}$ & $\stackrel{\circ}{\circ}$ & & $\therefore$ & & $\stackrel{N}{0}$ & & $\begin{array}{l}\circ \\
\circ\end{array}$ & & 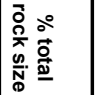 & $\begin{array}{l}v \\
v \\
v \\
g \\
g\end{array}$ \\
\hline$\stackrel{\infty}{-\infty}$ & & & $\overrightarrow{\mathrm{r}}$ & & & & $\vec{\circ}$ & & $\underset{\substack{0 \\
i}}{i}$ & 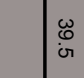 & & 嘼 & & $\stackrel{\circ}{\circ}$ & & $\infty$ & & 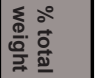 & \\
\hline$\stackrel{N}{N}$ & $\underset{\infty}{\tilde{\infty}}$ & $\vec{v}$ & \& & $\vec{\exists}$ & $\vec{v}$ & $f_{*}$ & $\overrightarrow{\tilde{N}}$ & * & 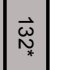 & $\rightarrow \mid$\begin{tabular}{l|l}
- & $\omega$ \\
$\&$
\end{tabular} & $\vec{A}$ & $\overrightarrow{\vec{b}}$ & $\underset{*}{\omega}$ & $\vec{\wp}$ & $\forall$ & 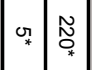 & $\oiint_{*}$ & 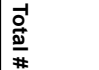 & \\
\hline$\stackrel{\infty}{\sim}$ & $\stackrel{\vec{D}}{v}$ & ir & $\vec{N}$ & $\stackrel{n}{-}$ & $\stackrel{\omega}{N}$ & $\stackrel{\bullet}{\rightarrow}$ & 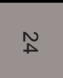 & $\vec{*}$ & 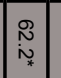 & \begin{tabular}{l|l}
\multirow{N}{*}{} & $\overrightarrow{\vec{H}}$ \\
\end{tabular} & $\stackrel{\omega}{\rightarrow}$ & $\stackrel{0}{ \pm}$ & $\mid \begin{array}{c}\tilde{0} \\
\rightarrow \\
*\end{array}$ & ખ & $\overrightarrow{\vec{v}}$ & 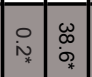 & $\underset{N}{N}$ & 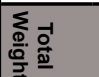 & \\
\hline 豙. & & & 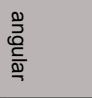 & & 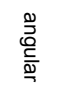 & \begin{tabular}{|l|} 
\\
$\frac{3}{3}$ \\
0 \\
0
\end{tabular} & 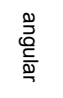 & 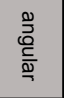 & 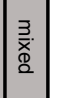 & 辛. & 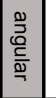 & $\begin{array}{l}\frac{3}{x} \\
\text { 竞 } \\
\end{array}$ & 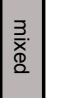 & 茎. & 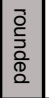 & 疍. & 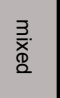 & 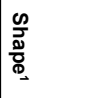 & \\
\hline 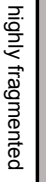 & & & 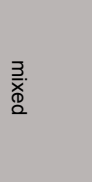 & & 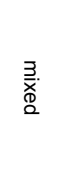 & 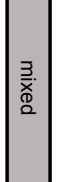 & 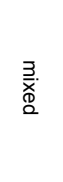 & 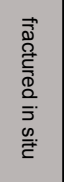 & 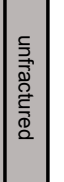 & 疍. & 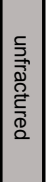 & 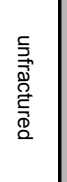 & 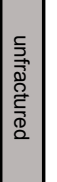 & 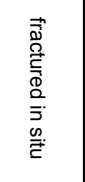 & \begin{tabular}{|l|} 
\\
3 \\
$x$ \\
0 \\
2
\end{tabular} & 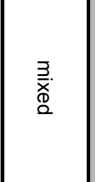 & 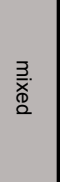 & 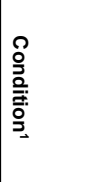 & \\
\hline 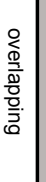 & & & 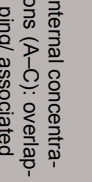 & & 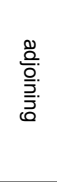 & 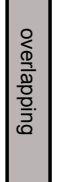 & 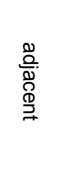 & $\begin{array}{l}\frac{0}{0} \\
\frac{0}{0.0} \\
\frac{\bar{z}}{0}\end{array}$ & 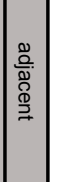 & 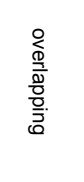 & 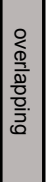 & 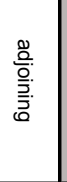 & 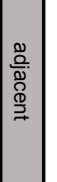 & 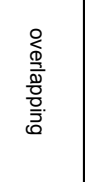 & 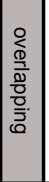 & 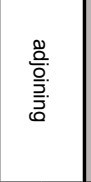 & $\begin{array}{l}\frac{0}{0} \\
\frac{0}{0 .} \\
\frac{\bar{z}}{0}\end{array}$ & 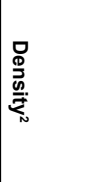 & \\
\hline 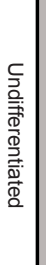 & & & 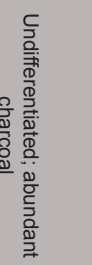 & & 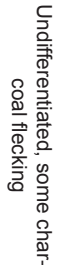 & 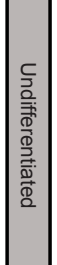 & 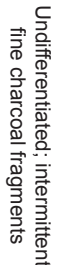 & 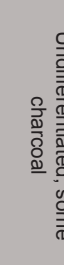 & & 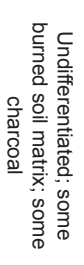 & 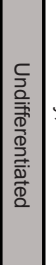 & 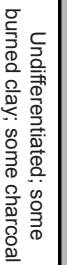 & 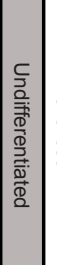 & 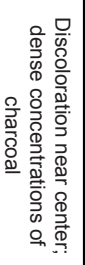 & 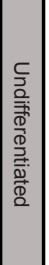 & 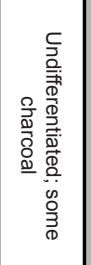 & 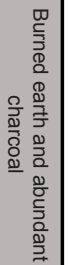 & 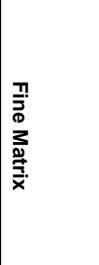 & \\
\hline
\end{tabular}

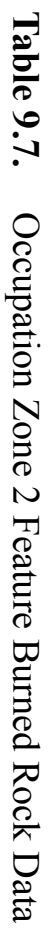




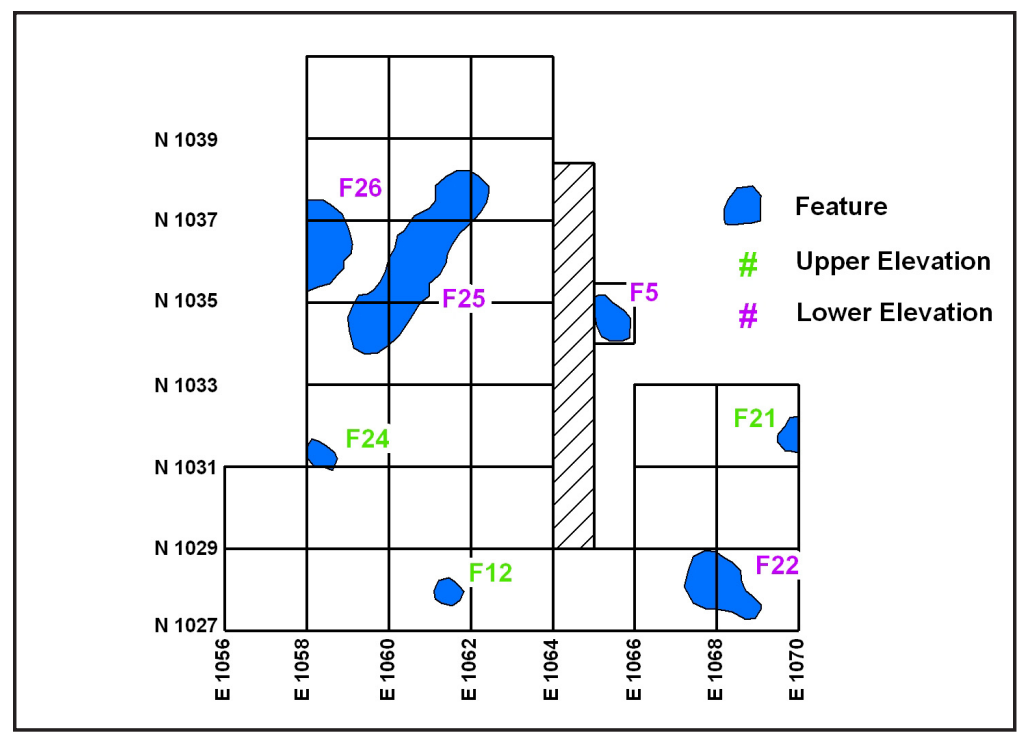

Figure 9.3. Occupation Zone 2 Area A-NE feature locations.

lower feature assemblage consists of Features 22, 25 and 26, and the upper assemblage of Features 12, 21 and 24 (see Figure 9.3). This division was made because of a distinctive change in the frequency of burned rock at these elevations, with $242 \mathrm{~kg}$ from the lower group and $55 \mathrm{~kg}$ from the upper group. In the lower group, most burned rock was in the northern half of Area A-NE, with the greatest accumulation associated with Feature 25. Because of the close proximity of Features 25 and 26 and similar base elevations, it was originally assumed that they were related (Appendix C Features); however, there is a significant difference in radiocarbon ages, with $1 \sigma$ conventional radiocarbon dates of $4550 \pm 40$ B.P. for Feature 25 and $6100 \pm 40$ B.P. for Feature

In Area NE, the mean center-to-center distance was $3.91 \pm 1.05 \mathrm{~m}$. Area A-NE encompassed almost $127 \mathrm{~m}^{2}$ of exposed excavations, and the features enclosed an area of approximately $101 \mathrm{~m}^{2}$. The nearest-neighbor coefficient was 1.47 , which suggests regular spacing of the features as opposed to clustering or true random distribution; however, the small sample size makes it more probable that the observed patterning is random. In Area A-SW, the nearest-neighbor distance is $1.74 \pm 1.15 \mathrm{~m}$, and the features encompassed an area $29.8 \mathrm{~m}^{2}$ within the $44 \mathrm{~m}^{2}$ exposed. The nearest-neighbor coefficient was 1.26 , which, like the features in A-NE, is an expected value for a regular spaced distribution, but again because of the sample size, it is more likely random. Within the excavated areas, the density of features was greater in Area A-SW with neighboring features less than half the distance apart than in Area A-NE. This suggests that activity in Area A-SW was more concentrated.

In Area A-NE the six features located on the excavation grid (i.e., excluding Feature 5 from testing) were divided by elevation into two groups; a lower group from 96.95-97.10 $\mathrm{m}$ and an upper group from $97.11-97.30 \mathrm{~m}$. The

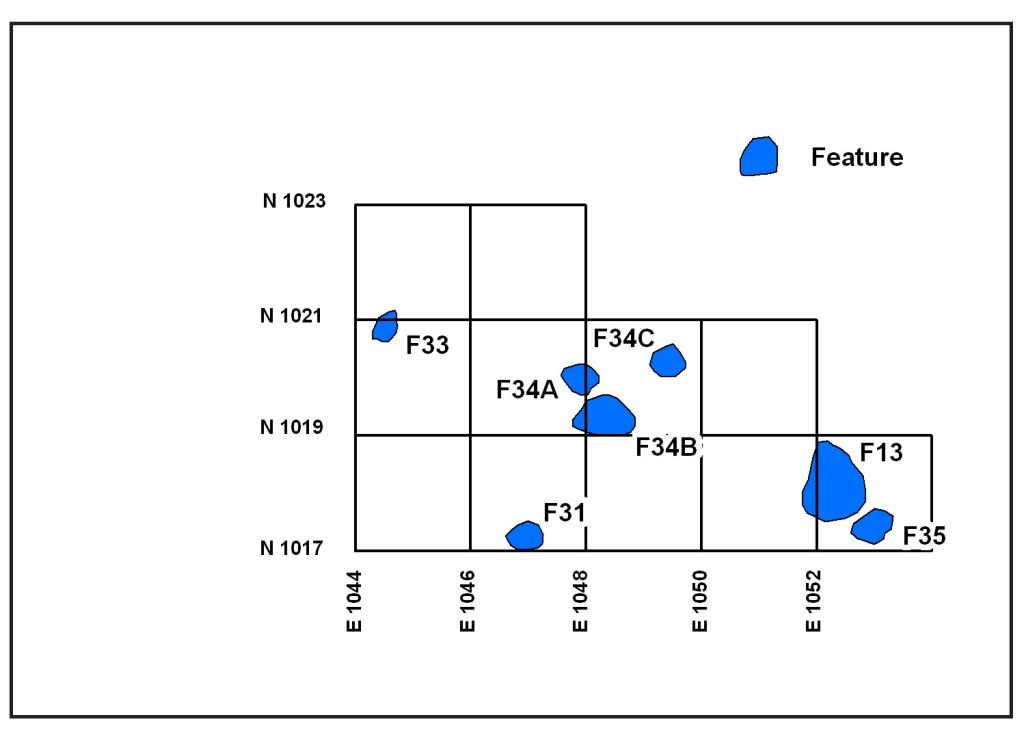

Figure 9.4. Occupation Zone 2 Area A-SW feature locations.
26. The clear void between the two features appears to be deliberately cleared, considering the diffuse burned scatter elsewhere in the level and around the features. The size of both features is similar to burned rock ovens, but the cleared area between them suggests that neither feature was a cap or lid for the other. An unconsolidated debris scatter at the north end of Feature 25 is more likely to be the lid debris of an earth oven. Based upon the radiocarbon dates from each of the features, Features 25 and 26 appear 


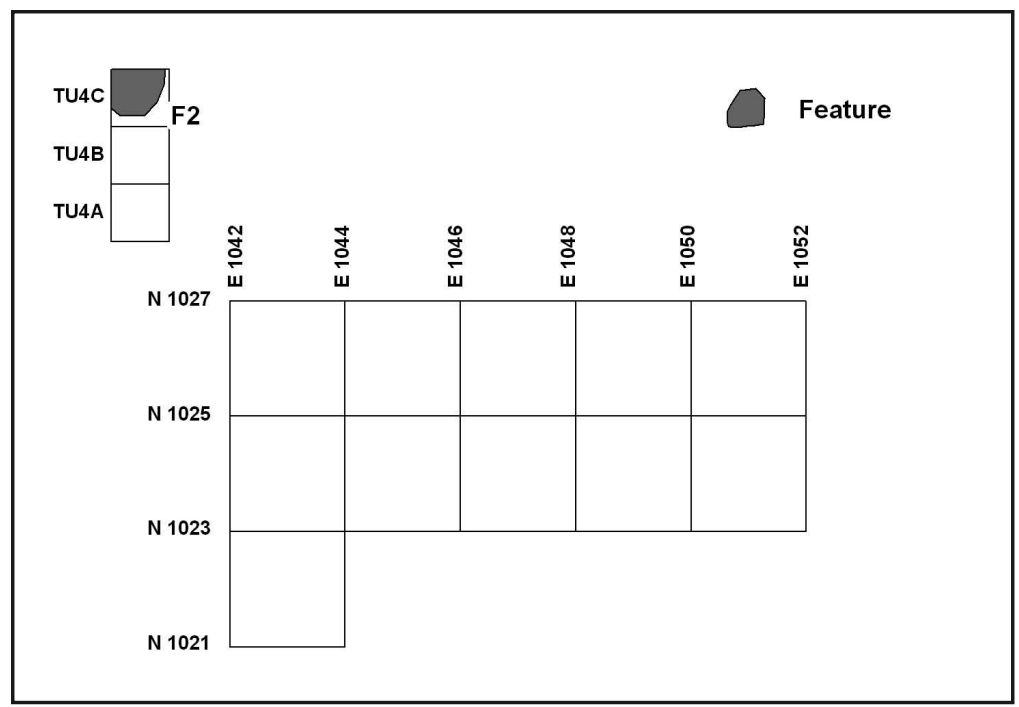

Figure 9.5. Occupation Zone 2 Area A-NW feature locations.

to be unrelated, though their close horizontal and vertical proximity argue against this. The differences in radiocarbon age suggest some level of mixing.

Feature 5 would be classified with the lower level Features 22, 25, and 26. Feature 5 is also an earth oven-like feature. The three lower features are in contrast to the upper three, Features 12, 21 and 24. These three features are less than $1 \mathrm{~m}$ in diameter and represent smaller cooking or heating elements rather than the larger earth oven like features in the lower group. These features are widely spaced apart in A-NE and correspond to elevations of decreasing burned rock frequency.

Area A-SW had a denser clustering of features than Area A-NE, both horizontally and vertically (see Figure 9.4). The features assigned to OZ2 from Area A-SW include Features 13, 31, 33, and 34. Features 13 and 35 have outlier burned rock that is commingled. Feature 35, the smaller more compact of the two, may have been constructed from Feature 13 rocks, given the similar size of the rock used and similar mixing of burned and unburned rock.

Feature 33, a mixture of lithic debris, burned rock, charcoal, and animal bone fragments, contained a partially reconstructed core, some of which was recovered from adjoining Unit N1021 E1044. The reconstructed core is mostly refitted blocky fragments of debitage recovered from a roughly $2-\mathrm{m}$ circle at a similar elevation. That the core could be partially reassembled from debitage in a localized area suggests it was reduced in a single episode. The core was recognized after the excavation, and, therefore, few of the refits were piece plotted, and only general comments can be made about the refit provenience to the nearest meter square of a $2 \times 2-m$ square. At least two additional cores were identified in the artifacts from Feature 33. Overall, vertical displacement appears to be minimal, with the core and refit flakes defining an occupation surface. Projectile points within a 3-m proximity to Feature 33 were a Gower point, a Martindale point, an Early Triangular point, and an Andice point. These types span approximately 1,500 years of use, but there are two radiocarbon dates from the feature, from ca. 5,600-5,400 B.P. Other sites with dates for Martindale points include the amino acid racemization dates from Cibolo Crossing of 5,953 and 6,290 в.P.; however, these are calendrical dates, and comparable corrected radiocarbon dates would be ca. 5,500-5,200 в.P. (Kibler and Scott 2000). Within Collins' (2004:Figure 3.9a) framework, Martindale are in use from ca. 7,000-6,000 B.P., while Johnson and Goode (1994:25) extend the use from ca. $4,900-4,500$ в.P.

\section{Projectile Points}

The distribution of the major projectile point styles was examined to see if there are meaningful patterns (Figures 9.6 and 9.7). Using point-plotted proveniences, projectile points were projected against OZ2 features. Three main groups or styles were analyzed together: Gower, Martindale, and Early Triangular. What is apparent is that all groups are distributed randomly across the site, as when two areas of point concentrations (Gower and Martindale) were examined in area A-NE (see Figure 9.6). Contained within 2-4-m diameter areas in what initially appear to be discrete clusters (in plan view), the point styles are evidently commingled along the natural slope of the OZ2 topography (as seen in profile). Select points were recovered in spatial association with certain features identified in OZ2, for instance Feature 25 contained a Martindale and Bandy point 


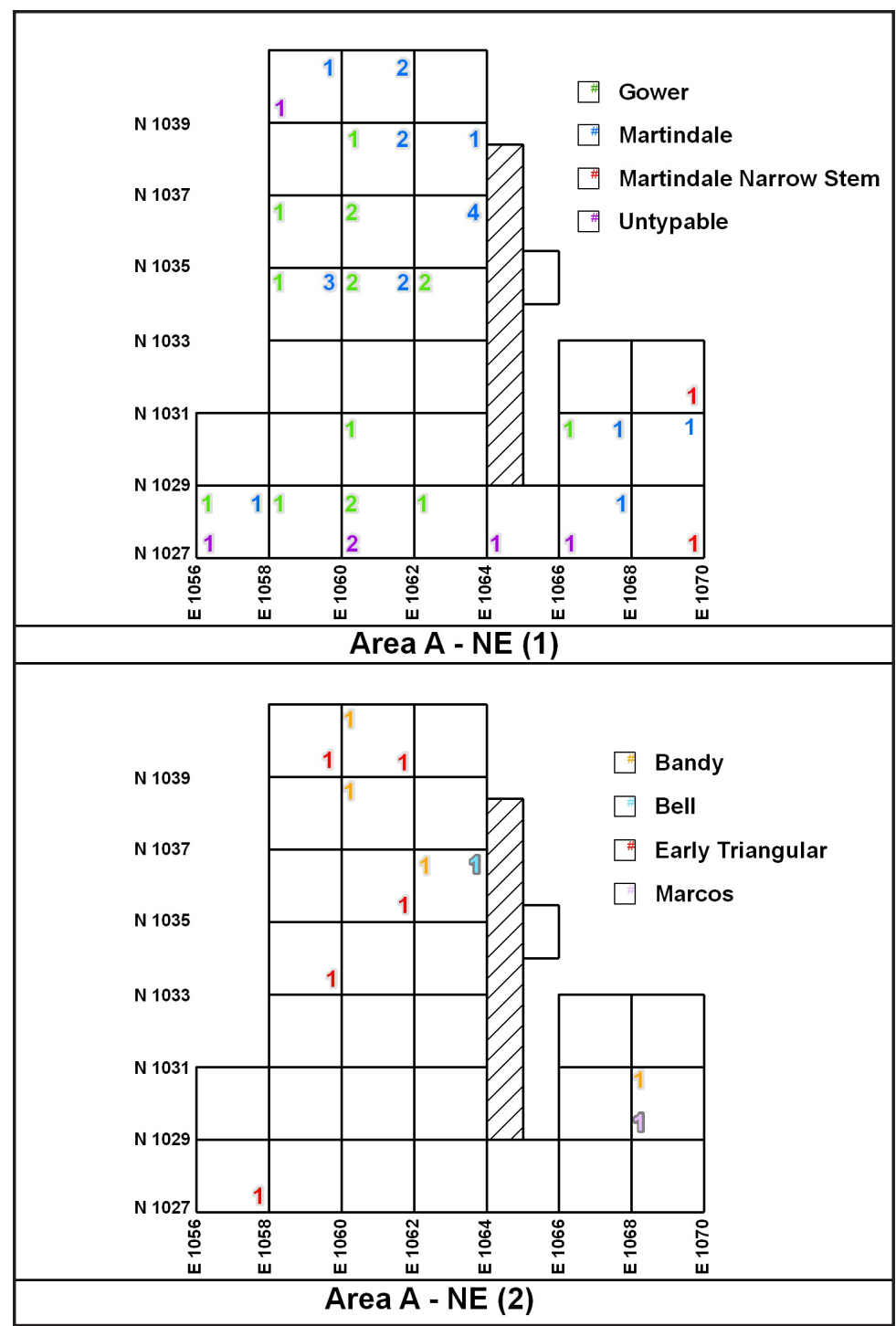

Figure 9.6. Occupation Zone 2 Area A-NE projectile point distribution.

within its matrix. However, overall, there appears to be no significant spatial patterning of the projectile points in OZ2.

\section{BIFACIAL TOOLS}

Bifacial tools were also examined in relationship to each other and to the features. The three bifacial tools from Area A-NE were a butted biface, a drill, and a Clear Fork tool. There is no discernible association between the tools and the features. A single Clear Fork tool was recovered from Area A-SW, approximately $3 \mathrm{~m}$ from the nearest feature.

\section{BIFACES}

Bifaces were the most common formal tool in Areas A-NE and A-SW. The density of bifaces was greater in Area A-SW, with late-stage bifaces, the predominant biface in both areas. The distribution of all bifaces, including tools for Areas A-NE and A-SW are displayed in Figures 9.8 and 9.9. Although the density of bifaces was almost twice as great in Area A-SW, the composition, distribution, and proportion between early and late-stage bifaces was similar to Area A-NE. In Area A-NE, 18 Stage 5 bifaces were found within a $2-$ $\mathrm{m}$ boundary around Features 24,25 , and 26. In Area A-SW, Stage 5 bifaces were concentrated in the lower half of the area. In Unit N1017 E1052 there were four bifaces within $1 \mathrm{~m}$ of Features 13 and 35. Six Stage 5 bifaces were located in N1017 E1044, a unit that included one late-stage 4 biface and a Clear Fork tool.

\section{FLAKE TOOLS}

Flake tool distributions for informal flake tools and formal flake tools are shown in Figures 9.10 and 9.11. The highest concentration of flake tools in OZ2 occurs in Area A-NE in N1033 E1060, where eight informal and two formal tools were recovered. Five of these specimens were within the base elevation of Features 25 and 26. Flake tools were preferentially made from hard hammer core reduction flakes, and in area A-NE, core reduction flake debitage was on average $37 \pm 14 \mathrm{~mm}$ in length. The mean length of a complete flake was approximately $60 \mathrm{~mm}$.

In Area A-SW, there was a higher overall density of formal flake tools then Area A-NE. In N1021 E1046 two of the scrapers were made from sequence flakes from similar material and possibly the same core. Of the six tools in OZ2 made on sequence flakes, four were in Area A-SW. The mean length of a flake tool in Area A-SW was $68.18 \mathrm{~mm}$, while the average core flake was $49.2 \pm 20 \mathrm{~mm}$. In Area A-SW, both flake 


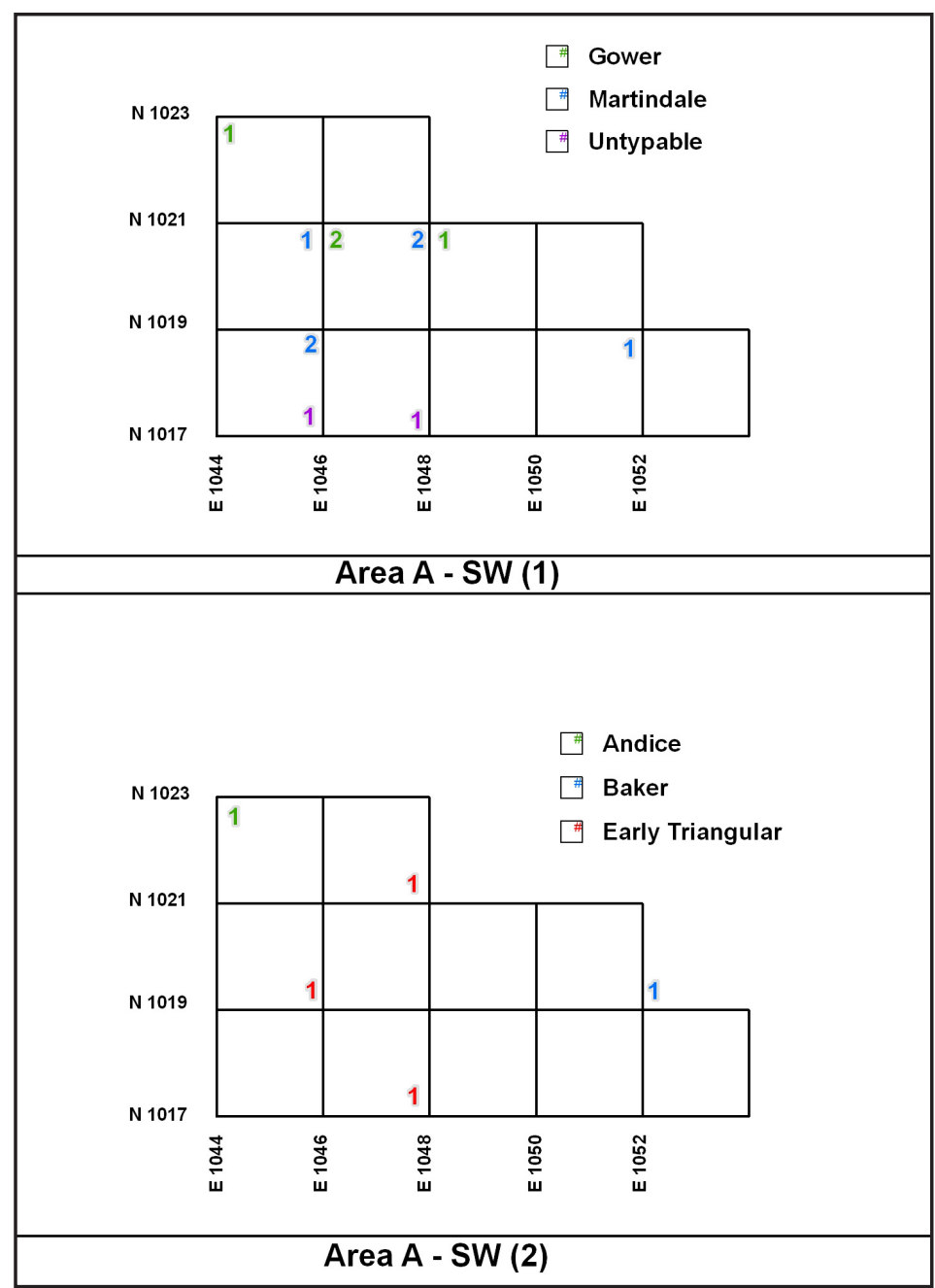

Figure 9.7. Occupation Zone 2 Area A-SW projectile point distribution.

tools and core debitage were significantly longer than in A-NE (core debitage, $\mathrm{t}=4.86 ; \mathrm{df}=86 ; \mathrm{p}<.05$ ).

\section{BIFACE AND CORE REDUCTION}

Overall, debitage is distributed unequally across areas A-NE and A-SW, both in quantity and in manufacturing technology. A t-test accounting for unequal variances between core reduction flakes and biface reduction flakes confirms the unequal distribution with $\mathrm{t}=-3.167 ; \mathrm{df}=16 ; \mathrm{p}<.05$, in Area A-NE. Biface flakes varied the greatest (variance of 4,622 for biface flakes versus 125.5 for core flakes) in frequency. The mean number of biface flakes for a 2 x 2-m unit was $89 \pm 67$ and for core flakes, $27 \pm 11$. In Area A-SW, the mean number of biface flakes was $133 \pm 62$ and core flakes was $29 \pm 10$, with a variance of 3,829 for bifaces and 96 for core flakes. While there was distributional variation between flake reduction methods within each area, proportionally there was no significant difference between Areas A-NE and A-SW. The composition of the debitage between the two areas was similar. A z-test for two sample means found no significant difference in the frequency of core $(\mathrm{z}=.28 ; \mathrm{p}>.05)$ and biface $(\mathrm{z}=1.39$; $\mathrm{p}>.05)$ flakes by unit.

\section{Cores and Core Reduction}

The distribution of debitage, flake tools, and cores do not appear to be correlated. Areas of higher concentrations of core debitage were not always associated with higher numbers of cores. It should be noted that cores can be reduced completely as with Feature 33 in A-SW, leaving only fragments. The distribution of cores and core reduction debitage are in Figures 9.12 and 9.13 .

The analysis of the distribution of flakes and cores was conducted dividing the 16 traditional $2 \times 2-m$ units of Area A-NE into high frequency, average frequency, and low frequency based upon the mean distribution and one standard deviation of the cell frequency. Two of the units were designated high frequency, 12 units were designated average frequency, and two units were designated low frequency. The average frequency was calculated as the mean average of the flakes per unit for the area plus and minus one standard deviation. Units in the average frequency category, which is approximately 66 percent of the sample, contained 38 to 16 flakes. Comparing presence and absence of cores within the debitage units, there is no significant correlation between core distribution and higher counts of core flake debitage, since cores were recovered from low frequency units as well.

The distribution of cores and core reduction flake counts was also examined in the six traditional units in Area A-SW (see Figure 9.13). While the density of cores is higher in Area A-SW, only six cores were recovered in traditional excavation units for a ratio of cores to units of 1 , while the ratio in Area 


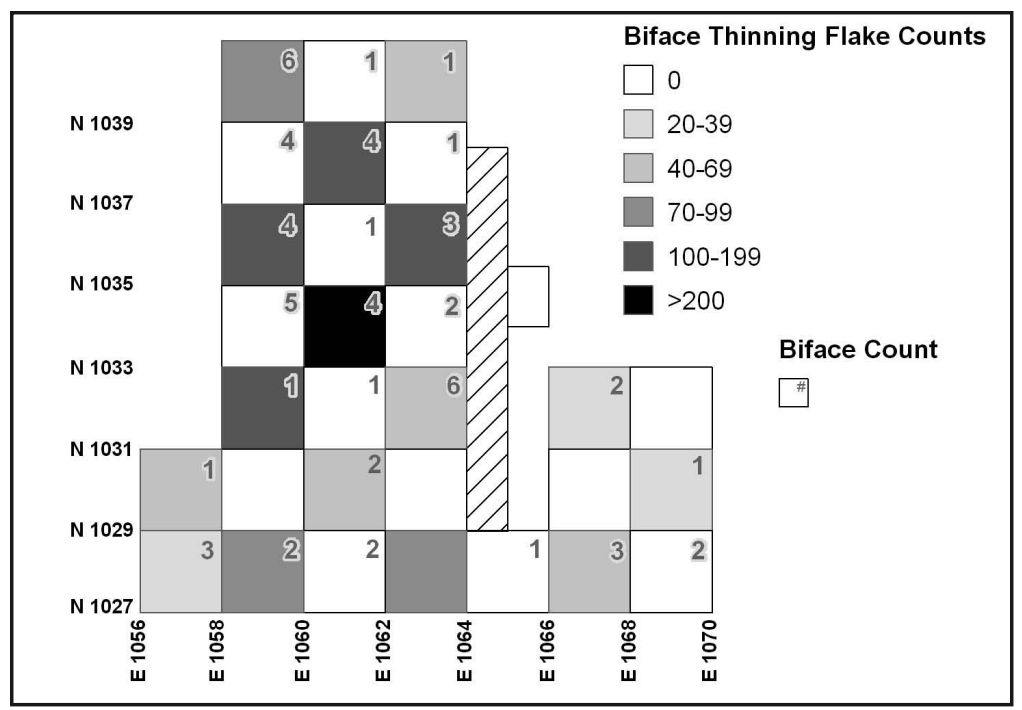

Figure 9.8. Occupation Zone 2 Area A-NE biface reduction flakes and biface distribution.
9.9). Bifaces were in every excavation unit. While proportionally, there is not a significant difference in the mean frequency of biface flakes by excavation units between Area A-NE and A-SW, there was a significant difference in the number of bifaces and the biface to core ratios. In Area A-SW the ratio bifaces to cores was 4.2:1 and in Area A-NE, 1.7:1.

Despite the core reduction in Feature 33, biface reduction was the dominant flint knapping technology in Area ASW. Even though the distribution of flakes is similar to Area A-NE, there was a concentration of bifaces and fewer cores, and biface reduction was clearly the dominant lithic reduction activity in Area A-SW.
A-NE was 22:16, or 1:1.375. As observed in A-NE, there does not appear to be a consistent correlation between higher core reduction debitage counts and multiple cores.

\section{Bifaces and Biface Reduction}

Unit N1033 E1060 contained the greatest amount of biface reduction debitage $(\mathrm{n}=281)$ in Area A$\mathrm{NE}$ and is correlated to a higher concentration of late-stage 4 and 5 bifaces, with five bifaces from N1033 E1058 that included late-stage manufacturing failures (see Figure 9.8). Unit N1035 E1058 contained the third greatest amount of biface debitage and four bifaces, two of which were broken in manufacture and one from use. This suggests an area of more intensive bifacial reduction and probable projectile point production. The biface distribution in Area A-NE is similar to the core distribution in that the presence of biface reduction flakes with bifaces occurs in all but two of the units. In Unit N1027 E1056, there were only 35 flakes, but three bifaces, all broken during manufacturing.

Biface flakes and bifaces were similarly examined for Area A-SW (see Figure

\section{SUMMARY}

In both Areas A-NE and A-SW, higher frequencies of informal flake tools are generally correlated with correspondingly fewer formal flake tools. Functionally, use-wear analysis identified hide working on both flake tools and bifaces, which were found together. In Area A-SW, Unit N1021 E1046, in addition to the three formal scrapers, there was a Stage 5 biface (Lot 849) that was used as a hafted hide scraper and was resharpened. A formal scraper (Lot 320.9) from

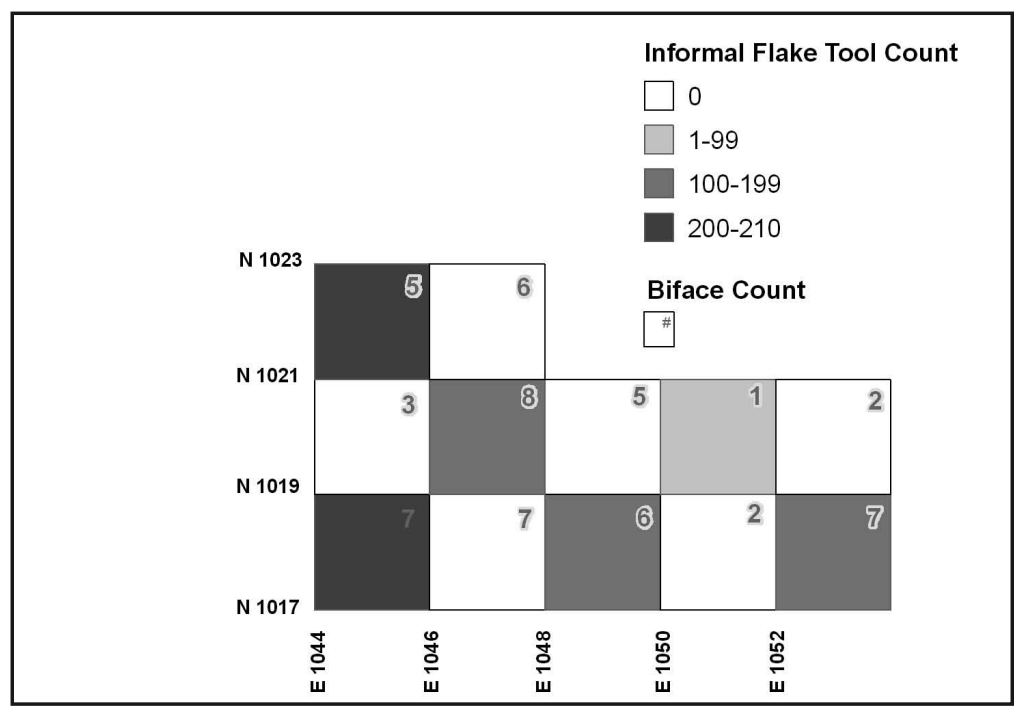

Figure 9.9. Occupation Zone 2 Area A-SW biface reduction flakes and biface distribution. 


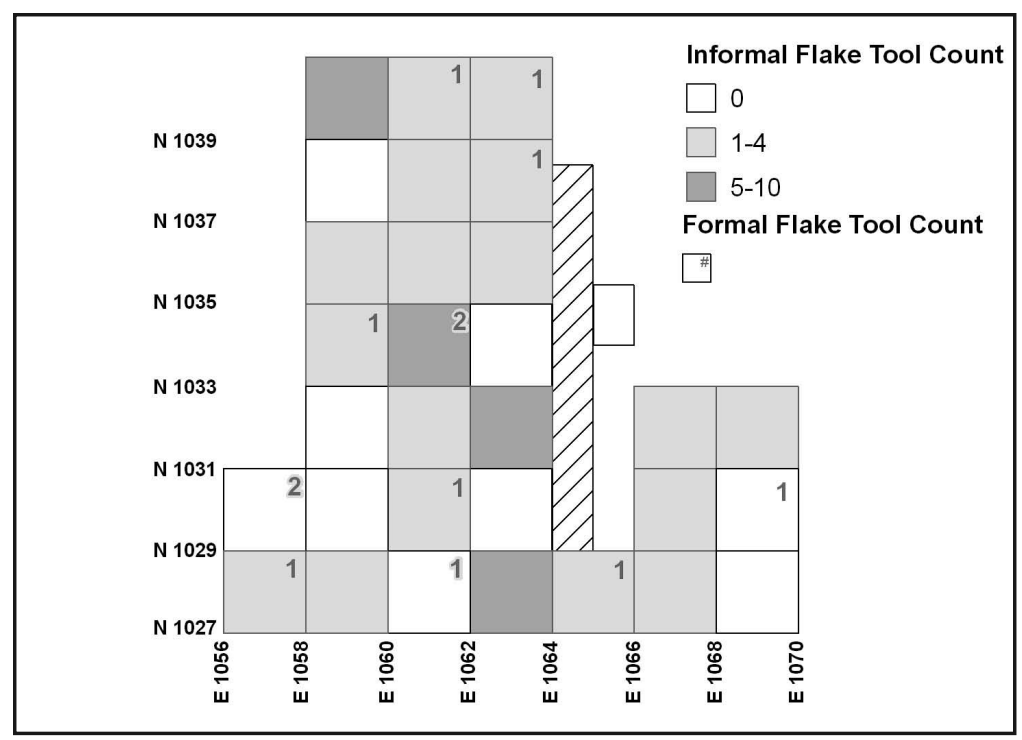

Figure 9.10. Occupation Zone 2 Area A-NE informal and formal flake tool distribution.

units with higher amounts of biface reduction debitage. The mean length of both core and biface debitage was significantly greater in Area A-SW, as were the length of flake tools.

The ratio of core flakes to biface flakes in Area A-SW is lower than Area A$\mathrm{NE}$, and Area A-SW is a denser area of features and artifacts, with varying biface reduction concentrated in smaller discrete area. In both areas, there was a lack of correlation between core reduction flakes and cores. This may be the result of the total reduction of cores into flakes and blocky debris. The greater likelihood of biface reduction refuse and bifaces to be associated suggests that discard occurred in the immediate vicinity of the activity. This could indicate that biface production

A-NE Unit N1033 E1060 was also hafted and used to scrape fresh hides.

One tentative spatial pattern that emerged from the features in Areas A-NE and A-SW was that the lower elevation features are larger, possibly more representative of earth ovens than the smaller features at slightly higher elevations. Whether this is a chronological difference or a result of feature construction is not entirely clear at this time. Despite the apparent temporal mixing within Areas A-NE and A-SW, there are similarities and differences between the areas. The types of bifaces and relative proportions of biface stages were similar. Biface reduction occurred in both areas and was the dominant lithic technology practiced. Debitage was proportionally similar by type between the areas, with no significant correlation between units with high amounts of core reduction debitage and the presence of cores. Biface reduction flakes were better correlated to the presence of bifaces in given units, particularly in Area A-NE when used as a ratio with core reduction flakes. The presence of early and late-stage biface manufacturing failures is weakly correlated to was a pervasive activity practiced across the site.

The attempt to definitively associate particular projectile point styles with activity areas and particular features has not been possible at the level of resolution used during the excavation at the Gatlin site. The mixing of temporally distinct projectile point styles indicates there was a potentially long period of landscape stability or contemporaneous use of different projectile point styles. In OZ2, features were created,

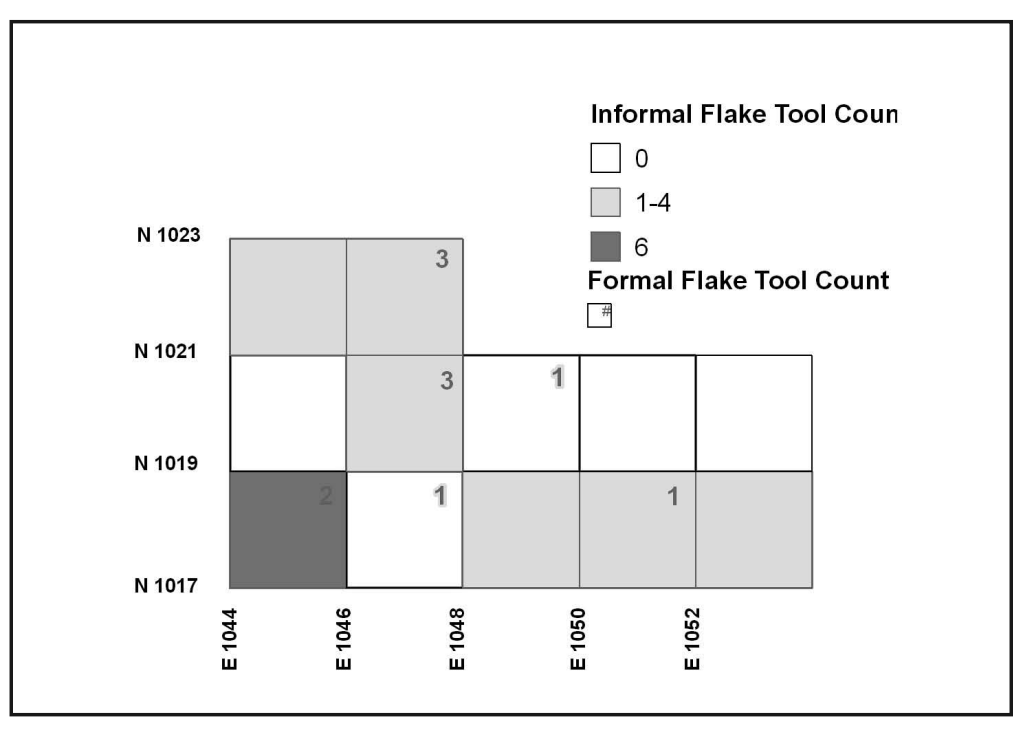

Figure 9.11. Occupation Zone 2 Area A-SW informal and formal flake tool distribution. 


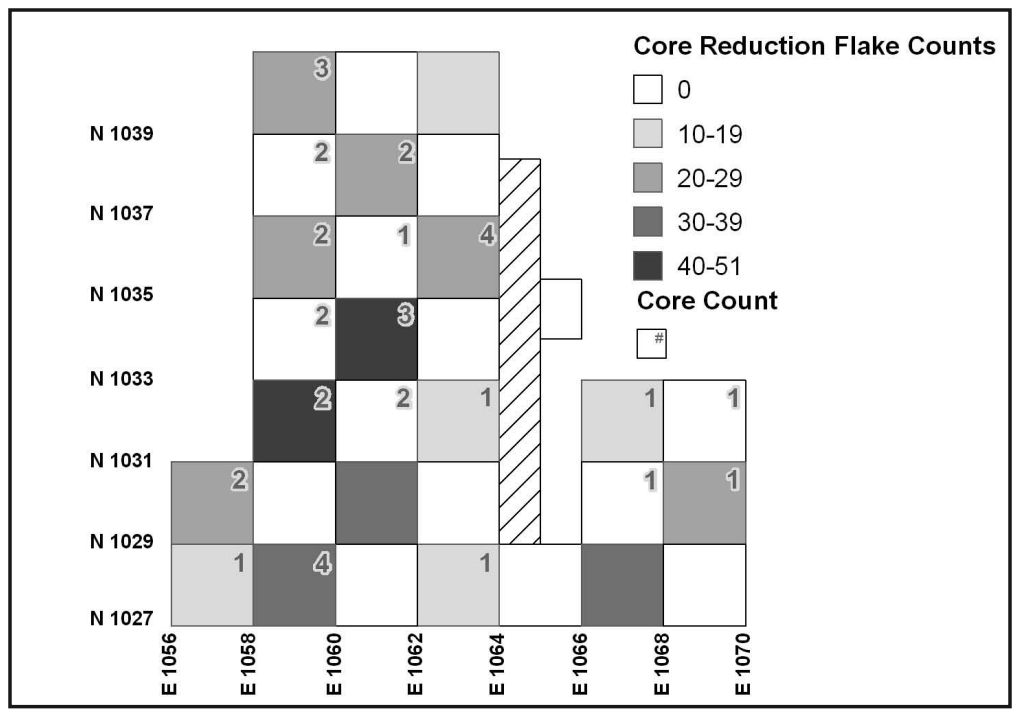

Figure 9.12. Occupation Zone 2 Area A-NE core reduction flakes and core distribution. ous features from the Gatlin site were from OZ2. With the greater diversity of features, there is a greater diversity in projectile points and an apparent increase in the frequency and intensity of use. The number of cores and flake tools increased over OZ1, but so does the overall numbers of bifaces. Biface tools are still relatively rare $(n=5)$, with one drill/perforators appearing in the assemblage. Interestingly, lithic technology in OZ2 is very similarly organized to OZ1; manufacturing bifaces was the significant lithic technology industry. The increase in the quantity of projectile points suggests that the site was repeatedly revisited by the similar groups and the presence of larger features also suggests that these groups were larger and/or stayed longer

reused, and scavenged. Stable surfaces make it difficult to establish refined radiometric chronologies because of the potential for mixing older and newer carbon. Despite some degree of mixing, it appears that similar lithic reduction strategies and preferences were maintained throughout the duration of OZ2; however, it is possible that core and biface reduction may have occurred at different times.

\section{Organization of Technology}

\section{INTRODUCTION}

OZ2 is at the transition between the Early and Middle Holocene. The projectile point assemblage contains points from near the beginning to the end of the Early Archaic. The Gower type represents the earlier occupations, Martindale points are most numerous and occur at the end of the early Archaic, and Early Triangular points represent the terminus of the Early Archaic. The mixture of these points suggests that there were episodes of landscape stability and/or erosion and that these effects varied across the site.

With the exception of the burned rock midden, the largest and most numer- than during OZ1.

The increase in the size of features also suggests that more groups instead of individuals visited the site for longer stays. The lone metate fragment suggests that plant resources were being processed, and that during at least one visit to the site, there was an increased diversity in domestic activity. The presence of a ground stone fragment is also suggestive of the presence of women, since ground stone use has been found in funerary associations with women (Taylor

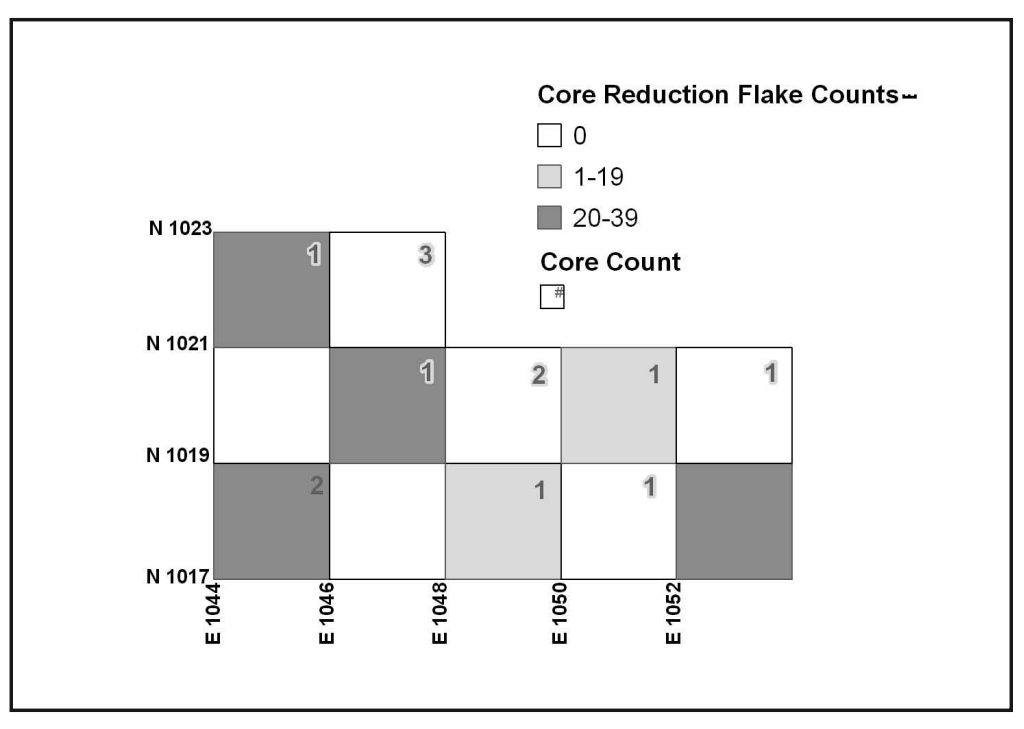

Figure 9.13. Occupation Zone 2 Area A-SW core reduction flakes and core distribution. 
and Highley 1995). Site usage was also more intensive in Area A-SW, where activities occurred within a smaller area than Area A-NE.

\section{Projectile Points}

The use of the Gatlin site as a refit site and probable short term camp during OZ2 is reflected in the projectile point assemblage, in which 47 percent of the points were broken in use and only 15 percent were unbroken. This pattern of use breakage is seen in most projectile point types from OZ2, from Gower through Early Triangular. Manufacturing failures accounted for 11 percent of point breakage. Thermal breakage was low, accounting for only 3.4 percent of the assemblage. The lack of preform failures suggests that the breakage rates were low and/or that few points were manufactured in the excavated portion of the site.

As Martindale types are the dominant projectile from the zone, a brief reiteration of observations from Hester and Shafer in Appendix $C$ is provided here. Blades on the Martindale type are broad, with small barbs, and are exceptionally well thinned. The technology and skill of thinning the blades is indeed a hallmark of the Martindale type in the Balcones Canyonlands. Blanks were flakes, sometimes very thin flakes, which were initially pre-formed using a punch or billet, but clearly completed using pressure flaking (see Appendix D). This model of production comports well with the high percentage of Stage 4 and 5 bifaces recovered from the zone as utilization of large flakes as performs is often reflected in higher numbers of late-stage bifaces. One of the most distinctive technological attributes noted is the manner in which blade edges were thinned and sharpened by fine pressure flaking. The pressure flaking is often exceptional with oblique or parallel flakes extending one-third the width of the blade and oriented toward the opposite blade corner. The skill displayed by the pressure flaking rivals that of certain Late Paleoindian points, particularly the oblique flaking often seen on Angostura genre points. This pressure flaking pattern is repeated often enough that it can be considered a stylistic trait in the Balcones Canyonlands. Blades frequently show evidence of reworking and retouching due to field maintenance.

One notable functional aspect of the sample is the frequency of direct impact fractures, strongly sug- gesting the primary function of the Martindale was as dart points or projectiles. Though use-wear on some specimens indicates use as a knife or multi-functional tool, the Martindale assemblage from OZ2 (and the Gatlin site) indicates usage as projectiles that were discarded or resharpened at the site.

\section{BIFACES AND BIFACE REDUCTION}

The biface assemblage is dominated by late-stage 4 and Stage 5 bifaces. Of the 113 general bifaces identified to a stage, Stages 4 and 5 account for 69 percent of the assemblage, an increase from OZ1. Approximately 98 percent of the biface debitage has no cortex, suggesting initial shaping occurred offsite, as in OZ1. The main cause of breakage is from manufacturing, which accounts for 80 percent of the fractures. Edge collapse flakes, errors that can lead to the complete breakage of the specimen, appear in the assemblage. Notching flakes represent final-stage trimming of hafted bifaces and projectile points. The presence of two blades is probably not indicative of true blade production. Use-wear was detected on only one biface specimen, suggesting that most bifaces were broken during manufacture and finished bifaces (or resulting tools) were removed after production/use. Both drill specimens were broken during manufacture and indicate the manufacture of hafted tools besides projectile points. The Clear Fork tools appear to have been discarded when they could not be resharpened. Use-wear indicates they were probably hafted and one was used as an adze, while the other was used as a plane. The butted biface was intended for heavier use and was used for both cutting and chopping.

The source of material for bifaces is probably the locally available fine-grained chert. Of the general bifaces and tools, 76 percent were from an unknown source, 14 percent were from a cobble, 6.8 percent were from interior flakes, and 3.4 percent were from cortical flakes. These large flake blanks were likely produced off-site.

\section{CoRes AND CoRE REDUCTION}

While it appears that core reduction increased dramatically from OZ1, the number of bifaces also increased. The ratio of core reduction flakes to biface reduction flakes is 0.271 , a substantial reduction in the ratio compared with OZ1. More formalized core 
types are used with several implications; a wider range of raw material parent form is used and/or specific flake types are associated with particular cores. All of this implies a wider range of activities were occurring at the site that needed flake tools.

\section{FLAKE TOOLS}

The greatest change from OZ1 is the flake tool assemblage. The increase in both formal and informal flake tools, like the variety of cores, indicates more intensive use and, possibly, greater processing needs. The range and varying condition of the flake tools also suggest that some processing or maintenance activities were performed at the site. The tools are a mixture of hand-held and hafted devices. Hafted tools were preferred for repetitive/larger tasks because of greater grip and leverage (Tomka 2001). Sequence flakes were used for end and end-and-side scrapers, accounting for six of the 31 formal flake tool specimens, and indicating a deliberate selection, preparation, and maintenance of the cores needed to produce the flakes. Sequence flake scrapers were noted with Gower points at the Sleeper site (Johnson 1991).

\section{IsSUes of Mobility, SPECIAL USE, CURATION}

There is a rise in expedient tool use from OZ1 to OZ2, although there is also an increase in formal flake tools. The ratio of bifaces to cores is $2.2: 1$, a reduction from 9.5:1 in OZ1. This abrupt reduction is more likely related to site function and usage than overall cultural practices. While a ratio of 2.2:1 is thought to indicate a higher measure of sedentism (Parry and Kelly 1987), it is not accompanied by a major change in the composition of the lithic assemblage. The production of flake tools is geared towards both immediate tasks, and, with formal flake tools, efficiency and durability. The formal flake tools are likely associated with scraping and hide preparation and to a lesser extent processing vegetal materials.
Maintenance and manufacturing of lithic tools during OZ2 is oriented towards hunting and the associated activities of small hunting groups. The need for more formal flake tools suggests there was an increase in processing intensity.

The ratio of curated to non-curated tools is $280: 127$ or 2.2:1, with curated tools being bifaces, formal flake tools, bifacial/unidirectional/bidirectional cores, and ground stone tools. Non-curated tools were informal flake tools and multi-directional and other non-patterned cores. The ratio is lower than in OZ1 and implies increasing utilization of local resources. The decline in the curated tool ratio implies that there is enough locally available chert to produce expedient tools. The difference between OZ1 and OZ2 is more in the overall quantity of tools rather than diversity. There is greater feature diversity in OZ2 when compared with OZ1 and the increase in flake tools correlates with the increasing diversity of burned rock features.

Like the measure for curation, the ratio of formal to informal tools as shown in Table 9.8, is similar to OZ1. It should be noted that although there is a rise in formal flake tools, the production of these tools is a relatively easy transition from retouched or utilized flakes. The actual time investment would be in the hafting of the tool. When comparing bifaces to formal flake tools the ratio is 7.5:1, a reduction from the 25:1 in OZ1. However, the result of OZ1 is based upon a single formal flake tool. The rise in formal flake tools indicates both the on site need for these tools and as part of a portable tool kit. The production of informal flake tools represents increasing number of site visits of longer duration.

With most projectile points broken from use, a significant activity at the site was the repairing and refitting of projectile systems. Notching flakes increase over OZ1, indicating hafted tools were being finished at the site. Of the 88 points, 45 of them were reworked along the blades, and four were

Table 9.8. Occupation Zone 2 Formal and Informal Stone Tools

\begin{tabular}{|c|c|c|c|c|c|c|c|c|}
\hline & $\begin{array}{l}\text { Projectile } \\
\text { Points }\end{array}$ & Bifaces & $\begin{array}{l}\text { Bifacial } \\
\text { Tools }\end{array}$ & $\begin{array}{l}\text { Flake } \\
\text { Tools }\end{array}$ & $\begin{array}{l}\text { Prepared } \\
\text { Cores }\end{array}$ & $\begin{array}{l}\text { Retouched and } \\
\text { Utilized Flakes }\end{array}$ & $\begin{array}{c}\text { Multidirectional } \\
\text { Cores }\end{array}$ & Total \\
\hline Formal & 88 & 139 & 5 & 31 & 16 & & & 279 \\
\hline Informal & & & & & & 85 & 39 & 124 \\
\hline Ratio & & & & & & & & $2.25: 1$ \\
\hline
\end{tabular}


reworked along the stem and blade, in which case, the point was unhafted. The blade reworking could be accomplished on a hafted specimen, developing the alternate beveling as seen on the Gower points. Resharpening and repair of the blade element while still hafted is a maintainable tool trait, where the tool is easily repaired in minimal time and effort. Gower, Martindale, and Early Triangular points are all maintainable types. As Hester and Shafer note in Appendix C, Early Triangular points are easily resharpened when dulled and easily repaired when the tip is broken from impact. The lack of stemmed base and barbs reduced breakage from use and during manufacture. From the submitted use-wear sample, the widest blades were more likely to be used as knives. Hester and Shafer also suggest that Early Triangular points were less efficient at creating large wound canals in prey; however, other large bladed points, such as Pedernales, Marcos, and Castroville, have been associated with prey such as bison. Johnson (2000:158) notes that large bladed points need greater force to penetrate to sufficient depth, and that unstemmed points are able to sustain the generated increase in force. The Clear Fork gouges are also a maintainable tool, easily resharpened while hafted. Unless broken in use, Clear Fork gouges are discarded when the bit edge recedes to the hafting element.

\section{FEATURES}

The burned rock features are divided between large and small. The larger features contain the largest rock specimens, although the mixture in rock sizes suggests that all available rocks at hand were used (probably including previously burned rock). The smaller features are more likely to incorporate smaller rocks that were previously burned and scavenged from other features. Scavenging can also account for some of the varied radiocarbon assay dates from within features and between adjacent features. The seven features in Area A-NE can be divided into two groupings of four and three features based upon base elevation. The lowest features, Features 5, 22, 25, and 26 from A-NE, represent probable earth ovens or large cooking features. These features are at the stratigraphic interface between OZ1 and OZ2 and represent the oldest cooking technology in OZ2.

\section{Subsistence Practices}

Bone preservation is poor in all feature fill, and identification to taxa is impossible in most instances because of the highly fragmented condition of the bone. Only Feature 34 contained identifiable deer, bison, and small mammal remains. Subsistence information from lipids indicates that plants and/or herbivores were cooked in Features 25, 26, 34, and 22 , and possibly 33 . The range of foods is characteristic of mobile hunter gatherers. There is no direct evidence that the earth ovens were used for bulk processing of plants such as lechuguilla or Camas sp., although these resources were likely available locally. The presence of mast remains such as walnut shell is probably incidental and does not represent a major resource.

The fatty acid composition of the lipid signatures and the presence of several large mammal bones and projectile points and formal scrapers indicate larger mammals such as deer and bison were processed at the site. Hide scrapers imply that complete animals were processed nearby. The presence of bison tooth and white-tailed deer antler suggest whole animals (as opposed to select portions) were butchered at the site. The slight increase in formal hide scrapers and the presence of a metate raises the possibility that larger groups that may have included family members, especially women, were at the site. The increase in formal scrapers also indicates more specialization and a need for efficiency in repetitive tasks. Previously, the individuals and small groups from OZ1 used informal flake tools for their tasks. This represents a change in the intensity of occupations and even site function.

\section{Summary OF OCCUPation Zone 2}

During the latter part of the Early Archaic, there was an increase in site use intensity from OZ1. Close proximity to abundant high-quality chert and access to deer and bison were the likely criteria for selecting the Gatlin site as a short-term camp (as in OZ1). In their examination of site distributions at Camp Bullis in Bexar County, Kibler and Scott (2000) note that Gower and Martindale points appeared together frequently, except that Martindale sites were fewer in upland areas. They suggest this was the result of increasing xeric conditions that led to sites being 
located near more-secure water sources. They saw a continuation in subsistence practices from the Gower period, with the use of a broad diet containing lower ranked resources such as plants. At the end of the occupation of OZ2, there is a transition from the Split Stem series of points to the unstemmed Early Triangular. This change is both technological and stylistic. The split stem point series can be viewed as a technological system and as a cultural marker or identity. The shift away from this tradition suggests that either new groups of people were using the Gatlin site or that the inhabitants adopted the new technology.

Alluviation from the Guadalupe River declined as the channel became more incised. Changing conditions, oscillating between xeric and mesic, has been proposed for this period by Collins (1995), Kibler and Scott (2000), and Bousman (1998) and by the varying paleoenviromental signatures from the features. During this time the Guadalupe River represented a stable supply of water, able to support mussels such as Tampico pearlymussel, which is now extirpated from the river.

At various times, different groups used the site. Multiple specimens of different projectile points spread across the site suggest these groups repeatedly revisited the Gatlin site-possibly in small groups that included women, and children. Larger features, an increase in flake tools and cores, and a metate fragment all suggest there was a greater diversity in group composition at the site. Although site use intensity increased, it should be noted that these occupations were probably still infrequent, given the long time span of OZ2. These tools were for immediate use or for tasks conducted during the course of a short stay. Higher density, longer term, and more repeated occupations would have generated more features and intensified the use of existing ones.

There is no significant increase in the diversity of tools as would be expected if the Gatlin site was used as a long term residential site. The greatest increase in tool types are formal flake tool types, specifically scrapers. The two gouges and two drills indicate that maintenance activities occurred on site and that a greater range of materials were being worked; however, the intensity of site use is still low. The low number of gouges also suggests that woodworking was not a major activity at the site. Several specific traits continue from OZ1, such as the use of sequence flakes for making scrapers. These scrapers were probably meant to be hand-held rather than hafted. Similar to OZ1, OZ2 data suggests that the Gatlin site was sporadically used by mobile groups practicing a forager or traveler subsistence strategy. During short visits to the Gatlin site, these groups engaged in tool maintenance/rejuvenation, food preparation, and hide preparation or processing activities resulting from the need to support hunting tasks. In addition to hunting, there are periodic episodes of earth oven construction that may have processed plants. 
9-44 Chapter 9 


\title{
Chapter 10
}

\section{OCCUPATION Zone 3}

\author{
Eric R. Oksanen, Mercedes C. Cody, and Kevin A. Miuer
}

\section{INTRODUCTION}

During the data recovery excavations, archaeologists observed what appeared to be a component with discrete features and abundant late Early Archaic/early Middle Archaic projectile points dominated by Early Triangular and later La Jita/Nolan points. These, along with examples of the Bell and Andice types, suggested a component reflecting the transition between the Early and Middle Archaic periods, a time frame often poorly represented at Central Texas sites. According to Johnson and Goode (1994), this is a period of significant technological and cultural changes though it retains a stylistic continuity with earlier periods. Previously not distinguished during the testing phase, this component became the focus of supplemental excavations and was later designated OZ3.

OZ3 contains a mixture of primarily Early and Middle Archaic cultural materials and small numbers of Late Archaic points. Though initially thought to be a fairly isolable component in the field, subsequent analysis has revealed $\mathrm{OZ} 3$ to be slightly more mixed and compressed than hoped. Evidence of Early Archaic occupation (Gower and Martindale projectile points) within OZ3 suggests some overlap with the previous OZ2. Similarly, the presence of La Jita and Nolan point types suggests overlap with the subsequent OZ4. In addition, radiocarbon dates strongly indicate mixing and later intrusive occupations as most of these dates are younger than the established dates for most of the recovered projectile point styles. However, other lines of evidence (soils, stratigraphic associations, artifact and feature distributions, changing projectile point styles) support the delineation of the occupation zone as a valid analytical unit for inquiry. While certain spatial and correlative analyses are hindered because of this mixing, studies have shown that even somewhat mixed sites on stable landforms can address important issues such as climatic changes, tool manufacture and use, and general prehistoric behavioral patterns (Mahoney et al. 2003a).

The excavations in OZ3 were primarily in areas A-NE and A-SW, and to a lesser extent, in areas B, A-NW, and A-SE (Figure 10.1; see Figures 7.6, 7.9, and 7.11). In Area B, artifacts from below $97.90 \mathrm{~m}$ elevation were included in OZ3. Approximately $68.5 \mathrm{~m}^{3}$ of OZ3 deposits were excavated during data recovery, exposing an area of $442 \mathrm{~m}^{2}$. Volumetrically, this is slightly more than double the $33 \mathrm{~m}^{3}$ of OZ2. The number of traditional units excavated by area in A-NE is 14, five in A-NW, three in A-SW, and seven in Area B. Concentrations of lithic debris and artifacts varied by excavation area, with dense concentration of bifaces and cores in areas A-NW and A-SW, along with mixtures of Early Archaic and Middle Archaic points.

Analysis of the zone materials indicates many similarities with the lithic assemblage from OZ2, suggesting

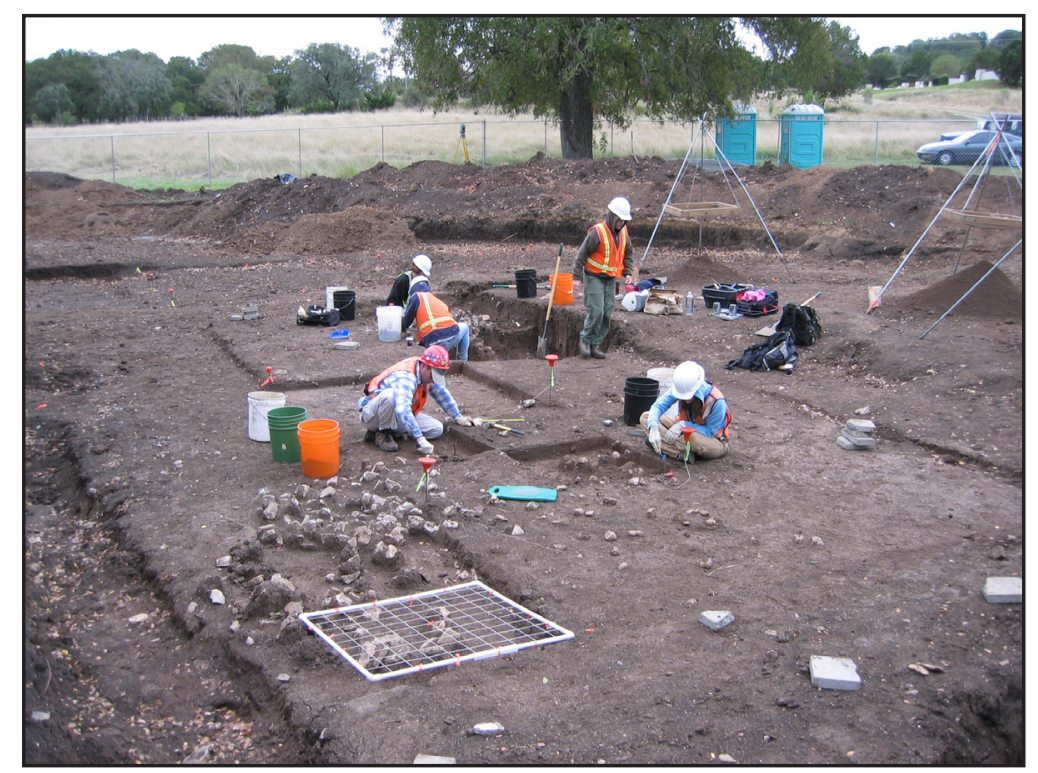

Figure 10.1. Area A-SW excavations in progress facing southeast. 
that the Gatlin site was utilized in a similar fashion as a hunting camp and lithic workshop. Primary lithic activities include the utilization of abundant local riverine cherts to replenish lithic tool supplies, particularly bifaces and projectile points. Most early-stage reduction of both bifaces and cores was conducted off site, after which they were brought onto the site for further or final reduction. The inhabitants of the Gatlin site, during OZ3, were relatively mobile foragers who briefly visited the site during hunting forays and to refit tools from nearby base camps. Similar to OZ2, the presence of several larger burned rock features indicates a growing utilization of possible lower ranked foodstuffs in earth ovens and a slight diversification of the subsistence base.

\section{Chronology}

In Area A-NE, the uppermost deposits of Late Archaic materials were mechanically removed, exposing OZ3 and OZ2. Within OZ3, there is a mixture of Early and Middle Archaic diagnostic cultural materials where Early Archaic points indicate time periods clearly earlier than radiocarbon dates obtained from features. This mixing is the likely result of a stabilizing ground surface as frequent flooding and alluviation decline sharply across the site. Down cutting of the Guadalupe channel increased from 5,000 to 4,000 в.P, cutting off regular deposition of alluvium across the site. As a result, pedogenic activity, erosion, and human agents such as trampling resulted in increased mixing of deposits. OZ3 was the upper cultural occupation identified by Frederick in BHT3 in soil zone 3 , soil horizon $2 \mathrm{Ab} 2$, at $70-75 \mathrm{~cm}$ below ground surface (see Chapter 6).

There were five radiocarbon assays, three from Area A blocks and two from Area B, that were used to define the absolute age of the OZ3 deposits. The proposed range, in radiocarbon years is from ca. 4,500-3,850 B.P.

Only a sample of the occupations was directly dated. In Area A, radiocarbon assays from Features 16/17 and 19 were the earliest direct dates. By combining the two dates from Feature 16/17 $(\mathrm{t}=1.347$; $\mathrm{df}=1$; $\mathrm{p}<.05$ ), the resulting $4175 \pm 28$ B.P. is in close agreement with $4110 \pm 40$ B.P. from Feature $19(\mathrm{t}=1.8 ; \mathrm{df}=1$; $\mathrm{p}=.05)$. A terminal date of $\mathrm{OZ} 3$ is less defined, since the upper deposits were removed in Area A-NE.
In Area B, Feature 38 was used to date the beginning of OZ3, with a radiocarbon assay of ca. $4530 \pm 40$ B.P. The terminal date for OZ3 is derived from Area B deposits and Feature 37 in OZ4 with a radiocarbon date of $3850 \pm 40$ B.P.

Overall, in A-NE and A-SW, the termination date of OZ3 cannot be defined with certainty. The young radiocarbon dates (in comparison to diagnostic tools) suggest that many of the features with associated radiocarbon dates in the zone may be somewhat intrusive into older deposits, further indicating a degree of compression and overprinting.

As mentioned, there are several diagnostic projectile point style intervals within OZ3, from the Early Archaic through the Middle Archaic. From the Early Archaic these are primarily Gower and Martindale/Bandy/Baker. Gower is securely dated at 41HY161 in San Marcos between ca. 7,700-6,650 B.P. (Oksanen 2005) and was found in OZ1 deposits at the Gatlin site dating from ca. 6,600-6,060 B.P. (see Chapter 8). The grouping of Martindale/Bandy/Baker is dated by Collins (2004) from ca. 7,000-6,000 B.P.; however, Johnson and Goode (1994) extend the Early Archaic Martindale/Bandy/Baker-like points to as late as 4,500 B.P.

Late Early to early Middle Archaic projectile point styles in OZ3 are Bell/Andice/Calf Creek, Early Triangular or Taylor, Nolan, and La Jita. Collins (2004) places the Bell/Andice/Calf Creek within a range ca. 6,000-5,000 B.P. and Early Triangular from ca. 5,000-4,500 в.P. The appearance of broad bladed points such as Bell/Andice/ Calf Creek is thought to correlate with the presence of bison during a mesic period at the beginning of the Middle Archaic (Collins 2004; Johnson and Goode 1994). Johnson and Goode (1994) place Bell/Andice/Calf Creek within an interval from ca. 4,900-4,500 B.P. and Early Triangular from ca. 4,500-4,100 B.P. While Hester and Shafer view Bell/Andice and Early Triangular as part of the same style interval, Collins (2004) views them as separate intervals, with Early Triangular proceeding Bell/Andice. An Early Triangular component at the Holt Site, 41HY341, is securely dated at ca. 4,750 B.P. (Brownlow 2004).

Nolan and La Jita points have been dated from ca. 5,000-4,600 B.P. (Nolan) and from ca. 4500-3900 (La Jita) as described in Appendix $\mathrm{C}$ although they 
may be contemporaneous regional variations. In Central Texas, Collins (2004) places Nolan with Travis and La Jita at between ca. 4,400-4,000 B.P., at the end of the Middle Archaic. Johnson and Goode (1995) place La Jita type points as preceding Nolan/Travis points, and suggest that La Jita is an earlier southwest Pecos region type point. Hester and Shafer (see Appendix C) view La Jita and Nolan as possible regional variants of the same style. According to Johnson and Goode (1995), the estimated appearance of Nolan points along the eastern edge of the Edwards Plateau is ca. 4,400 B.P., and slightly earlier in the south and west, especially La Jita points. Hester and Shafer note that Nolan points have been found in context beneath La Jita points (see Appendix C). The ambiguity over which style is older, La Jita or Nolan/Travis, may be based in regional factors as they may be variations of the same point type and are regionally coeval. The radiocarbon dates from features within OZ3 are more closely associated with the later Middle Archaic and within the proposed date range for La Jita and Nolan/Travis.

\section{Paleoenvironment}

During the time frame of occupation represented by OZ3, it is hypothesized that the climate shifted from a mesic episode of expanded grasslands and increased bison on the Edwards Plateau and Central Texas, to increasing aridity and warming and the retreat of bison and grasslands. However, there is some debate of the timing and regularity of these changes and whether they were cyclical. The phytolith record from OZ3 indicates cooler climatic conditions, changing between slightly drier to wet local conditions. However, this could be the result of localized site conditions such as increased shade. Also, the possible long-term exposure of the features means that certain types of analysis, such as pollen samples, are problematic, since later mixing likely occurred. The presence of weedy plants suggests the site was disturbed periodically. Fuel wood and nut hulls indicate hardwoods were present and habitat was suitable for deer and bison during the use of Features 16/17, 19 and 38. Bison were present at ca. 4,200-4,100 B.P. based upon the faunal evidence.

\section{Occupation Zone 3 Assemblage}

The remaining physical evidence of technology from the inhabitants at the Gatlin site is from the lithic artifacts (Table 10.1). There are eight features and 115 projectile points divided among 17 identified projectile point styles. Between OZ2 and OZ3 there is a shift in the projectile point technology from stemmed points such as Martindale to Early Triangular and back to stemmed points such as La Jita and Nolan. These groups represent the most numerous specimens in OZ3.

From $\mathrm{OZ} 2$ to $\mathrm{OZ} 3$, there is an increase in formal bifacial tools (from five to 14) and an increase in expedient flake tools versus formal flake tools. There is also an increase in the numbers of types of scrapers. There is a similarity between the debitage in OZ3 and OZ2: in OZ3, the percentage of core reduction, biface reduction, and indeterminate flakes, is approximately 66 percent, 19 percent, and 15 percent, while in OZ2 it was 68 percent, 18 percent, and 13 percent. The biface to core ratios are similar between OZ2 and OZ3. Individual attributes data for lithic tools, lithic cores, and ground stone/manuports are presented in Appendix E, consisting of E.1 through E.7.

All of the features contained burned rock; however, Feature 32 was classified as a debitage refuse pile. The other features were burned rock features of varying sizes that were heating and cooking appliances. There is a slight increase in the average overall size of the burned rock features in OZ3 compared with $\mathrm{OZ2}$, and an increase in the amount of burned rock recovered from features. Although some of this variability may be attributed to the difficulty of measuring the extent of features.

\section{Dart Points}

During testing and data recovery excavations at the Gatlin site a total of 115 projectile points were recovered from OZ3. Most of these were diagnostic types, such as Andice, Bell, and Early Triangular points associated with the late Early Archaic period $(n=47)$ according to Hester and Shafer (see Appendix C) or the beginning of the Middle Archaic according to Collins (2004) and Johnson and Goode (1994). These are followed in frequency by diagnostic types including Bandy, Gower, and Martindale points, associated with the Early Archaic $(n=22)$ and La Jita 
Table 10.1. Summary of Lithic Technology for Occupation Zone 3

\begin{tabular}{|c|c|c|}
\hline Category & Count & Description \\
\hline Features & 8 & $\begin{array}{l}6,15,16 / 17,18,19 \\
20,32,38\end{array}$ \\
\hline \multirow{18}{*}{ Projectile Points } & \multirow{18}{*}{115} & 5 Andice \\
\hline & & 3 Bandy \\
\hline & & 4 Bell \\
\hline & & 3 Bulverde \\
\hline & & 38 Early Triangular \\
\hline & & 5 Gower \\
\hline & & 8 La Jita \\
\hline & & 2 Lange \\
\hline & & 1 Langtry \\
\hline & & 1 Marshall \\
\hline & & 13 Martindale \\
\hline & & $\begin{array}{l}1 \text { Martindale- Narrow } \\
\text { stem }\end{array}$ \\
\hline & & 1 Montell \\
\hline & & 12 Nolan \\
\hline & & 1 Pandale \\
\hline & & 1 Pedernales \\
\hline & & 2 Tortugas \\
\hline & & 14 Untypable \\
\hline \multirow{4}{*}{ Bifacial Tools } & \multirow{4}{*}{14} & 7 Butted Biface \\
\hline & & 2 Clear Fork Tool \\
\hline & & 2 Gouge \\
\hline & & 3 Drill \\
\hline \multirow{6}{*}{ Bifaces } & \multirow{6}{*}{363} & 13 Stage 1 \\
\hline & & 35 Stage 2 \\
\hline & & 59 Stage 3 \\
\hline & & 55 Stage 4 \\
\hline & & 132 Stage 5 \\
\hline & & 69 Indeterminate \\
\hline
\end{tabular}

and Nolan points from the late Early Archaic/early Middle Archaic period $(n=20)$. The minority of the diagnostic types encountered within this zone are associated with the Middle Archaic $(\mathrm{n}=7)$ including Bulverde, Langtry, Pandale, and Tortugas points, a Pedernales point associated with the late Middle Archaic/Late Archaic and Lange, Marshall, and Montell points associated with the Late Archaic. In addition

\begin{tabular}{|c|c|c|}
\hline Category & Count & Description \\
\hline \multirow{7}{*}{ Flake Tools-Formal } & \multirow{7}{*}{36} & 1 Convergent Scraper \\
\hline & & $\begin{array}{l}4 \text { End and Side } \\
\text { Scraper }\end{array}$ \\
\hline & & 10 End Scraper \\
\hline & & 1 Graver \\
\hline & & 1 Indeterminate \\
\hline & & 17 Side Scraper \\
\hline & & 2 Transverse Scraper \\
\hline \multirow{2}{*}{ Flake Tools-Expedient } & \multirow{2}{*}{129} & 32 Utilized Flakes \\
\hline & & 97 Retouched Flakes \\
\hline \multirow{6}{*}{ Cores } & \multirow{6}{*}{171} & 5 Bidirectional \\
\hline & & 36 Bifacial \\
\hline & & 7 Indeterminate \\
\hline & & 109 Multidirectional \\
\hline & & 4 Slab \\
\hline & & 10 Unidirectional \\
\hline \multirow{3}{*}{ Ground Stone/Other Tools } & \multirow{3}{*}{5} & 3 Mano \\
\hline & & 1 Metate \\
\hline & & 1 Hammerstone \\
\hline $\begin{array}{l}\text { Total Flakes and Frag- } \\
\text { ments from Traditional } \\
\text { Units }\end{array}$ & 12,087 & $\begin{array}{l}\text { Does not include } \\
\text { shatter }\end{array}$ \\
\hline Core Reduction Flakes & 846 & \\
\hline Biface Reduction Flakes & 2881 & \\
\hline Indeterminate Flakes & 634 & \\
\hline Total Proximal Fragments & 3018 & \\
\hline Total of Complete Flakes & 1346 & \\
\hline $\begin{array}{l}\text { Complete Flakes Percent- } \\
\text { age of Total }\end{array}$ & $11.14 \%$ & \\
\hline Ratio of Bifaces to Cores & $2.2: 1$ & \\
\hline
\end{tabular}

to the diagnostic types, there were several $(n=14)$ untypable points recovered from this zone. The following counts and descriptions refer only to the specimens discovered within OZ3. Projectile point type morphology and metric attribute information is located within Appendix C, with individual metric attribute information located within Appendix E.1. 
ANDICE

$(\mathrm{n}=5)($ Lots 87.3, 147.5, 363, 811, 1315.2) (see Appendix C, Figure 7 a-Lot 811, b-Lot 363)

Nominal Attributes: There are a variety of flaking patterns observed for these points, including collateral, parallel, and chevron.

Condition and Breakage: One of these points is complete with evidence of a snap fracture. The remaining points are all basal fragments with snap fractures and a snap/impact fracture.

Reworking and Beveling: One specimen was reworked into a perforator, and two specimens were reworked along the blade. The one beveled specimen is beveled to the right.

Use-wear: N/A

Raw Material Attributes: All of these points are made of local Edwards fine-grained chert.

Comments: These points exhibit mainly snap fractures, many of which may be the result of direct impact, as well as a high frequency of reworking due to the high maintenance of these tools.

\section{BANDY}

$(\mathrm{n}=3)($ Lots 299, 352, 607) (see Appendix C, Figure $2 \mathrm{~g}, \mathrm{c}, \mathrm{e})$

Nominal Attributes: Two of these points exhibit flaking patterns including oblique subparallel and random.

Condition and Breakage: Two of these points are complete with one lacking breakage and the other exhibiting an impact fracture. The remaining point is a basal fragment demonstrating a snap fracture.

Reworking and Beveling: Reworking is observed along the blade of two of these points.

Use-wear: Use-wear analysis performed on two of these points indicates that both functioned as dart points. Additionally, one of these was also utilized as a light-duty knife.

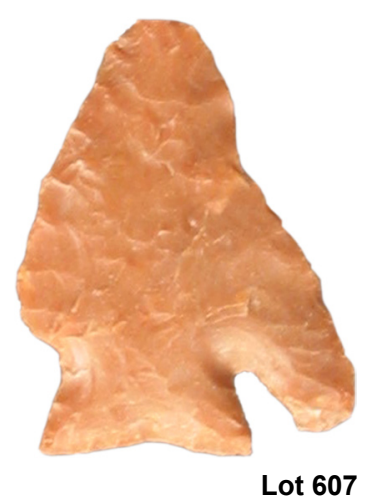

Raw Material Attributes: Raw material for all of these points is local Edwards fine-grained chert. Heat evidence is observed on two of the points through reddening, with potlids on one of these.

Comments: These points are distinguished by their small size, small stems, and very thin blades.

\section{BELL}

( $\mathrm{n}=4)$ (Lots 96.4, 787.1, 922, 1000) (see Appendix C, Figure 7 d-Lot 96.4, e-Lot 1000, f-Lot 922)

Nominal Attributes: An organized flaking pattern is present on two of these points with an oblique pattern on one and a chevron pattern on another.

Condition and Breakage: Only one of these points is complete. The remaining three points are basal fragments of which two exhibit impact fractures and one a snap fracture (most likely the result of impact).

Reworking and Beveling: Evidence of reworking is observed along the blade of two of these points.

Use-wear: N/A

Raw Material Attributes: All of these points are composed of local Edwards

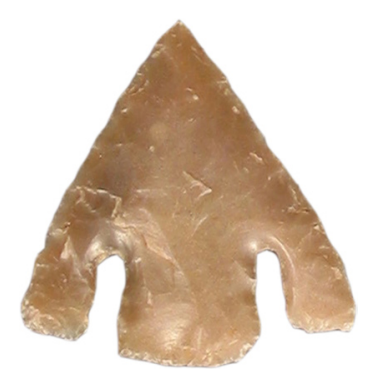
fine-grained chert. 


\section{BULVERDE}

$(\mathrm{n}=3)($ Lots $87.2,470,775)$

Nominal Attributes: Two of these points exhibit a random flaking pattern.

Condition and Breakage: Two of these points are mostly complete with one exhibiting an impact fracture. The remaining specimen is a basal fragment consisting of a stem and one barb (due to multiple indeterminate breaks).

Reworking and Beveling: Reworking is present along the blade of two of these points.

Use-wear: N/A

Raw Material Attributes: Raw material for all of these points is local Edwards fine-grained chert.

Comments: The distal portion of several of these points have been extensively reworked and shortened.

\section{Early Triangular}

$(\mathrm{n}=38)$

\section{Subtype Early Triangular $A$}

$(\mathrm{n}=12)$ (Lots 646, 740.2, 766.3, 860, 892, 893, 897.1, 904.6, 967, 995, 996, 1283.6) (see Appendix C, Figure 8 b-Lot 740.2, c-Lot 893, d-Lot 995)

Nominal Attributes: Most of these points exhibit oblique parallel flaking patterns, followed by oblique subparallel and subparallel.

Condition and Breakage: Five of these points are complete. While one exhibits no breakage, another demonstrates evidence of some impact breakage, two exhibit some indeterminate breakage along the basal margin, and one displays some thermal breakage. The remaining seven specimens are all basal fragments with five of these exhibiting impact fractures.

Reworking and Beveling: Evidence of reworking is apparent along the blade of four of these points. Evidence of beveling is on four of these points.

Use-wear: Use-wear analysis was performed on six of these points revealing two functioned exclusively as projectile points and four were utilized as both projectile points and light duty knives or butchering implements. Of note, one of the latter did not specifically have diagnostic projectile point

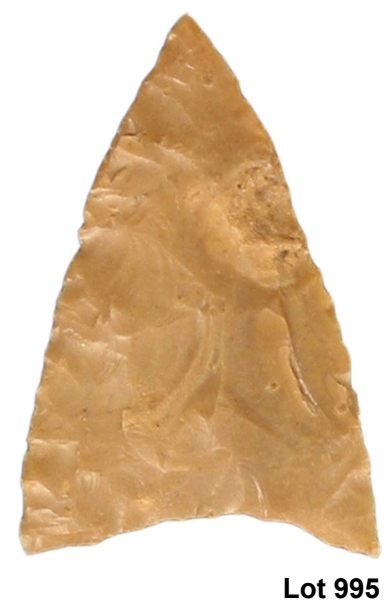
use-wear, but the tip design and form is identical to those utilized as points.

Raw Material Attributes: All of these points are composed of local Edwards fine-grained chert. Three specimens exhibit heat damage such as potlids, with crazing observed on two of these.

Comments: Most of these points exhibit use-wear impact fractures. Additionally, there is a higher frequency of beveling or twists among these points.

\section{Subtype Early Triangular B}

$(\mathrm{n}=17)($ Lots 80.3, 200.1, 204.2, 345, 479, 518.12, 647, 726, 741.1, 761.4, 774, 888.5, 898, 966, 994, 997, 1215.4) (see Appendix C, Figure 8 f-Lot 1215.4, g-Lot 726, h-Lot 204.2)

Nominal Attributes: Most of these points $(n=8)$ exhibit a random flaking pattern which may result from resharpening.

Condition and Breakage: Eleven of these points are complete, enough to gather measurements for length, width and thickness, and of these eleven, three have impact fractures. One of the three points 
with impact damage also has thermal fractures. The remaining six points are basal fragments demonstrating a variety of impact, manufacture, and postdepositional breaks.

Reworking and Beveling: Six of these points exhibit reworking mostly along the blade and one along the blade and basal margin. Beveling or a slight twist is evident among six of these points.

Use-wear: Seven of these points were submitted for use-wear analysis. Two of the specimens were exclusively utilized as projectile points. Another two functioned as projectile points, but were also used as light duty knives to cut soft meat or hide. One of the points functioned exclusively as a light duty knife to butcher soft meat or hide. The remaining two specimens were utilized as a light duty knife and tool to cut moderately resistant materials such as wood.

Raw Material Attributes: Raw material for all of these specimens is local Edwards fine-grained chert. Heat evidence is observed as potlids on four of the points and as reddening on two.

Comments: Reworked blades are common in the sample resulting in shorter blades with interrupted flaking patterns, and often with a slight bevel or twist to the blade.

\section{Subtype Early Triangular C}

$(\mathrm{n}=1)$ (Lot 763.1) (see Appendix C, Figure 8 i)

Nominal Attributes: This point exhibits an oblique subparallel flaking pattern.

Condition and Breakage: The specimen is a basal fragment with an impact fracture.

\section{Reworking and Beveling: N/A}

Use-wear: N/A

Raw Material Attributes: This specimen is made from local Edwards fine-grained chert.

Comments: This is the only Early Triangular $\mathrm{C}$ projectile point recovered from the entire Gatlin site.

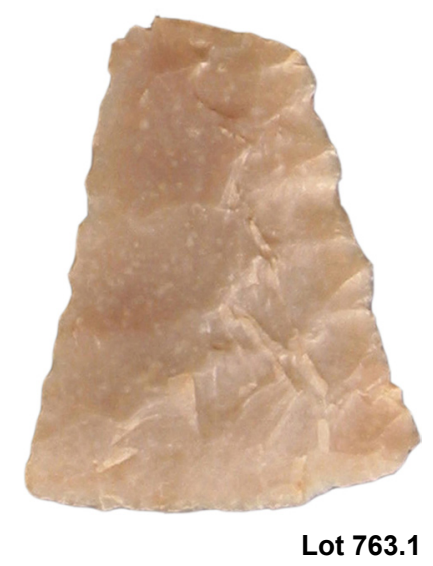

\section{Subtype Early Triangular Preform}

$(\mathrm{n}=7)$ (Lots 606, 658.1, 767, 805, 1030.2, 1515.3, 1554)

Nominal Attributes: Four of the points have a random flaking pattern. Six of these specimens have been classified as preforms.

Condition and Breakage: Three of these points are complete with one exhibiting no breakage and with two demonstrating some breakage due to flaking step fractures and material flaws. The remaining four points are all basal fragments with evidence of manufacturing breaks.

Reworking and Beveling: Reworking is evident along the blade of one of these points.

Use-wear: Only one of these points was submitted for use-wear analysis revealing it was solely used as a projectile point.

Raw Material Attributes: Raw material for all of these points is local Edwards fine-grained chert.

Comments: All of these specimens have been classified as preforms and do not fall within the base morphology subcategories except for one. 


\section{Subtype Early Triangular Knife}

$(\mathrm{n}=1)$ (Lot 921) (see Appendix C, Figure 8 e)

Nominal Attributes: An oblique parallel flaking pattern is observed on this point.

Condition and Breakage: This specimen is complete with no breakage.

Reworking and Beveling: N/A

Use-wear: Use-wear analysis was performed on this specimen, which revealed it is a large implement probably utilized as a light-duty butchering knife to cut soft materials such as meat or hide. There is no evidence of hafting and it may have been hand held during use.

Raw Material Attributes: This specimen is composed of local Edwards fine-grained chert.

Comments: This point exhibits fine pressure thinning or retouch, often oblique, which is an outstanding feature of the Early Triangular points.

\section{Gower}

$(n=5)$

\section{Subtype Gower $A$}

$(\mathrm{n}=2)($ Lots 477, 521)

Nominal Attributes: Both of these points exhibit an oblique parallel flaking pattern.

Condition and Breakage: One of these points is complete with no breakage and the other specimen is a basal fragment exhibiting a snap fracture.

Reworking and Beveling: One of the specimens is reworked along the blade.

Use-wear: Only one of these points was subjected to use-wear analysis which revealed it was utilized as both a projectile and light duty knife to butcher soft animal remains.

Raw Material Attributes: Both of these points are made of local Edwards fine-grained chert.

Comments: This stem form group is characterized by narrow blades with slight shoulders.

\section{Subtype Gower}

$(\mathrm{n}=3)$ (Lots 433.3, 519, 944) (see Appendix C, Figure 6 i-Lot 519, h-Lot-944)

Nominal Attributes: Two of these points exhibit systematic flaking patterns including oblique parallel and chevron.

Condition and Breakage: Two of these points are complete with one having an impact fracture. The remaining point is a stem fragment with evidence of a usewear breakage.

Reworking and Beveling: One of the specimens has been heavily reworked into a perforator.

Use-wear: Use-wear was performed on two of these points. One specimen was utilized as a rotary drill turned primarily in a clockwise direction. The other was utilized as both a dart point and a light duty knife used to butcher soft animal remains.

Raw Material Attributes: Raw material for all of these points is local Edwards fine-grained chert.

Comments: These points are characterized as the generic Gower form.

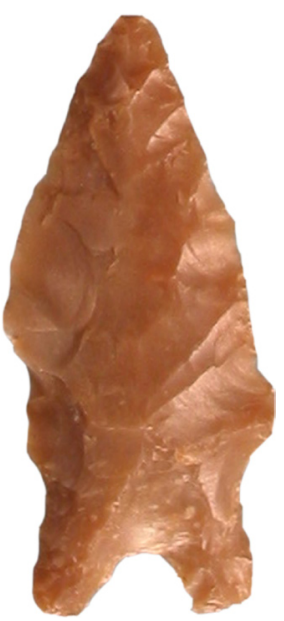

Lot 944 
LA JiTA

$(\mathrm{n}=8)$

\section{Subtype La Jita Group I}

$(\mathrm{n}=3)($ Lots 634.1, 747, 959)

Nominal Attributes: Only one of these points exhibits an organized collateral flaking pattern.

Condition and Breakage: All three points are basal fragments with two of the specimens exhibiting both impact and snap fractures, and one demonstrating thermal breakage.

Reworking and Beveling: Evidence of reworking along the blade, as well as a right bevel along the stem is apparent for one of these points.

Use-wear: N/A

Raw Material Attributes: All of the specimens are composed of local Edwards fine-grained chert.

Comments: The Group I subtype specimens are described as classic La Jita artifacts.

\section{Subtype La Jita Group II}

$(\mathrm{n}=4)$ (Lots 548, 686, 1284, 1515.2) (see Appendix C, Figure 10 e-Lot 1284)

Nominal Attributes: All of these points exhibit a random flaking pattern.

Condition and Breakage: Three of these points are complete and one shows signs of multiple impact fractures. The remaining specimen is a basal fragment demonstrating a distal snap fracture

Reworking and Beveling: Three of these points exhibit reworking, specifically along the blade for one and along the blade and stem for the other two. Beveling is apparent on two of the points.

Use-wear: Use-wear analysis was conducted on three of these points. One of the specimens was used exclusively as a projectile point, while another was utilized as a butchering knife to cut soft animal remains and appears to be an exhausted slug. The final specimen is a multifunctional tool utilized as a dart point, as well as a light duty knife used to butcher soft animal remains.

Raw Material Attributes: Raw material for all of these points is local Edwards fine-grained chert.

Comments: La Jita Group II subtype specimens are described as side notched with a basal concavity resulting from stem reshaping.

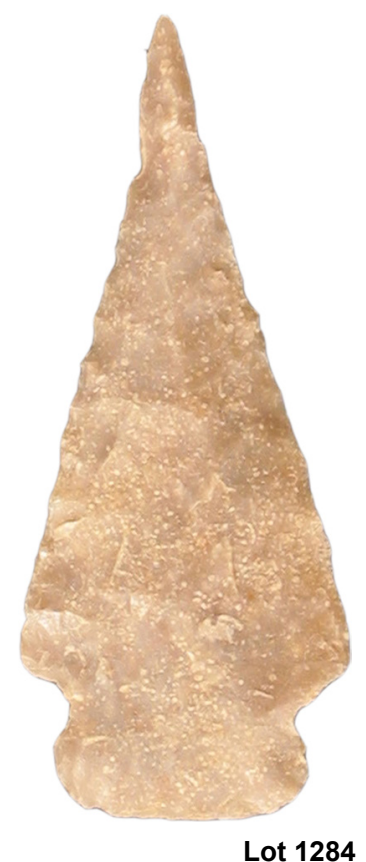

\section{Subtype La Jita Group III}

$(\mathrm{n}=1)($ Lot 1570) (see Appendix C, Figure $10 \mathrm{~h}$ )

Nominal Attributes: This point exhibits a random flaking pattern.

Condition and Breakage: The specimen is complete and does not exhibit breakage.

Reworking and Beveling: This point has been heavily reworked, but does not show signs of beveling.

Use-wear: Use-wear analysis was conducted on this specimen revealing it was utilized as both a projectile point, as well as a light duty cutting tool used to cut soft animal tissue such as flesh.

Raw Material Attributes: The raw material is local Edwards fine-grained chert.

Comments: This is the only La Jita Group III subtype projectile point encountered throughout the entire Gatlin site, which consists of specimens that have been heavily reworked, use-damaged, or exhibit intensive thermal fracturing. 
LANGE

$(\mathrm{n}=2)$ (Lots 327, 863) (see Appendix C, Figure 13 b, c)

Nominal Attributes: One of these points exhibits a random flaking pattern with a needle tip and recurved form.

Condition and Breakage: One specimen is complete while the other is a basal fragment exhibiting a snap fracture.

Reworking and Beveling: Reworking is apparent along the blade of both of these points.

Use-wear: N/A

Raw Material Attributes: Both points are made of local Edwards finegrained chert.

\section{LANGTRY}

$(\mathrm{n}=1)($ Lot 42.3) (see Appendix C, Figure 9 d)

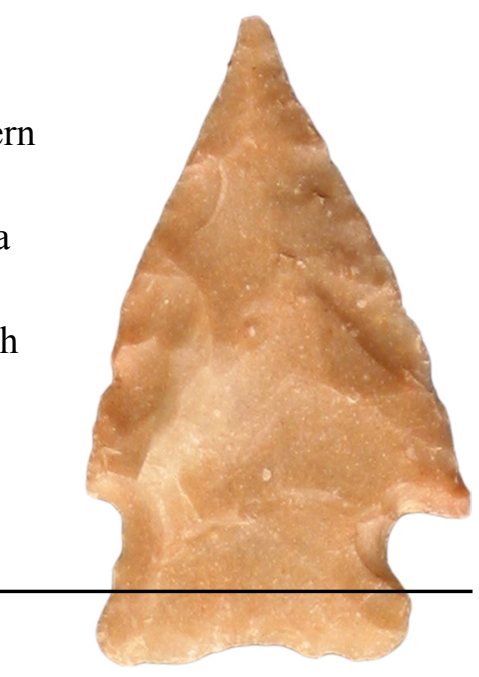

Lot 327

Nominal Attributes: This specimen exhibits a subparallel flaking pattern.

Condition and Breakage: This point is a basal fragment with evidence of a snap fracture, as well as a small amount of postdepositional excavation damage along the basal margin.

Reworking and Beveling: Reworking is evident along the blade, but there are no signs of beveling for this specimen.

Use-wear: N/A

Raw Material Attributes: The specimen is composed of local Edwards fine-grained chert.

\section{Marshall}

$(\mathrm{n}=1)($ Lot 790) (see Appendix C, Figure $14 \mathrm{c})$

Nominal Attributes: This point is classified as a preform.

Condition and Breakage: This is a complete point marked by crude step or hinge fractures.

Reworking and Beveling: These attributes were not recorded for this specimen.

\section{Use-wear: N/A}

Raw Material Attributes: Raw material for this point is local Edwards fine-grained chert.

Comments: Limited attributes, including condition, breakage, heat evidence, and weight, were recorded for some of the Marshall projectile points.

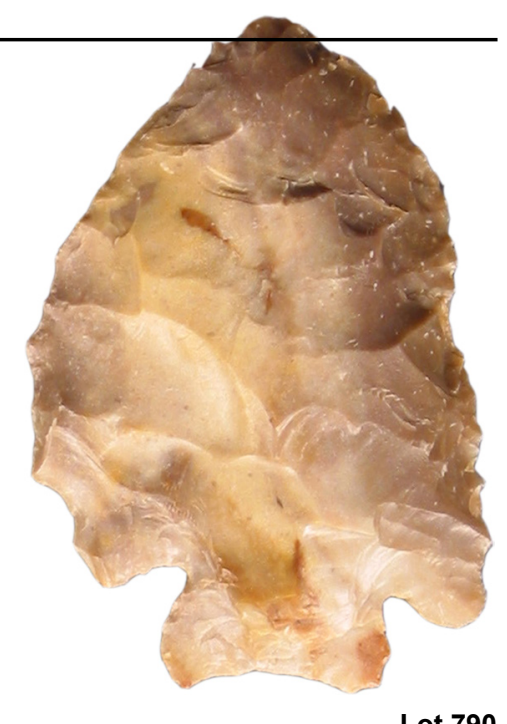

\section{Martindale}

$(\mathrm{n}=13)$

\section{Subtype Martindale A}

$(\mathrm{n}=8)($ Lots 267, 445, 465.2, 471, 520, 766.2, 998, 1538) (see Appendix C, Figure 3 b-Lot 471)

Nominal Attributes: Five of these points exhibit similar flaking patterns with three demonstrating an oblique subparallel pattern and two displaying an oblique parallel pattern. Other flaking patterns observed are random and chevron. 
Condition and Breakage: Three of the six complete points exhibit no breakage. The remaining three complete specimens had a variety of breakages including impact fractures, snap fractures, and thermal breakage. Two of the points are basal fragments with snap fractures.

Reworking and Beveling: Reworking is evident along the blade of six of these points. Beveling is observed on six of the specimens and is described as a slight twist to the left for one, alternate bevel to the left for two, and a slight bevel to the right for one.

Use-wear: Use-wear analysis was performed on four of these specimens, revealing three of the points were utilized as dart points as well as light duty knives or cutting tools to butcher soft animal remains. The fourth of the specimens submitted was utilized solely as a projectile point.

Raw Material Attributes: Raw material for all of these points is local Edwards fine-grained chert. Only one specimen exhibits evidence of heat alteration such as potlids, crazing, and reddening.

Comments: Points included in this Martindale stem group have the characteristic fish-tail base of the typology.

\section{Subtype Martindale C}

$(\mathrm{n}=5)$ (Lots 296, 652, 764.1, 862, 864) (see Appendix C, Figure 3 g-Lot 652)

Nominal Attributes: Two of these points exhibit an oblique subparallel flaking pattern, and two others exhibit a random flaking pattern. Of note, three of these points are serrated.

Condition and Breakage: Only one of these points is a complete specimen with no breakage. The remaining four points are all basal fragments with three exhibiting impact fractures and one exhibiting a snap fracture. Of these, one also shows signs of thermal breakage, and another also demonstrates a snap fracture.

Reworking and Beveling: Reworking is observed along the blade of three of these points. Beveling is present on two of the points; one has a slight bevel to the right and another has an alternate bevel.

Use-wear: Only one of these points was submitted for use-wear analysis, which revealed it was exclusively utilized as a projectile point.

Raw Material Attributes: Raw material for all of these points is local Edwards fine-grained chert. Heat evidence is observed on one specimen, demonstrated through crazing.

Comments: Martindale $\mathrm{C}$ stem group points have indented bases with usually sharp edges, and lack the fish-tail appearance of this typology.

\section{Subtype Martindale Narrow Stem}

$(\mathrm{n}=1)$ (Lot 151) (see Appendix C, Figure 4 a)

Nominal Attributes: This point has a wide blade with an oblique parallel flaking pattern.

Condition and Breakage: The specimen is a basal fragment exhibiting an impact fracture.

Reworking and Beveling: Reworking is evident along the blade, bur there are no signs of beveling.

Use-wear: Use-wear analysis was performed on this specimen, which revealed it was multifunctional tool utilized as a dart point, knife, and burin.

Raw Material Attributes: This point is composed of local Edwards finegrained chert.

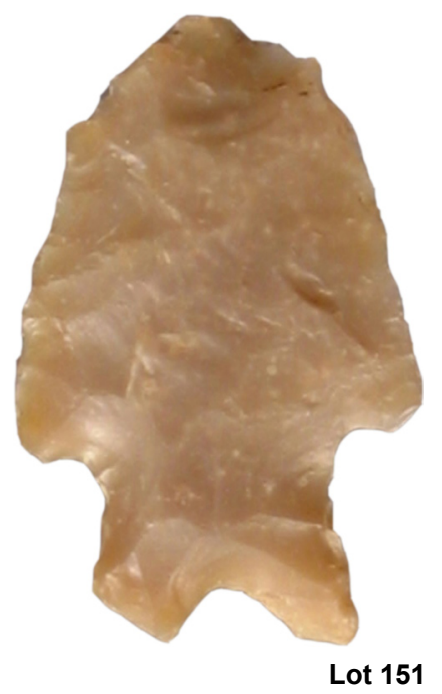

Comments: These points generally have expanding stems formed by deep corner notches, and weakly barbed shoulders. 


\section{Montell}

$(\mathrm{n}=1)($ Lot 147.7)

Nominal Attributes: N/A

Condition and Breakage: This point is a stem fragment with an indeterminate breakage.

Reworking and Beveling: N/A

Use-wear: N/A

Raw Material Attributes: This point is made of local Edwards fine-grained chert.

\section{NoLaN}

$(\mathrm{n}=12)$

\section{Subtype Nolan Group I}

$(\mathrm{n}=4)($ Lots 265, 537, 958, 1563)

Nominal Attributes: Each of these points exhibits its own distinct flaking pattern including chevron, parallel, and random.

Condition and Breakage: Two of these points are complete and both exhibit snap fractures. The other two points are basal fragments with one exhibiting distal damage and thermal breakage, while the other shows evidence of a snap fracture and postdepositional excavation damage.

Reworking and Beveling: Only one of these points exhibits reworking along both the blade and stem. One specimen is beveled along the stem.

\section{Use-wear: N/A}

Raw Material Attributes: Raw material for all of these points is local Edwards fine-grained chert. Heat evidence is only apparent on one of the specimens demonstrated through potlids.

Comments: This Nolan subtype group is described as classic Nolan with elongated blades, tapered shoulders, and steep alternate beveling on the stem.

\section{Subtype Nolan Group II}

$(\mathrm{n}=8)$ (Lots 266, 339.1, 459, 586, 729, 733, 906, 1553) (see Appendix C, Figure 11 d-Lot 906, f-Lot 266)

Nominal Attributes: Flaking patterns are varied for these points with three demonstrating a collateral pattern, two an oblique parallel pattern, and two a random pattern. Of note, two of the specimens have been classified as preforms, of which one demonstrates possible edge grinding.

Condition and Breakage: Most $(n=5)$ of these points are complete. Of these, three exhibit no breakage, one exhibits a burin break, and one has evidence of postdepositional excavation damage. The three remaining points are basal fragments with two exhibiting snap fractures, and one demonstrating thermal breakage.

Reworking and Beveling: Reworking is evident along the blade of three of these points and along the blade and stem of three. Beveling is apparent on many of these points $(n=6)$ either on the blade or stem, occurring more often on the stem. Beveling on the blade is apparent as a right bevel on

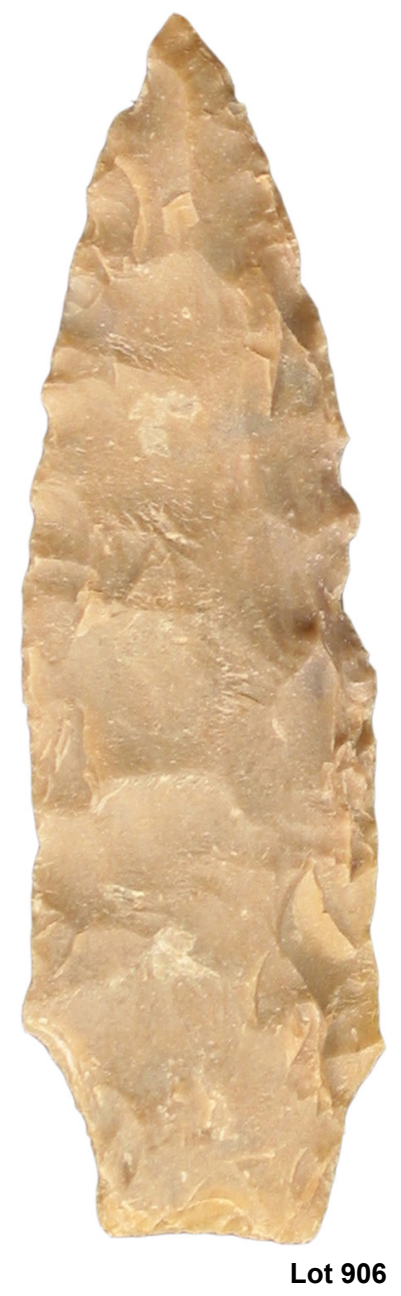


one point, and as a left bevel on another. Beveling on the stem is noted as beveling along the edge on two points, a left bevel on one, and a right bevel on another.

Use-wear: Use-wear analysis was performed on three of these points. One of the specimens was solely utilized as a dart point. Another of the points, a large stemmed bifacial implement, was utilized for hide scraping tissue removal and softening. The final specimen, a stemmed biface, was utilized as a light duty knife to cut soft animal tissue such as flesh.

Raw Material Attributes: Raw material for all of these points consists of local Edwards fine-grained chert. Evidence of thermal alteration including reddening appears on three specimens and potlids on one.

Comments: Group II Nolan projectile points are characterized as "Nolans later in life" (see Appendix D), with lateral edge reworking, diminished blade sizes, stem reshaping or alteration, impact and other fractures, and extensive thermal fractures.

\section{Pandale}

$(\mathrm{n}=1)$ (Lot 147.4) (see Appendix C, Figure 9 h)

Nominal Attributes: This point exhibits an oblique parallel flaking pattern.

Condition and Breakage: This is a complete specimen with no breakage.

Reworking and Beveling: The specimen has an alternately beveled stem and a slight twist to the blade.

\section{Use-wear: N/A}

Raw Material Attributes: This point is composed of dark local Edwards finegrained chert. The specimen is possibly burned.

Comments: Of note, the beveling that created the slight twists on the blades of these specimens is much less than the cork screw twist seen on Lower Pecos specimens.

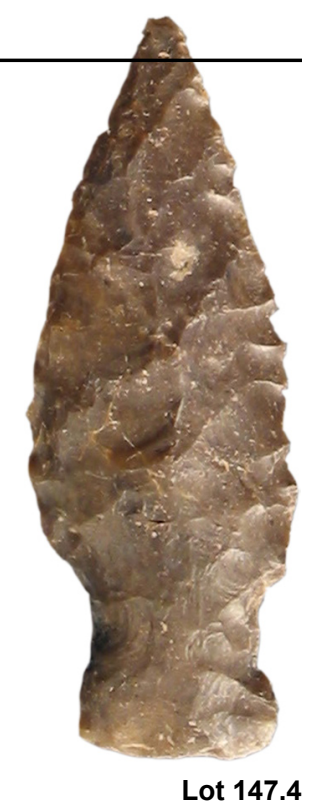

\section{Pedernales}

$(\mathrm{n}=1)$

\section{Subtype Pedernales Stem Form 1}

$(\mathrm{n}=1)($ Lot 728$)$

Nominal Attributes: Flaking pattern was not recorded for this specimen.

Condition and Breakage: This point is a complete specimen with no breakage.

Reworking and Beveling: These attributes were not recorded for this specimen.

Use-wear: N/A

Raw Material Attributes: This point is made of local Edwards fine-grained chert. Patination was not recorded for this specimen.

Comments: Limited attributes, including condition, breakage, heat evidence, and weight were recorded for Pedernales projectile points. 


\section{ToRTugas}

$(\mathrm{n}=2)($ Lots 776, 788) (see Appendix C, Figure 15 a-788, b-776)

Nominal Attributes: One of these points exhibits a random flaking pattern, and the other demonstrates an oblique subparallel pattern.

Condition and Breakage: Both specimens are complete with one exhibiting no breakage, while the other exhibits an impact fracture at the tip.

Reworking and Beveling: Reworking along the blade, as well as a bevel to the right is apparent on both of these points.

Use-wear: N/A

Raw Material Attributes: Raw material for these points is local Edwards fine-grained chert.

Comments: Based on the technology of manufacture, distinctive from that of Early Triangular points, these triangular points have been classified as Tortugas.

\section{UNTYPABLE}

$(\mathrm{n}=14)($ Lots 58.1, 87.1, 174.2, 378, 493.1, 518.17, 561, 562.4, 580, 720, 725, 904.7, 1015, 1145) (see

Appendix C, Figure 18 c-Lot 87.1, e-Lot 561, f-Lot 1145, g-Lot 720)

Nominal Attributes: Flaking pattern was only recorded for two of these points: one exhibited an oblique subparallel pattern and the other demonstrated a subparallel pattern. Of note, one of these specimens is probably a reworked (finished stage) Fairland projectile point. Additionally, one of the specimens has been classified as a preform.

Condition and Breakage: Seven of these points are complete specimens with three lacking breakage, one exhibiting a snap fracture, another demonstrating thermal breakage, and two with indeterminate breakages. Four of the specimens are basal fragments with one exhibiting a distal snap fracture, one showing signs of thermal breakage, and two consisting of fragments and refits due to postdepostional excavation damage. One of specimens is the blade section of a point, damaged at the distal end by impact. Another specimen is a shoulder fragment also with evidence of an impact fracture. The final specimen is a stem fragment terminating at the distal end in a snap fracture.

Reworking and Beveling: Reworking was only recorded on six of these points of which five exhibit such along the blade and one demonstrates this along the blade and stem. Beveling was not recorded for any of these points.

Use-wear: Only one of these points was subjected to use-wear analysis, which revealed it was utilized as a knife to cut moderately resistant materials as well as a rotary drill, and was discarded as an exhausted slug.

Raw Material Attributes: Raw material for all of these points is local Edwards fine-grained chert. Only two of the specimens exhibit evidence of heat alteration apparent as potlids. Patination was was absent on two of the points.

Comments: Limited attributes, including condition, breakage, heat evidence, and weight, were recorded for untypable projectile points.

\section{BIFACIAL TOOLS}

There were 14 formal bifacial tools recovered from OZ3. These were seven butted bifaces, three drills, two Clear Fork tools and two gouges. The seven butted bifaces are divided into two subgroups - modified bifacial edge and unifacial or minimally modified edge (See Appendix C). Lots 518.70, 558.2, 718.4 (see Appendix C, Figure 47), 991.18, and 1224.5, have minimally modified edges. The two modified bifacial edge specimens are Lots 1552.3 and 1564 . Specimen Lot 1552.3 is made from a large flake and resembles a pieces esquillees and was probably used as a wedge tool. Five of the specimens were 
made from upland round or tabular cobbles, while Lot 558.2 was made from a river-worn cobble. Lot 1552.3 was from an indeterminate source. The butted bifaces assemblage is primarily cobble-based tools that were minimally modified from the parent material. The implied functions are chopping, splitting, cutting, and scraping. Use-wear analysis of Lot 718.4 identified evidence of edge damage from cutting moderately hard material such as bone, wood, or antler. Specimen 1224.5 was large enough that it was probably used as a two-handed scraper.

The Clear Fork tools are specimen Lot 81.1 and Lot 387 (see Appendix C, Figure $44 \mathrm{~d}$ and e). Lot 81.1 is a classic-shaped bifacial Clear Fork tool that was resharpened before being lost or discarded. Lot 387 was made from a large percussion flake and retains part of the dorsal surface. Use-wear identified edge damage from scraping and chipping at hard organic material such as bone or antler, and traces of a reddish mineral residue that may be hafting mastic.

The gouges are Specimen Lots 268 and 478 (see Appendix C, Figure 45 a and c). Specimen Lot 268 resembles a Guadalupe Tool as it was shaped from the ventral face of the bit. The bit edge is convex and was used to scrape hard organic material. The lateral margins have indentations that suggest that it has hafted. Lot 478 resembles a thin Clear Fork tool that was also used to scrape hard organic material in a back and forth planing motion. The tool was broken, possibly by an attempt to further thin the specimen. The specimen was probably hafted and was exposed to high heat after discard.

The three drills are Specimen Lots 42.2, 455.2 and 1326.1 (see Appendix C, Figure 42 b, a, and d). Lot 1326.1 is the distal bit of a drill that was resharpened before being broken. Lots 42.2 and 1326.1 are complete and almost complete drills. Lot 42.2 is a t-shaped drill with a wide base that is missing the distal tip. It is made from a late-stage biface or recycled biface tool and the wide base suggests the tool was hand held. Use-wear indicates it was used in a rotary motion against a hard material and used after the tip was broken. The specimen feels as if it has been heat treated. Specimen 455.2 is a key-shaped tool that was probably hafted. The missing distal tip removed traces of use-wear.
Overall, the biface tool assemblage was used for a range of tasks against moderate to hard organic materials, examples of which are certain species of wood, bone, and antler. The parent source for the tools include cobble reduction as in the butted bifaces, large percussion flakes used for Clear Fork tools, and smaller flakes for tools such as drills. The more formal biface tools - the Clear Fork tools, gouges, and drills - appear to have all been used, resharpened, and maintained. These tools are found infrequently in all of the occupation zones at the Gatlin site, and were most frequently found broken from use or from resharpening or refurbishment. These tools were probably curated and portable tools that were taken from site to site. Functions such as chopping may have been performed at the Gatlin site with the more robust Butted Bifaces, which could account for the lack of broken gouge and Clear Fork tools.

\section{BIFACES}

There were 363 non-diagnostic bifaces recovered from $\mathrm{OZ} 3$ at the Gatlin site. This biface assemblage, categorized according to reduction stage, includes 13 Stage 1, 35 Stage 2, 59 Stage 3, 55 Stage 4, 132 Stage 5 , and 69 indeterminate stage bifaces (Table 10.2). Of the 13 Stage 1 bifaces, seven are complete, one is a basal fragment, one is a medial fragment, and four are indeterminate fragments. The shapes of the complete Stage 1 bifaces were ovate $(n=3)$, round $(\mathrm{n}=1)$, and amorphous $(\mathrm{n}=3)$. The average edge angle of the complete bifaces is 50.1 degrees. All of the Stage 1 bifacial fragments are made of fine-grained chert and were broken during manufacture. Only one of the fragments was heated, which occurred after it was discarded.

The Stage 2 bifaces consist of 15 complete bifaces, six basal fragments, one marginal fragment, and 13 indeterminate fragments. The two most common outline shapes of complete specimens were ovate $(n=5)$ and pointed oval $(\mathrm{n}=5)$. The average (mean) Width/ Thickness ratio of the complete Stage 2 bifaces is 2.6 and the average edge angle is 42.6 degrees. Most of the Stage 2 fragments have manufacturing breaks, but one was fractured from excessive heat. In addition, two of the complete bifaces and two additional fragments showed evidence of burning.

The Stage 3 bifaces consist of 21 complete bifaces, seven basal fragments, two marginal fragments, a 
Table 10.2. Occupation Zone 3 Attribute Measurements for General Bifaces by Stage

\begin{tabular}{|c|c|c|c|c|c|c|c|c|}
\hline & & \multicolumn{6}{|c|}{ Stage } & \multirow[b]{2}{*}{ Total } \\
\hline & & 1 & 2 & 3 & 4 & 5 & Indeter & \\
\hline \multirow{2}{*}{ Max L } & $\mathrm{N}$ & 8 & 15 & 20 & 16 & 11 & & 70 \\
\hline & Mean & 98.33 & 91.27 & 83.35 & 76.28 & 58.99 & & 81.31 \\
\hline \multirow{2}{*}{ Max W } & $\mathrm{N}$ & 12 & 28 & 40 & 41 & 87 & & 208 \\
\hline & Mean & 73.12 & 62.23 & 56.18 & 41.71 & 39.99 & & 48.35 \\
\hline \multirow{2}{*}{ Max Th } & $\mathrm{N}$ & 13 & 35 & 59 & 54 & 123 & 66 & 350 \\
\hline & Mean & 26.28 & 22.82 & 16.03 & 10.07 & 7.93 & 7.70 & 11.75 \\
\hline \multirow{2}{*}{ W/T Ratio } & $\mathrm{N}$ & 13 & 35 & 59 & 54 & 123 & 66 & 350 \\
\hline & Mean & 2.66 & 2.17 & 2.36 & 3.06 & 3.49 & 0.00 & 2.41 \\
\hline \multirow{2}{*}{ Weight } & $\mathrm{N}$ & 13 & 35 & 59 & 55 & 132 & 69 & 363 \\
\hline & Mean & 157.98 & 108.41 & 63.77 & 31.16 & 19.11 & 8.43 & 39.75 \\
\hline \multirow{2}{*}{ Edge Angle } & $\mathrm{N}$ & 13 & 35 & 58 & 55 & 127 & 66 & 354 \\
\hline & Mean & 46.92 & 41.86 & 34.64 & 29.62 & 26.83 & 26.58 & 30.72 \\
\hline
\end{tabular}

distal fragment, a medial fragment, an interior fragment, and 26 indeterminate fragments. During the later stages of biface reduction, there is a greater variability in the outline shape at the Gatlin site. The shapes and counts for the Stage 3 complete bifaces are: seven ovate, six pointed oval, two lanceolate, a lunate, a quadrilateral, a round, a teardrop, and two amorphous shaped specimens. Overall, the complete bifaces have a Width/Thickness ratio of 3.2 and an average edge angle of 35.4 degrees. The Stage 3 fragments consisted of mostly fragments broken due to manufacture $(n=33)$, with the others broken by exposure to extreme heat $(n=3)$ or post depositional actions $(n=1)$. Eight of the Stage 3 bifaces and fragments showed evidence of exposure to high heat through either reddening or the presence of pot lids.

The Stage 4 bifaces consist of 14 complete bifaces, nine basal fragments, 18 distal fragments, two medial fragments, two marginal fragments, and 10 indeterminate fragments. The complete specimens vary in overall shape, with four pointed oval, four subtriangular, two ovate, two lanceolate, one round, and one bipointed biface. The average Width/Thickness ratio of the complete specimens is 4.16 with an average edge angle of 30.6 degrees. Most of Stage 4 fragments $(n=37)$ are from manufacture failure, while the rest have damage caused by excessive heating and inderterminate causes. Within the Stage 4 bifaces, nine of the specimens have evidence of heating or burning.
Among the 132 Stage 5 bifaces, only eight are complete specimens. The 124 Stage 5 biface fragments are classified as: basal $(\mathrm{n}=53)$, distal $(\mathrm{n}=33)$, medial $(\mathrm{n}=18)$, marginal $(\mathrm{n}=8)$, and indeterminate $(\mathrm{n}=12)$. The shapes of the complete bifaces are three pointed oval, two lanceolate, two subtriangular, and one lunate. The complete specimens have an average Width/Thickness ratio of 4.4 and an average edge angle of 25.5 degrees. Four of the complete specimens were analyzed for use-wear, including two of the large, lanceolate shaped bifaces (Lots 559 and 1144), which determined they were used as butchering knives. A large, thin lunate biface (Lot 410) was percussion thinned and finished with marginal bifacial pressure flaking to shape the edges, similar to retouch noted in the Early Triangular projectile point assemblage. It was likely a light-duty knife used to cut soft materials such as hide or meat on the convex edge. The fourth biface analyzed for use-wear was a thin, ovate shaped bilateral knife (Lot 742) that was probably used to cut moderately resistant materials such as wood or soaked antler.

Seventeen of the 124 Stage 5 fragments are sufficiently large enough to determine the overall shape of the original specimen, including 11 lanceolate, four subtriangular, one triangular, and one pointed oval shaped bifaces. Manufacturing breakage accounts for 93 specimens, while the rest are fragmented due to natural breaks, burning, and indeterminate cause. Overall, 26 of the Stage 5 biface specimens show evidence of being heated or burned. 


\section{FLAKE TOOLS}

The modified flake tools assemblage from OZ3 consists of 17 side scrapers, 10 end scrapers, four end and side scrapers, two transverse scrapers, one convergent scraper, one graver, 32 utilized flakes, 97 retouched flakes, and one indeterminate modified flake tool (Table 10.3). Five of the end scrapers are complete with the remaining being distal fragments $(n=4)$ and one longitudinal fragment. All but one of the complete scrapers is unifacially modified towards the dorsal side. The remaining complete scraper is bifacially modified along the distal margin although the apparent utilized portion is unifacial towards the dorsal side. The mean percentage of the modified portion to the entire perimeter length of each complete scraper is 29 percent. Most of the end scraper fragments are unifacially modified along the dorsal side. One of these is bifacially modified (although not sufficiently to be classified a biface). Only one of the complete end scrapers was heated, causing slight reddening.

The four end and side scrapers are complete specimens. Seven of the 17 side scrapers are complete. The 10 fragments are: four proximal, four distal, one longitudinal, and one medial fragment. The complete side scrapers have unifacial modifications to the dorsal face - with two having modifications along the left lateral margin, four along the right lateral margin, and one with modifications along both lateral margins. The average modified portion a lateral edge of the scrapers is 40 percent of the total lateral edge lengths. One complete specimen, analyzed for use-wear, has one retouched edge that was used to scrape moderately resistant materials such as wood. In addition the specimen had cortical edge with unifacial step flaking, grinding, and areas of matte polish probably produced by raking a bone or antler across the edge to intentionally dull it. Of the side scraper fragments, all but one has unifacial modifications to the dorsal side with the remaining fragment being unifacially modified towards the ventral surface. As far as exposure to heat, one of the complete side scrapers and one of the side scraper fragments has slight reddening.

The one convergent scraper is a thick, unifacially retouched flake detached from an unprepared percussion core. Use-wear analysis indicates that all edges except the striking platform were used to scrape fresh hides. The modified portion of the lateral edge on the convergent scraper accounts for 74 percent of the entire lateral edge length. Both the transverse scrapers are complete and unifacial toward the dorsal surface with an average of 32 percent of the entire lateral edge of each scraper being modified. The graver has complete, continuous, modifications along the entire lateral edge.

The expedient flake tool assemblage consists of 32 utilized flakes and 97 retouched flakes. There are 19 complete utilized flakes, four proximal fragments, four distal fragments, two medial fragments, a longitudinal fragment, a marginal fragment, and two indeterminate fragments. Only two of the utilized flakes were heated or burned.

Table 10.3. Occupation Zone 3 Attribute Measurements for Complete Modified Flake Subcategories

\begin{tabular}{|c|c|c|c|c|c|c|c|c|c|c|}
\hline & & $\begin{array}{c}\text { End } \\
\text { Scraper }\end{array}$ & \begin{tabular}{|c|} 
End \& Side \\
Scraper
\end{tabular} & $\begin{array}{l}\text { Side } \\
\text { Scraper }\end{array}$ & \begin{tabular}{|c|} 
Transverse \\
Scraper
\end{tabular} & $\begin{array}{c}\text { Convergent } \\
\text { Scraper }\end{array}$ & Graver & $\begin{array}{l}\text { Utilized } \\
\text { Flake }\end{array}$ & $\begin{array}{c}\text { Retouched } \\
\text { Flake }\end{array}$ & Total \\
\hline Count & $\mathrm{N}$ & 5 & 4 & 7 & 2 & 1 & 1 & 19 & 38 & 77 \\
\hline Length & Mean & 70.55 & 62.41 & 80.72 & 57.78 & 86.39 & 43.83 & 63.06 & 70.79 & 68.90 \\
\hline Width & Mean & 63.15 & 59.95 & 50.25 & 57.68 & 47.78 & 31.82 & 53.44 & 61.36 & 57.79 \\
\hline Thickness & Mean & 15.18 & 17.66 & 15.30 & 9.34 & 11.88 & 8.34 & 13.86 & 20.81 & 17.50 \\
\hline Weight & Mean & 79.60 & 88.05 & 67.91 & 28.35 & 52.00 & 11.20 & 43.77 & 85.64 & 70.54 \\
\hline $\begin{array}{l}\text { Perimeter } \\
\text { Length }\end{array}$ & Mean & 220.26 & 208.12 & 217.58 & 193.73 & 210.70 & 130.69 & 179.27 & 215.31 & 205.05 \\
\hline $\begin{array}{l}\text { Perimeter } \\
\text { Retouch Length }\end{array}$ & Mean & 61.66 & 143.78 & 84.72 & 62.13 & 155.30 & 130.69 & 45.87 & 67.39 & 69.41 \\
\hline $\begin{array}{l}\text { Marginal } \\
\text { Retouch \% }\end{array}$ & Mean & 0.29 & 0.66 & 0.39 & 0.32 & 0.74 & 1.00 & 0.28 & 0.32 & 0.35 \\
\hline Max Edge Angle & Mean & 50.00 & 53.00 & 39.14 & 40.50 & 50.00 & 65.00 & 36.13 & 52.52 & 46.69 \\
\hline
\end{tabular}


The retouched flakes consist of 38 complete specimens, 15 proximal fragments, 15 distal fragments, 10 longitudinal fragments, six medial fragments, seven marginal fragments, and five indeterminate fragments. The retouched flakes have minimal retouch, and most of the retouch scars are on the dorsal face.

\section{CORES}

There were 171 cores recovered from OZ3. This includes 120 complete and 50 core fragments subdivided into the following categories: five bidirectional, 36 bifacial, 109 multidirectional, 10 unidirectional, four slab, and seven indeterminate cores (Table 10.4). The five bidirectional cores consist of four complete cores and one core fragment and are a mixture of nodular, tabular, and indeterminate rock parent material. Three of the bidirectional cores were made from fine-grained chert and none showed evidence of heat treatment.

Of the bifacial cores, 26 are complete, and most of these are from nodular fine-grained chert procured from a riverine environment. The rest are from upland lag gravels or indeterminate procurement locales. Two of the bifacial cores were heated or burned.

The largest category of cores recovered from $\mathrm{OZ} 3$ is multidirectional cores with a total of 109 specimens. Seventy-six of the specimens are complete and 33 are fragments. Based on cortex and overall shape, the parent material consists of nodular and tabular fine-grained riverine cobbles. Three of the complete multidirectional cores are made from upland lag gravels, demonstrating the clear preference for, or accessibility of, riverine cobbles. Sixteen of the multidirectional cores exhibit evidence of being heated or burned.
The 10 unidirectional cores were all complete and nine were made from fine-grained chert. Six specimens are from riverine cobbles and the source for the remaining four is indeterminate. The shapes of the parent cobble material are nodular $(\mathrm{n}=4)$, tabular $(n=3)$, and indeterminate $(n=3)$. All of the material for the cores was locally available. One of the cores may have been used as a battering or chopping tool. A single specimen was burned after being discarded.

Four slab cores were recovered from OZ3. These cores are complete with three of the specimens containing minimal flake scars (mean=2.7) and one having 10 flake scars. Three of the slab cores are from riverine procurement locales while the fourth is from an indeterminate locale. None of the slab cores show evidence of heat treatment or burning.

Core fragments make up most of the indeterminate cores found in OZ3 with only one complete specimen in this subcategory. The complete indeterminate core is a tabular specimen procured from a riverine environment. However, the specimen contained only one flake scar suggesting the core was a tested cobble. None of the indeterminate cores display evidence of heat treatment.

\section{DeBITAGE}

The flake reduction technology for debitage is shown in Table 10.5. The table includes complete flakes and proximal fragments. What is significant is that that the percentages of biface thinning, core reduction and indeterminate flakes are almost unchanged from OZ2 indicating that the same types of lithic reduction continue in $\mathrm{OZ3}$.

In OZ3, core reduction flakes with no cortex are on average $4 \mathrm{~mm}$ shorter than similar flakes in OZ2. While this implies that cores were reduced more intensively, overall, the size categories of debitage are

Table 10.4. Occupation Zone 3 Attribute Measurements for Complete Exhausted and Unexhausted Cores

\begin{tabular}{|l|l|c|c|c|c|c|c|c|}
\hline \multicolumn{2}{|c|}{} & Bifacial & Multidirectional & Bidirectional & Unidirectional & Slab & Indeter & Total \\
\hline Count & $\mathrm{N}$ & 26 & 76 & 4 & 10 & 4 & 1 & 121 \\
\hline Max Length & Mean & 95.44 & 95.96 & 95.43 & 81.03 & 62.94 & 114.14 & 93.66 \\
\hline Max Width & Mean & 75.25 & 72.21 & 71.76 & 63.52 & 41.12 & 77.46 & 71.15 \\
\hline Max Thickness & Mean & 34.97 & 40.03 & 45.61 & 42.03 & 13.21 & 33.86 & 38.35 \\
\hline Weight & Mean & 271.59 & 283.74 & 391.40 & 204.70 & 3208.25 & 378.10 & 375.61 \\
\hline Max Flake Scar Length & Mean & 42.68 & 45.54 & 36.11 & 40.41 & 12.24 & 42.68 & 43.05 \\
\hline \# Flake Scars & Mean & 7.65 & 5.84 & 4.25 & 5.90 & 4.50 & 1.00 & 6.10 \\
\hline
\end{tabular}


statistically the same, whether biface thinning flakes, core reduction or indeterminate flakes. The consistency in size of debitage and in the types and size of tools being produced appear to be conditioned, to a major degree, by the size range of available and utilized lithic material.

There is a slight increase in core reduction flakes with abraded platforms from OZ2. The increase is a modest 3 percent; however, when combined with the increase of flakes with no cortex, it suggests that greater core preparation is occurring in OZ3. The percentage of complete flakes, which drops to 11.17 percent is significant. The high breakage rate is characteristic of trampling and post depositional effects rather than a change in flake production.

The debitage analysis reflects the composition of the biface and flake tool assemblages and lithic reduction activities: late-stage biface reduction occurred on site, cores were reduced, and flake tools were being manufactured. Despite an increase in bifaces recovered from OZ3, there is not a proportional increase in the debitage, indicating that most early-stage biface reduction was still occurring off site. Using the diversity of projectile point styles recovered from $\mathrm{OZ} 3$ as an indicator, there were many groups using the Gatlin site over time. The amount of debitage created can be accounted for by brief, low intensity usage. The high breakage rate of the debitage suggests that there was little deposition occurring between these visits that resulted in trampling and breakage.

\section{GRound STONE TooLs}

There were three mano fragments, Specimen Lots 659.8 (see Appendix C, Figure 68 b), 731.2, and 991.19, a metate (Lot 777.1) (see Appendix C, Figure 69). Lot 659.8 the largest mano specimen, and was used on both faces and the edges were also rounded from use. The other two fragments were worn on both faces. All specimens were made from sandstone. The metate fragment Lot 777.1 is the only sandstone metate from the Gatlin site. The specimen is a radial fragment and is $70 \mathrm{~mm}$ thick at what would be the center of a complete metate, and $30 \mathrm{~mm}$ at the edge, suggesting the metate was well-worn, broken from use and discarded.

Although ground stone tools were relatively uncommon at the Gatlin site, they indicate that, periodically, other tasks were performed at the site besides lithic reduction, butchering, and cooking. There is a gender implication, since ground tools and food preparation are associated with women during the Middle and Late Archaic (Taylor and Highley 1995).

\section{FAUNAL ASSEMBLAGE}

The faunal assemblage from OZ3 includes 893 specimens weighing a total of $574.1 \mathrm{~g}$. Two taxa are recognizable in the assemblage, bison (Bison bison) and white-tailed deer (Odocoileus virginia$n u s)$. The bison is represented by one small tooth enamel fragment weighing 4.7 grams and four other bone fragments including one cranial fragment and a well-preserved whole cuneiform. The white-tailed deer $(n=31)$ is represented by a heavily weathered

Table 10.5. Biface, Core, Resharpening, and Indeterminate Flake Measurements from Occupation Zone3

\begin{tabular}{|c|c|c|c|c|c|}
\hline & \multicolumn{4}{|c|}{ Flake Type } & \multirow[b]{2}{*}{ Total } \\
\hline & $\begin{array}{l}\text { Biface } \\
\text { Thinning }\end{array}$ & $\begin{array}{c}\text { Core } \\
\text { Reduction }\end{array}$ & $\begin{array}{c}\text { Tool } \\
\text { Resharpening }\end{array}$ & Indeter & \\
\hline Count & 2881 & 846 & 3 & 634 & 4364 \\
\hline Max of Length (mm) & 74.2 & 100.3 & 39.6 & 88.9 & 100.3 \\
\hline Average of Length (mm) & 21.29 & 41.28 & 29.43 & 22.58 & 26 \\
\hline Max of Thickness (mm) & 48 & 26.6 & 8.9 & 11 & 48 \\
\hline Average of Thickness $(\mathrm{mm})$ & 2.55 & 8.17 & 3.9 & 3.6 & 3.95 \\
\hline Max of Width (mm) & 81.2 & 93.1 & 38.3 & 61.7 & 93.1 \\
\hline Average of Width (mm) & 14.86 & 32.43 & 20.57 & 16.71 & 19.07 \\
\hline Max of Wt (g) & 20.3 & 268.2 & 0 & 14.1 & 268.2 \\
\hline Average of Weight (g) & 0.89 & 9.92 & $\mathrm{~N} / \mathrm{A}$ & 1.22 & 2.54 \\
\hline Sum of Weight (g) & 1775.4 & 5344.2 & 0 & 589.6 & 7709.2 \\
\hline
\end{tabular}


astragalus fragment, two proximal antler fragments, cunate, femur, humerus fragments, a proximal ulna fragment, rib fragments, scapula fragments, various tooth fragments, and whole molars.

Large mammal ( $\mathrm{n}=72)$ was identified, including several shaft fragments (likely deer) and a small piece of tooth enamel. Also, three heavily burned and weathered fragments were classified as small mammal, possibly rabbit. With the exception of a few shaft fragments, the remaining 99 percent of the faunal assemblage from OZ2 generally includes small $(<3 \mathrm{~mm})$ fragments that primarily appear to be highly weathered large to medium mammal bone, likely white-tailed deer. Burning was noted on 16 percent of the bone specimens, with 4 percent of the assemblage burned, resulting in calcining of the bone. Almost all of the bone was classified as fragmented or extremely fragmented bone, reflecting the degraded nature of the assemblage. Slight to extreme weathering in the form of cracking and fragmentation was noted on most specimens. No cultural modifications in the forms of cutmarks or green-bone breaks were evident on any of the specimens.

As with the OZ2 assemblage, the poor state of preservation of the $\mathrm{OZ} 3$ assemblage hinders interpretations on foraging and butchering systems as well as general subsistence base and environmental reconstruction. It is obvious that large game in the form of bison and whitetailed deer formed a primary component of the overall hunting strategy. The presence of the teeth from both species suggests whole animals or select cranial portions (mandibles) where brought back to the site as opposed to strictly front or hind portions. Though some small mammal was identified, the overall absence of other species/taxa in the assemblage suggests a rather limited range of animal exploitation. However this interpretation must be weighed against the poor preservation of the bone and the likelihood that other species may have been present which are no longer visible.

\section{FEATURE ASSEMBLAGE}

The eight features encountered within OZ3 were located mainly within Area A-NE and several within Area A-SW. These include Features 6, 15, 16/17, 18, 19, 20, 32 and 38 (Figure 10.2; see Figures 7.6 and 7.9). Features 19 and 20 were not completely excavated due to feature boundaries extending beyond the excavation limits. Of note, in contrast to the burned rock features, Feature 32 was a dense cluster of debitage, including several large chert tablets and approximately 250 flakes. Although there were some associated burned rocks, the feature was not thought to be an actual burned rock feature/hearth. The debitage cluster had a crescent outline shape and a 9-cm-thick, stacked cross section, covering a $51 \times 47-\mathrm{cm}$ area. Two Early Triangular points were found in the same 10-cm excavation unit level and two more were found at the same level in an adjacent unit. This feature likely represents the remains of an individual flint-knapping episode where a core or cores were reduced. The full results of special studies from the burned rock features are located in Appendices E through I.

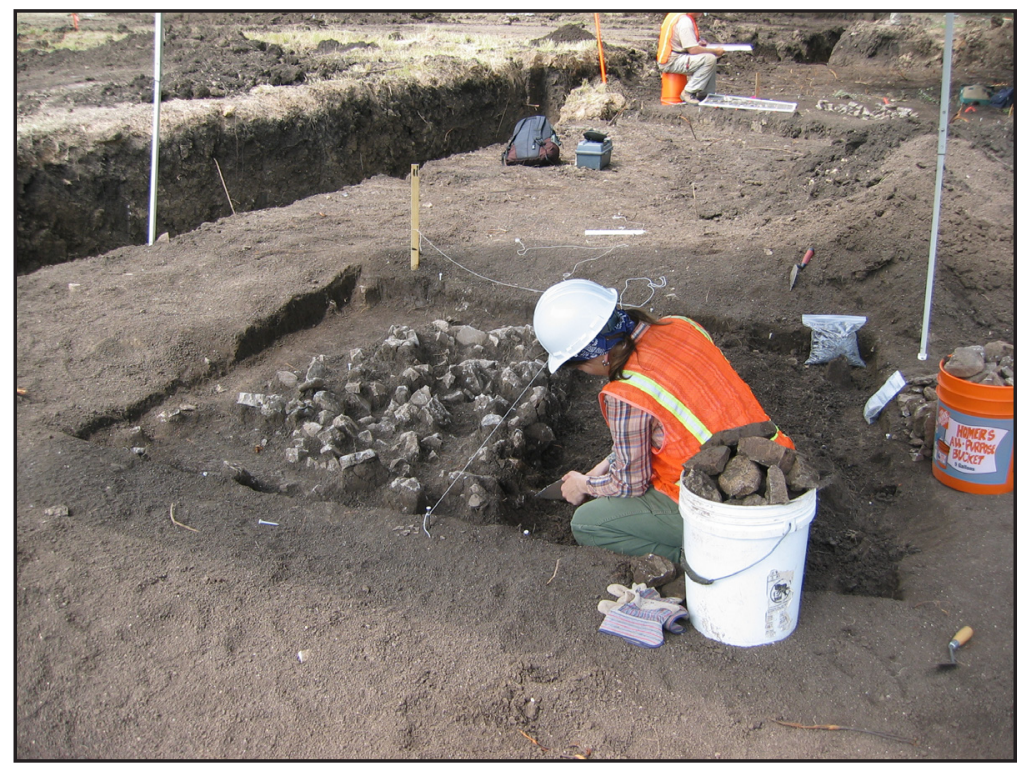

Figure 10.2. Feature 6 cross section facing west. 


\begin{tabular}{|c|c|c|c|c|}
\hline r & & Flotation Results & \multicolumn{2}{|c|}{$\begin{array}{l}\text { Chenopodium, hackberry, prostrate } \\
\text { spurge, grass family, prickly poppy }\end{array}$} \\
\hline & & Radiocarbon Dates & \multicolumn{2}{|l|}{ N/A } \\
\hline Feature Type & Burned rock cluster & \multirow{2}{*}{$\begin{array}{l}\text { Associated floor } \\
\text { elevation range }(\mathrm{m})\end{array}$} & \multirow{2}{*}{\multicolumn{2}{|c|}{$97.8-97.7 \mathrm{~m}$}} \\
\hline Occupation Zone & 3 & & & \\
\hline Stratigraphic Context & $2 A b 1 / 2 A b 2$ interface & \multirow{3}{*}{$\begin{array}{l}\text { Associated Diagnostics } \\
\text { (Lot No. and elevation) }\end{array}$} & Lange (655) & $97.76 \mathrm{~m}$ \\
\hline Area & A-NE & & La Jita (656) & $97.75 \mathrm{~m}$ \\
\hline Provenience & $\begin{array}{l}\text { Located during Gradall clearing; roughly } \\
\text { located N1027 E1060 }\end{array}$ & & $\begin{array}{l}\text { Narrow Stem Martindale } \\
\text { (Lot 657) }\end{array}$ & $97.51 \mathrm{~m}$ \\
\hline Center & ca. N1027.69 E1061.34 & \multirow{3}{*}{$\begin{array}{l}\text { Diagnostics above and } \\
\text { adjacent to feature (Lot No.) } \\
\text { proximity radius }=2.0 \mathrm{~m} \\
\text { proximity elevation }=0.1 \mathrm{~m}\end{array}$} & \multirow{3}{*}{\multicolumn{2}{|c|}{ None }} \\
\hline Top Elevation & $97.85 \mathrm{~m}$ & & & \\
\hline Bottom Elevation & $97.40 \mathrm{~m}$ & & & \\
\hline Size & $230 \times 170 \mathrm{~cm}$ & \multirow{6}{*}{$\begin{array}{l}\text { Diagnostics below and } \\
\text { adjacent to feature (Lot No.) } \\
\text { proximity radius }=2.0 \mathrm{~m} \\
\text { proximity elevation }=0.4 \mathrm{~m}\end{array}$} & Nolan (459) & $97.47 \mathrm{~m}$ \\
\hline Shape & Circular, basin shaped & & Bulverde (470) & $97.39 \mathrm{~m}$ \\
\hline Fuel Type & None & & Nolan (537) & $97.45 \mathrm{~m}$ \\
\hline Lipids & $\mathrm{N} / \mathrm{A}$ & & La Jita (548) & $97.44 \mathrm{~m}$ \\
\hline Faunal Evidence & None & & Untyped (561) & $97.47 \mathrm{~m}$ \\
\hline Pollen & $\mathrm{N} / \mathrm{A}$ & & Nolan (586) & $97.40 \mathrm{~m}$ \\
\hline
\end{tabular}

\section{Description}

Feature 6 was a dense cluster of overlapping and adjacent burned limestone cobbles. The circular configuration measured $230 \times 170 \mathrm{~cm}$ horizontally and was $45 \mathrm{~cm}$ thick. The horizontal and vertical margins were defined by the extent of burned rocks. In cross section, a clear basin-shaped morphology was apparent. The basal portion of the basin extended into the $B$ horizon, suggesting that the basin was prehistorically excavated into the B horizon. Based on this observation, it is possible that earlier sediments and artifacts were intermixed with the soil matrix of this feature. The fine matrix within Feature 6 was indistinguishable from the surrounding soil, and was collected for flotation analysis. No charcoal, charcoal flecking, or thermally altered soil were observed.

The total number and weight of limestone burned rocks associated with this feature was 1,019 and $203.5 \mathrm{~kg}$. Addtionally, two chert burned rocks weighing $0.4 \mathrm{~kg}$ were also observed. The rocks comprising the feature were a mixture of angular, rounded, and tabular limestone. However, it was noted that most of the burned rock over $15 \mathrm{~cm}$ consisted of large tabular limestone slabs. The condition of the burned rock was also mixed and consisted of highly fragmented, fractured in situ, and unfractured rocks.
The excavation of Feature 6 resulted in the recovery of 342 pieces of debitage, two biface fragments, two cores, and one utilized flake. Temporally diagnostic artifacts within a 1$\mathrm{m}$ radius of the feature's margins and within the associated 10-cm estimated floor elevation consist of one Lange dart point and one La Jita dart point. A Narrow Stem Martindale dart point was recovered within the matrix near the base of Feature 6. It is possible that the Narrow Stem Martindale point derives from soil sediments disturbed when the feature was prehistorically excavated into the B soil horizon.

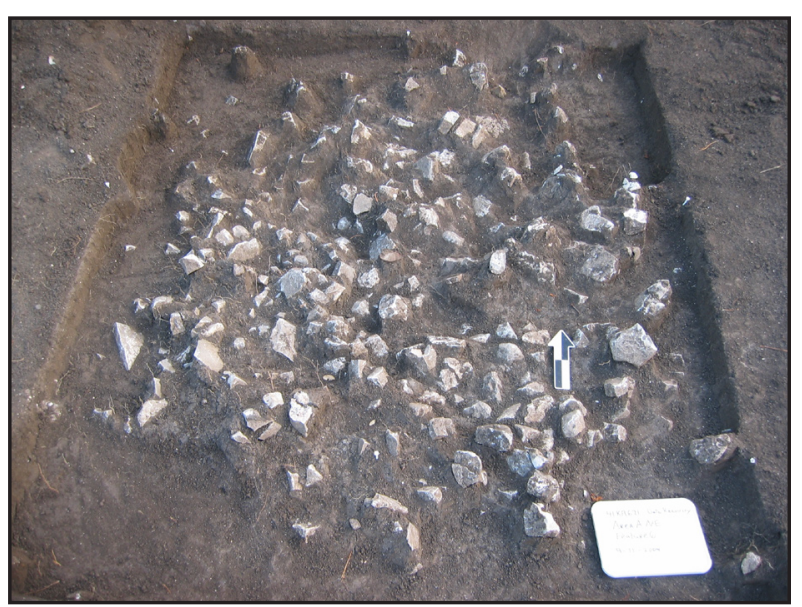

Overview of Feature 6. 


\begin{tabular}{|c|c|c|c|c|}
\hline 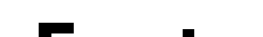 & & Radiocarbon Dates & \multicolumn{2}{|l|}{$\mathrm{N} / \mathrm{A}$} \\
\hline & & $\begin{array}{l}\text { Associated floor } \\
\text { elevation range }(\mathrm{m})\end{array}$ & \multicolumn{2}{|l|}{$97.30-97.20 \mathrm{~m}$} \\
\hline & & $\begin{array}{l}\text { Associated Diagnostics } \\
\text { (Lot No. and elevation) }\end{array}$ & \\
\hline Feature Type & Burned rock scatter & \multirow{8}{*}{$\begin{array}{l}\text { Diagnostics above and } \\
\text { adjacent to feature (Lot No.) } \\
\text { proximity radius }=2.0 \mathrm{~m} \\
\text { proximity elevation }=0.1 \mathrm{~m}\end{array}$} & \multirow[b]{2}{*}{ Martindale (488.1) } & \multirow{2}{*}{$\begin{array}{l}97.20- \\
97.10 \mathrm{~m}\end{array}$} \\
\hline Occupation Zone & 3 & & & \\
\hline Stratigraphic Context & $2 B \mathrm{w}$ & & \multirow{2}{*}{ Untyped (493.1) } & \multirow{2}{*}{$\begin{array}{l}97.40- \\
97.30 \mathrm{~m}\end{array}$} \\
\hline Area & A-NE & & & \\
\hline Provenience & N1027-1029 E1068 & & Martindale (638) & $97.28 \mathrm{~m}$ \\
\hline Center & N1028.60 E1069.60 & & Early Triangular (646) & $97.23 \mathrm{~m}$ \\
\hline Top Elevation & $97.48 \mathrm{~m}$ & & Early Triangular (647) & $97.25 \mathrm{~m}$ \\
\hline Bottom Elevation & $97.22 \mathrm{~m}$ & & Martindale (652) & $97.20 \mathrm{~m}$ \\
\hline Size & $100 \times 100 \mathrm{~cm}$ & \multirow{7}{*}{$\begin{array}{l}\text { Diagnostics below and } \\
\text { adjacent to feature (Lot No.) } \\
\text { proximity radius }=2.0 \mathrm{~m} \\
\text { proximity elevation }=0.1 \mathrm{~m}\end{array}$} & Gower (477) & $97.20 \mathrm{~m}$ \\
\hline Shape & Circular, relatively flat & & Early Triangular (479) & $97.20 \mathrm{~m}$ \\
\hline Fuel Type & Indeterminable hardwood & & Martindale (482) & $97.11 \mathrm{~m}$ \\
\hline Lipids & N/A & & Gower (483) & $97.12 \mathrm{~m}$ \\
\hline Faunal Evidence & None & & Marcos (503.1) & $\begin{array}{l}97.20- \\
97.10 \mathrm{~m} \\
\end{array}$ \\
\hline Pollen & $\begin{array}{l}\text { Quercus. Exploitable: mustard family, } \\
\text { hackberry; post-occupational: ragweed }\end{array}$ & & Untyped (513) & $\begin{array}{l}97.20- \\
97.10 \mathrm{~m}\end{array}$ \\
\hline Flotation Results & Chenopodium, amaranth & & Untyped (617) & $97.10 \mathrm{~m}$ \\
\hline
\end{tabular}

\section{Description}

Feature 15 consisted of a small, circular scatter of burned rock with a diameter of approximately $100 \mathrm{~cm}$ and a thickness of $26 \mathrm{~cm}$. The feature was associated with the $2 \mathrm{Bw}$ stratigraphic profile, and there was no noticeable difference between the internal feature matrix and the surrounding soil color.

A total of 37 burned limestone specimens was recovered from Feature 15. These weighed a total of $23.8 \mathrm{~kg}$. Angular rocks, rounded specimens, and flat slabs composed the feature, with no type predominating. The physical condition of the burned rocks was a mixture of highly fragmented, fractured in situ, and intact specimens. Less than 50 percent of these were adjacent or touching one another.

No organics (bone, mussel shell, or charcoal) were found within the feature matrix. Ten pieces of debitage were col- lected from the feature matrix. Although no diagnostic projectile points were recovered in direct association with Feature 15, two Early Triangular points (Lots 646 and 647) and a Martindale point (Lot 652) were found within $1 \mathrm{~m}$, at elevations of $97.23 \mathrm{~m}, 97.25 \mathrm{~m}$, and $97.2 \mathrm{~m}$, respectively. 


\section{Features 16 and 17}

\begin{tabular}{|c|c|}
\hline Feature Type & Burned rock cluster (F16) and scatter (F17) \\
\hline Occupation Zone & 3 \\
\hline Stratigraphic Context & Base of $2 \mathrm{Ab} 2$ \\
\hline Area & A-SW \\
\hline Provenience & N1019 E1044-1046; N1021 E1044-1046 \\
\hline Center & N1021.50 E1046.00 \\
\hline Top Elevation & $97.77 \mathrm{~m}$ \\
\hline Bottom Elevation & $97.55 \mathrm{~m}$ \\
\hline Size & $\begin{array}{l}\text { Cluster (F16) } 100 \times 100 \mathrm{~cm} / S \text { catter (F17) } 400 \mathrm{~cm} \\
\text { N-S and } 200 \mathrm{~cm} \mathrm{SW} \mathrm{to} \mathrm{NE}\end{array}$ \\
\hline Shape & $\begin{array}{l}\text { Cluster (F16) circular; some layering/Scatter (F17) } \\
\text { amorphous; relatively flat }\end{array}$ \\
\hline Fuel Type & Plateau live oak \\
\hline Lipids & High fat content food (seed/animal fat) \\
\hline Faunal Evidence & $\begin{array}{l}\text { Bison and white-tailed deer bone fragments and } \\
\text { teeth within feature; adjacent: large mammal and } \\
\text { unidentifiable bone fragments }\end{array}$ \\
\hline Pollen & $\begin{array}{l}\text { Quercus. Exploitable: mustard family and mallow } \\
\text { family }\end{array}$ \\
\hline Flotation Results & $\begin{array}{l}\text { Charred remains: walnut nutshell, hickory/walnut } \\
\text { nutshell, indeterminable seeds }\end{array}$ \\
\hline
\end{tabular}

\begin{tabular}{|c|c|c|}
\hline Radiocarbon Dates & \multicolumn{2}{|c|}{$\begin{array}{l}\text { Beta- } 206117: 4140 \pm 40 \text { B.P., } 4830-4530 \mathrm{cal} \\
\text { B.P. at } 97.65 \mathrm{~m} \text {; Beta-207377: } 4210 \pm 40 \text { B.P., } \\
4850-4800 \text { AND } 4770-4620 \text { cal B.P. at } 97.65 \mathrm{~m}\end{array}$} \\
\hline $\begin{array}{l}\text { Associated floor } \\
\text { elevation range }(\mathrm{m})\end{array}$ & \multicolumn{2}{|l|}{$97.70-97.60 \mathrm{~m}$} \\
\hline \multirow{6}{*}{$\begin{array}{l}\text { Associated Diagnostics } \\
\text { (Lot No. and elevation) }\end{array}$} & Early Triangular (994) & $97.65 \mathrm{~m}$ \\
\hline & Early Triangular (995) & $97.62 \mathrm{~m}$ \\
\hline & Early Triangular (996) & $97.72 \mathrm{~m}$ \\
\hline & Early Triangular (997) & $97.65 \mathrm{~m}$ \\
\hline & Martindale (998) & $97.67 \mathrm{~m}$ \\
\hline & Bell (1000) & $97.63 \mathrm{~m}$ \\
\hline \multirow{6}{*}{$\begin{array}{l}\text { Diagnostics above and } \\
\text { adjacent to feature (Lot } \\
\text { No.) proximity radius = } \\
2.0 \mathrm{~m} \\
\text { proximity elevation = } \\
0.1 \mathrm{~m}\end{array}$} & Early Triangular (860) & $97.75 \mathrm{~m}$ \\
\hline & Martindale (862) & $97.60 \mathrm{~m}$ \\
\hline & Lange (863) & $97.63 \mathrm{~m}$ \\
\hline & Martindale (864) & $97.60 \mathrm{~m}$ \\
\hline & Early Triangular (888.5) & $97.70 \mathrm{~m}$ \\
\hline & Gower (889.1) & $97.60 \mathrm{~m}$ \\
\hline \multirow{6}{*}{$\begin{array}{l}\text { Diagnostics below and } \\
\text { adjacent to feature (Lot } \\
\text { No.) proximity radius = } \\
2.0 \mathrm{~m} \\
\text { proximity elevation = } \\
0.1 \mathrm{~m}\end{array}$} & Martindale (867) & $97.58 \mathrm{~m}$ \\
\hline & Early Triangular (868) & $97.56 \mathrm{~m}$ \\
\hline & Martindale (885) & $97.57 \mathrm{~m}$ \\
\hline & Gower (1550) & $97.57 \mathrm{~m}$ \\
\hline & Andice (841) & $97.56 \mathrm{~m}$ \\
\hline & Early Triangular (853) & $97.53 \mathrm{~m}$ \\
\hline
\end{tabular}

\section{Description}

Features 16 and 17 consisted of two discrete areas of burned rocks, with one core cluster area (Feature 16) and one area of scattered burned rocks adjacent to the northwest (Feature 17). Features 16 and 17 were originally identified as separate burned rock features. However, subsequent excavations of these two features revealed that they were part of a single feature. Stratigraphically, Feature 16/17 was within the Compressed Early and Middle Archaic component, at the base of the $2 \mathrm{Ab} 2$ horizon. The feature measured approximately $400 \times 200 \mathrm{~cm}$ horizontally and $22 \mathrm{~cm}$ thick. The basal configuration of the dense central cluster was circular and measured $100 \mathrm{~cm}$ in diameter. In cross section, no apparent basin shaped profile was visible, although some rock layering was observed within the feature's core area.

A total of 654 burned rock specimens was recorded from Feature $16 / 17$. These specimens weighed a total of 144.8 $\mathrm{kg}$. The physical shape of the burned rocks was a mixture of both rounded and angular specimens. The physical condition of the Feature 16/17 burned rock was highly variable with no apparent patterns. Burned rocks were observed in highly fragmented, fractured in situ, and unfractured conditions. Within the feature's center, most of the burned rocks were adjacent and touching one another. However, along the feature periphery, burned rocks were more widely dispersed with less than 50 percent touching.

Burned rock samples collected for lipid analysis were obtained from the center of the feature. The analysis identified high fat content (seed/animal fat) cooking residue. This corresponds to the identification of bison, white-tailed deer, and large mammal bone fragments $(n=55+)$ within and adjacent to the feature. Charred walnut and hickory nutshells and unidentifiable seeds were recovered from the flotation and analysis of the feature matrix.

The excavation of Feature 16/17 resulted in the recovery of 1,633 pieces of debitage, numerous formal and informal tools, cores, and one ground stone fragment. Assocatied temporally diagnostic point types recovered consisted of four Early Triangular points, one Martindale point, and one Bell point.

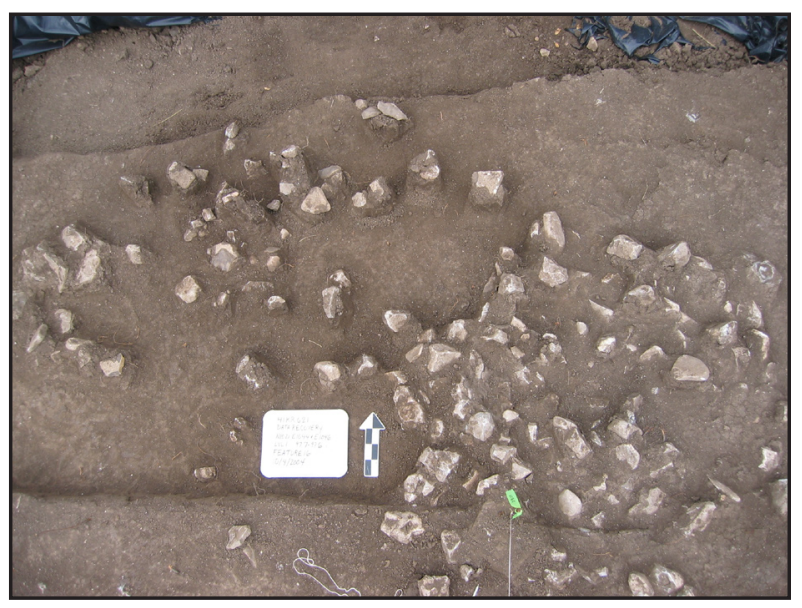

Overview of Feature 16/17. 


\begin{tabular}{|c|c|c|c|c|}
\hline & & Faunal Evidence & \multicolumn{2}{|c|}{ Unidentifiable bone fragments } \\
\hline & & Pollen & \multicolumn{2}{|c|}{ Exploitable: mustard family and hackberry } \\
\hline & & Flotation Results & \multicolumn{2}{|l|}{ None } \\
\hline & & Radiocarbon Dates & \multicolumn{2}{|l|}{ None } \\
\hline Feature Type & Small burned rock cluster & Associated floor & \multicolumn{2}{|l|}{$97.30-97.15 \mathrm{~m}$} \\
\hline Occupation Zone & 3 & \multirow{2}{*}{$\begin{array}{l}\text { Associated Diagnostics } \\
\text { (Lot No. and elevation) }\end{array}$} & \multirow{2}{*}{\multicolumn{2}{|c|}{ None }} \\
\hline Stratigraphic Context & $2 \mathrm{Bw}$ & & & \\
\hline Area & A-NE & \multirow{4}{*}{$\begin{array}{l}\text { Diagnostics above and } \\
\text { adjacent to feature (Lot } \\
\text { No.) proximity radius = } \\
2.0 \mathrm{~m} \text { proximity elevation } \\
=0.1 \mathrm{~m}\end{array}$} & Gower (477) & $97.20 \mathrm{~m}$ \\
\hline Provenience & N1029 E1066 & & Early Triangular (479) & $97.20 \mathrm{~m}$ \\
\hline Center & N1029.85 E1066.90 & & Untyped (493.1) & $97.40-97.30 \mathrm{~m}$ \\
\hline Top Elevation & $97.30 \mathrm{~m}$ & & Martindale (638) & $97.28 \mathrm{~m}$ \\
\hline Bottom Elevation & $97.15 \mathrm{~m}$ & \multirow{5}{*}{$\begin{array}{l}\text { Diagnostics below and } \\
\text { adjacent to feature (Lot } \\
\text { No.) proximity radius = } \\
2.0 \mathrm{~m} \\
\text { proximity elevation = } \\
0.2 \mathrm{~m}\end{array}$} & Martindale (482) & $97.11 \mathrm{~m}$ \\
\hline Size & $70 \times 60 \mathrm{~cm}$ & & Gower (483) & $97.12 \mathrm{~m}$ \\
\hline Shape & Circular, relatively flat & & Gower (497.1) & $97.00-96.90 \mathrm{~m}$ \\
\hline Fuel Type & None & & Untyped (513) & $97.20-97.10 \mathrm{~m}$ \\
\hline Lipids & $N / A$ & & Untyped (617) & $97.10 \mathrm{~m}$ \\
\hline
\end{tabular}

\section{Description}

Feature 18 was a small, discrete cluster of burned rock within the $2 \mathrm{Bw}$ soil horizon. It was roughly circular in outline and measured $70 \times 60 \mathrm{~cm}$. The feature was $15 \mathrm{~cm}$ thick. In cross section, there was no apparent layering of the burned rock, although a few small burned rocks were found beneath the feature. There was no distinguishable difference between the feature matrix and the surrounding soil. There was, however, evidence of burning below the feature as indicated by very fine charcoal fragments (not recovered).

Forty limestone burned rock specimens were recovered from the feature, which had a combined weight of 11.9 $\mathrm{kg}$. Additionally, three chert burned rocks were recovered and they weighed $0.1 \mathrm{~kg}$. The shape of the burned rocks was highly variable. The larger burned rocks were flat slabs with rounded edges, while the smaller burned rocks were either angular or rounded. Only one burned rock appeared fractured in situ. Most (>50 percent) of the burned rocks were adjacent and touching one another.
Organic preservation within the feature was minimal. No charcoal was recovered within the feature matrix, but a small bone fragment was collected. Debitage was observed throughout the feature matrix and collected. While no diagnostic artifacts were found within direct association with the feature, an Early Triangular point and a Gower point were found within the same unit, both at an elevation of $97.2 \mathrm{~m}$.

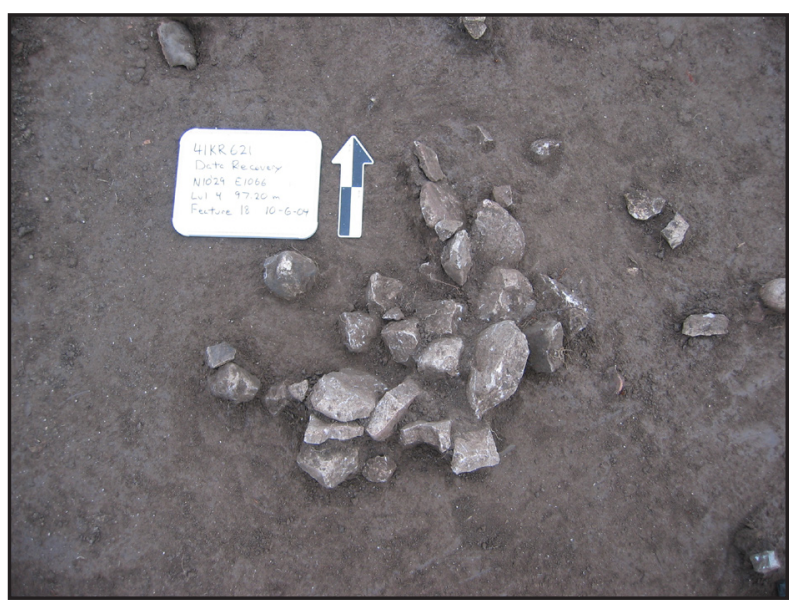

Close-up of Feature 18. 


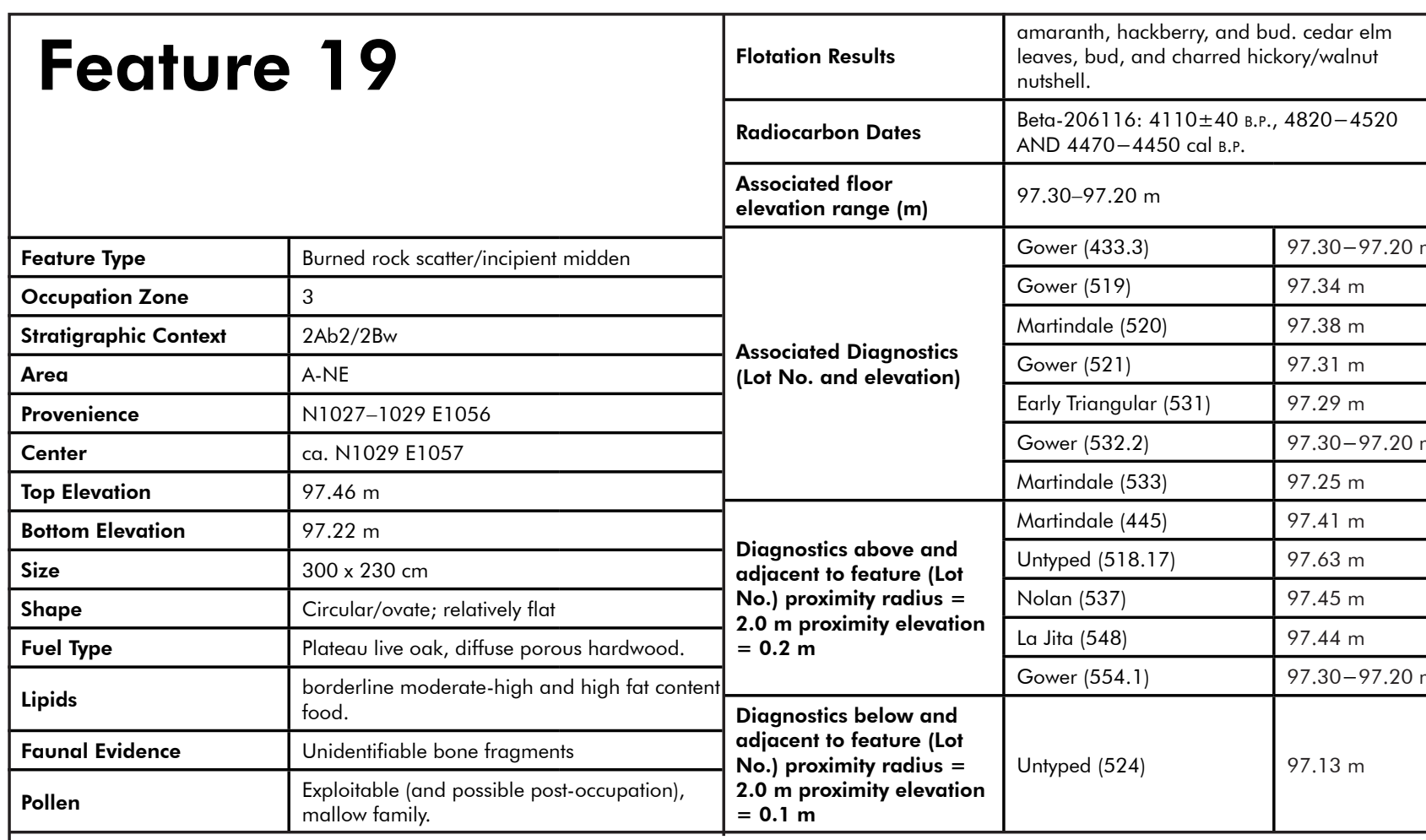

\section{Description}

Feature 19 was a dense scatter of burned rock, specifically limestone, covering an area of approximately $4 \mathrm{~m}^{2}$. It was located primarily within the $2 \mathrm{Ab} 2$ horizon, although portions extended approximately $5 \mathrm{~cm}$ into the $2 \mathrm{Bw}$ horizon below. The feature was circular/ovate in shape and apparently extended west and north beyond the excavated boundaries of Area A-NE.

The exposed maximum dimensions of Feature 19 were 300 $x 230 \mathrm{~cm}$, oriented roughly northwest-southeast. The feature was $24 \mathrm{~cm}$ thick. Dense concentrations of burned rock were found in various locations throughout the feature, with the two most discrete concentrations occurring in its southeastern and northwestern halves. The dense concentration of burned rock on the southeastern side was composed primarily of large $(>10 \mathrm{~cm}$ ) limestone rocks. In contrast, the northwestern burned rock concentration consisted of smaller $(5-10 \mathrm{~cm})$, more tightly packed rocks.

A total of 1,062 burned rock specimens was recorded from Feature 19. These specimens weighed a combined total of $174.2 \mathrm{~kg}$. The feature's components were an amalgam of rounded stones, angular specimens, and slab-like limestone. Similarly, the physical condition of the Feature 19 burned rocks was highly variable with no apparent patterns. The burned rocks were adjoining ( $<50$ percent touching) one another, while the layering and overlapping of rocks was observed to be most prevalent within the small dense concentration in the northwestern portion of the feature.

The only organics observed within Feature 19 were 42 small fragments of bone. None of the fragments were identifiable as to taxon or element. Charcoal samples were obtained from both the northern and southern portions of the feature, although only the southern specimen produced a viable date.

A total 632 individual pieces of debitage were collected from within the Feature 19 soil matrix. Additionally, six chert cores, a possible mano, and three bifaces were recovered from the matrix. One of the bifaces (Lot 410) is a very well made lunate-shaped biface encountered within the feature's northern portion at an elevation of $97.36 \mathrm{~m}$ (see Appendix C, Figure 49). Eight dart points were also recovered from within the feature or its immediate vicinity. These points include four Gower points, two Martindale points, an Early Triangular point, and one untyped dart point.

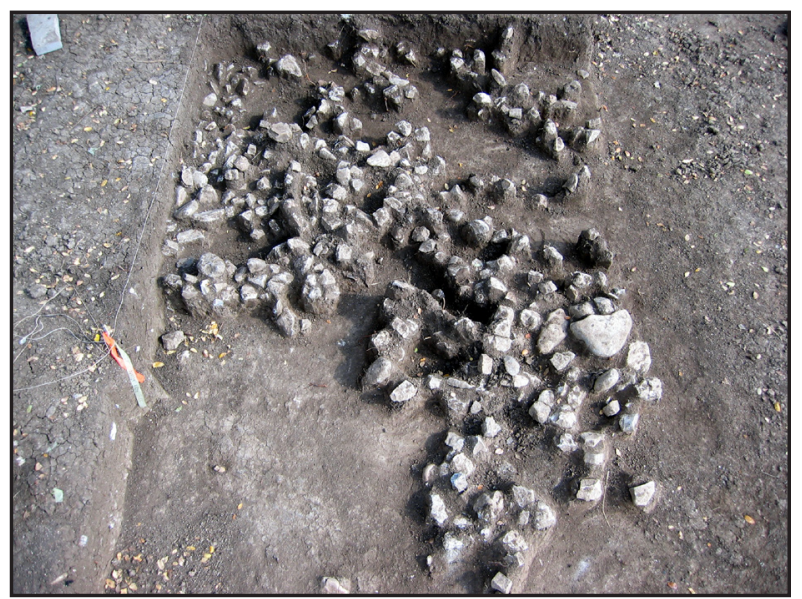

Overview of Feature 19, north is up. 


\begin{tabular}{|c|c|c|c|c|}
\hline & & Pollen & \multicolumn{2}{|c|}{$\begin{array}{l}\text { Exploitable (and possible post-occupation): } \\
\text { mustard family and mallow family }\end{array}$} \\
\hline & & Flotation Results & \multicolumn{2}{|l|}{ Hackberry, bud } \\
\hline Feature Type & Small burned rock cluster; rock-lined hearth & Radiocarbon Dates & \multicolumn{2}{|l|}{ None } \\
\hline Occupation Zone & 3 & \multirow{2}{*}{$\begin{array}{l}\text { Associated floor } \\
\text { elevation range }(\mathrm{m})\end{array}$} & \multirow{2}{*}{\multicolumn{2}{|c|}{$97.30-97.20 \mathrm{~m}$}} \\
\hline Stratigraphic Context & $2 \mathrm{Bw}$ & & & \\
\hline Area & A-NE & \multirow{4}{*}{$\begin{array}{l}\text { Associated Diagnostics } \\
\text { (Lot No. and elevation) }\end{array}$} & Martindale (303) & $97.25 \mathrm{~m}$ \\
\hline Provenience & N1033 E1058 & & Early Triangular (304) & $97.24 \mathrm{~m}$ \\
\hline Center & N1033.75 E1058.05 & & Nolan (339.1) & $97.3 \mathrm{~m}$ \\
\hline Top Elevation & $97.30 \mathrm{~m}$ & & Early Triangular (345) & $97.25 \mathrm{~m}$ \\
\hline Bottom Elevation & $97.19 \mathrm{~m}$ & \multirow{4}{*}{$\begin{array}{l}\text { Diagnostics above and } \\
\text { adjacent to feature (Lot } \\
\text { No.) proximity radius = } \\
2.0 \mathrm{~m} \text { proximity elevation } \\
=0.1 \mathrm{~m}\end{array}$} & Lange (327) & $97.30 \mathrm{~m}$ \\
\hline \multirow{2}{*}{ Size } & \multirow{2}{*}{$\begin{array}{l}\text { Exposed portion: } 60 \times 45 \mathrm{~cm} ; 3 \text { rocks scattered } \\
25 \mathrm{~cm} \text { south of main cluster }\end{array}$} & & Nolan (339.1) & $97.30-97.20 \mathrm{~m}$ \\
\hline & & & Early Triangular (345) & $97.25 \mathrm{~m}$ \\
\hline \multirow{2}{*}{ Shape } & \multirow{2}{*}{$\begin{array}{l}\text { Circular, slightly ovate; clear basin-like shape } \\
\text { with some layering }\end{array}$} & & & \\
\hline & & \multirow{4}{*}{$\begin{array}{l}\text { Diagnostics below and } \\
\text { adjacent to feature (Lot } \\
\text { No.) proximity radius = } \\
2.0 \mathrm{~m} \text { proximity elevation } \\
=0.1 \mathrm{~m}\end{array}$} & Gower (320.2) & $97.20-97.10 \mathrm{~m}$ \\
\hline Fuel Type & Plateau live oak, indeterminable charcoal & & Gower (320.3) & $97.20-97.10 \mathrm{~m} ;$ \\
\hline Lipids & $\mathrm{N} / \mathrm{A}$ & & Martindale (329) & $97.15 \mathrm{~m}$ \\
\hline Faunal Evidence & Highly fragmented bone (not collected) & & Martindale (330.2) & $97.10 \mathrm{~m}$ \\
\hline
\end{tabular}

\section{Description}

Feature 20 consisted of a small, circular cluster of burned rock found within the upper $2 \mathrm{Bw}$ soil horizon. The exposed horizontal dimensions of the feature were $60 \times 45 \mathrm{~cm}$, oriented north-south; however, the east-west axis was truncated by the unexcavated western wall of Area A-NE. The thickness of the feature was $11 \mathrm{~cm}$. In cross section, the feature exhibited a clear basin-like shape with some layering. Although there was no noticeable difference between the internal feature matrix and the surrounding brown soil color, the soil color beneath the burned rock was slightly darker.

All of the burned rock within Feature 20 was limestone. A total of 75 burned rock specimens, weighing a total of $12.0 \mathrm{~kg}$, was recovered from the feature. The burned rocks were mostly angular fragments, although several rounded specimens were also present. Although the rocks displayed evidence of burning, most were unfractured. The burned rocks were densely packed, with more than 50 percent of the burned rocks overlapping one another.
Thirty-seven pieces of lithic debitage were recovered from within the feature matrix. Although charcoal was not observed within the feature matrix, fragments were recovered when screening the feature matrix through $1 / 8$-inch screen. Four diagnostic projectile points were found within a $1-\mathrm{m}$ radius of Feature 20 and within the estimated $10-\mathrm{cm}$ floor level. These consisted of two Early Triangular points, a Martindale point, and a Nolan point. With the exception of the Nolan point, which was found within the screen, all of the projectile points were found within $1 \mathrm{~cm}$ (in elevation) of each other, suggesting a possible occupation floor.

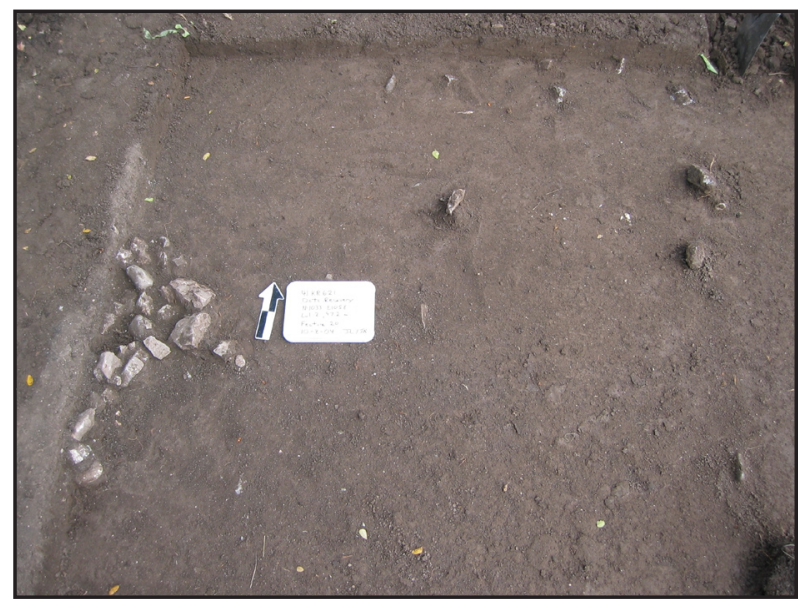

Overview of Feature 20. 


\begin{tabular}{|c|c|c|c|c|}
\hline & & Pollen & \multicolumn{2}{|l|}{ N/A } \\
\hline & & Flotation Results & \multicolumn{2}{|l|}{ N/A } \\
\hline & & Radiocarbon Dates & \multicolumn{2}{|l|}{$\mathrm{N} / \mathrm{A}$} \\
\hline & & \multirow{2}{*}{$\begin{array}{l}\text { Associated floor } \\
\text { elevation range }(\mathrm{m})\end{array}$} & \multicolumn{2}{|l|}{$97.70-97.60 \mathrm{~m}$} \\
\hline Feature Type & $\begin{array}{l}\text { Cluster of debitage and some burned } \\
\text { rock }\end{array}$ & & \multirow{2}{*}{\multicolumn{2}{|c|}{ None }} \\
\hline Occupation Zone & 3 & $\begin{array}{l}\text { Associated Diagnostics } \\
\text { (Lot No. and elevation) }\end{array}$ & & \\
\hline Stratigraphic Context & $2 \mathrm{Ab} 2$ & \multirow{7}{*}{$\begin{array}{l}\text { Diagnostics above and } \\
\text { adjacent to feature (Lot } \mathrm{No} \text {.) } \\
\text { proximity radius }=2.0 \mathrm{~m} \\
\text { proximity elevation }=0.1 \mathrm{~m}\end{array}$} & Early Triangular (892) & $97.65 \mathrm{~m}$ \\
\hline Area & A-SW & & Early Triangular (893) & $97.63 \mathrm{~m}$ \\
\hline Provenience & N1019 E1050 (NW) & & Early Triangular (897.1) & $97.60 \mathrm{~m}$ \\
\hline Center & N1020.62 E1050.18 & & Early Triangular (898) & $97.69 \mathrm{~m}$ \\
\hline Top Elevation & $97.71 \mathrm{~m}$ & & Untyped (904.7) & $97.75 \mathrm{~m}$ \\
\hline Bottom Elevation & $97.62 \mathrm{~m}$ & & Nolan (1553) & $97.63 \mathrm{~m}$ \\
\hline Size & $51 \times 47 \mathrm{~cm}$ & & Early Triangular (1554) & $97.68 \mathrm{~m}$ \\
\hline Shape & Crescent; stacked & \multirow{4}{*}{$\begin{array}{l}\text { Diagnostics below and } \\
\text { adjacent to feature (Lot No.) } \\
\text { proximity radius }=2.0 \mathrm{~m} \\
\text { proximity elevation }=0.1 \mathrm{~m}\end{array}$} & \multirow{4}{*}{ Gower (1557) } & \multirow{4}{*}{$97.56 \mathrm{~m}$} \\
\hline Fuel Type & N/A & & & \\
\hline Lipids & N/A & & & \\
\hline Faunal Evidence & Unidentifiable bone fragments & & & \\
\hline
\end{tabular}

\section{Description}

Feature 32 was a dense, crescent-shaped cluster of mostly large pieces of debitage with some burned rock. Feature 32 was within the lower $2 \mathrm{Ab} 2$ horizon, with the underlying $2 \mathrm{Bw}$ horizon beginning approximately $10 \mathrm{~cm}$ below the base of the feature.

The feature consisted of several large tablets of chert $(>10$ $\mathrm{cm})$, numerous large flakes $(>5 \mathrm{~cm})$, and pieces of burned limestone. The horizontal dimensions of the feature were 51 $x 47 \mathrm{~cm}$. In cross section, the feature materials appeared to be stacked in a pile approximately $9 \mathrm{~cm}$ thick. The density of debitage was greatest within the western half of the feature. No difference was observed between the feature matrix and the surrounding soil.

The burned rocks within Feature 32 were all limestone. A total of 39 burned rock specimens was recovered from Feature 32 , weighing a total of $4.3 \mathrm{~kg}$. Most of the rocks were rounded, fractured in situ, and adjoining one another.
Debitage formed the dominant artifact type within the feature, with 250 pieces. Many of these appear to derive from the same parent raw material and might refit onto one another. If this is the case, Feature 32 may represent an intact knapping surface. No charcoal was observed within or around the feature, but six fragments of bone were recovered from the feature matrix. Because Feature 32 did not appear to be hearth-like, no flotation, bulk matrix, burned rock, or pollen/phytolith samples were collected. Two Early Triangular dart points were found within the same level and unit quadrant as the feature at similar levels: $97.63 \mathrm{~m}$ and $97.65 \mathrm{~m}$. Two additional Early Triangular points were recovered to the southeast within $1 \mathrm{~m}$ of the feature and within the same estimated $10-\mathrm{cm}$ floor level.

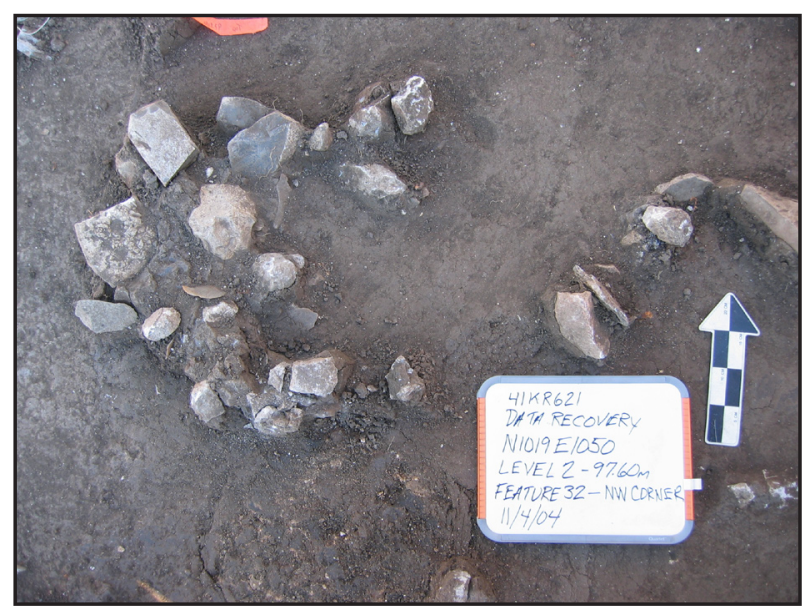

Overview of Feature 32. 


\begin{tabular}{|c|c|c|c|c|}
\hline 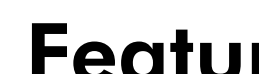 & & Flotation Results & \multicolumn{2}{|c|}{$\begin{array}{l}\text { Charred remains: hockor/walnut nutshell and } 1 \\
\text { indeterminable seed }\end{array}$} \\
\hline & & Radiocarbon Dates & \multicolumn{2}{|c|}{$\begin{array}{l}\text { Beta- } 207389: 4610 \pm 40 \text { в.P., } 5460-5380 \mathrm{cal} \text { B.P. } \\
\text { AND } 5340-5290 \mathrm{cal} \text { B.P. above feature at } 97.91 \mathrm{~m} \text {; } \\
\text { Beta- } 206131: 4530 \pm 40 \text { B.P., } 5310-5040 \mathrm{cal} \\
\text { B.P. at } 97.88 \mathrm{~m}\end{array}$} \\
\hline Feature Type & Small burned rock cluster & $\begin{array}{l}\text { Associated floor elevation } \\
\text { range }(m)\end{array}$ & \multicolumn{2}{|l|}{$97.90-97.80 \mathrm{~m}$} \\
\hline Occupation Zone & 3 & \multirow{2}{*}{$\begin{array}{l}\text { Associated Diagnostics } \\
\text { (Lot No. and elevation) }\end{array}$} & La Jita (1515.2) & $97.90-97.80 \mathrm{~m}$ \\
\hline Stratigraphic Context & $2 \mathrm{Bk}$ & & Early Triangular (1515.3) & $97.90-97.80 \mathrm{~m}$ \\
\hline Area & $\mathrm{B}$ & \multirow{8}{*}{$\begin{array}{l}\text { Diagnostics above and } \\
\text { adiacent to feature (Lot } \\
\text { No.): proximity radius = } \\
2.0 \mathrm{~m} \text {, proximity elevation } \\
=0.1 \mathrm{~m}\end{array}$} & Untyped (1411) & $98.05 \mathrm{~m}$ \\
\hline Provenience & N1014 E1036 (NE) & & Kinney (1430) & $97.97 \mathrm{~m}$ \\
\hline Center & N1015.70 E1037.46 & & La Jita (1431) & $97.94 \mathrm{~m}$ \\
\hline Top Elevation & $97.90 \mathrm{~m}$ & & La Jita (1432) & $97.92 \mathrm{~m}$ \\
\hline Bottom Elevation & $97.76 \mathrm{~m}$ & & Untyped (1518) & $98.00 \mathrm{~m}$ \\
\hline Size & $60 \times 50 \mathrm{~cm}$ & & Kinney (1526) & $98.04 \mathrm{~m}$ \\
\hline Shape & Roughly circular, relatively flat & & La Jita (1528) & $97.95 \mathrm{~m}$ \\
\hline Fuel Type & Unknown liana and indeterminable hardwood & & Bulverde (1529) & $97.94 \mathrm{~m}$ \\
\hline Lipids & Very high fat content food (seed/animal fat) & \multirow{3}{*}{$\begin{array}{l}\text { Diagnostics below and } \\
\text { adiacent to feature (Lot } \\
\text { No.): proximity radius }= \\
2.0 \mathrm{~m} \text {, proximity elevation } \\
=0.1 \mathrm{~m}\end{array}$} & \multirow{3}{*}{\multicolumn{2}{|c|}{ None }} \\
\hline Faunal Evidence & Unidentifiable bone fragments and tooth enamel & & & \\
\hline Pollen & $\begin{array}{l}\text { Low-spine Asteraceae. Post-occupational: mustard } \\
\text { family and mallow family }\end{array}$ & & & \\
\hline
\end{tabular}

\section{Description}

Feature 38 was a small, discrete cluster of burned rock found within the upper part of the 2Bk horizon. Composed mostly of rounded limestone cobbles, the feature was roughly circular in outline, extending $60 \times 50 \mathrm{~cm}$. The feature was $14 \mathrm{~cm}$ thick, and in cross section, no rock layering or discernible basin shape was noted. No distinguishable difference between the fine feature matrix and the surrounding soil was observed.

The burned rocks of Feature 38 were all limestone. A total of 11 burned rock specimens was recovered from the feature, and these specimens weighed a total of $9.1 \mathrm{~kg}$. The burned rocks were a mixture of unfractured and fractured round limestone cobbles. The feature was tightly clustered, with most of the burned rocks touching. No evidence of burning was observed within the surrounding soil, and no charcoal was observed within the feature. However, a small sample of wood charcoal was collected from just above the feature, and a second was found within the same level as the feature, but over a meter to the south; these were used to date the feature.
No temporally diagnostic points were found in direct association with Feature 38, although several hundred pieces of debitage and several bone fragments were collected from the feature matrix. A La Jita point and an Early Triangular point were found within a $1-\mathrm{m}$ radius of the feature and within the estimated $10-\mathrm{cm}$ floor level.

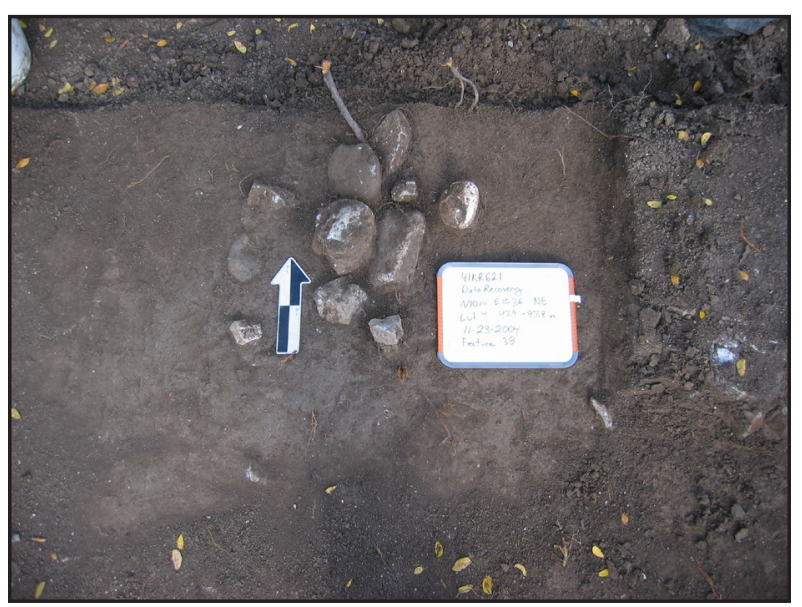

Overview of Feature 38. 


\section{Feature Summary}

Most of the feature assemblage from OZ3 can be characterized as small- to medium-sized, circular to ovate clusters of burned rock, with a few associated larger scatters. Of note, Feature 19 may represent an incipient midden, which integrated the remains of multiple overlapping features and contained dense concentrations of burned rock, particularly two discrete concentrations occurring in the southeastern and northwestern halves.

In terms of feature compositions, the features encountered within OZ3 were primarily composed of limestone (Table 10.6). Burned rock counts and weights ranged from 654-1062 rocks weighing between 144.8-203.5 kg. Of importance, the largest quantities of burned rock did not always represent the highest weights. Rock sizes for the burned rock features within OZ3 were within the range of $5->15 \mathrm{~cm}$. Most of the features exhibited the highest percentages of rock sizes within the 5-10 cm range, followed by highest percentages within the $0-5 \mathrm{~cm}$ range. All of the features within OZ3 exhibited mixed burned rock shapes, consisting of a combination of two or more shapes, such as flat slabs, rounded, or angular. Most of the features displayed mixed rock conditions with combinations of unfractured, fractured in situ, and highly fragmented attributes, suggesting various use-lives for the features. Almost all of the features within OZ3 contained feature matrices undifferentiated from surrounding soils but evidence of in situ burning (charcoal, charred or carbonized nutshells, and some bone) was present in many features.

Special samples analyzed from the OZ3 features provided radiocarbon, fuel, macrobotanical, pollen/ phytolith, faunal, and lipid residue data. Several fuel types were identified, mainly plateau live oak and hardwoods. Features 16/17, and 19 contained carbonized or charred nutshells, specifically walnut or hickory/walnut and indeterminable seeds within Feature $16 / 17$. Faunal remains were encountered within or immediately adjacent to five of the features within OZ3. Of these occurrences all were purely unidentifiable bone fragments except for Features 16/17, which contained evidence of bison and white-tailed deer, particularly teeth, as well as a large mammal. Lipid residue analysis was conducted on two of the features within OZ3, with Feature 16/17 containing evidence of a high-fat content food, seed or animal fat, and Feature 19 containing evidence of a borderline moderate-high and high-fat content food.

Overall, the feature assemblage is a mix of larger and small features and includes one non-heating/cooking feature (Feature 32). The sizes and contents of the features suggest functional differences. The small features may have been strictly for heating (hearths) or to prepare small quantities of food through grilling. The larger cooking features, Features 19 and $16 / 17$, possibly indicate larger quantities of food being prepared and possibly bulk processing. At the Richard Beene site, these types of features were identified as family unit cooking features, rather than true communal bulk-roasting or processing features (Clabaugh and Thoms 2005:251). The size of the larger features comports well with this model. Ethnographic studies among the !Kung link small features to nuclear family-centered activities, while larger features indicate communal activities (Lee 1984:31).

\section{Spatial Distribution in Occupation ZONE 3}

The distribution of the feature assemblage, projectile points, flake tools, cores, and debitage are examined in this section. In OZ3, the deposits are in areas ANE, A-SW, A-NW, and Area B and the distribution and density of artifacts varies between areas. The greatest quantity of OZ3 materials were recovered from A-NE, and the highest density of materials were from A-NW.

\section{FEATURES}

The location of features and projectile points in Areas A-NE and A-SW are shown in Figures 10.3 and 10.4. Most of the features were within Area A-NE where a nearest neighbor analysis was performed using the using the center locations of the A-NE features. The Nearest Neighbor coefficient value of 1.85 indicates that features are regularly distributed through the block and are not clustered. While the patterning between OZ3 features does not appear to be deliberate spacing, OZ3 features are located near earlier OZ2 features, suggesting this portion of the overall Gatlin site may have been a continual focus of burned rock technology/processing over thousands of years. 


\begin{tabular}{|c|c|c|c|c|c|c|c|c|c|}
\hline 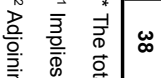 & $\stackrel{\sim}{\sim}$ & \% & $\vec{\Phi}_{*}$ & $\vec{\infty}$ & $\stackrel{\vec{g}}{\vec{v}}$ & $\vec{c}$ & 0 & 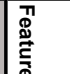 & \\
\hline 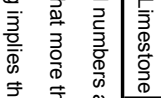 & 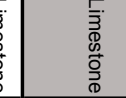 & 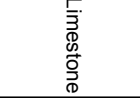 & $\begin{array}{l}\frac{5}{3} \\
\frac{0}{0} \\
\frac{0}{0} \\
\frac{0}{0}\end{array}$ & 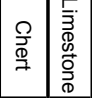 & 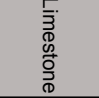 & 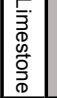 & 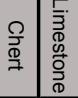 & 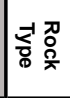 & \\
\hline 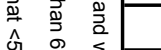 & $\overrightarrow{\mathrm{v}}$ & f & $\bar{N}$ & \begin{tabular}{|l|l|}
$\omega$ & $\vec{\sigma}$ \\
\end{tabular} & $\tilde{\Xi}$ & $\Delta$ & $\stackrel{\vec{s}}{a}$ & \# & \\
\hline $\begin{array}{cc}0 \\
0 \\
0\end{array}$ & $\stackrel{\circ}{\dot{9}}$ & : & $\begin{array}{l}\infty \\
\perp \\
\perp\end{array}$ & \begin{tabular}{|l|l}
$\circ$ & in \\
\end{tabular} & 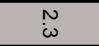 & \begin{tabular}{|l|l|} 
& \\
\end{tabular} & $\vec{v}$ & $\overline{6}$ & \\
\hline 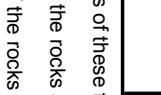 & 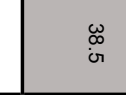 & 奋 & م్ & \begin{tabular}{l|l|}
$:$ & $\underset{N}{N}$ \\
\end{tabular} & 悤 & $\left|\begin{array}{l|}\overrightarrow{0} \\
\infty\end{array}\right|$ & $\stackrel{\omega}{\omega}$ & 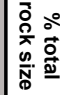 & $\hat{\hat{n}}$ \\
\hline 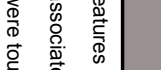 & 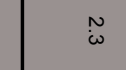 & II & $\stackrel{b}{\infty}$ & \begin{tabular}{l|l}
$\circ$ & $\vec{N}$ \\
$\infty$ &
\end{tabular} & $\vec{\sigma}$ & $\stackrel{\circ}{\perp}$ & 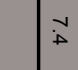 & 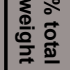 & \\
\hline 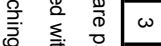 & $\tilde{\omega}$ & $\vec{A}$ & $\begin{array}{l}\mathscr{\infty} \\
\stackrel{\infty}{\infty}\end{array}$ & $\overrightarrow{0}$ & 芦 & $\vec{A}$ & \begin{tabular}{l|l}
$N$ & $\mathrm{f}$ \\
\end{tabular} & \# & \\
\hline 尊 & 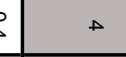 & $\omega$ & $\underset{N}{\vec{N}}$ & $\vec{v}$ & $\underset{\infty}{\mathbb{D}}$ & $\mid \begin{array}{c}\infty \\
N\end{array}$ & \begin{tabular}{l|l}
$\circ$ & 0 \\
& 9
\end{tabular} & 증 & \\
\hline 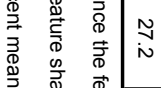 & 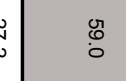 & $\stackrel{\vec{\infty}}{v}$ & $\stackrel{?}{\stackrel{P}{\perp}}$ & $\underset{\substack{\tilde{\omega} \\
\omega}}{\tilde{N}}$ & ज़े & $\underset{\infty}{\infty}$ & $\stackrel{i}{\omega} \underset{\omega}{\vec{\omega}}$ & $\mid$ & $\mid \begin{array}{l}0 \\
1 \\
0 \\
0 \\
3\end{array}$ \\
\hline 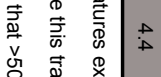 & 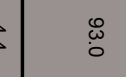 & 范 & 吕 & $\stackrel{\vec{i}}{i}$ & $\begin{array}{l}\omega \\
0 \\
0\end{array}$ & $\left|\begin{array}{c}\vec{\omega} \\
\overrightarrow{+}\end{array}\right|$ & $\begin{array}{l}\text { iv } \\
\text { N }\end{array}$ & 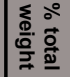 & \\
\hline 常 & $\vec{\Delta}$ & $\vec{\Delta}$ & $\infty$ & $\vec{N}$ & मे & $\overrightarrow{0}$ & $\underset{\infty}{\vec{D}}$ & \# & \\
\hline 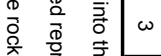 & i & $\underset{\infty}{\infty}$ & $\stackrel{\omega}{\omega}$ & $\tilde{\omega}$ & 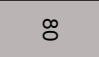 & \begin{tabular}{|l|}
$\infty$ \\
$\omega$ \\
$\omega$
\end{tabular} \mid & 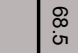 & $\bar{\theta}$ & \\
\hline 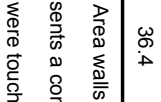 & 诧 & $\vec{f}$ & $\stackrel{\substack{\omega \\
\omega}}{\infty}$ & $\begin{array}{l}N \\
0 \\
0\end{array}$ & $\underset{\omega}{N}$ & $\mid \stackrel{\sim}{\sim}$ & $\vec{f}$ & 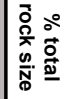 & 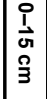 \\
\hline 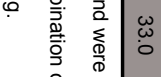 & $\stackrel{i}{i}$ & : & $\stackrel{\tilde{N}}{\sim}$ & $\begin{array}{l}8 \\
\infty \\
\infty\end{array}$ & i & $\begin{array}{l}\infty \\
\vdots \\
0\end{array}$ & $\underset{\omega}{\omega}$ & 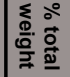 & \\
\hline 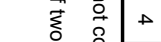 & $\Delta$ & $\omega$ & $\vec{A}$ & $N$ & $\vec{A}$ & 0 & $\tilde{\perp}$ & \# & \\
\hline 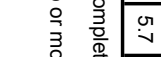 & s. & $\begin{array}{l}\omega \\
\omega \\
\omega\end{array}$ & $\begin{array}{l}\tilde{0} \\
0 \\
0\end{array}$ & \begin{tabular}{|l|l|l|}
$N$ \\
\end{tabular} & $\vec{v}$ & 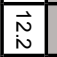 & $\widetilde{\sigma}$ & $\overline{6}$ & \\
\hline 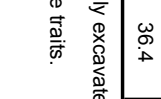 & s. & $\overrightarrow{0}$ & $\vec{\omega}$ & $\dot{v}$ & $\stackrel{N}{\sim}$ & $\mid \begin{array}{c}\tilde{N} \\
\hat{\omega}\end{array}$ & $\tilde{\omega}$ & 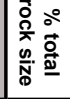 & 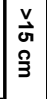 \\
\hline 啇 & 3 & $\stackrel{\omega}{\circ}$ & $\overrightarrow{\vec{\infty}_{0}}$ & مे & $\overrightarrow{\tilde{\omega}}$ & $\mid \stackrel{0}{\vec{\omega}}$ & $\vec{i}$ & 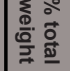 & \\
\hline$\vec{\Delta}$ & $\stackrel{\omega}{\omega}$ & जે & 茠 & \begin{tabular}{|l|l|}
$\omega$ & $\overrightarrow{0}$
\end{tabular} & 兽 & $\omega$ & $\sim \mid$\begin{tabular}{l|l}
$\overrightarrow{\vec{\sigma}}$ \\
$\vec{\omega}$
\end{tabular} & 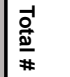 & \\
\hline$\stackrel{\bullet}{\bullet}$ & $\vec{\omega}$ & $\vec{*}$ & 离 & \begin{tabular}{l|l|}
$\stackrel{\overrightarrow{\vec{\theta}}}{\overrightarrow{0}}$
\end{tabular} & $\underset{\infty}{\vec{f}}$ & $\left|\begin{array}{c}\tilde{w} \\
\infty\end{array}\right|$ & 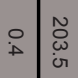 & 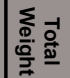 & \\
\hline $\begin{array}{l}\overline{0} \\
\text { 言 } \\
\frac{0}{0}\end{array}$ & $\begin{array}{l}\overline{0} \\
\text { 言 } \\
\frac{0}{0}\end{array}$ & 辛. & 롤. & 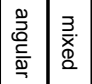 & 골. & 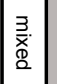 & 롱. & 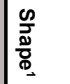 & \\
\hline 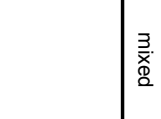 & 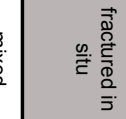 & 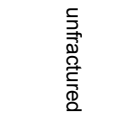 & 豙. & 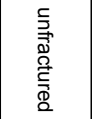 & 疍. & 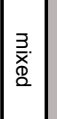 & 疍. & 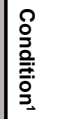 & \\
\hline 总 & $\begin{array}{l}\text { 产: } \\
\text { 言: } \\
\frac{1}{0}\end{array}$ & 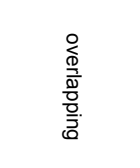 & 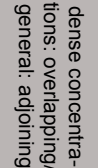 & 产 & 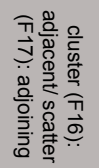 & $\mid$ & 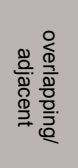 & 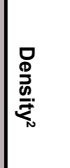 & \\
\hline 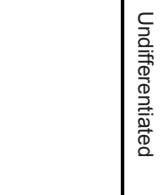 & 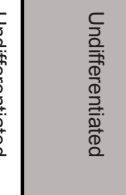 & 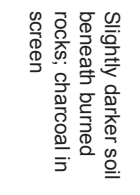 & 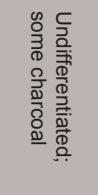 & 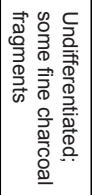 & 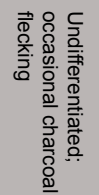 & 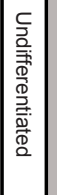 & 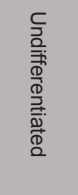 & 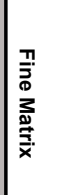 & \\
\hline
\end{tabular}




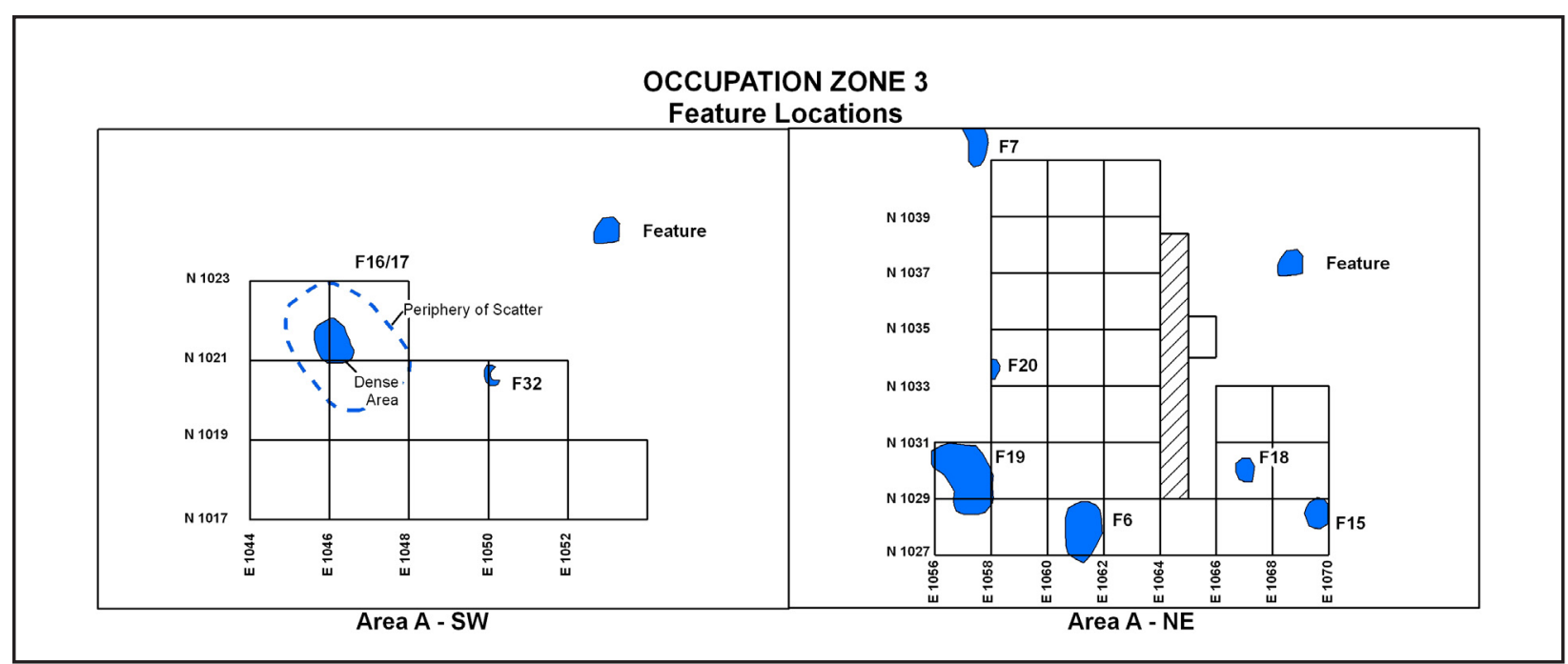

Figure 10.3 Occupation Zone 3 Area A-SW and Area A-NE feature locations.

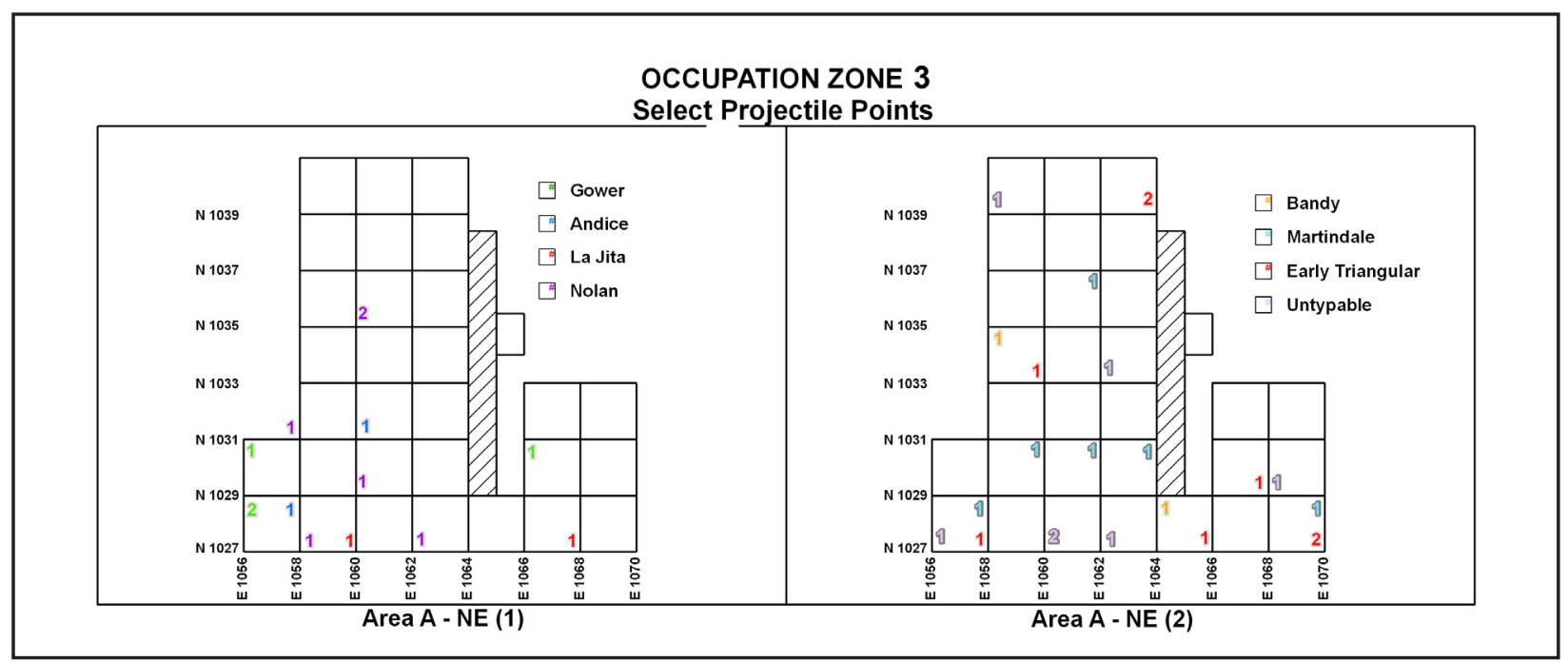

Figure 10.4. Occupation Zone 3 Area A-NE projectile point distribution.

An attempt to spatially correlate projectile points to particular features was not successful because of the apparent mixing and overprinting of cultural deposits resulting from slow rates of deposition. The dates from Feature 16/17 and Feature 19 suggest that these features could be contemporaneous, and are similar to the prescribed dates during which Nolan and La Jita points were used.

\section{Projectile Points}

When the locations of projectile points are observed, as in Figure 10.5, and compared with the feature locations, chronological mixing is evident, with units containing Early Archaic and Middle Archaic points in varying frequencies. Although there does not appear to be significant patterning in the distribution of the projectile points, it was hoped that there was some spatial clustering patterning in the Early Triangular assemblage, especially a point production area. The most obvious evidence of this would be the clustering of preforms and late stage manufacturing failures. An examination of the locational data found apparent spatial association between six Early Triangular point preforms and a late-stage triangular biface was recovered within a $2-m$ radius of these points. 


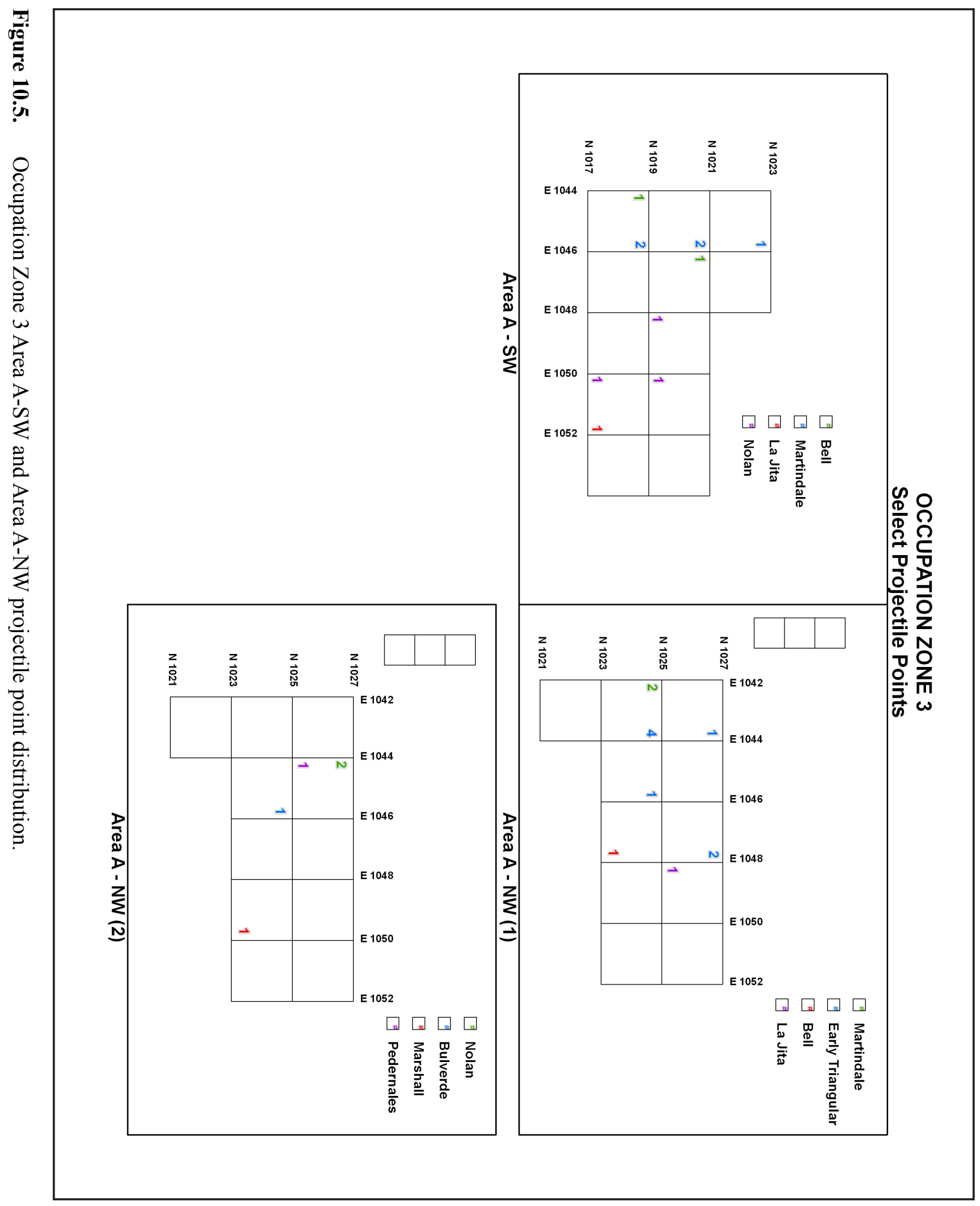




\section{FLAKE TOOLS}

There is a slight increase in formal flake tools from OZ2 to OZ3. The distributions of flake tools - formal and informal - are displayed in Figure 10.6. There are no observed associations between the distribution of formal and informal flake tools, although informal flake tools occur in greater density in Area A-NW. There is also no observed correlation between the location of flake tools and cores. However, there are some observations regarding the association between features and flake tools. In A-NE, expedient flake tools are more numerous in the southern half of the block and concentrated along the southern edge where the feature density is greatest. In Area A-SW, there were 14 flake tools from units in the periphery zone of Feature 16/17. These were three side scrapers, a convergent scraper, an end side scraper, and four utilized flakes and five retouched flakes.

\section{Cores and Core Reduction}

The distribution of cores and core reduction debitage are in Figure 10.7. The number of cores recovered increased in OZ3 from OZ2. Unlike the bifaces, there is no significant correlation between the presence of multiple cores and elevated counts of core reduction flakes. As with bifaces, cores are concentrated in A$\mathrm{NW}$; however, there is no significant increase in core reduction flakes. The low number of core reduction flakes suggests that in some instances, only a few flakes were removed from a core. For example, in Unit N1023 E1046, there were nine multidirectional and a single unidirectional core. The multidirectional cores had 10 or less flake scars and the unidirectional cores had six removal scars. Based upon the shape of the core and the color and texture of cortex, the cores represent a variety of parent material, tabular and rounded nodules found locally.

\section{BIFACES AND BIFACE REDUCTION}

Bifaces and bifacial debitage by excavation area are illustrated in Figure 10.8. What is apparent are the high numbers of bifaces in particular areas, namely A-NW, were 85 bifaces and biface fragments were recovered. All stages were found, with Stage 5 bifaces the most common. A concentration of eight Stage 5 bifaces was found in Unit N1025 E1044. Most of the specimens are small fragments, although one specimen (Lot 730.1) is complete and subtriangular in outline, and although it is not basally thinned like a finished Early Triangular, there were six Early Triangular recovered within a 2-m radius. Overall, only tentative observational associations can be made between types of projectile points and particular lithic reduction activities or areas.

Traditional units containing high numbers of bifaces usually had higher amounts of biface debitage, especially around Feature 32, where both core flakes and biface reduction flake counts were elevated. The surrounding unit also included 15 bifaces and three cores. Most of the biface specimens from this area were small marginal fragments broken during manufacture and made from locally available chert. The high density of bifaces and bifacial debitage suggests that some episodes of biface reduction were concentrated around Feature 32. The fragments vary in shape, material, and color, suggesting the biface fragments represents the remains of different specimens and that multiple reduction episodes or one very intensive episode of reduction occurred.

\section{Organization of Technology}

\section{INTRODUCTION}

During OZ3, various small groups of mobile hunter gatherers visited the site. During these visits, they hunted game such as bison and white-tailed deer. Several ground stone implements indicate plants were processed and that family groups may have been at the Gatlin site. The groups continued many of the lithic technology traits of the earlier inhabitants of OZ2. Most of initial lithic reduction appears to have occurred elsewhere, outside of the excavated areas, while partially reduced cores and later stage bifaces were reduced on site. The lithic tool assemblage in OZ3 appears to be oriented towards the production of hunting technology, with a focus on late-stage bifaces and finished points. The high numbers of late-stage bifaces and lower numbers of earlier stages suggests two possible lithic reduction trajectories or, more likely, a combination of the two, where both raw cobbles and flake blanks from core reduction were reduced to late-stage blanks, projectile points, and complete bifaces.

The lithic reduction strategies apparent in the OZ3 assemblage are remarkably the same as OZ2, with the same ratio of biface reduction and core reduction 


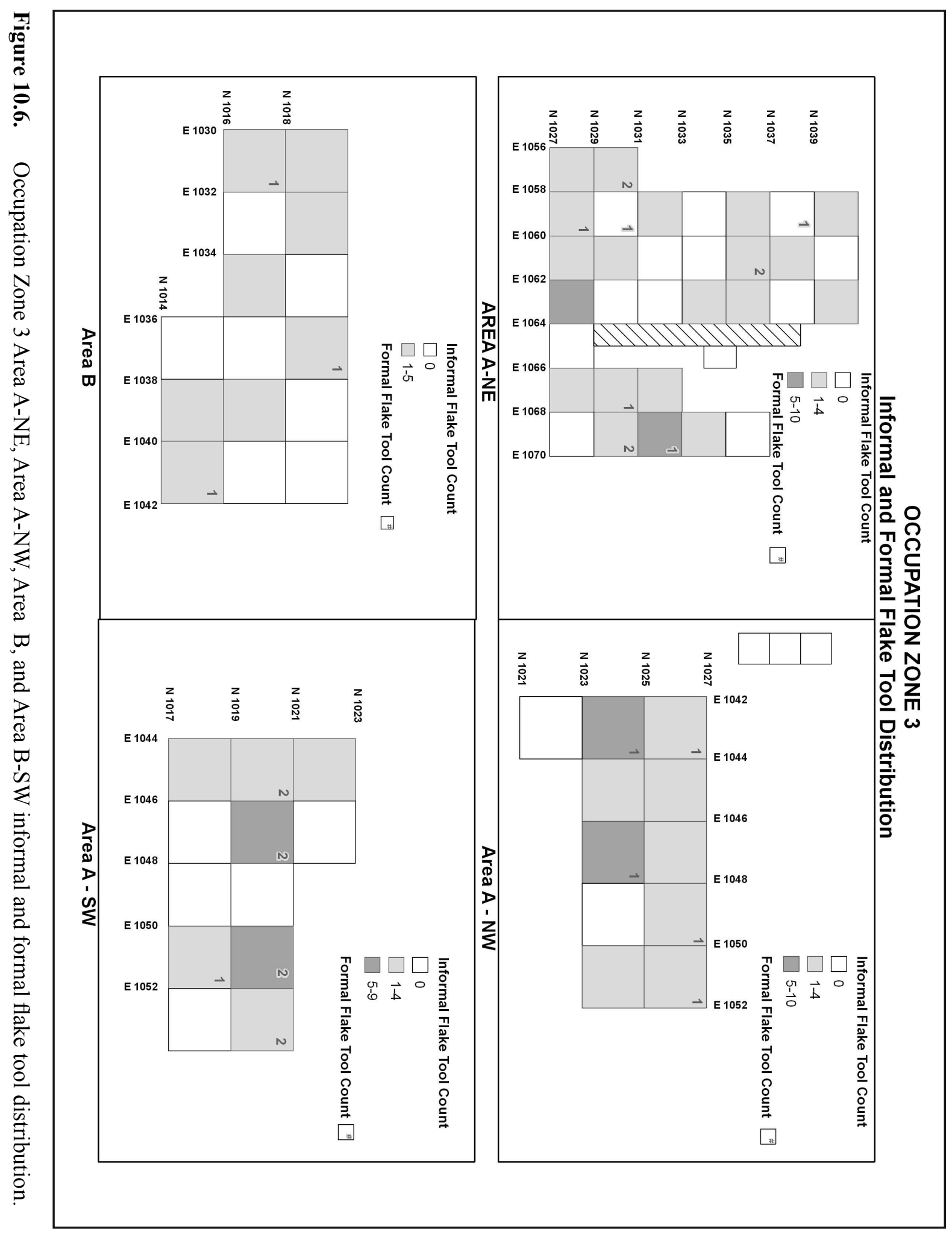




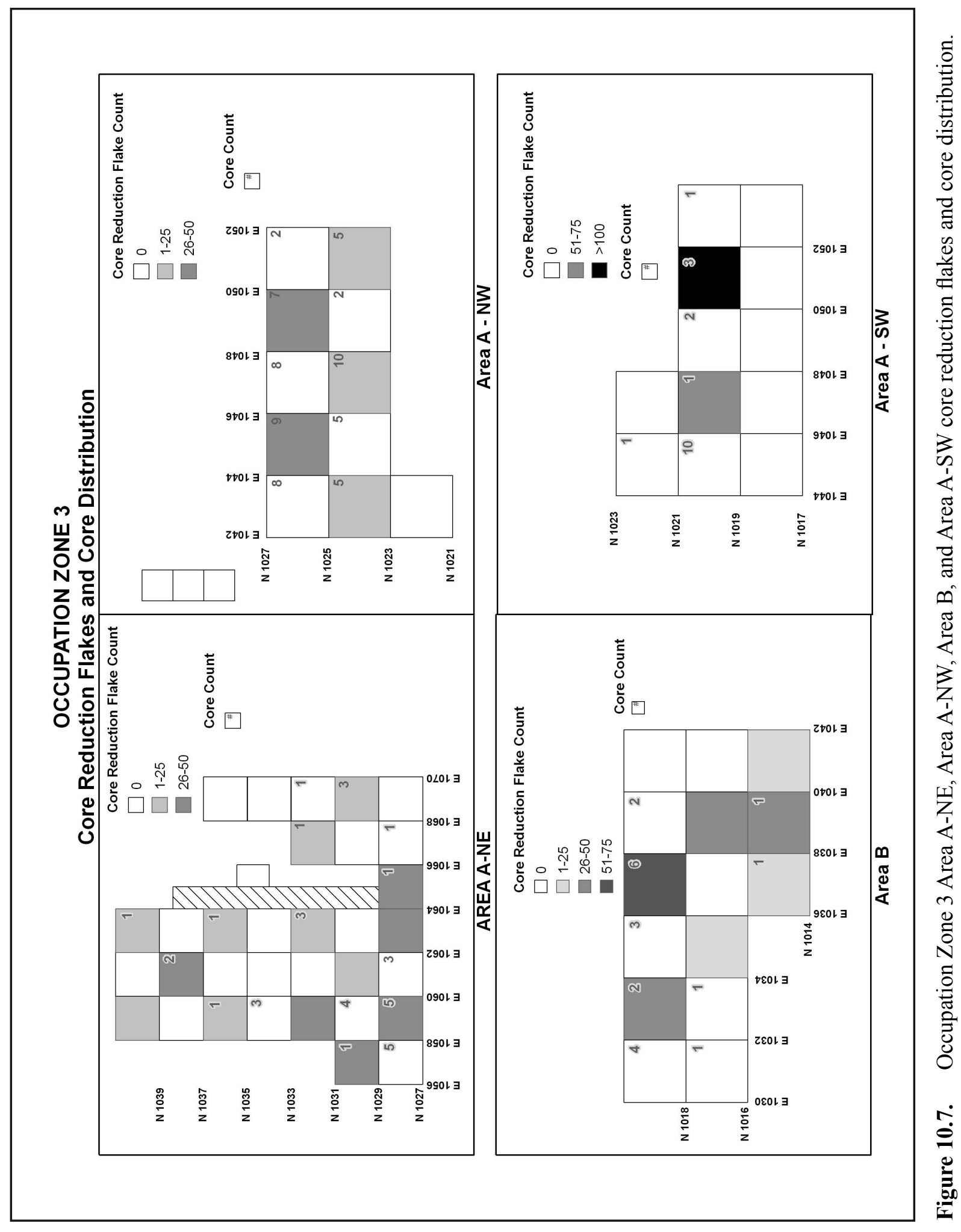




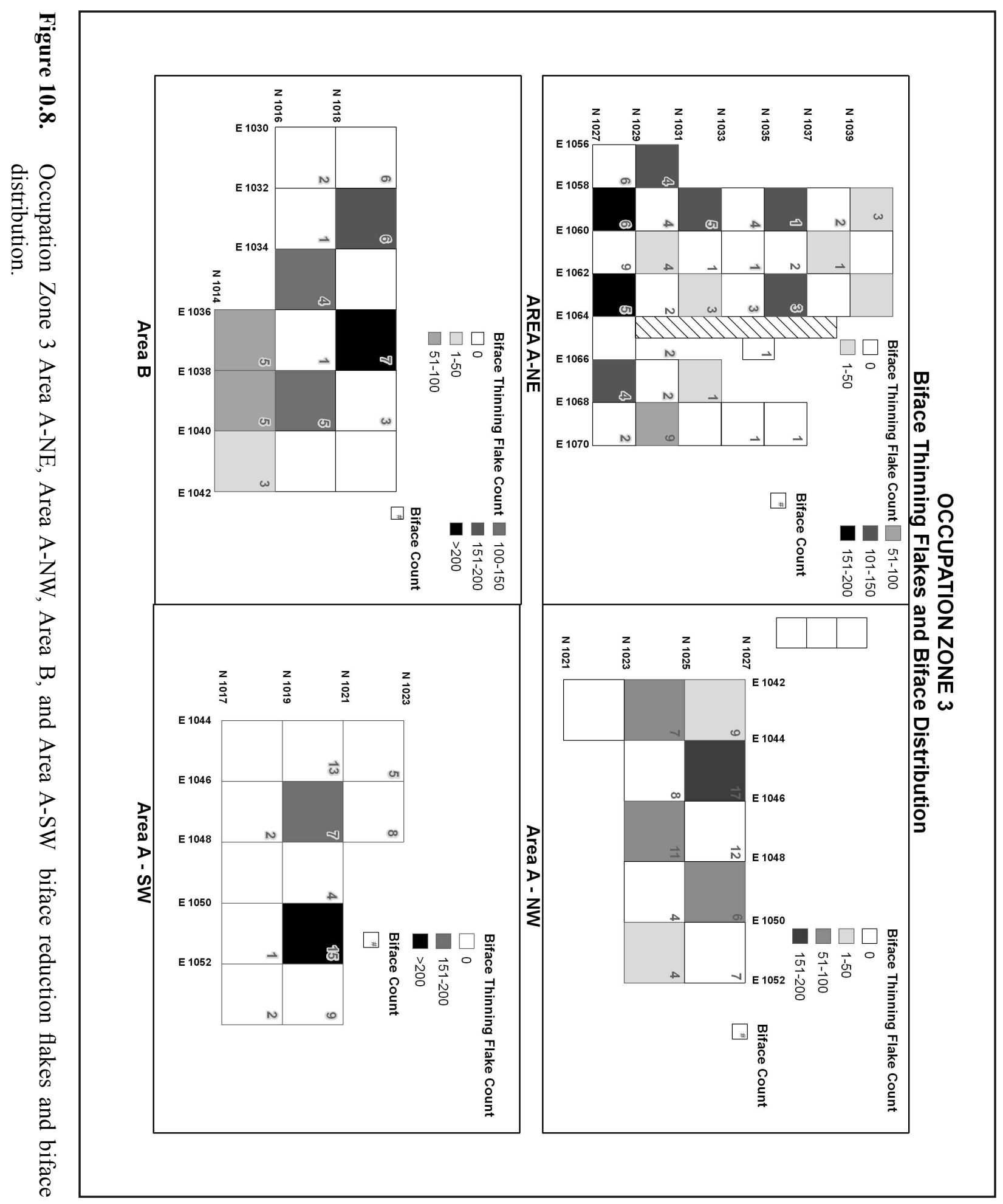


flakes in the debitage. There is a slight increase in flake tools, and almost the same number of formal flake tools, while bifaces and cores increased substantially. The increase in cores occurs without a comparable increase in flake tools or core reduction debitage. Instead of flake tools, the cores may have been used to produce flake blanks that were intended to be projectile points for both Martindale and Early Triangular points.

While there is continuity in the lithic technology between OZ2 and OZ3, there are some significant changes in the projectile points. Martindale points are still found in some quantity in OZ3; however, it is the appearance of Bell/Andice and Early Triangular, and the later La Jita and Nolan that are the significant lithic technological changes from OZ2. As Hester and Shafer note (see Appendix C), pressure flaking retouch on Early Triangular points bears similarities to Martindale points and both types of points could be made from small flake blanks. In regards to cooking technology, cooking features using heated rocks were constructed for both family-sized groups and smaller-sized groups and individuals, and there was limited evidence of large-scale plant or animal processing and cooking in the form of earth ovens.

\section{Projectile Points}

The large suite of projectile points from OZ3, many broken from use or resharpened, supports the scenario of the Gatlin site being a retooling/refitting station where exhausted or broken projectiles are discarded and new one produced. Within the assemblage, there are some interesting trends. The appearance of Early Triangular points marks a change in lithic technology that may be related to a change in subsistence (increase in bison). A temporal association between Bell/Andice/CalfCreek and Early Triangular points has been suggested by Hester and Shafer (see Appendix C), while Collins (2004) and Johnson and Goode (1994) regard Early Triangular as following Bell/Andice/Calf Creek. Early Triangular is the most numerous projectile point from $\mathrm{OZ3}$, accounting for almost 41 percent of the typed projectile points from within the zone. Thought of as a multipurpose tool used as a knife or projectile point, Early Triangular may have been easier to manufacture and maintain then Bell or Andice points. More than half of the Early Triangular points were reworked, with 90 percent of the rework occurring along the blade. All of the reworked Gower points were modified along the blade, suggesting this occurred while it was still hafted.

The transition to stemmed points is indicated by Nolan and La Jita points. Nolan points were resharpened 43 percent of the time along the blade and the majority of the time along the blade and base. Overall, 60 percent of the points in OZ3 were reworked while 75 percent of the points from OZ2 were reworked. There were varying levels of maintenance and reworking of projectile points from $\mathrm{OZ3}$, with the highest degree of reworking occurring with the Early Triangular points. Variations in the degree and extent of maintenance occur for several reasons, one being proximity to high quality cherts. When closer to a high grade abundant resource of raw lithic material, there is less need to conserve raw materials and recycle projectile points into other tools. Discarded points that were extensively reworked and resharpened reflect conservative use of chert resources. When chert, as found at the Gatlin site was available, these points were discarded and were replaced with new points. Risk avoidance may also have been a factor in replacing projectile points. As the negative consequences of failure increased, new, sharper, projectile points may have been used to increase the chance of hunting success (Bleed 1986, Bousman 1993).

Based on radiocarbon dates, Features 19 and 16/17 are associated tentatively with the Nolan points. Hester and Shafer (see Appendix C) divide Nolan into subgroups I and II, based for the most part on the extent of resharpening and use. The eight Nolan II points include two preforms and multipurpose specimens used as knives and scrapers. Only one of the 12 Nolan I points was reworked along the blade and stem. Two of these points were broken at the tip and were discarded. In other circumstances, away from the abundant chert resources at the Gatlin site, similar points would have been conserved through repair and resharpening.

\section{BIFACES AND BIFACE REDUCTION}

There is a slight increase in the percentage of earlystage bifaces from OZ2 to OZ3, while the percentage of Stage 5 bifaces is almost identical. Examining the biface assemblages' composition by percentages of stages, there is a small increase in earlier stage bifaces from OZ2 to OZ3 as shown in Table 10.7. 
Table 10.7. Biface Stage Distribution for Occupation Zones 2 and 3

\begin{tabular}{|l|c|c|}
\hline & \multicolumn{2}{|c|}{ Occupation Zone } \\
\hline Stage & 2 & 3 \\
\hline $\mathbf{1}$ & $2.36 \%$ & $3.38 \%$ \\
\hline $\mathbf{2}$ & $8.66 \%$ & $10.46 \%$ \\
\hline $\mathbf{3}$ & $14.17 \%$ & $15.69 \%$ \\
\hline $\mathbf{4}$ & $18.90 \%$ & $16.00 \%$ \\
\hline $\mathbf{5}$ & $37.80 \%$ & $36.62 \%$ \\
\hline Unknown & $18.11 \%$ & $17.85 \%$ \\
\hline
\end{tabular}

An analysis of the debitage assemblage supports this observed increase. Most biface thinning flakes from OZ3 are between 15-20 mm in length. While the increase in earlier stage bifaces did not significantly increase the average length of biface thinning flakes from OZ2 to OZ3, there is a difference when the lengths of complete biface thinning flakes from $\mathrm{OZ2}$ and OZ3 are compared. In OZ3, the greatest numbers of biface thinning flakes are from 15-20 $\mathrm{mm}$ in length, and in OZ2, the greatest numbers are from $10-15 \mathrm{~mm}$ in length, suggesting slightly larger, earlier-stage, bifaces were being reduced on site during OZ3. Despite the increase in the number of bifaces, there is no substantial increase in biface reduction flakes and no increase in cortex flakes. Overall, there is no increase in average biface flake size, yet there is some variation in biface thinning flake sizes between OZ2 and OZ3.

Breakage patterns are the same between OZ2 and OZ3, with approximately 63 percent of bifaces from OZ3 compared with 65 percent from OZ2 broken during manufacture. Use-breaks accounted for less than 1 percent in both OZ1 and OZ2 demonstrating that bifaces were not being used in their current form, and were intended for further reduction into formal tools or use elsewhere. On average, the Stage 5 bifaces from $\mathrm{OZ} 3$ are larger, wider, and thinner than their counterparts in OZ2, with more than 10 $\mathrm{mm}$ difference in length.

\section{BIFACIAL TOOLS}

Despite the large increase in bifaces compared with $\mathrm{OZ2}$, there is not a large increase in finished, formal bifaces from OZ3. The biface tool assemblage consists of rudimentary bifacial choppers or butted bifaces, and more formal Clear Fork tools, gouges, drills, and bifacial knives. The limited tool assemblage suggests that there was a limited range of activities conducted at the Gatlin site. Clear Fork tools and gouges, tools associated with working wood, bone, and antler are scarce. Either these activities were not major activities at the Gatlin site, or they were performed with other tools, although the former seems more plausible. Several of the Stage 5 bifaces were used as butchering knives to cut material such as wood or antler and were probably used unhafted. The large bifacial knives may have been purposely left unhafted. As Frison (2004:199) noted, hafting with elements like sinew weakens from the moisture produced when butchering large animals. These tools appear to be specially designed as skinning and butchering implements; however, modification appears to be minimal beyond edge trimming and resharpening. These well-made tools were left at the site, despite their remaining utility.

\section{CoRES AND CORE REDUCTION}

The number of cores increased dramatically in comparison with OZ2, although many of the cores are minimally used. The number of cores is greatest during OZ3 than at any other period at the Gatlin site, although there is not a similar increase in core reduction flakes. This suggests that (1) the initial reduction of many of the cores occurred off-site, and (2) that many of the cores had a limited number of flakes removed. Despite the increased use and preference for multidirectional, bifacial, and unifacial cores, there is not a concurrent rise in formal flake tools. The increase in prepared cores is usually associated with standardized tool production and conservation of material (Andrefsky 1994), neither of which was observed or needed at the Gatlin site. The prepared cores may have been intended for use elsewhere. Bifacial core technology may have been an extension of the extensive biface reduction occurring during $\mathrm{OZ3}$, and was a way to utilize thinner nodules and tabular materials found in the nearby Guadalupe River bedload.

\section{FLAKE TOOLS}

The modified or formal flake tools are presumably scrapers that were used both hafted and unhafted. The morphology used to define them is more than likely the result of use-wear and maintenance, as end scrapers become end side scrapers, and then convergent 
scrapers. An examination of the scraper assemblage and the scrapers illustrated in Appendix C, Figure 61 reveals how side scrapers, through use and further modification, can develop into a convergent scraper. This modification through use was applied by Dibble (1995) to challenge Bordes' typology of paleolitic scrapers. The OZ3 end scrapers, side scrapers, and retouched flakes are significantly longer than specimens from OZ2. Other flake tools are similar in length. The average length of a retouched flake from OZ3 is $70.5 \mathrm{~mm}, 11 \mathrm{~mm}$ longer than the average OZ2 retouched flake. The meaning of this discrepancy requires further exploration. Overall, there is only a slight increase in the formal flake tool assemblage, and in fact, the only substantial increase is in the number of side scrapers, while there is a decrease in all other formal flake tool categories compared with OZ2.

The formal flake tools from OZ3 were on average larger and not as intensively used as OZ2 specimens. Only one specimen, an end scraper (Lot 428.2), was exhausted. The use of sequential flakes as blanks for formal scrapers declined from six in OZ2 to two in OZ3. This suggests sequence flake blanks may be an Early Archaic trait, as they have been observed in other Early Archaic assemblages, such as the Sleeper site (Johnson 1991).

Less than half $(n=74)$ of the 165 flake tools are complete. The rest have various fractures most likely caused by use. Only one informal flake tool was identified as being made from a biface reduction flake, the rest of the flake tool assemblage was made from hard hammer core reduction flakes.

\section{Mobility, MaintenanCe, and CURation}

The lithic tool and feature assemblages are similar to OZ2, despite the shift in projectile point styles from stemmed, through unstemmed, and back to stemmed points. The ratio of bifaces to cores is $2.2: 1$, the same as during OZ2. Despite the increased biface production, core reduction continued at a similar rate. The increased biface production may reflect site use intensity, as larger quantities of bifaces were being made during a given occupation, rather than a significant change in mobility. The increase in biface production may also reflect "gearing up" or provisioning, where a lithic tool surplus was created in anticipation of future activities. One biface tool class that reflects on site camp maintenance activities is butted bifaces. These were probably intended to remain at the site and were used for heavy duty tasks as chopping, scraping, and cutting a variety of material that could include bone and other hard items as indicated by the use-wear analysis (see Appendix C). The presence of these tools suggests that there were varying lengths of occupations, with more butted bifaces equated with greater domestic activity.

Curated tools are created for anticipated future use or for repeated use. They were most likely transported from site to site. Examples of tools left behind for future site-specific uses include metates and manos, caches of which have been recovered from sites such as the Sleeper site (Johnson 1991). Portable curated tools include bifaces, projectile points, formal flake tools, and prepared cores. Non-curated tools include informal flake tools and unprepared or expedient cores. Sedentism and restricted mobility has been tied to the increase in expedient tools versus formal tool forms such as bifaces. There is only a slight rise in curated tools from OZ2, from 2.2:1 to 2.42:1, suggesting levels of mobility and technological organization were relatively similar.

Using another index, the comparison of formal to informal tools, the ratio is 2.43:1 (Table 10.8), again a slight increase from the 2.25:1 in OZ2. The increase reflects the emphasis on biface production, and a manufacturing trajectory focused on the production of late-stage, thin bifaces intended as knives and projectile points. Evidence of tool maintenance was found on the projectile points and

Table 10.8. Occupation Zone 3 Formal and Informal Stone Tools

\begin{tabular}{|l|c|c|c|c|c|c|c|c|}
\hline & $\begin{array}{c}\text { Projectile } \\
\text { Points }\end{array}$ & Bifaces & $\begin{array}{c}\text { Bifacial } \\
\text { Tools }\end{array}$ & $\begin{array}{c}\text { Flake } \\
\text { Tools }\end{array}$ & $\begin{array}{c}\text { Prepared } \\
\text { Cores }\end{array}$ & $\begin{array}{c}\text { Retouched and } \\
\text { Utilized Flakes }\end{array}$ & $\begin{array}{c}\text { Multidirectional } \\
\text { Cores }\end{array}$ & Total \\
\hline Formal & 115 & 363 & 14 & 36 & 51 & & & 579 \\
\hline Informal & & & & & & 129 & & 109 \\
\hline Ratio & & & & & & & & 238 \\
\hline
\end{tabular}


the biface assemblage. All of the Clear Fork tools and gouges had some evidence of resharpening, and two of the three drills were resharpened. It is unknown whether these specimens represent on site maintenance or were used elsewhere and discarded at the Gatlin site. A large percentage of projectiles are also resharpened.

\section{SUBSISTENCE}

In OZ3, features were constructed of burned rock of various sizes. As limestone is heated to a high enough temperature, it fractures, and when reused it becomes progressively fragmented. Depending on how rocks are used within a feature, such as a heating element for direct cooking or for lining a basin, its functionality decreases because of this fragmentation. Features 18 and 20 had the highest percentage of smaller burned rock suggesting multiple uses of the feature and/or scavenging of previously burned rock to construct the feature. The temperature of the features can also increase fragmentation rates. The mixture of burned and unburned rock within a feature implies different methods of food preparation, where unheated rocks were used as weights or ballast for holding cooking implements or food in place (Claybaugh and Thoms 2007).

The feature assemblage from OZ3 was used by small groups and/or individuals to prepare group-sized quantities of food. Some of the features contained the remains of large- and medium-sized game, with bone fragments that were burned by cultural fires. Although there was poor preservation of the faunal remains, the existing sample suggests that individual large game animals were being processed or cooked at the Gatlin site. The presence of formal flake tool scrapers and bifacial knives indicates that on site preparation and the processing of hides of large game such as bison and medium game such as whitetailed deer was occurring, and that the features were used for cooking. The presence of teeth at the site indicates that complete animals or heads or maxilla were brought to the site. In the case of deer, transporting the whole animal would be easier than a bison, while a bison maxilla may have been brought to the site to remove the tongue. Perhaps as important and reliable a food source was small game animals. An examination of faunal remains from other Early and Middle Archaic assemblages in Central Texas shows the changing size of prey selection that may reflect regional environmental changes (Oksanen and Bousman 2007). When bison is absent, deer is the desired prey, and when both bison and deer become scarce, a greater diversity of smaller animals and plant resources are exploited.

The transition from Early Triangular to Nolan and La Jita points has been noted with the regional reduction or disappearance of bison (Collins 2004). The large bladed points are instead replaced with the stemmed and narrower bladed Nolan and La Jita, with a focus on white-tailed deer as the most desirable or highest ranked prey. Dates from Features 16/17 and 19 are within the time period for Nolan points and likely represent a Nolan occupation.

The presence of ground stone tools such as manos and metates, indicates that some vegetal foods were processed at the site. Pollen and feature fill macrobotanical samples have identified potentially exploitable and edible plants, although the few numbers of these tools suggest plant processing was not a major activity at the Gatlin site and was more likely the activity of a small group or family unit.

\section{SuMmary OF OZ3}

OZ3 contains a mixture of predominantly Early and Middle Archaic projectile points. Radiocarbon dates from features are contemporaneous with the known age range of Early Triangular, Nolan, and La Jita points although there is evidence of mixing of deposits with earlier and later occupations. What is significant about OZ3 is that it contains cultural materials marking a shift between the Early and Middle Archaic, and it contains a record of diagnostic artifacts spanning the proposed date range of the Middle Archaic. This shift is represented in the technology as the wider, triangular-shaped points are replaced with the more narrow-stemmed types that may have been more efficient for hunting deer as opposed to bison.

When compared with OZ2, there are a remarkable number of similarities in the lithic assemblage, from feature functions to the numbers and types of tools being produced. Biface manufacturing, lithic projectile refitting and refurbishing continue almost uninterrupted, suggesting that while projectile point styles changed, the basic organization and structure 
of the lithic technology did not. What does vary is the construction of larger features, and although the site continues to be visited by small groups of people, larger groups - possibly extended or multiple family units - periodically visited the site. Plant processing appears to continue in growing importance as exemplified by the larger features, although the tool assemblage strongly suggests it was secondary to hunting. From the end of the Early Archaic and through the Middle Archaic, activities at the site focused on hunting large- and medium-sized game and produced bifaces and flake tools from the abundant high quality local chert.

The increasing diversity of projectile points in OZ3 suggests that populations were increasing in Central Texas and the Edwards Plateau. Along with the rise in population, it seems reasonable that territories would become increasingly defined. Likewise, projectile point styles become increasingly associated with particular regions, suggesting a decrease in longrange mobility compared with the Early Archaic. The inhabitants of the Gatlin site during OZ3 were relatively mobile, practicing a Forager or Traveler subsistence strategy that had been well established by the previous visitors to the site.

The Gatlin site may have served as a gearing up and a retooling locale within the mobility pattern of forager groups, where they replenished their lithic supplies after returning from resource poor areas, and stocked up on lithic supplies before heading to such areas. This is suggested by the discard of flake tools and projectile points with remaining utility, and the fact that there was no evidence of extensive reuse and recycling of tools. 
10-42 Chapter 10 


\title{
Chapter 11
}

\section{OCCUPATION Zone 4}

\author{
Eric R. Oksanen, Mercedes C. Cody, and Kevin A. Miller
}

\section{INTRODUCTION}

After the initial testing excavations of the Gatlin site, the Early Archaic cultural components were the primary target for further data recovery investigations. However, a limited portion of later deposits, mainly those thought to be associated with Feature 1 (the burned rock midden) were also a focus of the data recovery work and it is these cultural deposits that form OZ4. In Area B, mechanical stripping was used to remove culturally sterile overburden of colluvial deposits overlying what were believed to be stratified deposits of cultural material adjacent to the midden. Excavations were continued by hand. In Area A-NE, OZ4 was encountered during mechanical stripping operations, but was removed without further hand excavations to expeditiously expose the Early Archaic deposits beneath.

Although cultural materials recovered within OZ4 represent a broad period of time, most of the temporally diagnostic cultural materials are from the Middle to Late Archaic. The investigations of OZ4 were concentrated in Area B and Feature 1 (Figure 11.1; see Figure 7.11). In Area B, $36.04 \mathrm{~m}^{3}$ of deposits were originally excavated and an additional five supplemental units were excavated in the vicinity of the human skull fragment in Feature 23, bringing the total volume excavated to $43.04 \mathrm{~m}^{3}$. The area exposed was approximately $60 \mathrm{~m}^{2}$ because of the truncation along BHT4. The Area B block was divided between feature-focused Units $(n=6)$ and traditional units $(n=10)$. Many of the units were excavated as both feature-focused Units and as traditional units. This occurred when a feature was exposed in a feature-focused Unit and subsequent excavations continued as traditional units. The range in radiocarbon dates from OZ4 is from ca. 3,900-1,230 B.P., and within this range Feature 1 was repeatedly utilized with varying degrees of intensity.
There were 21 projectile point styles recovered within OZ4 deposits. Twelve of these styles are from the Middle and Late Archaic periods and comprise the majority ( $n=76,84$ percent) of the diagnostic projectile points from OZ4. There are large assemblages of $\mathrm{La}$ Jita, Nolan, and Pedernales points; however, because of the disturbed nature of the deposits, direct dating and further chronological refinement of these styles is not possible.

A significant change from OZ3 in subsistence economy at the site is reflected in the development of the burned rock midden. This indicates an expansion or diversification of the subsistence base and the regular or semiregular seasonal movements of the inhabitants across the landscape to exploit particular plant resources. The development of burned rock middens is used as a marker to define the Middle Archaic, as they begin to occur in Southwest Texas across the Edwards Plateau and along the Balcones Escarpment (Collins 2004, Johnson and Goode 1994). Through time, and while in use, the midden at the Gatlin site was very slowly buried by alluvium and colluvium.

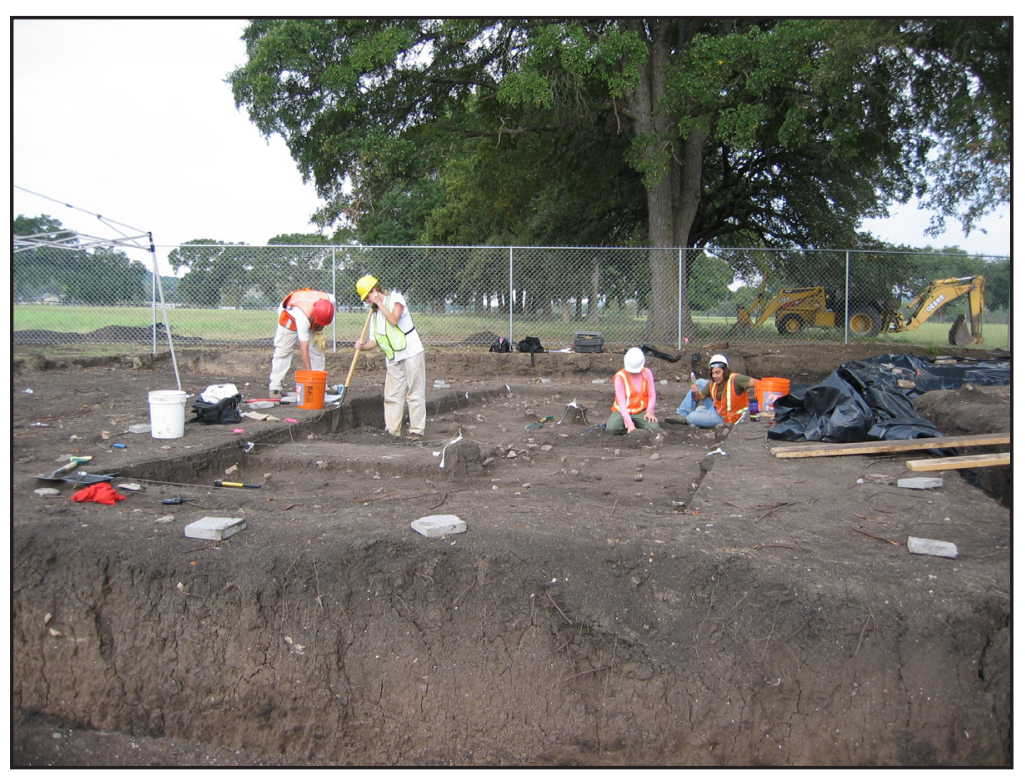

Figure 11.1. Area $B$ excavations in progress facing west. 
The material remains within OZ4 indicate the inhabitants were mobile bands of foraging hunter-gatherers. Their stays at the Gatlin site were brief, during which time they hunted, cooked food for small- to moderate-sized groups, and refurbished their lithic supplies. The major lithic manufacturing activity was the reduction of late-stage bifaces to produce projectile points and blanks for future use.

\section{Chronology}

In OZ4 there are temporally diagnostic projectile points spanning the Late Paleoindian to the Late Archaic. However, the focus of the OZ4 analysis is on the occupations associated with Middle and Late Archaic periods and the artifacts in use during the creation and formation of Feature 1. The formation and use of Feature 1 is a contributing agent in the mixing of these temporal markers. As demonstrated by Leach et al. (2005), earth ovens and cooking features can cause enormous disturbance to both the stratigraphy of a site as well as the lateral distribution of artifacts. Overall, cultural deposits can be reworked to incorporate younger and older materials and radiocarbon dating within a large feature like Feature 1 is problematic. It can, therefore, be difficult to correlate specific activities, dates, and artifacts to the makers of a particular projectile point style.

Feature 1 began forming less than 5,000 years ago, based upon the results of radiocarbon assays from below and within the midden deposits. Feature 1 is within the $\mathrm{AB}$ horizon and above the contact zone with the B horizon. A $1 \sigma$ conventional radiocarbon date of $4530 \pm 40$ B.P. (Beta 206131) comes from Feature 38 within the $B$ horizon and beneath the starting elevation of Feature 1. Another $1 \sigma$ conventional radiocarbon date of $4210 \pm 40$ B.P. (Beta 206129) comes from beneath the center of Feature 1. It is after this date range that Feature 1 began to form. The greatest accrual of burned rock occurs within the $\mathrm{AB}$ horizon, where a $1 \sigma$ conventional radiocarbon date of $3850 \pm 40$ B.P. (Beta 206132) comes from near Feature 37. This assay is used as the beginning date for occupations above the $\mathrm{B}$ horizon in the midden area and associated Area B OZ4. During the mechanized removal of $\mathrm{AB}$ horizon, just to the north of Area A-NE, Feature 7 was encountered. A piece of charcoal from within the feature has a $1 \sigma$ conventional radiocarbon date of $3400 \pm 40$ в.P. (Beta
206114). The upper age of OZ4 is dated from Feature 10 , which has a $1 \sigma$ conventional radiocarbon date of $1290 \pm 60$ B.P. (Beta 207392). The radiocarbon dates reflect activities from a range of occupations from approximately ca. $3,900-1,230$ B.P. The radiocarbon dates alone do not reflect all of the occupations within OZ4, since the temporal diagnostic dart points reflect a greater chronological range than the ca. 2,700 years implied through the radiocarbon dates.

Based upon the numbers and types of projectile points, the most intensive usage of Area B and the midden occurred during the end of the Middle Archaic and into the Late Archaic. As noted in Chapter 10, Nolan and La Jita points have been dated between ca. 5,000-4,000 в.P. There are few well-dated, stratigraphically preserved deposits from this period have been investigated. La Jita remains a poorly-dated point style and despite the large sample from the Gatlin site, and OZ4 in particular, refining the time period of La Jita may not be possible using the radiocarbon dates from OZ4. Nolan and La Jita may be regional style variations of a similar point, with the Central Texas and the eastern part of the region using Nolan points, and southern Texas-based occupations using La Jita points. The period of the formation and use of Feature 1 appears contemporaneous with the use of Nolan and La Jita points.

The Late Archaic is a return to larger bladed dart points with barbs and shoulders, such as Bulverde and Pedernales (and Kinney). These broad bladed points continue with Lange and Marshall, Marcos and Montell and the smaller Frio and Fairland. No arrow points were recovered in OZ4 deposits. The number of points from these groups decreases through time, with fewer younger-aged diagnostics. All of these Late Archaic dart points have been found at other sites in dated contexts within the temporal range of OZ4.

\section{Paleoenvironment}

Based upon other regional analyses (Bousman 1998; Collins 1995 and 2004; Johnson and Goode 1995) during the temporal range of OZ4, there were alternating periods of mesic and xeric conditions as the climate began to approach what would be recognized as the modern climatic patterns. Episodic colluvial deposition occurred on portions of the site. The implication is that colluvial deposition 
increased during xeric periods, when, due to reduced groundcover, groundwater and gravity were able to transport upland deposits downslope at greater rates. Only minor, periodic alluviation occurred during the formation of OZ4, as the Guadalupe River was incising deeper into its present day channel (see Chapter 6). As alluviation declined, colluvial action periodically covered the southern portion of Feature 1. The greatest rate of colluvial buildup appears to have occurred in historic times when the midden and site were completely buried.

Plant remains from feature samples and column samples within Feature 1 are consistent with a modern analogue, and include typical upland and riparian species still found around the site. The presence of bison was thought to increase dramatically at the end of dated deposits of OZ4, ca. 1,300-1,070 B.P., signifying the appearance or greater use of the bow and arrow, of which there is no evidence at the Gatlin site.

\section{Occupation Zone 4 Assemblage}

A variety of artifacts and ecofacts comprise the OZ4 assemblage (Table 11.1). Artifacts are mainly the byproducts of lithic technology, represented by the assemblage of tools, debitage, and features. Individual attribute data for lithic tools, lithic cores, and ground stone/manuports and ecofacts are presented in Appendix E, consisting of E.1 through E.7. The investigations in OZ4 concentrated on deposits in Area B, south and directly adjacent to the midden. The midden, accumulated on a relatively stable surface, was probably used for specialized hot rock cooking in varying levels of intensity throughout the duration of OZ4. It was during the early occupations of OZ4, those associated with Nolan and La Jita, when Feature 1 expanded to its greatest extent and saw the most intensive usage. This continued during occupations associated with Pedernales points, after which the usage of Feature 1 declined as it became slowly buried under a mixture of colluvium and alluvium and only portions of the midden continued to be used. Although no plant remains such as geophytes or xerophytes were recovered, the volume of rock in Feature 1 indicates that the use of earth ovens for bulk and/or specialized cooking likely resulted in the formation of the midden.
Other burned rock features found in OZ4 represent smaller group cooking elements that include lined basin hearths and remnants of probable small baking features. Feature 23 consists of human skull fragments that appear to be an isolated find since there was no evidence of burning, as would be associated with cremation, or of a burial pit.

\section{Dart Points}

There were 144 projectile points recovered from within OZ4 during testing and data recovery excavations at the Gatlin site. More than half of the projectile points are diagnostic types, most of which are associated with the Middle Archaic and include La Jita, Nolan, and Travis points $(n=37)$. Diagnostic types associated with the late Middle Archaic/Late Archaic period $(\mathrm{n}=30)$, which includes Bulverde, Pedernales, and Kinney points, are the next numerous.

Early Archaic projectile points ( $\mathrm{n}=5$ ) include Gower, Martindale, and Martindale Narrow Stem points; late Early Archaic points $(\mathrm{n}=11)$ include Andice, Bell, and Early Triangular points. Late Archaic period points $(n=13)$, are Lange, Marcos, Marshall, and Montell points. The remaining temporal periods represented include a single recycled Late Paleoindian Big Sandy point, and the Transitional Late Archaic $(\mathrm{n}=5)$ including Ensor, Fairland, and Frio points. OZ4 contains the largest quantity $(n=37)$ of untypable projectile points. The high number of untyped points is not unexpected, since there is a great diversity of projectile points with several base and stem shapes being manufactured. The following counts and descriptions refer only to the specimens discovered within this zone. Projectile point type morphology and metric attribute information can be found in Appendix C, with individual metric attributes information within Appendix E.1. When the extent of temporal mixing was noted during excavation and in the initial analysis, both excavations and analysis focused on the earlier occupation zones. As a result, detailed measurements were not collected from many of the dart point styles such as the Pedernales points and other Late Archaic and Transitional Archaic dart points. 


\section{1-4 Chapter 11}

Table 11.1. Summary of Lithic Technology for Occupation Zone 4

\begin{tabular}{|c|c|c|}
\hline Category & Count & Description \\
\hline Features & 10 & $\begin{array}{l}1,4,7,8,9,10,11,23 \\
36,37\end{array}$ \\
\hline \multirow{22}{*}{ Projectile Points } & \multirow{22}{*}{144} & 3 Andice \\
\hline & & 2 Gower \\
\hline & & 1 Martindale \\
\hline & & 7 Early Triangular \\
\hline & & 1 Bell \\
\hline & & 1 Big Sandy \\
\hline & & 23 La Jita \\
\hline & & 13 Nolan \\
\hline & & 7 Bulverde \\
\hline & & 1 Ensor \\
\hline & & 1 Fairland \\
\hline & & 3 Frio \\
\hline & & 2 Kinney \\
\hline & & 5 Langtry \\
\hline & & 2 Marcos \\
\hline & & 4 Marshall \\
\hline & & $\begin{array}{l}2 \text { Martindale- Narrow } \\
\text { stem }\end{array}$ \\
\hline & & 4 Montell \\
\hline & & 3 Lange \\
\hline & & 21 Pedernales \\
\hline & & 1 Travis \\
\hline & & 37 Untypable \\
\hline \multirow{4}{*}{ Bifacial Tools } & \multirow{4}{*}{8} & 3 Butted Biface \\
\hline & & 1 Drill \\
\hline & & 1 Gouge \\
\hline & & 3 Perforator \\
\hline
\end{tabular}

\begin{tabular}{|c|c|c|}
\hline Category & Count & Description \\
\hline \multirow{6}{*}{ Bifaces } & \multirow{6}{*}{445} & 6 Stage 1 \\
\hline & & 28 Stage 2 \\
\hline & & 54 Stage 3 \\
\hline & & 80 Stage 4 \\
\hline & & 192 Stage 5 \\
\hline & & 85 Unknown \\
\hline \multirow{4}{*}{ Flake Tools-Formal } & \multirow{4}{*}{7} & 2 End Scraper \\
\hline & & 1 Graver \\
\hline & & 2 Side Scraper \\
\hline & & $\begin{array}{l}2 \text { End and Side } \\
\text { Scraper }\end{array}$ \\
\hline \multirow{2}{*}{ Flake Tools-Expedient } & \multirow{2}{*}{76} & 24 Utilized Flakes \\
\hline & & 52 Retouched Flakes \\
\hline \multirow{6}{*}{ Cores } & \multirow{6}{*}{95} & 2 Bidirectional \\
\hline & & 18 Bifacial \\
\hline & & 12 Indeterminate \\
\hline & & 56 Multidirectional \\
\hline & & 1 Slab \\
\hline & & 6 Unidirectional \\
\hline Ground Stone Tools & 2 & 2 mano fragments \\
\hline $\begin{array}{l}\text { Total Flakes and Fragments } \\
\text { from Traditional Units }\end{array}$ & 4,442 & \\
\hline Core Reduction Flakes & 698 & \\
\hline Biface Reduction Flakes & 3,191 & \\
\hline Indeterminate Flakes & 552 & \\
\hline Total Proximal Fragments & 3,595 & 18 notching flakes \\
\hline Total of Complete Flakes & 847 & 7 notching flakes \\
\hline $\begin{array}{l}\text { Complete flakes percentage } \\
\text { of total }\end{array}$ & $19.07 \%$ & \\
\hline Ratio of Bifaces to Cores & $4.77: 1$ & \\
\hline
\end{tabular}

\section{ANDiCe}

$(\mathrm{n}=3)($ Lots $1383,1445.3$ 1500.7)

Nominal Attributes: Two of these points exhibit a flaking pattern, specifically a random pattern.

Condition and Breakage: Two of these specimens are basal fragments and one is a shoulder fragment (Lot 1383), with all three exhibiting use-wear impact or snap/impact fractures.

Reworking and Beveling: Reworking occurred along the blade of all three points

Use-wear: N/A

Raw Material Attributes: Raw material for these points is local Edwards fine-grained chert.

Comments: Most of the breaks associated with these points are impact or snap fractures. 
BELL

$(\mathrm{n}=1)($ Lot 1331)

Nominal Attributes: N/A

Condition and Breakage: This specimen is a basal fragment with evidence of an impact fracture.

Reworking and Beveling: N/A

Use-wear: N/A

Raw Material Attributes: This point is made of local fine-grained Edwards chert.

\section{Big SANDY}

$(\mathrm{n}=1)($ Lot 1486.3) (Appendix C, Figure 1)

Nominal Attributes: This point exhibits a parallel flaking pattern.

Condition and Breakage: The specimen is complete.

Reworking and Beveling: The blade and stem were reworked by bifacial pressure flaking.

Use-wear: Use-wear analysis revealed this point was scavenged millennia after its original discard. Its original use-wear is indeterminate; however, the recycled point was used briefly as a butchering implement to cut soft animal products, such as hide.

Raw Material Attributes: This point is made from local Edwards fine-grained chert with a heavy ( $>50$ percent) patina.

Comments: This is the only Paleoindian point recovered from the Gatlin site.

\section{BULVERDE}

$(\mathrm{n}=7)($ Lots $54.4,803,1254,1404,1490.2,1529,1533)$ (Appendix C, Figure 9 b-Lot 54.4, c-Lot 1254)

Nominal Attributes: Flaking patterns observed include random, oblique parallel, collateral, and chevron.

Condition and Breakage: All of the specimens are complete. Three specimens have one of the following fractures: snap, use-wear impact, and indeterminate breakage.

Reworking and Beveling: All of these specimens were reworked along the blade.

Use-wear: No use-wear analysis was performed on these points.

Raw Material Attributes: Raw material for all of these points is local Edwards fine-grained chert.

Comments: Distribution of this point type in the southwestern Edwards Plateau generally consists of two or three specimens at a site, although 10 were discovered at the Gatlin site.

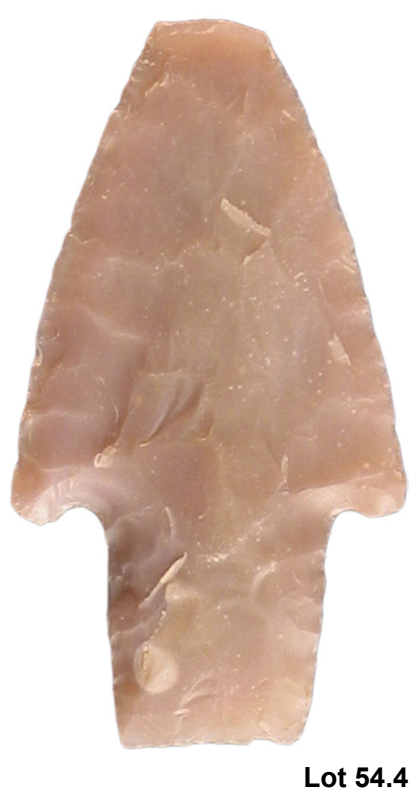

\section{Early Triangular}

$(n=7)$

\section{Subtype Early Triangular A}

$(\mathrm{n}=3)($ Lots 1292, 1296, 1497.4)

Nominal Attributes: Flaking patterns observed among the points are oblique parallel, oblique subparallel, and random. 
Condition and Breakage: All of these points are complete. Two have use-wear impact fractures and one has a snap fracture.

Reworking and Beveling: Reworking is evident along the blade of one specimen and the blade and basal margin of the other two. One specimen is beveled to the left and another is beveled to the right.

Use-wear: Two specimens were analyzed - a projectile point that was probably recycled as a burin, and a heavily resharpened tool that was used to scrape hard organic substances like bone or antler.

Raw Material Attributes: All three points are made of local Edwards fine-grained chert.

\section{Subtype Early Triangular B}

$(\mathrm{n}=3)($ Lots $1095,1213,1488)$

Nominal Attributes: One specimen has an oblique parallel flaking pattern.

Condition and Breakage: All three specimens are complete; with two having use-wear impact fractures.

Reworking and Beveling: Two of the points are reworked along the blade and one of these has a right bevel.

Use-wear: Use-wear analysis conducted on one specimen suggests it was used as both a projectile point and a light duty knife on meat or hide during butchering tasks.

Raw Material Attributes: All three points are local Edwards fine-grained chert.

\section{Subtype Early Triangular C}

$(\mathrm{n}=1)($ Lot 1484)

Nominal Attributes: This is an Early Triangular preform that has a random flaking pattern

Condition and Breakage: The specimen is complete with some flaking breakage.

Reworking and Beveling: Reworking occurs along the blade.

Use-wear: N/A

Raw Material Attributes: This point is made of local Edwards fine-grained chert.

\section{ENSOR}

$(\mathrm{n}=1)($ Lot 86.2) (Appendix C, Figure 17 a)

Nominal Attributes: N/A

Condition and Breakage: This specimen is a basal fragment with multiple fractures, some of which were caused by heating or burning.

Reworking and Beveling: N/A

Use-wear: N/A

Raw Material Attributes: The raw material for this point is local Edwards fine-grained chert.

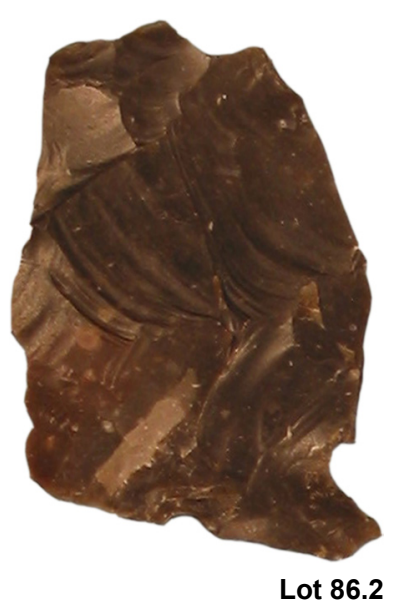




\section{FAIRLAND}

$(\mathrm{n}=1)$ (Lot 1149.3) (Appendix C, Figure 17 b)

Nominal Attributes: The flaking pattern is oblique parallel.

Condition and Breakage: This specimen is complete.

Reworking and Beveling: This point is heavily reworked distally along the blade and basal margin, and extensive stem reshaping diminished the size.

Use-wear: N/A

Raw Material Attributes: The specimen is made of local Edwards fine-grained chert.

\section{FRIO}

$(\mathrm{n}=3)($ Lots 36.3, 1229, 1370) (Appendix C, Figure $17 \mathrm{c}, \mathrm{e}, \mathrm{f})$

Nominal Attributes: Flaking patterns on two specimens are collateral and oblique subparallel.

Condition and Breakage: Two of these specimens are complete with one lacking any breakage (Lot 1370) and the other (Lot 36.3) with a possible use-wear impact fracture and evidence of postdepostional excavation damage. The third point is a stem fragment with a possible snap fracture.

Reworking and Beveling: The blades of both specimens are reworked.

Use-wear: N/A

Raw Material Attributes: Raw material for these points is local Edwards fine-grained chert. One of them is reddened, suggesting exposure to heat.

\section{Gower}

$(\mathrm{n}=2)$

\section{Subtype Gower A}

$(\mathrm{n}=2)($ Lots 1036.1, 1152) (Appendix C, Figure 6 c-Lot 1152)

Nominal Attributes: One of the points has a random flaking pattern and the other specimen has an oblique parallel flaking pattern.

Condition and Breakage: One point is complete with thermal breakage. The other point (Lot 1036.1) is a basal fragment with heavy damage from an impact fracture.

Reworking and Beveling: Both specimens are reworked along the blade, creating a slight twisting beveled edge on one specimen.

Use-wear: Both were utilized as projectile points.

Raw Material Attributes: Raw material for both of these points is local Edwards

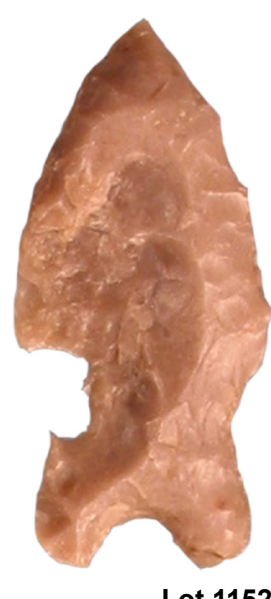
fine-grained chert. One of the points exhibits evidence of heat alteration through potlids and reddening.

\section{KINNEY}

$(\mathrm{n}=2)($ Lots 1430, 1526) (Appendix C, Figure $15 \mathrm{c}, \mathrm{d})$

Nominal Attributes: Flaking patterns were subparallel and collateral.

Condition and Breakage: One point is complete with a distal end snap fracture, while the other is a basal fragment with a snap fracture and postdepostional excavation damage.

Reworking and Beveling: N/A

Use-wear: Use-wear analysis on one specimen determining it was both a dart point and a light duty knife.

Raw Material Attributes: Both of these points are made of local Edwards fine-grained chert. 


\section{LA JiTA}

$(\mathrm{n}=23)$

\section{Subtype La Jita Group I}

$(\mathrm{n}=10)$ (Lots 46.1, 66.3, 1138, 1241, 1304, 1340, 1362.5, 1417, 1431, 1432)

(Appendix C, Figure 10 a-Lot 1432, c-Lot 1138, and d-Lot 1362.5)

Nominal Attributes: Five of the points have a collateral flaking pattern. The remaining specimens have random, oblique subparallel, and subparallel flaking patterns.

Condition and Breakage: Four of these points are complete with two specimens snapped at the distal tip. Six of the points are basal fragments including one showing signs of an impact fracture, and the other five exhibiting snap fractures at the distal tip. Three specimens also have postdepostional excavation damage.

Reworking and Beveling: Evidence of reworking is present along the blade of two of these points, and along the blade and stem of one. One of the points has a right-beveled blade.

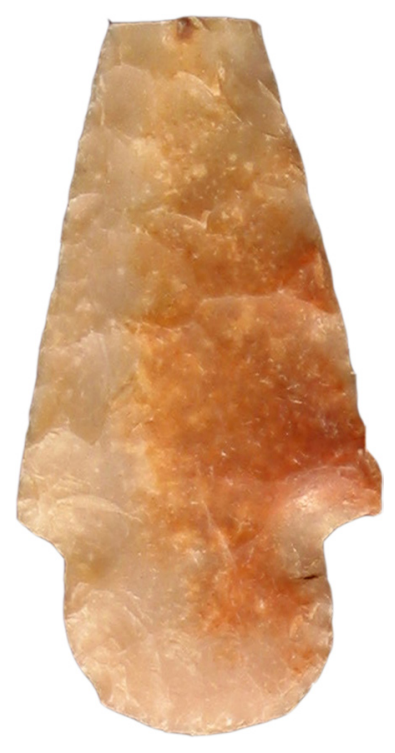

Lot 1432

Use-wear: Use-wear analysis was conducted on three of these points. One of these was solely utilized as a projectile point, while another was used to cut soft animal products, with incidental contact on harder materials such as bone. The last of the points was utilized in a variety of manners (e.g., as a projectile, a knife for cutting both soft and moderately resistant materials, and as a burnishing tool on hard material such as bone or antler).

Raw Material Attributes: All of these points are made from local Edwards fine-grained chert. One specimen was reddened from heat exposure.

Comments: This is the third largest typological category from the Gatlin site, and one of the largest samples of the La Jita type from an excavated site.

\section{Subtype La Jita Group II}

$(\mathrm{n}=13)($ Lots 40.8, 656, 1169, 1220, 1253, 1301, 1372, 1444, 1478.3, 1500.5, 1504, 1508, 1528)

(Appendix C, Figure 10 f-Lot 1528, g-Lot 1253)

Nominal Attributes: Flaking patterns are observed among 10 of these points and include four random, three oblique subparallel, two collateral, and one parallel.

Condition and Breakage: Most of these points $(n=7)$ are either complete with no breakage, or mostly complete ( $>90$ percent unbroken) specimens, of which four show evidence of impact fractures and three exhibit snap fractures at the tip. Four of the points are basal fragments, with two exhibiting distal snap fractures, one with evidence of thermal breakage, and the other consisting of a mid-blade indeterminate breakage. The remaining specimens are a blade fragment and a stem fragment consisting of a snap fracture at the stem.

Reworking and Beveling: Eight of these points show signs of reworking, particularly seven along the blade and one along the blade and stem. Only two of these points exhibit beveled edges.

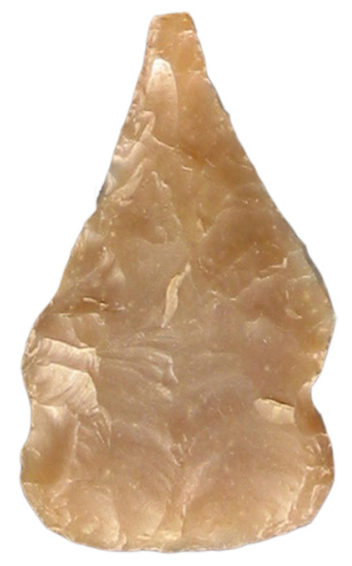

Lot 1253

Use-wear: Use-wear analysis was performed on three of these points. One point was utilized as a dart point, as well as to scrape and cut hard organic substances such as bone or soaked antler. Another of the specimens was used as a knife used to cut soft animal products with some contact with harder materials. The last of these specimens was used to cut and scrape soft and hard organic materials. 
Raw Material Attributes: All of these points are made from local Edwards fine-grained chert. Only one specimen exhibits evidence of heat exposure as indicated by potlids and reddening.

Comments: Group II are specimens that are side-notched and with a basal concavity.

LANGE

$(\mathrm{n}=3)($ Lots 132.4, 655, 1107) (Appendix C, Figure $13 \mathrm{a}, \mathrm{d}, \mathrm{e})$

Nominal Attributes: The flaking pattern for all three points is subparallel.

Condition and Breakage: All of these specimens are basal fragments. One of the points has a use-wear impact/snap fracture. The other two specimens exhibit snap fractures at the distal margin, as well as other locations such as at the stem corner and at the barb.

Reworking and Beveling: One of the points was reworked along the blade, which trimmed away a barb.

Use-wear: N/A

Raw Material Attributes: All of these points are composed of local Edwards fine-grained chert. One of the specimens was reddened by heat.

Comments: These points are often grouped with other corner-notched points, such as Marcos, Marshall, and Castroville, and they are all very

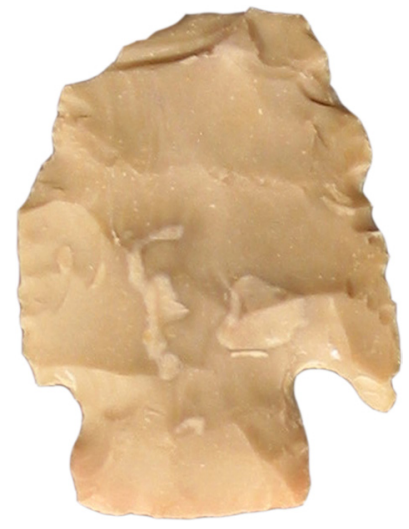
close in terms of chronology in the middle part of the Late Archaic.

LANGTRY

$(\mathrm{n}=5)($ Lots 1126, 1314, 1348, 1382.2, 1439.2) (Appendix C, Figure 9 e-Lot 1314, f-1382.2)

Nominal Attributes: Flaking patterns are observed on four of these points and include random, oblique parallel, and subparallel patterns.

Condition and Breakage: Three of these points are complete and two have indeterminate breakages with missing barbs. Of the remaining specimens, one is a basal fragment with a snap fracture, and the other is a shoulder fragment with thermal breakage.

Reworking and Beveling: Only one of these points was reworked. This was along the blade, which created a left bevel at the stem.

Use-wear: No use-wear analysis was performed on these points.

Raw Material Attributes: All of these points are composed of local Edwards fine-grained chert. Evidence of heat alteration is present as potlids on only one of these points.

\section{Marcos}

$(\mathrm{n}=2)$ (Lots 1120, 1196.4) (Appendix C, Figure $13 \mathrm{~g}, \mathrm{~h}$ )

Nominal Attributes: The one observed flaking pattern is random.

Condition and Breakage: Both specimens are basal fragments; one was fractured from heat, and the other's distal end has a snap fracture.

Reworking and Beveling: N/A

Use-wear: N/A

Raw Material Attributes: Both of these points are made of local Edwards fine-grained chert. Both specimens exhibit potlids and reddening from heating or burning.

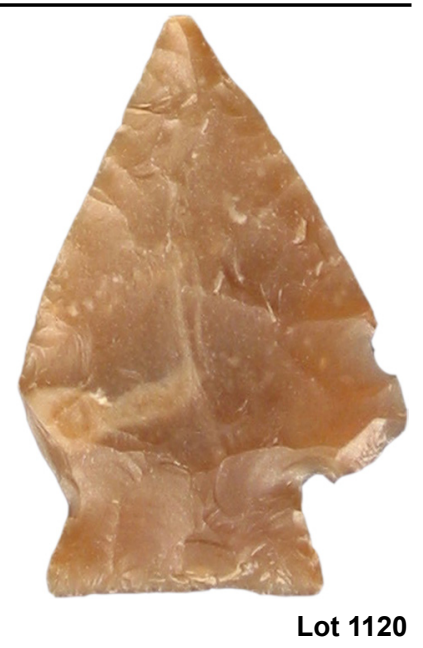




\section{Marshall}

$(\mathrm{n}=4)($ Lots 1051.2, 1114, 1319, 1321) (Appendix C, Figure 14 b-Lot 1321, d-Lot 1319)

Nominal Attributes: The one observed flaking pattern is random. One of these specimens is a preform that is asymmetrical in outline and crudely flaked.

Condition and Breakage: One of these points is complete, having only a small, indeterminate break. The remaining three points are all basal fragments, two of which had indeterminate breaks, while the third exhibits a snap fracture.

\section{Reworking and Beveling: None.}

Use-wear: None of these points were subjected to use-wear analysis.

Raw Material Attributes: All of the points are of local Edwards finegrained chert.

Comments: Limited attributes, including condition, breakage, heat evi-

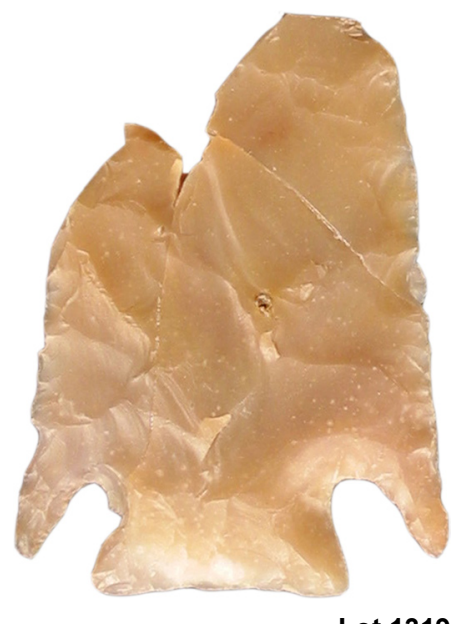
dence, and weight, were recorded for Marshall projectile points.

\section{Martindale}

$(\mathrm{n}=1)$

\section{Subtype Martindale A}

$(\mathrm{n}=1)($ Lot 1419)

Nominal Attributes: The specimen has an oblique subparallel flaking pattern.

Condition and Breakage: This specimen is a basal fragment with a snap fracture.

Reworking and Beveling: Reworking is evident on this point and the specimen is described as asymmetrical.

\section{Use-wear: N/A}

Raw Material Attributes: This point consists of local Edwards fine-grained chert.

\section{Subtype Martindale Narrow Stem}

$(\mathrm{n}=2)$ (Lots 657, 1080) (Appendix C, Figure $4 \mathrm{f}, \mathrm{g}$ )

Nominal Attributes: Both points have random flaking patterns.

Condition and Breakage: One specimen is complete and the other is a basal fragment. Both terminate in use-wear impact fractures.

Reworking and Beveling: Both of these points have reworking along the blade.

Use-wear: The point submitted for use-wear analysis was used solely as a projectile point.

Raw Material Attributes: Both points are made of local Edwards finegrained chert.

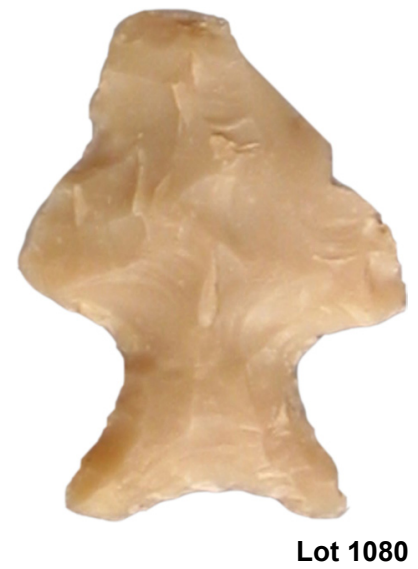


MontelL

$(\mathrm{n}=4)($ Lots 1098, 1195.1, 1322.4, 1396.2) (Appendix C, Figure $14 \mathrm{~g}$-Lot 1195.1, h-Lot 1098, i-Lot 1396.2)

Nominal Attributes: Collateral flake patterning occurs on one specimen.

Condition and Breakage: All of these specimens are basal fragments with a variety of breakages.

Reworking and Beveling: N/A

Use-wear: N/A

Raw Material Attributes: All of these points are made of local Edwards fine-grained chert. Three of the specimens were heated sufficiently to develop potlids and reddening.

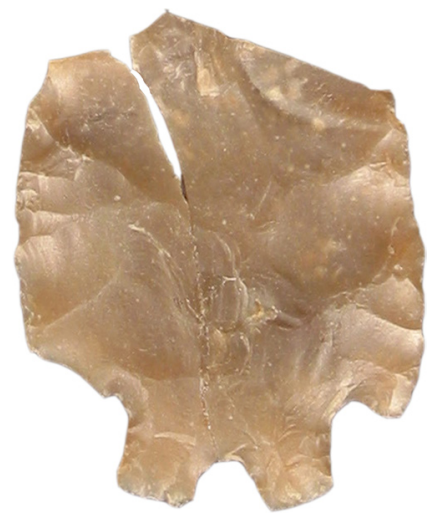

NoLAN

$(\mathrm{n}=13)$

\section{Subtype Nolan Group I}

$(\mathrm{n}=6)($ Lots 1139, 1252, 1261.4, 1356, 1364, 1501) (Appendix C, Figure 11 c-Lot 1252)

Nominal Attributes: Flaking patterns observed among these points include collateral and one random.

Condition and Breakage: One of these points is complete with no breakage. Four of the specimens are basal fragments, of which two have use-wear impacts and two have snap fractures.

Reworking and Beveling: The blade and stem of one of the points has been reworked, creating a beveled stem. Three other specimens have signs of beveling along the stem; two are beveled to the right and one to the left.

Use-wear: Use-wear analysis was performed on two of these specimens. One of these has a sharp needle tip and was most likely a dart point. The other specimen is a large, wide-bladed, stemmed biface used as a knife to cut wood or other moderately resistant materials.

Raw Material Attributes: All of these points are composed of local Edwards fine-grained chert. Of note, one of the points consists of a very dark grayish brown or black opaque chert. Heat evidence was observed on one point in the form of reddening.

Comments: Most of the Group I Nolan points are broken, primarily from

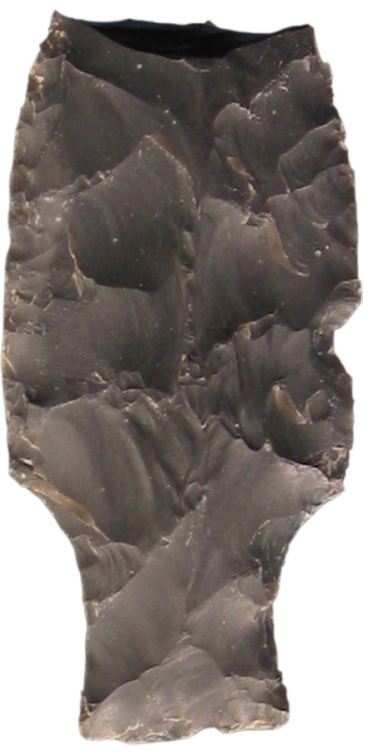
snap fractures that removed the distal ends.

\section{Subtype Nolan Group II}

$(\mathrm{n}=7)$ (Lots 41.2, 1141, 1256, 1374, 1398.1, 1482.4, 1500.6) (Appendix C, Figure 11 e-Lot 1374)

Nominal Attributes: Several flaking patterns are observed among these points including oblique parallel, oblique subparallel, subparallel, and random.

Condition and Breakage: Five of these points are complete specimens with two exhibiting impact fractures.

Reworking and Beveling: Reworking is evident along the blade of two specimens and along the blade and stem of three specimens. Beveling is apparent on two of the points. 
Use-wear: Use-wear analysis was conducted on two of these points. One specimen was utilized solely as projectile point while the other was also used as a stemmed biface knife for light butchering tasks, such as cutting soft animal materials, with occasional contact with harder materials.

Raw Material Attributes: Raw material for all of these points is local Edwards fine-grained chert. Only one of the points appears reddened from heat treatment.

Comments: Most of the Group II specimens have been narrowed or shortened by reworking after a distal break.

\section{Pedernales}

$(\mathrm{n}=21)$

\section{Subtype Pedernales Stem Form 0}

$(\mathrm{n}=1)($ Lot 1118)

Nominal Attributes: This point is classified as a preform.

Condition and Breakage: This specimen is a basal fragment with a snap fracture, as well as postdepostional excavation damage.

\section{Reworking and Beveling: N/A}

Use-wear: N/A

Raw Material Attributes: The raw material for this specimen is Edwards fine-grained chert.

Comments: Limited attributes, including condition, breakage, heat evidence, and weight, were recorded for Pedernales projectile points.

\section{Subtype Pedernales Stem Form 1}

$(\mathrm{n}=4)$ (Lots 1128.1, 1180, 1323, 1506.2) (Appendix C, Figure 16 a-Lot 1180, b-Lot 1323)

\section{Nominal Attributes: N/A}

Condition and Breakage: One of these points is a complete specimen with no breakage. The remaining three points are all basal fragments, two of which have use-wear impact fractures and one with a snap fracture.

Reworking and Beveling: N/A

Use-wear: N/A

Raw Material Attributes: All of these points are composed of local finegrained Edwards chert.

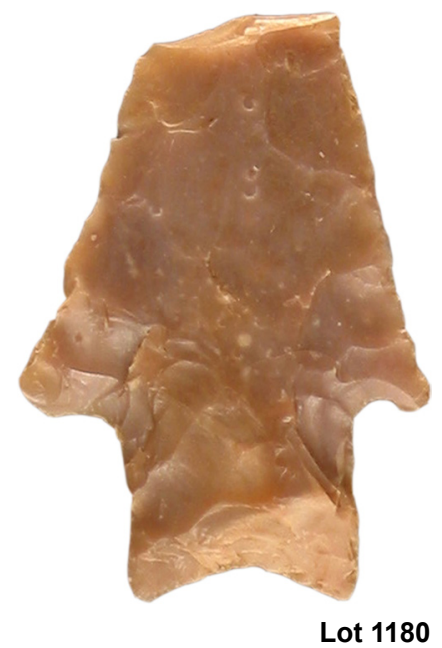

\section{Subtype Pedernales Stem Form 2}

$(\mathrm{n}=4)($ Lots 1132, 1173, 1237, 1409) (Appendix C, Figure 16 c-Lot 1132, d-Lot 1237)

Nominal Attributes: N/A

Condition and Breakage: Two of these points are complete specimens of which one has no breakage, and the other has postdepostional excavation damage. The other two specimens are basal fragments.

Reworking and Beveling: Although these attributes were not recorded systematically for these specimens, one specimen was reworked along the blade.

Use-wear: N/A

Raw Material Attributes: The specimens are made from local fine-grained Edwards chert. Three of the points were heated. 


\section{Subtype Pedernales Stem Form 4}

$(\mathrm{n}=9)($ Lots 1074, 1124, 1128.2, 1201, 1249, 1250, 1294.4, 1332,

1334) (Appendix C, Figure 16 e-Lot 1074, g-Lot 1334)

Nominal Attributes: One of these points is a preform.

Condition and Breakage: One specimen is a stem fragment that ends in a snap fracture. The remaining eight points are basal fragments with a variety of breakages. Four of these are snap fractures, two are impact fractures, and one is thermal breakage.

\section{Reworking and Beveling: N/A}

Use-wear: N/A

Raw Material Attributes: All of these points are composed of local Edwards fine-grained chert. Exposure to high heat caused potlid fractures and crenation on one specimen.

\section{Subtype Pedernales Stem Form 6}

$(\mathrm{n}=2)$ (Lots 1094, 1287) (Appendix C, Figure 16 h-1094, i-1287)

\section{Nominal Attributes: N/A}

Condition and Breakage: One of these points is a complete specimen and the other (Lot 1094) is a basal fragment. Both of these exhibit snap fractures.

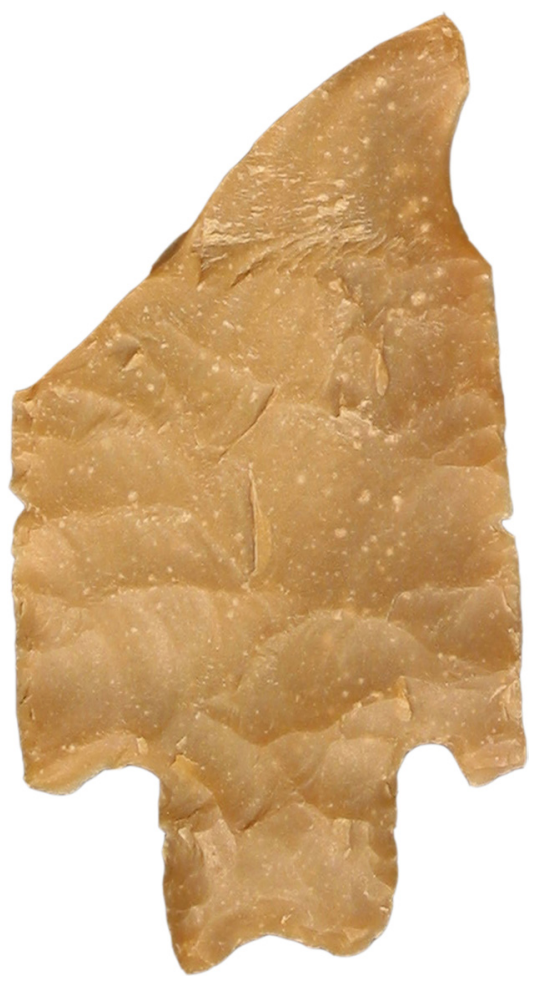

Reworking and Beveling: N/A

Use-wear: Use-wear analysis was not performed on these points.

Raw Material Attributes: Both of these points are composed of local Edwards fine-grained chert. One of the specimens shows signs of heat alteration in the form of reddening.

\section{Subtype Pedernales Stem Form N/A}

$(\mathrm{n}=1)$ (Lot 1179)

Nominal Attributes: N/A

Condition and Breakage: The specimen is a shoulder fragment with additional thermal breakage.

Reworking and Beveling: N/A

Use-wear: N/A

Raw Material Attributes: The specimen is made from local Edwards fine-grained chert.

\section{Travis}

$(\mathrm{n}=1)($ Lot 133.3) (Appendix C, Figure $12 \mathrm{a})$

Nominal Attributes: The specimen has a subparallel flaking pattern.

Condition and Breakage: The specimen is a basal fragment with evidence of a distal snap.

Reworking and Beveling: No reworking or beveling occurs on this specimen.

Use-wear: N/A

Raw Material Attributes: The raw material for this point is local Edwards fine-grained chert.

Comments: This specimen is a manufacturing failure. 


\section{UNTYPABLE}

$(\mathrm{n}=37)($ Lots 134.5, 134.6, 134.13, 136.1, 1069.1, 1072.1, 1099.2, 1109.1, 1109.2, 1112, 1121.1, 1123, $1142,1158,1160.1,1161,1172,1183.4,1184,1210.1,1226.2,1242,1276.2,1318.1,1322.7,1328.8$, $1339.2,1352,1360.1,1380.2,1387.2,1390.4,1397.2,1411,1442,1466.1,1518)$ (Appendix C, Figure 18 b-1318.1, h-Lot 1242)

Nominal Attributes: One of these points (Lot 1210.1) is possibly a preform.

Condition and Breakage: Only two of these points are complete with no breakage. Ten of the specimens are basal fragments, eight are stem fragments, eight are shoulder fragments, and two are blade fragments.

Reworking and Beveling: Three of the specimens exhibit reworking.

Use-wear: N/A

Raw Material Attributes: These specimens are made from local Edwards fine-grained chert. Twelve of these specimens were heated, causing potlids, reddening, and crazing.

Comments: Limited attributes, including condition, breakage, heat evidence, and weight, were recorded for these specimens.

\section{BIFACIAL TOOLS}

The bifacial tool assemblage consists of three butted bifaces (Lots 56.1, 1297.1, and 1460.2), three perforators (Lots 143.1, 1209, and 1363), a drill (1197.2), and a gouge (Lot 1303). These tools are described in detail in Appendix C. Butted biface Lot 56.1 has use-wear consistent with sickle sheen from scraping plant material. The other two were used for a combination of chopping and cutting. The perforators were assumed to be used as awls for piercing a material such as hide, and Lot 143.1 was also used as a cutting tool. No use-wear analysis was conducted on the drill (Lot 1197.2), but from the shape of the bit it was most likely used as a perforator. The single gouge (Lot 1303) was the largest of the Clear Fork tools and gouges and was probably hafted. The bit was resharpened in a manner common to Clear Fork tools (Hudler 1997), removing traces of use-wear. The bifacial tools indicate a range of activities associated with hide preparation and plant processing. The low numbers of these tools suggest that they were infrequently used and that the implied tasks were not major site activities.

\section{BIFACES}

A total of 445 bifaces and bifacial fragments were recovered from OZ4. This includes 47 complete bifaces, 75 basal fragments, 63 distal fragments, 62 medial fragments, four interior fragments, 100 marginal fragments, and 94 indeterminate fragments. Categorized according to the bifacial stages of reduction, there are six Stage 1, 28 Stage 2, 54 Stage 3, 80 Stage 4, and 192 Stage 5 bifaces (Table 11.2). Of the Stage 1 bifaces, three are complete with one being ovate-shaped and the other two being amorphous. The ovate-shaped biface was overexposed to heat. The Width/Thickness ratio of the complete Stage 1 bifaces is 2.6 with an average edge angle of 50.3 degrees. The Stage 1 bifacial fragments all have breakage due to manufacture.

Twelve of the Stage 2 bifaces are complete with the remaining specimens consisting of five basal fragments, one medial fragment, and 10 indeterminate fragments. The complete bifaces consist predominantly of ovate-shaped specimens $(n=9)$. Overall, the average edge angle of the complete bifaces is 41.3 degrees with a Width/Thickness ratio of 2.7. None of the complete bifaces show evidence of heat treatment or burning. All the Stage 2 bifacial fragments have manufacture breaks and only one has slight reddening.

The Stage 3 bifaces consist of 14 complete bifaces, six basal fragments, two medial fragments, one distal fragment, three marginal fragments, and 28 indeterminate fragments. The complete bifaces are comprised of seven pointed oval, three teardrop, 
Table 11.2. Occupation Zone 4 Attribute Measurements for General Bifaces by Stage

\begin{tabular}{|c|c|c|c|c|c|c|c|c|}
\hline & & \multicolumn{6}{|c|}{ Stage } & \multirow[b]{2}{*}{ Total } \\
\hline & & 1 & 2 & 3 & 4 & 5 & Indeter & \\
\hline \multirow{2}{*}{ Max L } & $\mathrm{N}$ & 3 & 13 & 14 & 14 & 7 & & 51 \\
\hline & Mean & 102.73 & 109.33 & 89.29 & 96.80 & 92.85 & & 97.74 \\
\hline \multirow{2}{*}{ Max W } & $\mathrm{N}$ & 6 & 26 & 43 & 61 & 120 & 1 & 257 \\
\hline & Mean & 65.08 & 66.78 & 53.02 & 44.22 & 38.03 & 21.80 & 45.48 \\
\hline \multirow{2}{*}{ Max Th } & $\mathrm{N}$ & 6 & 28 & 53 & 79 & 191 & 83 & 440 \\
\hline & Mean & 24.53 & 23.97 & 14.82 & 9.57 & 7.05 & 7.44 & 9.83 \\
\hline \multirow{2}{*}{ W/T Ratio } & $\mathrm{N}$ & 6 & 28 & 53 & 79 & 191 & 83 & 440 \\
\hline & Mean & 2.71 & 2.62 & 2.94 & 3.49 & 3.21 & 0.05 & 2.59 \\
\hline \multirow{2}{*}{ Weight } & $\mathrm{N}$ & 6 & 28 & 54 & 80 & 192 & 85 & 445 \\
\hline & Mean & 144.40 & 146.27 & 55.22 & 29.09 & 13.57 & 7.51 & 30.37 \\
\hline \multirow{2}{*}{ Edge Angle } & $\mathrm{N}$ & 6 & 26 & 54 & 79 & 192 & 80 & 437 \\
\hline & Mean & 47.33 & 40.88 & 33.83 & 28.15 & 25.05 & 26.40 & 28.19 \\
\hline
\end{tabular}

two subtriangular, one amorphous and a lanceolateshaped specimen. The average edge angle of the complete bifaces is 34.2 degrees with a Width/Thickness ratio of 3.7. While none of the complete bifaces show evidence of heat treatment, seven of the fragments are either reddened or contain pot lids.

The Stage 4 bifaces consist of 12 complete bifaces with six being pointed oval-shaped, one teardropshaped, two subtriangular-shaped, one lanceolateshaped, and two amorphous specimens. The Width/ Thickness ratio of the complete bifaces is 4.3 with an average edge angle of 31.5 degrees. The remaining Stage 4 biface specimens consist of 18 basal fragments, 8 distal fragments, 16 medial fragments, 6 marginal fragments, and 20 indeterminate fragments. Six of the basal fragments and one of the distal fragments contain enough attributes to determine the original bifacial shape: four are lanceolate-shaped, one is pointed oval-shaped, and another is subtriangular. The distal fragment is likely the remnant of a bipointed biface. Aside from five specimens with thermal fractures and one with a post-depositional break, all the fragments appear to have breaks caused by manufacture. In all, two of the complete bifaces and 13 of the bifacial fragments were exposed to heat that caused reddening and pot lid scars.

The Stage 5 bifaces consist of six complete bifaces, 45 basal fragments, 51 distal fragments, 41 medial fragments, 30 marginal fragments, and 19 indeterminate fragments. Of the complete bifaces, four are pointed oval-shaped, one is lunate-shaped, and one is subtriangular. Only the subtirangular biface has slight reddening indicative of heat treatment. The Width/Thickness ratio of the complete bifaces is 5.8 with an average edge angle of 26.2 degrees. Two of the complete bifaces analyzed for use-wear were a large thin, pointed oval, percussion-flaked biface (Lot 6) likely used as a butchering knife to cut soft material like hide or meat and a lunate-shaped, extremely thin, percussion-flaked hand-held knife (Lot 1443) used in butchering to cut hide and meat, with frequent contact on bone and cartilage.

Of the Stage 5 basal fragments, 10 contained enough attributes to determine the shape of the original biface. There are six lanceolate, four pointed oval, two triangular, and a subtriangular-shaped biface. Four of the basal fragments showed evidence of exposure to heat, causing reddening, the presence of pot lids, or crazing. The remaining bifacial fragments showed evidence of breakage occurring during manufacture. Use-wear analysis was conducted on two of the proximal fragments and one of the basal fragments. The proximal fragment of a large, percussion-thinned biface (Lot 1468) was broken by a transverse bend fracture. Following breakage, the tool was recycled as a burin and a plane worked on wood or bone. The proximal fragment of a large, thin biface (Lot 1341) was also broken by a transverse bend fracture with worked edges used to cut resistant materials, possibly wood, or cartilage and bone in heavy-duty butchering. The basal fragment is from a percussion-thinned 
lanceolate-shaped biface (Lot 1350) with the distal end removed by bend fracture. This specimen was a knife probably hafted and used to cut moderately resistant materials, such as wood.

Within the Stage 5 biface assemblage are 22 complete specimens of large thin bifaces, of which all but two are fragments. These were thought to represent a particular collection of thin bifaces. The distribution of these specimens occurs throughout Area $\mathrm{B}$, and it cannot be determined if they represent a single occupation or association with one particular projectile point style or lithic industry. Large, thin bifaces were a major part of the Round Rock phase lithic assemblage associated with Pedernales and Kinney points from the Anthon site in Uvalde County (Goode 2002).

\section{FLAKE TOOLS}

The modified flake tools from OZ4 consist of seven formal flake tools: two end scrapers, two end and side scrapers, two side scrapers, and one graver (Table 11.3). The 76 informal flake tools are 24 utilized flakes, and 52 retouched flakes. The two end scrapers are complete and unifacially worked on the distal edge towards the dorsal surface. The worked lateral edge is 29 and 46 percent of the entire lateral edge of each scraper, respectively. The two end and side scrapers consist of one complete specimen and a distal fragment. Each is unifacially worked toward the dorsal surface with the complete specimen worked along all margins and the fragment worked along the distal and left lateral margin. Sixty-three percent of the entire lateral edge of the complete end and side scraper is modified.
The two side scrapers are complete with one being trimmed bidirectionally and the other trimmed unifacially toward the dorsal end. The unifacial scraper is trimmed along the right lateral margin accounting for 31 percent of the entire lateral edge while the bidirectional scraper is modified on the left lateral margin toward the ventral surface and the right lateral margin toward the dorsal surface. The worked edge of the bidirectional scraper accounts for 69 percent of the total lateral margin edge for the specimen. The graver is worked along the distal and left lateral margin toward the dorsal surface encompassing 66 percent of the entire lateral margin length for the flaked tool. None of these scrapers are made from a sequence flake, suggesting that use of sequence flakes for flake tool blanks may be an Early Archaic trait at the Gatlin site.

Of the 76 expedient utilized and retouched flakes recovered in OZ4, 13 of the utilized flakes and 19 of the retouched flakes are complete. The rest are an assortment of distal $(n=16)$, proximal $(n=13)$, marginal $(n=3)$, medial $(n=3)$, longitudinal $(n=6)$, and indeterminate fragments $(n=3)$. Only five of the utilized and retouched flakes exhibit evidence of heat treatment.

\section{CORES}

Of the 95 cores recovered in OZ4, two are bidirectional, 18 are bifacial, 56 are multidirectional, six are unidirectional, one is a slab, and 12 are indeterminate (Table 11.4). Both bidirectional cores are complete and are from a riverine procurement locale based upon visible remaining cortex. One is

Table 11.3. Occupation Zone 4 Attribute Measurements for Complete Modified Flake Subcategories

\begin{tabular}{|l|l|c|c|c|c|c|c|c|}
\hline \multicolumn{2}{|l|}{} & $\begin{array}{c}\text { End } \\
\text { Scraper }\end{array}$ & $\begin{array}{c}\text { End \& Side } \\
\text { Scraper }\end{array}$ & $\begin{array}{c}\text { Side } \\
\text { Scraper }\end{array}$ & Graver & $\begin{array}{c}\text { Utilized } \\
\text { Flake }\end{array}$ & $\begin{array}{c}\text { Retouched } \\
\text { Flake }\end{array}$ & Total \\
\hline Count & $\mathrm{N}$ & 2 & 1 & 2 & 1 & 13 & 19 & 38 \\
\hline Length & Mean & 57.28 & 40.39 & 78.30 & 86.82 & 69.21 & 73.72 & 71.02 \\
\hline Width & Mean & 50.68 & 50.72 & 58.61 & 62.98 & 54.05 & 59.65 & 57.06 \\
\hline Thickness & Mean & 20.17 & 21.48 & 20.31 & 16.90 & 15.33 & 18.90 & 17.83 \\
\hline Weight & Mean & 54.40 & 37.50 & 84.60 & 74.30 & 51.79 & 86.08 & 71.02 \\
\hline Perimeter Length & Mean & 175.10 & 154.94 & 225.02 & 234.49 & 200.79 & 218.80 & 209.40 \\
\hline Perimeter Retouch Length & Mean & 64.80 & 101.18 & 110.89 & 155.25 & 65.58 & 82.88 & 79.87 \\
\hline Marginal Retouch \% & Mean & 0.38 & 0.65 & 0.50 & 0.66 & 0.31 & 0.37 & 0.37 \\
\hline Max Edge Angle & Mean & 80.50 & 67.00 & 54.00 & 27.00 & 35.62 & 50.94 & 46.89 \\
\hline
\end{tabular}


Table 11.4. Occupation Zone 4 Attribute Measurements for Complete Exhausted and Unexhausted Cores

\begin{tabular}{|l|l|c|c|c|c|c|c|}
\hline \multicolumn{2}{|c|}{} & Bifacial & Multidirectional & Bidirectional & Unidirectional & Slab & Total \\
\hline Count & $\mathrm{N}$ & 15 & 40 & 2 & 5 & 1 & 63 \\
\hline Max Length & Mean & 93.51 & 90.99 & 94.21 & 66.27 & 27.50 & 88.72 \\
\hline Max Width & Mean & 75.06 & 69.18 & 71.13 & 53.34 & 19.00 & 68.59 \\
\hline Max Thickness & Mean & 32.30 & 41.70 & 27.78 & 34.76 & 4.20 & 37.87 \\
\hline Weight & Mean & 284.79 & 274.03 & 246.10 & 116.98 & 4600.00 & 331.90 \\
\hline Max Flake Scar Length & Mean & 48.22 & 44.04 & 27.86 & 32.85 & 4.50 & 42.92 \\
\hline \# Flake Scars & Mean & 7.57 & 5.90 & 6.50 & 5.80 & 3.00 & 6.24 \\
\hline
\end{tabular}

a nodular specimen and the other from tabular parent material.

Of the 18 bifacial cores, 15 are complete. The complete specimens are predominantly tabular cores from riverine procurement locales. The three remaining bifacial core fragments consist of a nodular, a tabular, and one indeterminate specimen. Only one of the bifacial cores has evidence of heating, which caused some slight reddening.

Of the 56 multidirectional cores, 40 are complete specimens from either riverine or indeterminate procurement locales. Most of the complete specimens are of fine-grained chert from tabular parent material. The recovered core fragments are predominantly smaller pieces with an average of 4 flake scars. Four of the multidirectional cores have been heated causing reddening and crazing. Of the six unidirectional cores recovered in OZ4, five are complete specimens from an indeterminate parent material. The one frag- ment is a tabular specimen from a riverine procurement locale. One of the complete specimens is a slab core with only three negative flake scars and because of its large size it was probably worked in situ.

The indeterminate cores recovered from OZ4 are fragments from nodular, tabular, or indeterminate parent materials. Five of the cores were likely procured from a riverine environment while the remainder could not be sourced. The number of negative flake scars is minimal with an average of two scars per specimen. None of the specimens shows evidence of heat treatment.

\section{DEBITAGE}

The counts and metrics for debitage recovered from traditional units are in Table 11.5. Almost 4,500 pieces of debitage were recovered from OZ4, with most identified as biface thinning $(n=3191,72$ percent) with the remainder as core ( $\mathrm{n}=698,16$ percent)

Table 11.5. Biface, Core, Resharpening, and Indeterminate Reduction Flake Measurements from Occupation Zone 4

\begin{tabular}{|c|c|c|c|c|c|}
\hline & \multicolumn{4}{|c|}{ Flake Type } & \multirow[b]{2}{*}{ Total } \\
\hline & Biface Thinning & Core Reduction & Tool Resharpening & Indeter & \\
\hline Count & 3191 & 698 & 1 & 552 & 4442 \\
\hline Max of Length (mm) & 71.1 & 95 & & 62.5 & 95 \\
\hline Average of Length ( $\mathrm{mm})$ & 22.26 & 35.76 & & 20.19 & 25.47 \\
\hline Max of Thickness (mm) & 11.9 & 51 & & 8.2 & 51 \\
\hline Average of Thickness (mm) & 2.46 & 7.80 & & 3.06 & 3.93 \\
\hline Max of Width (mm) & 65.8 & 92.3 & & 57.7 & 92.3 \\
\hline Average of Width (mm) & 15.65 & 29.26 & & 15.65 & 19.18 \\
\hline Max of Wt (g) & 38.5 & 109.3 & 1.1 & 16.5 & 109.3 \\
\hline Average of Weight (g) & 0.89 & 8.63 & 1.10 & 0.99 & 1.93 \\
\hline Sum of Weight (g) & 2395.2 & 4126.5 & 1.1 & 430 & 6952.8 \\
\hline
\end{tabular}


or indeterminate ( $\mathrm{n}=552,12$ percent). In OZ4, there is an increase in biface reduction flakes from OZ3, from 66 percent to 72 percent and core reduction flakes decline 3 percent, from 19 to 16 percent. The average core flake also slightly declines in size from $41 \mathrm{~mm}$ in OZ3 to $36 \mathrm{~mm}$ in OZ4. The percentage of dorsal cortex is similar to OZ3, suggesting similar reduction strategies and raw material sources were being pursued. Overall, the debitage indicates a heavy emphasis on biface production by OZ4 occupants at the Gatlin site.

\section{GRound STONE Tools}

There were two fragments of sandstone manos from OZ4. Both specimens were recovered from featurefocused units and were smoothed from grinding on both faces. With only two specimens, there was a decline in the number of milling tools from OZ3, and overall, milling tools were found in low numbers at the Gatlin site. The metrics and descriptions of the ground stone fragments are in Appendix C. The low number of ground stone pieces suggests that milling activities were not associated with the use of Feature 1.

\section{FAUNAL ASSEMbLaGE}

The analyzed faunal assemblage from OZ4 is the most well-preserved from the site and includes 802 specimens weighing a total of 383.2 grams. The two taxa recognizable in the assemblage are white-tailed deer (Odocoileus virginianus), and turtle (species unknown). Large mammal bone fragments suggest the presence of bison (Bison bison). The white-tailed deer is represented by a number of elements, including: third phalanges, astragalus, cuneiform, femur, a metatarsal, a metacarpal, mandible, meatus, tooth fragments, and whole pre-molar. Most of the deer bone is fragmentary to highly fragmentary in nature with little burning. Possible juvenile elements were also noted, specifically the proximal epipheseal cap to a metatarsal and some un-erupted molars in a mandible fragment. The Minimum Number of Individuals (MNI) for the white-tail deer is two. The turtle is a small carapace fragment.

There were five large mammal (likely deer or perhaps highly fragmented bison) fragments that were identified, most appearing to be fragmented to extremely fragmented longbone shaft fragments. Six (less than 1 percent) small mammal fragments were identified, likely rabbit or similar sized animals. Fragmented to extremely fragmented unidentifiable specimens make up the remainder of the OZ4 assemblage, $(n=780,97$ percent). These are generally small $(<5 \mathrm{~mm}$ and/or $<2-3$ grams each) fragments that primarily appear to be highly weathered large to medium mammal bone. Many fragments are obviously from much larger elements that have severely weathered and deteriorated. Burning was noted on 270 bone specimens ( 34 percent), ranging from light to heavy, resulting in calcining of the bone. All of the bone was classified as fragmented or extremely fragmented bone with some classified as bone meal or powder, reflecting the degraded nature of the assemblage. Slight to extreme weathering in the form of cracking and fragmentation was noted on most specimens. No cultural modifications in the forms of cutmarks or green-bone breaks were evident on any of the specimens.

\section{FEATURE ASSEMBLAGE}

The 10 features identified in OZ4 were predominantly within Area B. These include Features 1 (midden), 4, 7, 8, 9, 10, 11, 23, 36, and 37 (Figure 11.2). However, Feature 4 was only partially excavated since it extended beyond the excavation area limits. Not depicted in Figure 11.2 is Feature 7, which was located to the north of the designated units in Area A-NE. Feature 8, just north of Area A-NW (Figure 11.3), was further subdivided into two burned rock clusters designated $\mathrm{A}$ and $\mathrm{B}$. There were two features within this occupation zone (Features 11 and 23) that were not burned rock features. Feature 11 was a small very tight, circular cluster of burned caliche like matrix material. This feature may be the basal remnants of a burned fence post. Feature 23 was a highly fragmented human skull fragment (occipital portion of the cranium) with no associated stone tools, charcoal, or burned rocks. The discovery of the fragment prompted additional supplemental units to be excavated to the south and east. No burials or evidence of other human remains were detected and the specimen appears to be an isolated occurrence of unknown origin. The full results of special studies from these features are located in Appendices E through I. 


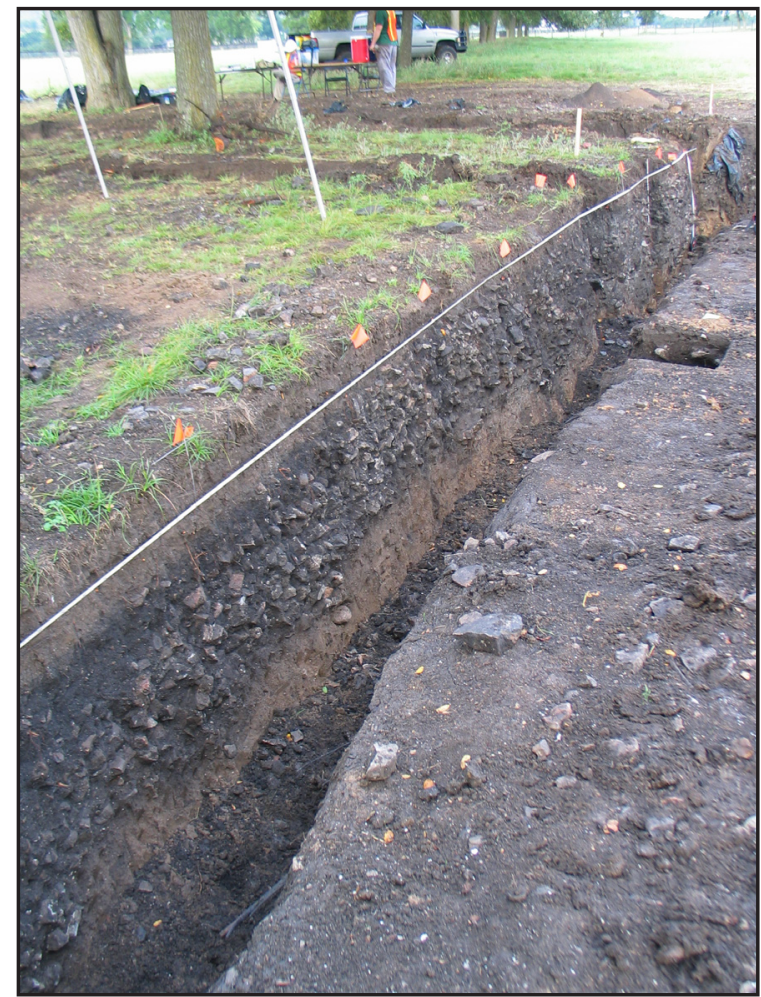

Figure 11.2. Midden profile Backhoe Trench 18 south wall.

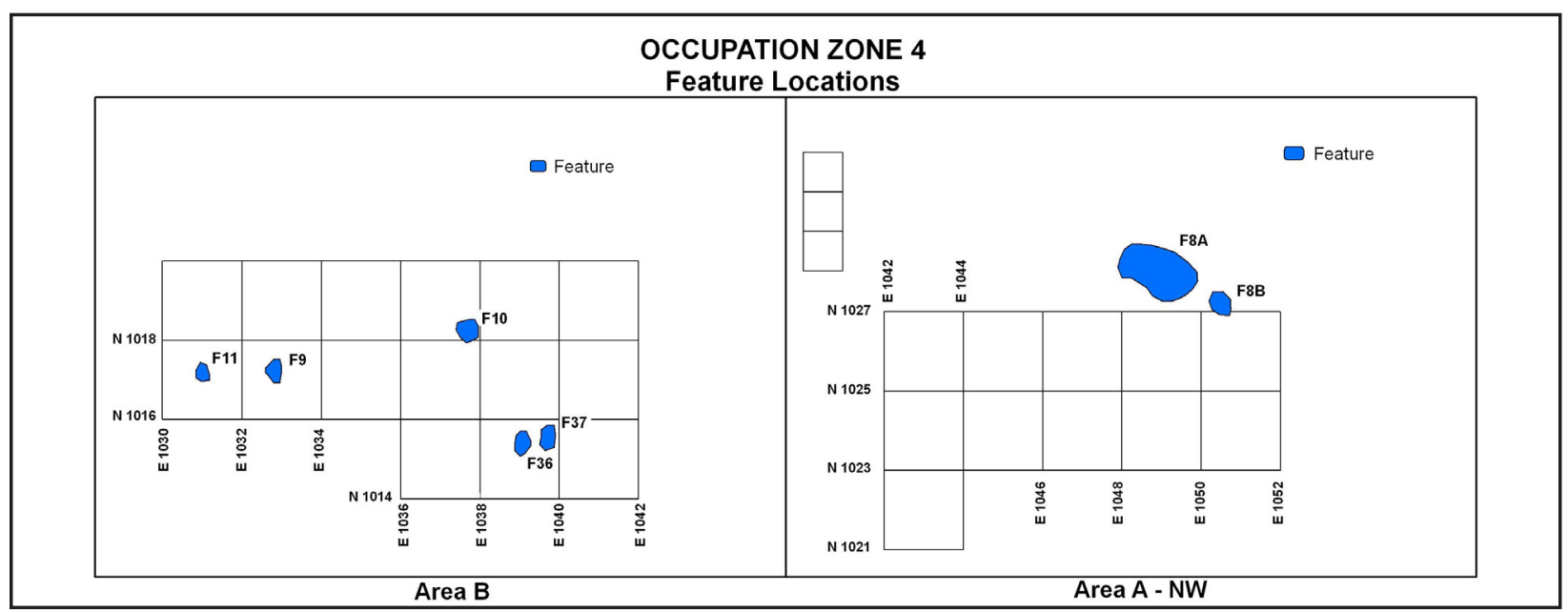

Figure 11.3. Occupation Zone 4 Area $B$ feature locations are depicted to the left while Occupation Zone 4 Area A-NW feature locations are on the right. 


\begin{tabular}{|c|c|c|c|c|}
\hline & & Faunal Evidence & \multicolumn{2}{|l|}{ None } \\
\hline & & Pollen & \multicolumn{2}{|l|}{$\mathrm{N} / \mathrm{A}$} \\
\hline & & Flotation Results & \multicolumn{2}{|c|}{$\begin{array}{l}\text { Chenopodium, amaranth, hackberry, dais } \\
\text { family, woodsorrel, and legume }\end{array}$} \\
\hline & & Radiocarbon Dates & \multicolumn{2}{|l|}{ N/A } \\
\hline Feature Type & Small cluster of burned material & Associated floor elevation & \multicolumn{2}{|l|}{$98.3-98.2 \mathrm{~m}$} \\
\hline Occupation Zone & 4 & \multirow{2}{*}{$\begin{array}{l}\text { Associated Diagnostics } \\
\text { (Lot No. and elevation) }\end{array}$} & \multirow{2}{*}{\multicolumn{2}{|c|}{ None }} \\
\hline Stratigraphic Context & $2 \mathrm{Ab} 1$ & & & \\
\hline Area & $B$ & \multirow{3}{*}{$\begin{array}{l}\text { Diagnostics above and } \\
\text { adjacent to feature (Lot No.): } \\
\text { proximity radius }=2.0 \mathrm{~m}, \\
\text { proximity elevation }=0.1 \mathrm{~m}\end{array}$} & \multirow{3}{*}{ Untyped (1 123) } & \multirow{3}{*}{$98.26 \mathrm{~m}$} \\
\hline Provenience & N1016E1030 & & & \\
\hline Center & N1017.18 E1030.96 & & & \\
\hline Top Elevation & $98.25 \mathrm{~m}$ & \multirow{6}{*}{$\begin{array}{l}\text { Diagnostics below and } \\
\text { adjacent to feature (Lot } \mathrm{No} \text {.): } \\
\text { proximity radius }=2.0 \mathrm{~m}, \\
\text { proximity elevation }=0.1 \mathrm{~m}\end{array}$} & Pedernales (1124) & $98.18 \mathrm{~m}$ \\
\hline Bottom Elevation & $98.12 \mathrm{~m}$ & & Langtry (1 126) & $98.15 \mathrm{~m}$ \\
\hline Size & $16 \mathrm{~m}$ in diameter & & Marshall (1319) & $98.17 \mathrm{~m}$ \\
\hline Shape & Circular; shallow, basin like & & Untyped (1318.1) & $98.20-98.10 \mathrm{~m}$ \\
\hline Fuel Type & Indeterminable hardwood & & Untyped (1328.8) & $98.20-98.10 \mathrm{~m}$ \\
\hline Lipids & N/A & & Untyped (1360.1) & $98.20-98.10 \mathrm{~m}$ \\
\hline
\end{tabular}

\section{DESCRIPTION}

Feature 1 was a large burned rock midden north of Area B. It was first discovered during the auger testing survey of the right-of-way and subsequently investigated during the survey and testing phases with BHTs 1 and 18, two column samples, and TUs 1-B, 18-A, and 18-B. During the data recovery phase, CT 3 was excavated to further explore the burned rock midden profile; seven column samples were placed within the midden's boundaries to compare artifact depths and densities across the midden.

The burned rock midden was buried by colluvium and, therefore, was not apparent on the surface. It was presumably oval or circular, but this is an assumption based on the comprehensive findings of the various backhoe trenches, column samples, and hand-excavated units. BHT 1 and CT 3 both cut through the midden along a north-south axis, while BHT 18 bisected it along an east-west axis. Based on these trenches, the midden was approximately $18 \mathrm{~m}$ in minimum diameter.

The midden was shallowly buried by colluvium and fully suspended within the A horizon. It appears to have straddled a low relief scarp, and this minor topographic feature seems to have separated primarily colluvial deposition (on the southern, higher side) from mostly alluvial sedimentation on the northern side of the midden.

The stratigraphy in BHT 18 contained five zones. The upper zone was a $20-50-\mathrm{cm}$ thick colluvial deposit of very dark grayish brown clay loam that buried the midden. The second zone was a black to very dark brown clay loam that corresponded to the A horizon. Contained within the A horizon, which was $40-80 \mathrm{~cm}$ thick, was the burned rock midden, Zone 3 . Zone 4 was the $\mathrm{B}$ horizon, a yellowish brown clay loam. The final zone was a firm, dark yellowish brown clay loam with 10 percent natural gravels.
The midden comprised a zone of tightly packed burned rocks, which became less compact and more dispersed at the edges of the feature. On the upslope side, there was evidence of vertical separation of midden-related occupation surfaces, the result of progressive burials of the midden by colluvium. At its densest point, the midden was approximately $100 \mathrm{~cm}$ thick.

Several pits, which appeared to be coeval with the midden, extended from the base of the midden, through the underlying $B$ horizon, and into the otherwise culturally sterile Zone 5. These pits were observed in BHT 18's northern and southern walls. In the southern profile, two very distinct pits were visible below the base of the midden. These cut through Zone 4 into Zone 5. The westernmost pit was generally flat bottomed with rounded corners. It measured approximately $46 \mathrm{~cm}$ in width and $20-25 \mathrm{~cm}$ in depth. The second pit was $30 \mathrm{~cm}$ east of the first; this pit was also flat bottomed and 20-25 cm deep, but slightly wider, measuring approximately $1 \mathrm{~m}$. Another pit was visible in the northern profile but did not appear to articulate with the southern ones. This pit was $1.55 \mathrm{~m}$ wide, basin shaped, and $20 \mathrm{~cm}$

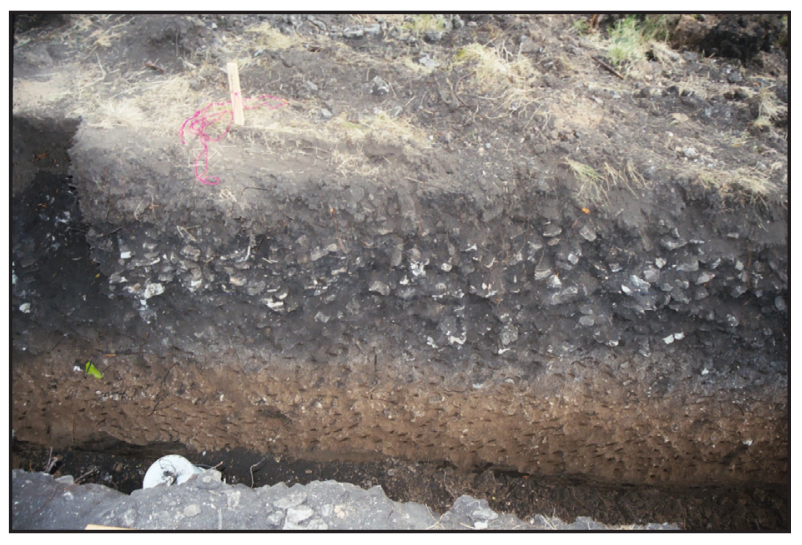

Close-up of profile of Feature 1. 


\section{Feature 1, continued}

deep. These pits were most likely related to the early use of the midden, as they underlie most of the burned rock and clearly cut through the underlying cultural component.

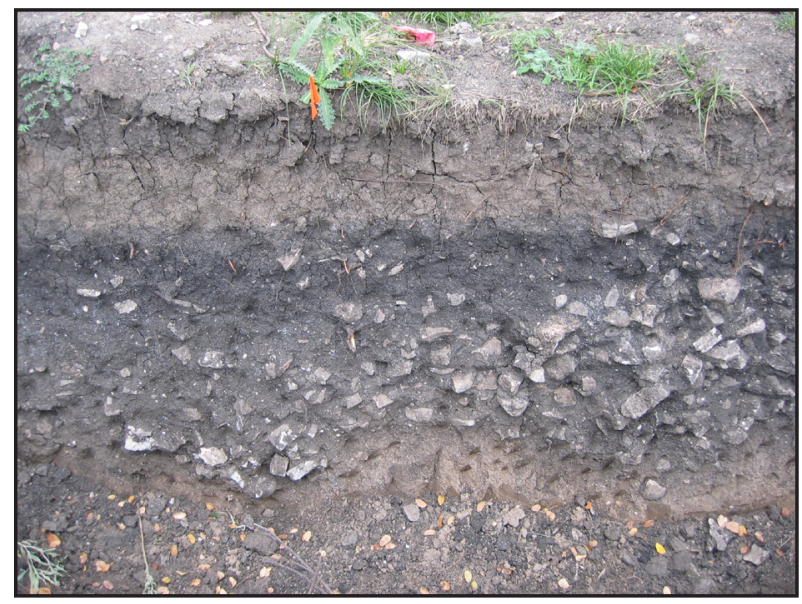

\section{Close-up profile of pit features in Feature 1.}

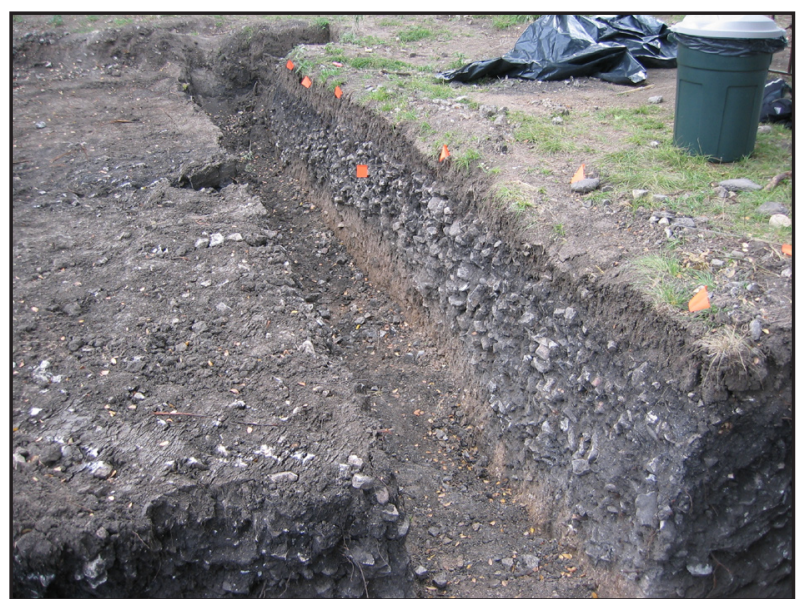

Profile of Feature 1 within BHT 18, facing east.

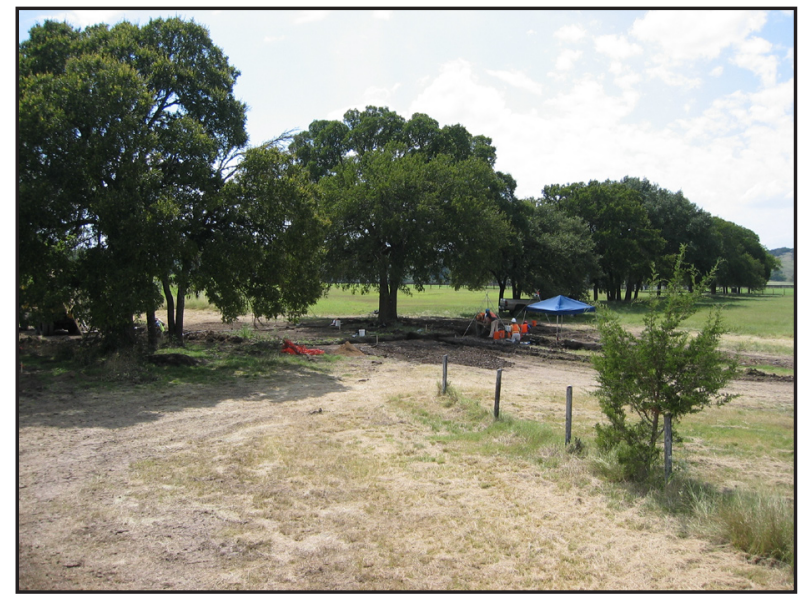

Overview of Feature 1 area.
Lithic debitage densities proved to be extremely high within the column samples located away from the center of the midden. These dropped significantly when excavations reached the $B$ horizon below the midden. Within the midden's center, debitage counts were, in general, far lower, although still average to high in comparison with the other components of the site. The test units and column samples produced a range of projectile points, including two La Jita points, six untyped dart points, and single examples of the Bulverde, Frio, Gower, Lange, Marshall, Narrow Stem Martindale, Nolan, Pedernales, and Travis types. The backdirt of the trenches also produced numerous points, including six La Jita points, three Pedernales points, two untyped dart points, and single examples of the following types: Bulverde, Early Triangular, Gower, Marshall, Martindale, Narrow Stem Martindale, and Nolan.

The midden did contain some faunal material, but in relatively small numbers, and charcoal was rarely noted. Preservation of charcoal proved to be much better below the midden, and several samples were obtained to date the deposits beneath the midden's base.

Based on the geoarchaeological assessment, it is likely that the midden began to form in the Early to Middle Archaic and continued into the Late Holocene. Throughout this prolonged use period, the midden appears to have been progressively buried, especially on the upslope or south side.

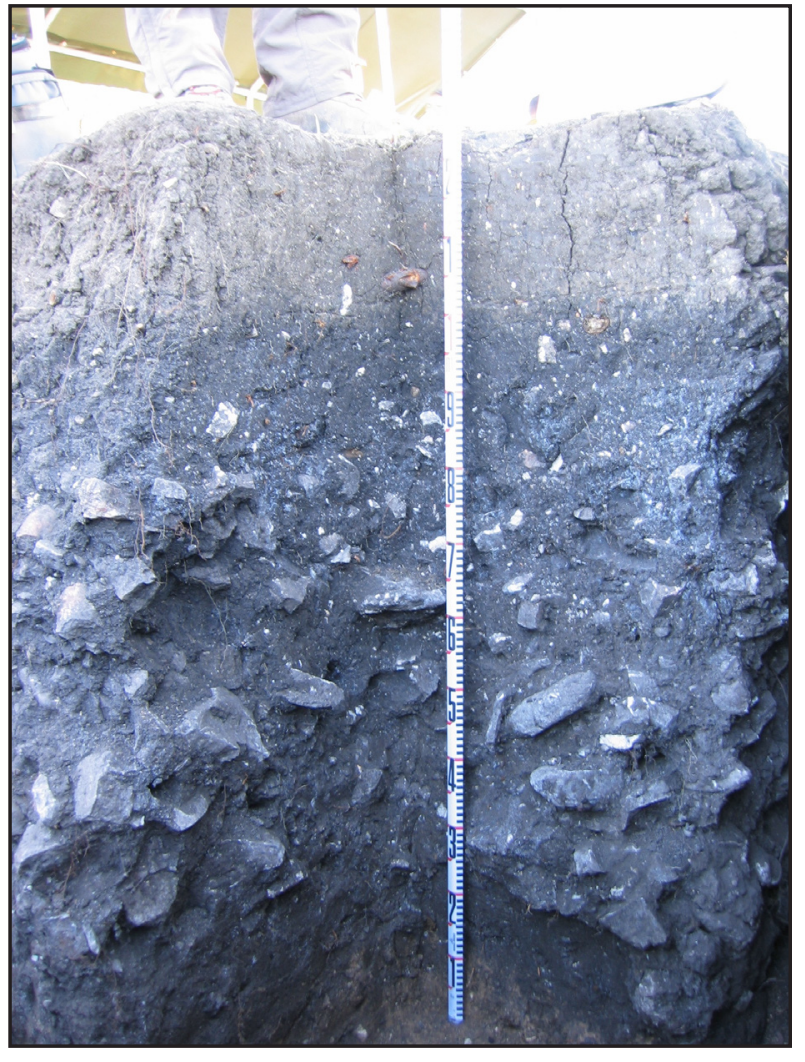

Profile close-up, CS3 of Feature 1. 


\begin{tabular}{|c|c|c|c|c|}
\hline & & Faunal Evidence & \multicolumn{2}{|l|}{ None } \\
\hline & & Pollen & \multicolumn{2}{|l|}{ N/A } \\
\hline & & Flotation Results & \multicolumn{2}{|l|}{ N/A } \\
\hline & & Radiocarbon Dates & \multicolumn{2}{|l|}{ N/A } \\
\hline Feature Type & Burned rock cluster & \multirow{2}{*}{$\begin{array}{l}\text { Associated floor elevation range } \\
\text { (m) }\end{array}$} & \multirow{2}{*}{\multicolumn{2}{|c|}{$97.80-97.70 \mathrm{~m}$}} \\
\hline Occupation Zone & 4 & & & \\
\hline Stratigraphic Context & $2 A b 2$ & \multirow{2}{*}{$\begin{array}{l}\text { Associated Diagnostics (Lot No. and } \\
\text { elevation) }\end{array}$} & \multirow{2}{*}{\multicolumn{2}{|c|}{ None }} \\
\hline Area & Midden & & & \\
\hline Provenience & TU 18-B & \multirow{5}{*}{$\begin{array}{l}\text { Diagnostics above and adjacent to } \\
\text { feature (Lot No.): proximity radius }= \\
2.0 \mathrm{~m} \text {, proximity elevation }=0.1 \mathrm{~m}\end{array}$} & \multirow{5}{*}{\multicolumn{2}{|c|}{ None }} \\
\hline Center & $N / A$ & & & \\
\hline Top Elevation & $97.80 \mathrm{~m}$ & & & \\
\hline Bottom Elevation & $97.70 \mathrm{~m}$ & & & \\
\hline Size & $60 \times 20 \mathrm{~cm}$ & & & \\
\hline Shape & Amorphous, flat & \multirow{3}{*}{$\begin{array}{l}\text { Diagnostics below and adjacent to } \\
\text { feature (Lot No.): proximity radius }= \\
2.0 \mathrm{~m} \text {, proximity elevation }=0.4 \mathrm{~m}\end{array}$} & Pandale (147.4) & $97.41 \mathrm{~m}$ \\
\hline Fuel Type & $\mathrm{N} / \mathrm{A}$ & & Andice (147.5) & $97.50-97.40 \mathrm{~m}$ \\
\hline Lipids & $\mathrm{N} / \mathrm{A}$ & & Montell (147.7) & $97.50-97.40 \mathrm{~m}$ \\
\hline
\end{tabular}

\section{DESCRIPTION}

Feature 4 was discovered immediately west of the burned rock midden in TU 18-B during the testing phase. The feature was only partially exposed by the test unit and apparently extended beyond the limits of the excavation to the north. Feature 4 was an amorphous cluster of tabular burned limestone rocks (Figure 12.15). The exposed portion measured $60 \times 20 \mathrm{~cm}$, oriented east-west. In cross section, Feature 4 measured only $10 \mathrm{~cm}$ thick and apparently rested on a flat surface. No rock layering or stacking was apparent. The rocks forming the feature were adjoining and included only seven rocks that were recorded in situ. Four of these were $5-10 \mathrm{~cm}$ in size, while the other three were $10-15 \mathrm{~cm}$. No distinction between the surrounding soil and the feature's fine matrix was evident. Due to the feature's proximity to the midden, it may represent burned rocks scattered from the midden itself.

From the excavation level containing the feature, the excavations recovered 104 pieces of debitage, two bifaces, three modified flakes, and three faunal bone fragments. No charcoal was noted within the feature, and no diagnostic artifacts were found within the estimated $10-\mathrm{cm}$ floor level. No temporally diagnostic dart points were recovered within the vertical estimated floor elevation of Feature 4 and within a $2-m$ radius of the feature.

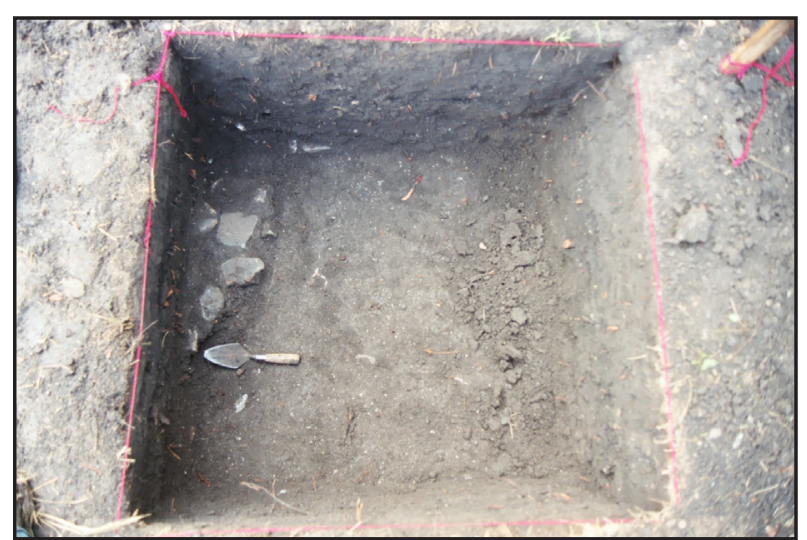

Overview of Feature 4 at $97.70 \mathrm{~m}$.

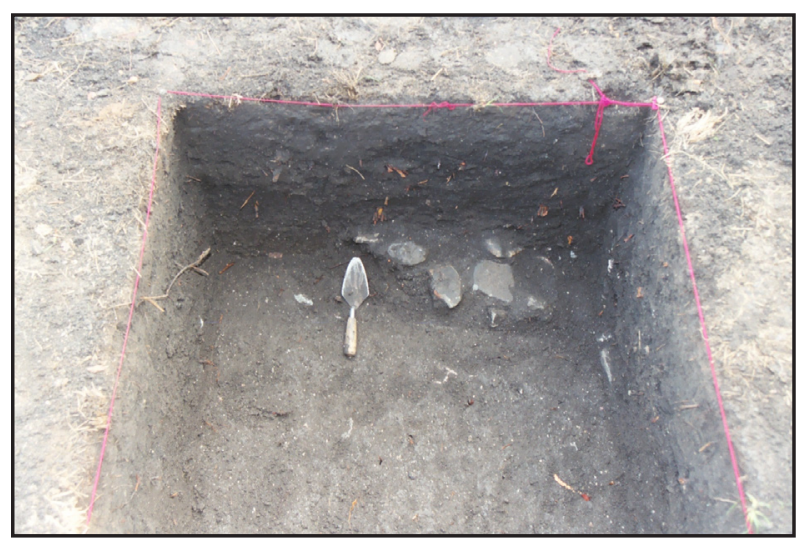

Profile view of Feature 4 at $97.70 \mathrm{~m}$. 


\begin{tabular}{|c|c|c|c|c|}
\hline E & & Fuel Type & \multicolumn{2}{|l|}{ None } \\
\hline & & Lipids & \multicolumn{2}{|l|}{ N/A } \\
\hline & & Faunal Evidence & \multicolumn{2}{|l|}{ None } \\
\hline Feature Type & Burned rock cluster & Pollen & \multicolumn{2}{|l|}{ N/A } \\
\hline Occupation Zone & 4 & Flotation Results & \multicolumn{2}{|c|}{ Charred: hickory/walnut shell } \\
\hline Stratigraphic Context & $2 \mathrm{Ab} 2 ? / 2 \mathrm{Bw}$ & \multirow{2}{*}{ Radiocarbon Dates } & \multirow{2}{*}{\multicolumn{2}{|c|}{$\begin{array}{l}\text { Beta- } 206114: 3400 \pm 40 \text { B.P., } \\
3720-3560 \mathrm{cal} \text { B.P. within } \\
\text { feature at } 97.19 \mathrm{~m}\end{array}$}} \\
\hline Area & A-NE & & & \\
\hline \multirow{2}{*}{ Provenience } & \multirow{2}{*}{$\begin{array}{l}\text { Located during Gradall clear- } \\
\text { ing; just north of N1039 E1056 } \\
\text { outside of excavation block } \\
\end{array}$} & Associated floor elevation range $(\mathrm{m})$ & \multicolumn{2}{|l|}{$97.50-97.40 \mathrm{~m}$} \\
\hline & & $\begin{array}{l}\text { Associated Diagnostics (Lot No. and } \\
\text { elevation) }\end{array}$ & \begin{tabular}{|l} 
Early \\
Triangular (658.1)
\end{tabular} & $97.19 \mathrm{~m}$ \\
\hline Center & N1041.88 E1057.76 & \multirow{3}{*}{$\begin{array}{l}\text { Diagnostics above and adjacent to fea- } \\
\text { ture (Lot No.) proximity radius }=2.0 \mathrm{~m} \text {, } \\
\text { proximity elevation }=0.1 \mathrm{~m}\end{array}$} & \multirow{3}{*}{\multicolumn{2}{|c|}{ None }} \\
\hline Top Elevation & $97.46 \mathrm{~m}$ & & & \\
\hline Bottom Elevation & $97.21 \mathrm{~m}$ & & & \\
\hline Size & $140 \times 80 \mathrm{~cm}$ & \multirow{2}{*}{$\begin{array}{l}\text { Diagnostics below and adjacent to fea- } \\
\text { ture (Lot No.) proximity radius }=2.0 \mathrm{~m} \text {, } \\
\text { proximity elevation }=0.1 \mathrm{~m}\end{array}$} & \multirow{2}{*}{\multicolumn{2}{|c|}{ None }} \\
\hline Shape & Semicircular, shallow basin & & & \\
\hline
\end{tabular}

\section{DESCRIPTION}

Feature 7 was recovered during the Gradall stripping of the Area A-NE overburden. The western half of Feature 7 was clipped and truncated by the Gradall. Once encountered, Gradall operations ceased and a feature recovery team hand exposed and documented the feature.

Feature 7 was a dense, semicircular cluster of burned limestone cobbles. The feature measured approximately 140 $x 80 \mathrm{~cm}$, oriented north-south, and roughly $25 \mathrm{~cm}$ thick. Feature 7 was bisected, and the feature profile revealed a stone lined, shallow, basin-like shape.

Stratigraphically, the upper soil matrix of Feature 7 was a black silty clay loam, while the internal feature matrix of Feature 7 was a brown clay loam. The uppermost portion of Feature 7 was approximately $15 \mathrm{~cm}$ above the targeted B soil horizon (97.3 m), and the lower portion of the feature extended into the $B$ horizon, suggesting that the base was excavated to construct the feature.

The total number and combined weight of the burned rocks associated with this feature were 202 and $39.8 \mathrm{~kg}$, respectively. All of the burned rocks were limestone. More than 50 percent of these were adjacent and touching one another. The burned rock had no predominant shape, consisting of a mixture of angular, rounded, and flat slabs. Most of the burned rock was highly fragmented, and around 10 percent was fractured in situ. Since many of the Feature 7 burned rocks were clipped by the Gradall blade, no samples of burned rock were collected for lipid analysis.

The fine matrix sample collected within Feature 7 was indistinguishable from the surrounding soil. The feature exhibited no evidence of in situ burning (e.g., stained or thermally altered sediment), however a small sample of charcoal was collected and used to date the feature.
Although debitage was observed throughout the feature matrix, none was collected. A single Early Triangular dart point was found just below Feature 7, at an elevation of $97.19 \mathrm{~m}$.

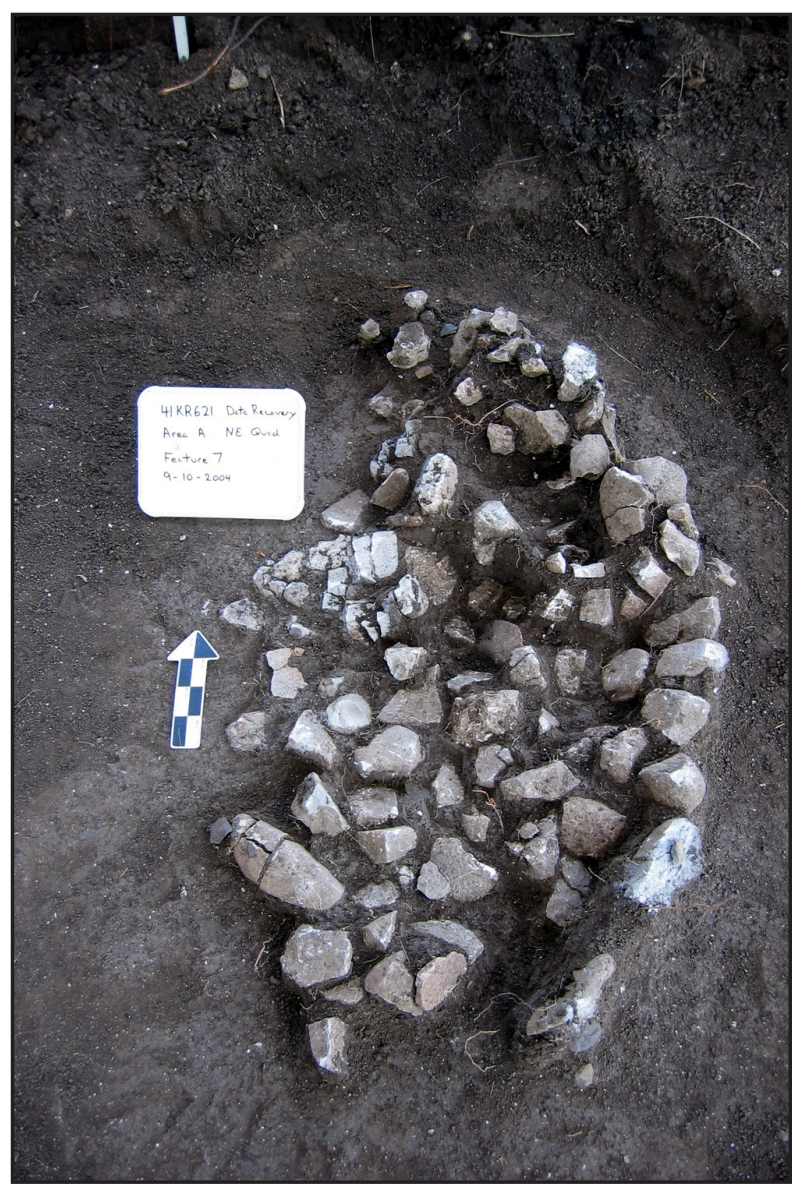

Overview of Feature 7. 


\begin{tabular}{|c|c|c|c|c|}
\hline 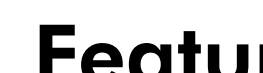 & & Shape & \multicolumn{2}{|c|}{$\begin{array}{l}\text { 8A: circular; 8B: roughly } \\
\text { ovate/scattered }\end{array}$} \\
\hline & & Fuel Type & \multicolumn{2}{|c|}{$\begin{array}{l}\text { 8A: indeterminable hardwood; } \\
\text { 8B: none }\end{array}$} \\
\hline & & Lipids & \multicolumn{2}{|l|}{ N/A } \\
\hline & & Faunal Evidence & \multicolumn{2}{|l|}{ None } \\
\hline & & Pollen & \multicolumn{2}{|l|}{ N/A } \\
\hline Feature Type & \& 8B) & \multirow{2}{*}{ Flotation Results } & \multirow{2}{*}{\multicolumn{2}{|c|}{$\begin{array}{l}8 \mathrm{~A} \text { : amaranth, ceder elm } \\
\text { leaves, bud grass family; } 8 \mathrm{~B} \text { : } \\
\text { prostrate spurge }\end{array}$}} \\
\hline Occupation Zone & 4 & & & \\
\hline Stratigraphic Context & $2 \mathrm{Ab} 2$ & Radiocarbon Dates & \multicolumn{2}{|l|}{ N/A } \\
\hline Area & $\mathrm{A}-\mathrm{NW}$ & Associated floor elevation range $(\mathrm{m})$ & \multicolumn{2}{|l|}{$97.90-97.80 \mathrm{~m}$} \\
\hline Provenience & $\begin{array}{l}\text { ca. N1025.50 E1051 (outside } \\
\text { of A-NW excavation block) }\end{array}$ & $\begin{array}{l}\text { Associated Diagnostics (Lot No. and } \\
\text { elevation) }\end{array}$ & Bulverde (803) & $97.82 \mathrm{~m}$ \\
\hline Center & N1027.16 E1052.23 & \multirow{2}{*}{$\begin{array}{l}\text { Diagnostics above and adjacent to fea- } \\
\text { ture (Lot No.): proximity radius }=3.0 \mathrm{~m} \text {, } \\
\text { proximity elevation }=0.1 \mathrm{~m}\end{array}$} & \multirow{2}{*}{\multicolumn{2}{|c|}{ None }} \\
\hline Top Elevation & $98.00 \mathrm{~m}$ & & & \\
\hline Bottom Elevation & $97.79 \mathrm{~m}$ & \multirow{2}{*}{$\begin{array}{l}\text { Diagnostics below and adjacent to fea- } \\
\text { ture (Lot No.): proximity radius }=3.0 \mathrm{~m} \text {, } \\
\text { proximity elevation }=0.1 \mathrm{~m}\end{array}$} & \multirow[b]{2}{*}{ La Jita (747) } & \multirow[b]{2}{*}{$97.73 \mathrm{~m}$} \\
\hline Size & $\begin{array}{l}8 \mathrm{~A}: 170 \times 120 \mathrm{~cm} ; 8 \mathrm{~B}: 100 \mathrm{x} \\
100 \mathrm{~cm}\end{array}$ & & & \\
\hline
\end{tabular}

\section{DESCRIPTION}

Feature 8 was recovered during the Gradall stripping of the Area A-NW overburden. When Feature 8 was encountered, Gradall operations stopped, and a feature recovery team moved in to document and expose the extent of the feature. Stratigraphically, Feature 8 was entirely encased within the $2 \mathrm{Ab} 2$ soil horizon, and did not extend into the B horizon. There was no difference between the internal feature soil color and the surrounding soil matrix.

Feature 8 consisted of two roughly circular clusters of burned limestone rocks. The larger of these two clusters was designated $8 \mathrm{~A}$ and was located $160 \mathrm{~cm}$ northwest of the smaller cluster, $8 \mathrm{~B}$. The horizontal extent of cluster $8 \mathrm{~A}$ was approximately $170 \times 120 \mathrm{~cm}$ (east-west). Cluster $8 \mathrm{~B}$ was approximately $100 \mathrm{~cm}$ in diameter. Both clusters were about $21 \mathrm{~cm}$ thick. When Feature 8 was bisected, no distinguishable profile shape, layering, or soil discoloration was observed.

The total number and weight of the burned rocks associated with Feature 8 was 233 and $51.3 \mathrm{~kg}$, respectively. Cluster $8 \mathrm{~A}$ comprised 186 pieces of burned rock, which weighed a total of $43.6 \mathrm{~kg}$. Cluster 8B contained 47 burned rocks weighing a total of $7.7 \mathrm{~kg}$.

All of the burned rocks within Feature 8 were limestone and represented a mix of angular, rounded, and flat slabs. More than 50 percent of the rocks were adjacent and touching one another, with most (>67 percent) of the burned rock fractured in situ. The feature exhibited no evidence of in situ burning (e.g., stained or thermally altered sediment).
A single Bulverde dart point was recovered in association with Feature 8 at an elevation of $97.82 \mathrm{~m}$. Debitage was observed throughout the feature matrix, but none was collected. No organics (bone, mussel shell, or charcoal) were found in association with this feature.

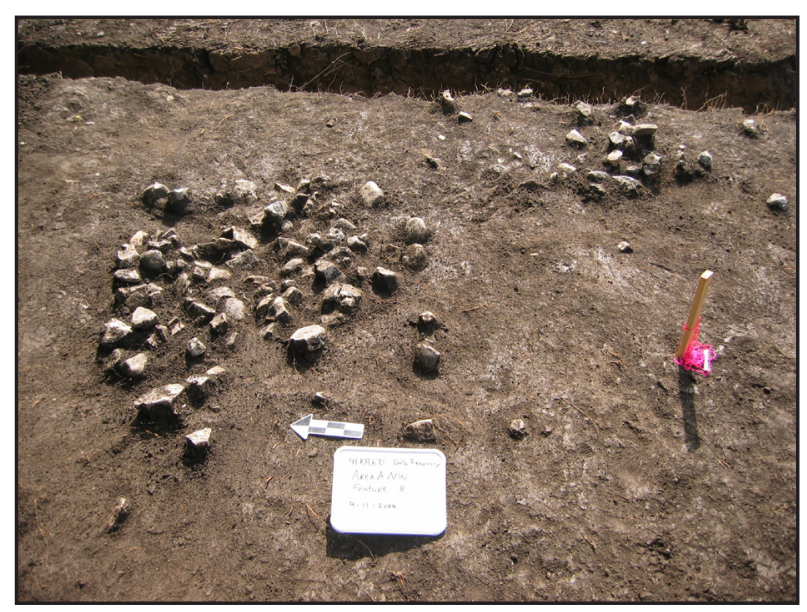

Overview of Feature 8. 


\begin{tabular}{|c|c|c|c|c|}
\hline & & Flotation Results & \multicolumn{2}{|l|}{ Bud } \\
\hline & & Radiocarbon Dates & \multicolumn{2}{|c|}{$\begin{array}{l}\text { Beta-207391: } 1810 \pm 60 \text { B.P., } \\
1880-1570 \text { cal B.P. from } 98.3-98.2 \mathrm{~m}\end{array}$} \\
\hline & & $\begin{array}{l}\text { Associated floor elevation range } \\
\text { (m) }\end{array}$ & \multicolumn{2}{|l|}{$98.30-98.20 \mathrm{~m}$} \\
\hline Feature Type & Small burned rock cluster & \multirow{2}{*}{$\begin{array}{l}\text { Associated Diagnostics (Lot No. } \\
\text { and elevation) }\end{array}$} & \multirow{2}{*}{\multicolumn{2}{|c|}{ None }} \\
\hline Occupation Zone & 4 & & & \\
\hline Stratigraphic Context & Within 2Abl & \multirow{3}{*}{$\begin{array}{l}\text { Diagnostics above and adjacent } \\
\text { to feature (Lot No.): proximity } \\
\text { radius }=2.0 \mathrm{~m} \text {, proximity eleva- } \\
\text { tion }=0.1 \mathrm{~m}\end{array}$} & Untyped (1352) & $98.32 \mathrm{~m}$ \\
\hline Area & $\mathrm{B}$ & & Montell (1396.2) & $98.40-98.30 \mathrm{~m}$ \\
\hline Provenience & N1016E1032 & & Untyped (1397.2) & $98.30-98.20 \mathrm{~m}$ \\
\hline Center & $\mathrm{N} 1017.30 \mathrm{E} 1033.00$ & \multirow{10}{*}{$\begin{array}{l}\text { Diagnostics below and adjacent } \\
\text { to feature (Lot No.): proximity } \\
\text { radius }=2.0 \mathrm{~m} \text {, proximity eleva- } \\
\text { tion }=0.1 \mathrm{~m}\end{array}$} & La Jita (1 169) & $98.14 \mathrm{~m}$ \\
\hline Top Elevation & $98.30 \mathrm{~m}$ & & Pedernales (1179) & $98.12 \mathrm{~m}$ \\
\hline Bottom Elevation & $98.20 \mathrm{~m}$ & & Pedernales (1 180) & $98.10 \mathrm{~m}$ \\
\hline Size & $70 \times 50 \mathrm{~cm}$ & & Untyped (1210.1) & $98.20-98.10 \mathrm{~m}$ \\
\hline \multirow{2}{*}{ Shape } & \multirow{2}{*}{$\begin{array}{l}\text { Ring like; relatively flat; tail extending } \\
\text { out from the cluster }\end{array}$} & & Untyped (1318.1) & $98.20-98.10 \mathrm{~m}$ \\
\hline & & & Marshall (1319) & $98.17 \mathrm{~m}$ \\
\hline Fuel Type & Indeterminable hardwood & & Untyped (1339.2) & $98.20-98.10 \mathrm{~m}$ \\
\hline Lipids & $\mathrm{N} / \mathrm{A}$ & & Untyped (1360.1) & $98.20-98.10 \mathrm{~m}$ \\
\hline Faunal Evidence & None & & Untyped (1380.2) & $98.20-98.10 \mathrm{~m}$ \\
\hline Pollen & $\mathrm{N} / \mathrm{A}$ & & Nolan (1398.1) & $98.20-98.10 \mathrm{~m}$ \\
\hline
\end{tabular}

\section{DESCRIPTION}

Feature 9 was a small, ring like cluster of burned limestone within the $2 \mathrm{Ab} 1$ soil horizon. Measuring approximately 70 x $50 \mathrm{~cm}$ horizontally, the cluster was roughly $10 \mathrm{~cm}$ thick. A linear scatter of burned rock extended from the ring approximately $130 \mathrm{~cm}$ to the southeast. When Feature 9 was bisected, no distinguishable profile shape, layering, or soil discoloration was observed.

A total of 46 burned rock specimens, all limestone and weighing a combined $18 \mathrm{~kg}$, was associated with Feature 9. In general, the burned rocks within the feature were rounded, and most (>67 percent) were fractured in situ. More than 50 percent of the rocks were adjacent and touching one another within the feature. These occurred along the outer edges of the feature, leaving the feature's center empty. No evidence of in situ burning (e.g., stained or thermally altered sediment) was observed within the feature.

No diagnostic points were recovered in clear association with this feature, although some debitage was present throughout the feature matrix. No organics (bone, mussel shell, or charcoal) were found within the feature. Due to the lack of charcoal, a bulk soil matrix sample was taken from directly below the burned rocks of Feature 9 for dating.

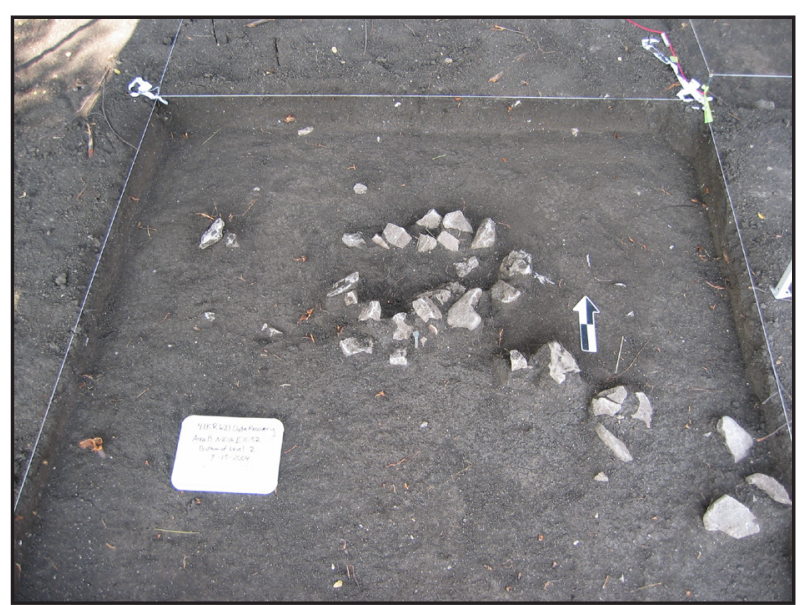

Overview of Feature 9 and surrounding unit.

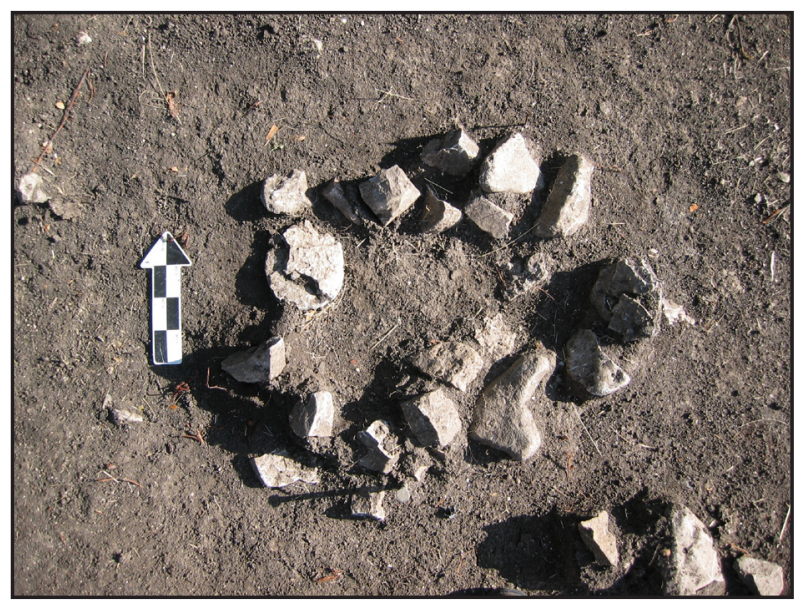

Close-up of Feature 9. 


\begin{tabular}{|c|c|c|c|c|}
\hline & & Flotation Results & \multicolumn{2}{|l|}{ Prostrate spurge } \\
\hline & & Radiocarbon Dates & \multicolumn{2}{|c|}{$\begin{array}{l}\text { Beta-207392: } 1290 \pm 60 \text { в.P., } 1300-1070 \\
\text { cal в.P. from } 98.3-98.2 \mathrm{~m}\end{array}$} \\
\hline & & $\begin{array}{l}\text { Associated floor elevation } \\
\text { range }(m)\end{array}$ & \multicolumn{2}{|l|}{$98.30-98.20 \mathrm{~m}$} \\
\hline Feature Type & Small burned rock cluster & \multirow{2}{*}{$\begin{array}{l}\text { Associated Diagnostics (Lot } \\
\text { No. and elevation) } \\
\end{array}$} & \multirow{2}{*}{\multicolumn{2}{|c|}{ None }} \\
\hline Occupation Zone & 4 & & & \\
\hline Stratigraphic Context & $2 A b l$ & \multirow{3}{*}{$\begin{array}{l}\text { Diagnostics above and } \\
\text { adjacent to feature (Lot } \mathrm{No} . \text { ): } \\
\text { proximity radius }=2.0 \mathrm{~m}, \\
\text { proximity elevation }=0.1 \mathrm{~m}\end{array}$} & Pedernales (1201) & $98.33 \mathrm{~m}$ \\
\hline Area & B & & Pedernales (1237) & $98.20 \mathrm{~m}$ \\
\hline Provenience & N1016-1018 E1036 & & Untyped (1466.1) & $98.32 \mathrm{~m}$ \\
\hline Center & N1018.22 E1036.78 & \multirow{10}{*}{$\begin{array}{l}\text { Diagnostics below and } \\
\text { adjacent to feature (Lot No.): } \\
\text { proximity radius }=2.0 \mathrm{~m}, \\
\text { proximity elevation }=0.2 \mathrm{~m}\end{array}$} & La Jita (1220) & $98.14 \mathrm{~m}$ \\
\hline Top Elevation & $98.30 \mathrm{~m}$ & & Frio (1229) & $98.15 \mathrm{~m}$ \\
\hline Bottom Elevation & $98.14 \mathrm{~m}$ & & Pedernales (1249) & $98.09 \mathrm{~m}$ \\
\hline Size & $60 \times 60 \mathrm{~cm}$ & & Pedernales (1250) & $98.02 \mathrm{~m}$ \\
\hline \multirow{2}{*}{ Shape } & \multirow{2}{*}{$\begin{array}{l}\text { Ring-like; slight basin-shape with some } \\
\text { layering; tail extending out from the cluster }\end{array}$} & & Frio (1370) & $98.16 \mathrm{~m}$ \\
\hline & & & La Jita (1372) & $98.01 \mathrm{~m}$ \\
\hline Fuel Type & Indeterminable hardwood & & Untyped (1390.4) & $98.20-98.10 \mathrm{~m}$ \\
\hline Lipids & N/A & & Pedernales (1409) & $98.17 \mathrm{~m}$ \\
\hline Faunal Evidence & Unidentifiable bone fragments & & Untyped (1411) & $98.05 \mathrm{~m}$ \\
\hline Pollen & $\mathrm{N} / \mathrm{A}$ & & La Jita (1417) & $98.00 \mathrm{~m}$ \\
\hline
\end{tabular}

\section{DESCRIPTION}

Feature 10 was a small, ring-like cluster of burned limestone roughly $60 \times 60 \mathrm{~cm}$ horizontally, similar to Feature 9 . The vertical thickness of the feature was approximately $16 \mathrm{~cm}$. A linear scatter of burned rock extended from the ring an additional $70 \mathrm{~cm}$ to the southeast. Bisection of Feature 10 revealed some layering, but no distinguishable profile shape or soil discoloration was apparent. An examination of the plan views from the two excavation levels occupied by Feature 10 suggests that the feature was slightly basinshaped, as the circumference of the feature decreases significantly with depth. Stratigraphically, Feature 10 was located within the $2 \mathrm{Ab} 1$ soil horizon. There was no difference between the internal feature soil color and the surrounding soil matrix.

The total number of burned rocks recovered from Feature 10 was 34 . These specimens weighed a total of $14.7 \mathrm{~kg}$. There was no predominant shape to the burned rocks, as the feature contained a mixture of angular, rounded, and flat slabs of limestone. Similarly, the burned rocks presented a range of specimens that were highly fragmented, unfractured, and fractured in situ. Despite the mixed shape and physical condition of the burned rocks, more than 50 percent overlapped one another. Besides the rocks themselves, no evidence of in situ burning (e.g., stained or thermally altered sediment) was observed within the feature.
Debitage was observed throughout the feature matrix, and all debitage was collected. No organics (bone, mussel shell, or charcoal) were found within the feature, although a couple of bone fragments were recovered within the same levels. Due to the lack of carbon, a bulk soil sample was used to date the feature. Two Pedernales dart points were recovered from within a $1-\mathrm{m}$ radius of the feature at elevations of $98.2 \mathrm{~m}$ and $98.17 \mathrm{~m}$.

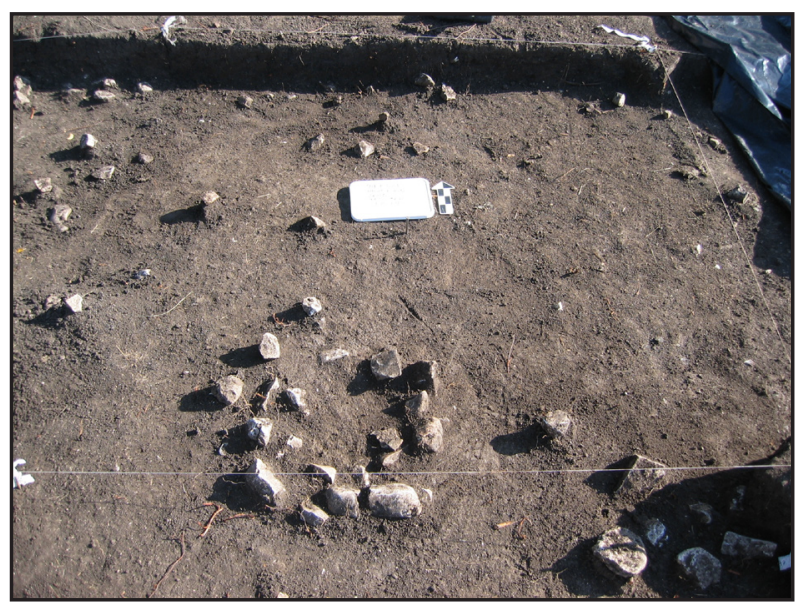

Overview of Feature 10 and surrounding unit. 


\begin{tabular}{|c|c|c|c|c|}
\hline & & Faunal Evidence & \multicolumn{2}{|l|}{ None } \\
\hline & & Pollen & \multicolumn{2}{|l|}{ N/A } \\
\hline & & Flotation Results & \multicolumn{2}{|c|}{$\begin{array}{l}\text { Chenopodium, amaranth, hackberry, daisy } \\
\text { family, woodsorrel, and legume }\end{array}$} \\
\hline & & Radiocarbon Dates & \multicolumn{2}{|l|}{$N / A$} \\
\hline Feature Type & Small cluster of burned material & Associated floor elevation & \multirow{2}{*}{\multicolumn{2}{|c|}{$98.3-98.2 \mathrm{~m}$}} \\
\hline Occupation Zone & 4 & & & \\
\hline Stratigraphic Context & $2 A b 1$ & $\begin{array}{l}\text { Associated Diagnostics (Lot } \\
\text { No. and elevation) }\end{array}$ & \multicolumn{2}{|l|}{ None } \\
\hline Area & $B$ & \multirow{3}{*}{$\begin{array}{l}\text { Diagnostics above and } \\
\text { adjacent to feature (Lot No.): } \\
\text { proximity radius }=2.0 \mathrm{~m}, \\
\text { proximity elevation }=0.1 \mathrm{~m}\end{array}$} & \multirow{3}{*}{ Untyped (1 123) } & \multirow{3}{*}{$98.26 \mathrm{~m}$} \\
\hline Provenience & N1016 E1030 & & & \\
\hline Center & N1017.18 E1030.96 & & & \\
\hline Top Elevation & $98.25 \mathrm{~m}$ & \multirow{6}{*}{$\begin{array}{l}\text { Diagnostics below and } \\
\text { adjacent to feature (Lot No.): } \\
\text { proximity radius }=2.0 \mathrm{~m}, \\
\text { proximity elevation }=0.1 \mathrm{~m}\end{array}$} & Pedernales (1124) & $98.18 \mathrm{~m}$ \\
\hline Bottom Elevation & $98.12 \mathrm{~m}$ & & Langtry (1126) & $98.15 \mathrm{~m}$ \\
\hline Size & $30 \times 27 \mathrm{~cm}$ & & Marshall (1319) & $98.17 \mathrm{~m}$ \\
\hline Shape & Circular; shallow, basin-like & & Untyped (1318.1) & $98.20-98.10 \mathrm{~m}$ \\
\hline Fuel Type & Indeterminable hardwood & & Untyped (1328.8) & $98.20-98.10 \mathrm{~m}$ \\
\hline Lipids & $N / A$ & & Untyped (1360.1) & $98.20-98.10 \mathrm{~m}$ \\
\hline
\end{tabular}

Feature 11 was a circular cluster of soft, caliche-like material that appeared to be burned. The material had the consistency and shape of clay, but did not appear to be clay. The horizontal dimensions of the feature were $30 \times 27 \mathrm{~cm}$. Feature 11 was $13 \mathrm{~cm}$ thick and, when bisected, displayed a shallow, basin-like cross section. Located within the $2 \mathrm{Ab} 1$ soil horizon, the internal feature material appeared somewhat lighter (yellowish brown) than the surrounding soil (black). This discoloration of the feature matrix and its unusual texture are likely due to in situ burning.

The caliche-like matrix was very tightly clumped, and no distinguishable burned rock was observed within it. Due to its small size, the entire Feature 11 matrix was collected as a flotation sample, which weighed $5.96 \mathrm{~kg}$.

No stone tools were recovered in direct association with Feature 11, but a Marshall point and two untyped projectile points were found within the same unit between $98.2 \mathrm{~m}$ and $98.1 \mathrm{~m}$. No organics (bone, mussel shell, or charcoal) were found within the feature.

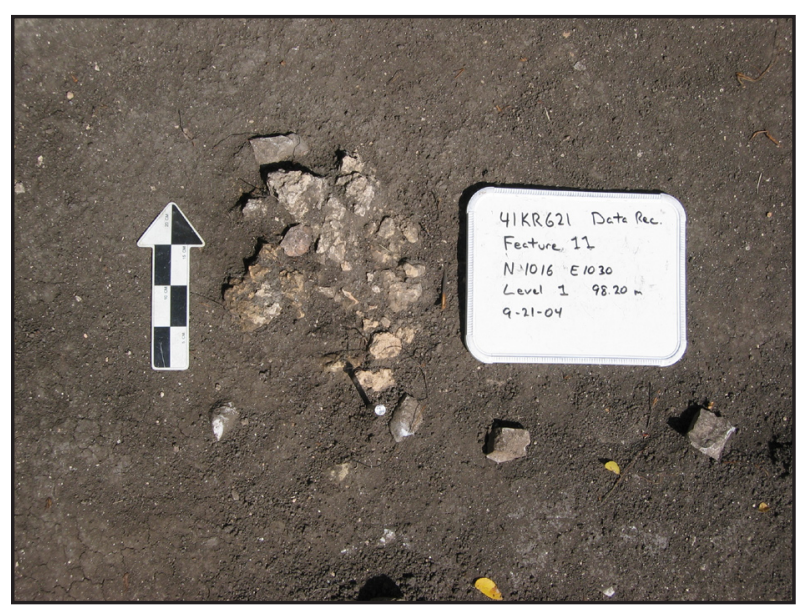

Overview of Feature 11.

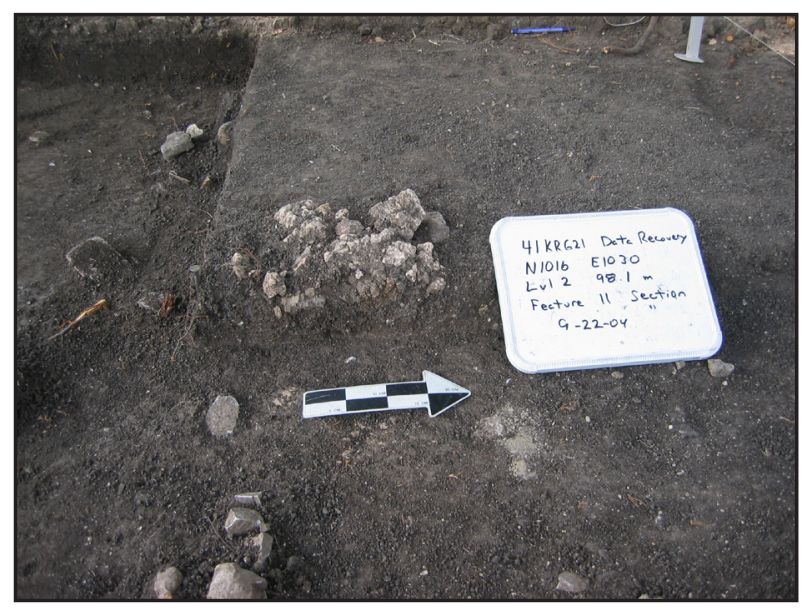

Side view of Feature 11. 


\begin{tabular}{|c|c|c|c|}
\hline & Shape & N/A \\
\hline & & Fuel Type & N/A \\
\hline & & Lipids & N/A \\
\hline & & Faunal Evidence & \\
\hline Feature Type & Human skull fragments & Pollen & N/A \\
\hline Occupation Zone & 4 & Flotation Results & N/A \\
\hline Stratigraphic Context & $2 A B k$ & Radiocarbon Dates & None \\
\hline Area & B & Associated floor elevation range $(\mathrm{m})$ & N/A \\
\hline Provenience & N1016 E1038 & \multirow{2}{*}{\begin{tabular}{|l|} 
Associated Diagnostics \\
(Lot No. and elevation)
\end{tabular}} & \multirow{2}{*}{ N/A } \\
\hline Center & N1017.14 E1038.38 & & \\
\hline Top Elevation & $\begin{array}{l}\text { Fragment 1: } 98.02 \mathrm{~m} ; \\
\text { Fragment 2: } 98.00 \mathrm{~m}\end{array}$ & $\begin{array}{l}\text { Diagnostics above and adjacent to feature } \\
\text { (Lot No.): proximity radius }=2.0 \mathrm{~m} \text {, } \\
\text { proximity elevation }=0.1 \mathrm{~m}\end{array}$ & N/A \\
\hline Bottom Elevation & $\begin{array}{l}\text { Fragment 1: } 98.00 \mathrm{~m} ; \\
\text { Fragment 2: } 97.95 \mathrm{~m}\end{array}$ & \multirow{2}{*}{$\begin{array}{l}\text { Diagnostics below and adjacent to feature } \\
\text { (Lot No.): proximity radius }=2.0 \mathrm{~m} \text {, } \\
\text { proximity elevation }=0.1 \mathrm{~m}\end{array}$} & \multirow{2}{*}{ N/A } \\
\hline Size & $10 \times 10 \mathrm{~cm}$ & & \\
\hline
\end{tabular}

\section{DESCRIPTION}

Feature 23 was an occipital human skull fragment recovered in Unit N1016 E1038 of Area B. The skull fragment was treated with dignity and respect during all stages of the data recovery. The cranial fragment was carefully excavated and recorded in situ before being stored in a locked facility at SWCA. The excavation block was expanded around the area of discovery, but no additional remains were encountered. No evidence of an intentional burial was observed to be associated with the skull fragment, and its deposition at the site appears incidental.

Feature 23 was unique at 41 KR621, constituting the only evidence of human remains encountered at the site. The skull fragments were recovered in two oval, highly fragmented pieces. One piece (Fragment 1) was positioned horizontally and located between $98.02 \mathrm{~m}$ and $98.00 \mathrm{~m}$. The other piece (Fragment 2) extended downward between 98.00 and $97.95 \mathrm{~m}$. These were tightly clustered in a 10-x-10-x-7-cm area. Stratigraphically, Feature 23 was located within the $2 \mathrm{ABk}$ soil horizon. There was no observable difference in the soil color above, beneath, or around the remains.

Three professional osteologists identified the two skull pieces as occipital cranial fragments. Each half was approximately $11 \times 8 \mathrm{~cm}$ in size. The fragmentation of the bone within each piece was high, as a total of 105 cranial fragments was counted, weighing a combined $87 \mathrm{~g}$. The only diagnostic skull attribute is a small margin of the foramen magnum. The curvature and thickness of the skull fragment are also suggestive of its occipital origin. The age and sex of the individual could not be determined.
No diagnostic stone tools or charcoal were recovered in association with Feature 23. Based on soil stratigraphy and vertical elevations, Feature 23 may have been associated with Feature 36 or Feature 37 . Feature 37 was less than 2 $\mathrm{m}$ south and shared a similar vertical elevation with Feature 23 (98.03-97.93 m).

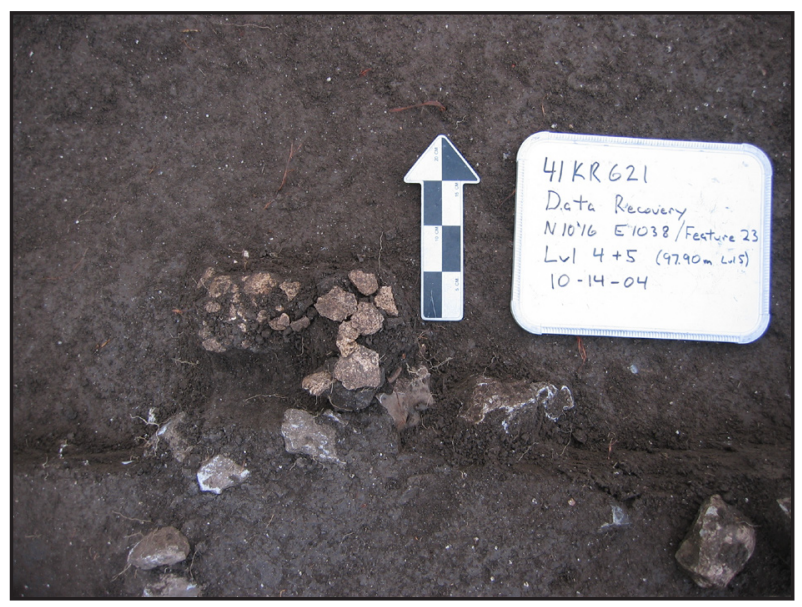

Overview of Feature 23. 


\begin{tabular}{|c|c|c|c|c|}
\hline & & Radiocarbon Dates & \multicolumn{2}{|l|}{$\mathrm{N} / \mathrm{A}$} \\
\hline & & $\begin{array}{l}\text { Associated floor eleva- } \\
\text { tion range }(\mathrm{m})\end{array}$ & \multicolumn{2}{|l|}{$98.10-98.00 \mathrm{~m}$} \\
\hline Feature Type & Small hurned reck cluster & \multirow{2}{*}{$\begin{array}{l}\text { Associated Diagnostics } \\
\text { (Lot No. and elevation) }\end{array}$} & La Jita (1508) & $98.02 \mathrm{~m}$ \\
\hline Occunation 70 e & 4 & & Untyped (1518) & $98.00 \mathrm{~m}$ \\
\hline Stratiaranhic Contert & $2 \triangle \mathrm{Rl}$ & \multirow{5}{*}{$\begin{array}{l}\text { Diagnostics above and } \\
\text { adiacent to feature (Lot } \\
\text { No.): proximity radius = } \\
2.0 \mathrm{~m} \text {, proximity eleva- } \\
\text { tion }=0.1 \mathrm{~m}\end{array}$} & Bulverde (1490.2) & $98.10-98.00 \mathrm{~m}$ \\
\hline Jir & $2 \mathrm{HDK}$ & & La Jita (1500.5) & $98.10-98.00 \mathrm{~m}$ \\
\hline Area & D & & Nolan (1500.6) & $98.10-98.00 \mathrm{~m}$ \\
\hline Provenience & N1014 E1038 & & Andice (1500.7) & $98.10-98.00 \mathrm{~m}$ \\
\hline Center & N1015.50 E1039.02 & & Kinney (1526) & $98.04 \mathrm{~m}$ \\
\hline Top Elevation & $98.12 \mathrm{~m}$ & \multirow{10}{*}{$\begin{array}{l}\text { Diagnostics below and } \\
\text { adiacent to feature (Lot } \\
\text { No.): proximity radius = } \\
2.0 \mathrm{~m} \text {, proximity eleva- } \\
\text { tion }=0.1 \mathrm{~m}\end{array}$} & & \\
\hline Bottom Elevation & $97.97 \mathrm{~m}$ & & Kinney (1430) & $97.97 \mathrm{~m}$ \\
\hline Size & $50 \times 42 \mathrm{~cm}$ & & La Jita (1431) & $97.94 \mathrm{~m}$ \\
\hline Shape & Roughly circular; stacked, relatively flat base & & La Jita (1432) & $97.92 \mathrm{~m}$ \\
\hline Fuel Type & Indeterminable hardwood & & Big Sandy (1486.3) & 98.00-97.90 m \\
\hline \multirow[b]{2}{*}{ Lipids } & \multirow{2}{*}{$\begin{array}{l}\text { Moderate-high fat content food (Texas ebony or } \\
\text { beaver) }\end{array}$} & & La Jita (1504) & $97.97 \mathrm{~m}$ \\
\hline & & & La Jita (1515.2) & 97.90-97.80 m \\
\hline Faunal Evidence & Unidentifiable bone fragments & & Early Triangular (1515.3) & 97.90-97.80 m \\
\hline Pollen & Exploitable: mustard family & & La Jita (1528) & $97.95 \mathrm{~m}$ \\
\hline Flotation Results & None & & Bulverde(1529) & $97.94 \mathrm{~m}$ \\
\hline
\end{tabular}

\section{DESCRIPTION}

Feature 36 was recorded by excavators as a small, discrete cluster of burned rock with associated projectile points and bone. Located within the 2ABk horizon, the feature was roughly circular in outline, extending across a surface area of $50 \times 42 \mathrm{~cm}$. The feature was $15 \mathrm{~cm}$ thick. In cross section, the burned rocks appeared stacked, and no distinguishable difference was observed between the fine feature matrix and the surrounding soil stratum.

Thirty burned rock specimens were recovered from Feature 36 , all of which were limestone. These specimens weighed a total of $10.8 \mathrm{~kg}$. The burned rocks were mostly angular in shape and, in most cases, highly fragmented. Most of the feature's burned rocks were adjacent and touching one another.

A single La Jita dart point was found along the southwestern edge of the feature at an elevation of $98.02 \mathrm{~m}$. Debitage was not observed within the feature matrix; however, it was present and collected in the surrounding unit/level. Nine bone fragments were recovered from within the feature matrix, but charcoal was absent.
Feature 36 was located immediately west of Feature 37 at a slightly higher elevation. Although this appears to suggest that Feature 36 is chronologically later than Feature 37, the exact relationship of the two features is unknown, as their elevation ranges slightly overlap one another. Because most of Feature 36 lies within the apparently mixed soils above $98.0 \mathrm{~m}$ in Area B, detailed analysis was not conducted for the artifacts within the associated floor level.

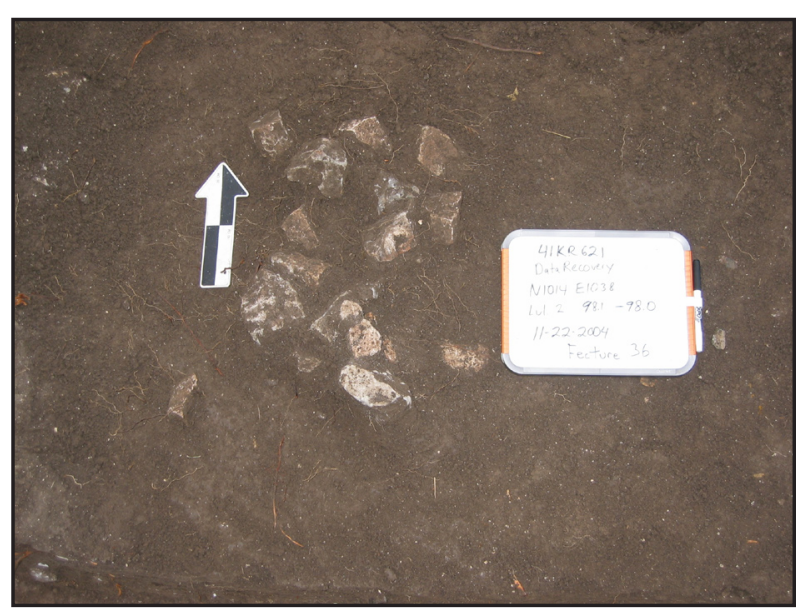

Overview of Feature 36. 


\begin{tabular}{|c|c|c|c|c|}
\hline 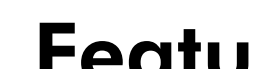 & & Pollen & \multicolumn{2}{|c|}{$\begin{array}{l}\text { High- and Low-spine Asteraceae, sunflower } \\
\text { family, and cheno-ams. }\end{array}$} \\
\hline & & Flotation Results & \multicolumn{2}{|l|}{ None } \\
\hline & Small h & Radiocarbon Dates & \multicolumn{2}{|c|}{$\begin{array}{l}\text { Beta-206132: } 3850 \pm 40 \text { B.P., } 4410-4150 \mathrm{cal} \\
\text { B.P. at } 97.94 \mathrm{~m} \text {, near but not within feature }\end{array}$} \\
\hline Occupation Zone & 4 & \multirow{2}{*}{$\begin{array}{l}\text { Associated floor elevation } \\
\text { range }(\mathrm{m})\end{array}$} & \multirow{2}{*}{\multicolumn{2}{|c|}{$98.00-97.90 \mathrm{~m}$}} \\
\hline Stratigraphic Context & $2 A B k$ & & & \\
\hline Area & B & \multirow{3}{*}{$\begin{array}{l}\text { Associated Diagnostics } \\
\text { (Lot No. and elevation) }\end{array}$} & Bulverde (1486.3) & $98.00-97.90$ m \\
\hline Provenience & & & La Jita (1528) & $97.95 \mathrm{~m}$ \\
\hline Center & N1015.58 E1039.80 & & Bulverde (1529) & $97.94 \mathrm{~m}$ \\
\hline Top Elevation & & \multirow{4}{*}{$\begin{array}{l}\text { Diagnostics above and } \\
\text { adjacent to feature (Lot } \\
\text { No.): proximity radius = } \\
2.0 \mathrm{~m} \text {, proximity elevation } \\
=0.1 \mathrm{~m}\end{array}$} & La Jita (1508) & $98.02 \mathrm{~m}$ \\
\hline Bottom Elevation & $9793 \mathrm{~m}$ & & Untyped (1518) & $98.00 \mathrm{~m}$ \\
\hline Size & $60 \times 50 \mathrm{~cm}$ & & Kinney (1526) & $98.04 \mathrm{~m}$ \\
\hline Shane & Roubbly circular relatively flat & & Bulverde (1533) & $98.00 \mathrm{~m}$ \\
\hline strape & kougmy circuiar, retaivery irar & \multirow{5}{*}{$\begin{array}{l}\text { Diagnostics below and } \\
\text { adjacent to feature (Lot } \\
\text { No.): proximity radius = } \\
2.0 \mathrm{~m} \text {, proximity elevation } \\
=0.1 \mathrm{~m}\end{array}$} & Early Triangular (1488) & $97.88 \mathrm{~m}$ \\
\hline Fuel Type & Plateau live oak and indeterminable hardwood & & La Jita (1515.2) & $97.90-97.80 \mathrm{~m}$ \\
\hline Lipids & Very high fat content food (seed/animal fat) & & Early Trianaular (1515 3) & $9790-9780$ m \\
\hline \multirow{2}{*}{ Faunal Evidence } & \multirow{2}{*}{$\begin{array}{l}\text { Unidentifiable bone fragments; white-tailed } \\
\text { deer molar fragment in same level }\end{array}$} & & Early Irlangular (1 & $97.90-91.00 \mathrm{~m}$ \\
\hline & & & Martindale (1538) & $97.82 \mathrm{~m}$ \\
\hline
\end{tabular}

\section{DESCRIPTION}

Feature 37 was a small, discrete cluster of burned rock located within the $2 \mathrm{ABk}$ stratigraphic profile. It was roughly circular in outline, measuring $60 \times 50 \mathrm{~cm}$ horizontally and $10 \mathrm{~cm}$ deep. No rock laying or discernible basin was observed in cross section, and no distinguishable difference between the fine feature matrix and the surrounding soil was noted.

All of the burned rocks within Feature 37 were limestone. Twenty-six burned rock specimens were recovered from the feature, which weighed a total of $7.7 \mathrm{~kg}$. The burned rocks are mostly flat slabs of limestone, including both unfractured and fragmented pieces. Most of the feature's burned rocks were adjoining, not touching. No evidence of burning was observed within the surrounding soil, and no charcoal was recovered.

Fifty pieces of debitage and five bone fragments were collected from the feature matrix. No charcoal was found within the feature matrix, but a small charcoal sample was obtained from the NW quadrant of the unit at a similar elevation; this yielded the radiocarbon age used to date the feature.
Feature 37 was encountered immediately east of Feature 36 and at a slightly lower elevation. Although this suggests that Feature 36 predates Feature 37, the exact relationship of the two features is unknown, as the elevation range of Feature 36 slightly overlaps that of Feature 37.

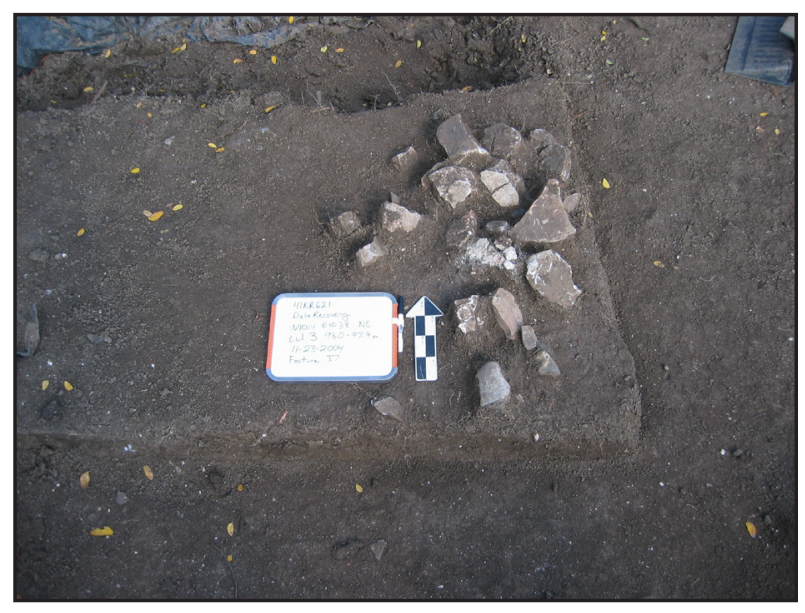

Overview of Feature 37. 


\section{Feature Summary}

Excluding Features 11 and 23, the OZ4 features were primarily burned rock, including the burned rock midden (Feature 1), burned rock clusters (Features $4,7,8 \mathrm{~A}$, and $8 \mathrm{~B}$ ), and numerous small burned rock clusters (Features 9, 10, 36, and 37).

Next to Feature 1, the largest burned rock feature within OZ4 was Feature 8 (A and B), which was approximately $1-2 \mathrm{~m}$ in diameter. Next was Feature 7 , at $140 \times 80 \mathrm{~cm}$, whose overall size was partially truncated during blading with the Gradall. Feature 7 was a semicircular stone-lined shallow basin that appeared to be formally constructed, containing almost $40 \mathrm{~kg}$ of a limestone basin, and seemed somewhat formal in composition.

But overall, small burned rock clusters, circular or oval in shape, predominated. Ring-like Features 9 and 10 had relatively distinct structures with a loose scatter or tail of burned rock extending out in a mostly straight line from the cluster. Their centers were devoid of burned rock, probably representing the remains of an upper layer or lid. In cross section, most of the burned rock features within OZ4 were flat or relatively flat. These features were composed exclusively of limestone (Table 11.6). The quantity of rock associated with the features varied, with most small features including burned rock counts that ranged from 7-47 rocks and weighing between $4.7-18.0 \mathrm{~kg}$. Regarding rock sizes, approximately half of the features contained high percentages of rock sizes within the $5-10-\mathrm{cm}$ range $(\mathrm{n}=4)$, while others had the highest percentages equally distributed within the 5-10-cm and the 10-15-cm ranges.

There was a rather even distribution among the rock shape categories within the burned rock features of OZ4. The conditions of the rock within the burned rock features mainly were fractured and highly fractured. While charcoal was present in many features, OZ4 burned rock feature matrices were generally undifferentiated from surrounding soils and no evidence of in situ burning was observed. Special samples were recovered from various features within OZ4, providing radiocarbon, fuel, macrobotanical, pollen/phytolith, faunal, and lipid residue data. Carbonized wood samples were encountered within most of the OZ4 features with fuel types identified exclusively as indeterminable hardwood. Minor oc- currences of various other botanical remains were also identified within the feature matrices. Pollen and phytolith samples from Features 36 and 37 contained evidence of local vegetation such as cheno-ams, and high and low spine Asteraceae. The only exploitable plant resource identified was mustard family within Feature 36. Lipid residue studies were conducted on three of the features and revealed various fatty acid compositions from plant and animal.

\section{Feature 1 - The Midden}

The feature assemblage is obviously dominated by the midden which likely served as an element of site furniture for thousands of years. The midden itself was explored with a variety of trenches, $1 \times 1 \mathrm{~m}$ hand excavation units, and numerous column samples. As described above, the midden formed sometime after approximately 5,000 B.P. and was utilized periodically into the Late Archaic. A possible central feature was noted in one trench as well as several pits at its base, extending into earlier Early Archaic deposits. A wide range of projectile points were recovered from the midden and debitage counts were very high on its margins but low in its center.

Overall, Feature 1 is a large circular burned rock midden extending approximately $16 \mathrm{~m}(\mathrm{~N}-\mathrm{S}) \times 16.5 \mathrm{~m}$ (E-W) in the northeastern portion of the investigated area of site 41KR621. The midden fits the central thermal feature model for burned rock middens, which suggests that middens are a result of a centralized cooking features or "earth ovens" displaying prolonged utilization or reuse over a long period of time (Black et al. 1997). The deduction of a centralized thermal feature model was taken from analyzing the patterns of burned rock counts, sizes, and weights relative to the central area of the midden (Mauldin et al. 2003). Using this general outline of analysis, the attributes of burned rock and general debitage counts were utilized to identify trends and characteristics of the midden feature at site 41KR621.

As the main objective of the data recovery excavations at the site were the Early Archaic deposits in Areas A and B, the analysis drew upon limited investigations within the midden in the form of trenches, column samples, and testing units. The column samples and testing units were located throughout the midden adjacent to three trenches that cut across the midden (BHT 1, BHT 18, and CT3; Figure 11.4). 


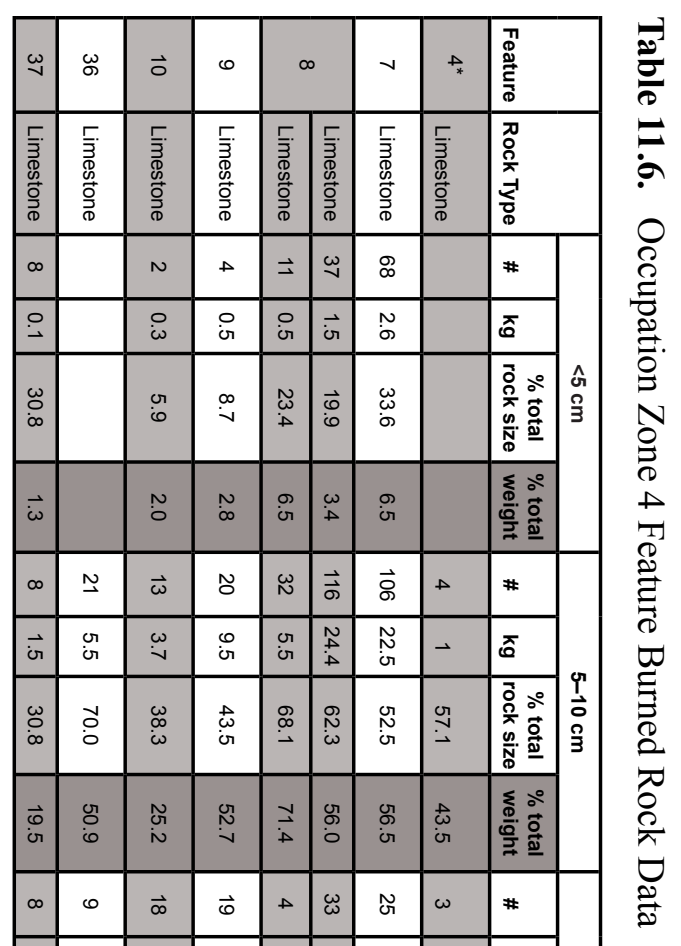

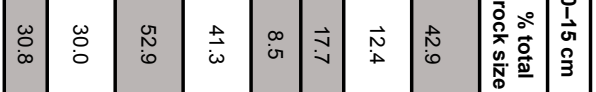

\begin{tabular}{|c|c|c|c|c|c|c|c|}
\hline 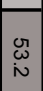 & $\stackrel{\vec{t}}{\rightarrow}$ & $\stackrel{\nexists}{\circ}$ & $\underset{\infty}{N}$ & 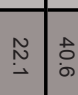 & $\stackrel{\tilde{O}}{\circ}$ & $\begin{array}{l}\text { or } \\
\text { or }\end{array}$ & 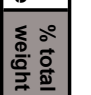 \\
\hline$N$ & & $\vec{A}$ & $\omega$ & & $\omega$ & & \# \\
\hline$N$ & & ir & $\omega$ & & $\underset{\sim}{w}$ & & $\bar{\theta}$ \\
\hline के & & $\tilde{\ddot{0}}$ & or & & $\vec{r}$ & & 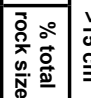 \\
\hline $\begin{array}{l}\tilde{\alpha} \\
0 \\
0\end{array}$ & & $\underset{\perp}{\omega}$ & $\overrightarrow{\vec{v}}$ & & $\stackrel{\infty}{\circ}$ & & 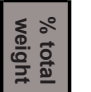 \\
\hline$\approx$ & $\ddot{\sigma}$ & $\stackrel{\omega}{\Perp}$ & के & $\vec{\sim} \overrightarrow{\mathrm{a}}$ & 芩 & 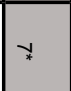 & 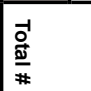 \\
\hline$\because$ & $\begin{array}{l}\overrightarrow{0} \\
\infty \\
\infty\end{array}$ & $\stackrel{\vec{f}}{\stackrel{\vec{v}}{v}}$ & $\vec{\infty}$ & $\therefore \vec{\omega}_{\sigma}^{\vec{\omega}}$ & $\begin{array}{l}\omega \\
\stackrel{\infty}{\infty} \\
\infty\end{array}$ & $\underset{*}{\tilde{\omega}}$ & 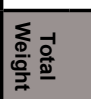 \\
\hline $\overrightarrow{\overrightarrow{\underline{F}}}$ & 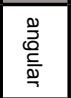 & 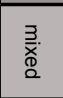 & $\begin{array}{l}\overrightarrow{0} \\
\text { 言 } \\
\underline{0} \\
\end{array}$ & $\begin{array}{l}\text { 灵. } \\
\text { 竞 }\end{array}$ & 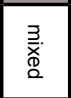 & 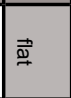 & \begin{tabular}{|c|}
$\frac{\infty}{3}$ \\
$\frac{\underline{z}}{0}$ \\
\end{tabular} \\
\hline 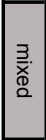 & 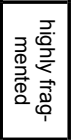 & 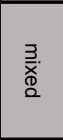 & 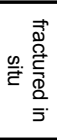 & 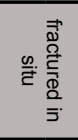 & 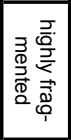 & 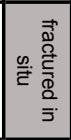 & 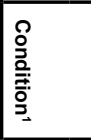 \\
\hline 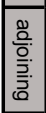 & 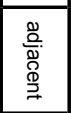 & 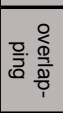 & 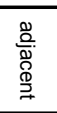 & 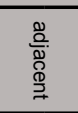 & 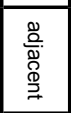 & 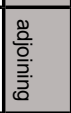 & 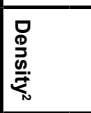 \\
\hline 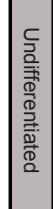 & 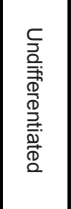 & 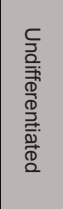 & 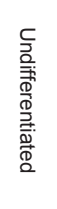 & 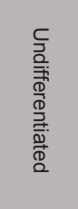 & 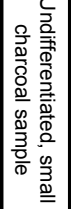 & 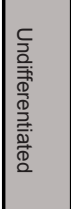 & 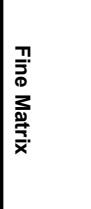 \\
\hline
\end{tabular}




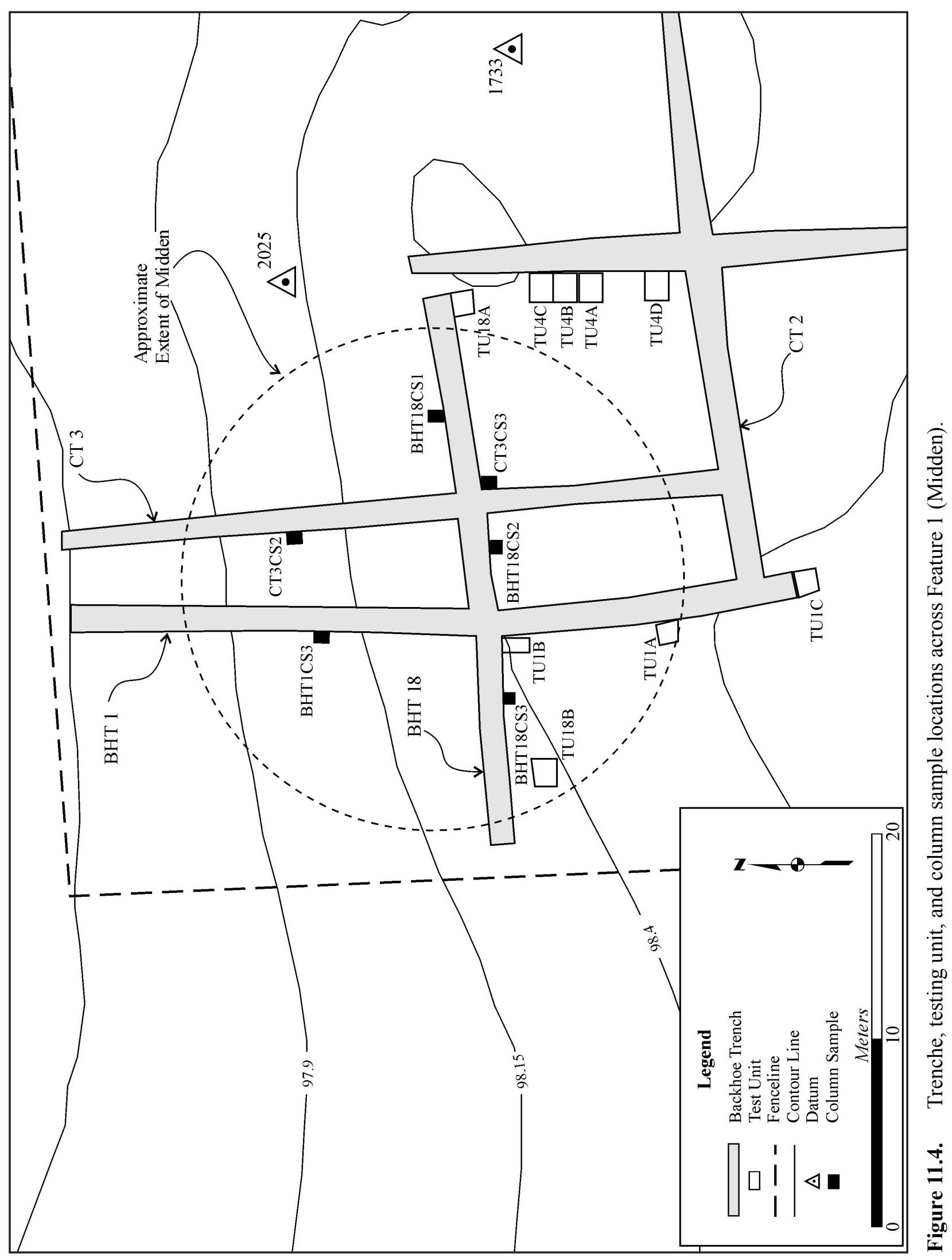


Auger samples obtained during testing established the general limits of the midden while the trenches confirmed its extent. The trench profiles of BHT 18 and CT 3 established the vertical extent of the midden, which the testing units and column samples then utilized to determine the termination depths of excavations. The excavation of these units recorded all artifact material recovered as well as burned rock counts and weights. In addition, special samples were collected from the column samples and testing units. This included pollen/phytolyths, macrobotanical/flotation, lipid (burned rock), and carbon samples. The special samples helped to determine the date range of midden use and to establish resources utilized within the feature. Debitage and burned rock data were then examined to identify patterns from within the burned rock midden.

In order to adequately quantify trends in the recorded burned rock and recovered debitage, the data had to be standardized from the available recovery counts and weights. For instance, the data recovery methods primarily utilized within the midden involved the excavation of $50 \times 50-\mathrm{cm}$ column sample units and 1 $\mathrm{x} 1-\mathrm{m}$ test units. In addition, the amount of excavated matrix varied from approximately $0.15 \mathrm{~m}^{3}$ to $0.36 \mathrm{~m}^{3}$ in the individual column samples and approximately $0.6 \mathrm{~m}^{3}$ to $1.3 \mathrm{~m}^{3}$ from the test units. Due to these variations, the overall counts and weights from the units were calculated to give an approximate amount for a standard $1 \times 1 \mathrm{~m}$ unit with a $10-\mathrm{cm}$ level, or $0.1-\mathrm{m}^{3}$. Table 11.7 shows the overall numbers of recovered material with appropriate calculations to show approximate $0.1 \mathrm{~m}^{3}$ recovery, accounting for the varying unit sizes.

So what do the numbers say? Table 11.6 shows the recovered count of burned rock, weight of burned rock, and debitage count from each excavated unit. The data are standardized to depict the estimated recovery of material in $0.1 \mathrm{~m}^{3}$ of soil at the column sample locations and the average amount of material recovered in $0.1 \mathrm{~m}^{3}$ of soil at the testing unit locations. As a general observation, the data show high counts of debitage throughout (but concentrated on the fringes of the midden) and a centralized focus of the feature indicated by increased weights and counts of burned rock. By spatially plotting the standardized amounts per $1 \mathrm{~m}^{3}$ for each category, a trend recognized in previously researched middens was observed. The amount and weight of burned rock from the midden tended to have higher values towards the center of the midden (Figures 11.5 and 11.6). The spatially plotted debitage depicted an almost opposite trend compared to the burned rock (Figure 11.7). The debitage on the periphery units had higher counts than the units in the center of the midden. A better representation of this trend is observed in the recovery of the units

Table 11.7. Standardized Burned Rock and Debitage Data from Feature 1 (Midden)

\begin{tabular}{|c|c|c|c|c|c|c|c|c|c|c|c|c|c|c|}
\hline \multirow[b]{2}{*}{ Unit } & \multirow{2}{*}{$\begin{array}{c}\text { Weight* }^{*} \\
\text { (kg) }\end{array}$} & \multirow{2}{*}{$\begin{array}{c}\text { Weight } \\
(\text { avg. kg) })^{* *}\end{array}$} & \multirow[b]{2}{*}{ Debitage* } & \multirow{2}{*}{$\begin{array}{c}\text { Debitage } \\
\text { (avg.) }^{* *}\end{array}$} & \multirow[b]{2}{*}{ BR \#* } & \multirow{2}{*}{$\begin{array}{c}\text { BR \# } \\
(\operatorname{avg})^{\star *}\end{array}$} & \multicolumn{4}{|c|}{ Size $(\mathrm{cm})$} & \multicolumn{4}{|c|}{ Average Weight $(\mathrm{kg})^{\star \star}$} \\
\hline & & & & & & & $<5$ & $5-10$ & $10-15$ & $>15$ & $<5$ & $5-10$ & $10-15$ & $>15$ \\
\hline TU18B & 42.9 & 5.4 & 1214 & 151.8 & 401 & 50.1 & 16.4 & 20 & 6.5 & 0 & 2.1 & 2.5 & 0.8 & 0.0 \\
\hline CS3-BHT18 & 235.2 & 19.6 & 8036 & 669.7 & 3220 & 268.3 & 10.7 & 38.5 & 9.6 & 0 & 3.6 & 12.8 & 3.2 & 0.0 \\
\hline TU1B & 448.7 & 49.9 & 1999 & 222.1 & 3613 & 401.4 & 31.8 & 248.9 & 153.8 & 4.7 & 3.5 & 27.7 & 17.1 & 0.5 \\
\hline TU1A & 62 & 4.8 & 4042 & 310.9 & 1261 & 97.0 & 15.7 & 30.4 & 13.6 & 2.3 & 1.2 & 2.3 & 1.0 & 0.2 \\
\hline CS3-BHT 1 & 341.2 & 37.9 & 2740 & 304.4 & 3828 & 425.3 & 15.6 & 53.7 & 14.1 & 1.9 & 6.9 & 23.9 & 6.3 & 0.8 \\
\hline CS2-BHT18 & 508.4 & 42.4 & 1340 & 111.7 & 6712 & 559.3 & 24.8 & 68 & 24.3 & 0 & 8.3 & 22.7 & 8.1 & 0.0 \\
\hline CS2-CT3 & 258 & 43 & 2852 & 475.3 & 2684 & 447.3 & 12.2 & 42.4 & 9.9 & 0 & 8.1 & 28.3 & 6.6 & 0.0 \\
\hline CS3-CT3 & 347.6 & 38.6 & 1328 & 132.8 & 4088 & 408.8 & 11.6 & 38.5 & 18.7 & 1 & 4.6 & 15.4 & 7.5 & 0.4 \\
\hline CS1-CT3 & 708.6 & 70.9 & 3960 & 440 & 7064 & 784.9 & 16.1 & 118.9 & 1.3 & 3 & 7.2 & 52.8 & 0.6 & 1.3 \\
\hline CS1-BHT18 & 648 & 49.9 & 1284 & 98.8 & 7216 & 555.1 & 15.9 & 110.3 & 35.8 & 0 & 4.9 & 33.9 & 11.0 & 0.0 \\
\hline TU18A & 89.4 & 14.9 & 1838 & 306.3 & 1464 & 244.0 & 7 & 13 & 5.9 & 2.8 & 1.2 & 2.2 & 1.0 & 0.5 \\
\hline
\end{tabular}

\footnotetext{
* The column sample recovered materials were multiplied by 4 to account for the smaller recovered units $(50 \times 50 \mathrm{~cm}$ column sample units)

** These totals were calculated by taking the total number recovered and dividing by the number of levels excavated.
} 


\section{Spatial Burned Rock Weights Distribution}

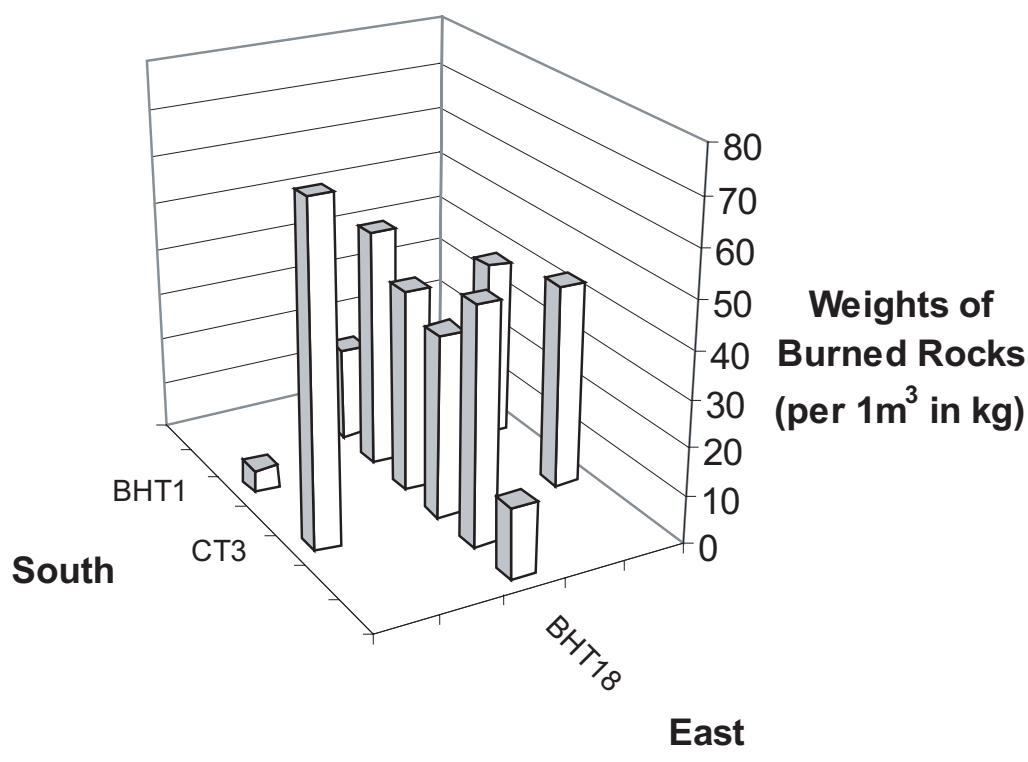

Figure 11.5. Feature 1 (Midden) spatial burned rock distribution.

\section{Spatial Burned Rock Distribution}

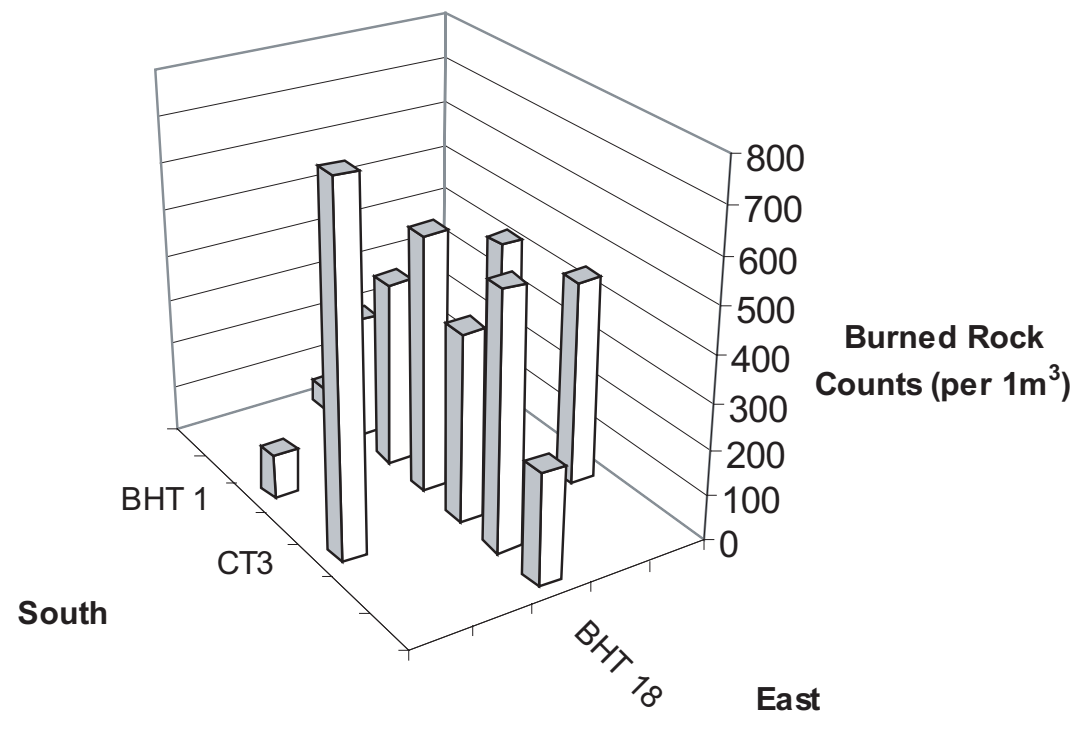

Figure 11.6. Feature 1 (Midden) spatial burned rock weights distribution. 


\section{Spatial Debitage Distribution}

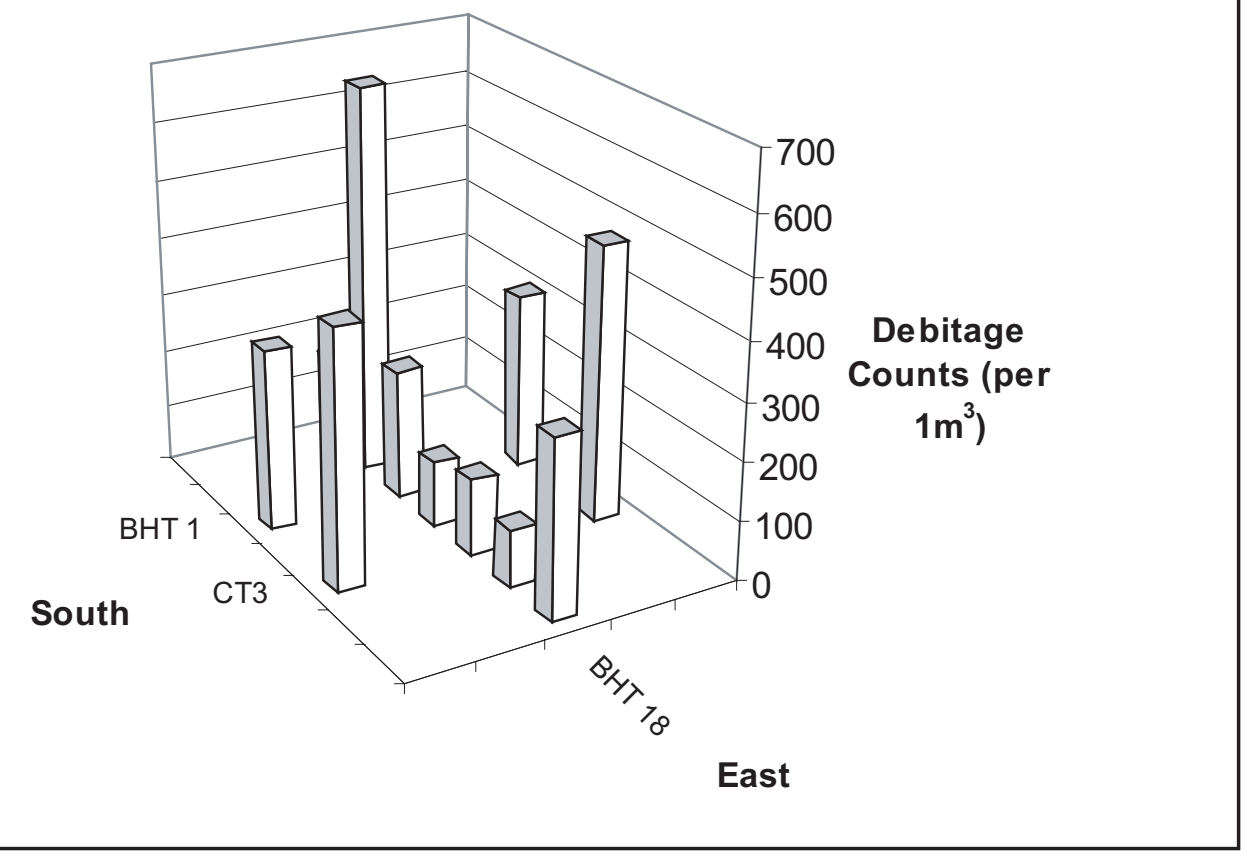

Figure 11.7. Feature 1 (Midden) spatial debitage distribution.

adjacent to BHT 18 bisecting the midden from east to west (Figure 11.8). Of interesting note is the slight dip in the observed burned rock count and weights from column sample CS3-CT3, the surmised heart of the midden. This may relate to a slight centralized depression recognized in profile that suggests a centralized pit location with a localized toss zone as a result of multiple cleaning out or discard episodes at the midden. Hence, a somewhat donut-shape is preserved in the data.

By taking these conclusions and comparing them to the profiles of CT3 and BHT 18, we can firmly establish that the higher burned rock counts and weights correlate with the approximate center of the midden (Figure 11.9). This observation comports with the conclusions of central thermal midden models outlined in the investigations at Fort Hood (Treirweiler 1996) and at four burned rock midden sites on the western Edwards Plateau (Black et al. 1997). In addition, the center of the midden also contained a very dark brown (10YR 2/2) ash stain. This correlates with features identified as burned rock middens during the Fort Hood investigations that typically exhibited a dense concentration of burned rocks within a very dark, organic-rich fine matrix. The midden features at Fort Hood also displayed a higher frequency of lithic tools, debitage, and ecofacts as compared to other burned rock features and were clearly important site furniture distributed at key locales across the landscape (Treiweiler 1996).

\section{Spatial Distribution in Occupation ZONE 4}

The investigations within OZ4 were concentrated within Area B at the periphery of Feature 1. In Area $\mathrm{B}$, a 2-m grid was used, while trenches and 1-m test units were excavated within Feature 1. The data examined in the analysis include the features, projectile points, bifaces, flake tools, cores, and debitage.

The vertical and horizontal distribution of artifact classes and features within OZ4 was examined for cultural patterning. An examination of the projectile point assemblage, where a wide temporal range of diagnostic projectile points were mixed together, supports the hypothesis that deposits above an elevation of $98.0 \mathrm{~m}$ compose a palimpsest surface with mixed Early Archaic through Late Archaic materials. Part of this disturbance is related to the construction of Feature 1, where episodes of construction mixed 

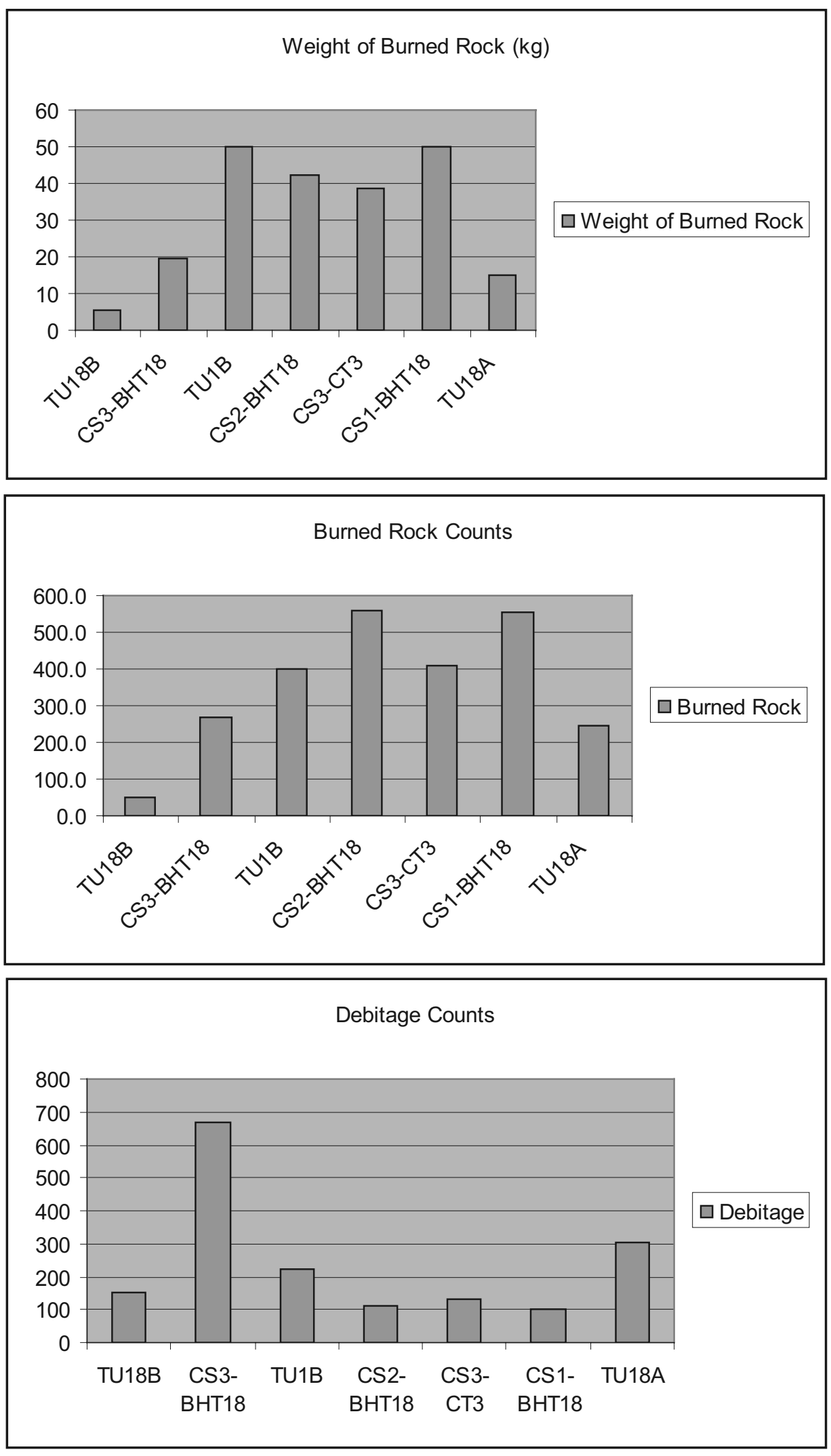

Figure 11.8. Feature 1 (Midden) burned rock weights and counts, and debitage counts. 


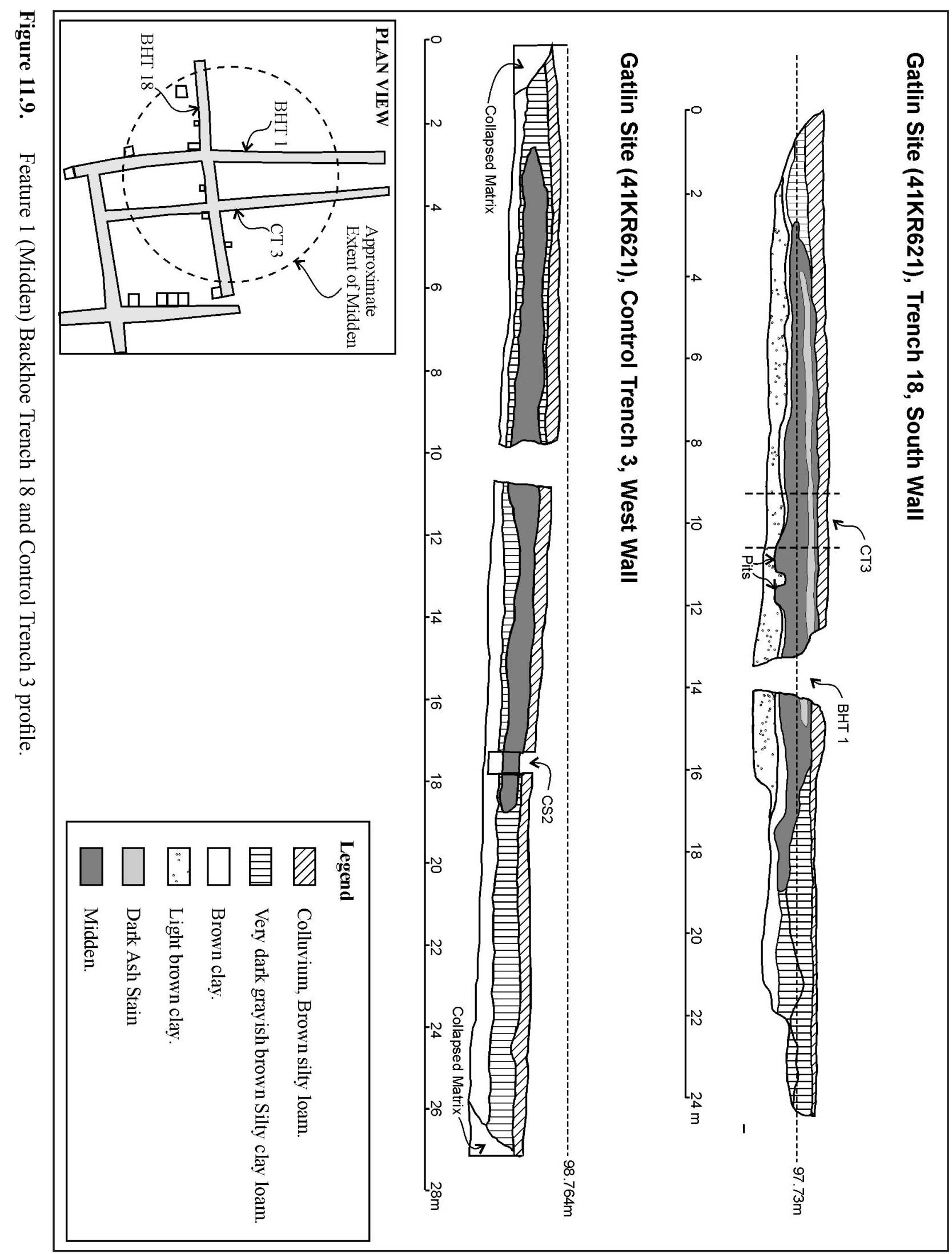


previously deposited cultural materials with newer materials. As a result, artifacts from or above this elevation had the greatest potential for being disturbed and out of their primary or even secondary spatial context. This includes the skull fragments of Feature 23 and may explain the presence of human remains without other elements or a defined grave. Horizontally, the test units from within Feature 1 contain fewer lithic artifacts at the center of the feature than from the middle, indicating that most flint knapping activity occurred around the feature rather than within.

\section{FEATURES}

The feature assemblage of OZ4 is concentrated in Area B (see Figure 11.3). Based on the density of features with Area B, it probably represents a small sample of the overall feature assemblage at the Gatlin site from OZ4. When the center locations of the features are compared using a nearest neighbor analysis, the result of 0.98 is strongly suggestive of a random pattern, even with the small sample size. The feature assemblage of OZ4 locations within Area A-NW are also illustrated in Figure 11.3.

\section{Projectile Points}

When compared stratigraphically by bottom elevation, the projectile point assemblage in Area B of OZ4 reflects the aforementioned overprinting and repetitive occupations over the course of thousands of years. The distribution of select projectile points is shown in Figure 11.10. Use-wear breakages were compared to manufacturing breakages to search for possible manufacturing and refit locales; however, the results were inconclusive, partially because only nine manufacturing errors were identified versus the 37 use-wear breakages, suggesting more tool discard occurred in the midden area. Two units contained use-wear breaks and manufacturing failures from similar elevations for Middle Archaic La Jita points and for Late Archaic Pedernales points.

\section{BIFACIAL TOOLS}

The sample size of five tools from Area B excavation units $(n=5)$ is too small for meaningful distributional analysis.

\section{BIFACES}

The distribution of bifaces and biface debitage is illustrated in Figure 11.11. As with the projectile points, the biface assemblage accumulated over a period of 2,500 years or more. Because of the mixing within Area B, the analysis focused on general observations and trends in the spatial distribution of bifaces. The units with higher numbers of bifaces contained the most manufacturing errors. The northernmost row of units along N1018 contained a more even distribution of biface stages than the southern part of Area B. In the southern unit rows N1014 and N1016, early-stage bifaces are underrepresented, as

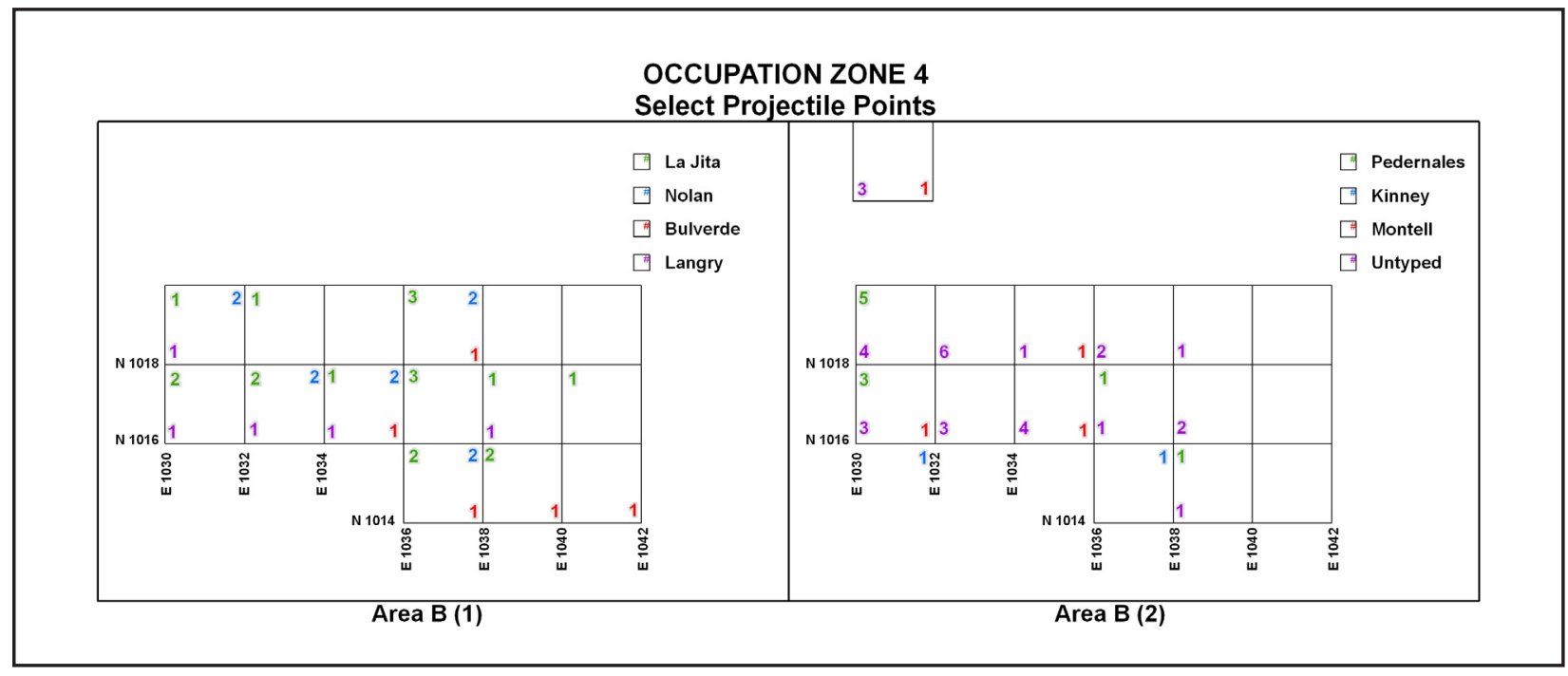

Figure 11.10. Occupation Zone 4 Area B projectile point distribution. 


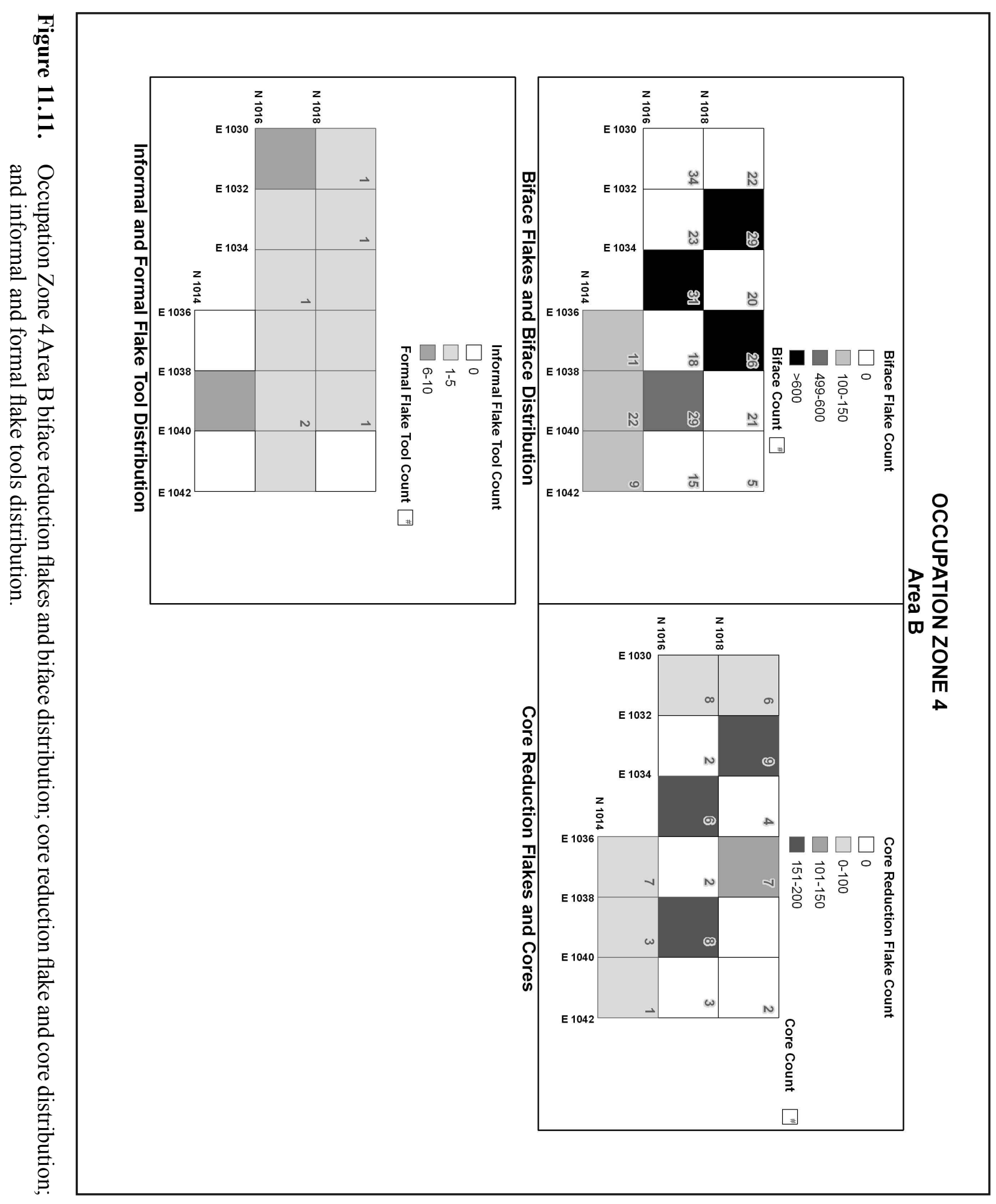


in Unit N1014 E1038, where there are 16 Stage 5 bifaces six earlier stage bifaces, and an indeterminate stage biface. In Unit N1016 E1036 where there are 11 Stage 5 bifaces, three earlier stage bifaces, and four indeterminate bifaces. This suggests that late-stage manufacturing was concentrated farther away from Feature 1, while earlier stage reductions occurred closer to Feature 1. The units with the greatest number of bifaces also had a greater number of stages represented, indicating there were possibly some spatial concentrations of lithic activity along the midden periphery.

\section{FLAKE TOOLS}

The six formal flake tools from Area B are distributed randomly with no apparent correlation with the features. In the informal flake tool assemblage, retouched flakes were more likely to be clustered in a unit than utilized flakes. The significance of this slight clustering is unknown, given the difficulty in recognizing and identifying use-wear on flake fragments. Plus, almost half of the retouched flakes in these units are fragments. The distribution of the flake tools is also illustrated in Figure 11.10 and shows the highest frequency of retouched flakes occurs in the same units (N1016 E1030), as Feature 11, and N1014 E1038, which contains Features 36 and 37. These features are all small burned rock features, and although there is no direct association, the retouched flake frequencies are highest within the vicinity of these features.

\section{BIFACE AND CoRE REDUCTION}

\section{Cores and Reduction Debitage}

No meaningful spatial patterns could be deduced utilizing the core data, and the patterning is conditioned by sample size. Units that contained multiple cores usually had a greater variety of core types. Two exceptions are Units N1016 E1038 and N1018 E1030 which had only multidirectional cores. Otherwise, cores and core reduction flakes are distributed in Area B with no identifiable pattern and no correlation between cores and high amounts of core debitage (see Figure 11.11)-further evidence of the mixing of numerous occupations.

\section{Bifaces and Biface Reduction}

Biface and biface reduction appears to correlate more than the core and core reduction debitage (see Figure 11.11). Units with high counts of biface thinning flakes typically have a greater number of bifaces, and more stages of bifaces. A notable exception is Unit N1014 E1038, which has just over 100 thinning flakes and 23 bifaces, the majority $(n=16)$ of bifaces being Stage 5. The low flake count may be the result of initial reduction occurring somewhere else. Biface thinning flakes are concentrated in the northern two rows of Area B.

\section{SUMMARY}

The distribution of artifacts in Area B within OZ4 represents more than 2,500 years of human activity at the Gatlin site. Because of the thin soil column due to limited episodes of aggradation, and the construction and use of Feature 1, OZ4 developed as a palimpsest, with isolated areas of more intact deposits where the evidence of subsequent visits was overprinted and combined with early occupations. In addition, the sample of OZ4 obtained in the Gatlin investigations is relatively small. In sum, these variables precluded the identification of any meaningful spatial patterns, besides the mentioned observations, of artifacts or features within OZ4.

\section{Organization of Technology}

\section{INTRODUCTION}

When compared to OZ3, the composition of the debitage by reduction technology continues with similar ratios between biface, core, and indeterminate, except for a slight increase in biface reduction flakes. Data from OZ4 indicates biface production remains the prevailing lithic reduction activity during the 2,500 or more year time frame. The dominant feature of OZ4 is Feature 1, the burned rock midden. Initiated during the Middle Archaic, Feature 1 was likely used to process locally procured plants. The quantity of rock eventually amassed for Feature 1 was the result of numerous visits over a period of relatively stable or static depositional environment. The size of Feature 1 suggests that it was originally used for the bulk processing of food requiring extending cooking periods at a constant temperature. These conditions are needed for cooking foods such 
as sotol, lechuguilla, and camas, whose insulin must be converted into digestible starch and sugars. This implies seasonality to some of the site visits when these plants would have been available to harvest. The other features may have been ancillary to Feature 1, and used for smaller cooking needs for a task force or family. In addition, the large assemblage of projectiles and knives indicates hunting was a major activity, with technology geared towards procuring white-tailed deer and bison. A tool class that declines in quantity and diversity are formal flake tools such as hide scrapers, which seems paradoxical, since bifaces and projectile point quantities increase in OZ4.

Using the quantity of projectile points as a measure of site use, there are two peaks of style intervals represented by these types: (1) La Jita, Nolan and Travis, and (2) Pedernales and Kinney. Both of these groupings of projectile points are associated with the use of burned rock middens in Central Texas (Collins 2004; Johnson and Goode 1994). According to Johnson and Goode (1994:26), it is during the later part of the Middle Archaic, when La Jita and Nolan points were used, that semisucculent plants are being processed in earth ovens on a larger scale than previously. During the Late Archaic through the Late Prehistoric, the use of burned rock middens increased on the Edwards Plateau. A radiocarbon date from a Pedernales and Kinney points component at the Anthon site was approximately $3120 \pm 99$ в.P. (Goode 2002), and the overall range of dates for Pedernales points is estimated at approximately ca. 3,600-3,300 в.P. by Johnson (2000), while Collins (2004) estimates it at ca. 3,300-2,500 в.P.

Tools such as gouges and drills that are usually associated with camp and maintenance activities were found in low numbers at the Gatlin site. Further more, there were few manufacturing failures for these types of tools. This suggests that the site was not used as a long-term base camp. The artifact assemblage supports the interpretation that small, mobile foraging groups repeatedly visited the Gatlin site. The ratio of bifaces to cores also supports a view of highly mobile groups, especially with a biface to core ratio of $6: 1$. With the exception of Feature 1, the feature assemblage is reflective of the needs generated by small, perhaps familial-sized groups. In most instances, these features may have been used once or a few times, based upon the intactness of some features. Larger groups would have required more or larger features, and engaged in activities requiring more and different tool forms (Odell 1996, 2004). Even if the members did not engage in different activities, the numbers of artifacts of existing types would increase. The decline in formal flake tools such as hide scrapers suggests that there was a decline in big game hunting at the site. The number of ground stone implements, although never common, declined in OZ4, and like the decline in formal flake tools, it may reflect changing subsistence patterns and perhaps environmental change from OZ3.

The lithic and feature assemblage supports a settlement model that OZ4 represents the remains of small groups of mobile foragers who utilized the Gatlin site as a temporary camp for hunting, lithic retooling, and biface manufacture. In addition, they repeatedly visited Feature 1, expanding its size over time.

\section{Projectile Points}

The diversity of projectile point type increases with time in OZ4 and many of the point styles are coeval. These point styles may represent regional and/or functional variation, such as Pedernales and Kinney knives, which are contemporaneous and possibly within the same tool kit (Goode 2000). Projectile point styles within OZ4 change from the thicker, narrower bladed and easily resharpened Nolan and La Jita points to thinner, broader bladed Bulverde and Pedernales points. Johnson (2000:158-159) views Pedernales points as an intermediary technological form between Middle Archaic points such as Nolan, Travis and La Jita, and the wide-bladed and barbed point such as Castroville. Like the Middle Archaic points, Pedernales could be extensively resharpened.

There are variations in the La Jita point assemblage that suggests different mobility patterns for groups who utilized the La Jita point styles. Hester and Shaffer divided the La Jita assemblage from the Gatlin site into three groups. Groups I and II are represented in the deposits from OZ4. Group I $(n=10)$ are the traditionally described points, with corner notching, long blades, and slight shoulders. Basal thinning creates a wedged-shaped profile and the stem edges are ground or crushed for hafting, resulting in rounded corners. The Group II points 
are more extensively reworked and modified La Jita points that developed side notching and a basal concavity as the result of stem reshaping. This suggests that Group II specimens were reworked and modified while unhafted. Despite the modification to the stem of Group II points, there is no difference in the stem length between the Groups I and II. The significant difference is in the overall length of the specimens, where complete Group I points average $61 \mathrm{~mm}$ in length and Group II points are $54.4 \mathrm{~mm}$ in length. Group II specimens are more intensively maintained than Group I points and the reshaping of the stem could result from adapting the stem to fit a variety of shafts. Group I and Group II points were recovered from the same 2-m excavation unit in only two instances, and there was a greater likelihood that multiple specimens from an excavation unit were from the same group. This suggests that the differences between Groups I and II may be more than just the extent of resharpening and reshaping, since it is reasonable to assume there would be more examples of commingling if they were part of the same lithic tool assemblage.

Nolan points are similarly divided into two main groups, with Group I being the classic, defined, specimens and Group II being "Nolans later in life" according to Hester and Shaffer in Appendix C. The groups are almost evenly split with six Group I and seven Group II specimens. Only three of the 13 specimens are unbroken and the remaining specimens were most likely broken during use. The Nolan assemblage is mostly represented $(n=7)$ by discarded, heavily utilized points that were broken from use as projectiles. There is a single Travis point, which occurs at other sites with Nolan points and is more commonly found along the eastern Edwards Plateau and Balcones Escarpment. The specimen from OZ4 is a late-stage preform that was abandoned before the base was thinned.

The assemblages of La Jita and Nolan points can be characterized by the effort expended in maintaining these tools until they were lost or discarded at the Gatlin site. La Jita points were resharpened and reshaped both when hafted and unhafted and they were used intensively — primarily as projectile points —although use-wear analysis identified other functions such as cutting, slicing, and scraping soft and hard organic materials. Nolan points were similarly used, with primary use as projectile points.

\section{BifaCES AND BIfACE REDUCTION}

There are a few bifacial tool forms from OZ4, but the dominant biface category is Stage 5 fragmentary manufacturing failures. From Area B there are 17 of these thin bifaces, only two of which are complete enough for overall measurements. The 17 bifaces are distributed randomly through Area B, with one unit containing three specimens. Associating these thin bifaces to a particular dart point through spatial distribution was inconclusive. Each of the three thin bifaces submitted for use-wear analysis had different use-wear. Lot 1468 was used as a burin after it was broken in manufacture, Lot 1341 was used to cut bone or wood and possibly as a butchering tool and was originally hafted, and Lot 1443 was also used as a butchering tool that frequently contacted materials such as bone and cartilage. Approximately 76 percent of the Stage 5 bifaces were broken during manufacture, followed by indeterminate breaks at 13.8 percent. Use-wear breaks were not noted amongst the Stage 5 bifaces. This is partially the result of several factors including the small size of some fragmentary specimens, breakage patterns that could not be clearly identified, and the use of the bifaces themselves. These bifaces may have been used infrequently or were not used with sufficient force to cause breakage. The butted bifaces were used for heavy processing, such as chopping, and may have spared the use of the thinner bifaces from these tasks. The heavy butted bifaces may also have reduced the need for of such tools as gouges.

The perforators and drills are easily made from small biface preforms, and the graver from recycled fragments. The gouge is made from a thicker blank than was being produced at the Gatlin site during OZ4, and there were no gouges broken in use or during manufacture. The Stage 5 bifaces were employed as knives, as detected by the use-wear, but because of the fragmentary nature of the assemblage, there use as tools may be underrepresented.

The parent material of almost 100 percent of the bifaces is fine-grained, locally available Edwards chert. The parent form of the specimens was possible to identify among 12 percent of the assemblage. Overall, 7.3 percent were from cobbles, 3.16 percent were from interior flakes, and 1.22 percent were from cortical flakes. There is a slight increase in the use of interior flakes in OZ4, up from the 1.94 percent in OZ3. 


\section{Cores ANd Core REDUCTION}

Cores decrease considerably in OZ4 from OZ3. The decrease is reflected in the core reduction to biface reduction debitage ratio, which decreases to 0.218 from the 0.292 in OZ3. The lower ratio reflects the decrease in core reduction flakes and increase in biface reduction. The composition of the core assemblage has fewer bifacial cores and multidirectional cores and more unidirectional and indeterminate cores as a percentage of the assemblage when compared to OZ3. The increase in bifaces without an increase in cores suggests that the cores were not a major source of flake blanks for biface reduction. The decrease in the number of cores also suggests that fewer formal flake tools were being produced and that their decrease in OZ4 deposits is not because they were produced and exported off-site.

\section{FLAKE TOOLS}

A comparison of bifaces to flake tools is a ratio of almost 64:1 in OZ4 and 10:1 in OZ3. The reduction in the formal flake tool assemblage is both in quantity and diversity from OZ3 reflects a change in site use. The fewer flake tools suggest that stays at the site were briefer, and that less camp activities were performed. If informal flakes are used as a measure of site use duration and the range of activities performed at the site, then visits to the site were briefer, and there was less emphasis on processing activities such as skinning and hide preparation. Some of the functions of the formal flake tool assemblage may have been replaced through the increasing use of bifaces or similar tasks. The fewer flake tools also suggest that smaller groups were using the site, despite the presence of the midden.

\section{ISSUES OF MobILITY, SPECIAL USE, AND CURATION}

During OZ4, there is an increase in the ratio of formal to informal tools from the lower OZ3 and
OZ2. The ratio increases to $5.19: 1$ from 2.33:1 in OZ3 (Table 11.8). The change is mainly due to the increased numbers of bifaces and projectile points and a decrease in the use of flake tools. Three of the large and thin Stage 5 bifaces had use-wear consistent with butchering, and one of the specimens was used as a hafted knife. The intended use of the finished bifaces may have fulfilled the role of formal flake tools which did not increase from OZ3.

The ratio of curated to non-curated tools increases from 2.18:1 in OZ3 to 3.69:1 in OZ4. As a measure of lithic material availability, tool use, and mobility, the increase reflects behavioral responses in the lithic assemblage. The changes are adaptations to a variety of localized and regional effects such as prey availability and climate change. Curation strategies are attempts to ameliorate negative effects from anticipated and unexpected risk.

There is a similar rise in the ratio of formal to informal flake tools to 5.19 in OZ4 from 2.33 in OZ3. The OZ4 materials appear to represent a more formalized tool kit, with a greater emphasis on bifaces than during OZ2 and OZ3. The reduction in informal flake tools supports the hypothesis that group sizes remained small at the Gatlin site; and that if more sustained habitation occurred, a greater amount of flake tools would be generated. The rise in formal tools does not extend to the flake tool assemblage nor does it extend to the biface tools, which decreased in diversity and quantity.

The lithic tools assemblage, particularly the projectile points, is characteristic of a maintainable system. The narrow bladed points like La Jita and Nolan were easily resharpened while hafted, creating the characteristic alternate beveling. Similarly, Pedernales points could be extensively resharpened, in part due to their large size. The lack of pronounced barbs on the dominant projectile point styles of OZ4 limited manufacturing failures and catastrophic breakages during use. Eleven of the $23 \mathrm{La}$ Jita points and six of

Table 11.8. Occupation Zone 4 Formal and Informal Stone Tools

\begin{tabular}{|c|c|c|c|c|c|c|c|c|}
\hline & $\begin{array}{c}\text { Projectile } \\
\text { Points }\end{array}$ & Bifaces & $\begin{array}{c}\text { Bifacial } \\
\text { Tools }\end{array}$ & $\begin{array}{c}\text { Flake } \\
\text { Tools }\end{array}$ & $\begin{array}{c}\text { Prepared } \\
\text { Cores }\end{array}$ & $\begin{array}{c}\text { Retouched and } \\
\text { Utilized Flakes }\end{array}$ & $\begin{array}{c}\text { Multidirectional } \\
\text { Cores }\end{array}$ & Total \\
\hline Formal & 144 & 445 & 8 & 7 & 26 & & & 630 \\
\hline Informal & & & & & & 76 & 56 & 132 \\
\hline Ratio & & & & & & & & $4.77: 1$ \\
\hline
\end{tabular}


11 Nolan points had been reworked along the blade or blade and stem. Hester and Shafer's analysis of the projectile points distinguishes subcategories within Nolan, La Jita and Pedernales point assemblages based upon the extent of reworking.

The different groups in the La Jita and Nolan assemblages suggest there was variation in the groups' mobility. Variations in resharpening, reuse, and raw material were examined by Odell (1996:74) in the context of curation and scarcity-induced economizing activity. Odell's analysis is in response to the definitions of curation offered by Binford (1973) and Bamforth (1986). In response to economizing activities, Odell characterized a range of behavioral responses relating to mobility and settlement, tool conservation, and tool extravagance. The availability of raw material may be equally significant a determinate for the composition of a lithic assemblage as mobility, and sometimes for contradictory reasons. The two groups of La Jita points appear to be contradictory in the context of the abundant chert resources at the Gatlin site. With such abundance, there should be decreased demand for tool maintenance and recycling strategies. However, the majority of projectile point assemblages at the Gatlin site, from all occupation zones, have emphasized maintainability in their designs. The Gatlin site is part of the imbedded mobility strategy of the makers of La Jita, and most likely, Nolan points. Exhausted points are left at the site after returning from resource poor areas, where chert was either poor quality or of limited availability. The relatively intact, or classic forms of La Jita, represent discard before venturing into resource poor areas. New points and tools are made in anticipation of imminent material shortages.

\section{FEATURES}

The feature assemblage within OZ4 reflects a long period of time during which different groups visited the Gatlin site. The formation of OZ4 began sometime in the Middle Archaic and extended to the Late Archaic before subsequently being fully buried. Over the course of time, various methods of hot rocks cooking were employed at the site and these techniques are reflected in the variation in OZ4 features. The majority of features from Area B and off-midden deposits were very small, ovate or circular clusters of fractured limestone. Some are ring-like with empty interiors while others are simple, flat clusters. These features were clearly intended for heating and/or the processing of limited amounts of food for small groups. According to Black et al. (1997:62), the contents and morphology of the smaller features suggest they were constructed to provide dry, radiant heat for tasks such as the grilling, smoking, searing, or drying of meats and other foods.

In contrast, Feature 1, the large midden was likely used as a large earth oven or series of ovens, which is a well-documented phenomena found across the Edwards Plateau (Black et al. 1997; Collins 1995). In a comprehensive study, Black and Creel (1997:271) define the classic Central Texas burned rock midden as a "complex, accumulative, episodic, multi-causal phenomena that characteristically formed over long spans of time on stable land surfaces..." In terms of prehistoric construction and utilization of burned rock features, the most commonly attributed functions are as ovens or hearths (Black et al. 1997). The thermal properties of stone, specifically limestone and sandstone, were clearly recognized by the ancient indigenous groups of Central Texas. Over the years, a number of different theories regarding the appearance of burned rock middens and/or large features have been suggested. Perhaps most relevant is the link between the processing of plant foods to the distribution of burned rock middens across the landscape (Black et al. 1997; Creel 1986; Hester 1973; Wilson 1930). Black et al.'s (1997) work on hot rock cooking strongly indicates that certain plant foodstuffs were critical to indigenous lifeways and likely played a causal role in the development of large concentrations of burned rock. They "hypothesize that, collectively, burned rock middens may have been in use year-round for different seasonally important plant resources; sotol and geophytes in the winter and spring, prickly pear in the summer, acorns in the fall, etc." (Black and Creel 1997:305).

Johnson and Goode (1994) have asserted that rock oven cooking began in Central Texas by 5,000 B.P. These facilities, many of which were repeatedly used and located in prepared areas, were no doubt fixtures for foraging societies. The use of burned rock midden localities may have increased through time, as populations increased. This may also reflect an increasing reliance on starch-based plants (Black and Creel 1997). It is clear that Middle and Late 
Archaic populations, were utilizing burned rock middens fairly extensively. It is also clear that these features were still being utilized through the Late and Transitional Archaic and into the Austin and Toyah phases (Black and Creel 1997:301). Recent comprehensive studies of burned rock middens have been instrumental in obtaining structural data and elucidating technological function regarding Central Texas burned rock features (Black et al. 1997; Hester 1991; Potter et al. 1995).

Stemming from this continued development of systematic recovery and interpretive techniques, broader theoretical issues addressing technology, as well as the utilization and accumulation of burned rocks, have been articulated. The development of relevant middle range theories has provided a link between the archaeological data and the behavior that resulted in what we are able to observe archaeologically (Binford 1962, 1968; Ellis 1997). The hypothesis that burned rock middens have a complex life-history and were used to some extent as activity areas where different foods were prepared and cooked, increases the interpretive value of these facilities in examining prehistoric life ways (see also Black and McGraw 1985; Black 1997). Cultural information about the utilization of burned rock features was transmitted within groups through production and use activities. This included the extensive re-use of burned rock midden materials and the refurbishment of ovens over the course of hundreds of years (Black et al. 1997). Large burned rock cooking features and middens may have served as fixed appliances or features on the landscape, prompting hunter-gatherers to return to the same location over long periods, and reused as foci of seasonal activities related to the procurement and processing of stable and predictable food resources (Smith and McNees 1999).

In their study of slab-lined cylindrical cooking basins in southeast Wyoming, Smith and McNees (1999) found that the basins served as enhancements to the landscape, prompting hunter-gatherers to return to the same location over long periods, using the space in the same manner to exploit seasonally available plant resources. The study of the slab-lined-basin sites considered the influence that the presence of relatively costly, enduring facilities had on longterm patterns of location. The construction of these costly features for anticipated future reuse suggests a multi-season planning depth (Smith and McNees 1999). It also suggests that mobility patterns were relatively stable and that exploitable resources were predictable and accessible (Smith and McNees 1999; Wandsnider 1992). The repeated use of certain locations by hunter-gatherer groups has typically been interpreted in terms of their relationship to natural features like water, fuel, and food resources (Binford 1982; Brooks and Yellen 1987). Of these three variables, food resources would seem to be the most important. As long as the food resources remained available, the presence of intact and usable features like slab-lined cooking facilities would likely influence the hunter-gatherers' decision to reuse the campsite (Smith and McNees 1999; Wandsnider 1992). Such features must be considered in light of the long-term mobility strategy, which is the cyclical movements of a group among a set of territories, that hunter-gatherers are thought to have employed (Binford 1982; Kelly 1992).

Taking this background context into consideration, the midden in OZ4 at the Gatlin site appears to represent several construction episodes of a series of large-scale, earth ovens to process foodstuffs. Based on its contents and structure, most of the midden likely formed over the course of several intense episodes of use and then was incrementally added to over time. Portions of the midden may have served as a repository of rock that was likely scavenged building material for smaller features of various functions (such as those exposed in Area B). In this scenario, the midden itself would have served as site furniture over the course of thousands of years, providing a fixed appliance on the landscape to which the small groups of foragers would return.

\section{Subsistence Practices}

Large and small animal remains such as bison, deer, rabbit, and turtle were recovered from features within OZ4, demonstrating the diet breadth that was exploited at the Gatlin site. However, similar to the situation in OZ3, the poor state of preservation of the OZ4 assemblage hinders interpretations on foraging and butchering strategies as well as general subsistence base and environmental reconstruction. Based on the lithic technology and faunal evidence, it is apparent that large game in the form of bison, and more importantly white-tailed deer, formed a 
major component of the hunting strategy employed by occupants in OZ4. The presence of the teeth and a wide range of elements suggests whole animals were brought back to the site as opposed to strictly front or hind portions. Final butchering and processing of the whole animal at the site would be what Binford would term bulk strategy (Binford 1978; Lyman 1994; Metcalfe and Jones 1998). Alternately, the bison tooth could be associated with the mandible section, resulting from a gourmet strategy where the highest yield elements were removed from the animal and brought to the site; in this case it was associated with the tongue. The absence of other species/taxa in the assemblage suggests a rather limited range of animal exploitation though very small amounts of turtle, rabbit, and unidentifiable small mammal were noted. These were likely abundantly available in the riverine setting of the site at the time of occupation.

Only Feature 1 contained bone fragments identifiable to species, in this instance bison and white-tailed deer. Features 10, 36, 37, and 38 all contain unidentified bone fragments, some of which was burned. Lipid residues were detected from rocks sampled in Features 1, 36, 37, and 38. In Feature 1, the residue contains lipid signatures from low fat plants to moderate and high plant fats. In Features 36 and 37, the signature is probably from fats from animals such as deer that consumed high fat vegetation such as acorns. In general, the lipid residue signature is vague as to the origins of the residues within the rock but they do suggest functional differences. Plants appear to have been processed in the midden while animals may have been the focus of cooking on the smaller features around the midden.

Ground stone implements are scarce in OZ4 and decline in number from OZ3. Food processed with mano and metates was probably not a significant contribution to the subsistence base during the occupations represented in OZ4.

\section{Summary OF OCCupation Zone 4}

Most of the investigations in OZ4 were focused on Feature 1 and the surrounding vicinity included in Area B. The excavations provide a representative, though limited sample of the range of activities represented in OZ4 deposits. Within OZ4, absolute dates from charcoal provide a range of the occupation between ca. 4,410 and 1,070 B.P., although earlier occupations are implied by older, temporally diagnostic projectile points. The majority of cultural deposits within OZ4 are mixed; however, making any specific spatial associations to a particular period difficult.

Created during the Middle Archaic, and some time after ca. 5,000 B.P., the midden continued to develop through the Late Archaic until it was completely buried some time after 1,300 B.P. Faunal remains within OZ4 demonstrate a more broad-spectrum diet than earlier occupations that included both terrestrial and riverine resources. However, a primary focus was obviously hunting large game such as deer and, to a lesser, extent bison. The smaller features represent individual and small group cooking appliances, and perhaps because of its proximity to Feature 1, only Feature 8 is greater than $1-\mathrm{m}$ diameter.

The creation and repeated use of Feature 1 indicates a change in the subsistence strategy, beginning during the earlier occupations within OZ4. Possibly related to xerification of the climate, Feature 1 may have resulted from a need to utilize lower-ranked food resources, as sotol and lechuguilla. These resources were available at differing times of the year and in varying concentrations across the landscape. Additionally, there may have been broader time periods when the local availability of these types of plants fluctuated at the Gatlin site. During the Middle and Late Archaic, climatic changes and the growing population in Central Texas increased the demand for reliable food resources, which was partially met through the exploitation of plants that required the use of this type of larger-scale burned rock technology. Interestingly, despite the large size of Feature 1, the cumulative time invested in its construction and use, and its implications for increasing sedentism, the cultural assemblages in OZ4 are more reflective of a continuing moderate to high degree of mobility. Exploiting geographically variable densities of resources requires a higher level of mobility. Taking current models of hunter-gatherer technological organization into consideration, the lithic assemblage evidence from within OZ4 suggests there was an increase in mobility from OZ3, with the decline in the frequency of informal flake tools and cores, and an increase in the biface to core ratio. A high mobility forager subsistence model emphasizes bifacial lithic technology. 
Though the sample size of materials from this zone makes interpretations difficult, the tool assemblage suggests that the Gatlin site OZ4 occupations represent a shift towards more of a residential base camp, periodically used for activities that involved huntingrelated tasks and as well as occasional preparation of plant foodstuffs utilizing larger hot rocks oven technology. The accumulation of assemblages of points such as Nolan and La Jita and the later Pedernales, suggests that the Gatlin site was within the territory of foraging groups who "mapped" on to the seasonal resources in the vicinity and processed them at the site. Over time, the intensity of site usage increased, both in the number of visits and, possibly, group size.

As Feature 1 developed over time, groups continued to practice an encounter-based hunting strategy, supplemented through bulk processing of plant resources. Encounter-based hunting provided immediate short term supplies of meat for small groups as opposed to large-scale seasonal hunting by collector groups where mass kills provided a surplus for future use. Encounter-based hunting employed a more generalized tool kit with few specialized tools, as observed within the lithic assemblage from OZ4. A generalized tool kit containing late-stage bifaces and easily maintained projectile points was readily adapted to a variety of tasks.

The non-burned rock feature, Feature 23, contains human cranial material, and although cemeteries are known from the Middle and Late Archaic periods, isolated finds and interments at open campsites do occur. There is no evidence of any burial pit or ceremonial artifacts that can be associated with the remains. The base elevation of Feature 23 is at approximately $98.0 \mathrm{~m}$ in Area B. Artifacts from this elevation and above may have been disturbed during the construction and use of Feature 1 and the fragment is probably not in situ.

Based upon projectile point styles and radiocarbon dates, the transition from the Middle to the Late Archaic occurs in the deposits of OZ4, during which time Nolan and La Jita points are followed by Bulverde and Pedernales points. All of these points are readily resharpened and form the central part of a maintainable lithic tool technology. Few of the points are recycled into other tool forms after breakage, in- dicating the nearby availability of high quality chert. Off-site, presumably in lithic poor areas, points were extensively resharpened, but were discarded for new points during refitting at the Gatlin site. Before heading into areas with uncertain chert resources, larger projectile points and lithic tools, that in other regions would be recycled, were discarded and replaced with new specimens. Towards the end of the Late Archaic, the diversity of projectile points increases; however, there are few specimens of each type. This suggests that the site was used less frequently and/or for shorter durations. The absence of arrow points is similarly suggestive of a decline in site use and changing cultural and physical landscapes at the end of the Late Archaic. 


\title{
Chapter 12
}

\section{Continuity and Change at the Gatlin Site}

\author{
Eric R. Oksanen, Brett A. Houk, and Kevin A. Miller
}

\section{INTRODUCTION}

The central research theme guiding the investigations at the Gatlin site was cultural change and continuity through the Middle Holocene within the Guadalupe River valley in Central Texas, with an emphasis on the basic domains of chronology, paleoenvironment, technology, site structure, and subsistence. Utilizing one of the largest excavated samples of Early and Middle Archaic cultural deposits in the southern Edwards Plateau, the results of these studies provide a unique look at human adaptation and basic lifeways at the site and surrounding region. The following sections synthesize the site data within the research domains, allowing a broader, holistic examination of the human occupants who made the Gatlin site over thousands of years.

\section{Chronology of 41KR621}

\section{Temporal Structure of the Gatlin Site}

The division of the occupation zones was determined by soil development, artifact distributions, and associated radiocarbon dates from both bulk humate and, more significantly, from radiocarbon assays from charcoal, with a greater emphasis upon samples from secure feature contexts. The latter proved more elusive as poor preservation of organic material made establishing a definitive association of charcoal to a particular feature more difficult. In several instances, charcoal dates were seemingly mixed with contradictory results. One example includes samples from Features 25 and 26. The $1 \sigma$ conventional radiocarbon date of $4550 \pm 40$ B.P. (Beta 207380) from Feature 25 is adjacent to a sample from Feature 26 that has a $1 \sigma$ conventional radiocarbon date of $6100 \pm 40$ B.P. (Beta 206122). In addition, Feature 34 has a $1 \sigma$ conventional radiocarbon date of $4090 \pm 40$ B.P. (Beta 207386), while two other samples from Feature 34 have $1 \sigma$ conventional radiocarbon dates of $4990 \pm 50$ в.P. (Beta 206128) and $150 \pm 40$ в.P. (Beta 207383). The latter date clearly indicates intrusive charcoal from recent deposits. As such, the occupation zone divisions are founded on the cumulative data, not just singular radiocarbon dates or diagnostic tools.

\section{OZ1}

The estimated date range of the deposits within OZ1 is from ca. 6,600-6,060 B.P. There were two assays used to define the boundaries: Feature 14 has a $1 \sigma$ conventional radiocarbon date of $6570 \pm 50$ B.P. (Beta 206115) and forms the stratigraphic and temporal lower boundary, while a $1 \sigma$ conventional radiocarbon date of $6100 \pm 40$ B.P. (Beta 206122) from Feature 26 in OZ2 is the upper boundary. These two features had a similar elevation but are clearly from two different occupations. The diagnostic point types from $\mathrm{OZ1}$ are Gower, Early Barbed Devil's River variant, Martindale, and Pandale (Figure 12.1).

\section{OZ2}

The radiocarbon dates from OZ2 give an estimated range from ca. $6,100-4,500$ B.P. There were 12 cultural radiocarbon assays within OZ2, with a strong indication of two distinct clustering of dates or ages, in radiocarbon years at ca. 5,500-5,300 B.P., and more significantly at ca. 4,950 в.P.

There are nine identifiable projectile point types out of 88 specimens attributed to OZ2 (see Figure 12.1). These are Andice, Baker, Bandy, Bell, Early Triangular, Gower, Marcos, Martindale and Martindale Narrow Stem. Martindale $(n=34)$ and Gower $(n=21)$ are the dominant types.

\section{OZ3}

In OZ3 deposits, the range in radiocarbon years is from ca. 4,500-3,850 B.P. Although five radiocarbon assays were used to date the occupation zone, only four of these dates are associated with features. The diversity of projectile points increases in OZ3 to 17 types and 101 identified specimens, almost doubling from the OZ2 occupations. The proliferation of projectile point 


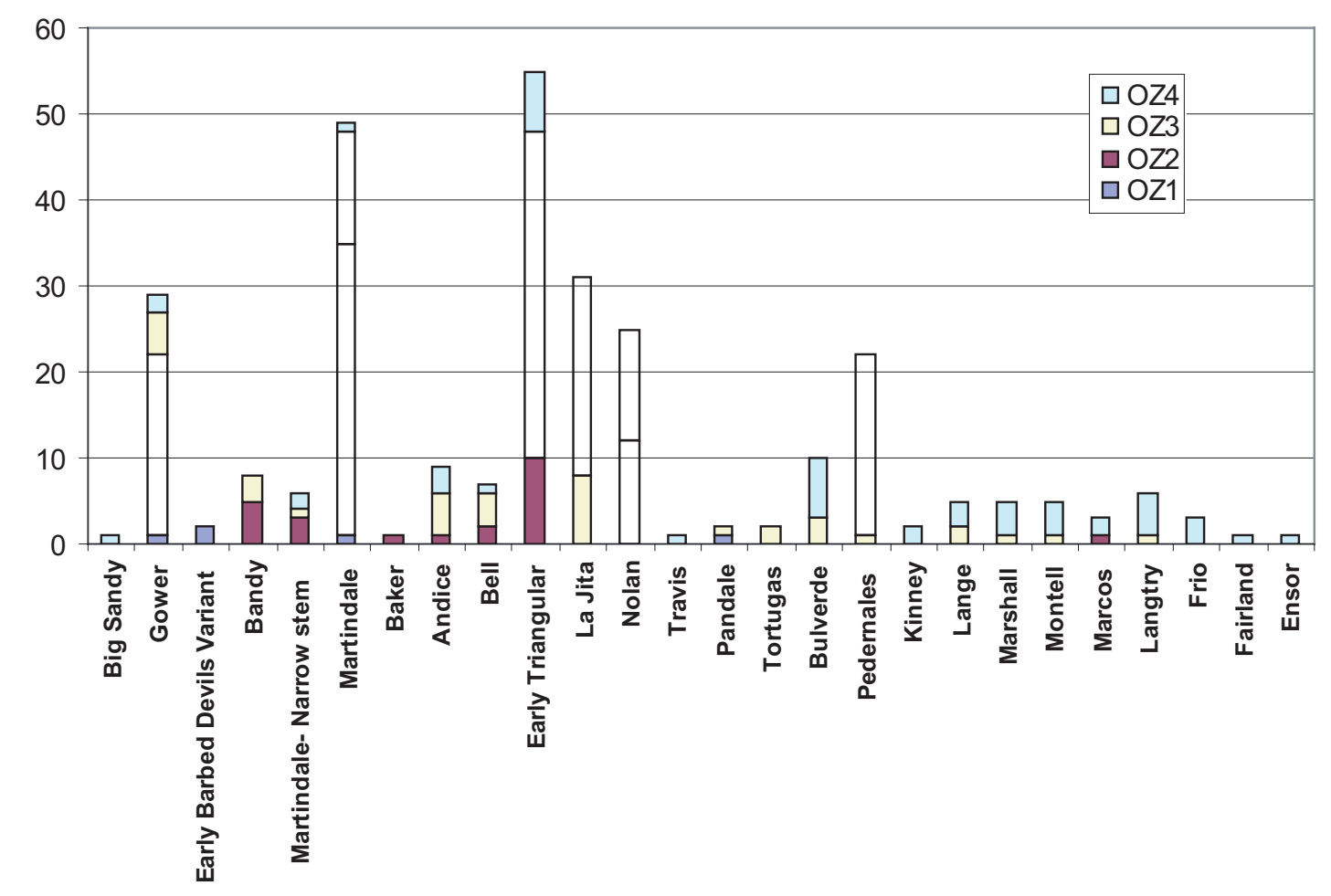

Figure 12.1. Projectile point types by occupation zone.

types includes the introduction of Middle Archaic types and a few Late Archaic types, and the continued presence of Early Archaic types. Early Triangular forms dominate the OZ3 assemblage but with increased mixing with later Bell/Andice, La Jita, and others (see Figure 12.1).

\section{OZ4}

The final dated occupation zone at ca. 3,900-1,250 B.P. was partially stripped of overburden, and it is possible that there were later occupations; however, there are no arrow points recovered from the Gatlin site. This supports an end date of ca. 1,250 в.P. In OZ4, the construction of the midden continued until it was finally buried sometime after ca. 1,250 cal B.P.

The diversity of projectile points reaches is zenith in OZ4, with 21 types recovered and 107 specimens of identified points (see Figure 12.1). Despite the broad diversity, over 50 percent of the points are typed into three major categories, La Jita, Nolan, and Pedernales. Most of the remaining types are represented by five or fewer specimens.

\section{Dating Considerations}

Two factors are considered in establishing the occupation zones' chronological order, radiocarbon calibration and projectile point existence intervals. The conversion from radiocarbon dates to calendrical years can change the measured duration between events. The radiocarbon dates were calibrated from the fractionation corrected radiocarbon assays using OXCAL 3.2. For example, in OZ1, the overall difference between calibrated and radiocarbon years is less when examining the possible minimal time period between the two radiocarbon dates Beta 206115 and Beta 206122. However, there is a difference in the potential date range of particular events. In the example of Beta-206122, the 2-sigma difference is 160 radiocarbon years, while the difference after calibrat- 
ing is almost 300 years. This has implications when trying to associate chronotypes such as projectile points to a feature or sample where the carbon was used for radiometric dating. The potential age of the feature is expanded. As an example, using calibrated dates, the date range for OZ1 is ca. 7,570-6,860 cal B.P. and the overall range of the OZ1 is approximately 710 years, a slight increase over the estimated 600 radiocarbon years.

For the purposes of the Gatlin study, radiocarbon years were utilized as they proved more effective for comparative purposes as most of the Central Texas paleoenvironmental work and models, chronologies, and geomorphological studies utilize similar dating. However, both corrected radiocarbon ages and calibrated dates are considered in Chapter 13.

As mentioned, the date range for each of the occupation zones is an estimated minimum resident time. Establishment of the minimum times proved challenging due to two significant agents of mixing natural and cultural deposits: (1) low rates of sedimentation, and (2) cultural overprinting and reuse of the surfaces through time (i.e., Schiffer 1983). Shallow deposits are more likely to be disturbed by subsequent cultural activities such as feature construction when new material is introduced into lower strata and buried material is excavated and moved up into a younger deposit.

As an example, Feature 1 midden, presented a challenge for radiometric dating because it represents multiple uses through time, during which material was added, removed, and mixed with previous material. Although examined as part of OZ4, initial formation likely began earlier in the deposits associated with the OZ2 and OZ3 transition. Different events are therefore reflected horizontally and vertically, making stratigraphic associations within Feature 1 difficult. There were 11 radiocarbon assays on charcoal collected directly from within Feature 1 and from the immediate vicinity and boundaries. Four of these dates are from within the midden deposits and range between ca. 4,210 B.P. and 2,120 B.P. However, there is a clear break from the underlying strata where three radiocarbon assays average ca. 4,700 B.P.

As in Feature 1, the radiocarbon dates from each occupation zone show concentrations of dates, and clear separations. Within each zone there is a core of dates with outliers that form boundaries with the adjoining occupation zones.

In regards to time diagnostic tools, while there are some problems, the dating of the various occupation zones and associated projectile points allows for refinement of the ongoing construction of a Texas projectile point chronology, particularly for the Early Archaic and the transition to the Middle Archaic. This is in part due to the robust radiocarbon sampling program and the large assemblage of projectile points.

Each of the projectile point styles is assumed to be a chronostratigraphic unit, in that they represent a period of time and have geographic boundaries (Blackham 1998:175). As a result, point types can vary in age depending on geographic location. This issue is evident when trying to determine the origin of point types such as Gower, Martindale, and Calf Creek-Bell-Andice. For example, the Rocky Mountains have been cited as a possible origin of certain split stem points such as Gower (Collins et al. 1998); however, the proposed dates for Pryor Stemmed in the Rocky Mountains is similar in age, or younger than recorded dates on Gower points in Central Texas (Oksanen 2004). If these types represent the diffusion or spread of technology, there should be a geographic temporal gradient. Regional fluctuations in the use of particular types, homologue points that appear related but are an independent development, and the dynamics of point types through selective replacement make it difficult to use projectile points alone as synchronic markers.

Each of the projectile point types has an existence interval which is the lifespan of usage (Blackham 1998:173; Schiffer 1996). If the existence interval of two artifacts is established, and they are found in spatial association, then certain deductions can be made. If they were known to coexist for a period of time then a minimum and maximum period of association can be established. If there is no demonstrable association, then the chronological model may need revision, or there are other factors such as palimpsests that created what was later determined to be an anomalous association.

Numerous diagnostic projectile points at the Gatlin site are found in contexts that support their previously established chronological ranges. Certain point 
types such as Early Barbed, Gower, and Martindale, have varying existence intervals according to the major central and south Texas chronologies. The wide range of dates reported for these and other points makes relative dating difficult as these points are also likely diachronous - originating from one area and diffusing across a region. The problem arises when multiple tools with a known existence of 1,000 years or more are used to define the age of a particular strata or a specific occupation.

The longevity of the type, therefore, makes defining the date of an occupation difficult unless other evidence is used (such as systematic radiometric samples) as a cross reference. For straight comparison dating using time diagnostics, they are most accurate when the scale of time being examined is within the overall age of the artifact. If an artifact had an existence of 10 years, the maximum temporal resolution of investigations is 10 years. In the instance of the Gatlin site, the existence interval of the points is greater than the defined interval for some of the occupation zones. The implications of this for the site point seriation and chronology are further explored in Chapter 13.

\section{Paleoenvironment and Site Formation Processes}

\section{SITE GEOMORPHOLOGY AND THE GUADALUPE RIVER}

The transition from the Pleistocene to the Holocene was a period of global climatic changes. During this period, streams on the Edwards Plateau abandoned their old channels, and created new, lower elevation floodplains as they began to incise their new channels. The warming of the climate during this period is correlated with increased erosion on the Edwards Plateau, and it is this erosion that provided the material that formed the $\mathrm{T} 1$ terrace at the site, what Abbot identified as allostratigraphic Unit 3 (Chapter 6). The development of Unit 3 was a combination of lateral accretion and vertical accretion, with lateral accretion the dominant process during the initial formation.

The human occupations at the site are contained within allostratigraphic Unit 3. The rate of alluvial deposition was greatest during the Late Pleistocene, beginning at ca. 12,400 в.P. and decreased during the
Holocene ca. 10,000 B.P. This decrease is partially the result of the downcutting of the Guadalupe River channel. As it became more entrenched, overbank flooding decreased and less sediment was deposited. Periodic, large-scale floods deposited gravels and fine matrix on the terrace surface, which included slack water deposits, but overall accumulation slowed. By ca. 5,000 B.P., or even earlier, the channel was fully entrenched, and alluviation decreased dramatically.

If the late Pleistocene is viewed as floodplain development through aggradation, by the early Holocene, as aggradation diminishes, soil development occurs on the increasingly stable surfaces. No disconformity was detected in the examined profiles, and Unit 3 was analyzed as a single depositional unit that developed during a long period of time. At the southern edge of the valley margin, colluvial deposition also occurred during prehistoric and historic times. Overall, colluvium was limited to those parts of the site adjacent to the margin edge of the valley.

Two areas of occupation were noted in the floodplain; a chute channel and the valley margin. Most of the investigations were conducted along the valley margin along the edge of the T1 terrace, with one test unit placed in the flood chute. Test Unit 5, which contained Feature 3, was located in the flood chute. The sparse artifact recovery suggests that these channel deposits were scoured by floodwaters and that the occupations were of short duration.

Areas immediately to the north of Feature 1, the burned rock midden, have been impacted by high energy floods that reduced the likelihood of having intact and preserved cultural deposits. Frederick identified at least two episodes of high energy, large magnitude flooding in BHT 19, as evidenced by matrix supported gravels. This intensity of flooding did not extend up to the southern terrace margin, although this was occasionally inundated with deposits of fine-grained sediment that helped to preserve cultural deposits.

As Fredrick describes in Chapter 6, individual flooding episodes and clear stratigraphic breaks are difficult to distinguish in alluvial settings such as the Gatlin site. Deep, slackwater inundation is necessary for the formation of thick alluvial deposits, as opposed to the thin alluvial deposits from higher 
energy overbank deposits. Thin deposits are more likely to be adversely impacted by the effects from processes such as pedoturbation and bioturbation. Developed A-horizons that formed on stable surfaces where high levels of organic materials accumulated, sometimes as the result of cultural activity, can be obscured and/or destroyed by these processes. Shallow soils are more likely affected. Rapid aggradation can help to preserve an A-horizon by removing the soil from the initial effects of pedogenisis and bioturbation. Rapid alluviation can also prevent the formation of an A-horizon, which needs a period of stability to form. This period can be as short as 100 years to over 1,000 , depending on the properties of the alluvium.

The development of the Guadalupe River floodplain from OZ1 through OZ4 can be characterized by decreasing rates of aggradation from alluviation. Episodic colluvial accumulations at the southern end of the site along the valley margin suggest there were periods of erosion, with the greatest accumulation occurring during historic or even modern times. Catastrophic flooding events were mainly confined to the northern end of the site excavations where the matrix supported gravels are concentrated and where at least two catastrophic flooding events occurred between 6,000-4,000 B.P., or within OZ2 and OZ3.

Floodplain evolution has been used as a proxy for climatic change, with increased sediment loads suggesting increased erosion of surrounding uplands. The sediments at the Gatlin site record a regional phenomenon of the southern Edwards Plateau, where older, reddish colored, remnant Pleistocene terrace deposits were eroded from upstream uplands, due to a reduction in binding groundcover. This is assumed to be the result of increasing aridity and more erratic climatic patterns. This widespread erosion is thought to be an expression of the Middle Holocene Altithermal. Terrace aggradation, and depositional regimes can result from locally specific conditions such as the width and shape of the channel (see Chapter 6). As Frederick notes in Chapter 6, there are numerous instances of sites missing sediment from a particular time range, only to have such deposits preserved a short distance away. The later Holocene deposits, corresponding to OZ3 and OZ4, are less preserved because of infrequent deposits of alluvium. Between episodic alluviation, argilliturbation, pedogenesis, bioturbation, and surface runoff were active natural agents, while cultural impacts included feature construction and recycling of artifacts.

There is evidence of occupations within the flood channel; however, these were probably negatively impacted by floodwaters. In addition, it is likely that other occupations were obscured or destroyed by flooding events. The best preserved occupations were toward the valley margin, and it is the earliest occupations, especially in OZ1 that benefited from low energy alluviation. The reduction is mainly the result of floodplain mechanics; less flooding as the floodplain height increased and the channel became more deeply incised. By the time of the occupations represented in OZ1, alluviation rates had declined from the Late Pleistocene/Early Holocene rate of $0.95 \mathrm{~mm} / \mathrm{yr}$ to approximately $0.42 \mathrm{~mm} / \mathrm{yr}$. This further decreased in $\mathrm{OZ3}$ and $\mathrm{OZ} 4$ to half as much, $0.21 \mathrm{~mm} / \mathrm{yr}$.

The primary location of the site, along the valley margin and away from the more active portions of the floodplain, likely began during the earliest settlements documented in OZ1. This location was likely a deliberate choice based upon several factors, including flood avoidance and proximity to abundant plant, animal, and mineral resources. Major site resources in the riparian zone included the edible plants and animals (deer being a main staple), chert for tool making, limestone for heating elements, and fuel in the form of firewood. Although it was not specifically mentioned in the examination of burned rock, the majority of limestone used in features was acquired from upland sources as opposed to river cobbles.

\section{PALEOENVIRONMENT}

As many Central Texas site studies have found, the reconstruction of paleoenvironments from the Early and Middle Holocene based solely on data from one site can be difficult and speculative. Given the poor preservation of a variety of perishable materials (wood, bone, plant remains, etc.), this pattern is no different for the Gatlin site. However, as shown in Chapter 13, a comprehensive review of paleoenvironmental data from a variety of sources can be more productive.

Still, inferences can be made with the site specific data. The pollen and phytolith assemblage from 
flotation samples contained evidence of what is likely post-depositional fill that accumulated after features were used. For instance, all of the species of vegetation identified in the special studies from the Gatlin site can still be found regionally. Preservation of the microbotanical evidence of pollen and phytoliths is conditioned by selective preservation and depositional history of the site surface. Slow aggrading surfaces are more likely to accumulate averages of surface vegetation, which is indicated by the relative homogeneity of the microbotanical assemblage. The numerous weedy plants and grasses identified in the pollen and phytoliths favor disturbed ground surface, which can occur from human activity and natural events such as fire, bioturbation, and flooding (Gibson 1989:144). Natural fire was a significant agent in the oak savanna that may have been adopted by aboriginal groups for hunting and habitation maintenance (i.e., Stahl 1996:140).

One possible exception is from Feature 5 in OZ2, where plant starches were detected by Cummings et al. (Appendix G). The implication is that starches were the remains of legume or seed roasting. A heat fractured metate fragment found within Feature 5 supports the hypothesis that plant seeds may have been processed in the feature.

Similarly, the sparse macrobotanical remains are both a process of selective preservation (for example, carbonized plants and certain plant species are more durable) and cultural selection. As with bone, certain species are more resistant to destructive taphonomic forces. In addition, feature and tool data suggest that there were not great quantities of vegetal matter processed and consumed at the site, with the exception of the midden occupation and its primary usage in the Late Archaic. Even then, the majority of plant use may have been as a fuel source for features. The abundance of hardwood charcoal — especially live oak-suggests that local resources were used as a fuel, and that available fuel may have been a factor in the utilization of some of the modest Middle and Late Archaic earth ovens and the large burned rock midden at the site.

The macrobotanical remains of charcoal specimens and seed casings from hackberry contain species that are still locally occurring and part of the Edwards Plateau stream regime vegetation as described by Riskind and Diamond (1986). The hackberry seed endocarps are probably modern, intrusive seeds, although they have ethnographic uses as noted by Bush (Appendix F). The dominant hardwoods identified from the macrobotanical samples are oaks (live oak in particular). This supports the current designation of the site location within a live oak savanna.

In regards to a reconstruction of the actual changes in the overall environment at the Gatlin site through time (i.e., cooler or warmer, wetter or drier), the recovered information lends itself to only conjecture with the geomorphic study having the strongest indicators. For instance, the modest macro- and microbotanical assemblage recovered from OZ1 features suggests there is a combination of climatic effects and seasonality, and most of the pollen and phytoliths were cooler and wetter weather species (Appendix G). These specimens commonly occur in alluvial settings and in the oak savanna grasslands. Historic reconstructions suggests that many areas of grassland and oak savanna had less woody cover in prehistoric times, and that arboreal cover has increased to its present levels during the past several hundred years (Archer 1990).

The geomorphic data from the site suggest similar trends in the paleoenvironment as those noted elsewhere, a gradual warming and drying from 8,000 в.P. to its maximum around 5,000 B.P when rivers/streams are entrenched and more xeric species intrude into the landscape. The Guadalupe River was basically in a similar pattern as today and likely ameliorated some of the overall environmental effects at the site with its lush riparian corridor.

\section{Game at the Gatlin Site}

Faunal remains, as previously noted and despite post-testing expectations, were poorly preserved at the Gatlin site, with no identifiable remains from OZ1. However, several species of animals could be identified throughout the other occupation zones, allowing for a reconstruction of the types of game present in the paleoenvironment exploited by the occupants of the site. Two primary game species identified in the site are bison and white-tailed deer. Grazing bison prefer areas with a higher grass-to-forb ratio (Fahnestock and Knapp 1993) and more open grasslands, while white-tailed deer prefer a mixture of grazing and browsing habitats. 
Historic accounts of bison show herds migrating from southern Texas in the winter months to the High or Central Plains in the summer. It seems likely to assume that the presence of bison in Central Texas occurred during the fall and winter months. Bison are mostly gregarious, traveling in herds, while older bulls were more likely to be solitary animals for most of the year. Bison remains were recovered from features in OZ2 and OZ3, and their presence is strongly inferred in OZ4 by fragments of large mammal bone. The presence of bison teeth suggests that the whole animal was procured locally, with final processing occurring at the Gatlin site. These are also some of the most taphonomically durable elements, and therefore, it is unknown how much of the animals were at the site. Hunting bison on foot suggests communal or group hunting was practiced, given the potential danger of the hunt and the expected quantity of meat acquired from such a kill. The seasonality of the bison would have made hunting them from the Gatlin or other nearby task-oriented sites a specific, timed occurrence.

White-tailed deer on the Edwards Plateau prefer hardwood areas, spending almost two thirds of their feeding time as grazers and one third as browsers (Schmidley 2004:276). As food choices increase, deer are increasingly selective of what they will feed on, and one characteristic of ecotonal regions and riparian corridors is that they have a high biological diversity. Modern studies of deer show they are closely tied to particular territories, rarely venturing beyond a range of a few hundred hectares or greater than $8 \mathrm{~km}$ distance (Schmidley 2004:277). Regionally, breeding season varies, with the season beginning in November on the Edwards Plateau, and as early as September along the southern Gulf Coast.

Since deer are found in localized areas, these areas would need time to replenish between episodes of hunting. The association of deer to particular areas would reinforce or encourage the establishment of territories of groups, especially since deer are the largest, available prey source available during the occupations at the Gatlin site. The quantities of identified white-tailed deer and related deer-sized faunal fragments from OZs 2-4 suggest deer were the primary large game for the hunters based at the Gatlin site.
Recovered within OZ2, eastern cottontail bones are the only identifiable small mammal remains. Found throughout archaeological sites in most of Texas, on the Edwards Plateau they settle along well drained streams and mixed grassland savannas (Schmidley 2004). Two species of mussel shell were identified from OZ1, OZ2, and OZ4. Tampico pearlymussel was found in OZ1, OZ2, and OZ4, and Threeridge was found in OZ2. The total amount of shell was very small, and none of the specimens had evidence of cultural modification such as heating or burning, suggesting they were not an appreciable source of food, and may be ecofacts at the Gatlin site. These two species, while not common in the Guadalupe River, were extirpated in recent times from the vicinity of the Gatlin site. As paleoenvironment indicators, they prefer well-watered channels, and their disappearance is related to the effects of reduced water flow and scouring floods. As indicators of flooding events, more specimens distributed in mounds or layers would be expected.

Limited fish remains were also found in the macrobotanical recovery and some fish lipid residue was noted in a feature from OZ2. Considering the close proximity of the river, it is not a surprise that the Gatlin site inhabitants utilized this game resource to supplement their diet.

\section{Technology}

Technology refers to the interaction between the inhabitants of the Gatlin site and the physical world. Technology incorporates behavior, knowledge, and objects that are replicated by a group through time (Schiffer and Skibo 1997).

The lithic technology of the Gatlin site is focused primarily around the use of stone as a medium for cutting, slicing, stabbing, scraping, chopping, and for the construction of heat retention facilities. Lithic technology includes both personal and portable items (e.g., projectile points) and site furniture-intended to be used at the site and left (e.g., large metates and some of the burned rock features). It is acknowledged that, without a doubt, this lithic assemblage represents but a part of the overall technological tool kit employed by the site inhabitants, as tools, structures, etc. would have been made of wood, plant, bone and other perishable materials. 
Nevertheless, the identification and exploration of variability or consistency within the lithic technology through time should allow insights into aspects of the inhabitants' behavior and cultural processes such as subsistence, group size, and social organization. One variation between occupation zone lithic assemblages is that of projectile point forms or styles. Style reflects both historical processes (Sackett 1982, 1986) and functional adaptation and cultural processes (Krieger 1944; Wiessner 1983). The lithic tool assemblage is a mixture of functional elements and style of varying degrees, with certain tools more likely to reflect or contain stylistic elements.

At the Gatlin site, certain tool types and forms persist through the occupation zones almost unchanged. The primary, significant change in tool form and style happens within the projectile point assemblage, which becomes increasingly diverse through time. However, when all of the tool classes are examined between occupation zones, there is a remarkable continuity in composition between occupation zone lithic assemblages with some minor differences.

Table 12.1 summarizes the lithic tool assemblage from each of the occupation zones. Throughout the assemblage and in all of the occupation zones, there are few completed formal tools, excluding projectile points, and these are from only a few tool classes (scraper, gouge, manos, etc.). The lack of diversity in tool forms also suggests that activities that required specialized implements were not major activities at the Gatlin site.

\section{OZ1 (CA. 6,600-6,060 в.P.)}

The oldest occupations recorded from the Gatlin site are from OZ1. The significant projectile point types are Early Archaic forms such as Early Barbed Devil's River Variant, Gower, and Martindale. Within OZ1 are two small burned rock features and two small clusters of burned material. Approximately $14.5 \mathrm{~m}^{3}$ of OZ1 deposits were excavated. OZ1 has the fewest artifacts and the least volume excavated of any of the occupation zones; however, the low artifact count is also the result of lower intensity site use. Overall, considering the major tool classes, OZ1 is the most different of the four zones by being the least diversified, although this may be a function of the smaller sample size.

Although there are only two cores in the OZ1 assemblage compared to 17 bifaces, OZ1 has the highest percentage of core reduction flakes, at 26.90 percent compared with a range of 16-19 percent from the later occupation zones. Core reduction likely served two purposes: producing flake blanks for expedient flake tools and blanks for small bifaces and/or points. This trajectory is supported by the presence of small late-stage bifaces made from flakes in the OZ1 assemblage.

The small size of the burned rock features, the low numbers of artifacts, and the lack of tool class diversity all suggest that the site was used by small groups for short periods and not as a large residential base camp. Biface reduction flakes are more numerous than core reduction flakes; thus, biface production appears to be the dominant lithic activity with emphasis on late-stage biface production in particular.

Table 12.1. Lithic Assemblages from Occupation Zones

\begin{tabular}{|c|c|c|c|c|c|c|c|c|c|c|c|c|c|c|}
\hline N & 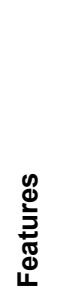 & 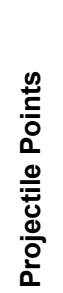 & 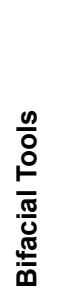 & 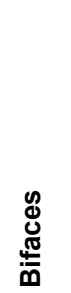 & 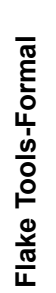 & 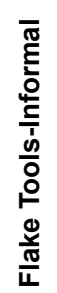 & $\stackrel{\mathscr{0}}{\stackrel{0}{0}}$ & 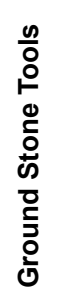 & 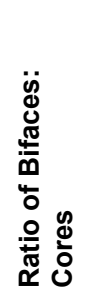 & 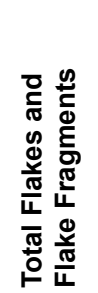 & 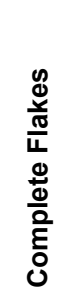 & 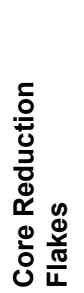 & 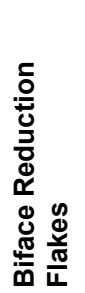 & 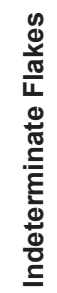 \\
\hline 1 & 4 & 6 & 2 & 17 & 1 & 8 & 2 & 1 & $9.5: 1$ & 692 & 116 & 86 & 188 & 45 \\
\hline 2 & 14 & 88 & 5 & 139 & 31 & 85 & 63 & 1 & $2.21: 1$ & 3382 & 1200 & 619 & 2307 & 454 \\
\hline 3 & 8 & 115 & 14 & 363 & 36 & 129 & 171 & 5 & 2.2 & 12,087 & 1356 & 846 & 2881 & 634 \\
\hline 4 & 10 & 144 & 8 & 445 & 7 & 76 & 75 & 2 & 4.77 & 4458 & 847 & 698 & 3191 & 552 \\
\hline
\end{tabular}


The remaining technology is suited toward small hunting parties or individuals. The OZ1 assemblage accumulated over a period of at least 600 radiocarbon years. This supports the hypothesis that the site was infrequently utilized but may have functioned as a task-oriented camp as part of a regular, seasonal, settlement pattern. The mixture of Early Barbed Devil's River Variant points (a south Texas type of point) with a Gower point (a primarily Central Texas point) suggests a high degree of mobility or wider territorial range during the Early Archaic.

\section{OZ2 (CA. 6,100-4,500 B.P.)}

OZ2 primarily contains artifacts from the late Early Archaic with some diagnostics from the beginning of the Middle Archaic. The lithic assemblage in OZ2 increases in size and diversity from OZ1, beyond what is expected from excavating a larger volume $\left(33.2 \mathrm{~m}^{3}\right)$ of deposits. The increases in diversity and quantity of artifacts, which extend to the feature assemblage, are interpreted as evidence for growing use of the Gatlin site, in intensity and possibly duration, and by larger groups. The dominant projectile points by estimated order of age beginning with the oldest are Gower; Martindale and variants, Bandy; and Early Triangular.

Within the OZ2 deposits is the transition from the earlier bifurcate stem base points such as Gower, Martindale, and Bandy to the unstemmed Early Triangular points. In their analysis in Appendix C, Hester and Shafer noted some technological similarities between some of the Martindale and Early Triangular points, particularly fine pressure flaking retouch along the lateral margins of several of the specimens. Both types of projectile points could be made from relatively small, thin flakes. Use-wear studies suggest they were used as projectiles or, just as frequently, as multi-functional tools (cutting, slicing, projectiles, etc.). Bandy points are stylistically similar to and diminutive of Martindale points, and as such, are closer in size to Early Triangular.

The perforators, drills, gouges and Clear Fork tools (1.21 percent of assemblage) indicate that a wider range of activities was conducted at the Gatlin site, although overall, formal specialized tools are a small percentage site wide (1.4 percent). These tools were used on a variety of materials such as hides and wood.
Flake tools compose over 28 percent of the tool assemblage of OZ2, the highest of any occupation zone, and include the most diversity in forms such as scrapers and gravers. Formal flake tools made from sequence flakes occur with the greatest frequency in OZ2. These formal flake tools are primarily associated with scraping activities, which likely includes hides. The increase in informal flake tools is further evidence of increasing on site activity.

Along with the increase in projectile point diversity, biface production and core reduction activities increase, resulting in same low biface to core ratio as $\mathrm{OZ3}$ at 2.21:1. Core reduction continues to provide blanks for flake tools and small bifaces and projectile points, although biface reduction was also a probable source for projectile points and larger bifaces. In biface and core reduction, most of initial reduction such as decortification occurred outside the excavated areas. The obvious source for the chert is the Guadalupe River channel, where high quality chert nodules are available within roughly $100 \mathrm{~m}$ of the Gatlin site. Tested and trimmed cores and bifaces were brought to the site for additional shaping and reduction.

In OZ2, small clusters of burned rock up to $1 \mathrm{~m}$ in diameter and larger clusters and scatters extending up to several square meters are present. The larger $(>1$ m) burned rock features (which includes the scatters), suggests longer term occupations, larger groups, and bulk processing and cooking of specialty foods.

Despite the intensifying utilization of the Gatlin site and the presence of several earth oven like features, ground stone tools remain scarce, with only a single metate fragment recovered. This is different from the Early Archaic Sleeper site (Johnson 1991) where baking pits and ground stone tools occurred together. Johnson (1991:146) hypothesized the milling activities associated with manos and many large, sandstone hearths/ovens involved sotol or yucca, grass seeds, or even acorns. Dating to the same time period, the differences in tool and feature relationships and functionality between the Sleeper and Gatlin sites suggests the processing of differing animal/plant resources.

Overall, the general technological organization suggests small groups infrequently visiting the site as part of a seasonal round or logistical, task-oriented 
network. Site activities, to name a few, included hunting, processing of game and plants, tool production, and the replenishment of systemic tool kits.

\section{OZ3 (CA. 4,500-3,850 B.P.)}

Materials recovered from OZ3 reflect the transition from the Early Archaic through the Middle Archaic periods of Central Texas. In OZ3, there is a bimodal distribution of Middle Archaic projectile point types with Early Triangular points as one mode and Nolan and La Jita points as the other. The Early Triangular type is the most numerous point and representative of the early Middle Archaic occupations, although a substantial number of Early Archaic Martindale points are in the OZ3 assemblage. The admixture of Martindale and Early Triangular points suggest some degree of landform stability and mixing of sediments. Nolan and La Jita points, as the other mode, represent the end of the Middle Archaic occupations and the return to stemmed projectile point forms. In fact, the La Jita point assemblage (including OZ3 and OZ4) is the largest ever reported from an excavated archaeological site.

Although there are variations in the frequencies of particular tool forms, the composition of the lithic assemblage is similar to OZ2, with diversity of tool types remaining almost the same. Almost half of all formal, specialized non-projectile tools from the Gatlin occupation zones are found in OZ3, and these tool forms are associated with both manufacturing activities such as scraping and adzing wood and possibly bone and antler, and with perforators used to pierce material such as hides.

The initial reduction of most of the cores and larger bifaces occurs off site, which is similar to OZ2. The overall biface reduction trajectory is almost the same as OZ2, although there is a slight increase in the percentage of early-stage bifaces. Formal core production also increases, although there was no corresponding large increase in flake tool production. The large increase in the number of cores can be accounted for, in part, by the low intensity reduction of many of the cores. Most of the cores have only a few flake scars after which the core was abandoned. With such low intensity reduction, more cores are needed to generate the volume of core reduction flakes. The length of flake tools increase from OZ2, which indicates that they were used less frequently or that larger flake blanks were selected.

The debitage assemblage from OZ3 is remarkably similar to OZ2, with one significant difference, the low percentage of complete flakes. Two factors that may explain this are taphonomic effects such as trampling (which fragments flakes) and changes in knapping technique. Thinner flakes from late-stage biface reduction are less robust, while core reduction can generate more incomplete flakes. Increased trampling reflected in the debitage further supports the pattern of surface stability at the site during occupations at this time.

Most of the Gatlin site ground stone tools are from OZ3 $(n=5)$, although it is still a very small number. The metate fragments likely represent small-scale grinding activities (seeds, acorns, etc.) by individuals, and not a long-term significant activity at the Gatlin site. The size range and types of the eight burned rock features are similar to OZ2, with small sub-meter sized features being the most common and also including several larger features that appear to be earth ovens or more substantial cooking features. The larger burned rock scatters are examples of disarticulated features on a stable surface.

Overall, the technological organization reflected in the OZ3 lithic assemblage is similar to OZ2, a moderate to high degree of mobility focused on hunting with slightly increasing usage of larger earth ovens and possibly bulk food processing. While still reflecting infrequent visits by relatively small groups of hunter-gatherers, OZ3 represents an increasing intensity of usage of the Gatlin site, given the narrower time range of the $\mathrm{OZ} 3$ deposits compared to OZ2.

\section{OZ4 (3,900-1,250 B.P.)}

The last defined occupation zone at the Gatlin site contains the greatest diversity of projectile points and the largest feature, the burned rock midden, Feature 1. The predominant projectile point types are La Jita, Nolan, and Pedernales. These types represent the end of the Middle Archaic and the start of the Late Archaic periods, with Pedernales points being one of the most numerous and far ranging types in Central Texas (Prewitt 1995). Within the assemblage, Hester and Shafer note different sub-groups in Nolan and La 
Jita projectile point types. These subgroups reflect the extent to which these points were resharpened and reworked and used for purposes other than as projectile points.

There are 20 previously recognized projectile point styles in the 144 projectile points from OZ4, and several of the types are clearly out of context, such as the Late Paleoindian Big Sandy point. Besides the increase in projectile points, the other notable changes in the lithic assemblage are the increases in bifaces and related biface production and precipitous declines in the quantities of cores and flake tools. The decrease in cores and increase in bifaces results in a sharp increase in the biface to core ratio to 4.77:1. The formal, specialized tool assemblage consists of several perforators, a drill, a gouge, and three butted bifaces. This is a similar assemblage composition to the bifacial tools from OZ3. Also, a number of large, thin Stage 5 bifaces considered to be specialized knives for butchering and skinning were recovered in OZ4.

The cores from OZ4 are for the most part minimally reduced with only a few flakes removed before they were discarded. This suggests that only larger flakes were selected, especially if they retained portions of cortex. It is also possible that the largest flakes were selected for biface production. In OZ4, core reduction flakes are the lowest percentage at 16 percent and biface flakes are the highest percentage at 72 percent (see Table 12.1). Overall, biface and projectile point production appear to be the focus of lithic activities during the occupations of OZ4.

The rise in the use of the midden had an inverse relationship on the size of other features observed in OZ4, as the use of large features declined, resulting in an increase in the ratio of small to large features compared to earlier occupations. The spacing of the smaller features indicates single-use hearths and cooking elements used by small groups around the midden, possibly for heat or cooking small food quantities. Interestingly, the formation of the midden (which many have suggested implies greater sedentism) occurs as the lithic assemblage indicates a greater use of biface and formal tools which are conversely thought to indicate greater group mobility. This contradiction is explored further below but it could be that midden acted as fixed appliance on the landscape, serving as an enhancement and prompting hunter-gatherers to return to the same location over long periods, using the space in the same manner to exploit seasonally available plant resources (Smith and McNees 1999).

\section{Stone Tool Categories Through Time}

As noted in the occupation zone summaries, the lithic assemblage from the Gatlin site shows a remarkable consistency through time, with regards to tool form, reduction trajectories, debitage, and functionality. Throughout the occupations, nearby chert sources, primarily from the Guadalupe River, were sampled, initially reduced, and brought onto the site. Following OZ1, the two significant trends are the increasing emphasis on bifaces and the growing diversity of projectile point styles through time. A few of these trends and patterns identified within certain tool categories are briefly explored here.

\section{Projectile Points}

There are 26 types or styles of projectile points noted in the Gatlin site artifact assemblage, and of the 409 projectile points 342 are typed. As a percentage of the occupation zone lithic assemblages, they account for 17.16 percent. What is apparent through time is that each occupation zone is dominated by a few projectile point styles and as time progresses, the number of styles or types proliferates while the relative contribution of any one type decreases. Projectile point types from each occupation zone are displayed in Figure 12.1. From this illustration the dominant projectile points are apparent. The results from OZ1, with 33 percent of the points being Early Barbed Devil's Variant, and 16 percent Gower points, are conditioned by the small sample size of six specimens; although it does show there are only a few types of projectile points from OZ1.

In OZ2, the dominant type is Martindale at 39 percent, followed by Gower at 24 percent, and equal percentages (11 percent) for untypable specimens and Early Triangular points. Both Gower points and Martindale points are further subdivided into subtypes, but these are more related to use-life and retain the basic form of the parent type. In OZ3, Early Triangular points are the dominant type at 33 percent and followed by untypable points at 12 percent and Martindale at 11 percent. Nolan points appear in the 
assemblage accounting for 10 percent in OZ3. Nolan and La Jita points are proposed as contemporary points. As percentages of each occupation zone assemblage total, Nolan is greater in OZ3, while La Jita is greater in OZ4. Part of this discrepancy may be from the concentration of Nolan points in Area $\mathrm{B}$, and the difficulty of clearly defining the ending of OZ3 and the beginning of OZ4.

By OZ4, there are 20 projectile point styles represented. The highest percentage types are La Jita at 16 percent, Pedernales at 15 percent, and Nolan at 10 percent. Early Triangular and Bulverde points each account for approximately 5 percent, with the Early Triangular points intrusive from mixing with lower deposits. The untyped category climbs to almost 25 percent of the assemblage, correlating with the rise in projectile point diversity. The age range of points from OZ4 shows the mix of Middle Archaic and Late Archaic points. If Nolan and La Jita points are contemporaneous, they represent more than 25 percent of the assemblage. If point types are used as a measure of site use and intensity of use, then Nolan and La Jita represent the earliest occupations within OZ4 and a substantial portion of the later occupations from OZ3.

\section{Specialized Tools}

Formal tools other than projectile points and knives are relatively rare throughout the Gatlin site artifact assemblage. The major bifacial form is projectile points, and, as the functional analysis confirmed, late-stage bifaces were used as knives. The types of formal, non-projectile tools recovered from the site are butted bifaces, Clear Fork tools, gouges, drills, and perforators. Although no separate category was used for knife like tools in the Stage 4 and Stage 5 biface assemblages, some of the specimens submitted for functional analysis showed evidence of hafting and use-wear. In addition, some of the categories of bifacial tools overlap or share morphological and presumably functional similarities.

There are 29 non-projectile, formal tools assigned to the occupation zones and these account for 1.41 percent of the total occupation zone assemblage. Overall, this appears to be a low number, given the frequency of bifaces recovered. From OZ1, the bifacial tools account for 10.5 percent of the total biface assemblage, and in OZ2 they are 3.47 percent, in OZ3 3.71 percent, and decreases to 1.77 percent in OZ4.

Although it is possible that finished formal tools were removed from the site, a lack of manufacturing failures of certain tool forms (Clear Forks, Guadalupe tools, etc.) suggests that the manufacture and use of these tools at the Gatlin site were not major activities. This also suggests that the site was not a long-term, residential base camp prior to OZ4 times, since larger quantities of these tools would be expected, as both discarded and exhausted specimens and as manufacturing failures (Andrefsky 1998; Odell 2004; Shott 1986).

\section{BIFACES}

Bifaces account for 46.86 percent of the lithic assemblage from all occupation zones. The biface assemblages for each occupation zone are summarized in Table 12.2. A cumulative percentage chart (Figure 12.2) shows the contribution of each reduction stage within each occupation zone. The assemblages were then compared to each other using Boone's measure of heterogeneity and Brainerd-Robinson (B-R) coefficient (Kintigh 2006). The coefficient can be used as a measure of similarity between occupation zone biface assemblages. The coefficient compares the percentage contribution of a tool form within one tool assemblage with another assemblage. The resulting coefficient is a value between 0 and 200 . The higher the coefficient, the more closely related the assemblages, with 200 being a perfect correlation. Using the biface stages by occupation zone for the analysis, a standardized B-R coefficient was generated by calculating the mean from each comparison for each occupation zone (Table 12.3).

The results show that the most even distribution of stages is in OZ2. The variation between OZ2, OZ3, and OZ4 appears to be slight. The analysis does

Table 12.2. Biface Reduction Stage Counts by Occupation Zone

\begin{tabular}{|l|c|c|c|c|c|c|}
\hline & Stage 1 & Stage 2 & Stage 3 & Stage 4 & Stage 5 & Total \\
\hline OZ1 & 1 & 1 & 3 & 2 & 8 & 15 \\
\hline $\mathbf{O Z 2}$ & 3 & 11 & 21 & 28 & 50 & 113 \\
\hline $\mathbf{O Z 3}$ & 13 & 35 & 59 & 55 & 132 & 294 \\
\hline $\mathbf{O Z 4}$ & 6 & 28 & 54 & 80 & 192 & 360 \\
\hline
\end{tabular}




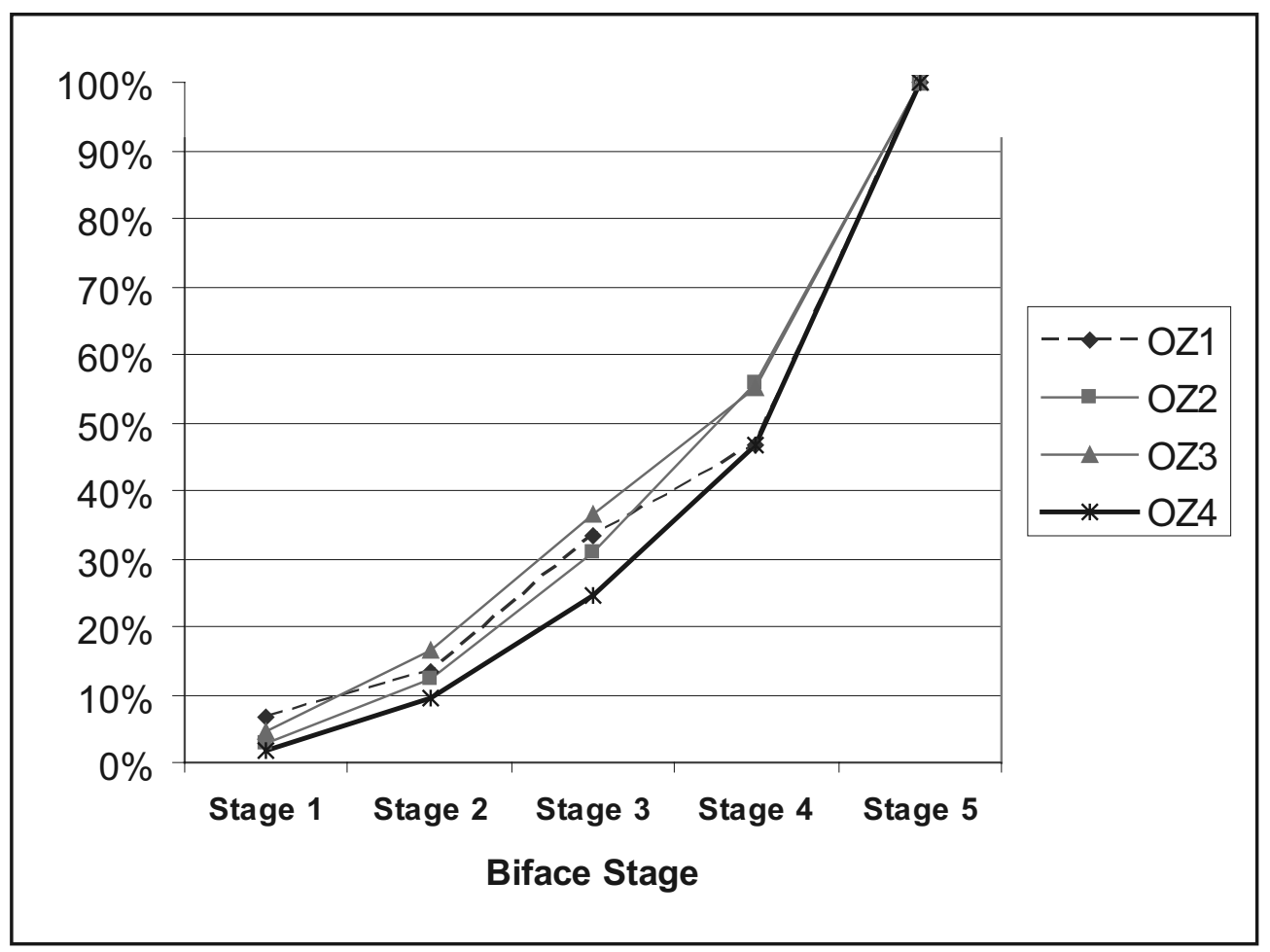

Figure 12.2. Percentage of cumulative frequency of biface stages by occupation zone.

suggest that OZ3 and OZ4 are the most alike assemblages, with the variation coming from a higher percentage of Stage 4 and 5 bifaces in OZ4. In OZ4, approximately 75 percent of the bifaces are Stage 4 or 5, with OZ2 the next highest at 69 percent and OZ1 at 68 percent. What is significant is the similarity in the composition of the biface assemblage through time.

An explanation for the lack of Stage 1 bifaces is that initial reduction occurs off site at the raw material source, although perhaps the classification criteria for identifying Stage 1 bifaces may also be responsible for fewer specimens. Bifaces are brought back to the Gatlin site in a Stage 2 or 3 level of reduction, and this is especially true when thin tabular cobbles are selected, since even minimally modified they already have a high width to thickness ratio. A plot of the mean length of complete bifaces by stage appears to show a trend of increasing mean lengths of biface stages through time, with OZ4 being the longest (Figure 12.3). However, when the length of each category is compared using an analysis of variance, the trend is less convincing and appears to be the result of the influence of a small number of larger bifaces on the means. An examination of complete Stage 5 bifaces, compared across occupation zones, found that the variation in the mean length was not significant according to an analysis of variance (ANOVA) where $\mathrm{F}=.831524, \mathrm{~d}=2,17, \mathrm{p}=.45233$. A comparison for each of the stages yielded similar results - that there was no overall significant difference in the average length of complete bifaces between the occupation zones.

Table 12.3. Summary Table of Boone's Measure of Assemblage Heterogeneity for Bifaces by Occupation Zone

\begin{tabular}{|l|r|r|r|r|r|r|r|r|r|}
\hline & \multicolumn{1}{|c|}{$\mathbf{n}$} & H & Hs & RMS(\%) & \multicolumn{1}{c|}{ BR } & \multicolumn{1}{c|}{ BRds } & G>obs & Arcsin $\sqrt{ } \mathbf{p}$ & RMS(Z) \\
\hline OZ1 & 15 & 0.051 & 10.08 & 4.67 & 178.6 & 0.107 & 0.879 & 7 & 1.534 \\
\hline OZ2 & 113 & 0.002 & 2.02 & 2.68 & 190.2 & 0.049 & 0.864 & 2.94 & 0.653 \\
\hline OZ3 & 294 & 0.008 & 3.97 & 2.66 & 187.3 & 0.063 & 0.182 & 3.6 & 0.96 \\
\hline OZ4 & 360 & 0.009 & 4.31 & 2.55 & 188.8 & 0.056 & 0.154 & 3.53 & 0.882 \\
\hline
\end{tabular}




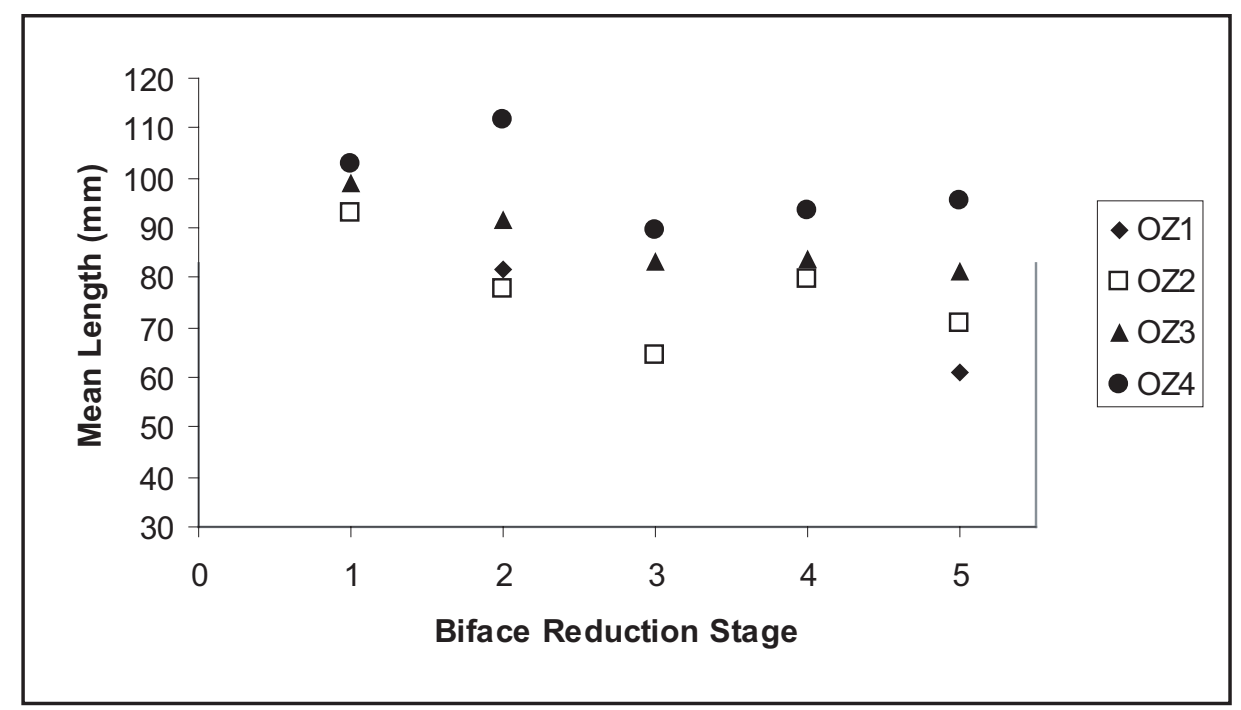

Figure 12.3. Mean length of biface stages by occupation zone.

For a given biface stage, there is little variation in average length of a complete specimen through time. This consistency is the probable result of several factors such as size constraints of the raw material and the limited size-range of the lithic tools, including projectile points, which could be manufactured from the late-stage bifaces.

\section{Formal Flake tools}

Formal flake tools account for 3.69 percent of the overall occupation zone lithic assemblage. The formal flake tool assemblage is highest in frequency in $\mathrm{OZ2}$ and OZ3. The diversity of scraper morphology is largely the product of edge retouch. The shape of a scraper may reflect part of its use life - the shape or form changes from episodes of resharpening and repair. The intensity of tool use is a measure of mobility (i.e., Blades 2003; Kuhn 1994).

The formal flake tool assemblage is shown in Table 12.4 as a count by occupation zone and as percentage of the assemblages. The two main types are end scrapers and side scrapers (which together account for 68 percent of the formal tool assemblage) followed by end/side scrapers (which account for 20 percent). There are several patterns in the scraper distribution by occupation zone. The highest frequency and diversity occurs in OZ3 followed by OZ2.

The preference for side scrapers in OZ2 suggests a change in scraper use, or a broadening of materials being worked such as plants. It is unclear how many of the scrapers were hafted; however, the larger size of the side scrapers makes them easier to hold. The

Table 12.4. Formal Flake Tool Counts and Percentages by Occupation Zone

\begin{tabular}{|c|c|c|c|c|c|}
\hline Flake Tool Category & OZ1 & OZ2 & OZ3 & OZ4 & Total \\
\hline End Scraper & (1) $1.33 \%$ & (14) $18.66 \%$ & (10) $13.33 \%$ & (2) $2.67 \%$ & (27) $36 \%$ \\
\hline Side Scraper & $0.00 \%$ & (5) $6.66 \%$ & (17) $22.67 \%$ & (2) $2.67 \%$ & (24) $32 \%$ \\
\hline End and Side Scraper & $0.00 \%$ & (9) $12 \%$ & (4) $5.33 \%$ & (2) $2.67 \%$ & (15) $20 \%$ \\
\hline Transverse Scraper & $0.00 \%$ & $0.00 \%$ & (2) $2.67 \%$ & $0.00 \%$ & (2) $2.67 \%$ \\
\hline Full-sided Scraper & $0.00 \%$ & (1) $1.33 \%$ & $0.00 \%$ & $0.00 \%$ & (1) $1.33 \%$ \\
\hline Convergent Scraper & $0.00 \%$ & $0.00 \%$ & (1) $1.33 \%$ & $0.00 \%$ & (1) $1.33 \%$ \\
\hline Indeterminate & $0.00 \%$ & $0.00 \%$ & (1) $1.33 \%$ & $0.00 \%$ & (1) $1.33 \%$ \\
\hline Graver & $0.00 \%$ & (2) $2.67 \%$ & (1) $1.33 \%$ & (1) $1.33 \%$ & (4) $5.33 \%$ \\
\hline Total & (1) $1.33 \%$ & (31) $41.33 \%$ & (36) $48 \%$ & (7) $9.33 \%$ & (75) $100 \%$ \\
\hline
\end{tabular}


side scrapers are also more variable in shape than the end scrapers, and therefore less standardized for hafting.

Specialty tools such as denticulates and thick, steepsided flake tools are noted at other Early Archaic sites in Central Texas (Collins et al. 1998; Johnson 1991; Schroeder 2002) but are uncommon at the Gatlin site. The abrupt decline of formal flake tools in the OZ4 assemblage suggests that the function of these tools was fulfilled using other forms, and/or that site use, subsistence practices, and tasks at the Gatlin site changed.

\section{Cores}

Cores comprise 15.96 percent of the lithic assemblage identified to occupation zones at the Gatlin site. A comparison of non-exhausted cores to exhausted cores shows a trend through time, with the ratio increasing from 0.969:1 in OZ2, when exhausted cores outnumbered non-exhausted cores, to 1.28:1 in OZ3, to 1.5:1 in OZ4 (Table 12.5). This suggests that through time, the site occupants became more liberal with their use of raw materials and cores were reduced less intensively, often discarded with remaining utility.

Cortex is found on almost all of the cores, and riverine cobble is the highest sourced parent material at 53 percent, while the next identifiable sourced material is upland lag gravels at 4.3 percent. Unidentified sources account for 39 percent of the core assemblage and we would guess that much of these are from river gravels. Overall, the high quality cherts found in the nearby river gravel bars and terraces were heavily utilized by the Gatlin site occupants. There is no substantial change in raw source locale through time, although there is a minor decrease of upland lag gravels from OZ3 to OZ4, where no such gravels were identified.
Excluding the two cores from OZ1, the core assemblages from the remaining occupation zones were compared. The composition of each assemblage was compared with the other occupation zones using a Brainerd-Robinson coefficient (Table 12.6). What is noticeable about the core assemblage is that there is a high degree of similarity between the occupation zone assemblages, since most of the cores are split between two categories, multidirectional and bifacial. These account for almost 62 percent and 20 percent, respectively, of the overall core assemblage.

\section{Debitage}

As with bifaces and cores, there is a striking similarity in the lithic debitage assemblages between occupation zones. The composition of the flake assemblage between biface thinning flakes, core reduction flakes and indeterminate varies only slightly. In OZ3, there is a slight increase in core reduction flakes, supporting the higher frequency of cores from the zone, and an increase in biface thinning flakes in OZ4 with a drop in core reduction and indeterminate flakes (Table 12.7). This also supports the increased biface and projectile point assemblage and the decreased core and flake tool assemblages in OZ4.

\section{Ground STONE USE}

While the major tool category is chipped stone tools, there is a small assemblage of ground stone tools. There are nine specimens assigned to an occupation zone, with each occupation zone having at least one specimen. Only those specimens assigned to an occupation zone are included in the analysis. The ground stone tools account for only 0.44 percent of the occupation zone lithic assemblage. The assemblage consists of a manuport from OZ1 that may have been used as an abrader, a metate fragment in OZ2, a hammerstone and four mano fragments in $\mathrm{OZ3}$, and two mano fragments in OZ4.

Table 12.5. Ratio of Unexhausted and Exhausted Cores

\begin{tabular}{|l|c|c|c|c|c|}
\hline \multicolumn{1}{|c|}{ Condition } & OZ1 & OZ2 & OZ3 & OZ4 & Totals \\
\hline Un-exhausted & & 31 & 96 & 57 & 184 \\
\hline Exhausted & 2 & 32 & 75 & 38 & 147 \\
\hline Ratio of Unexhausted:Exhausted & $\mathrm{n} / \mathrm{a}$ & $0.969: 1$ & $1.28: 1$ & $1.5: 1$ & 1.25 \\
\hline $\begin{array}{l}\text { Numbers are from cores when exhaustion measure } \\
\text { was made }\end{array}$ & & & & & \\
\hline
\end{tabular}


Table 12.6. Summary of Boone's Measure of Assemblage Heterogeneity for Cores by Occupation Zone

\begin{tabular}{|l|r|r|r|r|r|r|r|r|r|}
\hline & $\mathbf{n}$ & Boone's H & Scaled H & RMS(\%) & \multicolumn{1}{c|}{ BR } & \multicolumn{1}{c|}{ BRds } & \multicolumn{1}{c|}{ Prob } & $\begin{array}{c}\text { RMS } \\
\text { (Arc sin } \sqrt{ })\end{array}$ & \begin{tabular}{c} 
RMS(Z) \\
\hline OZ1
\end{tabular} \\
\hline OZ2 & 2 & 20.857 & 34.99 & 16.54 & 124.5 & 0.378 & 0.98 & 34.509 & 1.723 \\
\hline OZ3 & 171 & 0.124 & 13.32 & 2.29 & 187.9 & 0.061 & 0.157 & 9.314 & 1.106 \\
\hline OZ4 & 95 & 0.031 & 6.7 & 1.45 & 192.3 & 0.039 & 0.619 & 3.567 & 0.349 \\
\hline
\end{tabular}

Table 12.7. Counts and Percentage of Debitage by Flake Type

\begin{tabular}{|l|c|c|c|c|}
\hline $\begin{array}{c}\text { Occupation } \\
\text { Zone }\end{array}$ & $\begin{array}{c}\text { Core } \\
\text { Reduction Flakes }\end{array}$ & $\begin{array}{c}\text { Biface } \\
\text { Reduction Flakes }\end{array}$ & $\begin{array}{c}\text { Indeterminate } \\
\text { Flakes }\end{array}$ & Total \\
\hline OZ1 & $86(29.96 \%)$ & $188(58.93 \%)$ & $45(14.11 \%)$ & 319 \\
\hline OZ2 & $619(18.3 \%)$ & $2307(68.2 \%)$ & $454(13.42 \%)$ & 3382 \\
\hline OZ3 & $846(19.4 \%)$ & $2881(66.1 \%)$ & $634(14.5 \%)$ & 4361 \\
\hline OZ4 & $698(15.7 \%)$ & $3191(71.83 \%)$ & $552(12.42 \%)$ & 4442 \\
\hline
\end{tabular}

multifunctional, used as both projectiles and knives, while others functioned solely as projectiles. For instance, of the 14 Gower points analyzed, five were used as both projectile points and as butchering knives, seven were used as projectile points only, and one was used as a drill and another as a knife on hard material.

The six Bandy points are all projectile

The mano assemblage has both complete and fragmentary specimens, implying that they were used and discarded at the Gatlin site. The discarded specimens were unlikely to have been brought to the site in their current state only to be discarded. The presence of manos in burials at Loma Sandia (Taylor and Highley 1995) suggests they had symbolic significance and were likely associated with females. The manos are found in OZ3 and OZ4, suggesting a Middle Archaic to Late Archaic affiliation, which correlates to the time period of Loma Sandia (41LK28).

\section{FunCtional ANALYSIS OF THE LITHIC ASSEMBLAGE}

The use-wear analysis investigated the possible range of activities performed with stone tools at the Gatlin site with a goal of inferring function. Use-wear analysis records the end-life usage of a tool. From the small sample of 126 artifacts, several general assumptions can be made regarding tool form and tool use, and therefore, the frequency and intensity of certain activities can be gauged through time. What is clear is that hunting and associated tasks of butchering, skinning, and processing were the primary activities performed with most stone tools at the Gatlin site through the thousands of years spanning the occupation zones.

Most of the specimens analyzed for use-wear are projectile points, and the results indicate some were points and four were also used as butchering tools. The Martindale points are also multifunctional, with almost half of the 21 points analyzed used as projectile points. The remainder were used as combination tools for slicing, cutting, and prying. Twenty-two Early Triangular points were analyzed for use-wear; 16 had been used as projectile points and knives or scrapers. Six specimens, while probably hafted, had been used exclusively as knives and scrapers and not as projectile points.

There are four scrapers in the analysis, two from OZ2 and two from OZ3. One scraped a moderately resistant material such as bone or wood, another is a butchering knife and hide scraper, and the remaining two are hide scrapers. Although this is a small sample size, the results suggest that formal flake tool scrapers are associated with hide scraping and by association, hunting big game such as deer and bison.

A summary of positive results from the functional analysis of the more-specialized bifacial tools is shown in Table 12.8. Drills are used in a rotary fashion on moderately hard materials such as wood, antler, or bone, while perforators are used on softer materials in a twisting, piercing action, presumably on hide. It is interesting to note that none of the drills have reddening or other evidence of heat or burning at the bit. Reddening or evidence of excessive heat at the distal end can occur when drilling through 
Table 12.8. Summary of Bifacial Tool Functional Analysis

\begin{tabular}{|c|c|c|c|c|c|c|c|c|c|c|c|c|c|c|c|c|}
\hline & & & \multicolumn{7}{|c|}{ Action } & \multicolumn{5}{|c|}{ Target Material } & \multicolumn{2}{|c|}{$\begin{array}{c}\text { Maintenance/ } \\
\text { Design }\end{array}$} \\
\hline & Lot No. & Biface Category & 至 & $\frac{\text { D }}{\frac{D}{0}}$ & $\frac{\text { D }}{\stackrel{N}{N}}$ & $\frac{\text { D }}{\frac{D}{\frac{\pi}{\pi}}}$ & की & 兽 & $\begin{array}{l}\frac{O}{0} \\
\frac{0}{0} \\
\frac{0}{\alpha}\end{array}$ & $\frac{0}{\frac{0}{1}}$ & $\begin{array}{l}\stackrel{0}{0} \\
\stackrel{0}{0}\end{array}$ & 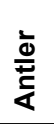 & $\begin{array}{l}\text { 잉 } \\
\stackrel{2}{3}\end{array}$ & $\frac{\overrightarrow{\frac{\pi}{\sigma}}}{\frac{\pi}{\alpha}}$ & $\begin{array}{l}\frac{5}{\Phi} \\
\frac{0}{\pi} \\
\frac{0}{\pi}\end{array}$ & 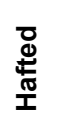 \\
\hline \multirow{5}{*}{ OZ2 } & 199 & Drill & & & & & & $?$ & & & & & & & & $?$ \\
\hline & 462 & Drill & & & & & & & $x$ & $x$ & & & & & $x$ & \\
\hline & 871 & Drill & & & & & & & & & & & & & & \\
\hline & 512.1 & Clear Fork Tool & & & $x$ & $\mathrm{X}$ & & & & & & & $x$ & & $x$ & \\
\hline & 925 & Clear Fork Tool & & & $x$ & $x$ & & & & & & & $x$ & & $x$ & $?$ \\
\hline \multirow{7}{*}{$\mathrm{OZ3}$} & 42.2 & Butted Biface & & & & & & & & & & & & & & \\
\hline & 81.1 & Drill & & & & & & $x$ & & & $x$ & & $x$ & & $x$ & $x$ \\
\hline & 268 & Clear Fork Tool & & & $x$ & & & & & & & & & & $x$ & \\
\hline & 478 & Clear Fork Tool & & & $x$ & $x$ & & & & & $?$ & $?$ & $?$ & & $x$ & $\mathrm{X}$ \\
\hline & 387 & Gouge & & & $x$ & $x$ & & & & & & & $x$ & & $x$ & $\mathrm{X}$ \\
\hline & 455.2 & Gouge & & & & $x$ & & & & & & & $x$ & & $x$ & $?$ \\
\hline & 718.4 & Butted Biface & $x$ & & & & & & & & & & & & & \\
\hline \multirow{5}{*}{$\mathrm{OZ4}$} & 143.1 & Perforator & $x$ & & & & & & $x$ & $x$ & & & & & & \\
\hline & 1209 & Perforator & & & & & & & $x$ & $x$ & & & & & $x$ & \\
\hline & 1363 & Perforator & & & & & & & $x$ & $\mathrm{X}$ & & & & & & \\
\hline & 1303 & Gouge & & & $\mathrm{x}$ & $x$ & & & & & & & $x$ & & $x$ & $\mathrm{X}$ \\
\hline & 56.1 & Butted Biface & & & & & $x$ & & & & & & & $x$ & & \\
\hline
\end{tabular}

wood, especially when the wood has been heated or charred to make woodworking easier.

All of the gouges and Clear Fork tools examined are resharpened, which removed portions of the working edge and traces of use-wear. They were likely used for a variety of tasks, from adzing and planning of hard materials to scraping and even cutting. The presence of both butted bifaces and gouges and Clear Fork tools together suggests that they were complimentary tools, with butted bifaces used for heavier chopping and cutting and gouges and Clear Fork tools used for finer shaping and finishing.

The 12 bifaces selected for use-wear study are late stage, well-thinned bifaces. Table 12.9 shows the bifaces according to occupation zone and to inferred functional use classification. Ten of the specimens are evenly split between being used as knives for cutting soft material such as flesh during butchering or harder material such as bone, wood or antler. The remaining two specimens were used as a hide scraper and as a burin/plane.
Overall, the functional analyses of the lithic assemblage demonstrate that most of the stone tools are associated with hunting tasks, from projectiles to butchering tools to plant/animal processing. While the sample of tools examined was not large, there does not appear to be any significant change in functional use between the occupation zones through time, as a similar range of daily activities were practiced at the Gatlin site.

\section{Lithic Assemblages Through Time- IMPLICATIONS FOR TECHNOLOGICAL ORGANIZATION}

According to conventional views of the Early to Middle Archaic adaptive patterns, changes in technological organization should be evident in the Gatlin site lithic assemblages through time. Notably, similar to Andrefsky's (1998) analysis of Parry and Kelly's (1987) data, there should be a decrease in biface production and an increase in expedient technology through the Archaic. If, as commonly thought, the 
Table 12.9. Summary of Functional Analysis of Thin Bifaces

\begin{tabular}{|c|c|c|c|c|c|}
\hline $\begin{array}{c}\text { Occupation } \\
\text { Zone }\end{array}$ & $\begin{array}{c}\text { Lot } \\
\text { Number }\end{array}$ & $\begin{array}{c}\text { Cutting } \\
\text { Soft material } \\
\text { Butchering }\end{array}$ & $\begin{array}{c}\text { Cutting } \\
\text { moderately hard } \\
\text { material }\end{array}$ & $\begin{array}{c}\text { Hide } \\
\text { Scraping }\end{array}$ & $\begin{array}{l}\text { Plane, } \\
\text { Burin }\end{array}$ \\
\hline \multirow[b]{2}{*}{$\mathrm{OZ2}$} & 849 & & & $x$ & \\
\hline & 975 & & $x$ & & \\
\hline \multirow[b]{4}{*}{ OZ3 } & 410 & $X$ & & & \\
\hline & 559 & $x$ & & & \\
\hline & 742 & & $x$ & & \\
\hline & 1144 & $x$ & & & \\
\hline \multirow[b]{5}{*}{ OZ4 } & 6 & $x$ & & & \\
\hline & 1341 & & $x$ & & \\
\hline & 1350 & & $x$ & & \\
\hline & 1443 & $x$ & & & \\
\hline & 1468 & & & & $x$ \\
\hline
\end{tabular}

Using Tools for Quantitative Analysis (TFQA) (Kintigh 2006), the assemblage categories by occupation zone are compared using Boone's H, which is designed to look at the distribution of the various tool categories and clarify differences among the various zones (Table 12.11). Based on the analyses, the OZ3 assemblage is the most heterogenous of the zones, meaning the various tool categories consistently contribute to the overall assemblage. Conversely, the least heterogenous is OZ1, which indicates a few categories are much more dominant than others, while OZ2 and OZ4 show similar scores between the extremes. The implication for OZ1 is that it is the most homogenous of the assemblages, and that a few categories are dominant in the assemblage. Both OZ2 and OZ4 deviate from OZ3 by approximately the same margin, although for different reasons - OZ2 has a greater proportion of projectile points to bifaces, while OZ4 differs most by having fewer flake tools and cores.

The Brainerd-Robinson Coefficient, which is designed to compare the degree of similarity among assemblages, shows that there is a slight, but measurable difference between the occupation zones. The overall assemblage at the Gatlin site is most closely approximated by OZ3, and OZ2 is the least similar assemblage, followed closely by OZ4. OZ1 contains too few artifacts to be an accurate result $(\mathrm{P}=.185)$. Although the occupation zones show a degree of variation, it should be noted that OZ2, OZ3, and OZ4 are similar overall according to the assessment. The OZ3 assemblage, as the representative assemblage, demonstrates there is a strong technological continuity from the Middle to Late Archaic in the ways the site was used. The assemblage from OZ3 is the most heterogeneous of the occupation zones and distinctive compared to the other zones. This suggests that specific activities from OZ2, namely hunting-related activities and biface production and core reduction continued in $\mathrm{OZ3}$, and that trends from $\mathrm{OZ} 3$ such as biface production were continued through OZ4.

time, or the lack thereof. In addition, these statistical measures allow comparisons to be made to other sites and assemblages by using the same analytical tool categories. 


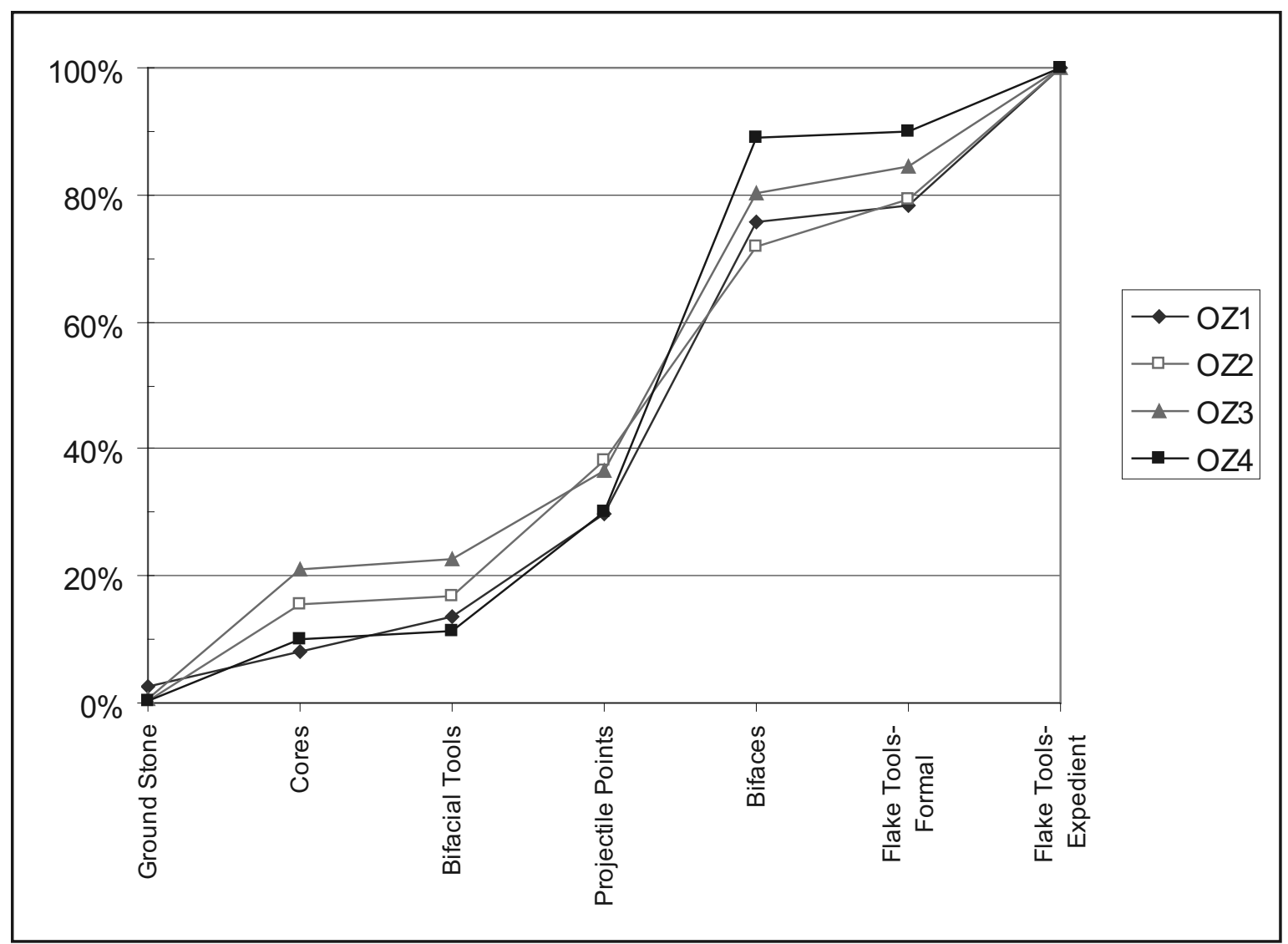

Figure 12.4. Cumulative frequency of tool categories within occupation zone.

Boone's scaled $\mathrm{H}$ value, which is used to pinpoint the actual differences among the assemblages and is standardized to weigh variables equally, can indicate more specialization or dominance of a particular tool type or types by occupation zone assemblage (see Table 12.11). OZ3 has the most even distribution of tool classes, and variation in the remaining assemblage can be compared with the OZ3 assemblage. Variation in OZ1 is from the high numbers of bifaces and few cores and formal flake tools, while in OZ2, there are higher proportions of projectile points and expedient flake tools, and a decrease in the proportion of bifaces. In OZ4, the specialization is the high numbers of projectile points and bifaces and a decrease in flake tools and cores.

\section{Technology Ratios}

The similarities and differences in the occupation zone assemblages and their implications for the organization of technology were explored further using a series of artifact ratios. Ratios among tool classes are used as a measure of technological organization, and contribute to considerations of mobility and settlement patterns. The ratios of three different aspects of technology, including bifaces to cores, curated to non-curated tools, and formal to informal tools, are defined for each occupation zone (Table 12.12). The ratios and their implications have been previously

Table 12.10. Cumulative Frequency of Tool Categories within Occupation Zones

\begin{tabular}{|l|r|r|r|r|}
\hline \multicolumn{1}{|c|}{ Tool Category } & \multicolumn{1}{c|}{ OZ1 } & \multicolumn{1}{c|}{ OZ2 } & \multicolumn{1}{c|}{ OZ3 } & \multicolumn{1}{c|}{ OZ4 } \\
\hline Ground Stone & $2.70 \%$ & $0.24 \%$ & $0.60 \%$ & $0.26 \%$ \\
\hline Cores & $8.11 \%$ & $15.53 \%$ & $21.13 \%$ & $10.17 \%$ \\
\hline Bifacial Tools & $13.51 \%$ & $16.75 \%$ & $22.81 \%$ & $11.23 \%$ \\
\hline Projectile Points & $29.73 \%$ & $38.11 \%$ & $36.61 \%$ & $30.25 \%$ \\
\hline Bifaces & $75.68 \%$ & $71.84 \%$ & $80.19 \%$ & $89.04 \%$ \\
\hline Flake Tools-Formal & $78.38 \%$ & $79.37 \%$ & $84.51 \%$ & $89.96 \%$ \\
\hline Flake Tools-Expedient & $100.00 \%$ & $100.00 \%$ & $100.00 \%$ & $100.00 \%$ \\
\hline
\end{tabular}


Table 12.11. Summary of Boone's Measure for Heterogeneity for Lithic Assemblage Summaries from Occupation Zones

\begin{tabular}{|l|r|r|r|r|r|r|r|r|r|}
\hline & \multicolumn{1}{|c|}{$\mathbf{n}$} & Boone's H & Scaled H & RMS(\%) & \multicolumn{1}{c|}{ BR } & \multicolumn{1}{c|}{ BRds } & Prob & $\begin{array}{c}\text { RMS } \\
\text { (Arc sin } \sqrt{ } \text { ) }\end{array}$ & RMS(Z) \\
\hline OZ1 & 37 & 0.131 & 13.67 & 5.19 & 173.2 & 0.134 & 0.181 & 9.599 & 1.525 \\
\hline OZ2 & 412 & 0.026 & 6.07 & 5.89 & 171.5 & 0.143 & 0 & 7.092 & 1.136 \\
\hline OZ3 & 833 & 0.004 & 2.34 & 2.48 & 186.8 & 0.066 & 0.003 & 3.225 & 0.587 \\
\hline OZ4 & 777 & 0.022 & 5.6 & 4.72 & 176.3 & 0.118 & 0 & 6.495 & 0.814 \\
\hline
\end{tabular}

Table 12.12. Lithic Technology Ratios by Occupation Zone

\begin{tabular}{|l|r|r|r|}
\hline & Biface:Cores & Curated:Non-curated & Formal:Informal \\
\hline OZ1 & $9.5: 1$ & $2.6: 1$ & $2.8: 1$ \\
\hline OZ2 & $2.21: 1$ & $2.2: 1$ & 2.25 \\
\hline OZ3 & $2.2: 1$ & $2.42: 1$ & $2.43: 1$ \\
\hline OZ4 & $4.77: 1$ & $7.61: 1$ & $4.77: 1$ \\
\hline
\end{tabular}

low ratio values suggest that the occupations contained in OZ2 are the least mobile of the site inhabitants, followed by OZ3. However, the overall range of activities and the diversity in the tool assemblage is limited, which would be the expected patterns of a shortterm campsite. The high ratios of non-curated tools and informal tools reflect the growing use of cores and flake tools. The inferred decreased mobility may reflect a more specialized type of movement, such as short-distance, short-term moves to the Gatlin site from a nearby residential site (Andrefsky 1998; Kelly 1992; Shott 1986). Alternately, the visits to the Gatlin site may have required longer stays, during which a limited range of specific activities were practiced that did not need a wide variety of tool types, and the emphasis remained on hunting, processing game, and lithic procurement, with episodic bulk plant cooking and processing. outnumber cores by almost 10:1. The emphasis was on creating formal tool forms, most likely projectile points and knives, given the lack of other tool forms in OZ1. While the inference is that during OZ1 visits were of short duration, the OZ4 artifacts suggest a different pattern, as discussed below.

All three ratios approach parity in OZ2, with all ratios at their lowest level, indicating a comparatively high proportion of cores, non-curated items, and informal tools. Occupational intensity and duration at the site increased during this time, resulting in a greater range of activities centered on projectile points and hunting that utilized both formal and informal flake tools. The

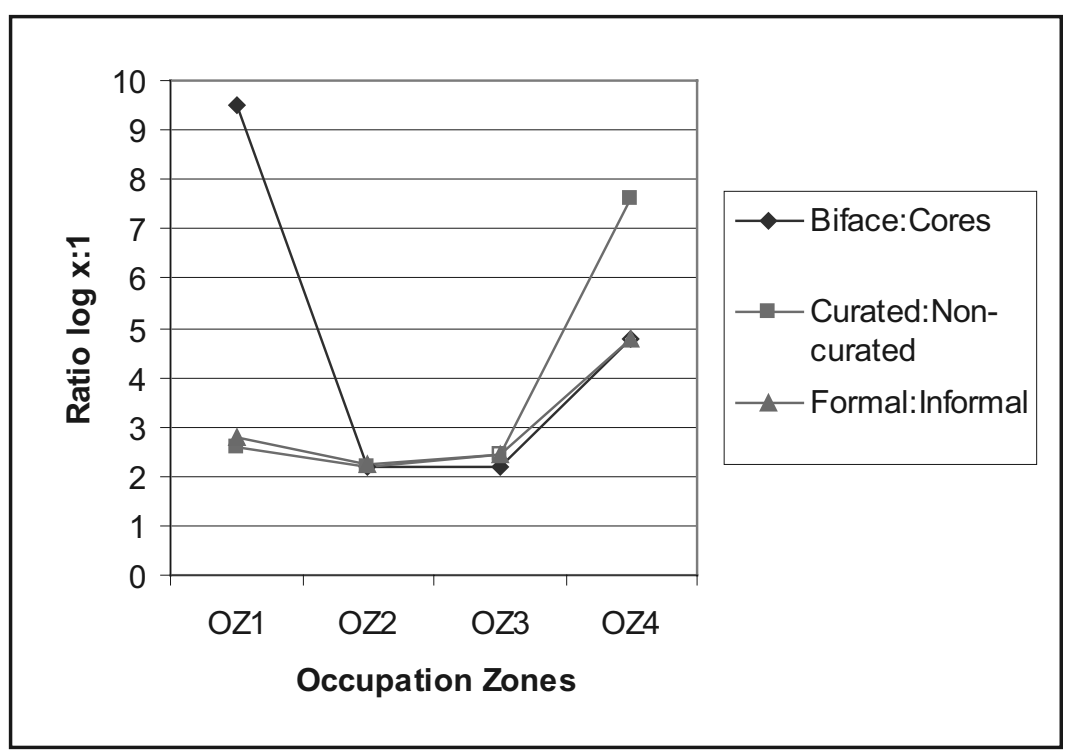

Figure 12.5. Three lithic technology ratios by occupation zone. 
OZ3 is the most heterogeneous assemblage at the Gatlin site against which the other assemblages are compared. Variation between OZ2 and OZ3 in technology ratios is less than between any other assemblages. The analyses of the assemblage by heterogeneity and B-R coefficient suggest that OZ3 and OZ4 are more similar (OZ1 scores for heterogeneity and B-R coefficient is negatively influenced by the small sample size). The apparent discrepancy between the association of OZ2/OZ3 and OZ3/OZ4 (technology ratios) may be accounted for by the fact that tasks may be fulfilled by different combinations of artifacts classes.

These differences are evident in the ratios of lithic tools in OZ4, since they increase significantly from the previous zones. Immediately apparent is the rise in formal tools relative to cores and flake tools, which decrease. Additionally, bifaces and projectile points are more prominent in the occupation zone assemblage. These trends suggest a change in technological organization, namely an increase in formal tool use. The concurrent decrease in informal tools may be the result of shorter duration visits to the site, when camp activities centered on more specialized tasks that required fewer cores or flake tools, and the need for informal flake tools for cutting and slicing may have been reduced in part by the use of bifacial knives.

\section{SumMary}

The Gatlin site was used by small groups of hunter gatherers over a 6,000-year period. Though populations fluctuated over time, the site record indicates short-duration stays by small groups. Throughout the occupation zones, the major lithic tool categories are bifaces, projectile points, and cores. Although they vary in frequency, there is a remarkable consistency in the lithic technology-specifically in terms of bifacial reduction, core technology, and projectile point manufacture.

The attractions of the Gatlin site for the inhabitants appear to be abundant highquality chert resources and abundant large game. At various periods, plant resources were processed on a bulk scale. These occupations, however, are not accompanied by a rise in a domestic lithic assemblage such as multipurpose flake tools and greater diversity and numbers of bifacial tools as would be expected at extended stay base camps such as Wilson-Leonard (Collins et al. 1998).

The technology ratios, as shown in Figure 12.5, show the highest ratios of bifaces, curated, and formal tools in the oldest and the youngest zones, OZ1 and $\mathrm{OZ4}$, respectively. Conversely, the OZ2 and OZ3 assemblages, with greater ratios of cores, non-curated technology, and informal tools, reflect decreased mobility. However, this may reflect reduced long range mobility, while the Gatlin inhabitants remained highly mobile within a restricted area or territory. The decrease in biface technology through the Archaic as seen in other regions (Odell 1998, 2004) does not occur at the Gatlin site. In fact biface technology reaches its highest level in OZ4.

\section{BURNED Rock TEChNOLOGY at GATLIN}

\section{Size and Composition of the Burned Rock Features}

Most of the burned rock features in all occupation zones at the Gatlin site are small (less than $1 \mathrm{~m}$ in diameter) and are interpreted as small group or individual cooking and heating features. Figure 12.6 is

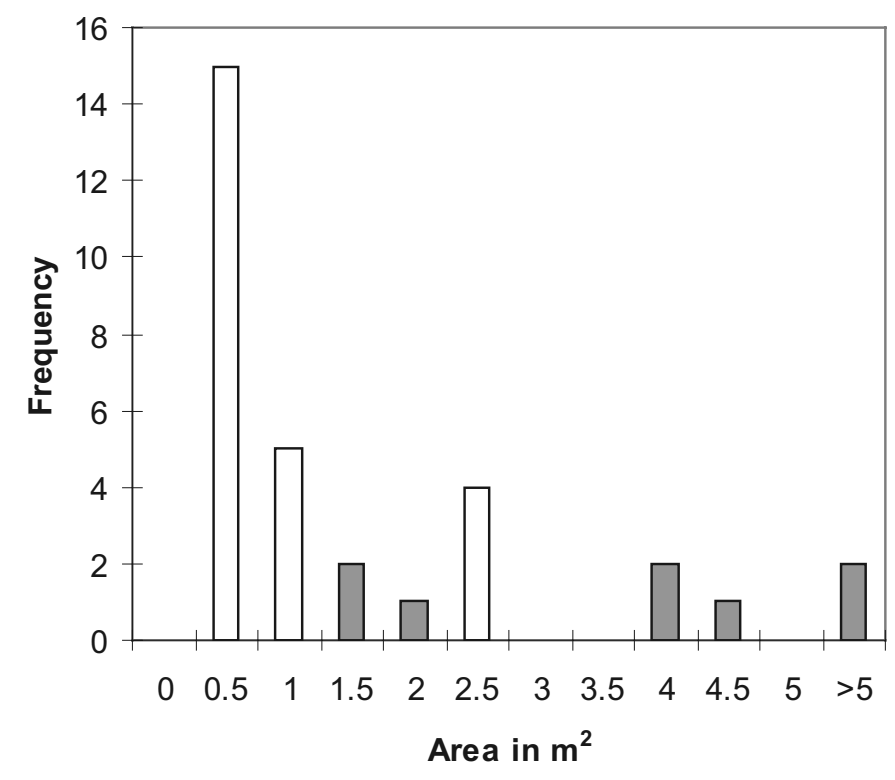

Figure 12.6. Histogram of burned rock feature sizes. 
a histogram of the frequency and size of the burned rock features (excluding Feature 1, the burned rock midden). The comparisons are made combining Feature 34 into a single feature size, while considering the two discrete parts of Feature 8 as separate features, therefore creating a total data set of 32 burned rock features. Twenty of the features are less than or equal to $1 \mathrm{~m}$ in area and 15 of these 20 are equal to, or less than, $0.5 \mathrm{~m}$ in area. The remaining features are in two main size ranges, with seven features greater than $1 \mathrm{~m}$ and less than $3 \mathrm{~m}$ in area and five features greater than was $3.5 \mathrm{~m}$ in area.

A scatter plot of area by occupation zone (Figure 12.7) shows the range or feature sizes, showing an evenly distributed range of sizes in OZ2 greater than 1-m diameter, while in OZ3 there is a bimodal cluster of large features and small sub-meter-sized features. By OZ4, there are fewer large features, and this decrease may be related to the use of Feature 1, which had a diameter of $16 \mathrm{~m}$. The burned rock midden may have been a focal point for repeatedly constructing larger burned rock ovens using the left over elements from previous cooking episodes. Several small features surrounding the midden likely represent heating hearths or facilities for cooking small quantities of food while the bulk resources baked, or they may represent entirely unrelated occupations. tion for many rocks since higher heat and repeated heating accelerates the fracturing of burned rock into increasingly smaller fragments. In addition, the frequency comparisons reveal a preference for rocks in the 5-10-cm size category for feature construction.

There is some variation in the composition of burned rock features between occupation zones. In OZ1, no burned rocks larger than $15 \mathrm{~cm}$ were used. Larger rocks are favored in OZ2 and in OZ3, and decrease in OZ4. OZ2 is the most equitable distribution of the larger rock size categories, with the fewest smaller rocks as a percentage of the burned rock assemblage weight.

The largest stone size category is noted in six of the sub-meter features, although these were usually a few specimens in each feature. Not surprisingly, the largest features contain the highest numbers and greatest weight of large stones, particularly from OZ2 (greater than $15 \mathrm{~cm}$ ). As a measure of feature use and intensity, the burned rock size and weight comparisons are inconclusive, but do show that OZ3 and OZ4 features contain more small rocks $(<5 \mathrm{~cm})$ than features from OZ2. The smaller size of the burned rocks may be the result of multiple uses of the same feature, or scavenging burned rock from a previous feature during repeated site occupations.

In Figure 12.8, the size class of burned rocks from feature contexts by occupation zone is compared.

Almost 50 percent of the burned rock recorded from features is from $5-10 \mathrm{~cm}$ in size. The bars show the percentage contribution by size class as a percentage contribution to the whole occupation zone assemblage. The smallest size class $(0-5$ $\mathrm{cm})$ is also a sizeable percentage of each occupation zone; however, when compared to the size contribution by weight, the smallest size contributes less than 10 percent of the overall burned rock weight. The greatest weight contribution is from the 5-10-cm size category (Figure 12.9). The differences in the burned rock sizes and weights reflect patterns of usage, discard, and reuse of heating elements (the rock) in cooking/heating facilities. The high frequency of small-sized rock suggests repeated use and high fragmenta-

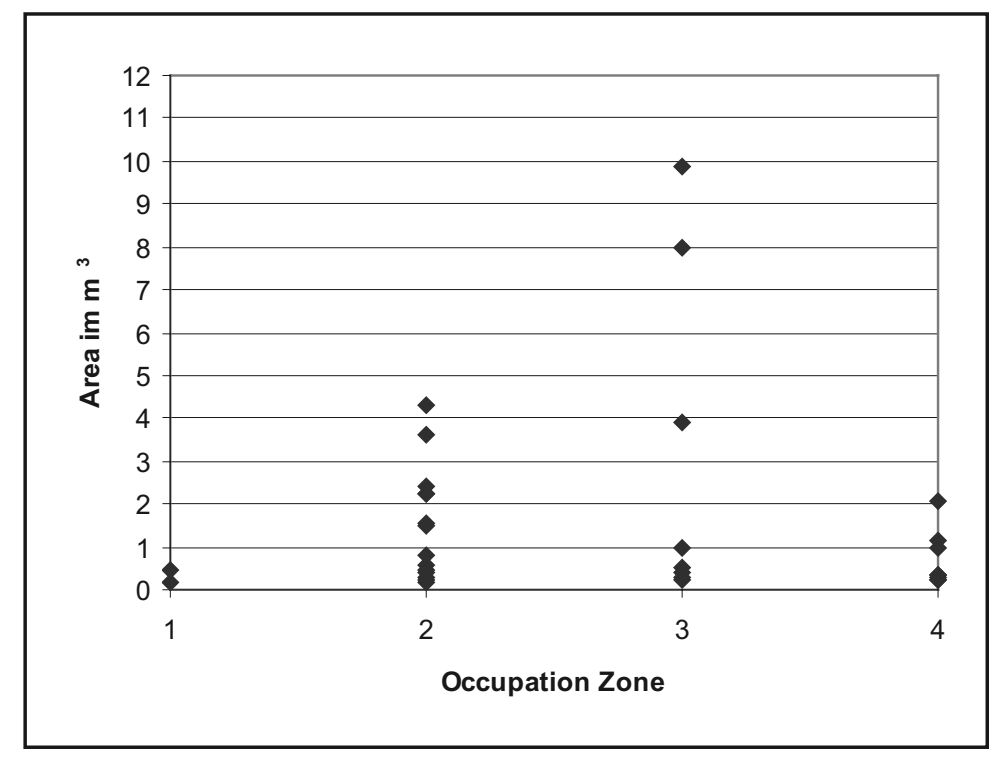

Figure 12.7. Distribution of burned rock feature sizes by occupation zone. 


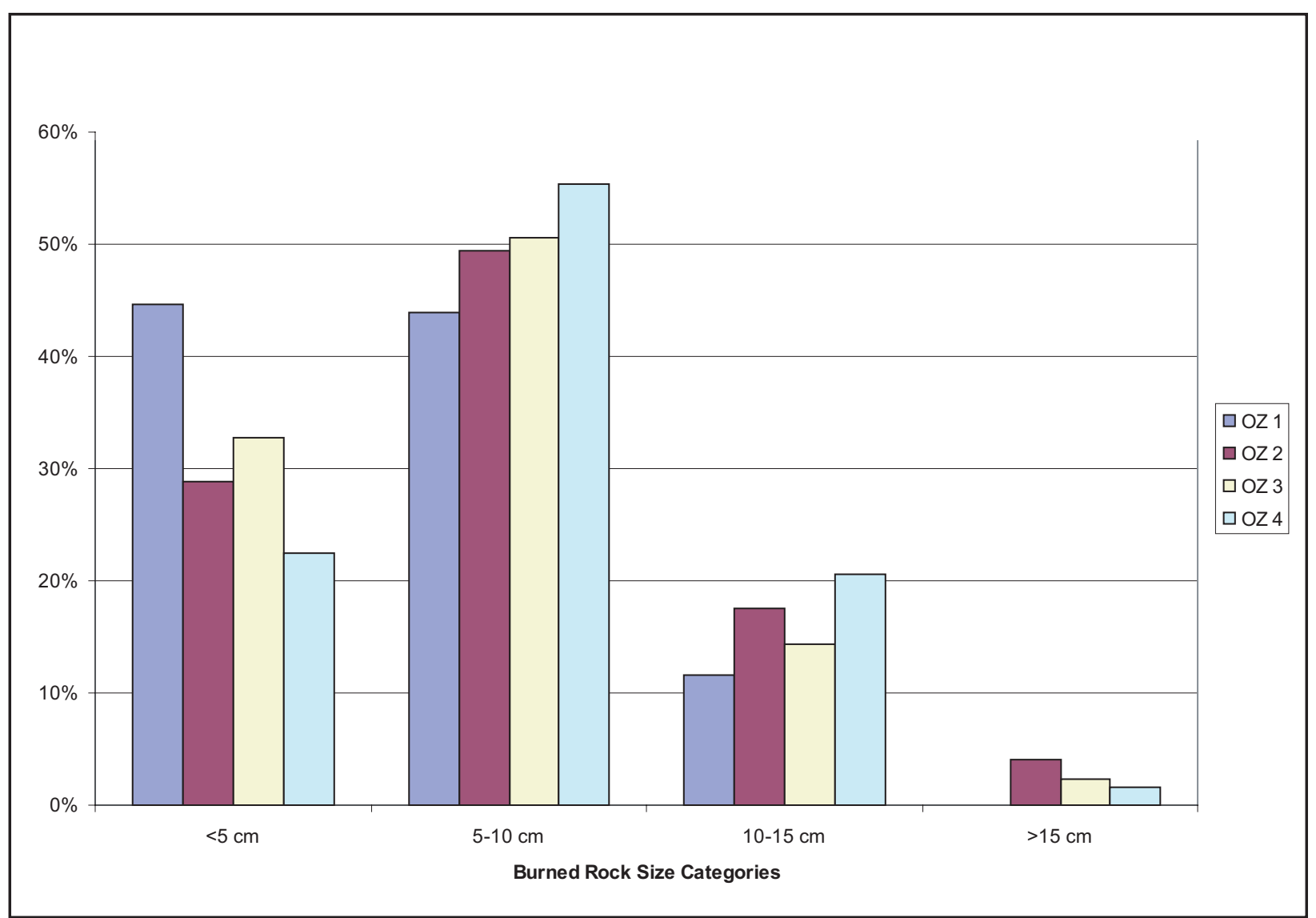

Figure 12.8. Burned rock size categories percentage quantities by occupation zone.

\section{Burned Rock Feature Fuel}

The preferential fuel type for the burned rock features is hardwood, which is still found locally. Other fuel includes juniper and vine stems. Feature 1 contains several different species, including live oak, elm/ mulberry, holly, and indeterminable hardwood. The seemingly continuous availability of fuel wood may have been part of the attraction of the Gatlin site when combined with the abundant lithic resources for use in hot rock cooking.

\section{Burned Rock Features and Subsistence}

Two types of cooking appear to be represented by the burned rock features at the Gatlin site, small-scale and short-duration, grilling, smoking, and roasting of animal and plant resources and long-duration larger scale baking of plants and possibly animals represented by the earth oven forms. While small features are usually one layer of rock in a coherent pattern, earth ovens are typically larger with layers of rock, possibly in a basin, in ovate to circular form, and with other packing materials sometimes represented by abundant charcoal (Decker et al. 2000:178).

As noted, most of the burned rock features are small and were likely used to process small quantities of food for immediate consumption. Suggested evidence from lipid analysis and faunal remains indicate that some of the small features are meat-cooking elements. The presence or absence of lipid residues and bone evidence can be the result of taphonomic effects, rather than cultural practices. However, the presence of bone with many features (for instance, 11 of 14 burned rock features in OZ2 contained faunal remains) suggests some functional relationship, whether it be related to cooking of the meat or discard of trash around a central hearth.

In regards to the probable earth ovens and largerscale baking, the largest site features (Features 5, 13, 22, 25, and 26) are from OZ2. Starch granules identified from Feature 5 are interpreted as evidence the feature was used for baking or roasting seeds or roots (see Appendix G). In OZ3, there are also several 


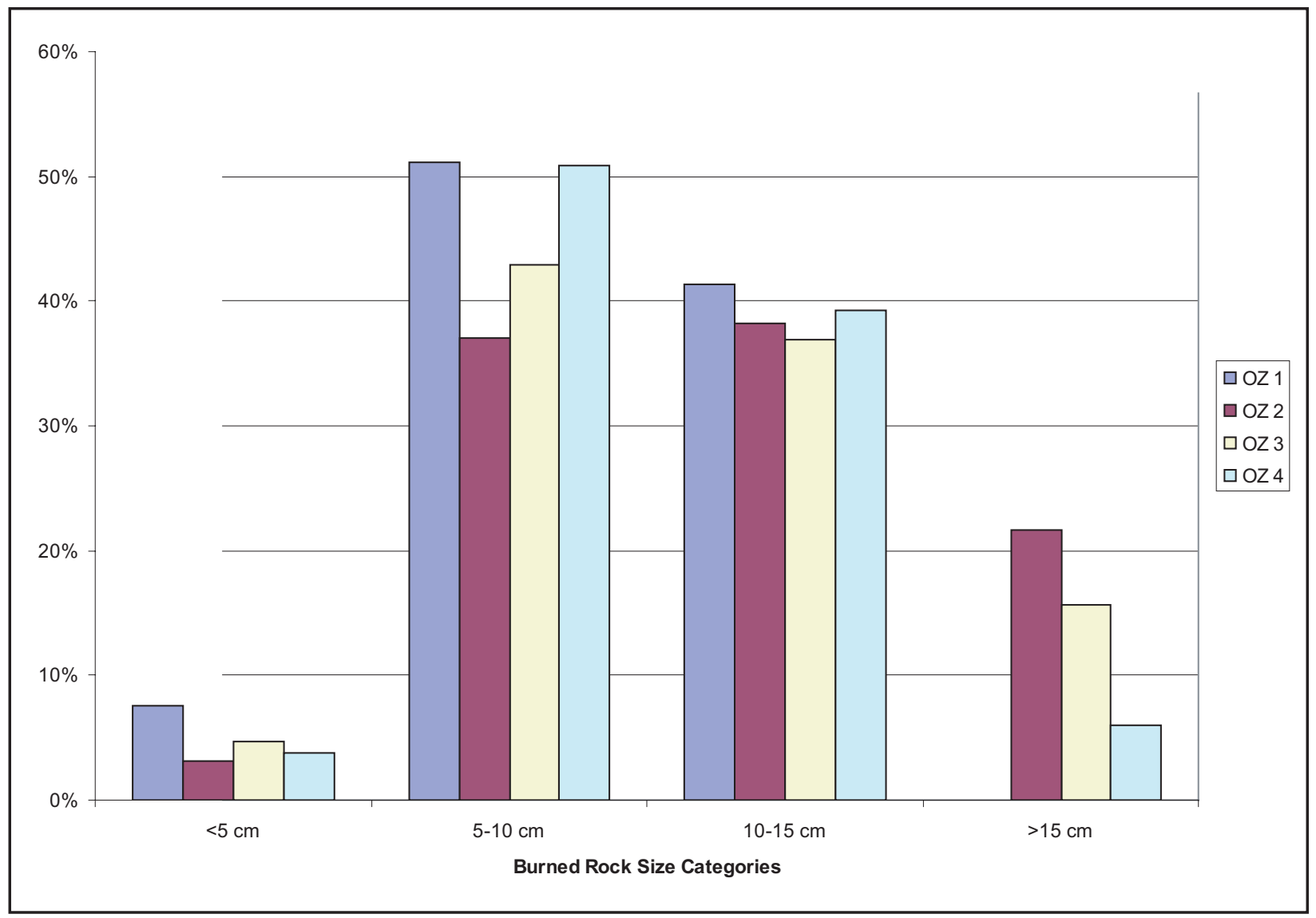

Figure 12.9. Percentage weight of burned rock size categories by occupation zone.

large features, such as Features 6, 16/17, and 19 that are probably bulk or large-scale cooking features. As an example, Feature 6 is a dense cluster of burned limestone that undoubtedly was an earth oven. The large quantity of burned rock and the size and morphology of the feature fit the pattern for an earth oven (Black 1997:257), and the feature is similar to those used to process plants such as camassia $\mathrm{sp}$. or geophytes such as sotol (Clabaugh and Thoms 2007). Though less numerous than the small features, the increase in frequency of these ovens through time (particularly at OZ2) suggests a broadening of the resource base to include a diversity of high rank (meat) and lower rank (geophytes, sotol, and other plants) foodstuffs.

This utilization of lower ranked resources (Derring 1999) with earth ovens culminates at the site in OZ4 with the construction of the burned rock midden. This dense accumulation of burned rock represents repeated episodes of large-scale baking of foodstuffs spanning the end of the Middle to Late Archaic.
Study of the midden structure suggests it has several overlapping ovens or former pits near its center and may have had a more ring-like structure in its earliest form during the Middle Archaic. Over time, reuse resulted in the formation of a more lens-shaped structure. How many episodes of use the midden represents and what resource was cooked within it unfortunately cannot be determined. As touched upon earlier, the midden is likely related to the exploitation of seasonally available plant resources and may have served as an attraction for reoccupation. The repeated use of certain locations by hunter-gatherer groups has typically been interpreted in terms of their relationship to natural features like water, fuel, and food resources (Binford 1982; Brooks and Yellen 1987). Of these three variables, food resources would seem to be the most important and it could be that a specific plant resource became available in the vicinity of the site during the Middle Archaic. 


\section{Subsistence}

As discussed above, the various lines of technological, macrobotanical, and paleoenvironmental evidence from the site allow for a partial reconstruction of the subsistence base of the occupants of the Gatlin site. While a lack of preservation of most perishable materials at the site hinders a total reconstruction, interpretations can be made as to the primary means of subsistence for hunter gatherers. Without a doubt, the lithic toolkit at the Gatlin site is focused on hunting and related resource processing. The lithic assemblage of each occupation zone is primarily a hunting assemblage of projectile points that could be multifunctional, used as both projectile points and butchering tools, and supplemented by formal and informal flake tools and bifacial knives as butchering, skinning and hide preparation and processing tools.

Game that was exploited by these hunters include bison, white-tailed deer, and to a lesser degree, rabbit, small mammals, and fish. Through all of the occupation zones, poor preservation of faunal remains make identifying butchering locales and processing areas impractical and tentative. However, the presence of axial elements and teeth suggest that whole large mammals such as bison and deer were butchered at the site. Besides the sparse faunal data, the functional analysis identified butchering tools and scrapers from OZ2, OZ3, and OZ4. The return of a large portion of a game animal or the complete animal back to the Gatlin site indicates that it was killed in the immediate vicinity of the site. The use of hafted end scrapers suggests a higher degree of specialization for efficient processing of hides (Tomka 2001). Additional tools such as perforators have use-wear traces of hide working, and therefore it is likely that game animals were exploited as both food and for materials such as hide, bone, and antler.

While large game animals were the desirable prey, the faunal assemblage contains small animals as well. While possibly related to differential preservation, the diversity in the faunal assemblage increases with time with OZ4 having the greatest diversity. The presence of fish indicates an increased diet breadth and different activity, given the number of ways fish can be collected from active fishing with line and hook (see bone fishhook from 41DL20 [Anthony and Brown (1994)]), spearing, or netting, and passive actions such as weirs and traps. Certain resources that include fish and other small animals have been shown to be collected or procured by women and children. Increased diversity in subsistence can indicate a more-diverse group, engaged in age- or genderdesignated tasks. However, while diversification in the subsistence base has been hypothesized to occur when the availability of higher ranked resources declines (Stiner and Munro 2002), the low numbers of faunal resources other than bison or deer at the Gatlin site suggests they were a supplement to a diet based on large game.

Burned rock facilities across the site represent two basic cooking techniques related to both plant and animal consumption, grilling/roasting over small features, and baking with earth ovens. The smaller features predominate at the site, suggesting a continuous pattern over thousands of years of cooking small-sized meals at the site. Three of these small features yielded carbonized walnut shells while others had lipid residues suggesting animal protein-illustrating the range of foods processed in these facilities. At the same time, large features, capable of cooking both bulk plant and/or animal resources occur in greater frequency through time in OZ2, OZ3, and OZ4. With the exception of the midden, most of these larger features represent short-term use features, and were not repeatedly reused. Proposed earth ovens at other sites such as Wilson Leonard (Collins et al. 1998) and Richard Beene (Clabaugh and Thoms 2007) contained geophytes, and it is plausible that some similar specialized plant cooking occurred in the latter three occupation zones at the Gatlin site.

Ground stone tools attributed to occupation zones include a metate fragment and manos $(n=6)$. Thus are not a significant component of the lithic assemblage at the Gatlin site, whereas at the Early Archaic Sleeper site, abundant ground stone tools suggest plant processing could be an important supplemental food source in the Early Archaic (Johnson 1991). The small assemblage of ground stone tools suggests low intensity and small scale processing of plant elements such as seeds or acorns. Ground stone tools are curiously few in number or often absent from central Texas site assemblages. Given that ground stone tools are costly to transport and are therefore often 
cached (i.e., they become site furniture) one would think that such tools would quickly accumulate at a site and/or would be easily recognized given their repeated used, but this often is not the case. The near absence of ground stone tools at most central Texas sites could mean a number of things, including that the plant foods utilized did not require a great amount of milling or pulverizing, or that milling and pulverizing activities were accomplished using implements of wood or bone.

While present, bulk cooking appears to have been an infrequent activity, and more as a supplemental activity to the main focus of hunting. In the Early Archaic occupation zones, the processing capacity of the earth ovens suggests they were used to supply the needs of small groups such as families or extended family units. It is only with the advent of the midden in the Middle to Late Archaic that bulk processing seems to increase in prominence within the subsistence economy of the site occupants.

The emphasis on hunting and processing of game and the manufacture and replacement of hunting tools suggests that the Gatlin site was a special purpose site where a limited range of subsistence tasks were performed, especially during the OZ1-OZ3 occupations. As the climate shifted and available resources changed, this included the construction of larger features and bulk processing of food resources beginning in the late Early Archaic on OZ2, and culminating in the burned rock midden in OZ4.

\section{Site Structure and Organization}

One of the primary factors guiding the excavation methodology and several research issues was the belief that the Gatlin site held relatively discrete, isolable cultural components with good spatial integrity. This belief was primarily based on the results of the accelerated testing program which showed good potential for intact artifact-to-feature associations and separation of cultural zones. As such, large horizontal excavations were undertaken to expose broad areas in an effort to delineate discrete locales of activity and perhaps living structures. Methods were geared towards quick exposure (feature-focused units) and good documentation of spatial data (piece-plotting with a TDS). Unfortunately, these efforts yielded results below our optimistic expectations and it was found that the earlier belief of the site's intact structure was partially incorrect. Instead, as in every excavation project, the site proved to be more complex and some compression between cultural occupations became evident. While OZ1 was found to be intact with good spatial integrity, OZ3 and OZ4 contained more overprinting than expected. In addition, a slight slope in the site deposits provided another challenge to correlating features, tools, and artifacts across the site. Nevertheless, attempts were made with the recovered data to explore spatial patterns and their relation to human activities and organization at the site.

An original intent of the spatial analysis was to search for evidence of domestic structures. No significant patterning was detected in the artifact distributions that could be interpreted as structures. Determining the effects of cultural and natural patterning on the distribution of artifacts made high resolution spatial analysis difficult. The depositional history of the Gatlin site illustrates a combination of punctuated periods of slow aggradation, rapidly aggrading events, and periods of landscape stability that can result in disturbed surface deposits. There are, however, several basic, yet interesting, patterns in the distributional data from the occupation zones.

In OZ1, the most notable association is between Feature 27 and Feature 14 and the Early Barbed Devil's Variant projectile points. The overall sparse distribution of tools indicates that the zone represents few visits as the site was infrequently occupied by individuals or small groups possibly over a period of 600 or more years.

In OZ2, meaningful spatial patterns are lacking. Several of the larger features, such as Feature 34, are composed of several rock concentrations which suggest some measure of reuse, with the smaller features possibly scavenged from a larger initial feature. The features are distributed equally throughout the excavation area blocks. The larger Features 25 and 26 , while having conflicting radiocarbon assays, are likely functionally related, with the void of burned rocks between them a result of cultural activity. A comparison of the burned rock size and weight categories shows they have a similar composition. The difference is that the smaller Feature 26 contains a higher percentage of larger and heavier rocks. These larger rocks may be the cap stones removed from the earth oven Feature 25. 
The distribution of projectile points in OZ2 is complex, but in general, the older points occur in the south end of the site, while the majority of younger points are in the northern half of the blocks. Biface and core reduction activities occur throughout the excavated areas; however, there are concentrations of flakes that may represent knapping locales, notably Feature 33. The conjoining of flakes to a core fragment suggests that the core in this feature was reduced in a single episode. The admixture of faunal material, burned rock, and charcoal fragments within this feature suggests it may have been part of a dump area.

In OZ3, there are areas of burned rock concentrations within diffuse scatter, such as Feature 16/17. In Area A-NE, most of the features are found in the south end of the block. The interval spacing suggests that these were discrete occupations, and that the smaller features such as 15 and 18 were single-use elements. Projectile points are more likely to be recovered near burned rock features. There is a moderate association between the distribution of biface debitage and bifaces in A-NE; and biface reduction appears more intensive in the southern edge of the block and near Features 6, 15, 18, and 19. In Area B, bifaces and bifacial debitage are clustered at the north end of the block. The distribution of flake debitage across all of the excavation units indicates there were repeated occupations of varying intensity at the Gatlin site during the formation of OZ3. This results in overprinting and mixing of discrete episodes of lithic manufacturing.

Concentrations of identifiable, late-stage bifaces occur, many with manufacturing breaks. These areas likely represent locales of production where late-stage bifaces are being produced and broken during the final reduction operations. It is reasonable to assume that a number of bifaces were reduced at a given time, and that work proceeded to another tool when one was broken or completed. The distribution of bifaces suggests numerous episodes of biface manufacturing occurred during different occupational episodes.

The investigations in OZ4 were limited, and horizontal spatial patterning was not a focus of the work. In OZ4, the investigations were concentrated within Area $B$ adjacent to Feature 1, the midden. One noted pattern is the presence of smaller burned rock features on the margins of the larger midden, suggesting the contemporaneous utilization of differing heating/cooking technologies. The intactness and discrete spacing between the smaller features suggests they were not reused. One scenario to explain this pattern could be the use of small hearths for warmth or for limited grilling/roasting by the site occupants while they waited for the larger bulk foodstuffs to bake in the midden. The smaller features may have supported or supplemented activities associated with the midden. As will be discussed in Chapter 13, this is a trend noted at other sites with middens in the region. Another explanation could be that the small features post-date the midden and represent an occupation after the midden had formed. The largest variety of projectile point styles occurs in OZ4, which chronologically suggests a broad temporal range for the features though many of these types overlap temporally. Unfortunately, the results of radiocarbon assays do not provide sufficient resolution to determine if the features are contemporaneous.

\section{Hunter Gather Organization at the Gatlin Site}

Given the body of data that tends to survive in the archaeological record, researching ecological adaptation and related hunter gatherer organization is among the most feasible analytical tacts in Central Texas archaeology. Foraging strategies pertain to the ways in which the site occupants organized themselves and their technology to interact with their physical setting. The general approach to the analysis of these is to examine the relationships among three data sets: (1) environmental data, (2) subsistencerelated data, and (3) technological data. A large body of middle-range theory, much of it deriving from ethnographic studies, must then be utilized to understand the dynamics among the datasets. The intent of such a study is to develop a site-specific model of strategy and organization through time, for comparison to the regional data.

\section{BACKGROUND AND GENERAL THEORY}

Hunter-gatherer foraging theory has long been a central research domain in archaeology. Its origins are perhaps most explicitly traced to Julian Steward's (1955) development of "cultural ecology," from 
which many see as the foundation of processualism with its ultimate objective of reconstructing cultural processes and change. Subsequently, in 1966, the symposium Man the Hunter and publication of its findings by Lee and DeVore (1968) fostered the growing realization that these cultural processes, which were so elusive to the archaeologist, were fully evident in the world's extant hunter-gatherers. As Binford (1978, 1980, 1982) and Schiffer (1976) more clearly defined, the great need in archaeology was to develop a means of relating patterns in the archaeological record to behaviors, then from the behaviors infer societies and cultural systems. Their development of middle-range theory set about defining the archaeological signatures of various foraging strategies. Perhaps the third milestone was the closely dated publications of Hunter-Gatherer Foraging Strategies (Winterhalder and Smith 1981) and Butzer's (1982) Archaeology as Human Ecology. The former established optimal foraging theory as a viable model for understanding hunter-gatherer economies, and the latter advanced the view of culture within a human ecosystem, or, in other words, the notion of a cultural landscape. These ideas form the basic framework for foraging theory.

From these seminal developments, a number of models have been developed, including Bettinger and Baumhoff's (1982) traveler and processor model, Binford's (1980) concept of collector and forager, and Woodburn's (1982) delayed return versus immediate return economies. Though the schemes are not precisely equivalent since each addresses a different fundamental aspect of society, all three typically incorporate mobility.

Since the literature of Central Texas, and elsewhere for that matter, typically uses Binford's terminology, the collector and forager model is utilized here. To generally describe the model, hunter-gatherers, when confronted with a highly variable distribution of resources across the landscape, often intensify their occupation and exploitation of ecological "sweet spots." Residential mobility decreases, but small task-oriented groups are sent out to procure resources. Accordingly, logistical mobility increases. Collector base camps, occupied for relatively longer periods, accumulate substantial debris, large features and other site furniture, and evidence of broad diet breadth that includes low-ranked resources (i.e., those with low caloric returns for the procurement efforts; [Derring 1999]). Conversely, when the landscape offers a more equitable distribution of critical resources or a higher availability of high-ranking resources (such as bison for example), groups often respond by increasing their mobility, exploiting the increased biomass availability, and dropping the more intensive processing of low ranked resources. As residential mobility increases, logistical mobility declines. These economic strategies are the driving force in subsistence selection and the organization of technology. No group operated exclusively at the extremes, and the model is intended to analyze sites along a continuum as Kelly (1992) and Bamforth (1998), among others, have noted.

For the purposes at hand, the significant aspect of these models is the archaeological signature of the different ends of the spectrum. What sort of material evidence suggests low residential mobility collector sites compared to higher-mobility forager base camps? What are the expectations of faunal assemblage, feature technology, lithic debris, ground stone, etc.? A fair amount of middle-range theory has been compiled to draw these inferences.

Foragers made more frequent residential moves to resources, while collectors returned resources to their residential camps. Away from residential camps and sites, the lithic assemblage of foragers emphasized adaptability, while collector assemblages were more specialized. The most common ratio that has been applied to explore this model is the ratio of bifaces to cores as proposed by Parry and Kelly (1987), where sedentism and reduced mobility is correlated to the increased use of expedient tools, the reduction of cores, and the decline in biface manufacturing. However, equating sedentism to core reduction is not a linear correlation.

As Andrefsky (1998) notes, factors such as the availability and quality of lithic material can affect the composition of a lithic assemblage so that it represents extreme ends of the continuum. Lithic reduction strategies can change how materials are reduced and the intensity of a tool's reuse. The lithic signature from a site that has chert resources like the Gatlin site, typically displays an abundance of both formal and informal core technologies. In areas with high quality material in low quantities, formal cores such 
as bifacial cores, and bifaces would be produced. Poor quality chert, regardless of its quantity would encourage primarily informal tool production.

Besides the technological data, subsistence remains at archaeological sites provide some of the best data on foraging strategy. The general principle is that subsistence diversification, mainly through adding new species to the diet, raises the carrying capacity of an environment. Evidence of increasing dietary breadth is expected by more species in the diet and/ or greater proportional equity among high-ranked and low-ranked food sources (Derring 1999) as a response to diminished availability of highly ranked resources. Accordingly, species diversity and minimum number of individuals (MNI) are indicators of foraging strategy.

The expectations in the subsistence remains for the two ends of the spectrum, from high to low mobility or forager to collector, are as follows. Longer durations in one spot would entail a more diverse diet and more intensive use of low-ranked resources. As the patchiness of the environment decreases (i.e., as uplands have an increased economic biomass), a more highly mobile foraging strategy is optimal to employ an encounter strategy for high-ranked resources such as medium- to large-sized mammals. With the increase in spatio-temporal patchiness of resources, such as when uplands become increasingly xeric and resource poor, intensification of ecological sweet spots fosters a logistical collector strategy. Collector residential bases, which are occupied for relatively longer duration, exhibit a broad diet breadth, and so the array of species expectedly includes lower ranked resources such as aquatic species, small mammals, reptiles, and plant resources.

\section{The GatLin Site OCCUPANTS}

Taken as a whole, the Gatlin site assemblage shows marked continuity but within this overarching characterization there are subtle but significant trends, notably a gradual shift toward diversification in resources and more-intense occupations. An examination of the various lines of evidence from the site indicates the earliest occupants of the Gatlin site would be best characterized as practicing a highly mobile, forager strategy. However, this strategy, based primarily on the hunting of large game, shifted slightly through time with increased subsistence diversification demonstrated by the earth ovens and plant resources that were used to supplement the diet. This shift indicates a modest increase in the occupational intensity of the site toward more of a collector-type residential base in the Middle to Late Archaic, culminating in the midden development. However, certain data contradict this, suggesting that while site function shifted, overall residential mobility remained high.

Technologically, the assemblages from occupations at the site remain strikingly similar, with an emphasis on retooling, heavy biface production, and the production of hunting apparatus. Based upon the biface to core ratios from each occupation zone, residential mobility is highest in Early Archaic OZ1 where a clear forager strategy is reflected, decreases to its lowest level in OZ2, rises slightly in OZ3 and more than doubles in value from OZ3 to the Middle to Late Archaic-aged OZ4. The lower ratios in OZ2 and OZ3 seem to imply decreasing mobility and slightly higher use of the site as a residential base. Though ratios represent high mobility in OZ4, other factors, such as the midden, suggest this mild trend continues.

While the data clearly show a slight shift in organization and site activities, it would be an over-simplification to claim, based on the above-mentioned ratios, that $\mathrm{OZ} 2$ and $\mathrm{OZ} 3$ correspond to increasing sedentism and represent a vast departure from the forager-oriented technology and subsistence of the earlier inhabitants. Rather, the shift appears slight, related to environmental adaptations, and does not likely represent a large swing toward the collector end of the spectrum. For instance, in OZ2 and OZ3, the majority of burned rock features are still very small, but some larger features that could have been used for larger groups and bulk processing start to appear. Furthermore, the range of functions represented by the lithic tools does not change substantially between OZ2, OZ3, and OZ4, (OZ1 is excluded based on its small sample size). The increase in tool diversity through time (ground stone tools, adzes, and scrapers) is also very slight and could be the result of several occupations and/or visits to the site by larger groups of people.

In OZ1, the lithic assemblage, biface to core ratio of 9.5:1, and burned rock features are all characteristic 
of small, mobile, forager groups or individual hunters who stayed briefly at the site. Materials from OZ2 indicate different groups used the site. Multiple specimens of different projectile points in the zone suggest these groups repeatedly revisited the Gatlin site, possibly in small groups that included women and children. Larger features, an increase in flake tools and cores, and a metate fragment all suggest there was a greater diversity in group composition at the site. Although the intensity of site usage increased and the duration of stays was perhaps longer, the assemblage still represents a forager-based strategy.

For OZ3, when compared with OZ2, there are a remarkable number of similarities in the lithic assemblage, from feature functions to the numbers and types of tools being produced. Biface manufacturing, lithic projectile refitting, and refurbishing continue almost uninterrupted, suggesting that while projectile point styles changed, the basic organization and structure of the lithic technology did not. What does vary is the construction of larger features, and although the site continues to be visited by small groups of people, larger groups - possibly extended or multiple family units-periodically visited the site. Plant processing appears to continue in growing importance as exemplified by the larger features, although the tool assemblage strongly suggests it was secondary to hunting. In all, occupants represented in OZ3 appear to still be organized toward the forager end of the spectrum but with more diversity as the site functioned as a short-term stop for the hunting and processing of game, occasional utilization of plant resources, and for important retooling and gear maintenance. The continuing slight increase in tool and feature diversity in OZ3 may indicate a decrease in long-range residential mobility compared with the Early Archaic.

The advent of the midden in OZ4 clearly represents a shift in organization and subsistence strategy but questions remain as to the magnitude and nature of the shift. Does the midden simply reflect the incorporation of an alternate food source within the long-established mobile forager strategy or a real shift to a more collector-based organization, with groups bringing low rank foodstuffs back to the site for processing? The site data suggests the former but the small sample size from the late Middle to Late Archaic deposits hinders this interpretation and fur- ther exploration of lithic assemblage characteristics from sites with middens is needed. More intensive processing of low-ranked foodstuffs undoubtedly occurs in OZ4 as illustrated by the presence of some ground stone and the midden itself. The generalized model of the paleoenvironment during OZ4 suggests increasing aridity and use of xerophytic plants. It is possible that the Gatlin site served as a sweet spot on the landscape during this interval, continuing to draw humans to the locale due to the availability of resources such as xerophytic plants, abundant highquality chert, and game along the riparian corridor of the valley margin.

Overall, evidence strongly suggests the Gatlin site was primarily utilized by small groups of foraging hunter-gatherers for short periods of time to acquire and process game, replenish their stocks of raw materials, and retool for future forays. The abundant game, plant foods, fuel, chert resources, and overall comfort of the riparian setting likely served as major draws for continuous occupation over thousands of years. Even with shifts in the environment that undoubtedly affected the nearby river regime and available plant and animal resources, the site locale proved advantageous. If viewed as one site within the territory or range of one or more groups, the Gatlin site was part of a larger settlement landscape throughout the Archaic. This concept is explored further in Chapter 13. 


\title{
Chapter 13
}

\section{The Gatlin Site in a Regional Context}

\author{
Brett A. Houk, Eric R. Oksanen, and Kevin A. Miller
}

\section{INTRODUCTION}

Much of this report has been a site-centric discussion of 41KR621, from its discovery during the survey of the Spur 98 extension to its data recovery excavation and analysis. In this final chapter we consider the Gatlin site in its broader regional context to search out patterns or trends. The Gatlin site represents the largest excavated sample of Early and Middle Archaic deposits to date in the southern Edwards Plateau and, therefore, contributes greatly to the regional archaeological database and our understanding of human lifeways in the early to middle stages of the Archaic. Specifically, this chapter will re-examine the Early-Middle Archaic chronology of south Central Texas in light of the projectile point sequence and suite of radiocarbon dates from $41 \mathrm{KR} 621$, and the prevailing models of paleoenvironmental reconstruction for the region, incorporating the data from the Gatlin site. Finally, we will discuss what the Gatlin site data, when compared to other excavated sites in the region, tell us about human adaptation during the Early and Middle Archaic on the southern Edwards Plateau.

\section{The Gatlin Site and the Early- Middle Archaic Chronology of the Southern Edwards Plateau}

The Gatlin site yielded one of the most robust assemblages ever recovered from an Early Archaic to Middle Archaic site on the southern margins of the Edwards Plateau and, as such, contributes greatly to our understanding of the chronology and culture history of the region. In fact, of the sites often cited as representative of the Early Archaic in southern Central Texas (cf. Collins 2004:Table 2), only Hall's Cave in Kerrville has chronometric dates associated with Early Archaic diagnostic artifacts. The dates from the Gatlin site, therefore, are important anchors for evaluating existing chronologies with temporally "floating" style intervals.
The Gatlin site, however, is not deeply stratified and in some cases there is little vertical separation between the occupation zones. This is due, in large part, to the sedimentation rates. In fact, the sedimentation rates observed at the Gatlin site during the period it was occupied were low, especially when compared to the apparent sedimentation rates during the early period of Unit 3 aggradation (see Chapter 6). It is worth noting that the sedimentation rate observed within Unit 3 , the culture-bearing unit, at the Gatlin site is similar to other alluvial terrace deposits in central Texas in that it was fairly rapid during the early phases $(0.95$ $\mathrm{mm} /$ year $)$ and gradually became slower $(0.21 \mathrm{~mm} /$ year in the block excavations, [i.e., during the period of occupation]) through time as the floodplain became progressively higher.

Along with natural and cultural transformation processes that acted on the cultural deposits for thousands of years, moving artifacts, ecofacts, and charcoal from one occupation zone to another, another important factor affecting the precision of the assigned boundaries between occupation zones at the site was the excavation methodology. The choice to excavate in arbitrary levels was a compromise between field time and desired results. Perhaps in a pure-research setting, the excavations would have proceeded in natural levels, which would have required much more time and been much slower. The arbitrary levels, especially in units as large as $2 \times 2 \mathrm{~m}$, have the potential to crosscut stratified cultural components, particularly on a site with sloping stratigraphy. This effect is magnified on a site with compressed stratigraphy. The unfortunate result of arbitrary levels slicing across sloping and compressed cultural components is blurred temporal and spatial boundaries between occupation zones.

Contributing to analytical difficulties caused by the compression of deposits is OZ3, the early Middle Archaic component. The rather limited testing regime at Gatlin (see Appendix K on Research Domain 6) did not identify this occupation zone, and, therefore, 
its discovery during data recovery was unexpected. Were this component not present-as we originally believed - the compression of the cultural material at the site would not appear as severe as it is in some places and time intervals. Had this component been anticipated, the excavation methodology could have been modified to investigate it more productively and to isolate it more effectively.

This is not to imply, however, that the various occupation zones at the Gatlin site are of poor integrity. On the contrary, when compared to other Early Archaic-Middle Archaic sequences, the Gatlin site deposits offer relatively good integrity, abundant chronometric dates, and a rich assemblage of diagnostic artifacts. Therefore, despite limitations imposed by the excavation methodology and compression of some of the deposits at the Gatlin site, the data aid tremendously in refining the chronology of the southern Edwards Plateau.

\section{ASSESSING THE INTEGRITY OF THE DEPOSITS AND THE GATLIN EARLY- Middle Archaic SEQUenCE}

As discussed in detail throughout this report, the excavations at 41KR621 defined four occupation zones (OZs 1-4) spanning the Early Archaic through Late Archaic periods. This discussion focuses on the first three, which span the Early Archaic through Middle Archaic periods. The most recent zone, OZ4, is associated with the period of time when the burned rock midden was in use at the Gatlin site. Cultural processes associated with the midden formation and related activities have mixed the cultural material from OZ4, and our data do little to address the chronological sequence of the Late Archaic.

The oldest occupation was the least well documented, and its age estimates should be considered less precise than those of the later components. Two radiocarbon assays bracket the component: Beta206155 from Feature 14 with a corrected radiocarbon age of $6570 \pm 50$ B.P. (calibrated 2-sigma date range of 7570-7420 cal. B.P.), and Beta-206122 with a corrected radiocarbon age of $6100 \pm 40$ B.P. (calibrated 2-sigma date range of $7160-6860 \mathrm{cal}$. B.P.). The older sample is considered to represent the stratigraphic and temporal lower boundary for the occupation of the site. The diagnostic point types associated with OZ1 include a Gower point, two Early Barbed Devil's River variants, a Martindale point, and a Pandale point. The Early Barbed specimens are the only two examples of the type found during the excavations, and it is likely that they are associated with the earliest occupation, represented by Feature 14. Both the Gower and Martindale points could be associated with the Feature 26 period of use of the site, although it is our impression - based on the seriation of types and their frequencies within the occupation zones - that the Gower type appeared first at the Gatlin site and was followed several centuries later by the Martindale type (Figure 13.1). If accurate, it is likely that the Martindale and Pandale specimens were incorporated into the older OZ1 deposits from younger deposits above through either natural or cultural transformation processes.

This impression of Gower first-Martindale second is supported by the artifact assemblage, including 77 typed projectile points, and the 12 chronometric dates from OZ2. Excluding the two youngest dates attributed to the occupation zone and the oldest, which is the temporal boundary between OZs 1 and 2 , the radiocarbon dates from OZ2 provide an estimated age range from $5570 \pm 40$ B.P. (Beta-207384; calibrated, 2-sigma range of $6440-6290$ cal. B.P.) to $4970 \pm 40$ B.P. (Beta-206124; calibrated, 2-sigma range of 5880-5600 cal. в.P.). The dates from the zone generally cluster into two ranges: five fall within $5570 \pm 40$ B.P. to $5280 \pm 50$ B.P. $(6440-5920$ cal. B.P.), and four fall within $4990 \pm 40$ B.P. to 4950 \pm 40 B.P. $(5900-5600$ cal. B.P.). Gower points $(n=21)$, Martindale/Martindale-Narrow Stem points $(n=37)$, and Bandy points $(n=5)$ account for 82 percent of the typed points from the zone. The remaining typed points, which include Early Triangular, Andice, Bell, and Marcos examples, are younger points mixed in the sample and not indicative of the true assemblage in our minds. The Marcos specimen is clearly intrusive, and the other types are representative of the blurred zone boundaries discussed above and in Chapter 12. We speculate that, in general, the Gower points are associated with the older date cluster, while the Martindale/Bandy points relate to the younger date cluster.

OZ3 is perhaps the most problematic of the four occupation zones because it has the most compressed stratigraphy. Four radiocarbon dates from features 


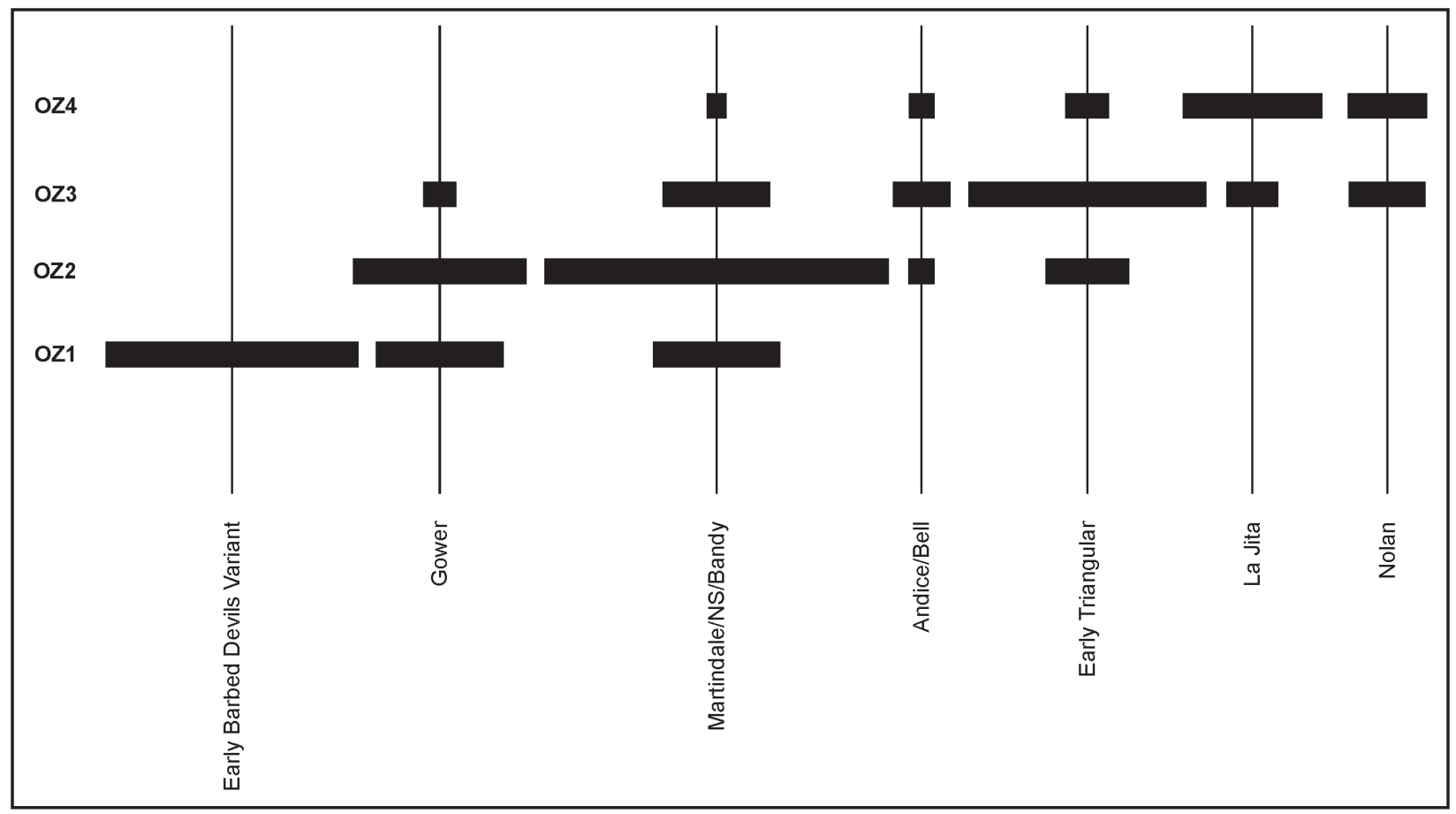

Figure 13.1. Seriation of major projectile point types by occupation zone at the Gatlin site.

provide a range of $4530 \pm 40$ B.P. (Beta-206131; calibrated, 2-sigma range of 5320-5040 cal. B.P.) to 4110 \pm 40 B.P. (Beta-206116; calibrated, 2-sigma range of $4830-4440$ cal. B.P.). If sample Beta-206131 is excluded, the remaining three dates all cluster between $4110 \pm 40$ в.P. to $4210 \pm 40$ в.P. ( $4850-4440$ cal. в.P.), a much tighter interval of time. The projectile point assemblage shows some blurring of the boundaries of the occupation zones above and below OZ2, or perhaps the persistent use of projectile point styles at the site. The Early Archaic point types in the assemblage include a handful of Gower points $(n=5)$ and over a dozen Bandy/Martindale points $(n=17)$. The bulk of the assemblage includes traditional early Middle Archaic types including Andice ( $\mathrm{n}=5)$, Bell, $(\mathrm{n}=4)$, and Early Triangular $(\mathrm{n}=38)$ points. The Early Triangular points account for 38 percent of the 101 typed points in the occupation zone. Late Middle Archaic points, such as La Jita $(n=8)$ and Nolan $(n=12)$, account for 20 percent of the points in the sample. The rest of the assemblage includes a variety of Late Archaic styles indicative of compression or mixing of younger material from OZ4 above.

As Figure 13.1 shows, which is admittedly a very gross seriation diagram, the temporal sequence of Early Archaic to late Middle Archaic point types at the Gatlin site is Early Barbed Devil's Variant, Gower, Martindale/Bandy, Early Triangular, Andice/Bell, Nolan, and La Jita. This sequence fits well with chronological orderings of points proposed by Johnson and Goode (1994:Figure 2) and Collins (2004:Fig. 3.9a) for Central Texas, and appears to represent the entire sequence typically expected for the time-frame in question.

\section{A Partial Chronology for the Southern EDWards Plateau}

The true contribution of the Gatlin site to the chronology of the southern Edwards Plateau is its suite of radiocarbon dates, which can be used to provide some better temporal parameters for the Early Archaic and Middle Archaic sequences. As mentioned above, most of the sites used to define the archaeological style intervals listed by Collins (2004:Fig. 3.9a) lack radiocarbon dates. Figure 13.2 represents a proposed chronology for the region based on the calibrated Gatlin site radiocarbon assays and the seriation of points shown in Figure 13.1. We have opted to present the chronology in calibrated dates to make it more comparable to the chronology proposed by Johnson and Goode (1994:Figure 2). The proposed date ranges for the various point types 


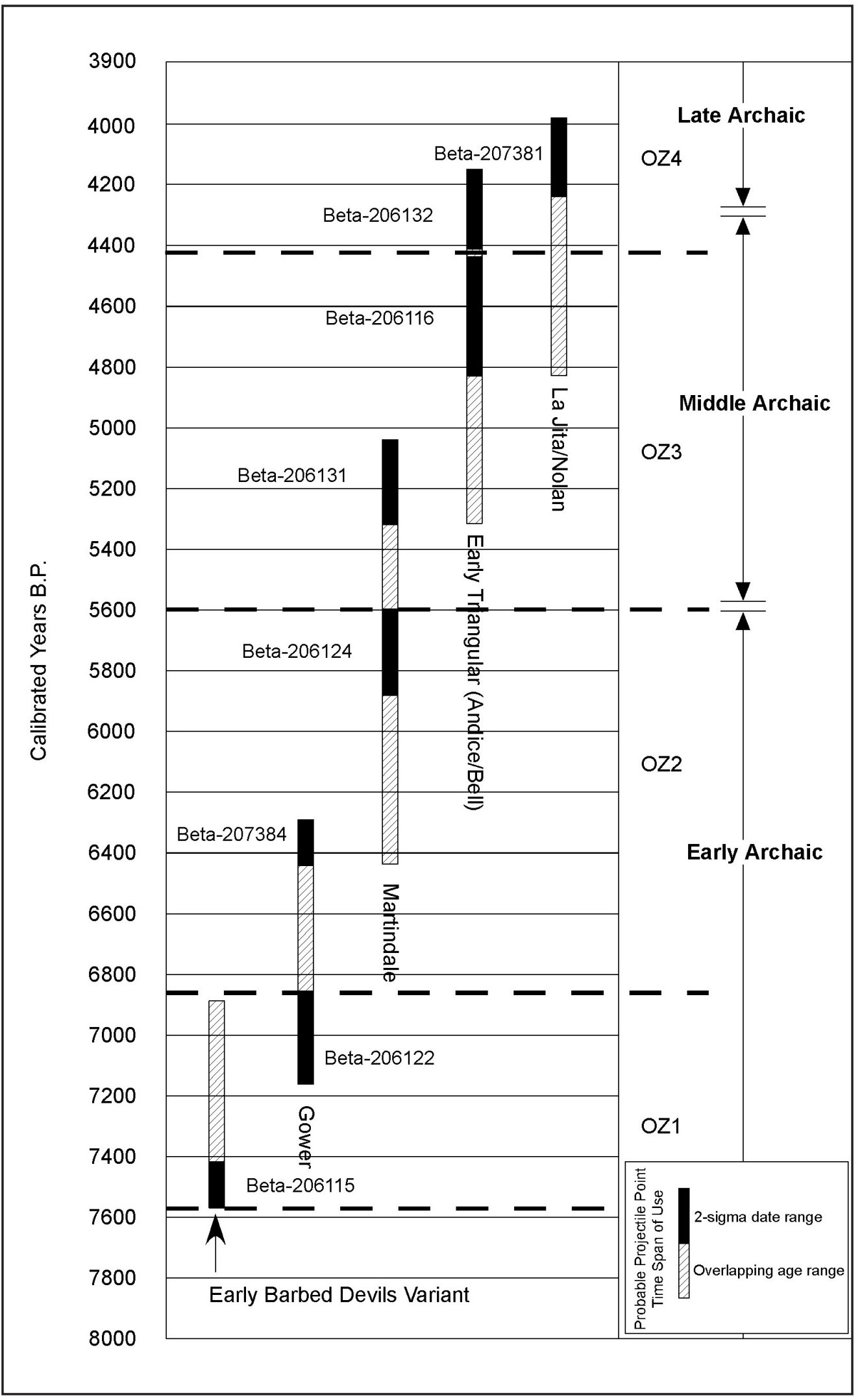

Figure 13.2. $\quad$ Proposed regional chronology based on Gatlin site radiocarbon dates and projectile point seriation. 
are a bit subjective in that they rely on dates from the same occupation zones as the points but are not necessarily related by spatial proximity to particular point types.

Occupation of the Gatlin site began during the Early Archaic and is marked by the appearance of Early Barbed Devil's Variant, Gower, and Martindale projectile points in OZ1. The sample of points from this zone is small and recovered from a large horizontal area, making our conclusions regarding the point sequencing somewhat tentative for the oldest components at the site. We propose, however, that the Early Barbed Devil's Variant points are slightly older than the Gower points, which become very common in the succeeding occupation zone. Our proposed end date for Early Barbed style at the site is ca. 6860 cal. B.P., although it may be somewhat earlier (ca. 7420 cal. B.P.). Either end date for the style compares favorably with the calibrated radiocarbon age range for the Early Barbed Series proposed by Johnson and Goode (1994:Figure 2), who place the style ca. $4200-5700$ cal. B.c.

Our data suggests the Gower style probably overlaps with the final centuries of use of the Early Barbed points, beginning in our sequence ca. 7160 cal. B.P. and extending to ca. 6290 cal. B.P. The Gower type is poorly dated elsewhere, making the Gatlin site assemblage with its associated dates unique. At the Youngsport site in Bell County, where the type was originally defined, it was stratigraphically isolated beneath Middle Archaic diagnostics, including Nolan points (Shafer 1963, 1979). At the Landslide site, Gower points were recovered with Martindale specimens and beneath Bell and Early Triangular points, and stratigraphically above Wilson (Sorrow et al. 1967:Table 1; Miscellaneous Specimen f). At Wilson-Leonard, where there was considerable intermingling of the Early Archaic components, Gower points were generally recovered stratigraphically above Angostura and Hoxie and below Bandy and Martindale (Collins et al. 1998:211-291). The Sleeper site (Johnson 1991) has an almost pure Gower component with a slight admixture of other Early Archaic types (Martindale and Bell/Andice), but lacks radiocarbon dates. Thus, other chronologies rely on cross-dating and relative stratigraphic position to assign a temporal range to the Gower type. Johnson and Goode (1994:Figure 2) place the Gower style, which they call Uvalde, around 4800 cal. B.c., which falls within the range proposed here.

In testing out our projectile point sequence for the oldest occupation, we relied on Johnson and Goode's $(1994: 22,24)$ research that suggests the Early Barbed series preceded the Gower and Martindale styles. The latter two types they call "the last Early Archaic dart points of the Edwards Plateau" (Johnson and Goode 1994:24). Others, however, would consider the Early Barbed and Gower types contemporaries, and, with such a small sample of points from OZ1, the Gatlin site data do not conclusively resolve this issue.

There are a number of sites where Gower and Martindale points occur together in the same components, as is the case at 41KR621. At Hall's Cave, for example, Gower (referred to as Uvalde) and Martindale points were recovered from approximately $1 \mathrm{~m}$ below surface in association with a radiocarbon date of 3550 в.C. (Tx-6413), depicted in Johnson and Goode (1994:Figure 4). Our data suggests the Martindale style, which we will use broadly to include Martindale, Narrow Stem, and Bandy in this discussion, appeared at the site ca. 6440 cal. B.P. and remained in use until $5040 \mathrm{cal}$. B.P. Therefore, it overlapped for at least a century with Gower, and perhaps longer. Martindale points were reported from good stratigraphic context at the Landslide site (Sorrow et al. 1967:Table 1) stratigraphically beneath Bell and above Wilson (described as Untyped Specimen L by Shafer in Sorrow et al. 1967:23-25), but there are no chronometric dates associated with that site. The large sample of Martindale points $(n=37)$ from the Woodrow-Heard site comes from an unclear stratigraphic context (Decker et al. 2000:263-265). Martindale points also were recovered at the Smith site in Uvalde County with a single radiocarbon date of 6280-6410 B.P. (Baker 2003:4), which is within the range proposed for the Gatlin site specimens.

We propose that the stratigraphic and temporal break between OZs 2 and 3, which unfortunately is perhaps the most blurred in terms of chronometric resolution due to compression, marks the transition from the Early Archaic to Middle Archaic at the site, ca. 5600 cal. B.P. Our interpretation is in line with Johnson and Goode's (1994:24-25) assertion that the first projectile point styles associated with the Middle Archaic were the Andice/Bell types, which were 
probably related to the Calf Creek phenomenon of north Texas and Oklahoma. These projectile points are believed to represent a bison hunting life way. In the Gatlin site assemblage (due the compression in this occupation zone) we are unable to separate Andice/Bell from Early Triangular temporally (see Figures 13.1 and 13.2). While it is possible, based on other chronologies, that Early Triangular followed Andice/Bell by several centuries, we cannot confirm it; the types are commingled in the OZ3 deposits. We propose a time span of ca. 5320 cal. B.P. to 4140 cal. B.P. for the three types, which overlaps with the last centuries of Martindale use at the site. This time range is several centuries younger than the five calibrated dates (1-sigma) of a component containing Bell and Early Triangular points at 41MM340: 5600-5480, 5740-5660, 5590-5460, 5590-5470, 5600-5520 в.P. (Mahoney, Tomka, et al. 2003b:55). It may be that because of compression at the Gatlin site, which was particularly pronounced in Area ASW where many of the Early Triangular points were found, our end date for the use of these styles is too recent. We may also have been too conservative in assigning a beginning date of $5320 \mathrm{cal}$. B.P. considering a handful of Early Triangular and Bell/Andice points were found in the underlying OZ2. Our range, however, partially overlaps with Collins' (2004:Fig. 3.9a) "Taylor" archaeological style interval, which, when converted to calibrated radiocarbon years, extends from ca. 5875 to 5050 B.P. Collins (2004: Fig. 3.9a) considers the Bell-Andice-Calf Creek style interval (ca. 6780 to 5875 cal. B.P.) to precede Early Triangular points, but we consider his proposed interval to be too old based on our data.

The final Middle Archaic point styles to appear at the Gatlin site (in large numbers) were La Jita and Nolan. In this case, we are again unable to separate the two types temporally; both are clearly associated with the end of OZ3 and carry over in use to OZ4. We are proposing a date range of ca. 4,820 to 3,980 cal. B.P. for these two types, although that may be too long lived. An alternative would be to place the end date for use of these point types at ca. 4,240 B.P. and consider the La Jita and Nolan points in OZ4 to be indicative of compression or mixing through cultural transformation processes. Calibrating Collins' (2004: Fig. 3.9a) dates for the Nolan archaeological style interval gives an age range of ca. 5040-4875 cal. B.P. to $4523-4420$ cal. B.P., which closely corresponds to the Gatlin site data. At 41BN63, a radiocarbon date of $4260 \pm 390$ в.P. (uncorrected; TX 7066) was linked to the La Jita type.

\section{Contributions to the REgIonal Chronological Database}

The Gatlin site represents one of the largest Early-toMiddle Archaic artifact assemblages associated with radiocarbon dates from an excavated site in Central Texas. As such, it is able to contribute significantly to the regional chronological database despite the compression of some of the sequence. In general, the Gatlin site chronology supports the relative sequence of point styles presented in both Collins (2004:Fig. 3.9a) and Johnson and Goode (1994:Figure 2), but provides chronometric ages for Gower, Martindale, Bell, Andice, Early Triangular, Nolan, and La Jita projectile point styles. Many of the sites used to establish the ages of most of the point types mentioned here were excavated prior to the widespread use of radiocarbon dating. For example, there are no dates for the following sites with Early Archaic contexts used by Collins (2004:Fig. 3.9a) to build his Central Texas chronology: the Sleeper, Youngsport, and Jetta Court sites and their high-integrity "Early Split Stem" components; the Camp Pearl Wheat site, which has a high-integrity Martindale-Gower component; the Landslide site with its moderate integrity Martindale-Gower component and highintegrity Bell-Andice-Calf Creek component; and the Wounded Eye site, with its moderate-integrity Early Triangular (Taylor) component.

Following Johnson and Goode (2004), we propose breaking the Early Archaic and Middle Archaic periods at ca. 5600 cal. B.P., based in large part on the appearance of Early Triangular points in great numbers with Bell and Andice points, as well as associated changes in feature patterning, feature form, and subsistence. This date is a few centuries younger than the one used by Collins (2004) for the beginning of the Middle Archaic. We also propose terminating the Middle Archaic with the decrease in La Jita point use at the Gatlin site and the beginning of the burned rock midden formation at the site ca. $4400 \mathrm{cal}$ B.P. Our period ending date corresponds well to those of Johnson and Goode (1994) and Collins (2004). 


\section{Paleolandscapes and Climate of Central Texas During the Middle Holocene}

The following section characterizes the environments encountered in Central Texas by the inhabitants of the Gatlin site during the Middle Holocene. Paleoenvironmental data collected from the Gatlin site is compared to previous studies other sites and similar stream systems. Although a continuous sequence of paleoenvironmental data was not obtained from the Gatlin site, there is evidence that region-wide paleoclimatic events were expressed at the Gatlin site. The occupations at the Gatlin site are examined in the regional context of climatic and environmental conditions for adaptive technological corollaries.

When examining the data sets, it is apparent that they are frequently contradictory. Additionally, two studies using similar data offer different conclusions. These include the disagreement between Holloway et al. (1987) and Bousman (1998) over the interpretation of pollen data from Boriak Bog. Contradictions can also be found in geomorphological interpretations between Johnson's (1994) model of central Texas Holocene climate and Nordt's (1992) interpretation of Fort Hood alluvium. These illustrate just two sorts of differing interpretations, and the problem with attaining data at a sufficient temporal resolution to accurately reflect conditions at a local and regional scale. Decker et al. (2000) disagree with Bousman's (1998) interpretations of both Boriak and Weakly bogs as having too little temporal control, making it difficult to accurately calculate rates of pollen influx resulting in a flawed model.

In general, because of problems with the precision of dating, taphonomic forces on samples, and methodology, (Bryant and Hall 1993) the interpretation of paleoenvironment proxy data and the resulting conclusions are frequently too vague or too site-specific to examine the relationship between the environment and the organization of technology.

An overview of environmental studies from selected sites and drainage systems is examined to determine the extent and severity of climatic variability in the regional record. These various regional paleoenvironmental data, contemporaneous with Early and
Middle Archaic occupations at the Gatlin site, are shown in Figure 13.3. The schematic depicts the variation in moisture (rainfall) and temperature through time. The scale of measurements for rainfall and temperature is not in units, but rather in variation from the modern climate and from the preceding climatic conditions.

If the effects of climatic and environmental change are sufficient to disrupt or alter the habitat of a major source of subsistence, there should be a human response. The form of response could be a change in mobility and settlement patterns as regions are abandoned and other areas are more intensively utilized; or it could be a change in material culture and the organization of technology. And, while both of these responses can be visible in the archaeological record, it is understood that the overall response to changing environments likely involves a more complex set of behaviors, which may be difficult to detect or interpret from the archaeological record. The Gatlin site contains cultural remains associated with several technological shifts that are thought to be adaptations to the changing environment.

\section{REGIONAL GEOMORPHIC ANALYSES of RIVER AND STREAM SYSTEMS}

The geomorphology of rivers and streams can provide paleoclimatic and environmental data based on inferences from the stream development. These studies have been used in concert with other analysis such as stable isotopes to develop a broad picture of Pleistocene and Holocene climate. As both Abbott and Frederick note in Chapter 6, the geomorphology of a stream can reflect responses to a changing environment, but is an inherently complex proxy.

\section{Fort Hood Brazos River Drainage}

Nordt's (2004) analysis of Fort Hood streams such as Cowhouse Creek, within the Brazos River drainage area, demonstrates that smaller streams can be more sensitive to environmental changes than larger rivers. Erosional boundaries between stratigraphic units occur from ca. 8,000 to 7,200 B.P. and from ca. 5,000 to 4,200 B.P. in the Cowhouse Creek profile; however, this erosion at ca. 5,000 B.P. appears in the Brazos River profile as a period of sedimentation. Of these two periods of erosion in the smaller channels, the ca. 5,000 в.P. erosion event best compares 


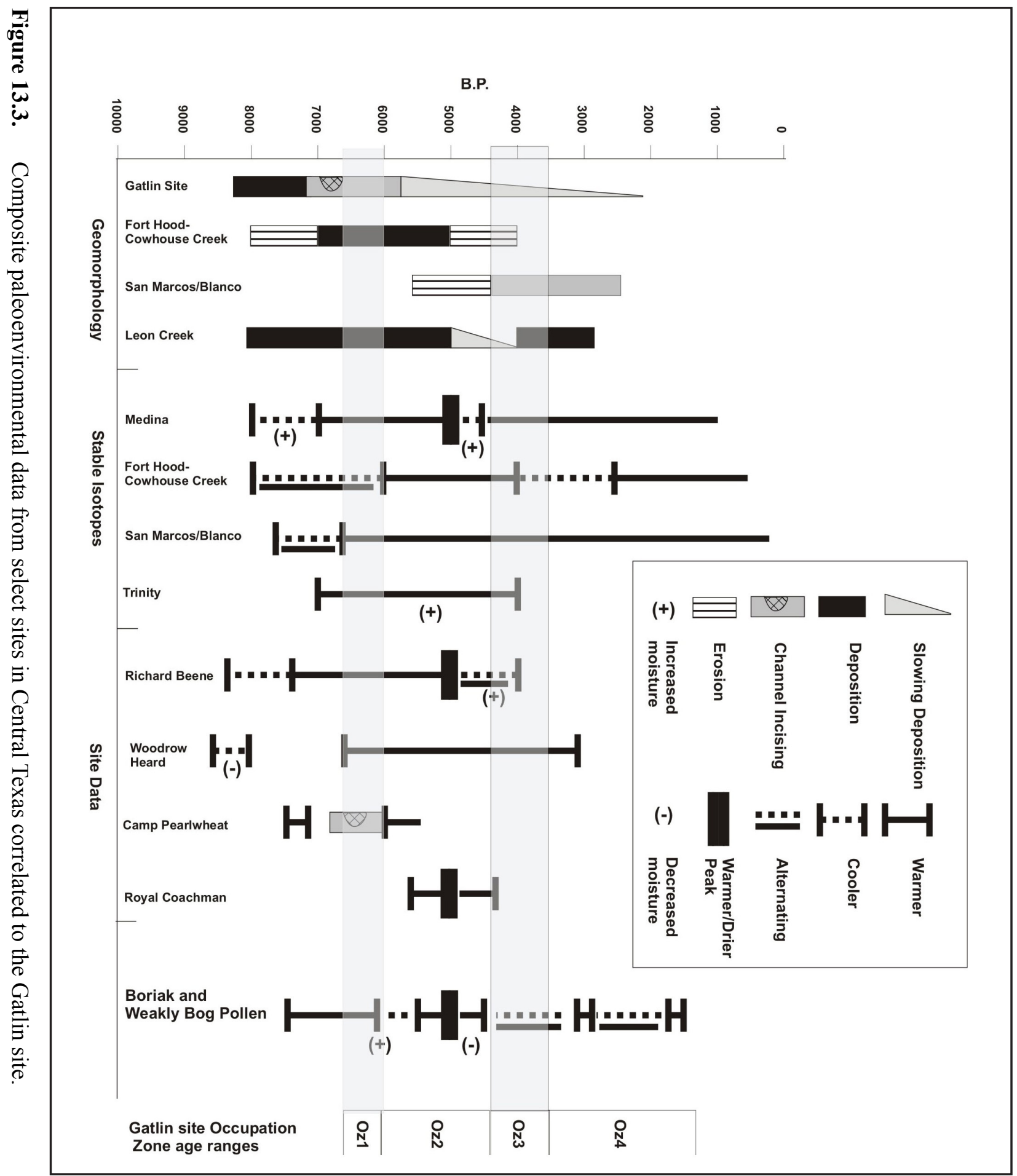


with the isotope data and pollen as a brief period of elevated temperature and decreased moisture. The earlier erosion event is at the transition to the Middle Holocene, and when the Brazos River had a period of stability followed by channel avulsion.

\section{San Marcos and Blanco Rivers}

Geomorphic analysis along the San Marcos and Blanco Rivers, tributaries of the Guadalupe River, include the Holt site (41HY341) (Brownlow 2004), the Armstrong site (41CW54) (Schroeder 2002), and 41HY165 at Spring Lake in San Marcos (Goelz 1999; Ringstaff 2000). Both the Armstrong site and Spring Lake site are missing a Middle Archaic archaeological record, which according to Ringstaff (2000), is due to regional effects of erosion. Additional excavations at Aquarena Springs documented an extensive Middle Archaic component; and therefore, the missing Middle Archaic component at 41HY165 is likely the result of stream channel migration. The Early Triangular points at the Holt site appear to be in fairly isolable stratigraphic components, again supporting a mechanical interpretation for the missing Middle Archaic components at 41HY165.

The Armstrong site (Oksanen et al. 2002; Schroeder 2002) contains an upper unit of Middle Holoceneaged deposits that lack any diagnostic materials from the Middle Archaic. The site location along a paleochannel of the Blanco River, suggests site use decreased dramatically sometime after ca. 6500 B.P., probably as the paleochannel dried and settlement shifted to the current San Marcos channel terraces.

\section{Medina River Basin}

Leon Creek is a tributary of the Medina River. Extensive testing of site 41BX47 was accompanied by Nordt's (1996) analysis of the upper Leon Creek basin. From 8,500 to 5,000 B.P. there was a rapid aggradation of terrace surfaces. At ca. 5,000 B.P. deposition slowed. By 4,000 B.P. high rates of deposition returned, along with gravel deposits that suggested one or both of the scenarios of higher energy floods and sediment erosion from the uplands.

\section{Pollen Studies}

The most cited pollen records for paleoenvironmental models in Central Texas are the Boriak and Weakly bogs.

\section{BoriaK ANd Weakly BogS}

Bousman's (1998) analysis of the Boriak and Weakly Bogs' pollen assemblage interprets fluctuations in the percentages of grasses and arboreal pollen as climatic changes. Two major events are the glacial meltwater releases into the Gulf of Mexico at the end of the Pleistocene and again in the Early Holocene. During the Holocene, Bousman's interpretation is woodlands increased from 9,000 to 8,000 B.P. during cooler conditions. From 8,000 to 7,000 B.P. there is a rapid change to grasslands, with a warmer period of 7,500 to 3,500 B.P. corresponding to the Altithermal. At ca. 6,000 B.P. there is brief mesic period when arboreal vegetation returns. The driest period is from 5,500 to 4,500 B.P., with the driest peak at ca. 5,000 в.P. The Weakly Bog analysis which begins at ca. 3,000 B.P., shows alternating periods of wet and dry and warmer and cooler, with drier events at ca. 1,500 and $300-500$ B.P., after which arboreal pollen increases rapidly to its modern equivalent.

Bousman's 1998 interpretation is used by other researches such as Nordt et al. (2002) as a proxy for climatic conditions that could explain the development of alluvial units. It is also used by others to explain geomorphology and for subsequent pollen, flora, and faunal studies. Despite the criticism of this model by Decker et al. (2000), Nordt (2004) uses Bousman's interpretation as a check on his Central Texas geochronology of streams.

\section{Camp Bullis}

Hudler's (2000) paleoclimate and paleoenvironmental modeling of the Holocene environment at Camp Bullis uses pollen extracted from cave sediments. These are not continuous samples and the data is from a limited range of dates. Located south of the Gatlin site at the southern edge of the Balcones Escarpment, Hudler also projected rainfall averages and evaporation rates, based on historic records. Hudler's model of the Early Archaic at ca. 7,250 B.P. corresponds to the Gower occupations at Camp Bullis. During this period, the climate was wetter than the Late Paleoindian period with increased arboreal pollen. Rainfall occurs with bimodality in the late winter/early spring, and the fall months. By ca. 6,000 B.P., smaller streams are seasonal as moisture levels decline. 


\section{STABLE ISOTOPE RESULTS}

Nordt et al. (2002) analyzed a continuous soil column from a profile along the Medina River of the Applewhite terrace alluvium at the location of the Richard Beene site (41BX831). Spanning the Last Glacial Maximum to the modern era, samples from the dated profile were examined for the carbon isotope $\delta^{13} \mathrm{C}$ to derive an approximation of the $\mathrm{C} 3$ and $\mathrm{C} 4$ plant communities through time. Abundant C4 indicates increased $\mathrm{C} 4$ vegetation of primarily warm weather grasses.

The carbon isotope signature was compared to stable isotope $\delta 18$ as measured in foraminifera from marine corals from the Gulf of Mexico. Oxygen isotope concentrations are environmentally sensitive to temperature change. Two major climatic events are correlated between the carbon and oxygen data sets - the end of the Pleistocene meltwater pulses and the Younger Dryas warming period. The time period that corresponds to the Gatlin site occupations is contained in the Medina and Leon Creek paleosols. The sequence proposed by Nordt et al. (2002) indicates cooler regional temperatures from $8,000-7,000$ B.P., followed by rising temperatures from 7,000-5,000 в.P.

In the Medina paleosol, there is a peak in $\delta^{13} \mathrm{C}$ at ca. 5,000 B.P. to approximately 62 percent of organic carbon, which suggests greater $\mathrm{C} 4$ vegetation as the result of warmer and drier conditions. After this peak, there is an abrupt decline at 4,500 B.P., after which $\mathrm{C} 4$ plants increase to levels from 65 percent and to 75 percent of the organic carbon to at least 1,500 в.Р.

Nordt et al. (1994) examined three streams at Fort Hood and built a depositional chronology derived, in part, from humate dates. This methodology is questioned by Johnson (1995) and Decker et al. (2000) as to the precision of the dated samples and the correlation to climatic conditions. However, as Abbott notes (see Appendix A), the Nordt et al. (1994) analysis is confirmed by numerous other studies, despite the discrepancy in some of the dates. The isotopic data used by Nordt et al. (1994) shows mixed $\mathrm{C} 3$ and $\mathrm{C} 4$ grasses during the Early Holocene ca. 8,000-6,000 в.P. This is followed by a period of increased temperatures and expansion of $\mathrm{C} 4$ grasses between ca. $6,000-4,000$ B.P. After 4,000 B.P., tem- perature declined and moister conditions returned that were similar to the transitional Early Holocene until 2,500 B.P. (Nordt et al. 1994:Figure 4).

Near the north Trinity River, Humphrey and Ferring (1994) document a warm Middle Holocene from ca. 7,000-4,000 B.P., when $\delta^{13} \mathrm{C}$ is enriched. They suggest that this was a period when reduced moisture and a slight rise in temperature favored the growth of $\mathrm{C} 4$ grasses over $\mathrm{C} 3$ grasses.

A sediment column from a paleochannel of the Blanco River immediately south of the Armstrong site shows $C 3$ vegetation varying from ca. 7,500-6,650 B.P. and in the undated upper sections $\mathrm{C} 4$ vegetation becomes increasingly dominant after 6,650 в.P. (Schroeder 2002).

\section{Archaeological Site Summaries of THE MIDDLE Holocene \\ PALEOENVIROMENT}

The paleoenvironmental data from the following selected sites is compared to the Gatlin site and synthesized as an environmental and climatic overview for the Early and Middle Archaic inhabitants of the Gatlin site and throughout Central Texas. Information summarized from the sites includes flora and faunal remains, sediment and geomorphology studies, and special studies such as stable isotope.

\section{RichaRd BeEne}

The Elm Creek occupations from 8,300-7,300 в.P. occurred during a cooler period from previous and preceding periods. The climate was variable with alternating periods of deposition and stability. The Medina component ca. 6,900 B.P. is at the end of the regional cooler period from $8,000-7,000$ B.P. (Thoms 2005:357). High rates of deposition continue to 5,000 в.P. The Upper Medina and Lower Leon Creek deposits from 4,500-4,100 B.P. are similar in age to $\mathrm{OZ3}$ at the Gatlin site. At Richard Beene, this is a period of cooler temperatures and wetter conditions from the preceding centuries and following centuries. At the start of 4,500 B.P., sedimentation was slowed, but increased at the end of the period. This supports other studies which suggest that there was a region-wide dry period at ca. 5,000 B.P., followed by a short mesic period. 


\section{Woodrow Heard}

At 41UV88, a variety of stable isotopic data was extracted from soil and snails. From 8,400-8,000 B.P., the climate was cooler and moister than later periods (Decker et al. 2000). From 6,500-3,000 B.P., riparian species were still present and the local environment did not change dramatically. The riparian setting was probably a factor in moderating the isotope signature. By ca. 3,000 в.P., mesquite appears in the record, and the coeval remains of bison and deer indicates that grasslands were a mixture of $\mathrm{C} 3$ and $\mathrm{C} 4$ grasses, and that substantial woodlands existed.

Site 41UV88 correlates with the general climatic and environmental models of the Holocene in Central Texas with warming from ca. 7,000-2,500 B.P. Overall, environmental change is gradual at 41UV88 and the large-scale changes in the pollen record at Boriak Bog are not evident.

\section{Camp Pearl Wheat}

The environmental analysis at Camp Pearl Wheat (41KR243) is based upon limited available data and is intended as a brief snapshot of the early Archaic on the Edwards Plateau (Collins et al. 1990). A humate sample dated to ca. 7,300 B.P. had a strong $\delta^{13} \mathrm{C}$ signature, consistent with warm grasslands savanna. The occupation of the site occurred 1,000 years later during a period of alluviation after down-cutting of the adjacent Town Creek channel. The pedogenic development in Zone V, which contained the Martindale points, suggests there were periods of landform stability at ca. 6,100 B.P.

\section{Royal Coachman}

The terrace surface of Cordova Creek on which the Early Triangular occupation occurred, ceased forming ca. 4,300 в.P. due to downcutting of the channel. Prior to this period, the development of the terrace is perceived to be a relatively slow process that may be coeval with the proposed region-wide stability at ca. 5,000-4,500 B.P. in the upper reaches of smaller rivers and streams of Central Texas (Nordt 2003). Shortly after ca. 4300 B.P., the surface was then capped by Late Holocene-aged deposits resulting from increased floods of higher magnitude.

As with the Camp Pearl Wheat, Royal Coachman is both a snapshot of a particular time period, and a broader picture, albeit at low resolution, of the paleoenvironment during the Middle Holocene and the transition to the Late Holocene.

\section{Cibolo Crossing}

The Early to Middle Holocene terrace formation at Cibolo Creek was truncated at ca. 5,000-6,000 B.P. after a long period of stability and pedogenic development. The erosion of this surface is equated by Kibler and Scott (2000:43) as evidence of a local effect from the Altithermal that is visible regionally in other analyses such as Nordt et al. (1994, 2002) and at sites such as Royal Coachman (Mahoney et al. 2003a). Further refinement of the timing of this episode was not possible with the available data.

\section{Sleeper Site}

The occupations at the Sleeper site are not radiocarbon dated. The major occupations coincided with early split stem points such as Gower. During this period, the adjacent Walnut Creek was probably larger. The earlier occupations occurred in a moremesic environment punctuated by periods of drying. Occupations above the rock zone had a more xeric environment (Johnson 1991).

\section{WILSON-LEONARD}

Numerous methods were used to generate paleoenviromental data. Several of these did not work, such as stable carbon isotopes and magnetic susceptibility. Phytolith analysis shows an increase in xeric grasses from ca. 9,500-8,700 в.P. Вy ca. 8,700-6,000 в.P., the phytolith signature is similar to modern local analogs (Fredlund 1998:1649). By ca. 4,000 B.P. the mixture of grass and overstory vegetation is similar to today. Although the focus of the fine-screened faunal remains analysis was the Paleoindian-aged deposits, the analysis indicates a general drying trend from 8,700-4,000 B.P. (Balinsky 1998).

\section{Armstrong}

Between ca. 7,560 and 6,650 B.P., local vegetation indicates a drying trend, favoring warmer and drier summers (Schroeder 2002; Cummings 2002). The location of the site (in the river bottom) probably acted as a buffer against extreme fluctuations. Of note is the presence of dung fungal spores suggesting large herbivores, particularly bison, were grazing on grasses during these periods. 
By ca. 6,400 B.P., occupation patterns change at the site, possibly the result of the paleochannel infilling. Subsequent occupations moved closer to the channels of the San Marcos and Blanco River.

\section{ICEHOUSE}

The Icehouse site uses magnetic susceptibility data to identify periods of deposition, erosion and pedogenesis. Approximately 1,000 years of occupations are contained in $70 \mathrm{~cm}$ of deposits from ca. 7,700-6,650 B.P. The upper deposits dating to the Late Archaic (ca. 3,450 в.P.) directly overlay Early Archaic materials (Oksanen 2005). The Middle- Archaic-aged sediments are absent from the profile, with the Late Archaic and Early Archaic discontinuity apparent in the soil susceptibility results. Given the location of the site in proximity to $41 \mathrm{HY} 165$, which was analyzed by Ringstaff (2000), the mechanism for the missing Middle Archaic-aged sediments is likely the same localized stream scouring.

\section{The GatLIN Site IN REGIONAL PALEOCONTEXT}

As this compilation of the regional paleoenvironmental data illustrates, a clear picture of climatic changes through time, from the end of the Late Pleistocene to the Middle Holocene, has not been developed. Discrepancies in data from different sites and studies due to poor preservation or lack of robust sampling programs cloud the picture. In addition, as noted, direct paleoenvironmental data from the Gatlin site was limited, although the artifact assemblages have yielded some clues. As such, only major trends in climate change at the Gatlin site can be postulated.

The transition to the Middle Holocene at ca. 8,000 B.P., was a cooler, more-mesic period along the southern boundary of the Edwards Plateau. By ca. 6,600 в.P. and the beginning of OZ1, most of the data shows a warming trend that was likely drier, while isotope studies in particular show varying periods of warmer and cooler. Cooler and wetter conditions are implied by bog pollen data at ca. 6,000 B.P. (the beginning of OZ2), that leads to gradual then abrupt warming at 5,000 B.P. (the Altithermal) and abruptly drops to cooler and wetter conditions at ca. 4,500 B.P. (the beginning of OZ3). After ca. 4,500 B.P., temperatures slowly increase while overall moisture tends to decline.
The warming event that occurs at ca. 5,500-4,500 B.P., is manifested at numerous regional sites as mixed cultural deposits with commingling of a variety of distinctive projectile point styles, particularly Martindale, Early Triangular, and Andice/Bell. As the drier conditions prevailed, both animals and people would have sought more dependable water sources and additional food sources. This likely included xerophytes, leading to the use and expanded range of earth oven technology.

During the period represented by OZ3, the climate shifted from a mesic episode of expanded grasslands and increased bison on the Edwards Plateau and Central Texas, to increasing aridity and warming and the retreat of bison and grasslands. The use of the unstemmed Early Triangular points may be coeval with the stemmed Nolan and La Jita points; although they may be a remnant style, well-suited to bison hunting that declined in use as the number of bison declined. White-tailed deer becomes the highest ranked resource on the plateau and Central Texas and the projectile points change to the more crudely made, stemmed Nolan points. Whether the Nolan points represent a new migratory group or represents an adaptive shift in technology is unknown at this time.

The ebb and flow of bison, conditioned by climatic shifts, is one of the major factors proposed for the change in the lithic technology assemblage in the Middle Archaic. The receding bison population as a result of increasing aridity and temperature is a major proposed factor for the intensifying use of xerophytic plants as well as a change in technology from the use of Early Triangular points to narrower-bladed and rectangular stemmed points such as La Jita and Nolan. With the scarcity of bison, there was a return to a more generalized hunting approach (Collins 2004; Johnson and Goode 1994).

As proposed by Abbott (Appendix A) and Fredrick (Chapter 6), the development of the river terraces used by the inhabitants of the Gatlin site is similar to other Texas stream regimes. The rate of sedimentation is also similar to other studied rivers, with the exception of the Medina River in the vicinity of Richard Beene, where the rate of deposition was substantially greater. 
The Guadalupe River channel was in its current location by the end of the Early Holocene and when the earliest occupations in OZ1 occurred. Similar to many stream regimes, a period of down-cutting of the Guadalupe River occurred ca. 5,000-4,000 B.P., limiting the effects of flooding and reducing alleviation at the site. The slow sedimentation rates occurring in OZ3 and OZ4 are most likely the result of stream mechanics, since later Holocene deposits occur at other regional streams.

The period of channel incising at ca. 5,000 B.P. is a similar response noted throughout Central Texas streams/sites and may be the result of increasing extreme weather where severe storms with rainfall coupled with the decreased vegetation in upland settings resulted in increased stream energy and severe flooding. The implications from this type of flooding on cultural materials exposed along terraces would create a mixing of components followed by more overprinting as floods receded. The resulting pattern of mixed Middle Archaic components occurs throughout the Central Texas region, making isolable finds from this period all the more scientifically valuable.

\section{Early ANd Middle Archaic Adaptation on the Southern Edwards Plateau}

The transition from the Early to Middle Holocene era was a period of climatic and environmental change, as the last lingering effects of the Pleistocene period diminished, and varied effects from the Middle Holocene Altithermal arose. Examined from a cultural ecology approach, these significant, but rather gradual - at least from the viewpoint of individual hunter-gatherers - climatic changes can be compared to concurrent modifications to human lifeways and adaptations to the environment. These cultural changes are reflected in settlement patterns, site types, and material culture, as well as subsistence remains found at archaeological sites.

The Gatlin site and other excavated sites along the margins of the Edwards Plateau provide a large, if somewhat inconsistent, data set with which to examine cultural adaptations and how they changed through time from the Early to Middle Archaic periods (Tables 13.1 and 13.2 also see Figure 3.1 in Chapter 3). Johnson (1991:149), using a similar but smaller data set, made some insightful observations about the nature of Early Archaic lifeways in an area he referred to as the Crescent, a sickleshaped area encompassing the eastern and southern margins of Central Texas from the Hill Country to the Lower Pecos that "constitutes an Early Archaic culture area all its own." While Early Archaic sites are now known from other parts of Central Texas, the Crescent is still an interesting concept because it generally applies to the ecotone between the Edwards Plateau and the Blackland Prairie to the east and the South Texas Brush Country to the south-basically, the same ecotone in which the Gatlin site resides. In this section, we examine some of Johnson's (1991) conclusions and observations using an expanded data set for the Early Archaic; we also extend our discussion into the Middle Archaic to highlight continuity and change in hunter-gather adaptations.

In constructing Tables 13.1 and 13.2, we selected sites that fall within the geographic range of Johnson's Crescent and attempted to isolate cultural components roughly contemporaneous with one or more of the Gatlin site occupation zones. Lacking radiometric dates from many of the selected components at many well-known sites, contemporaneity is frequently based on similar projectile point types and frequencies. We made efforts to use components from other sites that exhibited good integrity, although some degree of mixing is difficult to avoid, given the nature of the archaeological record from many Early to Middle Archaic sites in Central Texas. In some instances, we used only a sample of an excavated component in our comparison to minimize disturbances and mixing. When possible, the volume of a component and the area exposed are listed.

In selecting the types of data to compare, we chose categories that (1) are generally recorded and reported in older excavation reports; and (2) that we believe are likely to demonstrate differences in site use and highlight adaptations to the natural environment, particularly regarding subsistence and technological organization. These categories fall within three broad classes of data: tools, features, and subsistence. Tools include commonly recognized projectile point types from both time periods; specialized functional tool categories such as gouges, scrapers, and perforators; and ground stone artifacts. As for features, we 

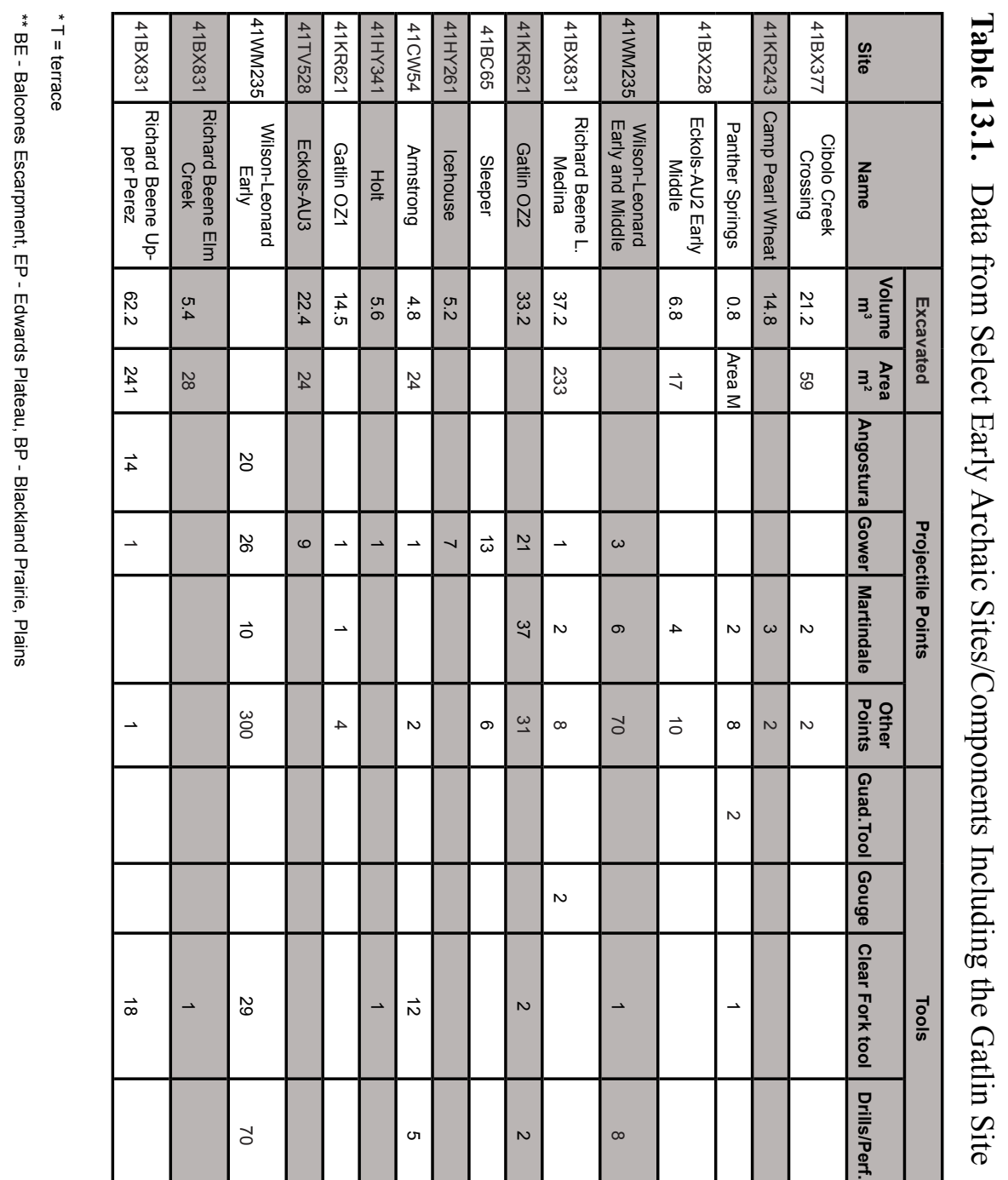


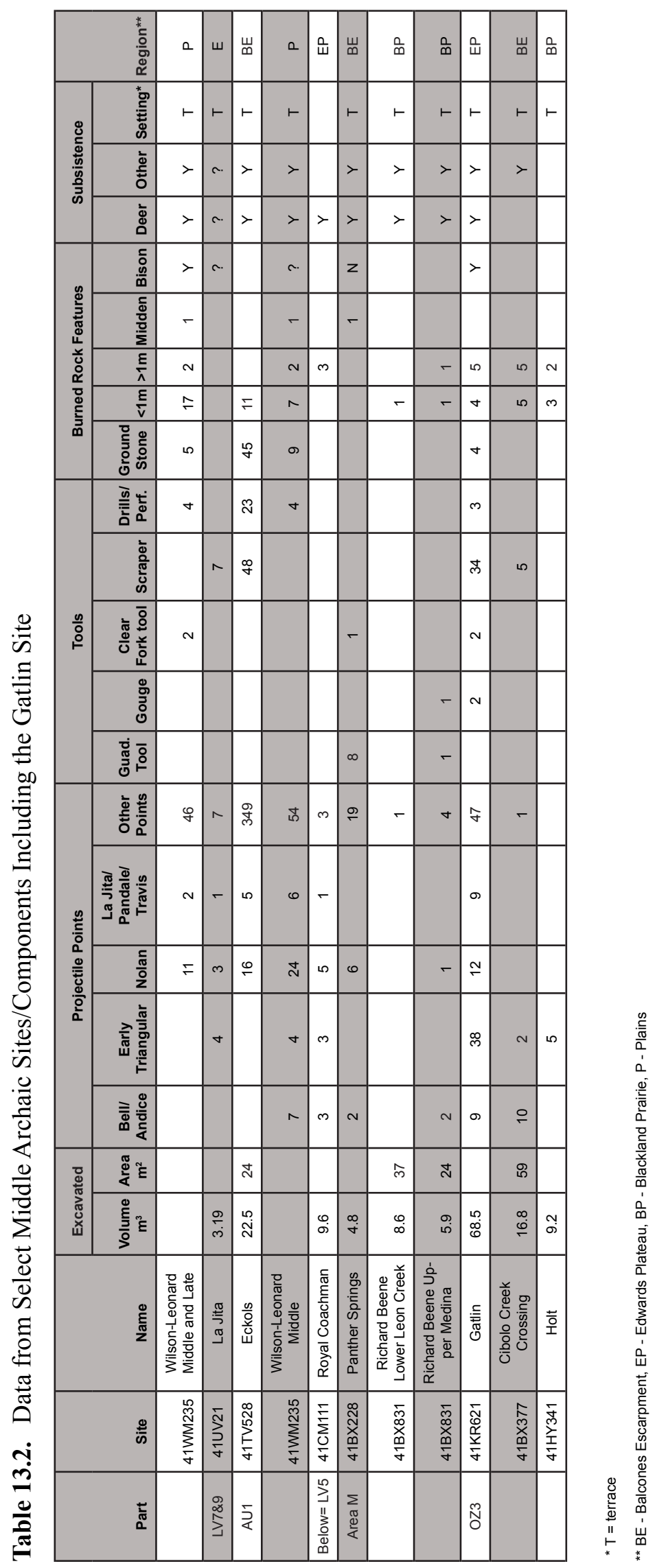


faced various difficulties in reconciling the types of data reported from each site for burned rock features, and we simply ended up classifying burned rock features as either small $(<1 \mathrm{~m}$ in diameter), large $(>1$ $\mathrm{m}$ in diameter), or as middens. The subsistence class of data can be thought of as overlapping to some degree with both the tools and features because those technologies often relate to collecting or processing foodstuffs. We also examined the selected sites for direct subsistence data in the form of faunal or other subsistence remains. Finally, we considered each site's setting in regards to position on the landscape and broader environmental region.

The sites chosen and components selected include several in Johnson's (1991) earlier study such as the Sleeper (Johnson 1991), La Jita (Hester 1971), and Panther Springs Creek (Black and McGraw 1985) sites. We also examined data from more recent excavations including the Camp Pearl Wheat (Collins et al. 1990), Icehouse (Oksanen 2005), Holt (Brownlow 2004:66), Armstrong (Oksanen and Schroeder 2002), Richard Beene (Thoms 2005), Cibolo Crossing (Kibler and Scott 2000), Eckols (Karbula 2000), Royal Coachman (Mahoney et al. 2003a), and Wilson-Leonard (Collins et al. 1998) sites (see Tables 13.1 and 14.2). Some of the sites appear on both tables, while others only have a relevant occupation from one of the two time periods.

For the Sleeper site, we considered all of Johnson's (1991) excavated sample, which is entirely of Early Archaic age. The Early Archaic Icehouse site components used include OZ1, OZ 2, and OZ 3, all of which correspond with Gower points (Oksanen 2005). For the Cibolo Crossing site, the Early Archaic component refers to their Martindale component, and the Middle Archaic component is their Bell-Andice component (Kibler and Scott 2000:60, 7). From Wilson-Leonard, the Early Archaic and mixed Early and Middle Archaic components as defined in Collins et al. (1998:Table 9-23) are included on the tables.

At the Richard Beene site, the Early Archaic components used are Upper Perez, Elm Creek, and Lower Medina (Thoms 2005). For the Middle Archaic components from that site, Table 13.2 uses the Upper Medina and Lower Leon Creek components. At Camp Pearl Wheat, the lower component associated with Martindale points is used (Collins et al. 1990).
At the Holt site, the Early Archaic component used is Zone II, from which a Gower point was recovered (Brownlow 2004:66). The Armstrong site Early Archaic component is from OZ4 as defined by Schroeder and Oksanen (2002:68).

At the Panther Springs Creek site, Area M excavations are used in the analysis because they are better preserved and are a more-discrete sample than other excavated areas. The also were part of the additional excavations conducted by CAR (Black and McGraw 1985:264, Table 48). The Early Archaic component is calculated from Area M elevations below 98.40 $\mathrm{m}$, while the Middle Archaic component is from 98.40-98.70 meters.

The Eckols site's Early Archaic components are AU3, a split stem or Gower-like projectile point component, and AU2, which contains Martindale points (Karbula 2000). The Middle Archaic component there also contains an admixture of late Archaic points and is similar to $\mathrm{OZ3}$ and $\mathrm{OZ} 4$ of the Gatlin site, primarily because of its assemblage of Nolan and similar age points. The La Jita site Middle Archaic component is located in Area A, levels 7 and 8 (Hester 1971:Table 6); and although Hester refers to this as an Early Archaic component, in this study it is considered a Middle Archaic component because it includes primarily Early Triangular and Nolan points.

The purpose of this exercise when initially conceived was not to re-examine Johnson's (1991) characterization of the Early Archaic, but, as we began to consider our data and draw some preliminary conclusions, we realized that many of Johnson's (1991) observations are still valid. Therefore, in many ways, our study is a reconsideration, update, and expansion on his earlier work. Johnson's (1991:158, Table 26) study of 10 Early Archaic sites in the Crescent showed tremendous variation in the types of activities that took place at the sites. Some activities, including late-stage knapping and tool maintenance, took place at all site and, therefore, "do not help to make functional or economic distinctions" (Johnson 1991:158). However, he was able to generally classify significant activities of functional and economic distinctions between hunting/butchering, heavy woodworking, early-stage knapping, and milling sites. Furthermore, he observed that sites with more 
than one major activity fall into two groups: sites where hunting/butchering and heavy woodworking were the dominant activities and sites where hunting/butchering and milling took place (Johnson 1991:158).

Another important observation arising from Johnson's (1991:159) study is that, of the 10 sites he examined, none could be classified as "central bases." This conclusion led to speculation that such camps might exist, but alternatively that whole groups of people may have moved from season to season. Johnson (1991:159-160) personally notes, "I can only guess that Early Archaic peoples in the eastern part of the Crescent were mainly foragers without base camps."

Although our pre-excavation expectations were that 41KR621 represented more of an Early Archaic residential base camp, as is discussed in Chapter 12 , this assumption appears incorrect for the earliest periods of site use. The artifact assemblage is more representative of one of Johnson's hunting/butchering sites, albeit a very large one, occupied repeatedly over thousands of years. In fact, the only site in Table 13.1 with an artifact assemblage we would expect from a residential base camp is Wilson-Leonard's Early Archaic component, where large numbers of projectile points, gouges, perforators, and ground stone artifacts were found with numerous burned rock features.

\section{EARLY ARCHAIC TRENDS}

At first glance, Table 13.1 may seem uninformative, but comparing the data from various sites yields sometimes obvious, yet important, observations. Most of the Early Archaic sites have artifact assemblages indicating mobile groups, primarily conducting hunting/butchering activities and retooling, although our data do not capture early-stage knapping activities. Feature data suggest that social organization includes small groups, moving regularly through the landscape to exploit various resources with a heavy emphasis on large game, primarily deer followed by bison, when available. Additionally, some evidence of gender-related differences in activities and site usage may be inferred from some of the technological data, particularly as it relates to ground stone artifacts.

\section{Observations on Ground Stone}

During the Early Archaic in Central Texas, ground stone technology is found in half of the examined components, and even when accounting for sampling biases, quantities are low. The generally infrequent counts of ground stones and their relatively small size (all of the manos appear to be used one handed), have several implications: the amount of food that could be processed was limited, these were durable tools that were left at sites for future use, and that they represent the exploitation of a lower ranked resource - presumably nuts or seeds.

The data may be a reflection of the seasonal use of most of the sites in the sample, suggesting they were occupied when nuts and grass seeds were not yet ripe, or it may be an indication of a more complicated settlement pattern. For example, if there were base camps, most milling activities may have taken place at them rather than at most of the sites in our sample, which would represent short-term specialized use areas visited by smaller groups of people in such a model. On the other hand, if the Early Archaic groups practiced a highly mobile settlement system keyed to the availability of resources, then presumably the lack of ground stone tools at most sites is a reflection of their being occupied during the late winter through spring.

The exception to this pattern is the Early Archaic component at Wilson-Leonard, which had 15 ground stone artifacts, and the Sleeper site, which had 108. As noted above, we consider the Wilson-Leonard example to be the most likely candidate for a base camp in our sample of sites. The relatively high number of ground stone artifacts (excluding the Sleeper site) is an indication of the diversity of activities that took place at the site during the Early Archaic. On the other hand, the high number of ground stone tools at the Sleeper site indicates a specialized technology around seasonal harvests of some sort of seeds; the site is a specialized task/group processing site. The caching of manos also suggests the site was located in the territory of a group that expected to return to the site (Johnson 1991:146). What is significant about the Sleeper site is that various types of plant resources were apparently being processed, since it is unlikely the larger features were used to process seeds and/or other plants such as sotol. 
At both the Wilson-Leonard and Sleeper sites, gender-based activities can be inferred from the higher frequencies of ground stone artifacts. Based on ethnographic studies, Johnson (1991) inferred that women were likely responsible for the milling and baking of plant foods. The low numbers of ground stone artifacts at most of the Early Archaic sites, do not necessarily mean that women were not present at these sites, but it raises the possibility of such avenues for future research. Ground stone tools are curiously few in number or often absent from central Texas site assemblages. Given that ground stone tools are costly to transport and are therefore often cached (i.e., they become site furniture) one would think that such tools would quickly accumulate at a site and/or would be easily recognized given their repeated used, but this often is not the case. The near absence of ground stone tools at most central Texas sites could mean a number of things, including that the plant foods utilized did not require a great amount of milling or pulverizing, or that milling and pulverizing activities were accomplished using implements of wood or bone.

\section{Observations on Burned Rock Features}

The Sleeper site is odd in another way: the ratio of small to large features is unique, at least as far as site data on Table 13.1 are configured. At sites with more than three total features, the ratio of small features to large features ranges from 1:1 to $3: 1$ except at the Sleeper site, where the ratio is 5.5:1. The other unique trait at the Sleeper site is the presence of a so-called rock stratum. As Johnson (1991:47) describes it, "the rock stratum is not a compact layer of stones, being instead a zone of fine-grained sediments in which stones occur irregularly_singly and in bunches." His illustration of the feature resembles what others have called sheet middens, but also indicates discrete clusters of rock which he has designated individual features (Johnson 1991:Figure 13). Ground stone artifacts occur throughout this rock stratum, as isolated tools or clusters with their own feature designation. As is discussed below, the ratio of large to small features at the Sleeper site is more reminiscent of the ratio seen at Middle Archaic sites that have burned rock middens.

At the Gatlin site, as was discussed in Chapter 12, two types of cooking appear to be represented by the burned rock features: small-scale grilling/smoking/roasting of animal and plant resources and larger scale baking of plants and possibly animal represented by the earth oven forms. As noted, most of the burned rock features in all occupation zones are small and likely used to process small quantities of food for immediate consumption; however, but there are differences between the various occupation zones. The largest site features (excluding the burned rock midden), are from OZ2 and include Features 5, 13, 22,25 , and 26 .

In general, there is a great deal of variation in the feature assemblages across our Early Archaic sample of sites. Some sites and components have no large features, while Panther Springs Creek site has no small features. Some sites have very few features, while the Gatlin and Wilson-Leonard sites have many. None of the sites in our sample has an Early Archaic burned rock midden. The most obvious observation that applies to sites with both small and large features is that the ratio of small to large features is between 1:1 and 3:1, with the Sleeper site being the exception, as noted above. Of the 16 components, nine have more of the smaller features than larger features.

Taken as a whole, the feature data show that all Early Archaic sites are not created equal. As is suggested by other lines of information, different activities took place at different sites, reflecting a complex settlement system involving highly mobile groups with small numbers of people exploiting different resources at different times across the landscape.

\section{Observations on Gouges, Guadalupe Tools, Clear Fork Tools, and Scrapers}

The inferred use of Guadalupe tools, Clear Fork tools, and gouges is to shape hard materials. Usewear analysis on Clear Fork tools, including the Gatlin site assemblage have found they have a more complex use life and were also used as hide scrapers. Guadalupe tools, Clear Fork tools, and gouges were hafted and likely part of a personal tool kit. Their presence implies both maintenance and manufacturing functions of tool components (hafts, shafts, handles, etc.) and site components such as structures (poles, supports, etc.). 
The greatest quantity of Clear Fork tools and gouges occurs in the earliest Early Archaic components. These are most often associated with Angostura and Early Split Stem points as at the Wilson-Leonard, Richard Beene, and Armstrong sites. These sites are located along the prairie edges in riparian areas. In later Early Archaic components at the same sites, there is a sharp decline in the number of Clear Fork tools, especially when compared with projectile points. There is a similar decline in formal drills and perforators from the beginning of the Early Archaic to the later period of Martindale type points.

Scrapers are more problematic to quantify, since they were rarely categorized in site descriptions. When they have been examined for use-wear, like Clear Fork tools, they where used to scrape a variety of materials. The high number of scrapers from OZ2 at the Gatlin site may be part of the site function, since they are also abundant in the Middle Archaic OZ3.

The Armstrong site stands out as unique in our Early Archaic sample; it has more Clear Fork tools $(n=12)$, scrapers $(n=7)$, and perforators $(n=5)$ than projectile points $(\mathrm{n}=3)$. Additionally, it has no burned rock features in the Early Archaic component, but does have evidence of subsistence related activities, including deer bone.

Johnson (1991:159) makes some provocative statements about the presence or absence of Guadalupe tools and other woodworking implements as they relate to seasonality. He suggests that sites with evidence of heavy woodworking, as indicated by a relatively high percentage of gouges, indicates cold weather occupation based on the assumption that woodworking tools were used to construct shelters or houses. While that is certainly a possibility, it remains difficult to prove or even to test. Following Johnson's logic, the Gatlin site may have been primarily occupied during the winter though only a handful of these tool types were recovered.

We offer an alternative idea that Guadalupe tools, in particular, may have been primarily used in the construction of canoes, as suggested by Dockall and Black (2006) to explain the high frequency of Guadalupe tools at the Morhiss Mound site far downstream along the Guadalupe River in Victoria County. The frequency of Guadalupe tools at Early Archaic sites may have more to do with the proxim- ity of the site to (1) a navigable waterway, and (2) suitable trees for making canoes than it does with seasonality. Because canoe making was presumably a slow and labor intensive process, we would expect higher percentages of Guadalupe tools to be found at base camps or sites occupied for several months at a time off of the Balcones Escarpment or very near its edge. Black and McGraw's (1985) preliminary map of Guadalupe tool distributions tentatively support this pattern. Small numbers of Guadalupe tools would still show up in the archaeological record at other sites as the result of general woodworking activities or as elements of personal toolkits. At this point, we offer this as a possible future research issue regarding Early Archaic site patterning and artifact assemblages.

\section{Observations on Projectile Points}

Lacking chronometric dates from most of the components in Table 13.1, the chronology we proposed in the beginning of this chapter can be used to assign relative ages to components based on the frequencies of projectile point types. This is a very gross way of ordering the components because it seems clear from our data that there is some temporal overlap in projectile point type styles (i.e., one type did not suddenly replace an earlier type in a group's artifact assemblage). The Early Archaic to late Middle Archaic point type sequence at the Gatlin site is Early Barbed Devil's Variant, Gower, and Martindale/Bandy for the Early Archaic, followed by Early Triangular, Andice/Bell, Nolan, and La Jita in the Middle Archaic. As the table shows, the sites span a large block of time in the Early Archaic, from Angostura occupation in the Richard Beene Upper Perez component to the handful of sites with Martindale occupations.

As features become more sophisticated in their use as plant processing appliances, other forms of lithic technology change, as well. Most notable is the development of regional variations in projectile point forms. The proliferation of projectile point forms, beginning with Angostura type points, slowly accelerates during the Early Archaic. The rather limited number of projectile point types found at the Early Archaic sites is in stark contrast to the Late Archaic component at the Gatlin site. Of the 26 point types identified at the Gatlin site, 20 are found in OZ4, the Late Archaic component. For the Early Archaic 
components in our sample, only the Wilson Leonard Early Archaic component has more than six different projectile points in the assemblage; the Wilson Leonard component used in the table is a conflation of several stratigraphic units and may, therefore, be misleading.

Another technological change observed is that as the number of point types increases, flaking characteristics become less patterned on both projectile points and other tool forms such as bifacial gouges and Clear Fork tools and perforators and drills. The reasons for this are unclear. However, it is important to point out that this is a non-quantified observation perhaps related to reworking of tools.

One noted trait of the early split stem points such as Hoxie and Gower and with Martindale points is that they were frequently used for additional tasks beyond a projectile point. Almost 50 percent of Gower points from Wilson-Leonard were used for other functions such as sawing and slicing during butchering, and 40 percent of the Early Archaic points from the Gatlin site were used for various other functions, including butchering.

All the examined components are near abundant quantities of usable and frequently high quality chert, and there is a noted lack of exotic materials. The lithic reduction occurring at the sites utilized the local supplies of chert, although in almost all instances the initial reduction occurred off site. Sources of raw materials include channel gravels, upland lag deposits, and primary deposits. Discarded tools and projectile points are also made of local material and, therefore, suggest increasing territoriality and restricted mobility further developing in the Early Archaic.

At the Gatlin site, the Early Archaic points are primarily Central Texas related styles with some types more commonly found in the Lower Pecos intermixed (Bandy and Baker points for example). As Hester and Shafer observe in Appendix C, the relationship between Bandy and Martindale points is not well understood, nor is the geographic distribution and frequency of Bandy points.

\section{Observations on Subsistence}

Of all the categories in our tables, the subsistence data are the most difficult to interpret. Poor preservation and inconsistent reporting methods hinder our analysis of subsistence, but general statements can still be made. First, there are, important differences between sites. The high frequency of ground stone at the Sleeper site, for example, suggests that milling nuts and seeds was a primary activity there. Most of the other sites, however, have faunal remains, tools, and features indicative of frequent hunting and butchering activities, with little or no evidence of milling.

A second general observation is that deer is present at most Early Archaic sites, indicating that it was the most stable and most important source of meat for the groups of people occupying the southern Edwards Plateau. Of the 15 Early Archaic components in Table 13.1, 11 had evidence of deer, while only three had bison remains. Interestingly, bison is not present in the older components; it first appears around the Gatlin site in OZ2.

From the Gatlin site data, we know that the game exploited by the Early Archaic hunters included rabbit, small mammals, and fish, although these were less important than deer and bison to the diet. The presence of axial elements and teeth suggest that whole, large mammals such as bison and deer were butchered at the Gatlin site, indicating they were killed nearby. In addition to food, these animals were exploited for materials such as hide, bone, and antler.

Meat was an important subsistence resource, but it was supplemented throughout the use of the site by plants. As early as OZ2 at the Gatlin site, people were making large features capable of cooking bulk quantities of plants. It is likely that many of the larger features at other Early Archaic sites in our sample were also used for preparing plant materials in large quantities; however, none of the sites suggest bulk processing of low-ranking plants on the order seen in the subsequent Middle Archaic period. Plants appear to be no more than a supplement to the main hunting diet during the Early Archaic.

The subsistence picture for the Early Archaic suggests, as Johnson (1991) noted previously, that different sites were geared toward different subsistence-related activities. Most appear to be primarily hunting and butchering locations, where plant resources were occasionally exploited as a supplement. At other sites, for example, the Sleeper site hunting was of 
secondary importance., and milling nuts and seeds was the primary task-oriented activity.

\section{Middle Archaic Trends}

The Gatlin site's occupation, as well as those of several other sites in our comparative study, spans the transition from the Early Archaic to the Middle Archaic. In general, excavated sites in Texas with Middle Archaic components are rare. When they have been documented, the assemblage is small. A notable exception is the Gatlin site. The $68.5 \mathrm{~m}^{3}$ of Middle Archaic deposits are three times larger than any other site with comparable data (see Table 13.2). Despite issues with the integrity of the OZ3 deposits at the Gatlin site, which have been addressed previously in this chapter, the component contributes significantly to our understanding of the adaptive changes to subsistence and technology during the Middle Archaic in the Southern Edwards Plateau. In general, the sites in our table show that certain Early Archaic lifeways continued, but others underwent some modifications. For example, group size was presumably still small and for the most part the people moving across the margins of the plateau traveled in small foraging groups. However, the appearance of burned rock middens in three of the site components in our table signals an intensification of the exploitation of certain low-ranking plants - probably a response to environmental changes in the subsistence base, as well as a possible decline in residential mobility.

It is our contention that much of the cultural change seen during the Middle Archaic, particularly in the form of feature technology and subsistence, is an adaptive response to changing environmental conditions. The warming event ca. 5000-4500 B.P. seen in paleoenvironmental data from the Gatlin site and other sites in the region not only necessitated changes in how humans utilized the landscape, but also affected the nature and quality of the archaeological deposits. At 41KR621 and numerous sites in the region, the drying trend is reflected archaeologically as a period of mixed or compressed cultural deposits. The most significant changes, as discussed below, occurred in projectile points, cooking technology, and subsistence strategies.

\section{Observations on Ground Stone}

Most of the Gatlin site ground stone tools are from OZ3 ( $n=4$, although it is still a very small number). The metate fragments likely represent small-scale grinding activities (seeds, acorns, etc.) by individuals, and not a long term significant activity at the Gatlin site. In general, ground stone artifacts are uncommon at the Middle Archaic components in the sample, the exception being the Eckols site, which had 45 ground stone specimens.

At the Wilson-Leonard site, ground stone artifacts are found with middens; however, middens do not occur in the Middle Archaic components at the Gatlin and Eckols sites, the only other components containing ground stone artifacts in our sample. Ground stone tools are most numerous along the edge of the Balcones Escarpment. At most sites, the paucity of such tools probably indicates limited exploitation of nuts and seeds by a small number of individuals, perhaps as a supplement to hunting. At the Eckols site, as was the case with the Sleeper site during the Early Archaic, the high number of ground stone implements indicates a heavy degree of milling activities. With numbers of ground stone far exceeding anything found at comparable sites, the Eckols site and Sleeper site undoubtedly represent task-specific camps where the processing of a seasonal plant (acorns, walnut, sotol, etc.) was conducted repeatedly over hundreds, if not thousands, of years. It is likely these two sites are located in a former "patch" of such resources, hence the repetitive occupations and site furniture. Possibly, much of this work would have been done by women; given that it is during the Middle Archaic that burials such as these at Loma Sandia contain ground stone tools as offerings in the burials of females (Taylor and Highley 1995).

\section{Observations on Burned Rock}

The Eckols site, mentioned above for its anomalous ground stone assemblage, is curious for other reasons as well. It has a higher frequency of projectile points, scrapers, and perforators than any other site in the sample, and an atypical feature assemblage. While its density of features per cubic meter is comparable to other sites in the table, it has 11 small features, and no features larger than $1 \mathrm{~m}$ in diameter. That is unique among the components with more than one feature. Perhaps the small burned rock features at 
the Eckols site were used for baking ground nuts and seed bread.

Most sites in the Middle Archaic sample have a nearly 1:1 ratio of small features to large features, a continuation of the general Early Archaic pattern. The two Middle Archaic components at the Wilson-Leonard site and the Panther Springs Creek Middle Archaic occupation provide exceptions to this trend. Both Wilson-Leonard components contain a burned rock midden, and the ratio of small to large features jumps to between 3.5:1 and 8.5:1. Panther Springs Creek's Middle Archaic component has no burned rock features, except for a midden. These middens represent large-scale processing features for lower ranking plants such as sotol and various geophytes.

At the Gatlin site, in OZ3, there are also several large features, such as Features 6, 16/17, and 19 that are probably bulk or large-scale cooking features. As an example, Feature 6 is a dense cluster of burned limestone that undoubtedly was an earth oven. The large quantity of burned rock and the size and morphology of the feature fit the pattern for an earth oven (Black 1997:257) and the feature is similar to those used to process plants such as camassia sp. or geophytes (Clabaugh and Thoms 2007). Though less numerous than the small features, the increase in frequency of these ovens through time suggests a broadening of the resource base to include a diversity of high rank (meat) and lower rank (geophytes, sotol, and other plants) foodstuffs.

This utilization of lower ranked resources with earth ovens culminated at the Gatlin site in OZ4 with the construction of the burned rock midden. This dense accumulation of burned rock represents repeated episodes of large-scale baking of foodstuffs spanning the Middle to Late Archaic periods. Study of the midden structure suggests it has several overlapping ovens or former pits near its center and may have had a more ring-like structure in its earliest form during the Middle Archaic. Over time, reuse resulted in the formation of a more lens-shaped structure. How many episodes of use the midden represents and what resource was cooked within it, unfortunately cannot be determined.

At sites with burned rock middens, the ratio of small to large features presumably goes up because the midden replaces multiple large features as the primary cooking apparatus for low ranking plants. The number of small features may go up as well, but is indicative of other needs such as heat or the cooking of smaller quantities of meat, nut/seed breads, or cakes.

\section{ObSERVATIONS ON ToOLKITS}

The fewer overall tool forms and quantity of tools all suggest that mobility was still high during the Middle Archaic, and that fewer activities were conducted at the examined sites. Gouge-like tools decline in frequency, with the exception of the Guadalupe tools from the Panther Springs Creek site. As an overall comparison, the ratio of points to gouges in the Early Archaic is 8.9:1, while in the Middle Archaic it is 43.1:1. Perforators are concentrated at only a few sites that also contain ground stone tools. The generalized toolkits, with low diversity, reflect the fact that certain projectile point types, including Early Triangular and La Jita points, were used as knives as well as darts. This is true of the sample of Early Triangular points from the Gatlin site; of the 22 Early Triangular points analyzed for use-wear, 16 had been used as projectile points and knives or scrapers, and six specimens, while probably hafted, had been used exclusively as knives and scrapers and not as projectile points. With chert widely available, the multipurpose nature of these tools reflects highly mobile groups.

The organization of lithic technology at the Middle Archaic sites continues to support the notion that these people were fairly mobile, organized in a similar fashion as Binford's foragers. However, as opposed to many sites, the Gatlin site data reflects a growing shift in this pattern of organization as larger features begin to appear and toolkits include a slightly more diverse suite of tools, with some ground stone, scrapers, gouges, and the like. This shift is subtle and likely occurred over a long period of time, as the environment entered the Altithermal and the drying conditions altered the regional vegetative regime.

\section{Observations on Projectile Points}

Although we proposed a Middle Archaic sequence of point types at the Gatlin site (Early Triangular, Andice/Bell, Nolan, and La Jita), we found it less 
useful for ordering our Middle Archaic sample of sites in a relative chronology. The ratio of point types at the various sites defies the simple application of our sequence as a gross means of assigning relative ages, presumably because of increased compression/mixing of deposits at most, if not all, of the sites in the sample. There are trends, however, in the geographic distribution of point types that were not observed in the Early Archaic.

The implication from previous studies is that the Bell/Andice makers are southern expressions of Calf Creek bison hunters from Oklahoma who followed bison herds southwards as grasslands became more expansive. The timing of a southward movement of these people probably occurred around ca. 5,000 B.P., based on radiocarbon dates in Oklahoma. It is also probable that when bison numbers increased in Central Texas, the existing technology of projectile points, skinning tools, and knives was quickly adapted to the new resource. In the sites in our sample, the greatest numbers of Bell/Andice points are along the southern edge of the Plateau in the Balcones Canyonlands and on the Edwards Plateau, while the greater quantities of stemmed Nolan, La Jita, and Travis points are along the eastern and northern edges of the Edwards Plateau and along the Balcones Escarpment (see Table 13.2).

Bell/Andice points co-occur with Early Triangular points in about half the sites that have one or both of the types. Hester (2004:137-138) speculates that some may be preforms for Bell/Andice points, while others may be knives. As noted above, the Gatlin site use-wear study suggests that Early Triangular points were used as both projectiles and knives. Unfortunately, we do not see a 1:1 correlation of either type with the presence of bison at the sites in our sample.

\section{Observations on Subsistence}

During the Middle Archaic, some important changes in subsistence are evident, although much of the data has to be inferred from other lines of evidence owing to poor faunal and flora preservation. Deer remains the most consistent and common, and presumably important, source of meat during the Middle Archaic, and bison appears in several components.
Many sites show a continuation of the Early Archaic trend of a nearly 1:1 ratio of small features to large, but three sites in our sample include burned rock middens for the first time. When the site occupants begin using middens, the relatively frequency of large features decreases notably; middens become the focus of subsistence-related activities associated with bulk processing of plant material. The large earth ovens of the Early Archaic, in essence, are replaced by one large feature. Smaller hearths still occur, and were presumably used for heat or to cook small quantities of meat.

Middens suggest repeated visits to the same location, presumably seasonally, possibly by larger groups of people. Interestingly, middens do not occur at all sites in the Middle Archaic. Hunting, obviously, remained the primary important subsistence activity, and hunting-specialized sites are common in the Middle Archaic.

\section{Final Thoughts}

Considering the Gatlin site in a regional context highlights the site's contributions to the growing body of knowledge about the Early and Middle Archaic periods in the southern Edwards Plateau and identifies persistent data gaps and lingering questions about human adaptation in Central Texas. The Gatlin site, despite common limitations imposed by geomorphological and paleoenvironmental conditions of site formation, represents one of the two or three largest-excavated and best-dated Early Archaic samples in Central Texas.

A significant, if not scientifically popular, contribution the site has made is to the Early Archaic and Middle Archaic chronology of the region. If one digs deep into the data used to identify the age ranges of various style intervals or subperiods of the Early Archaic, and to a lesser extent the Middle Archaic, it becomes clear that many of the primary sites commonly referenced the lack of radiocarbon dates. Thus, point sequences are based on relatively stratigraphic positions at a handful of sites and age ranges are assigned to style intervals somewhat arbitrarily. The data from 41KR621 have been used to propose a refined chronology for an important portion of the cultural sequence in southern Central Texas. 
The Gatlin site also contributes important data to our understanding of human lifeways and organization during the same time frame along the southern Edwards Plateau. As has been noted earlier, the testing investigations led to a preliminary assumption that the Early Archaic component at the Gatlin site was a large residential base camp. This conclusion was based in part on the fact that features and associated artifacts were found fairly far apart in backhoe trenches and test units in the southern part of the site. Our data, however, show that from the Early Archaic through the Middle Archaic, the site served as a short-term camp utilized by small groups of foragers. Within the categories of activities discussed previously in this chapter, the folks visiting the Gatlin site left behind an archaeological signature of activities focused primarily on hunting and butchering. The types of activities that took place primarily included chores associated with processing game, rejuventating weapons, and cooking small amounts of food suitable for a familial size group at the site. What is so interesting (and part of this observation may be biased by the fact that we are stuck excavating within the Area of Potential Effects for the Spur 98 project and know nothing of the area outside of the right-of-way), is that the types of activities that took place on this particular spot on the landscape varied little between OZ1 through OZ3. Admittedly, as the stone tool ratio studies show, there were differences in the types of materials left behind at the site from time to time, but in general the generations of people at the Gatlin site used it for the mainly the same purpose.

While signs of this change begin to show in the later occupations, it is only during OZ4 that the midden was created, perhaps signaling a shift in site function to more of a residential base camp. Curiously, the artifact data do not necessarily support this conclusion. Rather, they reflect a high degree of mobility, much more so than would be expected at a base camp. The data could be skewed by our excavation sample of OZ4, however; much of our information comes from one rather small area of the site south of midden and may not be representative of the site as a whole during the Late Archaic. Regardless, these contradictions present intriguing avenues for further study of changes in human organization and technology through the Middle to Late Archaic periods.
In a regional context, the Gatlin site is another example of the complexity and diversity in the Early Archaic settlement system noted by previous researchers. As Johnson (1991:159) states, "people acquired different foods at different suitable places," meaning that certain sites were visited repeatedly on a seasonal basis. However, our understanding of the actual Early Archaic settlement system that was responsible for the pattern we see in the archaeological record, including how it may have changed over time, is still maturing. The Gatlin site does begin to resolve the issue of whether or not the Early Archaic occupants of the southern Edwards Plateau moved as entire groups from site to site (foragers) or whether they occupied larger base camps for at least part of the year and sent small groups on specific tasks out to special purpose sites (collectors). Johnson (1991:160) speculated that folks in the eastern part of the Crescent may not have had large base camps, traveling from site to site in small groups; the Gatlin data for the Early Archaic and Middle Archaic periods supports this hypothesis.

However, unresolved issues remain about not only the size of groups in the Early and Middle Archaic, but also their ranges and seasonal movements. It seems logical that groups would have moved primarily up and down river valleys, but how far south of the escarpment and how far north into the Edwards Plateau a group may have moved over the course of a year on their seasonal rounds is still a mystery. If canoes were part of their toolkit, at least when they were off the Edwards Plateau, it is possible their range of movement was extensive.

These types of issues promise interesting lines of inquiry for future archaeological work in the area. In addition, we believe that the robust Gatlin site assemblage and dataset can still yield a wealth of information utilizing various research approaches. As just one example, a more in-depth analysis of the variability in populations of several projectile point types from the site (namely Martindale, Early Triangular, and La Jita) coupled with comparison with similar point assemblages from other sites in the region, could yield new information on hunting technology, projectile point mechanics, efficiency, and recycling, and possibly group movement across the landscape. Even after years of study, it is clear that that the site can continue to contribute to our un- 
derstanding of prehistoric lifeways in the Guadalupe River valley for many decades to come.

Finally, it is our hope that the lessons learned from excavating such a large and complex site are taken into consideration by future researchers who may be faced with challenges similar to those posed by the Gatlin site. As we discuss in Appendix K, we experimented with different approaches and techniques in both the field excavations and analyses. A critical examination of these approaches and the overall project progression yielded important considerations for future research. And while some of our different approaches to excavating the site worked and some did not, we firmly believe that Texas archaeologists need to continue to be creative and think "outside the box" when pulling apart a site and examining its various components. 
13-26 Chapter 13 


\section{REFERENCES}

Abbott, J. T.

1994 Geomorphic Context of the Barton Site (41HY202) and the Mustang Branch Site (41HY209). In Archaic and Late Prehistoric Human Ecology in the Middle Onion Creek Valley, Hays County, Texas, by R. A. Ricklis and M. B. Collins, pp. 12-1-12-46. Studies in Archeology 19, Texas Archeological Research Laboratory, The University of Texas at Austin.

2004 Stratigraphic and Geoarchaeological Investigations on the Guadalupe River: Interstate 35, Comal County, and Spur 98, Kerr County, Texas. In Interim Report: Survey and Testing Along Spur 98, Kerr County, Texas, by B. A. Houk and K. A. Miller, pp. 20-30. SWCA Environmental Consultants, Austin.

Aber, J. S.

1997 Chert Gravel and Neogene Drainage in East-Central Kansas. Current Research in Earth Sciences, Bulletin 240, Part 3, Kansas Geological Survey.

Ahler, S. A.

1989 Mass Analysis of Flaking Debris: Studying the Forest Rather than the Trees. In Alternative Approaches to Lithic Analysis, edited by D. Henry and G. Odell, pp. 85-119. Archaeological Papers of the American Anthropological Association No. 1.
Amick, D. S.

1994 Technological Organization and the Structure of Inferences in Lithic Analysis: An Examination of Folsom Hunting Behavior in the American Southwest. In The Organization of North American Chipped Stone Tool Technologies, edited by P. J. Carr, pp. 9-34. Archaeological Series 7, International Monographs in Prehistory, Ann Arbor.

1995 Patterns of Technological Variation Among Folsom and Midland Projectile Points in the American Southwest. Plains Anthropologist 40(151): 23-38.

Andrefsky, W., Jr.

1994 Raw-Material Availability and the Organization of Technology. American Antiquity 59(1):21-34.

1998 Lithics: Macroscopic Approaches to Analysis. Cambridge University Press, Cambridge.

Anthony, D. and D. Brown

1994 Archeological Investigations in the Denton Creek Floodplain: Data Recovery Excavations at 41DL279, Denton and Dallas Counties, Texas. Hicks \& Company Archeology Series 37, Austin, Texas.

Arbingast, S. A.

1976 Atlas of Texas. Bureau of Business Research, The University of Texas at Austin.

Archer, S.

1990 Development and Stability of Grass/Woody Mosaics in a Subtropical Savannah Parkland, Texas, U.S.A. Journal of Bigeography 17(4/5):453-462. 
Asselman, N. E., and H. Middelkoop

1993 Floodplain Sedimentation: Quantities, Patterns and Processes. Earth Surface Processes and Landforms 20:481-499.

Austin, R. J.

1999 Technological Characterization of Lithic Waste-Flake Assemblages: Multivariate Analysis of Experimental and Archaeological Data. Lithic Technology 24:53-68.

Bailey, V.

1905 Biological survey of Texas. Life zones, with characteristic species of mammals, birds, reptiles, and plants. Government Printing Office, Washington, D.C.

Baker, E.

20031989 and 1990 Excavations at the Smith Site (41UV132), Uvalde County, Texas. Bulletin of the Texas Archeological Society 74:1-30.

Baker, V. R., and R. C. Kochel

1988 Flood Sedimentation in Bedrock Fluvial Systems. In Flood Geomorphology, edited by V. R. Baker, R. C. Kochel, and P. C. Patton, pp. 123-137. John Wiley \& Sons, New York.

Baker, V. R., and M. M. Penteado-Orellana 1977 Adjustment to Late Quaternary Climate Change by the Colorado River of Central Texas. Journal of Geology 85:395-422.
Balinsky, R.

1998 Chapter 35: Pleistocene to Holocene Wilson-Leonard Microvertebrae Fauna and Its Paleoenvironmental Significance. In Wilson-Leonard: An 11,000-year Archeological Record of Hunter-Gatherers in Central Texas, Vol. V, edited by $\mathrm{M}$. B. Collins, pp. 1515-1542. Studies in Archeology 31, Texas Archeological Research Laboratory, The University of Texas at Austin. Archeology Studies Program Report 10, Environmental Affairs Division, Texas Department of Transportation, Austin.

Bamforth, D. B.

1986 Technological Efficiency and Tool Curation. American Antiquity 51:38-50.

1991 Technological Organization and HunterGatherer Land Use: A California Example. American Antiquity 56(2):216-234.

1998 Ecology and Human Organization on the Great Plains. Plenum Press, New York.

Banks, L. D.

1990 From Mountain Peaks to Alligator Stomachs: A Review of Lithic Sources in the Trans-Mississippi South, the Southern Plains, and Adjacent Southwest. Memoir 4, Oklahoma Anthropological Society, Norman.

Barker, R. A., P. W. Bush, and E. T. Baker, Jr. 1994 Geologic History and Hydrogeologic setting of the Edwards-Trinity Aquifer System, west-central Texas. Water Resources Investigations Report 94-4039. U.S. Geological Survey, Earth Science Center, Washington, D.C.

Barnes, V. E.

1981 Geologic Atlas of Texas: Llano Sheet. Bureau of Economic Geology, The University of Texas at Austin.

1983 Geologic Atlas of Texas: San Antonio Sheet. Bureau of Economic Geology, The University of Texas at Austin. 
Beadles, M.

1971a Interim Report on the Bammel Site (41KR10), Analysis of Vertical Distribution of Projectile Points. The Artifact 2(2).

1971b The Bammel Site (41KR10). The Artifact 3(1).

Bement, L. C.

1989 Lower Pecos Canyonlands. In From the Gulf to the Rio Grande: Human Adaptation in Central, South, and Lower Pecos Texas, by T. R. Hester, S. L. Black, D. G. Steele, B. W. Olive, A. A. Fox, K. J. Reinhard, and L. C. Bement, pp. 63-76. Research Series 33, Arkansas Archeological Survey, Fayetteville.

1991 The Statistical Analysis of Langtry Variants from Arenosa Shelter, Val Verde County, Texas. In Papers on Lower Pecos Prehistory, edited by S. A. Turpin, pp. 51-64. Studies in Archeology 8, Texas Archaeological Research Laboratory, The University of Texas at Austin

1994 Hunter-Gatherer Mortuary Practices During the Central Texas Archaic. University of Texas Press, Austin.

Bettinger, R. L., and M. A. Baumhoff

1982 The Numic Spread: Great Basin Cultures in Competition. American Antiquity 47(3):485-503.

Binford, L. R.

1962 Archeology as Anthropology. American Antiquity 28:217-225.

1964 A Consideration of Archaeological Research Design. American Antiquity 29:425-441.

1973 Interassemblage Variability: The Mousterian and the Functional Argument. In The Explanation of Cultural Change: Models in Prehistory, edited by C. Renfrew, pp. 227254. Duckworth, London.
1977 For Theory Building in Archaeology: Essays on Faunal Remains, Aquatic Resources, Spatial Analysis, and Systemic Modeling. Academic Press, New York.

1978 Nunamiut Ethnoarchaeology. Academic Press, New York

1979 Organization and Formation Processes: Looking at Curated Technologies. Journal of Anthropological Research 35:172197.

1980 Willow Smoke and Dogs' Tails: HunterGatherer Settlement Systems and Archaeological Site Formation. American Antiquity 45:4-20.

1982 The Archaeology of Place. Journal of Anthropological Archaeology 1(1):5-32.

1983 Working at Archaeology. Academic Press, New York

Binford, S. R.

1968 Ethnographic Data and Understanding the Pleistocene. In Man the Hunter, edited by R. Lee and I. DeVore, pp. 274-275. Aldine/Atherton, Chicago.

Bisson, M. S.

2000 Nineteenth Century Tools for TwentyFirst Century Archaeology? Why the Middle Paleolithic Typology of Francois Bordes Must Be Replaced. Journal of Archaeological Method and Theory 7(1):1-48.

Black, S. L.

1989 Central Texas Prairie Plateau. In From the Gulf to the Rio Grande: Human Adaptation in Central, South, and Lower Pecos Texas, by T. R. Hester, S. L. Black, D. G. Steele, B. W. Olive, A. A. Fox, K. J. Reinhard, and L. C. Bement, pp. 17-38. Research Series 33, Arkansas Archeological Survey, Fayetteville. 
1997 Chapter 7: The Corn Creek Sites: 41MK8 and 41MK9. In Hot Rock Cooking on the Greater Edwards Plateau: Four Burned Rock Midden Sites in West Central Texas, by S. L. Black, L. W. Ellis, D. G. Creel, and G. T. Goode. Studies in Archeology 22, Texas Archeological Research Laboratory, The University of Texas at Austin. Archeology Studies Program Report 2, Environmental Affairs Division, Texas Department of Transportation, Austin.

2003 Research Module 2: Studying the Hearths of the Greater Edwards Plateau. In Pavo Real (41BX52): A Paleoindian and Archaic Camp and Workshop on the Balcones Escarpment, South-Central Texas, by M. B. Collins, D. B. Hudler, and S. L. Black, pp. 375-405. Studies in Archeology 41, Texas Archeological Research Laboratory, The University of Texas at Austin.

Black, S. L., and D. G. Creel

1997 Chapter 11: The Central Texas Burned Rock Midden Reconsidered. In Hot Rock Cooking on the Greater Edwards Plateau: Four Burned Rock Midden Sites in West Central Texas, by S. L. Black, L. W. Ellis, D. G. Creel, and G. T. Goode, pp. 269-306. Studies in Archeology 22, Texas Archeological Research Laboratory, The University of Texas at Austin. Archeology Studies Program Report 2, Environmental Affairs Division, Texas Department of Transportation, Austin.

Black, S. L., and L. W. Ellis

1997 Chapter 1: Introduction: A Study of Four Burned Rock Midden Sites. In Hot Rock Cooking on the Greater Edwards Plateau: Four Burned Rock Midden Sites in West Central Texas, by S. L. Black, L. W. Ellis, D. G. Creel, and G. T. Goode, pp. 1-22. Studies in Archeology 22, Texas Archeological Research Laboratory, The University of Texas at Austin. Archaeology Studies Program Report 2, Environmental Affairs Division, Texas Department of Transportation, Austin.
Black, S. L., L. W. Ellis, D. G. Creel, and G. T. Goode

1997 Hot Rock Cooking on the Greater Edwards Plateau: Four Burned Rock Midden Sites in West Central Texas. 2 vols. Studies in Archeology 22, Texas Archeological Research Laboratory, The University of Texas at Austin. Archeology Studies Program Report 2, Environmental Affairs Division, Texas Department of Transportation, Austin.

Black, S. L., and A. J. McGraw

1985 The Panther Springs Creek Site: Cultural Change Within the Upper Salado Creek Watershed, South-Central Texas. Archaeological Survey Report 100, Center for Archaeological Research, The University of Texas at San Antonio.

Blackham, Mark

1998 The Unitary Association Method of Relative Dating and Its Application to Archaeological Data. Journal of Archaeological Method and Theory 5(2):165:207.

Blades, B. S.

2003 End Scraper Reduction and HunterGatherer Mobility. American Antiquity 68(1):141-156.

Blair, W. F.

1950 The Biotic Provinces of Texas. The Texas Journal of Science 2(1):93-117.

Bleed, P.

1986 The Optimal Design of Hunting Weapons: Maintainability or Reliability? American Antiquity 51(4):737-747.

Blum, M. D.

1987 Late Quaternary Sedimentation in the Upper Pedernales River, Texas. Unpublished M.A. thesis, Department of Geology, The University of Texas at Austin. 
Blum, M. D., R. S. Toomey, III, and S. Valastro

1994 Fluvial Response to Late Quaternary Climatic and Environmental Change, Edwards Plateau, Texas. Palaeogeography, Palaeoclimatology, Palaeoecology 108:121.

Blum, M. D., and S. Valastro, Jr.

1989 Response of the Pedernales River of Central Texas to Late Holocene Climatic Change. Annals of the Association of American Geographers 79(3):435-456.

1992 Quaternary Stratigraphy and Geoarchaeology of the Colorado and Concho Rivers, West Texas. Geoarchaeology 7:419-488.

Boam, J.

1989 Indiana Jones and the Last Crusade. Screenplay based on a story by George Lucas and Menno Meyjes.

Boszhardt, R. F. and J. McCarthy

1999 Oneota End Scrapers and Experiments in Hide Dressing: An Analysis From the La Crosse Locality Midcontinental. Journal of Archaeology 24(2):177-199.

Bourdieu, P.

1977 Outline of a Theory of Practice. Cambridge Press, Cambridge.

Bousman, C. B.

1992 Preliminary Oxygen-Isotope Evidence for Late Pleistocene-Early Holocene Climatic Change. Current Research in the Pleistocene 9:78-80.

1994 The Central Texas Pollen Record: A Reinterpretation. Current Research in the Pleistocene 11:79-81.

1998a Paleoenvironmental Change in Central Texas: Palynological Evidence. Plains Anthropologist 43(164):201-219. 1998b Late Paleoindian Archeology. In WilsonLeonard: An 11,000-Year Archeological Record of Hunter-Gatherers in Central Texas, Vol. I,, edited by M. B. Collins, pp. 161-210. Studies in Archeology 31, Texas Archeological Laboratory, The University of Texas at Austin. Archeology Studies Program Report 10, Environmental Affairs Division, Texas Department of Transportation, Austin.

Bousman, C. B., B. W. Baker, A. C. Kerr

2004 Paleoindian Archeology in Texas. In The Prehistory of Texas, edited by $\mathrm{T}$. K. Perttula, pp. 15-100. Texas A\&M University Press, College Station.

Bousman, C. B., and D. L. Nickels

1998 Summary, Conclusions, and Recommendations. In Test Excavations at the Culebra Creek Site, 41BX126, Bexar County, Texas, by D. L. Nickels, C. B. Bousman, J. D. Leach, and D. A. Cargill, pp. 215-221. Archaeological Survey Report, No. 265, Center for Archaeological Research, The University of Texas at San Antonio. Archeology Studies Program Report 3, Environmental Affairs Division, Texas Department of Transportation, Austin.

Boyd, C. E.

2003 Rock Art of the Lower Pecos. Texas A\&M University Press, College Station.

Briggs, A.K.

1971 An Archeological Survey of Ingram Reservoir. Archeological Survey Report No. 9, Texas Historical Survey Committee and Texas Water Development Board, Austin. 
Brooks, A. S., and J. E. Yellen

1987 The Preservation of Activity Areas in the Archaeological Record: Archaeological and Ethnoarchaeological Work in Northwest Ngamiland, Botswana. In Method and Theory of Activity Area Research, edited by S. Kent, pp. 63-106. Columbia University Press, New York.

Brownlow, R. K.

2004 Data Recovery Investigations at the Holt Site (41HY341) San Marcos, Hays County, Texas. Horizon Environmental Services, Inc., Austin.

Brune, G.

1981 Springs of Texas. Vol. 1. Branch-Smith Inc., Ft. Worth, Texas.

Bryant, V. M., Jr.

1966 Pollen Analysis: Its Environmental and Cultural Implications for the Amistad Reservoir Area. Unpublished M.A. thesis, Department of Anthropology, The University of Texas at Austin.

1969 Late Full-Glacial and Postglacial Pollen Analysis of Texas Sediments. Unpublished Ph.D. dissertation, Department of Anthropology, The University of Texas at Austin.

1977 A16,000 Year Pollen Record of Vegetational Change in Central Texas. Palynology 1:143-156.

1997 Pollen Analysis of Sediments in Arenosa Shelter. In Excavations at Arenosa Shelter, 1965-1966, by D. Dibble, pp. 77-85. Manuscript on file, Texas Archeological Salvage Project, the University of Texas at Austin.

Bryant, V. M., Jr. and S. A. Hall

1993 Archaeological Palynology in the United States: A Critique. American Antiquity 58(2):277-286.
Bryant, V. M., and R. G. Holloway

1985 A Late-Quaternary Paleo-environmental Record of Texas: An Overview of the Pollen Evidence. In Pollen Records of the Late Quaternary North American Sediments, edited by V. M. Bryant and R. G. Holloway, pp. 39-70. American Association of Stratigraphic Palynologists Foundation, Dallas.

Bryant V. M., Jr., and D. L. Larson

1968 Pollen Analysis of the Devil's Mouth Site, Val Verde County, Texas. In The Devil's Mouth Site: The Third Season 1967, by W. M. Sorrow, pp. 57-70. Papers of the Texas Archeological Salvage Project 14, The University of Texas, Austin.

Bryant, V. M., Jr., and H. J. Shafer

1977 The Late Quaternary Paleoenvironment of Texas: A Model for the Archeologist. Bulletin of the Texas Archeological Society 48:1-25.

Bullock, P., N. Federoff, A. Jongerius, G. Stoops, and T. Tursina

1985 Handbook for Soil Thin Section Decription. Waine Research Publications, Wolverhampton, UK.

Butzer, K. W.

1982 Archaeology as Human Ecology: Method and Theory for a Contextual Approach. Cambridge University Press, Cambridge, London, New York, New Rochelle, Melbourne, Sydney.

Byrd, C. L.

1971 Origin and History of the Uvalde Gravel of Central Texas. Baylor Geological Studies Bulletin No. 20, Baylor University, Waco. 
Callahan, E.

1979 The Basics of Biface Knapping in the Eastern Fluted Point Tradition: A Manual for Flintknappers and Lithic Analysts. Archaeology of Eastern North America 7(1):1-80.

Caran, S. C., and C. Hubbs

1994 Fishes. In Birds \& Other Wildlife of South Central Texas, by E. A. Kutac and S. C. Caran, pp. 131-145. The University of Texas Press, Austin.

Carroll, W. B.

1983 The Medina Point:A New Dart Point Type. La Tierra 10(1):29-31.

Chadderdon, M. F.

1983 Baker Cave, Val Verde County, Texas: The 1976 Excavations. Special Report 13, Center for Archaeological Research, The University of Texas at San Antonio.

Cheatham, S., M. C. Johnston, and L. Marshall

1995 Useful WildPlants of Texas, the Southeastern and Southwestern United States, the Southern Plains, and Northeastern Mexico. Useful Wild Plants, Inc., Austin.

Clabaugh, P. A. and A. V. Thoms

2007 Chapter 13: The Feature Assemblage at the Richard Beene Site. In Archaeological and Paleoecological Investigations at the Richard Beene Site 41BX831: South Central Texas, edited by A. V. Thoms and R. D. Mandel, pp. 251-302. Center for Ecological Archaeology, Texas A\&M University, College Station.

Coleman, S., G. L. Evans, and T. R. Hester 2001 An Overview of the Archeology at Montell Rockshelter, Uvalde County, Texas. TARL Research Notes 7(1):21-31.
Collins, M. B.

1994 Late Archaic Evidence in the Project Area. In Archaic and Late Prehistoric Human Ecology in the Middle Onion Creek Valley, Hays County, Texas, by R. A. Ricklis and M. B. Ricklis, pp. 101-189. Studies in Archeology 19, Texas Archeological Research Laboratory, The University of Texas at Austin.

1994 Cultural Background. In Archaic and Late Prehistoric Human Ecology in the Middle Onion Creek Valley, Hays County, Texas, by R. A. Ricklis and M. B. Ricklis, pp. 11-26. Studies in Archeology 19, Texas Archeological Research Laboratory, The University of Texas at Austin.

1995 Forty Years of Archeology in Central Texas. Bulletin of the Texas Archeological Society 66:361-400.

1998 Background to the Archaeological Investigations. In Wilson-Leonard: An 11,000-year Archeological Record of Hunter-Gatherers in Central Texas, Vol. I, edited by M. B. Collins, pp. 53-67. Studies in Archeology 31, Texas Archeological Research Laboratory, The University of Texas at Austin. Archeology Studies Program Report 10, Environmental Affairs Division, Texas Department of Transportation, Austin.

2004 Archeology in Central Texas. In The Prehistory of Texas, edited by T. K, Perttula, pp. 101-126. Texas A\&M University Press, College Station.

Collins, M. B. (editor)

1998 Wilson-Leonard, An 11,000-year Archeological Record of Hunter-Gatherers in Central Texas. 5 vols. Studies in Archeology 31, Texas Archeological Research Laboratory, The University of Texas at Austin. Archeological Studies Program, Report 10, Environmental Affairs Division, Texas Department of Transportation, Austin. 
Collins, M. B., B. Ellis, and C. Dodt-Ellis

1990 Excavations at the Camp Pearl Wheat Site (41KR243): An Early Archaic Campsite on Town Creek, Kerr County, Texas. Studies in Archeology 6, Texas Archeological Research Laboratory, The University of Texas at Austin.

Collins, M. B., J. Guy, and S. W. Dial

1998 The Archaic Period, 8800 to 1300 b.p. In Wilson-Leonard: An 11,000-Year Archeological Record of Hunter-Gatherers in Central Texas, Vol. I,, edited by M. B. Collins, pp. 211-270. Studies in Archeology 31, Texas Archeological Laboratory, The University of Texas at Austin. Archeology Studies Program Report 10, Environmental Affairs Division, Texas Department of Transportation, Austin.

Collins, M. B., and R. A. Ricklis

1994 Cultural Background. In Archaic and Late Prehistoric Human Ecology in the Middle Onion Creek Valley, Hays County, Texas, by R. A. Ricklis and M. B. Collins, pp. 11-26. Studies in Archeology 19, Texas Archeological Research Laboratory, The University of Texas at Austin.

Cooke, M. J.

2005 Soil Formation and Erosion in Central Texas: Insights From Relict Soils and Cave Deposits. Ph.D. dissertation, Department of Geology, The University of Texas at Austin.

Cooke, M. J., L. A. Stern, J. L. Banner, L. E. Mack, T. W. Stafford Jr., and R. S. Toomey

2003 Precise Timing and Rate of Massive Late Quaternary Soil Denudation. Geology 31(10):853-856.

Creel, D. G.

1986 AStudy ofPrehistoric BurnedRockMiddens in West Central Texas. Unpublished Ph.D. dissertation, Department of Anthropology, The University of Arizona, Tucson.
1990 Excavations at 41TG91, Tom Green County, Texas. Publications in Archeology Report 38, Highway Design Division, Texas State Department of Highways and Public Transportation, Austin.

Cummings, L. S.

2002 Appendix G: Pollen and Phytolith Analysis for 41CW54. In Data Recovery at the Armstrong Site (41CW54), Caldwell County, Texas, edited by E. A. Schroeder. Paul Price Associates Inc., Austin.

Curran, J. C., D. Bryan, and M. Jennings

2005 A Comparison of Modeled Flood Characteristics to Measurements of the 2002 Flood on the Guadalupe River, Texas. Physical Geography 26:396-408.

Dalquest, W.W., E. Roth, and F. Judd

1969 The Mammal Fauna of Schulze Cave, Edwards County, Texas. Bulletin of the Florida State Museum 13(4):205-276.

Davis, W. B.

1974 The Mammals of Texas. Bulletin 41, Texas Parks and Wildlife Department, Austin.

Davis, W. B., and D. J. Schmidly

1994 The Mammals of Texas. Texas Parks and Wildlife Department, Austin.

Day, P. R.

1965 Particle Fractionation and Particle Size Analysis. In Methods of Soil Analysis, edited by C. A. Black, D. D. Evans, J. L. White, L. E. Ensminger, and F. E. Clark, pp. 545-567. Agronomy Series Number 9 Part 1, American Society of Agronomy Inc., Madison, Wisconsin. 
Decker, S., S. L. Black, and T. Gustavson

2000 The Woodrow Heard Site, 41UV88: A Holocene Terrace Site in the Western Balcones Canyonlands of Southwestern Texas. Studies in Archeology 33, Texas Archeological Research Laboratory, The University of Texas at Austin. Archeology Studies Program Report 14, Environmental Affairs Division, Texas Department of Transportation, Austin.

Dering, J. P.

1995 Appendix II: Macrobotanical Analysis of Deposit Samples. In Past Cultures and Climates at Jonas Terrace, 41ME29, Medina County, Texas, by L. Johnson, pp. 301-305. Office of the State Archeologist Report 40, Texas Historical Commission, and Texas Department of Transportation, Austin.

1999 Earth-Oven Plant Processing in Archaic Period Economies: An Example from a Semi-arid Savannah in South-Central North America. American Antiquity 64(4):659-674.

Derrida, J.

1978 Writing and Difference. Translated by Alan Bass. University of Chicago Press, Chicago.

Dial, S. W. and M. B. Collins

1998 Bifaces, Bifacial Tools, Perforators, Burins, and Spalls. In Wilson-Leonard: An 11,000-Year Archeological Record of Hunter-Gatherers in Central Texas. Vol. II, edited by M. B. Collins, pp. 537-596. TARL Studies in Archeology 31; Texas Department of Transportation Archeology Studies Program Report 10. vol. II. V vols. Texas Archeological Research Laboratory, University of Texas at Austin: Texas Dept. of Transportation, Environmental Affairs Division, Austin, Texas.
Dial, S. W., A. C. Kerr, and M. B. Collins

1998 Projectile Points. In Wilson-Leonard: An 11,000-year Archeological Record of Hunter-Gatherers in Central Texas, Vol. II, edited by M. B. Collins, pp. 211-270. Studies in Archeology 31, Texas Archeological Research Laboratory, The University of Texas at Austin. Archeology Studies Program, Report 10, Environmental Affairs Division, Texas Department of Transportation. Austin.

Diamond, D. D., D. H. Riskind, and S. L. Orzell

1987 A Framework for Plant Community Classification and Conservation in Texas. The Texas Journal of Science 39(3):203221.

Dibble, D. S.

1967 Excavations at Arenosa Shelter, 1965-66. Report submitted to the National Park Service by the Texas Archeological Salvage Project, The University of Texas at Austin.

Dibble, D. S., and D. Lorrain

1968 Bonfire Shelter: A Stratified Bison Kill Site, Val Verde County, Texas. Texas Memorial Museum, Miscellaneous Papers No.1, The University of Texas at Austin.

Dibble, $\mathrm{H}$.

1995 Middle Palaeolithic Scraper Reduction: Background, Clarification, and Review of the Evidence to Date. Journal of Archaeological Method and Theory 2:299-368.

Dice, L. R.

1943 The Biotic Provinces of North America. University of Michigan Press, Ann Arbor.

Dillehay, T. D.

1974 Late Quaternary Bison Population Changes on the Southern Plains. Plains Anthropologist 19(65):180-196. 
Dittemore, W. H. and W. C. Coburn

1986 Soil Survey of Kerr County, Texas. Electronic Version ed. United States Department of Agriculture Soil Conservation Service in cooperation with Texas Agricultural Experimental Station.

Dixon, J. R.

1987 Amphibians and Reptiles of Texas. Texas A\&M University Press, College Station.

Dockall, J. E.

1997 Wear Traces and Projectile Impact: A Review of the Experimental and Archaeological Evidence. Journal of Field Archaeology 24 321-331.

Dockhall, J. E., and S. L. Black

2006 Morhiss Mound, Texas Beyond History. Electronic document, http://www. texasbeyondhistory.net/morhiss/index. html, accessed November 15, 2007.

Dockall, J. E. and C. D. Pevny

2005 Chapter 10: Lithic Assemblages: Transitions of Holocene Technological Organization at the Richard Beene Site. In Archaeological and Paleoecological Investigations at the Richard Beene Site 41bx831: South Central Texas, edited by A. V. Thoms and R. D. Mandel, pp. 175-228. Reports of Investigations No. 8. Center for Ecological Archaeology, Texas A\&M University, College Station.

Dornheim, S. K. L.

2002 The Archaeology of Site 41BN63, Bandera County, Texas. Unpublished M.A. thesis, Department of Anthropology, The University of Texas at Austin.

Dreimanis, A.

1962 Quantitative Gasometric Determination of Calcite and Dolomite by Using a Chittick Apparatus. Journal of Sedimentary Petrology 32:520-529.
Driskell, B. N.

1998 An Assessment of Use-Wear Traces on Chipped Stone Artifacts. In WilsonLeonard: An 11,000-Year Archeological Record of Hunter-Gatherers in Central Texas, edited by M. B. Collins, pp. 732744. vol. III: Artifacts and Special Artifact Studies. V vols. Texas Archeological Research Laboratory, University of Texas at Austin: Texas Dept. of Transportation, Environmental Affairs Division, Austin, Tex.

Ellis, L. W.

1997 Hot Rock Technology. In Hot Rock Cooking on the Greater Edwards Plateau: Four Burned Rock Midden Sites in West Central Texas, Vol. 1, by S. L. Black, L. W. Ellis, D. G. Creel, and G. T. Goode, pp. 43-76. Studies in Archeology 22, Texas Archeological Research Laboratory, The University of Texas at Austin. Archeology Studies Program Report 2, Environmental Affairs Division, Texas Department of Transportation, Austin.

Ellis, L. W. and S. L. Black

1997 Chapter 2: Defining the Study Area. In Hot Rock Cooking on the Greater Edwards Plateau: Four Burned Rock Midden Sites in West Central Texas, by S. L. Black, L. W. Ellis, D. G. Creel, and G. T. Goode, pp. 23-42. Studies in Archeology 22, Texas Archeological Research Laboratory, The University of Texas at Austin. Archaeology Studies Program Report 2, Environmental Affairs Division, Texas Department of Transportation, Austin.

Ellis, L. W., G. L. Ellis, and C. D. Frederick

1995 Implications of Environmental Diversity in the Central Texas Archeological Region. Bulletin of the Texas Archeological Society 66:401-426. 
Ellis, G. L., C. Lintz, W. N. Trierweiler, and J. M. Jackson

1994 Significance Standards for Prehistoric Cultural Resources: A Case Study from Fort Hood, Texas. Mariah Associates, Inc., Austin.

Enquist, M.

1987 Wildflowers of the Texas Hill Country. Lone Star Botanical, Austin.

Fahnestock, J. T. and A. K. Knapp

1993 Water Relations and Growth of Tallgrass Prairie Forbs in Response to Selective Grass Herbivory by Bison. International Journal of Plant Sciences 154(3):432440.

Ferring, C. R.

1994 Late Quaternary Geology of the Upper Trinity River Basin, Texas. Unpublished Ph.D. dissertation, Department of Geology, The University of Texas at Dallas, Richardson.

Ferring, C. R., and B. C. Yates

1997 Holocene Geoarchaeology and Prehistory of the Ray Roberts Lake Area, North Central Texas. Institute of Applied Sciences, University of North Texas, Denton.

Foley, D and C.M. Woodruff, Jr.

1986 Geothermal Resources along the Balcones Escarpment. In The Balcones Escarpment: Geology, Hydrology, Ecology and Social Development in Central Texas, edited by Patrick Abbott and C.M. Woodruff, pp. 145-152. Geological Society of America Annual Meeting, San Antonio, Texas.

Ford, O. A. and A. S. Lyle

1998 Archaeological Investigation of a Spring Lake Lot for Joe's Crab Shack Parking Lot. Archaeological Survey Report, No. 277. Center for Archaeological Research, The University of Texas, San Antonio
Frederick, C. D.

2003 Geoarchaeological Field Investigations Along the Spur 98 Right-of-Way, Kerr County, Texas. In Interim Report: Survey and Testing Along Spur 98, Kerr County, Texas, by B. A. Houk and K. A. Miller, pp. 20-30. SWCAEnvironmental Consultants., Austin.

Frederick, C. D., and C. Ringstaff

1994 Lithic Resources in Fort Hood: Further Investigations. In Archaeological Investigations on 571 Prehistoric Sites at Fort Hood, Bell, and Coryell Counties, Texas, edited by W. N. Trierweiller, pp. 125-179. Archeological Resource Management Series Research Report 31, United States Army, Fort Hood, Texas. Mariah and Associates, Austin.

Frederick, C. D., L. K. Trask, and S. A. Skinner 2006 Archaeological Testing for the Trinity Parkway. Cultural Resources Report 200632, AR Consultants, Dallas.

Fredlund, G.

1998 Chapter 41: Phytolith Analysis. In WilsonLeonard: An 11,000-Year Archeological Record of Hunter-Gatherers in Central Texas, edited by M. B. Collins, pp. 16371649. vol. V: Special Studies. V vols. Texas Archeological Research Laboratory, University of Texas at Austin: Texas Dept. of Transportation, Environmental Affairs Division, Austin, Tex.

Frison, G. C.

2004 Survival by Hunting: Prehistoric Human Predators and Animal Prey. University of California Press, Berkeley.

Garber, J. F. and D. M. Glassman

1992 Excavation of Human Remains from the Fish Pond Site, 41HY161, in San Marcos, Hays County, Texas. Texas Antiquities Permit Number 338. Department of Sociology/Anthropology, Southwest Texas State University. 
Gee, G. W., and J. W. Bauder

1986 Particle-Size Analysis. In Methods of Soil Analysis, Part 1: Physical and Mineralogical Methods. Agronomy Monograph No. 9, edited by A. Klute, pp. 383-412. American Society of AgronomySoil Science Society of America, Madison.

Gerstle, A., T. C. Kelly, and C. Assad

1978 The Fort Sam Houston Project: An Archaeological and Historical Assessment. Archaeological Survey Report 40, Center for Archaeological Research, The University of Texas at San Antonio.

Gibson, D. J.

1989 Effects of Animal Disturbance on Tallgrass Prairie Vegetation. American Midland Naturalist 121(1):144-154.

Goelz, M.

1999 Geoarchaeological Assessment of the Texas River Center, San Marco, Texas. Prewitt and Associates, Inc.

Gomez, B., J. D. Phillips, F. J. Magilligan, and L. A. James

1997 Floodplain Sedimentation and Sensitivity: Summer 1993 Flood, Upper Mississippi River Valley. Earth Surface Processes and Landforms 22:923-936.

Goode, G. T.

2000 Appendix D: An Analysis of Stone Artifacts From the Armstrong Site 41CW54. In Data Recovery at the Armstrong Site 41CW54 Caldwell County, Texas. Cultural Resources Report No. 0330, Paul Price Associates, Inc., Austin.

2002 The Anthon Site: A Prehistoric Encampment in Southern Uvalde County, Texas. Archeological Studies Program Report 38, Environmental Affairs Division, Texas Department of Transportation, Austin.
Gould, F. W.

1962 Texas Plants: A Checklist and Ecological Survey. Texas Agricultural Extension Service, Texas A\&M University, College Station.

1978 Common Texas Grasses: An Illustrated Guide. Texas A\&M University Press, College Station.

Gould, R. A.

1969 Yiwara Foragers of the Australian Desert. Charles Scribner's Sons, New York

1980 Living Archaeology. Cambridge University Press, New York.

Graham, R. W.

1976 Pleistocene and Holocene Mammals, Taphonomy and Paleoecology of the Freisenhahn Cave Local Fauna, Bexar County, Texas. Unpublished Ph.D. dissertation, Department of Paelontology, The University of Texas at Austin.

1985 Response of Mammalian Communities to Environmental Changes During the Late Quaternary. In Community Ecology, edited by J. Diamond and T. J. Case, pp. 300-313. Harper and Row, New York.

Gunn, J.

1984 Occupation and Settlement in the Lower Fredericksburg Basin on the Edwards Plateau. Special Report 14, Center for Archaeological Research, The University of Texas at San Antonio.

Gunn, J., and R. A. Mahula

1977 Hop Hill: Culture and Climatic Change in Central Texas. Special Report 5, Center for Archaeological Research, The University of Texas at San Antonio.

Hall, G. D.

1981 Allens Creek: A Study in the Cultural Prehistory of the Lower Brazos River Valley, Texas. Research Report 16, Texas Archeological Survey, The University of Texas at Austin. 
Hampton, N.

1994 Amphibians and Reptiles. In Birds \& Other Wildlife of South Central Texas, by E. A. Kutac and S. C. Caran, pp. 113-130. University of Texas Press, Austin.

Hayden, B.

1977 Stone Tool functions in the Western Desert. In Stone Tools as Cultural Markers, edited by R. V. S. Wright, pp. 178-188. Australian Institute of Aboriginal Studies, Canberra.

Hegmon, $\mathrm{M}$.

2003 Setting Theoretical Egos Aside: Issues and Theory in North American Archaeology. American Antiquity 68:213-244.

Henry, D. O., C. V. Haynes, and B. Bradley

1976 Quantitative Variations in Flaked Stone Debitage. Plains Anthropologist 21:5761.

Hester, T. R.

1971 Archeological Investigations at the La Jita Site, Uvalde County, Texas. Bulletin of the Texas Archeological Society 42:51-148.

1973 The Formation of a Burned Rock Midden:A California Example. The Record 29(3):4.

1978 Early Human Occupations in South Central and Southwestern Texas: Preliminary Papers on Baker Cave and St. Mary's Hall Sites. Center for Archaeological Research, University of Texas at San Antonio.

1979 Problems in Typology: The Case of the "Medina" Points. La Tierra 10(3):41-42.

1983 Late Paleoindian Occupations at Baker Cave, Southwestern Texas. Bulletin of the Texas Archeology Society 53:101-119.

1985 UTSA Archaeological Field School Excavations in Bandera and Victoria Counties, Texas. Friends of Archaeology Newsletter 2:11-15. Center for Archaeological Research, The University of Texas at San Antonio.
1989 Chronological Framework for Lower Pecos Prehistory. Bulletin of the Texas Archeological Society 59 (for 1988):5364.

2004 The Prehistory of South Texas. In The Prehistory of Texas, edited by T. K. Perttula, pp. 127-154. Texas A\&M University Press, College Station.

Hester, T. R. (editor)

1991 The Burned Rock Middens of Texas: An Archeological Symposium. Studies in Archaeology No. 13, Texas Archeological Research Laboratory, The University of Texas at Austin.

Hiscock, P.

2002 Quantifying the Size of Artifact Assemblages. Journal of Archaeological Science 29:251-258.

Holloway, R. G.

1985 Diet and Medicinal Plant Usage of a Late Archaic Population from Culberson County, Texas. Bulletin of the Texas Archeological Society 54:319-329.

Holloway, R. G., L. M. Raab, and R. Stuckenrath

1987 Pollen Analysis of Late Holocene Sediments from a Central Texas Bog. Texas Journal of Science 39:71-79.

Houk, B. A., W. B. Law, K. A. Miller, and C. D. Frederick

2005 Final Research Design for Data Recovery at the Gatlin Site, 41KR621, Kerr County, Texas. SWCA Environmental Consultants, Austin.

Houk, B. A., and K. A. Miller

2004a Interim Report: Survey and Testing along Spur 98, Kerr County, Texas. SWCA Environmental Consultants, Austin.

2004b Preliminary Research Design and Proposed Scope of Work for Data Recovery at 41KR621, Kerr County, Texas. SWCA Environmental Consultants, Austin. 
Hudler, D. B.

1997 Determining Clear Fork Function through Use-wear Analysis: A Discussion of Use-Wear Methods and Clear Fork Tools. Studies in Archeology 25, Texas Archeological Research Laboratory, The University of Texas at Austin.

2000 Modeling Paleolandscapes in Central Texas. Unpublished Ph.D. Dissertation, Department of Anthropology, The University of Texas at Austin.

Hudson, P. F.

2003 Floodplain Complexity and Connectivity of Coastal Rivers. Electronic document. http:// www.twdb.state.tx.us/InstreamFlows/Studies/ Geomorphoogy/PDF/Hudson.pdf, accessed August 2006.

Huebner, J. A.

1991 Late Prehistoric Bison Populations in Central and Southern Texas. Plains Anthropologist 36(137):343-358.

Humphreys, G. S. and C. R. Ferring

1994 Stable Isotopic Evidence for the Latest Pleistocene and Holocene Climatic Change in North-Central Texas. Quaternary Research 41:200-213.

Jarrett, R. D., and J. F. England

2002 Reliability of Paleostage Indicator for Paleoflood Studies. In Ancient Floods, Modern Hazards: Principles and Applications of Paleoflood Hydrology, edited by P. K. House, R. H. Webb, V. R. Baker, D. R. Levish, pp. 91-110. Water Science and Application Vol. 5, American Geophysical Union, Washington D.C.

Johnson, L., Jr.

1964 The Devil's Mouth Site: A Stratified Campsite at Amistad Reservoir, Val Verde County, Texas. Archeology Series 6, Department of Anthropology, The University of Texas at Austin.
1991 Early Archaic Life at the Sleeper Archeological Site, 41BC65 of the Texas Hill Country, Blanco County, Texas. Report 39, Publications in Archeology, Texas State Department of Highways and Public Transportation, Highway Design Division, Austin.

1994 The Life and Times of Toyah-Culture Folk, The Buckhollow Encampment, Site 41KM16, Kimble County, Texas. Report No. 38, Office of the State Archeologist, Texas Historical Commission and Texas Department of Transportation Austin.

1995 Past Cultures and Climates at Jonas Terrace, 41ME29, Medina County, Texas. Report No. 40, Office of the State Archeologist, Texas Historical Commission and Texas Department of Transportation, Austin.

1997 The Lion Creek Site (41BT105), Aboriginal Houses and Other Remains at a Prehistoric Rancheria in the Texas Hill Country (Burnet County). Report 41, Office of the State Archeologist, Texas Historical Commission, Austin. Report No. 1, Archeology Studies Program, Environmental Affairs Division, Texas Department Transportation, Austin.

2000 Life and Death As Seen at the Bessie Cruze Site 41 WM13 on the Blackland Prairie of Williamson County, Texas. Archeology Studies Program, Report 22. Texas Department of Transportation, Austin.

Johnson, L., Jr., and G. T. Goode

1994 A New Try at Dating and Characterizing Holocene Climates, As Well As Archeological Periods On the Eastern Edwards Plateau. Bulletin of the Texas Archeological Society 65:1-54. 
1995 Holocene Climates and Archeological Periods on the Eastern Edwards Plateau. In Past Cultures and Climates at Jonas Terrace, 41ME29, Medina County, Texas, by L. Johnson, pp. 70-102. Report No. 40, Office of the State Archeologist, Texas Historical Commission and Texas Department of Transportation Austin.

Johnson, L., D. A. Suhm, C. Tunnel

1962 Salvage Archeology of Canyon Reservoir: The Wunderlich Footbridge and Oblate Sites. Texas Memorial Museum Bulletin 5, The University of Texas at Austin.

Justice, N. D.

1987 Stone Age Spear and Arrow Points of the Midcontinental and Eastern United States. Indiana University Press, Bloomington.

Karbula, J. W.

2000 Investigations of the Eckols Site (41TV528): A Stratified Prehistoric Terrace Site on Barton Creek in Travis County, Texas. Unpublished Ph.D. dissertation, Department of Anthropology, The University of Texas at Austin.

Kay, M.

1996 Microwear Analysis of Some Clovis and Experimental Chipped Stone Tools. In Stone Tools: Theoretical Insights into Human Behavior, edited by G. H. Odell, pp. 315-344. Plenum Press, New York.

Keeley, L. H.

1980 Experimental Determination of Stone Tool Uses: A Microwear Analysis. University of Chicago Press, Chicago.

Keen-Zebert, A.

2005 Spatial Variation of Channel Reach Type and in the Guadalupe River, a Mixed Alluvial-Bedrock River in Central Texas. Abstract, Southwest Association of American Geographers Meeting, Available online at http://www.uark.edu/campusresources/imachar/Abstracts.pdf.
Keen-Zebert, A. and J. Curran

2006 Bar Spacing in Alluvial and Bedrock Confined Reaches of the Guadalupe River, a Mixed Morphology or Hybrid River in Central Texas. Abstract, Geological Society of America Annual Meeting, Philadelphia, Available online at http://gsa. confex.com/gsa/2006AM/finalprogram/ abstract_113152.htm.

Kelley, J. H., and M. P. Hanen

1988 Archaeology and the Methodology of Science. University of New Mexico Press, Albuquerque.

Kelly, R. L.

1988 The Three Sides of a Biface. American Antiquity 53:717-734.

1992 Mobility/Sedentism: Concepts, Archaeological Measures, and Effects. Annual Review of Anthropology 21:43-66.

Kelly, T. C.

1979 Gower Projectile Points? La Tierra 6(2):13-19.

Kelly, T. C., and T. R. Hester

1976 Archaeological Investigations at Sites in the Cibolo Creek Watershed, Central Texas. Archaeological Survey Report 17, Center for Archaeological Research, The University of Texas at San Antonio.

Kennett, D. J.

1996 General Systems Theory. In The Oxford Companion to Archaeology, edited by B. M. Fagan, pp. 245-246. Oxford University Press, New York.

Kerr, A. C.

2000 Systematic Analysis of Unfluted Lanceolate Projectile Points. Unpublished M.A. thesis, Department of Anthropology, The University of Texas at Austin. 
Kerr, A. C. and S. W. Dial

1998 Statistical Analysis of Unfluted Lanceolate and Early Bifurcate Stem Projectile Points. In Wilson-Leonard: An 11,000year Archeological Record of HunterGatherers in Central Texas, Vol. II, edited by M. B. Collins, pp. 447-507. Studies in Archeology 31, Texas Archeological Research Laboratory, The University of Texas at Austin. Archeology Studies Program Report 10, Environmental Affairs Division, Texas Department of Transportation, Austin.

Kibler, K. W., and A. M. Scott

2000 Archaic Hunters and Gatherers of the Balcones Canyonlands: Data Recovery at the Cibolo Crossing Site (41BX377), Camp Bullis Military Reservation. Report of Investigations No. 126, Prewitt and Associates, Austin.

Kintigh, K. W.

2006 Boone: Boone's Measure of Assemblage Heterogeneity (Homogeneity). In Tools for Quantitative Archaeology: Programs for Quantitative Analysis in Archaeology. Keith W. Kintigh, Tempe.

Knox, J. C.

2006 Floodplain Sedimentation in the Upper Mississippi Valley: Natural Versus Human Accelerated. Geomorphology 79(3/4);286-310..

Kochel, R. C.

1980 Investigation of Flood Paleohydrology Using Slackwater Deposits, Lower Pecos and Devil's River, Southwest Texas. Unpublished Ph.D. dissertation, Department of Geology, The University of Texas at Austin.

Krieger, A. D.

1944 The Typological Concept. American Antiquity 9(3):271-288.
Kuhn, S.

1989 Hunter-Gatherer Foraging Organization and Strategies of Artifact Replacement and Discard. In Experiments in Lithic Technology, edited by D. Amick and R. Mauldin, pp. 33-48. British Archaeological Reports International Series 528, Oxford.

1994 A Formal Approach to the Design and Assembly of Mobile Toolkits. American Antiquity 59:426-442.

1995 Mousterian Lithic Technology. Princeton University Press.

Kutac, E. A.

1994 Birds. In Birds \& Other Wildlife of South Central Texas, by E. A. Kutac and S. C. Caran, pp. 47-102. University of Texas Press, Austin.

Kutac, E.A., and S. C. Caran

1994 Birds and Other Wildlife of South Central Texas. University of Texas Press, Austin.

Larkin, T. J., and G. W. Bomar

1983 Climatic Atlas of Texas. Texas Department of Water Resources, Austin.

Larson, D. A., V. M. Bryant, and T. S. Patty

1972 Pollen Analysis of a Central Texas Bog. The American Midland Naturalist 88(2):358-367.

Law, W. B., B. A. Houk, K. A. Miller, and C. D. Frederick

2005 Interim Report: Data Recovery Investigations at 41KR621, Kerr County, Texas. SWCA Environmental Consultants, Austin.

Leach, J. D., C. B. Bousman and D. L. Nickels

2005 Comments on Assigning a Primary Context to Artifacts Recovered from Burned Rock Middens. Journal of Field Archaeology 30(2):201-203. 
Lecce, S. E.

1997 Spatial Patterns of Historical Overbank Sedimentation and Floodplain Evolution, Blue River, Wisconsin. Geomorphology 18:265-277.

Lechtman, $\mathrm{H}$.

1977 Style in technology-some early thoughts. In Material Culture: Styles, Organization, and Dynamics of Technology (eds $\mathrm{H}$. Lechtman and R.S. Merrill). St Paul: West Publishing, pp. 3-20.

Lee, R. B.

1979 The!Kung San: Men, Women, and Work in a Foraging Society. Cambridge University Press, Cambridge.

1984 The Dobe!Kung. CBS College Publishing, New York.

Lee, R. B., and I. DeVore (editors)

1968 Man the Hunter. Aldine, Chicago.

Leroi-Gourhan, A.

1972 Annexe IV, Vocabulaire. In Fouilles de Pincevent: Essaid'Analyse Ethnographique d'un Habitat Magdalenian, by A. LeroiGourhan and M. Brezillon. CNRS, Paris.

1984 Pincevent: Campement Magdalenien de Chasseurs de Rennes. Ministere de la Culture, Paris.

Lidiak, E. G., C. C. Almy, Jr., and J. J. W. Rogers 1961 Precambrian Geology of Part of the Little Llano River Area, Llano and San Saba Counties, Texas. Texas Journal of Science 13(2):255-289.

Lintz, C., M. Blum, R. Holloway, and L. ScottCummings

1993 Paleoenvironmental Reconstruction. In Cultural Resource Investigations in the O. H. Ivie Reservoir, Concho, Coleman, and Runnels Counties, Texas, edited by $\mathrm{C}$. Lintz, W. N. Trierweiler, A. C. Earls, F. M. Oglesbay, M. Blum, P. L. O’Neill, J. Kuhl, R. Holloway, L. Scott-Cummings, and D. Scurlock, pp. 261-343. Technical Report No. 346-I, Mariah and Associates, Inc.
Lintz, C., A. Treece, and F. Oglesby

1995 The Early Archaic Structure at the Turkey Bend Ranch Site (41CC112), Concho County. In Advances in Texas Archeology, edited by J. E. Bruseth and T. K. Perttula, pp. 155-186. Cultural Resource Management Report 5, Texas Historical Commission, Austin.

Luke, C. J.

1980 Continuing Archaeology on Highway 16: The Shep Site (41KR109) and The Wounded Eye Site (41KR107). Publications in Archeology 19. Texas State Department of Highways and Public Transportation, Austin.

Lukowski, P. D.

1988 Archaeological Investigations at 41BX1, Bexar County, Texas. Archaeological Survey Report, No. 135. The University of Texas at Austin, Austin.

Lyle, A. S., C. E. Horrell, S. A. Tomka, and D. A. Cargill

2000 Archaeological Testing at the Headwaters of the San Marcos River: Southwest Texas State University Raw Water Supply Project. Archaeological Survey Report, No. 293. Center for Archaeological Research, San Antonio.

Lyman, R. L.

1994 Vertebrate Taphonomy. Cambridge University Press, Cambridge.

Mahoney, R. B., H. J. Shafer, S. A. Tomka, L. C. Nordt, and R. P. Mauldin

2003a Royal Coachman (41CM111): An Early Middle Archaic Site Along Cordova Creek in Comal County, Texas. Report 332, Center for Archaeological Research, The University of Texas at San Antonio. Archeological Studies Program Report 49, Environmental Affairs Division, Texas Department of Transportation, Austin. 
Mahoney, R. B, S. A. Tomka, R. P. Mauldin, H. J. Shafer, L. C. Nordt, R. D. Greaves, and R. R. Galdeano

2003b Data Recovery Excavations at 41MM340: A Late Archaic Site along Little River in Milam County, Texas. Report 340, Center for Archaeological Research, The University of Texas at San Antonio. Archeological Studies Program Report 54, Environmental Affairs Division, Texas Department of Transportation, Austin.

Mandel, R. D., J. S. Jacob, and L. C. Nordt

In pressGeomorphic Investigations at the Richard Beene Site. In Archaeological and Paleoecological Investigations at the Richard Beene Site, 41BX831, SouthCentral Texas, edited by A. V. Thoms and R. D. Mandel, pp. 27-59. Reports of Investigation No. 8, Center for Ecological Archaeology, Texas A\&M University, College Station.

Mauldin, R. P., R. B. Mahoney, H. J. Shafer, and B. A. Meissner

2004 Chapter 5: Recovered Data. In Millican Bench (41TV163): A Multicomponent Site in Travis County, Texas, by R. P. Mauldin, S. A. Tomka, and H. J. Shafer, pp. 25-50. Report 351, Center for Archaeological Research, The University of Texas at San Antonio. Archeological Studies Program Report 66, Environmental Affairs Division, Texas Department of Transportation, Austin.

McKinney, W. W.

1981 Early Holocene Adaptations in Central and Southwestern Texas: The Problem of the Paleoindian-Archaic Transition. Bulletin of the Texas Archeological Society 52:91-120.

McReynolds, R.

1993 Some Examples of Bandy Points. La Tierra 20(3):9-16.
Mear, Charles E.

1995 Quaternary Geology of the Upper Sabinal River Valley, Uvalde, and Bandera Counties, Texas. Geoarchaeology 10(6):457-480.

Metcalfe, D., and K. T. Jones

1988 A Reconsideration of Animal Body-Part Indicies. American Antiquity, 533:486504.

Miller, K. A.

1993 A Study of Prehistoric Biface Caches from Texas. Unpublished M.A. thesis, Department of Anthropology, The University of Texas at Austin.

Morrow, T. A.

1997 A Chip off the Old Block: Alternative Approaches to Debitage Analysis. Lithic Technology 22(1):51-69.

Mueggenborg, H. E.

1994 Excavations at the Blue Hole Site, Uvalde County, Texas. Bulletin of the Texas Archeological Society 62:1-52.

Neck, R. W.

1986 The Balcones Fault Zone as a Major Zoogeographic Feature. In The Balcones Escarpment: Geology, Hydrology, Ecology, edited by P. L. Abbott and C. M. Woodruff, pp. 35-40. Geological Society of America, San Antonio.

Nickels, D. L., C. B. Bousman, J. D. Leach, and D. A. Cargill

1998 Test Excavations at the Culebra Creek Site, 41BX126, Bexar County, Texas. Archaeological Survey Report No. 265, Center for Archaeological Research, The University of Texas at San Antonio. Archeology Studies Program Report 3, Environmental Affairs Division, Texas Department of Transportation, Austin. 
Nordt, L. C.

1992 Archeological Geology of the Fort Hood Military Reservation, Ft. Hood, Texas. Archeological Research Management Series Research Report 25, United States Army, Fort Hood, Texas.

1993 Additional Geoarcheological Investigations at the Fort Hood Military Reservation, Ft. Hood, Texas. Archeological Research Management Series Research Report 29, United States Army, Fort Hood, Texas.

1996 Geoarchaeology of 41BX47, Upper Leon Creek Basin. In Archaic Land Use of Upper Leon Creek Terraces: Archaeological Testing in Northern Bexar County, Texas, by Cindy Tennis, pp. 11-19 and 69-72. Archaeological Survey Report No. 234, Center for Archaeological Research, The University of Texas at San Antonio.

2001 Geoarchaeology of 41BX126. In Test Excavations at the Culebra Creek Site, 41BX126, Bexar County, Texas, by D. L Nickels, C. B. Bousman, J. D. Leach, and D. A. Cargill, pp. 36-44 and 270-274. Archaeological Survey Report No. 265, Center for Archaeological Research, The University of Texas at San Antonio.

2002 Late Quaternary Alluvial Stratigraphy of a Low-Order Tributary in Central Texas, USA and Its Response to Climate and Sediment Supply. Quaternary Research 62:289-300.

2004 Late Quaternary Alluvial Stratigraphy of a Low-Order Tributary in Central Texas, USA and Its Response to Climate and Sediment Supply. Quaternary Research 62(3):289-300.

Nordt, L. C., T. W. Boutton, C. T. Hallmark, and M. R. Waters

1994 Late Quaternary Vegetation and Climate Changes in Central Texas Based on Isotopic Composition of Organic Carbon. Quaternary Research 41:109-120.
Nordt, L. C., T. W. Boutton, J. S. Jacob, and R. D. Mandel

2002 C4 Plant Productivity and Climate-CO Variations in South-Central Texas During the Late Quaternary. Quaternary Research 58:182-188.

Nordt, L. C., C. T. Hallmark, L. P. Wilding, and T. W. Boutton

1998 Quantifying Pedogenic Carbonate Accumulations Using Stable Isotopes. Geoderma 82:115-136.

Odell, G.H.

1996 Stone Tools and Mobility in the Illinois Valley: From Hunter-Gatherer Camps to Agricultural Villages. International Monographs in Prehistory, Ann Arbor.

1998 Investigating Correlates of Sedentism and Domestication in Prehistoric North America. American Antiquity 63:553571.

2000 Stone Tool Research at the End of the Millenium: Procurement and Technology. Journal of Archaeological Research 8:269-331.

2001 Research Problems R US. American Antiquity 66(4):679-685.

2004 Lithic Analysis. Kluwer Academic/Plenum Publishers, New York.

Oksanen, E. R.

2004 Early Archaic Investigations at the Icehouse Site, 41HY161. Paper presented at the Texas Archeological Society $75^{\text {th }}$ Annual Meeting, College Station, Texas. Center for Archaeological Studies-Texas State University San Marcos, College Station, Texas.

2005 Archaeological Investigations at 41HY161, the Icehouse Site. Paper presented at the Texas Archeological Society $76^{\text {th }}$ Annual Meeting, Austin, Texas. Center for Archaeological Studies-Texas State University San Marcos, College Station, Texas. 
Oksanen, E. R., and C. B. Bousman

2007 All Creatures Great and Small: The Cultural Implications from Prey Size and Selection during the Early Archaic in Central Texas. Paper presented at the Society for American Archaeology 72nd Annual Meeting, Austin, Texas.

Oksanen, E. R., and E. A. Schroeder

2002 Archeological Testing of Four Prehistoric Sites Along the Guadalupe-Blanco River Authority's San Marcos Raw Water Pipeline, Caldwell and Hays Counties, Texas. Paul Price Associates, Austin, Texas.

Oksanen, E. R., C. A. Weaver, E. A. Schroeder, G. T. Goode

2002 Archeological Testing of Four Prehistoric Sites Along the Guadalupe-Blancho River Authority's Caldwell and Hays Counties, Texas. PPA Cultural Resources Report No. 262. Paul Price Associates, Inc., Austin.

Owens, J. D.

2003 Data Recovery Excavations at the Varga Site (41ED28), Edwards County, Texas: Final Research Design. TRC, Austin.

Parry, W. J., and R. L. Kelly

1987 Expedient Core Technology and Sedentism. In The Organization of Core Technology, edited by J. Johnson and C. Morrow, pp. 285-304. Westview Press, Boulder.

Patterson, L.

1990 Characteristics of Bifacial-Reduction Flake-Size Distribution. American Antiquity 55(3):550-558.

Patterson, P. E.

1987 Archaeological Excavations at 41LL78, the Slab Site, Llano County, Texas. Publications in Archaeology Report 34, Highway Design Division, Texas State Department of Highways and Public Transportation, Austin.
Perttula, T. K., M. R. Miller, R. A. Ricklis, D. J. Prikryl, and C. Lintz

1995 Prehistoric and Historic Aboriginal Ceramics in Texas. Bulletin of the Texas Archeological Society 66:175-235.

Pickup, G.

1991 Event Frequency and Landscape Stability on the Floodplain Systems of Arid Central Australia. Quaternary Science Reviews 10: 463-473.

Pizzuto, J. E.

1987 Sediment Diffusion During Overbank Flows. Sedimentology 34:301-317.

Potter, D. R., and S. L. Black

1995 Archeology Along the Wurzbach Parkway, Module 2, Initial Testing and Evaluation of Five Prehistoric Sites in the Upper Salado Watershed, Bexar County, Texas. Studies in Archeology 18, Texas Archeological Research Laboratory, The University of Texas at Austin.

Potter, D. R., S. L. Black, and K. Jolly

1995 Archeology Along the Wurzbach Parkway, Module 1, Introduction, Conceptual Framework, and Contexts of Archeological Investigations in Bexar County, SouthCentral Texas. Studies in Archeology 17, Texas Archeological Research Laboratory, The University of Texas at Austin.

Prewitt, E. R.

1966 A Preliminary Report on the Devil's Rockshelter Site, Val Verde County, Texas. Texas Journal of Science 18:206-224.

1981 Culture Chronology in Central Texas. Bulletin of the Texas Archeological Society 52:65-89.

1983 Andice, An Early Archaic Dart Point Type. La Tierra 10(3):1-6.

1983 From Circleville to Toyah: Comments on Central Texas Chronology. Bulletin of the Texas Archeological Society 54:201-238. 
1994 Burned Rock Middens: A Summary of Previous Investigation and Interpretations. In The Burned Rock Middens of Texas: An Archeological Symposium, 2nd ed., edited by T. R. Hester, pp. 25-32. Studies in Archeology 13, Texas Archeological Research Laboratory, The University of Texas at Austin.

1995 Distributions of Typed Projectile Points in Texas. Bulletin of the Texas Archeological Society 66:83-173.

Quigg, M.

2005 The Early Components at the Varga Site (41ED28). Paper presented at the Council of Texas Archeologists Annual Spring Meeting, Camp Mabry, Austin.

Ricklis, R. A.

2004 Chapter 5: Prehistoric Occupation of the Central and Lower Texas Coast. In The Prehistory of Texas, edited by $\mathrm{T}$. K. Perttula, pp. 155-180. Texas A\&M University Press, College Station.

Ricklis, R. A., and M. B. Collins

1994 Introduction. In Archaic and Late Prehistoric Human Ecology in the Middle Onion Creek Valley, Hays County, Texas, by R. A. Ricklis and M. B. Collins, pp. 1-10. Studies in Archeology 19, Texas Archeological Research Laboratory, The University of Texas at Austin.

Ringstaff, C. W.

2000 A Study of Landform Evolution and Archaeological Preservation at Site 41HY165, San Marcos, Texas, Southwest Texas State University.
Riskind, D. H. and D. D. Diamond

1986 Communities of the Edwards Plateau of Texas: An Overview Emphasizing the Balcones Escarpment Zone between San Antonio and Austin with Special Attention to Landscape Contrasts and Natural Diversity. In The Balcones Escarpment: Geology, Hydrology, Ecology and Social Development in Central Texas, edited by P. L. Abbot and C. M. Woodruff, pp. 2132. Geological Society of America, San Diego.

Ritter, D. F.

1975 Stratigraphic Implications of CoarseGrained Gravels Deposited As Overbank Sediment, Southern Illinois. Journal of Geology 83:645-650.

1986 Process Geomorphology. 2nd ed. William C. Brown Publishers, Dubuque, Iowa.

Ritter, D. F., and W. F. Kinsey, III

1973 Overbank Sedimentation in the Delaware River Valley During the Last 6,000 Years. Science 179:374-375.

Root, M. J., J. D. Williams, M. Kay, and L. K. Shifrin

1999 Folsom Ultrathin Bifaces and Radial Break Tools in the Knife River Flint Quarry Area. In Folsom Lithic Technology: Explorations in Structure and Variation, edited by D. Amick, pp. 144-168. International Monographs in Prehistory, Ann Arbor.

Rose, $\mathrm{P}$.

2004 Regional Perspectives on the Edwards Group of Central Texas: Geology, Geomorphology, Geohydrology, and Their Influence on Settlement History. Paper presented at the South Texas Geological Society and Austin Geological Society Edwards Water Resources in Central Texas: Retrospective and Prospective Symposium, San Antonio. 
Ross, R. E.

1965 The Archeology of Eagle Cave. Miscellaneous Papers 7, Texas Archaeological Salvage Project, The University of Texas at Austin.

Rots, V. and B. S. Williamson

2004 Microwear and Residue Analyses in Perspective: The Contribution of Ethnoarchaeological Evidence. Journal of Archaeological Science 31(9):1287.

Russ, J., D. H. Loyd, and T. W. Boutton

2000 A Paleoclimate Reconstruction for Southwestern Texas Using Oxalate Residue from Lichen as a Paleoclimate Proxy. Quaternary International 67:29-36.

Sackett, J. R.

1982 Approaches to Style in Lithic Archaeology. Journal of Anthropological Archaeology 1:59-112.

1986 Isochrestism and Style: A Clarification. Journal of Anthropological Archaeology 5(3):266-277.

Schiffer, M. B.

1972 Archaeological Context and Systemic Context. American Antiquity 37:156165.

1976 Behavioral Archeology. Academic Press, New York

1983 Toward the Identification of Formation Processes. American Antiquity 48(4):675706.

1995 Behavioral Archaeology: First Principles. In Foundations of Archaeological Inquiry. University of Utah Press, Salt Lake City.

1996 Some Relationships Between Behavioral and Evolutionary Archaeologies. American Antiquity 61(4):643-662.

Schiffer, M. B. and J. M. Skibo

1997 The Explanation of Artifact Variability. American Antiquity 62(1):27-50.
Schmidly, D. J.

2004 The Mammals of Texas: Revised Addition. Sixth ed. University of Texas Press, Austin.

Schroeder, E. A.

2002 Data Recovery at the Armstrong Site (41CW54), Caldwell County, Texas. Vol. II. Texas Antiquities Permit \#2250. PPA Cultural Resources Report No. 0330, Paul Price Associates, Inc., Austin.

Schroeder, E. A., and E. R. Oksanen

2002 Data Recovery at the Armstrong Site 41CW54 Caldwell County, Texas. Vol. I. Texas Antiquities Permit \#2250. PPA Cultural Resources Report No. 0330, Paul Price Associates, Inc., Austin.

Schumm, S. A.

1977 The Fluvial System. John Wiley and Sons, New York.

Schumm, S. A., and R. W. Lichty

1963 Channel Widening and Flood-Plain Construction along Cimmaron River in Southwestern Kansas. United States Geological Survey Professional Paper 252D:71-88.

Sellards, E. H., W. S. Adkins, and F. B. Plummer

1981 The Geology of Texas. Vol. 1. Bulletin 3232. The University of Texas at Austin.

Shafer, H. J.

1963 Test Excavations at the Youngsport Site in Bell County, Texas. Bulletin of the Texas Archeological Society 34:57-81.

1979 Comments on Kelly's “Gower Projectile Points” Article. La Tierra 6(3):9-20.

1986 Ancient Texans: Rock Art and Lifeways along the Lower Pecos. Texas Monthly Press, Austin.

1987 Ancient Texans. San Antonio Museum Association, San Antonio, Texas. 
1997 Goals of Archaeological Investigation. In Field Methods in Archaeology, 7th ed, by T. R. Hester, H. J. Shafer, and K. L. Feder, pp. 5-20. Mayfield Publishing Company, Mountain View.

2005a People of the Prairie: A Possible Connection to the Davis Site Caddo Module. Prepared for the Texas Department of Transportation. Manuscript submitted to Prewitt and Associates, Inc., Austin.

2005b There is More to Langtry Than Looks: The Uses and Abuses of Texas Point Typology. La Tierra 31(2):9-14.

Shafer, H. J., and V. M. Bryant, Jr.

1977 Archeological and Botanical Studies at Hinds Cave, Val Verde County, Texas. Special Studies No.1, Anthropology Laboratory, Texas A\&M University, College Station.

Shaffer, B. S.

1995 Appendix III: Analysis of the Vertebrate Fauna. In Past Cultures and Climates at Jonas Terrace, 41ME29, Medina County, Texas, by L. Johnson, T. R. Hester, and J. B. Sollberger, pp. 306-325. Report No. 40, Office of the State Archeologist, Texas Historical Commission and Texas Department of Transportation, Austin.

1972 The Strohacker Site: A Review of PreArchaic Manifestations in Texas. Plains Anthropologist 17(58):326-344.

Shennan, S.

1997 Quantifying Archaeology. 2nd ed. Edinburgh University Press, Edinburgh.

Shott, M. J.

1986 Technological Organization and Settlement Mobility: An Ethnographic Examination. Journal of Anthropological Research 42:15-51.

1994 Size and Form in the Analysis of Flake Debris: Review and Recent Approaches. Journal of Archaeological Method and Theory 1:69-110.
Simpson, B. J.

1988 AField Guide to Texas Trees. Texas Monthly Field Guide Series. Texas Monthly Press, Austin.

Skinner, S. A.

1974 Prehistoric Settlement of a "Natural" Area. Unpublished Ph.D. dissertation, Department of Anthropology, Southern Methodist University.

Smith, C. S., and L. M. McNees

1999 Facilities and Hunter-Gatherer Long-Term Land Use Patterns: An Example from Southwest Wyoming. American Antiquity 64(1):117-136.

Sorrow, W. M.

1968 The Devil's Mouth Site: The Third Season 1967. Papers of the Texas Archaeological Salvage Project 14, The University of Texas, Austin.

Sorrow, W. M ., H. J. Shafer, and R. E. Ross

1967 Excavations at Stillhouse Hollow Reservoir. Papers of the Texas Archaeological Salvage Project 11, The University of Texas at Austin.

Spearing, D.

1991 Roadside Geology of Texas. Roadside Geology Series. Mountain Press Publishing Company, Missoula.

Stafford, T.

1998 Chapter 25: Radiocarbon Stratigraphy. In Wilson-Leonard: An 11,000-Year Archeological Record of Hunter-Gatherers in Central Texas. Volume V, edited by M.B. Collins, pp.1039-1066. Studies in Archeology 31. Texas Archeological Research laboratory, University of Texas at Austin. Texas Department of Transportation, Environmental Affairs Division, Austin, Texas. 
Stahle, D. W., and M. K. Cleaveland

1994 Texas Paleoclimatic Data from Daily to Millenial Time Scales. In The Changing Climate of Texas: Predictability and Implications for the Future, edited by J. Norwine, J. R. Giardino, G. R. North, and J. B. Valdes, pp. 49-69. GeoBooks, Texas A\&M University, College Station.

Stahle, D. W, and J. E. Dunn

1982 An Analysis and Application of the Size Distribution of Waste Flakes from the Manufacturing of Bifacial Stone Tools. World Archaeology 14:84-97.

Steward, J. H.

1955 Theory of Culture Change. University of Illinois Press, Urbana.

Stiner, M. C. and N. D. Munro

2002 Approaches to Prehistoric Diet Breadth, Demography, and Prey Ranking Systems in Time and Space. Journal of Archaeological Method and Theory 9(2):181-214.

Story, D. A.

1985 Adaptive Strategies of Archaic Cultures of the West Gulf Coastal Plain. In Prehistoric Food Production in North America, edited by R. I. Ford, pp. 19-56. Anthropological Papers 75, Museum of Anthropology, University of Michigan, Ann Arbor.

Stuiver, M., P. J. Reimer, E. Bard, J. Beck, G. S. Burr, K. A. Hughen, B. Kromer, G. McCormac, J. Van Der Plicht, and M. Spurk

1998 INTCAL98 Radiocarbon Age Calibration, 24,000-0 cal B.P. Radiocarbon 40.3:1041-1083.

Suhm, D. A.

1960 A Review of Central Texas Archeology. Bulletin of the Texas Archeological Society 29:63-107.
Suhm, D. A., A. D. Krieger, and E. Jelks

1954 An Introductory Handbook of Texas Archeology. Bulletin of the Texas Archeological Society 25.

Sullivan, A. P., III, and K.C. Rozen

1985 Debitage Analysis and Archaeological Interpretation. American Antiquity 50:755779.

Sullivan, J. E.

1983 Geomorphic Effectivenesss of a HighMagnitude Rare Flood in Central Texas. Unpublished M.A. thesis, Department of Geology. The University of Texas at Austin.

Taylor, A. J.

1995 Summary and Consideration of Cultural Features. In Archeological Investigations at the Loma Sandia Site 41LK28: A Prehistoric Cemetery and Campsite in Live Oak County, Texas, by A. J. Taylor and C. L. Highley, pp. 359-404. Studies in Archeology 20, Texas Archeological Research Laboratory, The University of Texas at Austin.

Taylor, A. J., and C. L. Highley

1995 Archeological Investigations at the Loma Sandia Site (41LK28): A Prehistoric Cemetary and Campsite in Live Oak County, Texas. 2 vols. Studies in Archeology 20, Texas Archeological Research Laboratory, The University of Texas at Austin.

Tennis, C. T.

1996 Archaic Land Use of Upper Leon Creek Terraces: Archaeological Testing in Northern Bexar County, Texas. Report 234, Center for Archaeological Research, The University of Texas at San Antonio.

Thomas, D. H.

1981 Archaeology. 2nd ed. Holt, Rinehart, and Winston, Orlando, Florida. 
Thoms, A. V.

1989 The Northern Roots of Hunter-Gatherer Intensification: Camas and the Pacific Northwest. Unpublished Ph.D. dissertation, Department of Anthropology, Washington State University, Pullman.

2005 An Overview of Early Archaic Components at the Richard Beene Site, Bexar County, Texas. Paper presented at the Council of Texas Archeologists Annual Spring Meeting, Camp Mabry, Austin.

Thoms, A. V., D. D. Kuehn, B. W. Olive, J. E. Dockall, P. A. Clabaugh and R. D. Mandel

1996 Early and Middle Holocene Occupations at the Richard Beene Site: The Southern Texas Archaeological Association Field School Project. La Tierra:8-36.

Tomka, S. A.

2001 The Effect of Processing Requirement on Reduction Strategies and Tool Form: A New Perspective. In Lithic Debitage Context, Form, Meaning, edited by W. Andrefsky, Jr., pp. 207-233. The University of Utah Press, Salt Lake City.

Tomka, S. A., R. B. Mahoney, and H. J. Shafer

2003 Summary and Conclusions. In Royal Coachman (41CM111), An Early Middle Archaic Site Along Cordova Creek in Comal County, Texas, by R. B. Mahoney, H. J. Shafer, S. A. Tomka, L. C. Nordt, and R. P. Mauldin, pp. 87-92. Archaeological Survey Report 332, Center for Archaeological Research, The University of Texas at San Antonio. Archeological Studies Program Report 49, Environmental Affairs Division, Texas Department of Transportation, Austin.
Tomka, S. A., H. J. Shafer, and R. P. Mauldin

2003 Chapter 12: Lithic Technology at 41MM340. In Data Recovery Excavations at 41MM340: A Late Archaic Site along Little River I Milam County, Texas, by R. B. Mahoney, S. A. Tomka, R. P. Mauldin, H. J. Shafer, L. C. Nordt, R D. Greaves, and R. R. Galdeano. Archaeological Survey Report 340, Center for Archaeological Research, The University of Texas at San Antonio. Archeological Studies Program Report 54, Environmental Affairs Division, Texas Department of Transportation, Austin.

Toomey, R. S., III

1993 Late Pleistocene and Holocene Faunal Changes at Hall's Cave, Kerr County, Texas. Unpublished Ph.D. dissertation, Department of Geology, The University of Texas at Austin.

Toomey, R. S., III, M. D. Blum, and S. Valastro, Jr.

1993 Late Quaternary Climates and Environments of the Edwards Plateau, Texas. Global and Planetary Change 7:299-320.

Törnqvist, T. E., and J. S. Bridge

2002 Spatial Variation of Overbank Aggradation Rate and Its Influence on Avulsion Frequency. Sedimentology 49:891-905.

Torrence, R.

1983 Timebudgeting and Hunter-Gatherer Technology. In Hunter-Gatherer Economy in Prehistory: A European Perspective, edited by G. Bailey, pp. 11-22. Cambridge University Press, Cambridge.

1989 Retooling: Towards a Behavioural Theory of Stone Tools. In Time, Energy and Stone Tools, edited by R. Torrence, pp. 57-66. Cambridge University Press, Cambridge.

Turner, E. S., and T. R. Hester

1993 A Field Guide to the Stone Artifacts of Texas Indians. 2nd ed. Gulf Publishing, Houston. 
1999 A Field Guide to Stone Artifacts of the Texas Indians. $3^{\text {rd }}$ ed. Gulf Publishing, Houston.

Turpin, S. A.

1986 Bonfire Shelter:AnAncient Slaughterhouse. In Ancient Texans: Rock Art and Lifeways Along the Lower Pecos, by Harry Shafer, pp. 88-93. Texas Monthly Press, Austin.

1988 Seminole Sink: Excavation of a Vertical Shaft Tomb in Val Verde County, Texas. Texas Archeological Survey Research Report 93, The University of Texas at Austin.

1991 Time Out of Mind: The Radiocarbon Chronology of the Lower Pecos Region. In Papers on Lower Pecos Prehistory, edited by S. A. Turpin, pp. 1-50. Studies in Archeology 8, Texas Archeological Research Laboratory, The University of Texas at Austin.

2004 The Lower Pecos River Region of Texas and Northern Mexico. In The Prehistory of Texas, edited by T. K. Perttula, pp. 266-282. Texas A\&M University Press, College Station.

Turpin, S. A., and L. C. Bement

1992 Skyline Shelter and Devil's Triangular Dart Points: Evidence for a New Component of the Lower Pecos Early Archaic Sequence. Plains Anthropologist 37(138):41-57.

Van Auken, O. W.

1988 Woody Vegetation of the Southern Escarpment and Plateau. In Edwards Plateau Vegetation: Plant Ecological Studies in Central Texas, edited by B. B. Amos and F. R. Geilbach, pp. 43-55. Baylor University Press, Waco.

Vermersch, T. G.

1992 Lizards and Turtles of South-Central Texas. Eakin Press, Austin.
Walling, D. E., and Q. He

1997 The Spatial Variability of Overbank Sedimentation on River Floodplains. Geomorphology 24:209-223.

Wandsnider, L.

1992 The Spatial Dimension of Time. In Space, Time, and Archeological Landscapes, edited by J. Rossignol and L. Wandsnider, pp. 257-282. Plenum Press, New York.

1997 The Roasted and the Boiled: Food Composition and Heat Treatment with Special Emphasis on Pit-Hearth Cooking. Journal of Anthropological Archaeology 16:1-48.

Weber, C. D.

2002 Andice/Bell Point Use Fractures. La Tierra 29(2):31-44.

Weedman, K. J.

2002 On the Spur of the Moment: Effects of Age and Experience on Hafted Scraper Morphology. American Antiquity 67(4):731-744.

Weir, F. A.

1976 The Central Texas Archaic Reconsidered. In The Texas Archaic: A Symposium, edited by T. R. Hester, pp. 60-66. Special Report 2, Center for Archaeological Research, The University of Texas at San Antonio.

West, L. T., L. R. Drees, L. P. Wilding and M. C. Rabenhorst

1988 Differentiation of Pedogenic and Lithogenic Carbonate Forms in Texas. Geoderma 43:271-287.

Whitley, D. S.

1998 New Approaches to Old Problems: Archaeology in Search of an Ever Elusive Past. In Reader in Archaeological Theory: Post-Processual and Cognitive Approaches, edited by D. S. Whitley, pp. 1-30. Routledge, New York. 
Whittaker, J. C.

1994 Flintknapping: Making and Understanding Stone Tools. University of Texas Press, Austin.

Whittaker, John C., Douglas Caulkins, Kathryn A.

Kamp

1998 Evaluating Consistency in Typology and Classification. Journal of Archaeological Method and Theory 5(2):129-164.

Wiessner, P. A.

1983 Style and Social Information in Kalahari San Projectile Points. American Antiquity 49:253-276.

Wilson, Ernest W.

1930 Burned Rock Mounds of Southwest Texas. Bulletin of Texas Archeological and Paleontological Society 2:59-63.

Winterhalder, B., and E. A. Smith (editors)

1981 Hunter-Gatherer Foraging Strategies. University of Chicago Press, Chicago.

Wolman, M. G., and L. B. Leopold

1957 River Floodplains: Some Observations On Their Formation. U. S. Geological Survey Professional Paper 282-C, pp. 87-107.

Woodburn J.

1982 Egalitarian societies. Man 17, 431-451.

Word, J. H. and C. L. Douglas

1970 Excavations at Baker Cave, Val Verde County, Texas. Bulletin of the Texas Memorial Museum 16, Austin.

Wykoff, D. G.

1995 A Summary of the Calf Creek Horizon in Oklahoma. Bulletin of the Oklahoma Anthropological Society 42:179-210. 
R-28 References 


\title{
APPENDIX A
}

STRATIGRAPIC AND GEOARCHEOLOGICAL INVESTIGATIONS ON THE GUADALUPE RIVER: INTERSTATE 35, COMAL COUNTY, AND SPUR 98, KERR COUNTY, TEXAS

JAMES T. ABBOTT

\begin{abstract}
MATRIX-SUPPORTED FLOODPLAIN GRAVELS: IMPLICATIONS FOR FLOODPLAIN FORMATION PROCESSES
\end{abstract}

DR. CHARLES D. FREDERICK

BACKHOE TRENCH DESCRIPTIONS 



\section{Stratigraphic and Geoarcheological Investigations on the Guadalupe River: Interstate 35, Comal County, and Spur 98, Kerr County, Texas \\ James T. Abbott \\ TxDOT - Environmental Affairs Division}

\section{INTRODUCTION}

The Guadalupe River rises in western Kerr County as two forks that converge at Hunt, Texas, and flow approximately 230 miles $(370 \mathrm{~km})$ to the Gulf of Mexico. In this distance, the Guadalupe River crosses the Edwards Plateau and Western Gulf Coastal Plain, and drains an area of approximately 6,070 square miles $\left(15,720 \mathrm{~km}^{2}\right)$. This document describes stratigraphic investigations conducted at two locations on the Guadalupe River in central Texas. The first investigation reported here consists of a series of three cores taken from a high (approx $10 \mathrm{~m}$ ) Holocene terrace at the crossing of Interstate 35 in New Braunfels, Texas. The second investigation consists of a series of fifteen hollow auger cores extracted from locations along the alignment of the proposed extension of Spur 98 in Kerrville, Texas, near the upper end of the Guadalupe basin. Spur 98 is a proposed relief route that crosses the Guadalupe River on the western side of Kerrville, connecting existing Spur 98 with SH 27 and FM 1338. It lies approximately 30 miles from the twin headwaters of the stream in western Kerr County. These two localities are separated by approximately 70 miles $(112 \mathrm{~km})$ (Figure 1), and occupy very different landscape settings. Spur 98 is situated in a well-defined limestone valley in the heart of the Texas Hill Country. The New Braunfels site, in contrast, is situated in a more open, geologically-diverse setting in the Balcones Fault zone, the transition from the Edwards Plateau to the Western Gulf Coastal Plain.

Coring investigations were undertaken on the south bank of the Guadalupe River at the crossing of IH 35 in New Braunfels during December 1999, while the work on planned Spur 98 at Kerrville occurred in January of

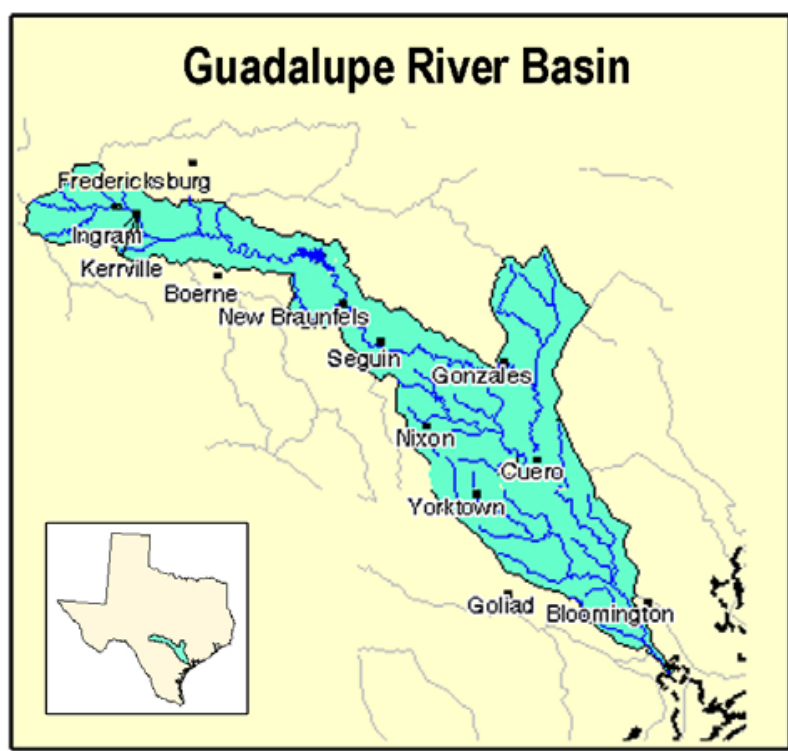

Figure 1: Map of the Guadalupe River drainage basin. The coring investigations reported here were conducted near Kerrville and at New Braunfels. 2000. Both investigations were performed to provide information on the archeological potential of stream deposits in the areas scheduled for impact, so that the level of effort necessary to effectively investigate each area in advance of planned construction could be determined. While these determinations were made relatively quickly (and, as of this writing, the New Braunfels locality is far into construction), this report describes the results of the investigations in detail. 


\section{INVESTIGATIONS AT IH-35 AND THE GUADALUPE RIVER}

\section{THE STUDY AREA}

The New Braunfels study area occupies an incised meander of the Guadalupe River. The locality is situated in the Balcones Fault Zone, near the transition from relatively hard Lower Cretaceous limestones of the Edwards Formation to softer Upper Cretaceous limestones, chalks, and clays of the Pecan Gap Formation and the Navarro Group and Marlbrook Marl Formations (undivided) (Barnes 1983). A number of southwest to northeast trending, en echelon faults cross the Guadalupe valley in this reach, sometimes dictating the alignment of tributaries (e.g., the Dry Comal River). As the Guadalupe crosses the fault boundary between the lower and upper Cretaceous rocks, the valley changes abruptly from a relatively narrow, limestone-bounded trench with little to no preserved alluvium to a broad $(6-7 \mathrm{~km})$ valley containing thick alluvial deposits. Mapped alluvial units in the valley include minor amounts of Holocene floodplain alluvium (Qal), unnamed Pleistocene fluviatile terrace deposits (Qt), and the early to middle Pleistocene Leona Formation (Qle) (Figure 2).

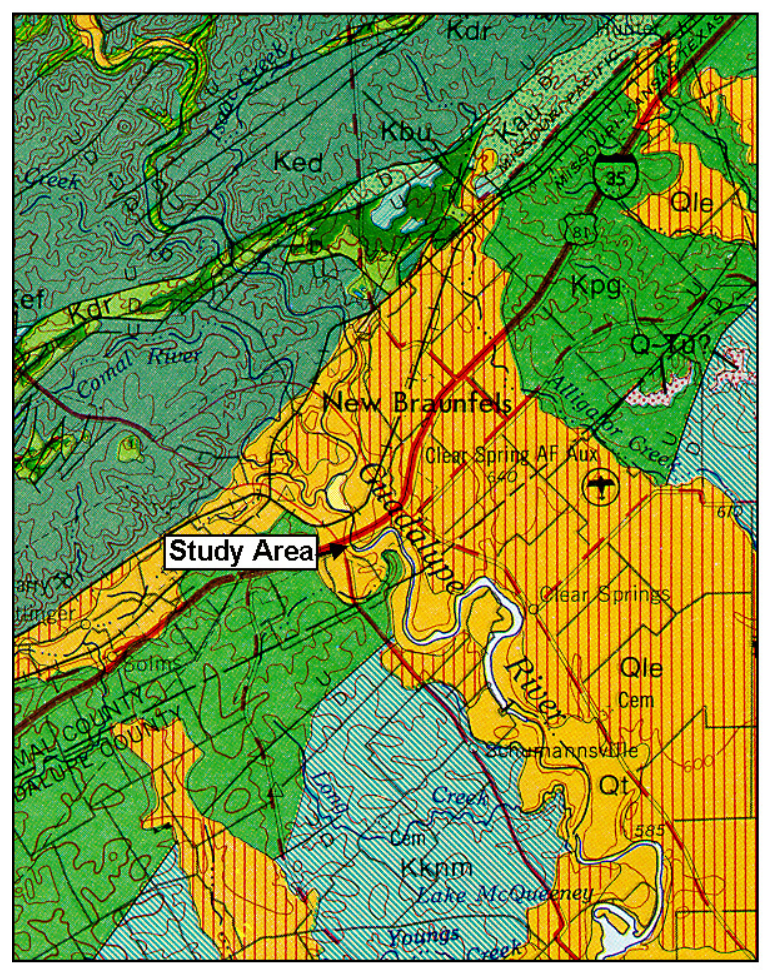

\section{GEOLOGICAL SETTING Guadalupe River at I-35}

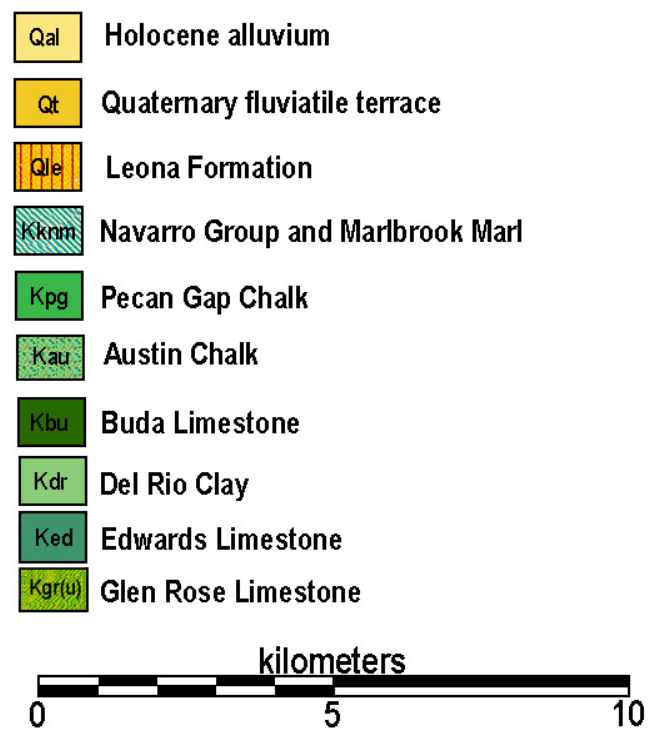

Figure 2: Geologic setting of the New Braunfels locality, illustrating the dramatic expansion of the Guadalupe Valley on the downthrown side of the fault zone.

Although the entire valley cross-section at the I-35 crossing is mapped as Pleistocene by the Bureau of Economic Geology (see Figure 2), field inspection indicated that significant portions of the alignment traverse Holocene alluvial deposits. In particular, the low, convex north bank of the river was clearly mantled with loamy to gravelly point bar deposits of recent origin. While the Holocene age of these deposits was considered obvious based on their character and relationship to the modern channel, the area has been disturbed relatively intensely, and the gravelly, high-energy character of the sediments on the lower point bar did not appear particularly conducive to site preservation. However, examination of the cutbank on the southwestern side of the stream suggested that the thick terrace deposits on the south side and the deposits higher on the point bar on the north side were also consistent with central Texas deposits 
of culturally-relevant age. Coring investigations were conducted to provide deep, low-footprint windows into these deposits to assess their context and archeological potential at the I-35 crossing and in similar settings elsewhere.

Soils mapped by the USDA-SCS (now NRCS) include Oakalla soils, frequently flooded, on the lower point bar, Gruene clay, 1-5\% slopes on the middle elevations of the point bar, Boerne fine sandy loam, 1$3 \%$ slopes on the upper point bar, Lewisville silty clay, $1-3 \%$ slopes on a narrow, low inset below the cutbank, and Sunev silty clay loam, 0-1\% slopes on the level terraces on both sides of the river (Batte 1984). Oakalla soils are classified as cumulic Haplustolls, Gruene soils are Petrocalcic Paleustolls, Boerne soils are fluventic Ustochrepts, and Lewisville and Sunev soils are typic Calciustolls. This mapping is somewhat problematic, because moderately developed (Oakalla, Lewisville) and strongly developed (Gruene) soil series are mapped at low elevations on the point bar in positions that stratigraphic relationships suggest should be relatively young, while weakly developed alluvial soils (Boerne) are mapped at higher elevations.

As is typical of streams on the eastern Edwards Plateau, the Guadalupe River is subject to occasional intense flooding. The flashy character of the flow is illustrated by daily mean discharge data from USGS gauging station 08168500, situated on the Guadalupe immediately above the confluence of the Comal River. Between 1928 and the present, mean discharge has averaged approximately $460 \mathrm{cfs}$ per day, with the largest flood on record peaking at 101,000 cfs on July 3, 1932. The flashy character of the flow has been controlled to a large extent by the construction of Canyon Dam, which was closed in June 1964. Although the dam has limited damaging floods, they have not been eliminated. Three floods greater than $10,000 \mathrm{cfs}$ have been recorded since June 1964 (including one of more than 37,000 cfs in October 1998), compared to 20 in the period from 1928 through 1964. More significant effects of Canyon Dam are the increased incidence of more moderate, prolonged floods as discharge from large events is controlled and marked effect on low stage flow (Figure 3)

The high southwestern bank of the river consists of a heavily modified (urbanized) alluvial surface that lies approximately 35-40 $\mathrm{ft}(10.7-12.2 \mathrm{~m})$ above the modern channel. It was examined with three deep hollow auger cores. The locations of the cores are indicated in Figure 4.

\section{METHODS}

Coring investigations were conducted with a truck mounted, hollow-stem auger capable of extracting a core 2.25 inches $(5.7 \mathrm{~cm})$ in diameter. Coring was performed by the Bureau of Economic Geology, University of Texas at Austin, under the direction of the author. Three cores were drilled to bedrock and extracted for storage at the Bureau core facility in Austin. Detailed examination, description, and sampling of the cores was performed at the Bureau facility in Austin. Sampling consisted of three bulk sediment samples taken from Core \#1 for radiocarbon dating. Radiocarbon determinations were made by Beta Analytic, Inc. (see Table 1 at end of document).

\section{RESULTS AND DISCUSSION}

Cores 1 and 2 were extracted from remnants of the original alluvial surface overlooking the Guadalupe channel, while Core 3 was extracted from a grassy flat between the highway and the frontage road where up to 2 meters of sediment had been previously removed, probably for use as fill for the highway embankment. All three cores revealed a similar profile through the same alluvial fill, although the profile in Core 3 was strongly truncated. 
Stratigraphic and Geoarcheological Investigations on the Guadalupe River

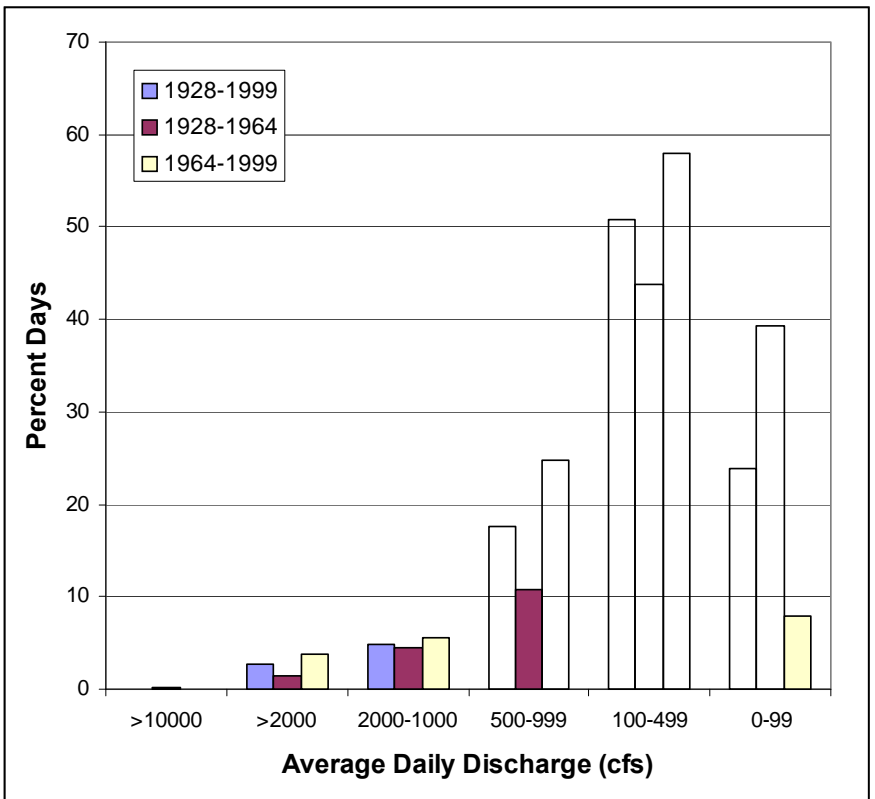

Figure 3: Illustration of daily average discharge in the Guadalupe River at a station immediately above the confluence of the Comal River (i.e., approx. $1.5 \mathrm{~km}$ upstream of the study area), illustrating the effect of the construction of Canyon Dam (closed June 1964) on flow dynamics.

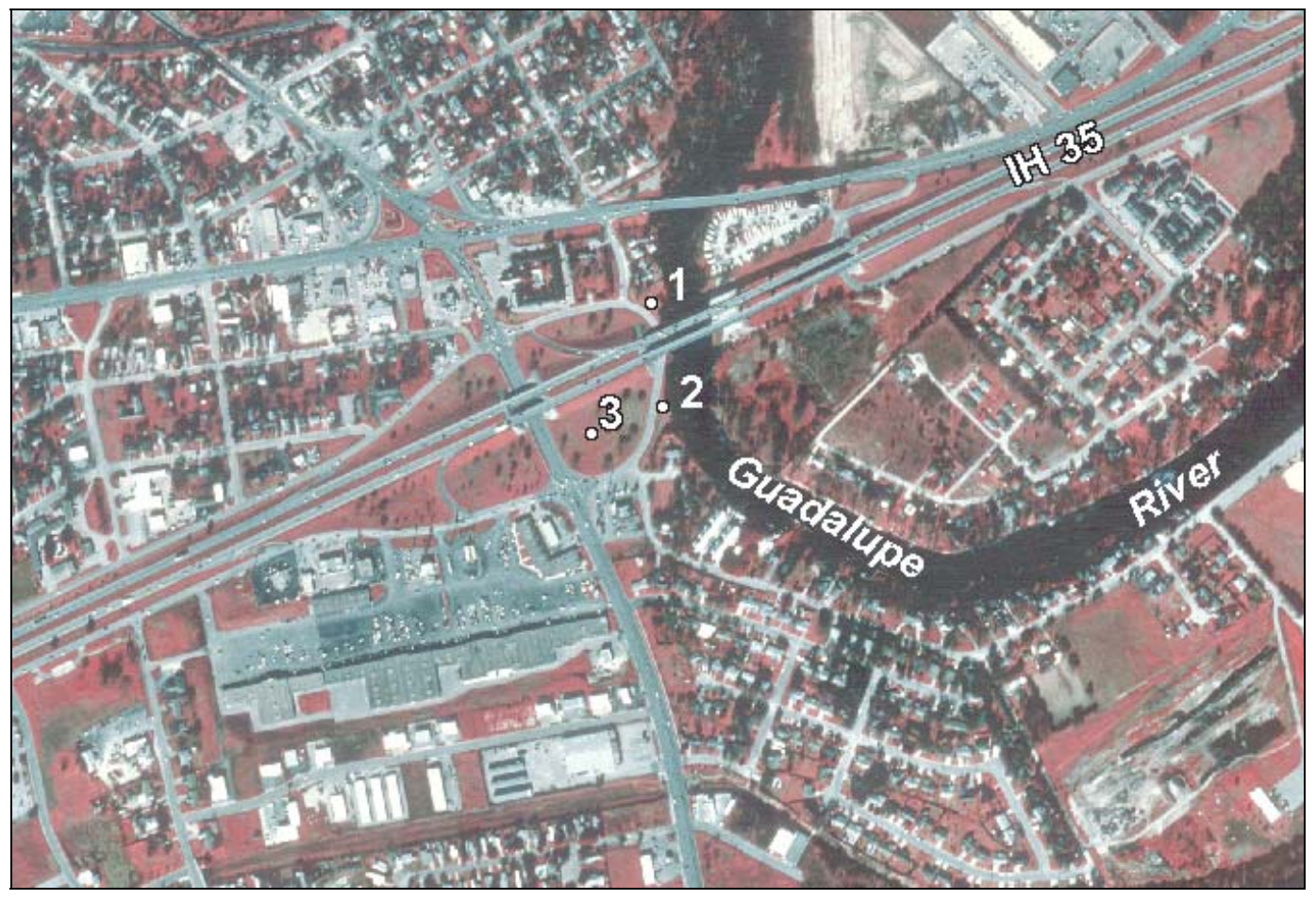

Figure 4: Detail of USGS DOQQ illustrating the location of the three cores taken during the New Braunfels study. 
Figure 5 illustrates the character of Core 1. It consisted of approximately $7 \mathrm{~m}$ of loamy to silty alluvium overlying approximately $5 \mathrm{~m}$ of gravel, and supports an Ap-2Bk-2C1-2C2 profile. The upper meter of material appears to represent reworked fill associated with highway construction (Ap horizon). No longterm paleosurfaces were identified in the sequence, which is interpreted as a single fill. While three intervals when relatively structured, fine-grained facies were accumulating are represented in the core (at approximately $4 \mathrm{~m}, 5.5 \mathrm{~m}$, and $6.5 \mathrm{~m}$ ), only the lowest exhibits evidence of secondary carbonate accumulation, and none can be correlated with similar facies in the other two cores. Radiocarbon ages from the core are internally consistent, and range from $5420 \pm 60$ B.P. in the Bk horizon to $9800 \pm 80$ B.P. just above the thick gravels. Therefore, the sequence is interpreted as a single fining-upward point bar to floodplain sequence of early to middle Holocene age.

The same geomorphic surface is preserved on both sides of the Guadalupe River, and extends back from the channel for a considerable distance $(>1 \mathrm{~km})$. It includes areas mapped as Late Pleistocene terrace and the Leona (early-middle Pleistocene) terrace by the Bureau of Economic Geology. While it is very unlikely that all of these areas are actually underlain by Holocene alluvium, it does appear that the extent and depth of culturally-relevant deposits is greater (and possibly far greater) than previously recognized. Similar results were obtained by Blum and Valastro (1994), who found that extensive Colorado River deposits that had been previously interpreted as Pleistocene in age (e.g., Baker and Penteado-Orellana 1977) were in fact Holocene deposits.

\section{INVESTIGATIONS AT SPUR 98, KERR COUNTY}

\section{THE STUDY AREA}

The Spur 98 study area occupies a cut limestone valley in the Texas hill country. Unlike the New Braunfels project, it represents a new location project in an area that has not been severely impacted by urbanization and highway construction. The planned Spur 98 extension will cross the Guadalupe River west of downtown Kerrville, linking FM 1338 and SH 27 with the south side of the river (Figure 6). The project begins at the existing terminus of Spur 98 and skirts the colluvial toeslope along the path of an existing county road on the south side of the valley for approximately a kilometer before turning north and crossing the river and SH27, terminating at FM1338. All cores were situated along this cross-valley transect; no subsurface investigations were conducted in the area skirting the toeslope.

The channel along this reach is modified by a series of small retention structures that cause the river to pool into a narrow lake without overtopping the margins of the natural (formerly gravelly) channel. Local relief is on the order of $115 \mathrm{~m}$, varying between approximately $495 \mathrm{~m}(1625 \mathrm{ft})$ at the crossing and $610 \mathrm{~m}$ (2000 ft.) on the upland ridges overlooking the valley. The valley bottom is approximately $1.6 \mathrm{~km}$ wide at the project location, and exhibits an asymmetric cross-section. Several constructional alluvial surfaces are present: a low, narrow floodplain $\left(\mathrm{T}_{0}\right)$ surface situated primarily on the south side of the river, a broad, gently sloping terrace $\left(T_{1}\right)$ surface that is situated on both sides of the stream, and narrow, poorly preserved higher terrace $\left(T_{2}\right)$ surface on the south side of the river. The $T_{1}$ surface rises for a considerably distance on the north side of the stream, ramping up from an elevation of approximately 1645 feet to almost 1700 feet above mean sea level, where it merges with a colluvial apron shed from the valley wall. The alignment covers the portion between approximately 1645 feet and 1670 feet, and is underlain by both Holocene and Pleistocene alluvial and colluvial deposits.

The bedrock unit mapped in the vicinity of the project is the Glen Rose Limestone, while rocks of the Edwards Group cap the surrounding uplands (Barnes 1981) (Figure 7). The Glen Rose Limestone consists of alternating beds of relatively hard limestone and softer marl which weather into a distinct "stairstep" topography. The alluvial fill in the Guadalupe valley is inset into these lower Cretaceous rocks. It is 
mapped as low terrace deposits (Qat), which are described as "mostly low terrace deposits above flood level along entrenched streams, some alluvium; gravel, sand silt clay, and organic matter" (Barnes 1981). This designation, rather than the more common Qal unit mapped in the valleys of most central Texas streams, implies that the Guadalupe rarely overtops the terrace surface in the study area.

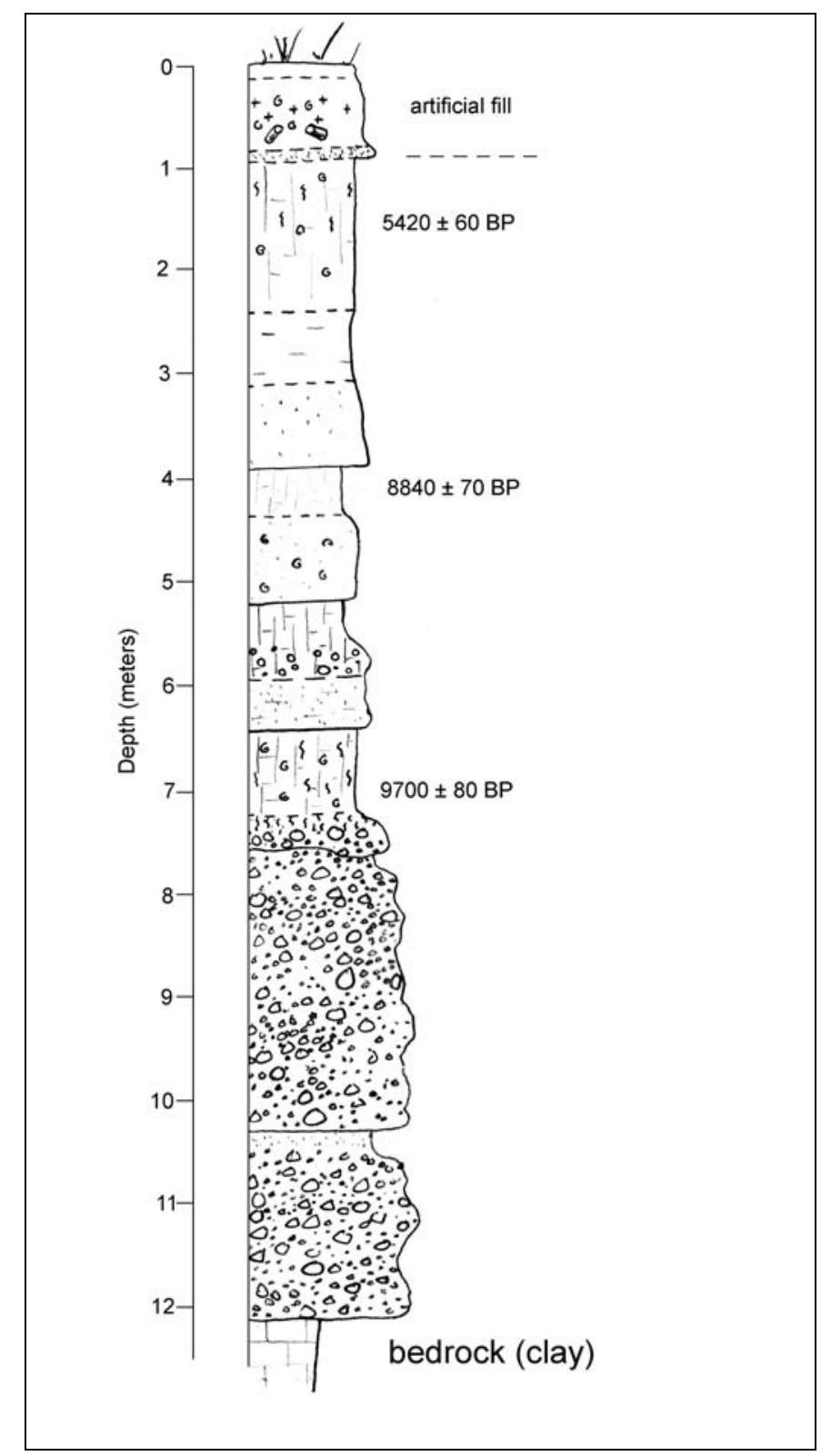

Figure 5: Schematic illustration of core NB\#1, illustrating sediment character and radiocarbon ages. This core is representative of all three taken from the New Braunfels study area. The irregular boundary of the right side of the column is a schematic representation of textural (grain size) variation, with the right side representing coarser textures. 


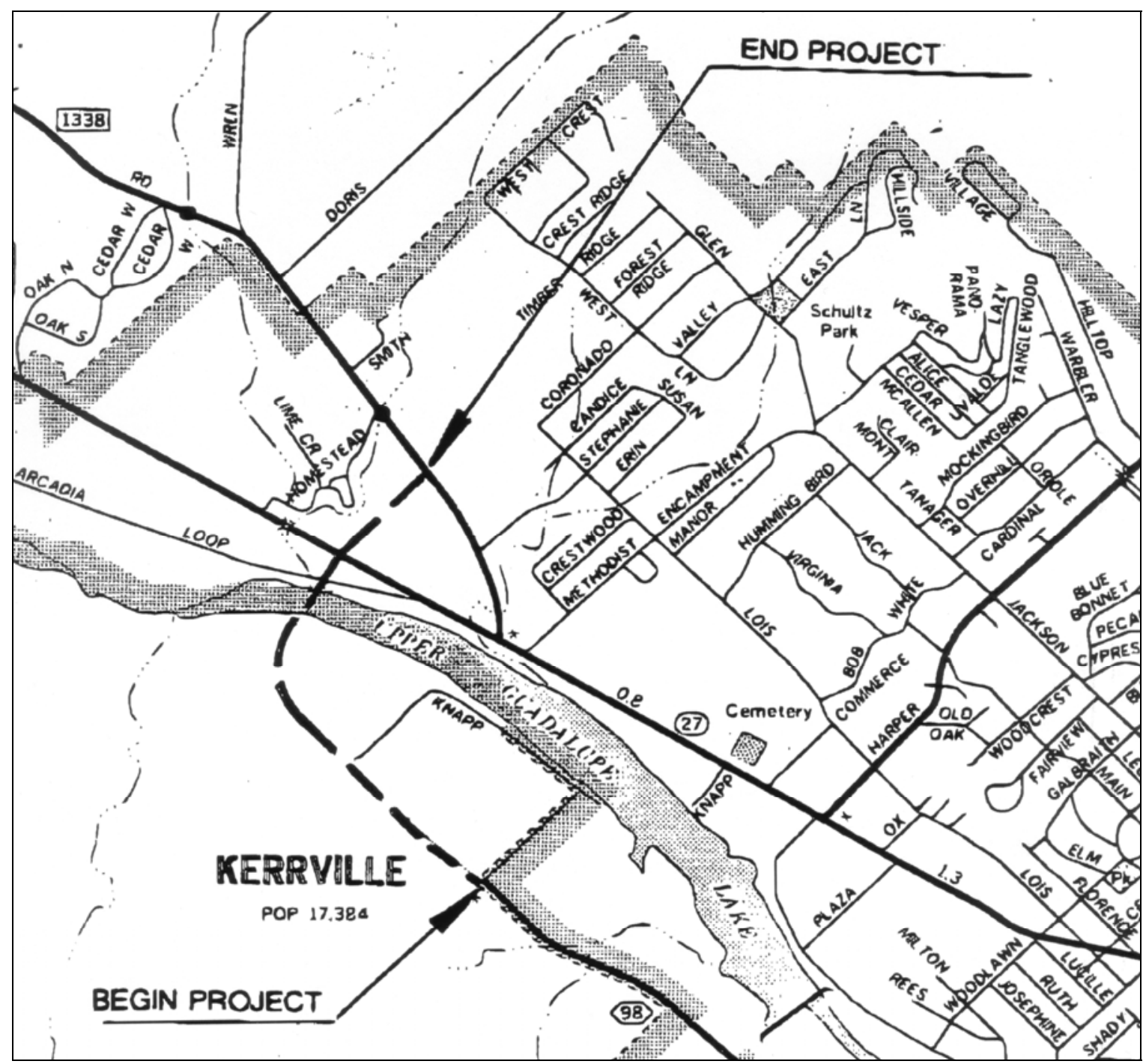

Figure 6: Location of the planned Spur 98 extension.

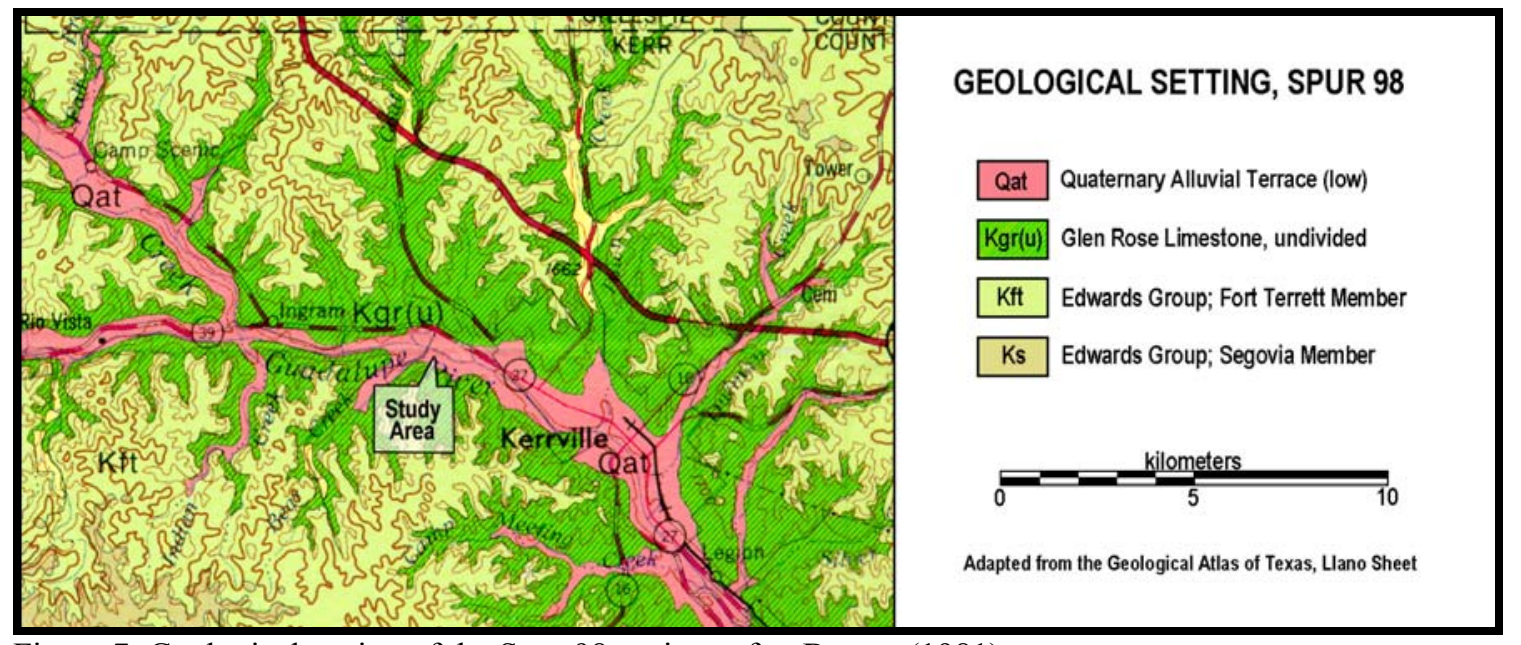

Figure 7: Geological setting of the Spur 98 project, after Barnes (1981). 
While there is no gauging station on the Guadalupe at Kerrville, stream discharge data is available from gauging stations upstream (at Hunt) and downstream (at Comfort) (Figure 8). The Hunt gauging station is situated approximately $15 \mathrm{~km}$ upstream from the study area, at an elevation of $1722 \mathrm{ft}$. above msl, and represents a drainage basin of $288 \mathrm{mi}^{2}$ in the upper part of the basin. The Comfort station is situated at an elevation of $1369 \mathrm{ft}$ about $32 \mathrm{~km}$ downstream from the study area, and represents a drainage basin almost three times as large $\left(839 \mathrm{mi}^{2}\right)$. Peak mean daily discharge over the sixty-two years of record at Comfort is $74,200 \mathrm{cfs}$, while the Hunt station's shorter period of record (thirty-six years) peaks at a much more

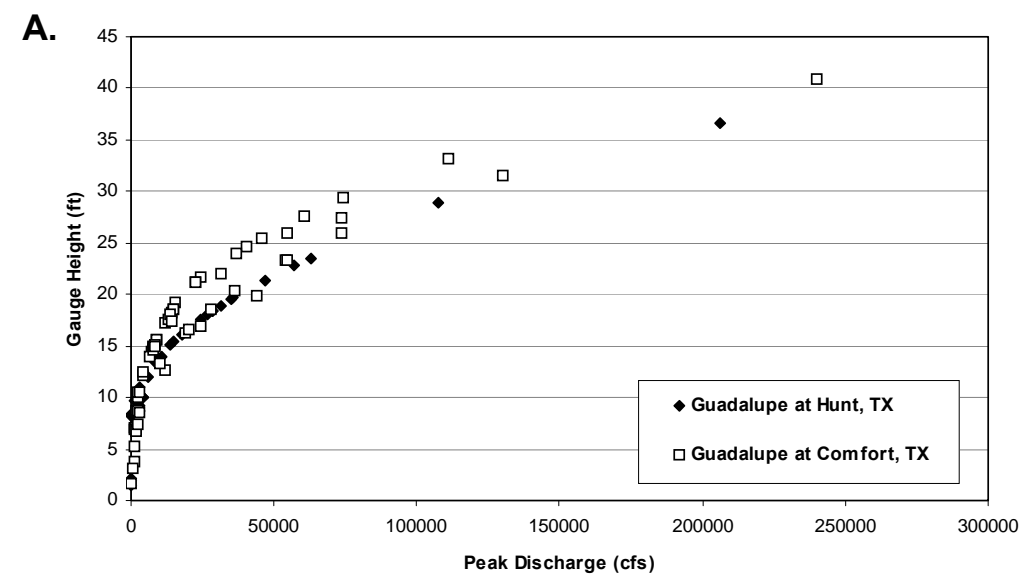

B.

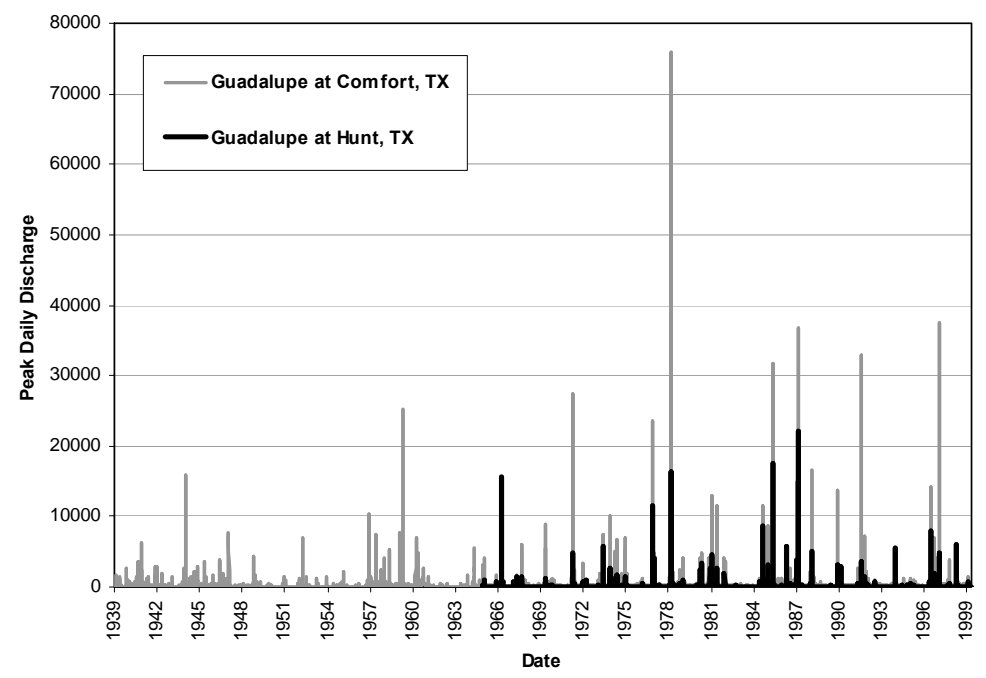

Figure 8: Stream discharge data from the Guadalupe River, Kerr County. A: Peak discharge vs. gauge height for flood events over the period of record. B: Daily mean discharge over the period of record.

modest 22,200 cfs. Notably, however, the date of the peak discharge at Comfort overlaps the record from Hunt, which recorded a much more modest discharge of 16,300 cfs on the same day (August 2, 1978, when remnants of tropical storm Amelia caused severe flooding and resulted in the loss of 27 lives in Bandera, Kerr, Kendall, and Gillespie Counties)(Kingston 1986). Comparison of the long-term records from the two stations indicates that daily flow at the Comfort station averages 3.22 times that at Hunt, which is similar to the difference in drainage basin size (Comfort drains roughly 2.9 times the area). However, the flow at Comfort has been exceeded by that at Hunt roughly $3 \%$ of the time, while it has exceeded five times the flow at Hunt more than $10 \%$ of the time. The greatest disparity occurred on June 12, 1982, when the flow at Comfort was more than 62 times the flow at Hunt as a result of intense thunderstorms downstream of Hunt. 
The plot of gauge height versus peak discharge suggests that this increase in average discharge at Comfort is not mirrored by a concomitant increase in average or peak flood height. At both stations, inundation of the flood terrace surface is relatively rare, but does occur when stage exceeds approximately $20 \mathrm{ft}$. The largest recorded floods at both stations exhibit stages between 35 and 45 feet above base flow, which would be sufficient to inun-date all but the highest parts of the study transect (as well as much of downtown Kerr-ville). Mapped soils within and immediately adjacent to the alignment include Nuvalde silty clay on the main terrace surface, Krum soils flanking small tributaries that traverse the terrace on both sides of the river, and the Orif-Boerne association on the flood-plain and terrace flanks. Other soils mapped in the area include Depalt silty clay loam and Doss silty clay in the valley and Kerrville, Krum, and Real soils on the adjacent uplands (Dittemore and Coburn 1986). All soil descriptions and classifications follow the descriptions published on the USDA-NRCS website (http://www.statlab.iastate.edu).

Nuvalde silty clay soils are very deep, well-drained moderately permeable soil characteristic of older stream terraces underlain by calcareous alluvium. They typically exhibit an Ap-A-Bw-Bk1-Bk2-BCk profile with Stage II carbonate morphology, are greater than $214 \mathrm{~cm}$ (84 in.) thick, and are classified as Typic Calciustolls. Krum soils are very deep, well-drained, moderately slowly permeable soils formed in calcareous clayey deposits on nearly level to moderately sloping terraces and toeslopes. They are classified as Udertic Haplustolls and exhibit a typical Ap-A-Bw-Bk1-Bk2 profile. Orif soils are deep, well drained, rapidly permeable soils formed in gravelly alluvium on level to gently sloping floodplains. The typically exhibit an A-2C1-3C2 profile and are classified as Typic Ustifluvents. Boerne soils are very deep, well-drained, moderately rapidly permeable, calcareous soils typical of loamy deposits underlying floodplains and low terraces. They are classified as Fluventic Haplustepts, and typically exhibit an ApBk-Bk2 profile. Depalt soils are deep, well-drained, very slowly permeable soils formed in calcareous clayey alluvium and colluvium. They exhibit an A-Bss1-Bss2-Bk1-Bk2 profile, and are classified as Chromic Haplusterts. Doss soils are shallow, well-drained, moderately slowly permeable soils over weakly cemented limestone. They exhibit a thin A-Bk-Cr profile and are classified as Typic Calciustolls. Kerrville soils are somewhat deeper, well drained, moderately permeable soils formed in residuum and colluvium. They exhibit an A-Bk-Bk/R-R profile and are classified as Typic Calciustepts. Finally, Real soils are shallow, well-drained soils formed in hard limestone. They exhibit an A-Ak-Cr profile, and are classified as Typic Calciustolls.

\section{METHODS}

As at New Braunfels, the coring investigations were conducted under the direction of the author by the Bureau of Economic Geology, University of Texas at Austin, using a truck mounted, hollow-stem auger. A total of fifteen cores were extracted from the cross-valley transect, seven of which were situated north of the stream and eight south of the stream. All cores were extended either to bedrock (Cores 3, 4, 6, 7, 8, $10,13,14$, and 15) or to refusal by dense gravels or gravel calcrete (Cores 1, 2, 5, 9, 11, and 12). Detailed examination, description, and sampling of the cores was performed at the Bureau facility in Austin. Primary measurement of the cores was performed using English measurements to accommodate the native units of the coring equipment (particularly the five foot [1 $1.524 \mathrm{~m}$ ] core barrel), with conversion to metric units performed subsequently. Nineteen radiocarbon samples on bulk humates were extracted from the cores and submitted to Beta Analytic, Inc. for chronological control (see Table 1). Additional observations were made in existing exposures, particularly in a shallow water line trench that happened to be open across the $T_{1}$ surface during fieldwork. The location of cores is illustrated in Figure 9. 


\section{RESULTS}

The results of coring are presented in Figure 10. Overall, the Spur 98 sequence exhibits a sequence of relatively coarse-grained, high energy deposits interbedded with relatively thin muds and overlain by thicker deposits of fine-grained sediment with interbedded gravels. A total of fifteen cores were excavated in a cross-valley transect along the new part of the Spur 98 alignment. A minimum of four informal, inset allostratigraphic units were identified at the cross-section on the basis of sedimentary character and bounding unconformities. These units are informally termed the "high Pleistocene fill" (Unit 1), the "Late Pleistocene fill" (Unit 2), the "Late Pleistocene-Holocene fill" (Unit 3) and the "Recent fill" (Unit 4) in the following discussion.

\section{UNIT 1}

The high Pleistocene fill (Unit 1) consists of reddish brown to yellowish brown, loamy to gravelly alluvium supporting a strong, thick calcic soil. It was encountered in BT8 and BT9 on the south side of the valley underlying a narrow, poorly preserved $T_{2}$ terrace remnant at an elevation of approximately 1680 $\mathrm{ft}$. $(512 \mathrm{~m})$ above msl. Any comparable fill on the north side of the valley are situated upslope of the project area. BT8 exemplifies the soil profile developed in Unit 1. It exhibits an A-AB-2B1k-2B2k-2B3k2BC-2Ck-2C profile developed in a silty to gravelly alluvial fill approximately 39 feet $(11.9 \mathrm{~m})$ thick. The upper 1.5 feet $(50 \mathrm{~cm})$ of the sequence consists of a thin sequence of very dark grayish brown (10YR $3 / 2$ ), slightly stony clay loam (A horizon) underlain by subangular limestone gravels in a clay loam matrix (AB horizon). This material represents relatively recent (probably middle-late Holocene) slopewash shed from the valley slopes. Beneath this veneer, the deposit grades through 3 feet $(0.9 \mathrm{~m})$ of a brown to pale brown sandy loam containing small stones and pebbles (2B1k-2B2k horizons) into a thick sequence of strong brown (7.5YR 4/6) silty clay containing abundant large carbonate nodules and soft masses (2B3k horizon). This complex Bk horizon is approximately $10 \mathrm{ft}(3 \mathrm{~m})$ thick, and grades into approximately 13 feet $(4 \mathrm{~m}$ ) of massive loamy silt (2BC horizon) that ranges from 7.5YR 5/5 to 10YR 6/4 with depth. Discrete zones of carbonate cementation are common in the lowest meter of the silts, which rests on approximately 11 feet $(3.35 \mathrm{~m})$ of crudely bedded gravels and gravelly sands with fine sand and mud interbeds. The fill rests on a cut bedrock surface at an elevation of approximately 1643 feet above msl.

One radiocarbon age was processed from Unit 1. This sample, taken from a depth of 5.7-6.0 ft (roughly $1.7-1.8 \mathrm{~m}$ ) in the upper part of the 2B3k horizon, yielded a conventional age of $8,150 \pm 40$ B.P.. Given the suite of ages from the subsequent unit, this age clearly post-dates deposition of the Unit 1 , and is interpreted as a mean residence age of a soil developed in a much older stratigraphic unit.

\section{UNIT 2}

Unit 2, the Late Pleistocene fill, was encountered in Cores 1 and 2 on the north side of the valley. Probable equivalent deposits were identified at depth in Core 11 (see Figure 10) beneath the $T_{1}$ surface. The unit is dominated by thick gravels that fine upward into loams and support relatively mature soils with rubified $\mathrm{Bt}$ horizons and prominent Stage II to III calcic horizons. Little useful radiocarbon information is available from the unit, because both ages from it were from capping soils and appear to provide minimum (mean-residence) ages.

Core 1, situated near the northern limit of the project, is overlain by a very thin and plow-disturbed veneer of deposits associated with the subsequent (Late Pleistocene-Holocene) unit. The core exhibits an A-Btk$\mathrm{K}-\mathrm{Ck} 1-\mathrm{Ck} 2$ profile developed in gravelly and sandy deposits almost $10 \mathrm{~m}$ thick. The Ap horizon is approximately $30 \mathrm{~cm}$ thick and consists of dark brown (7.5YR 3/2) structureless loam containing fine 


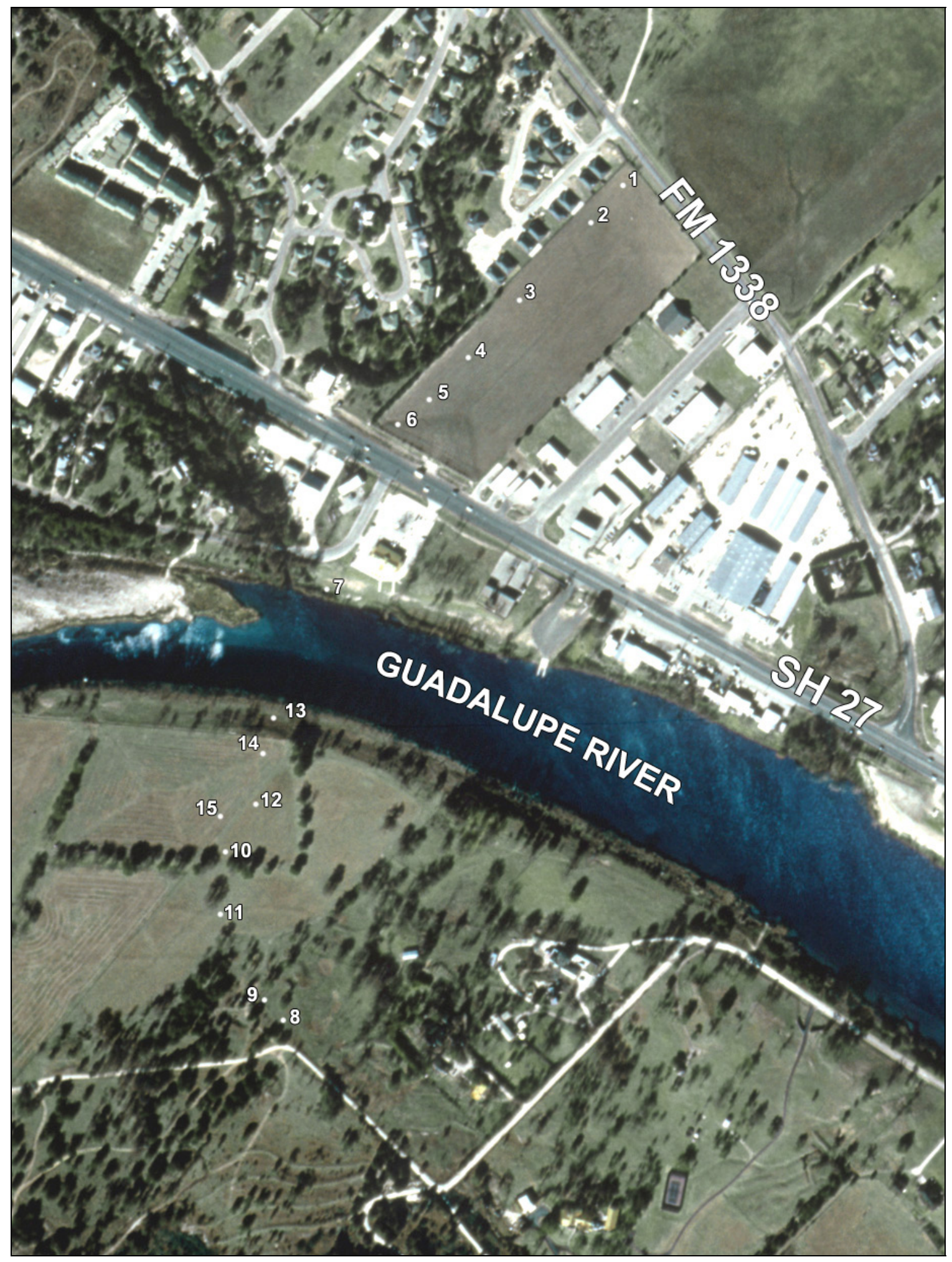

Figure 9: DOQQ image of the Spur 98 study area, with core locations indicated. 
gravels, occasional loose carbonate nodules, and finely-divided and partially-decomposed organic material. It grades abruptly into a moderately-structured, reddish brown (5YR 4/4) sandy clay loam containing large, hard solution-pitted nodules, small limestone gravels, and very coarse sands. This horizon was underlain by a carbonate-dominated, light gray (10YR 7/2) K horizon developed in silty sand to gravelly sand. From approximately $1.5 \mathrm{~m}$ to $3 \mathrm{~m}$, the sequence consists of thick alternating beds of silty clay, and loamy to silty gravelly fine sand. Colors vary considerably, but are dominated by pinkish-gray and reddish brown mottling. Below $3 \mathrm{~m}$, the sequence consists of gravelly sands, sandy gravels, and coarse limestone gravels dominated by shades of pale yellow and pale brown (10YR 6/3 to 10YR 7/4). Brown redox mottling is faint but apparent at a number of places in the section. The core was unable to penetrate a zone of cementation at $9.1 \mathrm{~m} \mathrm{bgs}(1635 \mathrm{ft}$ amsl). Based on the elevation of bedrock in subsequent cores, this zone of cementation is interpreted as either the bedrock contact or a dense groundwater calcrete mantling the relatively impervious bedrock contact.

Only one date was obtained from Core 1. A humate sample obtained from the Btk horizon at the top of the core yielded a conventional age of $3280 \pm 40$ B.P. Given the ages from Unit 3, this age is clearly too young to represent the age of deposition, and is interpreted as a mean residence age for the terrace soil.

Core 2, situated a few meters down the gently-sloping terrace surface from Core 1, exhibits the clearest contact between Units 2 and 3. The upper $2 \mathrm{~m}$ of the core represents Unit 3, which is separated from the thicker Late Pleistocene fill by a truncated, rubified paleosol. The upper material consists of approximately 1-1.2 m of brown gravelly clay loam over a meter of carbonate-enriched limestone gravel, and supports an Ap-A-Btk-Bk-C profile. The underlying deposit exhibits a $2 \mathrm{Bt}-2 \mathrm{BC}-2 \mathrm{BCk}-2 \mathrm{C}$ profile. The rubified soil capping this unit consists of less than half a meter of massive, dark reddish brown to reddish brown clay loam over a thick accumulation of subrounded limestone gravel in a pink to white, silty loam matrix. The fine matrix and the incorporated gravel clasts are enriched with diffuse matrix carbonate and carbonate rinds, respectively. Below approximately $3 \mathrm{~m}$, secondary carbonate content is sharply diminished, resulting in a light yellowish brown sandy gravel with faint, dark yellowish brown iron staining. The core was unable to penetrate any further at the depth of $7.6 \mathrm{~m}$, which interestingly is almost exactly the same elevation that Core 1 was refused (1635 ft above msl; see Figure 10). This suggests that the Late Pleistocene unit rests on a buried bedrock strath surface that is $2.5-3 \mathrm{~m}$ higher than that underlying Unit 3, suggesting that the two deposits were separated by a phase of stream incision that cut into the bedrock. However, because both Core 1 or Core 2 terminated at a calcrete rather than bedrock, this conclusion must remain tentative. Nevertheless, it is this apparent difference in bedrock elevation, coupled with the somewhat more oxidized appearance (including 5YR hues) of the matrix sediments and soils and the character of the contact in Core 2, which supports the interpretation that two different units are represented. Two different ages were obtained from this core. An age of $3700 \pm 40$ B.P. was obtained from the Btk horizon of the soil developed in Unit 3, and an age of $9640+80$ B.P. was obtained from the $2 \mathrm{Bt}$ horizon of the rubified soil developed at the top of Unit 2. Both of these ages are also probably mean-residence ages, reflecting the admixture of clastic and soil organics. With the possible exception of the base of Core 11, all the remaining cores exposed deposits believed to represent Unit 3 and 4.

\section{UNIT 3}

Unit 3, the Late Pleistocene-Holocene fill, represents the bulk of deposits investigated by the Spur 98 cores. It was encountered in Cores $3,4,5,6,10,11,12,14$, and 15 (see Figure 10) beneath the $T_{1}$ surface. As Figure 10 illustrates, the unit incorporates a diverse suite of sediments dominated by thick gravels that fine upward into loams. Radiocarbon data from Unit 3 suggest that these deposits aggraded relatively rapidly through the Latest Pleistocene, accumulating up to 7-8 of predominantly gravelly sediments by approximately $10 \mathrm{ka}$, then slowed markedly, accumulating approximately $2-2.5 \mathrm{~m}$ of predominantly loamy and clayey alluvium through the Holocene (Figure 11). The unit is inset against and partially 


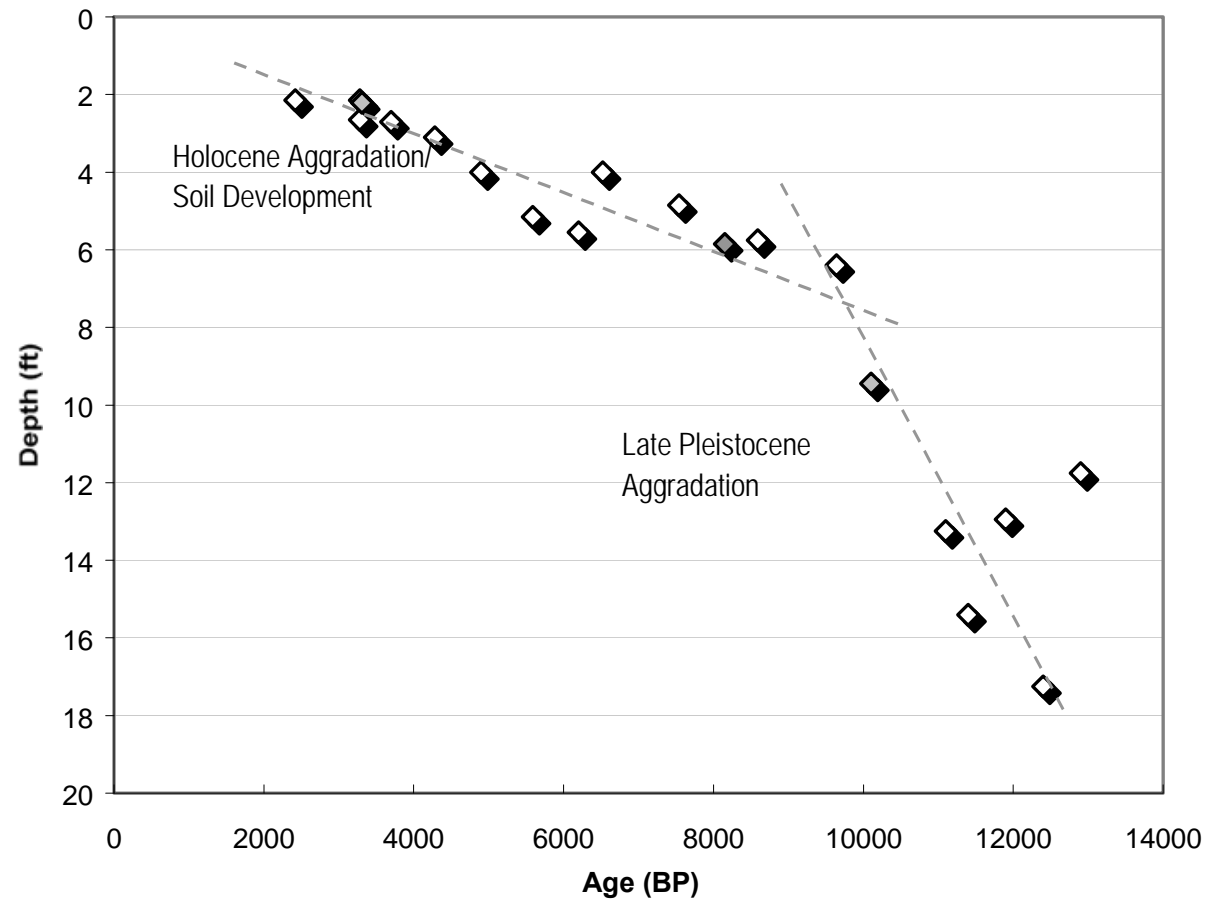

Figure 11: Plot of conventional radiocarbon age vs. depth for dated samples from the study area. Shaded symbols represent dates interpreted as mean residence ages from Units 1 and 2. All other ages were obtained from Unit 3 sediments. Lines are for illustration purposes only and do not represent regression fit.

overlaps Unit 2 on the north, where it appears to pinch out in the vicinity of Core 1. On the south side of the valley, the unit overlaps and buries a probable remnant of Unit 2 at depth and is inset against Unit 1, where it interfingers with Late Pleistocene-Holocene colluvium shed off the southern valley wall. Although buried soils were identified locally in a few cores (i.e., Core 6 and Core 10), no laterally traceable unconformity or bounding topographic discontinuity was detectable in the sequence, which is therefore treated as a single, informal allostratigraphic unit.

Because the unit is vertically and laterally heterogeneous, several different cores must be described to present an overview of the deposits associated with Unit 3. Core 4 is representative of the sequence on the north side of the river. The upper $3 \mathrm{~m}$ of Core 4 consists of an Ap-Bk-BC-C sequence developed primarily in clay loam with occasional dispersed limestone gravels. The Ap horizon is approximately 30 $\mathrm{cm}$ thick and consists of a very dark grayish brown loam (10YR 2/2-10YR3/2). It grades abruptly into a subangular blocky, very dark grayish brown (10YR 3/2) clay loam Bk horizon containing fine gravels and some small, soft nodules. With depth, this deposit gradually loses structure and lightens in color, grading into a stiff, dark brown (10YR 3/3) clay loam with occasional carbonate masses. At approximately $1.5 \mathrm{~m}$ bgs, the deposit grades gradually into a light brownish yellow (10YR 6/6) stiff silty clay loam containing occasional masses of carbonate, some or all of which may be framework grains attacked by groundwater solution. Clay content and carbonate inclusions decrease with depth, so that at $2.75 \mathrm{~m}$ the deposit consists of a brittle, light brownish yellow massive silt loam. Below $3 \mathrm{~m}$, the deposit grades into $5.2 \mathrm{~m}$ of poorly sorted sandy limestone gravel. It rests on marly weathered limestone at approximately $1626 \mathrm{ft}(495 \mathrm{~m})$ above msl. The elevation of bedrock in Cores 3, 6, and 7 is within a couple of feet of this figure, indicating that the fill rests on a relatively level bedrock strath. No radiocarbon ages were obtained from Core 4. Ages from other Unit 3 deposits on the north side of the river range from $2420 \pm 40$ B.P. (in the $\mathrm{ABk}$ horizon of Core 6) to $12,900 \pm 120$ B.P. (from just above the gravels at $3.6 \mathrm{~m}$ bgs in the same core). 
Stratigraphic and Geoarcheological Investigations on the Guadalupe River

\section{RESULTS OF CORING INVESTIGATIONS ACROSS THE GUADALUPE RIVER AT PLANNED SPUR 98 EXTENSION, KERRVILLE}

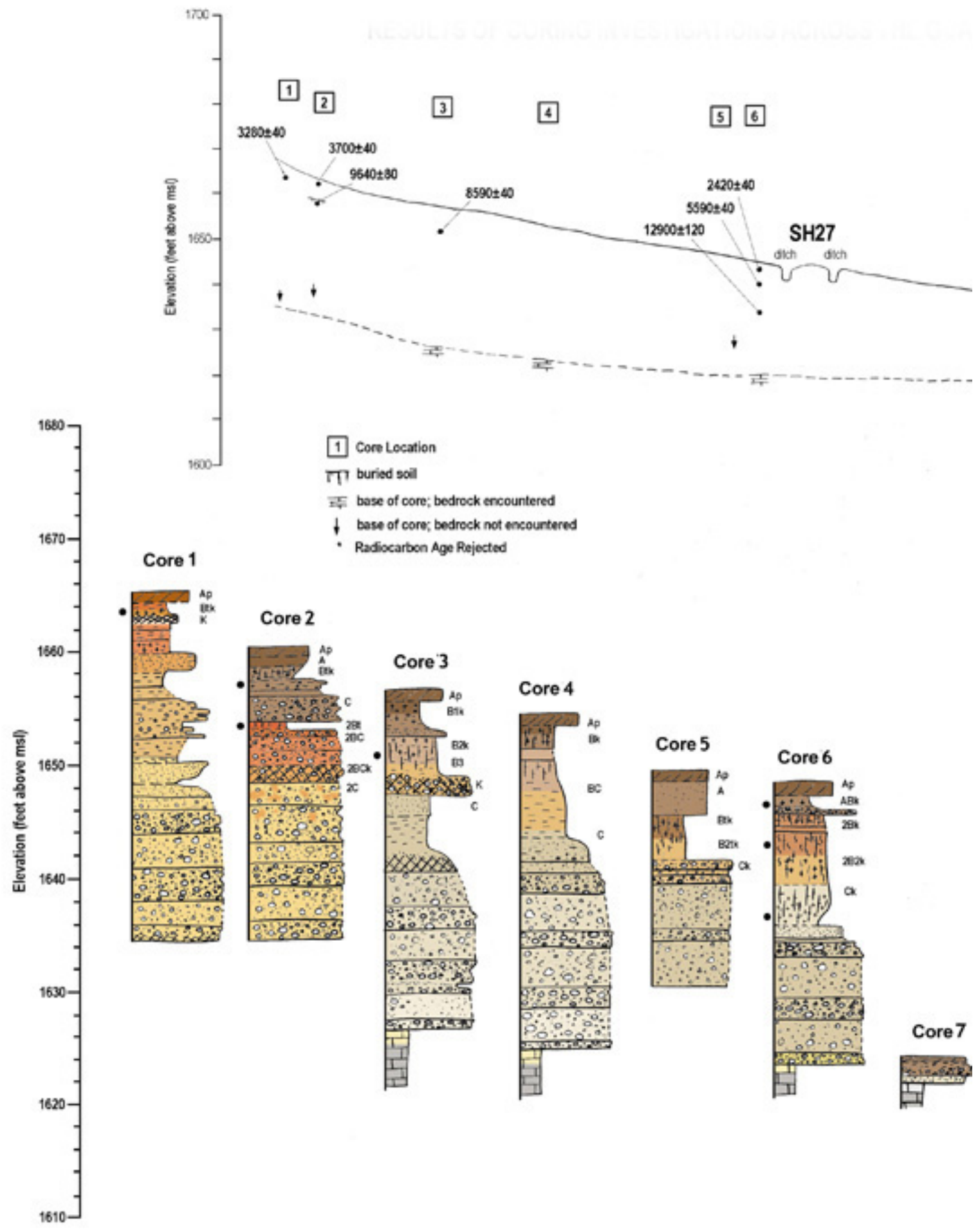


Stratigraphic and Geoarcheological Investigations on the Guadalupe River

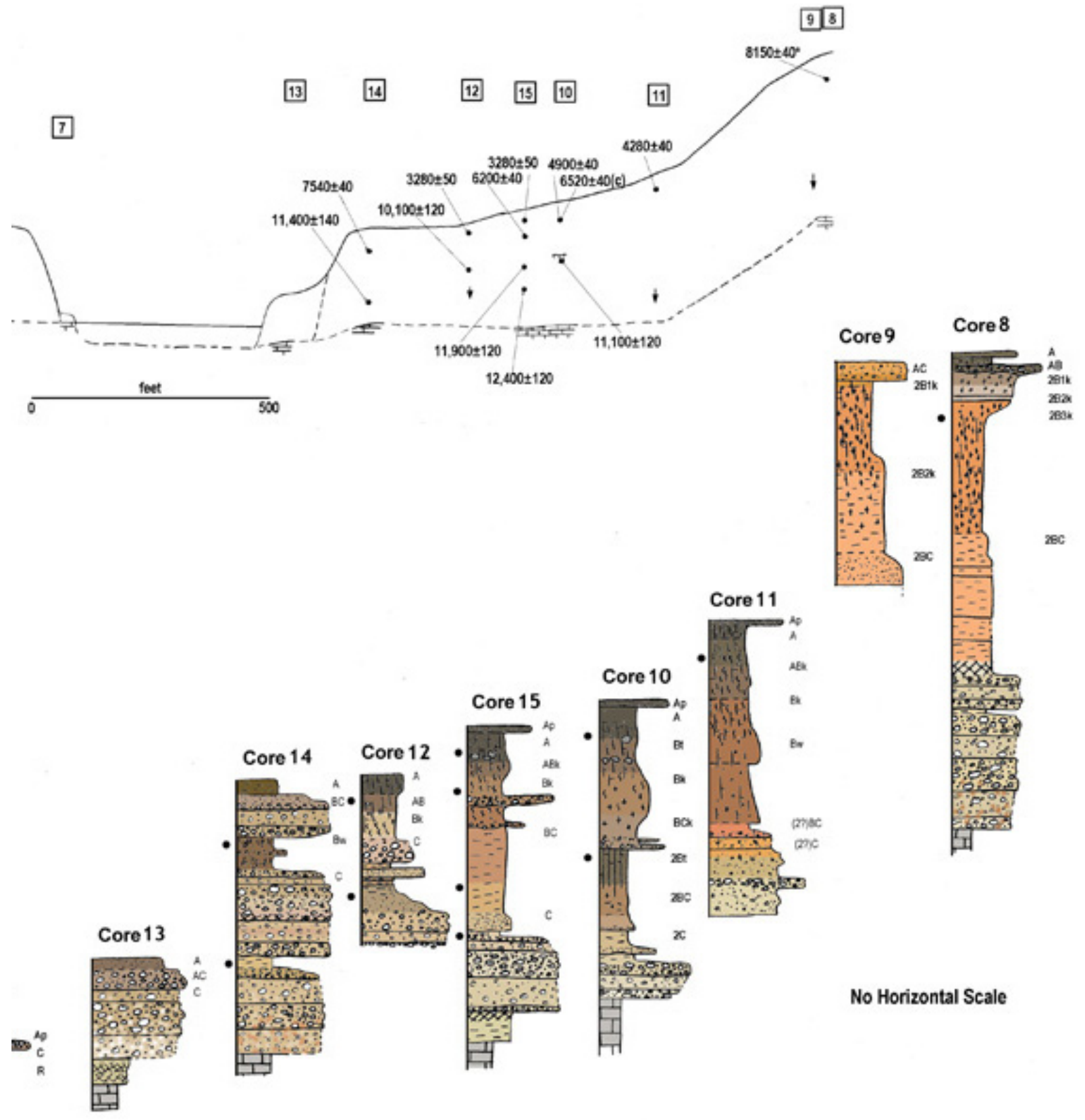


Intermediate ages of $8590 \pm 40$ B.P. and $5590 \pm 40$ B.P. were obtained from the Bk horizon of Core 3 and Core 6 , respectively.

Core 14 was placed on the outer part of the $\mathrm{T}_{1}$ terrace on the south side of the stream overlooking the narrow floodplain. It exhibits an A-BC-2Bw-C profile developed in a sequence dominated by crudely bedded muddy and sandy gravel with interbeds of clay loam and silty clay. The sequence is $7 \mathrm{~m}$ thick overall, of which roughly $5.5 \mathrm{~m}$ is gravel-dominated. The fine-grained interbeds occur as packets $40-80$ $\mathrm{cm}$ thick, and all contain some dispersed limestone gravels. Colors vary from dark brown (10YR 3/3) and dark grayish brown (10YR 4/2) through brown (7.5YR 4/4; 7.5YR 5/4) and strong brown (7.5YR 4/6) to pale brown (10YR 6/3) and light yellowish brown (10YR 6/4), with faint orange and brown redox mottling common near the base of the section. It rests on bedrock at an elevation of $1623 \mathrm{ft}(494.7 \mathrm{~m})$ above msl. Overall, the most striking aspect of the Core 14 sequence is the degree to which it is graveldominated, particularly high in the section. Two radiocarbon ages were obtained from Core 14. The upper sample, obtained from the Bw horizon immediately below a thick (approximately $1.3 \mathrm{~m}$ ) accumulation of gravels and sands in the upper sequence, yielded a conventional age of $7540 \pm 40$ B.P. The lower sample was obtained from a thin silty clay bed interbedded in the thick gravels at a depth of $4.7 \mathrm{~m} \mathrm{bgs}$, and yielded a conventional age of 11,400 B.P. Core 12, which was situated at a slightly more distal position of the proximal $T_{1}$ terrace and also exhibited a profile punctuated by thick gravel beds in the upper five meters of the section, yielded two additional radiocarbon ages. The upper age was obtained from 70 cmbs in a transitional AB horizon of the surface soil, and yielded a conventional age of $3280 \pm 50$ B.P. The lower age was obtained from a silty clay interbed at a depth of $2.9 \mathrm{~m} \mathrm{bgs}$, and yielded a conventional age of 10,100 B.P.

Cores 10 and 15 typify the more distal part of the level $T_{1}$ terrace south of the stream. At the time of coring, a shallow (approx. $1 \mathrm{~m}$ ) trench had been opened across the $\mathrm{T}_{1}$ terrace surface by the landowner, revealing burned rock and flakes associated with a dark, mollic epipedon. Both cores penetrated to bedrock at an elevation of $1624 \mathrm{ft}(495 \mathrm{~m})$ and $1628 \mathrm{ft}(496 \mathrm{~m})$ above msl, respectively, and both exhibited relatively classic fining-upward sequences with gravels largely restricted to the lower portion of the cores. Significantly, cultural material was noted at several levels (separated by approximately $50 \mathrm{~cm}$ ) in Core 10, suggesting that multiple components may be represented in the archeological strata. The upper part of Core 10 exhibits an Ap-A-Bt-Bk-BCk profile almost 4 m thick. The Ap horizon consists of $10-15 \mathrm{~cm}$ of brown sandy material interpreted as slopewash. The A horizon is roughly $40 \mathrm{~cm}$ thick and consists of granular to fine subangular blocky structured, black (10YR 2/1) clay loam. It grades down into a very dark grayish brown to dark brown (10YR 3/2 to $10 \mathrm{YR} 3 / 3$ ), moderate blocky structured clay loam. It in turn gradually grades into a weak blocky structured, brown to yellowish brown (10YR 3/4 to $10 \mathrm{YR}$ 4/4) sandy clay loam containing common filaments and fine, soft nodules. This horizon becomes increasingly sandy with depth to approximately $2.75 \mathrm{~m} \mathrm{bgs}$, then becomes somewhat darker (10YR 3/3 to 10YR 3/4) and slightly more clay-rich to a depth of approximately $3.5 \mathrm{~m}$, where a significant number of subrounded to subangular limestone clasts appear. These gravels are suspended in the fine matrix, and appear to represent colluvial input. At approximately $3.8 \mathrm{~m}$, the unit abruptly transitions into a dark brown, strongly prismatic structured clay loam paleosol exhibiting a $2 \mathrm{Bt}-2 \mathrm{BC}-2 \mathrm{C}$ profile. This buried soil grades into bedded sandy clay, silty clay, and gravel at approximately $5.8 \mathrm{~m}$ bgs. This coarse-grained deposit is dominantly pale brown in color, but exhibits relatively prominent brown iron mottling in the lower meter. Bedrock was encountered at an elevation of $1624 \mathrm{ft}(495 \mathrm{~m})$. Two radiocarbon ages on humates and one paired charcoal age were obtained from Core 10. The upper humate age was obtained from the base of the surface A horizon at a depth of $1.2 \mathrm{~m}$, and yielded an age of $4900 \pm 40$ B.P. During pretreatment of core plug, Beta Analytic identified a charcoal inclusion in the sediment sample. This charcoal was dated separately, and yielded an age of $6520 \pm 40$ B.P., suggesting that the accuracy of the humate ages was influenced by the subsequent accumulation of soil organics. The lower humate sample was taken from the upper part of the buried paleosol at a depth of $4.0 \mathrm{~m}$, and yielded a conventional age of 11,100 B.P. 
Core 15 is similar in character to the upper portion of Core 10, but lacks the buried soil. It exhibits an ApA-Bt-Bk-BC-C profile. Burned rock and culturally-stained sediments are present in the lower A horizon and $\mathrm{ABk}$ horizon. Carbonate morphology is largely limited to filaments, although some possible fine nodules are present below $2 \mathrm{~m}$. Several thin $(<30 \mathrm{~cm})$ beds of sands and gravels that may represent chute channel deposits are present between 1.5 and $2.25 \mathrm{~m}$, but the majority of the deposit between the base of the A horizon at approximately $1 \mathrm{~m}$ bgs and the top of the gravel at $5.5 \mathrm{~m}$ bgs consists of a dense loamy silt to silt loam. The coarse basal gravels and sands are somewhat thicker than in Core 10 (approximately $3 \mathrm{~m}$ ), and the section rests on bedrock at an elevation of $1628 \mathrm{ft}(496 \mathrm{~m})$. Finally, unlike every other core that was able to penetrate entirely through the alluvium, gravel does not mantle the alluvial bedrock contact in Core 15. Rather, the basal $70 \mathrm{~cm}$ of the section consists of almost pure silt that is massive in the lower part and fissile and carbonate cemented in the upper part. Radiocarbon ages from Core 15 include a conventional age of $3280 \pm 40$ B.P. from the cultural zone in the lower A horizon ( $0.8 \mathrm{~m} \mathrm{bgs})$, a conventional age of $6200 \pm 40$ B.P. from the Bk horizon $(1.7 \mathrm{~m}$ bgs), a conventional age of $11,900+120$ B.P. from thick, massive silts exhibiting weak pedogenic modification at (3.9 m bgs), and 12,400+120 B.P. from thin muds interbedded in the upper gravels (5.25 $\mathrm{m} \mathrm{bgs})$.

A final, somewhat more ambiguous section was revealed by Core 11. This core was situated on an apparent colluvial apron representing the transition from the $T_{2}$ terrace to the broader $T_{1}$ terrace. Overall, the section exhibits an Ap-A-Abk-Bk-Bw-2BC-2C profile developed in brown to yellowish brown sandy clay and clay loam containing fine, matrix supported limestone gravels. Carbonate development is largely limited to film, filaments, and weak gravel pendants (Stage I morphology), although some larger, apparently reworked nodules are present. Although the A horizon is somewhat overthickened (grading through an Ap-A-Abk sequence nearly two meters thick), the character of the sediment implies that it is largely of alluvial (as opposed to colluvial) origin. At a depth of approximately $5 \mathrm{~m}$, this deposit transitions into a thin, reddish brown to yellowish red clay loam. The coarse basal material consists of pale brown to yellowish brown gravelly sands with interbedded gravels. The core was unable to penetrate any farther at $7.6 \mathrm{~m}(1635 \mathrm{ft}$ above $\mathrm{msl})$. Both the elevation and the character of these deposits are similar to the deposits in Cores 1 and 2, and these basal deposits are also interpreted as belonging to Unit 2. One age of $4280 \pm 40$ B.P. was obtained from the lower part of the A horizon at a depth of $95 \mathrm{cmbs}$.

\section{UNIT 4}

Unit 4 represents deposits underlying the narrow modern floodplain. It consists of between $0.5 \mathrm{~m}$ (north of the channel) and $2.7 \mathrm{~m}$ (south of the channel) of pale brown and light gray loamy gravel capped with a thin veneer of brown sandy loam. Secondary carbonate of phreatic origin is common in the profile, particularly in the lower meter. Although separated from Unit 3 by a prominent terrace scarp, the character of the gravels is similar to the lower gravels in the adjacent cores (Cores 12 and 14), and it is unclear whether the gravelly fill underlying the surface represents a recent fill, an alluvial strath continuous with the gravelly deposits underlying the $T_{1}$ terrace, or a combination of the two. However, given the character of the fill, the potential for archeological materials to be preserved in reasonable context in Unit 3 is negligible. No radiocarbon ages were obtained from Unit 4.

\section{DISCUSSION}

Before addressing the implications of the Spur 98 sequence, the approach to dating it merits some discussion. All but one of the twenty radiocarbon ages collected and analyzed during the study dated bulk organic components contained in the sediment - the type of samples that are often colloquially termed

"humate ages." In actuality, these samples provide an estimate of the average time since death for a wide variety of organic components contained in the deposit, including finely divided plant material, 
carbonized remains, and a wealth of decay products such as humic substances, cellulose, lipids, proteins, and carbohydrates (Abbott 1997). As is the case with soil ages (e.g., Wang et al. 1996), bulk humate ages on sediments and weak alluvial soil have often been demonstrated to yield anomalous ages (e.g., Nordt 1992; Frederick and Higgins 1993; Abbott 1994) and therefore have been treated with skepticism (e.g., Nordt 1992) or dismissed outright (e.g., Johnson 1995; Decker et al. 2000:33). However, bulk humate ages have also been used to advantage in a number of stratigraphic studies (e.g., Blum and Valastro 1992; Mandel 1991; May 1991; Abbott 1997; Waters et al. 1999; Abbott 2001; see also the compendium referenced in Johnson et al. 1997), and Abbott (1997) has demonstrated how systematic errors in such ages can be used to make valuable inferences about trajectories in landscape evolution.

Radiocarbon ages on upland soils provide an estimate of the average age of organic matter in the system, which can subsume components of a wide variety of ages and origins. Dates obtained from this material are termed a soil's "mean residence age." Because it is dominated by in situ organic matter from organisms growing and decomposing in the soil system through the centuries, an upland soil's mean residence age is almost always less than the soil's true age. Typically, the apparent age of such a soil (as measured by radiocarbon) will increase with depth due to the dynamic nature of organic matter translocation. The difference between the apparent and true age of a soil will also increase as a soil ages, but at a certain point it will reach rough equilibrium, such that the input of new organic matter balances the loss of older organics and the apparent age stops increasing (Birkeland 1984; Wang et al. 1996). The time necessary to achieve this quasi-equilibrium varies under the influence of the other soil forming factors (e.g. climate, relief), but appears to range from approximately $10^{2}$ to $10^{4}$ years (Birkeland 1984). Therefore, the age obtained from a buried soil can overestimate the age of burial by an amount up to this steady-state age.

In contrast, alluvial sediments incorporate both contemporary organics and older material derived from erosion of soils in the basin, and usually date somewhat older than their true age. The degree to which this occurs reflects the relative importance old, allogenic organic matter in the overall organic suite, as well as the typical AMRT age of soil contributing sediment to the sequence. Abbott (1997) has demonstrated that high volumes of old soil entering an alluvial system as a result of regional soil disturbance (whether anthropic or climatic in origin) can strongly affect this ratio between contemporary and older organic matter, sometimes resulting in apparent stratigraphic reversals in a dated sedimentary column. Weak alluvial soils present an even more complex dynamic, because they may either be dominated by authigenic organics (and thus date too young) or allogenic organics (and thus date too old). In either case, the maximum error that may be encountered is roughly the time necessary for soil organics to reach a steady state in the floodplain or in the contributing catchment.

For these reasons, uncritical acceptance of radiocarbon ages on sediment is highly inadvisable. However, careful selection of a suite of samples whose spatial and stratigraphic relationships are known can provide powerful data for interpreting the age of related deposits, provided that the analyst takes a realistic view of the precision possible with such data. Moreover, uncritical acceptance of data from charcoal contained in alluvial sequences is equally inadvisable. While concentrated charcoal from cultural contexts or other in situ burn events is usually a good indicator of the age of surrounding sediments (even here, factors such as the use of old wood can bias the results), finely-divided charcoal is subject to both transport by the system and translocation within the sediment column. Thus, it too can provide an age that is either too old or too young. Thus, the precision of radiocarbon ages on bulk humates is such that careful and critical interpretation is warranted. In particular, isolated ages are somewhat problematic and should not be relied on too heavily. However, examination of a series of stratigraphically-related ages can be quite informative when viewed from a realistic perspective. In particular, despite frequent colloquial pronouncements to the contrary, most anomalous ages are not "bad dates" (i.e., assays incorrectly processed by a radiocarbon laboratory or which otherwise yield results not consistent with their age). Rather, modern laboratories usually provide a highly accurate estimate of the mean age of carbon contained within the sample, and it 
is fact the analyst's expectations (i.e., that the carbon in the sample is representative of the age of deposition) that are in error. If the context of the organic matter contained within dating samples is viewed within a realistic interpretive framework, humate ages can provide an extremely valuable (albeit sometimes relatively low-precision) mechanism for dating clastic stream deposits.

The ages from the Spur 98 sequence provide a good example of the problems that can occur in the application of humate ages. Sediment dating was used in the study because sediments were the only material that could be predictably extracted from the cores. As might be expected, many of the samples yielded ages that are probably affected to one degree or another by the problems outlined above. In particular, several of the obtained ages are demonstrably too young due to the influence of pedogenesis, while a number of others are also believed to also exhibit a pedogenic age bias (see Figure 10). Nevertheless, when considered in aggregate, the ages present a relatively coherent picture for the aggradation of the Late Pleistocene and Holocene deposits at Spur 98. That sequence is described below.

The earliest episode of alluviation represented in the extant Spur 98 sequence is deposition of Unit 1, which currently occupies a relatively narrow, poorly-preserved terrace on the south side of the valley. It is likely that associated deposits also underlie portions of the broad, dipping alluvial complex on the north side of the valley, but if preserved these deposits are upslope of the study area. Unit 1 is approximately 11 $\mathrm{m}$ thick at the examined locality, and consists of approximately $4 \mathrm{~m}$ of poorly sorted, silty and sandy gravel overlain by deposits that grade upward from loamy silts to silty clays. Despite its proximity to the valley wall, gravel is almost entirely absent in the fine-grained portion of the sequence, suggesting that the valley side-slopes were much more stable than at present during the aggradation of the deposit. A prominent Stage II+ calcic soil is developed in the deposits. This thick $(3 \mathrm{~m}+)$ soil is strongly truncated and overlain by up to $2 \mathrm{~m}$ of gravelly loam and gravelly clay loam colluvium. The deposit forms a narrow, indistinct terrace at an elevation of approximately 1680-1690 ft above msl, and rests on an apparent bedrock strath surface at an elevation of $1643 \mathrm{ft}$ above msl.

Only one age ( $8150 \pm 40$ B.P.) was obtained from the two cores that penetrated Unit 1 . Given that it postdates many of the ages from Unit 3, this age is rejected as an indication of the age of Unit 1 . There is therefore no direct evidence for assigning an age to the unit. However, a minimum age for the unit is indicated by the oldest ages from Unit 3, which are approximately 12-13 ka B.P. (equivalent to roughly13$14,000 \mathrm{BC}$ ). Moreover, intervening presence of Unit 2 suggests that Unit I predates these ages by a substantial period. Possible analogues to Unit 1 defined by other authors include Blum's Unit $\mathrm{C}$ on the Pedernales River (Blum 1987; Blum and Valastro 1989), Blum's Unit QT-2 on the Colorado River at O. H. Ivie Reservoir (Blum and Valastro 1992; Blum and Lintz 1993); Mear's (1995; 1998) Pleistocene high terrace deposits on the Sabinal River, and Nordt's (1992) Reserve alluvium on the Leon River. Like the Unit 1 deposits, several of these alluvial fills are described as relatively silty (Mear 1995) and/or with strong argillic (Nordt 1992; Blum 1987) or calcic (Mear 1995; Blum 1987) horizons. Neither Nordt nor Mear obtained radiometric ages for their units, and Blum only obtained one date from Unit $\mathrm{C}$ on the Pedernales River. Here, a sample from an interbedded mud near the base of Unit $\mathrm{C}$ yielded an age of $33,020 \pm 1620$ B.P.. Blum interpreted this as a minimum age, and used the degree of petrocalcic horizon development to postulate a middle Wisconsinan (i.e., roughly 30-50 ka ) age for his Unit C. Given the age of Unit 1, the potential for it to contain cultural material of Clovis age or younger is considered negligible. However, the unit is mantled unconformably by a colluvial deposit up to a meter thick. Although it is undated, its appearance is consistent with Holocene-age deposits, and buried cultural material is therefore possible in this veneer.

Following abandonment of Unit 1, the Guadalupe River entrenched its valley, cutting at least $2 \mathrm{~m}$ into the underlying Glen Rose Formation, and Unit 2 began to aggrade. Unit 2 is present on the north side of the study corridor, and a truncated remnant is inset against Unit 1 on the south side of the valley. It consists of gravelly to loamy deposits that rest on an apparent bedrock ledge mantled with a dense, impenetrable 
calcrete at approximately $1635 \mathrm{ft}$ above msl. The unit supports a moderately to strongly truncated calcic soil characterized by a reddish brown $\mathrm{Bt}$ horizon and a strong $\mathrm{Bk}$ to $\mathrm{K}$ horizon. Underlying sediments are dominantly gravels and sands, but they do fine upwards to silty clay in Core 1. Colors in the lower sediments are dominantly browns and yellowish browns, and are noticeably stronger than the pale colors at depth in Unit 3, suggesting that they have been subjected to less prolonged saturation over the last few millennia. Overall thickness of Unit 2 is approximately 9-10 m.

Radiocarbon ages from the Unit 2 are limited and not representative of the age of the deposits. One age was obtained from a sample of the Btk horizon in Core 1. This sample, which yielded a conventional age of $3280+40$ B.P., was recovered from a depth of 2.0-2.3 ft (approximately $60-70 \mathrm{~cm}$ ) in the active surface soil. Although this age is clearly too young to represent deposition of Unit 2, it is interesting to note that it is identical to two ages from the surface soil developed in Unit 3 (in Core 12, from approximately 60-70 $\mathrm{cmbs}$, and Core 15 , from approximately $75-85 \mathrm{cmbs}$ ). Other ages from the upper meter of Unit 3-all also believed to represent mean residence ages - ranged from 2420 B.P. to 3700 B.P. This suggests that pedogenic processes, rather than periodic introductions of allogenic organics through flooding, have dominated in forming the organic component of the modern terrace soil.

The other age from Unit $2-9640 \pm 80$ B.P. - was obtained from the truncated Bt horizon of the buried soil in Core 2. This sample is also believed to represent a mean soil age, but in this case representing the period when the soil was erosively truncated and then buried by the last few meters of Unit 3 . Therefore, while the maximum age of Unit 2 is not known, the oldest ages from Unit 3 constrain its minimum age. Five ages ranging from 12,900 B.P. to 11,100 B.P. were obtained from depths between $3.5 \mathrm{~m}$ and $5.3 \mathrm{~m}$ in Unit 3, suggesting that deposition of Unit 2 ceased well before the Clovis period. However, the sample from the buried soil in Core 2 suggests that the proximal part of the terrace underlain by Unit 2 was not overtopped for several thousand more years. Therefore, while the possibility that the Unit 2 deposits contain pre-Clovis archeological remains cannot be ruled out, any Paleoindian or later remains should mantle the paleosurface of Unit 2 or be associated with subsequent units.

While the age of Unit 2 is not well established, broadly similar units have been described and dated by Nordt (1992) and Blum (1987; Blum and Valastro 1992; 1994) and identified by Mear (1995), and Gustavson (Decker et al.2000). The stratigraphic context and sedimentological/ pedogenic character of Unit 2 is similar to units identified and dated to 15,000-20,000 B.P. elsewhere in central Texas, such as Nordt's Jackson Alluvium in the Fort Hood area(Nordt 1992), Blum's Unit D on the Pedernales River (Blum 1987), Blum's Unit QT-1 on the middle Colorado River near San Angelo (Blum and Valastro 1992; Blum and Lintz 1993), and Blum and Valastro's (1994) Eagle Lake Alloformation on the lower Colorado River. On this basis, the unit is tentatively interpreted as an alluvial deposit laid down somewhere around the time of the last Full Glacial (18-16 ka). Poorly dated and undated deposits that appear to represent roughly the same time period and stratigraphic-architectural context have been identified by on the Sabinal (Mear 1995) and on upper Brushy Creek (Collins and Mear 1998). In contrast, deposits that date to roughly the same period but occupy very different settings in the their respective valley systems have been identified on the Medina River by Mandel (1991), on the Dry Frio River by Gustavson (Decker et al. 2000), and on the lower Brazos River by Abbott (2001).

Around 18-15 ka, deposition of Unit 2 appears to have ended and the system incised again, apparently entrenching into bedrock an additional 2-2.5 m. By the beginning of the Holocene (10 ka), the system had aggraded between 7-8 m of predominantly gravelly alluvium, and deposition of Unit 3 was already beginning to slow markedly. Ages from the deeper parts of Unit 3 range from 12,900 \pm 120 B.P. in Core 6 to $10,100 \pm 120$ B.P. in Core 12 (see Figure 11). The early-middle Holocene witnessed continued slow alluviation dominated by loams and silty clays, although occasional lenses of gravel and/or coarse sand attest to periodic periods of high flow across the alluvial surface. Although deposition was clearly slowing by around $10 \mathrm{ka}$, it is unclear when the terrace was effectively abandoned by incision, because ages 
relevant to termination of the deposit are affected by pedogenic processes. While ages from relatively deep in fine-grained veneer that appear to be relatively unaffected by soil carbon range from $8590 \pm 40$ B.P. to $7540 \pm 40$ B.P., ages from depths less than about four feet appear to be influenced by postdepositional soil organic matter and therefore date too young. This is demonstrably the case in Core 10, where cultural charcoal contained within the sediment sample was isolated and dated separately, yielding an age 1620 years older than the sediment encasing it (6520 \pm 40 and $4900 \pm 40$, respectively). As discussed above, it also seems the best explanation for the high degree of similarity among dates from the surface soil, which range from 3700 B.P. to 2420 B.P. Therefore, the terminal age for Unit 3 is not well established. However, it is likely that the deposit was largely abandoned by downcutting around $5 \mathrm{ka}$, and that soil processes were dominant following this period. Given the decreased rate of deposition and increasingly fine-grained character of the deposits after approximately $10 \mathrm{ka}$, it seems likely that incision of the stream may have begun in the early Holocene, although this change may also reflect a change in the character of sediments being introduced into the system. In any case, it seems clear that by about 5 ka the $\mathrm{T}_{1}$ terrace was all but abandoned by downcutting and was only receiving fresh sediment during occasional high magnitude floods. Such periodic events appear to have punctuated long periods of terrace stability, resulting in the deposition of approximately 1-1.5 $\mathrm{m}$ of cumulic terrace soils in the last 5-6 ka, and burying several strata of archeological remains.

Unit 3 has crude temporal analogues in several other stratigraphic studies in the central Texas area. Just north across the drainage divide, Blum (1987) identifies his Unit E as a dominantly fine-grained unit that accumulated between approximately $11 \mathrm{ka}$ and $7 \mathrm{ka}$. It is typically buried by the subsequent late Holocene fill (Unit F). At Ivie reservoir on the Colorado River, Blum and Lintz (1993) identify unit Qal-2, which is inset against the Late Pleistocene unit (Qt-1) and onlapped and partially buried by a late Holocene unit (Qal-1). Radiocarbon data on sediments suggest that Unit Qalo-2 accumulated between approximately 10$5 \mathrm{ka}$. On the lower Colorado, Blum and Valastro (1994) identify Columbus Bend Alloformation, Member 1, which accumulated between approximately 13 and $5 \mathrm{ka}$. In the Fort Hood area, Nordt (1992) identifies two discrete units termed the Georgetown Alluvium and Fort Hood Alluvium that are attributed to the periods between approximately 11-9 ka and 8-5 ka, respectively. On the Dry Frio River, Gustavson (Decker et al. 2000) identifies a channel shift that occurred sometime in the early Holocene, creating two scroll bars with an intervening swale. Ages from the older unit range from 8380 to 8010 B.P., while ages from the younger unit range from 6430 to 3290 B.P. Apparent depositional hiatuses in the sequence occur around 6-5.6 ka and 4.5-4 ka. On upper Brushy Creek, Collins and Mear (1998) identify their culturebearing Q-2 deposit, which accumulated between approximately 12-4.4 ka. Other roughly equivalent deposits were described by Mandel (1991) on the Applewhite terrace of the Medina River and by Kibler and Gardner (1997) on Cibolo Creek north of San Antonio. The terrace described earlier in this study, from downstream on the Guadalupe at I-35, also appears equivalent to Unit 3.

While the timing of incision is not well-established, it seems relatively clear that the Guadalupe River incised again sometime around 5-4 ka in the vicinity of Spur 98, just as had occurred at many other localities throughout central Texas. What is less understandable is why no extensive deposits appear to have accumulated in the study area during the Late Holocene, as they did in most other described sequences At the outset of the discussion, it must be emphasized that no cores were placed streamward of $\mathrm{SH} 27$ on the $\mathrm{T}_{1}$ terrace north of the river due to urbanization, and is possible that some Late Holocene deposits are preserved there; however, given the configuration of the terrace and the volume available, this is not considered particularly likely. Assuming, then, that Late Holocene deposits are not present, the obvious question to be answered is why they are absent. Thick and laterally extensive Late Holocene deposits are common in most of the other studies cited above, including Blum's Unit F on the Pedernales River (Blum 1987; Blum and Valastro 1989), Nordt's upper and lower West Range Alluvium on Fort Hood (Nordt 1992), Blum's Unit Qal-1 near the Colorado-Concho confluence (Blum and Lintz 1993), Blum's Columbus Bend Member 2 on the lower Colorado (Blum and Valastro 1994), and Mear's (1995) Unit Q1 on the Sabinal River. 
While prominent Late Holocene fills appear to be the norm, areas missing a substantial Late Holocene record are also known. Examples include Brushy Creek in the vicinity of the Wilson Leonard Site (Collins and Mear 1998), and the Dry Frio River in the vicinity of the Woodrow Heard site (Decker et al. 2000). In the case of Brushy Creek, studies downstream (Kibler 2000; Abbott 2003) demonstrate that significant deposits were accumulating elsewhere on Brushy Creek during the Holocene. This in turn indicates that the reason that Late Holocene is not represented by a discrete fill in the Wilson Leonard site area relates to local dynamics rather than overall behavior. In other words, the local area was a zone of sediment bypass. Examination of the 41UV88 setting suggests that this is probably true here also, as more recent sediment deposition would be concentrated on the meander downstream of the site cross-section. It is considered likely that a similar situation is represented at Spur 98. Here, the modern Guadalupe channel trench is relatively narrow and straight, and would sustain a flow with relatively strong erosive potential during times of high-magnitude flow. Based on his work in the adjacent Pedernales drainage, Blum (1987) interprets the Late Holocene as a time when high magnitude events were relatively frequent, but that such storms were less flashy and more sustained. In the Pedernales system, this period saw the delivery of tremendous quantities of gravel into a trunk system ill-equipped to handle them, leading to aggradation and a wide, gravelly channel. At the Spur 98 study area, it appears that these events were sufficient to keep Late Holocene alluvium in transit, with minimal lateral cutting into the older deposits and minimal long-term storage. The few Late Holocene deposits that were laid down were probably thin veneer sands and muds draped on top of the terrace and quickly incorporated into the maturing terrace soil and gravels stored temporarily in the channel.

The final deposit identified in the study area, Unit 4, is undated. It consists of a relatively thin, narrow shelf of dominantly gravelly sediments situated on the south side of the crossing. It is unclear whether the sediments underlying this surface all represent the same fill, or a veneer of recent deposits resting unconformably on an alluvial strath eroded into the gravels of Unit 3. No radiocarbon ages are available from the unit, but its character and stratigraphic position suggest that it is recent. It is tentatively correlated with units identified elsewhere as dating to the last millennium, such as Blum's Unit G on the Pedernales River (Blum 1987), Blum's Columbus Bend Member 3 on the Colorado River (Blum and Valastro 1994), and Nordt's Ford Alluvium on Fort Hood. Due to its restricted occurrence and gravelly character, Unit 4 is believed to have low archeological potential in the study area.

\section{CONCLUSION}

This study describes investigations of Late Pleistocene/Holocene stratigraphy at two very different localities on the Guadalupe River. It illustrates that at both localities, the principal low terrace is dominated by thick alluvial deposits dating to the Latest Pleistocene though Middle Holocene. In general, the fine-grained facies of these deposits have good potential to contain archeological materials with sufficient integrity to qualify for eligibility to the National Register, and should therefore be examined with mechanical subsurface prospection to determine whether sites are present. At Spur 98, one site has previously been identified buried in the $\mathrm{T}_{1}$ terrace fill on the south side of the river, but requires additional evaluation before an eligibility determination can be made. Additional prospection should be conducted on both sides of the river to determine if deeply buried components are present. At I-35 and the Guadalupe River, archeological prospection was accomplished with a combination of trenching and periodic monitoring of construction activities. No sites were identified and no further work is recommended.

In contrast to the thick Late Pleistocene-Early Holocene fill, little Late Holocene deposition is evident in either location, although some overbank alluvium and colluvium dating to the Late Holocene probably accumulated on the terrace at Spur 98. However, the paucity of Late Holocene deposits is believed to be a 
circumstance of location, as it is considered probable that extensive Late Holocene sediments are preserved elsewhere in the upper-middle Guadalupe system. Given that the cycles of aggradation and incision are typically interpreted as responses to climatic changes (e.g., Bull 1991; Blum 1987; Nordt 1992), it seems unlikely that a major fill present in the other systems described above does not have an equivalent in the Guadalupe system.

In their review of the geomorphic evidence of Holocene environmental change in Texas accompanying the report on the Woodrow Heard site (Decker et al. 2000), Tom Gustavson and his colleagues (Decker et al. 2000) point out that attempts to define sharply bounded periods of climatically-controlled stream behavior frequently do not stand up to scrutiny. In particular, Decker et al. critique Nordt's (1992) Fort Hood sequence for internal inconsistency in dating of the Georgetown fill, and emphasize that his sharply demarcated temporal boundaries are not realistic. While elements of their critique are too harsh, ascribing far more weight to Nordt's temporal boundaries than he probably intended, it does illustrate a common pitfall in discussions of alluvial history such as the current study. Simply put, stream systems, like all natural systems, react to external stimula in complex ways. Variability in thresholds and pre-existing system states exerts strong control over the character and timing of responses to external changes. It is therefore unreasonable to expect different stream systems, or even different reaches of the same system, to react in exactly the same way or at precisely the same time. In fact, the response of different parts of a system may be diametrically opposed. For example, rapid incision in the upstream reaches of a system may introduce high volumes of sediment into the trunk stream, causing concomitant aggradation downstream (e.g., Abbott 2003).

Nevertheless, such comparison is a very valuable exercise. While the exact timing of incision and subsequent aggradation almost certainly varied among different localities, there indeed appears to be a series of broadly correlable Late Pleistocene and Holocene alluvial fills in the central Texas area, and this sequence clearly has very important implications for interpreting the character of regional climate change. While it is frequently very difficult to precisely date alluvial discontinuities, it is important to realize that such ages measure the systemic response rather than the change itself, so that even when very precise ages are obtained the time-transgressive nature of such changes renders the precision of local importance only. Within the broader context, the general trends are the key to understanding linkages among different alluvial systems as they respond to climate change.

In addition to providing climatic insights, alluvial stratigraphic studies provide an invaluable baseline for geoarcheological investigation. Despite the criticism leveled by Decker et al. (2000) Nordt's 1992 study has proven to be an extremely valuable tool for subsequent archeological work on Fort Hood (e.g., Trierweiler 1994; Abbott and Trierweiler 1995). Similarly, Blum's work on the Colorado and its tributaries provided an extremely useful framework for examining the archeological record at $\mathrm{O}$. H. Ivie Reservoir (Lintz et al. 1993). Perhaps more importantly, these studies and others like them provide a general framework that is useful beyond these specific study areas, providing a context (whether implicitly or explicitly) for interpretation of stratigraphy and geoarcheological potential in the region as a whole. 
Table 1: Results of radiocarbon samples analyzed during this study.

\begin{tabular}{|c|c|c|c|c|c|c|}
\hline Sample & Provenience & $\begin{array}{c}\text { Age BP } \\
\text { (measured) }\end{array}$ & $\begin{array}{c}\text { Age BP } \\
\text { (corrected) }\end{array}$ & Age AD/BC (calibrated) & $\overline{8} 3 \mathrm{C}$ & $\begin{array}{l}\text { method/ } \\
\text { material }\end{array}$ \\
\hline beta-142313 & $\begin{array}{l}\text { Spur } 98, \text { Core } \\
15,2.5-2.8^{\prime}\end{array}$ & $3260 \pm 50$ & $3280 \pm 50$ & BC 1680 to 1435 & -23.8 & $\begin{array}{c}\text { AMS } \\
\text { (humate) }\end{array}$ \\
\hline beta-148583 & \begin{tabular}{|l} 
Spur 98, Core 1, \\
$2.0-2.3^{\prime}$
\end{tabular} & $3110 \pm 40$ & $3280 \pm 40$ & BC 1650 to 1450 & -14.4 & $\begin{array}{c}\text { AMS } \\
\text { (humate) }\end{array}$ \\
\hline beta-148584 & \begin{tabular}{|l} 
Spur 98, Core 2, \\
$2.5-2.9^{\prime}$
\end{tabular} & $3560 \pm 40$ & $3700 \pm 40$ & BC 2200 to 1960 & -16.2 & $\begin{array}{c}\text { AMS } \\
\text { (humate) } \\
\end{array}$ \\
\hline beta-148585 & \begin{tabular}{|l} 
Spur 98, Core 2, \\
$6.2-6.6^{\prime}$
\end{tabular} & $9510 \pm 80$ & $9640 \pm 80$ & BC 9250 to 8760 & -16.9 & $\begin{array}{c}\text { AMS } \\
\text { (humate) }\end{array}$ \\
\hline beta-148586 & \begin{tabular}{|l|} 
Spur 98, Core 3, \\
5.6-5.9'
\end{tabular} & $8490 \pm 40$ & $8590 \pm 40$ & BC 7620 to 7570 & -18.8 & $\begin{array}{c}\text { AMS } \\
\text { (humate) }\end{array}$ \\
\hline beta-148587 & $\begin{array}{l}\text { Spur 98, Core 6, } \\
\text { 2.0-2.3' }\end{array}$ & $2270 \pm 40$ & $2420 \pm 40$ & $\begin{array}{c}\text { BC } 760 \text { to } 620 \\
\text { BC } 590 \text { to } 400\end{array}$ & -15.9 & $\begin{array}{c}\text { AMS } \\
\text { (humate) }\end{array}$ \\
\hline beta-148588 & \begin{tabular}{|l} 
Spur 98, Core 6, \\
$5.0-5.3^{\prime}$
\end{tabular} & $5500 \pm 40$ & $5590 \pm 40$ & BC 4490 to 4350 & -19.3 & $\begin{array}{c}\text { AMS } \\
\text { (humate) }\end{array}$ \\
\hline beta-148589 & \begin{tabular}{|l} 
Spur 98, Core 6, \\
$11.6-11.9^{\prime}$
\end{tabular} & $12850 \pm 120$ & $12900 \pm 120$ & BC 14070 to 12450 & -22 & $\begin{array}{c}\text { AMS } \\
\text { (humate) }\end{array}$ \\
\hline beta-148590 & $\begin{array}{l}\text { Spur 98, Core 8, } \\
5.7-6.0^{\prime}\end{array}$ & $8130 \pm 40$ & $8150 \pm 40$ & BC 7290 to 7060 & -23.5 & $\begin{array}{c}\text { AMS } \\
\text { (humate) }\end{array}$ \\
\hline beta-148591 & $\begin{array}{l}\text { Spur } 98, \text { Core } \\
10,3.9-4.1^{\prime}\end{array}$ & $4840 \pm 40$ & $4900 \pm 40$ & BC 3760 to 3640 & -21.2 & $\begin{array}{c}\text { AMS } \\
\text { (humate) }\end{array}$ \\
\hline beta-148592 & $\begin{array}{l}\text { Spur 98, Core } \\
10,13.0-13.5^{\prime}\end{array}$ & $11020 \pm 120$ & $11100 \pm 120$ & $\begin{array}{l}\text { BC } 11480 \text { to } 10920 \text { and } \\
\text { BC } 10760 \text { to } 10720\end{array}$ & -20.4 & $\begin{array}{c}\text { AMS } \\
\text { (humate) }\end{array}$ \\
\hline beta-148593 & \begin{tabular}{|l} 
Spur 98, Core \\
$11,3.0-3.2^{\prime}$
\end{tabular} & $4150 \pm 40$ & $4280 \pm 40$ & BC 2920 to 2870 & -17.3 & $\begin{array}{c}\text { AMS } \\
\text { (humate) }\end{array}$ \\
\hline beta-148594 & \begin{tabular}{|l} 
Spur 98, Core \\
$12,2.1-2.3^{\prime}$
\end{tabular} & $3140 \pm 50$ & $3280 \pm 50$ & BC 1680 to 1440 & -16.2 & $\begin{array}{c}\text { AMS } \\
\text { (humate) }\end{array}$ \\
\hline beta-148595 & $\begin{array}{l}\text { Spur 98, Core } \\
12,9.3-9.6^{\prime}\end{array}$ & $10020 \pm 120$ & $10100 \pm 120$ & BC 10400 to 9270 & -20.3 & $\begin{array}{c}\text { AMS } \\
\text { (humate) }\end{array}$ \\
\hline beta-148596 & \begin{tabular}{|l} 
Spur 98, Core \\
$14,4.7-5.0^{\prime}$
\end{tabular} & $7460 \pm 40$ & $7540 \pm 40$ & \begin{tabular}{|c|}
$\mathrm{BC} 6450$ to 6370 and $\mathrm{BC}$ \\
6300 to 6270
\end{tabular} & -19.9 & $\begin{array}{c}\text { AMS } \\
\text { (humate) }\end{array}$ \\
\hline beta-148597 & $\begin{array}{l}\text { Spur } 98, \text { Core } \\
14,15.3-15.5^{\prime}\end{array}$ & $11350 \pm 140$ & $11400 \pm 140$ & $\begin{array}{l}\text { BC } 11870 \text { to } 11650 \text { and } \\
\text { BC } 11620 \text { to } 11060\end{array}$ & -21.8 & $\begin{array}{c}\text { AMS } \\
\text { (humate) }\end{array}$ \\
\hline beta-148598 & \begin{tabular}{|l} 
Spur 98, Core \\
$15,5.4-5.7^{\prime}$
\end{tabular} & $6110 \pm 40$ & $6200 \pm 40$ & BC 5290 to 5040 & -19.4 & $\begin{array}{c}\text { AMS } \\
\text { (humate) }\end{array}$ \\
\hline beta-148599 & $\begin{array}{l}\text { Spur } 98, \text { Core } \\
15,12.8-13.1^{\prime}\end{array}$ & $11840 \pm 120$ & $11900 \pm 120$ & $\begin{array}{l}\text { BC } 13190 \text { to } 12820 \text { and } \\
\text { BC } 12350 \text { to } 11530\end{array}$ & -21.1 & $\begin{array}{c}\text { AMS } \\
\text { (humate) }\end{array}$ \\
\hline beta-148600 & $\begin{array}{l}\text { Spur } 98, \text { Core } \\
15,17.1-17.4\end{array}$ & $12370 \pm 120$ & $12400 \pm 120$ & BC 13550 to 12140 & -23.1 & $\begin{array}{c}\text { AMS } \\
\text { (humate) }\end{array}$ \\
\hline beta-149031 & \begin{tabular}{|l} 
Spur 98, Core \\
$10,3.9-4.1^{\prime}$
\end{tabular} & $6530 \pm 40$ & $6520 \pm 40$ & \begin{tabular}{|c|} 
BC 5520 to 5450 and $B C$ \\
5410 to 5390
\end{tabular} & -25.5 & $\begin{array}{c}\text { AMS } \\
\text { (charcoal) }\end{array}$ \\
\hline beta-142305 & $\begin{array}{l}\text { New Braunfels } \\
\# 1,5.0-5.2^{\prime}\end{array}$ & $5370 \pm 60$ & $5420 \pm 60$ & BC 4355 to 4065 & -22.2 & $\begin{array}{c}\text { AMS } \\
\text { (humate) }\end{array}$ \\
\hline beta-142306 & $\begin{array}{l}\text { New Braunfels } \\
\# 1,12.4-12.6^{\prime}\end{array}$ & $8820 \pm 70$ & $8840 \pm 70$ & BC 8230 to 7715 & -23.9 & $\begin{array}{c}\text { AMS } \\
\text { (humate) }\end{array}$ \\
\hline beta-142307 & $\begin{array}{l}\text { New Braunfels } \\
\# 1,21.8-22.2^{\prime}\end{array}$ & $9680 \pm 80$ & $9700 \pm 80$ & $\mid \begin{array}{c}\mathrm{BC} 9275 \text { to } 9080 \text { and } \mathrm{BC} \\
9035 \text { to } 8805\end{array}$ & -23.9 & $\begin{array}{c}\text { AMS } \\
\text { (humate) }\end{array}$ \\
\hline
\end{tabular}




\section{REFERENCES}

Abbott, James T.

1994 Geomorphic Context of the Barton Site (41HY202) and the Mustang Branch Site (41HY209). In: Archaic and Late Prehistoric Human Ecology in the Middle Onion Creek Valley, Hays County Texas, Volume 2: Topical Studies, R. A. Ricklis and M. B. Collins, (eds.), pp. 353-379. Studies in Archeology 19, Texas Archeological Research Laboratory, University of Texas at Austin.

1997 Late Quaternary Alluviation and Soil Erosion in Southern Italy. PhD. Dissertation, The University of Texas at Austin.

2000 Houston Area Geoarcheology: A Framework for Archeological Investigation, Interpretation, and Cultural Resources Management in the Houston Highway District. Archeological Studies Program Report 27, Environmental Affairs Division, Texas Department of Transportation.

2003 Stratigraphic and Geomorphic Evaluation of Brushy Creek at FM 973. In: Archeological Investigations at 41WM815, a Blackland Prairie Site, Williamson County, Texas, by R. K. Brownlow. Studies in Archeology 36, Texas Archeological Research Laboratory, the University of Texas at Austin, and Report 23, Archeology Studies Program, Environmental Affairs Division, Texas Department of Transportation.

Abbott, J. T., and W. N. Trierweiler

1995 NRHP Significance Testing of 57 Prehistoric Sites on Fort Hood, Texas, Vol. I-II. United States Army Fort Hood, Archeological Resource Management Series, Research Report No. 34.

Baker, V. R., and M. M. Penteado-Orellana

1977 Adjustment to Late Quaternary Climate Change by the Colorado River of Central Texas. Journal of Geology85: 395-422.

Barnes, V. E.

1983 Geologic Atlas of Texas, San Antonio Sheet, Revised Edition. Bureau of Economic Geology, University of Texas at Austin.

Batte, C. D.

1984 Soil Survey of Comal and Hays Counties, Texas. United States Department of Agriculture, Soil Conservation Service, in cooperation with the Texas Agricultural Experiment Station.

Birkeland, P. W.

1984 Soils and Geomorphology. Oxford University Press. New York.

Blum, M. D.

1987 Late Quaternary Sedimentation in the Upper Pedernales River, Texas. Unpublished M.A. Thesis, University of Texas at Austin.

1990 Modern Depositional Environments and Recent Alluvial History of the Lower Colorado River, Gulf Coastal Plain of Texas. Unpublished Ph.D. Dissertation, The University of Texas at Austin.

Blum, M. D., and C. L. Lintz

1993 Late Quaternary Geology in the Reservoir Basin. In: Cultural Resource Investigations in the O. H. Ivie Reservoir, Concho, Coleman, and Runnels Counties, Texas, Volume I: Project Introduction, Setting, and Methods, by C. Lintz, W. N. Trierweiler, A. C. Earls, F. M. Oglesby, 
M. Blum, P. L. O’Neill, J. Kuhl, R. Holloway, L. Scott-Cummings, and D. Scurlock, pp.280315. Mariah Associates, Inc., Technical Report 346-I, Austin.

Blum, M. D., and S. Valastro, Jr.

1989 Response of the Pedernales River of Central Texas to Late Holocene climatic change. Annals of the Association of American Geographers 79: 435-456.

1992 Quaternary stratigraphy and geoarchaeology of the Colorado and Concho Rivers of west Texas. Geoarchaeology 7: 419-448.

1994 Late Quaternary sedimentation, lower Colorado River, Gulf Coastal Plain of Texas. Geological Society of America Bulletin 106: 1002-1016.

Bull, W. B.

1991 Geomorphic Responses to Climate Change. Oxford: Oxford University Press.

Collins, M. B., and C. E. Mear

1997 The site and its setting. In: Wilson Leonard: An 11,000-year Archeological Record of Hunter Gatherers in Central Texas, Volume I: Introduction, Background, and Syntheses, assembled and edited by M. B. Collins, pp. 5-32. Studies in Archeology 31, Texas Archeological Research Laboratory, University of Texas at Austin, and Archeology Studies Program, Report 10, Texas Department of Transportation, Environmental Affairs Division.

Decker, S., S. L. Black, and T. Gustavson

2000 The Woodrow Heard Site, 41UV88: A Holocene Terrace Site in the Western Balcones Canyonlands of Southwestern Texas. Studies in Archeology 33, Texas Archeological Research Laboratory, the University of Texas at Austin, and Report 14, Archeology Studies Program, Environmental Affairs Division, Texas Department of Transportation.

Dittemore, W. H., Jr., and W. C. Coburn

1986 Soil Survey of Kerr County, Texas. United States Department of Agriculture, Soil Conservation Service, in cooperation with the Texas Agricultural Experiment Station.

Frederick, C. D., and H. C. Higgins

1993 Results of Geoarchaeological Investigations, Rio Grande American Canal Extension, El Paso County, Texas. Report prepared for the International Boundary Water Commission, U. S. Section, El Paso, Texas, by Mariah Associates, Albuquerque.

Johnson, L.

1995 Past Cultures and Climates at Jonas Terrace, 41ME29, Medina County, Texas. Report 40, Office of the State Archeologist. Texas Department of Transportation and Texas Historical Commission, Austin. 
Johnson, W. C., D. W. May, and R. D. Mandel

1996 A Data Base of Alluvial Radiocarbon Ages from the Central Great Plains (Kansas and Nebraska). Current Research in the Pleistocene 13: 79-81.

Kibler, K.

2000 Appendix I: The Bessie Kruse Site and Environs: Landforms, Alluvium, and Cherts. In: Life and Death as seen at the Bessie Kruse Site (41WM13) on the Blackland Prairie of Williamson County, Texas, by L. Johnson, p. 207-212. Texas Historical Commission and Texas Department of Transportation.

Kibler, K. W., and K. M. Gardner

1997 Archeological Survey and National Register Testing at 41BX377, Camp Bullis Military Reservation, Bexar and Comal Counties, Texas. Repots of Investigations 101, Prewitt and Associates, Inc., Austin.

Kingston, M.

1986 Texas Almanac, Sesquicentennial Edition. Dallas: Dallas Morning News.

Lintz, C., W. N. Trierweiler, A. C. Earls, F. M. Oglesby, M. Blum, P. L. O’Neill, J. Kuhl, R. Holloway,

L. Scott-Cummings, and D. Scurlock

1993 Cultural Resource Investigations in the O. H. Ivie Reservoir, Concho, Coleman, and Runnels Counties, Texas, Volume I: Project Introduction, Setting, and Methods. Mariah Associates, Inc., Technical Report 346-I, Austin.

Mandel, R. D.

1991 Geoarchaeology of a deeply-stratified Paleoindian through Late Prehistoric site (41BX831) in the lower Medina River Valley, South Texas. Program and Abstracts, $49^{\text {th }}$ Plains Conference, Lawrence, KS.

May, D.

1991 Landforms and stratigraphy of the Medicine Creek basin, and the Solomon River valley, Kansas. Program and Abstracts, $49^{\text {th }}$ Plains Conference, Lawrence, KS.

Mear, C. E.

1995 Quaternary geology of upper Sabinal River valley, Uvalde and Bandera Counties, Texas. Geoarchaeology 10: 457-480.

1998 Terrace deposits and Late Quaternary climate, South-Central Edwards Plateau, Texas. Bulletin of the Texas Archeological Society 69: 79-88.

Nordt, L. C.

1992 Archaeological Geology of the Fort Hood Military Reservation, Fort Hood, Texas. U.S. Army Fort Hood, Archaeological Resource Management Series, Research Report No. 25.

Trierweiler, W. N.

1994 Archeolgical Investigations on 571 Prehistoric Sites at Fort Hood, Bell and Coryell Counties, Texas. United States Army Fort Hood, Archeological Resource Management Series, Research Report No. 31.

Wang, Y., R. Amundson, and S. Trombatore

1996 Radiocarbon dating of soil organic matter. Quaternary Research 45: 282-288. 
Stratigraphic and Geoarcheological Investigations on the Guadalupe River

Waters, M. R., B. F. Byrd, and S. N. Reddy

1999 Geoarchaeological Investigations of San Mateo and Las Flores Creeks, California: Implications for Coastal Settlement Models. Geoarchaeology 14:289-306. 


\title{
MATRIX-SUPPORTED FLOODPLAIN GRAVELS: IMPLICATIONS FOR FLOODPLAIN FORMATION PROCESSES
}

\author{
Dr. Charles D. Frederick
}

\section{INTRODUCTION}

Some of the more striking deposits observed at the Gatlin site were exposures in the middle of the $\mathrm{T}_{1}$ surface (typified by Trenches 2 and 19), which exhibited numerous gravels suspended in a fine-grained silty clay matrix (also known as matrix-supported gravel). The creation of such deposits can occur through depositional or post-depositional processes.

Terrestrial processes which transport sediment can often be identified on the basis of the particle size distribution, because these processes bias the size of sediment moved on the basis of the mechanics of transport and the nature of the sediment supply. Some processes are capable of moving a wide range of sediment sizes and don't discriminate on the basis of size (as in the case of glaciers, or mass wasting deposits), and such processes often yield poorly sorted sediment called diamictons, which are mixtures of gravel and mud. At the opposite extreme are processes like eolian transportation, which is capable of moving particles of a very limited size, and therefore typically creates very well sorted sediments.

Conversely, matrix-supported gravels can also be created by processes that operate on sediments after normal geological deposition has ceased. Indeed, a wide range of post-depositional processes are capable of mixing once stratified sediment into a single homogeneous body which bears little resemblance to the original sedimentary deposit (cf. Johnson et al., 2005; 1987). Being able to differentiate which of these situations is responsible for the origins of such deposits holds implications for the evaluation of archaeological integrity. Unfortunately, deciphering which process(es) are responsible for the creation of a given sediment may be challenging owing problems of equifinality. For instance, the particle size distribution alone is of little use because more than one depositional process can yield similar results. As a result, the most successful approaches to interpreting such deposits employ multiple methods of analysis.

This section briefly reviews the processes which may have resulted in the matrix-supported gravels observed at the Gatlin site, and then examines the deposits in order attempt to resolve how such sediments were created and what implications these processes hold for archeological integrity.

\section{Depositional Processes}

As noted before, there is a limited suite of depositional processes that result in the formation of matrixsupported gravelly deposits. Given that these sediments were observed in a riverine setting, the review starts with alluvial processes, and then turns to slope processes.

\section{AlLuVial DEposition}

Rivers move a wide range of sediment sizes, and create deposits that range from well-sorted to poorly sorted. The size of the sediment deposited in any given depositional environment within a river valley typically reflects the current velocity in that landscape setting. Coarse sediments (typically sand, gravel and boulders) are moved in river channels where the current velocities are highest and the coarsest material in fluvial systems are generally restricted to these settings. Fine sediment is mostly deposited in areas where current velocities are slow, as in the case of floodplains and abandoned channels. Given that the deposits in question observed at the Gatlin site were mostly observed in a floodplain setting, the most likely depositional process is overbank flooding, and a general overview of the sedimentary processes that 
Matrix-Supported Floodplain Gravels:

Implications For Floodplain Formation Processes

operate on floodplains is provided in Chapter 6 of this report. But if these are flood deposits, they are not "normal" flood deposits. Rather, they are probably the result of uncommon events, the most likely of which are large magnitude overbank floods.

\section{OVERBANK FLOODING}

The geomorphological and sedimentological effects of large magnitude flooding on streams are diverse, and have been discussed in general by various authors (e.g. Martini et al. 2002; Baker et al. 1988; Ritter 1988; Kochel 1988; Ritter 1975). There are also several case studies of such processes for central and southwest Texas streams which provide a suite of recent observations useful in the interpretation of Holocene age central Texas stream deposits (e.g. Baker 1977; 1975; Baker et al 1974; Caran and Baker 1986:7-8; Sullivan 1983; Patton and Baker 1977; Kochel 1980; Kochel et al 1982; Kochel and Baker 1982).

One of the less often cited effects of large floods is the deposition of coarse sediment such as gravel on the floodplain. Gravel, being one of the coarsest components of a river's sediment load, is typically restricted to the channel, and can only be moved out of the channel under fairly unusual conditions which typically involve high current velocities and overbank flooding. Kochel (1988:172-173) summarized the geomorphic effects of catastrophic floods and noted that overbank gravels were common on almost half of the examples cited, which included several central Texas streams (e.g. the Medina River and Elm Creek and Bleiders Creek [near New Braunfels]) and several east coast rivers.

Few authors have examined the deposition of gravel on alluvial floodplains in detail, but in general terms, the transportation and deposition of gravel on floodplains is controlled by transport capacity and sediment supply. Normally, overbank current velocities on floodplains are too slow to entrain and/or move gravel, and the current velocity typically declines dramatically away from the channel. So even if coarse sediment was locally available for transport on floodplains, most floods would be incapable of moving it in this setting. During large magnitude floods, however, there may be sufficient velocity to move gravel sized material on the floodplain, but the main limitation is sediment supply. Coarse material is generally limited to the channel and lifting gravel out of the channel and onto the floodplain surface is the main limiting factor.

Ritter $(1975$; 1988) discusses three principal mechanisms by which gravel can be deposited on river floodplains. The first process involves the construction of sand and gravel ramps within the channel that facilitate the lifting of sediment from the channel onto the floodplain (presumably by rolling or saltating). Ritter (1988:247) notes that this occurs most often on the inside of meander bends, and it is undoubtedly associated with a lateral shift in the thread (or course) of the maximum current velocity that often occurs during overbank flooding. This spatial shift involves moving the thread of maximum current velocity from the low water channel onto the floodplain toward the inside of meander bends (Baker 1977), thereby avoiding the increased roughness associated with fringing galleria forests and the more sinuous path of low flow channels (see Baker 1988:86 for a dramatic photo illustration of this process on the Medina River, just south of the Guadalupe River at Kerrville). This process creates features known as chutes on the point bars of streams with variable discharge (cf. McGowan and Garner 1970). The second process by which gravel can reach the floodplain is identical to normal floodplain deposition, namely the gravel is carried in suspension in the flood water (Ritter 1975). Ritter inferred this process from gravel bars created on floodplains where no enchannel ramp was observed, as well as from evidence of damage to floodplain trees where coarse material in the suspension load had battered tree trunks well above the transport height normally associated with the traction or bedload of the stream. The third process by which this can occur is the local erosion of gravels from floodplain deposits during a flood, whereby gravelly sediment is locally available for transport on the floodplain and it does not need to be lifted out of the channel (Baker 
1977; Ritter 1975). Erosional scour is a common effect of large magnitude flooding on river floodplains, especially at the margin of the overbank environment where fairly high current velocities are present (cf. Magilligan et al. 1998; Gomez et al. 1997; Sullivan 1983) and the liberation of gravel by this processes would seem to be likely, if it is present in the pre-existing deposits.

Where significant floodplain gravel deposits have been observed their plan morphology is typically described as either sheet-like or lobate, with the latter being plano-convex in cross-section (planar side down). Interestingly, floodplain gravel deposition is not necessarily preceded by scour of the floodplain surface (Baker 1977; see also Figure 3 in Williams and Costa 1988:72).

Local descriptions of large magnitude flooding are perhaps more useful and there are several cases which can be examined in detail, primarily associated with the hurricane Amelia flood of 1978 (Sullivan, 1983), and the 1972 New Braunfels flood on Bleiders and Elm Creeks (Baker 1975; 1977; Patton and Baker 1977). Perhaps the most detailed suite of observations are those of Sullivan, (1983) who documented the effects of the 1978 Tropical Storm Amelia flood on the Medina River, just south of Kerrville. Sullivan (1983:142-144) described the deposition of gravel lag deposits on the Medina River floodplain as follows:

"Large areas of the low flat surfaces adjacent to the Medina channel are covered with poorly-sorted lag deposits of cobble gravel and scattered small boulders. These deposits appear to be only a few clasts thick. Spatial dimensions range from tens to several hundred meters in length and width. ...Large-scale bedforms are not apparent across this gravel surface although its downstream terminus is a prominent gravel chute bar. Surface variation was commonly observed as a difference in clast size, with concentrations of very coarse clasts marking the paths of waning flow channels. The clast size is similar to that forming the armor on the stoss side of large transverse bars [mean b-axis length ranged from 5 to $12 \mathrm{~cm}]$. The smaller clasts are generally more diffuse, while larger cobbles and boulders are often distinctly imbricated."

Baker $(1975 ; 1977)$ and Patton and Baker (1977) also describe the effects of exceptionally large floods on two small tributaries of the Guadalupe River near New Braunfels, Texas (Bleiders and Elm Creeks). Although the focus of these papers was changes in the channel facies, observations on floodplain erosion and deposition were made, and in each case, the deposition of gravel on the floodplain was observed (Patton 1988).

From this brief review it is clear that the deposition of gravel on river floodplains, although unusual, can occur, and indeed, may be a common effect of large-magnitude floods on central Texas bedrock and mixed bedrock-alluvial rivers. It is clear that during catastrophic overbank floods, both sediment supply and transport capacity maybe sufficient to result in the transport and deposition of gravel on surfaces normally dominated by the deposition of mud.

\section{COLLUVIAL OR SLOPE SEDIMENTATION}

Slope sediments or colluvial deposits generally experience very limited distance transport and depositional energy and therefore often exhibit poor sorting (Goldberg and Macphail 2006:77-84; Gerrard 1981:34-60). A wide variety of transport processes operate on slopes, and sediment movement ranges from processes similar to streams (where water may transport sediment in channel confined flows as in the case of rills and gullies, or in unconfined flows across broad surfaces (as in the case of sheetwash), to 
mass movements where gravity is the main agent of movement (in which transport may be incremental (as in creep) or episodic (as in debris flows)).

Incrementally deposited water borne sediments on slopes are not normally matrix-supported, but in landscapes where the bedrock is hard and stony, rock fragments may be intimately mixed with fine earth material. In such settings, the slow sedimentation rate in combination with variations in the nature of sediment transported through time may create a deposit that is matrix-supported or close to it. The spatial and stratigraphic occurrence of colluvial deposits is generally limited to slopes, aprons at the foot of slopes, and localized fans which may be either on the slope or situated at the foot of the slope. In locations like the Gatlin site, it is common to have interfingering of alluvial and colluvial sediments and this was observed in the valley margin settings.

Mass movements, on the other hand create matrix-supported colluvial deposits, and debris flows are the most common form of this. There exists a continuum of transport processes ranging from essentially clear water at one end, to extremely sediment laden water at the other, and as the amount of sediment increases, the nature of the deposits changes from clast-supported to matrix-supported (Costa 1988). Water flows with high sediment concentration (hyperconcentrated flows and debris flows) are most often found in small, high relief (mountainous) drainage basins and it would be extremely unusual to encounter them in a river valley the size of the Guadalupe. Furthermore, such sediments should be limited to the foot of the upland slopes, not found in the middle of the floodplain.

Beyond their depositional setting, the identification of colluvial deposits is often facilitated by attention to the lithology and roundness of the coarse fraction, given that such deposits have experienced limited transport and the sediments are therefore often angular and of a local lithology.

\section{POST-DEPOSITIONAL PROCESSES}

There are a number of processes which are capable of modifying stratified coarse and fine sediments into a single deposit which may be of similar appearance to those observed at the Gatlin site. These processes, often referred to as proisotropic processes, mix the deposits within a stratigraphic profile (or solum) thereby destroying evidence of once obvious bedding (Johnson et al 1987; Johnnson 2005; Schaetzel and Anderson 2005). The progressive effects of proisotropic pedotrubation are very apparent when examining alluvial deposits of different age, because primary bedding features such as sedimentary structures, which are readily visible throughout late Holocene alluvial deposits, are rarely visible near the surface of early Holocene or older deposits. Several distinct pedotrubation processes could account for the dissemination of gravel from discrete thin beds into a fine-grained muddy matrix, with mixing by flora, burrowing fauna, and shrink-swell clays being the most likely processes.

In addition to pedoturbation, the saturation of open framework gravel deposits with suspended sediment laden water during flooding could also result in significant mud being worked into gravel deposits after the gravelly sediment was deposited. So, assuming gravel could be deposited on the Guadalupe River floodplain by flooding, there are a variety of processes that are capable of leading to diamictons like those at the Gatlin Site. 


\section{METHODS}

In order to explore the formation of matrix-supported gravels at the Gatlin Site, we selected three vertical profiles that exhibited a range of features which represented different potential formation processes:

1) colluvial deposits from behind the burned rock midden in Trench 1 profile $C$;

2) point bar/near channel overbank gravels and muds in Trench 20; and

3) matrix supported gravelly muds in Trench 19.

The analytical methods employed are identical to those described in Chapter 6 (the Paleoenvironment chapter), which primarily were granulometry, micromorphology, and clay mineralogy. In addition to these lab methods, we hoped to use field observations of the 1978 Medina River flood deposits (mapped by Sullivan 1983) to evaluate the rate of pedoturbation of fine sediment into floodplain gravels (see below).

\section{INSIGHTS FROM THE MEDINA RIVER FLOOD OF 1978}

One way we attempted to address the issue of pedoturbation of fines into floodplain gravels was to revisit some of the areas where Sullivan (1983) mapped floodplain gravel deposition following the devastating flood associated with the passage of Tropical Storm Amelia in August of 1978. A 52 hour rainfall total of $122 \mathrm{~cm}$ (48 inches) occurred near the intersection of Kerr, Bandera and Kendall counties and created severe flooding along the Guadalupe and Medina Rivers. The effects of this flood on the Medina River were studied by Sullivan (1983) who mapped geomorphic and depositional features along a roughly 60 mile long segment, from about 6 miles west of the point highway 16 crosses the river near the confluence with Wallace Creek (due south of Kerrville), to near the confluence of the Medina River and Red Bluff Creek downstream of Bandera. Although flooding occurred on other streams in the region including the Guadalupe River, Sullivan chose to study the Medina River because the magnitude of the damage was greatest there.

Revisiting areas where Sullivan mapped floodplain gravel deposition was thought to be worthwhile, because if these areas had remained undisturbed since the flood, examination of the deposits would permit comment on the nature of redistribution of the fine-grained matrix in the 28 years since the flood by flora and fauna. With this in mind several of Sullivan's map areas (specifically Plate 3 and Plate 4 ) in the reach between Bandera and Kerrville along and near Highway 16 were visited and the flood deposits examined. Unfortunately, this work failed to achieve the desired results for two reasons. First, several of the areas we examined were places where there was no fine-grained floodplain sediment under the 1978 flood gravel, and these areas were unsuitable for the purposes of this study. The second problem encountered was the disturbance of the surface in the period since the flood, primarily through clearance or plowing which destroyed the fabric of the flood deposit.

\section{OBSERVATIONS FROM THE GATLIN SITE DEPOSITS}

\section{Colluvial Deposits}

Samples of what were inferred in the field to be mixed alluvial-colluvial deposits were examined in Trench 1 profile $\mathrm{C}$, and could be separated into two groups: the upper colluvium, and mixed alluviumcolluvium. The upper colluvium exhibited a depositional geometry that was undoubtedly colluvial (a 
wedge that thickened upslope and pinched out onto the floodplain), whereas colluvial contributions to the underlying deposits did not exhibit such clear stratigraphic geometry, but rather appeared to be more intimately interbedded with the floodplain alluvium.

In general terms, the upper colluvium deposits in Trench 1 exhibited small amounts of matrix-supported gravel, part of which was distinguishable from the alluvial deposits on the basis of lithology. In specific, around $20 \%$ of the coarse clasts comprising this deposit were reworked pedogenic carbonate nodules from an older alluvial deposit that crops out upslope of the site, and unlike in situ pedogenic carbonates from the Unit 3 deposits, these reworked nodules exhibited sharp edges in thin section and were often broken fragments of larger nodules. Limestone fragments in the colluvial component were fairly small and less rounded than the alluvial gravels, but otherwise, lithologically, they were similar to the alluvial gravels. The thin sections and the imbedded slabs from which they were prepared showed fairly small amounts of gravel to be present, but gravel ubiquity would undoubtedly increase closer to the slope. Interestingly, the upper colluvium contained the smallest amount of lattice expandable clay (specifically mixed layer IlliteSmectite) in our sample, which supports the inference that these matrix-supported gravels were probably not attributable to argilliturbation.

\section{Near ChanNel OVERBANK Deposits}

Several of the beds in the point bar/near channel overbank facies of Trench 20 were either matrix-rich clast supported deposits or matrix-supported gravelly muds. Petrographic examination of these deposits revealed a continuum of morphological expression from open framework gravel and sand with little or no mud, progressing to thin grain coats and pelletal infill (excrement) pedofeatures (associated with faunal movement of fines), to massive matrix supported gravels with open and close porphyric related distributions.

Close examination of the sequence of deposition of mud and pedogenic carbonate within predominantly gravelly beds permits some comment about the relative timing of mud deposition. Open framework coarse gravelly deposits exhibited pendant calcium carbonate cements on the bottom of larger framework grains (which is consistent with observations on the formation of such features elsewhere (e.g. TreadwellSteitz, and McFadden 2000). In some cases, thin mud coats were present on the top of and bridging grains which presumably are due to downward migration of mud through the deposit. None of these mud coats, however, exhibited birefringence typically associated with illuvial clay. Pendants appeared not to form where the gravels rested on muddy sediment and they appeared to have formed before mud coats were present. On some samples it was clear that small-scale sediment movement by fauna upwards across the original depositional boundary had injected fine-grained mud into the interstices of a gravelly sediment. In general, both faunal mixing and infiltration appear to have contributed to the deposition of silty clay in these deposits, and these attributes were most apparent on samples that were not mud dominated.

\section{MATRIX-SUPPORTED FLOODPLAIN GRAVELS IN THE MEDIAL FLOODPLAIN}

The matrix-supported gravelly sediments in Trench 19 were present in two zones, an upper zone between 40 and $80 \mathrm{~cm}$ below surface, and a lower zone between $\sim 1.2$ and $1.6 \mathrm{~m}$ below surface. These deposits were clearly composed of alluvial gravel, and the lithology of this gravel was similar to that observed in the Trench 20 gravel beds (typically about 90\% limestone, 5\% chert, and trace amounts of quartz, snail shell and fossil shell fragments). The lower gravel-rich zone contained considerable amounts of coarse sand, which together with the gravel suggest a primarily detrital origin of a higher energy deposit. The coarse-fine related distribution of these deposits was typically open to close porphyric, but in a few places 
where fine gravels were concentrated into what looked like thin, dispersed beds, the coarse/fine related distribution was enaulic and there were an unusually large number of excrement pedofeatures present. In general, however, the all of these deposits exhibited infill pedofeatures which ranged from dense to loose, and there was not a disproportionate amount of them in the clearly porphyric (matrix dominated) zones.

\section{Argilliturbation}

As an explanatory hypothesis for matrix-supported gravels in this setting, argilliturbation seems unlikely for a variety of reasons. First, although the clay mineralogy from Trench 19 yielded the greatest amount of lattice-expandable clay (generally between $20-30 \%$ of the clay sized fraction), the frequency of these clays decreased up the profile. Second, this clay was not expressed in the deposits as either macrofeatures (e.g. slickensides, pressure faces, or crack fills, etc...) or microfeatures typically associated with shrink-swell processes (e.g. masepic, vosepic and lattiseptic fabrics; Wilding and Tessier 1988: 78). Wilding and Tessier (1988) note that stress microfabrics may not be apparent in calcic vertisols without first pretreating the thin sections to remove the carbonates, and that was not done in this case. Granted, the soils are clearly not vertisols, but the absence of stress related microfabrics could be an artifact of the thin section preparation. Even if the soils did crack, some of the gravels present were larger than could reasonably be expected to fall down dry season cracks. Furthermore, shrink-swell soils are well-known for moving coarse clasts upwards (Schaetzl and Anderson 2005). Hence, although these soils may have cracked during dry periods, it seems unlikely that argilliturbation was anything other than a minor factor in the dispersion of gravel.

\section{SUMMARY}

Overall, the origin of the medial floodplain matrix supported gravel deposits is most consistent with an alluvial depositional process, most likely intermittent large magnitude flooding. The lithology of the coarse fraction of these sediments is clearly alluvial (virtually identical to point bar gravels) in both composition and rounding. This is in stark contrast to colluvial deposits at the rear of the floodplain which are more angular and exhibit a somewhat different composition. While it is clear that small scale postdepostional movement of fines has occurred in all settings, there is no evidence to support pedoturbation as the principal means of creating these deposits. If large-scale mixing by fossorial animals was the cause, some evidence of krotovina should have been visible, but they were not. It is possible that tree-throw may have played a role, but identification of such processes in deposits lacking well-developed soil horizons is generally problematic. Likewise, argilliturbation is unlikely to have been the formative process given that there are fairly small amounts of shrink-swell clay and that the deposits lack features indicative of this process.

It is most likely that the alternating deposition of dispersed gravel and mud on the floodplain is the most likely process that created these deposits. The spatial location of these deposits (the medial floodplain) is consistent with a flood chute, and modern observations of large magnitude floods on Hill Country streams suggest that such features are commonly activated during extreme overbank floods.

The presence of alluvial gravel in floodplain contexts at other central Texas alluvial archaeological sites suggest that this process, although rarely reported in the sedimentological literature, may be fairly common in this region. For instance, at the Richard Beene Site on the Medina River south of San Antonio, Thoms (in press) describes an Early Archaic occupation surface within the Perez paleosol that appeared to have been adversely affected by overbank flooding. The cultural materials in this component lack wellpreserved features and were mixed with stream-worn pebbles up to $4 \mathrm{~cm}$ in diameter, and these materials were encompassed within a silty clay floodbasin matrix. Likewise, at the 41TG309, an Early Archaic site 
on the Concho River, Quigg et al. (1996:163-166) observed a tear-dropped shaped discrete accumulation of river cobbles, small gravels and mussel shell (Feature 4) in Early Holocene floodplain sediments which was interpreted as coarse material that accumulated behind a flow obstacle on the floodplain. As both of these examples suggest, large magnitude floods are capable of moving gravel sized material, and this includes prehistoric cultural residues, and sites in high energy floodplain settings may be adversely affected by such flows. That said, Greaves and Tomka (2003) observed no deleterious effects of floods on cultural deposits at 41MM340 on the Little River, where gravels were commonly encountered in floodplain deposits. Greaves and Tomka (2003) did, however use the variations in the stratigraphic occurrence of gravels to infer changes in the flood frequency at the site through time. 


\section{REFERENCES}

Baker, Victor R

1977 Stream-channel response to floods, with examples from central Texas. Geological Society of America Bulletin 88:1057-1071.

Baker, Victor R.

1975 Flood Hazards along the Balcones Escarpment in Central Texas: Alternative Approaches to their Recognition, Mapping and Management. Geological Circular 75-5. Bureau of Economic Geology, The University of Texas at Austin, Austin, Texas.

1988 Flood Erosion. In Flood Geomorphology, edited by Victor R. Baker, R. Craig Kochel, and Peter C. Patton, pp. 81-95. John Wiley \& Sons, New York.

Baker, Victor R., James Samson and Charles M. Woodruff, Jr.

1974 Geomorphic and Hydrologic Features of the Central Texas Hill Country. Austin Geological Society Field-Trip Guidebook. Austin Geological Society, Austin, Texas.

Baker, Victor R., R. Craig Kochel, and Peter C. Patton (eds.)

1988 Flood Geomorphology. John Wiley \& Sons, New York.

Caran, S. Christopher and Victor R. Baker

1986 Flooding along the Balcones Escarpment. In The Balcones Escarpment, Central Texas, edited by Patrick L. Abbott and C. M. Woodruff, Jr., pp. 1-14. Geological Society of America Field Trip Guidebook, 1986 Annual Meeting, San Antonio, Texas.

Costa, John E.

1986 Rheologic, geomorphic, and sedimentologic differentiation of water floods, hyperconcentrated flows, aand debris flows. In Flood Geomorphology, edited by Victor R. Baker, R. Craig Kochel, and Peter C. Patton, pp. 113-122. John Wiley \& Sons, New York

Gerrard, A. J.

1981 Soils and landforms: An integration of geomorphology and pedology. George Allen \& Unwin, Lodon.

Goldberg, Paul and Richard I. Macphail

2006 Practical and Theoretical Geoarchaeology. Blackwell Publishing: Oxford, UK.

Gomez, Basil, J. D. Phillips, F. J. Magilligan, and L. A. James

1997 Floodplain sedimentation and sensitivity: Summer 1993 flood, Upper Mississippi River Valley. Earth Surface Processes and Landforms 22:923-936.

Greaves, Russel D., and Steve A. Tomka

2003 Stream suspension loads and gravels from 41MM340. In Data Recovery Investigations at 41MM340: A Late Archaic Site along Little River in Milam County, by

Johnson, Donald L., and Wattson-Stegner, D.,

1987 Proisotropic and proanisotropic processes of pedoturbation. Soil Science 143:278-292. 
Johnson, Donald L. Domier, J. E. J., and Johnson, D. N.,

2005 Reflections on the Nature of Soil and Its Biomantle. Annals of the Association of American Geographers 95(1):11-31.

Kochel, R. Craig

1988 Geomorphic impact of large floods: Review and new perspectives on magnitude and frequency. In Flood Geomorphology, edited by Victor R. Baker, R. Craig Kochel, and Peter C. Patton, pp. 169-188. John Wiley \& Sons, New York.

1980 Investigation of flood paleohydrology using slackwater deposits, lower Pecos and Devils River, Southwest Texas. Ph.D. Dissertation, The University of Texas at Austin.

Kochel, R. Craig, and Victor R. Baker

1982 Paleoflood Hydrology. Science 215:353-361.

Kochel, R. Craig, Victor R. Baker and Peter C. Patton

1982 Paleohydrology of southwest Texas. Water Resources Research 18:1165-1183.

Magilligan, Francis J., Jonathan D. Phillips, L. Allen james, and Basil Gomez

1998 Geomorphic and Sedimentological Controls on the Effectiveness of an Extreme Flood. The Journal of Geology 106:87-95.

Martini, L. Peter, Victor R. Baker, and Guillermina Garzón

2002 Flood and Megaflood proceses and deposits: Recent and Ancient Examples. Special Publication No. 32, International Association of Sedimentologists, Blackwell Science, Oxford, UK.

McGowan, J. H., and L. E. Garner

1970 Physiographic features and stratifcation types of coarse-grained point bars: Modern and ancient examples.

Patton, Peter C., and Victor R. Baker

1977 Geomorphic response of central Texas stream channels to catastrophic rainfall and runoff. In Geomorphology of Arid Regions, edited by D. O. Doehring, pp. 189-217. State University of New York, Binghampton.

Quigg, J. Michael, Jay Peck and Christopher R. Lintz

1996 Results of Stage I Mitigation at 41TG309. In Early Archaic Use of the Concho River Terraces: Cultural Resource Investigations at 41 TG307 and 41TG309, by J. Michael Quigg, Jay Peck, Christopher Lintz, Abby C. Treece, Charles D. Frederick, Roman Clem, G. Lain Ellis, Paul Schuchert, and James T. Abbott, pp. 155-183, Tom Green County, San Angelo, Texas. Technical Report 11058, TRC Mariah Associates Inc., Austin, Texas.

Ritter, Dale F.

1988 Floodplain erosion and deposition during the December 1982 floods in Southeast Missouri. In Flood Geomorphology, edited by Victor R. Baker, R. Craig Kochel, and Peter C. Patton, pp. 246259. John Wiley \& Sons, New York.

1975 Stratigraphic implications of coarse-grained gravels deposited as overbank sediment, southern Illinois. Journal of Geology 83: 645-650. 
Schaetzl, Randall, and Sharon Anderson

2005 Soils: Genesis and Geomorphology. Cambridge University Press: Cambridge.

Sullivan, J. E.

1983 Geomorphic Effectivenesss of a High-magnitude Rare Flood in Central Texas. Unpublished MA Thesis, The University of Texas at Austin.

Thoms, Alston

in press Excavation Strategies and the General Nature of Archaeological Deposits. In Archaeological and Paleoecological Investigations at the Richard Beene Site, 41BX831, South-Central Texas, edited by Alston V. Thoms and Rolfe D. Mandel, pp.137-174. Reports of Investigation 8, Center for Ecological Archaeology, Texas A\&M University, Texas A\&M University.

Treadwell-Steitz, C., and L. D. McFadden

2000 Influence of parent material and grain size on carbonate coatings in gravelly soils, Palo Duro Wash, New Mexico. Geoderma 94:1-22.

Wilding, Larry and D. Tessier

1988 Genesis of Vertisols: Shrink-swell Phenomena. In Vertisols: Their Distribution, Properties, Classification and Management, edited by Larry P. Wilding and Ruben Puentes, pp. 55-82. Technical Monograph No. 18, Soil Management Support Services, Texas A\&M Printing Center, College Station, Texas.

Williams, Garnett P., and John E. Costa

1988 Geomorphic Measurements after a flood. In Flood Geomorphology, edited by Victor R. Baker, R. Craig Kochel, and Peter C. Patton, pp. 65-77. John Wiley \& Sons, New York. 
Matrix-Supported Floodplain Gravels: Implications For Floodplain Formation Processes 


\section{BACKHOE TRENCH DESCRIPTIONS}

\section{Trench 1}

\begin{tabular}{|c|c|c|c|}
\hline \multicolumn{2}{|c|}{ Geologic Units: } & \multicolumn{2}{|c|}{$\begin{array}{l}\text { Unit } 3 \text { of Abbott (this volume), Early to Middle Holocene alluvium overlain by recent } \\
\text { colluvium. }\end{array}$} \\
\hline \multicolumn{2}{|c|}{ Cultural material: } & \multicolumn{2}{|c|}{$\begin{array}{l}\text { Numerous occupation remains in zone } 2 \text {, and zone } 3 \text { is the burned rock midden. An } \\
\text { isolated occupation is present at the top of zone } 4 \text {. No cultural material was noted below } \\
\text { zone } 4 \text {. }\end{array}$} \\
\hline \multicolumn{2}{|c|}{ Comments: } & \multicolumn{2}{|c|}{$\begin{array}{l}\text { The depths in this description are relevant to the long profile illustration of Trench 1, and } \\
\text { are therefore variable. The reader is referred to Figure Trench } 1 \text { Profile for the depth of } \\
\text { the various zones. Calcium carbonate nodules seem to be restricted to the finer textured } \\
\text { units, specifically silty clays. }\end{array}$} \\
\hline Zone & Horizon & Depth & Description \\
\hline 1 & A & See drawing & $\begin{array}{l}\text { Very dark gray (10YR } 3 / 1, \text { moist) slightly gravelly silty clay loam, } \\
\text { friable, strong, fine subangular blocky structure, abrupt, smooth } \\
\text { boundary, }<1 \% \text { coarse gravel fragments, few, thin discontinuous beds } \\
\text { of slightly more gravely material of colluvial origin. }\end{array}$ \\
\hline $1 \mathrm{a}$ & A & See drawing & $\begin{array}{l}\text { Black (10YR } 2 / 1 \text {, moist) silty clay loam, friable, moderate, medium } \\
\text { subangular blocky structure parting to strong medium granular } \\
\text { structure, abrupt, smooth boundary. }\end{array}$ \\
\hline 2 & $2 \mathrm{Ab}$ & See drawing & $\begin{array}{l}\text { Black (10YR } 2 / 1 \text {, moist) silty clay, friable, moderate, medium to coarse } \\
\text { angular blocky structure parting to strong medium to fine granular } \\
\text { structure, gradual smooth boundary, numerous } 1-2 \mathrm{~mm} \text { diameter broken } \\
\text { snail shell fragments, } 1-3 \% \text { coarse fragments, }<1 \% \text { calcium carbonate } \\
\text { filaments. }\end{array}$ \\
\hline $2 a$ & $2 \mathrm{Ab}$ & See drawing & $\begin{array}{l}\text { Very dark gray-very dark grayish brown (10YR3/1.5, moist) slightly } \\
\text { gravelly silty clay loam, moderate to strong medium to coarse } \\
\text { subangular blocky structure, gradual smooth boundary, numerous } 1-2 \\
\text { mm diameter broken snail shell fragments, } 1-3 \% \text { coarse fragments, } 0- \\
3 \% \text { calcium carbonate filaments. }\end{array}$ \\
\hline 3 & $2 A p$ & See drawing & $\begin{array}{l}\text { Black (N } 2 / 0 \text { to } 10 \mathrm{YR} 2 / / 1 \text {, moist) very to extremely fine to coarse } \\
\text { gravelly silt loam to silty clay loam, very friable, moderate fine to very } \\
\text { fine crumb structure, abrupt smooth boundary, } 0-3 \% \text { calcium carbonate } \\
\text { filaments, numerous snails. This is the burned rock midden, primarily } \\
\text { clast supported. }\end{array}$ \\
\hline 4 & 2Bk1 & See drawing & $\begin{array}{l}\text { Yellowish brown (10YR 5/4, moist) slightly gravelly silty clay, hard } \\
\text { (dry), weak moderate prismatic structure parting to strong moderate } \\
\text { subangular blocky structure, gradual, smooth boundary, } 3-5 \% \text { calcium } \\
\text { carbonate filaments, } 3-7 \% \text { coarse fragments of colluvial origin. }\end{array}$ \\
\hline 5 & $2 \mathrm{Bk} 2$ & See drawing & $\begin{array}{l}\text { Yellowish brown (10YR } 5 / 4 \text {, moist) slightly gravelly clay, extremely } \\
\text { hard, strong, very coarse prismatic structure parting to strong fine } \\
\text { angular blocky structure, abrupt smooth boundary, } 3-5 \% \text { calcium } \\
\text { carbonate filaments, few }(1-2 \%) \text { medium to coarse calcium carbonate } \\
\text { nodules in the matrix. }\end{array}$ \\
\hline $5 a$ & 2Bk2 & See drawing & $\begin{array}{l}\text { Yellowish brown (10YR } 5 / 4 \text {, moist) slightly gravelly silty clay loam, } \\
\text { friable, moderate medium prismatic structure parting to moderate } \\
\text { medium subangular blocky structure, abrupt smooth boundary, } 1-3 \% \\
\text { calcium carbonate filaments, } 1 \% \text { coarse fragments. }\end{array}$ \\
\hline 6 & $2 \mathrm{C}$ & See drawing & $\begin{array}{l}\text { Yellowish brown (10YR 5/4, moist) muddy sandy gravel (fine earth is a } \\
\text { sandy clay), friable, single grained, abrupt smooth boundary. }\end{array}$ \\
\hline 7 & 2Bk' & See drawing & $\begin{array}{l}\text { Brown ( } 7.5 \text { YR } 4 / 4, \text { moist) silty clay, very friable to friable, weak to } \\
\text { moderate medium prismatic structure, } 3-5 \% \text { calcium carbonate } \\
\text { filaments, few medium to coarse, light brown }(7.5 \text { YR } 6 / 3) \text { popcorn-like } \\
\text { (hollow) calcium carbonate nodules. }\end{array}$ \\
\hline
\end{tabular}




\section{Trench 2}

\begin{tabular}{|c|c|c|c|}
\hline \multicolumn{2}{|c|}{ Geologic Units: } & \multicolumn{2}{|c|}{ Unit 3 of Abbott (this volume), Early to Middle Holocene alluvium. } \\
\hline \multicolumn{2}{|c|}{ Cultural material: } & \multicolumn{2}{|c|}{ One distinct occupation at the top of zone 2 , no other features noted. } \\
\hline \multicolumn{2}{|c|}{ Comments: } & \multicolumn{2}{|c|}{ Like Trench 1, the carbonate nodules are largely restricted too fine textured deposits. } \\
\hline Zone & Horizon & Depth & Description \\
\hline 1 & A & $0-48$ & $\begin{array}{l}\text { Black (10YR } 2 / 1 \text {, moist) slightly gravelly silty clay, friable, moderate } \\
\text { coarse subangular blocky structure parting to strong medium to fine } \\
\text { granular structure, clear smooth boundary, } 1-2 \% \text { coarse fragments, one } \\
\text { fairly clear stringer of gravel at about } 25 \mathrm{~cm} \text { depth. }\end{array}$ \\
\hline 2 & $\mathrm{AB}$ & $48-87$ & $\begin{array}{l}\text { Brown ( } 7.5 \text { YR } 4 / 3 \text {, moist) slightly gravelly clay loam, friable, moderate } \\
\text { to strong coarse subangular blocky structure, clear smooth boundary, } 3- \\
5 \% \text { coarse fragments, several distinct but discontinuous gravel stringers, } \\
\text { one distinct occupation at the top of the zone as denoted by small basin } \\
\text { shaped burned rock feature between } 48-65 \mathrm{~cm} \text {. A single very large } \\
\text { boulder was present resting at or near the base of this zone; this boulder } \\
\text { was about } 30 \mathrm{~cm} \text { in diameter. }\end{array}$ \\
\hline 3 & Bw & $87-105$ & $\begin{array}{l}\text { Brown (7.5YR 4/4, moist) slightly gravelly clay, firm, strong coarse } \\
\text { subangular blocky structure, clear, smooth boundary, } \sim 1 \% \text { coarse } \\
\text { fragments, no discernible bedding. }\end{array}$ \\
\hline 4 & Bk1 & $105-122$ & $\begin{array}{l}\text { Brown (7.5YR 4.5/4, moist) clay, firm, moderate coarse subangular } \\
\text { blocky structure, clear smooth boundary, } 5-7 \% \text { calcium carbonate } \\
\text { filaments, few coarse irregular (popcorn-like, hollow) calcium carbonate } \\
\text { nodules. }\end{array}$ \\
\hline 5 & $\mathrm{Bk} 2$ & $122-145$ & $\begin{array}{l}\text { Brown-strong brown }(7.5 \text { YR } 4 / 5 \text {, moist }) \text { slightly gravelly to gravelly } \\
\text { clay loam, friable, weak coarse subangular blocky structure, clear } \\
\text { smooth boundary, } 15-30 \% \text { coarse fragments, } 5-7 \% \text { calcium carbonate } \\
\text { filaments, few thin }(<1 \mathrm{~mm}) \text { pendants on gravel clasts, few medium } \\
\text { irregular (popcorn-like hollow) calcium carbonate nodules. }\end{array}$ \\
\hline 6 & $\mathrm{C}$ & $145-180$ & $\begin{array}{l}\text { Brown ( } 7.5 \text { YR } 4 / 4 \text {, moist) slightly gravelly clayey sand, friable, weak to } \\
\text { moderate coarse subangular blocky structure, gradual smooth boundary, } \\
3-5 \% \text { coarse fragments, } 1 \% \text { calcium carbonate filaments. }\end{array}$ \\
\hline 7 & $\mathrm{C}$ & $180-340$ & $\begin{array}{l}\text { Brown ( } 7.5 \text { YR } 4.5 / 4 \text {, moist) loam to sandy clay loam, very friable, weak } \\
\text { coarse to medium subangular blocky structure, } 1 \% \text { coarse fragments, } \\
\text { few discernible thin gravel stringers (up to } 3 \% \text { coarse fragments). }\end{array}$ \\
\hline
\end{tabular}




\section{Trench 3}

\begin{tabular}{|c|c|l|l|}
\hline \multicolumn{2}{|l|}{ Geologic Units: } & Unit 3 of Abbott (this volume), Early to Middle Holocene alluvium. \\
\hline \multicolumn{2}{|l|}{ Cultural material: } & \begin{tabular}{l} 
At least two occupations, one near 70-75 cm, and a second around 120 cm depth. \\
\hline \multicolumn{2}{|l|}{ Comments: }
\end{tabular} & $\begin{array}{l}\text { This soil displays some vertic tendencies, such as the tonguing of zone 3 into zone 4, and } \\
\text { the frequent pressure faces. }\end{array}$ \\
\hline Zone & Horizon & Depth (cm) & \multicolumn{1}{c|}{ Description } \\
\hline 1 & $\mathrm{C}$ & $0-13$ & $\begin{array}{l}\text { Brown (7.YR 5/4, moist) loam, very friable, moderate fine subangular } \\
\text { blocky structure, abrupt smooth boundary, recent colluvium/road } \\
\text { wash. }\end{array}$ \\
\hline 2 & $2 \mathrm{Ab} 1$ & $13-48$ & $\begin{array}{l}\text { Black (10YR 2/1, moist) clay, friable, moderate medium columnar } \\
\text { structure parting to moderate medium to fine subangular blocky } \\
\text { structure, clear smooth boundary. }\end{array}$ \\
\hline 3 & $2 \mathrm{Ab} 2$ & $\begin{array}{l}\text { Very dark grayish brown (10YR 3/2, moist) clay, friable to firm, } \\
\text { moderate to strong medium subangular blocky structure, gradual } \\
\text { smooth boundary, few 1-2 mm snail shell fragments, occupation } \\
\text { around 70-75 cm. }\end{array}$ \\
\hline 5 & $2 \mathrm{Bw}$ & $\begin{array}{l}\text { Brown (7.5YR 4/3, moist) clay, firm, moderate to strong medium } \\
\text { prismatic structure parting to strong medium angular blocky structure, } \\
\text { gradual smooth boundary, 1-3\% calcium carbonate filaments, few } \\
\text { patchy pressure faces, few 1-2 cm wide tongues of zone 3 that } \\
\text { decrease in width with depth, occupation surface near the top of this } \\
\text { zone around 120 cm. }\end{array}$ \\
\hline 5 & $2 \mathrm{Bk}$ & $\begin{array}{l}\text { Brown (7.5YR 5/3, moist) clay-silty clay loam, friable, strong medium } \\
\text { angular blocky structure, common discontinuous pressure faces, 5-7\% } \\
\text { calcium carbonate filaments, few medium hollow (popcorn-like) } \\
\text { irregular calcium carbonate nodules. }\end{array}$ \\
\hline
\end{tabular}

\section{Trench 4}

\begin{tabular}{|c|c|c|c|}
\hline \multicolumn{2}{|c|}{ Geologic Units: } & \multicolumn{2}{|c|}{ Unit 3 of Abbott (this volume), Early to Middle Holocene alluvium. } \\
\hline \multicolumn{2}{|c|}{ Cultural material: } & \multicolumn{2}{|c|}{ Multiple prehistoric occupations are present in zones 2 and 3.} \\
\hline \multicolumn{2}{|c|}{ Comments: } & \multicolumn{2}{|l|}{ None. } \\
\hline Zone & Horizon & Depth (cm) & Description \\
\hline 1 & Ap & $0-51$ & $\begin{array}{l}\text { Very dark grayish brown (10YR } 3 / 2 \text {, moist) slightly gravelly silty clay } \\
\text { loam to a sandy clay, firm to friable, moderate extremely coarse } \\
\text { subangular blocky structure, abrupt smooth boundary, } 1-3 \% \text { coarse } \\
\text { fragments, few discontinuous beds of granule to fine gravel of a } \\
\text { colluvial origin. }\end{array}$ \\
\hline 2 & $2 \mathrm{Akb}$ & $51-82$ & $\begin{array}{l}\text { Black (10YR } 2 / 1 \text {, moist) slightly gravelly clay loam, friable, moderate } \\
\text { medium to coarse subangular blocky structure parting to strong medium } \\
\text { granular structure, clear smooth boundary, } 3 \% \text { calcium carbonate } \\
\text { filaments, } 1 \% \text { coarse fragments, At least one occupation around } 50 \mathrm{~cm} \text {, } \\
\text { but probably more than one is present in this zone. }\end{array}$ \\
\hline 3 & $2 \mathrm{ABk}$ & $82-127$ & $\begin{array}{l}\text { Very dark grayish brown (10YR } 3 / 2 \text {, moist) slightly gravelly silty clay } \\
\text { loam, friable, strong fine subangular blocky structure, gradual smooth } \\
\text { boundary, } 1-3 \% \text { coarse fragments, } 1-3 \% \text { calcium carbonate filaments, at } \\
\text { least two prehistoric occupation surfaces, one near } 80-90 \mathrm{~cm} \text {, and } \\
\text { another around } 120 \mathrm{~cm} \text {. }\end{array}$ \\
\hline 4 & $2 \mathrm{Bk}$ & $127-170$ & $\begin{array}{l}\text { Yellowish brown ( } 10 \text { YR } 5 / 4 \text {, moist) slightly gravelly clay, firm, } \\
\text { moderate to strong medium angular blocky structure, } 3 \% \text { coarse } \\
\text { fragments, } 5-7 \% \text { calcium carbonate filaments. }\end{array}$ \\
\hline
\end{tabular}




\section{Trench 5}

\begin{tabular}{|c|c|c|c|}
\hline \multicolumn{2}{|c|}{ Geologic Units: } & \multicolumn{2}{|c|}{$\begin{array}{l}\text { Unit } 3 \text { of Abbott (this volume), Early to Middle Holocene alluvium. Channel to near } \\
\text { channel overbank facies. }\end{array}$} \\
\hline \multicolumn{2}{|c|}{ Cultural material: } & \multicolumn{2}{|c|}{$\begin{array}{l}\text { One occupation around } 90-95 \mathrm{~cm} \text { depth. Large clast burned rock feature is conspicuous } \\
\text { because there was little thermal degradation of the rocks. }\end{array}$} \\
\hline \multicolumn{2}{|c|}{ Comments: } & \multicolumn{2}{|c|}{$\begin{array}{l}\text { Channel deposits present almost to the modern surface. The gravels of Zone } 3 \text { have } \\
\text { bleached appearance owing to the continuous carbonate coats. }\end{array}$} \\
\hline Zone & Horizon & Depth (cm) & Description \\
\hline 1 & A & $0-38$ & $\begin{array}{l}\text { Very dark gray (10YR } 3 / 1 \text {, moist) slightly gravelly loam, friable, moderate } \\
\text { medium subangular blocky structure, clear smooth boundary, } 1-3 \% \text { coarse } \\
\text { fragments. }\end{array}$ \\
\hline 2 & Bk1 & $38-95$ & $\begin{array}{l}\text { Yellowish brown (10YR 5/4, moist) slightly gravelly sandy loam, very friable, } \\
\text { weak medium subangular blocky structure, abrupt smooth boundary, } 3 \% \\
\text { coarse fragments, } 1-3 \% \text { calcium carbonate filaments, prehistoric occupation } \\
\text { and a conspicuous very large stone burned rock feature at the base of the zone. }\end{array}$ \\
\hline 3 & Bk2 & $95-138$ & $\begin{array}{l}\text { Yellowish brown (10YR } 5 / 4 \text {, moist) extremely gravelly loam, loose to very } \\
\text { friable, single grained, abrupt smooth boundary, }>660 \% \text { coarse fragments, } \\
\text { gravel clasts are coated with calcium carbonate and many clasts have } 1-2 \mathrm{~mm} \\
\text { thick pendants of calcium carbonate. }\end{array}$ \\
\hline 4 & Bk3 & -170 & $\begin{array}{l}\text { Brown ( } 7.5 \text { YR } 4 / 4 \text {, moist) slightly gravelly loam, very friable, weak medium } \\
\text { subangular blocky structure, clear smooth boundary, 3-5\% coarse fragments, } \\
1-3 \% \text { calcium carbonate filaments. }\end{array}$ \\
\hline 5 & Bk4 & -195 & $\begin{array}{l}\text { Yellowish brown (10YR 5/4, moist) gravelly sandy clay, friable, single } \\
\text { grained, clear smooth boundary, } 1-3 \% \text { calcium carbonate filaments, } \\
\text { approximately } 30 \% \text { coarse fragments. }\end{array}$ \\
\hline 6 & C & $195-280$ & $\begin{array}{l}\text { Brown ( } 7.5 \text { YR } 4 / 4 \text {, moist) sandy gravel, loose, single grained, multiple beds, } \\
\text { no obvious sedimentary structures. }\end{array}$ \\
\hline
\end{tabular}

\section{Trench 6}

\begin{tabular}{|c|c|l|l|}
\hline \multicolumn{2}{|l|}{ Geologic Units: } & \multicolumn{2}{l|}{$\begin{array}{l}\text { Unit } 3 \text { of Abbott (this volume), Early to Middle Holocene alluvium. Base of the trench is } \\
\text { channel facies and the upper 1.5 m is overbank facies. }\end{array}$} \\
\hline \multicolumn{2}{|l|}{ Cultural material: } & \multicolumn{2}{l|}{ No obvious cultural material was observed. } \\
\hline \multicolumn{2}{|l|}{ Comments: } & $\begin{array}{l}\text { Both of the gravels in this trench contained a significant clay component that presumably is } \\
\text { post-depositional. }\end{array}$ \\
\hline Zone & Horizon & Depth (cm) & \multicolumn{1}{c|}{ Description } \\
\hline 1 & A & $0-38$ & $\begin{array}{l}\text { Very dark gray (10YR 3/1, moist) silty clay, friable, moderate coarse } \\
\text { subangular blocky structure parting to moderate very coarse granular structure, } \\
\text { clear smooth boundary. }\end{array}$ \\
\hline 3 & AB & $38-72$ & $\begin{array}{l}\text { Dark grayish brown (10YR 4/2, moist) clay, friable to firm, moderate coarse } \\
\text { subangular blocky structure parting to moderate very coarse granular structure, } \\
\text { gradual smooth boundary. }\end{array}$ \\
\hline 4 & Bk & $117-155$ & $\begin{array}{l}\text { Brown (10YR 4/3, moist) silty clay to clay, firm, moderate medium angular } \\
\text { blocky structure, clear smooth boundary, 1\% calcium carbonate filaments. }\end{array}$ \\
\hline 5 & C & $155-210$ & $\begin{array}{l}\text { Brown (7.5YR 4.5/5, moist) slightly gravelly silty clay loam, friable, weak to } \\
\text { moderate medium subangular blocky structure, abrupt smooth boundary, 5-7\% } \\
\text { coarse fragments, 1-3\% calcium carbonate filaments, few medium irregular } \\
\text { (popcorn like hollow) calcium carbonate nodules. }\end{array}$ \\
\hline 6 & C & $210-225$ & $\begin{array}{l}\text { Brown (7.5YR 4/4, moist) gravelly to extremely gravelly sand to sandy clay } \\
\text { loam, friable, single grained, abrupt smooth boundary, 40-80\% coarse } \\
\text { fragments, some vague hints of stratification. }\end{array}$ \\
\hline 7 & C & $\begin{array}{l}\text { Brown (7.5YR 4/4, moist) slightly gravelly silty clay loam, firm, massive } \\
\text { structure, abrupt smoth boundary, 3-5\% coarse fragments. }\end{array}$ \\
\hline & $225-265$ & $\begin{array}{l}\text { Brown (7.5YR 4/4, moist) gravelly to extremely gravelly sandy clay loam, } \\
\text { friable, massive, 40-80\% coarse fragments, no obvious sedimentary structures. }\end{array}$ \\
\hline
\end{tabular}




\section{Trench 7}

\begin{tabular}{|c|c|c|c|}
\hline \multicolumn{3}{|c|}{ Geologic Units: } & $\begin{array}{l}\text { Unit } 3 \text { of Abbott (this volume), Early to Middle Holocene alluvium. Base of the trench } \\
\text { is channel facies and the upper } 1.5 \mathrm{~m} \text { is overbank facies. }\end{array}$ \\
\hline \multicolumn{3}{|c|}{ Cultural material: } & No cultural material was observed. \\
\hline \multicolumn{2}{|c|}{ Comments: } & & None. \\
\hline Zone & Horizon & Depth (cm) & Description \\
\hline 1 & A & $0-29$ & $\begin{array}{l}\text { Black (10YR } 2 / 1 \text {, moist) clay loam to loam, friable, strong coarse subangular } \\
\text { blocky structure parting to medium moderate granular structure, clear smooth } \\
\text { boundary. }\end{array}$ \\
\hline 2 & $\mathrm{AB}$ & $29-48$ & $\begin{array}{l}\text { Dark grayish brown - brown (10YR } 4 / 2.5 \text {, moist) slightly gravelly loam, very } \\
\text { friable, moderate coarse subangular blocky structure, clear smooth boundary, } \\
1 \% \text { coarse fragments, } 1-2 \% \text { calcium carbonate filaments. }\end{array}$ \\
\hline 3 & Bk1 & $48-90$ & $\begin{array}{l}\text { Dark yellowish brown (10YR } 4 / 4 \text {, moist) slightly gravelly loam, friable, } \\
\text { moderate, medium to coarse angular blocky structure, clear smooth boundary, } \\
1 \% \text { coarse fragments, } 3-7 \% \text { calcium carbonate filaments. }\end{array}$ \\
\hline 4 & Bk2 & $90-121$ & $\begin{array}{l}\text { Brown ( } 7.5 \text { YR } 4 / 3 \text {, moist) slightly gravelly loam, very friable, weak medium } \\
\text { subangular blocky structure, clear smooth boundary, } 1-2 \% \text { coarse fragments, } \\
1-3 \% \text { calcium carbonate filaments. }\end{array}$ \\
\hline 5 & $\mathrm{C}$ & $121-136$ & $\begin{array}{l}\text { Brown ( } 7.5 \text { YR } 4 / 3 \text {, moist) silty clay loam, friable to firm, strong, medium to } \\
\text { coarse angular blocky structure, abrupt smooth boundary. }\end{array}$ \\
\hline 6 & $\mathrm{C}$ & $136-152$ & $\begin{array}{l}\text { Brown ( } 7.5 \text { YR } 4 / 4 \text {, moist) very gravelly silty clay loam, friable to firm, strong } \\
\text { very coarse angular blocky structure, abrupt smooth boundary. }\end{array}$ \\
\hline 7 & $\mathrm{C}$ & $152-190$ & $\begin{array}{l}\text { Brown ( } 7.5 \text { YR } 4 / 3 \text {, moist) silty clay to clay, friable, strong medium subangular } \\
\text { blocky structure, abrupt smooth boundary. }\end{array}$ \\
\hline 8 & $\mathrm{C}$ & $190-220$ & $\begin{array}{l}\text { Dark yellowish brown (10YR } 4 / 4 \text {, moist) extremely gravelly sandy clay, } \\
\text { friable, massive, } 1-2 \% \text { calcium carbonate filaments, } \sim 90 \% \text { coarse fragments. }\end{array}$ \\
\hline
\end{tabular}




\section{Trench 8}

\begin{tabular}{|c|c|c|c|}
\hline \multicolumn{2}{|c|}{ Geologic Units: } & \multicolumn{2}{|c|}{$\begin{array}{l}\text { Unit } 3 \text { of Abbott (this volume), Early to Middle Holocene alluvium. Primarily overbank } \\
\text { facies. }\end{array}$} \\
\hline \multicolumn{2}{|c|}{ Cultural material: } & \multicolumn{2}{|c|}{ None observed. } \\
\hline \multicolumn{2}{|c|}{ Comments: } & \multirow{2}{*}{\begin{tabular}{c|c} 
& None. \\
Depth (cm)
\end{tabular}} & \\
\hline Zone & Horizon & & Description \\
\hline 1 & $\mathrm{C}$ & $0-3$ & $\begin{array}{l}\text { Yellow (10YR 7/7, dry) silt loam, hard, moderate very coarse crumb structure, } \\
\text { abrupt smooth boundary, numerous worm casts of zone } 2 \text { material, colluvium. }\end{array}$ \\
\hline 2 & $2 \mathrm{Ab}$ & $3-40$ & $\begin{array}{l}\text { Black (10YR 2/1, moist) clay, firm, moderate coarse subangular blocky } \\
\text { structure parting to strong medium to coarse granular structure, gradual } \\
\text { smooth boundary. }\end{array}$ \\
\hline 3 & $2 \mathrm{ABb}$ & $40-63$ & $\begin{array}{l}\text { Very dark grayish brown (10YR } 3 / 2 \text {, moist) silty clay, friable, moderate to } \\
\text { strong medium angular blocky structure, gradual smooth boundary. }\end{array}$ \\
\hline 4 & $2 \mathrm{Bwb}$ & $63-95$ & $\begin{array}{l}\text { Brown (10YR } 4 / 3 \text {, moist) silty clay loam, friable to firm, moderate medium to } \\
\text { fine subangular blocky structure, clear smooth boundary, few patchy pressure } \\
\text { faces. }\end{array}$ \\
\hline 5 & $2 \mathrm{Bk} 1 \mathrm{~b}$ & $95-170$ & $\begin{array}{l}\text { Dark yellowish brown (10YR } 4 / 4 \text {, moist) silty clay loam, friable, strong } \\
\text { medium to fine angular blocky structure, abrupt smooth boundary, few } \\
\text { medium irregular (hollow popcorn-like) calcium carbonate nodules, } 3-5 \% \\
\text { calcium carbonate filaments. }\end{array}$ \\
\hline 6 & $2 \mathrm{Bk} 2 \mathrm{~b}$ & $170-210$ & $\begin{array}{l}\text { Yellowish brown (10YR 5/6, moist) sandy clay loam, friable, strong medium } \\
\text { angular blocky structure, abrupt smooth boundary, 3-5\% calcium carbonate } \\
\text { filaments, few discontinuous strong brown ( } 7.5 \text { YR } 4 / 6) \text { clay/carbonate coats } \\
\text { on ped faces. }\end{array}$ \\
\hline 7 & $2 \mathrm{C}$ & $210-220$ & $\begin{array}{l}\text { Strong brown ( } 7.5 \text { YR 5/6, moist) gravelly clay, firm, massive, abrupt smooth } \\
\text { boundary, few pressure faces. }\end{array}$ \\
\hline 8 & $2 \mathrm{C}$ & $220-240$ & $\begin{array}{l}\text { Strong brown ( } 7.5 \text { YR } 4 / 6 \text {, moist) sandy clay loam, very friable, weak coarse } \\
\text { angular blocky structure, abrupt smooth boundary, few to common thin } \\
\text { discontinuous brown }(7.5 \text { YR } 4 / 4) \text { clay coats on ped faces }\end{array}$ \\
\hline 9 & $2 \mathrm{C}$ & $240-280+$ & $\begin{array}{l}\text { Strong brown ( } 7.5 \text { YR } 5 / 6 \text {, moist) gravelly clay, firm, massive, abrupt smooth } \\
\text { boundary, few pressure faces. }\end{array}$ \\
\hline
\end{tabular}

\section{Trench 9}

\begin{tabular}{|c|c|l|l|}
\hline \multicolumn{2}{|l|}{ Geologic Units: } & $\begin{array}{l}\text { Unit } 3 \text { of Abbott (this volume), Early to Middle Holocene alluvium. Primarily distal } \\
\text { overbank facies in the top meter and channel facies or near channel overbank facies at } \\
\text { depth. }\end{array}$ \\
\hline \multicolumn{5}{|c|}{ Cultural material: } & None observed. \\
\hline Comments: & A & $0-38$ & $\begin{array}{l}\text { Black (10YR 2/1, moist) clay loam, friable, moderate coarse subangular blocky } \\
\text { structure parting to strong coarse granular structure, clear smooth boundary. }\end{array}$ \\
\hline 1 & AB & $38-68$ & $\begin{array}{l}\text { Very dark grayish brown (10YR 3/2, moist) clay loam, friable, moderate coarse } \\
\text { subangular blocky structure, gradual smooth boundary. }\end{array}$ \\
\hline 3 & Bw & $68-110$ & $\begin{array}{l}\text { Brown (7.5YR 4/3.5, moist) silty clay loam, firm to, moderate coarse prismatic } \\
\text { structure parting to moderate medium subangular blocky structure, clear } \\
\text { smooth boundary, 1\% calcium carbonate filaments. }\end{array}$ \\
\hline 4 & Bk & $110-133$ & $\begin{array}{l}\text { Brown (7.5YR 4/4, moist) slightly gravelly silty clay loam, strong medium } \\
\text { subangular blocky structure, abrupt smooth boundary, 5\% coarse fragments, 3- } \\
5 \% \text { calcium carbonate filaments, few medium irregular (hollow popcorn-like) } \\
\text { calcium carbonate nodules. }\end{array}$ \\
\hline 5 & $\mathrm{C}$ & $133-165$ & $\begin{array}{l}\text { Strong brown (7.5YR 5/6, moist) extremely gravelly clay loam, firm, massive, } \\
\sim 60 \% \text { coarse fragments, 1\% calcium carbonate filaments, few thin (1 mm) } \\
\text { pendant cements on gravel clasts. }\end{array}$ \\
\hline
\end{tabular}




\section{Trench 10}

\begin{tabular}{|c|c|c|l|}
\hline \multicolumn{2}{|l|}{ Geologic Units: } & \multicolumn{2}{l|}{ Unit 3 of Abbott (this volume), near channel overbank setting. } \\
\hline Cultural material: & $\begin{array}{l}\text { One prominent occupation at 24-27 cm, which appears to be associated with a burned } \\
\text { rock midden that was outside the right-of-way but about 30 m away, perched on the } \\
\text { cutbank overlooking the confluence of an unnamed tributary and the Guadalupe River. }\end{array}$ \\
\hline \multicolumn{2}{|l|}{ Comments: } & $\begin{array}{l}\text { In this trench the cultural material appears to be at a relatively discrete depth, which is } \\
\text { not the case at nearby Trench 15. }\end{array}$ \\
\hline Zone & Horizon & Depth (cm) & \multicolumn{1}{c|}{ Description } \\
\hline 1 & Ap & $0-15$ & $\begin{array}{l}\text { Very dark gray (10YR 3/1, moist) slightly gravely silt loam, extremely hard, } \\
\text { strong extremely coarse subangular blocky structure parting to strong medium } \\
\text { granular structure, clear smooth boundary, 3-10\% coarse fragments (rounded } \\
\text { limestone pea gravel (zone 1, Trench 11)), some glass, extremely hard and } \\
\text { probably compacted by construction and use of this area as a road. }\end{array}$ \\
\hline 3 & Bk1 & $15-30$ & $\begin{array}{l}\text { Very dark grayish brown (10YR 3/2, moist) loam, very friable, moderate } \\
\text { medium subangular blocky structure, clear smooth boundary, common worm } \\
\text { casts. }\end{array}$ \\
\hline 4 & Bk2 & $\begin{array}{l}\text { Yellowish brown (10YR 5/4, moist) sandy loam, very friable, weak to } \\
\text { moderate medium subangular blocky structure, clear smooth boundary, 5-7\% } \\
\text { calcium carbonate filaments inside peds, 30-40\% discontinuous calcium } \\
\text { carbonate coats on ped faces. }\end{array}$ \\
\hline 5 & Bk3 & $\begin{array}{l}\text { Light yellowish brown (10YR 6/4, dry) sandy loam, very friable, weak to } \\
\text { moderate subangular blocky structure, clear smooth boundary, 5-7\% calcium } \\
\text { carbonate filaments inside peds, 30-40\% discontinuous calcium carbonate } \\
\text { coats on ped faces. }\end{array}$ \\
\hline
\end{tabular}




\section{Trench 11}

\begin{tabular}{|c|c|c|c|}
\hline \multicolumn{2}{|c|}{ Geologic Units: } & \multicolumn{2}{|c|}{ Unit 3 of Abbott (this volume), primarily near channel overbank setting. } \\
\hline \multicolumn{2}{|c|}{ Cultural material: } & \multicolumn{2}{|c|}{ Very sparse cultural material at about $93 \mathrm{~cm}$. } \\
\hline \multicolumn{2}{|c|}{ Comments: } & \multicolumn{2}{|c|}{$\begin{array}{l}\text { Top of this section has been augmented by construction by addition of materials } \\
\text { (limestone pea gravel, top soil and fine caliche) and the compaction of these and pre- } \\
\text { existing deposits. Carbonate expression in this relatively coarse facies is very different } \\
\text { from finer textured units. }\end{array}$} \\
\hline Zone & Horizon & Depth (cm) & Description \\
\hline 1 & Ap & $0-7$ & $\begin{array}{l}\text { Limestone pea gravel, loose, single grain, abrupt smooth boundary, introduced } \\
\text { fill. }\end{array}$ \\
\hline 2 & Ap & $7-15$ & $\begin{array}{l}\text { Very dark gray (10YR } 3 / 1 \text {, moist) slightly gravely silty clay, extremely hard, } \\
\text { strong, coarse to medium angular blocky structure, abrupt smooth boundary, } \\
\text { introduced and artificially compacted fill. }\end{array}$ \\
\hline 3 & Ap & $15-20$ & $\begin{array}{l}\text { Pink ( } 7.5 \text { YR } 7 / 4, \text { moist) silt loam, extremely hard, strong fine angular blocky } \\
\text { structure, abrupt smooth boundary, } 1 \% \text { coarse fragments, few worm casts in } \\
\text { less dense areas, introduced fine caliche fill, artificially compacted. }\end{array}$ \\
\hline 4 & $2 \mathrm{Ap}$ & $20-39$ & $\begin{array}{l}\text { Very dark grayish brown (10YR } 3 / 2 \text {, moist) silty clay loam, firm, strong fine } \\
\text { angular blocky structure, abrupt smooth boundary, very dense; thee structure } \\
\text { appears to have been augmented by construction related compaction, and has } \\
\text { an almost spheroidal fracture. }\end{array}$ \\
\hline 5 & $2 \mathrm{~A}$ & $39-59$ & $\begin{array}{l}\text { Very dark grayish brown (10YR } 3 / 2 \text {, moist) loam, very friable, weak to } \\
\text { moderate medium subangular blocky structure parting to moderate medium } \\
\text { granular structure, gradual smooth boundary, numerous worm casts. }\end{array}$ \\
\hline 6 & 2Bk1 & $59-89$ & $\begin{array}{l}\text { Dark grayish brown-brown ( } 120 \mathrm{YR} 4 / 2.5 \text {, moist) loam to silt loam, very } \\
\text { friable, moderate coarse to medium subangular blocky structure, clear smooth } \\
\text { boundary, } 1-3 \% \text { calcium carbonate filaments, } 10 \% \text { faint discontinuous coats of } \\
\text { calcium carbonate on ped faces. }\end{array}$ \\
\hline 7 & 2Bk2 & $89-166$ & $\begin{array}{l}\text { Dark yellowish brown-yellowish brown (10YR } 4.5 / 4 \text {, moist) loam to silt loam, } \\
\text { very friable, weak to moderate medium to coarse subangular blocky structure, } \\
\text { clear smooth boundary, } 1-3 \% \text { calcium carbonate filaments, } 10 \% \text { faint } \\
\text { discontinuous coats of calcium carbonate on ped faces, one prehistoric } \\
\text { occupation near the top of this zone around } 93 \mathrm{~cm} \text {. }\end{array}$ \\
\hline 8 & $\mathrm{C}$ & $166-240$ & $\begin{array}{l}\text { Yellowish brown ( } 10 \text { YR } 5 / 4 \text {, moist) sandy loam, very friable, weak to } \\
\text { moderate medium to fine subangular blocky structure, abrupt smooth } \\
\text { boundary, } 1 \% \text { calcium carbonate filaments. }\end{array}$ \\
\hline 9 & $\mathrm{C}$ & $240-320$ & $\begin{array}{l}\text { Brown ( } 7.5 \mathrm{YR} 4 / 3 \text {, moist) silt loam, very friable, moderate medium } \\
\text { subangular blocky structure, } 1 \% \text { calcium carbonate filaments. }\end{array}$ \\
\hline
\end{tabular}




\section{Trench 12}

\begin{tabular}{|c|c|c|l|}
\hline \multicolumn{2}{|l|}{ Geologic Units: } & \multicolumn{2}{l|}{ Unit 3 of Abbott (this volume), distal overbank setting. } \\
\hline \multicolumn{2}{|l|}{ Cultural material: } & $\begin{array}{l}\text { There was a sparse scatter of cultural material on the surface of the plowed field but none } \\
\text { was observed in the trench profile. }\end{array}$ \\
\hline Comments: & \multicolumn{1}{l|}{ None. } \\
\hline Zone & Horizon & Depth (cm) & \multicolumn{1}{c|}{ Description } \\
\hline 1 & Ap & $0-16$ & $\begin{array}{l}\text { Very dark grayish brown (10YR 3/2, moist) slightly gravely silty clay, friable, } \\
\text { weak coarse subangular blocky structure, clear smooth boundary, 1-3\% coarse } \\
\text { fragments. }\end{array}$ \\
\hline 3 & A & $16-36$ & $\begin{array}{l}\text { Dark grayish brown (10YR 4/2, moist) slightly gravely silty clay, friable, } \\
\text { strong medium too fine subangular blocky structure parting to strong fine } \\
\text { granular structure, diffuse smooth boundary, 3\% coarse fragments. }\end{array}$ \\
\hline 4 & Bk1 & $105-140$ & $\begin{array}{l}\text { Dark grayish brown to brown (10YR 4/2.5, moist) slightly gravely silty clay to } \\
\text { clay, firm, strong, medium to fine angular blocky structure, gradual smooth } \\
\text { boundary, 1-3\% coarse fragments. }\end{array}$ \\
\hline 5 & Bk2 & $\begin{array}{l}\text { Brown (7.5YR 4/3, moist) clay, firm, strong medium prismatic structure } \\
\text { parting to strong fine angular blocky structure, clear smooth boundary, 3\% } \\
\text { coarse fragments, few medium irregular (hollow popcorn-like) calcium } \\
\text { carbonate nodules situated on ped faces, 3-5\% calcium carbonate filaments. }\end{array}$ \\
\hline & $140-175$ & $\begin{array}{l}\text { Brown (7.5YR 5/4, moist) silty clay, firm, strong fine prismatic structure, few } \\
\text { medium to coarse irregular (hollow popcorn-like) calcium carbonate nodules, } \\
5-7 \% \text { discontinuous thin coats of calcium carbonate on ped faces blurred by } \\
\text { pressure faces, 3\% coarse fragments. }\end{array}$ \\
\hline
\end{tabular}

\section{Trench 13}

\begin{tabular}{|c|c|c|l|l|}
\hline \multicolumn{2}{|l|}{ Geologic Units: } & \multicolumn{2}{l|}{ Unit 3 of Abbott (this volume), distal overbank setting. } \\
\hline \multicolumn{2}{|l|}{ Cultural material: } & \multicolumn{2}{l|}{ None observed. } \\
\hline Comments: & None. \\
\hline Zone & Horizon & Depth (cm) & Description \\
\hline 1 & Ap & $0-16$ & $\begin{array}{l}\text { Very dark grayish brown (10YR 3/2, moist) silty clay loam, friable, weak to } \\
\text { moderate medium subangular blocky structure, abrupt smooth boundary, 3\% } \\
\text { coarse fragments. }\end{array}$ \\
\hline 2 & A & $16-36$ & $\begin{array}{l}\text { Black (10YR 2/1, moist) silty clay loam, friable, strong fine subangular blocky } \\
\text { structure parting to strong medium granular structure, clear smooth boundary, } \\
\text { 3\% coarse fragments. }\end{array}$ \\
\hline 3 & Bw & $36-93$ & $\begin{array}{l}\text { Dark grayish brown-brown (10YR 4/2.5, moist) clay, firm, moderate medium } \\
\text { prismatic parting to moderate medium to fine angular blocky structure, clear } \\
\text { smooth boundary, 3-5\% coarse fragments, 3\% calcium carbonate filaments. }\end{array}$ \\
\hline 5 & Bk1 & $93-118$ & $\begin{array}{l}\text { Brown (10YR 4/3, moist) slightly gravely clay, firm to extremely firm, strong } \\
\text { medium prismatic parting to strong fine to medium angular blocky structure, } \\
\text { clear smooth boundary, 1\% coarse fragments, 1-3\% calcium carbonate } \\
\text { filaments inside peds, few thin discontinuous carbonate films on ped faces, } \\
\text { few medium irregular (hollow, popcorn-like) calcium carbonate nodules. }\end{array}$ \\
\hline 5 & Bk2 & $118-160$ & $\begin{array}{l}\text { Brown (10YR 4/3, moist) slightly gravely clay, firm, strong medium prismatic } \\
\text { parting to strong fine angular blocky structure. 1\% calcium carbonate } \\
\text { filaments, few thin discontinuous carbonate films on ped faces, few medium } \\
\text { irregular (hollow, popcorn-like) calcium carbonate nodules. }\end{array}$ \\
\hline
\end{tabular}




\section{Trench 14}

\begin{tabular}{|c|c|c|c|}
\hline \multicolumn{3}{|c|}{ Geologic Units: } & Unit 3 of Abbott (this volume), distal overbank setting \\
\hline \multicolumn{3}{|c|}{ Cultural material: } & None observed. \\
\hline \multicolumn{2}{|c|}{ Comments: } & None & \\
\hline Zone & Horizon & Depth (cm) & Description \\
\hline 1 & Ap & $0-15$ & $\begin{array}{l}\text { Very dark brown (10YR } 2 / 22 \text {, moist) silty clay loam, friable, weak extremely } \\
\text { coarse subangular blocky structure, abrupt smooth boundary, } 1 \% \text { coarse } \\
\text { fragments. }\end{array}$ \\
\hline 2 & A & $15-44$ & $\begin{array}{l}\text { Very dark grayish brown (10YR } 3 / 2 \text {, moist) clay, friable, strong medium } \\
\text { subangular blocky structure parting to strong medium to fine granular } \\
\text { structure, gradual smooth boundary, } 1 \% \text { coarse fragments (granule size } \\
\text { material). }\end{array}$ \\
\hline 3 & $\mathrm{AB}$ & $44-65$ & $\begin{array}{l}\text { Brown ( } 7.5 \text { YR } 4 / 2 \text {, moist) silty clay loam, friable, strong coarse subangular } \\
\text { blocky structure, parting to strong coarse granular structure, clear smooth } \\
\text { boundary. }\end{array}$ \\
\hline 4 & Bk1 & $65-76$ & $\begin{array}{l}\text { Brown ( } 7.5 \mathrm{YR} 4 / 3 \text {, moist) gravelly to very gravelly silt loam, friable, } \\
\text { moderate medium subangular blocky structure, clear smooth boundary, } 5-7 \% \\
\text { calcium carbonate filaments, } 30-40 \% \text { coarse fragments (poorly sorted gravel). }\end{array}$ \\
\hline 5 & Bk2 & 76-102 & $\begin{array}{l}\text { Brown ( } 7.5 \text { YR } 4 / 3 \text {, moist) silty clay loam, friable, moderate medium to coarse } \\
\text { subangular blocky structure, clear smooth boundary, } 5-7 \% \text { calcium carbonate } \\
\text { filaments. }\end{array}$ \\
\hline 6 & $\mathrm{Bk} 3$ & $102-150$ & $\begin{array}{l}\text { Brown ( } 7.5 \text { YR } 4 / 3 \text {, moist) clay, friable to firm, strong medium to fine angular } \\
\text { blocky structure, } 3 \% \text { calcium carbonate filaments, few medium irregular } \\
\text { (hollow, popcorn-like) calcium carbonate nodules. }\end{array}$ \\
\hline
\end{tabular}

\section{Trench 15}

\begin{tabular}{|c|c|c|c|}
\hline \multicolumn{3}{|c|}{ Geologic Units: } & Unit 3 of Abbott (this volume), near channel overbank setting \\
\hline Cultur & material: & Cultu & al material (burned rock and lithic debitage) scattered between 27 and $55 \mathrm{~cm}$. \\
\hline \multicolumn{2}{|c|}{ Comments: } & & None. \\
\hline Zone & Horizon & Depth (cm) & Description \\
\hline 1 & $\mathrm{C}$ & $0-27$ & Recent construction fill, not described in detail \\
\hline 2 & $\mathrm{Ab}$ & $27-49$ & $\begin{array}{l}\text { Brown ( } 10 \mathrm{YR} 4 / 3 \text {, moist) loamy sand, weak coarse subangular blocky } \\
\text { structure, clear smooth boundary. }\end{array}$ \\
\hline 3 & $\mathrm{ABb}$ & $49-68$ & $\begin{array}{l}\text { Yellowish brown (10YR 5/4, moist) sandy loam, weak medium to coarse } \\
\text { subangular blocky structure, clear smooth boundary, } 5-7 \% \text { calcium carbonate } \\
\text { filaments, common excrement pedofeatures (mostly worms and ants). }\end{array}$ \\
\hline 4 & $\mathrm{Bk}$ & $68-145$ & $\begin{array}{l}\text { Yellowish brown (10YR 5/4, moist) slightly gravelly sandy loam, very friable, } \\
\text { weak coarse subangular blocky structure, 5-7\& calcium carbonate filaments, } \\
\text { few dispersed and discontinuous fine gravel stringers. }\end{array}$ \\
\hline
\end{tabular}

\section{Trench 16}

\begin{tabular}{|c|c|l|l|}
\hline \multicolumn{2}{|l|}{ Geologic Units: } & \multicolumn{2}{l|}{ Unit 3 of Abbott (this volume), distal overbank setting } \\
\hline \multicolumn{3}{|l|}{ Cultural material: } & \multicolumn{2}{l|}{ None observed. } \\
\hline Comments: & \multicolumn{1}{|c|}{ None. } \\
\hline Zone & Horizon & Depth (cm) & \multicolumn{1}{c|}{ Description } \\
\hline 1 & Ap & $0-25$ & $\begin{array}{l}\text { Black (10YR 2/1, moist), clay loam, friable, weak very coarse subangular } \\
\text { blocky structure, clear smooth boundary. }\end{array}$ \\
\hline 2 & AB & $25-43$ & $\begin{array}{l}\text { Brown (7.5YR 4/2, moist) clay, firm to friable, moderate medium subangular } \\
\text { blocky structure, clear smooth boundary. }\end{array}$ \\
\hline 3 & Bk & $43-97$ & $\begin{array}{l}\text { Brown (7.5YR 4/4, moist) slightly gravelly clay loam, firm, weak to moderate } \\
\text { coarse subangular blocky structure, abrupt smooth boundary, 7-10\% coarse } \\
\text { fragments, 3-5\% calcium carbonate filaments. }\end{array}$ \\
\hline 4 & C & $97-120$ & Coarse limestone gravel, single grain. \\
\hline
\end{tabular}




\section{Trench 17}

\begin{tabular}{|c|c|c|l|}
\hline \multicolumn{2}{|l|}{ Geologic Units: } & \multicolumn{2}{l|}{ Unit 2 of Abbott (this volume). } \\
\hline \multicolumn{2}{|l|}{ Cultural material: } & \multicolumn{2}{|l|}{ None observed. } \\
\hline \multicolumn{2}{|c|}{ Comments: } & \multicolumn{1}{c|}{ This soil has prominent vertic tendencies. } \\
\hline Zone & Horizon & Depth (cm) & \multicolumn{1}{c|}{ Description } \\
\hline 1 & Ap & $0-21$ & $\begin{array}{l}\text { Very dark brown (10YR 2/2, moist) slightly gravelly clay, friable, weak very } \\
\text { coarse subangular blocky structure parting to moderate very fine granular } \\
\text { structure, abrupt smooth boundary. }\end{array}$ \\
\hline 2 & Bsst1 & $21-86$ & $\begin{array}{l}\text { Very dark brown (7.5YR 2.5/3, moist) slightly gravelly clay, friable, strong } \\
\text { medium subangular blocky structure parting to strong medium granular } \\
\text { structure, clear smooth boundary, few slickensides, few 1-2 cm wide tongues } \\
\text { of zone 1 (cracks filled with zone 1 material). }\end{array}$ \\
\hline 3 & Bsst2 & $86-190$ & $\begin{array}{l}\text { Dark brown (7.5YR 3/4, moist) clay, friable, strong fine to medium wedge } \\
\text { structure, abrupt smooth boundary, few 1-2 cm wide tongues of zone 1 (cracks } \\
\text { filled with zone 1 material), common discontinuous coats of calcium } \\
\text { carbonate on some ped faces, common slickensides. }\end{array}$ \\
\hline 4 & Bk & $190-210$ & $\begin{array}{l}\text { Yellowish red (5YR 5/6, moist) silt loam, very friable, weak fine subangular } \\
\text { blocky structure, abundant finely disseminated calcium carbonate, few coarse } \\
\text { to very coarse calcium carbonate nodules. }\end{array}$ \\
\hline
\end{tabular}




\section{APPENDIX C}

\section{TECHNOLOGY}

ERIC R. OKSANEN, THOMAS R. HESTER, HARRY J. SHAFER, AND MERCEDES CODY SWCA ENVIRONMENTAL CONSULTANTS 



\section{Appendix C}

\section{Technology}

Eric R. Oksanen, Thomas R. Hester, Harry J. Shafer, and Mercedes C. Cody

\section{INTRODUCTION}

Technology is a subsystem of culture and is the physical expression of the interaction between humans and the physical world. At the Gatlin site, the lithic assemblage is the best preserved record of the technological organization of the site's various inhabitants. The nature and composition of the lithic assemblage is directly related to environmental adaptation and subsistence practices. The assemblages from stratified and temporally isolated Occupation Zones allow for the analysis of diachronic changes in site use and function and inferences about group size, mobility, subsistence practices, and social organization and affiliation.

The lithic assemblage consists of two major categories - portable lithics, such as chipped stone tools, and the non-portable items, namely hot rock features. This appendix examines the manufacturing technology of the portable lithic tool assemblage, referred to as lithic artifacts, and the types and traits of the non-portable features.

\section{Lithic Artifacts}

The testing and data recovery excavations at the Gatlin site recovered more than 150,000 lithic stone artifacts. Faced with the challenge of investigating this large lithic assemblage, a system was devised to categorize and analyze the artifacts in a consistent and efficient manner. This appendix discusses the methods employed in analyzing the Gatlin lithic artifact assemblage and presents an introduction to the lithic materials inventory recorded and/or recovered from the site. The complete artifact assemblage from the Gatlin site has been divided into categories and sub-categories reflecting the various artifact types and manufacturing technologies. Within the categories and sub-categories, the assemblage is further defined by characteristics reflecting specific nominal and metrical attributes of artifacts in each class. At the broadest level, the assemblage is divided into three primary categories: chipped stone tools, lithic debitage, and non-chipped stone tools. The chipped stone tool assemblage includes the sub-categories of projectile points, bifaces, modified flakes and unifaces, and cores, while the assemblage of non-chipped stone tools consists of groundstone and battered stone. The data gathered through these analytical methods has helped to establish a quantitative and qualitative data set that will be used to address broader issues such as duration of site use, technological organization, and investigation of site taphonomy.

The detailed analysis of the cultural and organic materials recovered during the testing and data recovery investigations was combined with the results of the data recovery excavations. For intrasite comparisons, artifacts from the testing phase have been grouped together with the data recovery materials corresponding to the approximate Area of their provenience, as follows:

Area A-SE: includes material from Gradall scraping and data recovery units.

Area A-NW: includes material from testing units (TUs 4-A-D), Gradall scraping, trench column samples (CT1, CS3-4; CT2, CS3), and data recovery units.

Area A-NE: includes material from TU 3-A, Gradall scraping, trench column samples (CT2, CS1-2), and data recovery units.

Area A-SW: includes material from Gradall scraping, trench column samples (CT1, CS1-2), and data recovery units.

Area B: includes material from TU 1-C, trench backdirt, Gradall scraping, and data recovery units (including N 1022 E 1030).

Midden: includes material from TUs (1-A-B, 18A-B), BHTs $(1,18$, CT3), and column samples (BHT1, CS1-3; BHT18, CS1-3; CT3, CS1-3).

Feature Focused units resulted in skewed artifact counts, since artifacts were not systematically and uniformly collected and matrix was not screened. 
Comparisons between Areas and Occupation Zones using debitage were made using data only from levels excavated by Traditional methods. The artifact discussions and totals below, however, incorporate all of the recovered artifacts.

Artifacts have been grouped according to Occupation Zones based on the unit/levels in which they were found. The four temporal zones are also linked to particular excavated areas of the site. OZ1 is the lower Early Archaic; OZ2 is the upper Early Archaic; OZ3 is the mixed Early Archaic and Middle Archaic; and OZ4 contains the Middle Archaic, the mixed Middle and Late Archaic, and mixed Late Archaic deposits.

This appendix describes the technological traits of the artifact assemblage as a whole. The study of the Gatlin site's projectile points, which includes the typology, chronology, technology, and comparative data, was written by Dr. Thomas Hester and Dr. Harry Shafer. Included with each type are summaries of any use-wear analysis.

\section{USE-WEAR ANALYSIS}

The association of lithic technology to cultural practices is in most instances inferential. Few projectile points are found in situ with prey species and little is known about the perishable tool assemblages of wood and other plant products. Use-wear analysis of the stone tool assemblage can detect the presence of woodworking, hide scraping and butchering activities. The presence of hafting suggests a more formalized and specialized tool form.

In the analysis of the Gatlin site's stone tool assemblage, low powered microscopy was used to examine selected stone tools for use-wear patterns, animal hairs, or plant fibers. For this analysis, SWCA contracted Dr. Matthew J. Root of Rain Shadow Research Inc., a qualified, use-wear specialist, to examine a select sample of 125 stone tools (Appendix D). These were selected by SWCA archaeologists based on their context, their ability to represent a typological group, and visible use-wear. This sample is not a representative sample of the overall artifact assemblage and was not intended to be a random sample.

\section{Chipped Stone Tools}

Individual attributes data for lithic tools, lithic cores, and groundstone/manuports is presented in Appendix E, consisting of E.1 through E.7.

\section{Projectile Points}

A total of 409 projectile points was recovered during testing and data recovery excavations, including diagnostic types associated with the Early Archaic through the Late Prehistoric period. The overwhelming majority of the diagnostic projectile points are associated with the Early Archaic period, with the rest divided primarily between Middle Archaic and Late Archaic types. Several of the projectile point types from the Early Archaic and Middle Archaic were represented by enough specimens to undergo a valid statistical analysis. Because of suspected stratigraphic mixing and smaller sample sizes, the Later Archaic types and single Late Prehistoric point were not subjected to detailed metrical analysis because these were recovered from demonstrably disturbed contexts and the emphasis of the Because of the variety and number of specimens, the Gatlin site's point assemblage provided an excellent opportunity to study inter- and intra-assemblage projectile point variation.

Next to bifaces, projectile points are the most numerous of the formal tool categories at the Gatlin site. In Table 1 the projectile point types are presented according to their association with Occupation Zones.

\section{RECORDED ATtRIBUTES}

Dr. Thomas R. Hester and Dr. Harry J. Shafer, leading experts in Central and South Texas projectile point typologies, performed the primary analysis of the projectile points and point fragments. Following this, an SWCA analyst refined certain attributions based on stratigraphic evidence not available to Drs. Hester and Shafer at the time of their analyses.

Following typological designations, nominal (qualitative) and metrical (quantitative) attributes were recorded for each point specimen and entered into a database. Recorded nominal attributes included information such as cortex, raw material type, color, patination, evidence of heat treatment, breakage, beveling, and reworking. Metrical attributes recorded 
Table 1. Projectiles Point Types by Occupation Zone

\begin{tabular}{|c|c|c|c|c|c|c|}
\hline & \multicolumn{4}{|c|}{$\begin{array}{c}\text { Occupation } \\
\text { Zone }\end{array}$} & \multirow[t]{2}{*}{ Unk } & \multirow[t]{2}{*}{ Total } \\
\hline & 1 & 2 & 3 & 4 & & \\
\hline Andice & & 1 & 5 & 3 & & 9 \\
\hline Baker & & 1 & & & & 1 \\
\hline Bandy & & 5 & 3 & & & 8 \\
\hline Bell & & 2 & 4 & 1 & & 7 \\
\hline Big Sandy & & & & 1 & & 1 \\
\hline Bulverde & & & 3 & 7 & 1 & 11 \\
\hline Castroville & & & & & 2 & 2 \\
\hline Early Barbed Devils Variant & 2 & & & & & 2 \\
\hline Early Triangular & & 10 & 38 & 7 & 6 & 61 \\
\hline Ensor & & & & 1 & & 1 \\
\hline Fairland & & & & 1 & & 1 \\
\hline Frio & & & & 3 & 1 & 4 \\
\hline Gower & 1 & 21 & 5 & 2 & 5 & 34 \\
\hline Kinney & & & & 2 & & 2 \\
\hline La Jita & & & 8 & 23 & 13 & 44 \\
\hline Lange & & & 2 & 3 & & 5 \\
\hline Langtry & & & 1 & 5 & & 6 \\
\hline Marcos & & 1 & & 2 & & 3 \\
\hline Marshall & & & 1 & 4 & 3 & 8 \\
\hline Martindale & 1 & 34 & 13 & 1 & 5 & 54 \\
\hline Martindale-Narrow Stem & & 3 & 1 & 2 & 1 & 7 \\
\hline Montell & & & 1 & 4 & 1 & 6 \\
\hline Nolan & & & 12 & 13 & 3 & 28 \\
\hline Pandale & 1 & & 1 & & 1 & 3 \\
\hline Pedernales & & & 1 & 21 & 7 & 29 \\
\hline Tortugas & & & 2 & & & 2 \\
\hline Travis & & & & 1 & 2 & 3 \\
\hline Untypable & 1 & 10 & 14 & 37 & 5 & 67 \\
\hline Total & 6 & 88 & 115 & 144 & 56 & 409 \\
\hline
\end{tabular}

for each specimen were similar to those measured by Hudler (1996), including variables such as blade and stem dimensions (length, width, thickness, weight), haft length, base depth, base width, and neck width.

During the sorting, it was noted whether a particular specimen was a preform or not, whether it was complete or not, and, if not, how it was broken. Numerous specimens in certain categories (such as Early Triangular) were also examined for evidence of use-wear with a 10X power hand lens. Comments were made regarding technological nuances such as fine pressure thinning or retouch, edge twisting, edge beveling, blade retouch, stem grinding, and burning. These observations were synthesized in the narrative descriptions of each type, and additional details on each specimen within a type are found in Appendix E.1.

\section{Introduction to Projectile Points Results}

A total of 409 artifacts classified as projectile points or projectile point fragments was recovered from the Gatlin site during testing and data recovery. One objective of the Gatlin site's research design (see Chapter 5) was to refine the cultural chronology for the upper Guadalupe River valley. The large projectile point sample offers an excellent opportunity to examine the stylistic patterns and variability among established point types and to correlate these (along with other formal tools) with geomorphological and paleoenvironmental frameworks. A desirable outcome of this exercise is to identify projectile point types or stylistic attributes that may be used as chronological markers and cross-dating tools.

Projectile points represent one tool type that may prove to be sensitive to ecological and paleoenvironmental changes. For example, adjustments in blade technology from narrow blades such as seen on Gower to broad, thin razor-sharp blades on Martindale may be reflecting what was hunted as well as the hunting/butchering patterns of the hunters. Attention will be given to technological style (Lechtman 1977; Shafer 2005a) that might be reflected in the manner of thinning and retouching of blades.

An 11,000-year broad regional chronology has been established for Central Texas and the southwestern Balcones Canyonlands (Collins 2004:113, Fig. 3.9a). This broadly applicable chronology is based on specific projectile point types. However, sub-regional temporal and spatial variation in projectile point technology and morphology has not been widely addressed (see Johnson [1995] and Tomka et al. [2003] for exceptions). Nevertheless, the use of the cultural-historical approach has been successful in 
establishing chronological schemes and effective relative dating markers throughout most of the state, especially the Central Texas, South Texas, and Lower Pecos regions (Hester 2004; Shafer 2005a).

Pre-industrial technologies were sensitive to ecological changes and adjusted to conform to changing ecological circumstances across a broad region and through time, circumstances that could, for example, occur with the ebb and flow of bison across the Southern Plains and Canyonlands. Ecological changes brought about by long-term xeric or mesic intervals may seem minor overall, but may indeed have resulted in technological adjustments and stylistic trends that left their mark in the material record, such as changes in projectile point styles.

A worthy objective of material culture studies is to attempt to identify sub-regional patterns that may either reflect subtle shifts in technological responses or shifts in geographic ranges of people or resources. Another focus of material culture studies is to attempt to identify technological styles that might identify ancient social patterns (Lechtman 1977; Shafer 2005b). A third objective is the identification of cultural patterns reflected in material assemblages that cross-cut different geographical regions. These are trans-regional and cultural-geographical in nature. The primary objective of this study at the Gatlin site, however, is to identify the typological groups and morphological and technological stylistic variability within and between the groups.

Typological sorting is based on the original ordering provided by Suhm et al. (1954) and Turner and Hester (1999). As Johnson (1995) recognized, current typologies are not necessarily fixed or standardized, but decisions are often made on the whims or biases (or years of experience) of the analyst. In sorting and analyzing the collection, Krieger's (1944) guidelines for formally identifying a type and Suhm, et al.'s (1954) application of Krieger's concept were firmly recognized. Suhm, et al. (1954) emphasized morphological attributes and did not consider technology and technological styles as factors in defining their types. Typology is but a mere analytical tool for ordering phenomena through time and space, and not all specimens, indeed, often not even the majority, will conform to the "norm" because of changes and modification in form and size during the course of use, retouch, and resharpening. Subtleties in blade technology (e.g., thinning by pressure flaking instead of punch or soft hammer) may prove to be either a regional phenomenon or a functional one. These kinds of attributes were given attention during the analysis. Variability in form, style, blade retouch, or base treatment can be expected, and therefore may lead to problematic circumstances as to which specific type is linked to a specific artifact. Overall technology, base and stem attributes, patterning in blade thinning and resharpening, were all taken into consideration when typological decisions were being made.

In accordance with the presentation of the Gatlin site's temporal components, the projectile point types will be discussed below in approximate chronological order from the earliest to the latest types. When points are greater than 90 percent complete, measurements were reconstructed.

\section{Projectile Point Descriptions}

\section{Late Paleoindian}

\section{Big Sandy (1 specimen)}

This typological label (Justice 1987:60ff) has been used for an unusual specimen from the Gatlin site. The artifact (Lot 1486.3) is a large well-made dart point, side-notched and with a concave basal edge (Figure 1). Its technology is very distinctive. It has a marked biconvex cross section (a "fat feel"), with parallel flaking on both faces. After it was deposited at the site, it developed a thick white patina. Later, it was "recycled," with new chipping at the tip and on the margin of one ear. The chipping revealed a light brown chert beneath the patina. Measurements on the Big Sandy specimen are represented in Table 2.

The specimen is clearly out of context, if it is indeed a Big Sandy point. Dial et al. (1998:Fig. 13-102) illustrate a proximal fragment, which they label as Big Sandy, almost identical to the Gatlin site specimen. Another specimen, distally reworked but with a similar stem, was found at Camp Bullis, Bexar County, and reported as "Big Sandy-like" (Gerstle et al. 1978:Fig. 15.1). While the type is included in the "Early Archaic" of the eastern United States (6000-8000 B.C.; Justice 1987:60ff), its temporal niche in Central Texas would fall within the Late Paleoindian era. 
The single Big Sandy point is a heavily patinated specimen that was scavenged millennia after its original discard and reworked by bifacial pressure flaking. The tip was probably snapped off during manufacture, a common occurrence. The extremely light-intensity abrasive wear suggests that the reworked blade was used to cut soft animal products, such as hide for a short time.

\section{Early Archaic}

\section{Bandy (8 specimens)}

Bandy is very closely linked technologically to Martindale but with some distinguishing attributes that set the two types apart. Bandy points are small, very thin, and have distinctively small stems (see McReynolds 1993). The relative size of Bandy stems is notably smaller than that of Martindale. All eight specimens collected during excavations at the Gatlin Site are illustrated in Figure 2. Some Bandy points also have the "fishtail" base like Martindale (e.g., Lot 607, Lot 299; Figure 2 e and g), although slightly indented bases are more frequent (e.g., Lot 279.1, Lot 505, and Lot 198; Figure $2 \mathrm{~b}$, d, and h). Barbs are rounded (e.g., Lot 607, Lot 299, Lot 505, and Lot 198) - almost Andice-like barbs rather than the sharp barbs on Martindale (Figure $2 \mathrm{~b}$, $\mathrm{d}$, e, and $\mathrm{g}$ ). Blades are thinned by fine pressure flaking, some of which is oblique. The thin, pressure-flaked blades may also be serrated (e.g., Lot 198 and Lot 662; Figure $2 \mathrm{~b}$ and $\mathrm{f}$ ), and tips are often needle-like. Measurements for the Bandy specimens are presented in Table 3.

Bandy points are consistently recovered from Early Archaic contexts. The initial recognition was at Baker Cave where the point was originally named (Hester 1978a; Word and Douglas 1970:Fig. 10). Bandy points also were recovered from dated contexts at Hinds Cave (Shafer and Bryant 1977). At Wilson-Leonard, Bandy points were recovered from stratigraphic contexts dating 6,500/6,000-4,000 B.P. (Dial et al. 1998:340-342). Recent reanalysis of the Hinds Cave point sequence places Bandy point securely in Early Archaic contexts dating from 8,900-4,100 B.P. Most were recovered from Analysis Unit 7, which is dated 5,500-4,000 B.P. (H. Shafer, personal communication 2005;

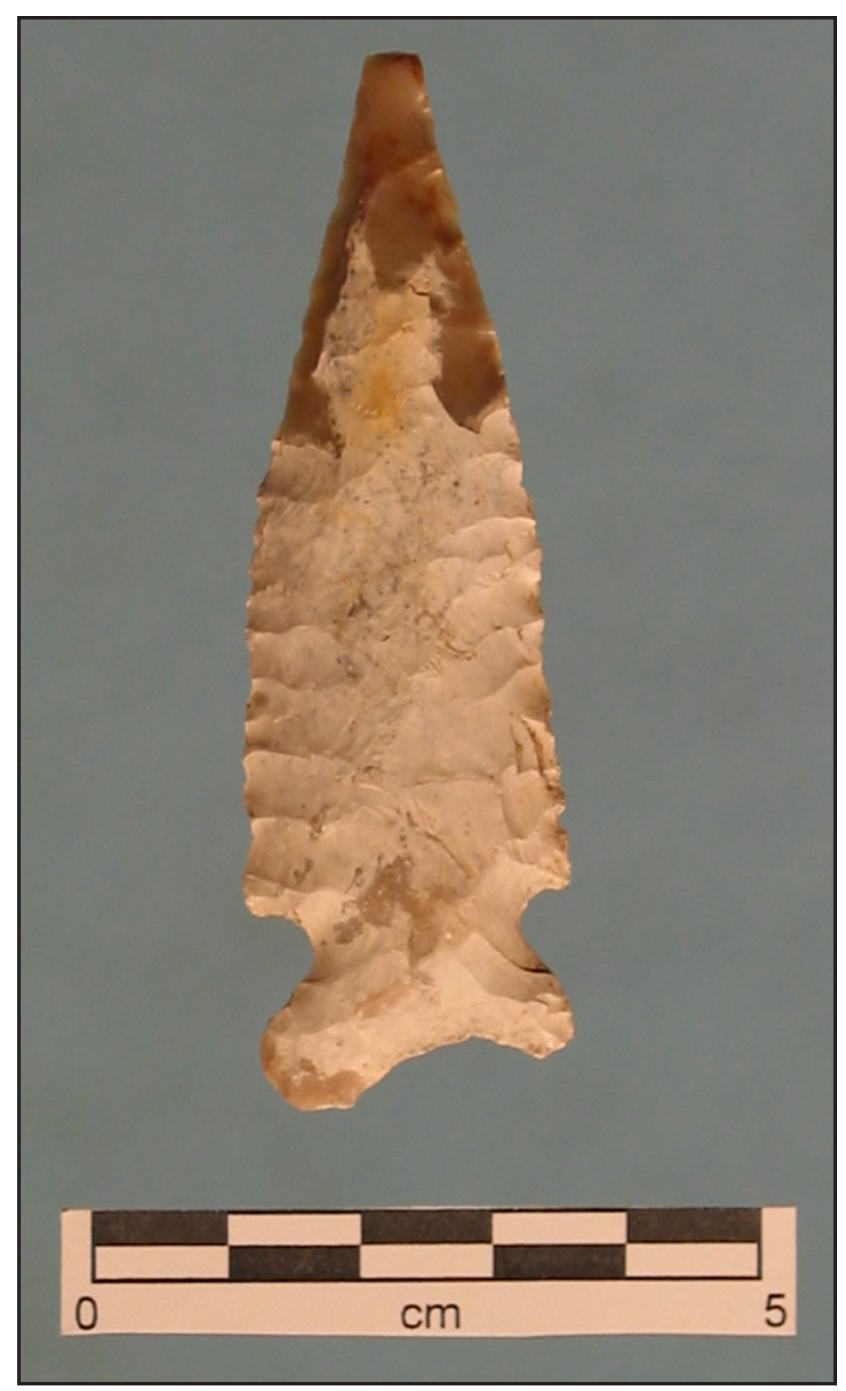

Figure 1. Big Sandy projectile point, Lot number 1486.3.

Table 2. Big Sandy Projectile Point Attributes Measurements

\begin{tabular}{|l|l|r|r|r|r|}
\hline \multicolumn{1}{|c|}{} & \multicolumn{1}{c|}{ N } & Mean & Min & \multicolumn{1}{c|}{ Max } \\
\hline \multirow{4}{*}{ Big Sandy } & Max L & 1 & 80.70 & 80.70 & 80.70 \\
\cline { 2 - 6 } & Max Blade W & 1 & 24.30 & 24.30 & 24.30 \\
\cline { 2 - 6 } & Blade Mid Th & 1 & 7.60 & 7.60 & 7.60 \\
\cline { 2 - 6 } & Max Stem L & 1 & 14.60 & 14.60 & 14.60 \\
\cline { 2 - 6 } & Stem Neck W & 1 & 15.60 & 15.60 & 15.60 \\
\cline { 2 - 6 } & Stem Base W & 1 & 23.10 & 23.10 & 23.10 \\
\cline { 2 - 6 } & Basal Depth & 1 & 2.30 & 2.30 & 2.30 \\
\cline { 2 - 6 } & Weight & 1 & 15.10 & 15.10 & 15.10 \\
\hline
\end{tabular}




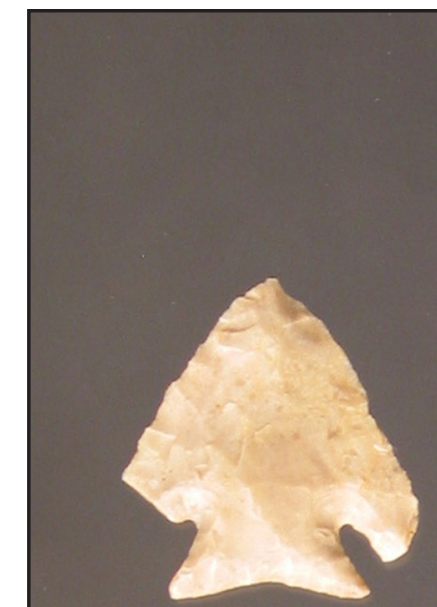

a)

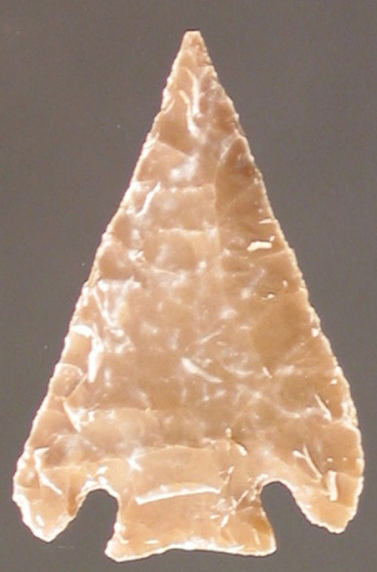

d)

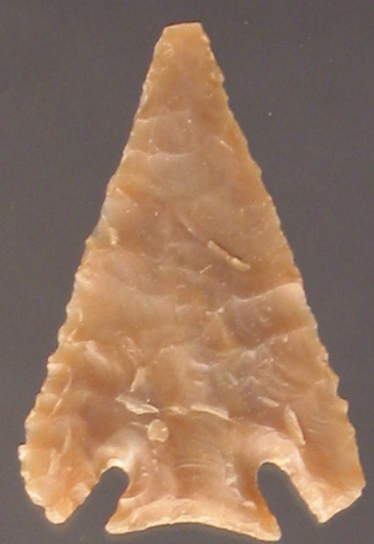

b)

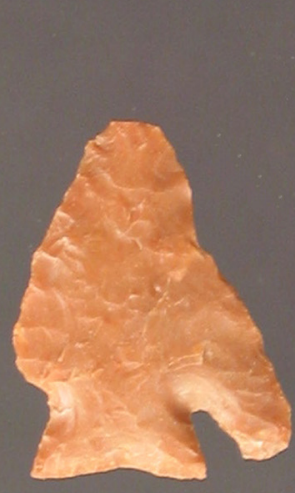

e)

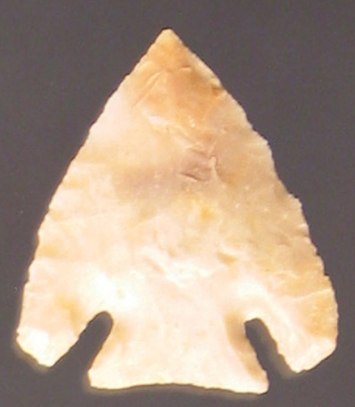

c)

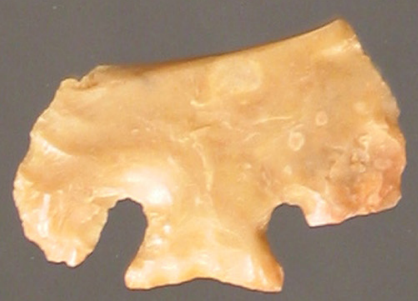

g)

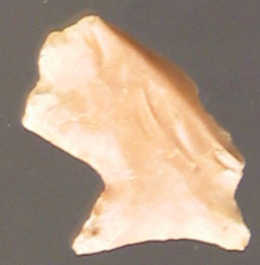

h)

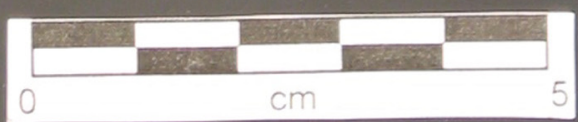

Figure 2. Bandy projectile points. Lot numbers: a) 228; b) 198; c) 352; d) 505; e) 607 ;) 662 ; g) 299; h) 279.1. 
Table 3. Bandy Projectile Points Attributes Measurements

\begin{tabular}{|l|l|r|r|r|r|r|}
\hline \multicolumn{1}{|c|}{} & N & Mean & Min & Max & Std Dev \\
\hline \multirow{5}{*}{ Bandy } & Max L & 8 & 37.80 & 23.10 & 52.50 & 11.036 \\
\cline { 2 - 7 } & Max Blade W & 8 & 31.51 & 21.80 & 37.00 & 4.664 \\
\cline { 2 - 7 } & Blade Mid Th & 6 & 3.88 & 3.20 & 4.90 & 0.618 \\
\cline { 2 - 7 } & Max Stem L & 8 & 7.55 & 6.40 & 8.90 & 0.864 \\
\cline { 2 - 7 } & Stem Neck W & 8 & 13.09 & 12.30 & 13.80 & 0.651 \\
\cline { 2 - 7 } & Stem Base W & 8 & 17.21 & 15.20 & 19.20 & 1.314 \\
\cline { 2 - 7 } & Basal Depth & 8 & 1.20 & 0.70 & 1.70 & 0.342 \\
\cline { 2 - 7 } & Weight & 8 & 4.40 & 1.80 & 6.40 & 1.524 \\
\hline
\end{tabular}

Shafer et al. 2005) The association of Bandy with Martindale is problematic. Dial et al. (1998:340-342) note that the two types overlap stylistically, sharing the expanding stem, fish-tail or indented bases, thin blade, and barbs. The two point types are assumed to be contemporaneous (Dial et al. 1998:342), although this has not been fully determined, as they do not always occur together. Bandy and Martindale occurred together in the Martindale component at the Cibolo Crossing site; the dating of this component at that site was, however, problematic (Kibler and Scott 2000:61, 62). Collins (2004), in his recent review of Central Texas prehistory, places Bandy in the Martindale component, at 7,000-6,000 B.P. Martindale points were absent at Hinds Cave in deposits yielding Bandy points while Bandy points were absent at the Woodrow Heard site (Decker et al. 2000:249-267). It is very possible that the difference between the two point types represents different technological styles (Lechtman 1977).

The technological style of Bandy points is worthy of note. The points are distinguished by their small size, small stems, and very thin blades, even compared to Martindale. The flaking is almost always bifacial with only rare glimpses of the original flake blank surfaces (e.g., Lot 505; Figure 2 d). Blades are thinned by pressure flaking. In McReynolds (2002), use-wear data obtained by C. K. Chandler, using microscopic analysis, found that the majority of specimens were used as knives, as well as points. Unfortunately, no details on the use-wear procedures are available.

It would be fruitful to examine the geographic distribution and frequency of Bandy points closely. Upon cursory inspection of the literature cited, the frequency appears to increase westward along the Balcones Escarpment to the Lower Pecos where the points have their highest representation.

Six (75 percent) of the eight Bandy type projectiles recovered from the Gatlin site were subjected to use-wear analysis. All of these tools functioned as dart points, and four (Lot 198, Lot 352, Lot 505 and 622; Figure $2 \mathrm{~b}, \mathrm{c}, \mathrm{d}$, and f) were multifunctional tools used as light-duty butchering implements. In addition, a burination scar had removed most of one blade edge on one specimen (Lot 607; Figure 2 e).

\section{Martindale (54 specimens)}

This large sample of Martindale points provided an excellent opportunity to examine the variability in both stem and blade treatment. Three distinctive stem groups were identified in the sample along with variations in the blade technology. Figure 3 illustrates examples of these three variants. It is unknown if differences in the treatment of stems have temporal significance. The stem forms are:

Martindale A (n=26): These points have the fish-tail base characteristic of Martindale (Figure $3 \mathrm{a}-\mathrm{c}$ ).

Martindale B ( $\mathbf{n}=7)$ : These points have an expanding stem with a U-shaped notch, and the base edges are round (Figure $3 \mathrm{~d}-\mathrm{f}$ ).

Martindale $\mathbf{C}(\mathbf{n}=\mathbf{1 8})$ : Specimens in this group lack the fish-tail base and instead their bases are indented and the base edges are usually sharp (Figure $3 \mathrm{~g}-\mathrm{i}$ ). The blade technology and morphology is otherwise indistinguishable to Martindale A and is probably a mere variant of the type.

Martindale-like $(\mathbf{n}=\mathbf{3})$ : These three specimens resemble Martindale points but have missing or damaged base portions or have the closest resemblance to Martindale points.

Blades on the Martindale type are broad, with small barbs, and are exceptionally well thinned. The technology and skill of thinning the blades is indeed a hallmark of the Martindale type in the Balcones Canyonlands. Blanks were flakes, sometimes very thin flakes, which were probably preformed initially using a punch but clearly completed using pressure flaking. One of the most distinctive technological 


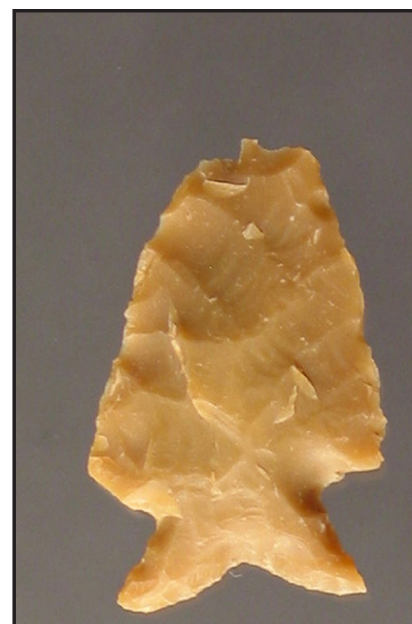

a)

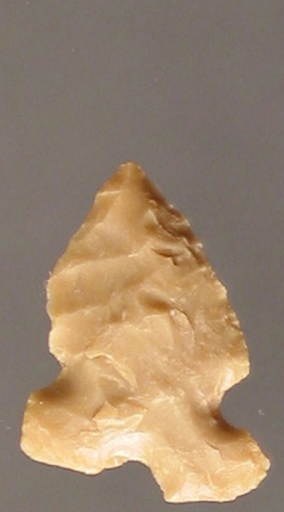

d)

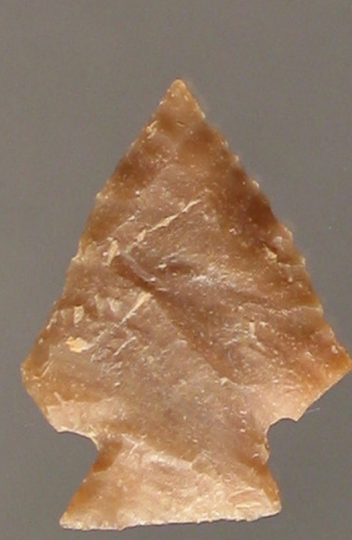

g)

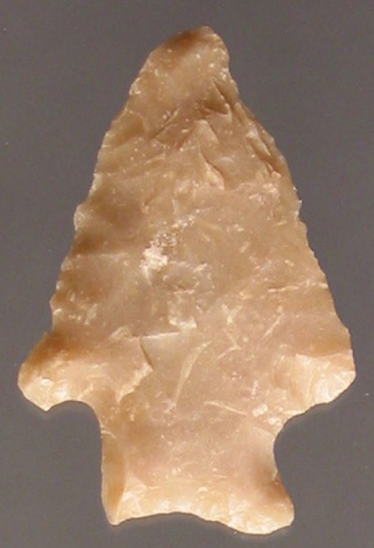

b)

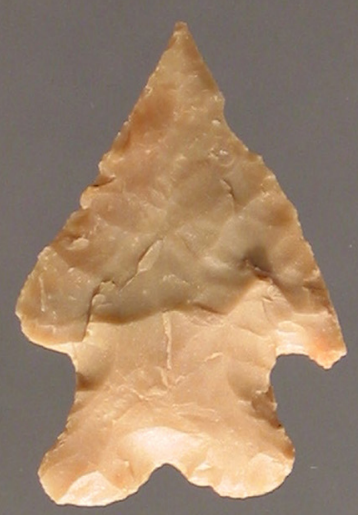

e)

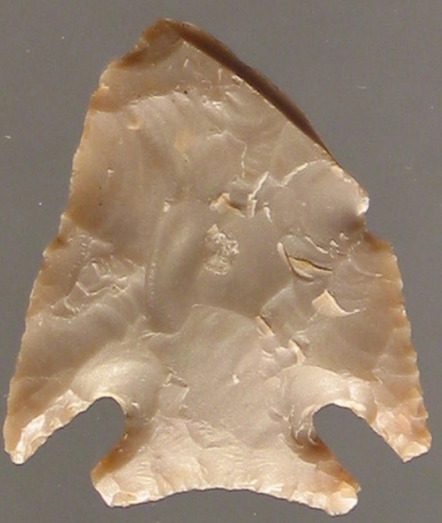

h)

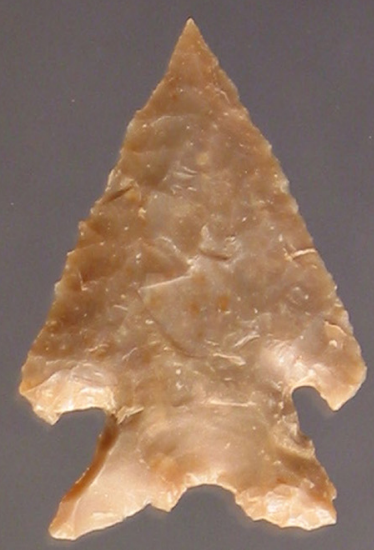

c)

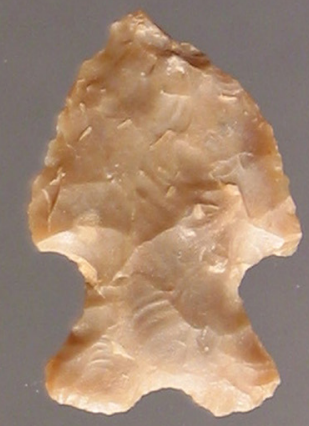

f)

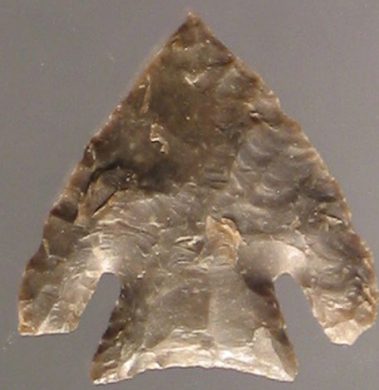

i)

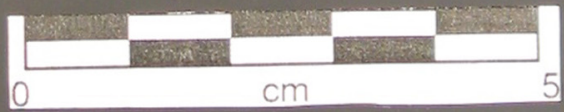

Figure 3. $\quad$ Martindale projectile points. Lot numbers: a) 74.4 ; b) 471 ; c) 867 ; d) 307; e) 927 ; f) 292.3 ; g) 652 ; h) 638 ; i) 661 . 
attributes noted is the manner in which blade edges were thinned and sharpened by fine pressure flaking. The pressure flaking is often exceptional with oblique or parallel flakes extending one-third the width of the blade and oriented toward the opposite blade corner. The skill displayed by the pressure flaking rivals that of certain Late Paleoindian points, particularly the oblique flaking often seen on Angostura genre points. This pressure flaking pattern is repeated often enough that it can be considered a stylistic trait in the Balcones Canyonlands. Blade retouch often results in a slight twist to the left (e.g., Lot 998, Lot 471, Lot 880, Lot 89.1 , and Lot 471 ; Figure 3 b) or slight bevel to the right (e.g., Lot 465.2, Lot 652,; Figure 3 g). The fine pressure retouch may also result in a slight, but very effective serration of the blade edge (e.g., Lot 862 and Lot 867; Figure $3 \mathrm{c}$ ). Blades frequently show evidence of reworking and retouching due to field maintenance. On UI 191 (Lot 307; Figure 3 d), for example, the blade has been extensively reworked, shortening the specimen; an edge of one barb may be missing. This retouch often intersects with previous flaking and may result in slight twisting or beveling of the edge. Measurements for the Martindale specimens are presented in Table 4.

One notable functional aspect of the sample is the frequency of direct impact fracture. The precise frequency of this form of breakage cannot be accurately determined since specimens with snapped tips also may have been fractured by impact; however, 23 of the 54 specimens have damage that may have been caused by impact that created a burin scar or a snap fracture.

Collins (1994a) places Martindale points chronologically between 7,000 and 6,000 B.P. Martindale points have been recovered from Early-Middle Archaic contexts at the Wilson-Leonard site (Dial et al. 1998:357-360), where the sample was divided into two separate morphological groups, Martindale A and Martindale B. Wilson-Leonard Martindale A fits the description of Martindale Ain the Gatlin site sample, while Wilson-Leonard Martindale B is more consistent with the Narrow Stem Martindale described below. Martindale points were reported from good stratigraphic context at the Landslide site (Sorrow et al. 1967:Table 1) stratigraphically beneath Bell and above Wilson (described as Untyped Specimen L by Shafer in Sorrow et al. 1967:23-25). A large sample of Martindale points $(\mathrm{n}=37)$ was recovered from the Woodrow-Heard site, but the stratigraphic association is not at all clear at that site (Decker et al. 2000:263-265). The point type is dated to about 5,000 B.P., however (Decker et al. 2000:263). Martindale points also were recovered from an Early Archaic, albeit poorly dated, component at the Cibolo Crossing site (Kibler and Scott 2000:61-62), and at the Smith site with a single radiocarbon date of 6,280-6,410 B.P. (Baker 2003:4).

The most distinctive technological style feature of Martindale points from the Balcones Canyonlands is the attention devoted to the blades. Blades are very thin, and edges were kept very sharp by skilled pressure thinning. The pressure thinning often resulted in parallel or oblique flaking reminiscent of Late Paleoindian craftsmanship. Obviously the intent was to create a very sharp edge with an angle of 10-15 degrees. How do these features provide a functional advantage and toward what end? Were the hunters trying to design a weapon tip that would effectively penetrate a deer or bison hide, or were the blades kept very sharp because they were multi-functional and used as knives as well as points? Their primary use as projectile points is undisputed given the relatively high frequency of impact fractures. This potentially controversial dual function issue can be resolved by a thorough use-wear study of a randomly selected sample, with the caveat presented in the Early Triangular discussion regarding other attributes of impact wear such as striations and polish (Dockall 1997).

Table 4. Martindale Projectile Points Attributes Measurements

\begin{tabular}{|l|l|r|r|r|r|r|}
\hline \multicolumn{2}{|c|}{} & N & Mean & \multicolumn{1}{c|}{ Min } & Max & Std Dev \\
\hline \multirow{7}{*}{ Martindale } & Max L & 52 & 44.39 & 21.40 & 74.90 & 9.833 \\
\cline { 2 - 7 } & Max Blade W & 52 & 31.87 & 19.50 & 42.50 & 4.909 \\
\cline { 2 - 7 } & Blade Mid Th & 48 & 5.45 & 4.00 & 7.80 & 0.869 \\
\cline { 2 - 7 } & Max Stem L & 53 & 11.46 & 7.10 & 15.40 & 1.710 \\
\cline { 2 - 7 } & Stem Neck W & 51 & 16.50 & 12.50 & 23.70 & 2.097 \\
\cline { 2 - 7 } & Stem Base W & 52 & 23.14 & 17.40 & 29.90 & 2.856 \\
\cline { 2 - 7 } & Basal Depth & 53 & 2.50 & 0.00 & 4.70 & 0.996 \\
\cline { 2 - 7 } & Weight & 54 & 8.39 & 2.60 & 22.10 & 3.356 \\
\hline
\end{tabular}


A total of 21 (39 percent) Martindale type points recovered from the Gatlin site was subjected to use-wear analysis. All but one of these points show evidence of use as dart tips, and most display impact fractures. Several were also used as light-duty knives, and use-wear patterning indicates that they were multifunctional; that is, they were not projectiles recycled as knives. Four of these specimens (Lots 90.4, 292.3, 590, 867; Figure $3 \mathrm{c}$ and f) were recycled as burins or planes following breakage. Only the largest of these tools was not used as a dart point (Lot 303). It is possible that this large, wide-bladed tool was never designed to be a dart point, but rather was designed to function as a knife.

\section{Martindale, Narrow Stem (7 specimens)}

There is a potentially important variant of Martindale (or perhaps a separate type?) that has been recognized in this study. Hester and Shafer have tentatively called them "Narrow Stem Martindale" and illustrated them under that rubric (Figure 4).

These specimens have expanding stems formed by deep corner notches, and weakly barbed shoulders. The term "Narrow Stem Martindale" is descriptively applied in order to emphasize the "fish-tail"-like base morphology, although similar specimens have been described as Uvalde (Turner and Hester 1999: Fig. 191, top two specimens). All have expanded stems, and stems and blades are narrower than the Martindale type. They are also separated from Gower on the basis of the base treatment and the fact that blades tend to be wider than are normally found on Gower.

Blades were broken on all examples, four by direct impact and three by snap fractures. Blades on four were reworked prior to breakage. Craftsmanship is good, but not exceptional as is often seen on Martindale specimens. Large pressure thinning flakes are apparent on the blade of specimen UI 240 (Lot 653; Figure $4 \mathrm{~d}$ ), but this artifact retains the largest portion of the blade. Field maintenance reduced the size of the blades on most (five) examples. Measurements for the Martindale Narrow Stem specimens are presented in Table 5.

Early Archaic points with this stem morphology often fall unto the Uvalde conundrum (Decker et al. 2000:265). Points comparable to the Narrow Stem
Martindale have been reported from Early Archaic contexts at Woodrow Heard (Decker et al. 2000: Fig. 185e), and described by Dial et al. (1998:358) as Martindale B from the Wilson-Leonard Site (see also Collins 2004:Fig. 3.13). Baker (2003:Fig. 10, first point on his second row) illustrates one point.

Reluctantly, Hester and Shafer are introducing another term for an early bifurcated stem form (see Dial et al. 1998, 488-505, for an excellent discussion on the bifurcated stem quandary). The use of the name Martindale is purposeful to emphasize the fish-tail like base. This narrow stem group may simply be technological variants of Martindale fashioned to fit narrow hafts. Nevertheless, this stylistic attribute may carry spatial implications, although none are obvious yet. The Narrow Stem Martindale style is a minor variant across the Balcones Canyonlands and has been variously classified as Uvalde or Early Bifurcated Stem. Stratigraphically, Narrow Stem Martindale points are recorded as an Early Archaic point style associated with Uvalde and Martindale at the Woodrow Heard site (Decker et al. 2000:Fig. 185 b,c,e), at Wilson-Leonard (Dial et al. 1998:358,359), and at the Smith Site (Baker 2003). The Uvalde-Martindale component in which this style occurs is dated to 7,000-6,000 B.P. (Kibler and Scott 2000:62).

Four (57 percent) of the seven Narrow Stem Martindale type points recovered from the Gatlin site were subjected to use-wear analysis. Use-wear patterns suggest that all of these points were projectile tips and two (Lots 29.16 and 151; Figure $4 \mathrm{a}$ and c) were multifunctional, both appearing to have seen use as burins and knives for cutting soft materials.

\section{Baker (1 specimen)}

The single Baker point (Lot 909; Figure 5) is isolated from the Gower group largely on the basis of the blade technology. The bifurcated stem is slightly expanding, longer than Gower, and has rounded basal corners. The original blade of this specimen was broad and probably long, and has been extensively reworked. It is now asymmetrical and has a moderate bevel along the right edge of both facets. The tip is sharp. Measurements on the Baker specimen are represented in Table 6.

Baker points are a minor type in the Edwards Plateau Canyonlands (Dial et al. 1998:340), but may 


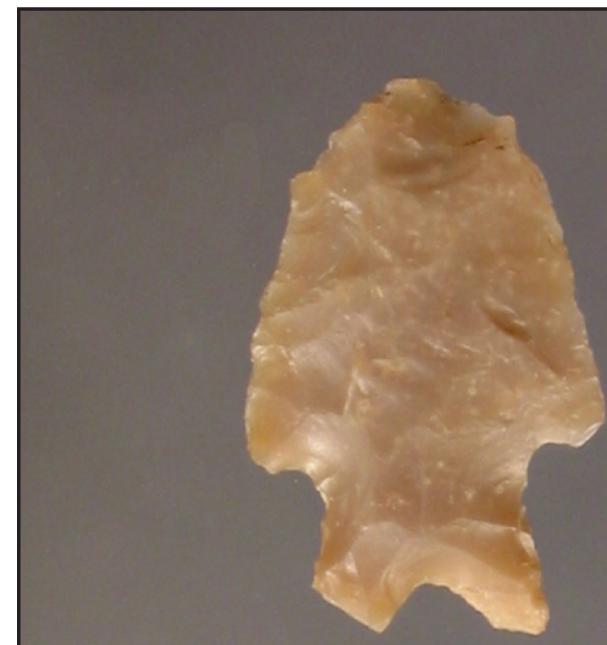

a)

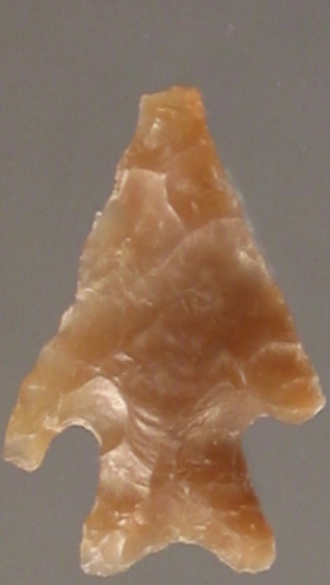

c)

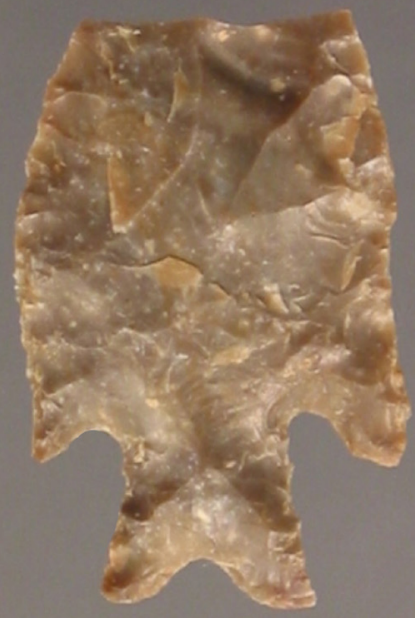

d)

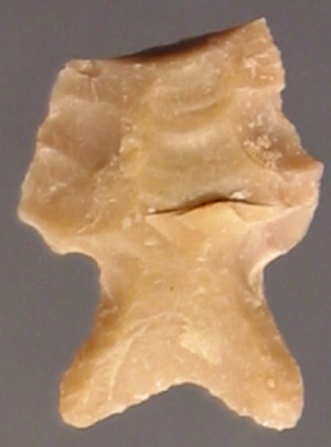

b)

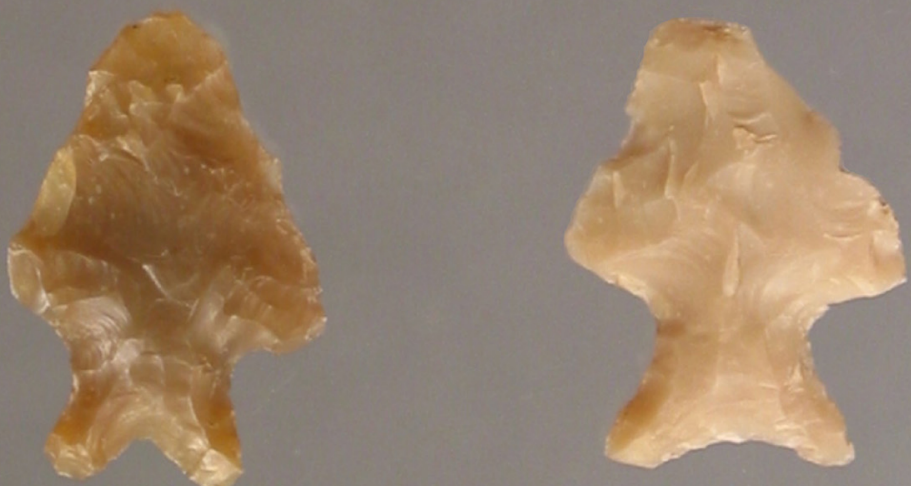

f)

g)

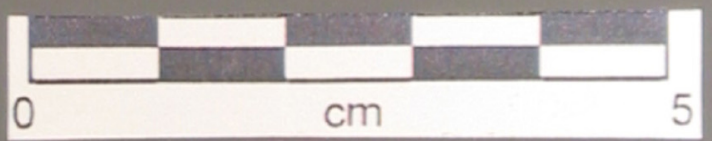

Figure 4. Martindale, Narrow Stem projectile points. Lot numbers: a) 151; b) 1033.2; c) 29.16; d) 653; e) 408.2; f) 657; g) 1080. 
Table 5. Martindale, Narrow Stem Projectile Points Attributes Measurements

\begin{tabular}{|c|l|r|r|r|r|r|}
\hline \multicolumn{2}{|c|}{} & N & Mean & Min & Max & Std Dev \\
\hline \multirow{4}{*}{$\begin{array}{c}\text { Martindale, } \\
\text { Narrow Stem }\end{array}$} & Max L & 7 & 38.50 & 31.60 & 46.10 & 5.005 \\
\cline { 2 - 7 } & Max Blade W & 7 & 26.34 & 23.30 & 29.70 & 2.062 \\
\cline { 2 - 7 } & Blade Mid Th & 6 & 4.85 & 3.60 & 6.00 & 0.834 \\
\cline { 2 - 7 } & Max Stem L & 7 & 13.06 & 11.20 & 15.50 & 1.442 \\
\cline { 2 - 7 } & Stem Neck W & 7 & 12.69 & 10.90 & 15.90 & 1.564 \\
\cline { 2 - 7 } & Stem Base W & 7 & 17.79 & 15.10 & 20.00 & 1.907 \\
\cline { 2 - 7 } & Basal Depth & 7 & 2.69 & 1.30 & 3.60 & 0.873 \\
\cline { 2 - 7 } & Weight & 7 & 5.70 & 3.80 & 10.30 & 2.350 \\
\hline
\end{tabular}

be more common in Early Archaic components in the Lower Pecos region (Turner and Hester 1999:77; Word and Douglas 1970). The type occurs in stratigraphic association with other Early Archaic point types, including Bandy, Martindale, Uvalde, and other bifurcated stem forms. Dating of the point is problematical, but cross-dating with the Martindale-Bandy-Uvalde association would place the chronology about 7,000-6,000 B.P. As Dial et al. (1998:340) note, faulty classification makes tracking the temporal and spatial distribution of the type difficult.

\section{Gower (34 specimens)}

Gower points are small, made on bifacial preforms (probably using a punch), and finished with marginal pressure retouch. Blades are characteristically narrow with small shoulders, and some have small barbs. Examples of the Gower specimens recovered from the Gatlin site are represented in Figure 6. Only one of the Gatlin site examples has ground stem edges. Fine pressure retouch of the blade occurs (e.g., Lot 483 and Lot 1550; Figure $6 \mathrm{a}$ and $\mathrm{b}$ ) and is even rarely oblique (e.g., Lot 1007.1 and Lot 554.1; Figure 6 e), but is not a common feature as it is on Martindale and Early Triangular types. Blades are often extensively reworked (e.g., Lot 1152, Lot 320.2, Lot 408.2, Lot 1550, Lot 1080, among others; Figure $6 \mathrm{~b}$ and $\mathrm{c}$ ); none are beveled, however, resharpening may result in a slight twist to the blade (e.g., Lot 1152; Figure 6 c). Direct impact fractures $(n=10)$ were a common cause of failure along with snapped blades $(n=11)$, which were also likely caused by impact. Kelly (1979) used microscopic examination to recognize what he believed are wear patterns, and suggested Gower points also served as knives and scrapers. Measurements for the Gower specimens are presented in Table 7.

The Gower sample contains a variety of stem forms, which were divided into the following categories: Gower A, Gower B, and Gower. The particular classification of "Gower" for these indented base points was chosen since the sample fits the original Gower description by Shafer (1963) and Sorrow et al. (1967) more closely than the similarly bifurcated stemmed and wider blade Uvalde.

Gower A ( $\mathbf{n = 1 5 ) :}$ These points have expanding stems formed by corner notching and deeply indented bases (Figure $6 \mathrm{a}-\mathrm{c}$ ). Base edges tend to be rounded;

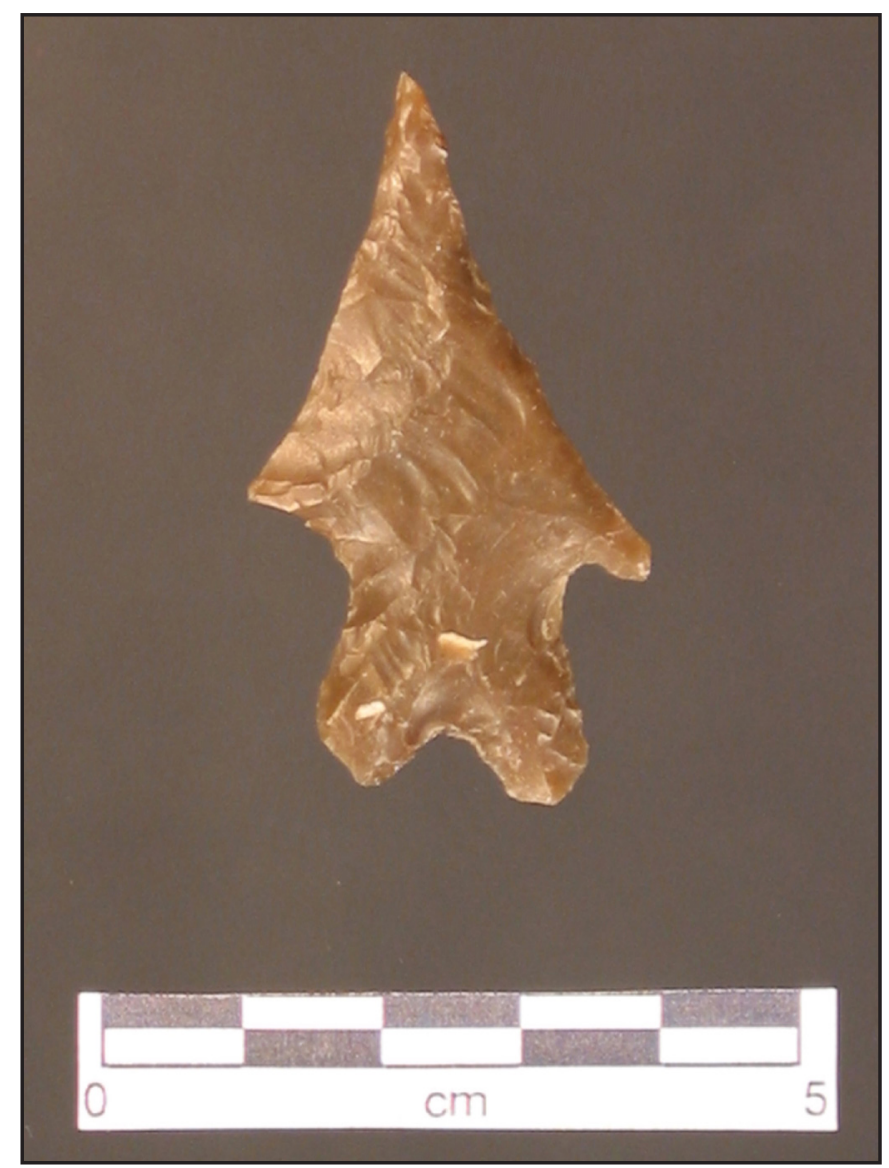

Figure 5. Baker projectile point, Lot number 909. 
Table 6. Baker Projectile Point Attributes Measurements

\begin{tabular}{|c|l|r|r|r|r|}
\hline \multicolumn{2}{|c|}{} & N & Mean & Min & \multicolumn{1}{c|}{ Max } \\
\hline \multirow{5}{*}{ Baker } & Max L & 1 & 50.80 & 50.80 & 50.80 \\
\cline { 2 - 6 } & Max Blade W & 1 & 29.50 & 29.50 & 29.50 \\
\cline { 2 - 6 } & Blade Mid Th & 1 & 4.60 & 4.60 & 4.60 \\
\cline { 2 - 6 } & Max Stem L & 1 & 16.80 & 16.80 & 16.80 \\
\cline { 2 - 6 } & Stem Neck W & 1 & 16.70 & 16.70 & 16.70 \\
\cline { 2 - 6 } & Stem Base W & 1 & 19.60 & 19.60 & 19.60 \\
\cline { 2 - 6 } & Basal Depth & 1 & 3.70 & 3.70 & 3.70 \\
\cline { 2 - 6 } & Weight & 1 & 5.70 & 5.70 & 5.70 \\
\hline
\end{tabular}

some are shaped almost like "little booties" (e.g., Lot 1550; Figure $6 \mathrm{~b}$ ). Stem edges also are often convex (e.g., UI 178 Lot 483; Figure 6 a). Blades are characteristically narrow with slight shoulders.

Gower B (n=12): Specimens in this subgroup have approximately straight stems and concave bases, with pointed or slightly blunted basal corners (Figure $6 \mathrm{~d}-\mathrm{f})$. The indention is often unifacial, a type feature found on specimens from the Youngsport site (Shafer 1963). Blades are narrow with straight or slightly barbed shoulders.

Gower $(\mathbf{n}=\mathbf{6})$ : These are corner notched points with the generic Gower form but without any real distinguishing attribute that sets them apart or allows for inclusion in the above groups (Figure $6 \mathrm{~g}-\mathrm{i}$ ).

The Gower type was originally defined at the Youngsport site in western Bell County, where it was stratigraphically isolated beneath then untyped Middle Archaic diagnostics, including Nolan (Shafer 1963, 1979). At the Landslide site, Gower points were recovered with Martindale and beneath Bell and Early Triangular (then called Untyped Group 3 ), and stratigraphically above Wilson, (Sorrow et al. 1967: Table 1; Miscellaneous Specimen f). Gower points and similarly bifurcated stem examples were generally recovered stratigraphically above Angostura and Hoxie and below Bandy and Martindale at Wilson-Leonard, although a considerable amount of intermingling occurred with the Early Archaic components at this site (Collins et al. 1998:211-291). Specimens from the Sleeper site similar to those classified here as Gower were termed Uvalde by Johnson (1991).
The Uvalde type name has been avoided in this study because, as currently being applied, it has been a catch-all category for a wide variety of bifurcated and split-stem early Archaic forms, including specimens classed here as Gower and Narrow Stem Martindale. The problematic use of the term Uvalde has been discussed elsewhere (Black and McGraw 1985:123; Decker et al. 2000:265; Kerr and Dial 1998:503-504 [for an excellent discussion on the bifurcated stem classification problem]). Therefore, in order to define regional variation across Central Texas and the Canyonlands, stylistic differences need to be defined and understood. The experimental study by Tomka et al. (2003) showed the value in exploring for differences in technological styles across the greater Central Texas region. One problem facing Texas archaeologists is the difficulty in locating sites such as Youngsport and Landslide that have a clear stratigraphic separation of Early Archaic point styles. The Sleeper site (Johnson 1991) is an exception in that is an almost pure Gower component with a slight admixture of other Early Archaic types (Martindale and Bell/Andice), but unfortunately no radiocarbon dates were obtained from that site to securely date the component. Johnson relied on cross-dating to assess the antiquity of the deposits at that site. Johnson classed all bifurcated points as Uvalde, but the sample is very comparable to that from the Gatlin site. Site formation processes are such that clear stratigraphic separation among Early Archaic point styles is often lacking, as shown by such sites as Camp Pearl Wheat and also at Wilson-Leonard.

Dating the Gower component is possible using cross-typing and cross-dating, that is to say, points that would be included as Gower here have been typed and dated as Uvalde. Uvalde components have been dated by Collins (2004) at 7,000-6,000 B.P. and 6000-5500 B.P. by Johnson and Goode (1994). Unfortunately, the three sites with the best isolated Gower components (Youngsport, Landslide, and Sleeper) have not been dated chronometrically.

Fourteen (41 percent) of the 34 Gower type points recovered from the Gatlin site were subjected to use-wear analysis. All but two (Lots 335 and 1036.1; Figure $6 \mathrm{~d}$ ) of these 14 points have evidence of use as 


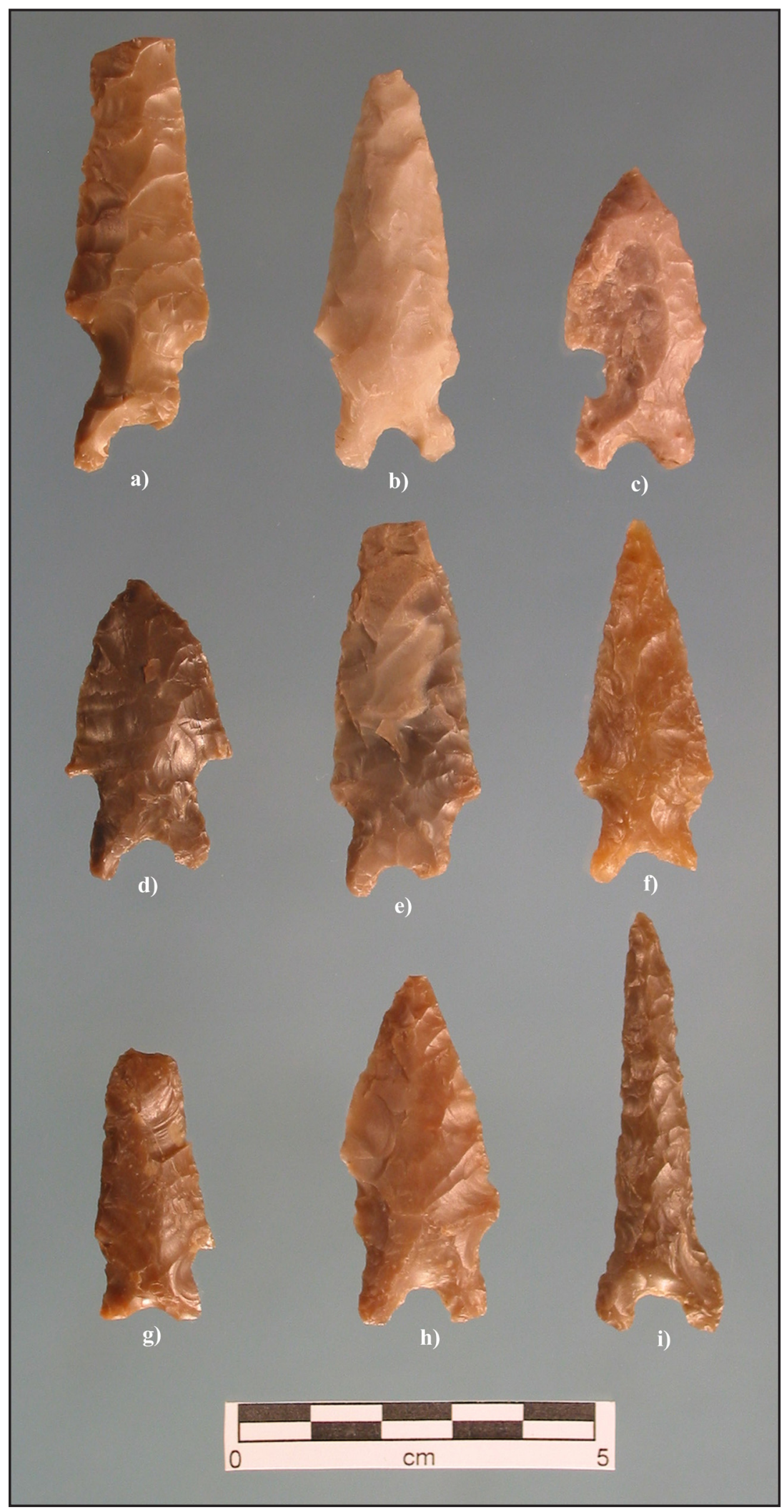

Figure 6. Gower projectile points. Lot numbers: a) 483; b) 1550; c) 1152 ; d) 335 ; e) 554.1 ; f) 564 ; g) 244.21 ; h) 944 ; i) 519 . 
Table 7. Gower Projectile Point Attributes Measurements

\begin{tabular}{|l|l|r|r|r|r|r|}
\hline \multicolumn{1}{|c|}{} & \multicolumn{1}{c|}{ N } & Mean & Min & Max & Std Dev \\
\hline \multirow{5}{*}{ Gower } & Max L & 31 & 42.63 & 13.20 & 59.60 & 12.246 \\
\cline { 2 - 7 } & Max Blade W & 31 & 21.90 & 11.50 & 27.30 & 3.427 \\
\cline { 2 - 7 } & Blade Mid Th & 27 & 5.67 & 3.80 & 7.50 & 0.988 \\
\cline { 2 - 7 } & Max Stem L & 30 & 13.14 & 9.00 & 18.20 & 2.366 \\
\cline { 2 - 7 } & Stem Neck W & 29 & 13.52 & 10.40 & 17.70 & 1.870 \\
\cline { 2 - 7 } & Stem Base W & 30 & 16.41 & 12.40 & 23.50 & 2.044 \\
\cline { 2 - 7 } & Basal Depth & 32 & 3.97 & 1.60 & 6.60 & 1.237 \\
\cline { 2 - 7 } & Weight & 34 & 5.23 & 1.00 & 10.20 & 2.076 \\
\hline
\end{tabular}

of Texas, including most of central and east Texas and the Canyonlands (Decker et al. 2000:254-255). Andice/ Calf Creek points have been dated to 4,700-5,000 B.P., but, to the knowledge of the analysts, no isolated Andice component has been dated in Central Texas or the Canyonlands. Decker et al. (2000:254-256) have presented a lengthy discussion on the Bell/Andice/ Calf Creek issue, and that discussion need not be repeated here. Presumably, Andice points are chronologically cona projectile point, probably for small atlatl darts. Five tools (Lots 148.2, 483, 519, 594.1, and 944; Figure $6 \mathrm{a}, \mathrm{h}$, and i) have evidence of multifunctional use as both projectiles and knives. Only one specimen has evidence of use only on moderately resistant materials.

\section{Early Archaic (Late)}

\section{Andice (9 specimens)}

The Andice type is distinguished by the deep basal notches cut into a convex base preform probably by carefully controlled punch notches bifacially removed alternately. The result is massive barbs with rounded or squared tips, and a long parallel-sided bifacially beveled stem. Bases are usually straight. Three of the nine Andice specimens collected at the Gatlin site are illustrated in Figure 7 a-c. Blades exhibit evidence of reworking, and one (Lot 811; Figure 7 a) is beveled to the right. Blades were broken either by direct impact or by snap fractures (a review of breakage patterns on Andice elsewhere in Central Texas can be found in Weber [2002]). Measurements for the Andice specimens are presented in Table 8.

Andice points were first defined by Prewitt (1983) to correctly distinguish them from Bell and Bulverde. Technologically they are similar to Bell but have broader blades and longer stems. Andice points, perhaps even more than Bell, are high maintenance tools. Barbs were easily broken and rejuvenation of the blades resulted in shorter, shouldered blades.

Andice points are currently assumed to be part of the Calf Creek horizon that extends from centraleastern Oklahoma to the central coastal plains temporaneous with Bell and Early Triangular since no stratigraphic separation has yet to be recognized between Andice and Bell.

\section{Bell (7 specimens)}

Bell points have straight or slightly expanding stems with straight or slightly convex or concave bases. The distinguishing characteristic is the base-length barbs on the less modified examples created by deep basal notching a rounded base preform. Blades are very thin, another characteristic feature of the type. Blades are often reworked by pressure flaking, (Lot 922; Figure $7 \mathrm{f}$ ) resulting in a slight twist to the left (Lot 277.1; Figure $7 \mathrm{~g}$ ) or serration (Lot 1000; Figure 7 e). Oblique pressure thinning was noted on one example (Lot 96.4; Figure 7 d). Direct impact fractures $(n=5)$ and snap fractures $(n=2)$ were the causes of failure. Snap fractures mostly likely were the result of impact as well. Measurements for the Bell specimens are presented in Table 9.

Technologically, Bell points are high maintenance weapon tips that, once put to use, also apparently had a high incidence of breakage, especially at the barbs. Therefore, points with reworked blades are usually shouldered rather than barbed, but are identifiable as Bell on the basis of the stem morphology and possible evidence of bifacial punch flaking along the stem edge. Bell points are thinner than Andice and have shorter stem and barbs (Decker et al. 2000:254-256).

Bell points have been securely fixed chronologically in Early Archaic contexts beneath Nolan and above Martindale and Gower at the Landslide site, and this stratigraphic position was independently confirmed at 41BX377 (Kibler and Scott 2000:74-99). The 


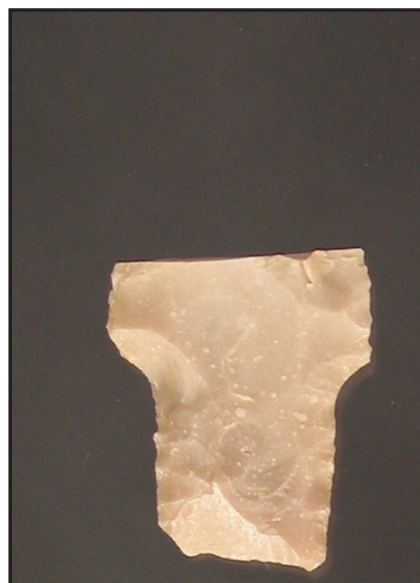

a)

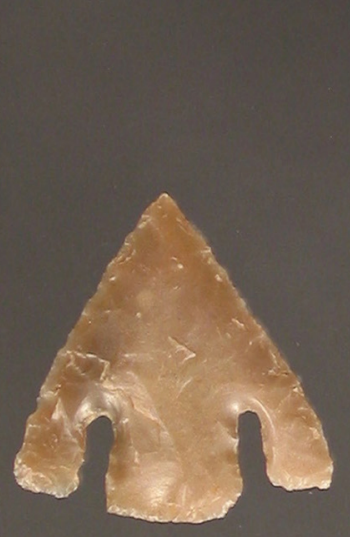

d)

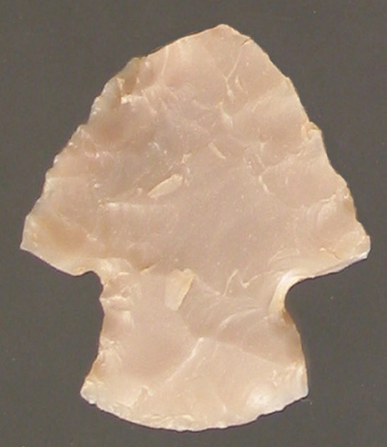

g)

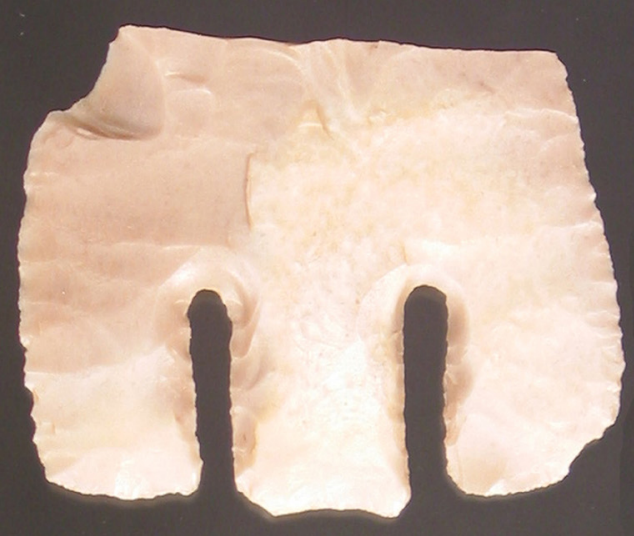

b)

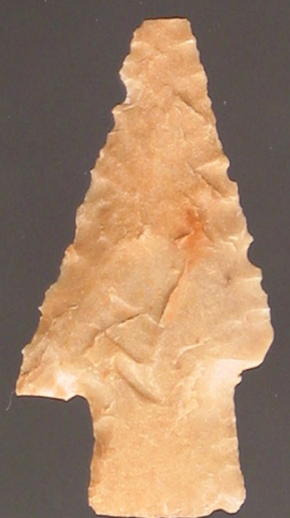

e)

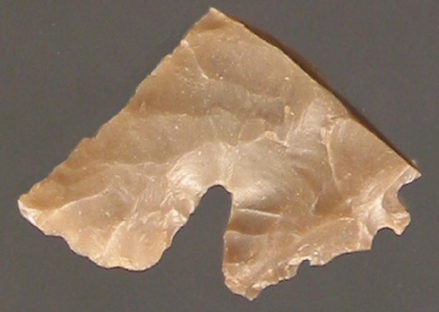

h)

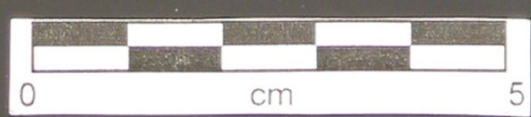

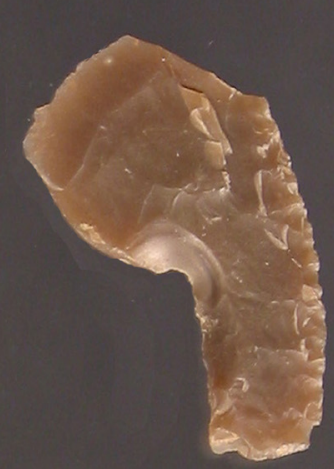

c)

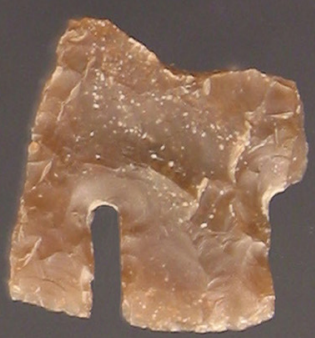

f)

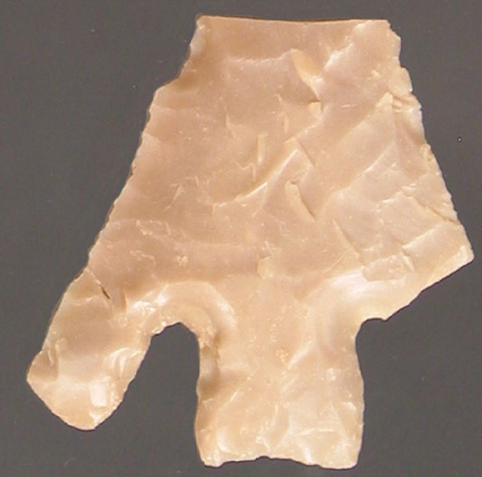

i)

Figure 7. Andice projectile points. Lot numbers: a) 811; b) 363; c) 841. Bell projectile points. Lot numbers: d) 96.4; e) 1000; f) 922; g) 277.1. Early Barbed Devil's Variant projectile points. Lot numbers: h) 571 ; i) 641.1 . 
Table 8. Andice Projectile Points Attributes Measurements

\begin{tabular}{|l|l|r|r|r|r|r|}
\hline \multicolumn{2}{|c|}{} & N & Mean & Min & Max & Std Dev \\
\hline \multirow{7}{*}{ Andice } & 9 & 42.41 & 33.40 & 51.30 & 6.306 \\
\cline { 2 - 7 } & Max L & 8 & 33.31 & 23.00 & 62.90 & 12.455 \\
\cline { 2 - 7 } & Bax Blade W & 4 & 5.98 & 4.80 & 6.90 & 0.929 \\
\cline { 2 - 7 } & Made Mid Th & 8 & 19.31 & 14.40 & 23.60 & 2.721 \\
\cline { 2 - 7 } & Stem Stem L & 7 & 18.49 & 15.80 & 19.60 & 1.279 \\
\cline { 2 - 7 } & Stem Base W & 7 & 17.71 & 15.20 & 19.50 & 1.587 \\
\cline { 2 - 7 } & Basal Depth & 7 & 0.06 & 0.00 & 0.40 & 0.151 \\
\cline { 2 - 7 } & Weight & 9 & 9.96 & 5.00 & 27.80 & 6.873 \\
\hline
\end{tabular}

Table 9. Bell Projectile Points Attributes Measurements

\begin{tabular}{|r|l|r|r|r|r|r|}
\hline \multicolumn{2}{|c|}{} & N & Mean & Min & Max & Std Dev \\
\hline \multirow{5}{*}{ Bell } & Max L & 7 & 35.64 & 25.20 & 52.60 & 9.465 \\
\cline { 2 - 7 } & Max Blade W & 7 & 28.79 & 24.40 & 36.50 & 4.642 \\
\cline { 2 - 7 } & Blade Mid Th & 3 & 4.13 & 3.90 & 4.30 & 0.208 \\
\cline { 2 - 7 } & Max Stem L & 7 & 13.83 & 11.30 & 15.50 & 1.553 \\
\cline { 2 - 7 } & Stem Neck W & 6 & 15.98 & 13.30 & 19.20 & 2.093 \\
\cline { 2 - 7 } & Stem Base W & 7 & 17.09 & 14.20 & 23.70 & 3.209 \\
\cline { 2 - 7 } & Basal Depth & 7 & -0.40 & -1.80 & 0.90 & 0.900 \\
\cline { 2 - 7 } & Weight & 7 & 5.09 & 3.10 & 7.90 & 1.768 \\
\hline
\end{tabular}

faintly convex and are finely thinned by oblique pressure flaking. Measurements on these two specimens are represented in Table 10.

This variety has been reported from the Devil's Mouth site (Johnson 1964:55; Fig. 17J), Devil's Rockshelter (Prewitt 1966:Fig. 4F, G), Wilson-Leonard (Kerr and Dial 1998:Fig. 13-56), and Woodrow Heard (Decker et al. 2000:Fig. $177 \mathrm{e}-\mathrm{g})$. The distinctive style occurred in Early Archaic context at each of the above sites.

Stratigraphic position of the point has been recorded at the Devil's Rockshelter (Prewitt 1966). The points were stratigraphically above points untyped by Prewitt but which would now be classed as Gower. Unfortunately, no dates were obtained at Devil's Rockshelter. The WilsonLeonard specimens were recovered in Early Archaic contexts grouped with Martindale-Uvalde and dated

stratigraphic association with Nolan was less clear at 41CM111 (Mahoney et al. 2003:64-69). Bell points were associated with Early Triangular at Landslide, 41BX377, and at 41CM111, and the blades often exhibit the same fine pressure thinning seen on Early Triangular specimens. The Bell component at the Richard Beene site has been dated to ca. 4,500 B.P. (Thoms et al. 1996). The Bell-Andice component is dated 5,300-4,800 B.P. at the Cibolo Crossing Site (Kibler and Scott 2000:93). The undated Bell component at Landslide site was associated with a large thermal feature with bison bone (Sorrow et al. 1967:41).

\section{Early Barbed, Devil's variant (2 specimens)}

During the review of the Bell materials from the Gatlin site, the analysts noted two specimens, both proximal fragments that are large barbed points similar to Bell (Lot 571 and Lot 641.1; Figure $7 \mathrm{~h}$, i), but that have wider, squared tip barbs that slightly flare. The one complete base (Lot 641.1; Figure 7 i) is slightly indented; the stem on this specimen has slightly convex blade edges. The blade edges are to about 7,000-6,000 B.P. (Collins 2004:119; Dial et al. 1998:362-365).

\section{Early Triangular (61 specimens)}

The large sample of Early Triangular artifacts, like the Martindale sample, provides for a new and detailed examination of the variability within a collection from the same site. Examples from this large sample are represented in Figure 8. The sample was divided on the basis of base morphology: indented (ETA) (Figure $8 \mathrm{a}-\mathrm{d}$ ), straight (ETB) (Figure $8 \mathrm{e}-\mathrm{h}$ ), or convex (ETC) (Figure $8 \mathrm{i}$ ). The degree of indention in the base can be subtle or moderate. The significance of the base variation is unknown at this time, and may simply have been determined at the time the base was being thinned, or perhaps if the hunter wanted slight barbs to the shoulders; if the latter, then the basal indention would be a technological nuance. Most shoulders are sharp, but rounded shoulders did occur on one example (Lot 1215.4; Figure 8 f). Blades are characteristically wide in relation to length; five specimens fall into a narrow, lanceolate subgroup (e.g., Lots 687.1, 687.1, 892, 893, and 
1030.2; Figure $8 \mathrm{c}$ ). Measurements for the Early Triangular specimens are presented in Table 11.

The sample fits the description of the type in Turner and Hester (1999:108-110) well in that all of the blade characteristics mentioned are present in this sample. Early Triangular points have been variously typed as Baird bifaces (Kibler and Scott 2000:73), Taylor bifaces (Collins 2004:113), and "Devil's Triangular" (Turpin and Bement 1992:52), and "Untyped 3" (Sorrow et al. 1967:22). The outstanding feature of Early Triangular artifacts is the fine pressure thinning or retouch (FPR), often oblique, that may be unifacial along the right edge or bifacial on both edges. With the former, a slight twist or bevel to the right is apparent (e.g., Lots 82.2, 479, 774, 898, and 1283.6; Figure 8 a). Rarely, retouching will result in a twist to the left (e.g., Lot 740.2; Figure $8 \mathrm{~b}$ ). The thinness and sharpness of the edges are other outstanding attributes of the group. Lightly serrated blades also occur in the sample (e.g., Lot 204.2; Figure 8 h).

Reworked blades are common in the sample, resulting in shorter blades with interrupted flaking patterns, and often with a slight bevel or twist to the blade. The most frequent cause of breakage $(n=21)$ was due to direct impact resulting in a smashed tip or a bending break with its characteristic reverse fluting originating from the top or subsequent break at the tip (see Dockall [1997] for an excellent description of projectile point impact fractures). Snap fractures (abrupt bending breaks) near the tip or near midpoint on the blades also were common $(n=8)$. While several specimens exhibited suspicious use-wear characteristics (e.g., Lot 967, Lot 996, Lot 897.1, Lot 726, among others; Figure $8 \mathrm{~g}$ ), the impact fractures make a convincing case that the primary function was that of a projectile point, although some of the specimens possibly were used as knives.

The assumption that lateral smoothing and striations along the edges of projectile points is due to use as knives has not been adequately tested in Hester and Shafer's opinion. Use-wear experiments are invariably tied to the assumption that hafted points doubled as knives (and they may very well have been used in this fashion [cf. Decker et al. 2000:256-263]), but wear types attributed to impact have not received equal attention (see Kay 1996). Impact fractures based on experiments and fracture characteristics are visually apparent, but attrition caused by abrasive impact has yet to be fully considered in Texas studies (see Dockall [1997] and Kay [1996] for literature reviews on this subject). Impact wear can result in linear polishes and surface and edge rounding and dulling (Dockall 1997).

The first clear chronological placement for Early Triangular points came from the Landslide site, where the points were typed "untyped group 3" (Sorrow et al. 1967:22) in association with Bell points and stratigraphically above Gower. Good context dates have been reported from 41CM111 (Mahoney et al. 2003) and 41BX377, the Cibolo Crossing site (Kibler and Scott 2000). Five calibrated dates (1 sigma: 5600-5480, 5740-5660, 5590-5460, 5590-5470, $5,600-5,520$ в.Р.) came from 41MM340 in association with Bell points (Mahoney et al. 2003b:55). Other sites with Early Triangular samples include the Cibolo Crossing site where the Bell/Andice/Baird component had a temporal span of 5,300-4,800 B.P. (Kibler and Scott 2000:93). Less well-dated components yielding Early Triangular points were reported at Wilson-Leonard (Dial et al. 1998:416) and at the Woodrow Heard site (Decker et al. 2000), although Decker et al. (2000:3) place Early Triangular points in the 5,200-4,500 B.P. range. Given the dated components in which Early Triangular points have been

Table 10. Early Barbed, Devil's Variant Projectile Points Attributes Measurements

\begin{tabular}{|l|l|r|r|r|r|r|}
\hline \multicolumn{2}{|c|}{} & N & Mean & Min & Max & Std Dev \\
\hline \multirow{4}{*}{$\begin{array}{c}\text { Early Barbed } \\
\text { Devils Variant }\end{array}$} & Max L & 2 & 38.35 & 29.40 & 47.30 & 12.657 \\
\cline { 2 - 7 } & Max Blade W & 1 & 50.80 & 50.80 & 50.80 & \\
\cline { 2 - 7 } & Blade Mid Th & 1 & 4.80 & 4.80 & 4.80 & \\
\cline { 2 - 7 } & Max Stem L & 1 & 14.10 & 14.10 & 14.10 & \\
\cline { 2 - 7 } & Stem Neck W & 1 & 16.70 & 16.70 & 16.70 & \\
\cline { 2 - 7 } & Stem Base W & 1 & 17.60 & 17.60 & 17.60 & \\
\cline { 2 - 7 } & Basal Depth & 1 & 1.00 & 1.00 & 1.00 & \\
\cline { 2 - 7 } & Weight & 2 & 9.45 & 5.10 & 13.80 & 6.152 \\
\hline
\end{tabular}




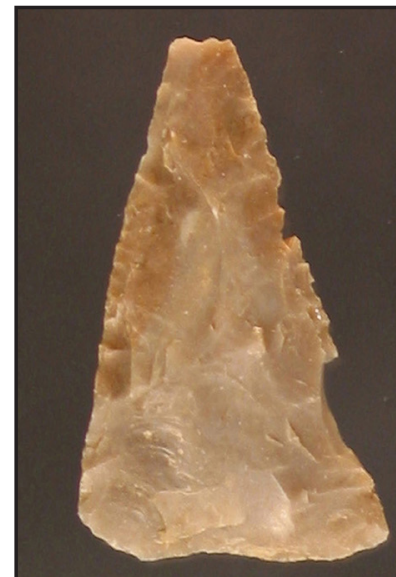

a)

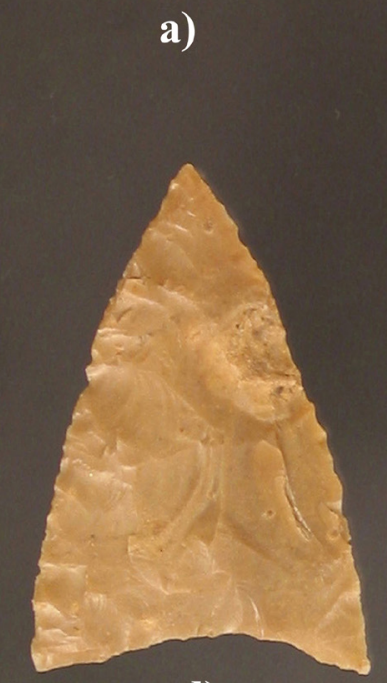

d)

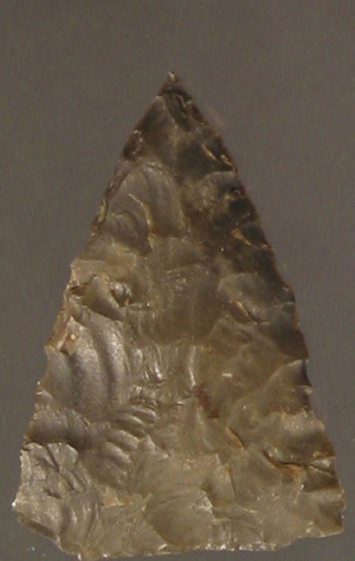

g)
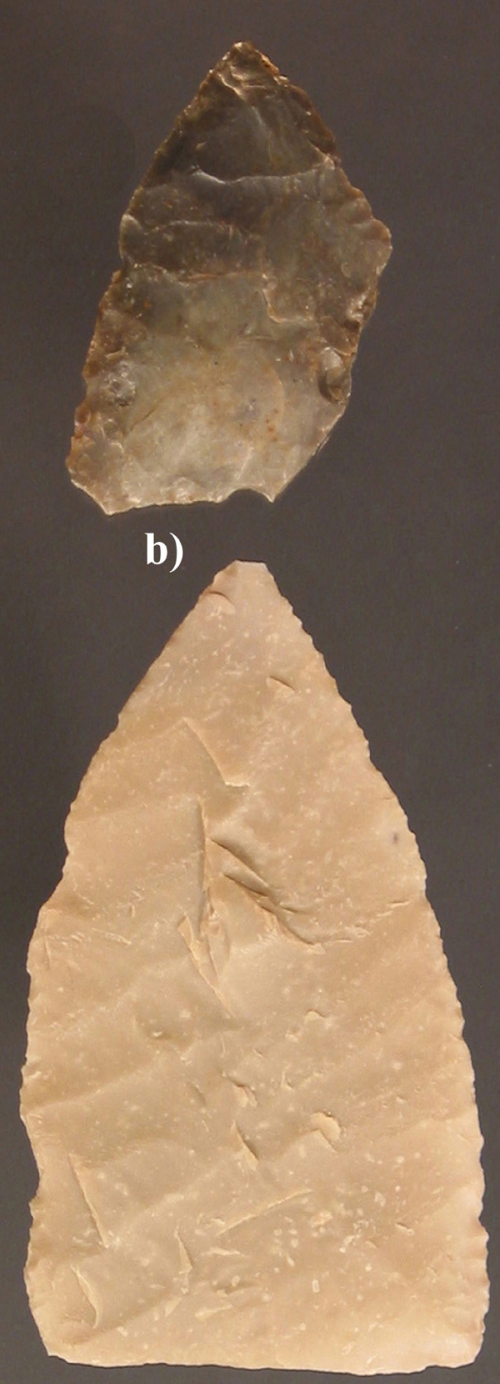

e)

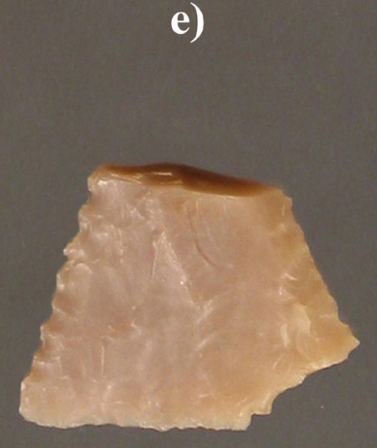

h)

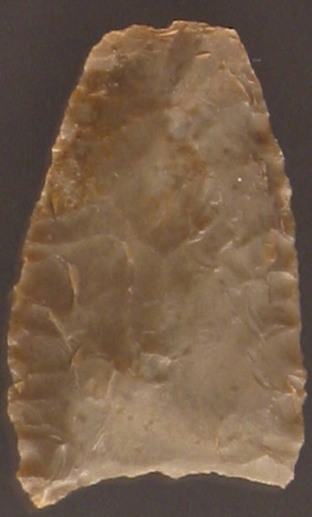

c)
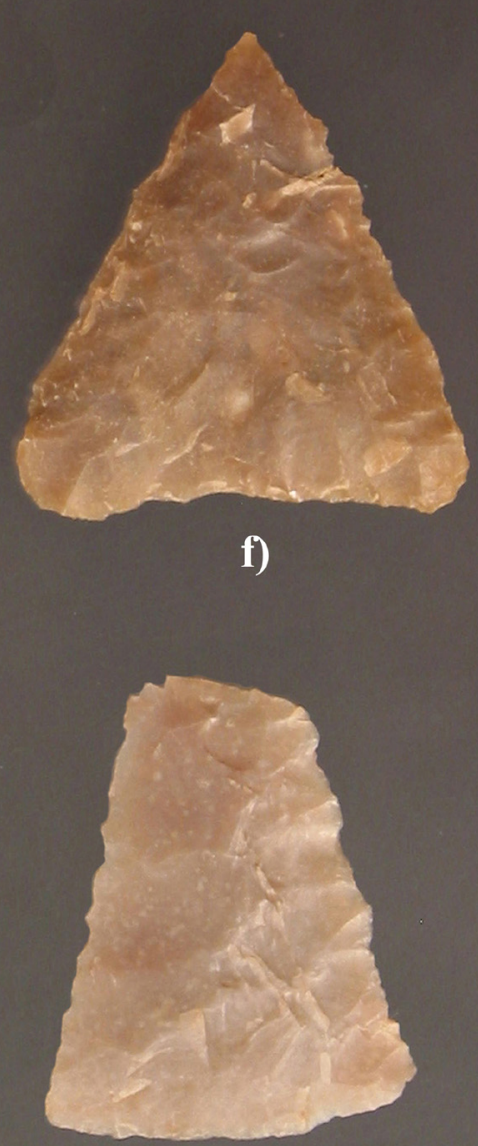

i)

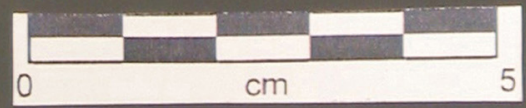

Figure 8. Early Triangular projectile points. Lot numbers: a) 82.2; b) 740.2; c) 893; d) 995; e) 921; f) 1215.4; g) 726; h) 204.2; i) 763.1. 
Table 11. Early Triangular Projectile Points Attributes Measurements

\begin{tabular}{|l|l|r|r|r|r|r|}
\hline \multicolumn{1}{|c|}{} & N & Mean & Min & Max & Std Dev \\
\hline \multirow{5}{*}{ Early Triangular } & Max L & 61 & 51.20 & 26.60 & 88.20 & 13.001 \\
\cline { 2 - 7 } & Max Blade W & 57 & 37.00 & 26.30 & 50.20 & 5.727 \\
\cline { 2 - 7 } & Blade Mid Th & 53 & 6.05 & 3.70 & 8.80 & 1.005 \\
\cline { 2 - 7 } & Max Stem L & & & & & \\
\cline { 2 - 7 } & Stem Neck W & & & & & \\
\cline { 2 - 7 } & Stem Base W & 52 & 36.97 & 26.30 & 50.20 & 5.927 \\
\cline { 2 - 7 } & Basal Depth & 52 & 1.09 & -2.40 & 4.80 & 1.588 \\
\cline { 2 - 7 } & Weight & 61 & 11.56 & 4.40 & 34.10 & 5.570 \\
\hline
\end{tabular}

recovered, the point type is placed conservatively between 5,700 and 4,800 B.P.

One final technological comment is appropriate for the Early Triangular flaking technology. The fine marginal pressure flaking (FPR) — often obliqueseen on many of the examples rivals that seen on certain Late Paleoindian points, in terms of skill. The purpose of FPR on Early Triangular points, however, was to thin the edge to create a very sharp angle of ca. 10-15 degrees, ideal for sharp-edge cutting or piercing. This same technology was noted on many Martindale points as well. Interestingly, fine marginal pressure flaking was noted on two Bell specimens, presumably a type contemporary with Early Triangular, but it is not a technological characteristic of Bell as it is on Early Triangular and Martindale points.

Of the 61 Early Triangular points recovered during the Gatlin site excavations, 22 (36 percent) were subjected to use-wear analysis. Based on the morphology of these large, wide-bladed, unnotched triangular points, these blades would likely be less efficient at creating an entry wound for deep weapon penetration than narrower blades. Fifteen specimens exhibit definite, massive impact fractures, however, demonstrating that many of the Early Triangular points recovered from the Gatlin site did tip weapons. Eight of the 15 also show use-wear patterns indicative of a dual utility as a knife. Interestingly, most of the tools that are widest in relation to their length do not show any evidence of projectile point use and only exhibit use-wear patterns associated to their use as knives. Perhaps these were used initially as knives and then as projectile points.
The hafting method of these points is a bit unclear. Edge grinding and other intentional dulling are limited to the basal corners that extend for less than $1 \mathrm{~cm}$ from the base. The basal corners are usually moderately ground, and grinding continues on to the basal margin. The central part of bases, where the point was presumably placed into a foreshaft, are usually not ground, but only lightly rounded and polished. Areas of bright polish occur on both small facets on basal edges, and on flake arises along the base on some points, suggesting light abrasion with hard stones. This wear is certainly from hafting, and suggests that the points were placed in a split or a V-notched foreshaft. Lashing was likely restricted to the lower centimeter of the blade (or less), coincident with the limits of edge-dulling. These points may have been attached to the haft principally with mastic or hide glue.

\section{Middle Archaic}

\section{Bulverde (11 specimens)}

The Bulverde points from the Gatlin site closely fit the attributes summarized and illustrated in Turner and Hester (1999:82-83) and the large sample $(\mathrm{n}=56)$ described by Karbula (2000:251ff) from the Eckols site in Travis County. Three selected Bulverde specimens from the Gatlin site are illustrated in Figure $9 \mathrm{a}-\mathrm{c}$.

One specimen (Lot 29.18; Figure 9 a) is made of a high-quality brown chert, which appears to have been heat-treated given its extensive sheen. Snap breaks are on the distal portions of two specimens (Lot 1529 and Lot 54.4; Figure $9 \mathrm{~b}$ ). The distal portions of several points have been extensively reworked and shortened (Lot 803, Lot 470, Lot 1254, Lot 1404, and Lot 87.2; Figure 9c). Measurements for the Bulverde specimens are presented in Table 12.

Distribution of the type in the southwestern Edwards Plateau generally consists of two or three specimens at a site (Dornheim 2002; Hester 1971), and Johnson (1995) does not report any of the type at 41ME29. However, Black and McGraw (1985:115) report 


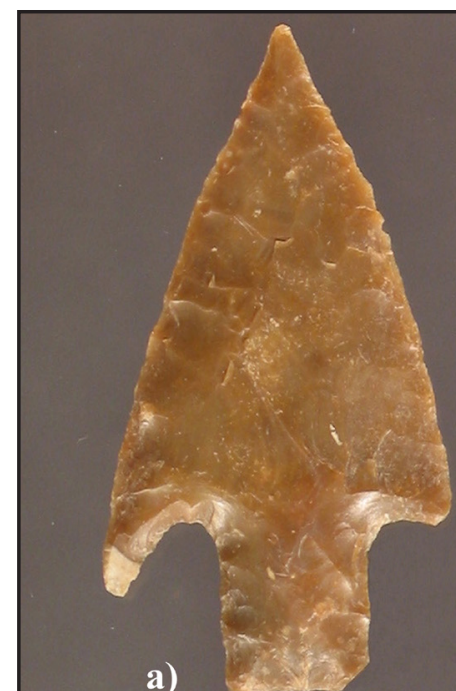

a)
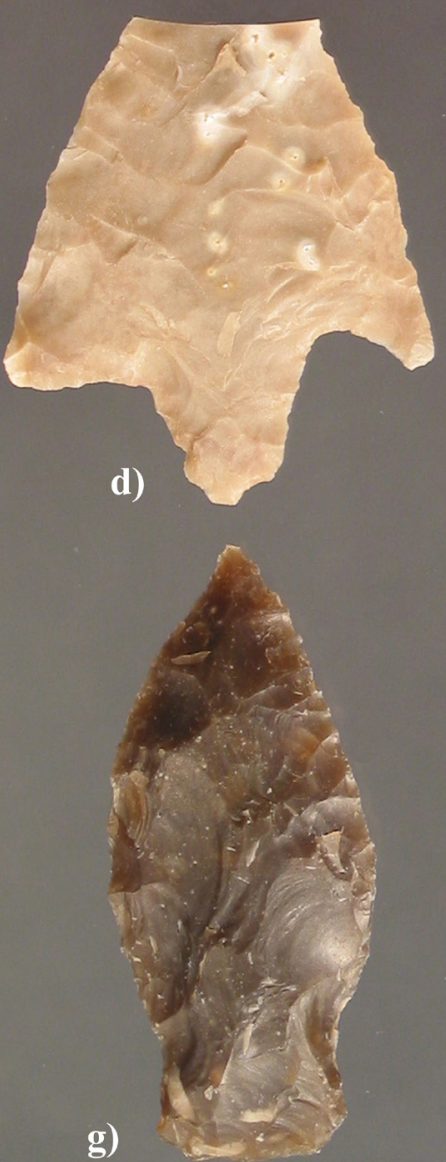
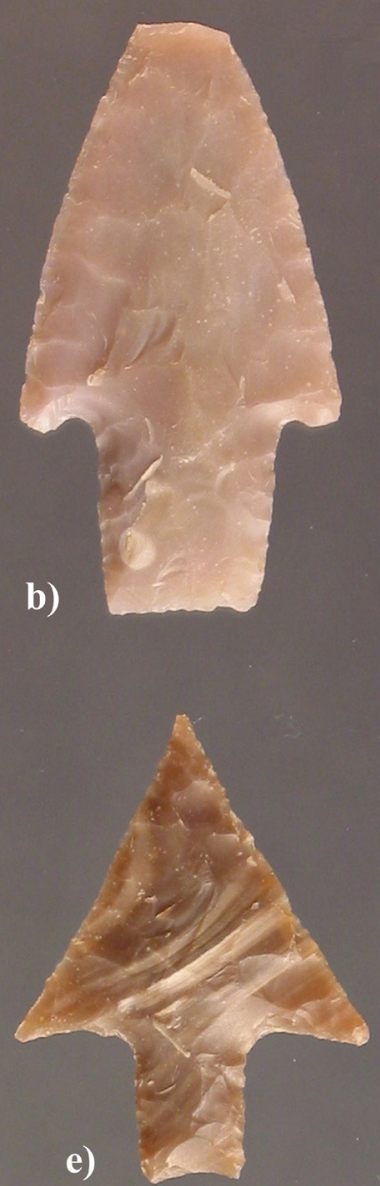

e)

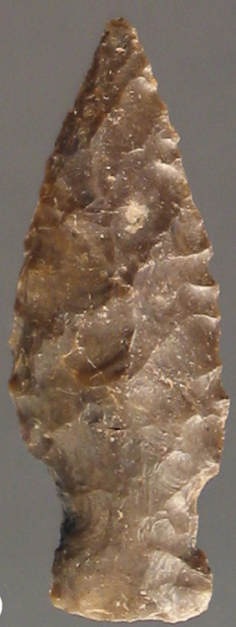

c)
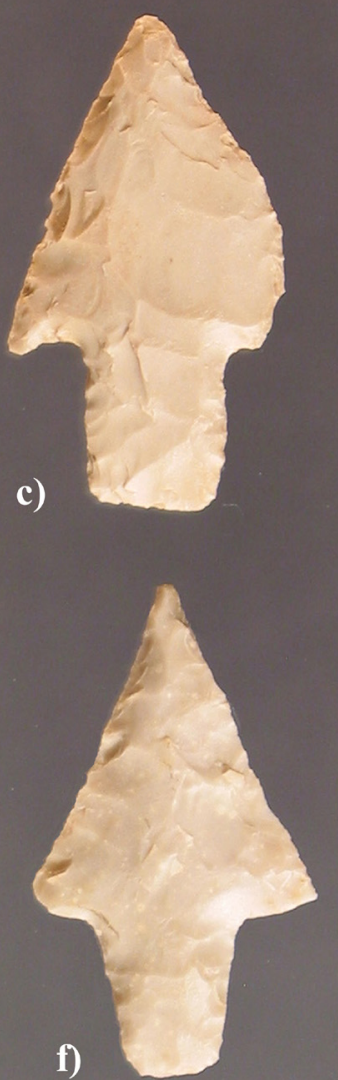

f)

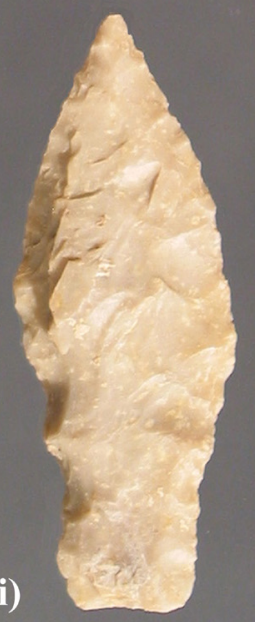

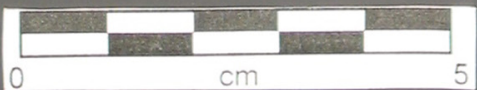

Figure 9. Bulverde projectile points. Lot numbers: a) 29.18; b) 54.4; c) 1254 . Langtry projectile points. Lot numbers: d) 42.3; e) 1314; f) 1382.2.

Pandale projectile points. Lot numbers: g) 20.3; h) 147.4; i) 314. 
Table 12. Bulverde Projectile Points Attributes Measurements

\begin{tabular}{|r|l|r|r|r|r|r|}
\hline \multicolumn{1}{|c|}{} & N & Mean & Min & Max & Std Dev \\
\hline \multirow{5}{*}{ Bulverde } & Max L & 11 & 57.09 & 33.90 & 75.70 & 12.921 \\
\cline { 2 - 7 } & Max Blade W & 10 & 31.88 & 23.70 & 41.50 & 5.617 \\
\cline { 2 - 7 } & Blade Mid Th & 10 & 5.16 & 4.10 & 5.80 & 0.615 \\
\cline { 2 - 7 } & Max Stem L & 11 & 19.63 & 15.00 & 24.10 & 2.366 \\
\cline { 2 - 7 } & Stem Neck W & 10 & 18.82 & 16.40 & 22.60 & 1.850 \\
\cline { 2 - 7 } & Stem Base W & 11 & 16.38 & 14.90 & 18.60 & 1.292 \\
\cline { 2 - 7 } & Basal Depth & 11 & 0.00 & 0.00 & 0.00 & 0.000 \\
\cline { 2 - 7 } & Weight & 11 & 10.53 & 6.20 & 17.60 & 3.541 \\
\hline
\end{tabular}

24 specimens from the Panther Springs Creek site, and Decker et al. (2000) tabulated 11 Bulverde points. Bulverde points predate Pedernales and are placed in the early part of the Late Archaic by Collins (2004:113), with a suggested age range of ca. $3,500-4,000$ years ago.

\section{Langtry (6 specimens)}

These points generally exhibit the attributes of the Langtry type, most common in the Lower Pecos region (Turner and Hester 1999:143-144) but also present in considerable numbers in the southwestern Edwards Plateau and in southern Texas. The following describes the Langtry specimens recovered from the Gatlin site of which a select few are represented in Figure $9 \mathrm{~d}-\mathrm{f}$. Four have contracting stems, wide, slightly barbed shoulders, and thin blades. Another would fit in this group, but it is essentially a "medial" fragment. Intense thermal fracture has removed the distal part of the blade, as well as the proximal end of the stem. A sixth specimen is also of "classic" form except for the stem, which is rectangular and with a slightly concave base.

All are made of brown to gray brown chert, with the exception of an unusual whitestreaked brown chert used for Lot 1314 (Figure 9 e). These six points could be referred to as an "Edwards Plateau variety" of Langtry, with many other examples from the Canyonlands area (e.g., Coleman et al. 2001; Decker et al. 2000; Black and McGraw 1985), as they lack the beveled contracting stem often found on Lower Pecos examples. The five specimens excavated at
41BN63 (Dornheim 2002:Fig. 3.4) are remarkably similar to the Gatlin site specimens. In the Lower Pecos, Langtry is usually placed in the Middle Archaic, around 4,000 years ago (Hester 1989:13). At site 41BN63, Langtry points occurred below the burned rock midden, and just above La Jita, in terms of chronology (Dornheim 2002; Hester 1985).

\section{Pandale (3 specimens)}

Though typical of the Lower Pecos area, Pandale points are occasionally found at sites in the southwestern Edwards Plateau (Decker et al. 2000; Hester 1971). All three specimens from the Gatlin site are complete (Figure $9 \mathrm{~g}-\mathrm{i}$ ). One of these (Lot 147.4; Figure $9 \mathrm{~h}$ ) is made of a very dark chert, possibly burned. It has an alternately beveled stem and a slight twist to the blade. One lateral edge is slightly serrated. The blade is marked by very fine flaking, parallel oblique on one face.

The second specimen (Lot 20.3; Figure $9 \mathrm{~g}$ ) is very similar, though wider. It is made of a dark brown semi-translucent chert. One of the stem edges is beveled, and the blade is slightly twisted. Flaking is fairly crude, possibly the result of reworking the tip and blade edges. Similar crude flaking patterns were observed on the third specimen (Lot 314; Figure $9 \mathrm{i}$ ). The stem is slightly twisted and a platform remnant is still present suggesting the specimen was manufactured from a flake. Measurements on these 3 specimens are represented in Table 13.

While the Pandale classification appears a sound one, it must be noted that the beveling that created

Table 13. Pandale Projectile Points Attributes Measurements

\begin{tabular}{|l|l|r|r|r|r|r|}
\hline \multicolumn{2}{|c|}{} & N & Mean & Min & Max & Std Dev \\
\hline \multirow{5}{*}{ Pandale } & Max L & 3 & 69.80 & 68.60 & 71.20 & 1.312 \\
\cline { 2 - 7 } & Max Blade W & 3 & 27.03 & 24.50 & 31.30 & 3.717 \\
\cline { 2 - 7 } & Blade Mid Th & 3 & 8.50 & 7.60 & 9.30 & 0.854 \\
\cline { 2 - 7 } & Max Stem L & 3 & 15.67 & 13.50 & 17.20 & 1.930 \\
\cline { 2 - 7 } & Stem Neck W & 3 & 17.70 & 16.20 & 20.60 & 2.512 \\
\cline { 2 - 7 } & Stem Base W & 3 & 18.83 & 15.50 & 21.90 & 3.208 \\
\cline { 2 - 7 } & Basal Depth & 3 & -1.70 & -3.30 & 0.00 & 1.652 \\
\cline { 2 - 7 } & Weight & 3 & 17.37 & 13.80 & 22.30 & 4.412 \\
\hline
\end{tabular}


the slight twists on the blades of these specimens is much less than the corkscrew twist seen on Lower Pecos specimens (Turner and Hester 1999:168). Pandale points were recovered from possible Early/ Middle Archaic components, at 41CM111 (Mahoney et al. 2003:40, Table 7-5), and at Panther Springs Creek (Black and McGraw 1985:120). In the Lower Pecos, Pandale points are placed in the Middle Archaic period (Shafer 1986). A radiocarbon date from Baker Cave (Hester 1983:104) obtained just below a distinctive Pandale occupation and garbage pit is $4690 \pm 140$ B.P. (uncorrected). Hester (1989:59) also notes radiocarbon assays for Pandale from several Lower Pecos sites, falling in the 4,700-4,100 B.P. time frame.

\section{Middle Archaic (Early) or Early Archaic (Late)}

\section{La Jita (44 specimens)}

This is the third largest typological category from the Gatlin site, and the largest sample of the La Jita type ever reported from an excavated site. Samples of these are illustrated in Figure 10. The type was originally defined by Hester $(1971: 74,76)$ based on specimens found at the La Jita site (41UV21) in the Sabinal Canyon (see Turner and Hester 1999:140). In finished form, La Jita points are corner notched, with elongate blades, slight shoulders, and broad, short stems. The stem is usually thinned by two to three longitudinal flakes from the basal edge. Removal of these flakes sometimes leaves the impression of a "concave" base when the platform area is not trimmed. The thinning often creates a "wedge-shaped" stem (cf. Nickels et al. 2000:155). The stem is sometimes beveled on one edge, and, occasionally, it is alternately beveled. However, the beveling seems to be directed at crushing or dulling the stem edges, perhaps to aid in hafting. A very distinctive trait is very steep, short retouch flakes that continue, unifacially or bifacially, around the stem corners. The corners are usually rounded, but the stem edge trimming is occasionally more extensive, leading to rounded or bulbous stem shapes.

La Jita points often have very heavily reworked blades, shortening the specimen and often creating slightly concave lateral edges. In most cases, the reworking appears designed to keep the specimen in use as a dart tip. However, no systematic high microscopy has previously been done to look for use-wear. The modifications of individual points

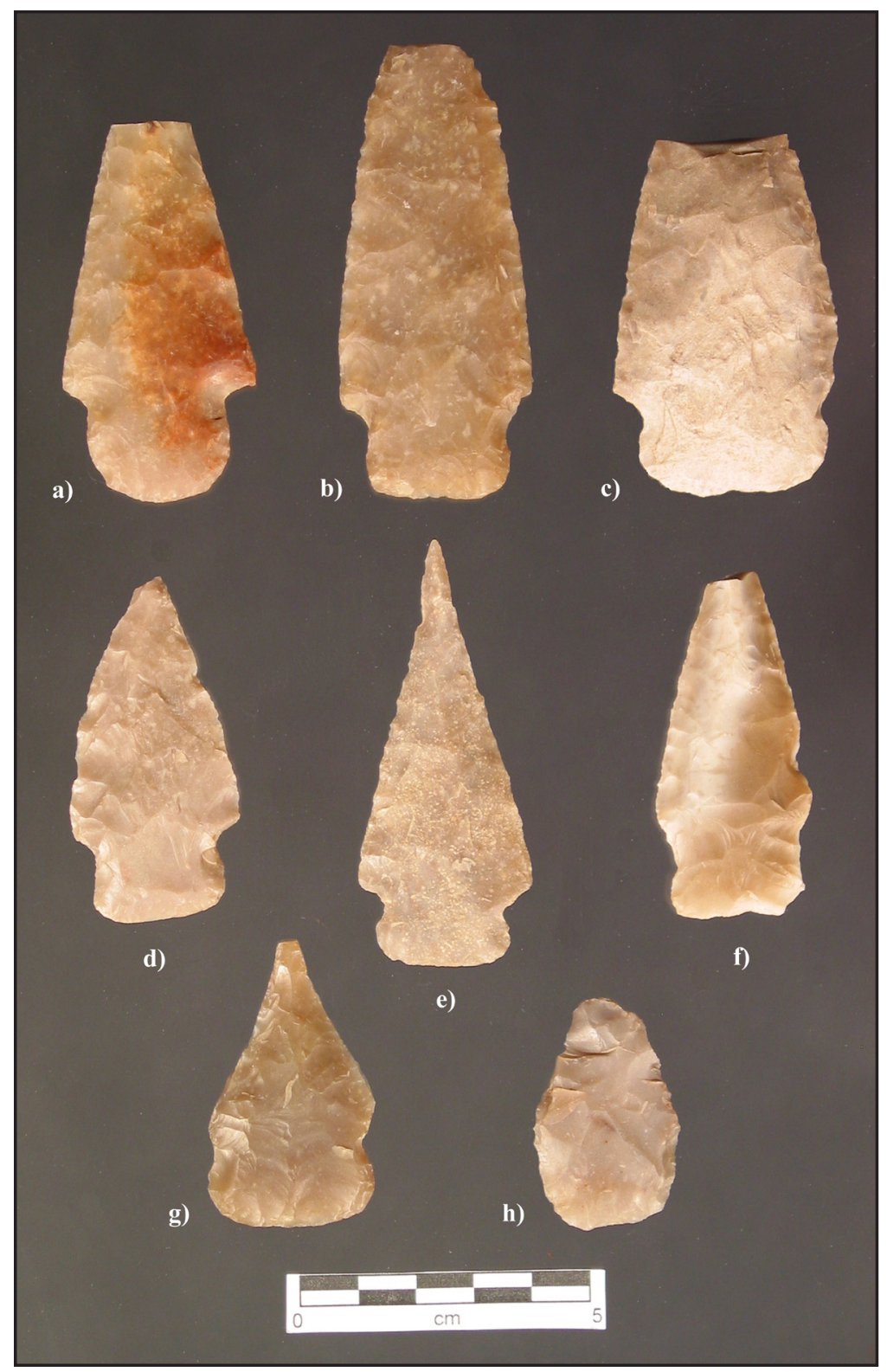

Figure 10. La Jita projectile points. Lot numbers: a) 1432; b) 1019 ; c) 1138 ; d) 1362.5 ; e) 1284 ; f) 1528 ; g) 1253 ; h) 1570 . 
sometimes affect the stems, with corner notching becoming side notching (usually located near the juncture of the stem with the blade), and the base is re-trimmed, making it slightly concave. These traits probably represent the re-seating and rehafting of the point on a dart shaft (or foreshaft).

In reviewing the La Jita sample, the points were sorted into three groups. Group I are "classic" La Jita artifacts, matching the description provided here (Figure $10 \mathrm{a}-\mathrm{d}$ ). Group II are specimens that are "side notched" and with a basal concavity; these are apparently the result of stem reshaping (Figure $10 \mathrm{e}-\mathrm{g}$,). Group III consists of points that have been heavily reworked, use-damaged, or exhibit intensive thermal fracturing. One example (Lot 1570; Figure $10 \mathrm{~h}$ ) has been so altered that it appears, at first glance, to be a small ovate triangular dart point. However, it still retains the distinctive stem-edge trimming of La Jita. Measurements for the La Jita specimens are presented in Table 14.

The La Jita type has been the subject of considerable discussion in publications dealing with the southwestern Edwards Plateau. In Hester's (1971:74) original description, based on seven specimens from the La Jita site and a number of others from site collections at TARL, it was offered as a "tentative new type." In the late 1970s, the point type was reported from several sites in the region (e.g., Gerstle et al. 1978; Kelly and Hester 1976). Carroll (1983) reported "over 150" specimens from a site on Winans Creek in Bandera County. He proposed the type name "Medina," but Hester (1983) pointed out that the specimens were of the previously published La Jita type.

Table 14. La Jita Projectile Points Attributes Measurements

\begin{tabular}{|l|l|r|r|r|r|r|}
\hline \multicolumn{2}{|c|}{} & \multicolumn{1}{c|}{ N } & Mean & \multicolumn{1}{c|}{ Min } & Max & Std Dev \\
\hline \multirow{7}{*}{ La Jita } & Max L & 43 & 52.42 & 23.90 & 84.00 & 13.328 \\
\cline { 2 - 7 } & Max Blade W & 41 & 31.76 & 23.50 & 40.80 & 3.697 \\
\cline { 2 - 7 } & Blade Mid Th & 32 & 6.23 & 3.90 & 7.60 & 0.739 \\
\cline { 2 - 7 } & Max Stem L & 41 & 15.40 & 11.60 & 19.40 & 1.828 \\
\cline { 2 - 7 } & Stem Neck W & 39 & 23.87 & 18.50 & 30.80 & 2.293 \\
\cline { 2 - 7 } & Stem Base W & 38 & 24.81 & 21.30 & 32.20 & 2.290 \\
\cline { 2 - 7 } & Basal Depth & 40 & -0.94 & -5.30 & 2.40 & 2.051 \\
\cline { 2 - 7 } & Weight & 44 & 12.42 & 5.50 & 22.40 & 3.566 \\
\hline
\end{tabular}

Turner and Hester (1999:140) suggest that La Jita might be an unfinished stage in the manufacture of Nolan points (see also Black and McGraw [1985:117-118], who noted that La Jita may "grade" into Nolan). However, 1985 excavations at 41BN63 (Dornheim 2002:27-28; Hester 1985) recovered 15 specimens. A number were found beneath the burned rock midden at the site, associated with small pits containing scattered charred acorns. A radiocarbon date of $4260 \pm 390$ B.P. (uncorrected; TX 7066) was obtained from one of the acorns and is directly linked to the La Jita type. Baker (2003:21-22) reports 30 La Jita excavated at the Smith site (41UV132), on the Sabinal River just upstream from the La Jita site. Baker (2003:21-22) notes that La Jita points occur somewhat above Nolan points at this site. Nickels et al. (2001:216) report two radiocarbon dates for Nolan at 41BX126: $4630 \pm 40$ B.P. and $4940 \pm 50$ B.P. (both uncorrected).

Although no descriptive details are available, a point sequence published by Skinner 1974:143) for Bushwhack Shelter (41KR116) shows what is clearly a La Jita point at the bottom of the deposits. However, since Martindale points are in the level above, this part of the stratigraphy is either mixed or compressed.

Of the 44 specimens representing the La Jita type at the Gatlin site, 14 (32 percent) were subjected to usewear analysis. Overall, this type has several patterns that typically occur on most tools, including the corpus of tools recovered from the Gatlin site. All tools have hafting wear, not surprising given their stems and shallow notches. Shallow notches generally have moderate to pronounced step flaking, which served to dull the notch for lashing. Most basal indentations have little or no wear, but display clean bending initiations from final basal thinning. Adjacent basal edges have contiguous bifacial flaking and polish, which dulled the base in areas that were next to the tool haft. Most tools also evidence resharpening in the form of pressure flakes with bending initiations that cleanly cross-cut abrasive or flaking wear. Most points display clear impact fractures indicative of dart 
points, in addition to wear patterns suggesting multifunctional use.

\section{Nolan (28 specimens)}

The Nolan sample sorts mainly into two groups. Group I ( $\mathrm{n}=12)$ can be described as "classic" Nolan (Turner and Hester 1999:164), with elongate blades, tapered shoulders, and steeply alternately beveling on the stem (Figure $11 \mathrm{a}-\mathrm{c})$. Group II $(\mathrm{n}=14)$ are clearly Nolan points, but are best characterized on technological grounds as "Nolans later in life"-with lateral edge reworking leading to diminished blade sizes, stem reshaping or alteration, impact and other fractures, as well as extensive thermal fractures (Figure $11 \mathrm{~d}-\mathrm{f}$ ).

Several Group I Nolan points are broken, most by snap fractures that removed the distal ends. One extremely well made Nolan (Lot 807.6; Figure 11 b) has impact damage at its tip. Another, Lot 15.1 (Figure $11 \mathrm{a}$ ), appears to be made from heat-treated chert. Most interesting are two Nolan points (Lot 265 and Lot 1252; Figure $11 \mathrm{c}$ ) that are made from a very dark gray-brown ("black") opaque chert, a material seen rarely in this assemblage.

In Group II, most of the specimens have been narrowed or shortened by reworking after a distal break. Others have been split or fragmented by intense burning. Specimen Lot 1374 (Figure 11 e) exhibits distal reworking, along with the reshaping of one entire side (shoulder removed). One (Lot 1256) may be made on heat-treated chert, and another (Lot 1141) is of the "black" chert noted above.

One large, thick, stemmed biface UI 288 (Lot 906; Figure 11 d) is most likely a Nolan preform. It has a long blade, with many step fractures (hinging) along one edge (this appears to be from efforts at thinning, not use-wear). The stem contracts slightly and there is a steep bevel on one edge. The preform was probably abandoned because of the

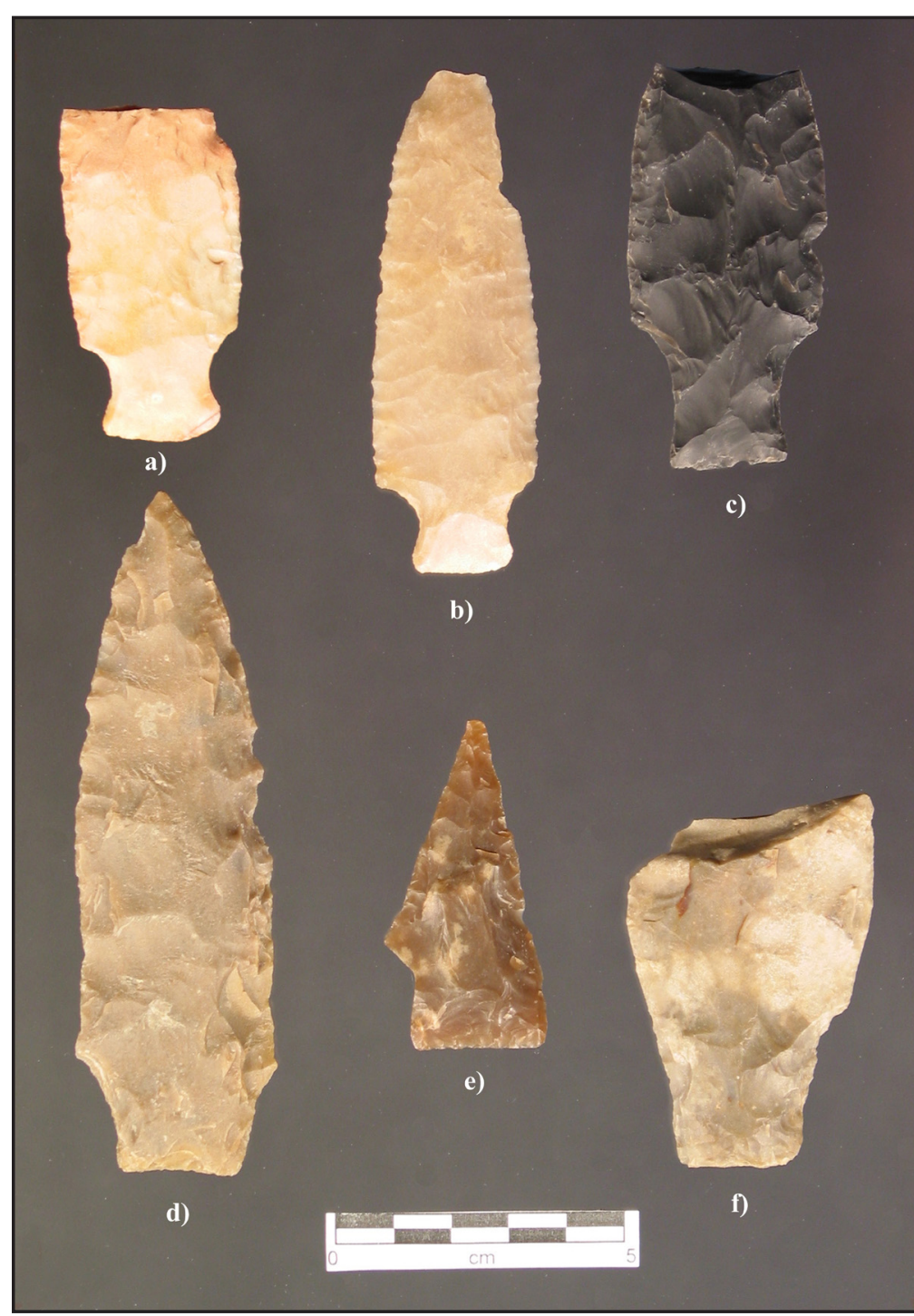

Figure 11. Nolan projectile points. Lot numbers: a) 15.1; b) 807.6; c) 1252; d) 906; e) 1374; f) 266. extensive hinging. The hinging may have resulted in an effort to set up that edge for pressure thinning. A second preform (Lot 266; Figure $11 \mathrm{f}$ ) is roughly lanceolate in outline and broken at midsection by a snap break. The break appears to have happened during efforts by the flintknapper to remove a hinge "stack" near one edge. The basal edges are slightly concave, one being a bit more inset and beveled along the edge. Light dulling can be felt along the lateral edges, perhaps edge-grinding for final thinning.

Measurements for the Nolan specimens are presented in Table 15. Nolan points are much more common in Central Texas than in the southwestern Edwards Plateau (e.g., Dial et al. 1998; Karbula 
Table 15. Nolan Projectile Points Attributes Measurements

\begin{tabular}{|l|l|r|r|r|r|r|}
\hline \multicolumn{1}{|c|}{} & \multicolumn{1}{c|}{ N } & Mean & Min & Max & Std Dev \\
\hline \multirow{7}{*}{ Nolan } & Max L & 28 & 58.43 & 21.20 & 117.40 & 19.080 \\
\cline { 2 - 7 } & Max Blade W & 25 & 28.80 & 23.50 & 41.80 & 4.479 \\
\cline { 2 - 7 } & Blade Mid Th & 18 & 6.88 & 5.30 & 10.10 & 1.383 \\
\cline { 2 - 7 } & Max Stem L & 27 & 15.80 & 11.40 & 22.90 & 2.580 \\
\cline { 2 - 7 } & Stem Neck W & 26 & 18.41 & 13.70 & 24.80 & 2.785 \\
\cline { 2 - 7 } & Stem Base W & 27 & 19.27 & 10.80 & 24.60 & 2.794 \\
\cline { 2 - 7 } & Basal Depth & 27 & -0.26 & -2.90 & 1.00 & 0.847 \\
\cline { 2 - 7 } & Weight & 28 & 13.36 & 2.80 & 42.70 & 7.954 \\
\hline
\end{tabular}

2000:248-249). Decker et al. (2000:Table 13) report 10 specimens from 41 UV88 in the Dry Frio River drainage, while Dornheim (2002:28-29) notes only three from 41BN63.

Collins (2004:113) places Nolan in the late part of his Middle Archaic, roughly 4,000-4,500 B.P. Wood charcoal associated with Nolan and "Travis-like" points is dated at $3560 \pm 70$ B.P. (uncorrected) at the Olmos Basin site, 41BX1 (Lukowski 1988:15; TX2927).

A total of 10 specimens ( 36 percent) from the Gatlin site were subjected to use-wear analysis. These tools exhibit a variety of use-wear patterns representative of dart points (one of which was also a knife), a drill, and knives used to cut various contact materials. The largest of these tools was a hide scraper. Most of these tools were extensively resharpened and reworked, and therefore, the remaining traces of wear represent the functions at the end of each tool's use-life.

\section{Travis (3 specimens)}

Specimens sorted into the Travis type are often those that cannot be put safely into Nolan, often due to the absence of beveling on the stem edges (Karbula 2000:249). However, artifacts from the Gatlin site fit the description in Turner and Hester (1999:189), with rounded shoulders and stems that are generally rectangular (Figure 12). Of particular interest in this small sample is one specimen (Lot 149; Figure 12 b)

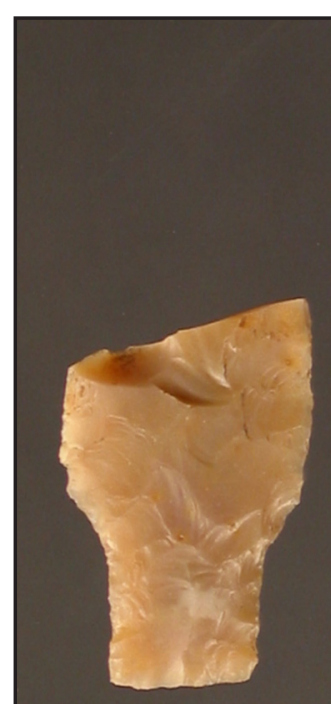

a) represented in Table 16.

that had apparently patinated before being reworked, exposing brown chert. It has a small impact fracture at the tip, and one shoulder was also removed likely from impact. Another specimen is a late-stage Travis preform. The stem has not been thinned, and a portion of the flake platform remains on the basal edge. Additionally, the lateral edges are not thinned, due to repeated hinging, or step fractures. Measurements on these 3 specimens are Although Travis points are commonly reported in Central Texas (Karbula 2000), the integrity (or usefulness) of the type in the southwestern Edwards Plateau is still a matter of contention. It is rarely reported, usually represented by one or two specimens (e.g., Hester 1971). Collins (2004:113) places Travis, along with Nolan, in the late part of the Middle Archaic.

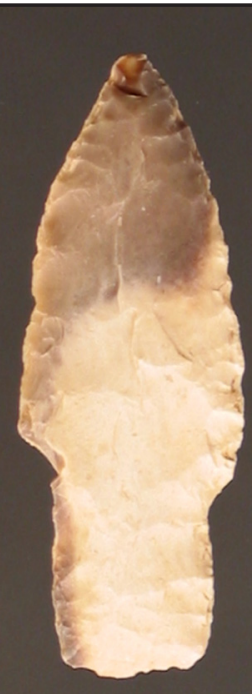

b)

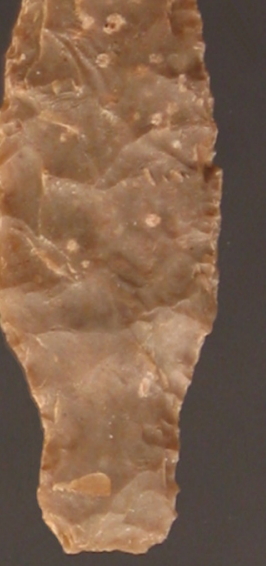

c)

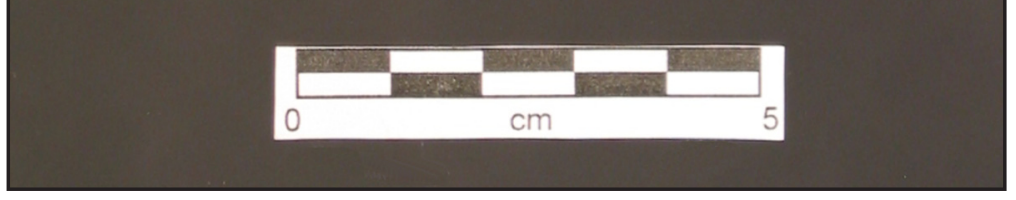

Figure 12. Travis projectile points. Lot numbers: a) 133.3; b) 149; c) 807.5. 
Table 16. Travis Projectile Points Attributes Measurements

\begin{tabular}{|l|l|r|r|r|r|r|}
\hline \multicolumn{2}{|c|}{} & \multicolumn{1}{c|}{ N } & Mean & Min & Max & Std Dev \\
\hline \multirow{5}{*}{ Travis } & Max L & 3 & 55.93 & 40.80 & 66.80 & 13.515 \\
\cline { 2 - 7 } & Max Blade W & 3 & 25.03 & 24.20 & 26.70 & 1.443 \\
\cline { 2 - 7 } & Blade Mid Th & 2 & 6.40 & 5.90 & 6.90 & 0.707 \\
\cline { 2 - 7 } & Max Stem L & 3 & 17.17 & 15.70 & 18.10 & 1.286 \\
\cline { 2 - 7 } & Stem Neck W & 3 & 15.90 & 14.50 & 16.60 & 1.212 \\
\cline { 2 - 7 } & Stem Base W & 3 & 15.73 & 15.10 & 16.20 & 0.569 \\
\cline { 2 - 7 } & Basal Depth & 3 & 0.17 & 0.00 & 0.50 & 0.289 \\
\cline { 2 - 7 } & Weight & 3 & 10.63 & 6.80 & 13.70 & 3.513 \\
\hline
\end{tabular}

\section{Late Archaic}

\section{Lange (5 specimens)}

Lange specimens recovered during excavations at the Gatlin site are shown in Figure 13 a-e. One specimen (Lot 327; Figure $13 \mathrm{~b}$ ) is complete, made of light brown chert. It has a "needle point" tip, corner-notched stem, and vertical flakes thinning the stem. One large thinning flake removed a portion of the basal edge, giving it a "recurved" form. A second specimen (Lot 132.4; Figure 13 d) of dark brown chert is large and heavy, and is likely a latestage preform. A snap break at the distal end has at least one large flake removed from its edge, running back toward the proximal end. The specimen is corner notched, with one barb broken. The third artifact (Lot 1107; Figure 13 a) has been considerably reworked, with removal of broad flakes on one face. The distal break may combine both snap and impact fractures. Material is light brown chert. The final two specimens include a stem fragment (UI 291; Lot 863; Figure $13 \mathrm{c}$ ) and a heavy specimen lacking the tip (snap break) and one corner of the stem (UI 9; Lot 655; Figure 13 e)

Lange typology is often an exercise in guesswork. Various analysts will sort corner-notched dart points into Marcos, Marshall, Castroville, and Lange. All are very close in terms of chronology, in the middle part of the Late Archaic (Collins 2004:113). The specimens from the Gatlin site fit well into the type as defined and illustrated by Karbula (2000:261), where a large sample $(n=36)$ was available from the Eckols site.

\section{Marcos (3 specimens)}

All of the Marcos specimens collected at the Gatlin site are illustrated in Figure $13 \mathrm{f}-\mathrm{h}$. Two are badly fragmented proximal fragments, though they retain the corner notching, expanding stem and flaking technology characteristic of Marcos. The third has been badly damaged by thermal fracturing, but retains stem and flaking characteristics of the type.

It is interesting that Marcos distribution is irregular in the southwestern Edwards Plateau. For example, at excavated sites in the Sabinal Canyon, none were found at $\mathrm{La}$ Jita (Hester 1971), yet 18 were found at 41UV159 (Mueggenborg 1994), and Baker (2003:Table 3) tabulates (but does not illustrate) 10 specimens from the Smith site (4lUV132). Marcos is roughly contemporary with Montell and Castroville, in the Late Archaic (Collins 2004:113).

\section{Marshall (8 specimens)}

Of the eight Marshall specimens encountered at the Gatlin site, five are represented in Figure 14 ae).Three of the specimens are preforms, although Lot 1091.1 (Figure 14 a) is likely a "late-stage preform." It was broken during excavation, but appears to be unfinished due to a gray, coarse inclusion at the tip. Additionally, a thinning flake ("flute") was removed from the basal edge, but the edge was never trimmed, leaving an atypical "recurved" shape. The other two preforms (Lots 1321 and 790; Figure $14 \mathrm{~b}$ and c) are both crude, marked by step or hinge fractures.

Common in the Central Texas Late Archaic (Collins 2004:113), Marshall points sometimes seem to overlap typologically and technologically with Pedernales and Lange (Karbula 2000:264). For example, both Pedernales and Marshall have stems typically thinned by broad flute-like flakes; reworked specimens in both types sometimes overlap. The expanding stem found on Marshall can also cause problems with separating these points from Lange (cf. Turner and Hester 1999:141); additionally, strongly barbed Marshall points (such as Lot 1319; Figure $14 \mathrm{~d}$ ) resemble the Castroville type (cf. Black and McGraw 1985:111).

\section{Montell (6 specimens)}

Five of the specimens are easily classified as Montell (Turner and Hester 1999:157), and all are proximal 


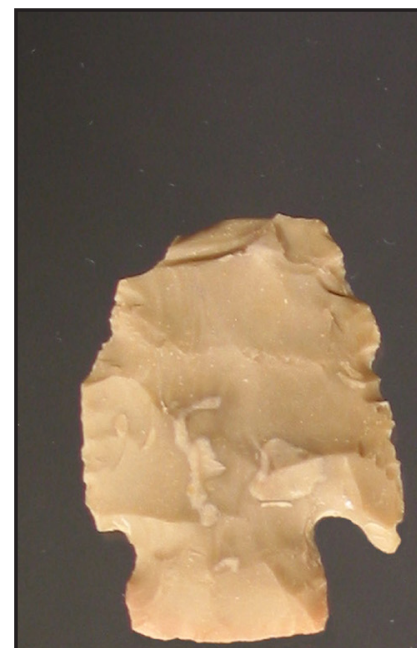

a)

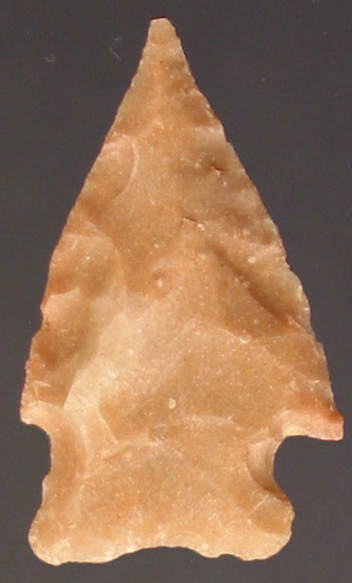

b)

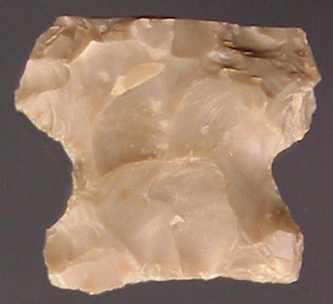

c)

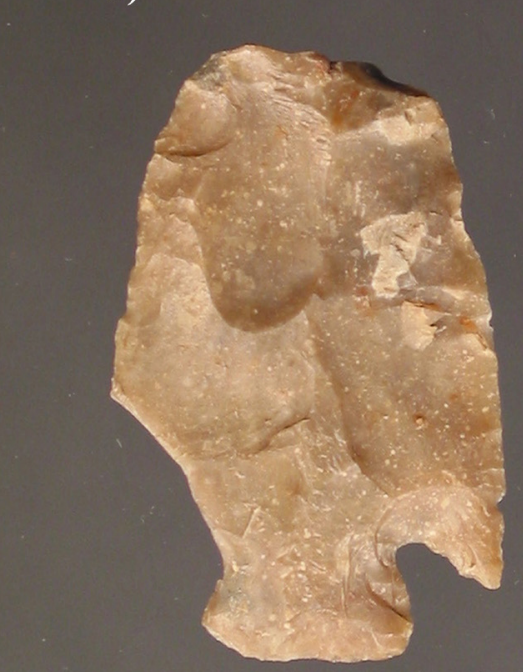

d)

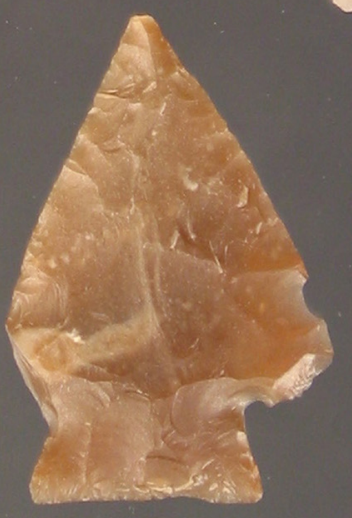

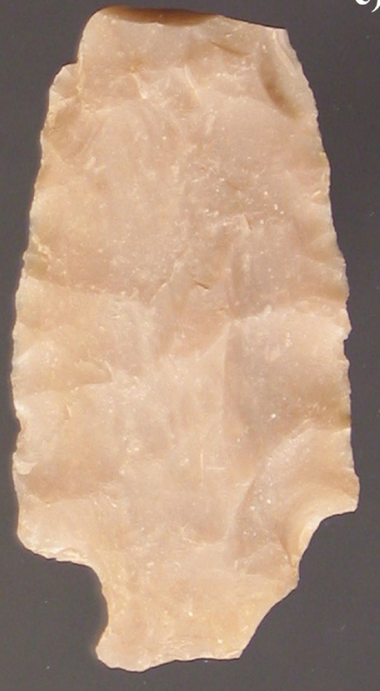

e)

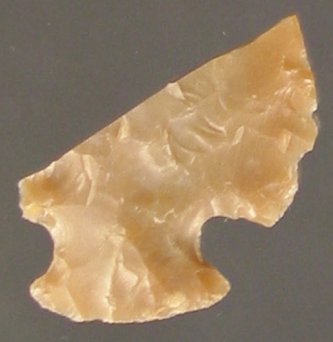

f) g)

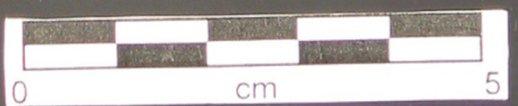

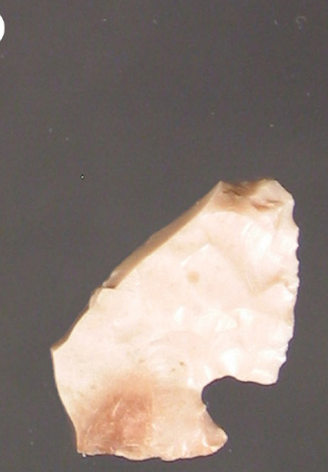

h)

Figure 13. Lange projectile points. Lot numbers: a) 1107 ; b) 327 ; c) 863 ; d) 132.5 ; e) 655. Marcos projectile points. Lot numbers: f) 503.1; g) 1120; h) 1196.4. 


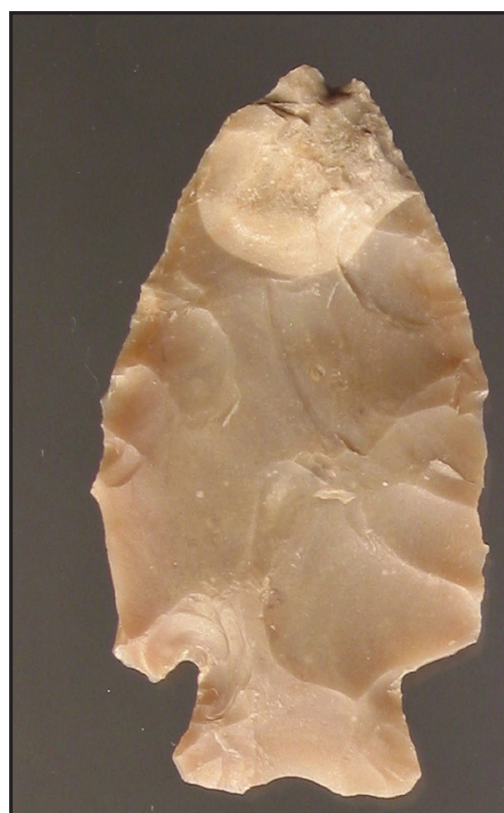

a)

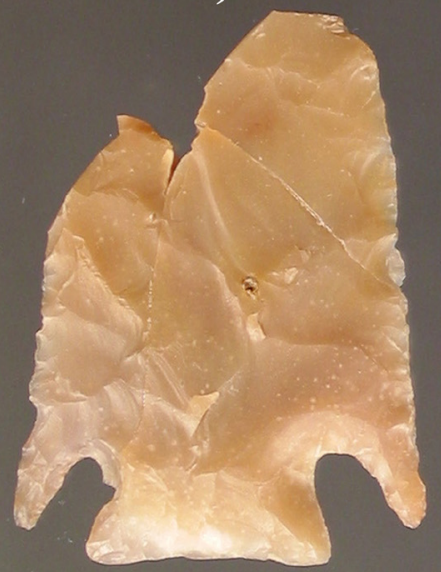

d)

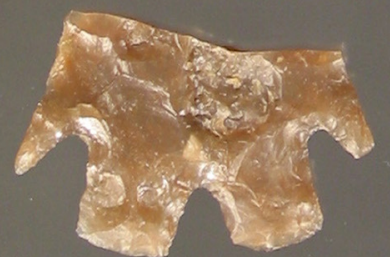

g)

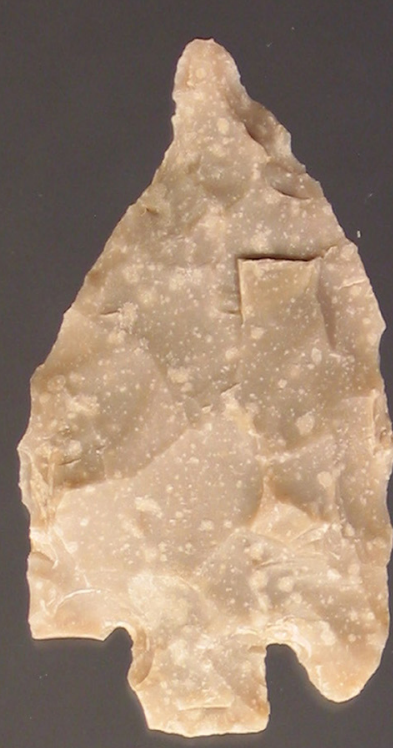

b)

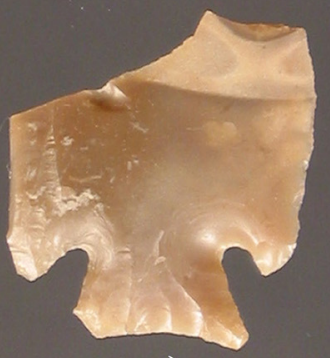

e)

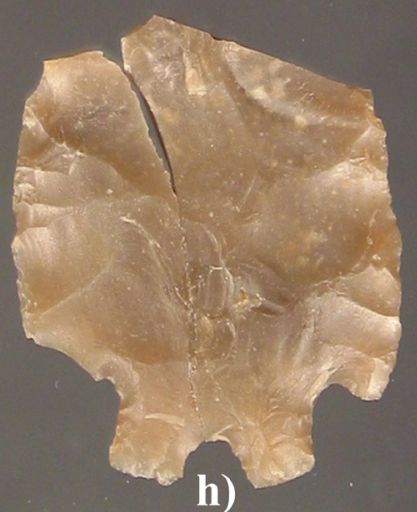

h)

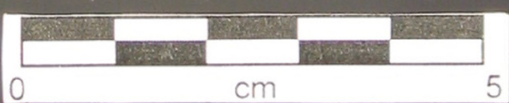

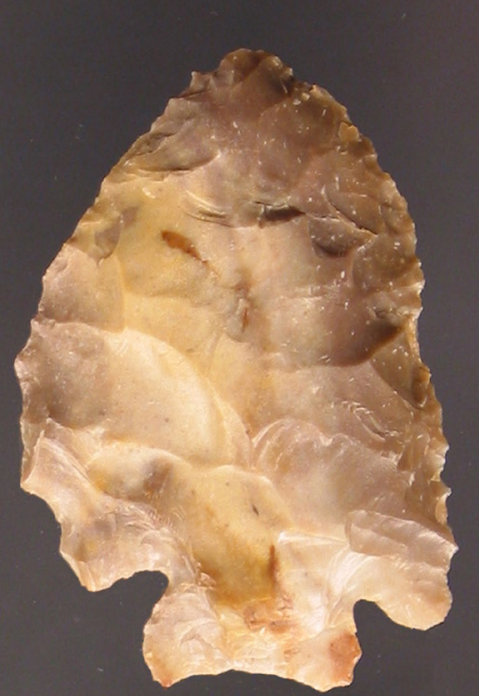

c)

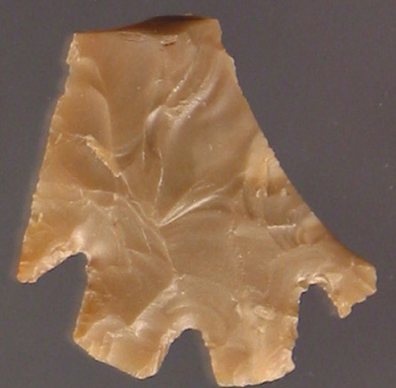

f)

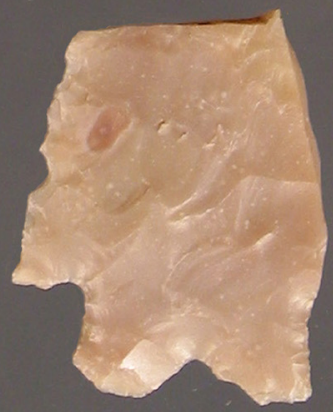

i)

Figure 14. Marshall projectile points. Lot numbers: a) 1091.1; b) 1321; c) 790; d) 1319; e) 1543.1 . Montell projectile points. Lot numbers: f) 10; g) 1195.1; h) 1098; i) 1396.2. 
fragments (Figure $14 \mathrm{f}-\mathrm{i}$ ). One (Lot 1322.4) is a large proximal fragment with one ear snapped off, and-combined with the missing barbs and snap break at the distal end-barely resembles Montell at first glance.

Montell is an extremely common type in the Late Archaic of the southwestern Edwards Plateau. Though the sample at the Gatlin site is small and sheds little light on Montell technology, a larger sample $(\mathrm{n}=88)$ from 41ME29 allowed Johnson (1995:207ff) to review in detail the variations in preforms and of reshaping within the type (similar data for a smaller sample $[\mathrm{n}=16]$ was published by Goode [2002:69]). In excavated samples of substantial size, there are preforms (usually with the stem shaped before the distal portion is reduced and thinned) and considerable variation in blade shape due to reworking (see Dornheim 2002:51).

\section{Late/Middle Archaic}

\section{Tortugas (2 specimens)}

Based on the technology of manufacture, distinctive from that of Early Triangular, these triangular points are classified as Tortugas (Figure 15 a and b). One specimen (Lot 776; Figure 15 b) was broken by impact fractures (a flake and a separate impact "burin") at the tip, then was reworked by beveling one of the lateral edges. Measurements on these two specimens are represented in Table 17.

Until the 1970s, the Tortugas classification was used to include Early Triangular points. Points separated from Early Triangular and recognized as Tortugas are fairly rare in the Canyonlands (Turner and Hester 1999). Moreover, separating Tortugas from what Goode (2002:Fig. 15) has defined as used/rejuvenated Kinney points would be almost impossible. Turner and Hester (1999:188) assign Tortugas to the late part of the Middle Archaic in south Texas, but its full chronological range remains unclear.

\section{Middle Archaic (Late) and Late Archaic}

\section{Kinney (2 specimens)}

Two Kinney points were recovered from the Gatlin site (Figure $15 \mathrm{c}$ and d). One specimen (Lot 1526; Figure 15 d) is marked by a concave base, broad

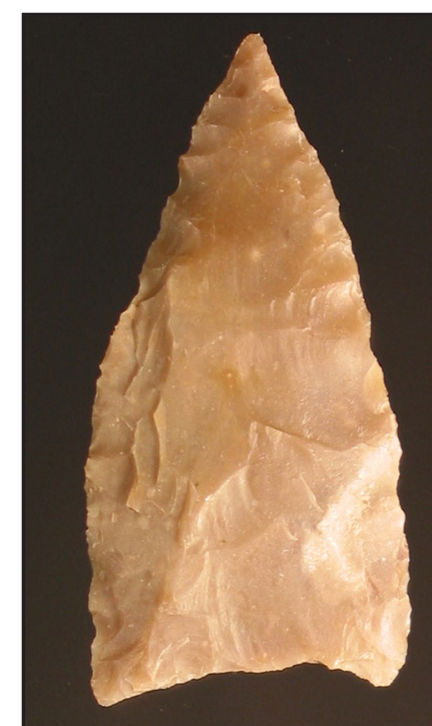

a)

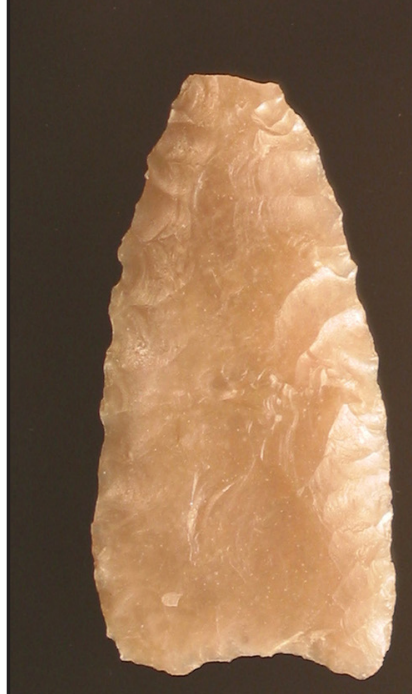

c)

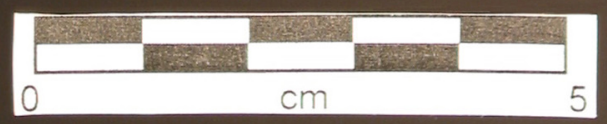

Figure 15. Tortugas projectile points. Lot numbers: a) 788; b) 776. Kinney projectile points. Lot numbers: c) 1430; d) 1526. 
Table 17. Tortugas Projectile Points Attributes Measurements

\begin{tabular}{|l|l|r|r|r|r|r|}
\hline \multicolumn{1}{|c|}{} & \multicolumn{1}{c|}{ N } & Mean & Min & Max & Std Dev \\
\hline \multirow{5}{*}{ Tortugas } & Max L & 2 & 58.45 & 55.90 & 61.00 & 3.606 \\
\cline { 2 - 7 } & Max Blade W & 2 & 28.55 & 27.80 & 29.30 & 1.061 \\
\cline { 2 - 7 } & Blade Mid Th & 2 & 7.50 & 6.80 & 8.20 & 0.990 \\
\cline { 2 - 7 } & Max Stem L & & & & & \\
\cline { 2 - 7 } & Stem Neck W & & & & & \\
\cline { 2 - 7 } & Stem Base W & 2 & 28.55 & 27.80 & 29.30 & 1.061 \\
\cline { 2 - 7 } & Basal Depth & 2 & 1.05 & 0.00 & 2.10 & 1.485 \\
\cline { 2 - 7 } & Weight & 2 & 13.95 & 12.80 & 15.10 & 1.626 \\
\hline
\end{tabular}

Pedernales (29 specimens)

Pedernales points were sorted on the basis of blade and stem forms following Tomka et al. (2003:133-145). The purpose of using this model is to add to the broader database investigating for stylistic and technological variability in Pedernales points across the greater central Texas region. Pedernales stem forms were divided into six stylistic groups based on shape (Tomka et al. 2003:Fig.

flaking on the blade, and a small remnant of cortex on one face. At the distal end, there appears to be a snap break. An excavation break (shovel?) has badly damaged one lateral edge. Goode (2002) has published a detailed analysis of Kinney points from the Anthon site. He argues that an "amalgamation" of Kinney and Pedernales points is found in southern Uvalde County, though his map (Goode 2002:Fig. 109) notes Kinney's wider distribution into Kerr and other south-central Texas counties.

Kinney appears at most sites to be contemporary with Pedernales (Collins 2004:113). At the southern edge of the Canyonlands, at site 41BX1 (Olmos Basin site), Lukowski (1988:15) reports an uncorrected radiocarbon assay (on wood charcoal) of $3710 \pm 250$ B.P. for Kinney. Collins (2004:113) puts Kinney in the middle part of his Late Archaic, around 2,500-3,500 B.P.

One of the two Kinney specimens (UI 210, Lot 1430; Figure $15 \mathrm{c}$ ) from the Gatlin site was subjected to use-wear analysis. The specimen likely served first as a dart point and later as a light duty knife. The widest part of the blade is at the ground margin, suggesting that the blade was once much wider, but was resharpened. Additionally, the blade edges display discontinuous, light-intensity, rounding and matte polish with a portion of the blade edge unworn. This pattern of use-wear suggests its utility as a knife to cut soft animal products. The point in its present condition would have little ability to create an entry wound and penetrate a prey animal. Thus, its use-life as a projectile point had reached an end, though there was remaining utility as a knife.
12-1). These stem forms are described as follows (from Tomka et al. 2003:134-136; Fig. 12-1) and examples of such from the Gatlin site are illustrated in Figure 16. All specimens have indented bases to varying degrees.

Stem Form 1 are described as having straight stem with convex stem edges and rounded stem corners. Bases are slightly to moderately indented (Figure $16 \mathrm{a}$ and $\mathrm{b}$ ).

Stem Form 2 are distinguished by barrel-shaped stems with convex stem edges and rounded stem corners (Figure $16 \mathrm{c}$ and d).

Stem Form 3 specimens have slightly expanding stems, straight stem edges, and sharp stem corners. Bases are slightly indented compared to other forms. often becoming slightly convex at the basal corner, rounded stem corners, and deeply indented bases (Figure $16 \mathrm{e}-\mathrm{g}$ ).

Stem Form 5 points are distinguished by slightly contracting stems with straight edges, usually sharp base corners, and shallowly to moderately indented bases.

Stem Form 6 is similar to Stem Form 2 by their contracting stems with convex, barrel-shaped edges, moderately to deeply indented base (Figure $16 \mathrm{~h}$ and i).

Blade technologies were grouped into three technological categories by Tomka et al. (2003:136; Figures 21-2, 12-3, and 12-4), who noted that a combination of certain stem and blade forms did show significant,
Stem Form 4 examples have straight stem edges 


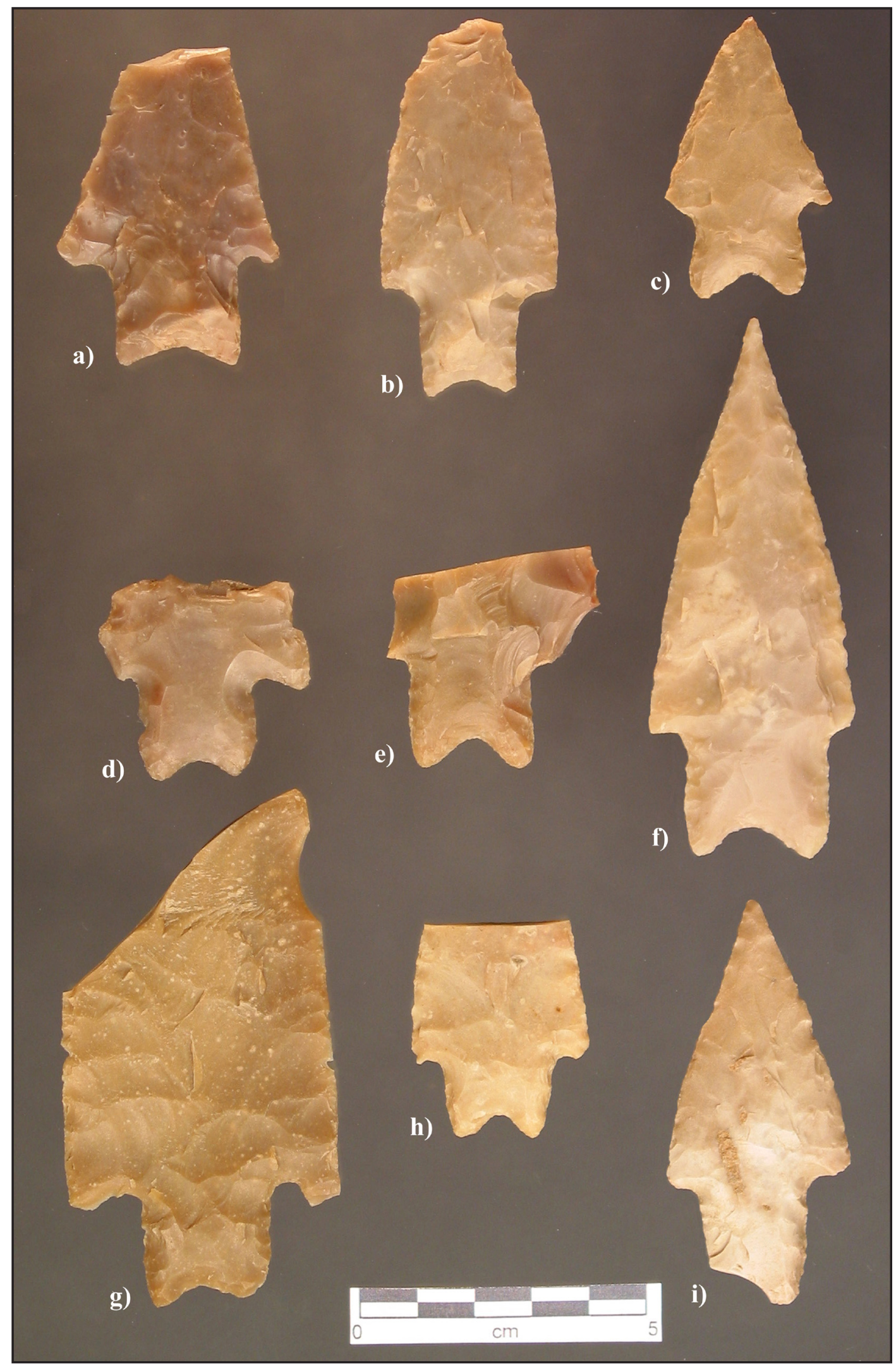

Figure 16. Pedernales projectile points. Lot numbers: a) 1180; b) 1323; c) 1132; d) 1237; e) 1074; f) 12; g) 1334; h) 1094; i) 1287. 
albeit hazy, geographic distribution across Central Texas. Of the three blade forms, Blade Form $2(n=1)$ and Blade Form $3(n=18)$ were present in the Gatlin site sample. Blade Form 2 is the heavily barbed variety, and Blade Form 3 is the broadly shouldered, slightly barbed variety.

The Pedernales sample from the Gatlin site is more varied with regards to stem forms than blade forms. Where classification was possible, the sample included Stem Forms $1(n=6)$, Stem Form $2(n=4)$, Stem Form $4(n=13)$, and Stem Form $6(n=3)$.

Technological variation within the sample was minimal. The technology employed to thin and marginally finish Pedernales points is notably different from that observed with Early Triangular and Martindale. The fine pressure retouch technology noted on Martindale and Early Triangular blades was absent in the Pedernales sample. Basal thinning on 17 specimens was accomplished by fluting the base from one or both sides. This is a very common method of basal thinning on Pedernales points across much of Central Texas (Tomka et al. 2003:134).

A further comparison of the Gatlin site sample to that reported by Tomka et al. (2003) provides some information suggesting there are indeed regional varieties within the Pedernales stem morphology. In their study, Tomka et al. (2003) noted that Stem Forms 1 and 5 showed significant distributions in Bell and Milam Counties, respectively. Stem forms 2 and 4 are the most common throughout central Texas and the Canyonlands, with Stem Forms 1 and 5 either being very weakly represented or not represented at all in the Canyonlands. Distinguishing between Stem Forms 2 and 4 is often like determining the differences between shades of gray. If these two forms are collapsed in the data presented in Tomka et al. (2003), then regional variants of Pedernales become a bit more apparent. Stem forms 2 and 4 predominate in the Hill Country; Stem Form 1 is the most prominent in the Lampasas Cut Plain; and Stem Form 5 predominates in the Blackland Prairie. It would indeed be interesting to compare these stylistic patterns to the distribution of other kinds of material culture at this time period throughout Central Texas.

Four Pedernales preforms are in the sample. Two were broken by snap fractures, another by a perverse fracture, and one damaged during excavation (Lot 16). Preforms are common in Pedernales assemblages in the southwestern Edwards Plateau (Black and McGraw 1985; Goode 2002; Hester 1971; Johnson 1995) and Goode (2002) suggests that the reduction sequence started in at least two different ways. In one, a bifacial preform is produced, the base is corner notched, and the shape of the stem is completed. In the other trajectory, the stem is carefully shaped before any major work was done on a bifacial blank (e.g., carefully shaped stems are often found on thick flakes [Hester 1971]). Decker et al. (2000:235ff) provide a detailed description and numerous illustrations regarding Pedernales manufacturing strategies, based on their sample of 105 specimens at the Woodrow Heard site (41UV88).

Pedernales points are usually grouped into the "Middle Archaic" in conventional Canyonlands chronology. Collins (2004:113), however, aligns this era as the "middle" part of his Late Archaic period, roughly 2,500-3,500 B.P., while Turner and Hester (1999:171-172), using the Middle Archaic label, place them at ca. 3,200-4,000 years ago. A radiocarbon date from a hearth with associated Pedernales points comes from the Blue Hole site in the Sabinal Canyon (Mueggenborg 1994; TX-7057). Uncorrected, the assay is in the 4,420-4,100 B.P. range. Lot 335 and Lot 519 were used as drills.

\section{Late Archaic (Transitional)}

\section{Ensor (1 specimen)}

The one Ensor point (Lot 86.2; Figure 17 a) is a highly fragmented specimen. It is side-notched, and has a slight notch in the middle of the basal edge. Karbula (2000:272) reviews the typological overlaps with Ensor, Frio, and Fairland in the Transitional Archaic (see Black and McGraw 1985:105; Collins 2004:113).

In his lengthy review of Ensor and Frio points from the Blue Hole site, Mueggenborg (1994:37 ff) illustrates several points similar to the specimen from the Gatlin site, referring to them as Frio/Ensor Group 3 (Mueggenborg 1994:Fig. 21). The basal notches in the Blue Hole specimens are better defined than this artifact. 


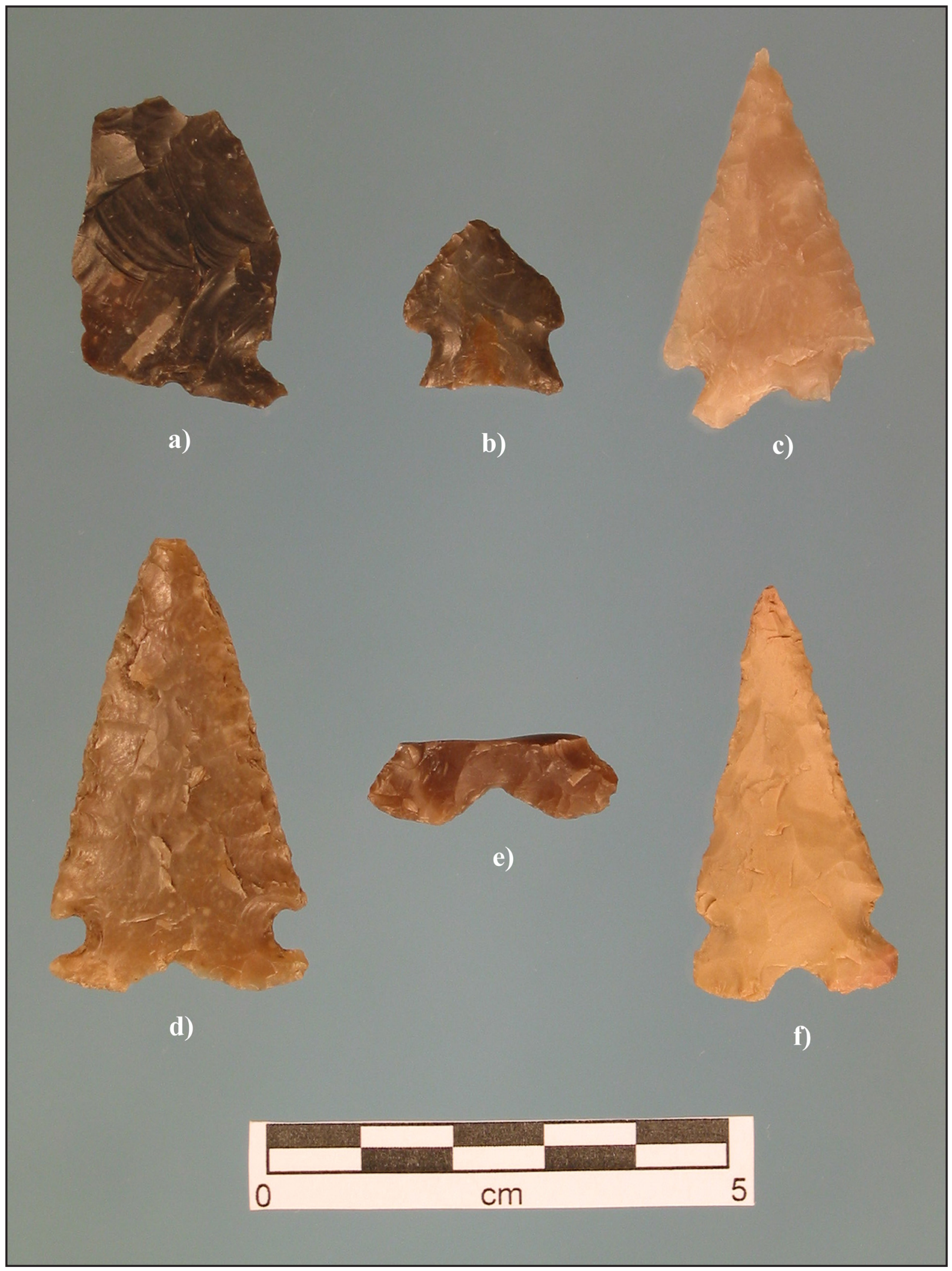

Figure 17. a) Ensor projectile point, Lot number 86.2. b) Fairland projectile point, Lot number 1149.3. Frio projectile points. Lot numbers: c) 36.3; d) 22; e) 1229; f) 1370. 


\section{Fairland (1 specimen)}

Lot 1149.3 (Figure 17 b) is an extremely small Fairland point, also of very dark brown chert. While it is the size of an arrow point, it exhibits dart point technology and is almost certainly the "discard" stage for a Fairland, having been heavily worked distally and the stem reshaped.

Fairland dates very late in the Archaic, essentially contemporary with Darl, Frio, and Ensor (Turner and Hester 1999:114). Black and McGraw (1985:106) note that the type is rare in the region, and estimate its date as A.D. 200-700. Goode (2002:Fig. 32) reports only three specimens from the Anthon site in Uvalde County. A large sample of Fairland points $(n=23)$ were recovered from Area $\mathrm{C} / \mathrm{D}$ at the Millican Bench site (41TV163), but the specimens were only listed and not described or illustrated (Mauldin et al. 2004:Table 5-2).

\section{Frio (4 specimens)}

All specimens in this collection are relatively small, classic examples of the Frio type (Figure $17 \mathrm{c}-\mathrm{f}$ ). Lot 1229 (Figure 17 e) represents the lower portion of the stem, snapped at the bottom of the stem neck. A discussion of a large sample of excavated Frio points $(n=47)$, variation within the type, and difficulties encountered in separating between Frio and Ensor is published in Mueggenborg (1994:37ff). Frio points are contemporary with Fairland and Ensor, in the very late part of the Central Texas Late Archaic (Collins 2004:113). This period is sometimes called the Terminal or Transitional Archaic (e.g., Coleman et al. 2001; Decker et al. 2000).

\section{Untypable Projectile Points (67 specimens)}

Samples of these points recovered from the Gatlin site are illustrated in Figure 18. These are mostly dart points that have been highly fragmented. Snap breaks, heavy thermal fracturing, and reworking have obscured typological traits. Additionally, on some specimens, the stems have been snapped off, or modified in other ways, preventing type assignments. Remnants of the

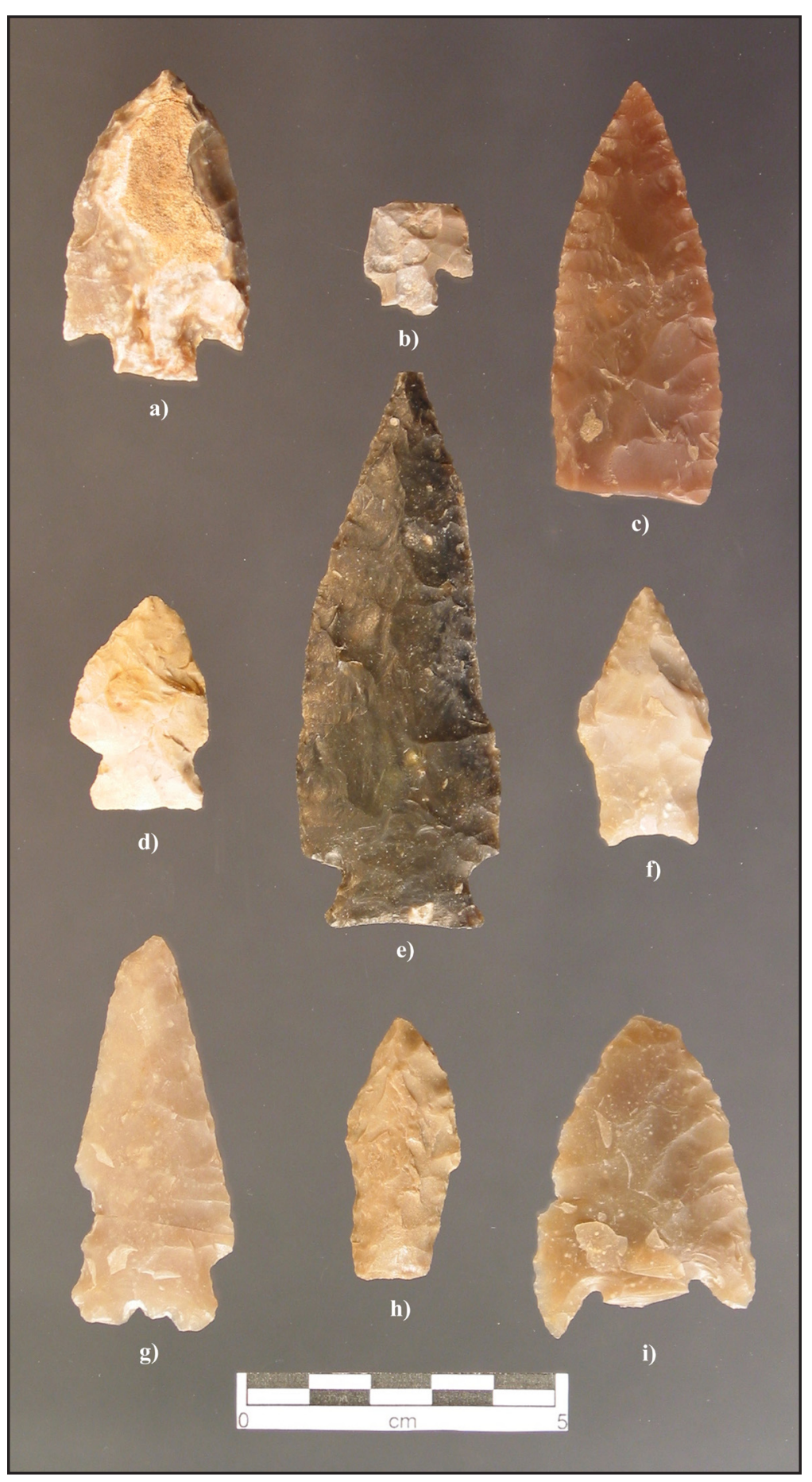

Figure 18. Untypable projectile points. Lot numbers: a) 27; b) 1318.1 ; c) 87.1 ; d) 617 ; e) 561 ; f) 1145 ; g) 720 ; h) 1242 ; i) 568 . 
stems themselves are in the sample. There are also barbs and stem ears; some of the latter may be from Montell points, but were simply too fragmentary to be certain.

There are two complete points. One is a small corner-notched dart point (UI 197; Lot 617; Figure 18 d) that could perhaps be forced into a type category, but the analysts felt it had been too greatly reworked. Another specimen (Lot 27; Figure 18 a) is a unique unifacial point. Made on a cortex flake (some cortex remains on the dorsal surface), it has been steeply trimmed around the blade edges and a notched stem created. Co-author Shafer, an experienced flintknapper, thinks this might well represent efforts or practice by a novice. For example, it appears that the knapper didn't have the strength (or experience) to pressure flake from the edges.

These two specimens represent the size range in Fairland. As it relates to the reworking of a point through time, Lot 561 (Figure 18 e) is probably a "finished stage" Fairland, a very large point made on a very dark brown ("black") chert. It has some concavity on one lateral edge, which may be resharpening related to use-wear.

Projectile point Lot 1145 (Figure $18 \mathrm{f}$ ) was originally typed as a Nolan point, but further examination of the point and its context called this designation into question and suggested that it remain untyped.

Finally, the only possible arrow point that the analysts noted in the Gatlin site assemblage is Lot 1318.1 (Figure $18 \mathrm{~b}$ ). It is highly thermal fractured, but just enough remains to identify it as an arrow point, perhaps corner-notched or stemmed.

\section{BifACES}

As a category of chipped stone tools, bifaces are characterized and defined by sequential flake removal that has occurred on both surfaces of a flake or core to form a single edge. Lithic bifacial reduction has consistently been viewed as a stage or step-like production process along a trajectory, from raw material to finished tool (Callahan 1990; Patterson 1977:60; Whittaker 1994). As a biface is reduced, it goes through several sequential stages or steps differentiated from one another by the manufacturing implement employed, the size and thickness of the biface, and its form. The sequence and nature of these stages or steps differ, depending upon numerous variables, including the desired end product of the reduction process, the form and quality of the parent raw material, and the style or technique in which flint knapping is performed. Previously completed tools may be reintroduced into the production trajectory and be repaired, rejuvenated or recycled into a different form.

Although projectile points are bifaces, they are their own analytical category and are not included in the biface totals. Of the 1,085 bifaces recovered from the site, 31 specimens are classified into specific subtype categories and the remaining 1,054 bifaces are included in the general category of bifaces. Excluding projectile points, four biface sub-categories are gouges, Clear Fork tools, drills and perforators, and butted or naturally backed bifaces. These represent morphological and technological categories that are recognized as specialized forms and the deliberate completion of the manufacturing trajectory.

\section{Analytical Methods}

The Gatlin site's 1,085 bifaces and biface fragments were analyzed adapting Callahan's (1979) biface staging methodology. Although Callahan identified nine stages in biface production, only stages 1 through 5 were used in the study of biface production at the Gatlin site. Specimens that could not be placed within a stage were classified as Indeterminate. These were usually biface fragments for which an edge angle and width/thickness ratio could not be measured. In Callahan's analysis, stages 6 through 9 are related to the creation of hafting elements and notching. Callahan's Stage 1 is a cobble, flake, or shatter blank that has not been further modified. At the Gatlin Site, Stage 1 bifaces have been initially bifacially trimmed about their circumference, which is similar to Whittaker's (1994:201) Soft Hammer Percussion Biface Stage 1. Depending on the parent source, cortex may remain on either or both faces.

The two primary variables used to define the stages of the reduction sequence were the width/thickness ratio $(\mathrm{W} / \mathrm{T})$ and average edge angle measurement. The edge angle and width/thickness ratios can vary between sites and within assemblages based upon the parent source being either flakes or cobbles and the desired finished product (Callahan 1979, Andrefsky 1998). In Callahan's model, width/thickness ratios 
increase as the biface is thinned in each successive stage. The final shaping stage can reduce the ratio when no further thinning occurs and the edge is trimmed. Resharpening and rejuvenation also can reduce the ratio. Morphological attributes, including edge sinuosity, biface cross section, and flaking patterns are also used to characterize each reduction stage. Two other attributes that were noted for bifaces were the outline shape of complete specimens and the fracture patterning on fragmentary specimens.

The majority of the biface assemblage is comprised of fragmentary specimens. The type of fragment was recorded for each specimen, according to its position and orientation on a complete specimen, such as: proximal fragment for the base; distal end for tips and working bits; medial fragment between the two ends; marginal fragment, along an edge; interior fragment, having no other portion of the biface edges; and indeterminate, having multiple traits making a definite selection impossible. Individual attributes are presented for the general bifaces in Appendix E.2 and for the specific biface sub-categories in Appendix E.3.

\section{Breakage}

Breakage occurs during manufacture, use, discard, and taphonomic factors. Using breakage pattern criteria found in Andrefsky (1998), Callahan (1979), and Whittaker (1994), breakage patterns were summarized into six categories.

The first is manufacturing breaks that occur when the biface is being made. These can occur at different stages in production depending on the raw material and method of manufacture and the final desired product. Breakage increases at later stages as bifaces become thinner and are more susceptible to bending type fractures. Internal flaws in the material such as voids, crystals, and changes in texture may not be evident before the tool has progressed to a certain stage.

Use fractures include impact fractures on projectile points and snap and bending fractures on slicing and cutting implements. Chopping activities can cause impact fractures as well. As opposed to a use-wear interpretation, the fracture has caused the removal of a portion of the specimen. Post depositional breaks occur after a specimen is no longer used and can oc- cur as a result of human agents such as trampling and camp maintenance activities, and from the modern effects of mechanical equipment during plowing and during excavation of a site.

Natural fractures are caused by natural forces. The taphonomic effect of erosion can tumble artifacts and cause scree slides and ceiling falls in caves. The mechanical effects of soil formation, freezing, thawing, and tree throws also affect artifacts (Odell 2004). Thermal fractures occur when the specimen is exposed to a heat source high enough to cause fractures. Continued exposure to high heat degrades the internal structure of the chert causing fracture planes and weakening the specimen. Excessive heat can cause diagnostic pot lid scars, caused by the removal of heat spalls, flakes that lack a platform and have a conical or convex ventral face.

Thermal damage can be caused during the use of the tool, such as drills or adzes used to work hot wood or charcoal, although it is thought to usually occur after the specimen is discarded. Sustained forest and grass fires may reach sufficient heat to fracture chert, although larger specimens with greater mass would have a greater resistance to this type damage (Buenger 2003). Indeterminate breaks have no diagnostics traits to assign them to a category.

\section{Shape}

There are 11 defined shape categories determined by the overall outline of a specimen. The outline shape is determined by the rough shape of the biface blank and the intended final tool shape. The shape categories are: Amorphous, Bipointed, Indeterminate, Lanceolate, Lunate, Oval Pointed, Ovate, Quadrilateral, Round, Subtriangular, Teardrop, and Triangular. A twelfth shape, Butted, was originally used, however, these specimens were designated a separate tool type.

Amorphous specimens have an irregular outline. Bipointed specimens taper to a point at the distal and proximal ends. Indeterminate is a category applied to fragmentary specimens. Lanceolate are narrow with parallel margins, while Lunate are a crescent shape. Oval Pointed has a rounded proximal end and tapers to a pointed distal tip. Ovate specimens taper at either end. Quadrilaterals are rectangular having straight parallel opposite edges. Round specimens 
are almost circular in outline. Subtriangular and triangular both have three edges, while they differ in that subtriangular is rounded at the basal apexes. Teardrop is similar in form to Pointed Ovate, except in this instance, the distal end tapers abruptly to an elongated distal tip.

\section{RESULTS}

The analysis examines two samples of bifaces: designated forms or types, and undifferentiated bifaces. There are 31 specimens assigned to types and 1,054 undifferentiated bifaces. Both groups together form a biface population. In the category of bifaces, only 158 of the 1,054 are complete specimens or nearly complete for measurements. Of these 158 specimens, 156 specimens have complete metrics, one specimen lacks total length, and one specimen lacks maximum width. Selected attribute measurements for all reduction stages of the biface population are summarized in Table 18. Boxplots of lengths, widths, thicknesses, width/thickness ratios, and weights of biface reduction stages are illustrated in Figures 19-23. Throughout the manufacturing trajectory, the one dimension that changes the least from Stage 1 through Stage 5 is overall length, while the greatest change is in width and weight.

The Gatlin Site bifaces stage divisions and counts $(\mathrm{nc}=$ complete, $\mathrm{nf}=$ fragmentary) are:

\section{Stage $1(\mathrm{nc}=14, \mathrm{nf}=14)$}

These specimens have an average (mean) Width/ Thickness ratio between 2 and 3 and an average (mean) edge angle between 50 degrees and 80 degrees. This is a quick preliminary stage where there is little modification such as prepared platforms. Flake scars are typically deep and short resulting in a scalloped or sinuous edge. These deep scars are characteristic of hard hammer percussion which can leave a pronounced negative bulb. The profile is strongly biconvex when blanks are from thick, blocky, flakes or cobbles (Figure 24).

Selected attribute measurements for complete and reconstructed specimens are presented in Table 19. The greatest variation is in weight and the least variation is thickness. The edge angle has a mean of approximately 50 degrees, which is at the minimum angle for Stage 1 bifaces.

The sample is evenly split between complete and fragmentary specimens at 14 . This is the only stage where they are found in equal proportions. The low percentage and overall number of broken Stage 1 bifaces suggests that the rough shaping and trimming rarely caused a catastrophic break, although manufacturing breakage was recorded on 12 of the specimens (Figure 25). Other inferences about the low number of Stage 1 bifaces include the ideas that reduction frequently continued beyond the earliest stage and that early reduction occurred at the procurement locale as part of the selection process.

The shape of the Stage 1 bifaces is generally amorphous or ovate, and likely resembling the shape of the parent lithic source (Figure 26). This is also evident when examining the ranges of width to length. Stage 1 bifaces were the final reduction stage for almost half of the naturally backed or butted bifaces.

\section{Stage $2(n c=41, n f=46)$}

These specimens have a Width/Thickness ratio between 2 and 3. Longer flakes are removed and flake scars continue to the center of the biface, especially on bifaces produced from cobble blanks. Edge angles are from 40 to 50 degrees. Cortex may still remain, especially at the center of faces. Examples of these complete specimens are illustrated in Figure 27. Selected attributes measurements for these specimens are presented in Table 20.

During the transition from Stage 1, weight is the greatest reduction as cortex removal continues. The shapes become more regular and generic like Ovate and Oval Pointed (Figure 28). Similar to the Stage 1 bifaces, the numbers of complete and fragmentary specimens are almost equal proportions, with the overwhelming cause of breakage being manufac-

Table 18. Biface All Stages Attribute Measurements

\begin{tabular}{|l|r|r|r|r|r|r|}
\hline & L $\mathbf{~ m m}$ & $\mathbf{W} \mathbf{~ m m}$ & \multicolumn{1}{c|}{$\mathbf{T ~} \mathbf{~ m m}$} & \multicolumn{1}{c|}{$\mathbf{W} / \mathbf{T}$} & \multicolumn{1}{|c|}{$\mathbf{W t ~ g}$} & Edge Angle $^{\circ}$ \\
\hline $\mathbf{n}$ & 156 & 157 & 158 & 157 & 158 & 158 \\
\hline Mean & 89.66 & 55.12 & 17.02 & 3.52 & 97.27 & 36.12 \\
\hline Min & 7.10 & 22.20 & 6.30 & 1.84 & 9.60 & 20.00 \\
\hline Max & 180.80 & 155.50 & 37.40 & 8.76 & 516.10 & 62.00 \\
\hline Std Dev & 26.04 & 17.01 & 6.90 & 1.13 & 85.40 & 8.03 \\
\hline
\end{tabular}




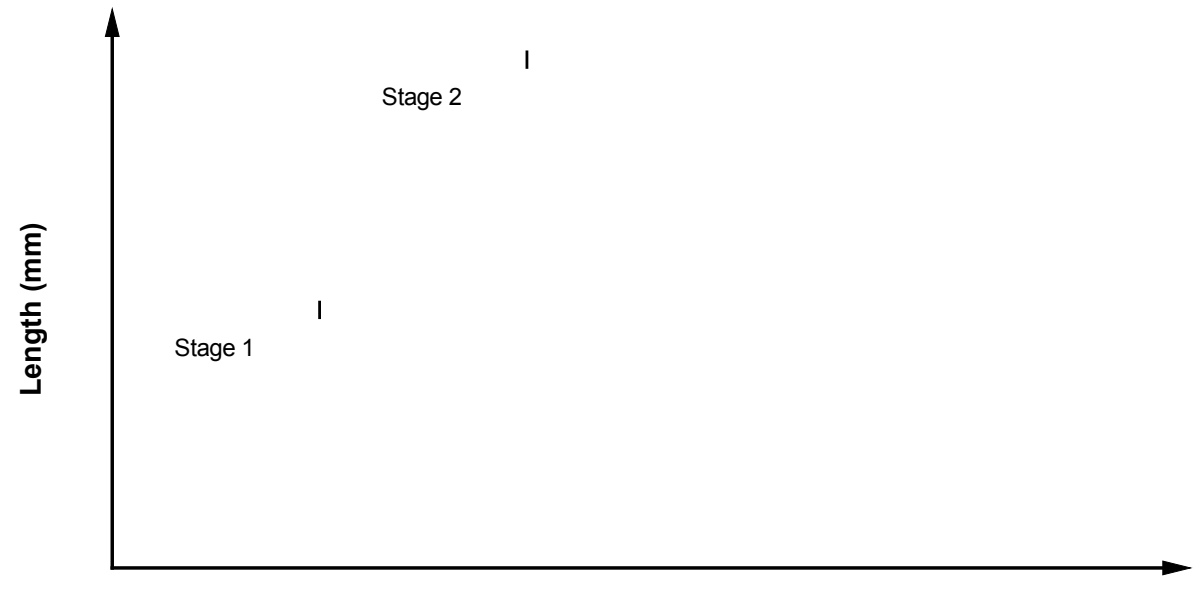

Figure 19. Boxplot of lengths of stages.

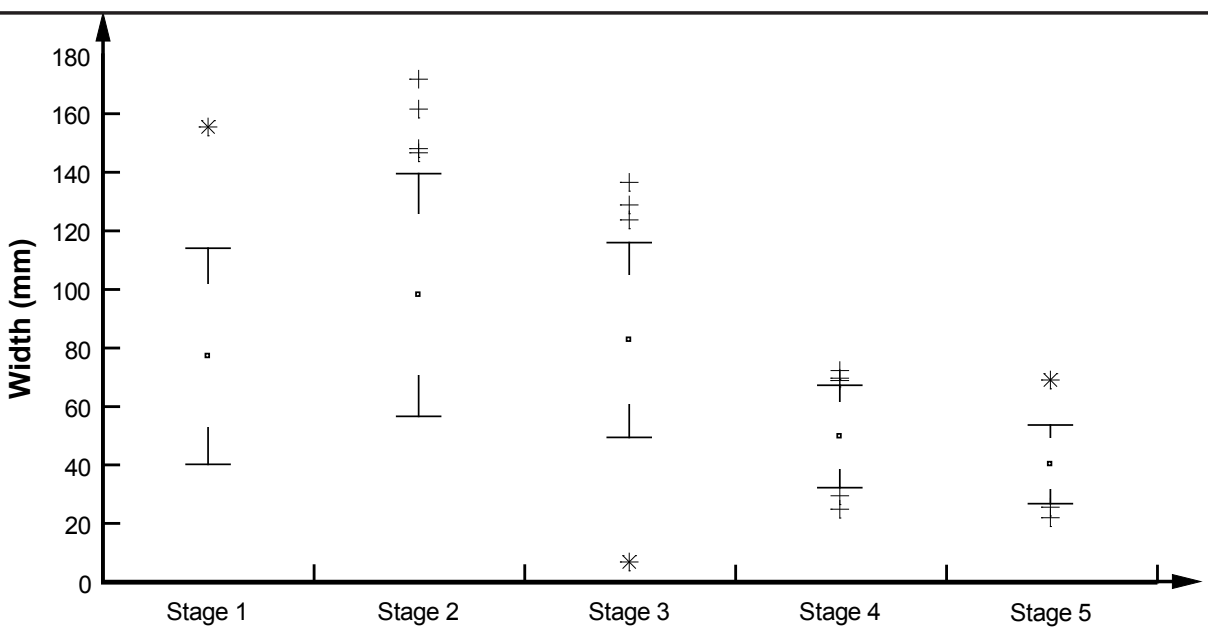

Figure 20. Boxplot of widths of stages.

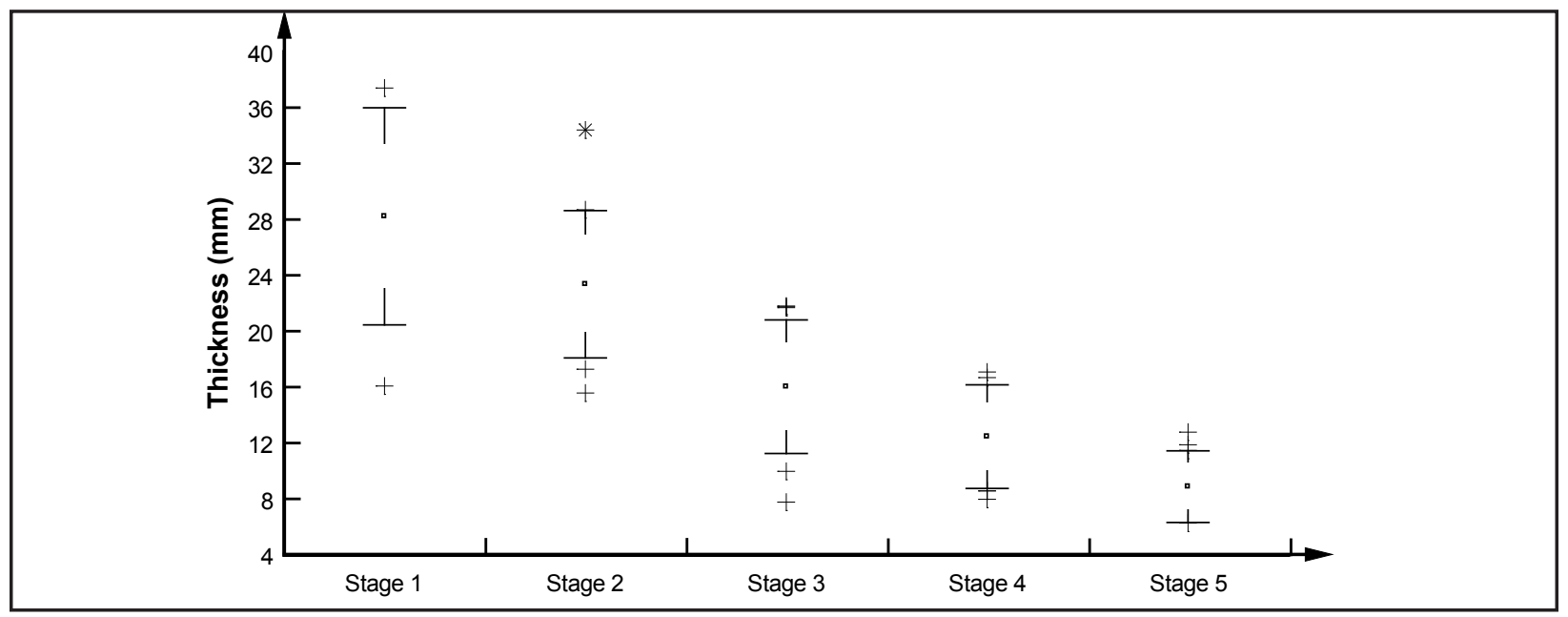

Figure 21. Boxplot of thicknesses of stages. 
Stage 5

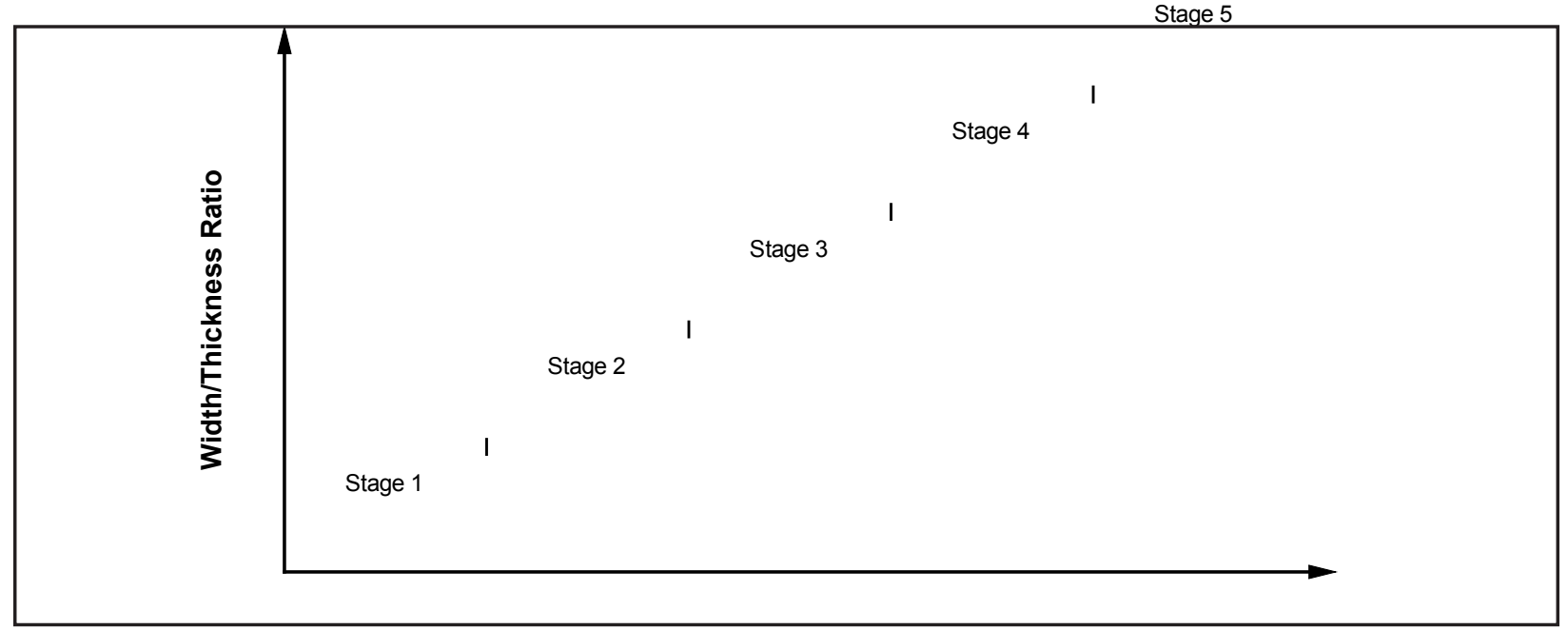

Figure 22. Boxplot of mean width/thickness ratio of stages.

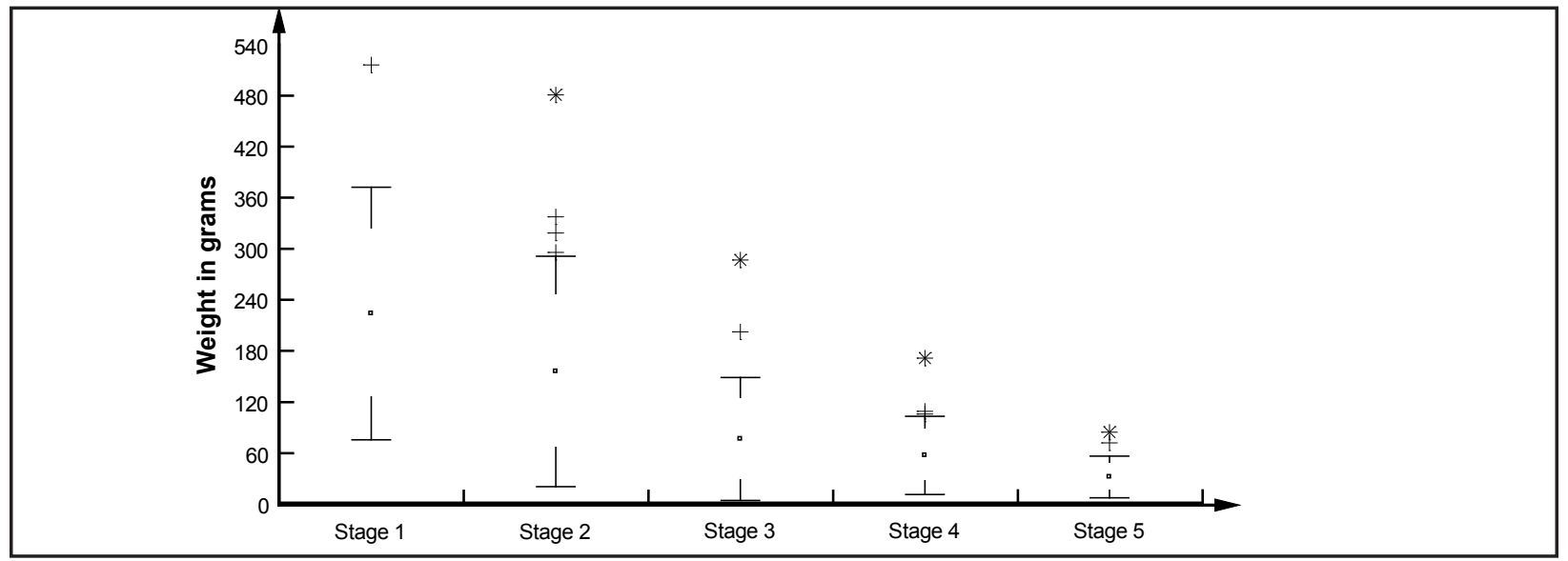

Figure 23. Boxplot of weights of stages.

Table 19. Biface Stage 1 Attributes Measurements

\begin{tabular}{|l|r|r|r|r|r|r|}
\hline & $\mathbf{L}(\mathbf{m m})$ & $\mathbf{W}(\mathbf{m m})$ & $\mathbf{T}(\mathbf{m m})$ & \multicolumn{1}{|c|}{$\mathbf{W} / \mathbf{T}$} & $\mathbf{W t}(\mathbf{g})$ & Edge Angle $\left(^{\circ}\right)$ \\
\hline Total & 14.00 & 14.00 & 14.00 & 14.00 & 14.00 & 14.00 \\
\hline Mean & 103.57 & 77.27 & 28.23 & 2.84 & 223.25 & 50.64 \\
\hline Min & 66.70 & 48.60 & 16.10 & 1.84 & 118.30 & 42.00 \\
\hline Max & 152.10 & 155.50 & 37.40 & 5.63 & 516.10 & 62.00 \\
\hline Std Dev & 21.24 & 24.57 & 5.17 & 1.11 & 99.19 & 6.28 \\
\hline
\end{tabular}



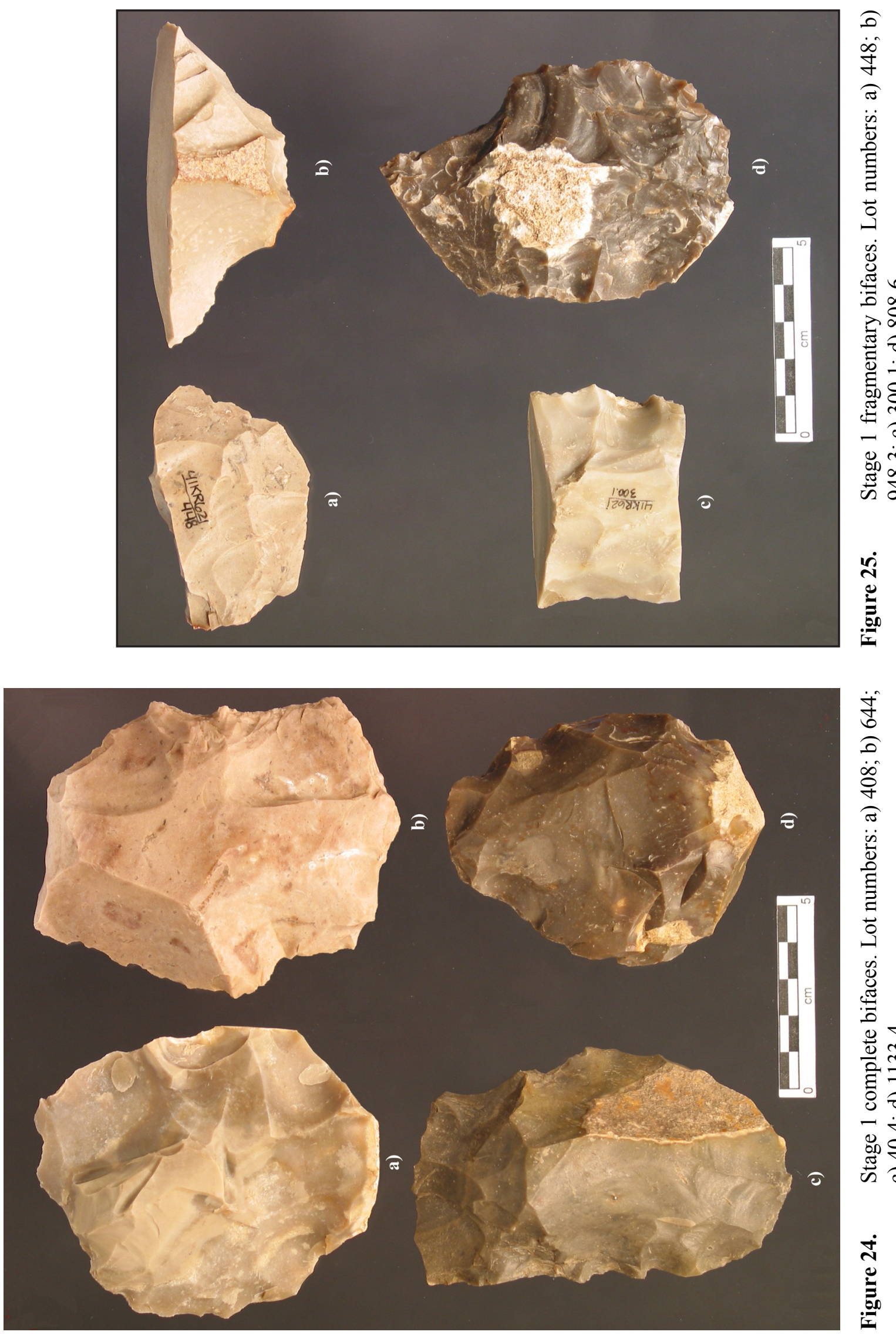

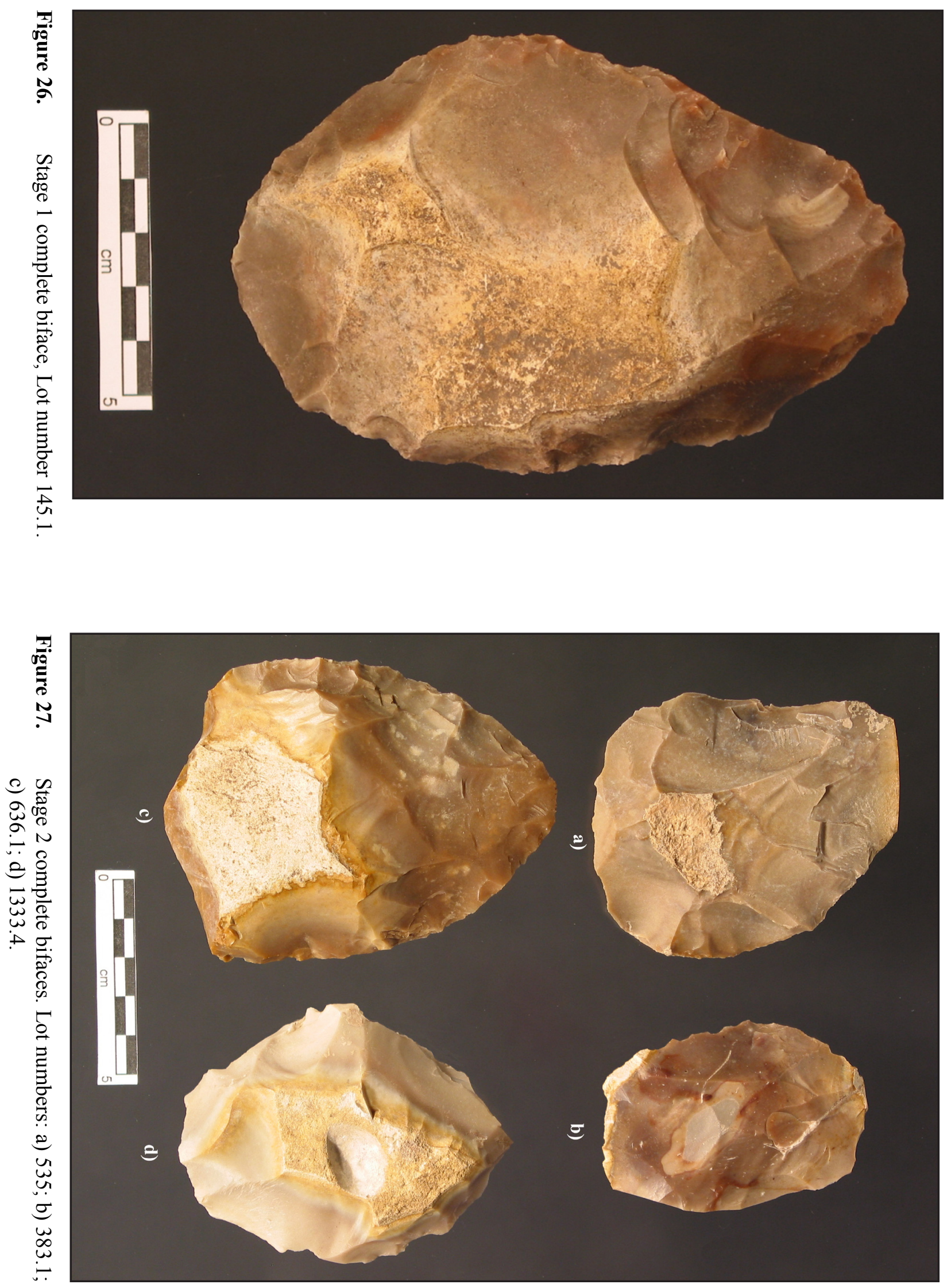
Table 20. Biface Stage 2 Attributes Measurements

\begin{tabular}{|l|r|r|r|r|r|r|}
\hline & $\mathbf{L}(\mathbf{m m})$ & $\mathbf{W}(\mathbf{m m})$ & $\mathbf{T}(\mathbf{m m})$ & \multicolumn{1}{|c|}{$\mathbf{W} / \mathbf{T}$} & $\mathbf{~ W t} \mathbf{( g )}$ & Edge Angle $\left.\mathbf{(}^{\circ}\right)$ \\
\hline Total & 41.00 & 41.00 & 41.00 & 41.00 & 41.00 & 41.00 \\
\hline Mean & 98.19 & 63.04 & 23.37 & 2.70 & 155.03 & 42.37 \\
\hline Min & 59.90 & 39.90 & 15.60 & 2.07 & 39.90 & 35.00 \\
\hline Max & 171.80 & 107.00 & 34.40 & 4.31 & 480.80 & 54.00 \\
\hline Std Dev & 27.60 & 14.70 & 3.51 & 0.53 & 90.50 & 4.40 \\
\hline
\end{tabular}

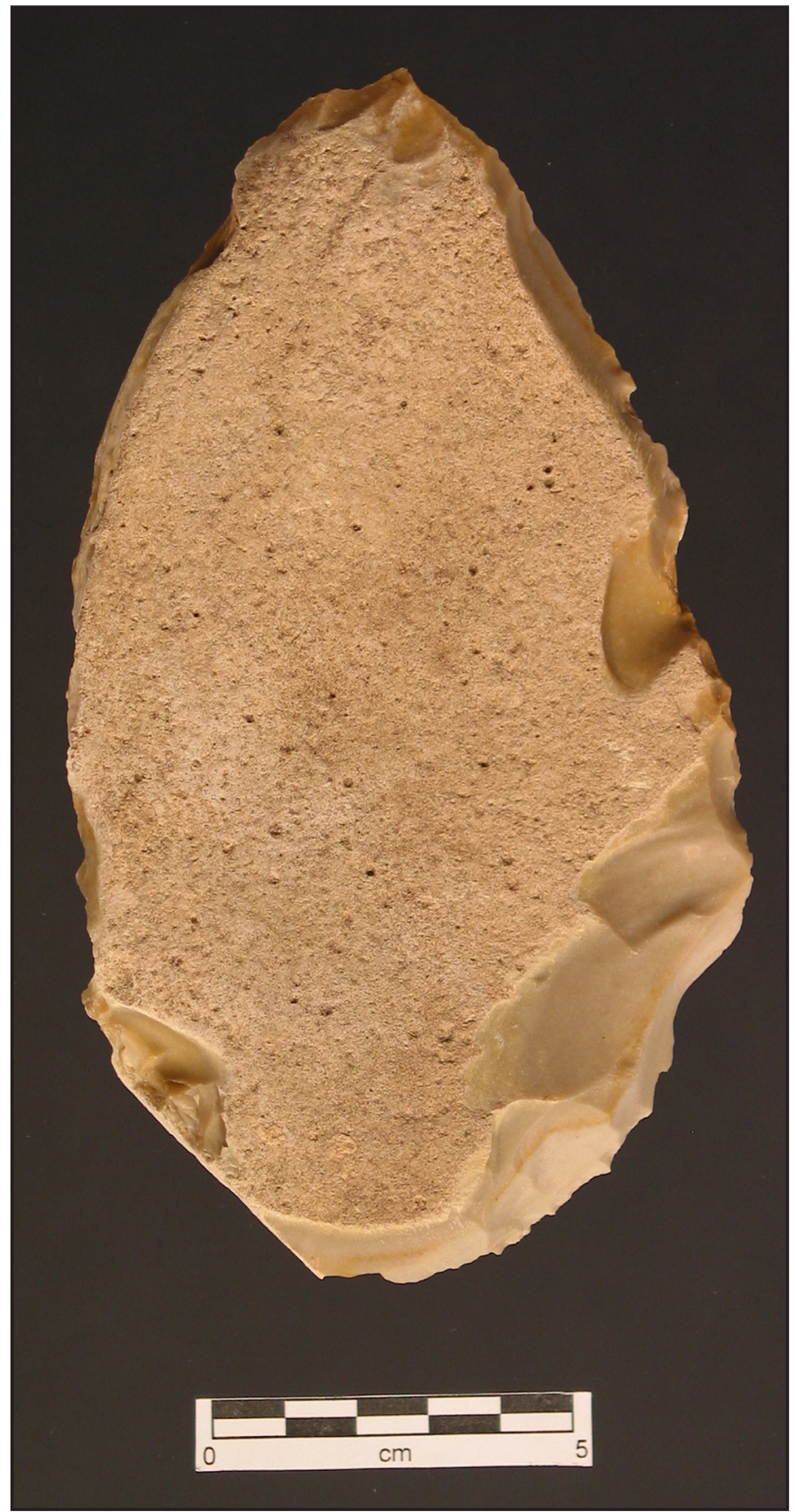

Figure 28. Stage 2 complete biface, Lot number 1311.2. 
turing error (Figure 29). There were 41 complete or nearly complete bifaces and 46 fragmentary pieces.

\section{Stage $3(n c=41, n f=112)$}

During this stage the greatest thinning occurs with the mean weight between Stages 2 and 3 almost halved (Figure 30). The average Width/Thickness ratio is between 3 and 4 . The edge angle is between $30-40$ degrees. Flake scars are large and shallow and cross the medial centerline of the biface and the biconvex profile is less pronounced. The edge is less sinuous and the outline of the biface is defined. The number of shapes becomes increasingly diversified, with Oval Pointed being the highest, and with Teardrop shapes reaching its highest number. Selected attributes measurements for these specimens are presented in Table 21.

There are 41 complete or almost complete bifaces and 112 fragmentary bifaces. This suggests that they are becoming increasingly fragile, and more susceptible to breakage as they are reduced. As an intermediate stage, a variety of percussive techniques that may have been used on the more robust earlier stages may expose previously hidden flaws in the material, and the consequence of misplaced blows becomes more damaging (Figure 31). The trend is accelerated in the final stages, when the affects from material flaws or knapping mistakes results in catastrophic fracture.

\section{Stage $4(n c=35, n f=158)$}

These specimens have an average minimum Width/ Thickness ratio of 4 and an edge angle of 30 degrees. The cross section profile is less pronounced and the edge profile is straighter. The outline of the biface may be further shaped or refined at this stage. Selected complete specimens are illustrated in Figure 32. There are 35 bifaces from this stage and 158 fragmentary specimens. Manufacturing breaks account for over 80 percent of the fractures (Figure 33).

Selected attributes measurements for these specimens are presented in Table 22. Oval Pointed is the predominant shape followed by subtriangular. The ovate shapes category is reduced when compared with Stage 3, while subtriangular and lanceolate categories both increased as part of the overall percentage

\section{Stage $5(n c=26, n f=407)$}

This is the final stage of a biface without a formal tool designation (Figure 34). The average Width/ Thickness ratio is greater than 5 and the edge angle between 20 and 30 degrees. The edges are centered and straightened and are sharpened or serrated at this stage. Hafting elements may be created at this stage in the Gatlin site assemblage. Selected attributes measurements for these specimens are presented in Table 23.

There are 26 complete or nearly completed specimens and 407 fragmentary specimens. Manufacturing is still the predominate type of fracture, although indeterminate fractures increase, probably as a result of the fragility of the thinner bifaces (Figure 35).

\section{Stage Indeterminate $(\mathbf{n}=228)$}

These are typically biface fragments without enough characteristics to place within a stage category. The thickness of the fragments averages $7.37 \mathrm{~mm}$, with a maximum thickness of $23.2 \mathrm{~mm}$, a minimum of 1.6 $\mathrm{mm}$, and a median of $6.5 \mathrm{~mm}$. These data suggests that the likely source for these fragments is late-stage biface manufacturing failures.

\section{Thin Bifaces $(\mathrm{nc}=22)$}

Additionally, a number of large, thin bifaces $(n=22)$ was recovered during testing and data recovery. Despite the mixed contexts associated with OZ3 and OZ4, it was hoped that these bifaces represented a specific technological strategy. The bifaces are Stage 5 specimens that are less than $8 \mathrm{~mm}$ thick and have a width to thickness ratio of 6 or greater. However, when the provenience data was examined there was no significant clustering of the bifaces, and therefore it was not possible to associate the bifaces to a particular dart point style.

\section{Use Wear Analysis}

\section{BIFACE TYPE DESCRIPTIONS}

Twelve bifaces were selected for use-wear analysis. Selected attribute measurements for all of the specimens are presented in Table 24. These specimens are all thin bifaces thought to be specialized cutting tools, although they have no formal type. Individual attribute measurements for the specimens are presented in Table 25. The sample assemblage was selected because it had visible use-wear. Shape 

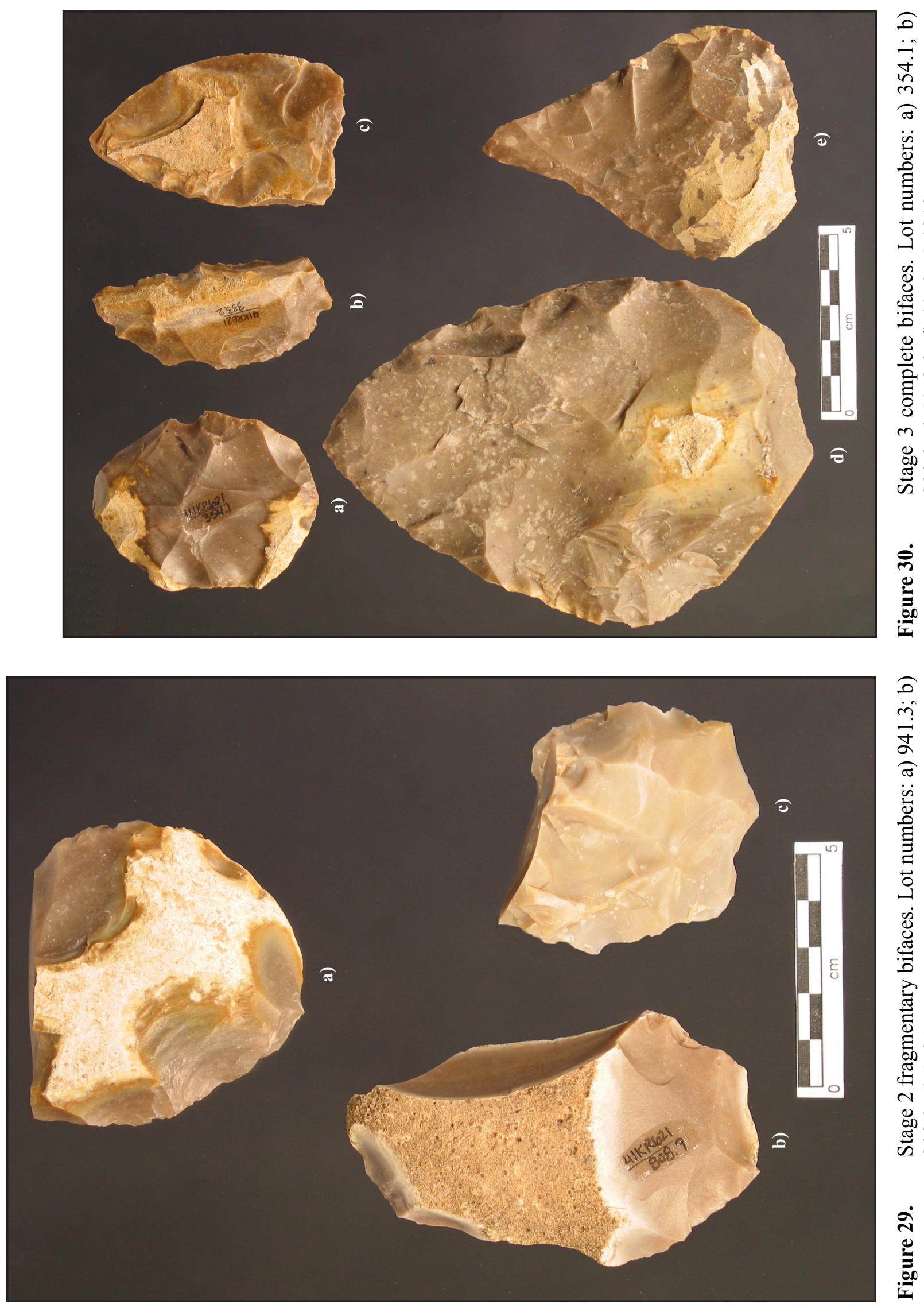

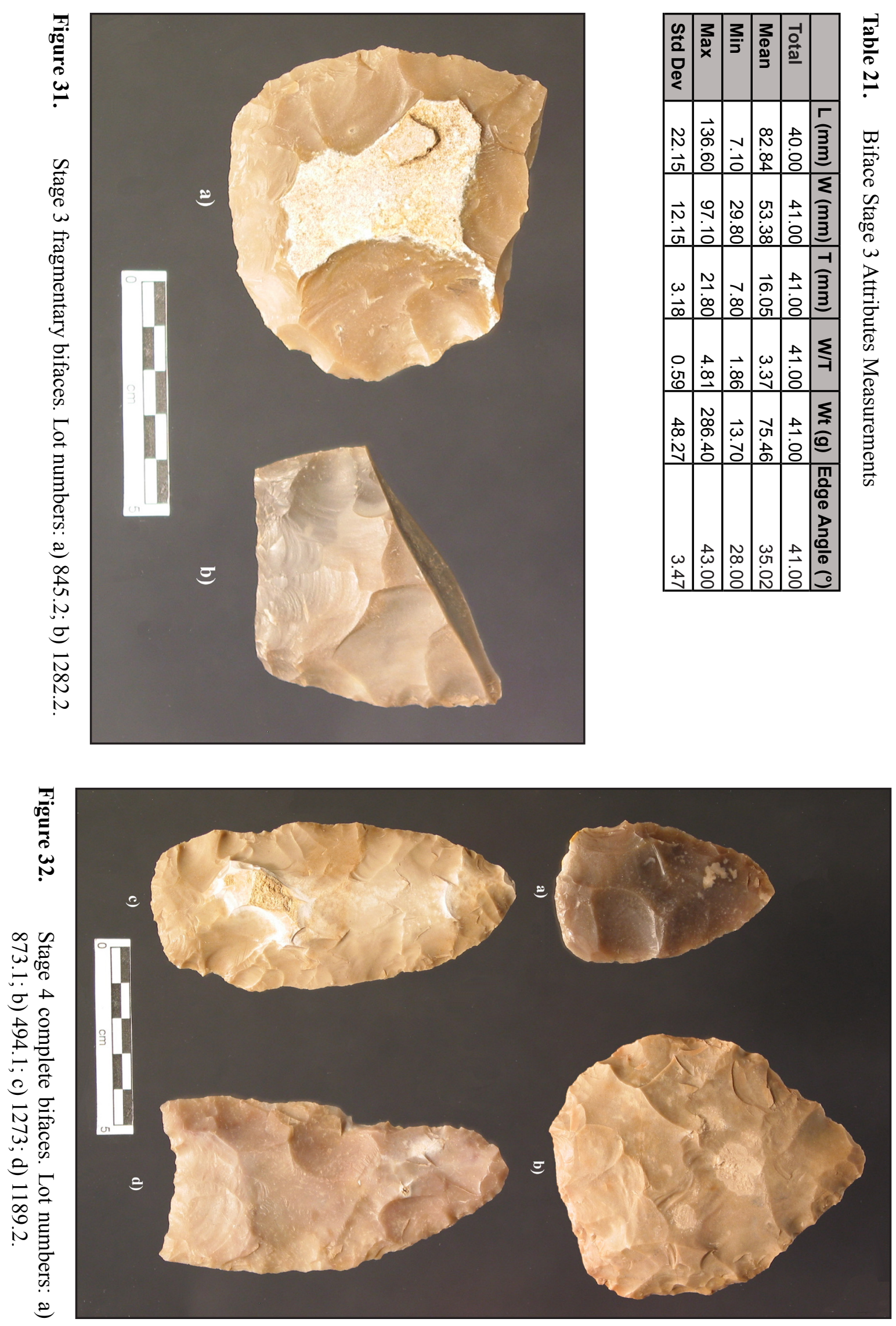


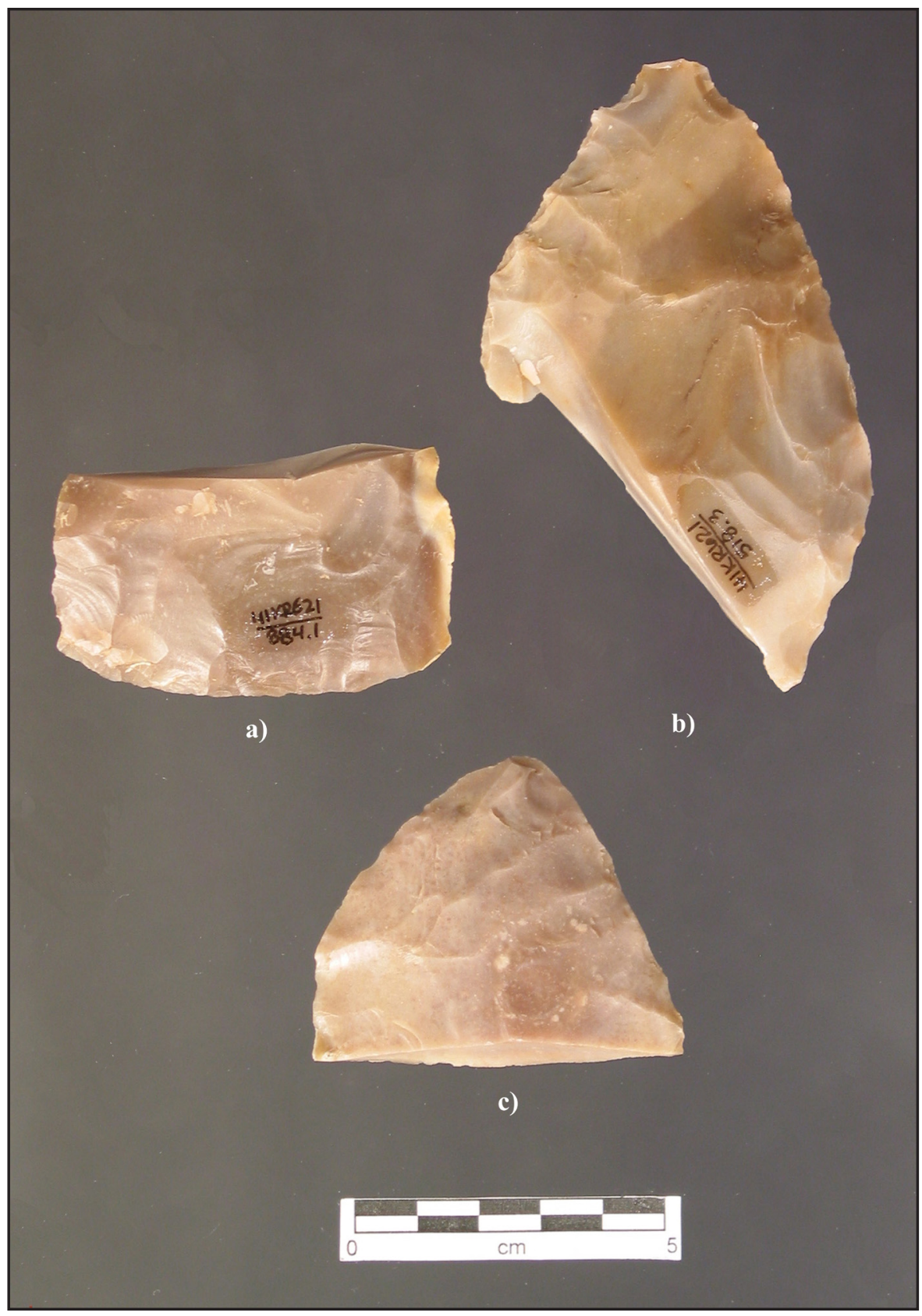

Figure 33. Stage 4 fragmentary bifaces. Lot numbers: a) 884.1 ; b) 518.3; c) 1214.2 .

Table 22. Biface Stage 4 Attributes Measurements

\begin{tabular}{|l|r|r|r|r|r|r|}
\hline & $\mathbf{L}(\mathbf{m m})$ & $\mathbf{W}(\mathbf{m m})$ & $\mathbf{T}(\mathbf{m m})$ & \multicolumn{1}{|c|}{$\mathbf{W} / \mathbf{T}$} & $\mathbf{W t} \mathbf{( g )}$ & Edge Angle $\left.\mathbf{(}^{\circ}\right)$ \\
\hline Total & 35.00 & 35.00 & 35.00 & 35.00 & 35.00 & 35.00 \\
\hline Mean & 88.05 & 49.92 & 12.48 & 4.06 & 56.11 & 31.29 \\
\hline Min & 59.00 & 25.10 & 8.00 & 2.11 & 15.30 & 24.00 \\
\hline Max & 180.80 & 72.40 & 17.10 & 5.96 & 170.70 & 37.00 \\
\hline Std Dev & 24.67 & 11.65 & 2.47 & 0.87 & 30.71 & 3.59 \\
\hline
\end{tabular}




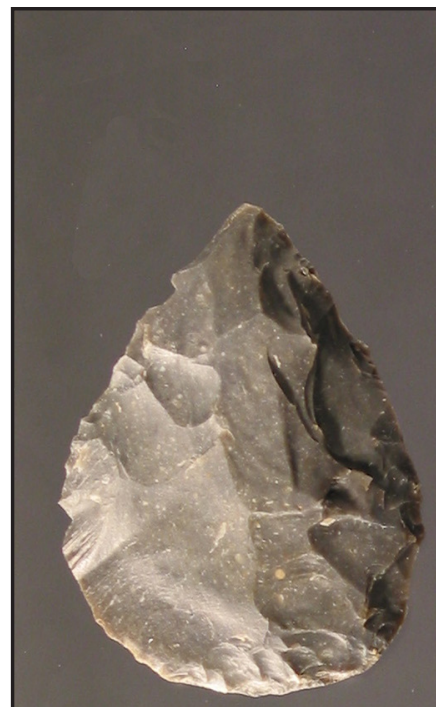

a)

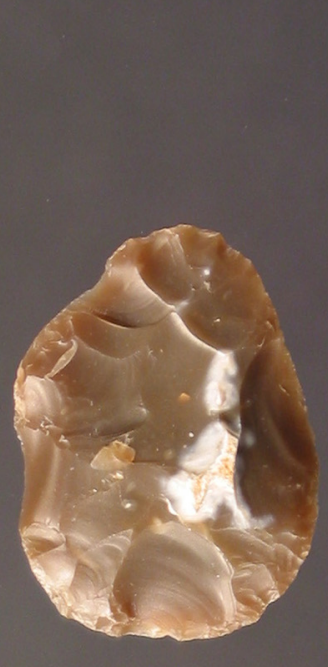

b)

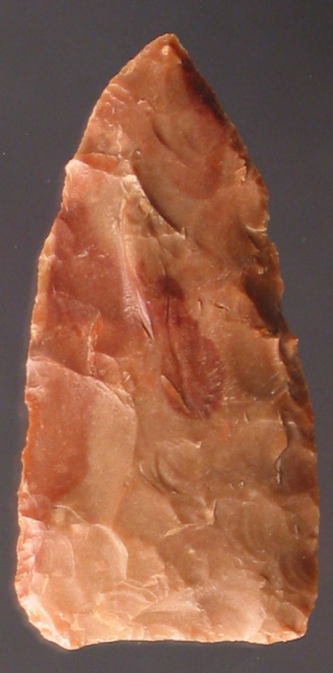

c)

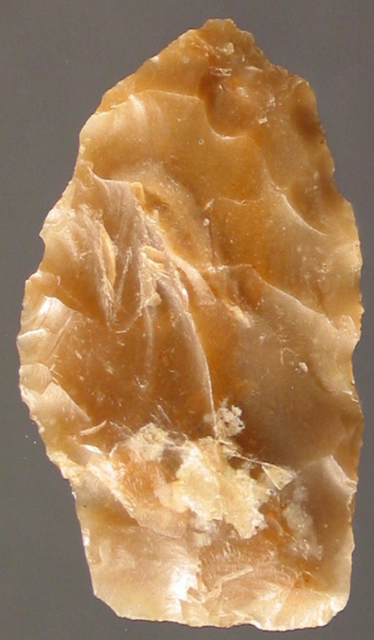

d)

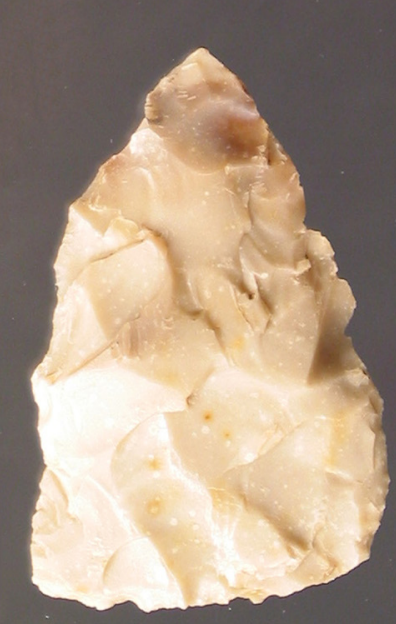

e)

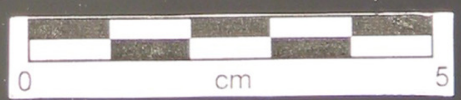

Figure 34. Stage 5 complete bifaces. Lot numbers: a) 551.1; b) 274; c) 753.1; d) 1487.1; e) 332 .

Table 23. Biface Stage 5 Attributes Measurements

\begin{tabular}{|l|r|r|r|r|r|r|}
\hline & $\mathbf{L}(\mathbf{m m})$ & $\mathbf{W}(\mathbf{m m})$ & $\mathbf{T}(\mathbf{m m})$ & W/T & Wt $\mathbf{( g )}$ & Edge Angle $\left.\mathbf{(}^{\circ}\right)$ \\
\hline Total & 26.00 & 26.00 & 27.00 & 26.00 & 27.00 & 26.00 \\
\hline Mean & 81.40 & 40.43 & 8.90 & 4.70 & 30.73 & 26.92 \\
\hline Min & 48.90 & 22.20 & 6.30 & 2.85 & 9.60 & 20.00 \\
\hline Max & 156.30 & 69.20 & 12.80 & 8.76 & 83.50 & 33.00 \\
\hline Std Dev & 27.93 & 8.95 & 1.71 & 1.41 & 16.36 & 3.16 \\
\hline
\end{tabular}




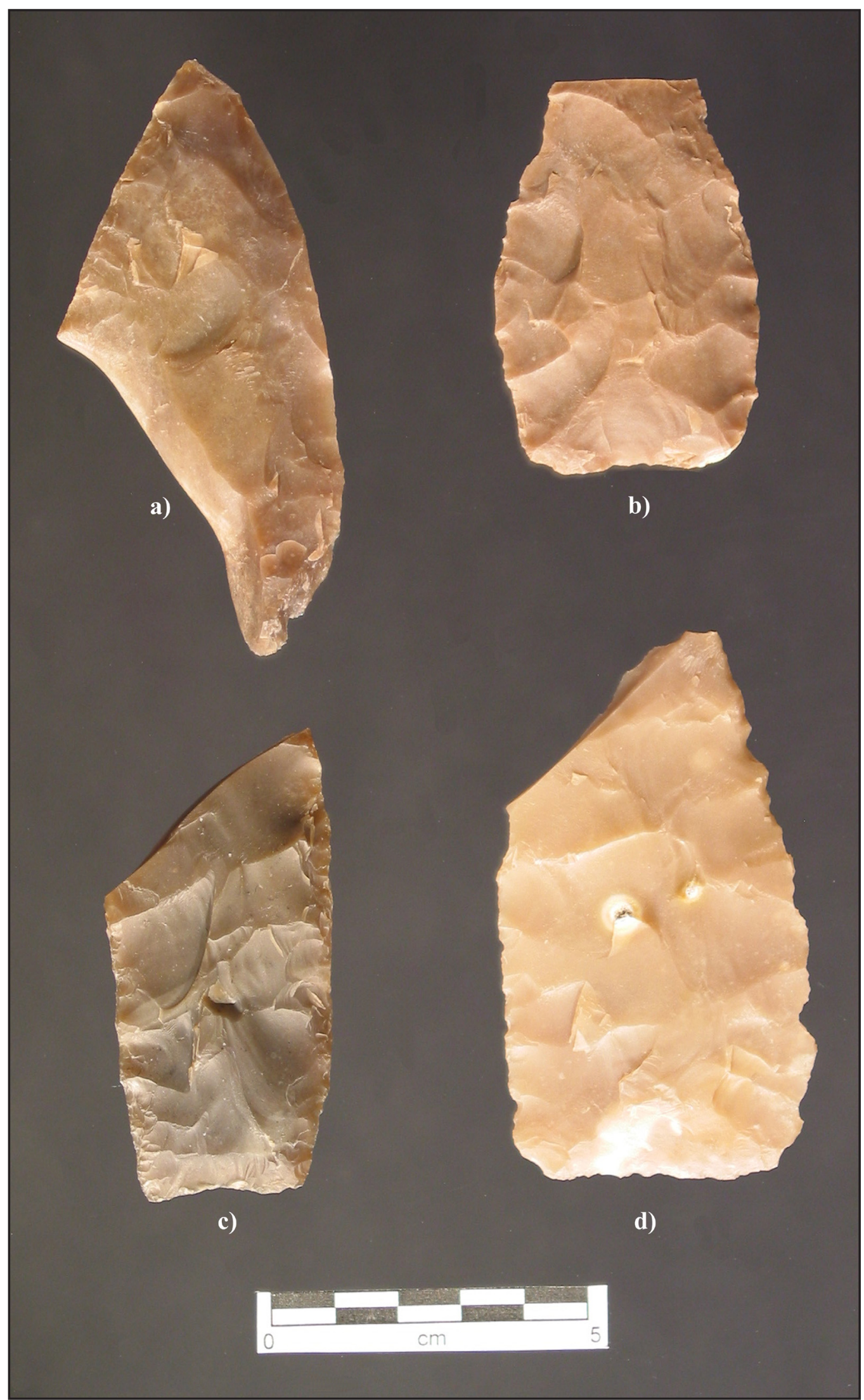

Figure 35. Stage 5 fragmentary bifaces. Lot numbers: a) 570; b) 752.1; c) 965; d) 1290 . 
Table 24. Attribute Measurements for 12 Bifaces Selected for Use-Wear Analysis

\begin{tabular}{|l|c|c|c|c|c|c|}
\hline & $\mathbf{L}(\mathbf{m m})$ & $\mathbf{W}(\mathbf{m m})$ & $\mathbf{T}(\mathbf{m m})$ & $\mathbf{W} / \mathbf{T}$ & $\mathbf{W t} \mathbf{( g )}$ & Edge Angle $\left.\mathbf{(}^{\circ}\right)$ \\
\hline $\mathbf{N}$ & 8 & 12 & 12 & 12 & 12 & 12 \\
\hline Range & 96.9 & 39.9 & 3.8 & 5.39 & 70.1 & 10 \\
\hline Min & 59.4 & 29.3 & 6.3 & 3.49 & 13.4 & 20 \\
\hline Max & 156.3 & 69.2 & 10.1 & 8.87 & 83.5 & 30 \\
\hline Mean & 117.454 & 48.492 & 8.225 & 5.987 & 45.35 & 24.75 \\
\hline Std. Error & 10.385 & 3.576 & 0.358 & 0.486 & 6.034 & 0.863 \\
\hline Std. Dev & 29.373 & 12.389 & 1.243 & 1.685 & 20.902 & 2.989 \\
\hline Variance & 862.821 & 153.499 & 1.546 & 2.841 & 436.905 & 8.932 \\
\hline
\end{tabular}

Table 25. Individual Attribute Measurements for 12 Bifaces Selected for Use-Wear Analysis

\begin{tabular}{|c|c|c|c|c|c|c|}
\hline Lot No. & Stage & $\mathbf{L}(\mathbf{m m})$ & $\mathbf{W}(\mathbf{m m})$ & $\mathbf{T}(\mathbf{m m})$ & $\mathbf{W} / \mathbf{T}$ & $\mathbf{W t .}(\mathbf{g})$ \\
\hline 6 & 5 & 140.5 & 69.2 & 7.9 & 8.76 & 83.5 \\
\hline 410 & 5 & 156.3 & 52.8 & 7.5 & 7.04 & 70.9 \\
\hline 559 & 5 & 115 & 37.4 & 7.2 & 5.19 & 30 \\
\hline 742 & 4 & 105.5 & 40.6 & 8.6 & 4.72 & 38.1 \\
\hline 813 & 5 &. & 58.3 & 10.1 & 5.77 & 68.6 \\
\hline 849 & 5 & 59.4 & 35.1 & 7 & 5.01 & 13.4 \\
\hline 975 & 5 & 103.9 & 29.3 & 8.4 & 3.49 & 28.5 \\
\hline 1144 & 4 & 131.1 & 40.3 & 9.4 & 4.29 & 49.8 \\
\hline 1341 & 5 &. & 59.1 & 9.6 & 6.16 & 42.4 \\
\hline 1350 & 5 &. & 51.7 & 9.6 & 5.39 & 56.7 \\
\hline 1443 & 5 & 127.9 & 45.1 & 6.3 & 7.16 & 32.5 \\
\hline 1468 & 5 &. & 63 & 7.1 & 8.87 & 29.8 \\
\hline
\end{tabular}

category percentages for the 12 bifaces are illustrated in Figure 36.

\section{Lot 6 (Figure 37)}

This specimen is ovate-shaped and well-thinned. The distinguishing characteristic is a small notched tang at the proximal base. The tang was created by indention, and the stem base is in plane with the biface edge.

The last thinning was by soft hammer percussion, with the flakes meeting at the center. A small knot remains at the center of one face. One edge has been worked on both faces with small 3-5 mm wide pressure flakes, and unifacially on the other edge. Small step and feather terminations are on portions of both margins. The material is a fine-grain, opaque tan chert with several oval-shaped fossil inclusions. The material is well represented at the site.
Use-wear suggests that the specimen was used as a tool to cut soft animal material such as flesh or hide, with occasional contact with bone. Polish on one face resembles prehension marks.

\section{Lot 410 (Figure 38 a)}

This is a lunate-shaped specimen that was damaged during excavation and later reassembled. One end is more pointed than the other, and it appears that the pointed end has been resharpened. Final thinning of the specimen was by soft hammer percussion that left scars meeting along the centerline of both faces. Fine pressure-flaking occurs around the circumference of the specimen. The material is fine-grain tan chert, similar to specimen Lot 6 , and common throughout the lithic assemblage.

Use-wear indicates that the convex edge was the tool edge and that it was used as a light duty knife for 


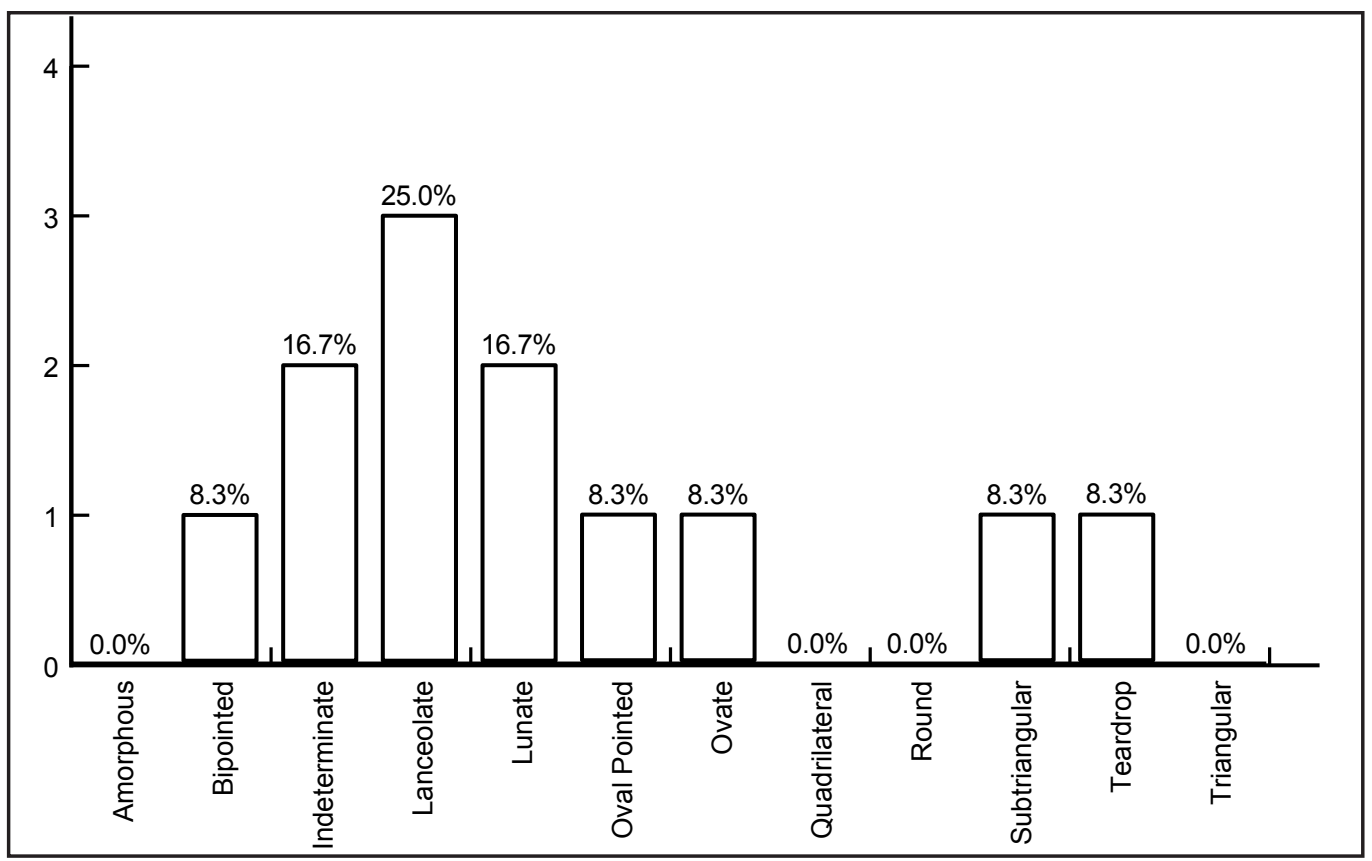

Figure 36. Shape of 12 bifaces selected for use wear.

cutting meat or hide. There is no evidence of hafting. The straight edge probably served as the grasping point, and although the edge has step terminations, there does not appear to be a deliberate effort to dull the edge for prehension.

\section{Lot 559 (Figure 39 a)}

The specimen is lanceolate-shaped. Thinning flakes are parallel to sub-parallel oblique pressure flakes on one face. On the obverse face, thinning flake scars are larger and less patterned and meet at a central arras. At the distal end, both margins have been resharpened multiple times. The base has been thinned by the removal of small, vertical, percussive flakes. The edge flaking pattern is similar in appearance to Late Paleoindian and Early Archaic patterning. A circular scar on one face is the result of excavation damage. The material is a fine-grain, semi-opaque tan chert found locally.

Functional analysis indicates that the specimen was used as a butchering knife and was resharpened probably several times, since polish developed along recent fractures. The tip may have been used as perforator. Although there were no traces of hafting noted in the analysis, the basal thinning suggests that the maker intended for it to be hafted.
Lot 742 (Figure $40 \mathrm{~b}$ )

The specimen is bipointed. At one end there is a small area of gray patina at the tip. Portions of both lateral margins have been retouched by pressure flaking, while the last thinning removed small percussive flakes in random and parallel patterning which end at the center line. Portions of stacked step flaking occur along one margin from attempts to further thin the specimen. Excavation damage detached a portion of one lateral margin that was subsequently refitted.

The tip opposite the patinated end has been resharpened. Two small notches are probably for platform isolation rather than serration, which were not utilized. The material is an opaque, fine-grain, grayish $\tan$ chert with small gray and red inclusions. The small portion of patina indicates that the material would develop a grayish blue patina.

The use-wear analysis identified areas of a matte polish, suggesting that the specimen was used as a knife on moderately hard material such as wood.

\section{Lot 813.1 (Figure 41 a)}

The specimen is approximately two-thirds complete, with the distal end missing. The specimen is wide and thin and the profile shape of a complete specimen would be subtriangular. The distal end terminates in a transverse snap fracture. 

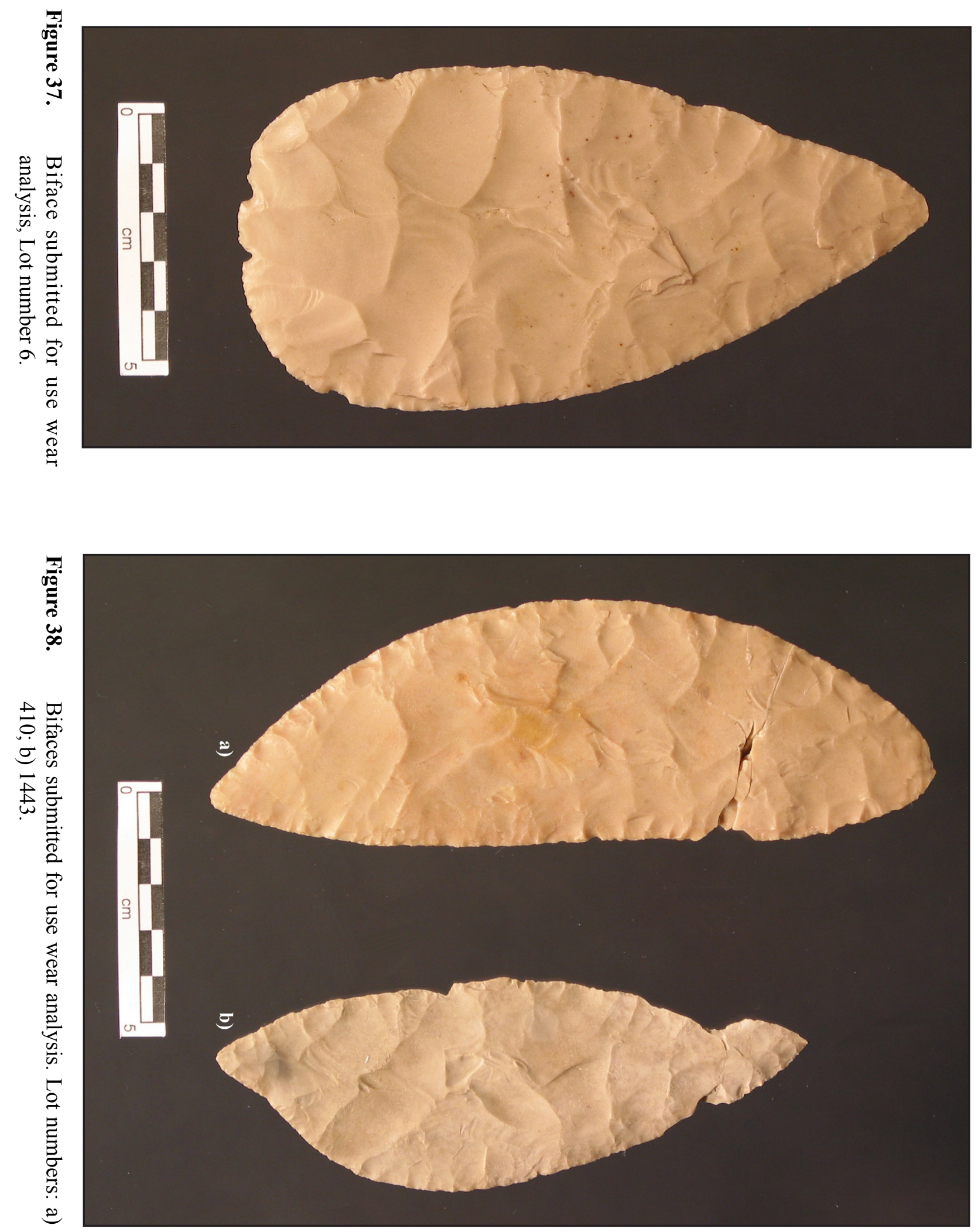

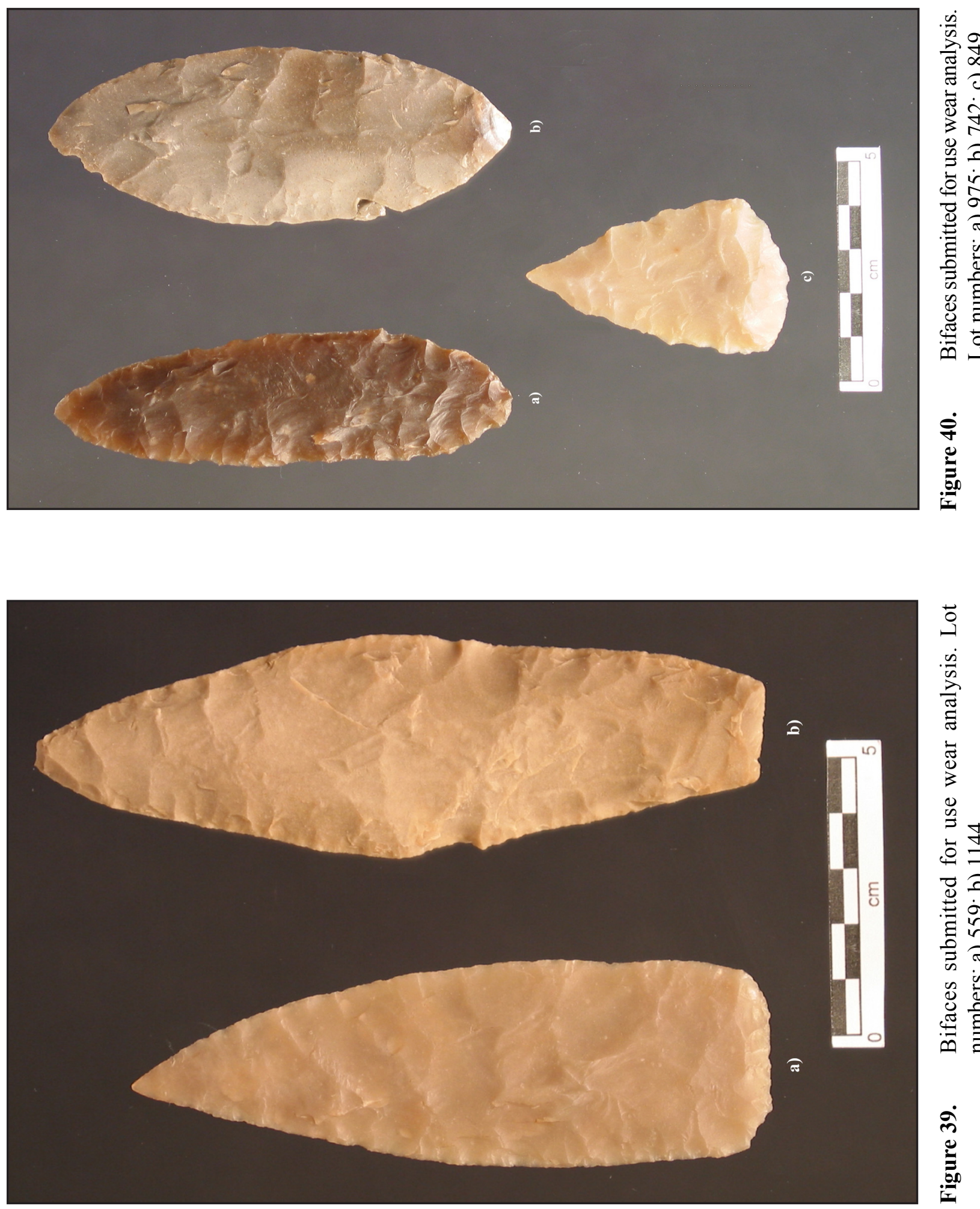

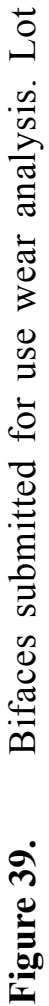




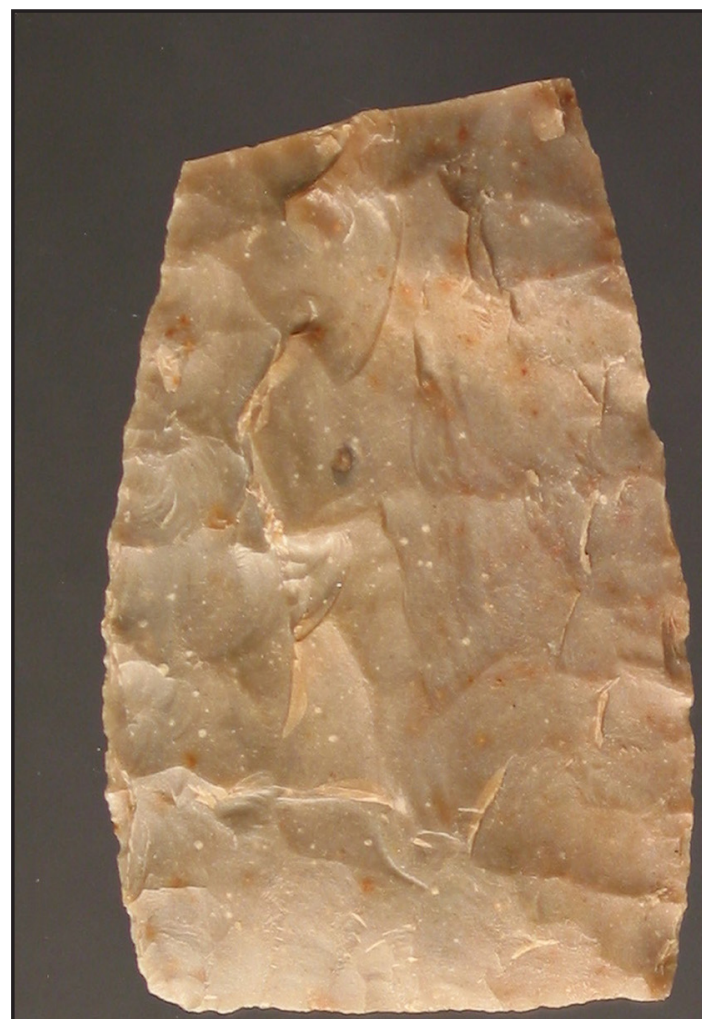

a)

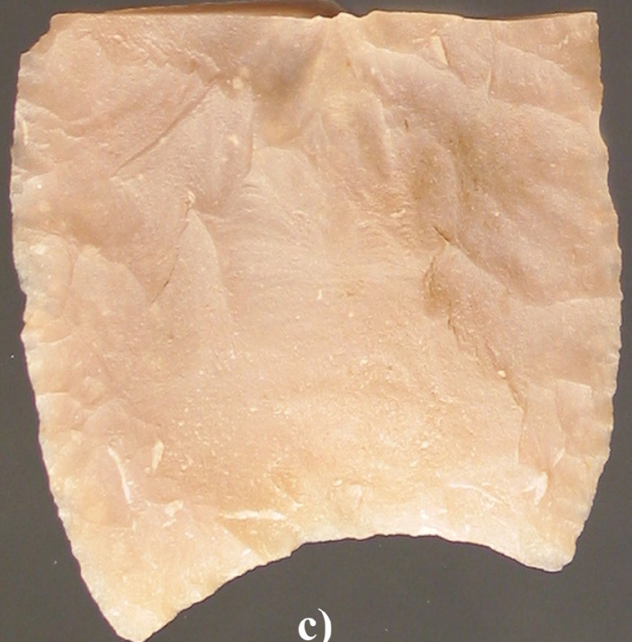

c)

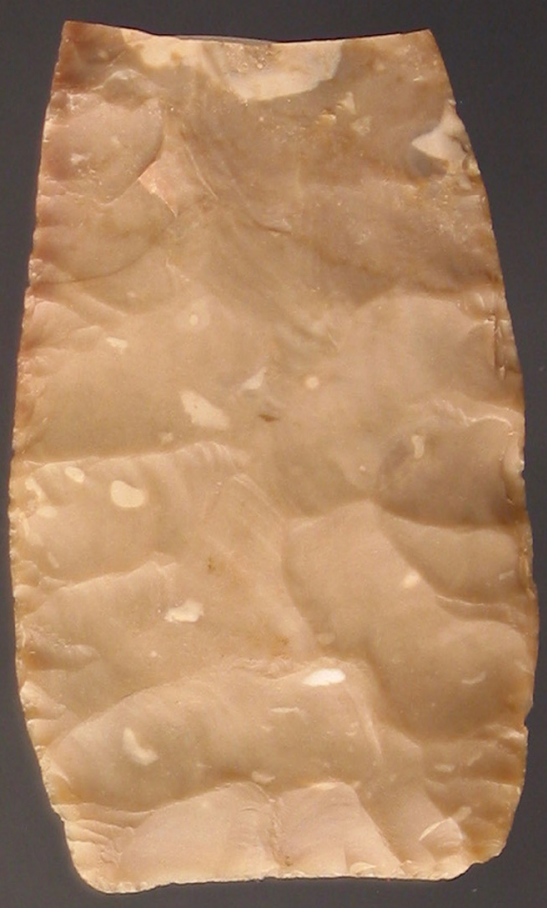

b)

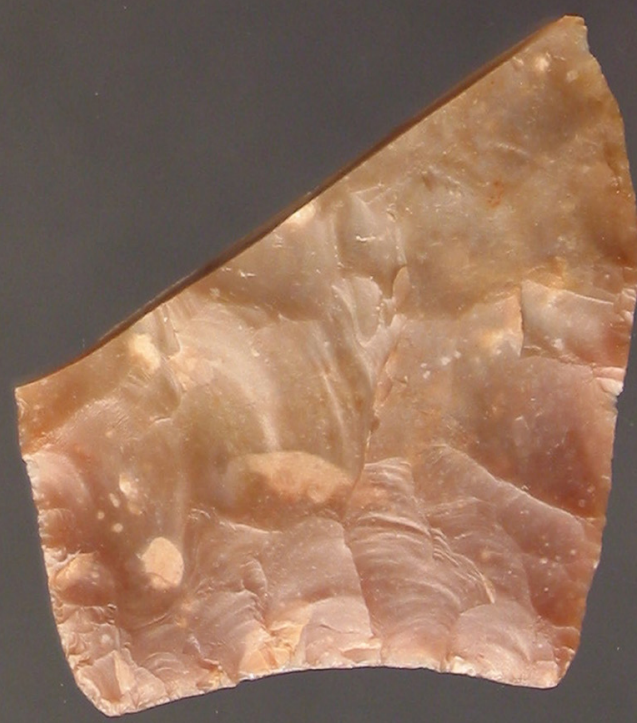

d)

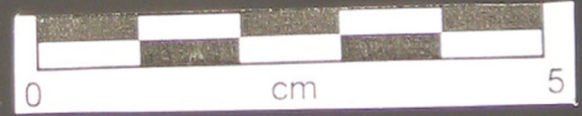

Figure 41. Bifaces submitted for use wear analysis. Lot numbers: a) 813.1 ; b) 1350 ; c) 1341 ; d) 1468. 
Latter stage thinning was by billet hammer. Stacked step fractures occur on both faces along one margin. These scars are mostly absent from the other edge. The stacked scar edge has been extensively resharpened which includes fine serrations along the edge. The wide base has been thinned by long, narrow pressure flakes along one face and by percussive flakes on the other face.

The material is a fine-grain, opaque grayish tan chert with small gray and red inclusions. The red inclusions appear to be from oxidation, perhaps from exposure to heat. The material is common in the assemblage.

Use-wear analysis did not find evidence of hafting, although there are portions near the base with polish possibly from prehension. The biface was used as a knife to cut moderately hard material such as wood.

\section{Lot 849 (Figure $40 \mathrm{c}$ )}

The specimen is a small subtriangular biface and is the smallest complete biface analyzed in the group. The pointed end is the proximal end while the rounded end is the distal end.

The proximal tip has been resharpened and is alternately beveled. The lateral margins and base have been thinned with small percussive flake removals. The distal end has slight rounding of the flake scar edges. The cross section overall is almost planoconvex and suggests that the specimen may have been made from a flake blank, with the proximal end being the proximal end of the flake. The material is the fine-grain, opaque tan chert common throughout the lithic assemblage and available locally.

The use-wear analysis indicates that the specimen was used as a scraper, with the rounded end as the bit, to scrape a material such as hide. Damage and reworking at the pointed proximal end is related to hafting.

\section{Lot 975 (Figure 40 a)}

The specimen is narrow and bipointed, with one end more pointed. The proximal end is slightly rounded. The edges have been retouched with both pressure flaking and small hammer percussion. The overall flaking pattern is parallel collateral flaking to parallel oblique flaking. The flaking from the lateral edges meets at a center arras on both faces.

The distal tip has been reworked along one edge. The specimen has the appearance of not being able to be thinned further because of the insufficient remaining width, probably because of repeated resharpening. The material is a fine-grain, semi-opaque light brown chert that is common on the Edwards Plateau.

The use-wear analysis did not indicate traces of hafting. The specimen was used as a knife against a moderately hard material such as wood and was extensively resharpened.

\section{Lot 1144 (Figure 39 b)}

The specimen is a large lanceolate biface with a clearly defined haft. The blade is bifacially resharpened along both edges with small pressure flakes. Overall, the flaking is unpatterened in sections and parallel in others. A large overshot flake on one face overthinned the middle of the blade.

The base is straight and has a wedge-shaped profile and has been dulled, while the stem is tapered. The material is a fine- to medium-grain tan colored opaque chert with gray banding and mineral inclusions that are the result of patination. A small amount of mineral precipitate adheres on one face.

The use-wear suggests that the specimen was hafted, was used as a butchering tool to cut flesh, and came into frequent contact with bone and cartilage.

\section{Lot 1341 (Figure $41 \mathrm{c}$ )}

The specimen is the basal fragment of a large, thin biface. The dominant feature is the indented base, the inside of which is lightly abraded. Large billet flakes were detached from the base almost as fluting flakes on both faces. Stacked step flake scars are at the center of one face. The distal end terminates in a bending fracture.

The lateral edges are convex, with one edge retouched bifacially with small pressure flakes. Most of the working edges are missing. The material is a fine- to medium-grain, semi-opaque tan gray chert that is common in the lithic assemblage, although this specimen is slightly coarser grained.

The use-wear indicates that the specimen was used for heavy cutting tasks such as those associated with 
butchering. The base has been deliberately dulled and the specimen was hafted.

\section{Lot 1350 (Figure $41 \mathrm{~b}$ )}

The specimen is the basal section of a well thinned biface. Final thinning was done with small billet flakes in a parallel pattern. These flakes did not reach to the center of the biface. Earlier billet flake scars extend to the center and beyond.

The lateral edges are slightly convex and the base is concave. The distal end terminates in a straight bending fracture. Both lateral margins have been retouched with pressure flaking, and show evidence of use-wear with small overlapping step flake scars. The base has been bifacially thinned with small vertical flakes and is lightly ground. The material is fine-grain tan gray chert with small gray inclusions and a reddish hue, oxidation possibly caused by exposure to heat.

The use-wear analysis suggests that the specimen was hafted and used to cut moderately hard material such as wood.

\section{Lot 1443 (Figure 38 b)}

The specimen is a bipointed biface that was damaged during excavation and subsequently repaired. The outline is asymmetrical with one lateral edge more convex than the other. The point opposite the excavation break has been resharpened into a centered point. The earlier thinning was by billet flakes that are parallel and slightly oblique. These flakes alternated from edge to edge when crossing the centerline. Edge sharpening is by pressure flaking that has created a bevel along parts of the blade. The material is finegrain, opaque tan gray chert; the gray the result of a developing patina.

Use-wear analysis found no traces of hafting and the specimen was a hand-held knife used for butchering and cutting hide, with frequent contact with bone and cartilage. The convex edge was the predominant working edge. The resharpened point had a developed polish related to butchering.

Lot 1468 (Figure $41 \mathrm{~d}$ )

The specimen is a basal fragment similar in size and appearance to Lot 1341 and to Lots 1350 and 813.1. The base is concave and the lateral edges ta- per towards the base. The remaining flake scars are parallel patterned and all edges, including the base, have retouched with small pressure flaking. The base has been thinned with small, parallel, vertical flakes, and then lightly ground. The distal end terminates in a transverse bending fracture. The material is semiopaque fine-grain tan chert that has been exposed to heat, giving the specimen a reddish hue and slightly glossy texture.

The use-wear analysis determined that the specimen is the hafted element of a likely bifacial knife used as a butchering tool. The edge grinding on the base and lateral margins was for hafting. Post break, the specimen was utilized as a scraper or plane on a hard material such as wood, with the broken edge used as the bit. The lateral edges and distal end form a thin burin edge that was used to score bone or wood.

Use-wear summary: Most of these tools are extremely large, thin implements with very acute working edges. Five were probably butchering implements. Another five were used to work materials such as wood or soaked antler. One was a hide scraper. One broken tool was used as a scraper or plane, and engraver after it was broken. The large, unbroken tools retain a considerable amount of utility and have much remaining use-life. The butchering implements are generally very thin with flat to biconcave cross sections. The low-magnification wear patterns exhibited on the thin tools are similar to those documented on Folsom ultrathin bifaces, which were also used as meat knives and light-duty butchering tools. That functional inference was confirmed by high-magnification use-wear analysis (Root et al. 1999).

\section{Formal Bifacial Tools}

\section{Drills and Perforators $(\mathrm{n}=9)$}

Drills and perforators are used to make holes. In this analysis, drills have a bifacially worked, long, and cylindrical or diamond cross section bit (Figure 42). Perforators are shorter, thinner, protrusions extending from the body of a flake or biface (Figure 43). Both drills and perforators were likely used in a rotary or twisting motion, since tips are more likely to break when pressed directly into a material (Keeley 1980). Keeley refers to the action as "boring" using a bidirectional and/or unidirectional twisting motion while 

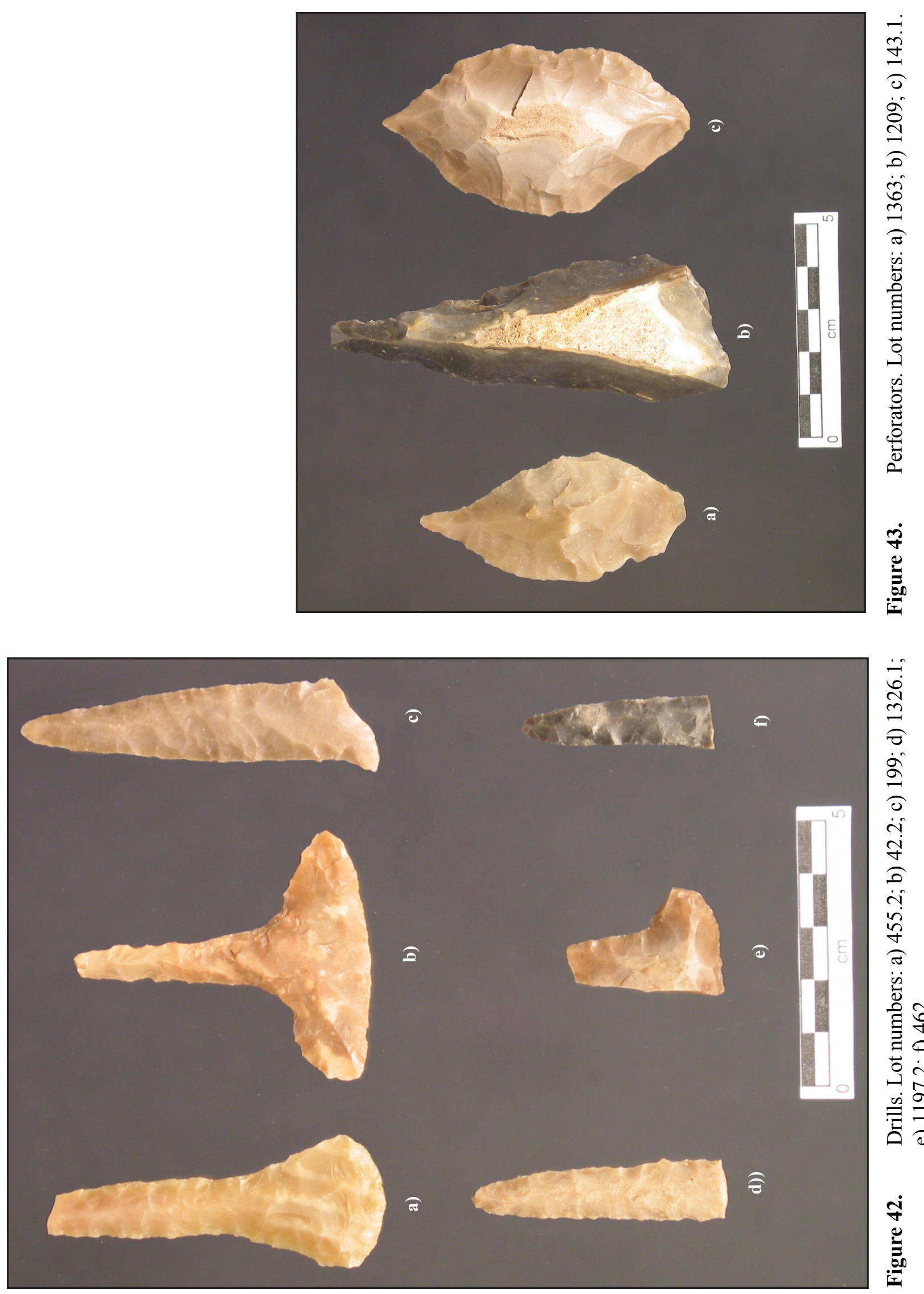
applying force. Dial and Collins (1998) suggest that some of the perforators from Wilson-Leonard may have been used as awls and used in weaving. Their analysis, which included use-wear on a number of specimens, found that cylindrical bits were more likely to be drills used in harder materials, while broader, thinner, tapering bits were used like awls for textiles and or cordage, and for perforating softer materials. The proximal end of the tools seemed prehensile, suggesting that the specimens were hand held and not hafted. Several of the Wilson Leonard specimens had been heated at the tip from the friction generated from drilling in wood.

At Wilson-Leonard, the manufacture of perforators does not appear to be a formal process as they were frequently made from rejuvenated or recycled bifaces such as projectile points. As a tool class they are relatively infrequent, although almost half of the 143 specimens were from Early Archaic context.

At the Gatlin site, drills and perforators are a small percentage of the tool population compared with the projectile points and general bifaces. Overall, only nine specimens in the Gatlin lithic assemblage are classified as drills or perforators.

\section{Perforators $(\boldsymbol{n}=3)$}

\section{Lot 143.1 (Figure $43 \mathrm{c}$ )}

The perforator tip is a made on one end of a small ovate-shaped biface. The broad based tip extends $18.2 \mathrm{~mm}$ from the biface and is diamond-shaped in cross section and the outline of the bit is triangular.

The biface is made from a tabular cobble with weathered upland cortex remaining on both dorsal and ventral surfaces. The biface was shaped using hard hammer percussion that did not extend to the center of either face. The lateral edges are sharpened around the circumference of the tool.

Use-wear traces suggest multiple uses for the specimen, with the bit used as a perforator on a material such as hide, and the lateral edges were used for cutting. The edge preparation of the distal end suggests that it was capable of being shaped into a bit.

The material is an opaque fine-grain, tan gray chert, with banding of light tan and grays. This material is found throughout the assemblage and likely repre- sents a local source. The weathered cortex indicates that the blank was acquired from the surface.

\section{Lot 1363 (Figure 43 a)}

The bit end of Lot 1363 is made on the distal end of a hard hammer flake that has been bifacially shaped. The bit is triangular in cross section and almost unifacial. In profile, the tip slightly curves to the right. As in Lot 143.1, the lateral edges are sharpened with pressure flakes indicating the tool was used also for slicing.

Use-wear examination and a replication experiment suggest that the tip was used to repeatedly pierce a material such as animal hide.

Lot 1209 (Figure 43 b)

Lot 1209 is a complete tool made from a blade-like flake that is triangular in outline and cross section. The specimen is bifacially flaked on the ventral surface with cortex remaining on the dorsal ridge.

The bit is formed from the heavily shaped and reworked proximal end of the flake that has removed both the platform and bulb. The distal end has been minimally trimmed.

The material is a dark gray Edwards chert similar to Lot 462 . The cortex is a weathered fine-grain cream color consistent with upland surface deposits.

Use-wear analysis suggested that the tip was used as a punch or awl-like perforator rather than a rotary drill.

\section{Drills (n=6)}

The other six specimens are what would be termed drills. Two of the specimens are distal tips, two are missing the tips, one is broken at the distal end, and one specimen is fractured at both the proximal and distal ends.

\section{Lot 1326.1 (Figure $42 \mathrm{~d}$ )}

Lot 1326.1 is a distal tip is $42.5 \mathrm{~mm}$ in length and 6.1 $\mathrm{mm}$ thick and $10.9 \mathrm{~mm}$ wide at the broken section. The cross section is diamond to cylindrical, with a central arras on either face. The specimen has been shaped though bifacial pressure flaking. The tip was last sharpened from flakes removed from one face and parallel to the edges. 
The proximal end terminates in a straight bending fracture. The material a fine-grain, tan colored, opaque, chert that is common in the lithic assemblage.

\section{Lot 462 (Figure $42 \mathrm{f}$ )}

Lot 462 is a distal tip $31.1 \mathrm{~mm}$ in length, $9.8 \mathrm{~mm}$ wide and $4.9 \mathrm{~mm}$ thick at the proximal end break. The cross section is diamond-shaped at the tip, becoming biconvex at the break. The specimen has been resharpened by pressure flaking which is patterned oblique parallel on one surface. Remnant flake scars suggest the tool was shaped from a larger biface and may be a recycled tool. Both lateral margins starting $5 \mathrm{~mm}$ behind the bit are lightly ground, and it is unclear if this is from platform preparation for edge sharpening or from use. The bit has small $(1 \mathrm{~mm})$ step and scalar fractures at the tip consistent with usewear (Keeley 1980). The proximal end terminates in an oblique hinge or snap fracture that is likely the result of bending forces (Whittaker 1994).

The material is a fine-grain dark gray Edwards chert with oval fossil inclusions. This material is also found throughout the assemblage.

Lot 199 (Figure 42 c)

Lot 199 is an almost complete bifacial drill. The cross section is diamond-shaped and slightly asymmetrical, or alternately beveled from sharpening. The missing section is at the right basal ear. The flaking pattern is patterned oblique pressure flaking with some of the scars being overshots. The edges of the tip are lightly ground. Flaking and edge grinding at the proximal end is consistent for hafting preparation. The basal break appears to be an impact fracture.

The material is a fine-grain opaque tan gray chert with small white and gray inclusions. The use-wear analysis proposed two uses for the specimen; as primarily a cutting tool on a soft material such as hide, and to pierce such material.

Lot 455.2 (Figure $42 \mathrm{a}$ )

Lot 455.2 is missing the distal tip. The outline of the tool is key-shaped with a rounded basal end. The specimen is bifacial and the bit cross section is diamond-shaped to rounded, with lateral margins trimmed and sharpened by ( $3-5 \mathrm{~mm}$ in width) small percussion flakes and pressure flakes that are paral- lel and overlapping. The basal end is ground and not thinned in the same manner as the lateral edges, where larger flakes were used to create a wedge profile, tapering at the proximal end.

At the distal end, the bit was removed in a transverse snap break. The material is fine-grain, opaque tan chert with grayish banding and flecking. Use-wear analysis determined the specimen was probably hafted, but there was no evidence for a specific use or a target material.

\section{Lot 42.2 (Figure 42 b)}

Lot 42.2 is a T-shaped drill that is almost complete, missing only the distal end. Made from a latestage biface or recycled tool, the cross section is strongly alternately beveled, more so then any of the other specimens and suggests that the specimen was extensively resharpened. The base is slightly convex. The basal ears on the proximal side of the base were notched and thinned after the creation of the drill body in preparation for hafting. The basal end is unifacially thinned although the dorsal side was retouched with continuous, small, pressure flakes. Patches of mineral inclusions caused areas of stacking of step fractures. Use-wear supports the classification of the specimen as a rotary drill used in a clockwise motion on a moderately hard organic material. Use continued after the tip was broken.

The material is the same tan chert with small inclusions and gray banding found in the assemblage. A slight reddening and vitreous feel suggests the material was exposed to heat perhaps for deliberate heat-treating.

Lot 1197.2 (Figure $42 \mathrm{e}$ )

Lot 1197.2 is a basal and shaft fragment of a probable bifacial drill or perforator. The fragment is similar to Lot 42.2 in form, although based on the taper towards the proximal end the bit length was considerably shorter. The cross section of the bit is biconvex, and flatter than the other drills, although the shaft becomes flatter closer to proximal end on the other specimens.

The tip ends in a oblique fracture and small (1mm) scalar flake scars at the tip suggest the edge was used after breaking. The left margin is a snap fracture that has split the specimen longitudinally. No use-wear 
was performed on the specimen. The material is fine-grain opaque tan chert with light gray patination developing on the surface. This chert is similar to the material from Specimen 199.

\section{USE-WEAR SUMMARY:}

Use-wear analysis was conducted on six drills and perforators. Some $(n=2)$ were also used to cut soft materials. Additionally, only two of the projectile points examined were used as drills, again suggesting that drills and perforators were not a major tool category at the Gatlin site.

\section{Clear Fork Tools and Gouges $(n=8)$}

The overwhelming majority of the non-projectile bifaces found during the Gatlin site excavations are not temporally diagnostic. However, one type of biface that can provide a temporal range is the distally beveled Clear Fork tool. The Clear Fork tool was originally categorized by Cyrus Ray (1941) for a series of gouge-like tools collected along the Clear Fork drainage. The tools were most likely hafted, the type and method of hafting being a source of debate. The tool occurs as a biface and a uniface, and the biface is generally the older of the two forms, with the bifacial form appearing during the Late Paleoindian period and the unifacial form appearing in the Middle and Late Archaic when it becomes the predominant form (Dial and Collins 1998; Taylor and Highly 1995). Experimental studies by Howard (1975) and use-wear by Hudler (1996) demonstrate Clear Fork tools were used for multiple tasks. The various forms of the tool from thick, cylindrical cross sections to almost flat biconvex also suggest different uses, with the more robust forms used as adzes and scrapers, and the thinner tools used as planes.

Clear Fork tools and gouges were recovered in relatively low numbers at the Gatlin site. Although the Clear Fork tool was the principle form identified, some gouge specimens resemble (in general morphology) the Guadalupe tool, another distally modified form that also has a geographic and temporal association. Since the subsistence-settlement pattern of the people who created these tools is trans-physiographic in nature, the scarcity of these tool forms may be related to seasonality of site use, site function, or environmental setting. For these reasons, the Clear Fork tools and gouges were investigated as a separate subunit of the greater biface assemblage.
Ray had originally proposed over 20 forms of Clear Fork tools. These types are more likely stages in the use-life a particular tool rather than an actual type. Resharpening of the bit reduces the overall length of the tool and also changes the bit angle (Dial 1998, Decker et al. 2000). Resharpening while the tool remains hafted also changes the overall morphology and outline of the tool, and as the tool becomes shorter, the triangular or subtriangular outline becomes more pronounced.

Raw material selection may be a factor in the Clear Fork form. The thinner specimens from sites such as Wilson-Leonard (Dial 1998) and Armstrong (41CW54) (Goode 2002) are made from a finer grain chert. Tougher material with larger grain size may be preferential for tools that were intended to be adzes or used for chopping.

At some point in the tool lifecycle, further resharpening is halted and the specimen is discarded. This suggests that there is a critical length that may be related to hafting.

The specimens from the Gatlin site are all complete and no fragmentary specimens were noted. The lack of broken specimens has several implications - that the tools were not intensively employed at the site, that they were used in a manner that did not generate broken tools, or that they were used at another portion of the site or were used at other sites and were curated at the Gatlin Site.

If the specimens represent discarded tools, this would suggest that they were being replaced at the site, therefore suitable blanks for manufacturing Clear Fork tools should exist in the assemblage.

Qualitative and quantitative data on tool form and function was gathered on these tools, and selected attribute measurements for these specimens are presented in Table 26.

Use-wear analysis was conducted on five Clear Fork tools and three gouges. These thick, bifacial implements have beveled bits and were probably used to work wood or other moderately resistant materials. One tool was apparently a scraper used on hard to moderately resistant organic materials, at least late in its use life. Most tools exhibit extensive and pronounced flaking use-wear, suggesting percussion uses, but some may also have been used in planing motions. 
Table 26. Attribute Measurements of Clear Fork Tools and Gouges

\begin{tabular}{|c|c|c|c|c|c|c|c|c|c|c|}
\hline Lot No. & Type & $\mathrm{L}(\mathrm{mm})$ & $\mathrm{W}(\mathrm{mm})$ & $\mathrm{T}(\mathrm{mm})$ & $W / T$ & Wt. (g) & Bit T & Bit Height & Bit W & Bit Angle \\
\hline 81.1 & Clear Fork & 85.3 & 53 & 20.6 & 2.57 & 85.1 & 19.4 & 13.9 & 52.2 & 45 \\
\hline 387 & Clear Fork & 89.5 & 46.9 & 23.5 & 2 & 79 & 19.9 & 10.5 & 47.1 & 50 \\
\hline 871 & Clear Fork & 107.7 & 54.7 & 26 & 2.1 & 144.5 & 21.8 & 18.8 & 49.6 & 55 \\
\hline 925 & Clear Fork & 89.7 & 46.2 & 22.7 & 2.04 & 71.5 & 18.2 & 12.8 & 45.5 & 40 \\
\hline 268 & Gouge & 85.4 & 43.1 & 16 & 2.69 & 47.3 & 10.7 & 7.1 & 40.8 & 50 \\
\hline 478 & Gouge & 104.6 & 34.5 & 15 & 2.3 & 47.3 & 9.3 & 5.4 & 32.9 & 37 \\
\hline 1303 & Gouge & 114.8 & 55.5 & 17.2 & 3.23 & 107.5 & 17 & 9.8 & 47.6 & 30 \\
\hline \multicolumn{2}{|c|}{ Mean } & 96.71 & 47.70 & 20.14 & 2.42 & 83.17 & 16.61 & 11.19 & 45.10 & 43.86 \\
\hline \multicolumn{2}{|c|}{ Median } & 89.7 & 46.9 & 20.6 & 2.3 & 79 & 18.2 & 10.5 & 47.1 & 45 \\
\hline \multicolumn{2}{|c|}{ Minimum } & 85.3 & 34.5 & 15 & 2 & 47.3 & 9.3 & 5.4 & 32.9 & 30 \\
\hline \multicolumn{2}{|c|}{ Maximum } & 114.8 & 55.5 & 26 & 3.23 & 144.5 & 21.8 & 18.8 & 52.2 & 55 \\
\hline \multicolumn{2}{|c|}{ Std. Deviation } & 12.04 & 7.49 & 4.18 & 0.45 & 34.36 & 4.77 & 4.48 & 6.43 & 8.71 \\
\hline
\end{tabular}

\section{Clear Fork Tools $(n=5)$}

Lot 925-Area A-SW (Figure $44 \mathrm{c}$ )

The specimen has been extensively utilized. The outline of the bit is convex, as is the side profile. One of the characteristics of Clear Fork tools is that the bit face is concave or "scooped"; however, this may change based upon how the tool was used and re-sharpened.

The cross section of the tool is dihedral, with a central arras on both the dorsal and ventral faces. The flake scars appear to be hard hammer, with few of the scars crossing the center line. The lateral edges have been straightened by the removal of small (10 $\mathrm{mm}$ and less) flakes that has reduced the sinuosity of the edge while centering the edge between the faces. The ventral face of the bit has been mostly removed in what appears to be an attempt to re-sharpen the bit. The remaining bit is almost planoconvex in cross section. Stacked step flake scars extend inwards from the margin of the bit up to $10 \mathrm{~mm}$. A knot of crystal filled fissures on the ventral side was not removed. The attempts to remove it from both the bit end and from the lateral margins ended in hinged and step scar fractures.

At the poll or proximal end, none of the edges are ground or smoothed, although this may not be a requirement for hafting. The material is a mottled and banded, opaque, tan gray chert of fine to medium fine-grain size with fossiliferous and crystalline inclusions.

Use-wear analysis suggests that both ends were utilized. The distal bit was used for low-angled percussive work against moderately resistant materials. The use-wear on the proximal end resembles bidirectional planing; however, it seems more plausible that this is the result of hafting wear.

Lot 81.1 (Figure $44 \mathrm{~d}$ )

This specimen was recovered during the testing excavation. The outline is subtriangular and the cross section is biconvex without a pronounced central arras. All of the flake scars are hard hammer with many of the larger scars crossing the centerline. The lateral edges have a pronounced sinuousity created by hard hammer flake removals from alternating faces.

The bit end is more characteristic of a typical Clear Fork tool then Specimen 303, with a beveled edge. Like Specimen 303, the bit on the ventral surface has been removed. Hard hammer flakes were removed perpendicular to the front of the bit. The edge has been abraded for platform preparation and the flakes were removed on the ventral surface only. These flake scars extend approximately $20 \mathrm{~mm}$ from the bit edge into the interior of the tool where they end in hinge fractures. Underlying flake scars suggest that this was an attempt to rejuvenate a dulled or broken bit. Because of the resharpening, evidence of use-wear was not detected. 


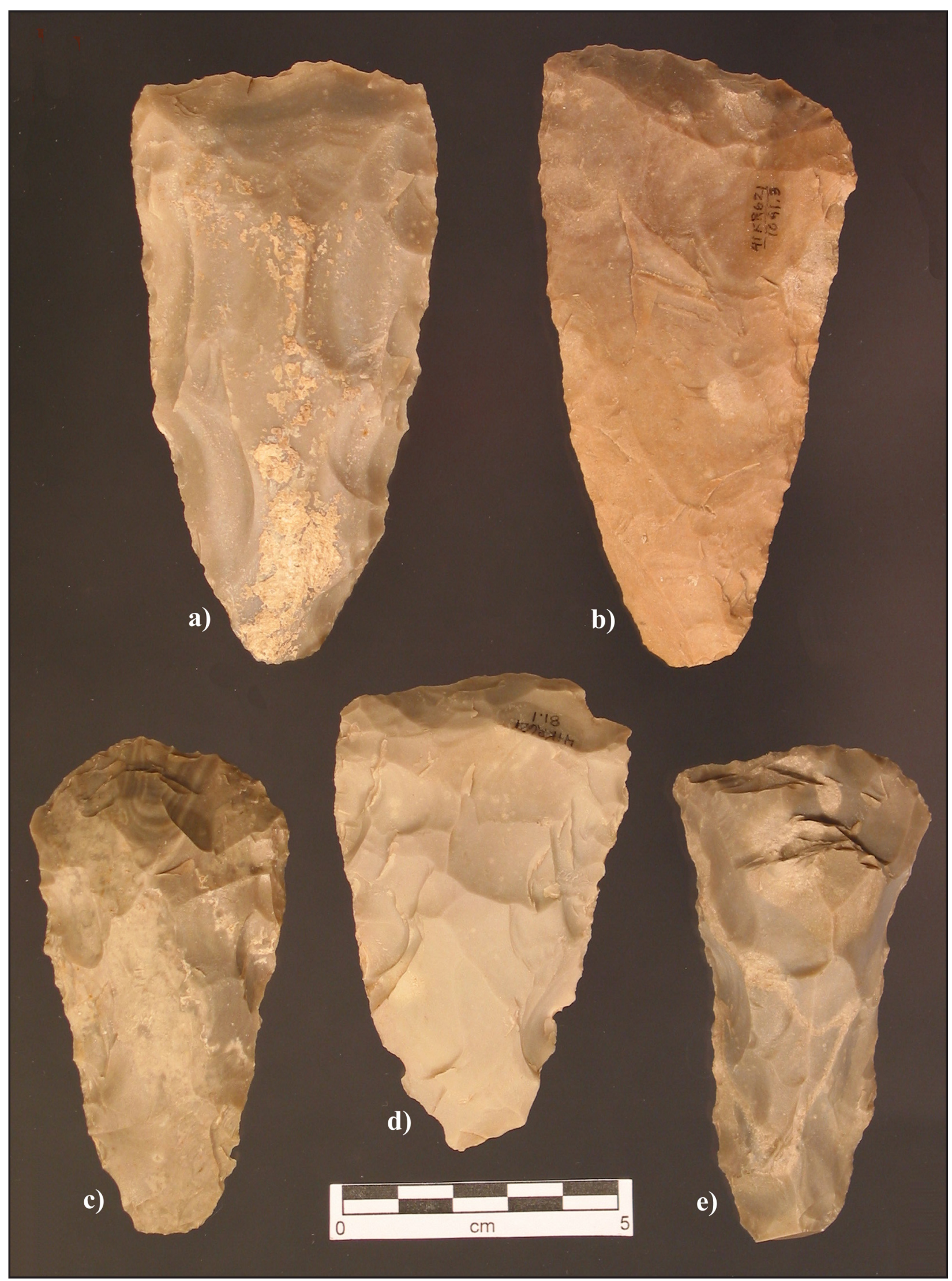

Figure 44. Clear Fork Tools. Lot numbers: a) 871; b) 1091.3; c) 925; d) 81.1; e) 387 . 
The material is an opaque, light gray, fine-grain chert with small fossil inclusions. Edge grinding along portions of the lateral margins is sporadic and appears to be for platform preparation for flake removals rather then hafting dulling.

\section{Lot 387 (Figure 44 e)}

The tool has a strong planoconvex profile and retains a portion of the original ventral flake surface at the distal bit. The dorsal side has a prominent central arras, while the ventral side has been worked along the proximal two thirds resulting in a single facet bit characteristic of a Guadalupe tool.

The bit has been sharpened and shaped along the dorsal face from the ventral surface. A thick knot of material on the dorsal face prevented further flake removals from the bit. The specimen is made from the same chert as Lot 1303, with a pronounced band of coarser material impeding the removal of flakes and creating stacked and stepped flake scars.

At the proximal end there is a single facet that appears to be the original striking platform for the blank. The flake scars on the ventral face removed the bulb of percussion, a Guadalupe tool trait.

Use-wear analysis indicates that the tool was last used to scrape moderately hard to hard organic material. An unidentified reddish mineral residue on the lateral margins may be related to hafting material.

Lot 871 (Figure 44 a)

This specimen is larger than the previous three examples and has the Clear Fork "scooped-out" distal bit face. The visible flake scars are all hard hammer, with the larger scars extending to the enhanced center arras on both faces, creating a dihedral cross section.

The bit has been formed by the removal of several flakes using the ventral surface as the platform. The bit is slightly convex in outline. Lateral flake scars have been overlapped by the bit, indicating that the length of the tool has been reduced through resharpening.

Use-wear indicates two possible types of use, low angle impact and/or bidirectional planing. Damage along the lateral edges is both from manufacture and probable hafting.
The material is fine-grain, light gray, opaque chert with whitish banding and fossil inclusions. Mineral precipitate adheres along portions of the dorsal face.

\section{Lot 1091.3 (Figure 44 b)}

This is one of the larger of the Clear Fork tools and is similar in length to Lot 871 . The bit face is slightly dished or scooped out and the profile is convex and asymmetrical, unlike the other tools which were symmetrical. The profile is planoconvex, with the dorsal face being the flatter of the surfaces. The bit has been unifacially sharpened.

The tool was shaped using hard hammer percussion with small flake removals used to straighten the lateral edges. The material is a fine- to mediumgrain tan gray opaque chert with coarse gray fossil inclusions.

Use-wear on the bit end indicates light percussive and/or unidirectional planing contact. Portions of the straightened lateral margins have been slightly dulled and rounded suggesting hafting damage or preparation.

The material is a medium to fine-grain opaque gray chert with circular, gray, medium-grain, fossil inclusions.

\section{Gouges ( $n=3)$}

\section{Lot 1303 (Figure 45 b)}

This is the largest of the gouge tools. The specimen lacks a pronounced ridge behind the bit and has a greater width/thickness ratio than a Clear Fork tool. Looking at the specimen from the bit end, the profile is scooped or hollowed, where it is high at the lateral margins and low at the center. Viewed from above, the bit edge is straight.

The bit has been bifacially worked with several large flakes removed from both the ventral face and the dorsal face in contrast to the Clear Fork tools which are shaped primarily on the dorsal face. The bit angle is the shallowest of this category, at 30 degrees. The tool was formed using hard hammer percussion and an irregular flaking pattern, with some scars passing the central median. Indentations along the lateral margins towards the proximal end have been rounded 


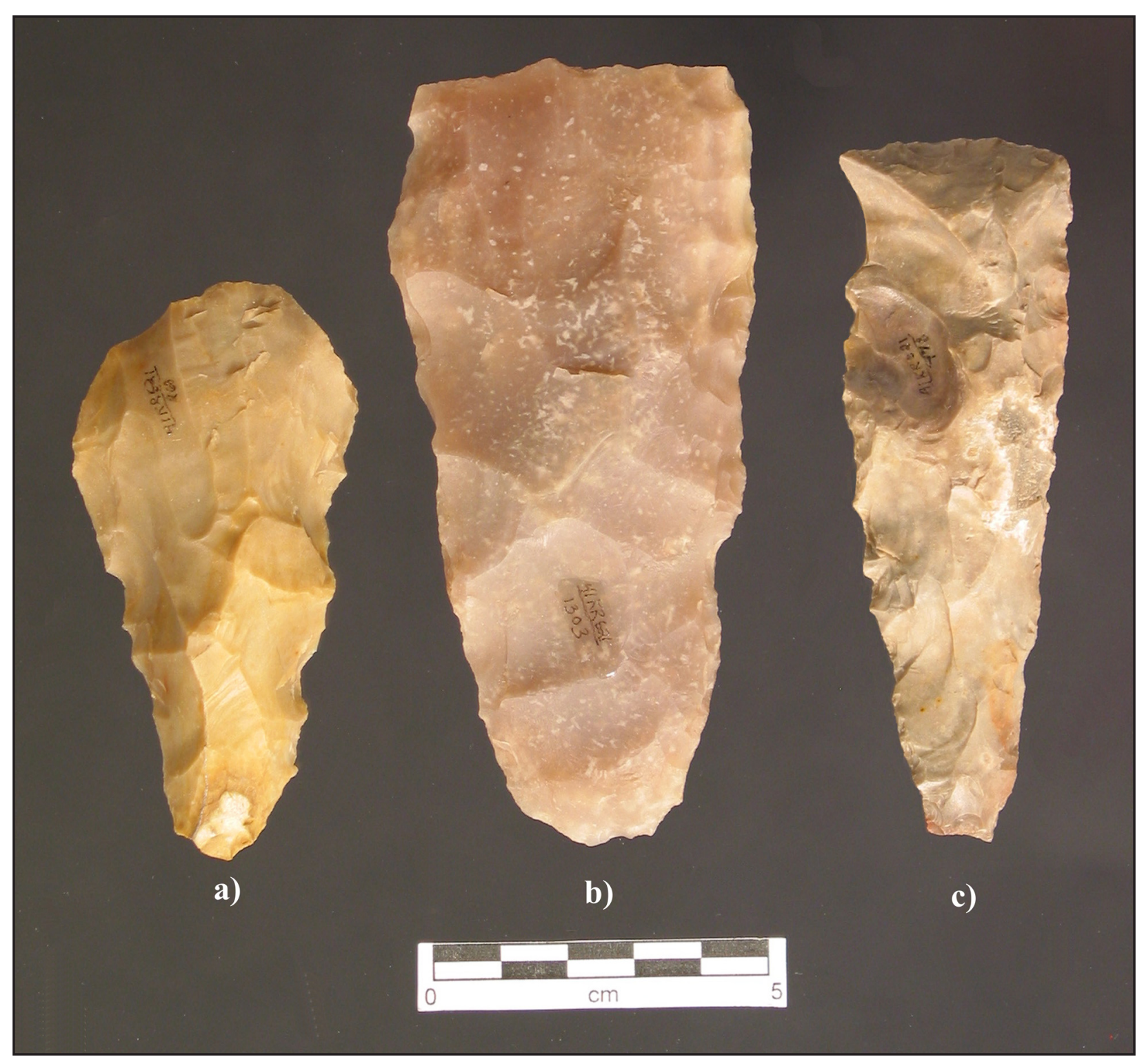

Figure 45. Gouges. Lot numbers: a) 268; b) 1303; c) 478 .

or abraded. This may be for hafting lashing as suggested by the use-wear analysis or from attempts to further thin a knot of whitish gray inclusion. The straightening of the poll end edges while the rest of the edge remains sinuous suggests that the tool was hafted.

The material is a fine- to medium-grain tan gray chert with small to large mineral and fossil inclusions.

\section{Lot 478 (Figure $45 \mathrm{c}$ )}

This is a narrow tool with a strong biconvex profile. The bit has a pronounced scooped cross section and is slightly convex in profile. The bit has been created on the dorsal surface.

The tool was formed through hard hammer percussion with the scars reaching to the center of the tool and forming a sinuous arras. Large flake scars near the distal bit on the left margin removed a large portion of the specimen, possibly over-thinning the surface.

Use-wear suggests that the bit was used in a back and forth planing motion. The material is a fine- to medium-grain, opaque tan and gray chert with coarse grained mineral and fossil inclusion. The tool surface 
has a vitreous feel that may be the result of burning or deliberate heat treating.

\section{Lot 268 (Figure 45 a)}

This tool has been extensively resharpened. The bit has been resharpened on the dorsal face from platforms created on the edge of the bit.

In contrast to the Clear Fork and other gouge tools, the bit is strongly convex. The outline of the bit is also convex. Flake removals on the bit are on the dorsal surface with smaller flake removals on the ventral face appearing to create platforms for removal from the dorsal face. Side indentation formed by notches may have been used for hafting.

Characteristics of the original parent flake blank remain including a portion of the flake surface and a small patch of cortex on the dorsal face at the proximal end.

\section{Butted or Backed Bifaces $(n=14)$}

These 14 specimens are distinguished from the general biface population because they have a bit, or working edge, opposite a cortical edge. Twelve of the specimens were recovered during the data recovery and two were from the testing phase. The assumption is that these are hand held tools and that the proximal cortex was deliberately left in place. Selected attributes for these specimens are presented in Table 27. On some specimens, other sharp, non-working edges were deliberately dulled, again to aid in prehension. With the exception of two specimens, Lots 1552.3 and 640.1, the backed bifaces are made by reducing and trimming tabular cobbles. The two specimens are likely made from small cobbles, and one specimen may be made on a thick hardhammer flake.

These tools were likely produced and used on site, and therefore represent activities or processes practiced at the site. It is also possible that they represent a curated technology, and that they were left or cached at the site for future use.

Table 27. Attributes Measurements of Butted or Backed Bifaces

\begin{tabular}{|r|r|r|r|r|r|}
\hline \multicolumn{1}{|c|}{ Lot No. } & $\begin{array}{c}\text { Max. Length } \\
(\mathbf{m m})\end{array}$ & $\begin{array}{c}\text { Max. Width } \\
(\mathbf{m m})\end{array}$ & $\begin{array}{c}\text { Medial Thickness } \\
(\mathbf{m m})\end{array}$ & $\begin{array}{c}\text { Average Edge } \\
\text { Angle }\end{array}$ & $\begin{array}{c}\text { Weight } \\
(\mathbf{g})\end{array}$ \\
\hline 56.10 & 127.00 & 88.00 & 34.00 & 40.00 & 422.20 \\
\hline 718.40 & 120.00 & 89.00 & 46.00 & 53.00 & 546.00 \\
\hline 148.10 & 96.00 & 83.00 & 21.00 & 36.00 & 255.80 \\
\hline 518.70 & 90.00 & 70.00 & 33.00 & 43.00 & 247.40 \\
\hline 640.10 & 88.00 & 62.00 & 24.00 & 38.00 & 168.20 \\
\hline 558.20 & 114.00 & 112.00 & 41.00 & 50.00 & 649.00 \\
\hline 512.10 & 78.00 & 126.00 & 29.00 & 45.00 & 393.10 \\
\hline 211.10 & 96.00 & 77.00 & 37.00 & 54.00 & 302.50 \\
\hline 1552.30 & 77.00 & 76.00 & 29.00 & 44.00 & 198.50 \\
\hline 1564.10 & 116.00 & 85.00 & 48.00 & 54.00 & 500.80 \\
\hline 1460.20 & 126.00 & 88.00 & 40.00 & 42.00 & 401.50 \\
\hline 1224.50 & 142.00 & 106.00 & 42.00 & 51.00 & 750.00 \\
\hline 1297.10 & 122.00 & 94.00 & 31.00 & 45.00 & 460.10 \\
\hline 991.20 & 117.00 & 87.00 & 28.00 & 43.00 & 417.00 \\
\hline & 14.00 & 14.00 & 14.00 & 14.00 & 14.00 \\
\hline & 107.84 & 88.59 & 34.44 & 45.57 & 408.01 \\
\hline & 115.35 & 87.25 & 33.45 & 44.50 & 409.25 \\
\hline N & 77.00 & 62.00 & 21.00 & 36.00 & 168.20 \\
\hline Mean & 142.00 & 126.00 & 48.00 & 54.00 & 750.00 \\
\hline Median & 20.058 & 16.733 & 8.189 & 5.919 & 168.122 \\
\hline Minimum & & & & & \\
\hline Maximum & & & & & \\
\hline Std. Deviation & & & & & \\
\hline
\end{tabular}


Dial and Collins (1998) classified similar tools from Wilson-Leonard as Core Tools, emphasizing their function. These were variously known as choppers and scrapers, having a bifacial distal end created by the removal of several large flakes and generally retaining 50 percent or more cortex.

At the Gatlin site, cobbles were selected that were close in size to the finished tool. Varying degrees of cortex was removed from the specimens and they vary in the amount of trimming necessary to create the working edge. Trimming appears to be universally hardhammer and some of the specimens may have been used as cores. The side profile of the specimen is wedge-shaped, with the proximal end being the thickest.

While tools of this description have been called choppers or hand axes, many of these specimens appear to be scrapers or combination tools used for scraping, cutting and/or chopping.

The chert is similar in color and grain size to many of the other bifaces and tools observed in the assemblage, specifically tan and tan gray cherts with grayish banding and mottles. Cortex is generally upland surface cortex; however, on several of the specimens, there is mineral staining and smoothing consistent with alluvial gravels. These specimens were originally upland cobbles that were later rounded and smoothed in stream channels.

Use-wear analysis was conducted on Lot 56.1 and Lot 718.4. Results indicate that Lot No. 56.1 was used to process soft vegetal material. The flaking wear on Butted Knife 718.4 indicates contact with moderately resistant material, probably in a cutting motion. There is no clear evidence of hafting on either specimen.

\section{Specimen Lot 56.1 (Figure 46)}

The specimen is made from a tabular upland cobble that acquired a mineral patina from contact with ground water. The chert is finegrain semi-opaque brown chert noted in the lithic assemblage.
Approximately three quarters of the edge was trimmed, with only the proximal end left with its cortex. Cortex remains at the proximal end of both faces. There is glossy use-wear along segments of the bit that is interpreted as silica sheen or sickle sheen, a well-developed polish from repeated contact with a soft vegetal material. The polish is developed on both faces of the edge. The use-wear analysis did not determine the directionality of use and it is likely that it was used for both cutting and scraping. Resharpening flakes cross cut the use-wear and subsequent use did not develop a polish on the new surface. The modifications along the lateral margins at the proximal end appear to be deliberate dulling for prehension.

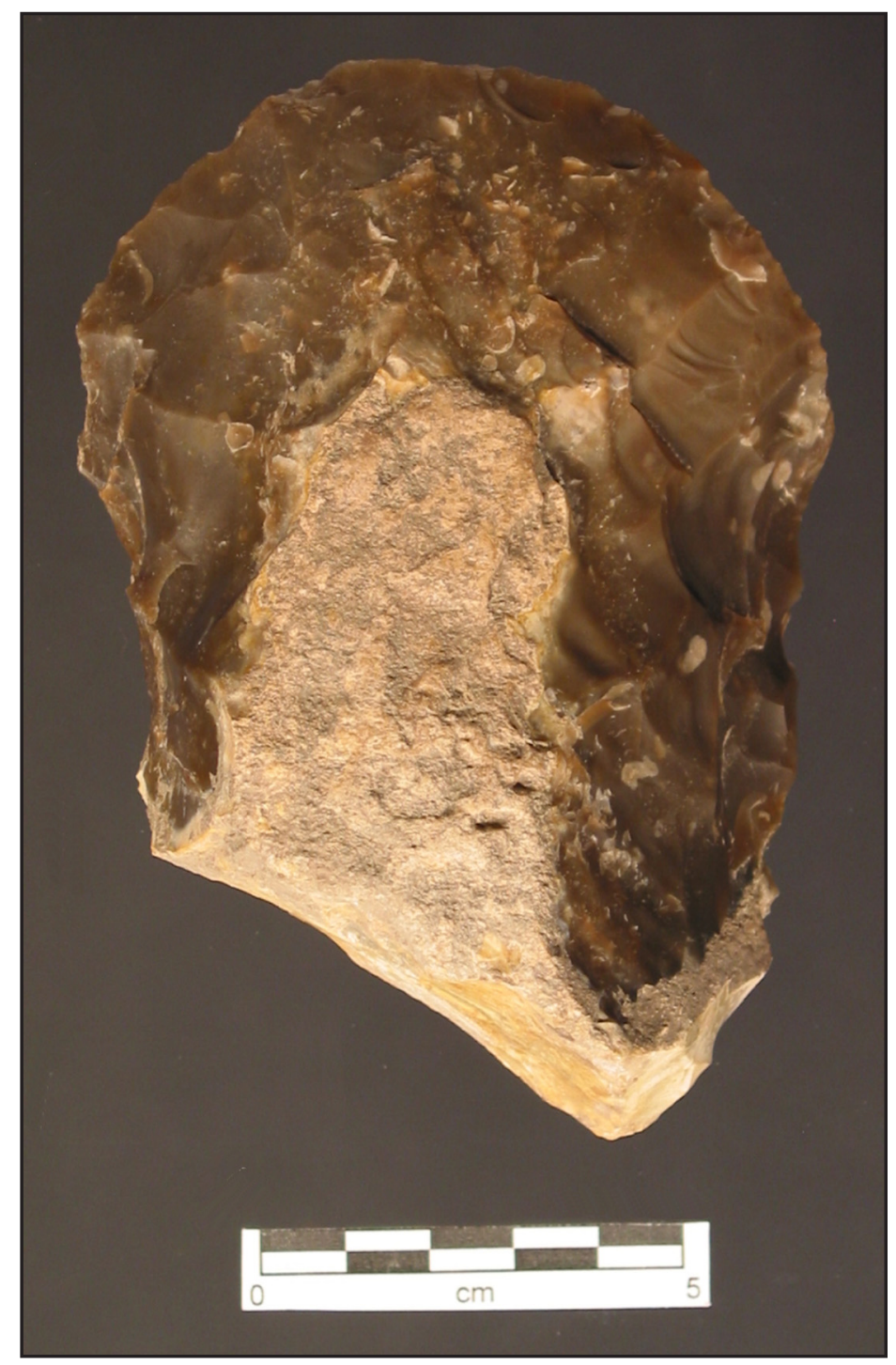

Figure 46. Butted or backed biface, Lot number 56.1. 


\section{Lot 718.4 (Figure 47)}

The specimen is made from a sub-triangular upland cobble that has mineral staining from contact with water. The bit edge is opposite the apex, which is the prehensile end that has been intentionally dulled.

The bit has been trimmed on one surface with narrow, parallel flake removals extending $20 \mathrm{~mm}$ onto the face. The cortex on the opposite face has been removed using only a few large flake detachments. Cortex still covers approximately 50 percent of the specimen. The material is a fine-grain semi-opaque tan gray chert with small grayish inclusions.

Use-wear analysis suggests that the tool was used in a cutting motion against a moderately hard material. Additional edge dulling along the lateral margins may be from hafting, although it seems more likely that the edge dulling resulted from attempts to further thin the specimen.

\section{BIFACE SUMMARY}

Bifaces were found in either every excavation area or in every Occupation Zone, with the greatest concentration occurring in Area B, followed by Area A-NE (Table 28). Biface production increases from the Early Archaic OZ1 to the Middle/Late Archaic OZ4 in the deposits closest to the midden.

\section{Modified Flake Tools}

A modified flake has been retouched along a lateral margin. In some cases, the retouching of the margin is intentional, often resulting in a purposefully shaped formal tool, such as a scraper or other unifacial tools. Therefore, a formal flake tool has been modified to accommodate hafting and/or standardize or regularize the shape of the artifact. In other instances, marginal retouching is unintentional and may have been caused by use or by post-depositional processes (e.g. trampling, erosion, or bioturbation). When a modified flake has been minimally retouched it is referred to as an informal tool.

\section{ANALYTICAL METHODS}

The Gatlin site's modified flake assemblage, excluding those from mixed contexts in Area B, was subdivided into four categories. These categories are descriptive, and to some extent functional, and are based upon overall specimen morphology and the intensity and extent of use-wear and /or modification. These categories, in approximate order from least modified to most modified are: utilized flake, retouched flake, graver and scraper. Further divisions were made in some of these sub-categories although several of these sub-categories had only one specimen. One specimen was classified as "indeterminate" and was not included with any of the categories.

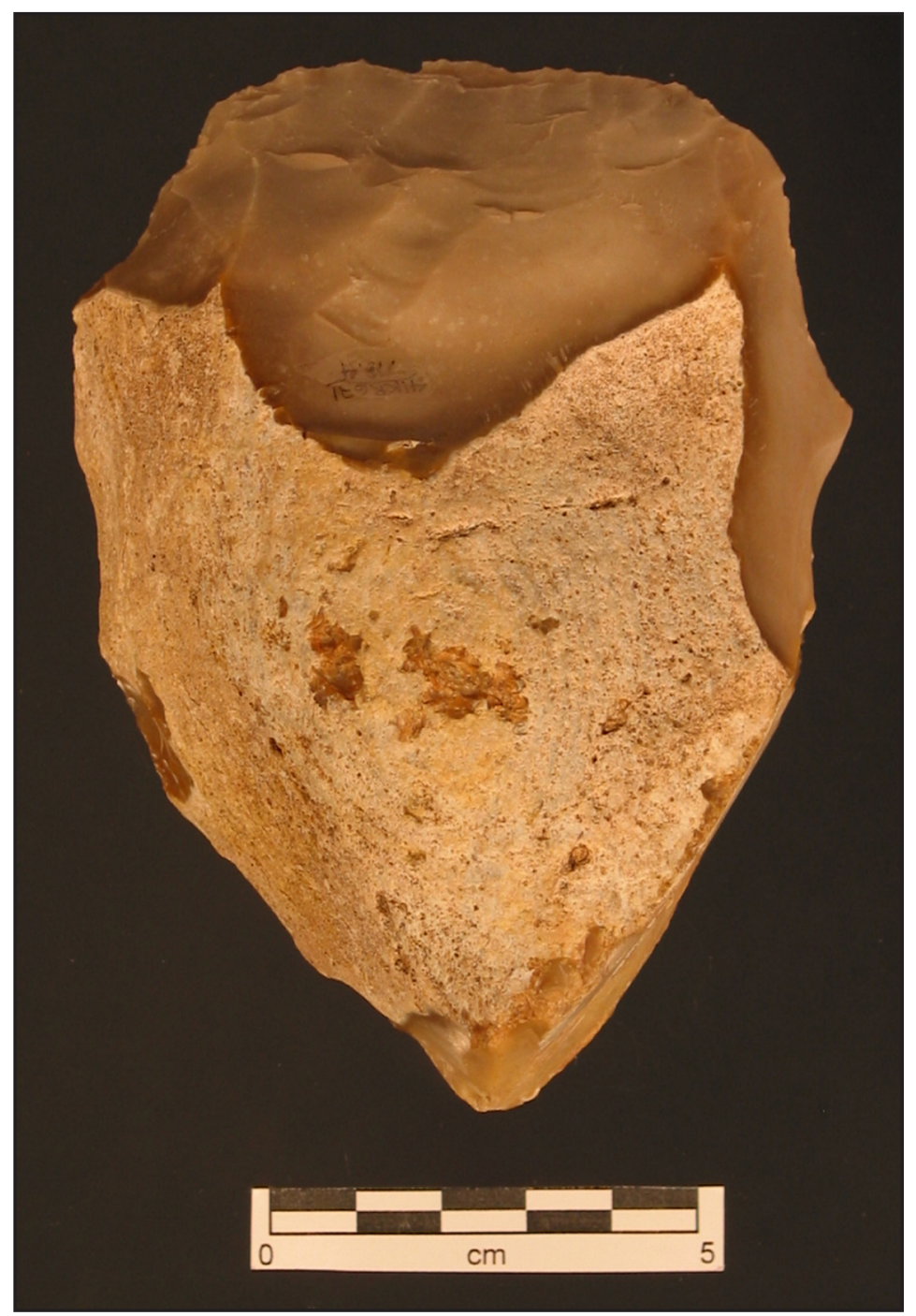

Figure 47. Butted or backed biface, Lot number 718.4. 
Table 28. Biface Distribution by Occupation Zone and Area

\begin{tabular}{|r|r|r|r|r|r|r|r|r|}
\hline Occupation Zone & Unk & A-NE & A-NW & A-SE & A-SW & B & Midden & \multicolumn{1}{l|}{ Total } \\
\hline 1 & & 19 & & & & & & 19 \\
\hline 2 & 1 & 68 & 10 & 1 & 61 & 2 & 1 & 144 \\
\hline 3 & 4 & 103 & 94 & 20 & 80 & 58 & 18 & 377 \\
\hline 4 & 5 & 9 & 14 & 0 & 5 & 341 & 79 & 453 \\
\hline N/A & 34 & 2 & 7 & 10 & 14 & 2 & 23 & 92 \\
\hline Total & $\mathbf{4 4}$ & $\mathbf{2 0 1}$ & $\mathbf{1 2 5}$ & $\mathbf{3 1}$ & $\mathbf{1 6 0}$ & $\mathbf{4 0 3}$ & $\mathbf{1 2 1}$ & $\mathbf{1 0 8 5}$ \\
\hline
\end{tabular}

Based upon the extent of modification, the modified flakes tools are categorized as informal and formal flake tools.

\section{Informal Tools}

The first two categories, utilized flake and retouched flakes, are considered informal tools, having been minimally modified through use or minimally trimmed when manufactured. Typically, flaking scars do not extend into the interior of the flake surface and are confined to less than $10 \mathrm{~mm}$ of the lateral margins.

Utilized Flakes are modified through use with no deliberate trimming, and are thought to be expedient tools, used for a variety of cutting and scraping tasks and discarded. They may also serve as blanks for further tool production. Utilized flakes can be difficult to identify accurately since edge damage through use is created through intensity, duration, and type of use.

Retouched Flakes are minimally trimmed with scars not extending onto the flake surface. The original shape of the flake is not altered but can change through use and reuse.

\section{Formal Flake Tools}

The remaining categories are classified as formal flake tools. Scrapers and gravers are considered formal tools with the connotation that these tools represent an increased investment in time, have an intended form, and are used for specific purposes. Flake scaring can extend onto the dorsal surface of the tool and modification may have been made for hafting, with the latter further categorized into end scrapers, side scrapers, transverse scrapers, convergent scrapers, end and side-scrapers, and full side or all edges scrapers. In the following figures, abbre- viations are used for the tool categories as follows: end scraper (End Scr), end and side scraper (E\&S Scraper), convergent scraper (ConScr), transverse scraper (Tr Scr), full side scraper (FullSScr), graver (Graver), indeterminate (Ind), retouched flake (Ret $\mathrm{Fl}$ ), and utilized flake (Uti Fl).

End Scrapers are flake tools where the modification is along the distal end of the parent flake. Examples of end scrapers are in Figures $48 \mathrm{a}$ and c, and $49 \mathrm{c}-\mathrm{e}$.

End and Side Scrapers have modifications along the distal end and at least one lateral margin. Examples of end and side scrapers are in Figures $48 \mathrm{~b}$ and 49 $a$ and $b$.

Side Scrapers are modified along one or more lateral margins which are separated by the unmodified distal end (Figure $48 \mathrm{~d}$ ). Side Scrapers on triangular flakes can become convergent scrapers through repeated use and maintenance (Figure $50 \mathrm{a}$ and c).

Convergent Scrapers are really a subset of side scrapers. The two worked edges taper to an apex, usually at the distal end (Figure $50 \mathrm{~b}$ ).

Transverse Scrapers are fashioned along a transverse fractured edge of a flake (Figure 48 e). Transverse scrapers can represent reuse and recycling of otherwise discarded tools, or it can be a deliberate manufacturing process to use the thicker part of the flake interior.

Full Sided Scrapers are circular in outline and continuously modified along the edge (Figure 49 f), maximizing the utility of the flake. There is no evidence of hafting in the form of edge grinding or hafting notches and the specimens may have been hand held and rotated to present sharper scraping edges. Because these specimens appeared to be extensively modified, and were perhaps made from 


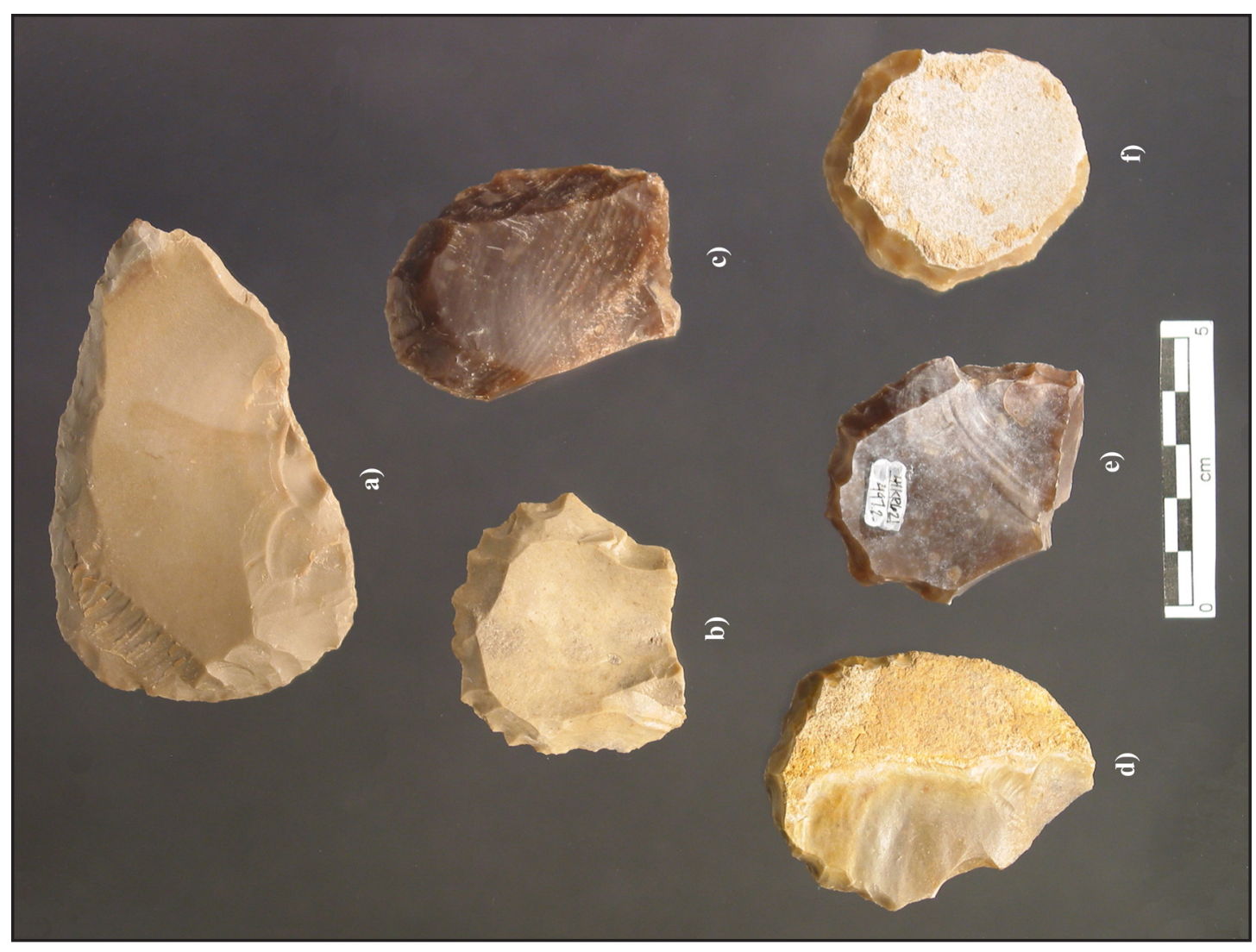

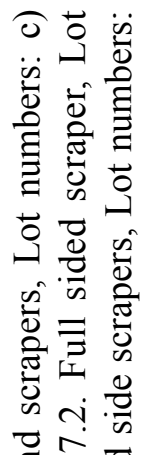

호웜

응 모

$\circ \ddot{\infty}$

충

든 능

어음

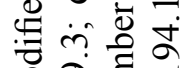

它 $\infty$

$\stackrel{8}{\stackrel{9}{0}}$

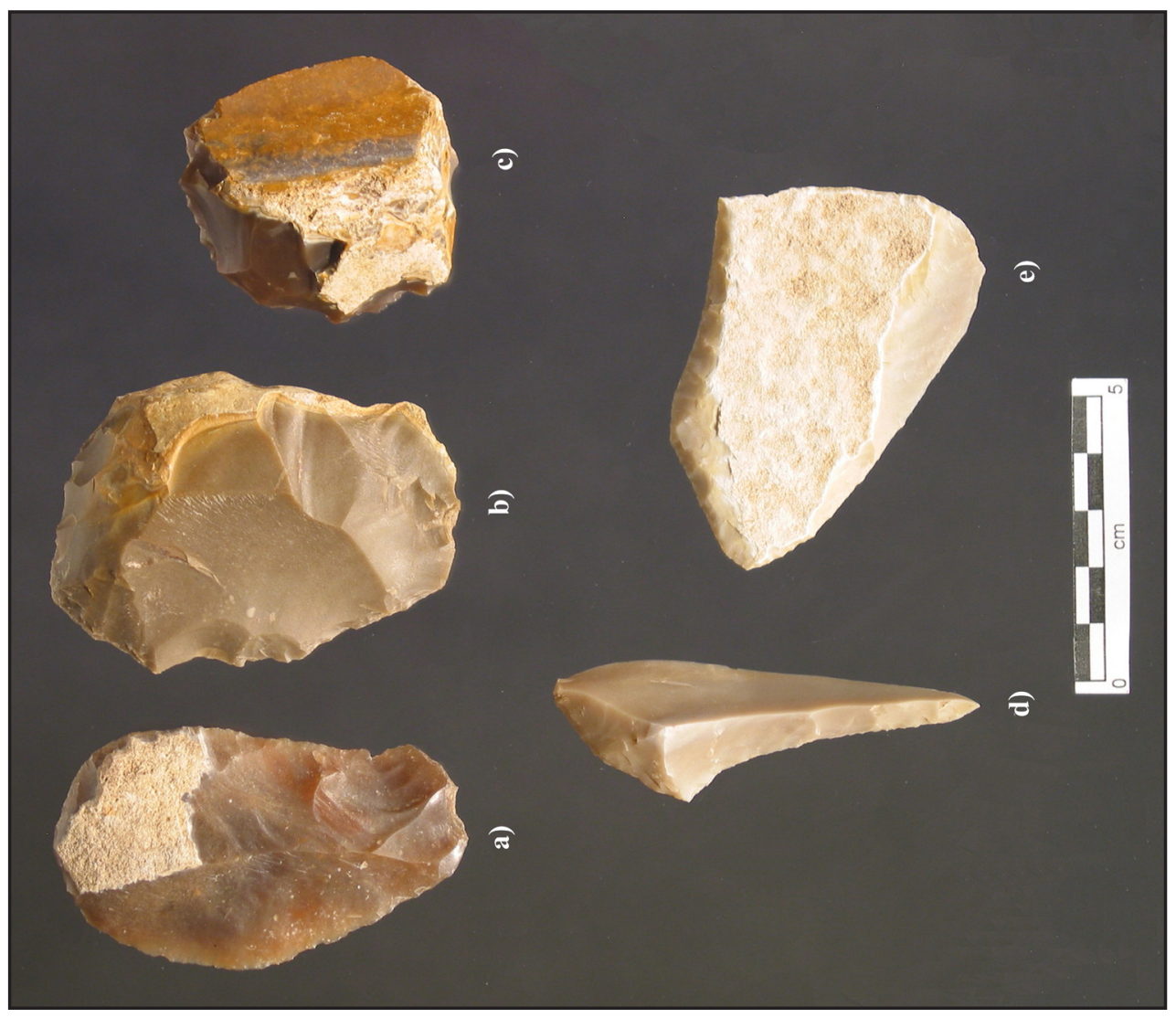

ำ

๙ิ

离合

हิ

寻㐫

율 范

s 어

हैं

㝌

तुํำ

되 过

$\dot{0}$ के

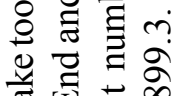

丞州 0

赵

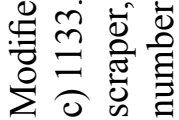

$\stackrel{\infty}{+}$

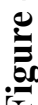




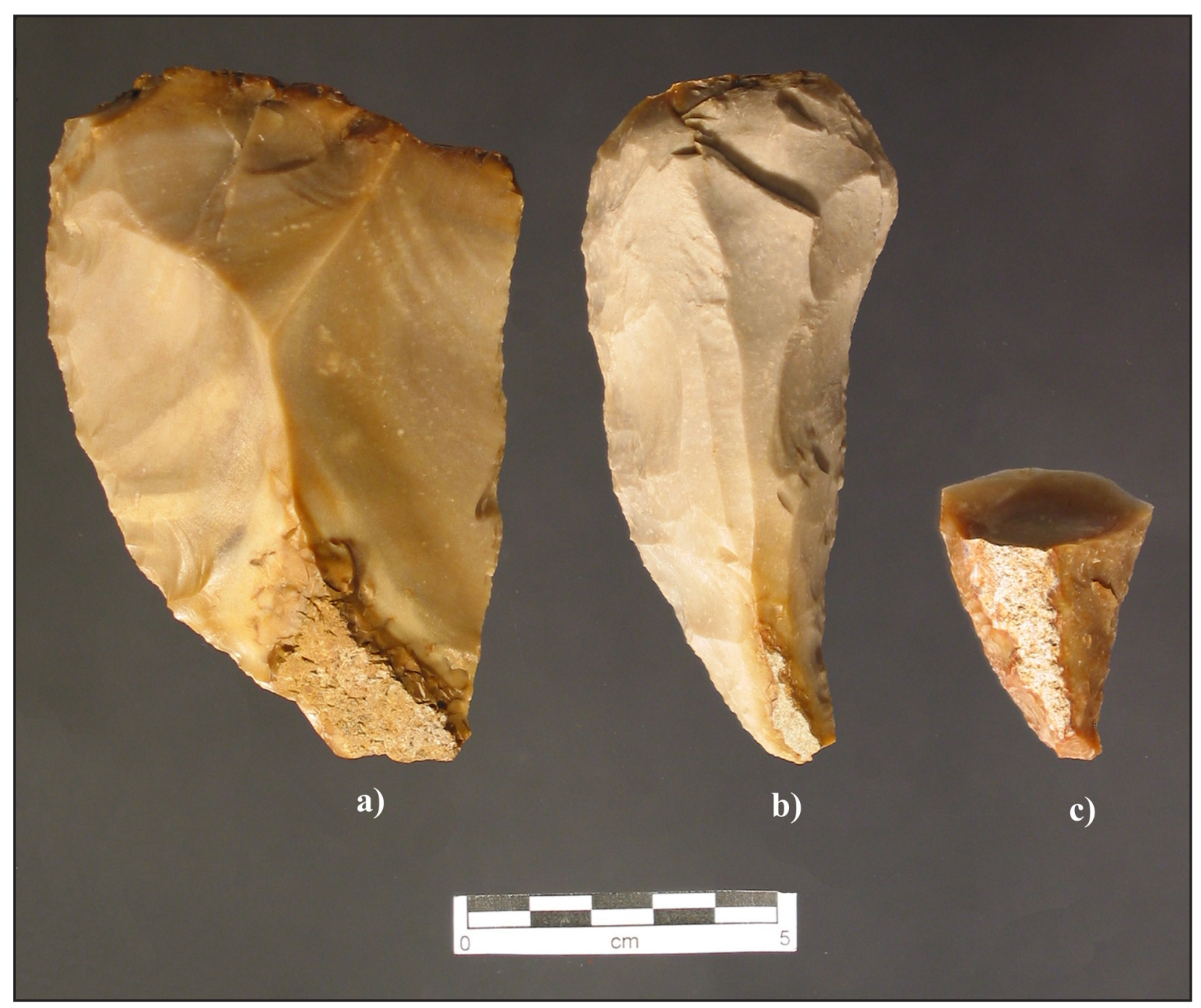

Figure 50. Modified flake tools. Convergent scraper, Lot number b) 807.13. Side scrapers, Lot numbers: a) 813.11 ; c) 978.4 .

other previously hafted scrapers, they may represent a strategy of utilizing exhausted scrapers.

Gravers are deliberately modified to produce a protrusion or spur from an edge, frequently through notching on either side of the spur. Graver bits are thought to be incising and/or perforating tools.

Variation in scraper morphology, according to Bordes' typology, equates overall shape to an analytical unit, with little accounting for use life events such as reuse and resharpening (Bisson 2000, Dibble 1995, Odell 2001, Shott 1995). Certain tasks such as hide softening do not require a sharp edge, and scrapers used for such tasks may resemble exhausted scrapers. When hafted, scrapers are more easily resharpened than replaced, with resharpening taking less than a minute (Bozszhardt and McCarthy 1999).
In studies of ethnographic use of lithic scrapers, neighboring ethnic groups used different hafting techniques and scraper shapes for similar activities (Weedman 2002). Scraper use also varied according to the type of hide being worked and the intended final product (Rots and Williamson 2004).

A variety of nominal (e.g., morphology, condition, breakage, cortex, heat, patination, retouch type, retouch distribution, and retouch location) and scalar attributes (e.g., overall specimen measurements, platform measurements, and measurements associated with retouch scars) were recorded for each specimen. Nominal and scalar attributes for each uniface and modified flake specimen were then entered into a database and used to search for patterning within and between uniface and modified flake production 
and usage (e.g., resharpening techniques, reduction sequences, and edge modification). Individual attributes are presented for the formal tools in Appendix E.4 and for the informal tools in Appendix E.5. One measurement in particular, percentage of edge used is a composite measurement derived from the maximum potential useable edge and the utilized edge. High percentages can indicate more intensive usage or more formalized tool design. As a specimen is resharpened the overall perimeter is reduced in relation to the worked edge. However, a smaller percentage can occur with forms of end scrapers, such as those made on long blades.

The shapes of scrapers within the Gatlin Site assemblage appear to be conditioned by the parent material, which includes tabular and rounded cobble cores. Flakes detached by hard hammer from the edge of tabular cores have a low length-to-width ratio, and the width can be greater than the length. These flakes can be detached from prepared cores, since several specimens could be termed sequential flakes, having a large negative bulb of percussion on the dorsal side, resembling a "gull winged" profile when observed from the platform. These flakes tend to have relatively constant thickness throughout their length. Scraper specimens made in this manner are similar in appearance to the Tula method of scraper production in Queensland, Australia, where their primary source material is tabular chert cobbles. Flake blanks are removed sequentially with a deliberate emphasis at producing a pronounced gull-wing or saddle-shaped platform profile (Moore 2004).

The production and use of sequential flake tools was noted at the Woodrow Heard (UV88) in Uvalde County. Decker et al. (2000:268) associate the form with Early Archaic assemblages and with butchering and propose it as a temporally diagnostic technology for the Early Archaic. Another characteristic of this type of reduction is that some of these flakes bulge at the distal end as a result of the bulb of percussion on the ventral face and the negative scar on the dorsal face.

Resharpening of scrapers can also create a "gullwing" like cross section. Shafer (1970) illustrates a method (Method B) of resharpening (Figure 1d) that removes previous edge retouch and creates a sinuous edge profile. This edge profile remains if the scraper is not resharpened.

The third category of flake blanks is cortical flakes from tabular cores, some of which are thin and possibly functioned as scrapers and cutting tools.

The ratio between counts of bifaces to flake tools has been used as a measure of mobility (Odell 2005, Parry and Kelly 1987, Kelly 1988), with greater numbers of flake tools and cores assumed to be indicators of decreased mobility. High mobility has been equated with higher levels of biface usage, where bifaces are used as cores and tools, as proposed for Folsom assemblages (Amick 1995).

The production of flake tools occurred concurrently with biface production; however, the overall number of modified flakes remaining at the site is low, especially when compared to size of the overall debitage and biface assemblages. Several of the more formalized scrapers were reduced to the point of discard, and there are few examples of edge rejuvenation flakes. There are several implications from these data: the exhausted condition of formalized scrapers suggests that they were used at the site until discarded, or they were brought to the site in an advanced stage of use and then were discarded and replaced. A single edge rejuvenation flake suggests that scrapers were infrequently resharpened in this way, or it may be a simple correlation to the few formal flake tools at the site. Overall, scraping may not have been a major activity, as scrapers produced at the site were employed elsewhere.

While the use of scrapers may not have been a primary activity at the site, there are several examples of a manufacturing and reduction trajectory, from sequential flakes and from large tabular core flakes. In Figure 49, for example, all of the specimens are made on sequential flakes.

The large tabular core flakes were struck from the cortical edge. These flakes are triangular in outline, with the proximal end being the widest. A proposed sequence for convergent scrapers using these large flakes is shown in Figure 50. Through use and reduction, a concave or straight edge and a convex edge are created. The proximal end becomes tapered giving an outline appearance of a Guadalupe tool or gouge; however, there is no use-wear along the proximal 
end. Overall, the use of these large flakes appears to maximize the useable edge of the flake.

\section{AN INVENTORY OF Modified FlaKes}

The total number of specimens, complete and fragmentary, categorized as modified flakes is 380 . Retouched flakes were the most numerous, $\mathrm{n}=221$; then utilized flakes, $n=78$; scrapers, $n=76$; and gravers, $n=4$. A single specimen was classified as indeterminate. The total number of formal tools is 80 and the total number of informal tools is 300 Tables 29 and 30 show the composition by flake tool types of complete specimens and fragmentary specimens by occupation zone. Modified flakes are found in all areas and occupation zones at the site (Tables 31 and 32). Metric measurement summaries are listed in Table 33 for complete and mostly complete specimens.

\section{Formal Flake tools}

Graphed measurements illustrate the similarities and variation within the assemblage. Figures 51-58 show boxplot graphs of eight selected measurements: length, width, thickness, weight, platform thickness, maximum edge angle, percentage of edge modified, and retouch scar thickness. The box encloses 50 percent of the sample with the line indicating the median. The location of the median bar within the box illustrates how clustered the measurements are. The circles represent outliers. A line close to the bottom as in the Side Scraper category in Figure 51 , shows that there is a higher frequency of tools with lengths constrained between 69 and $73 \mathrm{~mm}$. The extended error bars show the upper and lower quartiles. The symmetry of the box plot and the ratio of box length and error bar length illustrate the shape of the distribution curve and skewness of the data. Even length bars, the same length as the box, represent an even distribution. Most gravers are relatively short in length and cluster in Figure 51 near the bottom of the bar.

The overall length of complete specimens according to artifact sub-categories in Figure 51, illustrates several similarities, notably the relationship between end and end side scrapers and retouched and utilized flakes.

End $(n=19)$ and end side scrapers $(n=14)$ have a similar overall length as indicated by a two sample $t$-test $(t=-0.36, \alpha=.05$, df 31). When the length of end and side scrapers are compared, there is a significant difference between the two samples $(\mathrm{t}=-2.777, \alpha=.05$, df 30). This supports the hypothesis that end side scrapers are modified end scrapers, rather than side scrapers. The demarcation between end scraper and side and end scraper is problematic on many of the specimens, especially flakes with rounded distal ends since it is difficult to distinguish the boundary between lateral edges and the distal end. The flakes selected for end scrapers have a wide or expanding proximal end.

Side scrapers are also made on these types of flakes and triangular, tapering, flakes. When the width of the three sub-categories are compared with analysis of variance (ANOVA), there is no significant difference between them $(\mathrm{F}(2,44)=0.926, \mathrm{p}>.05)$; however, when a derived size scale is used, length divided by width (W/T), there is a significant difference between end scrapers and side scrapers, and between end side scrapers and side scrapers $(\mathrm{F}(2,44)=6.144$, $\mathrm{p}<.05, \omega=0.422$.

Table 29. Distribution of Complete Flake Tools by Occupation Zone

\begin{tabular}{|r|r|r|r|r|r|r|r|r|r|r|r|}
\hline \multirow{2}{*}{$\begin{array}{c}\text { Occupation } \\
\text { Zone }\end{array}$} & \multicolumn{7}{|c|}{ Subcategory } & & \\
\hline & End Scr & E\&S Scr & S Scr & ConScr & Tr Scr & FullSScr & Graver & Ind & Ret FI & Uti FI & Total \\
\hline 4 & 2 & 1 & 2 & & & & 13 & 1 & 19 & 13 & 38 \\
\hline 3 & 5 & 4 & 7 & 1 & 2 & & 1 & 38 & 19 & 77 \\
\hline 2 & 10 & 8 & 3 & & & & 1 & 2 & 23 & 12 & 59 \\
\hline 1 & 1 & & & & & & & & & 1 & 2 \\
\hline N/A & 1 & 1 & 1 & 1 & 1 & & & & 1 & & 6 \\
\hline Total & 19 & 14 & 13 & 2 & 3 & 1 & 4 & $\mathbf{8 1}$ & $\mathbf{4 5}$ & $\mathbf{1 8 2}$ \\
\hline
\end{tabular}


Table 30. Distribution of Fragmentary Flake Tools by Occupation Zone

\begin{tabular}{|r|r|r|r|r|r|l|l|r|r|r|r|}
\hline \multirow{2}{*}{$\begin{array}{c}\text { Occupation } \\
\text { Zone }\end{array}$} & \multicolumn{7}{|c|}{ Subcategory } & \\
\hline & End Scr & E\&S Scr & S Scr & ConScr & Tr Scr & FullSScr & Graver & Ind & Ret FI & Uti FI & Total \\
\hline 4 & & 1 & & & & & & & 33 & 11 & 45 \\
\hline 3 & 5 & & 10 & & & & & 1 & 58 & 14 & 88 \\
\hline 2 & 4 & 1 & 2 & & & & & & 44 & 6 & 57 \\
\hline N/A & & & & & & & & & 5 & 2 & 7 \\
\hline Total & & & 1 & & & & & & & & 1 \\
\hline
\end{tabular}

Table 31. Distribution of Complete Flake Tools by Excavation Area

\begin{tabular}{|c|c|c|c|c|c|c|c|c|c|c|c|}
\hline Count of Lot No. & \multicolumn{10}{|c|}{ Subcategory } & \multirow[b]{2}{*}{ Total } \\
\hline Area & End Scr & E\&S Scr & S Scr & ConScr & Tr Scr & FullSScr & Graver & Ind & Ret FI & Uti FI & \\
\hline A-NE & 5 & 5 & 4 & & & & 1] & & 28 & 19 & 62 \\
\hline A-NW & 6 & & 1 & & & & 2 & & 13 & 6 & 28 \\
\hline A-SE & & & 2 & 1 & & & & & 3 & & 6 \\
\hline A-SW & 4 & 7 & 4 & 1 & 1 & 1 & & & 10 & 5 & 33 \\
\hline $\mathrm{B}$ & 3 & 1 & 1 & & 1 & & 1 & & 21 & 10 & 38 \\
\hline Backdirt & 1 & & & & & & & & 1 & & 2 \\
\hline Midden & & & 1 & & & & & & 5 & 5 & 11 \\
\hline $\mathrm{N} / \mathrm{A}$ & & 1 & & & 1 & & & & . & & 2 \\
\hline Total & 19 & 14 & 13 & 2 & 3 & 1 & 4 & & 81 & 45 & 182 \\
\hline
\end{tabular}

Table 32. Distribution of Fragmentary Flake Tools by Excavation Area

\begin{tabular}{|c|c|c|c|c|c|c|c|c|c|c|c|}
\hline \multirow{2}{*}{$\frac{\text { Count of Lot No. }}{\text { Area }}$} & \multicolumn{10}{|c|}{ Subcategory } & \multirow[b]{2}{*}{ Total } \\
\hline & End Scr & E\&S Scr & S Scr & ConScr & Tr Scr & FullSScr & Graver & Ind & Ret FI & Uti FI & \\
\hline A-NE & 3 & 1 & 7 & & & & & 1 & 56 & 15 & 83 \\
\hline A-NW & 3 & & 2 & & & & & & 24 & 4 & 33 \\
\hline A-SE & & & 1 & & & & & & & & 1 \\
\hline A-SW & 2 & & 2 & & & & & & 21 & 2 & 27 \\
\hline$B$ & 1 & 1 & & & & & & & 24 & 6 & 32 \\
\hline Midden & & & & & & & & & 15 & 6 & 21 \\
\hline $\mathrm{N} / \mathrm{A}$ & & & 1 & & & & & & & & 1 \\
\hline Total & 9 & 2 & 13 & & & & & 1 & 140 & 33 & 198 \\
\hline
\end{tabular}

\section{Informal Flake tools}

The difference between the informal tools and types of formal tools is the degree and location of modification. Informal tools, through use, may become formal tools. The example of retouched flake becoming a side scraper and reduced into a convergent scraper demonstrates the fluidity of the assemblage categories.

Within the overall assemblage, the length between retouched and utilized flakes does not vary signifi- cantly (two sample t-test, t $(129)=-0.693, \mathrm{p}>.05)$, nor does width, $\mathrm{t}(123)=0.900, \mathrm{p}>.05)$. Surprisingly, there was no significant difference between the percentages of overall edge used. Significant differences between retouched flakes and utilized flakes occur in flake scar length along edges and average edge angle (Figure 56). Flake scar length is an indicator of the degree of modification and is significant with $\mathrm{t}(89.848)=-7.738, \mathrm{p}<.05$ with a strong effect of $\mathrm{r}=0.632$. Edge angle differences are significant with $\mathrm{t}(105)=-3.817, \mathrm{p}<.05$. 
Table 33. Attributes Measurements of Complete and Mostly Complete Modified Flakes

\begin{tabular}{|c|c|c|c|c|c|c|c|c|c|}
\hline \multicolumn{2}{|c|}{ Subcategory } & Length & Width & Thickness & $\begin{array}{c}\text { Weight } \\
\text { (g) }\end{array}$ & $\begin{array}{l}\text { Perimeter } \\
\text { Length }\end{array}$ & $\begin{array}{c}\text { Perimeter } \\
\text { Retouched Length }\end{array}$ & $\begin{array}{c}\% \text { of } \\
\text { Perimeter used }\end{array}$ & $\begin{array}{c}\text { Max Edge } \\
\text { Angle }\end{array}$ \\
\hline \multirow{7}{*}{$\begin{array}{l}\text { End } \\
\text { Scraper }\end{array}$} & $\mathrm{N}$ & 19.00 & 19.00 & 19.00 & 19.00 & 19.00 & 19.00 & 19.00 & 13.00 \\
\hline & Mean & 61.17 & 59.78 & 14.63 & 59.59 & 197.68 & 70.87 & 36.45 & 53.31 \\
\hline & Median & 60.74 & 56.83 & 14.43 & 60.10 & 197.49 & 71.58 & 36.18 & 54.00 \\
\hline & Minimum & 35.20 & 41.10 & 6.40 & 23.00 & 110.00 & 36.90 & 19.06 & 20.00 \\
\hline & Maximum & 110.40 & 92.00 & 27.30 & 206.00 & 332.50 & 106.50 & 50.40 & 90.00 \\
\hline & Range & 75.20 & 50.90 & 20.90 & 183.00 & 222.50 & 69.70 & 31.34 & 70.00 \\
\hline & $\sigma$ & 17.84 & 14.77 & 5.73 & 42.58 & 45.20 & 18.87 & 8.34 & 20.29 \\
\hline \multirow{7}{*}{$\begin{array}{c}\text { End \& Side } \\
\text { Scraper }\end{array}$} & $N$ & 14.00 & 14.00 & 14.00 & 14.00 & 14.00 & 14.00 & 14.00 & 14.00 \\
\hline & Mean & 61.39 & 53.74 & 15.40 & 60.71 & 193.19 & 115.78 & 58.87 & 49.57 \\
\hline & Median & 57.89 & 50.30 & 14.96 & 50.10 & 193.21 & 104.42 & 57.22 & 44.00 \\
\hline & Minimum & 40.40 & 33.90 & 9.30 & 22.00 & 149.60 & 74.50 & 43.18 & 30.00 \\
\hline & Maximum & 91.70 & 76.50 & 21.50 & 192.00 & 284.70 & 252.00 & 88.52 & 78.00 \\
\hline & Range & 51.30 & 42.60 & 12.20 & 169.00 & 135.10 & 177.50 & 45.34 & 48.00 \\
\hline & $\sigma$ & 15.60 & 10.79 & 4.01 & 42.85 & 37.05 & 45.61 & 12.96 & 14.49 \\
\hline \multirow{7}{*}{$\begin{array}{l}\text { Side } \\
\text { Scraper }\end{array}$} & $N$ & 13.00 & 13.00 & 13.00 & 13.00 & 13.00 & 13.00 & 13.00 & 13.00 \\
\hline & Mean & 80.69 & 54.25 & 16.62 & 80.88 & 221.55 & 86.12 & 39.07 & 42.85 \\
\hline & Median & 75.90 & 57.60 & 14.49 & 71.70 & 222.09 & 90.78 & 33.37 & 39.00 \\
\hline & Minimum & 35.10 & 35.90 & 8.10 & 10.00 & 128.50 & 39.30 & 23.36 & 32.00 \\
\hline & Maximum & 114.40 & 76.80 & 32.10 & 232.00 & 289.00 & 150.90 & 71.00 & 70.00 \\
\hline & Range & 79.30 & 40.90 & 24.00 & 221.00 & 160.50 & 111.60 & 47.63 & 38.00 \\
\hline & $\sigma$ & 21.80 & 12.88 & 7.10 & 56.17 & 48.11 & 32.43 & 14.40 & 10.85 \\
\hline \multirow{7}{*}{$\begin{array}{c}\text { Convergent } \\
\text { Scraper }\end{array}$} & $N$ & 2.00 & 2.00 & 2.00 & 2.00 & 2.00 & 2.00 & 2.00 & 2.00 \\
\hline & Mean & 98.65 & 48.35 & 19.26 & 95.20 & 239.78 & 192.17 & 79.45 & 56.00 \\
\hline & Median & 98.65 & 48.35 & 19.26 & 95.20 & 239.78 & 192.17 & 79.45 & 56.00 \\
\hline & Minimum & 86.40 & 47.80 & 11.90 & 52.00 & 210.70 & 155.30 & 73.71 & 50.00 \\
\hline & Maximum & 110.90 & 48.90 & 26.60 & 138.00 & 268.90 & 229.00 & 85.19 & 62.00 \\
\hline & Range & 24.50 & 1.10 & 14.80 & 86.00 & 58.20 & 73.70 & 11.49 & 12.00 \\
\hline & $\sigma$ & 17.33 & 0.80 & 10.44 & 61.09 & 41.12 & 52.14 & 8.12 & 8.49 \\
\hline \multirow{7}{*}{$\begin{array}{c}\text { Transverse } \\
\text { Scraper }\end{array}$} & $N$ & 3.00 & 3.00 & 3.00 & 3.00 & 3.00 & 3.00 & 3.00 & 3.00 \\
\hline & Mean & 58.88 & 64.10 & 10.01 & 38.13 & 203.57 & 64.10 & 31.55 & 37.33 \\
\hline & Median & 61.08 & 64.60 & 11.27 & 33.70 & 195.75 & 65.42 & 30.48 & 37.00 \\
\hline & Minimum & 51.80 & 50.80 & 7.40 & 23.00 & 191.70 & 58.80 & 30.05 & 31.00 \\
\hline & Maximum & 63.80 & 77.00 & 11.40 & 58.00 & 223.30 & 68.00 & 34.12 & 44.00 \\
\hline & Range & 12.00 & 26.20 & 3.90 & 35.00 & 31.60 & 9.20 & 4.07 & 13.00 \\
\hline & $\sigma$ & 6.30 & 13.11 & 2.25 & 17.77 & 17.17 & 4.75 & 2.24 & 6.51 \\
\hline \multirow{7}{*}{$\begin{array}{l}\text { Full Sided } \\
\text { Scraper }\end{array}$} & $N$ & 1.00 & 1.00 & 1.00 & 1.00 & 1.00 & 1.00 & 1.00 & 1.00 \\
\hline & Mean & 48.12 & 47.73 & 9.14 & 25.40 & 152.33 & 152.33 & 100.00 & 60.00 \\
\hline & Median & 48.12 & 47.73 & 9.14 & 25.40 & 152.33 & 152.33 & 100.00 & 60.00 \\
\hline & Minimum & 48.10 & 47.70 & 9.10 & 25.00 & 152.30 & 152.30 & 100.00 & 60.00 \\
\hline & Maximum & 48.10 & 47.70 & 9.10 & 25.00 & 152.30 & 152.30 & 100.00 & 60.00 \\
\hline & Range & 0.00 & 0.00 & 0.00 & 0.00 & 0.00 & 0.00 & 0.00 & 0.00 \\
\hline & $\sigma$ & . & . & & . & . & 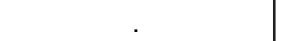 & & . \\
\hline
\end{tabular}


Table 33. Attributes Measurements of Complete and Mostly Complete Modified Flakes, continued

\begin{tabular}{|c|c|c|c|c|c|c|c|c|c|}
\hline \multicolumn{2}{|c|}{ Subcategory } & Length & Width & Thickness & $\begin{array}{l}\text { Weight } \\
\text { (g) }\end{array}$ & $\begin{array}{c}\text { Perimeter } \\
\text { Length }\end{array}$ & $\begin{array}{c}\text { Perimeter } \\
\text { Retouched Length }\end{array}$ & $\begin{array}{c}\% \text { of } \\
\text { Perimeter used }\end{array}$ & $\begin{array}{c}\text { Max Edge } \\
\text { Angle }\end{array}$ \\
\hline \multirow{7}{*}{ Graver } & $\mathrm{N}$ & 4.00 & 4.00 & 4.00 & 4.00 & 4.00 & 4.00 & 4.00 & 3.00 \\
\hline & Mean & 54.63 & 60.22 & 10.97 & 34.58 & 186.54 & 120.22 & 67.83 & 45.33 \\
\hline & Median & 44.59 & 62.83 & 9.32 & 26.40 & 190.49 & 123.26 & 66.69 & 44.00 \\
\hline & Minimum & 42.50 & 31.80 & 8.30 & 11.00 & 130.70 & 79.10 & 37.93 & 27.00 \\
\hline & Maximum & 86.80 & 83.40 & 16.90 & 74.00 & 234.50 & 155.30 & 100.00 & 65.00 \\
\hline & Range & 44.30 & 51.60 & 8.60 & 63.00 & 103.80 & 76.20 & 62.07 & 38.00 \\
\hline & $\sigma$ & 21.49 & 21.27 & 4.05 & 27.65 & 45.10 & 31.87 & 25.38 & 19.04 \\
\hline \multirow{7}{*}{$\begin{array}{l}\text { Retouched } \\
\text { Flake }\end{array}$} & $\mathrm{N}$ & 80.00 & 80.00 & 80.00 & 81.00 & 80.00 & 80.00 & 80.00 & 69.00 \\
\hline & Mean & 69.19 & 59.11 & 18.86 & 79.25 & 211.90 & 69.05 & 32.66 & 50.77 \\
\hline & Median & 67.50 & 58.57 & 15.86 & 64.50 & 213.86 & 58.96 & 28.11 & 50.00 \\
\hline & Minimum & 29.70 & 16.10 & 4.20 & 2.00 & 85.70 & 12.50 & 8.34 & 15.00 \\
\hline & Maximum & 137.60 & 97.80 & 67.70 & 364.00 & 337.80 & 188.90 & 94.46 & 105.00 \\
\hline & Range & 107.90 & 81.80 & 63.50 & 363.00 & 252.10 & 176.40 & 86.12 & 90.00 \\
\hline & $\sigma$ & 24.16 & 17.64 & 10.42 & 69.02 & 53.33 & 41.52 & 18.15 & 16.98 \\
\hline \multirow{7}{*}{$\begin{array}{l}\text { Utilized } \\
\text { Flake }\end{array}$} & $\mathrm{N}$ & 43.00 & 43.00 & 43.00 & 45.00 & 44.00 & 44.00 & 44.00 & 41.00 \\
\hline & Mean & 65.52 & 55.82 & 14.56 & 51.75 & 192.14 & 57.59 & 29.31 & 38.76 \\
\hline & Median & 65.42 & 53.30 & 13.96 & 41.90 & 194.56 & 42.88 & 24.62 & 36.00 \\
\hline & Minimum & 19.70 & 9.50 & 1.90 & 1.00 & 60.50 & 13.30 & 7.18 & 19.00 \\
\hline & Maximum & 110.00 & 137.70 & 29.20 & 218.00 & 373.10 & 185.70 & 86.58 & 80.00 \\
\hline & Range & 90.30 & 128.20 & 27.40 & 217.00 & 312.70 & 172.40 & 79.40 & 61.00 \\
\hline & $\sigma$ & 24.29 & 23.20 & 6.69 & 43.35 & 66.08 & 46.11 & 18.94 & 14.52 \\
\hline \multirow{7}{*}{ Total } & $\mathrm{N}$ & 179.00 & 179.00 & 179.00 & 182.00 & 180.00 & 180.00 & 180.00 & 159.00 \\
\hline & Mean & 67.40 & 57.54 & 16.57 & 67.31 & 204.09 & 74.19 & 36.40 & 46.89 \\
\hline & Median & 65.09 & 56.02 & 14.66 & 51.90 & 200.24 & 67.84 & 32.22 & 45.00 \\
\hline & Minimum & 19.70 & 9.50 & 1.90 & 1.00 & 60.50 & 12.50 & 7.18 & 15.00 \\
\hline & Maximum & 137.60 & 137.70 & 67.70 & 364.00 & 373.10 & 252.00 & 100.00 & 105.00 \\
\hline & Range & 117.90 & 128.20 & 65.90 & 364.00 & 312.70 & 239.50 & 92.82 & 90.00 \\
\hline & $\sigma$ & 23.03 & 17.97 & 8.56 & 57.65 & 54.27 & 45.01 & 20.01 & 16.54 \\
\hline
\end{tabular}

\section{Modified FlaKe FraGMENTS (N=198)}

Of the 380 modified flakes, 182 are classified as complete and 198 are fragmentary (see Table 29). One of these fragments was classified as indeterminate and was not categorized as to tool type. Of the 198 fragments, 24 were identified as scraper fragments while the remainder was from informal flake tools. Completeness is problematic in some instances because both formal tools and flake fragments may have been modified and utilized. These fragments are distinguished by having modifications along the fractures.

The 198 fragments were divided into the categories distal, proximal, medial, marginal, longitudinal, and indeterminate, based upon the fragment location as part of a complete flake (Table 34). On 60 of the specimens there was edge use or modification along the distal end. Of these 60,54 are utilized or retouched flakes and 6 are end and end side scrapers. Of the 44 proximal fragments only 5 fragments were utilized along the break edge, or distal edge. Only 2 of the 63 distal fragments broken transversely are retouched along the break. This suggests that the majority of the fragments were not refurbished. The transverse break observed on a specimen was usually a bending type fracture that can occur during use, refurbishment, and post depositionally from natural effects and effects such as trampling. Given the low rates of modified flake tool resharpening, and the 


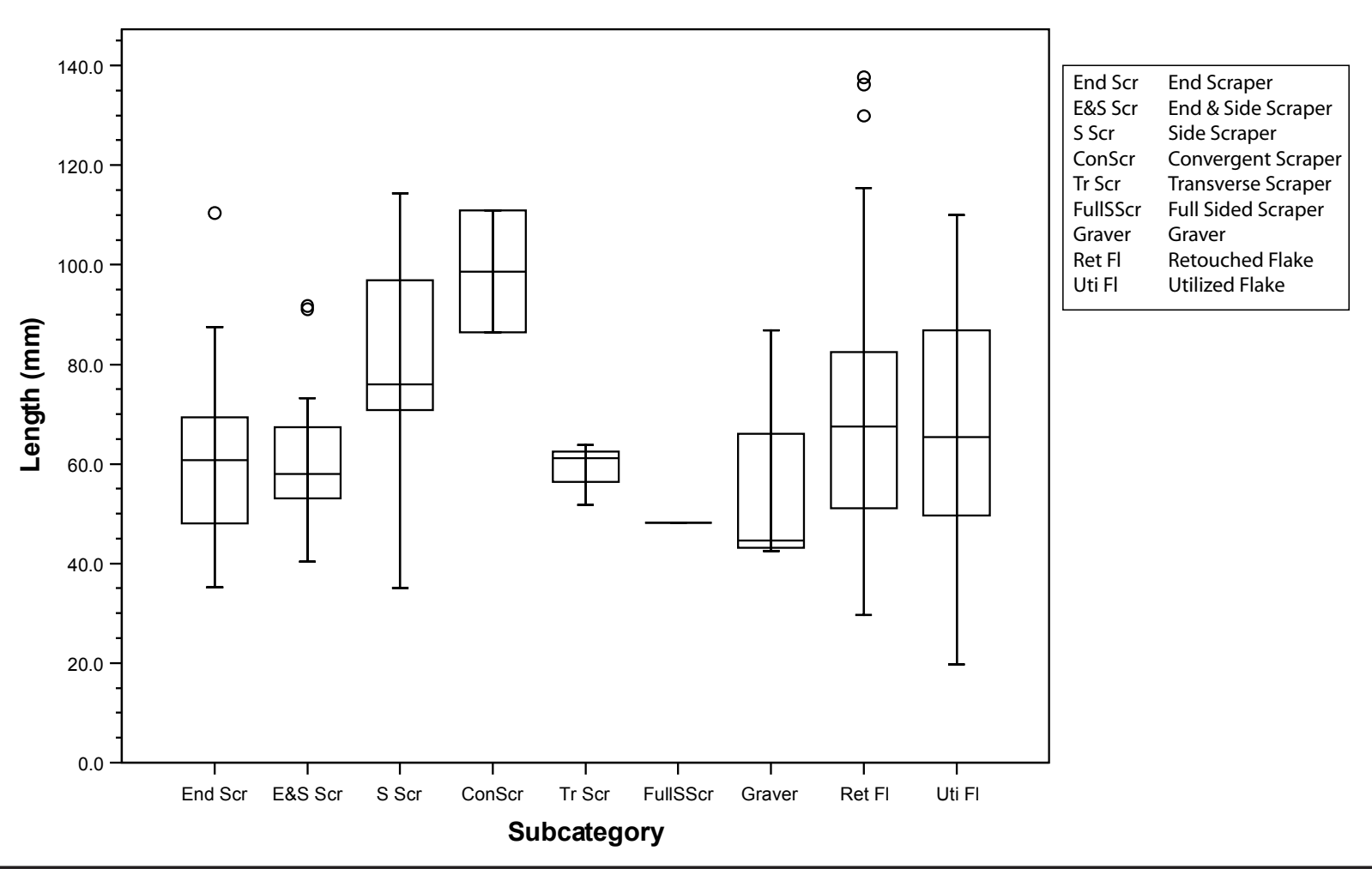

Figure 51. Boxplot of lengths of modified flake tool subcategories.

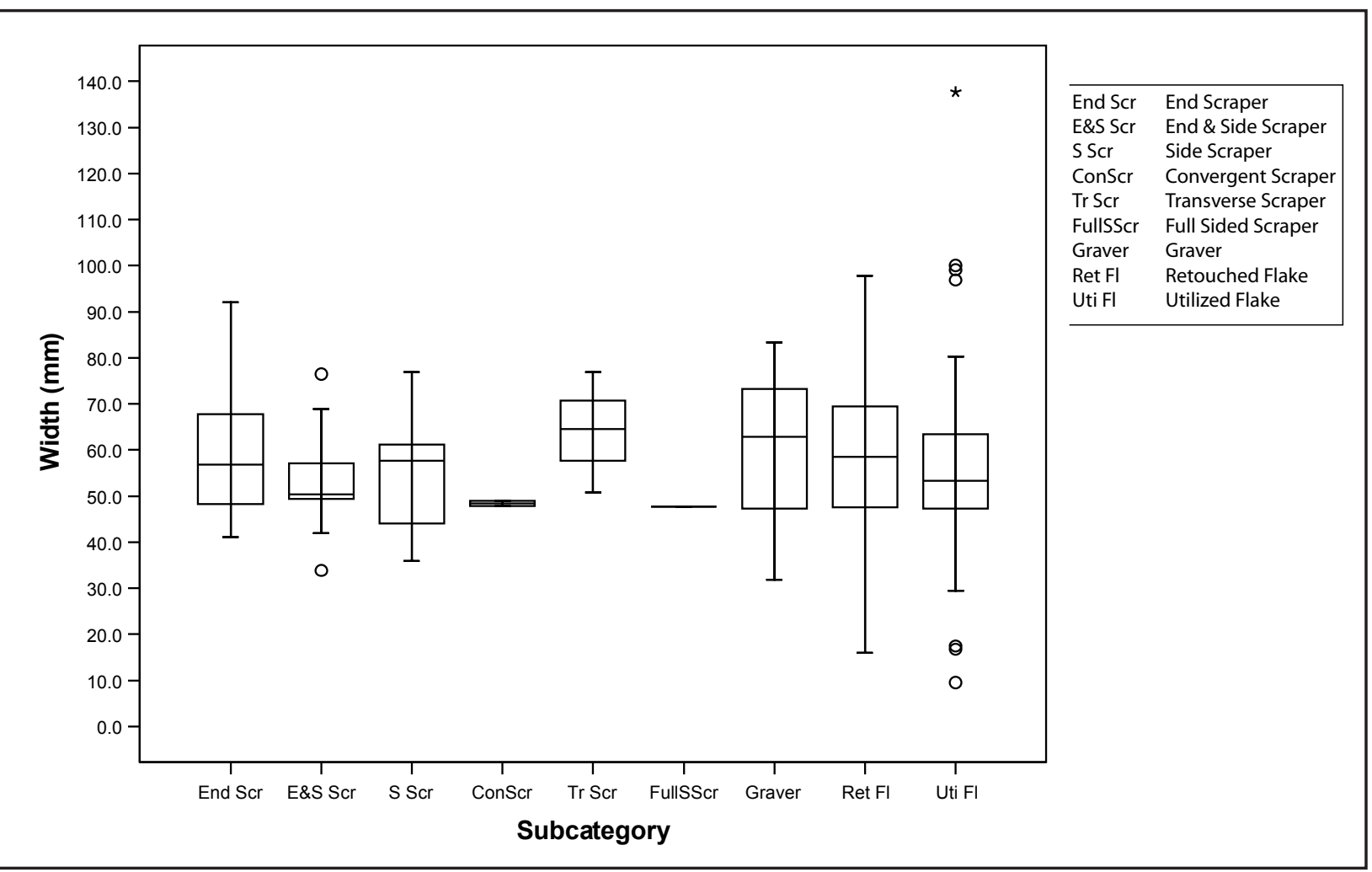

Figure 52. Boxplot of widths of modified flake tool subcategories. 


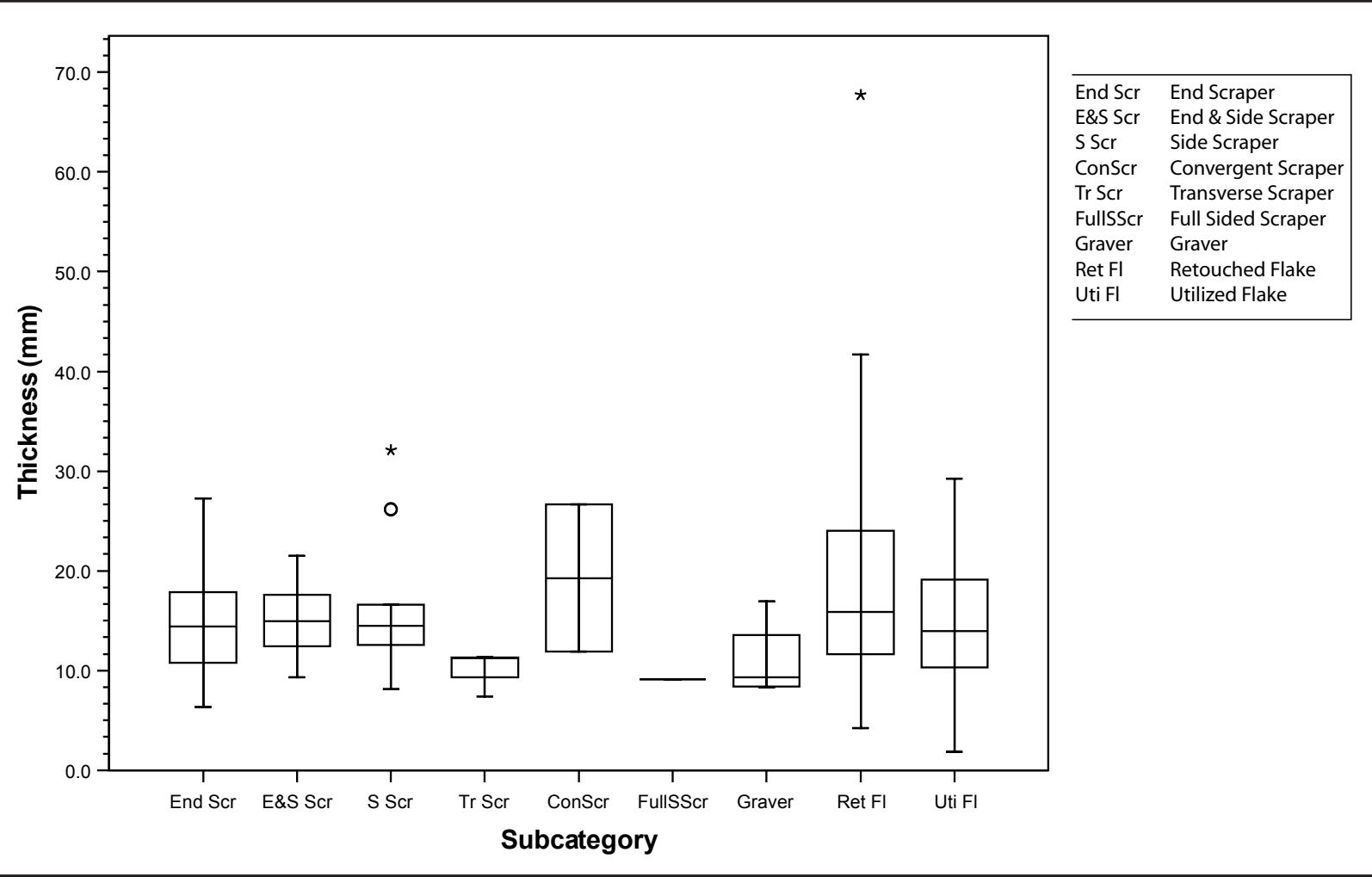

Figure 53. Boxplot of thicknesses of modified flake tool subcategories.

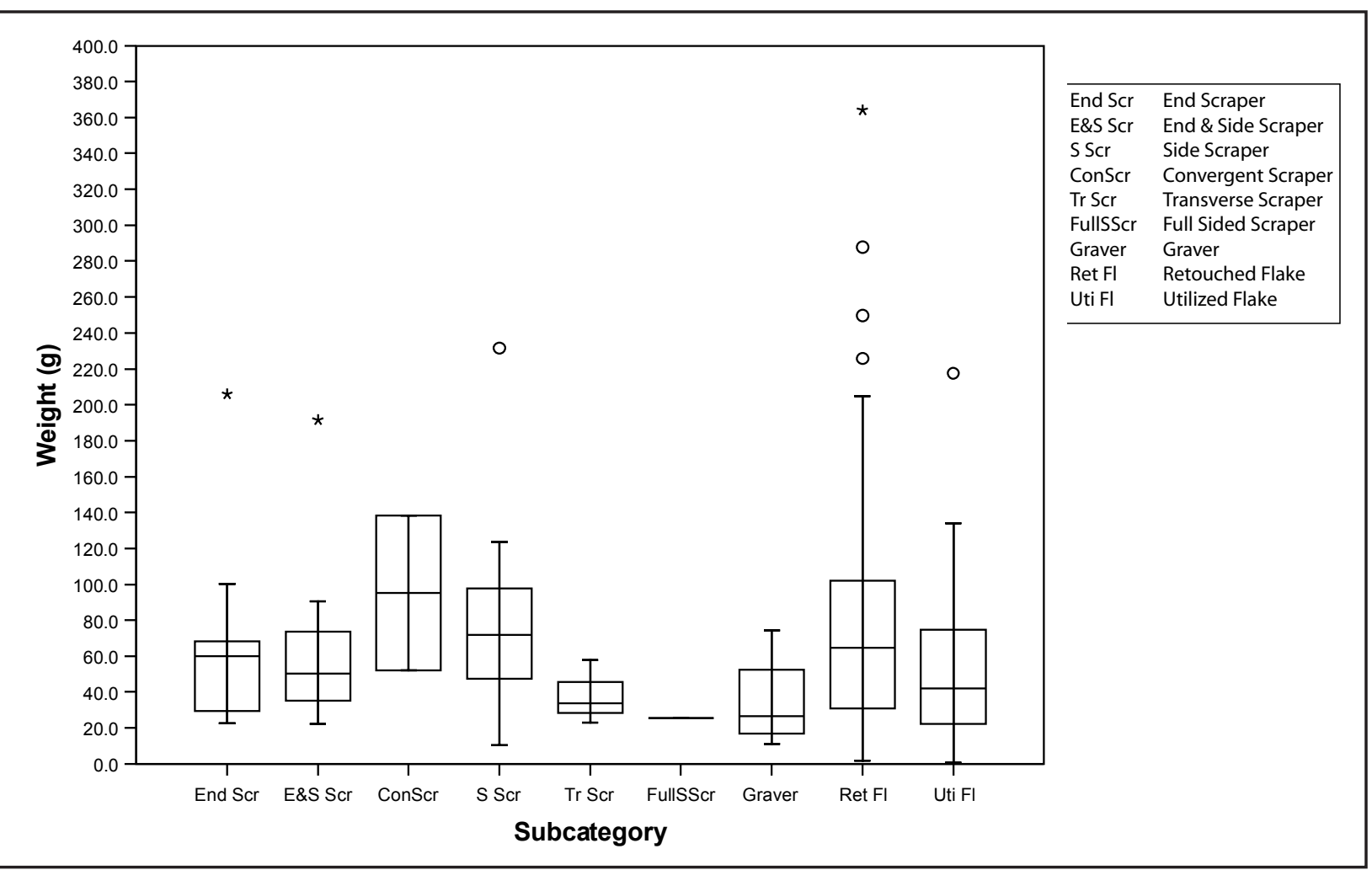

Figure 54. Boxplot of weights of modified flake tool subcategories. 


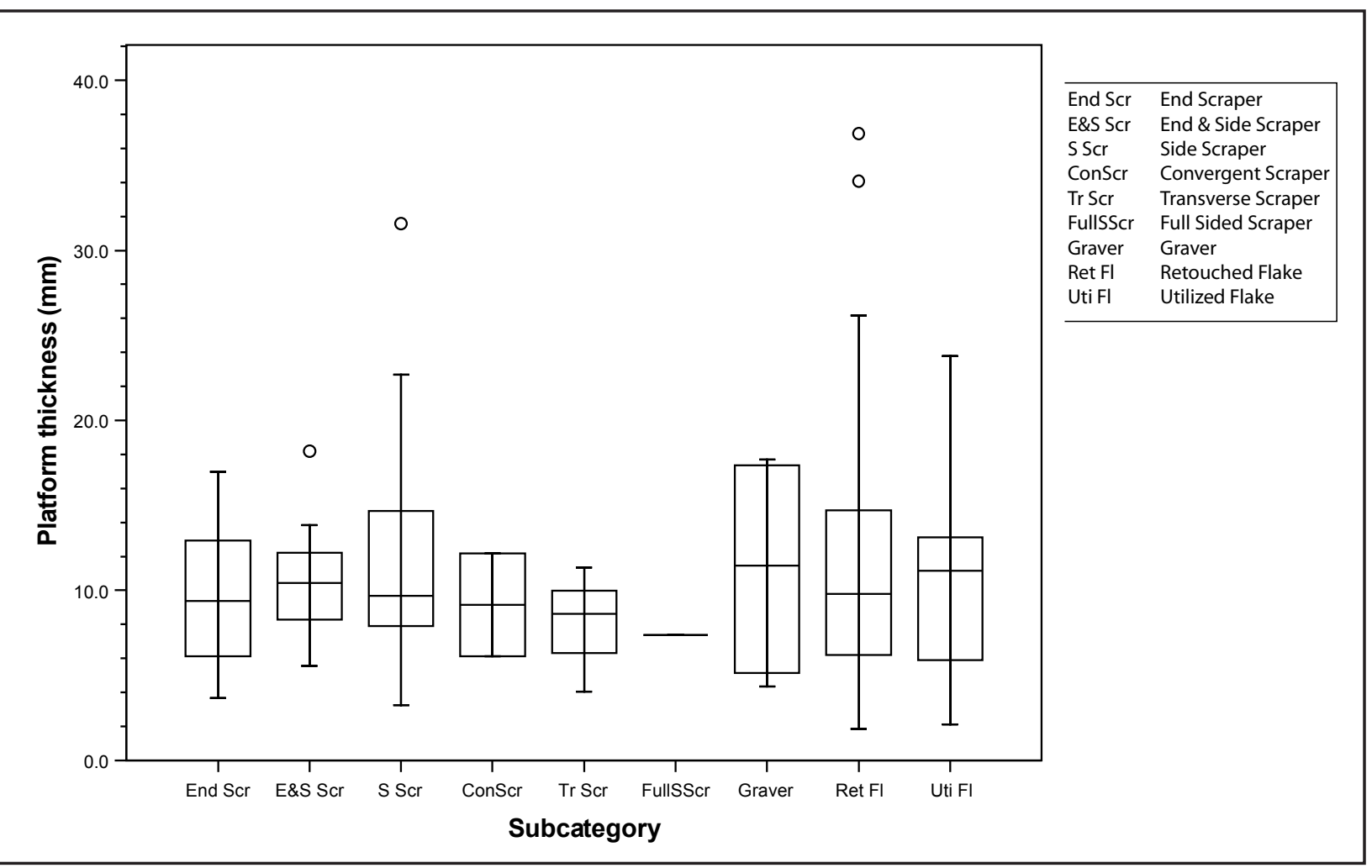

Figure 55. Boxplot of platform thicknesses of modified flake tool subcategories.

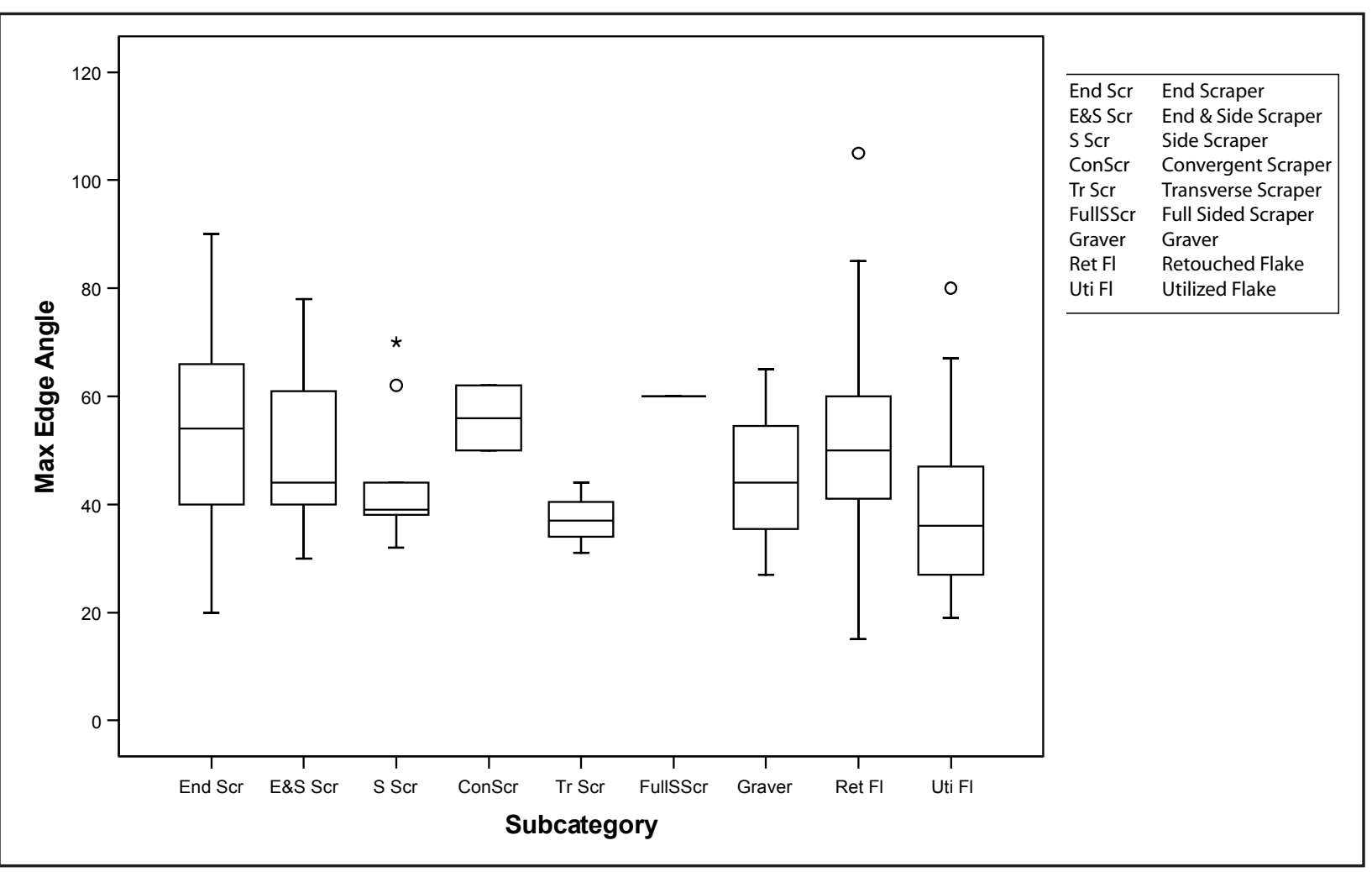

Figure 56. Boxplot of maximum edge angles of modified flake tool subcategories. 


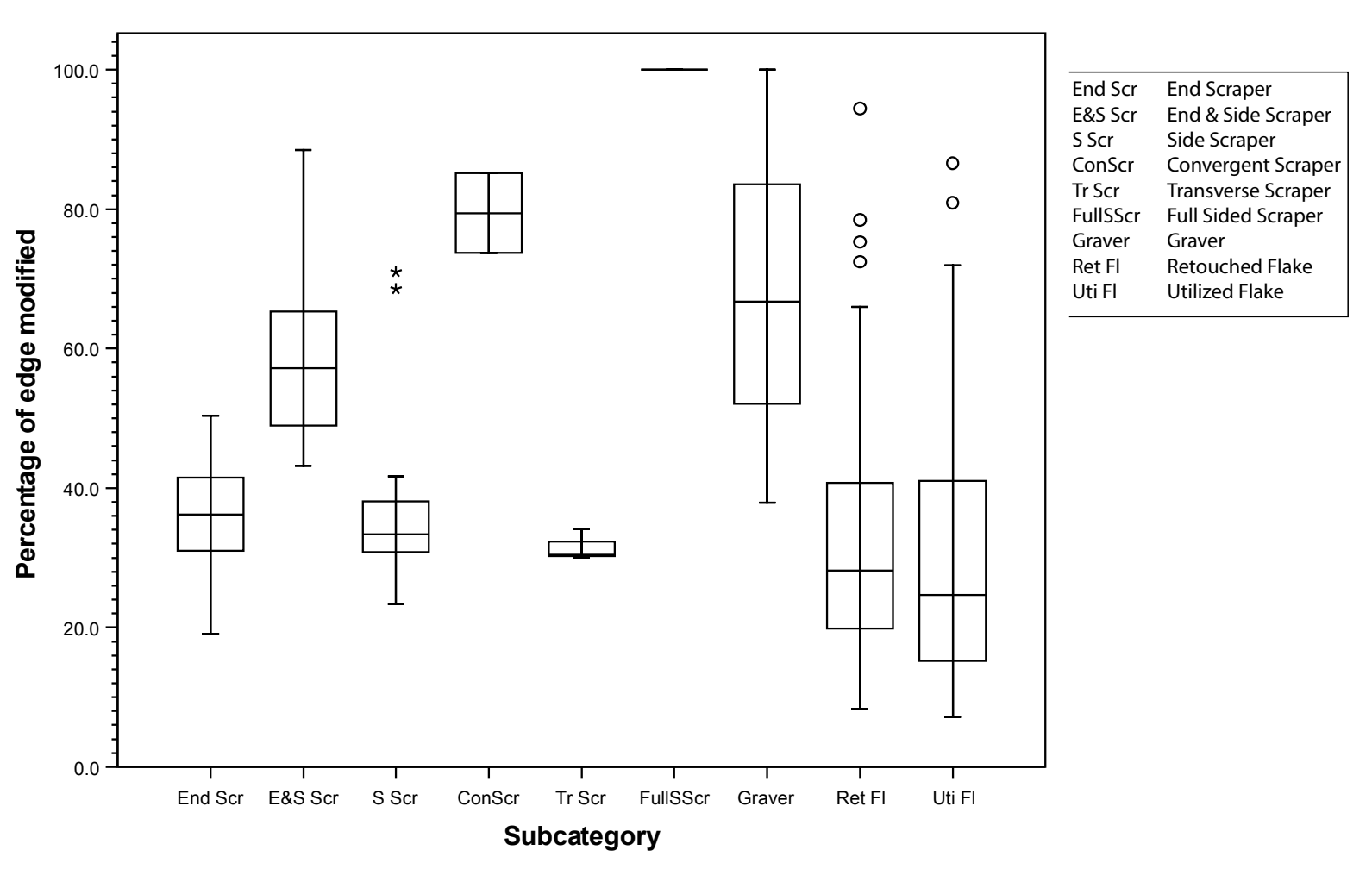

Figure 57. Boxplot of edge modfied percentages of modified flake tool subcategories.

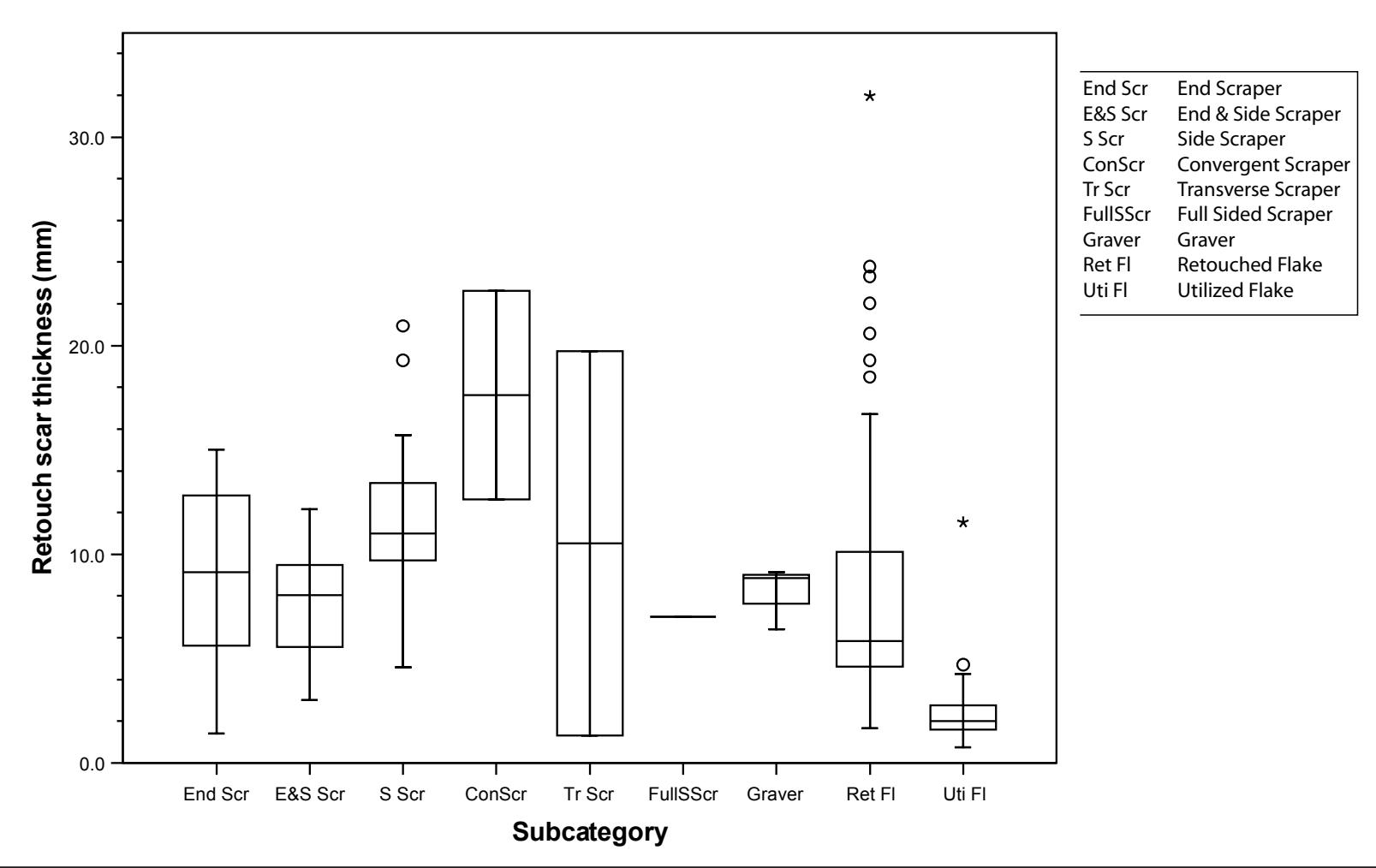

Figure 58. Boxplot of retouch scar thicknesses of modified flake tool subcategories. 
Table 34. Modified Flakes Fracture Types Counts and Percentages

\begin{tabular}{|c|c|c|}
\hline Fracture type & $\mathbf{n}$ & $\%$ \\
\hline Distal Fragment & 63 & 31.82 \\
\hline Indeterminate Fragment & 20 & 10.10 \\
\hline Longitudinal Fragment & 35 & 17.68 \\
\hline Marginal Fragment & 17 & 8.59 \\
\hline Medial Fragment & 19 & 9.60 \\
\hline Proximal Fragment & 44 & 22.22 \\
\hline Total & $\mathbf{1 9 8}$ & \\
\hline
\end{tabular}

minimal modification of the informal flake tools, use-wear and post depositional damage are the most likely scenario. Lot 239.1 was the only noted specimen of a rejuvenation flake, where the bit edge was removed by burination.

Flake blanks, for the most part, appear to be interchangeable between the formal and informal flake tools. The width and thickness of remnant platforms are not significantly different between modified flake categories (Platform thickness $\mathrm{p}=0.925, \alpha=.05$, $\mathrm{F}=0.389$, df 8, 174; Platform width $\mathrm{p}=0.963, \alpha=.05$, $\mathrm{F}=0.305$, df 8,174$)$. Of the characteristics least likely to be modified through use-platform thickness, platform width, and maximum flake width, there is no significant overall correlation with tool type. Not surprisingly, retouch flake length, a measure of invasiveness and modification, varied significantly between categories. Between formal and informal tools, scrapers and flakes, weight varied, partially because it correlates to size; however, within the categories weights were similar, such as between end scrapers, side scrapers, and end and side scrapers.

Cortical flakes were used extensively for scraper blanks. This was conditioned by the dimensions of the available raw material. The cortex of the flake blanks provided the desired thickness and perhaps as a backing, especially on larger specimens with no visible evidence of hafting. The removal of cortex from some of the specimens was a result of reduction from use and resharpening. The full scraper, or all sided scraper, has 100 percent cortex on the dorsal face. This high percentage is due to the small size of the specimen through reduction. Cortex occurs on approximately 79 percent of end scrapers, 66 percent of the side end scrapers, and 76 percent of side scrapers.

\section{USE-WEAR SUMMARY}

Use-wear was conducted on four of the Gatlin site's scrapers, which represent five percent of the assemblage. Use-wear patterns on these scrapers indicated that specimens Lots 320.9, 488.3, and 1001 were used to scrape fresh hide. Lot 320.9 was probably hafted and Lot 488.3 was also used as a knife for butchering. Lot 494.2 was used to scrape a moderately resistant material such as wood and was deliberately dulled along the proximal end to facilitate prehension.

\section{Cores}

An assemblage of 343 cores was analyzed from the Gatlin site excavations. Cores are objective pieces of lithic material from which another piece is detached (Andrefsky 1998). Although they can be utilized as tools, they are part of the lithic debitage. They exhibit negative flake scars created by fracturing, a reductive process that involves the removal of flakes from the core by striking it with a percussor such as a billet or hammer stone. Flakes may also be detached through indirect percussion using a punch and through pressure. The primary purpose of cores is a source of flakes, which may be utilized or further reduced into stone tools. In some instances, a sharp margin of the core itself may be utilized as a stone tool. The butted or backed bifaces probably functioned in this role, as did the early biface manufacturing stages.

\section{ANALYTiCAL MEthods}

To explore the nature of core reduction and core technology at the Gatlin site, detailed analysis was performed on all cores from the midden and Areas $\mathrm{A}$ and $\mathrm{B}$, excluding those from contexts above $98.0 \mathrm{~m}$ in Area B (which contained an admixture of components). These cores were examined and classified according to their reduction attributes. Nominal attributes (e.g., cortex type, raw material type, color, heat exposure, striking platform, number of flake scars, morphology) and metrical attributes (e.g., weight, dimensions) were noted for each core specimen and recorded in a database.

Maximum flake scar length was calculated along the longest flake scar from platform to termination and parallel to the scar surface. Overall length, width, and thickness measurements were recorded as maximum dimensions with the orientation of the 
core in the perceived position of use. As noted by both Andrefsky (1998) and Odell (2004), cores are difficult to measure consistently, which makes intersite comparison of assemblages difficult.

The core assemblage was further divided into categories based upon the flaking patterns of remnant flake scars and the location of platforms from where flakes were detached. The categories are multidirectional, bidirectional, bifacial, unidirectional, slab, bipolar, and indeterminate. Indeterminate specimens were blocky fragments that did not exhibit characteristics of the other categories.

Multidirectional cores have striking platforms on different axis and flakes are removed in numerous directions.

Bidirectional cores have opposing or perpendicular platform surfaces, with flakes detached in two different directions.

Bifacial cores have flakes detached along both faces of an edge, with the edge serving as the platform. This category may have been used as tools.

Unidirectional cores have a single platform surface and flakes are detached in the same direction. This creates a conical shape tapering towards the distal end when flake removals continue around the platform perimeter. Polyhedral blade cores in Central America and small micro cores from the Arctic small tool tradition are two examples of the range in unidirectional cores. Rejuvenation flakes from these cores are distinctive in the debitage. This type of core reduction is usually classified as a formal core reduction, especially when blade flakes are produced. It is an efficient use of lithic material to produce a consistent flake shape.

Slab cores can be unidirectional or bidirectional. These cores were found along the Guadalupe drainage locally, although still a distance from the site. These are frequently large specimens and were probably manuports.

Bipolar cores are held against an anvil at the distal end as a flake is detached from the opposing ends. This can split the core longitudinally. The resulting pieces may then be used for further reduction, using the new ventral surface as a platform. Small pebbles may be split this way. A single example (Lot 237.3) was classified at the Gatlin site. It is probably not a deliberate attempt at bipolar reduction.

Cores were divided into complete and incomplete or fragmentary specimens. Fragmentary specimens were determined by fracture scars that intersected flake scars. Complete cores were further subdivided into two stages: exhausted and unexhausted. Exhausted cores are assumed to be discarded after no more usable flakes could be detached and therefore had exhausted their utility as a core. Unexhausted specimens are capable of providing additional flakes. Within each category of cores, core utility was determined by examining the platforms and termination scars. Exhausted cores have few remaining surfaces for platform use or preparation. Flake terminations are abrupt and unsuitable for edge propagation when they end in step and hinge fractures.

Stages of core reduction were investigated using methods like those outlined in Andrefsky (1998). Each of the core categories can be placed into two broad categories, formal and informal. Formal cores exhibit a greater investment in time, with an emphasis on platform preparation. The intention is to reliably produce flakes, frequently within a particular form and/or size range. The use of formal cores may have had intent as tools for use during the uselife of the specimen as a core and post core usage, such as a bifacial chopper or knife. Formal core types are bifacial, bidirectional, unidirectional and slab. Informal core types are multidirectional and the bipolar specimen (Lot 237.3) and the Indeterminate (Lot 117.1).

Individual attributes are presented in Appendix E.6.

\section{AN INVENTORY OF CORES}

Of the 343 cores and core fragments analyzed from the Gatlin site, 237 are complete specimens and 106 are fragments. Table 35 displays the measurements from each core category for complete specimens. The distribution of cores by Occupation Zone is displayed in Table 36 and by excavation Area and Occupation Zone in Table 37. Figures 59-61 illustrate examples of the core categories. Multidirectional and bifacial cores account for more than 80 percent of the core assemblage, with 60.6 percent $(n=208)$ multidirectional cores and bifacial cores at 21.0 percent $(n=72)$. Indeterminate at 7.0 percent $(n=24)$ 
Table 35. Attributes Measurements of Cores

\begin{tabular}{|c|c|c|c|c|c|c|c|c|c|}
\hline \multicolumn{2}{|c|}{ Attribute } & BiD & $\mathrm{BiF}$ & BiP & Ind & MultiD & Slab & Uni & Total \\
\hline \multirow{5}{*}{ Length (mm) } & $\mathrm{N}$ & 10 & 57 & 1 & 1 & 144 & 9 & 15 & 237 \\
\hline & Mean & 94.62 & 97.38 & 133.21 & 114.14 & 93.80 & 45.03 & 76.11 & 91.98 \\
\hline & Min & 70.35 & 62.36 & 133.21 & 114.14 & 59.67 & 16.70 & 45.01 & 16.70 \\
\hline & Max & 114.17 & 130.07 & 133.21 & 114.14 & 162.35 & 166.55 & 107.60 & 166.55 \\
\hline & Std. Dev & 14.66 & 16.82 & & & 18.22 & 46.67 & 21.18 & 22.26 \\
\hline \multirow{4}{*}{ Width (mm) } & Mean & 71.10 & 76.65 & 85.55 & 77.46 & 71.95 & 29.05 & 60.13 & 70.75 \\
\hline & Min & 59.50 & 34.72 & 85.55 & 77.46 & 40.00 & 14.50 & 40.93 & 14.50 \\
\hline & Max & 86.78 & 105.49 & 85.55 & 77.46 & 148.58 & 111.27 & 82.36 & 148.58 \\
\hline & Std. Dev & 9.93 & 16.66 & & & 16.21 & 31.01 & 13.30 & 18.86 \\
\hline \multirow{4}{*}{ Thickness (mm) } & Mean & 36.06 & 34.53 & 42.12 & 33.86 & 39.77 & 8.09 & 39.61 & 37.12 \\
\hline & Min & 14.11 & 3.00 & 42.12 & 33.86 & 18.00 & 2.50 & 19.24 & 2.50 \\
\hline & Max & 51.09 & 73.14 & 42.12 & 33.86 & 73.76 & 38.62 & 67.10 & 73.76 \\
\hline & Std. Dev & 12.83 & 11.64 & & & 12.64 & 11.50 & 13.37 & 13.75 \\
\hline \multirow{4}{*}{ Weight (g) } & Mean & 294.53 & 278.72 & 656.00 & 378.10 & 274.87 & 3608.44 & 175.46 & 398.97 \\
\hline & Min & 65.50 & 6.41 & 656.00 & 378.10 & 8.32 & 772.00 & 58.50 & 6.41 \\
\hline & Max & 508.00 & 705.00 & 656.00 & 378.10 & 1627.00 & 6200.00 & 366.00 & 6200.00 \\
\hline & Std. Dev & 163.05 & 143.92 & & & 200.95 & 1994.35 & 97.10 & 758.56 \\
\hline \multirow{4}{*}{$\begin{array}{l}\text { Flake Scar Length } \\
\qquad(\mathrm{mm})\end{array}$} & Mean & 35.12 & 44.50 & 38.24 & 42.68 & 45.00 & 8.05 & 37.89 & 42.55 \\
\hline & Min & 21.52 & 19.35 & 38.24 & 42.68 & 15.85 & 2.50 & 17.92 & 2.50 \\
\hline & Max & 58.68 & 82.41 & 38.24 & 42.68 & 85.76 & 35.44 & 59.10 & 85.76 \\
\hline & Std. Dev & 12.71 & 13.28 & & & 14.53 & 10.34 & 10.47 & 15.50 \\
\hline \multirow{4}{*}{ No. Flake Scars } & Mean & 5.80 & 7.71 & 6.00 & 1.00 & 5.80 & 4.00 & 5.87 & 6.17 \\
\hline & Min & 3 & 3 & 6 & 1 & 1 & 2 & 2 & 1 \\
\hline & Max & 10 & 14 & 6 & 1 & 15 & 10 & 9 & 15 \\
\hline & Std. Dev & 2.25 & 2.83 & & & 2.69 & 2.40 & 2.23 & 2.82 \\
\hline
\end{tabular}

Table 36. Distribution of Complete and Incomplete Cores Categories and Bifaces by Occupation Zone

\begin{tabular}{|c|c|c|c|c|c|c|c|c|c|c|}
\hline \multirow[b]{2}{*}{ Zone } & \multicolumn{9}{|c|}{ Core Categories } & \multirow{2}{*}{$\begin{array}{c}\text { Ratio of Bifaces } \\
\text { to Cores }\end{array}$} \\
\hline & Bifacial & Bidirectional & Bipolar & Indeterminate & Multidirectional & Slab & Unidirectional & Total & Bifaces & \\
\hline 1 & & & & & 2 & & & 2 & 19 & 9.50 \\
\hline 2 & 12 & 4 & 1 & 5 & 39 & 2 & & 63 & 144 & 2.29 \\
\hline 3 & 36 & 5 & 可 & 7 & 109 & 4 & 10 & 171 & 377 & 2.20 \\
\hline 4 & 18 & 2 & 2 & 12 & 56 & 1 & 6 & 95 & 416 & 4.38 \\
\hline $\mathrm{NA}$ & 7 & & & & 2 & 3 & & 12 & & \\
\hline \begin{tabular}{|l|l|} 
Total \\
\end{tabular} & 72 & 11 & 1 & 24 & 208 & 10 & 16 & 343 & & \\
\hline
\end{tabular}

Table 37. Core Distribution by Occupation Zone and Area

\begin{tabular}{|c|c|c|c|c|c|c|c|c|}
\hline \multirow[b]{2}{*}{ Occupation Zone } & \multirow[b]{2}{*}{ Unk } & \multicolumn{4}{|c|}{ Area } & \multirow[b]{2}{*}{ B } & \multirow[b]{2}{*}{ Midden } & \multirow[b]{2}{*}{ Total } \\
\hline & & A-NE & A-NW & A-SE & A-SW & & & \\
\hline & & 2 & & & & & & 2 \\
\hline 2 & & 37 & 12 & & 14 & & & 63 \\
\hline 3 & & 40 & 69 & 3 & 30 & 22 & 7 & 171 \\
\hline 4 & & 2 & 2 & & & 72 & 19 & 95 \\
\hline $\mathrm{NA}$ & 8 & & 1 & 2 & & & 1 & 12 \\
\hline Total & 8 & 81 & 84 & 5 & 44 & 94 & 27 & 343 \\
\hline
\end{tabular}




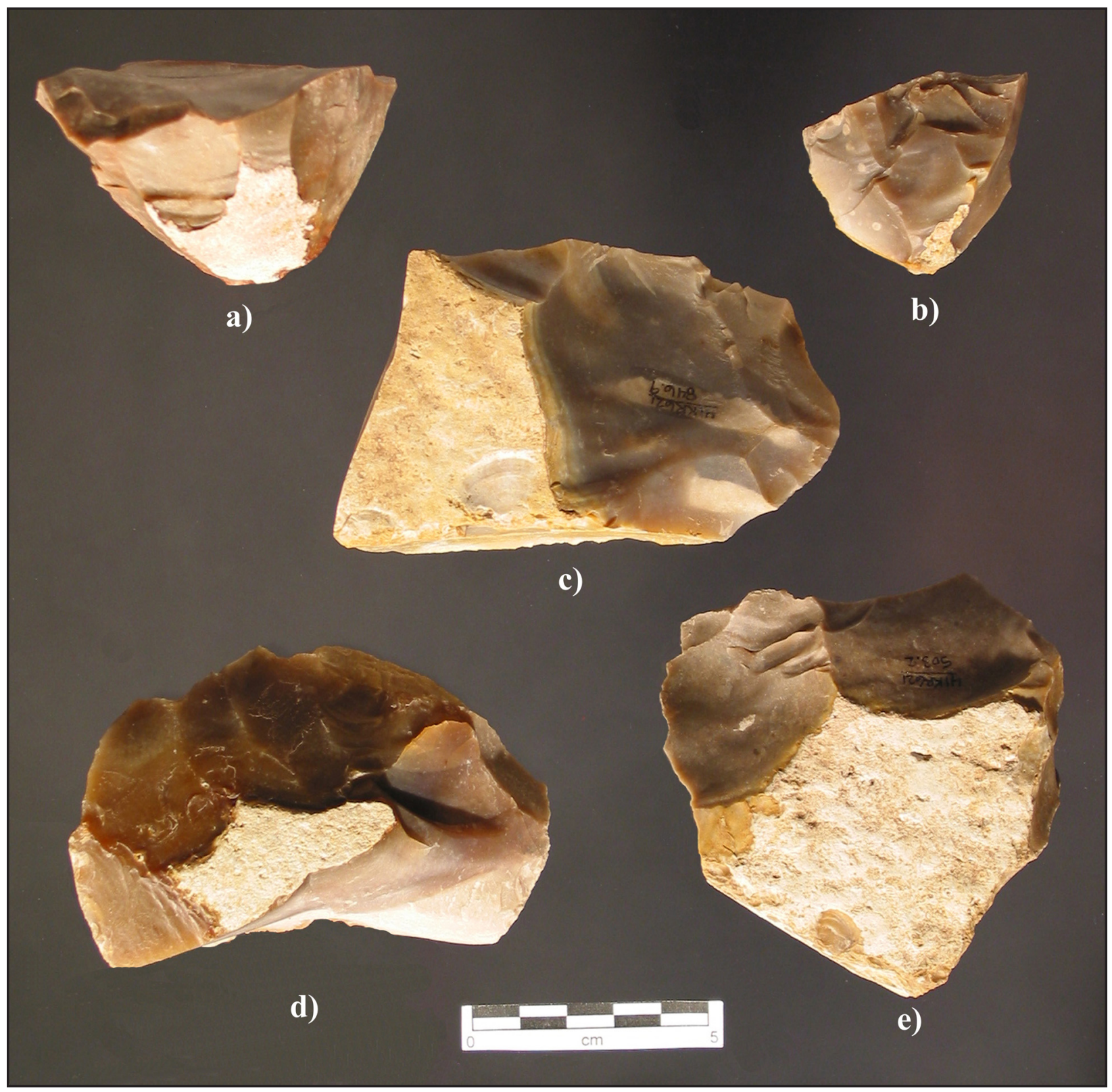

Figure 59. Cores. Unidirectional cores, Lot numbers: a) 780.2; b) 1540.4. Bidirectional cores, Lot number c) 846.9. Bifacial cores, Lot numbers: d) 415.1; e) 503.2. 

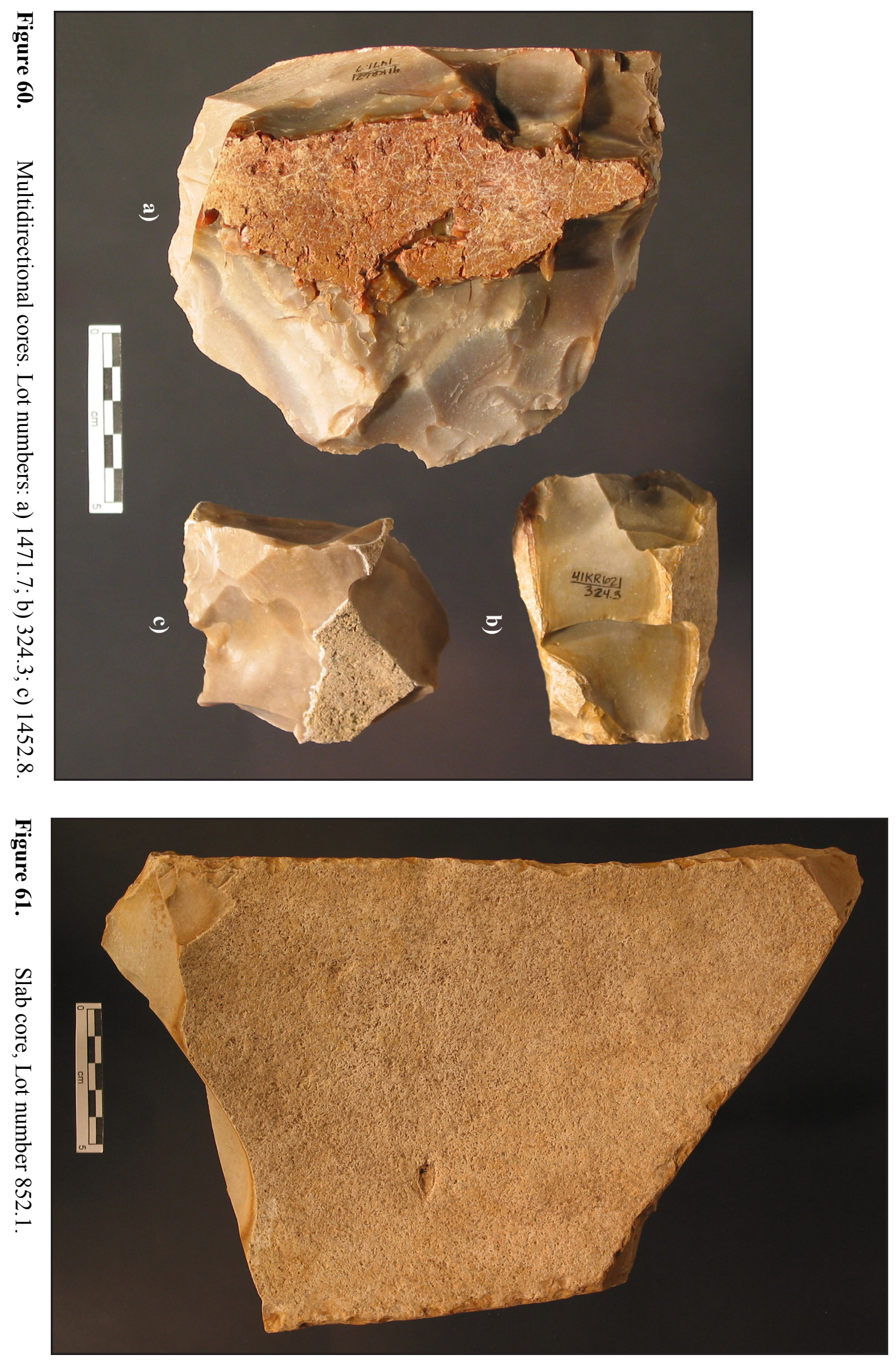
and unidirectional core at 4.7 percent $(n=16)$ are the next numerous categories. There are 11 bidirectional (3.2 percent) and ten ( 2.92 percent) slab cores and a single bipolar core.

The boxplot graph in Figure 62 shows the distribution of the maximum lengths of cores by category. The two most numerous categories, multidirectional and bifacial cores, are similar in overall length. They are also similar with regard to maximum flake scar length (Figure 63). A t-test of the maximum flake lengths finds that are statistically similar, $\mathrm{t}(195)=0.231, \mathrm{p}>.05$. This suggests a common size of raw material.

When separated into exhausted and unexhausted categories, the two categories of bifacial and multidirectional are proportionally similar in length (Figure 64) and maximum flake scar length (Figure 65). For bifacial cores, the cores are exhausted with median and mean scar lengths of $30.88 \mathrm{~mm}$ and $37.4 \mathrm{~mm}$ and for multidirectional cores, the median is $40.4 \mathrm{~mm}$ and mean is 42.39. Discard occurs for bifacial cores when the median decreases $15 \mathrm{~mm}$ and the mean 10 $\mathrm{mm}$. For multidirectional, the decrease in median is 5 $\mathrm{mm}$ and the mean approximately $4 \mathrm{~mm}$. Accounting for this seemingly small change are several factors, one being the reduction sequence of these cores, as they are rotated they lose size in all dimensions relatively equally and quickly. There also seems to be a preferential size of both the core to be held and the intended flakes. The available platform width is quickly reduced, limiting the size of potential flakes. A similar ending trajectory occurs with the bifacial cores as the edge angle increases and the specimen becomes narrower. Bifacial cores are exhausted at an average length of $90 \mathrm{~mm}$ and a width of $60 \mathrm{~mm}$. The width is twice the length of the median maximum flake scar lengths.

If mass is also used as an indicator of core size and available utility, both bifacial and multidirectional cores were reduced approximately the same amount (Figure 66). For bifacial cores, the difference between exhausted and unexhausted mean and median weight is $135.4 \mathrm{~g}$ and $112 \mathrm{~g}$, and for multidirectional cores, it is 154.9 and $117 \mathrm{~g}$ (Figure 67). The weights of the exhausted cores are similar, $\mathrm{t}(63)=0.261$, $\mathrm{p}>.05$. Unidirectional and bifacial cores are similar in size and provide a similar size range in flakes. They are both exhausted when they are at a similar length and mass.
The division between formal and informal categories of cores for all Occupation Zones is approximately 30 percent formal cores and 70 percent informal. Some of the early stage bifaces were likely used as cores; although, even when they are added to the total of formal cores, multidirectional cores are still the predominant form. Variability in measured characteristics was compared through the Occupation Zones, as was raw material types for complete and incomplete specimens.

Based on the analyzed counts of 343 cores and core fragments and 1085 bifaces and biface fragments from the Gatlin Site, the overall site ratio of bifaces to cores is 3.16:1. The overall ratio at Wilson-Leonard of bifaces and biface fragments to cores and core fragments, is 7.11:1 (Collins et al. 1998). At the Late Paleoindian/Early Archaic Armstrong site (Schroeder 2002), the ratio is 29 bifaces to 12 cores, or 2.41:1.

\section{Core Parent Material}

Tabular cobbles were the source for 45 percent of the cores and nodular cobbles were 19 percent, with the remainder being indeterminate. In Table 38 , source material is compared by core categories and Occupation Zones. For multidirectional cores, tabular sources were used almost three times as often as nodules ( $n=91$ versus $n=31$ ), while 35 of the bifacial cores were tabular cobbles and 22 were nodular cobbles. The thickness of tabular cobbles is similar to the slab cores, which were likely from the same source. Proportionally, nodular cobbles were selected more for bifacial cores than for multidirectional cores, although tabular cores were the predominant parent material for all categories with the exceptions of bidirectional and unidirectional cores. The greatest use of nodular material occurs during OZ3.

Cortex remains on over 95 percent of the cores, with approximately 46 percent of the specimens having greater than 50 percent cortex remaining (Table 39). Based upon the type of cortex, the primary locale from which lithic material was obtained was riverine (50.4 percent), followed by indeterminate (43.4 percent), with upland lag gravels (3.8 percent) and in situ deposits (2.3 percent) (Table 40).

Because many of the specimens retained a high percentage of cortex, it is likely the raw material was procured locally. This also suggests that there was 


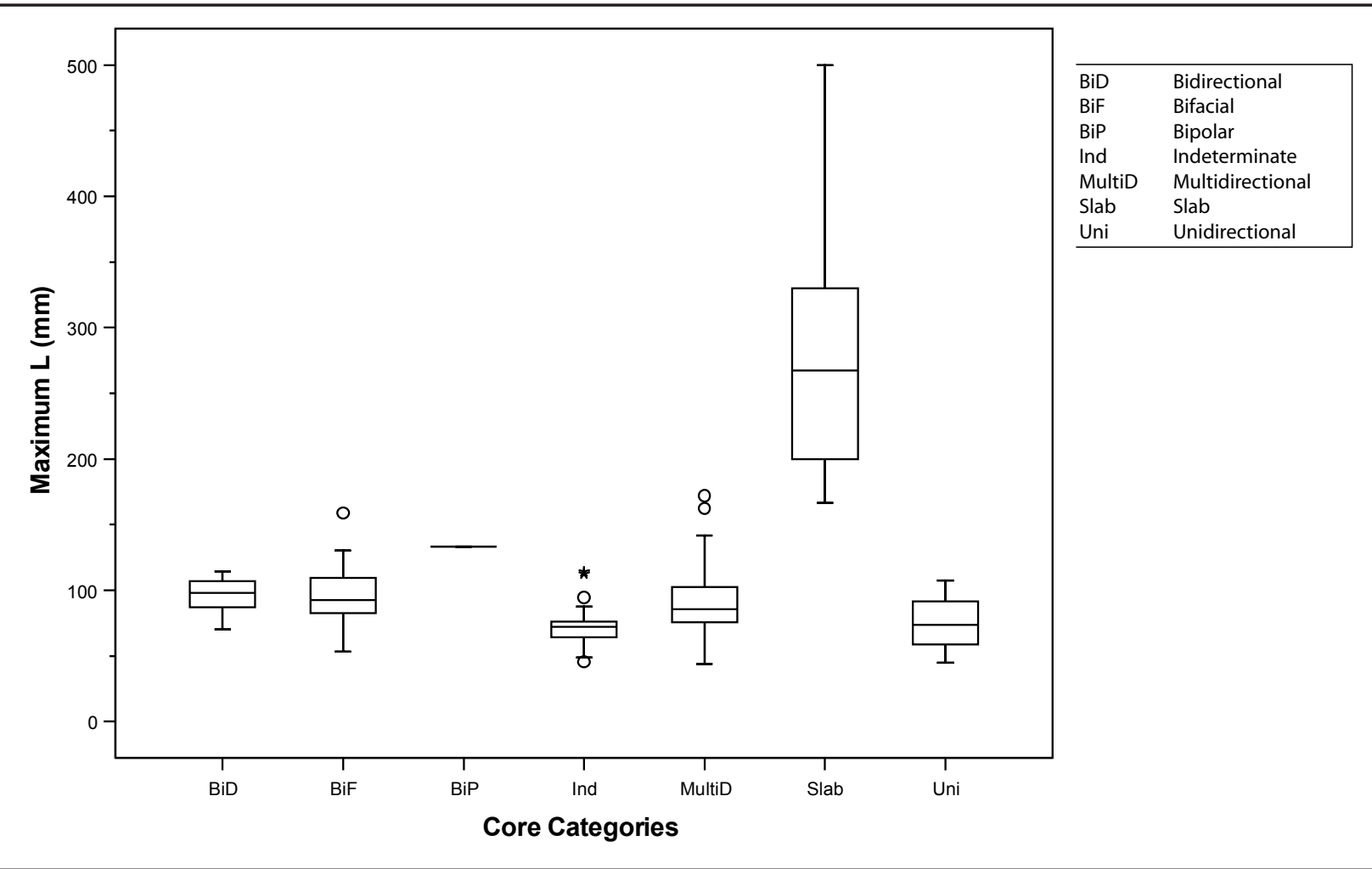

Figure 62. Boxplot of maximum lengths of core categories.

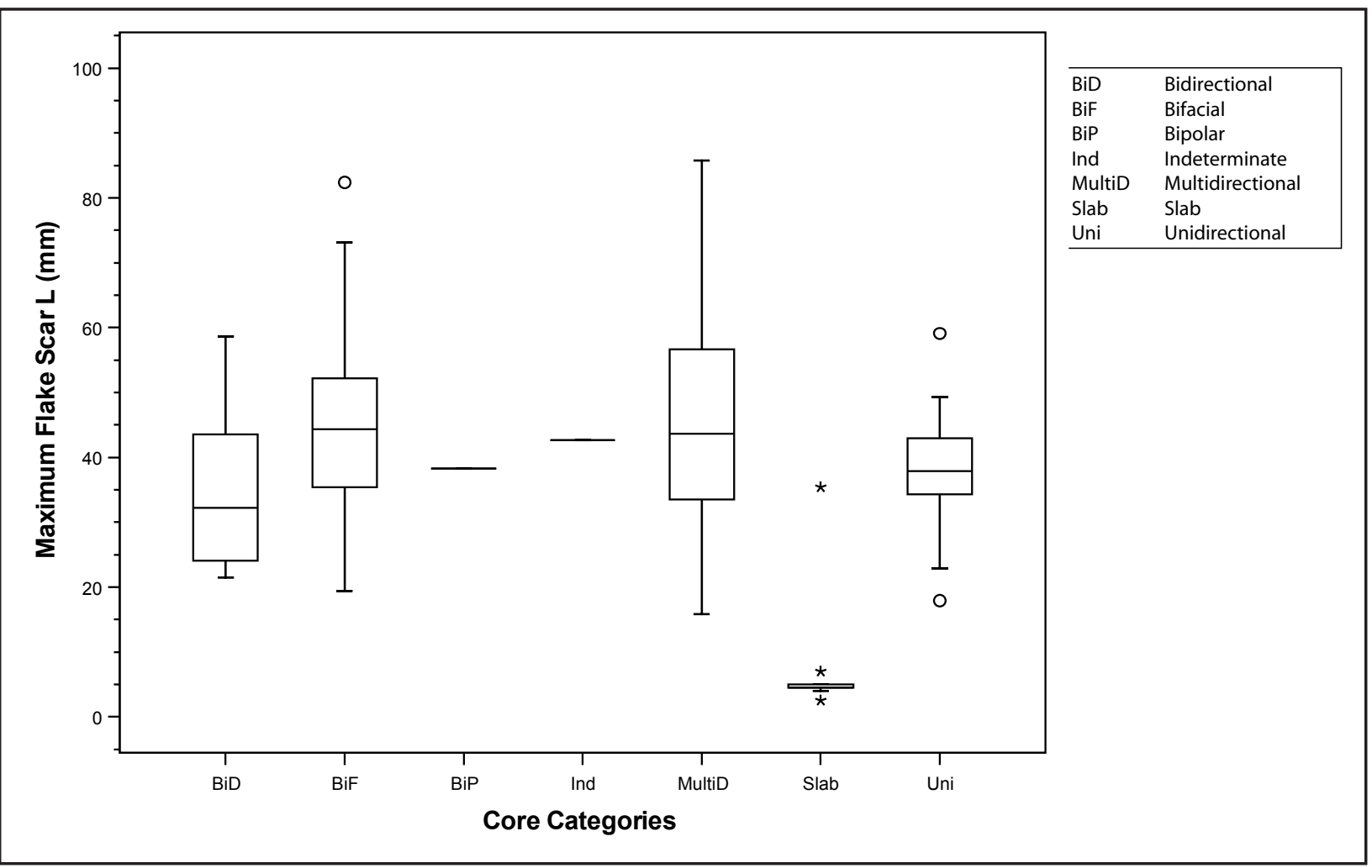

Figure 63. Boxplot of maximum flake scar lengths of core categories. 


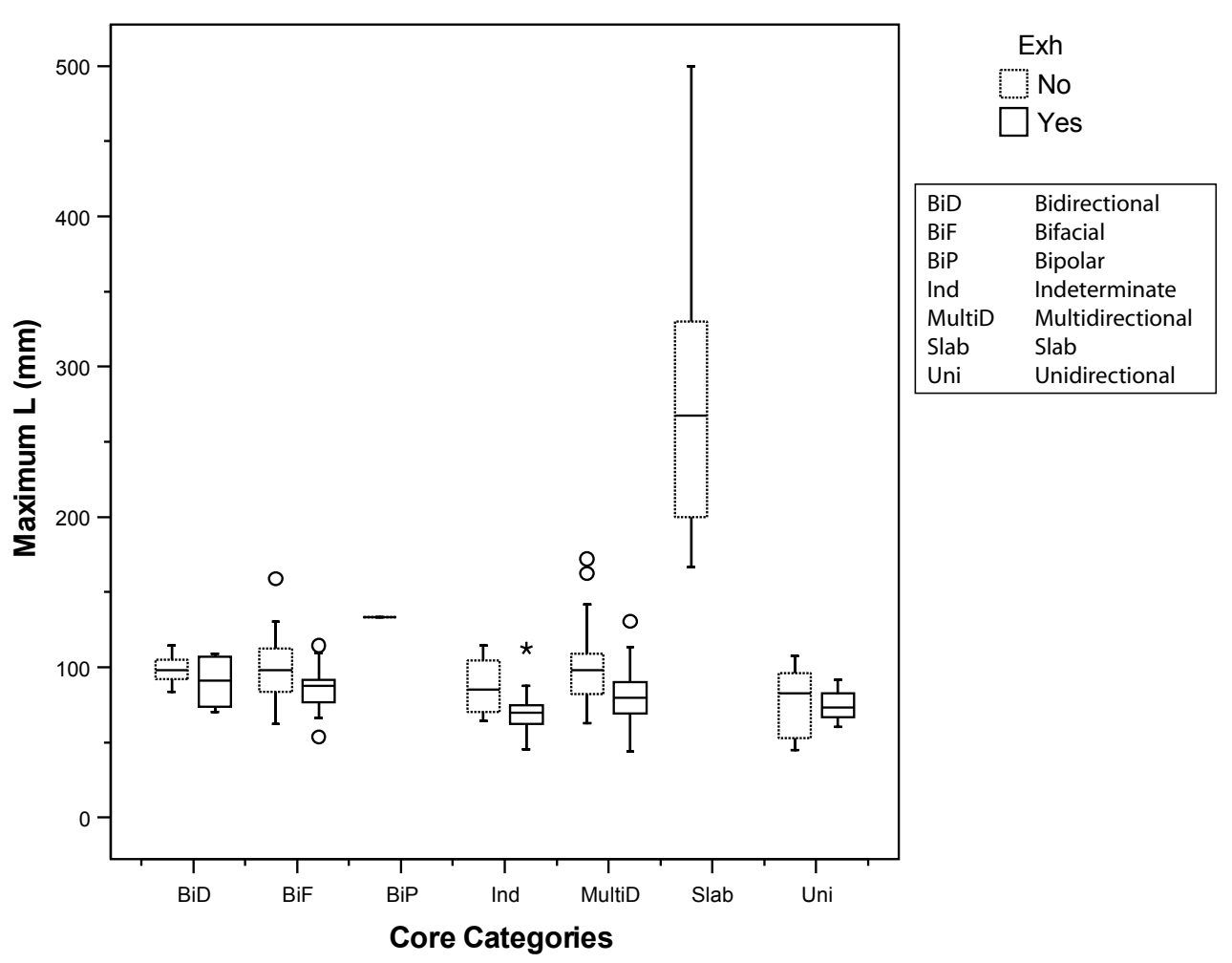

Figure 64. Boxplot of maximum lengths of exhausted and unexhausted core categories.

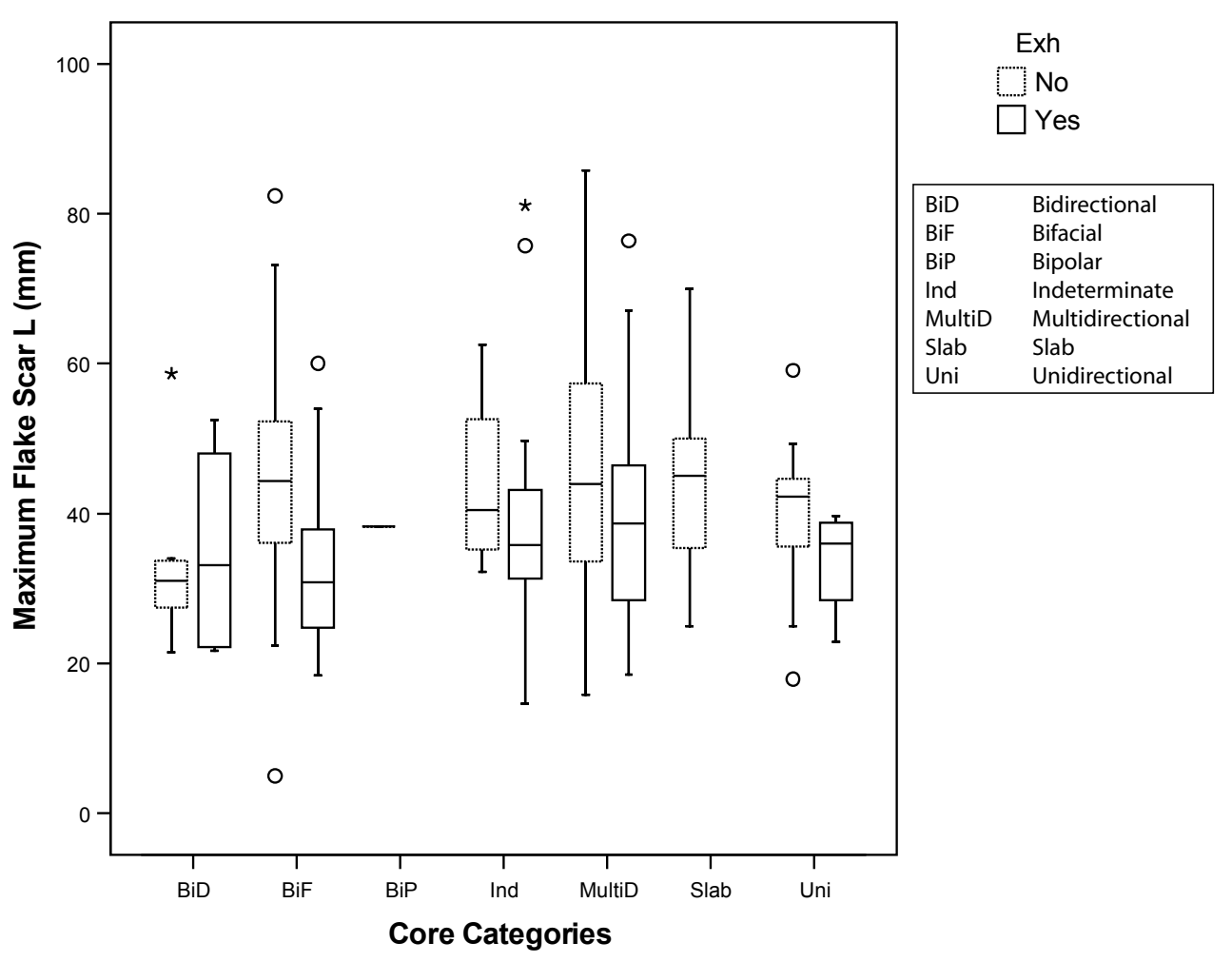

Figure 65. Boxplot of maximum flake scar lengths of exhausted and unexhausted core categories. 


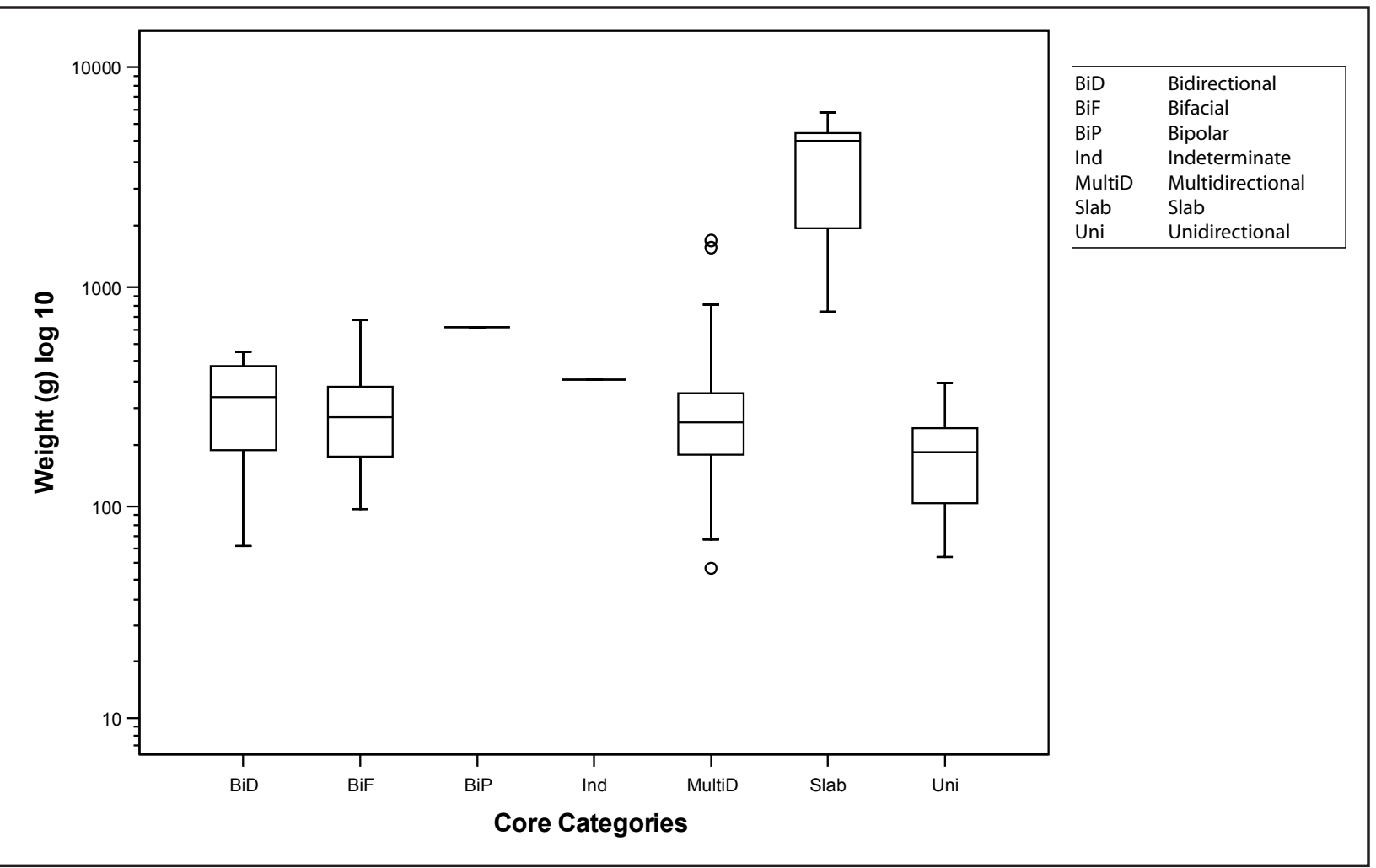

Figure 66. Boxplot of weights of core categories.

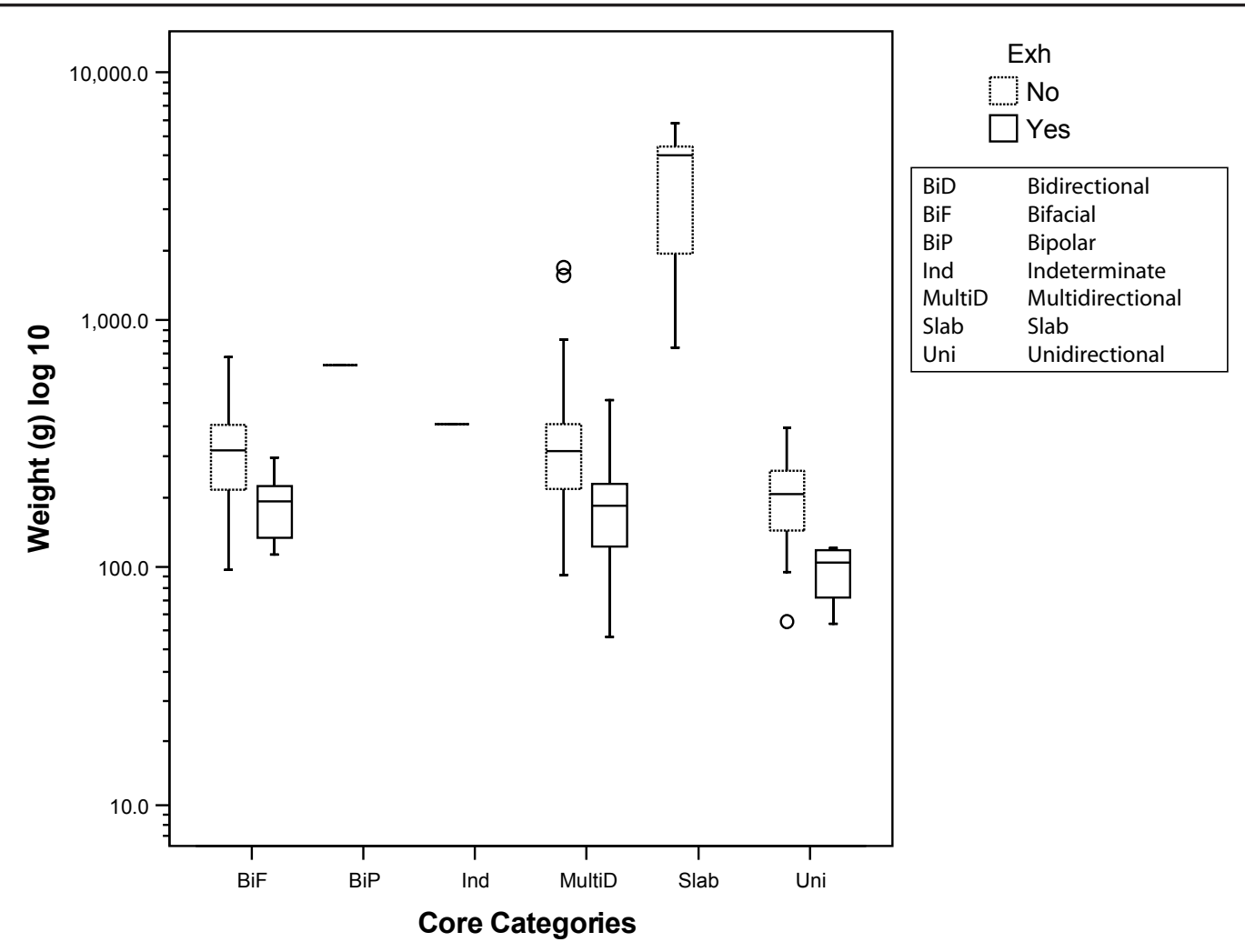

Figure 67. Boxplots of weights of exhausted and unexhausted core categories. 
Table 38. Source Material by Core Category and Occupation Zone

\begin{tabular}{|c|c|c|c|c|c|c|c|c|c|}
\hline \multirow[b]{2}{*}{$\begin{array}{c}\text { Occupation } \\
\text { Zone }\end{array}$} & \multirow[b]{2}{*}{$\begin{array}{c}\text { Rock } \\
\text { Description }\end{array}$} & \multicolumn{7}{|c|}{ Core Categories } & \multirow[b]{2}{*}{ Total } \\
\hline & & Bidirectional & Bifacial & Bipolar & Ind. & $\begin{array}{c}\text { Multi- } \\
\text { directional }\end{array}$ & Slab & Unidirectional & \\
\hline 1 & Tabular & & & & & 2 & & & 2 \\
\hline \multirow{3}{*}{2} & Indeterminate & 1 & 1 & & 2 & 16 & & & 20 \\
\hline & Nodular & 2 & 3 & & 2 & 5 & & & 12 \\
\hline & Tabular & 1 & 8 & 1 & 1 & 18 & 2 & & 31 \\
\hline \multirow{3}{*}{3} & Indeterminate & 1 & 8 & & 3 & 39 & & 3 & 54 \\
\hline & Nodular & 2 & 12 & & & 22 & & 4 & 40 \\
\hline & Tabular & 2 & 16 & & 4 & 48 & 4 & 3 & 77 \\
\hline \multirow{3}{*}{4} & Indeterminate & & 7 & & 3 & 31 & & 5 & 46 \\
\hline & Nodular & 1 & 3 & & 2 & 2 & & & 8 \\
\hline & Tabular & 1 & 8 & & 7 & 23 & 1 & 1 & 41 \\
\hline \multirow{3}{*}{ Unk } & Indeterminate & & 1 & & & & & & 1 \\
\hline & Nodular & & 4 & & & 2 & & & 6 \\
\hline & Tabular & & 2 & & & & 3 & & 5 \\
\hline \multirow{4}{*}{ Totals } & Indeterminate & 2 & 17 & & 8 & 86 & & 8 & 121 \\
\hline & Nodular & 5 & 22 & & 4 & 31 & & 4 & 66 \\
\hline & Tabular & 4 & 34 & 1 & 12 & 91 & 10 & 4 & 156 \\
\hline & Grand Total & 11 & 73 & 1 & 24 & 208 & 10 & 16 & 343 \\
\hline
\end{tabular}

Table 39. Cortex Percentages by Core Category

\begin{tabular}{|c|c|c|c|c|c|c|}
\hline \multirow[b]{2}{*}{ Core Categories } & \multicolumn{5}{|c|}{ Cortex \% } & \multirow[b]{2}{*}{ Total } \\
\hline & 0 & $1-25$ & $26-50$ & $51-75$ & $76-100$ & \\
\hline Bidirectional & 0.43 & 0.43 & 0.43 & 1.70 & 1.28 & 4.26 \\
\hline Bifacial & 1.28 & 2.55 & 5.96 & 7.66 & 6.38 & 23.83 \\
\hline Bipolar & & & & & 0.43 & 0.43 \\
\hline Indeterminate & & & 0.43 & & & 0.43 \\
\hline Multidirectional & 2.13 & 18.72 & 17.45 & 16.60 & 5.96 & 60.85 \\
\hline Slab & & & & 0.43 & 3.40 & 3.83 \\
\hline Unidirectional & 0.43 & 1.70 & 1.70 & 1.70 & 0.85 & 6.38 \\
\hline Total & 4.26 & 23.40 & 25.96 & 28.09 & 18.30 & 100.00 \\
\hline
\end{tabular}

Table 40. Source Material Primary Locale by Core Category

\begin{tabular}{|l|r|r|r|r|r|}
\hline \multirow{2}{*}{ Core Categories } & \multicolumn{4}{|c|}{ Location } & \multirow{2}{*}{ Total } \\
\cline { 2 - 6 } & \multicolumn{1}{|c|}{ In Situ } & Indeterminate & Riverine & Upland Lag Gravel & \multicolumn{1}{c|}{ T.58\% } \\
\hline Bidirectional & $0.29 \%$ & $0.87 \%$ & $1.46 \%$ & $1.46 \%$ & $21.28 \%$ \\
\hline Bifacial & $0.29 \%$ & $7.29 \%$ & $12.24 \%$ & $0.00 \%$ & $0.29 \%$ \\
\hline Bipolar & $0.00 \%$ & $0.00 \%$ & $0.29 \%$ & $0.29 \%$ & $7.00 \%$ \\
\hline Indeterminate & $0.00 \%$ & $2.62 \%$ & $4.08 \%$ & $1.46 \%$ & $60.64 \%$ \\
\hline Multidirectional & $0.87 \%$ & $30.03 \%$ & $28.28 \%$ & $0.00 \%$ & $2.92 \%$ \\
\hline Slab & $0.87 \%$ & $0.58 \%$ & $1.46 \%$ & $0.00 \%$ & $4.66 \%$ \\
\hline Unidirectional & $0.00 \%$ & $2.04 \%$ & $2.62 \%$ & $\mathbf{3 . 7 9} \%$ & $\mathbf{1 0 0 . 0 0 \%}$ \\
\hline
\end{tabular}


abundant local material and less of a need to conserve or maximize their use of chert supplies (Andrefsky 1998, Odell 2004). This is also similar to the biface assemblage, since there is also a high percentage of cortex remaining. In this instance it is, in part, due to abundant local availability and the shape of the raw material and the already thin tabular cobbles that required less thinning.

Chert was graded into fine-grained, coarse- grained, and quartzite. Fine-grained chert accounted for almost 75 percent of the cores, while coarse-grained accounted for the remainder. There was only a single quartzite specimen. As illustrated in Table 41, nine of ten slab cores were coarse-grained, while multidirectional cores were just as likely to be coarse-grained as bifacial cores.

\section{Tool usage}

Approximately 10 percent of the cores were utilized as tools, with both exhausted and unexhausted being used. Table 42 shows the core categories, whether the specimens are exhausted, and the presence of use-wear. No detailed use-wear was performed on the core specimens and all use-wear observations were based upon macro damage. Only two of the biface specimens appeared to be choppers, while the remainder had battering damage and edge damage from hammering, cutting and scraping. All of the damage is indicative of informal or expedient use, and cores were not a substantial source for recycled tools.

\section{LITHIC DEBITAGE}

Most of the stone artifacts recovered from the Gatlin site were categorized as lithic debitage, which Sullivan and Rozen (1985:755) define as, "chipped stone artifacts that are not cores or tools." Debitage consists of a mixture of complete flakes, broken flakes, nondiagnostic flaking shatter, and post-depositional heat shattered flaked fragments. Debitage is often viewed as the unused, "waste" byproduct of flintknapping activities (Austin 1999); however, ethnographic studies have shown that debitage is regularly utilized by hunter-gather groups as expedient tools (Hayden 1977).

At the Gatlin site, a total of 15,606 pieces of debitage was recovered from the testing phase, and 135,300 pieces were collected during data recovery. Moreover, these totals reflect only a part of the original debitage assemblage from the excavated areas. Although approximately $90-95$ percent of the debitage from Area B was collected, the excavation techniques used during data recovery (i.e., Feature Focused and Traditional units) essentially resulted in the sampling of approximately 50 percent of the debitage within the excavated volume of Area A.

\section{Analytical Methods}

Following the excavations, it was determined that the upper levels of Area B contained an admixture of components and therefore the contextual integrity was compromised. For this reason, all debitage from contexts above $98.0 \mathrm{~m}$ in elevation was culled and not analyzed. In addition, for the purpose of facilitating the comparisons with Area A, the debitage

Table 41. Raw Material Grades Counts and Percentages by Core Category

\begin{tabular}{|c|c|c|c|c|c|c|}
\hline \multirow[b]{2}{*}{ Core Categories } & \multicolumn{3}{|c|}{ Material } & \multirow[b]{2}{*}{$\%$ Quartzite } & \multirow[b]{2}{*}{$\begin{array}{c}\% \\
\text { Coarse-grained }\end{array}$} & \multirow[b]{2}{*}{$\begin{array}{c}\% \\
\text { Fine-grained }\end{array}$} \\
\hline & $\begin{array}{c}\text { Coarse-grained } \\
\text { Chert }\end{array}$ & $\begin{array}{c}\text { Fine-grained } \\
\text { Chert }\end{array}$ & Quartzite & & & \\
\hline Bidirectional & 2 & 9 & & $0.00 \%$ & $18.18 \%$ & $81.82 \%$ \\
\hline Bifacial & 18 & 55 & & $0.00 \%$ & $24.66 \%$ & $75.34 \%$ \\
\hline Bipolar & & 1 & & $0.00 \%$ & $0.00 \%$ & $100.00 \%$ \\
\hline Indeterminate & 4 & 20 & & $0.00 \%$ & $16.67 \%$ & $83.33 \%$ \\
\hline Multidirectional & 47 & 160 & 1 & $0.48 \%$ & $22.60 \%$ & $76.92 \%$ \\
\hline Slab & 9 & 1 & & $0.00 \%$ & $90.00 \%$ & $10.00 \%$ \\
\hline Unidirectional & 3 & 13 & & $0.00 \%$ & $18.75 \%$ & $81.25 \%$ \\
\hline Total & 83 & 259 & 1 & $0.29 \%$ & $24.20 \%$ & $75.51 \%$ \\
\hline
\end{tabular}


Table 42. Use Wear Presence and Exhausted Core Percentages by Core Category

\begin{tabular}{|l|r|r|r|r|r|}
\hline \multirow{2}{*}{ Core Categories } & \multicolumn{2}{|c|}{ Exhausted } & \multicolumn{3}{c|}{ Use Wear } \\
\cline { 2 - 6 } & \multicolumn{1}{c|}{ No } & \multicolumn{1}{c|}{ Yes } & \multicolumn{1}{c|}{ No } & \multicolumn{1}{c|}{ Yes } & \multicolumn{1}{c|}{ Total } \\
\hline Bidirectional & 7 & 4 & 10 & 1 & 11 \\
\hline Bifacial & 55 & 18 & 59 & 14 & 73 \\
\hline Bipolar & 1 & & 1 & & 1 \\
\hline Indeterminate & 4 & 20 & 23 & 1 & 24 \\
\hline Multidirectional & 102 & 106 & 191 & 17 & 208 \\
\hline Slab & 10 & & 10 & & 10 \\
\hline Unidirectional & 12 & 4 & 14 & 2 & 16 \\
\hline Total & $\mathbf{1 9 1}$ & $\mathbf{1 5 2}$ & $\mathbf{3 0 8}$ & $\mathbf{3 5}$ & $\mathbf{3 4 3}$ \\
\hline
\end{tabular}

Table 43. Area B Sampled Debitage

\begin{tabular}{|c|c|}
\hline Unit & Level \\
\hline N1014/E1036 & All \\
\hline N1014/E1038 & All \\
\hline N1014/E1040 & All \\
\hline N1016/E1034 & All \\
\hline N1016/E1038 & All \\
\hline N1018/E1030 & 6 \\
\hline N1018/E1032 & All \\
\hline N1018/E1036 & All \\
\hline
\end{tabular}

from Area B was subjected to a roughly 50 percent sampling of the unit levels. This sampling was performed by choosing the debitage from alternating units, utilizing a similar checkerboard pattern to that employed in Area A (Table 43). After these modifications were made, analyses including initial type sorting, size sorting, and detailed attribute analysis were conducted on the sample from Area B, all of the debitage collected from the testing phase, and all debitage collected from within Area A during data recovery. Due to the mixed nature of the deposits, column samples from within the midden were excluded from sorting and detailed analysis.

To collect data to address issues such as duration of site use, the frequency of knapping activities, and site taphonomy, the debitage from the Gatlin site was sorted and quantified by type. Using a combination of methods outlined by Andrefsky (1998) and Hiscock (2002), the debitage assemblage was sorted into the following categories: 1) complete flakes, 2) proximal flake fragments, 3) non-platform bearing broken flake fragments (medial, distal, and longitudinal cone split flake fragments), 4) indeterminate flaking shatter, and 5) non-diagnostic heat shattered fragments (i.e., crazed debitage and potlids). Specimens exhibiting edge modification or possible usewear were culled and analyzed as modified flakes, as previously discussed in the Flake Tools section. The aim of this initial sort was to obtain count and weight information for each category, which was then used to calculate a minimum and maximum number of flake initiations, the frequency of flake breakage, and debitage density.
Because the site contained Occupation Zones with stratigraphic integrity, a more intensive technological study was performed on the debitage assemblage associated with those Occupation Zones in an attempt to determine lithic reduction techniques and possible activity areas. Debitage analysis typically falls into two schools of thought - aggregate analyses, such as mass analysis (Ahler 1989; Henry et al. 1976) and size sorting analysis (Patterson 1990), or individual specimen analysis (Shott 1994) - SWCA's examination combined the two analytical approaches, as recommended by Shott (1994) and Morrow (1997). The analyses and results are included in the Occupation Zone chapters.

Following the initial sort, the complete flakes from the sampled assemblage were subjected to a size-sort analysis. Using a methodology similar to that outlined in Henry et al. (1976), Stahle and Dunn (1982), and Ahler (1989), the assemblage of complete flakes was size sorted into 10 size classes-from less than 0.25 inch to greater than 2.25 inches-for each unit/level. The objective of the size sort was to reveal patterns indicative of the overall stages of lithic reduction. For example, if primarily late-stage reduction activities (e.g., biface thinning, pressure flaking, tool maintenance/rejuvenation) occurred at the Gatlin site, then the number of flakes sorted into smaller size classes should be proportionally higher than the number of flakes in larger size classes. Conversely, early stage reduction activities should be indicated by a high percentage of complete flakes in large size classes.

Supplementing the size sort, a detailed individual flake analysis was conducted on the site's platform- 
bearing flakes (i.e., complete flakes and proximal flake fragments). As with the previous analyses, this excluded those flakes found above $98.0 \mathrm{~m}$ and the culled 50 percent from Area B, as well as those from the midden column samples. The individual flake analysis recorded eight nominal attributes and two metrical attributes for each proximal or complete flake specimen. Nominal attributes included both technological and physical variables, including: flake type and subtype, raw material, reduction method, percentage of dorsal cortex, platform type, heat exposure, and abrasion.

Flake types included categories of normal flakes, comprising 98 percent of the identifiable flake types in examined assemblage, blade, burin, edge collapse, notching and overshot.

Flake technology categories were biface reduction, core reduction, indeterminate and uniface tool resharpening/rejuvenation flakes. Biface reduction also includes biface thinning flakes. The categories are largely defined by the platform characteristics as outlined in Whittaker (1994) and Adrefsky (1998).

The metrical attributes were platform width and weight. Three additional metrical attributes - length, width, and thickness-were recorded for each proximal flake. These attributes were chosen based on their potential to provide information on the frequency of site use, the use of local resources, the quantity and degree of knapping activities, and the technological skill of the prehistoric site inhabitants. These particular research issues were discussed within the individual Occupation Zone Chapters.

\section{An Inventory of Debitage}

Within the sampled units and features there were approximately 48,040 pieces of debitage. Table 44 shows the number of complete flakes to flake fragments by Occupation Zone. Flake fragment percentages increase through time, and this percentage increase even more when proximal flakes are included in the fragment totals. Factors accounting for this increase include changes in flake technology such as an increase in core reduction. More cores were recovered from OZ1 through OZ3 and in OZ4 the production of bifaces increases as does the percentage of biface reduction flakes. Flake fracturing is also related to the lengths of flakes being produced, but the mean length of complete flakes does not change significantly through time. Choice of raw materials is uniformly fine-grain cherts versus coarser grain materials, and the seeming variation between fractured and complete flakes may not be significant.

From the numerous bifaces at the site and the relatively low number of cores recovered, the inference is that biface reduction was the dominant lithic activity performed at the site. In Table 45, core reduction is highest in the Early Archaic OZ1, with an increase in biface thinning flakes at the end of the Early Archaic in OZ2, reaching the highest percentage in the Middle to Late Archaic, OZ4. The increase in OZ4 coincides with the production of thin bifaces found in Area B. The percentage of biface thinning flakes increases without a substantial increase in biface production suggesting that more flakes are removed from a biface than previously., or that the bifaces made on site were removed subsequently. The size composition of flakes does not change significantly between the Occupation Zones. The variations in OZ3, the mixed Early and Middle Archaic component, suggest that OZ4 materials are contributing more to the assemblage composition than the Early Archaic with an increase in the largest size categories (Table 46).

The amount of cortex present on complete flakes does not vary significantly between Occupation Zones, with the exception of OZ1, with almost 10 percent of the flakes having greater than 50 percent cortex and 69 percent of the flakes having no cortex. The amount of cortex decreases slightly in the latter part of the Early Archaic in OZ2 to 8.46 percent having greater than 50 percent cortex and 73 percent without cortex (Table 47). There is a slight rise in flakes with 100 percent cortex. Comparing OZ1 to OZ4, there is a seven percent increase in tertiary flakes (no cortex) in OZ4, indicating a greater amount of later stage biface reduction and the use of trimmed cores.

One activity under-reflected or perhaps under-detected in the assemblage is resharpening of unifacial flake tools. There are burin-edge spalls, but short edge trimming flakes have been too small to be collected during the excavation. Burin spalls are also relatively rare and not all are related to unifacial tool resharpening or rejuvenation (Table 48). Notching 
Table 44. Counts and Percentages of Complete Flakes and Proximal Flakes and Flake Fragements by Occupation Zone

\begin{tabular}{|c|c|c|c|c|c|}
\hline $\begin{array}{l}\text { Occupation } \\
\text { Zone }\end{array}$ & $\begin{array}{l}\text { Complete and } \\
\text { Proximal Flakes No. }\end{array}$ & $\begin{array}{c}\text { Broken } \\
\text { Flakes No. }\end{array}$ & Total & $\begin{array}{c}\text { Complete and } \\
\text { Proximal Flakes \% }\end{array}$ & Broken Flakes \% \\
\hline 1 & 339 & 403 & 742 & $33.36 \%$ & $66.64 \%$ \\
\hline 2 & 4434 & 6370 & 10804 & $34.42 \%$ & $65.58 \%$ \\
\hline 3 & 5504 & 10485 & 15989 & $41.04 \%$ & $58.96 \%$ \\
\hline 4 & 6840 & 13665 & 20505 & $45.69 \%$ & $54.31 \%$ \\
\hline Total | & 17117 & 30923 & 48040 & & \\
\hline
\end{tabular}

Table 45. Flake Technology Categories Percentages by Occupation Zone

\begin{tabular}{|c|c|c|c|c|c|c|c|c|c|}
\hline $\begin{array}{c}\text { Occupation } \\
\text { Zone }\end{array}$ & $\begin{array}{c}\text { Biface } \\
\text { Reduction }\end{array}$ & $\begin{array}{c}\text { Core } \\
\text { Reduction }\end{array}$ & Indeterminate & $\begin{array}{c}\text { Tool } \\
\text { Resharpening } \\
\end{array}$ & Total & \begin{tabular}{|c|} 
Biface \\
Reduction
\end{tabular} & $\begin{array}{c}\text { Core } \\
\text { Reduction }\end{array}$ & Ind. & $\begin{array}{c}\text { Tool } \\
\text { Resharpening } \\
\end{array}$ \\
\hline 1 & 202 & 92 & 48 & & 342 & $59.06 \%$ & $26.90 \%$ & $14.04 \%$ & $0.00 \%$ \\
\hline 2 & 2975 & 754 & 594 & 3 & 4327 & $68.75 \%$ & $17.43 \%$ & $13.73 \%$ & $0.07 \%$ \\
\hline 3 & 1572 & 475 & 347 & 1 & 2396 & $65.61 \%$ & $19.82 \%$ & $14.48 \%$ & $0.04 \%$ \\
\hline 4 & 6892 & 1798 & 1366 & 4 & 9989 & $69.00 \%$ & $18.00 \%$ & $13.68 \%$ & $0.04 \%$ \\
\hline Total & 11641 & 3051 & 2354 & 8 & 17054 & $68.26 \%$ & $17.89 \%$ & $13.80 \%$ & $0.05 \%$ \\
\hline
\end{tabular}

Table 46. Size Grades of Complete Flakes Percentages by Occupation Zone

\begin{tabular}{|c|c|c|c|c|c|c|c|c|c|c|c|}
\hline \multirow[b]{2}{*}{ Occupation Zone } & \multicolumn{10}{|c|}{ Size grades in inches } & \multirow[b]{2}{*}{ Total } \\
\hline & $\begin{array}{l}\text { SG } 1 \\
(<.25)\end{array}$ & $\begin{array}{c}\text { SG } 2 \\
(.25-.50)\end{array}$ & $\begin{array}{c}\text { SG 3 } \\
(.50-.75)\end{array}$ & $\begin{array}{c}\text { SG } 4 \\
(.75-1.0)\end{array}$ & $\begin{array}{c}\text { SG 5 } \\
(1.0-1.25)\end{array}$ & $\begin{array}{c}\text { SG } 6 \\
(1.25-1.5)\end{array}$ & $\begin{array}{c}\text { SG } 7 \\
(1.5-1.75)\end{array}$ & $\begin{array}{c}\text { SG } 8 \\
(1.75-2.0)\end{array}$ & $\begin{array}{c}\text { SG 9 } \\
(2.0-2.25)\end{array}$ & $\begin{array}{c}\text { SG } 10 \\
(>2.25)\end{array}$ & \\
\hline Occupation Zone 1 & $0.00 \%$ & $7.14 \%$ & $20.71 \%$ & $14.29 \%$ & $15.00 \%$ & $13.57 \%$ & $15.71 \%$ & $3.57 \%$ & $4.29 \%$ & $5.71 \%$ & $100.00 \%$ \\
\hline Occupation Zone 2 & $0.20 \%$ & $9.25 \%$ & $24.17 \%$ & $21.34 \%$ & $14.11 \%$ & $9.18 \%$ & $7.09 \%$ & $4.86 \%$ & $3.17 \%$ & $6.62 \%$ & $100.00 \%$ \\
\hline Occupation Zone 3 & $0.00 \%$ & $10.66 \%$ & $23.83 \%$ & $15.79 \%$ & $12.59 \%$ & $10.02 \%$ & $7.69 \%$ & $5.89 \%$ & $4.02 \%$ & $9.50 \%$ & $100.00 \%$ \\
\hline Occupation Zone 4 & $0.08 \%$ & $11.37 \%$ & $24.10 \%$ & $18.15 \%$ & $13.35 \%$ & $9.46 \%$ & $6.94 \%$ & $4.65 \%$ & $4.12 \%$ & $7.78 \%$ & $100.00 \%$ \\
\hline otal & $0.09 \%$ & $10.31 \%$ & $23.92 \%$ & $18.18 \%$ & $13.36 \%$ & $9.70 \%$ & $7.53 \%$ & $5.14 \%$ & $3.79 \%$ & $7.98 \%$ & $100.00 \%$ \\
\hline
\end{tabular}

Table 47. Cortex Percentages on Complete Flakes by Occupation Zone

\begin{tabular}{|c|c|c|c|c|c|c|c|}
\hline \multirow[b]{2}{*}{ Occupation Zone } & \multicolumn{6}{|c|}{ Cortex percentage categories } & \multirow[b]{2}{*}{ Total } \\
\hline & $0 \%$ & $100 \%$ & $1-25 \%$ & $26-50 \%$ & $51-75 \%$ & $76-99 \%$ & \\
\hline 1 & $69.30 \%$ & $0.58 \%$ & $15.79 \%$ & $4.68 \%$ & $3.80 \%$ & $5.85 \%$ & $100.00 \%$ \\
\hline 2 & $72.85 \%$ & $1.22 \%$ & $13.59 \%$ & $5.06 \%$ & $3.54 \%$ & $3.70 \%$ & $100.00 \%$ \\
\hline 3 & $74.71 \%$ & $0.54 \%$ & $12.52 \%$ & $4.59 \%$ & $3.21 \%$ & $4.38 \%$ & $100.00 \%$ \\
\hline 4 & $76.02 \%$ & $1.21 \%$ & $12.25 \%$ & $4.80 \%$ & $2.54 \%$ & $3.12 \%$ & $100.00 \%$ \\
\hline Total & $74.90 \%$ & $1.11 \%$ & $12.70 \%$ & $4.83 \%$ & $2.91 \%$ & $3.50 \%$ & $100.00 \%$ \\
\hline
\end{tabular}


flakes have the highest percentage in OZ1 at 2.34 percent.

In Table 49, the length of flake technological categories is compared within each category by Occupation Zones. Biface reduction flakes do not change significantly in length through time; however, core reduction flakes vary in length between Occupation Zones, from a mean length of $33.61 \mathrm{~mm}$ in OZ1, ris- ing to $39.63 \mathrm{~mm}$ in OZ2, and statistically the same the same through OZ3 and OZ4.

Indeterminate flakes are longest in the Early Archaic OZ1, at $28.09 \mathrm{~mm}$ and shortest in the OZ3 at 20.05 $\mathrm{mm}$. The tool resharpening category includes six specimens. Given the number of resharpened and worked flake tools and bifaces at the Gatlin site, the low number of resharpening flakes is the likely result of recovery methods and identification criteria.

Table 48. Flake Type Percentages by Occupation Zone

\begin{tabular}{|r|r|r|r|r|r|r|r|}
\hline $\begin{array}{c}\text { Occupation } \\
\text { Zone }\end{array}$ & \multicolumn{1}{c|}{ Blade } & \multicolumn{1}{c|}{ Burin } & $\begin{array}{c}\text { Edge col- } \\
\text { lapse }\end{array}$ & $\begin{array}{c}\text { Notching } \\
\text { flake }\end{array}$ & $\begin{array}{c}\text { Overshot } \\
\text { flake }\end{array}$ & \multicolumn{1}{c|}{ Normal } & Grand Total \\
\hline 1 & $0.00 \%$ & $0.00 \%$ & $0.29 \%$ & $2.34 \%$ & $0.00 \%$ & $97.37 \%$ & $100.00 \%$ \\
\hline 2 & $0.23 \%$ & $0.07 \%$ & $0.39 \%$ & $1.64 \%$ & $0.07 \%$ & $97.60 \%$ & $100.00 \%$ \\
\hline 3 & $0.16 \%$ & $0.04 \%$ & $0.43 \%$ & $1.54 \%$ & $0.05 \%$ & $97.77 \%$ & $100.00 \%$ \\
\hline 4 & $0.10 \%$ & $0.09 \%$ & $0.44 \%$ & $0.69 \%$ & $0.00 \%$ & $98.69 \%$ & $100.00 \%$ \\
\hline Grand Total & $\mathbf{0 . 1 5} \%$ & $\mathbf{0 . 0 6 \%}$ & $\mathbf{0 . 4 2} \%$ & $\mathbf{1 . 2 4} \%$ & $\mathbf{0 . 0 4} \%$ & $\mathbf{9 8 . 0 9} \%$ & $\mathbf{1 0 0 . 0 0 \%}$ \\
\hline
\end{tabular}

Table 49. Flake Length ( $\mathrm{mm})$ by Flake Technology and Occupation Zone

\begin{tabular}{|c|c|c|c|c|c|c|c|}
\hline Flake Type & $\mathrm{OZ}$ & $\mathbf{N}$ & Mean & Median & Minimum & Maximum & Std. Deviation \\
\hline \multirow{5}{*}{ Biface reduction } & 1 & 69 & 21.69 & 19.10 & 8.10 & 54.10 & 9.997 \\
\hline & 2 & 913 & 20.23 & 18.40 & 3.60 & 71.30 & 9.456 \\
\hline & 3 & 286 & 20.49 & 17.90 & 4.00 & 72.00 & 11.360 \\
\hline & 4 & 1625 & 21.83 & 18.70 & 3.90 & 74.20 & 11.657 \\
\hline & Total & 2893 & 21.19 & 18.40 & 3.60 & 74.20 & 10.961 \\
\hline \multirow{5}{*}{ Core reduction } & 1 & 49 & 33.61 & 31.60 & 12.60 & 70.60 & 12.354 \\
\hline & 2 & 351 & 39.63 & 38.70 & 5.70 & 127.40 & 16.677 \\
\hline & 3 & 91 & 38.34 & 33.30 & 9.00 & 100.70 & 20.658 \\
\hline & 4 & 615 & 39.42 & 36.90 & 9.10 & 108.60 & 18.144 \\
\hline & Total & 1106 & 39.14 & 36.95 & 5.70 & 127.40 & 17.718 \\
\hline \multirow{5}{*}{ Indeterminate } & 1 & 11 & 28.09 & 29.00 & 14.50 & 48.50 & 12.349 \\
\hline & 2 & 203 & 21.02 & 19.70 & 5.40 & 71.50 & 9.171 \\
\hline & 3 & 80 & 20.05 & 18.25 & 7.90 & 48.20 & 8.295 \\
\hline & 4 & 312 & 21.58 & 17.80 & 4.90 & 88.90 & 12.859 \\
\hline & Total & 606 & 21.31 & 18.55 & 4.90 & 88.90 & 11.212 \\
\hline \multirow{4}{*}{$\begin{array}{c}\text { Unifacial tool resharp- } \\
\text { ening }\end{array}$} & 2 & 2 & 38.65 & 38.65 & 35.50 & 41.80 & 4.455 \\
\hline & 3 & 1 & 6.90 & 6.90 & 6.90 & 6.90 & \\
\hline & 4 & 3 & 29.43 & 31.60 & 17.10 & 39.60 & 11.405 \\
\hline & Total & 6 & 28.75 & 33.55 & 6.90 & 41.80 & 13.819 \\
\hline \multirow{5}{*}{ Total } & 1 & 129 & 26.76 & 25.40 & 8.10 & 70.60 & 12.420 \\
\hline & 2 & 1469 & 25.00 & 21.40 & 3.60 & 127.40 & 14.184 \\
\hline & 3 & 458 & 23.93 & 19.35 & 4.00 & 100.70 & 15.114 \\
\hline & 4 & 2555 & 26.04 & 21.90 & 3.90 & 108.60 & 15.574 \\
\hline & Total & 4611 & 25.52 & 21.50 & 3.60 & 127.40 & 15.030 \\
\hline
\end{tabular}


Resharpening flakes are identified as burin removals, and do not include the smaller trimming flakes.

\section{Summary}

The debitage assemblage shows some variation in composition between Occupation Zones; however, this variation is small and subtle. The debitage reflects the tool assemblage of bifaces and flake tools and the cores, the same lithic materials were reduced at the Gatlin site through the Occupation Zones using similar techniques. Biface flakes vary little in size through time; however there is some variance in the average size of the core reduction flakes through time.

\section{Non-CHIPPED Stone Tools}

A small number of non-chipped stone tools were recovered from the Gatlin Site. These 27 specimens include 20 modified stones and seven manuports.

\section{Categories}

The six categories for the specimens were determined according to inferred function, technology, morphological, and material attributes. Basic measurements were made for the specimens such as length, width, thickness, weight, and parent material. Individual attributes are presented in Appendix E.7.

\section{MANOS}

These are hand-held stones used against a larger millstone for grinding. All of the specimens are made from sandstone. This material was selected for its abrasive properties and through use, the mano develops a heel facet (Johnson 1995). The use of milling stones is seen as a hallmark of an Archaic lifestyle (Collins 2004). Manos may indicate gender divisions of labor and may have been used and maintained by women. For example, specimens of manos and grinding slabs were interred with female burials at Loma Sandia (Taylor and Highley 1995).

\section{METATES}

These are grinding surfaces used with a mano or other grinding implement. At the Sleeper Site, metates were selected from local abrasive sandstones, schists, and quartzites (Johnson 1991). If the stone did not have a natural depression, an initial depression was created by pecking the surface with a pointed stone bit. Grinding stones could have two surfaces, a one coarse and the other fine. This may be a deliberate design, since varying abrasiveness accommodates different ginding stages and tasks (Johnson 1995). These specimens represent technology curated as site furniture in that they remained at the site for future use.

In the southwest, metates and manos were more formalized and larger at larger architectural settlements; however, when compared to temporary sites, there was no difference in the ratios of expended and exhausted ground stones. This suggests that there was no correlation between site permanence and processing intensity (Odell 2000:309).

Grinding stones and metate are differentiated by the grinding motion of the mano on the surface and the resulting impression of depression of the surface(s). Ground stones have ovate or circular depressions caused by a rotary motion when grinding with an irregular shaped mano. Metates having a trough-like depression from a back and forth grinding motion with a two handed brick-like mano (Taylor and Highley 1995). Applying these criteria to the specimens from the Gatlin Site assemblage, specimens identified as metates are more likely grinding stones. The surfaces of the grinding stone specimens do not have unidirectional striae, but instead exhibit a uniform smoothing consistent with the rotary movement of a mano. The manos recovered from the Gatlin site, far from being crudely shaped, are rounded tabular pieces that are ovate or circular in outline.

\section{LIMESTONE COBBLES}

These represent manuports brought to the site from the river channel and from nearby exposures of tabular limestone. These specimens exhibit minimal modification and many of the surface markings could be naturally occurring.

\section{INDETERMINATE}

These are specimens that are unusual by shape or material. Like the limestone cobbles they may be manuports.

\section{Nutting Stone}

These are anvil stone where a food source is pounded, pecked, or cracked. The small depressions are to 
hold a seed or nut in place while another implement is used to crack it.

\section{HAMMERSTONE}

These are percussors that exhibit battering damage on one or more ends. They can form part of a lithic manufacturing and maintenance tool kit.

\section{An Inventory of Non-Chipped Stone Tools}

The distribution of non-chipped stone specimens by Occupation Zone is displayed in Table 50.

\section{$\operatorname{ManOS}(N=9)$}

There were nine manos and mano fragments recovered from the Gatlin Site. The two complete specimens and the seven fragments all represent one-handed manos. Specimen Lot 152, illustrated in Figure 68 (a), has a tapered profile from the development of a heel. The thinner area is where the greatest force was applied and indicates that the stone was held in the same direction. The flat ventral side of the specimen suggests that the metate surface was large and flat and the mano was worked back and forth. At the Sleeper Site, the average diameter of a complete mano was $93.7 \pm 17.6 \mathrm{~mm}$, with a thickness of $39.6 \pm 10.4 \mathrm{~mm}$. The size of the two complete specimens are at the upper range of the Sleeper Site with Lot 152 at a diameter of approximately 109 $\mathrm{mm}$. Lot 806 is larger at approximately $135 \mathrm{~mm}$ in diameter. The specimens are similar in average mean thickness at $39.06 \mathrm{~mm}$ (Table 51). Seven of the nine specimens were used on both faces and one specimen was used on both faces and an edge. All of the specimens are made from sandstone, with the river being the probable source.

\section{Metates $(N=4)$}

There are four metates and metate fragments recovered from the site. One specimen is complete and the other three are fragments. Three of the four specimens are limestone and the fourth is sandstone (Lot 777.1), illustrated in Figure 69. Lot 75.2 is a fractured specimen recovered from Feature 5 and has a ground depression when the fragments are reconstructed. The fracturing occurred from being heated. Specimen Lot 125.1 is a large limestone cobble with an insipient depression forming in the center that is $70 \mathrm{~mm}$ in diameter. The area is stained with possible organics. Lot 815 has an elongate ovalshaped depression approximately $300 \mathrm{~mm}$ in length and $120 \mathrm{~mm}$ across with the depression $13 \mathrm{~mm}$ deep at the center. Lot 777.1 is a radial medial fragment that tapers to $7 \mathrm{~mm}$ thick at one end from $30 \mathrm{~mm}$ at the edge. The specimen represents a tool exhausted from use that was subsequently heated. The mean thickness of metates from the Sleeper Site is $43 \pm 18$ $\mathrm{mm}$, and at the Gatlin Site the mean thickness is $59 \pm 27 \mathrm{~mm}$ (Table 52).

Table 50. Distribution of Ground Stone Artifact Class and Categories by Occupation Zone

\begin{tabular}{|c|c|c|c|c|c|c|c|c|}
\hline \multirow[b]{2}{*}{$\begin{array}{l}\text { Cultural } \\
\text { Horizon }\end{array}$} & & \multicolumn{6}{|c|}{ Category } & \multirow[b]{2}{*}{ Grand Tota } \\
\hline & & Hammerstone & Ind. & $\begin{array}{l}\text { Limestone } \\
\text { Cobble }\end{array}$ & Mano & Metate & $\begin{array}{l}\text { Nutting } \\
\text { Stone }\end{array}$ & \\
\hline Occupation Zone 1 & Groundstone & & 1 & & & & & 1 \\
\hline \multirow{2}{*}{ Occupation Zone 2} & Groundstone & & 1 & & & 1 & & 2 \\
\hline & Manuport & & & 1 & & & & 1 \\
\hline \multirow{2}{*}{ Occupation Zone 3} & Groundstone & 1 & 3 & & 3 & 1 & & 8 \\
\hline & Manuport & & 2 & 2 & & & & 4 \\
\hline \multirow{2}{*}{ Occupation Zone 4} & Groundstone & & & & 2 & 1 & & 3 \\
\hline & Manuport & & 1 & 1 & & & & 2 \\
\hline \multirow{2}{*}{ Unknown } & Groundstone & & & & 4 & 1 & 1 & 6 \\
\hline & Total & & & & 4 & 1 & 1 & 6 \\
\hline \multirow{3}{*}{ Total } & Groundstone & 1 & 5 & & 9 & 4 & 1 & 20 \\
\hline & Manuport & & 3 & 4 & & & & 7 \\
\hline & Total & 1 & 8 & 4 & 9 & 4 & 1 & 27 \\
\hline
\end{tabular}




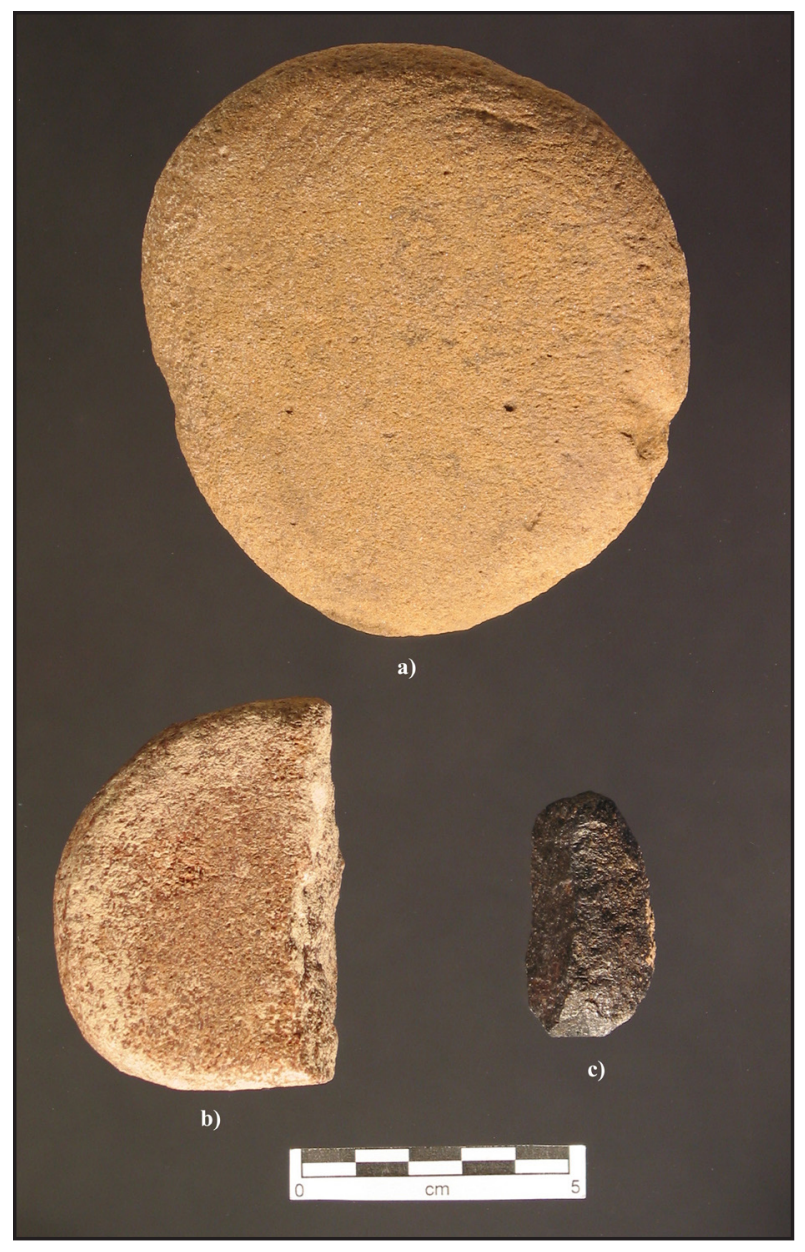

Figure 68. Manos, Lot numbers: a) 152; b) 659.8. Iron concretion, Lot number c) 395.1 .

\section{Limestone Cobbles (N=4)}

While these specimens may have been transported to the site, they exhibit no definitive signs of usewear function. These represent unaltered pieces of limestone some of unusual shape, although not rare. A cultural use for the specimens is unknown. Measurements from the specimens are in Table 53.

\section{INDETERMINATE $(\mathrm{n}=8)$}

These specimens represent fragments of unidentified larger specimens and unusual looking material. Lot 416 is a lozenge-shaped smoothed carbonate. The shape could be the result of weathering. A small iron concretion, Lot 395.1, shown in Figure 68 c, was collected as a possible ground stone perhaps for a palette. Examination of the surface facets found no indication of grinding. The visible slight smoothing could be naturally occurring. Measurements for these specimens are in Table 54.

\section{Nutting Stone $(N=1)$}

Specimen 1546.2 is a massive slab of limestone with a small area of depression, $130 \mathrm{~mm}$ by $90 \mathrm{~mm}$. The length of the slab is $580 \mathrm{~mm}$, width $360 \mathrm{~mm}$, thickness $120 \mathrm{~mm}$, and weight is $27 \mathrm{~kg}$. The pecked depression imay be an incipient depression for a grinding stone or bedrock mortar.

\section{HAMMERSTONE $(N=1)$}

Specimen Lot 300.5 is a hammerstone made from a tabular chert core fragment (Figure 70). The use end is heavily battered and step fractured. The specimen

Table 51. Measurements ( $\mathrm{mm})$ for Manos and Mano Fragments

\begin{tabular}{|c|l|r|r|r|r|}
\hline Cultural Horizon & \multicolumn{1}{|c|}{ Lot No. } & Max Length & Max Width & Max Thickness & \multicolumn{1}{c|}{ Weight } \\
\hline \multirow{4}{*}{ Occupation Zone 3 } & 659.8 & & 70.47 & 31.36 & 208.20 \\
\cline { 2 - 6 } & 731.2 & & & 28.22 & 59.30 \\
\cline { 2 - 6 } & 991.19 & & & 36.72 & 108.50 \\
\hline \multirow{3}{*}{ Occupation Zone 4 } & 1502 & & 80.30 & 33.27 & 178.80 \\
\cline { 2 - 6 } & 1569 & & 82.00 & 43.52 & 344.40 \\
\cline { 2 - 6 } & & & $\mathbf{8 2 . 0 0}$ & $\mathbf{4 3 . 5 2}$ & $\mathbf{3 4 4 . 4 0}$ \\
\hline \multirow{4}{*}{ N/A } & & 103.62 & 70.35 & 367.00 \\
\cline { 2 - 7 } & 1004 & & & 48.04 & 316.20 \\
\cline { 2 - 7 } & 152 & 109.43 & 108.97 & 26.33 & 346.30 \\
\cline { 2 - 7 } & 806 & 137.35 & 130.55 & 29.22 & 823.00 \\
\hline Mean & & $\mathbf{1 2 3 . 3 9}$ & $\mathbf{9 3 . 9 9}$ & $\mathbf{3 9 . 0 6}$ & $\mathbf{3 0 9 . 6 1}$ \\
\hline
\end{tabular}


is roughly spherical and is $42.34 \mathrm{~mm}$ across at the widest and it weighs $715 \mathrm{~g}$. This is one of the few identified hammerstone specimens at the Gatlin Site and represents part of the personal gear of visitor to the site. Although battering was noted on artifacts such as cores, there was no systematic recording of hammering damage. Angular core fragments, not

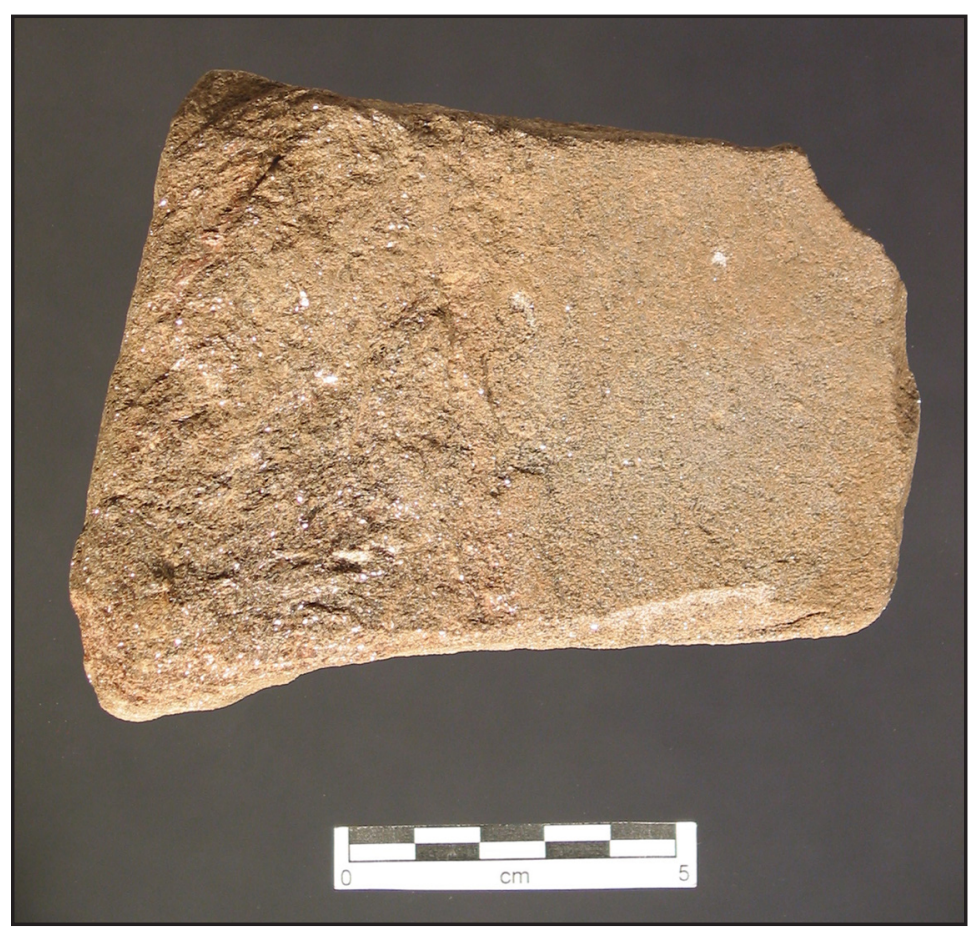

Figure 69. Metate fragment, Lot number 777.1. recovered or recognized may have been used as pecking and battery tools.

\section{SUMMARY OF NON-CHIPPED STONE TOOLS.}

Low number of manos, metates, and other ground stone tools were recovered from the Gatlin site. The presence of site furniture indicates that the site was repeatedly used, and represents a diversification of diet. Suitable local stone was available to make manos and metates, although no identification of materials was conducted on the assemblage or the raw material sources. The collection of unusually shaped limestone and other mineral manuports appear to be naturally occurring materials with little or no evidence of possible cultural modification.

\section{RAW MATERIAL}

The early inhabitants of the Gatlin site had access to numerous lithic raw materials in the surrounding landscape, one of the most abundant and extensive outcrops of chert in the United States - the Edwards Limestone Group (Frederick and Ringstaff 1994). Chert was readily available within the Guadalupe riverbed, within the Edwards limestone formation of the surrounding hills, and within Tertiary-aged

Table 52. Measurements ( $\mathrm{mm})$ for Metate and Metate Fragments

\begin{tabular}{|r|l|r|r|r|r|}
\hline \multicolumn{1}{|c|}{ Cultural Horizon } & \multicolumn{1}{|c|}{ Lot No. } & Max Length & \multicolumn{1}{c|}{ Max Width } & Max Thickness & \multicolumn{1}{c|}{ Weight } \\
\hline Occupation Zone 2 & 75.2 & 235.00 & 240.00 & 60.00 & 2200.00 \\
\hline Occupation Zone 3 & 777.1 & 122.38 & 96.18 & 30.07 & 486.00 \\
\hline Occupation Zone 4 & 815 & 310.00 & 185.00 & 50.00 & 3400.00 \\
\hline N/A & 125.1 & 215.00 & 205.00 & 95.00 & 3800.00 \\
\hline Mean & & $\mathbf{2 2 0 . 6 0}$ & $\mathbf{1 8 1 . 5 5}$ & $\mathbf{5 8 . 7 7}$ & $\mathbf{2 4 7 1 . 5 0}$ \\
\hline Std Dev. & $\mathbf{7 7 . 2 0}$ & $\mathbf{6 1 . 2 8}$ & $\mathbf{2 7 . 1 7}$ & $\mathbf{1 4 8 8 . 0 6}$ \\
\hline
\end{tabular}

Table 53. Measurements ( $\mathrm{mm})$ for Limestone Cobbles

\begin{tabular}{|c|c|c|c|c|c|}
\hline Cultural Horizon & Lot No. & Max Length & Max Width & Max Thickness & Weight \\
\hline Occupation Zone 2 & 309 & & 34.40 & 14.61 & 49.10 \\
\hline \multirow{2}{*}{ Occupation Zone 3} & 80.5 & 117.34 & 104.13 & 65.24 & 1142.00 \\
\hline & 87.8 & 117.80 & 117.51 & 63.24 & 1147.00 \\
\hline Occupation Zone 4 & 1373.6 & 113.07 & 26.59 & 12.07 & 53.50 \\
\hline Mean & & 116.07 & 70.66 & 38.79 & 597.90 \\
\hline
\end{tabular}


Table 54. Measurements ( $\mathrm{mm}$ ) for Indeterminate Specimens

\begin{tabular}{|c|c|c|c|c|c|}
\hline Cultural Horizon & Lot No. & Max Length & Max Width & Max Thickness & Weight \\
\hline Occupation Zone 1 & 395.1 & 44.85 & 22.48 & 22.06 & 52.80 \\
\hline Occupation Zone 2 & 416 & 78.87 & 28.48 & 6.89 & 17.30 \\
\hline \multirow{5}{*}{ Occupation Zone 3} & 1224.9 & 193.25 & 59.19 & 24.81 & 401.10 \\
\hline & 413 & & & & 33.20 \\
\hline & 562.3 & & & & 18.00 \\
\hline & 718.13 & 72.70 & 54.28 & 24.74 & 125.30 \\
\hline & 737.5 & & & & 52.50 \\
\hline Occupation Zone 4 & 1382.5 & & & 6.60 & 9.40 \\
\hline Mean & & 97.42 & 41.11 & 17.02 & 88.70 \\
\hline
\end{tabular}

lag gravel deposits in upland settings. Samples of unmodified chert from the first two of these localities were available and were collected as part of this data requirement. Attributes of these chert samples such as color, texture, and cortex type (e.g., rounded, tabular, weathered) were compared with the Gatlin site stone artifact assemblage to ascertain prehistoric raw material procurement behaviors.

To investigate questions regarding prehistoric lithic procurement behaviors at the Gatlin site, raw material specimens were collected from natural chert outcrops in various regional landforms. These specimens were then used in comparison with the Gatlin site's artifact specimens. During the testing and data recovery, excavators noted several different forms of exterior cortex on primary flakes, cores, and unmodified raw materials. Examples of rounded, tabular, weathered, and nodular cortex types were observed throughout the assemblage, and colors differed between cortex types. The study of the raw materials therefore began with the hypothesis that cortex and color would be good diagnostic indicators for identifying non-local chert specimens and determining from which landforms chert was more frequently procured. It was hoped that this information could also indicate which chert varieties were preferred for stone tool making or were selected for heat treatment.

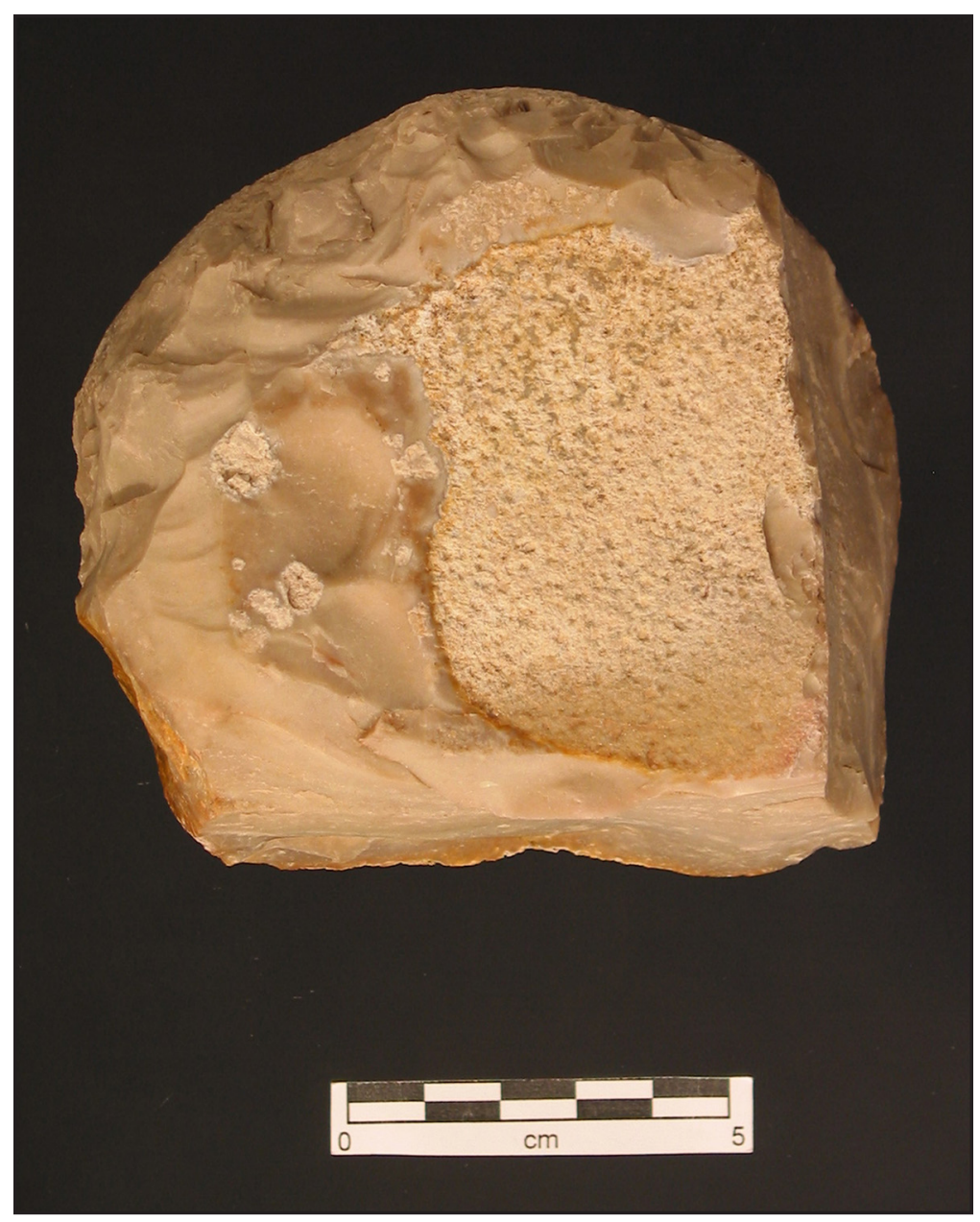

Figure 70. Hammerstone from chert core fragment, Lot number 300.5 . 
tent with the variety of types and colors of Edwards cherts. This is an observational analysis and is not presented numerically, in part because of the varying recording attributes for the chert. It is possible, given the large size ( $>150,000$ pieces) of the lithic assemblage that some exotic or non-local material may be present and was brought to the site. Because of the lack of observed non-local chert at the Gatlin site, it is also possible that that the majority of chert artifacts from the Gatlin site are made from Edwards cherts, and also likely that the raw material used for cores and bifaces was procured in the immediate vicinity of the Gatlin site. The variability in chert colors

The almost exclusive use of locally occurring or available material for both formal and informal tools suggests that there were abundant quantities of high quality chert, and that it was a significant resource that was used throughout all of the occupations at the Gatlin site.

\section{Burned Rock Technology}

In addition to the technology expressed by individual artifacts, technology is expressed in features, which are remnants of discrete cultural activities. These types of features include cooking and heating features containing rocks and accumulations of lithic material associated with tool manufacturing.

The use of heated rocks is a technological adaptation allowing a greater range of food resources to be utilized, such as geophytes that include lily bulbs, or Camassia sp. Other plants include sotol and lechiguilla. These types of resources need long periods of sustained heat to make them edible, the type of heat generated in buried earth ovens.

Hot rocks were also used as direct cooking elements, where food was placed directly on the hot rock surface. Rocks could also be used as boiling stones, where hot rocks were added to a container. The way in which rocks were used for heating elements can be informative about the foods being processed and consumed for subsistence (Black et al. 1997). The size and quantity of heating features contains information about group size and group composition.

As discussed within Chapter 5, burned rock features are ubiquitous throughout central Texas. While these can represent a wide array of cultural activities or technological processes (Ellis 1997:48-50), the most commonly recognized purpose of such features is for cooking technologies and food processing. Such technologies take advantage of the thermal qualities of rock to store and slowly release heat, thereby providing better control over the cooking process and reducing the amount of necessary fuel (Ellis 1997:47; Black 2003:380). The number of specific cooking techniques (e.g., smoking, grilling, boiling, baking) is seemingly boundless (see Ellis 1997), and many of these produce similar archaeological signatures. Yet while some types of burned rock cooking features may be more formal than others (e.g., those incorporating dug pits, basins, or slab-lined walls), all essentially represent variants of a single technological theme: the use of heated rock as an underlying thermal element, which, in most cases, was heated over flame and then covered by a layer (or layers) of earth, vegetal matter, or additional heated rocks (Black 2003:382). As both Ellis (1997) and Black (2003:380) point out, however, such thermal elements could also be used, uncovered, to roast, broil, or parch certain food types.

The Gatlin site investigations documented a total of 37 features. Five of these were recorded within the testing phase, and the remaining 32 were discovered during the course of the data recovery excavations. Of the features encountered during testing, only Feature 1, the burned rock midden, was further investigated during data recovery. Thirty-one of the site's features were composed of burned rock. These ranged from dense concentrations, such as the midden, to somewhat diffuse scatters, with the majority constituting relatively discrete clusters of varying sizes. The six remaining features were two concentrations of lithic debitage; two clusters of debitage, small pebbles, and fire-cracked rock; a small area of burned organic material; and fragments of a human skull. When possible, the features were assigned to the four identified Occupation Zones on the basis of radiocarbon dates, geological strata, and associated diagnostic artifacts.

During the testing phase of investigations at the Gatlin site, features were most often recognized during the course of trenching, which consequently impacted these features and limited the identification of exact feature morphology and artifact associations. The test units placed to investigate such fea- 
tures provided, in most cases, only limited horizontal exposures. During the data recovery phase, features exposed during trenching or Gradall stripping were defined using hand excavation methods. The majority of the data recovery features were identified during the course of systematic excavations and excavated in their entirety. However, due to the spatial constraints of the defined excavation blocks, some of the features extended into unit walls and were not pursued further.

SWCA's excavation of the Gatlin site's features incorporated systematic excavation techniques (Collins and Ricklis 1994; Black et al. 1997) within a robust recording, treatment, and sampling plan (Houk and Miller 2004a). This included the recovery of fine matrix, coarse matrix, and non-matrix samples, as well as the recording of the size, weights, and positions of clusters of burned rock. The association of rocks with features was based on perceived rock clustering, and, as such, was necessarily somewhat subjective. Counts and weights of the features therefore include all of the specimens considered to compose the feature. When two relatively distinct yet presumably linked concentrations (e.g., Feature 8) were recorded, the component stones were counted, weighed, and noted separately. In cases where the scattered stones were strongly suggested to be part of the main feature (e.g., Feature 22), the combined numbers and weights were taken, thus reflecting the original totals. For the site's burned rock features, field observations were also made regarding differences in feature size and rock composition within and between cultural components.

Additionally, counts, sizes, and weights were obtained for non-feature burned rock from most of the individual levels as well. These were used to examine the density of burned rock activities across the site and for comparison of burned rock size between nonfeature and feature contexts. It was presumed that, if the non-feature burned rock represented stones that had been discarded as too small for reuse within features, then the average weight of such stones would be considerably lower than that of burned rocks from feature contexts.

The analysis of feature form was based almost exclusively on observations, photographs, and drawings made during the excavations. Due to the homogeneous nature of the soils within most feature contexts, actual outlines of possible pit basins could not be clearly defined. Rather, these were, when possible, observed in profile or inferred by the bottom elevations of each feature's lowest course of stones. Feature chronology was determined by the dating of carbon (when available) or bulk matrix samples, by association with diagnostic point types, and by the relative positioning of features in regards to one another and the surrounding soil strata. Feature function was evaluated by analyzing data made available by the processing of a variety of special samples including macrofaunal and macrofloral remains, pollen/phytoliths, lipid residues, and the flotation of bulk matrix (Appendices E through I). Function was also evaluated based on the other artifacts associated with individual features and through comparison to features from other sites. This evidence was used to determine where particular foci of activities were located, as well as the cultural formation processes that resulted in the use and/or discard of burned rocks.

\section{Explanation of FEATURE DESCRIPTIONS}

Full descriptions of the Gatlin site's features are found by occupation zone in Chapters 8-11, each accompanied by a table providing basic information on provenience, context, morphology, the results of radiocarbon and other special samples, and artifact associations.

Of the Gatlin site's 37 features, 31 (84 percent) are composed primarily of burned rock. These ranged in size from the approximately 18 x $18-\mathrm{m}$ burned rock midden to small concentrations of burned rock less than $0.5 \mathrm{~m}$ in diameter. Burned rock features are classified as clusters or scatters, based upon the density and association of burned rock in a defined area. Within these broad categories, features were classed as large or small. The burned rock midden (Feature 1) has its own analytical category.

\section{Burned Rock Clusters and Scatters}

Due to the lack of visibly oxidized soils and other definitive markers within the majority of the Gatlin site's features, most-following Mahoney et al.'s (2003) categories (see Chapter 5) — qualify simply as burned rock clusters and burned rock scatters. These broad classes can cover a wide range of technological signatures, including the thermal elements of earth ovens, discard piles, clean-out piles, boiling stone dumps, or simply random clusters of stone (Black 
2003:378). At the Gatlin site, a further distinction has been made within these basic descriptions; the term "burned rock cluster" here applies to groupings of burned rock generally greater than $1 \mathrm{~m}$ in diameter, while those clusters smaller than $1 \mathrm{~m}$ in diameter are described as "small burned rock clusters."

However, the discrete nature of the majority of the features at the Gatlin site and the prepared surfaces of several suggest that many fall under Black's (2003:378) more inclusive and functional classification of hearths or ovens, depending on size. Black (2003:383-384) terms as hearths those burned rock features measuring less than $1 \mathrm{~m}$ in diameter, while those greater than $1 \mathrm{~m}$ are given the rubric of "oven." While essentially the same technologically, the size of the features may reflect a difference in usage and purpose. Black (2003:383) argues that almost all burned rock cooking features over $1 \mathrm{~m}$ in diameter were intended as specialized earth ovens "where otherwise inedible plants, mainly roots/bulbs/bases (collectively, geophytes), were prepared." In contrast, the smaller rock hearths could be used for a variety of purposes, including the cooking of various plants or animals in smaller batches that required less effort and shorter cooking times (Black 2003:384). Indeed, Black views these smaller hearths as representing ordinary domestic features, which may have been associated with housing structures.

\section{SMall BuRned Rock Clusters}

Fifteen of the Gatlin site's features appear to fit the category of small hearth. An additional feature, Feature 34, may also be included within this group, as it comprised three separate clusters of burned rock that were found in close proximity; though they were recorded together, each appears to be a fairly tight cluster and may represent a separate hearth. For the most part, the small hearths at the Gatlin site are discrete, round or oval clusters of burned rocks, averaging about $60-70 \mathrm{~cm}$ in diameter. Most appeared relatively informal, with only three displaying a noticeable dip in central elevations, suggesting that they were constructed within shallow, prepared basins. In contrast to the other small burned rock features, Feature 20 appeared more formal in composition, having a distinct basin lined with relatively flat stones. Small burned rock clusters were associated with all of the recognized cultural horizons at the Gatlin site, and, with the exception of Feature
20 , do not appear to have varied greatly in form or function with time.

The sizes of rocks within these features varied, but the majority was mixed fairly evenly between 5 and $15 \mathrm{~cm}$ in length. The small size of these features was also reflected in their weight, with the total weight of burned rock in the majority $(n=9)$ falling between 9 and $18 \mathrm{~kg}$; most of the remaining examples weighed far less (in some cases due to partial excavation). The exception to this was Feature 21, measuring $80 \mathrm{~cm}$ at its greatest extent and weighing $29.4 \mathrm{~kg}$; because this feature extended into the block wall and was not excavated completely, it is quite probable that it was originally larger than $1 \mathrm{~m}$ in diameter.

In general, the Gatlin site's small burned rock clusters most likely represent small rock hearths of single or short-duration use. The angular nature of many of the stones suggests that they may have been reused within multiple cooking episodes, although they are still, on average, larger in size than the majority of burned rocks found outside of features.

It must be noted that of the burned rock clusters, two smaller clusters, Features 9 and 10, and a slightly larger one, Feature 22, displayed a rather distinct form not evidenced in other features at the Gatlin site. These features were relatively ring-like in shape, with loose scatters of burned rock extending away from the center in a relatively straight line. These associated scatters are interpreted to be the remains of an upper layer of burned rock, or "lid," whose dismantling was required to remove the processed food from within (Black et al. 1997). Only Feature 10 exhibited evidence of a slight basin shape, while the other two were constructed on relatively level surfaces. The centers of all three features were devoid of burned rocks, suggesting that whatever foodstuff was being processed was placed directly on the earth, or possibly atop a layer of perishable material, and then covered with a pile of heated stones. The dispersed nature of the scatter and their relative length (between 70 and $130 \mathrm{~cm}$ ) could suggest that the top layers of the features were dismantled quickly, while still warm or hot, to get to the food within. What exactly that may have been is unclear, although a single lipid sample from Feature 22 suggested that possibly mesquite, corn, or fish were processed in the feature; given the site's setting, the last of these would not be surprising. The "corn" interpretation 
can be disregarded, and is reported by the analyst because of the similar lipid signatures to mesquite and fish. Interestingly, the rock scatters from all three features were oriented in almost exactly the same direction, to the southeast, despite the range of time between them; while the smaller features both produced dates associated with the Late Archaic period, charcoal from Feature 22 dated to the upper Early Archaic.

\section{BURNED Rock CLUSTERS}

The category of larger burned rock clusters, includes Features 3, 6, 7, 8, 13, 16/17, 22, 25, and 26. These occurred primarily within OZ2, and in OZ3 and OZ4, but not OZ1.

Only Feature 7 appeared rather formal in construction, consisting of a semi-circular stone-lined basin. Measuring approximately $140 \times 80 \mathrm{~cm}$, the feature was truncated during the machine stripping of Area A and would originally have been larger. Due to its size and more substantial nature, Feature 7 most likely represents an earth oven intended for larger-scale and more intensive processing of plant foods.

In contrast, the majority of the larger burned rock clusters presented relatively flat accumulations of burned rock. With the exception of Feature 6, which was slightly basin-shaped in profile, these appeared to have been constructed on level surfaces. Most consisted of rather compact accumulations of rock with some slight layering of stone, primarily near their centers. These tended to be vaguely circular or oval, typically measuring between 1 and $2 \mathrm{~m}$ in diameter, with only one (Feature 25) measuring more than $4 \mathrm{~m}$ in length and less than $1 \mathrm{~m}$ in width. Two (Features 13 and 25) displayed some irregular voids of rock, which may reflect the later borrowing of stones for use in other features.

In general, however, most of these clusters resemble what Johnson (1991:49-51) has termed at the Sleeper site "baking heaps." These are defined as relatively flat rock piles built on a level ground surface, on top of which a fire was built directly. Once the fire had burned down, the ash and charcoal were swept away and the food placed directly among the rocks, possibly covered with vegetal matter or earth to hold in the heat (Johnson 1991:49). Unfortunately, due to the state of preservation, the fine matrices of most of the Gatlin site's features were undifferentiated from the surrounding soils, with only some carbon flecking throughout; as a result, it is difficult to distinguish whether these features represent ovens, with the heat source beneath, or "baking" surfaces, with the fire built directly on the rock. Only Feature 13 produced large amounts of carbon, and these were found above, within, and below the feature; this would appear to suggest that the fire was built on top of the feature, with the carbon subsequently filtering down between the stones.

Three of these larger clusters, Features 6, 16/17, and 25 , each consisted of burned rock weighing a combined total of more than $140 \mathrm{~kg}$. The weighed rock of Feature 3, which was only partially recorded due to truncation by BHT 5, totaled over $100 \mathrm{~kg}$. In contrast, the other features were substantially smaller, ranging between approximately 40 and 60 $\mathrm{kg}$. In general, the component stones of these features were not significantly larger than those of the smaller burned rock clusters; although, burned rocks greater than $15 \mathrm{~cm}$ in length did form large portions of Features 3, 25, and 26.

\section{Partially Exposed Clusters}

Features 2, 4, and 5 have been loosely defined as burned rock clusters, but this is mainly due to a lack of evidence for a more secure identification. These features were recognized during the testing excavations but were not fully excavated. As such, their original shape and dimensions are only speculation, although the observed portions appeared to be resting on rather level surfaces.

\section{BURNED ROCK SCATTERS}

Two features (Features 15 and 19) have been described simply as burned rock scatters due to their amorphous shapes and lack of obvious structure. While Feature 15 may represent the remains of a dispersed hearth, Feature 19 appears to be somewhat more substantial. Extending within the unexcavated block walls, the feature covered an area of approximately $5 \mathrm{~m}^{2}$ and consisted of over $170 \mathrm{~kg}$ of burned rock. This may represent an incipient midden, which incorporated the remains of multiple overlapping features. 


\section{Burned Rock Midden}

The burned rock midden, Feature 1, was not a primary focus of the Gatlin Site investigations yet informative data was gained through select trenching and hand excavations (see Chapter 11 OZ4 for full discussion of this feature). The complex use life of middens makes it difficult to identify discrete occupation zones and this was true in the case of the Gatlin site. On a slowly aggrading or stable surface, the formation of the midden can occur over hundreds or even thousands of years, evidence of which is the chronological range of projectile points recovered from the matrix.

\section{Feature Material}

With few exceptions, the site's burned rock features were composed exclusively of limestone. Only one piece of sandstone and five pieces of non-debitage chert were recorded within feature contexts. Given the abundance of chert at the site, it is just as likely that these represent chance additions to the matrix rather than deliberate elements of feature construction. The use of limestone for the Gatlin site's features is hardly surprising considering its relative abundance within the surrounding hills and the nearby river. Additionally, limestone has long been recognized for its ability to absorb and retain heat reasonably well, and, in central Texas, for its relative superiority as a reusable thermal storage material (Black 2003:397). Indeed, these qualities make it an ideal component for thermal elements within earth ovens. In contrast, limestone is relatively vulnerable to quicker fragmentation when exposed to rapid cooling, such as the heating/dowsing episodes associated with stone boiling activities (Ellis 1997:54). Quartzites and cherts are more resistant to such fracturing and can thus be reused more often (Ellis 1997:54). However, no such concentrations of these stones were found at the Gatlin site, suggesting that stone boiling was not a technique utilized at the site, at least within the portions excavated.

\section{Feature Fuels}

Of the 15 features from which identifiable carbonized wood samples were obtained (see Appendix F for the full results of the macrobotanical analysis), 12 contained evidence of live oak. These features span almost the entire period of occupation at the
Gatlin site, with the exception of OZ1, which may be related to preservation. Forming 60 percent of the total collected samples and 79 percent of the identifiable specimens, live oak was the predominantly recognized type. However, as noted by Bush (Appendix F), live oak is probably overrepresented in the archaeological record at the Gatlin site due to its inherent density and the toughness and durability of its charcoal.

Juniper, was the second most common identifiable wood (8.5 percent of the total; 11.1 percent of the identifiable samples), and was recognized primarily in Feature 13 (70 percent), with the remaining samples occurring in three separate units within Feature 1 , the burned rock midden. Therefore, juniper is represented at the site within contexts ranging from OZ2 through OZ4. As Bush states (Appendix F), due to their susceptibility to fire and their slow regeneration, juniper may have been a relative rarity.

Wood from other species was present in relatively isolated examples. Carbon from an unknown liana or wood vine, along with samples of an indeterminable hardwood, was found within Feature 38. Feature 33 contained not only live oak and other indeterminable hardwoods, but elm/mulberry as well. Only Feature 2 , which contained live oak, also contained madrone. An ethnographic example of using madrone was noted by Bush (Appendix F): it was used by the Tepehuan as a protective layer when cooking sotol in earth ovens (Cheatham, et al. 1995:433). These woods, like live oak, are also common within the vicinity of the Guadalupe River today.

Feature 1, the burned rock midden, was in use throughout the Middle and Late Archaic and would have required vast amounts of fuel. Various units placed throughout the midden produced numerous specimens, predominant among them being live oak, followed by juniper, holly, and elm/mulberry. Nineteen additional samples were indeterminable, with the majority identified at least as hardwoods.

\section{Organic Remains}

Organic remains were recovered from the matrix within features and consisted of faunal and botanical remains. In addition, burned rock specimens were analyzed for the presence of lipid residues to 
determine what types of foods were being cooked (Appendix H). The lipids are the remnant chemical signature of fats trapped within the surface of heated rocks as they cool. Different fats are associated with different plants and animals. The plants that animals consume determine the lipid signature that remains when that animal is subsequently cooked. Within the small rock hearths at the Gatlin site, 12 features produced evidence of faunal remains in or immediately surrounding the feature, most of which were unidentifiable. Only Feature 34 contained relatively high amounts of identifiable bone, which included white-tailed deer, bison, and the remains of a small mammal. Three of the small rock hearths (Features 12,28 , and 38) yielded carbonized walnut shells, with burned rocks from two of these (Features 12 and 28) also yielding lipid samples indicating high or very high fat content foods such as seeds or animal fats. Similar results came from Feature 37, while Features 14, 34, and 36 showed evidence of moderate to high fat content foods.

\section{Non-Feature Burned Rock}

Although relatively obvious, it is important to note that copious amounts of burned rock were present within the excavation blocks that could not be firmly identified as, or with, features. Although the exact type of stone was not explicitly noted in every case, the overwhelming majority was limestone, with few other stone types recognized other than chert. Clearly, these stones were deliberately brought to the site and then altered (i.e., burned) by human agency. For this reason, the density of non-feature burned rock at the site is significant. These burned rocks may represent the possible debris of lids removed from cooking features or, more likely, the discarded components of previous features at the site that were deemed too small or fragmented to be reused. Indeed, a comparison of the average weights of feature versus non-feature rocks (total weights divided by total numbers per component) shows the component stones of features are typically between two to four (or greater) times larger than burned rocks from non-feature contexts. 
106 Appendix C 


\title{
APPENDIX K
}

\section{EVALUTION OF PROJECT METHODOLOGY}

\author{
BRETT A. HOUK, ERIC R. OKSANEN, \\ AND KEVIN A. MILLER \\ SWCA ENVIRONMENTAL CONSULTANTS
}





\section{APPENDIX K: EVALUATING THE PROJECT'S METHODOLOGY}

As we noted in the research design (Chapter 5), it is the responsibility of archaeologists as scientists to describe not only their data, but also how they collected that data so that others may evaluate the legitimacy of their conclusions. Beyond the resource being investigated - the nature of which is beyond the archaeologist's control-two factors primarily influence the quality of archaeological data: the pre-field plan or scope-of-work and the way in which that plan is implemented. As an element of the research design for the Gatlin data recovery investigations, SWCA proposed a research domain specifically aimed at critically examining the methodology proposed for the Gatlin site and the manner in which it was executed in the field. The goal of this exercise is to highlight strengths and weaknesses in the approach to benefit future investigators.

The field methodology employed during the data recovery phase at the Gatlin site was novel, at least for Central Texas, and represents something of a compromise between traditional excavation methodologies and a desire to expose a large horizontal area. The events leading up to the data recovery excavations-including the timeframe in which the survey and testing were performed and the pre-survey expectations-influenced the preliminary assessment of the site, which in turn directed the data recovery excavations toward certain research issues and away from others. Therefore, this appendix considers the effectiveness, strengths, and limitations of data recovery field methods in the context of the Gatlin site investigations as a whole, from pre-survey expectations to post-fieldwork analysis.

The research design (Chapter 5) proposed a series of questions regarding the project's methodology, and this appendix considers each question separately. The questions can largely be grouped into the following categories: scheduling-related questions and methodological questions. To address the questions, 1) a project narrative was written, which outlined when and why certain steps were taken in the field, 2) elements of the original scope of work that either did not work or had to be modified were identified and assessed, and 3 ) the project supervisory personnel made an objective review of the methods and data to identify how the methodology affected the quality of the data and the validity of the resulting interpretations, as related to the other five research domains.

The research questions were proposed shortly after the fieldwork had been completed and prior to beginning any detailed artifact or sample analysis. Therefore, they reflect concerns or problems identified during the fieldwork and anticipated during the subsequent analysis.

\section{SCHEDULING RELATED QUESTIONS}

Three question generally related to scheduling issues were proposed for the research domain. They are:

- Did the fact that survey and testing were planned together prior to any investigations adversely affect the testing phase?

- What effect did the project schedule, from survey to data recovery, have on the methods and excavations?

- How much did weather affect the excavations, and how could that effect have been minimized?

The first two questions require a summary of the project schedule before answering. The project proceeded from the beginning under somewhat unusual circumstances, which affected the methodology for survey, testing, and data recovery. The main factor driving the scheduling of all phases of the investigations was a fall/winter 2004 letting date for the construction project. That more or less inflexible date, at least from SWCA's point of view, marked the end point for all stages of fieldwork. Delays at each stage of the archaeological work, therefore, resulted in a compression of the archaeological research timeframe, not delays in the San Antonio District's construction schedule.

Nearly four years prior to SWCA's involvement in the Spur 98 project, TxDOT archaeologists had conducted geoarchaeological investigations along a portion of the proposed right-of-way. During those investigations they noted "a shallow (approx. $1 \mathrm{~m}$ ) trench had been opened across the T1 terrace surface by the landowner, revealing burned rock and flakes associated with a dark, 
mollic epipedon" and recovered evidence from geoarchaeological cores that "multiple components may be represented in the archaeological strata" (Abbott, Appendix A). Therefore, TxDOT archaeologists had reason to believe that an archaeological site was present in the proposed right of way but did not record it because it was located on private property for which limited right of entry had been granted. The impression that a stratified and extensive archaeological site was located across the project right of way affected the project planning from the beginning.

Although SWCA entered preliminary discussions with TxDOT about the proposed extension of Spur 98 as early as the fall of 2003, various factors delayed the initial archaeological survey until May 2004 (Table J-1). Since the letting date was fixed, the available window in which to conduct the survey was rapidly closing. As the survey would presumably result in the discovery of the site noted by TxDOT archaeologists in 2000 , the opportunity for subsequent phases of research was also quickly evaporating. Thus, it was decided that the initial work authorization and Texas Antiquities permit application would include an intensive survey of the right-of-way and limited testing investigations; this would eliminate the need to prepare a survey report and research design for testing prior conducting the anticipated second phase of investigations. Additionally, it was decided that the survey of the southern half of the APE would greatly exceed the THC's minimum survey standards because of the anticipated discovery of a stratified site. SWCA proposed and implemented a systematic auger-testing program combined with backhoe trenching for the southern half of the APE and a backhoe trenching survey for the northern half.

SWCA conducted survey and testing between May 17 and June 26, and submitted an interim report to TxDOT on July 19, 2004. The interim report process included characterizing the deposits at 41KR621 and 41KR622, but did not include any detailed artifact analyses or special sample processing other than limited radiocarbon analysis. The initial research design for data recovery was prepared subsequently, based on the preliminary results of survey and testing (see Table J-1). After a series of negotiations with TxDOT, SWCA proposed a methodology for investigating the Gatlin site that was designed to maximize the collection of data relevant to the various research issues outlined in the initial research design (Houk and Miller 2004b). The preliminary research design, which was used throughout the data recovery fieldwork, was submitted to TxDOT on August 25, 2004.

Data recovery excavations were initiated on September 9, 2004, and completed on November 26,2004 . SWCA prepared an interim report on the investigations and submitted it to TxDOT on February 25, 2005. A final research design was then prepared and delivered to TxDOT on April 25,2005 . TxDOT's comments on the research design were dated May 24, 2005, and were incorporated by reference into SWCA's final research design.

The compressed timeframe in which SWCA and TxDOT archaeologists operated put stress on each aspect of the investigations. The two steps of the project which were most affected detrimentally were the testing investigations of 41KR621 and the preparation of the initial research design prior to data recovery. While the plan to include survey and testing under the same work authorization and permit application definitely facilitated SWCA's completing the initial evaluation of the site quickly, there was no time to process the survey data and ponder an effective testing plan. Rather, a previously determined number of cubic meters of site deposits to be tested was placed on backhoe trenches opened during survey with a generic research design in place, which basically focused on potential data yield and integrity. In hindsight, a more robust testing plan should have been implemented, perhaps doubling the amount of excavations conducted prior to developing a data recovery plan.

The compressed time frame's greatest effect, however, was on the initial research design, which SWCA prepared within a few weeks of submitting the testing interim report. With no detailed artifact analysis having been conducted and no time to conduct extensive background research into useful or novel research questions, SWCA prepared a preliminary research design, which in turn was influenced by the assumptions made based on the limited testing data. 
In summary, to answer the first two questions, it is clear that planning the testing phase prior to the site identification phase adversely affected the testing investigations and the hastily developed data recovery excavation methodology. Undoubtedly, more time to ruminate over the survey results would have allowed SWCA to develop a more appropriate and thorough testing program for 41KR621. Such a program would likely have resulted in a more accurate characterization of the site's deposits, which would have in turn aided in the preparation of the data recovery plan.

The data recovery plan was predicated on the conclusion that there was an extensive Early Archaic residential base camp at the site, stratigraphically isolable from the overlying deposits. This conclusion was based on limited testing data and no artifact analysis. Additional testing would have shown the deposit to be less discrete than believed, and artifact analysis would have suggested the site was perhaps a repeatedly occupied short-term hunting camp rather than a residential base camp. Had the latter conclusion been made, the subsequent data recovery plan would have been radically different. A primary expectation was that a large Early Archaic residential base camp offered an excellent opportunity to examine the use of space at such a site and to perhaps locate evidence of a structure. Given those expectations, SWCA's excavations were designed to expose large horizontal areas at the expense of other data. As the data recovery analysis shows, the underlying assumption that the site was a base camp, appears to be false.

The third scheduling-related question involved the effects of weather on the excavations. Given the length of the data recovery project and the season in which it was conducted, it is remarkable that weather did not affect the excavations to a greater degree. During testing, SWCA learned that during heavy rains tremendous amounts of water would run onto the site from the neighborhood on the hill to the south, and steps were taken to prevent the excavation block from being flooded by runoff. However, despite the precautions, one severe rainstorm near the end of the project flooded the units, particularly Area B, and a pump was needed to drain the areas being excavated. However, weather remains an unpredictable variable in any excavation project. Fortunately, the effects of weather on the Gatlin site data recovery project were minor, and it is not likely that they could have been minimized further.

\section{METHODOLOGICAL QUESTIONS}

From the survey to the data recovery, SWCA utilized an innovative methodology to meet the requirements of the project in the restricted time frame of operation. The primary departure from standard operating procedure at the survey level was an intensive and systematic auger test survey, and the first methodological questions posed in the research design dealt specifically with the effectiveness of the auger testing:

- How effective was auger testing as a survey method? How do the auger test results compare to the backhoe trench data?

\section{Auger Testing}

The first question is related to the survey of the southern approach; auger testing was the method proposed to investigate quickly and intensively the terrace of the river where TxDOT anticipated discovering a buried archaeological site. At the time of the survey, the southern approach was a grassy pasture with no indication of an archaeological site visible on the surface. SWCA established a metric grid and excavated auger tests at 10-m intervals across the APE. Ultimately 106 auger tests were excavated. As is described in Chapter 4, the auger testing was successful in identifying a buried archaeological site extending over almost the entire southern approach from the base of the upland slope to the scarp above the river. Artifact counts in the auger tests were generally very low, a reflection of the fact that the auger created large chunks of matrix that could not be screened. It was necessary to break the chunks of soil by hand and then visually inspect the matrix for artifacts. Therefore, the density of cultural material indicated by the auger tests is not an accurate reflection of the amount of cultural material actually present in the area of the test. This is illustrated in Table Appendix J-2, which compares column sample data from backhoe trenches to auger test data within $5 \mathrm{~m}$ of the trench. Although each excavation area is unique, 
the table shows that in most cases the amount of debitage observed in auger tests is substantially lower than the amount collected from nearby backhoe trench column samples, which were excavated and screened in 20-cm levels. Burned rock quantities are much more comparable, because most burned rock was clearly visible in both auger tests and column samples without screening.

Another factor that must be considered in auger testing is the near total lack of vertical control over the depth of recovered cultural material. Despite efforts in the field to identify the depth from which artifactual material was coming, it was usually not possible to be precise because of the manner in which the auger brings up the excavated matrix. Column sampling off backhoe trenches or even shovel testing offers far more vertical control over the provenience of cultural material.

Auger testing, however, proved extremely effective in locating the buried deposits of 41KR621, including the burned rock midden at the site, which was not visible on the surface. As such, it is an extremely efficient site discovery tool. It fails, however, as a method of evaluating site structure or integrity. Therefore, auger testing at this level of investigation should be supplemented with controlled vertical excavations, such as column samples, shovel tests, or test units, to assess more fully the nature of the discovered cultural deposits.

\section{DATA RECOVERY METHODOLOGY}

The data recovery field methods included backhoe trenching, mechanical stripping, and hand excavations. These methods were utilized in this particular order to identify the relevant cultural components, remove non-sensitive deposits, and to investigate the targeted materials. At the heart of the methodology was a series of compromises, three more significant than others. First, assumptions were made about the nature of the younger deposits away from the midden, and large portions of the post-Early Archaic materials were mechanically removed with only minimal documentation. Second, within Area A, which targeted the Early Archaic component, artifact recovery was minimized in favor of maximizing the amount of horizontal exposure; this was accomplished through the use of "Feature
Focused" units, which were not screened unless a feature was encountered. Third, investigations of the burned rock midden were minimized, and greater attention was paid to the midden-related components in Area B.

The concept of Feature Focused units, which is something of a misnomer as it turns out, developed during conversations between SWCA and TxDOT in late August 2004, only a few weeks before the data recovery began. In part, the initial research design focused on determining associations between features by opening up broad exposures to get a wide view of the range of contemporary behaviors occurring on the site. In particular, one research question asked, "Can the possible locations of structures be inferred through the distribution of features, artifacts, and negative space?" To address this issue, TxDOT recommended that SWCA consider alternative excavation methods rather than the 1-x-1-m unit approach so commonly employed in Central Texas. From these discussions arose the concept of a Feature Focused unit. As envisioned, approximately 50 percent of the excavations in Area A of the site would not require matrix screening, unless a feature were discovered. As implemented, SWCA decided to intersperse 2-x-2$\mathrm{m}$ feature focused units with 2-x-2-m Traditional Units, which were screened and excavated in 1-x1-m quadrants, in a checkerboard pattern across Area A. Because this approach was developed quickly and had not been field tested, it was unknown exactly what the results would be.

Many of the original methodological research questions relate to the uncertainty over the strengths and weakness of the Feature Focused approach. The remaining questions are:

- How and why did the proposed methodology change during implementation?

- Did the use of Feature Focused units create data gaps that adversely affected the understanding and interpretation of the Early Archaic component?

- Did the use of 2-x-2-m units excavated in quadrants offer any apparent benefits over 1-x-1-m units?

- Were the field forms and recording procedures adequate and appropriate? 
- What factors played a part in the decisionmaking process related to where excavation units were placed?

\section{Changes to Methodology}

The most significant change to the project methodology involved feature sampling. An element of the original data recovery plan called for special microfauna recovery procedures to be implemented in approximately 25 percent of the features. The plan was to establish a cruciform of $50-\mathrm{x}-50-\mathrm{cm}$ blocks extending $2 \mathrm{~m}$ in the grid's cardinal directions over each feature to be sampled. The matrix (approximately $2-\mathrm{cm}$ thick) from the $50-\mathrm{x}-50-\mathrm{cm}$ blocks was to be collected for wet screening through fine mesh in the laboratory to look for microfauna. These data were to be used to examine use and discard patterns among the features. While there is little doubt that implementing this would have been useful, in the field it proved extremely problematic because of the excavation methodology. The combination of Feature Focused units checker boarded with Traditional Units, and the procedure of excavating Traditional Units in 1-x-1-m quadrants, usually meant that much of the area to be sampled by the cruciform of $50-\mathrm{x}-50-\mathrm{cm}$ blocks had been excavated prior to the discovery of the feature. Because the purpose of the sampling was to investigate patterns of use and discard around features, the project archaeologist determined that only collecting one or two of the arms might bias the sampling. Therefore, the procedure was never implemented.

\section{DATA GAPS}

While the use of Feature Focused units created problems for feature sampling in the field, it created more significant difficulties during the analysis phase of the research. One difficulty was generating artifact density models for excavation areas, since Feature Focused units acted as boundaries and created voids. Secondly, correlating artifacts from Feature Focused units to features could be problematic, since only larger artifacts and potential diagnostics and tools were likely to be noted in field forms and recovered. When a feature was uncovered, and matrix was screened, there was no control sample of screened matrix from the surrounding area.

\section{UNIT Size AND APPROACH}

As noted above, Traditional units were $2 \times 2 \mathrm{~m}$ in size, but excavated in $1-x-1-m$ quadrants. There were two benefits to this approach. First, using the same size 2-x-2-m blocks for both Traditional and Feature Focused units made it easier to checker board the excavations. Second, excavating the 2-x$2-m$ units in 1-x-1-m quadrants provided the provenience resolution of smaller units with onefourth the paper work. Cutting down on the number of field forms increased efficiency in the field with little or no loss of accuracy. An unanticipated benefit of this approach was that the "vision" of field crews increased; they began to notice patterns across a larger area than if they had been focused on a small $1-\mathrm{x}-1-\mathrm{m}$ window into the site. Therefore, using a quadrant approach offered significant benefits over 1-x-1-m units.

\section{FIELD FORMS}

As with any archaeological project, the Gatlin site data recovery employed a host of field forms to record excavation data and artifact provenience information. For the most part, the field forms used were modified versions of forms SWCA had used with success on previous testing and data recovery projects. The Unit/Level Form for Traditional Units, reduced the amount of redundant data that would be generated by four individual forms. And as the units were excavated by quadrant, the resulting exposure resulted in better photographs, drawings and notes about patterning and possible associations of artifacts. The obvious newcomer to the suite of forms was the Feature Focused unit/level form. These forms treated the $2-\mathrm{x}-2$ unit as a single provenience, reducing some of the repetitive task of filling in provenience data, and as mentioned, reducing the volume of paperwork. When features were encountered in either type of unit, an SWCA Feature Form was used to specifically record the feature, and this is a standard practice for many organizations. The Feature Form is valuable as a checklist for the recording and sampling of a feature, although it can create a separate provenience for data that can be difficult to compare with material excavated from a unit. Since the expectations were that most of the features would be composed of burned rock, the recording and sampling guidelines of the form 
were designed to collect burned rock data. An unintended consequence was that features such as debitage or tool clusters and clusters of animal bone were less likely to be recorded as features in the field.

\section{Unit Placement}

Numerous factors influenced the placement and order of excavation units during the data recovery fieldwork, but an overarching concern on the part of the supervisory staff was crew productivity. The tight timeframe for field work and the contractual goal of a set number of cubic meters to be excavated meant that it was incumbent upon the project archaeologist and his assistant to keep the field crews digging with minimal down time. This problem was acerbated by the fact that the planned start date of fieldwork was delayed by one week. The original scope-of-work called for a reduced crew to conduct backhoe trenching and mechanical stripping for a week before the full crew arrived on site. However, the work authorization for fieldwork was not in place in time, and it was necessary to conduct trenching and stripping with the full project crew on hand.

The initial excavation units in Area A were placed in the northeastern quadrant because it was the first area ready for excavations. As it turned out, Area A NE proved to be less compressed than other parts of Area A, and the bulk of excavations was ultimately focused in that portion of the site. Late in the project, a decision was made to expand Area A NE to the north to chase Features 25 and 26. The project archaeologist concluded that expanding the excavations in the areas of those features would be more productive than opening excavations in Area A SE. As a result of that decision, Area A SE remained unexcavated.

Similarly, the unanticipated discovery of what became OZ 3 in Area A SW resulted in a supplemental agreement to expand the excavations into Area A NW, and the recovery of Feature 23, the partial human skull fragment in Area B, required an unplanned expansion of the excavations in that portion of the site. In the latter case, new units were opened up to ensure that no additional human remains were in the area.

\section{DISCUSSION}

A critique of the methods used on a data recovery project such as the Gatlin site excavations could extend to many different facets of the investigations including the choice of field personnel, the composition and size of the crew, collection procedures, analytical methods, etc., but we have chosen to limit our discussion to the questions posed in the research design. Those questions largely reflect concerns held by the supervisory staff - shortly after the fieldwork had been completed - about the nature and quality of the data collected under the tight project schedule and through the use of non-traditional and untested excavation methods.

As the preceding narrative indicates, the compressed project schedule put stress upon everyone involved in the project; sometimes this stress resulted in novel and innovative solutions. In other cases, the stress resulted in hasty decisions that resulted in subsequent headaches.

\section{Auger Testing}

To begin with the earliest phases of the project, this study demonstrates the utility of auger testing as an expedient method of site discovery. The results of the auger testing, however, will underrepresent the amount of cultural material at a site, particularly from classes of small artifacts like debitage, and will not provide good vertical control. Therefore, auger testing should be supplemented with another form of data collection that will allow for recovery of smaller artifacts and control for vertical provenience of discovered materials. The use of backhoe trenching with column sample excavations is an excellent approach because it not only satisfies the requirements of recovery and vertical control but it also provides a better stratigraphic picture of the subsurface.

\section{FEATURE FOCUSED UNITS}

The use of Feature Focused units during data recovery greatly increased the area and volume of excavations. In Area A NE, Feature Focused units accounted for $49.63 \mathrm{~m} 3$ of excavations and Traditional units accounted for $38.48 \mathrm{~m} 3$. Based on field notes, the excavation rate of Feature Focused units on average was twice as fast as 
Traditional units, meaning that two Feature Focused unit/levels could be excavated for every one Traditional unit/level. Had Area A NE been excavated only with Traditional Units, the overall excavation volume would have been approximately $63 \mathrm{~m} 3$ rather than the $88 \mathrm{~m} 3$ achieved through checker boarding the two excavation methods. Therefore, the by alternating the two types of units, SWCA was able to excavate 40 percent more of Area A than would have been possible otherwise.

As employed, however, Feature Focused excavations created sampling and analytical problems. Had these been anticipated more fully some of the problems could have been minimized. One alternative approach would be to employ the two techniques side-by-side rather than intermeshed. In other words, the eastern half of Area A NE could have been excavated using exclusively Traditional units and the western half with only Feature Focused units.

In similar situations, where broad horizontal exposures are the goal and features, rather than debitage, are the target, a more radical approach would be to abandon Traditional units altogether and excavate the entire block using a Feature Focused method. Taking systematic control samples, say a $20-\mathrm{x}-20-\mathrm{cm}$ block from each $1-\mathrm{x}-1-$ $\mathrm{m}$ quadrant, in each 2-x-2-m unit/level would provide a statistically representative sample of debitage and other small artifacts. In fact, the control samples could be waterscreened through fine mesh to provide improved recovery of macrofloral and macrofaunal materials. It is estimated that by using entirely Feature Focused units with systematic control samples, twice as much volume could be excavated in the field, and laboratory processing and curation costs would be significantly reduced. Of course, the research questions would have to be tailored to these unusual excavation methods.

\section{OTHER METHODOLOGICAL SUGGESTIONS}

Large-scale excavations, such as occurred at the Gatlin site, are inherently complex. With an emphasis on artifact distributions and spatial analysis, a valuable aid in future excavations might be areas or blocks of units where artifacts are piece plotted with a Total Data Station. This method can be time consuming and expensive, especially on large sites; however, if used to record particular types of artifacts, such as diagnostics and all sampling locations, a higher degree of spatial resolution may be obtained, against which the other traditionally recorded data is compared or calibrated to.

The information gained from hand excavations is more detailed than that gained through mechanical methods. The standards of excavation necessary to determine eligibility at the state and federal levels may be insufficient in resolution to provide an accurate model of the true nature of the archeological deposits. The use of additional sondage units, either during a significance testing, or prior to data recovery excavations, can help to refine a research design. This information could help determine the excavation strategy-from the placement of units to the excavation of arbitrary 5-cm levels-and whether these changes would provide better data.

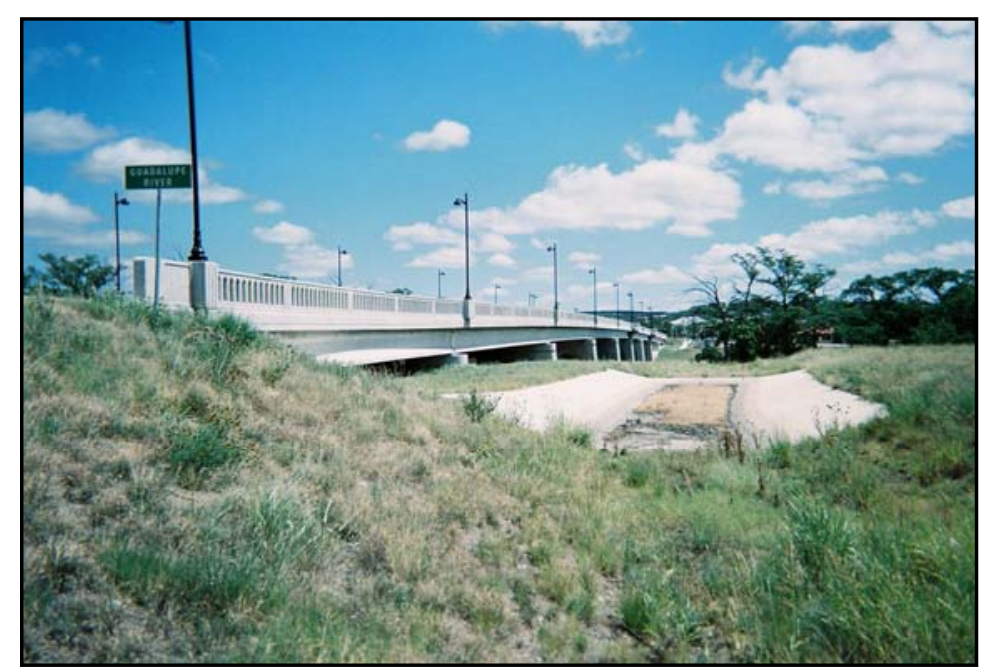

Figure 1. The completed Spur 98 bridge over the Guadalupe River in 2008, facing north from eastern side of right-of-way. 
Table Appendix K-1. Summary of Key Dates in the Spur 98 Timeline

\begin{tabular}{|l|l|}
\hline \multicolumn{1}{|c|}{ Dates } & \multicolumn{1}{|c|}{ Activitiy } \\
\hline January 2000 & TxDOT geoarchaeological investigations of Spur 98 APE \\
\hline ca. November 2003 & $\begin{array}{l}\text { SWCA enters preliminary discussions with TxDOT regarding } \\
\text { survey }\end{array}$ \\
\hline May 17, 2004 & Survey of Spur 98 APE begins \\
\hline May 17-21, 2004 & SWCA conducts auger testing of southern approach \\
\hline May 24-28, 2004 & SWCA conducts backhoe trenching of southern approach \\
\hline May 27, 2004 & SWCA conducts backhoe trenching of northern approach \\
\hline May 27-June 4, 2004 & SWCA conducts testing at 41KR621 \\
\hline June 14-25, 2004 & SWCA conducts testing at 41KR621 \\
\hline June 22-23, 2004 & Survey and testing of Spur 98 APE ends \\
\hline June 26, 2004 & SWCA submits interim report on survey and testing \\
\hline July 19, 2004 & $\begin{array}{l}\text { SWCA submits preliminary research design for data recovery at } \\
\text { 41KR621 }\end{array}$ \\
\hline August 19, 2004 & $\begin{array}{l}\text { SWCA submits revised research design for data recovery at } \\
\text { 41KR621 }\end{array}$ \\
\hline August 25, 2004 & SWCA conducts data recovery at 41KR621 \\
\hline September 9-November 26, 2004 & SWCA submits interim report on data recovery \\
\hline February 25, 2005 & SWCA submits final research design for data recovery \\
\hline April 25, 2005 & $\begin{array}{l}\text { TxDOT submits comments on final research to SWCA; } \\
\text { comments incorporated by reference }\end{array}$ \\
\hline May 24, 2005 & \\
\hline
\end{tabular}


Table Appendix K-2. Comparison of Artifact Recovery from Backhoe Trench Column Samples and Nearby Auger Tests

\begin{tabular}{|c|c|c|c|}
\hline Unit & Flakes & FCR & Other \\
\hline $\mathrm{BHT} 1, \mathrm{CS} 1$ & 406 & 92 & 9 \\
\hline AT N120 E1030 & 7 & 36 & 0 \\
\hline BHT 1, CS 2 & 178 & 244 & 4 \\
\hline AT N1030 E1030 & 13 & 200 & 0 \\
\hline BHT 2 & 19 & 5 & 0 \\
\hline AT N1080 E1030 & 0 & 2 & 0 \\
\hline AT N1090 E1030 & 0 & 0 & 0 \\
\hline BHT 3 & 35 & 10 & 0 \\
\hline AT N1030 E1060 & 10 & 5 & 0 \\
\hline AT N1040 E1060 & 2 & 11 & 1 \\
\hline AT N1030 E1070 & 2 & 1 & 0 \\
\hline AT N1040 E1070 & 2 & 0 & 0 \\
\hline BHT 4 & 224 & 26 & 3 \\
\hline AT N1020 E1040 & 5 & 15 & 0 \\
\hline AT N1030 E1040 & 8 & 20 & 0 \\
\hline BHT 6 & 4 & 0 & 0 \\
\hline AT N1140 E1020 & 0 & 0 & 0 \\
\hline AT N1140 E1030 & 0 & 0 & 0 \\
\hline BHT 7 & 5 & 0 & 0 \\
\hline AT N1150 E1040 & 0 & 0 & 0 \\
\hline AT N1150 E1050 & 1 & 0 & 0 \\
\hline AT N1160 E1040 & 1 & 1 & 0 \\
\hline AT N1160 E1050 & 1 & 0 & 0 \\
\hline BHT 8 & 8 & 3 & 3 \\
\hline AT N1070 E1060 & 3 & 4 & 0 \\
\hline AT N1070 E1070 & 2 & 0 & 2 \\
\hline AT N1080 E1060 & 2 & 5 & 0 \\
\hline AT N1080 E1070 & 5 & 6 & 0 \\
\hline BHT 9 & 5 & 1 & 0 \\
\hline AT N1090 E1060 & 4 & 1 & 0 \\
\hline AT N1090 E1070 & 1 & 19 & 0 \\
\hline AT N1100 E1060 & 0 & 0 & 0 \\
\hline AT N1100 E1070 & 0 & 2 & 0 \\
\hline
\end{tabular}


